\title{
A Geographical Analysis of the Hazardscape of the Wellington Region: Influences on Intra-Regional Response
}

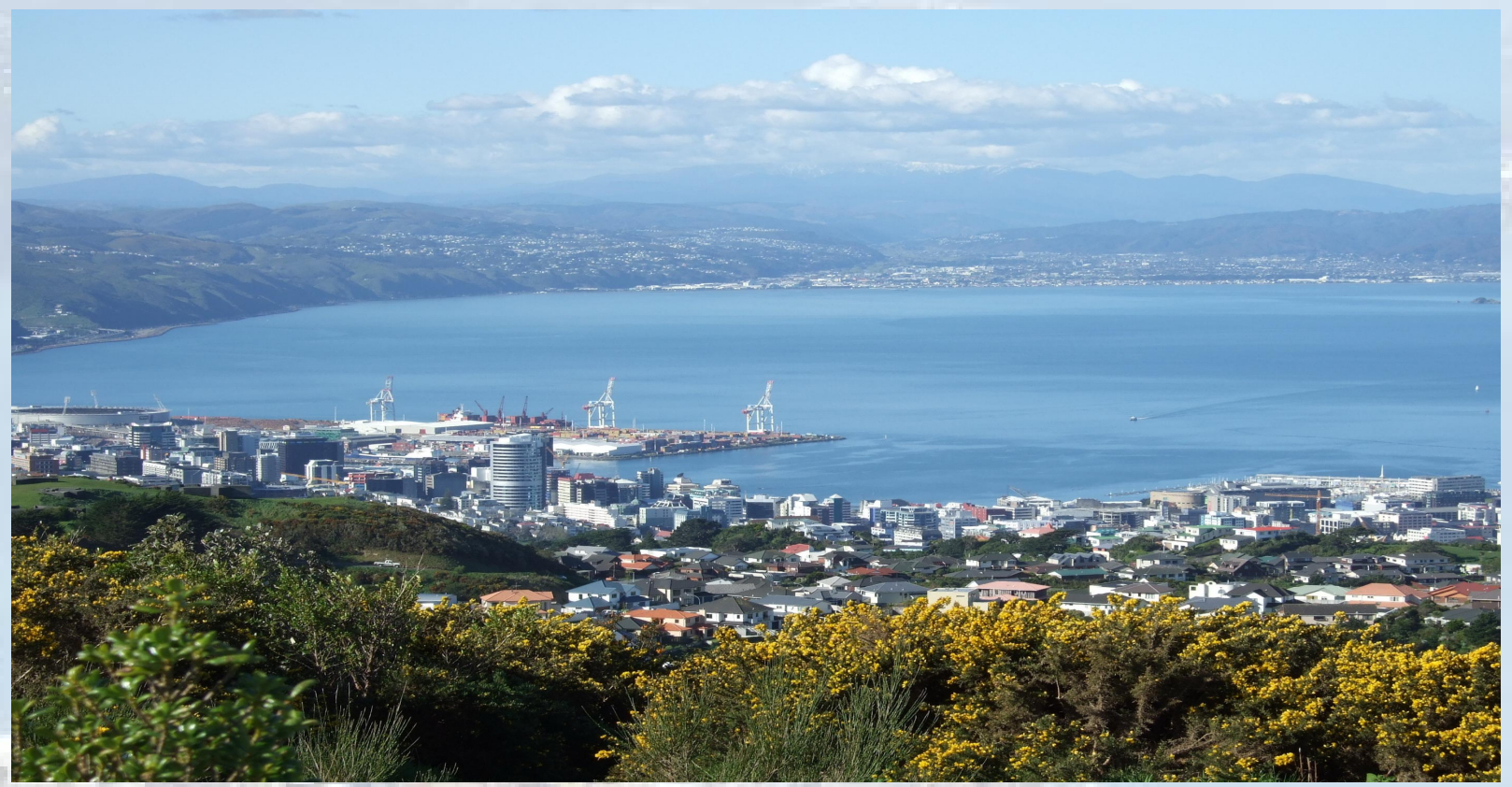

Supervised by Prof. Michael Crozier Mr. Richard Willis

A thesis submitted in fulfilment of the requirements for the degree of Doctor of Philosophy in Physical Geography

Submitted by

Shabana Khan

School of Geography, Environment \& Earth Sciences

Victoria University of Wellington (2006-2009) 


\section{A Geographical Analysis of the Hazardscape of the Wellington Region: Influences on Intra-Regional Response}

A thesis submitted in fulfilment of the requirements for the degree of Doctor of Philosophy in Physical Geography

Supervised by Prof. Michael J. Crozier

Mr. Richard Willis

Submitted by

Shabana Khan

School of Geography, Environment and Earth Sciences

Victoria University of Wellington

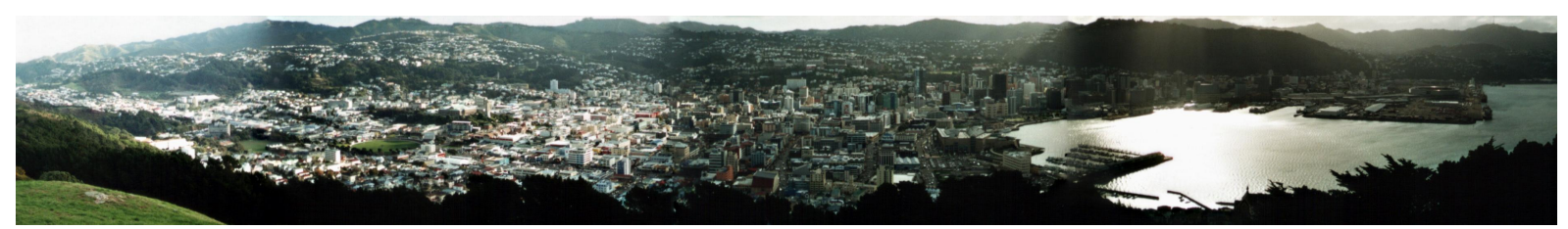




\begin{abstract}
This thesis defines and explores the hazardscape of the Wellington Region and investigates its influences on variations in the hazard response from local people and administration throughout the region.

The research first identifies and argues for a holistic conceptual framework such as 'hazardscape' to study multiple hazards and associated issues at a place. Although the need for a holistic approach has been recognised in the literature, conventional research has generally been compartmentalized into the individual study of hazards, issues and response. Despite the fact that geography has a tradition of using an ecological approach to study natural hazards, the holistic approach has been compromised for various reasons. Behavioural, perception, vulnerability and resilience models, although covering significant aspects of hazards, present only a partial reality. A skewed focus on humans, although a popular emphasis, also detracts from the ability of hazard geography to attain a truly holistic view. Even though it has been recognized that natural hazards result through interaction of human and natural systems, the separation of the two fails to explain many complexities that result through ecosystem functioning. Studies of hazards and disasters are predominantly focused on single hazard assessment of an area, and there is a gap in the literature that deals with multiple hazards and associated issues. With the background of these shortcomings, this thesis explores the concept of 'hazardscape' for a more holistic framework to study various aspects of hazards at a place.
\end{abstract}

The thesis broadly contains three parts. In the first part, it gives the conceptual framework to study the hazardscape. It defines 'hazardscape' as a dynamic scape, which reflects the physical susceptibility of a place and vulnerability of human life and assets to various hazards in a given human ecological system. The research uses the term 'hazardscape' for its geographical connotation, its ability to express the ecological perspective behind hazard creation and its merits over the other related term 'riskscape'. The study also argues the significance of hazardscape in the shifting paradigm of both subject matter and method of evaluation i.e. from descriptive account of individual factors to a holistic analysis.

The second part of the thesis examines the hazardscape of the Wellington Region, by assessing its physical susceptibility, human vulnerability and spatio-temporal occurrence of hazards in the region. This investigation is primarily based on the secondary data, and attempts to provide an overall picture of the local hazardscape. It highlights a few distinctive characteristics of the hazardscape of the Wellington Region including its excessive physical susceptibility to a wide 
range of hazards along with varied human vulnerability and the history of extreme events in the region. The nature and amount of impact from past events differ over space, and is heavily skewed towards the urban areas in the western section of the region.

The third section of the thesis assesses the influences of hazardscape on hazard response of local people and administration. The hypothesis used to guide the study is "whereas integrated regional planning is likely to produce a uniform response to hazard, hazardscape introduces variations in the local response throughout the region". It was formulated because the establishment of a Regional Policy Statement and a Regional Civil Defence and Emergency Management Plan could be expected to lead to uniform responses throughout the region. However, the expectation was that aspects of the hazardscape would continue to influence response, despite the existence of the over-arching plan. The analysis is based on both primary and secondary data, and involves both quantitative and qualitative data and methods to present the findings. The primary data is based on the interview schedules and structured questionnaires conducted with local people and administration throughout the region. The sample was selected through a stratified purposive sampling method based on the location of respondents with respect to their hazard exposure. This method, while providing an unsuitable platform for rigorous statistical testing, has been designed to capture the extreme range of conditions and responses. It is also able to reveal trends and indicative relationships that can be matched with expectations and theory.

The research finds that various characteristics of the hazardscape including hazards, physical susceptibility and vulnerability have influenced and produced variations in the hazard response over space. It argues that a detailed analysis of a hazardscape can contribute to effective hazard management along with human response to hazards. The thesis therefore has both theoretical significance and a practical validity. 


\section{Preface \& Acknowledgment}

The Wellington Region occupies an active and young landscape where humans and nature have lived a short but rich culture of adjustments and adaptations to each other. The region, with an area of a few thousand square kilometres, provides a laboratory to study multiple hazards in a much smaller place compared to the rest of the world. It is also unique in the sense that it acts as a niche for people from different parts of the world who share varied hazard experiences and traditions of hazard management. These different and yet the same people are exposed to varied combinations of hazards in the region. Their varied socio-economic differences produce variations in the local vulnerability that shapes and modifies the perception and response to the local hazards.

This research is exploratory in nature. It aims for a grounded theory where conceptual background guided the research and at the same time it is modified and rebuilt with the progress of the research. It shows that both hazardscape and response influence and represent each other. However, despite having a clear idea, the research suffered many problems due to time constraints, uncertainties associated with incomplete and inadequate data along with methodological issues. Yet it is successful enough to present a holistic picture within the given limitations.

A hazardscape tells the story of land, process and life, the three dominant elements of an ecosystem that over time build a hazardscape. A hazardscape represents a state in an ecosystem where broken rules and unlearnt lessons about how to absorb and evolve with the change, either in the biophysical or in human processes, have produced a range of hazards in the system. Changes in the system are not only inherent or natural, but are also significant for its evolution. An understanding of these changes and ecosystem laws is essential for human survival. Integration is required not only in administrative response but also between a community and the environment. It is important to create works that understand processes, places that accommodate change, and people who adapt and integrate across a vulnerability scale for response at different stages.

The first chapter of the thesis introduces the research context, rationale and methodology, while the second chapter explores the conceptual framework of the hazardscape. The next three chapters present the hazardscape of the Wellington Region by focusing on physical susceptibility, human vulnerability and spatio-temporal occurrences of hazards at the local level. The following two chapters analyse the hazard response from people and the local administration with respect to the hazardscape of the Wellington Region. The thesis ends with the chapter on syntheses and conclusions drawn from previous chapters, and giving the perspectives for a new beginning.

In my short journey of research, I have come to realise that research is more of a collective output rather than an individual contribution. It is the support and contribution of other people, either directly by providing data, views, answering long questionnaires and giving interviews, or indirectly by helping me to manage my personal life and supporting me at each and every stage that has made this research possible. I pay my sincere gratitude to all the contributors. 
First of all, I would like to give my sincere thanks my primary supervisor Prof. M. J. Crozier, who accepted me as a $\mathrm{PhD}$ student and helped me at each and every step of this project. It would not be wrong to say that without his support, this project would not have been possible. The freedom he gave me to choose my topic and research methodologies, helped me to explore various fronts of this research and learn through my mistakes. His confidence and knowledge in the field have enriched this research in many ways. His support at the final stages of this thesis has been remarkable that helped me to achieve the target within a limited time.

I am also grateful to my second supervisor Mr. Richard Willis for his guidance and support throughout the research. His sincere inputs for my proposal and thesis chapters helped me to refine my focus. I would also like to pay sincere thanks to our Heads of School Ass. Prof. Mike Hannah and Prof. Phillip Morrison for their support and approval of grants, which enabled this research to be completed successfully.

I would like to thank Mr. David Johnston from the Institute of Geological and Nuclear Sciences and Massey University for conference grants that helped me to know about the current research on hazards in New Zealand and present my own research at different stages. I am also grateful to him for suggesting further literature as my examiner that helped to improve this thesis.

I am also thankful to my other two examiners including Dr J. M. McKinnon from Victoria University of Wellington and Dr. Irasema Alcántara-Ayala from National Autonomous University of Mexico for their encouraging and useful comments which helped to improve the thesis. I am also grateful to Dr. N. Britton for his timely help by sending me one of his old articles to fulfill the literature gaps. I am also grateful to Dr. Andy Reisinger for his support and encouragement to refine my very final draft.

I am highly grateful to the officers from different institutions who provided their generous support and the data without which this research could not have been completed. I give my sincere gratitude to Rian van Schalkwyk, John Gibson, Iain Dawe, Craig Hamilton and Tony Faulkner from the Wellington Regional Council; David Heron, Sam Macole and Grant Dellow from the Institute of Geological and Nuclear Sciences; Lance Dixon from the Earthquake Commission; Ewan Jonasen, Kimberly Cullen and Sarah Cowell from Statistics New Zealand; Neil Challands from the National Rural Fire Authority; Blyss Wagstaff from the New Zealand Historic Places Trust; and Graeme Henderson from Eagle. I also pay my sincere thanks to the National Instritute of Water and Atmospheric Research and the Wellington Regional Council Office at Masterton which provided me valuable data.

I am extremely grateful to the fourteen civil defence officers and district planners for giving their valuable time and answering my lengthy questionnaires. I am also grateful to the people of the Wellington Region who gave their precious time and filled in my questionnaires. I am also thankful to Mr. Peter Wood from Ministry of Civil Defence and Emergency Management, Kylie Berg from Department of Internal Affairs, Parsons Waverley from the Kapiti Coast District Council, who helped me to provide important contacts for this research. 
I am very thankful to my friends who provided their valuable assistance and escorted me to distant places for my fieldwork. These include Ruddy \& Liandri Harmse, Alvin Divinagracia, Tina and Ursula Faulkner, Abu Conteh, Katha and Phillipa Bennett.

I am also grateful for the support I got from the school. I would like to give my sincere thanks to Mairead de-Roiste, Andrew Rae, Anke Timmermann and Matthew Banks for helping me with GIS problems; Nokuthaba Sibanda for answering my statistical queries and Jack McConchie for giving me advice on rainfall stations. I would also like to thank the other teaching staff at the school, who have been very friendly and their helpful attitude made my stay at the university a lot easier.

I also offer my sincere thanks to the administrative staff at the school who provided constant help and support. These include Shona de Sain, Keith Willett, Hayley Maguren, Suzanne Weaver, Susan Cayless, Gillian Ruthven and Lin James. I am also thankful to the university librarians, ITS group and the caretakers of the school for their kind help and support at different stages.

I am extremely thankful to my graduate friends who helped me at the final stages of my thesis through proof reading or giving their valuable suggestions and help. These include Alison Adams-Smith, Patrick Coelho, Ed Challies, Jan Thompson, Rajarshi Dasgupta, Claire Storkey, Dorothy Quade, Roshan Williams, Alvin Divinagracia, Mohammad Faisal, Eunica Aure, Zoe Lawton, Deb Maxwell and Simon Norbet.

I am grateful to my ex-supervisor Dr. Anu Kapur who encouraged me at each stage to achieve my objectives in life and for PhD. I am also grateful to my friends including Ira Misra, Gabi Hufshmidt, Deeptima Massey, Anjum Zafar, Eunica Aure, Dorothy Quade, Bharti Arya, Alison Adams-Smith, Rimi Goswami, Punam Tripathi, Reena Singh, Ruddy and Liandri Harmse, Andreas Mahn, Nichole Mahn, Kanchan Chug, Britta Hollermann, Ritika Shremali, Mohammad Hussain Shukri, Rajshekhar Vadlamannati, Bushra Nur, Alvin Divinagracia, Riyad M Mucadam, Piyush Mishra and Sinith Sittirak for their valuable help and kind support.

Last but not the least, I am extremely grateful to my parents, sisters and jiju for being so supportive and helping me manage my life in New Zealand despite being so far away. I am also grateful to my God who showed me the right way whenever I was confused and helped me to pass this test of life.

In the end, I owe a sincere apology to those whom I have forgotten to put in this list, and I dedicate this thesis to all its contributors for their kind and genuine help and support. 


\section{Contents}

Title

Page

Abstract

Preface \& Acknowledgement

Contents

vii

List of Tables

xiii

List of Figures

xvii

List of Maps

$\mathrm{xxv}$

List of Plates

xxix

Text Box

xxix

List of Photographs

xxix

List of Acronyms \& Abbreviations

$\mathrm{xxxi}$

\section{Contents}

1 Introduction 1

1.1. Rationale and Justification for the Study of the Hazardscape of the Wellington Region

1.2. Aims and Objectives 16

$\begin{array}{lll}1.3 \text { Hypothesis } & 17\end{array}$

1.4 Area of Study 17

1.5 Research Methodology 19

1.5.1. Data Collection 19

1.5.2 Data Analysis \& Representation 26

1.6 Limitations 36

$\begin{array}{lll}1.7 & \text { Chapter Outline of Thesis } & 37\end{array}$

2 Hazardscape: The Conceptual Framework 39

2.1 Definition 39

2.2 The Ecological Perspective 40

2.3 Hazardscape and Ecosystem 42

2.4 Elements of a Hazardscape $\quad 47$

2.5 Hazards 47

2.6 Physical Susceptibility 49

2.7 Vulnerability 50

2.8 Response 52

2.9 Differences in Hazardscape and Riskscape 55 
3 Physical Susceptibility of the Wellington Region to Natural Hazards

$\begin{array}{lll}3.1 \text { Location } & 59\end{array}$

$\begin{array}{lll}3.2 & \text { Geology } & 61\end{array}$

3.3 Physiography 66

3.4 Meteorology and Climate $\quad 71$

$\begin{array}{lll}3.5 & \text { Drainage and Hydrology } & 79\end{array}$

$\begin{array}{lll}3.6 & \text { Vegetation } & 83\end{array}$

3.7 Soils 87

3.8 Connectivity of the System and Susceptibility to Hazards 90

4 Human Vulnerability to Natural Hazards in the Wellington Region 97

$\begin{array}{ll}\text { 4.1 Demographic Vulnerability } & 97\end{array}$

$\begin{array}{ll}\text { 4.1.1 Population Distribution } & 97\end{array}$

$\begin{array}{lll}4.1 .2 \text { Women } & 100\end{array}$

$\begin{array}{lll}4.1 .3 & \text { Children } & 102\end{array}$

$\begin{array}{lll}\text { 4.1.4 The Elderly } & 102\end{array}$

$\begin{array}{lll}\text { 4.1.5 Disabled } & 104\end{array}$

$\begin{array}{lll}\text { 4.1.6 Movement for Migration and Tourism } & 105\end{array}$

$\begin{array}{ll}\text { 4.1.7 Demographic Vulnerability Index } & 108\end{array}$

$\begin{array}{lll}4.2 & \text { Social Vulnerability } & 109\end{array}$

$\begin{array}{lll}\text { 4.2.1 Family } & 109\end{array}$

4.2.2 Household Composition 111

$\begin{array}{lll}4.2 .3 \text { Education } & 113\end{array}$

$\begin{array}{lll}\text { 4.2.4 Language Barrier } & 114\end{array}$

$\begin{array}{lll}\text { 4.2.5 Ethnicity } & 115\end{array}$

$\begin{array}{ll}\text { 4.2.6 Social Vulnerability Index } & 121\end{array}$

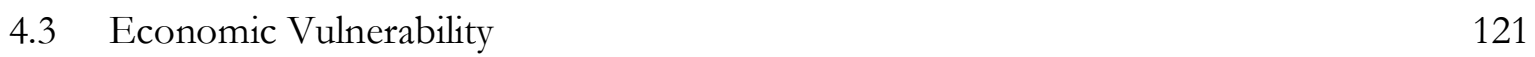

$\begin{array}{lll}\text { 4.3.1 Employment \& Occupation } & 121\end{array}$

4.3.2 Dependent and Unemployed Population 126

$\begin{array}{lll}4.3 .3 & \text { Income } & 130\end{array}$

$\begin{array}{lll}\text { 4.3.4 Housing } & 134\end{array}$

$\begin{array}{lll}\text { 4.3.5 Means of Communication } & 138\end{array}$

4.3.6 Economic Vulnerability Index 141

4.4 Infrastructure Vulnerability 141

$\begin{array}{lll}\text { 4.4.1 Buildings } & 142\end{array}$

$\begin{array}{lll}\text { 4.4.2 Infrastructure for Transport and Communication } & 144\end{array}$

$\begin{array}{ll}\text { 4.4.3 Gas, Water and Sewerage System } & 145\end{array}$

4.5 Administrative and Political Vulnerability 146

$\begin{array}{ll}\text { 4.6 Composite Vulnerability } & 149\end{array}$

5 Spatio-temporal Occurrence of Hazards in the Wellington Region 155

5.1 Geological Hazards 155

$\begin{array}{lll}\text { 5.1.1 } & \text { Earthquakes } & 155\end{array}$ 
$\begin{array}{lll}\text { 5.1.2 Landslides } & 168\end{array}$

$\begin{array}{lll}5.1 .3 & \text { Tsunami } & 181\end{array}$

5.1.4 Volcanic Ash fall 184

5.2 Meteorological and Climatic Hazards 187

5.2.1 Frosts, Snowfall and Heat Waves 187

5.2.2 Windstorms, Tornadoes, Water Spouts, Cyclones and Sea Surges 188

5.2.3 Hails, Lightning, Thunderstorms and Rainstorms 191

$\begin{array}{lll}\text { 5.2.4 Bushfires } & 194\end{array}$

5.3 Hydrological Hazards 195

$\begin{array}{lll}\text { 5.3.1 Flooding } & 195\end{array}$

$\begin{array}{lll}\text { 5.3.2 Droughts } & 201\end{array}$

5.4 Connectivity of Processes and Changing Hazard Frequency 206

6 Local Response to Hazards in the Hazardscape of the Wellington Region 209

6.1 Overview of Hazard Response in the Wellington Region 209

6.2 Variations in Response to Hazards and Influences of the Hazardscape 212

6.2.1 Influences of Hazard Characteristics 212

6.2.1.1 Time Specific Hazard Characteristics 213

6.2.1.2 Space Specific Hazard Characteristics 217

6.2.1.3 Damage Specific Hazard Characteristics 217

6.2.2 Influences of Physical Susceptibility 221

6.2.2.1 Geology 221

6.2.2.2 Physiography 226

6.2.2.3 Area Below 10m Contour 237

6.2.2.4 Distance from Fault 241

6.2.2.5 Rainfall 245

6.2.2.6 Floodplain $\quad 250$

6.2.2.7 Wind Speed 253

6.2.2.8 Bushfire Susceptibility 258

6.2.3 Influences of Human Vulnerability 262

6.2.3.1 Exposure 262

6.2.3.2 Fragility and Coping Capacity 269

6.2.4 Influences of Overall Hazardscape 292

6.2.4.1 Awareness 301

6.2.4.2 Perception 302

6.2.4.3 Past Experiences 306

6.2.4.4 Response Culture 313

6.2.4.5 Effectiveness of Response Measures and Trust in
Response Agencies

7 Administrative Response to Hazards of the Wellington Region 325

7.1 Overview of Administrative Response in the Wellington Region 325

7.2 Administrative Response for Hazard Mitigation in the Wellington Region 326

$\begin{array}{lll}\text { 7.2.1 Plans \& Policies } & 327\end{array}$ 
$\begin{array}{lll}\text { 7.2.2 Structural Measures } & 329\end{array}$

$\begin{array}{lll}\text { 7.2.3 Non-structural Measures } & 330\end{array}$

7.3 Administrative Preparedness for Hazards in the Wellington Region 333

7.3.1 Plans and Policies 333

$\begin{array}{lll}\text { 7.3.2 Emergency Stock } & 335\end{array}$

$\begin{array}{lll}\text { 7.3.3 Emergency Exercises } & 335\end{array}$

7.3.4 Public Information for Preparedness 337

7.4 Administrative Arrangements for Emergency Response in the Wellington Region 339

$\begin{array}{lll}7.4 .1 & \text { Plans } & 339\end{array}$

$\begin{array}{lll}\text { 7.4.2 Warning Systems } & 340\end{array}$

$\begin{array}{lll}\text { 7.4.3 Staff and Other Resources } & 340\end{array}$

$\begin{array}{lll}\text { 7.4.4 Alternative Arrangements } & 341\end{array}$

7.5 Administrative Response for Recovery in the Wellington Region 341

7.6 Factors Influencing the Administrative Response to Hazards in the
Wellington Region

7.6.1 Hazard Characteristics and Occurrence $\quad 342$

$\begin{array}{lll}\text { 7.6.2 Physical Characteristics } & 344\end{array}$

7.6.3 Rural Urban Divide 346

$\begin{array}{lll}\text { 7.6.4 Hazard Perception and Fatalism } & 347\end{array}$

$\begin{array}{lll}\text { 7.6.5 Economic Viability } & 348\end{array}$

7.6.6 Political Motivation 351

7.6.7 Globalization and Connectivity of Biophysical and Human
Processes

7.7 Shortcomings of Administrative Response with Respect to the Hazardscape of the Wellington Region 354

7.7.1 Lack of Detailed Hazard Management Plan at Local Level 354

$\begin{array}{lll}\text { 7.7.2 A Generalised Approach } & 355\end{array}$

7.7.3 Bias Towards the Type of Hazards 355

7.7.4 Bias Towards Hazards over Disasters 356

7.7.5 Bias Towards Response Type 358

7.7.6 Focus on Risks from Hazards Rather than the Hazardscape 358

8 Synthesis and Conclusion $\quad 363$

8.1 Concept and Definition of Hazardscape 363

8.2 The Hazardscape of the Wellington Region 363

8.2.1 Physical Susceptibility of the Wellington Region to Natural Hazards 363

8.2.2 Human Vulnerability to Hazards in the Wellington Region 364

8.2.3 Natural Hazard Occurrence in the Wellington Region 365

8.3 Public Response to Hazards and Influences of the Hazardscape 366

8.3.1 Influences of Hazard Characteristics on Response 366

8.3.2 Influences of Physical Susceptibility on Response 367 
8.3.3 Influences of Vulnerability on Hazard Response

8.3.4 Influences of the Overall Hazardscape Characteristics on Response

8.4 Administrative Response to the Hazardscape of the Wellington Region

8.5 Research Caveats and Perspectives

8.6 Hypothesis Revisited

Bibliography

Appendix-1: Questionnaire: Local People

Appendix-2: Questionnaire: Civil Defence Officers 409

Appendix-3: Questionnaire: District Planners 


\section{List of Tables}

Title

Page

1.1 Focus of Questions in Questionnaire Survey in the Wellington Region (2007) 21

1.2 Particulars of Primary Survey Conducted in the Wellington Region (2007) 22

1.3 Sample Characteristics and Distribution 24

1.4 Factors, Parameters and Indicators selected for Vulnerability Index 27

1.5 Selected Indicators and Their Mean 29

1.6 Centralized Score for the Selected Indicators. 29

$1.7 \quad$ Individual Scores for Selected Indicators 30

1.8 Weighted Scores for Selected Indicators 30

1.9 Composite Vulnerability Score for Mesh blocks 30

$1.10 \quad$ Composite Vulnerability Index without Weight 31

$1.11 \quad$ Composite Vulnerability Index with Weight 31

1.12 The Variations in the Final Output Through Maximum and Minimum

3.1 Extreme Temperature Deviation from Mean Minimum Winter and Mean Maximum Summer in the Wellington Region

3.2 Flammability of Vegetation Types by LCDB Classification in the Wellington Region

3.3 Soil Characteristics in the Wellington Region 87

4.1 Population Distribution in the Wellington Region (2006) 97

4.2 Demographic Characteristics Associated with Vulnerability in the Wellington Region (2006)

4.3 Family Structure in the Wellington Region (2006) 109

4.4 Household Composition in the Wellington Region (2006) 111

4.5 Main Language Spoken in the Wellington Region (2006) 114

4.6 Ethnic Composition in the Wellington Region (2006) 115

4.7 Population Characteristics of Ethnic Groups in the Wellington Region (2006) 118

4.8 Work Status in the Wellington Region (2006) 122

4.9 Population Living on Benefits or Pension or Allowances in the Wellington Region (2006)

4.10 Vulnerability Linked with Income in the Wellington Region (2006) 131

4.11 Vulnerability Linked with Housing in the Wellington Region (2006) 134

4.12 Vulnerability Linked with Communication in the Wellington Region (2006) 138 
5.1 Magnitude of Earthquakes Recorded in the Wellington Region (1840-2008)

5.2 Depth of Earthquakes Recorded in the Wellington Region (1840-2008) 156

5.3 Damaging Earthquakes in the Wellington Region (1840-2008)

5.4 Damage Distribution and Magnitudes of Earthquakes in the Wellington Region (1996-2007)

5.5 Claims Distribution and Depth of Earthquakes in the Wellington Region (1996-2007)

5.6 Number of Claims and Earthquake Characteristics in the Wellington Region (1996-2007)

5.7 Earthquake Characteristics and Money Paid by the Earthquake Commission (1996-2007)

5.8 Earthquake Damage Claims Made at the EQC in the Wellington Region (1996-2007)

5.9 Money Paid by the EQC for Earthquake Claims in the Wellington Region (1996-2007)

5.10 Frequency of Earthquakes in the Wellington Region

5.11 Probability of Earthquakes of Seven or More Magnitude from Faults in the Wellington Region

5.12 Characteristics of Earthquake-Induced Landslides in the Wellington Region

5.13 Rainfall Induced Landslide Years in the Wellington Region (1880-1995)

5.14 Landslide Incidents in the Wellington Region (1996-2006)

5.15 Landslide Incidents and their Spatial Extent in the Wellington Region (19962006)

5.16 Landslide Size in Wellington Region (1996-2006)

5.17 Materials Eroded Through Landslides in the Wellington Region (1996-2006)

5.18 Type of Landslide Movements in the Wellington Region (1996-2006)

5.19 Landslide Triggers in the Wellington Region (1996-2006)

5.20 Secondary Causes of Landslides in the Wellington Region (1996-2006)

5.21 Number of Claims and Landslide Characteristics in the Wellington Region (1996-2007)

5.22 Money Paid by the EQC for Landslide Damages in the Wellington Region (1996-2007)

5.23 Money Paid by the EQC for Landslide Damages in LTAs (1996-2007)

5.24 Personal Damages Due to Landslides in the Wellington Region (1996-2006)

5.25 Transport Damages from Landslides in the Wellington Region (1996-2006)

5.26 Tsunami Affected Areas in the Wellington Region (1840-2000)

5.27 Probability of Tsunami Occurrence in the Wellington Region 
5.29 Possible Impacts of Volcanic Ash Fall in the Wellington Region 186

5.30 Damage Claims Due to Rainstorms in the Wellington Region (2002-2006) 193

$5.31 \quad$ Flood Damages in the Wellington Region (1840-1990) 196

5.32 Flood Damages in the Wellington Region (2002-2006) 198

5.33 Flood Damage Claims Made to the EQC in the Wellington Region (20022006)

5.34 Money Paid by the EQC for Flood Damages in the Wellington Region (20022006)

5.35 Claims Made to the EQC for Flood Damages in the Wellington Region (20022006)

5.36 Money Paid by the EQC for Flood Damages in the Wellington Region (19962007)

5.37 Flood Protection Works Damages from Flooding in the Wellington Region

5.38 Soil Moisture Deficits in the Wellington Region (1933-2000) 202

5.39 Mean Return Period of Droughts in the Wellington Region 203

5.40 Soil Moisture Deficits during Droughts in the Wellington Region (1934-2008) 204

6.1 Hazard Frequency as Perceived by Respondents at their Place of Residence 214

6.2 Problems from Hazards in the Wellington Region 218

6.3 People Perceived to be Affected by the Most Feared Hazard of Respondents 264

6.4 Factors Influencing the Vulnerability of Respondents in the Region 269

6.5 Characteristics of Respondents and Response to Hazards 274

6.6 Main Source of General Hazard Information for Respondents 297

6.7 Perceived Feeling of Well-being against Hazard by Respondents 303

6.8 Perceived Possibility of Reduction of Potential Damage from Different Hazards

6.9 The Reason behind Particular Thinking on the Possibility of Hazard

Reduction

6.10 The Year of Hazard Experienced by Respondents 306

6.11 Type and Extent of Damage Experienced by Respondents 308

6.12 Type and Effects of Damage Experienced by Respondents 308

6.13 Coping Strategies Adopted by Respondents for hazards 309

6.14 Cultural or Traditional Methods Adopted by Respondents to Deal with Hazards

6.15 Lessons Learnt by Respondents who Experienced Hazards 310

6.16 Number of Times Hazards Experienced by Respondents 311

6.17 Influences of Hazard Experience on Preparedness of Respondents 311

6.18 Influences of Hazard Experience on Coping Strategy of Respondents 312 
6.19 Influences of Hazard Experience on Recovery of Respondents 312

6.20 Influences of Hazard Experience on Vulnerability of Respondents 313

6.21 Influences of Hazard Experience on Thinking of Respondents about Hazards 313

6.22 Reasons for Not Being Prepared for Hazards 315

6.23 Availability of Hazard Safety Measures at the Workplace of Respondents 318

6.24 Type of Hazard Safety Measures at the Workplace of Respondents 318

6.25 Type of Hazard Safety Measures at the Community Level in the Wellington $\begin{array}{ll}\text { Region } & 319\end{array}$

6.26 Reason for Trust in the Most Trusted Agency 321

6.27 Reason for Lack of Trust in the Least Trusted Agency 322

7.1 Natural Hazards Mentioned in the District Development Plans of the Region 327

7.2 Hazard Information Provided to Local Population as Mentioned by Civil Defence Officers 330

7.3 Work Done in Territorial Authorities to Reduce Individual Vulnerability to Hazards 332

7.4 Disaster Scenario Conducted in the Wellington Region (2003-2007) 335

7.5 Hazard Information Provided to Local People as Mentioned by Civil Defence Officers

7.6 Community Preparedness Level in the Wellington Region

7.7 Staff in Civil Defence Emergency Management Offices in the Wellington Region

7.8 Current Level of Effort for the Identified Hazards and Risk in the Wellington Region 


\section{List of Figures}

Title

1.1 Research Methodology 20

1.2 A Possible Scenario of Population Characteristics for Composite Index 33

2.1 A Venn Diagram of Hazardscape 47

2.2 Relationship Between Hazardscape and Response 52

2.3 Relationship Between Hazardscape and Riskscape 55

3.1 Tectonic Forces Shaping the Wellington Region 66

3.2 Mean Monthly Temperature and Rainfall in the Wellington Region 71

3.3 Connectivity of Various Processes and Hazards Susceptibility in the Wellington 90

4.1 Occupational Structure of the Wellington Region (2006) 122

5.1 Magnitude and Depth of Earthquakes Recorded in the Wellington Region (18402008) 157

5.2 Damage Claims, Depth and Magnitude of Recorded Earthquakes in the Wellington Region (1996-2007)

5.3 Earthquake Claims and Money Paid by the EQC in the Wellington Region (19962007)

5.4 Damage Claims from Different Magnitudes of Earthquakes Made to the EQC in the Wellington Region (1996-2007) 164

5.5 Damage Claims and Depth of Earthquakes in the Wellington Region (1996-2007) 165

5.6 Distribution of Money Paid by EQC in the Wellington Region (1996-2007) 165

5.7 Landslide Incidents in the Wellington Region (1996-2007) 172

5.8 Monthly Landslide Damage Claims Made to the EQC (1996-2007) 175

5.9 Landslide Claims Paid by the EQC (1996-2007) 177

5.10 Type of Landslide Damage Claims Paid by the EQC (1996-2007) 178

5.11 Type of Damage from Severe Winds in the Wellington Region (1996-2007) 189

5.12 Area Affected by Bushfire in the Wellington Region (1995-2005) 194

5.13 Area Affected by Bushfire in Local Territorial Authorities of the Wellington

6.1 Adjustments Made by Respondents In or Outside their Houses to Reduce Hazards 210

6.2 Hazard Safety Measures Adopted by Respondents 210

6.3 Contents of Survival Kit Stored by Respondents Who Said to Have Made Survival Kit 211

6.4 Hazards for Which Safety Measures Taken by Respondents 212 
6.5 Hazards Preparedness of Respondents

6.6 Recorded Frequency of Hazards and Response in the Wellington Region

6.7 Perceived Hazard Frequency and Response in the Wellington Region

6.8 Proximity of Hazards in Future as Perceived by Respondents in the Wellington Region

6.9 Perceived Proximity, Speed of Onset of Hazards and Response in the Wellington Region

6.10 Duration, Temporal Spacing, Predictability of Hazards and Response in the Wellington Region

6.11 Areal Extent of Hazards and Response in the Wellington Region

6.12 Spatial Dispersion and Response in the Wellington Region

6.13 Problems from Hazards and Response in the Wellington Region

6.14 Damage, Controllability, Protection \& Risks from Hazards and Response in the Wellington Region

6.15 Potential Damage from Hazards as Perceived by Respondents

6.16 Perceived Risks from Hazards and Response in the Wellington Region

6.17 Intensity of Hazards and Response in the Wellington Region

6.18 Problems Experienced from Earthquakes in Areas Susceptible to Liquefaction in the Wellington Region

6.19 Perceived Frequency of Earthquakes in Area Susceptible to Liquefaction

6.20 Proximity of Earthquake Occurrence in Future as Perceived by Respondent Living in Areas Susceptible to Liquefaction in the Wellington Region

6.21 Potential Damage Perceived from Earthquakes in Areas Susceptible to Liquefaction in the Wellington Region

6.22 Perceived Feeling of Well-being against Earthquake, Most Feared Hazard and Information Provided by Council in Areas Susceptible to Liquefaction

6.23 Hazard Awareness of Respondent When First Settled at the Current Place of Residence

6.24 Hazard Mitigation Measures Taken by Respondent Living in Areas Susceptible to Liquefaction When First Moved into the House

6.25 Types of Safety Measures for Hazards Taken by Respondent Living on Soft Ground

6.26 Perceived Earthquake Preparedness of Respondents Living on Soft Ground

6.27 Perceived Hazard Exposure of Respondents Living at Different Slope Angles

6.28 Problems from Hazards to Respondents Living across Slopes

6.29 Frequency of Hazards Experienced by Respondents Living on Different Slope Angles

6.30 Hazard Occurrence in Future as Perceived by Respondents Living on Different Slope Angles 
6.31 Potential Danger from Hazards Faced by Respondents Living on Different Slope Angles

6.32 Perceived Situation against Hazards of Respondents Living on Different Slope

Angles

6.33 The Most Feared Hazard by Respondents Living on Different Slope Angles

6.34 Awareness of Hazard Information Provided by the Local Council to Respondents across Slopes

6.35 Hazard Awareness When First Settled at the Current Place of Residence of Respondents Living on Different Slope Angles

6.36 Hazards Considered and Mitigation Measures Taken by the Respondents across Slopes When First They Settled at Current Residence

6.37 Type of Hazard Mitigation Measures Taken and Changes Made by the Respondent Living on Different Slope Angles When First Moved into Current Residence

6.38 Safety Measures Taken by Respondents across Slopes 235

6.39 Perceived Hazard Preparedness Levels of Respondents across Slopes 236

6.40 Problems and Frequency of Tsunami in Susceptible Areas

6.41 Tsunami Occurrence in the Future as Perceived by Respondent in Susceptible Areas in the Wellington Region

6.42 Perceived Potential Damage, Feeling of Well-being against Hazard and Most Feared Hazard by Respondents in Susceptible Areas

6.43 Hazard Awareness When First Settled at the Current Place of Residence of Respondents in Areas Susceptible to Tsunami

6.44 Hazard Awareness When First Settled at the Current Place of Residence of Respondent Living in Area Susceptible to Tsunami

6.45 Hazard Mitigation Measures and Safety Measures Taken by Respondents Living in Areas Susceptible to Tsunami

6.46 Hazards for Which Safety Measures Taken by Respondents in Areas Susceptible to Tsunami

6.47 Perceived Preparedness for Tsunami by Respondents Living in Areas Susceptible to Tsunami

6.48 Perceived Exposure to Earthquake by Respondents at Varied Distance from Fault

6.49 Problems, Frequency, Proximity in the Future, Potential Damage and Perceived Feeling of Well-being against Earthquake by the Respondents Living at Varied Distance from Fault

6.50 Most Feared Hazard, Hazard for Which Information Provided by Local Council and Hazard Awareness of Respondents When they First Moved into House, at Varied Distance from Fault

6.51 Hazard Consideration and Mitigation Measures Taken by Respondents When First Moved into House, with Distance from Fault 
6.52 Hazard Mitigation Measures Taken by Respondents When First Moved into the House, with Distance from Fault

6.53 Type and Hazards for Which Safety Measures Taken by Respondents Living at Varied Distance from Fault

6.54 Hazard Preparedness of Respondents with Distance from Fault

6.55 Hazard Exposure in Rainfall Zones

6.56 Problems Faced Through Hazards in Rainfall Zones 246

6.57 Frequency of Hazards in Rainfall Zones 246

6.58 Perceived Future Occurrence, Potential Damage and Feeling of Well-being against Hazard by Respondents in Rainfall Zones

6.59 Most Feared Hazard, Awareness of Hazard Information Provided by the Local Council and Hazard Awareness When Respondents First Moved into Their House, in Rainfall Zones

6.60 Response to Hazards by Respondents in Rainfall Zones

6.61 Hazard Preparedness of Respondents in Rainfall Zones

6.62 Problems, Frequency, Proximity in the Future and Potential Danger Perceived from Flood in the 100 Year Floodplain

6.63 Perceived Feeling of Well-being against Flood and the Most Feared Hazard in the 100 Year Floodplain

6.64 Awareness of Hazard Information Provided by Local Council to Respondents Living in the Floodplain

6.65 Hazard Awareness and Response by Respondents When First Settled into the House, in the Floodplain

6.66 Hazard Mitigation Measures Taken by Respondents When First Moved into the House, in the Floodplain

6.67 Type and Hazards for Which Safety Measures Taken by Respondents Living in the Floodplain

6.68 Hazard Preparedness of Respondents Living in the Floodplain

6.69 Hazards Exposure in Wind Speed Zones of 142 Year Wind Gust

6.70 Perceived Problems and Frequency of Hazards in Wind Speed Zones (142 Year Wind Gust)

6.71 Frequency, Proximity of Hazard Occurrence, Potential Damage and Perceived Situation against Hazards by Respondents in Wind Speed Zones (142 Year Wind Gust)

6.72 Most Feared Hazard and Awareness of Hazard Information Provided by the Local Council to Respondents in Wind Speed Zones

6.73 Hazard Consideration, Measures Taken by Respondents When First Moved into the House, in Wind Speed Zones

6.74 Hazard Awareness and Mitigation Measures Taken by Respondents When First Moved into the House, in Wind Speed Zones 
6.75 Types and Hazards for Which Safety Measures Taken by Respondents in Wind Speed Zones

6.76 Preparedness of Respondents in Wind Speed Zones (142 Year Wind Gust) 257

6.77 Perceived Exposure to Bushfire vs. Susceptibility 258

6.78 Perceived Problems and Frequency of Bushfire in Susceptible Areas 258

6.79 Perceived Future Occurrence, Potential Damage, Feeling of Well-being and Most Feared Hazards in Areas Susceptible to Bushfire

6.80 Awareness of Hazard Information Provided by the Local Council, Hazard Consideration, Awareness and Mitigation Measures Taken by Respondents When They First Moved into the House, in Bushfire Susceptible Areas

6.81 Type and Hazards for Which Safety Measures Taken by Respondents in Bushfire Areas

6.82 Perceived Hazard Preparedness of Respondents in Bushfire Susceptible Areas

6.83 Perceived Type and Number of Hazard Exposure by Respondents at Their Residence

6.84 Areas Perceived to be Most and Least Exposed to Hazards by Respondents

6.85 Reasons Perceived by Respondents for Being Affected by Their Most Feared Hazard

6.86 Hazard Exposure Perceived in Age Groups

6.87 Perception of Hazard Exposure vs. Gender

6.88 Perception of Hazard Exposure vs. Ethnicity

6.89 Perception of Hazard Exposure vs. General Education and Hazard Education of Respondents

6.90 Perception of Hazard Exposure vs. Occupation of Respondents

6.91 Perception of Hazard Exposure vs. Time of Stay in New Zealand, Current Area or House

6.92 Perception of Hazard Exposure vs. Composite Vulnerability Index Score

6.93 Response to Vulnerability through Hazard Exposure

6.94 Exposure to Number of Hazards vs. Number of Hazards for Which Safety Measures Taken and Hazard Preparedness of Respondents

6.95 Perceived Level of Effect of Different Factors on Vulnerability of Respondents

6.96 Perceived Effects of Factors on Vulnerability vs. Education and Religion of Respondents

6.97 Perceived Effects of Financial Constraints on Vulnerability of Respondents vs. Their Work Status, Occupation and Income

6.98 Perceived Effects of Time of Stay in New Zealand on Vulnerability of Respondents

6.99 Perceived Effects of Factors on Vulnerability of Respondents Living in Vulnerable Areas 
6.100 Response to Hazards by Respondents Living in Vulnerable Areas

6.101 Duration of Stay in New Zealand, Residential Area and House, and Measures Adopted by Respondents

6.102 Gender, Ethnicity, Age, Education, Hazard Education, Ownership of House, Work Status, Income, Occupation and Mitigation Measures Adopted by Respondents

6.103 Measures Taken for Natural Hazards by Respondents Living in Vulnerable Areas

6.104 Gender, Ethnicity, Age, Number of Family Members, Education, Hazard Education, Work Status, Income, Occupation and Changes Made in House to Reduce Hazards by Respondents

6.105 Type and Degree of Changes Made in Houses and Insurance Taken by Respondents Living in Vulnerable Areas

6.106 Gender, Age, Education, Hazard Education, Number of Children, Family Members, Work Status, Ethnicity, Religious Orientation, Income, Years of Stay in New Zealand and Current Area vs. Safety Measures Adopted by Respondents

6.107 Gender, Age, Education, Hazard Education, Occupation, Income, Ethnicity, Years of Stay in New Zealand and Current Area vs. Hazards for Which Safety Measures are Adopted by Respondents

6.108 Type and Hazards for Which Safety Measures Taken by Respondents Living in Vulnerable Areas

6.109 Gender, Age, Hazard Education and Education vs. Preparedness of Respondents

6.110 Ethnicity vs. Preparedness of Respondents to Hazards

6.111 Religious Orientation and Ownership of House vs. Preparedness of Respondents

6.112 Work Status and Annual Income vs. Preparedness of Respondents

6.113 Number of Children and Family Members vs. Preparedness of Respondents

6.114 Preparedness of Respondents and Time of Stay in New Zealand, Residential Area and Current Houses

6.115 Hazard Preparedness of Respondents in Vulnerable Areas

6.116 Preparedness of Respondents Living in Vulnerable Areas

6.117 Hazard Exposure Perceived by Respondents in LTAs

6.118 Problems from Hazard Faced by Respondents in LTAs

6.119 Frequency of Hazards as Experienced by Respondents in LTAs

6.120 Proximity of Hazards in the Future as Perceived by Respondents in LTAs

6.121 Potential Damage from Hazards As Perceived by Respondents in LTAs

6.122 Perceived Feeling of Well-being against Hazards Perceived by Respondents in LTAs

6.123 Most Feared Hazards by Respondents in LTAs

6.124 Awareness of Respondents for Hazard Information Provided by Councils in LTAs 
6.125 Hazard Awareness and Mitigation Measures Taken by Respondents When First Moved into the House

6.126 Type and Hazards for Which Safety Measures Taken by Respondents

6.127 Preparedness of Hazards by Respondents in LTAs

6.128 Hazard Awareness of Respondents When First Settled at the Current Residence

6.129 Most Feared Hazard by Respondents at Their Residence

6.130 Primary Cause of Hazards as Perceived by Respondents

6.131 Damage Experienced from Hazards by Respondents

6.132 Degree of Effort Made by Respondents to Reduce Hazards in the Wellington Region

6.133 Agency Trusted by Respondents for Hazard Information

6.134 Agency Most Trusted by Respondents

6.135 Agency Least Trusted by Respondents

7.1 Administrative Response in the Wellington Region (1839-2007)

7.2 Hazard Information Given to Local People in the Region as Mentioned by Civil Defence Officers and District Planners

7.3 Hazard Awareness of Local Population as Perceived by Civil Defence Officers

7.4 Public Awareness of Hazards as Perceived by Civil Defence Officers and District Planners

7.5 Types of Work Done to Reduce Different Hazards as Mentioned by Civil Defence Officers and District Planners

7.6 Hazard Specific Plans as Mentioned by Civil Defence Officers and District Planners

7.7 CDEM Plan for the Staff in the Office of Civil Defence Officers and District Planners

7.8 Administrative Preparedness to Deal with Hazards in Local Councils as Perceived by Civil Defence Officers and District Planners

7.9 Administrative Preparedness for Employees as Perceived by Civil Defence Officers and District Planners

7.10 Proportion of Local People Prepared for Hazards as Perceived by Civil Defence Officers and District Planners

7.11 Extent to Which Local People are Perceived to be Prepared for Different Hazards by Civil Defence Officers and District Planners

7.12 Hazard Characteristics in the Region as Perceived by Civil Defence Officers and District Planners

7.13 The Wellington Region: East \& West Divide

7.14 Areas Most and Least Susceptible to Hazards as Perceived by Civil Defence Officers and District Planners 
7.15 Extent to Which Potential Damage from Hazards can be Reduced as Perceived by Civil Defence Officers and District Planners

7.16 Incomplete Wellington Fault Line in the Wellington District Plan 349

7.17 Finance as a Barrier to Reduce Potential Damage 349

7.18 Financial Constraints as Barrier to Public and Administrative Preparedness as Perceived by Civil Defence Officers and District Planners

7.19 Acts for Hazard Response in the Wellington Region (1840-2008) 


\section{List of Maps}

Title

1.1 Study Area: The Wellington Region. $\quad 18$

1.2 Distribution of Respondents in the Wellington Region 22

1.3 Difference in Final Output of Composite Index with and without Weight 33

$1.4 \quad$ Difference in Final Output of Composite Index with and without Weight 34

3.1 Location of the Wellington Region on the Pacific Rim as a Cause for its Exposure to Earthquakes and Volcanic Ash Fall 59

3.2 Tsunami Possibility Scenario for New Zealand and the Wellington Region 60

3.3 Relative Location of New Zealand in Relation to Global Winds and Ocean Currents

3.4 Cyclone Tracks Within 300km of the Wellington Region (1960-1989) 61

3.5 Rocks of the Wellington Region 63

3.6 Liquefaction and Ground Shaking Susceptibility of the Wellington Region 65

3.7 Physiography of the Wellington Region 68

3.8 Bathymetry of the Wellington Region 70

3.9 Average Annual Snowfall Days in the Wellington Region 72

3.10 Wind Gust of 1 in 142 years Probability in the Wellington Region 74

3.11 Mean Annual Rainfall in the Wellington Region 75

3.12 Rainfall from 1 in 142 years North-westerly and Easterly Storms in the
Wellington Region

3.13 Surface Drainage in the Wellington Region 79

3.14 Flooding Areas in the Wellington Region 80

$3.15 \quad$ Ground Water Zones in the Wellington Region 81

3.16 Forests and Vegetation in the Wellington Region 83

3.17 Bushfire Susceptibility of the Wellington Region 86

3.18 Soils of the Wellington Region 88

3.19 Hazard Susceptibility of the Wellington Region 93

4.1 Population Density in the Wellington Region (2006) 98

4.2 Population Distribution in Relation to Earthquake Related Hazards (2006) 98

4.3 Population Distribution in Relation to Flood, Drought and Windstorm (2006) 99

4.4 Population Growth in the Wellington Region (1996-2006) 99

4.5 Female Population in the Wellington Region (2006) 101 
4.6 Children Less Than Five Years in the Wellington Region (2006) 102

4.7 Elderly Population of Age 65 or More in the Wellington Region (2006) 103

4.8 Population Living on Sickness Benefit in the Wellington Region (2006) 104

4.9 Population Using NZ Sign Language in the Wellington Region (2006) 104

4.10 Population Living for Less than One Year at their Current Residence in the Wellington Region (2006) 105

4.11 Population Living Overseas Five Years Ago in the Wellington Region (2006) 106

4.12 Single Parent Families in the Wellington Region (2006) 110

4.13 Females Having Four or More Children in the Wellington Region (2006) 111

4.14 Household Composition in the Wellington Region (2006) 112

4.15 Population without Educational Qualification in the Wellington Region (2006) 113

4.16 Population for Whom English May Not Be the First Language in the Wellington Region (2006)

4.17 Ethnic Composition in the Wellington Region (2006) 116

4.18 Agriculture and Fisheries Workers in the Wellington Region (2006) 123

4.19 Sales and Services Workers in the Wellington Region (2006) 124

4.20 Workers in Elementary Occupations in the Wellington Region (2006) 125

4.21 Unemployed Population in the Wellington Region (2006) 127

4.22 Population Dependent on Benefits, Pension or Allowances for Income in the Wellington Region (2006)

4.23 Population with No Source of Income in the Wellington Region (2006) 131

4.24 Income Characteristics in the Wellington Region (2006) 132

4.25 Dwelling Density in the Wellington Region (2006) 134

4.26 Distribution of Population According to House Size in the Wellington Region (2006) 136

4.27 Population Living in Dwelling Not Owned by Them in the Wellington Region (2006)

4.28 Median Rent in the Wellington Region (2006) 137

4.29 Population without Access to Telecommunications in the Wellington Region 139 (2006)

4.30 Population with No Motor vehicle in the Wellington Region (2006) 139

4.31 Vulnerable Infrastructure in the Wellington Region 145

4.32 The Wellington Province (1870) and the Wellington Region (2009) 147

5.1 Distribution of High Magnitude Earthquakes and Density of Shallow and Deep Earthquakes in the Wellington Region (1840-2008) 157

5.2 Hazards Associated with Historical Earthquakes in the Wellington Region 158 
5.3 Earthquake Claims Made to the EQC in the Wellington Region (1997-2006) 163

5.4 Probability of 7, 8, 9 and 10MM Earthquakes in the Wellington Region 167

5.5 Earthquake-Induced Landslides in the Wellington Region 170

5.6 Rainfall Induced Landslides in the Wellington Region (1996-2007) 171

5.7 Landslide Claims Made to the EQC in the Wellington Region (1997-2006) 179

5.8 Dominant Wind Directions and Relative Location of the Wellington Region to Volcanic Fields

5.9 Average Annual Ground Frost Days and Screen Frost Days in the Wellington Region

5.10 Lightning and Hail Days in the Wellington Region 191

5.11 Average Annual Thunder Days in the Wellington Region 192

5.12 Flood Claim Made to the EQC in the Wellington Region (2002-2006) 199

5.13 Drought Frequency in the Wellington Region 203

7.1 Existing and Proposed Stop Banks at the Otaki River 357

7.2 Proposed River Design for Otaki, Hutt and Waikanae Rivers 360 


\section{List of Plates}

Title

Page

3.1 Varied Landslide Susceptibility of the Wellington Region 91

4.1 Demographic Vulnerability Index of the Wellington Region (2006) 107

4.2 Social Vulnerability Index of the Wellington Region (2006) 120

4.3 Economic Vulnerability Index of the Wellington Region (2006) 140

4.4 Composite Vulnerability Index of the Wellington Region (2006) 150

4.5 Variations in Vulnerability Index on Different Spatial Scales in the Wellington Region (2006)

\section{Text Box}

7.1 An Influence of International Hazard Event

\section{List of Photographs}

3.1 Landslide Susceptibility of Hills in the Wellington Region 67

3.2 K-surfaces in Wellington Against the Steep Slopes of the Tararua Range 68

3.3 Changing Coastlines of the Wellington Region 70

5.1 Earthquake god Rūaumoko 155

5.2 Earthquake Damage in Masterton (24 June, 1942) 159

5.3 Gold's Slide: Earthquake-Induced Landslide in Wellington (1855) 169

5.4 Damage to Houses in Eastbourne from Debris Flow (October, 2006) 181

5.5 Eruption at Ruapehu (1996) 184

5.6 Damage from the Wahine Storm (10 April, 1968) 189

5.7 Bushfires in New Zealand 195

5.8 Flooding in Kilbernie, Wellington (November, 1994) 200

5.9 Drought in South Wairarapa (2008) 205

6.1 Hazard Mitigation Measures Adopted for Houses in the Wellington Region 209

7.1 Hazard Preparedness Brochures Provided by the Greater Wellington Regional Authority 


\section{List of Acronyms \& Abbreviations}

1. CAE: Centre for Advanced Engineering

2. CBD: Central Business District

3. CDEM: Civil Defence and Emergency Management

4. DIA: Department of Internal Affairs

5. DPB: Domestic Purpose Benefit

6. EQC: Earthquake Commission

7. ELSI: Economic Living Standards Index

8. GNS: Institute of Geological and Nuclear Sciences

9. GWRC: Greater Wellington Regional Council.

10. ha: Hectare

11. IB: Invalid Benefit

12. LCDB: Land Cover Database

13. LTA: Local Territorial Authority

14. MB: Mesh block

15. MCDEM: Ministry of Civil Defence and Emergency Management

16. MELAA: Middle Eastern, Latin American and African

17. MfE: Ministry for the Environment

18. MM: Modified Mercalli (earthquake intensity scale)

19. MSD: Ministry of Social Development

20. Ng: Ground Flash Density (flashes per square kilometres per year)

21. NIWA: National Institute of Water and Atmospheric Research

22. NZS: New Zealand Superannuation or Veteran Pension

23. NZD: New Zealand Dollar

24. NZDep: New Zealand Deprivation Index

25. OGB: Other Government Benefits/Payments/Pension

26. OSPA: Other Superannuation, Pension, Annuities

27. ODESC: Official Committee for Domestic \& External Security Coordination

28. PSC: Public Safety Conservation

29. RMA: Resource Management Act

30. SGEES: School of Geography, Environment and Earth Sciences

31. sqkm: Square Kilometres

32. SA: Student Allowance

33. SOP: Standard Operating Procedure

34. UB: Unemployment Benefit 
35. WELA: Wairarapa Engineering Lifeline Association

36. WRC: Wellington Regional Council.

37. WRCDEMG: Wellington Region Civil Defence Emergency Management Group 
Chapter: 1

Introduction

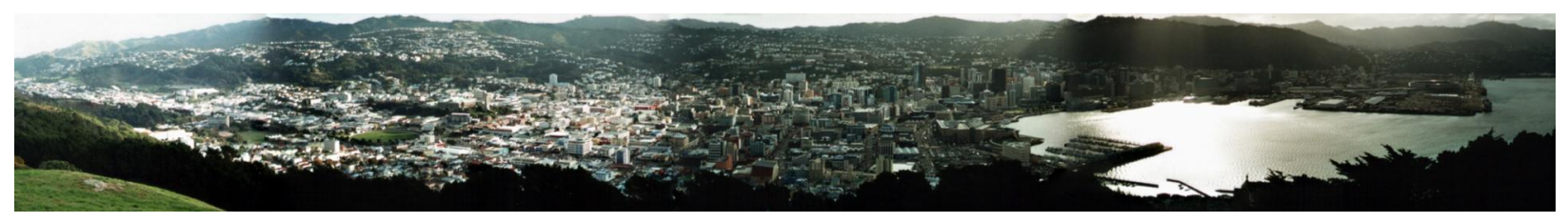


In its short history of colonisation and development, the Wellington Region has experienced a range of natural hazards. A few of them are earthquakes, landslides, flooding, windstorms, cyclones, tsunami and droughts. Although the region has not experienced any disaster in recent years, a considerable amount of money is spent every year on the protective measures and recovery from hazard damage. The Earthquake Commission [EQC] alone has paid damage claims valued at 5,014,880 NZD from earthquakes, 17,000,000 NZD from landslides, and 6,774,174 NZD from floods between 1997 and 2007. It is important to note that these payments represent only 53 percent of total EQC claims. This does not include other industrial and public property loss. In addition, the Greater Wellington Regional Council has faced damage of value greater than NZD11 million from flooding between 1995 and 2005. Apart from the monetary loss, four people lost their lives in these flood incidents (Grant, 2005, 20). The region has the largest flood protection works in New Zealand which cost millions of dollars annually to maintain. In 2008 Greater Wellington Regional Council spent about 12,931,000 NZD as operating costs on top of the total capital investment of 8,499,000 NZD for flood protection in the region (GWRC, 2008, 150). In addition, there are three long term flood plain management plans for the Hutt, Otaki and Waikanae rivers, which will require a total capital expenditure of about 92,800,000 NZD by 2040 (GWRC, 2002, 57). The overall trend shows a consistent increase in the total risk and the amount spent on hazard protection in the region. This indicates that the beautiful landscape of the Wellington Region conceals the hazardscape of its physical susceptibility and human vulnerability.

The existence of multiple natural hazards in the region raises many questions, which are crucial for their effective management and reduction. These questions include: Do people know that they are exposed to so many hazards? What is their source of hazard information? Have they prepared to face any major natural hazard in the future? Which are the dominant factors that influence their decision-making? What is their response to risk? Is the individual response to hazards the same all over the region or does it vary according to the dominance of any particular hazard? Have administrative bodies made preparations to deal with all kinds of natural hazards? Have they responded to all hazards? How have they responded? Such questions have been widely studied in hazard geography. The response governing factors that have come out of previous studies include risk perception (Saarinan, 1969, Burton et al, 1993, and Smith, 2004), attitude (Tuan, 1974, Saarinan, 1969) knowledge, awareness and resource availability (Burton et al, 1993) as well as lack of resource accessibility and vulnerability (Wisner et al, 2003).

This research aims to assess how various aspects of the hazardscape influence the hazard response at the local level. It also examines whether there is any spatial pattern in the hazard response, and if so, then which factors govern these spatial arrangements. To do this a number of broad objectives have been set and these are addressed in the following sections for the purpose of providing a justification and rationale for this research. 


\subsection{Rationale and Justification for the Study of the Hazardscape of the Wellington Region}

The study of the hazardscape of the Wellington Region is significant for many reasons. These vary from filling the gaps in the literature to assessing the local hazardscape and its influences on the response to natural hazards.

\subsubsection{To Address Gaps in the Literature for Holistic Hazard Assessment for the Wellington Region}

Holistic hazard assessment here not only refers to the study of multiple hazards at a place, but also to their various aspects including variable nature and characteristics of hazards, physical susceptibility of the place, and human vulnerability and response to hazards. In the vast literature of natural hazards and disasters, very few studies focus on multiple hazards or analyse all hazards in a place. Recognising this gap in the literature, Hewitt and Burton (1971) studied all hazards at the southwest part of Ontario in Canada. It was an exploratory study, which was designed with the aim of theory building in order to understand impact and response to multiple hazards. The study included a range of natural and social hazards. It first assessed the impact and response to individual hazards, and then classified them according to their damage potential. The study also developed a scale for hazard classification which was later refined in Burton et al (1974 \& 1993). The scale depicting the hazard characteristics has been frequently used to study multiple hazards by various scholars including Ericksen (1990), Gee (1992) and Paterson (1999), but has been rarely applied for holistic hazard assessment at the community level by incorporating both physical and social aspects of hazards.

In New Zealand, while a few research articles are based on multiple hazards, there are a number of institutional publications that deal with multiple hazards. Most of this literature is recent, prompted by the establishment of Resource Management Act in 1991. Wellington, as the capital of the country, attracted maximum attention. Gee (1992) studied the hazardousness of the Wellington Region from 1968 to 1986 for his doctoral research. The focus of the study was restricted to four city councils of the current Wellington Region including Wellington, Lower Hutt, Upper Hutt and Porirua. The author explored the spatial distribution of 18000 hazard incidents from different sources, assessed their spatial history and ranked various hazards on the basis of their potential threat. He linked the spatial pattern of hazard occurrence with geology, landform, topography, land use and urban development, and developed a landform classification for the spatial analysis of hazards. He also plotted the landslide zones for the Korokoro area and mapped the multiple hazard zones for the Seatoun and Tawa areas of Wellington City. The study thus presents information for the main cities as well as detailed analysis of some sections of the current Wellington Region, and therefore leaves scope for their integration and holistic analysis at the regional level.

Paterson (1999) explored the risk of 27 natural hazards and their likely impacts in Marlborough district. The study ranked the relative risks from various hazards by using the Federal Emergency Management Agency (FEMA) and Potential Event Severity Ranking methods. The study ranks hazards on the basis of physical characteristics of events and potential material damage they can cause (i.e. threat to life, duration of the hazard, areal extent, speed of onset, predictability 
and controllability). The study also included vulnerability, but mainly in terms of degree of potential loss to life and resources. It did not go into depth to assess various aspects of vulnerability at the community level. Like Gee (1992), this study also emphasised mapping of hazard micro zones in order to assist administrative planning and response, but it did not look into the community response.

Crozier and Aggett (2000) in very general terms described the hazards and risks in Wellington city from earthquakes, ground shaking, liquefaction, surface fault rupture, rainfall induced landslides and tsunami. They explained why Wellington has a greater risk of natural hazards compared to other territories. They also portrayed the dominant characteristics of various historical catastrophic events including the 1848, 1855 and 1942 earthquakes, the 1968 Wahine windstorm and 1976 floods and landslides. The purpose of the study was to describe the nature of risks from various hazards in Wellington, and therefore it did not analyse the social vulnerability or community response.

Wairarapa Engineering Lifelines Association [WELA] (2003) assessed the risks to lifelines from various natural hazards in the Wairarapa Region which includes three rural districts of the eastern Wellington Region i.e. South Wairarapa, Carterton and Masterton. The study examined the dominant hazards including earthquake, tsunami, heavy rain, severe storms, windstorms, cyclones of tropical origin, lightning, snow, flooding, landslides, coastal erosion, wildfires and volcanic ash fall. It used GIS techniques to overlay the findings of five different task groups on hazard identification and assessment, civil services (water supply, sewage, drainage, flood protection), transportation (including fuel supplies), electrical, communications and broadcasting, and critical facilities. The study calculated the overall risk and identified specific risk areas of infrastructural vulnerability. However, because of its limited focus, the study did not attempt to link its findings with overall vulnerability and response of the exposed community to various hazards.

In the same year, Wellington Region Emergency Management Group [WREMG] (2003) carried out hazard and risk analysis for the Wellington Region. The aim of this exercise was to rank the risks from various hazards in order to draw up the Regional Civil Defence Emergency Management [CDEM] Group Plan. The study used SMUG (Seriousness, Manageability, Urgency, Growth) analysis as a methodology and calculated risk ratings for likelihood, consequences, assessing seriousness (S) in human, economic, social, infrastructure and geographic terms, manageability $(\mathrm{M})$, urgency $(\mathrm{U})$ and growth $(\mathrm{G})$ of hazards. The report describes characteristics of hazards in the region including earthquake, tsunami, volcanic ash fall, storm, landslide, flooding, drought, rural and urban fire, hazardous substances, transportation accident, biological and agricultural hazards and terrorism. It explains their context, likelihood scenario, growth, urgency, possible consequences, seriousness and management mechanisms for each hazard separately. It finally ranks the risk from different hazards, but does not correlate it with the social vulnerability of local communities and their response.

The Wellington Region Civil Defence Plan (2005) subsequently used the risk rating from WREMG (2003) to plan for hazard response in the region. The plan summarises the characteristics of Wellington Region and its hazards to establish the context for administrative arrangements and an operational framework for effective emergency management. The plan identifies strategic issues, 
objectives and methodology for hazard reduction, readiness, response and recovery. It discusses the general vulnerability of the region in terms of concentration of population and resources from a management point of view. It omits an assessment of specific vulnerabilities attributed to age, disability or other socio-economic conditions, which are likely to influence the impact of hazards. Further, the assessment of community response is also missing in the plan.

Grant (2005a) prepared a background report of natural hazards in the Wellington Region. It explains earthquake, tsunami, flooding, landslides, coastal erosion, severe wind, wildfire, drought and volcanic hazards in the region. It describes each hazard individually by outlining the state, hazard occurrence in the past 10 years, pressures accelerating the growth of hazards and institutional responses to them. The institutional responses illustrate the plans and policies along with the roles and responsibilities of Greater Wellington Regional Council [GWRC], Local Territorial Authorities [LTAs], Ministry of Civil Defence and Emergency Management [MCDEM], Ministry for the Environment [MfE], Wellington Region Civil Defence Emergency Management Group [WRCDEMG], Earthquake Commission, Institute of Geological and Nuclear Sciences [GNS], National Institute of Water and Atmospheric Research [NIWA] and engineering and lifeline groups. It also discusses common response for all hazards along with information barriers, but does not refer to variations in the local vulnerability and community response.

Seville and Metcalfe (2005) developed a hazard risk assessment framework for the state highway network in New Zealand. They looked at road vulnerability to multiple hazards including seismic events, volcanic events, landslides and avalanches, flooding, snow and ice, tsunami and wild fire. In order to calculate risk, they focused on three factors, i.e. likelihood and magnitude of hazard event, vulnerability of the road network to damage from hazard, and the social, environmental and economic impacts of road damage or network disruption. They used a walkthrough scenario approach in which hazard events throughout New Zealand are randomly simulated over a long time scale, giving a simulated data set for probabilistic analysis of total risk. The study thus assessed the vulnerability of roads and associated risk factors and was aimed at formulating a cost effective and workable risk management framework rather than analysing hazards in totality.

The Official Committee for Domestic \& External Security Coordination [ODESC] (2007) produced a 'National Hazardscape Report', which describes the major hazards and associated risks along with their management within the country. The report summarises the physical characteristics of hazards, their occurrence and impacts along with their spatial distribution and administrative arrangements for hazard reduction, readiness, response and recovery. It also mentions various sources for further information on the details provided. The report therefore, acts as a source book on hazards, their management and information sources in New Zealand rather than a holistic analysis of hazardscape by assessing its various aspects.

The overall research on multiple hazards in the region is therefore skewed towards measuring and ranking risks, assessing material vulnerability and discussing institutional response and management of hazards rather than understanding hazards as a problem. 


\subsubsection{To Study the Influences of Differential Physical Susceptibility on Hazard Response}

Studies show that Wellington Region has differential physical susceptibility to various hazards. Even though the region is exposed to multiple hazards, not all places are equally susceptible to all hazards. Location, physiography, geology, climate and other distinctive features such as fault alignments, soils and vegetation in variable combinations produce variations in the physical susceptibility to different hazards in space. Where coastal areas of Wellington, the Kapiti Coast, Porirua and Lower Hutt are susceptible to tsunami, cyclones and drought, hilly areas of Wellington, Lower Hutt, Porirua and Upper Hutt are exposed to frequent landslides, windstorms and bushfires. The low lying areas in the three eastern districts, on the other hand, experience frequent flooding and are susceptible to liquefaction. Hazards also vary among similar topography. While the Western Hills in the region are exposed to landslides and fault movement, the Eastern Hills face regular droughts and erosion. Such variations in the physical susceptibility may not only influence the perception and attitude of the local population towards different hazards, but could also govern individual priorities and the nature of response to them. This would generate variations in the hazard response within the region, and such considerations are used to formulate the guiding hypothesis (Section: 3) of this research.

Irrespective of varied physical susceptibility of the Wellington Region to multiple hazards, there are very few studies that focus on this aspect. Crozier (1990) plotted varied physical susceptibility to landslides in the Wairarapa Region. He assessed the differences in the erosional processes and landslips in the region in accordance with the variations in the geological formation, landforms and climate. However, because of the focus on physical characteristics of landscapes, the study did not look into the influences of varied physical susceptibility on the social response to landslides. McConchie (2000) studied the physical susceptibility of Wellington to earthquakes and associated risks. The author explained the causes and factors affecting the intensity of earthquakes in the region. But again, due to the limited focus on geomorphic aspects of earthquakes and related risks, the study did not link their influences to the social behaviour. GeoEnvironmental Consultants (2001) prepared a report of tsunami hazard and its risks for the Wellington Region. The study identified five hotspots and plotted the tsunami susceptible zones on the basis of history of tsunami incidents in the region. The purpose of the study was to use the resultant information for planning hazard management from an administrative point of view, and therefore it did not make an attempt to use its findings to study community perception and response.

A number of flood susceptibility maps have been produced for different river management plans within the region. Easther (1991) produced a detailed report on the history of the Hutt River from 1840 to 1990 in terms of its physical characteristics and changes in the Hutt Valley before and after European colonisation. The report also provides the technical details of various drainage works that have been carried out on the river for flood protection and control. However, the findings of the report have been rarely used to correlate with the social response. Similarly, the Waikanae Floodplain Management Plan by the Wellington Regional Council [WRC] (1997) and Otaki Floodplain Management Plans by WRC (1998a) plot the flood susceptibility zones of Waikanae and Otaki rivers respectively. Both describe the river catchments, flood problems, 
people's vulnerability and management strategies in a similar fashion. Once again, these reports look at the problem from a management point of view, rather than for community response.

There is also a scarcity of literature on multiple hazard susceptibilities in the region. Gee (1992) plotted all hazard susceptibility in Seatoun and Tawa areas. Since these areas cover a very small extent of Wellington City, it leaves scope for further study of physical susceptibility of the whole Wellington Region and also to build the story by linking these susceptibilities to the response of community and local administration. Linking physical susceptibility with hazard response would not only help in understanding local response behaviour, but also in addressing the identified gap in the literature.

\subsubsection{To Study the Influences of Hazard Occurrence and Their Social Cost on Hazard Response}

There are few studies that have looked into the social cost of hazards and their influences on human vulnerability and response in New Zealand in general and Wellington in particular. This is because the major research institutions such as the former Geophysical Division of New Zealand DSIR or its successor the Institute of Geology and Nuclear Sciences [GNS], and the National Institute of Water and Atmospheric Sciences [NIWA] mainly deal with physical aspects of natural hazards and therefore the social aspects of hazards have traditionally been neglected within the region (Dibble, 1984; Ridgway, 1984). Having said this, over the past few years GNS and to an extent NIWA have made major advances in the study of vulnerability and social response in general. A few of these studies are referred in Sections 1.1.4 and 1.1.5.

Studies on the impacts of hazards are rather fewer and more recent. Grapes (2000) investigated the huge destruction that resulted from 1855 earthquake and highlighted the inherent vulnerability of people in Wellington. He effectively demonstrated the grim impact of the earthquake on the newly settled European residents, but since the study was a historical account, it did not link the past effects with the current hazard response. McLaren (2002) studied the 1942 Wairarapa earthquakes and wrote a detailed account of earthquake damage due to a large number of unsafe buildings. The study again did not link the influences of earthquake occurrence to the current response pattern. McConnochie (2004) compiled the letters and interviews from the survivors of the 1931 Hawke's Bay earthquake and presented an account of fear, panic and misery of people who faced the earthquake. The work contains the database for damage and response to earthquake hazard in Hawke's Bay, but does not include any analysis of relationships between impact and community response or their variations in time or space. Glade and Crozier (2005) assessed the factors triggering landslides, landslide types, their characteristics and possible impacts by taking examples from New Zealand. They also plotted the probability of occurrence of daily precipitation having a threshold of triggering landslides in Wellington and explained vulnerability in brief. However, they did not study the social aspects of hazard occurrence and response behaviour. Similarly, Fuller (2005) studied the causes and consequences of the February 2004 Manawatu floods in New Zealand, and explained the geomorphic and fluvial impacts of the flood. He concluded that although extreme events are natural, their intensity is exacerbated by human activities within catchments. Even though the study links the physical and social aspects of hazards, 
it only highlights the one way relationship of cause and effect rather than assessing the two way relationships between physical and social factors.

McFadgen (2007) studied the catastrophic events in the prehistoric context and their impacts on the Maori communities living in the coastal areas of New Zealand. He looked into physical susceptibility of the country to various geological hazards, particularly major earthquakes, tsunami and volcanic eruptions, based on the geological evidence and analysis of archaeological deposits. The study discusses the possible occurrence and characteristics of major catastrophic events in the Wellington Region, and broadly describes the impact of these events on Maori in the form of disruption of livelihoods through salt water contamination, sand dune spreading or disruption of natural resources through earthquakes, tsunami or landslides. It also points to migration as the social response to such events. However, since the prehistoric communities were simple in terms of their livelihood and social organisation, the study contributes less to the understanding of social vulnerability and response to these hazards in the modern multicultural complex societies.

Cousins, et al. (2008), on the other hand, calculated the combined possible losses from earthquakes and tsunami in the Wellington Region in today's context. They selected different scenarios for likely earthquakes in the Wellington Region having the potential to generate tsunami. Despite having a conservative approach to estimate the damage, they found that such events may cause a significant amount of monetary loss in the region. They noted that an earthquake of $\mathrm{Mw}$ 7.5 at Wellington fault could produce maximum damage through ground shaking in the region of 13,700m NZD with 40m NZD of tsunami loss. Maximum tsunami loss could occur in the region as a result of an earthquake of Mw8.9 at the Pacific plate subduction zone of 2,300m NZD with $6,100 \mathrm{~m}$ NZD of earthquake loss. Since the aim of the report was to project the total loss, it did not look for response implications in depth.

Johnston, et al. (2008) studied the tsunami response to $25^{\text {th }}$ May 1960 tsunami in New Zealand. The study is based on the content analysis of articles on the event from 38 newspapers in May-Jun 1960 along with interviews with 18 eyewitnesses of 1960 tsunami who were evacuated. Oral accounts were collected from Akaroa (2), Blenheim, Christchurch (2), Lyttelton, Napier (2), Okains Bay, Opotiki, Paroa, Pigeon Bay, Te Awanga, and Whitianga (5). The study highlights the response behaviour and shortcomings in the tsunami response and it's after effects. It finds that an effective integrated warning system is required to address the residual risk.

The overall trend shows that there is a gap in the literature that assesses the influences of the varied social impacts of multiple hazards in the Wellington Region.

\subsubsection{To Study the Influences of Varying Human Vulnerability on Hazard Response}

Uneven human characteristics of places, from entirely remote and rural communities to self sufficient urban areas, create diverse vulnerability patterns throughout the region, which in turn are likely to produce variations in the response to local hazards. In urban areas, where distribution of services reduces vulnerability, the excessive concentration of population and resources put people in a higher risk zone. Vulnerability of major infrastructure throughout the region including the water supply system, sewer systems, railway station and airport to fault movements, earthquakes, 
landslides and ground settlement (Centre for Advanced Engineering [CAE], 1991a), could influence the coping capacity of the local community in a disaster. However, there have been few attempts to link various aspects of local vulnerability with hazard response of people.

The literature on vulnerability analysis in New Zealand and the Wellington Region is limited. The Centre of Advanced Engineering (1991) assessed the vulnerability and mitigation of lifelines in the Wellington Region in case of any geological hazard, particularly earthquake. They assessed lifelines including water, sanitary drainage, storm water drainage, gas, electricity, telecommunications and broadcasting, transportation, building services and buried pipelines individually as well as in groups. The aim of the study was to identify the vulnerable infrastructure and to rank its risks in order to reduce its vulnerability. The study therefore did not attempt to link its findings with the overall vulnerability of local communities and their response to hazards. Using the findings of CAE, Leighton (2002) assessed the vulnerability of lifelines including transportation, communication, water supply, electricity, gas and sewage disposal in Porirua City. She explored mitigation measures and planning along with the strengths and weaknesses of these lifelines. This study again revolved around the vulnerability of infrastructure and administrative response rather than community response. Along similar lines, WELA (2003) assessed the vulnerability of lifelines in the eastern section of the region. This study therefore completed the assessment of lifeline vulnerability for the whole Wellington Region, but was limited to lifelines. The study did not look into the interlinked social vulnerability or community response.

While a number of studies focus on infrastructural vulnerability, there are a few studies which have looked into the vulnerability of local community. Miller, et al. (1999) explored the psychological aspects of community vulnerability following the 1995 and 1996 eruptions at Ruapehu volcano. They tested the sense of community, coping style, self-efficacy, social support and age on post disaster vulnerability of the Ohakune population. They found that self efficacy and a problem focused approach helps to reduce vulnerability. The research therefore covered only one aspect of a holistic assessment of a community's vulnerability and its influences on the response behaviour.

Measuring vulnerability is a common method of assessing vulnerability in the international literature. However, very few studies have made attempts to measure vulnerability to natural hazards in New Zealand. On the other hand, a few studies have focused on measuring socioeconomic conditions that could contribute to local vulnerability. Salmond, Crampton and Sutton (1998) developed the New Zealand Deprivation Index (NZDep) as the measure of health and equity at the mesh block level. It included seven dimensions of socio-economic deprivation i.e. income, transport, living space, home ownership, employment, qualification and support, which were captured by various census variables (Salmond, Crampton, and Sutton, 1998, 835). The authors validated the index by correlating the deprivation index with health outcomes including lung cancer in New Zealand, discharge ratio and mortality in Wellington. The index is widely used for exploring deprivation in New Zealand, and has been subsequently calculated for each census year i.e. 1996, 2001 and 2006, with some modification. The NZDep96 is an area based index that is compared with the socio-economic deprivation for individuals, and correlated with smoking behaviour (Salmond and Crampton, 2001). Salmond and Crampton (2001) found that the small 
area index of deprivation is weakly correlated to the individual deprivation index and there are gaps that required to be filled by individual information. However, both area and individual deprivation index values are strongly correlated with smoking behaviour, and provide the contextual information. The NZDep2001 provides deprivation for small areas in two forms i.e. an ordinal and a continuous score. It gives score ranging from 1 to 10 on ordinal scale. It divides the New Zealand into tenth of the distribution of the first principal component scores, where 10 indicates the most deprived mesh block in the country (Salmond and Crampton 2002). Salmond, et al. (2006) also developed the NZiDep i.e. New Zealand index of socioeconomic deprivation for individuals. The aim of the research was to identify the key indicators of individual deprivation appropriate for all ethnic groups. NZiDep index is based on eight simple questions which may take 2-3 minutes to administer. The questions are based on using food grants or banks, buying cheap food to make ends meet, feeling cold to save heating costs, being out of work for more than one month, having to wear shoes with holes, living on a means tested benefit, going without fresh fruits and vegetables, and having help from a community organisation. The index provides a significant tool for measuring individual position on socio-economic continuum. The index is validated by using information on tobacco smoking, which is known to be strongly related to deprivation.

Another similar measure is that of the Economic Living Standards Index [ESLI] which is developed by the Ministry of Social Development [MSD]. Jensen, et al. (2006) portrayed the living standards in New Zealand in 2004 on the basis of ESLI scale. ESLI is mainly based on the population's consumption behaviour, their various sources of recreation, social participation and household facilities rather than general income, resources or other assets (Jensen, 2006, 19). However, since the focus of this study is to present living standards, it does not link its findings either to hazard vulnerability or response.

Paton, et al. (2006) explored the mapping of social vulnerability by using GIS for Napier City. In order to map the vulnerability they first created hazard layers of liquefaction amplification and landslide, and then overlaid the findings on the deprivation index scores for mesh blocks of the city. They pointed to various aspects of vulnerability that could influence the response and that are therefore important in assessing hazard planning and management. However, the study is more about discussing the methodology and findings with respect to their implications for planners rather than understanding the details of local vulnerability and its influences on community's response behaviour.

Finnis, K. (2006) studied the community vulnerability and resilience to volcanic hazards in Mt. Taranaki, and assessed their perception and preparedness for these. She studied various socioeconomic and socio-psychological characteristics of the community contributing to the vulnerability and resilience to volcanic hazards. These include age, gender, ethnicity and socioeconomic status along with socio-cognitive factors such as risk perception, self efficacy, coping style, sense of community and prior experience of hazards. The research also looked in depth at children's perception, psychological issues and influences of hazard education on their and their family's preparedness for volcanic hazards. She also carried out a spatial analysis of risk for Inglewood, Stratford and Opunake by overlaying a hazard map on deprivation index values and comparing them with the census data for population density, female, child and adult population, 
socio-cognitive factors i.e. self efficacy, action coping and sense of coping and finally preparedness measure index. But her research did not find the spatial analysis very useful due to small data sets. It also suggests guidelines for enhancing the effectiveness of public information systems and thereby resilience of the community. The study therefore looked into various aspects of hazards, susceptibility, vulnerability, resilience and response to volcanic ash fall, but the focus was limited to volcanic hazards and response mainly in the form of preparedness.

Paton, Miller and Johnston (2001) studied the community resilience to volcanic hazard consequences. They emphasised that risk management principles should also incorporate community resilience aspects. They assessed the role of self-efficacy, problem-focused coping, sense of community and age in predicting resilience of the community. They developed a model that can be used to predict resilience in an all-hazard management framework.

As shown above, the overall literature on vulnerability in New Zealand shows that there is a lack of holistic assessment of local vulnerability in the Wellington Region and its influences on the community response.

\subsubsection{To Study Variations in Local Hazard Response across the Wellington Region}

Local response to various hazards in the region could be governed by various factors of hazardscape, which may produce variations over space and time. For example, the perception and response of people may vary within the region according to the type and characteristics of local hazards, variations in physical susceptibility and their vulnerability. Therefore, even though the entire region is highly vulnerable to earthquakes, flood may preoccupy the minds of people living in the Hutt Valley and this could result in a passive response to earthquake compared to flood. Similarly, people having assets in the coastal areas may be more fearful of tsunami than earthquake. Frequency and intensity of hazards would also influence the perception of hazards. Age, gender and socio-economic status of people are other factors which could govern the response to local hazards. Therefore, the analysis of variations in response over space and the influences of hazardscape in these variations could be useful for informing the hazard response management in the region.

Hazard perception and attitude have been identified as important factors of influencing response. The studies of hazard perception in the region are mainly focused on the geological hazards. Simpson-Housley and Curtis (1983) carried out a survey in Newlands, Wellington to study earthquake occurrence along with its experience and appraisal by the residents. They examined association of gender, age and earthquake experience with attitudes of residents towards hazard. The study therefore assessed the influence of individual factors on attitude towards earthquake for a small area in Wellington City, leaving scope for further assessment of overall vulnerability affecting hazard response throughout the region. Johnston, et al. (1999) studied the change in hazard perception in two communities of Whakatane and Hasting in the North Island before and after the Ruapehu volcanic eruption in 1995. They noticed significant change in hazard perception in Hastings, which experienced a direct impact of volcanic eruption compared to Whakatane, which was not affected by the hazard to the same extent. The study therefore links the influence of 
hazard occurrence on variations in perception over space. However, it does not go into details on other factors that govern variations in hazard response at the local level.

Vorcoe (2002) examined the effect of hazard education in the formation of risk perception in Wellington and compared that with scientifically calculated risk values. She found that formal education along with personal experiences, media and other alternative information sources have helped people to get an accurate hazard picture. Because of the limited focus on accuracy of hazard perception, the study does not look into how this perception has influenced the response of people to local hazards. Harmsworth and Raynor (2005) studied the role of indigenous knowledge on risk perception of Maori people of Aotearoa. They evaluated indigenous belief, values and social structure along with changing socio-economic structure, and identified five strands of risk perception including loss of natural resource, economic resource, personal or human resource, cultural resource and education. This study again had a very limited focus on indigenous risk perception rather than that of the whole community and its influence on total response.

A number of studies have looked into influence of perception and other cognitive factors on hazard preparedness in New Zealand. Cowan (1998) examined the various psychological factors that influence earthquake preparedness. He studied effects of media descriptions on people's judgement about earthquakes especially for information about earthquake agency along with general and specific hazard damage. The findings of the study are therefore, specific to the influences of media. It did not assess the differences in these influences over space or in time or on response behaviour.

Marriott (2002) assessed the influence of risk perception on earthquake preparedness in Newlands, Wellington. She noticed that though risk perception has increased among people, it had not significantly affected their preparation against earthquake. She also noted the impact of gender and education on perception and preparedness level. Spittal (2003) correlated demographic and psychological factors with earthquake preparedness in Wellington. He evaluated risk propensity and locus of control, risk and earthquake preparation between university students and Wellington residents. Both studies thus assessed the factors affecting preparedness for earthquake mainly from a psychological point of view, rather than holistic assessment of overall response to hazards.

Johnston, et al. (2002) studied the community perception of flooding in the Waikanae River in August 2001. They assessed the residents' attitudes and their understanding of flood warning and management. They studied various aspects related to risk perception, previous exposure, information received from government, hazard preparedness activities, information sought for preparedness purposes and the extent to which people are engaged in management activities. They found that flooding is well perceived in the region and majority of residents are concerned about it. However, less than 45 percent have seen the flood map, and about 85 percent were aware of some sort of flood warning. A moderate to high preparedness is noted. The study identifies four phases of interventions in order to build local resilience i.e. improving communities hazard knowledge and risk perception; promoting intentions to adopt preparatory measures; converting intentions into actual behaviour and maintaining the capability.

In addition, a number of studies have looked into children's perception of hazards and its influences on hazard preparedness. Ronan and Johnston (2001) studied the risk perception of 560 
school children in Auckland about future hazard occurrence and likelihood of injury and emotional factors like fear. They examined the emotional coping capacity of children with or without hazard education. They found that hazard education at school is helpful in increasing hazard adjustment at home particularly the specific knowledge on emergency management. Later, Ronan and Johnston (2003) extended their previous research by speculating on the effect of emergency management education compared to hazard knowledge. They examined the perception of 219 school children and found the emergency management education to be more effective and helpful in enhancing both child and parent reported hazard adjustment. Finnis, et al. (2004), by following a similar line of investigation studied children's understanding of natural hazards in Christchurch. They studied risk perception, level of preparedness and participation in education programmes of 102 children in a school. They found that although the course was attended by the majority of students, the level of household preparedness remained low. Tiper (2007) also studied the risk information provided in schools and its influence on how children perceived the risk associated with natural hazards. The study was based on the survey conducted with 122 School children of 11-13 years of age in Porirua. It found that most students had attended the hazard education programmes but their overall knowledge and understanding of natural hazards differed. The study also compared the findings with the results obtained from Auckland and Christchurch studies and supported the need of a continued hazard education programme as an effective means of increasing individual and home based preparedness levels. All of these studies support the provision of pre-event hazard education compared to post event education, as it could lead to effective hazard response and behaviour.

Coomer et al (2008) studied the emergency management teaching and exercises carried out in schools of Wellington region along with information and material available for education and preparedness for any emergency situation. The study area mainly included Wellington, the Hutt Valley, Porirua, and the Kapiti Coast Schools. Both questionnaire surveys and interviews were conducted. The study found that around 70 percent of schools in the areas surveyed seemed to be somewhat prepared for a hazard event, but the response varied from a few schools which were totally prepared with training, resources and supplies, to others the extent of involvement was no more than one or two evacuation practices per year. Overall, the schools used a variety of resources but only 62 percent used the local government agencies of emergency management/civil defence and their resources which are readily available. Many schools actively involve caregivers in their emergency management programmes and some link to community initiatives, but this appears to depend on the individual schools. However, the focus of these studies was limited only to the influence of hazard education on hazard perception of children and their families rather than the whole community and the range of other factors that influence hazard response.

The literature on community response therefore is skewed towards the risk perception and preparedness, which mainly focuses on geological hazards (i.e. earthquakes and volcanoes). There has been little attempt to study how the community responds when exposed to multiple hazards and how their presence influences individual decision making. 


\subsubsection{To Study the Administrative Response to Hazards and to Identify Gaps with Respect to the Hazardscape of the Wellington Region.}

Besides assessing the community response to hazards, it is also imperative to evaluate the administrative response for hazard management in relation to the local hazardscape and to the community's response. There are a number of studies which have focused on the administrative response to hazards in New Zealand. They can be broadly divided into two groups. One set of studies has looked into administrative response with respect to a particular event, other group has studied the legislation, planning, administrative response methods.

Paton, et al. (1998) examined the response of thirty organisations to volcanic eruptions at Ruapehu in 1995. They pointed to lack of co-ordination, inadequate communication among organisations and community, lack of trained personnel, management issues and media problems. The study mainly focused on assessing the problems in effective operation of the existing hazard management system rather than finding the gaps that are not covered by current response arrangements. Ronan et al. (2000) emphasised the multidisciplinary approach to management of the volcanic eruption of Mount Ruapehu in 1995-96. They highlighted the significance of coherent research carried out by natural and social scientists to reduce the impacts of volcanic hazards by assisting individuals, communities and organizations. The study emphasised holistic hazard assessment, but only looked at volcanic hazards when the response of the local communities may also be modified by the presence of other hazards in a place.

Kingsbury (2000) explored the flood hazard and its warning and awareness at Blandswood Peel forest, South Canterbury in New Zealand. He elucidated the impact of a 1975 flood on livelihoods and on flood hazard mitigation and planning, including major steps taken by the administration for flood awareness, such as flood warning systems, flood danger signs, flood warning notices, information brochures and flood level signs. The study mainly focused on the administrative response to flood, and did not link its findings with community perception or response to the hazard.

Becker and Johnston (2002) studied the administrative planning for earthquakes in New Zealand. They assessed the legislation dealing with the natural hazards such as the Resource Management Act (1991), the Building Act (1991) and other statutes along with regional and local plans and policy statements for their treatment of earthquake hazard and response. The study assessed 24 district plans along with respective regional policy statements in Hawke's Bay, Bay of Plenty, Waikato and the Wellington Region. It found that not all district plans closely follow their Regional Policy Statement [RPS], and the proportion of district plans that follow RPS varies from 17 percent in Bay of Plenty, 50 percent in the Wellington Region to 70 percent in Hawke's Bay and Waikato. They also studied the correlation of districts plans within the same region and found variations across regions. The districts plan in the Wellington Region showed a better correlation than other areas for earthquake. This is because the common fault lines cross a few districts in the region. However, certain contents such as rules differed between districts despite having a common source of hazards.

Kerr, et al. (2003) prepared guidelines to assist resource management planners in New Zealand for the development of land or buildings located close to active faults. They discussed four 
principles for planning approaches that included gathering accurate information, planning to avoid hazards in the pre-developed areas, taking a risk-based approach to plan for post-developed areas, and using communication as a tool for mitigating hazard in the built up areas of possible fault rupture. They also defined and discussed earthquakes and active faults, methods of using a risk based approach, mapping active faults, fault complexity, interval occurrence, building importance categories and various planning tools and related issues along with resource consents. The study also presents case studies for implementing the guidelines. Following this trend, Saunders and Glassey (2007) compiled guidelines for assessing planning policy and consent requirements for landslide prone areas. They discussed the nature of landslide hazards along with the need for landslide planning and guidelines and the four principles for planning approach as discussed by Kerr, et al. (2003). The aim of both of these studies was to provide the information support for hazard planning and decision making to the local councils rather than looking for existing shortcomings in the system.

Webb (2005) reviewed the preparedness for local and distant tsunami in New Zealand, and assessed various warning systems operating at international, national and regional levels along with seismic and sea-level monitoring systems. The study found that there is no formal system existing for regional tsunami events, and the nature and effectiveness of tsunami warning would differ according to the lead time available for an evacuation. It subsequently reviewed the effectiveness of warning systems based on 95 percent of evacuation for a distant tsunami with a long warning time, and 10 percent evacuation in case of a local tsunami with a short lead time. The report also discussed various other components of tsunami warning relating to research, planning, cooperation, discussion, communication, education, evacuation, exercises and evaluation. It therefore mainly focused on the administrative capacity, response and shortcomings and made a number of recommendations for improvement in preparedness for tsunami response.

Institutional response to flooding in New Zealand has been studied in detail by Ericksen. He identified ten factors that have influenced the administrative flood response in New Zealand, which he published in two parts in 2005. In the first publication, Ericksen (2005a) identified five factors that have produced gaps in the legislative intent and actual response to flooding in the country. These include the differences in the understanding of flood return period, changing flood characteristics, understanding of flood hazard, underselling the mandate such as RMA and limited cooperation in different government agencies. In the second publication, he highlighted another five factors that include issues surrounding the managerialism and integration within local councils, legal issues in depicting flood prone areas, the influence of disclosure of such information on property values, freedom of response choices and information access, as well as mainstreaming risk reduction into policies, plans and practices (Ericksen 2005b). He found that these factors need to be considered as an important factor of vulnerability rather than the physical change in the flooding event itself. The findings are therefore, limited to the shortcomings in the administrative system in general rather than linking them to local vulnerability and response of local people.

Crozier (2005) explained the issues related to landslide risk management. He examined the role of hazard and risk management protocols and their mitigation options. He evaluated landslide planning in New Zealand in its legislative framework and fundamental requirements to enable 
effective management. Phillips and Marden (2005) reviewed the role of vegetation in modifying landslide processes and assessed the record of efforts taken by the New Zealand government to manage the landslide risk in the East Coast Region, particularly the East Coast Conservation Forestry Scheme. Both studies thus assessed the administrative response to landslide hazard in depth, but their focus was limited to a single hazard and they did not link that with the overall hazardscape and community response.

A few studies also looked at administrative response to multiple hazards. Pearse, et al. (2001) explored the management of natural hazards in Hawke's Bay. They described the natural hazards of the region and explored risk analysis and risk management by local and regional councils. They emphasised the need for clear understanding and continuing research on natural hazards for effective management strategies. The study, although including multiple hazards, was focused on administrative response only, and did not look for community response and regional differences. Grant (2005) also assessed the administrative response to multiple hazards in the region but again did not correlate this with community response.

Some other studies have focused on the individual administrative response to hazards, either in the form of a plan or policies, or any response structure. Jensen (1998) reviewed New Zealand's emergency management plan for Wellington and changes in its nature, services, approach and objectives. He explained the Council's plan for integrated response and recovery planning and an incident management system. Hence the focus of this study was very specific to emergency management planning. Middleton (2001) traced the origin of insurance and its use in hazard management. He described the origin and role of the New Zealand Earthquake Commission before and after catastrophes and for facilitating research and educating people.

A few studies have also looked into overall administrative response to hazards. Britton assessed the administrative response to hazards in general and those of New Zealand in particular. Britton and Lindsay (1995a) discussed the reasons for integrating city planning and emergency preparedness in general. They discussed the need as well as how this integration can be achieved. In their next paper, Britton and Lindsay (1995b) presented two case studies from Australia and Canada respectively to highlight the need to integrate city planning and emergency preparedness with examples. This paper discussed the issue of growth of vulnerability in urban areas as the unintended outcome of city planning, which they pointed out can be reduced by involving city planners in mitigating hazards and emergency management. Britton (1999) elaborated on the role of emergency managers in contemporary society. He noted six positive developments in terms of realistic context, educational programs, links between research and practice, increase in the interest in uncertainty, systematisation and multidisciplinary orientation. He also noted six counterbalancing issues with response orientation i.e. mainly towards preparedness, focused recruitment especially to 'macho male', an 'open season on all hazard approach' that could lead to response governed by command and control, information sensitivity (i.e. denial of information for research), lack of accepted terms and quality control. He also identified the future role of emergency managers in building resilient communities, sustainable development, long term hazard reduction, building equilibrium between human and natural environmental interaction, appropriate emergency 
mechanism for risk management, and the ability to understand and link emergency management concepts and practices with wider community management practices and process.

In 2001 Britton traced the changes in natural hazard emergency response from a reactive event based response to integrated emergency management in New Zealand in parallel with such developments in other parts of the world. He emphasised the inclusion of community sustainability and resilience for effective emergency management. He identified six drivers of change including sustainability, resilience, integrated management, governance, partnerships and economic efficiency. He also highlighted various obstacles in the risk management process that broadly included vertical and horizontal fragmentation of governance systems, inadequate linkages between public and private sectors or research and communities, technical problems in identifying hazards, defining risk and planning and implementing response for mitigation, preparedness, emergency response and recovery. He pointed out that emergency management is starting to become more politically salient and needs to be mainstreamed for land use planning and other development decisions that influence hazard occurrence. Saunders, Forsyth, Johnston and Becker (2007) also highlighted the significance of strengthening linkages between land use planning and emergency management in New Zealand. They highlighted that even though both the New Zealand Civil Defence Emergency Management Act (2002) and Resource Management Act (1991) aim for sustainable development by reducing hazard, they work in isolation. They presented the framework and the tools that can be used to combine the philosophies of the two acts in order to mitigate hazards and enhance community resilience.

It is therefore clear that most studies have assessed administrative response to hazard from a management point of view, and have not linked that with community vulnerability and response. Also, a number of studies have assessed response to particular hazards, and there is a gap in the literature looking at the responses when a place is exposed to multiple hazards.

This research therefore contributes towards filling these gaps by integrating various aspects of hazardscape of the Wellington Region including hazard characteristics, physical susceptibility and human vulnerability along with local and administrative responses. In accordance with the rationale and justification given above, specific aims and objectives can be formulated along with a research hypothesis as following.

\subsection{Aims and Objectives}

The aim of the research is to explore the hazardscape of Wellington Region and its influences on response of local people and administration to different hazards. The objectives of the research therefore are to:

1. Evaluate physical susceptibility of the Wellington Region to various hazards.

2. Assess human vulnerability to natural hazards throughout the Wellington Region.

3. Examine spatio-temporal occurrences of hazards in the region.

4. Analyse variations in intra-regional hazard response and identify influences of hazardscape behind these differences. 
5. Study administrative response to hazards with respect to the hazardscape of the Wellington Region.

A study of the existing literature, as outlined above, provides the rationale and justification for the overall hypothesis. The objectives listed represent the tasks required to investigate the hypothesis.

\subsection{Hypothesis}

'Whereas integrated regional planning is likely to produce a uniform response to hazards, hazardscape introduces variations in the local response throughout the region.'

This hypothesis is constructed because the Civil Defence Emergency Management [CDEM] Act and National CDEM Strategy emphasises an integrated regional planning to deal with natural hazards at a regional level. This leads to an overarching Regional Civil Defence and Emergency Management Plan for each region which needs to be consistent with other strategic documents including the Regional Policy Statement. The integrated planning system is aimed at attaining uniform response to hazards throughout the region. However, as the rationales for the research suggest, various aspects of hazardscape may influence the local response by defying the single risk values calculated for hazard management at the regional level. This thesis explores various characteristics of the hazardscape of the Wellington Region which could produce variations in the local response to hazards, and therefore, may prohibit regional planning from attaining uniform response throughout the region.

\subsection{Area of Study}

Wellington Region is located at the southern tip of the North Island of New Zealand. It is spread over an area of $8,124 \mathrm{sqkms}$ from $40.4^{0} \mathrm{~S}$ to $41.6^{\circ} \mathrm{S}$ latitudes and from $174.5^{\circ} \mathrm{E}$ to $176.2^{0} \mathrm{E}$ longitudes. The region has an overall hilly terrain and a long coastline of nearly 500 kilometres, which touches the Tasman Sea in the west and the Pacific Ocean in the east.

The location of the region, on the frontal ridge of the Indo-Australian plate at its boundary with the Pacific plate, makes it susceptible to earthquakes, liquefaction, subsidence and uplift. It is also subject to the effects of changes resulting from displacement under the ocean including, submarine earthquakes, landslides, and tsunami. Its location in the mid latitudes exposes it to migratory anticyclones, tropical cyclones and wave depressions. The region experiences the highest number of gusty days in New Zealand i.e. 61 days with wind speed of over 93 kilometres per hour along with the highest average annual wind speed, which bestows its main city with the title of 'Windy Wellington'. Its maritime location stimulates coastal hazards, while its moist climate of 123 wet days per year with frequent rainstorms is responsible for recurrent floods. The hilly terrain of the region is susceptible to landslides and influences drought occurrence in adjoining areas. (Hatherton, 1984, Hessell, 1984 and McConchie, 2000a). 
Map: 1.1. Study Area: The Wellington Region

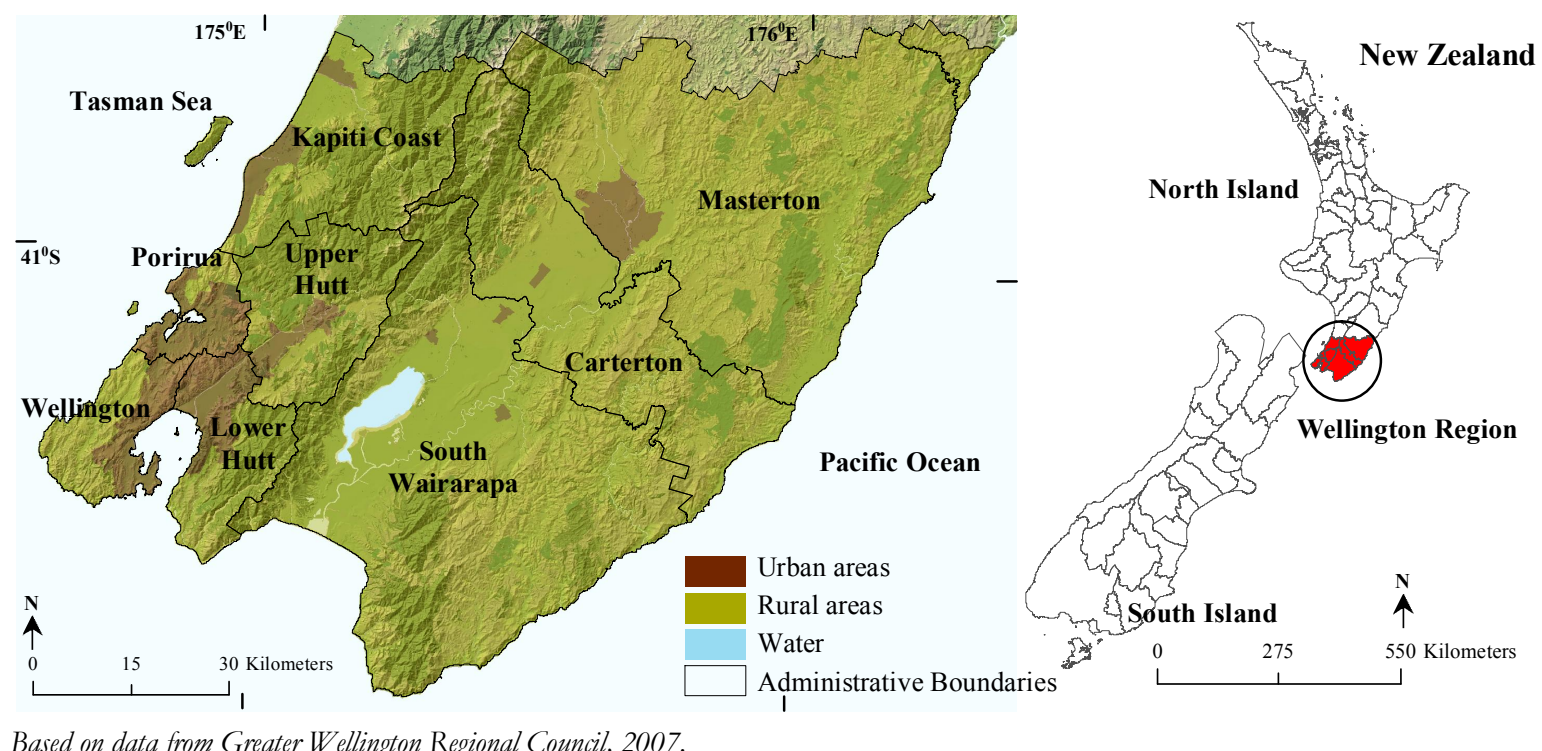

Based on data from Greater Wellington Regional Council, 2007.

Note: This map should be referenced as the standard map for coordinates, north pointer and scale for the following maps

The multiple hazard susceptibility supports frequent occurrence of hazards in the region. The recurrence period of an earthquake of magnitude seven on Mercalli scale is between 20-80 years in the region. It has been also estimated that there is a moderate to high probability of Wellington fault displacement, as the elapsed time (300-350 years) from its last displacement is approaching its recurrence time (485-783 years) (Centre for Advanced Engineering, 1991). The return period of moderate to severe flood event in Wellington varies from 50 to 100 years, while for tsunami of magnitude less than five metres it is 34 years, and for ten metres tsunami it is 84 years (GeoEnvironmental Consultants, 2001).

With a total population of 448,956 Wellington is the third most populated region of New Zealand (Statistics New Zealand 2006). With a mere three percent of the spatial coverage of New Zealand, the region supports more than 11.3 percent of the total population. It is divided into eight district councils, namely Wellington City Council, Hutt City Council, Upper Hutt City Council, Porirua City Council, Kapiti Coast District Council, South Wairarapa District Council, Carterton District Council and Masterton District Council. About 70 percent of the population is European, 13 percent is Maori and 8 percent is Asian and Pacific each, one percent is Middle Eastern Latin American and African [MELAA] and 11 percent is from other ethnic group (Statistics New Zealand 2006). More than 96 percent of the total population of the region is urban, while only one percent of its population lives in entirely rural and remote areas or rural areas with very low urban effects (Statistics New Zealand, 2006). Wellington City is the capital of New Zealand, and is the centre of its socio-economic and political influence. It therefore, attracts a significant number of visitors. The vulnerability profile of the region therefore not only includes elderly, disabled, ethnic minorities and a population with socio-economic differences, but also the visiting population, which is likely to be unaware of local hazards. Exposure to a wide range of hazards, different degrees of susceptibility throughout the region, marked physical contrasts in climate and topography together with a record of occurrence of major hazard events qualifies the region as a suitable study area. 


\subsection{Research Methodology}

Developing a conceptual framework was the first step of this research, which was then used as an explicit guiding framework for further work. The subsequent phases involved data collection, analysis and representation. The conceptual framework is discussed in the following chapter. This section describes the methods of data collection, data analysis and representation (Fig: 1.1).

\subsubsection{Data Collection}

In order to meet the aim and objectives of the research, both primary and secondary data were collected. Secondary data were sought for the historical occurrences and physical characteristics of hazards in the region along with their social impact, and variations in response to them over time. Primary data were collected to determine the current response and identify the variations in the public and administrative response over space.

1.5.1.1. Secondary Data: Secondary data were collected from various sources. Local and national government bodies were the main sources of hazard information in the region. The digital data about hazards and other physical characteristics of the region were collected from Wellington Regional Council offices based at Wellington and Masterton. Local city and district councils were also approached for local hazards data as well as for information for administrative response and district development plans. Ministry of Civil Defence and Emergency Management [MCDEM] was also consulted for the national plans, policies and for other related reports.

Data about geological hazards (i.e. earthquake probability of 7-10MM of ground shaking and landslide occurrence from 1996-2007 in the region) were collected from GNS. Data stored at the School of Geography, Environment and Earth Sciences [SGEES], Victoria University of Wellington were used to map the soils in the region. The National Rural Fire Authority was also consulted for fire data, but because of incomplete data in terms of spatial coverage, it could not be used.

The damage data for earthquake, landslide and flooding from 1996 to 2007 were obtained from the Earthquake Commission. Data about heritage buildings were collected from New Zealand Historic Places Trust at Wellington and Heritage Inventory Reports, 1991 and 2001 from Wellington City Library. In order to present the socio-economic characteristics and vulnerability pattern in the region, census data were collected from Statistics New Zealand for the years 1996, 2001 and 2006. The area data for all mesh blocks were also collected from Statistics New Zealand in order to calculate population density. Websites were another important source of secondary data for this research. In addition, the journal articles on hazards, various reports about local hazards, statistics and other details were retrieved from the official websites of local and national institutions. Websites maintained by Ministry for the Environment [MfE], MCDEM, Wellington Regional Council along with individual district/city websites were used to access reports, plans and progress in hazard research in the region. The website of Te Ara- Encyclopedia was used for information about the region, its physical characteristics along with history of hazards. The data on 
Fig: 1.1. Research Methodology

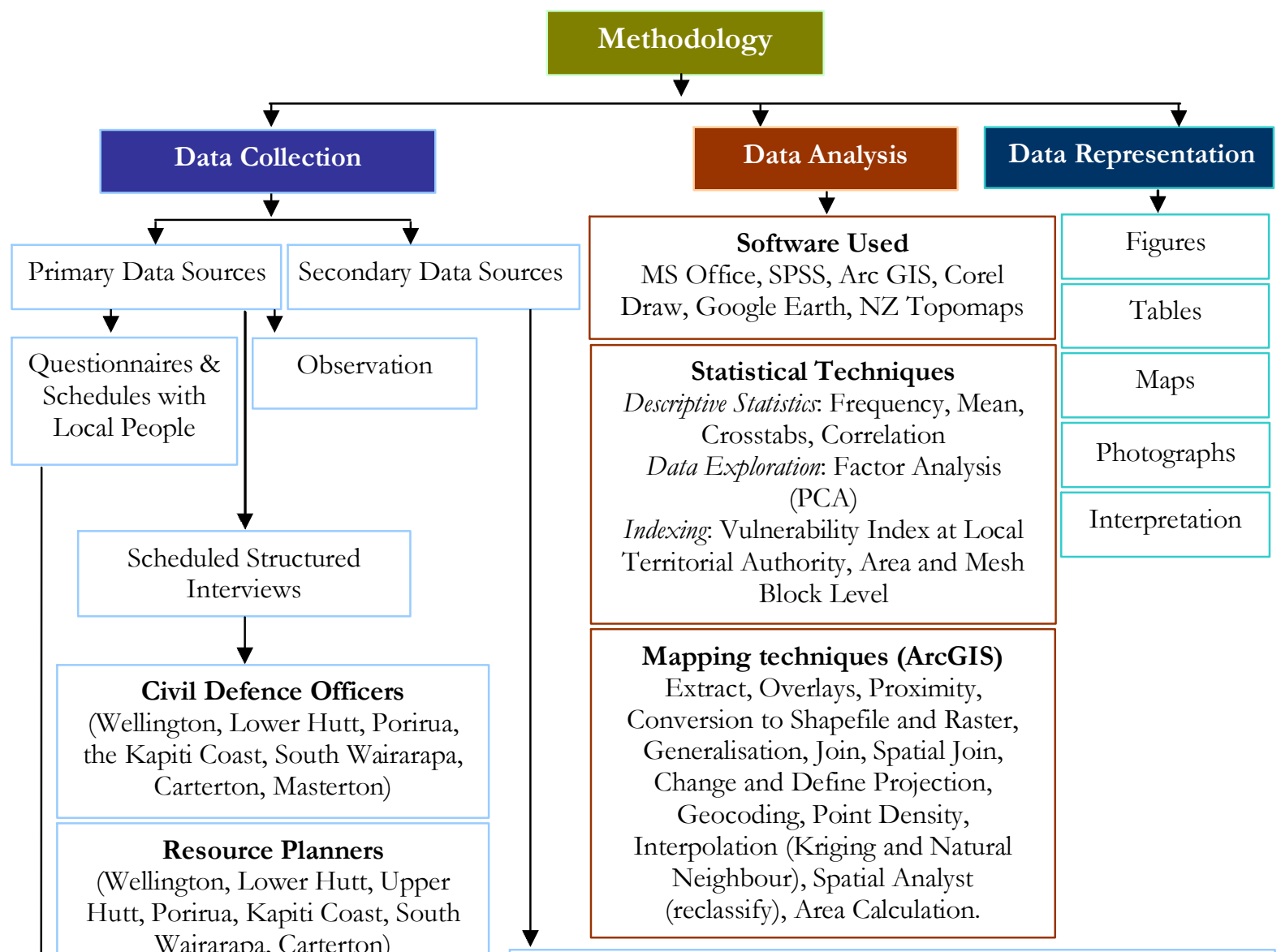

Ministry of Civil Defence and Emergency Management Greater Wellington Regional Council, Wellington \& Masterton

Local City/District Councils

Statistics, New Zealand

Earthquake Commission

Institute of Geological \& Nuclear Sciences

Geonet, GNS

CliFlo, NIWA

National Rural Fire Authority

New Zealand Historic Places Trust, Wellington

Met services

Libraries, Internet, Newspapers

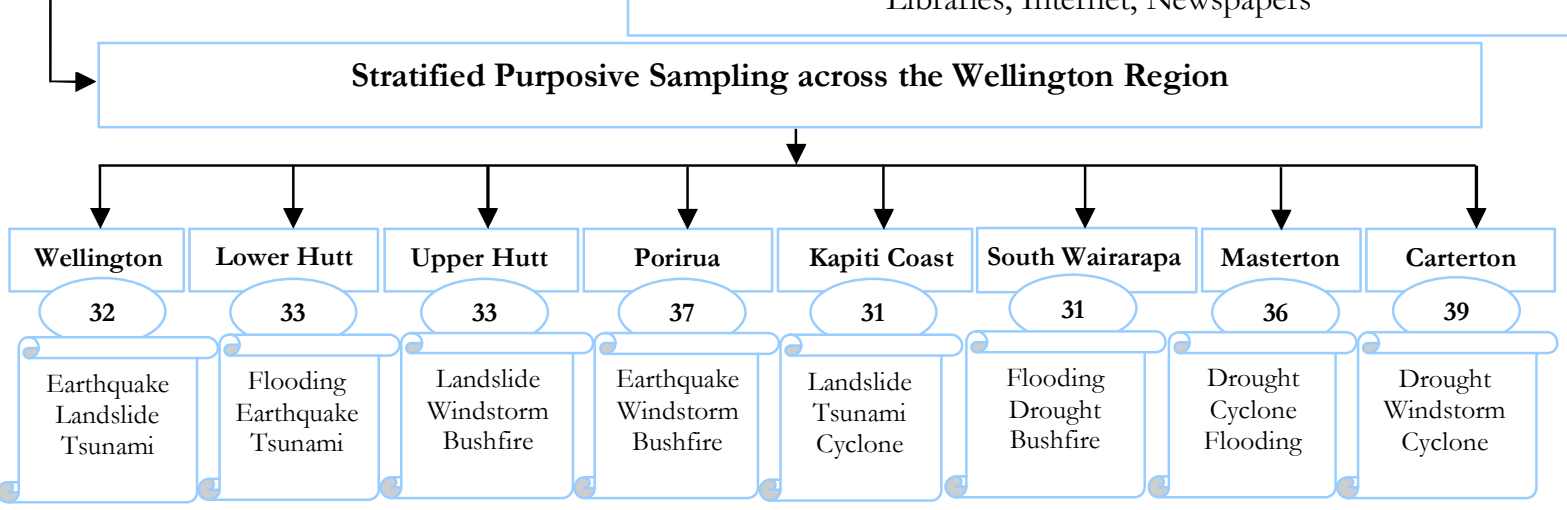

historical occurrences of geological hazards especially earthquake from 1800 to January 1, 2008, from latitude 41.719833 to -40.66818 and 174.39735 to 176.31789 , and volcanic ash fall was retrieved from Geonet, a website maintained and operated by GNS. The data for meteorological characteristics and hazards of the region including temperature, rainfall, lightening, thunderstorm, wind speed, gales, frost days, hail days, drought and soil moisture balance along with soil moisture 
runoff and deficit were retrieved from the CliFlo website run by NIWA. Annual climate summary reports from 2000-2007 and season climate summaries from 2007-2008 were also retrieved from the NIWA website. Also, internet, libraries and local newspapers were consulted for secondary data.

1.5.1.2. Primary Data: Primary data involved scheduled structured interviews and questionnaires with local administrators and people throughout the region. Since the survey involved people and administration, ethical approval was first obtained from Victoria University of Wellington Ethics Committee. Ethical considerations included ensuring written and oral consents as appropriate from all research participants, a disclosure of aim and objectives of the research, anonymity and confidentiality of research participants, their right to recall any information, appropriate and safe storage of information provided and disposal of questionnaires two years after research completion.

The primary survey was done in two phases. In the first phase scheduled structured interviews or questionnaires were conducted with district planners and civil defence officers in all eight local city and district councils. However, one interview with the district planner of Masterton could not be conducted because of time constraints. These interviews were primarily designed to identify the local hazards, associated problems, perspective and response of local administration in different districts.

In the second phase, questionnaires and scheduled interviews were conducted with local people. A separate questionnaire was formed for local people, which was designed to serve the purpose of both self administered questionnaires and scheduled interviews. It included both open, closed and semi closed questions to allow the respondents to express their point of view and at the same time was restricted enough that the information provided was comparable. In total 26 main questions were asked with 103 sub questions (Table: 1.1).

Table: 1.1. Focus of Questions in Questionnaire Survey in the Wellington Region (2007)

\begin{tabular}{lcc|ccc}
\hline Focus of Questions & \multicolumn{4}{c}{ Type and Number of Question } \\
\cline { 2 - 6 } & $\begin{array}{c}\text { Main } \\
\text { Question }\end{array}$ & $\begin{array}{c}\text { Sub } \\
\text { questions }\end{array}$ & Closed & $\begin{array}{c}\text { Semi } \\
\text { Closed }\end{array}$ & Open \\
\hline Hazard characteristics & 4 & 4 & 4 & 0 & 0 \\
Susceptibility & 1 & 18 & 0 & 0 & 18 \\
Vulnerability & 1 & 17 & 17 & 0 & 0 \\
Information and awareness about hazards & 3 & 4 & 0 & 3 & 1 \\
Perception & 4 & 6 & 4 & 1 & 1 \\
Experience & 1 & 11 & 0 & 3 & 8 \\
Trust in agencies & 1 & 3 & 1 & 0 & 2 \\
Mitigation & 2 & 3 & 1 & 1 & 1 \\
Preparedness & 3 & 6 & 2 & 2 & 2 \\
Response & 4 & 6 & 1 & 3 & 1 \\
Recovery & 1 & 3 & 2 & 1 & 0 \\
Information about respondents & 1 & 22 & 8 & 13 & 1 \\
Total & $\mathbf{2 6}$ & $\mathbf{1 0 3}$ & $\mathbf{4 1}$ & $\mathbf{2 7}$ & $\mathbf{3 5}$ \\
\hline
\end{tabular}


Table: 1.2. Particulars of Primary Survey Conducted in the Wellington Region (2007)

\begin{tabular}{l|l}
\hline $\begin{array}{l}\text { Primary Survey } \\
\text { Purpose }\end{array}$ & $\begin{array}{l}\text { Questionnaire and Schedules } \\
\text { To assess the variations in hazard response throughout Wellington Region and to } \\
\text { identify the factors influencing hazard response } \\
\text { Pilot Survey Dates }\end{array}$ \\
$\begin{array}{l}\text { Pilot Sample Size } \\
\text { Main Survey Dates }\end{array}$ & 10 \\
Sample Size & 22.08 .2007 to 15.08 .2007 \\
Sampling Method & Stratified Purposive Random Sampling \\
Stratification & Across eight local territorial authorities and three hazards for each district \\
Target Population & Local residents in specific hazard zones across the Region \\
Sampling frame & Individual/households \\
Mode of Administration & Households were personally invited to participate and for interview. \\
Observation Unit & Individual/households \\
Response Rate & $44.44 \%$ \\
Refused to participate & $18.30 \%$ \\
Non response & $37.25 \%$ \\
\hline
\end{tabular}

The questionnaire was divided into seven sections that cover various issues related to hazard response, such as hazard characteristics of the area, hazard perception, response, preparedness and past hazard experiences. Before the actual survey, a pilot survey was conducted with ten respondents in order to test the readability and usability of the questionnaire. The particulars of both pilot and main survey are given in table 1.2.

Map: 1.2. Distribution of Respondents in the Wellington Region

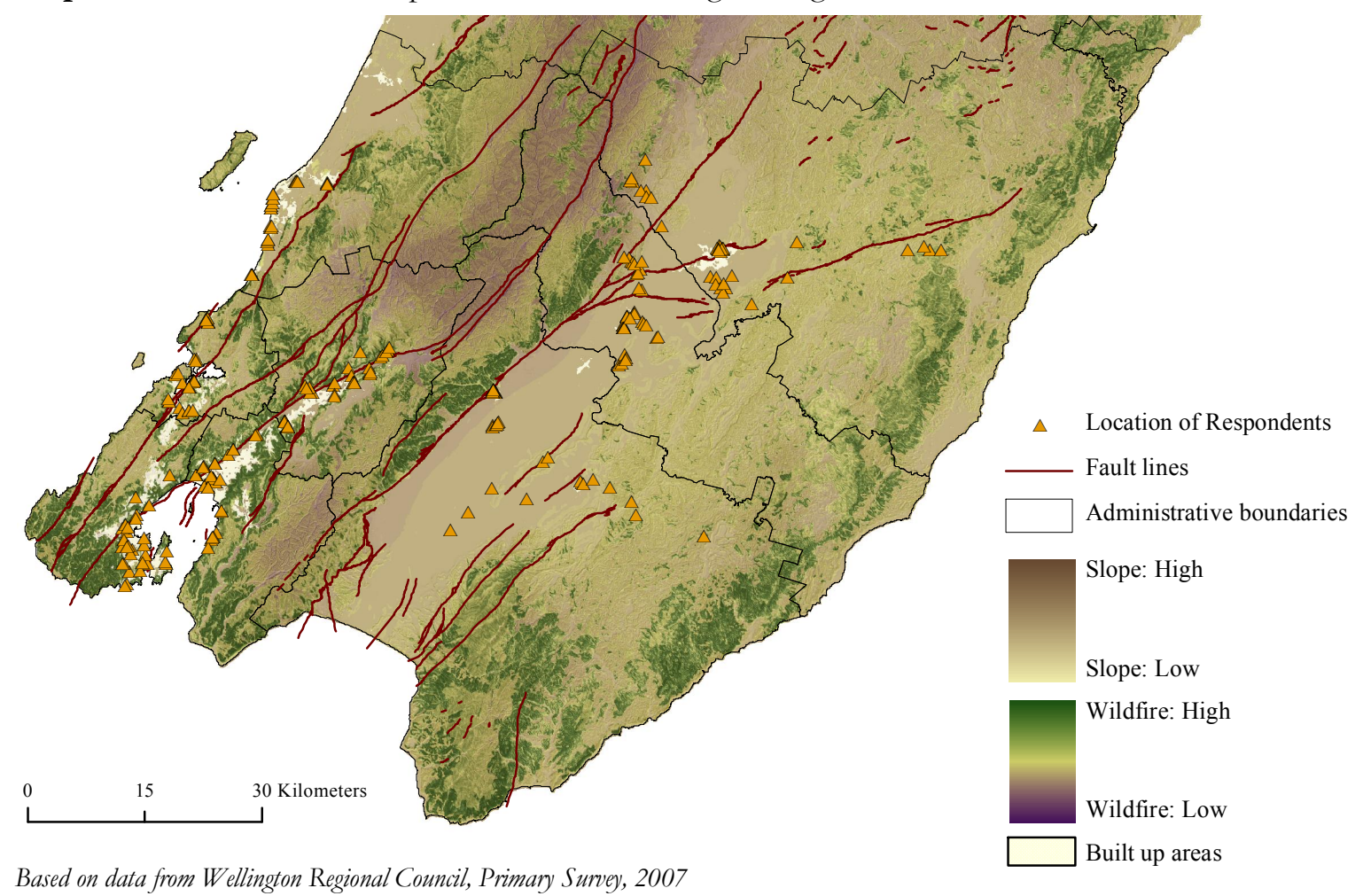

In order to find factors and variations in hazard response, the sample had to be distributed throughout the region, and hence a Stratified Purposive Sampling method was selected. Stratified sampling helped in giving equal representation to each city and district of the region, which differ 
in physical, socio-economic and hazard characteristics. Purposive sampling helped to identify and approach the appropriate sample in terms of location or occupation, such as farming. This is because often these factors play a dominant role in the impact of a particular hazard and therefore the local response. Since it may not have been possible to meet the right respondents through a random probability sampling method within a restricted timeframe, the purposive sampling method was adopted. The method also had the advantage of providing information rich and deviant cases that allow for diversity in the sample and therefore give an overall view of the factors that could affect response (Babbie, 2008, 204).

The sample was therefore first stratified across eight city and district councils of the region and then for three main hazards in each district. These hazards were not necessarily the three dominant hazards of the respective districts, but perceived as the major hazards of the district. These hazards were selected to assess the influences of specific hazard susceptibility on hazard response and were chosen in a way that most of the dominant hazards are covered with comparable sample size throughout the region. One hazard per district was also considered as an option to select samples, but this was not preferred as many districts have a common dominant hazard and their selection would not have given the option of considering all or most hazards. In the final survey, therefore, eight hazards were selected for identifying sample locations i.e. earthquake, flooding, landslide, tsunami, cyclone, windstorm, drought and bushfire. Volcanic ash fall was not chosen because of perceived low risk by local people and because it might have a common impact over the whole region. Finally, about ten respondents were selected for each of three different hazards from each district. The sample location was broadly selected in order to keep flexibility in the selection of respondents, as for many places no respondent could be found. The general criteria taken for location and identification of respondents with respect to different hazards included nearness to fault line, river, coast, farms and dense vegetation or bush in close proximity of the house. Availability and consensus of respondents however played a significant role in the final output. Therefore, for the final analysis of the data all samples were combined to see if some differences appear as expected in response. The sample selection was therefore, defined by the presence of hazards, physical susceptibility of a place and vulnerability mainly in terms of exposure.

The survey included both a simple questionnaire as well as scheduled structured interviews. Every respondent was personally approached for the interview. However, a few respondents found it more suitable to fill in the questionnaire by themselves and sent it back by post. The reason for approaching respondents personally was to achieve a better response and higher completion rate, which is otherwise found to be very low in straight-forward mail or telephone surveys (Babbie, 2008, 286). In total about 612 people were approached of which 112 refused to participate for several reasons. The reasons for refusals included being busy or 'not interested' ( $\sim 70$ percent of refusal), 'I am fine-thank you' and could not speak or understand English, five percent each, 'I usually do not live here' i.e. they were either at farm, friend's place or holiday homes (four percent), 'questionnaire is too big' (four percent), 'I am not well or sick' (three percent), 'I am new to the place' (three percent), 'getting married' (two percent), 'pregnant and too close to delivery time' (one 
Table: 1.3. Sample Characteristics and Distribution

\begin{tabular}{|c|c|c|c|c|c|}
\hline \multirow[t]{2}{*}{ Characteristics } & \multicolumn{2}{|c|}{$\begin{array}{l}\text { Respondents (in } \\
\text { percent) }\end{array}$} & \multirow[t]{2}{*}{ Characteristics } & \multicolumn{2}{|c|}{$\begin{array}{l}\text { Respondents (in } \\
\text { percent) }\end{array}$} \\
\hline & Number & Percent & & Number & Percent \\
\hline Liquefaction Susceptible Area & 87 & 32 & Work St & tatus & \\
\hline \multicolumn{3}{|c|}{ Slope angle } & Not answered & 1 & 0.4 \\
\hline $0-2$ degree & 134 & 49.3 & Unemployed & 30 & 11 \\
\hline $2-5$ degree & 34 & 12.5 & Employed full time & 110 & 40.4 \\
\hline 5-10 degree & 39 & 14.3 & Employed part time & 55 & 20.2 \\
\hline 10-18 degree & 45 & 16.5 & Pension or benefits & 76 & 27.9 \\
\hline More than 18 degree & 20 & 7.4 & Total & 272 & 100 \\
\hline Area under $10 \mathrm{~m}$ contour & 52 & 19 & \multicolumn{3}{|c|}{ Occupation } \\
\hline \multicolumn{3}{|c|}{ Distance from fault by WRC } & $\begin{array}{l}\text { Not applicable/not } \\
\text { answered }\end{array}$ & & 27.2 \\
\hline Within $150 \mathrm{~m}$ & 18 & 7 & Work on farm & 22 & 8.1 \\
\hline $150-300 \mathrm{~m}$ & 29 & 11 & Self employed/business & 40 & 14.7 \\
\hline $300-600 \mathrm{~m}$ & 39 & 14 & $\begin{array}{l}\text { Administration/Public } \\
\text { sector }\end{array}$ & 29 & 10.7 \\
\hline $600-1200 \mathrm{~m}$ & 57 & 21 & Housewife/mother & 18 & 6.6 \\
\hline $1200-2400 \mathrm{~m}$ & 59 & 22 & Student & 11 & 4 \\
\hline more than $2400 \mathrm{~m}$ & 70 & 26 & Sales and service sector & 7 & 2.6 \\
\hline Total & 272 & 100 & $\begin{array}{l}\text { Information technology } \\
\text { (IT) }\end{array}$ & 6 & 2.2 \\
\hline \multicolumn{3}{|c|}{ Rainfall (in $\mathrm{mm}$ ) } & Academic & 10 & 3.7 \\
\hline Less than 800 & 14 & 5 & Professional & 29 & 10.7 \\
\hline $800-1000$ & 33 & 12 & NGO/community support & 2 & 0.7 \\
\hline $1000-1200$ & 112 & 41 & Medical/nurse/caregiver & 6 & 2.2 \\
\hline $1200-1400$ & 72 & 26 & $\begin{array}{l}\text { Labourer/blue collar } \\
\text { workers }\end{array}$ & 7 & 2.6 \\
\hline $1400-1600$ & 34 & 13 & Other & 11 & 4 \\
\hline $1600-2000$ & 7 & 3 & Total & 272 & 100 \\
\hline Total & 272 & 100 & \multicolumn{3}{|c|}{ Income (NZD) } \\
\hline Flood Plain & 10 & 4 & Not answered & 33 & 12.1 \\
\hline \multicolumn{3}{|c|}{ Wind speed zones (142 year wind gust) } & None & 3 & 1.1 \\
\hline Less than $45 \mathrm{~m} / \mathrm{s}$ & 33 & 12 & Less than 20,000 & 23 & 8.5 \\
\hline $45-55 \mathrm{~m} / \mathrm{s}$ & 218 & 80 & $20-50,000$ & 80 & 29.4 \\
\hline $55-65 \mathrm{~m} / \mathrm{s}$ & 21 & 8 & $50-70,000$ & 52 & 19.1 \\
\hline Total & 272 & 100 & $70-100,000$ & 39 & 14.3 \\
\hline \multicolumn{3}{|c|}{ Bushfire susceptibility } & More than 100,000 & 42 & 15.4 \\
\hline Not susceptible & 167 & 61.4 & Total & 272 & 100 \\
\hline Low & 72 & 26.5 & \multicolumn{3}{|c|}{ Number of Family Members } \\
\hline Medium & 17 & 6.3 & Not answered & 3 & 1.1 \\
\hline High & 8 & 2.9 & 1 & 42 & 15.4 \\
\hline Very high or extreme & 8 & 2.9 & 2 & 110 & 40.4 \\
\hline Total & 272 & 100 & 3 & 39 & 14.3 \\
\hline \multicolumn{3}{|c|}{ Age Group } & 4 & 39 & 14.3 \\
\hline $16-30$ years & 37 & 13.6 & 5 or more & 39 & 14.3 \\
\hline $31-45$ years & 70 & 25.7 & Total & 272 & 100 \\
\hline $46-60$ years & 73 & 26.8 & \multicolumn{3}{|c|}{ Number of dependents } \\
\hline 61 and above & 92 & 33.8 & Not answered & 182 & 66.9 \\
\hline Total & 272 & 100 & 1 & 26 & 9.6 \\
\hline \multicolumn{3}{|c|}{ Gender } & 2 & 35 & 12.9 \\
\hline Not answered & 1 & 0.4 & 3 & 19 & 7 \\
\hline Male & 112 & 41.2 & 4 or more & 10 & 3.7 \\
\hline Female & 159 & 58.5 & Total & 272 & 100 \\
\hline Total & 272 & 100 & \multicolumn{3}{|c|}{ Continued on page 25} \\
\hline
\end{tabular}




\begin{tabular}{|c|c|c|c|c|c|}
\hline & & & \multicolumn{3}{|c|}{ Year of residence in NZ } \\
\hline \multicolumn{3}{|c|}{ Ethnicity } & Not answered & 4 & 1.5 \\
\hline European & 222 & 81.6 & Less than a year & 6 & 2.2 \\
\hline Maori & 11 & 4 & $1-5$ years & 13 & 4.8 \\
\hline MELAA & 2 & 0.7 & $5-10$ years & 6 & 2.2 \\
\hline Pacific & 4 & 1.5 & More than 10 years & 243 & 89.3 \\
\hline Asian & 10 & 3.7 & Total & 272 & 100 \\
\hline $\begin{array}{l}\text { Other (American, Australian, } \\
\text { English ) }\end{array}$ & 6 & 2.2 & \multicolumn{3}{|c|}{ Year of residence in area } \\
\hline European and Maori mix & 8 & 2.9 & Not answered & 2 & 0.7 \\
\hline New Zealander & 9 & 3.3 & Less than a year & 29 & 10.7 \\
\hline Total & 272 & 100 & $1-5$ years & 52 & 19.1 \\
\hline \multicolumn{3}{|c|}{ Religion } & $5-10$ years & 42 & 15.4 \\
\hline Not answered & 2 & 0.7 & More than 10 years & 147 & 54 \\
\hline None & 108 & 39.7 & Total & 272 & 100 \\
\hline $\begin{array}{l}\text { Christian (Anglican, Catholic, } \\
\text { Presbyterian, Salvation army) }\end{array}$ & 146 & 53.7 & \multicolumn{3}{|c|}{ Year of residence in house } \\
\hline Buddhism & 1 & 0.4 & Not answered & 2 & 0.7 \\
\hline Hinduism & 7 & 2.6 & Less than a year & 41 & 15.1 \\
\hline Islam & 1 & 0.4 & $1-5$ years & 77 & 28.3 \\
\hline Other & 7 & 2.6 & $5-10$ years & 51 & 18.8 \\
\hline Total & 272 & 100 & More than 10 years & 101 & 37.1 \\
\hline \multicolumn{3}{|c|}{ Religious Inclination } & Total & 272 & 100 \\
\hline Not answered & 2 & 0.7 & \multicolumn{3}{|c|}{ Place of residence before current } \\
\hline Do not follow any Religion & 108 & 39.7 & $\begin{array}{l}\text { Not answered/not } \\
\text { applicable }\end{array}$ & 18 & 6.6 \\
\hline Follow a Religion & 162 & 59.6 & $\begin{array}{l}\text { Within the city/district } \\
\text { council }\end{array}$ & 95 & 34.9 \\
\hline Total & 272 & 100 & Within the region & 83 & 30.5 \\
\hline \multicolumn{3}{|c|}{ First Language } & Within New Zealand & 44 & 16.2 \\
\hline Not answered & 1 & 0.4 & Overseas & 32 & 11.8 \\
\hline English & 246 & 90.4 & Total & 272 & 100 \\
\hline Maori & 4 & 1.5 & \multicolumn{3}{|c|}{ Ownership of house } \\
\hline Other & 21 & 7.7 & Not answered & 2 & 0.7 \\
\hline Total & 272 & 100 & Owned & 210 & 77.2 \\
\hline \multicolumn{3}{|c|}{ Residency Status } & Rent & 55 & 20.2 \\
\hline Citizen & 213 & 78.3 & $\begin{array}{l}\text { Came with job/live with } \\
\text { family/friend }\end{array}$ & 5 & 1.8 \\
\hline Permanent resident & 50 & 18.4 & Total & 272 & 100 \\
\hline Work permit & 4 & 1.5 & \multicolumn{3}{|c|}{$\begin{array}{c}\text { Composite Vulnerability Score Based on } \\
\text { Minimum Imputed values }\end{array}$} \\
\hline Student visa & 4 & 1.5 & -12773 to -4481 & 75 & 27.6 \\
\hline Tourist visa & 1 & 0.4 & -4480 to -994 & 133 & 48.9 \\
\hline Total & 272 & 100 & -993 to 2370 & 47 & 17.3 \\
\hline \multicolumn{3}{|c|}{ Education } & 2371 to 9884 & 11 & 4.0 \\
\hline Not answered & 1 & 0.4 & 9885 to 30689 & 6 & 2.2 \\
\hline None & 5 & 1.8 & Total & 272 & 100 \\
\hline School & 20 & 7.4 & \multicolumn{3}{|c|}{$\begin{array}{c}\text { Composite Vulnerability Score Based on } \\
\text { Maximum Imputed Values }\end{array}$} \\
\hline College & 110 & 40.4 & -7351 to -2318 & 80 & 29.4 \\
\hline University & 125 & 46 & -2317 to -517 & 131 & 48.2 \\
\hline Vocational & 11 & 4 & -517 to 1327 & 44 & 16.2 \\
\hline \multirow[t]{3}{*}{ Total } & 272 & 100 & 1328 to 5762 & 11 & 4.0 \\
\hline & & & 5763 to 18104 & 6 & 2.2 \\
\hline & & & Total & 272 & 100 \\
\hline
\end{tabular}

Based on Primary Survey, Young, 1972, and data from Wellington Regional Council, 2006, Grant, 2005

Note: Since in religious classification, many categories had insufficient sample to be able to compare them across, they are reclassified in to those who follow religion and those who don't. 
percent), 'it is not of any relevance' (one percent), 'we don't face any hazard' (one percent) and one percent of respondents offended by the question on income. However, about 500 people agreed to either fill in the questionnaire or to be interviewed. In total about 112 respondents were interviewed and 157 respondents returned the questionnaire. The total response received (272) was higher than what was initially aimed (240), because more questionnaires were distributed in order to get at least 30 samples from each district to compare the data. The distribution of respondents is shown in the map 1.2 and their characteristics are described in the table 1.3.

Besides questionnaires and interviews, photographs, sketches, observation and field notes were other sources of primary information for the research. The data thus included both qualitative and quantitative data.

\subsubsection{Data Analysis \& Representation}

The very first step of data analysis involved data cleaning as the data from various sources had to be combined in order to present a holistic picture. In order to clean and assess the validity of data, a triangulation method was adopted, i.e. by cross checking the data collected through multiple sources including interviews, observation, photographs and document analysis.

After cleaning the data, various descriptive and other statistical methods were used to analyse the data. Secondary data is mainly used to present the conditions of hazards. While the assessment of hazard characteristics and physical characteristics of Wellington Region are based on previous studies and reports and the digital records from the Wellington Regional Council and SGEES, human vulnerability of the region had to be calculated from census data because no such records were found for the region. The detailed methodology for the vulnerability index is given below.

1.5.2.1. Vulnerability Index: Vulnerability is an important component of hazardscape, and in order to present it over space, a composite vulnerability index was calculated using 2006 Census data from Statistics New Zealand. The index is calculated at two different levels i.e. at territorial local authority level and at mesh block level. At territorial local authority level, the aim of the composite index was to determine relative vulnerability of a district or a city in the region and to evaluate its influence on administrative response to hazards and vice-versa. The index at mesh block level on the other hand, aimed to portray a more detailed picture of local vulnerability, which could be linked with local response to hazards in the region. The index is calculated for 4,682 mesh blocks and eight territorial local authorities in Wellington region. Vulnerability scores of mesh blocks were summed to get scores at area level.

A range of methods has been used in the hazard and disaster literature to calculate the vulnerability index, each of which varies in terms of conceptual framework, selection of indicators, numerical treatment such as normalizing data and weighting methods (Guillaumont, 2003; Rygel, Sullivan, \& Yarnal, 2006; Briguglio, L. 2008). Various aspects of vulnerability have been highlighted and can be grouped into three broad categories: exposure; resistance or fragility; the resilience or coping capacity (Cordana, 2006, 195; Birkmann, 2006a). The indicators selected for the index in this research are therefore based on those population characteristics which could have affected either one or all three aspects of vulnerability. The role of selected indicators in producing 
vulnerability has been either established from the literature or there is a strong theoretical rationale for their inclusion. However, the availability of data has played a key role in the selection of indicators for this study. Certain potential indicators were initially considered for vulnerability assessment but have ultimately been rejected for the index. These include those indicators, which could have affected vulnerability both in positive and negative ways e.g. population growth, or

Table: 1.4. Factors, Parameters and Indicators selected for Vulnerability Index

\begin{tabular}{|c|c|c|c|c|}
\hline $\begin{array}{l}\text { Factor } \\
\text { (Group) }\end{array}$ & $\begin{array}{l}\text { Parameter } \\
\text { (Subgroup) }\end{array}$ & $\begin{array}{l}\text { Indicator } \\
\text { (Variables) }\end{array}$ & Unit & $\begin{array}{l}\text { Index } \\
\text { Loading }\end{array}$ \\
\hline \multirow[t]{7}{*}{ Demographic } & Distribution & Population density & Person per sqkm & + \\
\hline & Gender & Female & Percent population & + \\
\hline & Age & Children (less than five years) & Percent population & + \\
\hline & & Elderly (65 years or more) & Percent population & + \\
\hline & Disability & People on sickness benefit & Percent population & + \\
\hline & & NZ Sign Language & Percent population & + \\
\hline & Migration & Usual residence overseas five years ago & Percent population & + \\
\hline \multirow[t]{9}{*}{ Social } & Family type & Single parents & Percent families & + \\
\hline & & Four or more children & $\begin{array}{l}\text { Percent females of } \\
\text { above } 15 \text { years }\end{array}$ & + \\
\hline & Education & No qualification (above 15 years of age) & Percent population & + \\
\hline & Language & English not the first language & Percent population & + \\
\hline & Ethnicity & Mäori ethnic group & Percent population & + \\
\hline & & Pacific peoples ethnic groups & Percent population & + \\
\hline & & Asian ethnic groups & Percent population & + \\
\hline & & MELAA* ethnic groups & Percent population & + \\
\hline & & Other ethnic groups & Percent population & + \\
\hline \multirow[t]{21}{*}{ Economic } & Income & $\begin{array}{l}\text { Individual annual income less than } \\
10,000 \mathrm{NZD}\end{array}$ & Percent population & + \\
\hline & & $\begin{array}{l}\text { Family annual income less than } 20,000 \\
\text { NZD }\end{array}$ & Percent families & + \\
\hline & $\begin{array}{l}\text { Source of } \\
\text { income }\end{array}$ & No source of income & Percent population & + \\
\hline & & NZ Superannuation or Veterans Pension & Percent population & + \\
\hline & & $\begin{array}{l}\text { Other Superannuation, Pensions, } \\
\text { Annuities }\end{array}$ & Percent population & + \\
\hline & & Unemployment Benefit & Percent population & + \\
\hline & & Domestic Purposes Benefit & Percent population & + \\
\hline & & Invalids Benefit & Percent population & + \\
\hline & & Student Allowance & Percent population & + \\
\hline & & $\begin{array}{l}\text { Other Government } \\
\text { Benefits/Payments/Pension }\end{array}$ & Percent population & + \\
\hline & Employment & Unemployed & Percent population & + \\
\hline & Occupation & Agriculture and Fisheries workers & Percent workers & + \\
\hline & & Workers in Elementary Occupations & Percent workers & + \\
\hline & Housing & Dwelling density & Dwellings per sqkm & + \\
\hline & & One room house & Percent dwellings & + \\
\hline & & Two room house & Percent dwellings & + \\
\hline & & One bedroom house & Percent dwellings & + \\
\hline & & $\begin{array}{l}\text { Dwelling not owned by the usual } \\
\text { residents }\end{array}$ & Percent dwellings & + \\
\hline & & Median rent & Median rent & - \\
\hline & Communication & No access to telecommunication & Percent households & + \\
\hline & & No motor access to household & Percent households & + \\
\hline
\end{tabular}

*MELAA = Middle Eastern, Latin American and African. 
indicators for which literature support is not found, such as single/multiple person/family households etc. The significance of these indicators is discussed in chapter four. Since many indicators such as income or disability affect more than one aspect of vulnerability (i.e. resistance as well as coping capacity), a single composite index for exposure, resistance and resilience is preferred over three separate indexes, and is referred to as a composite vulnerability index. This is done in order to avoid the repetitive counting of indicators. Thirty seven indicators were selected for the index (Table: 1.4), and then classified into demographic (7), social (9) and economic (21) categories.

Since census data were in absolute numbers, they were first standardized by converting them into percentages or another unit in order to compare them across districts or mesh blocks within the region. The values of indicators were then coded in a way that higher values would show higher vulnerability. For the only indicator where low values represented higher vulnerability (i.e. median rent) data have been first reversed in order to get higher values for higher vulnerability before use in the index. The formula applied for this is $1 / \mathrm{a}^{*} 100$, where (a) is the value of a particular indicator for individual district or mesh block.

For a number of mesh blocks, data given at household and individual level were confidential for several indicators. The number of such mesh blocks varied for different indicators (e.g. 374 for female population, 769 for child population, 2,021 for total family income, 3,081 for people living on sickness benefit, to as high as 4,278 for median rent etc). For these areas approximate values have been imputed for the composite index. Since the minimum number of individuals or households for which data are given is three, possible imputations that could therefore be made were one and two. Accordingly, two composite indexes have been calculated at mesh block level with maximum two and minimum one as imputed values. The only indicator for which imputation values could have ranged from one to sixty is median rent. But since indexes are manually calculated using Microsoft Excel, two values were selected as maximum and minimum, which included sixty as maximum and ten as minimum rent.

The data were then standardized for each indicator by centralizing them towards the mean. Because of a skewed population distribution in the region, the common procedure for normalizing data by calculating a $\mathrm{Z}$ score has not been used. Another common method of normalization i.e. by adjusting indicator values between 0 and 1 (Briguglio, 2008), was also not used in order to avoid significant deviation from the original character of data and to be able to put some weight to indicators at a later stage. The formula used for centralizing data is:

$$
\mathrm{x}^{*}=\mathrm{x} \text {-mean, }
$$

Where, $\mathrm{x}$ is the value of a particular indicator for a given mesh block and $\mathrm{x}^{*}$ is the centralized value for the same. The mean is the average value of a given indicator for all mesh blocks in the region (Step: 1, table 1.5).

After centralizing the data (Step: 2, table 1.6), a correlation matrix was formed for all indicators within a subgroup. Individual scores were calculated for all indicators within a subgroup of parameters, showing their contribution to the total matrix value. It was calculated by dividing 
the total matrix value by the sum of the individual indicator value (Step: 3, table 1.7). These individual scores were taken as weights and then multiplied with centralized scores for their respective indicators (Step: 4, table 1.8). The obtained values for indicators were aggregated at subgroup level and the procedure of weighting was repeated at group level. The weighted values for groups were then finally added to get a composite vulnerability index (Step: 5, table 1.9).

An example of vulnerability index calculated for five indicators for ten mesh blocks is as follows.

Step: 1. To convert raw data into percentages or another comparable unit and to calculate the mean for individual indicators. The data on population distribution were converted into density and in percentage for female, children, elderly and population living on sickness benefits in each mesh block, and labeled as $\mathrm{x} 1$ to $\mathrm{x} 5$ (table 1.5).

Table: 1.5. Selected Indicators and Their Mean

\begin{tabular}{lccccc}
\hline Mesh block & $\begin{array}{c}\text { Population } \\
\text { Density }\end{array}$ & $\begin{array}{c}\text { Percent } \\
\text { females }\end{array}$ & $\begin{array}{c}\text { Percent } \\
\text { children } \\
\text { (<5 years) }\end{array}$ & $\begin{array}{c}\text { Percent elderly } \\
\text { (65 years or more) }\end{array}$ & $\begin{array}{c}\text { Percent population } \\
\text { living on sickness } \\
\text { benefit }\end{array}$ \\
\cline { 2 - 6 } & $\mathbf{x} \mathbf{1}$ & $\mathbf{x} \mathbf{2}$ & $\mathbf{x 3}$ & $\mathbf{x} \mathbf{3}$ & $\mathbf{x}$ \\
\hline MB 1874202 & 460.3 & 60 & 6.7 & 20 & 4.4 \\
MB 1874203 & 997.7 & 56 & 8 & 24 & 2.7 \\
MB 1874204 & 231.8 & 47.3 & 3.6 & 20 & 0 \\
MB 1874205 & 1298.1 & 55.3 & 6.4 & 19.1 & 2.1 \\
MB 1874206 & 427.9 & 48 & 7.1 & 17.3 & 1 \\
MB 1874300 & 251.3 & 57.1 & 9.5 & 9.5 & 9.5 \\
MB 1874400 & 723.5 & 52.4 & 4.8 & 14.3 & 3.2 \\
MB 1985800 & 1.2 & 66.7 & 66.7 & 66.7 & 66.7 \\
MB 2026201 & 0.2 & 66.7 & 66.7 & 66.7 & 66.7 \\
MB 2025900 & 0 & 66.7 & 66.7 & 66.7 & 66.7 \\
Total & $\mathbf{4 3 9 2 . 1}$ & $\mathbf{5 7 6 . 1}$ & $\mathbf{2 4 6 . 1}$ & $\mathbf{3 2 4 . 3}$ & $\mathbf{2 2 3}$ \\
Mean & $\mathbf{4 3 9 . 2 1}$ & $\mathbf{5 7 . 6 1}$ & $\mathbf{2 4 . 6 1}$ & $\mathbf{3 2 . 4 3}$ & $\mathbf{2 2 . 3}$ \\
\hline
\end{tabular}

Step: 2. To centralize data towards mean $\left(\mathrm{x}^{*}=\mathrm{x}-\right.$ mean) (table 1.6).

Table: 1.6. Centralized Score for the Selected Indicators

\begin{tabular}{lcccccccccc}
\hline Mesh block & $\mathbf{x 1}$ & $\mathbf{x} \mathbf{*}$ & $\mathbf{x} \mathbf{2}$ & $\mathbf{x} \mathbf{*}$ & $\mathbf{x 3}$ & $\mathbf{x} \mathbf{3}$ & $\mathbf{x} \mathbf{4}$ & $\mathbf{x} \mathbf{4}$ & $\mathbf{x} \mathbf{5}$ & $\mathbf{x} \mathbf{5}$ \\
\hline MB 1874202 & 460.3 & 21.1 & 60.0 & 2.4 & 6.7 & -17.9 & 20.0 & -12.4 & 4.4 & -17.9 \\
MB 1874203 & 997.7 & 558.5 & 56.0 & -1.6 & 8.0 & -16.6 & 24.0 & -8.4 & 2.7 & -19.6 \\
MB 1874204 & 231.8 & -207.4 & 47.3 & -10.3 & 3.6 & -21.0 & 20.0 & -12.4 & 0.0 & -22.3 \\
MB 1874205 & 1298.1 & 858.9 & 55.3 & -2.3 & 6.4 & -18.2 & 19.1 & -13.3 & 2.1 & -20.2 \\
MB 1874206 & 427.9 & -11.3 & 48.0 & -9.7 & 7.1 & -17.5 & 17.3 & -15.1 & 1.0 & -21.3 \\
MB 1874300 & 251.3 & -187.9 & 57.1 & -0.5 & 9.5 & -15.1 & 9.5 & -22.9 & 9.5 & -12.8 \\
MB 1874400 & 723.5 & 284.3 & 52.4 & -5.2 & 4.8 & -19.8 & 14.3 & -18.1 & 3.2 & -19.1 \\
MB 1985800 & 1.2 & -438.0 & 66.7 & 9.1 & 66.7 & 42.1 & 66.7 & 34.2 & 66.7 & 44.4 \\
MB 2026201 & 0.2 & -439.0 & 66.7 & 9.1 & 66.7 & 42.1 & 66.7 & 34.2 & 66.7 & 44.4 \\
MB 2025900 & 0.0 & -439.2 & 66.7 & 9.1 & 66.7 & 42.1 & 66.7 & 34.2 & 66.7 & 44.4 \\
\hline
\end{tabular}


Step: 3: To correlate the centralized score and calculate individual scores from correlation matrix.

Table: 1.7. Individual Scores for Selected Indicators

\begin{tabular}{|l|c|c|c|c|c|c|}
\hline Correlation Matrix & $\mathbf{x}$ 1 & $\mathbf{x}$ *2 & $\mathbf{x}$ *3 & $\mathbf{x}$ 4 & $\mathbf{x}$ 5 & Total \\
\hline $\mathrm{x} * 1$ & 1.00 & & & & & \\
\hline $\mathrm{x} * 2$ & -0.47 & 1.00 & & & & \\
\hline $\mathrm{x} * 3$ & -0.68 & 0.86 & 1.00 & & & \\
\hline $\mathrm{x} * 4$ & -0.62 & 0.84 & 0.98 & 1.00 & & \\
\hline $\mathrm{x} * 5$ & -0.69 & 0.88 & 1.00 & 0.97 & 1.00 & \\
\hline Total & -1.46 & 3.58 & 2.98 & 1.97 & 1.00 & 8.07 \\
\hline Individual score & -0.18 & 0.44 & 0.37 & 0.24 & 0.12 & 1.00 \\
\hline
\end{tabular}

Step: 4. To put a weight on centralized data by using individual score (table 1.8).

Table: 1.8. Weighted Scores for Selected Indicators

\begin{tabular}{|c|c|c|c|c|c|c|c|c|c|c|}
\hline \multirow[t]{2}{*}{ Mesh block } & $\mathrm{x} * 1$ & $\mathrm{x} * 1 * 0.18$ & $x * 2$ & $\mathrm{x} * 2 * 0.44$ & $x * 3$ & $\mathrm{x} * 3 * 0.37$ & $x * 4$ & $x * 4 * 0.24$ & $x * 5$ & $x * 5 * 0.12$ \\
\hline & & $\overline{\mathrm{Z} 1}$ & & $\mathrm{Z2}$ & & $\overline{Z 3}$ & & $\mathrm{Z4}$ & & Z5 \\
\hline MB 1874202 & 21.1 & -3.8 & 2.4 & 1.1 & -17.9 & -6.6 & -12.4 & -3.0 & -17.9 & -2.14 \\
\hline MB 1874203 & 558.5 & -100.5 & -1.6 & -0.7 & -16.6 & -6.1 & -8.4 & -2.0 & -19.6 & -2.36 \\
\hline MB 1874204 & -207.4 & 37.3 & -10.3 & -4.5 & -21.0 & -7.8 & -12.4 & -3.0 & -22.3 & -2.68 \\
\hline MB 1874205 & 858.9 & -154.6 & -2.3 & -1.0 & -18.2 & -6.7 & -13.3 & -3.2 & -20.2 & -2.42 \\
\hline MB 1874206 & -11.3 & 2.0 & -9.7 & -4.2 & -17.5 & -6.5 & -15.1 & -3.6 & -21.3 & -2.55 \\
\hline MB 1874300 & -187.9 & 33.8 & -0.5 & -0.2 & -15.1 & -5.6 & -22.9 & -5.5 & -12.8 & -1.53 \\
\hline MB 1874400 & 284.3 & -51.2 & -5.2 & -2.3 & -19.8 & -7.3 & -18.1 & -4.4 & -19.1 & -2.30 \\
\hline MB 1985800 & -438.0 & 78.8 & 9.1 & 4.0 & 42.1 & 15.6 & 34.2 & 8.2 & 44.4 & 5.32 \\
\hline MB 2026201 & -439.0 & 79.0 & 9.1 & 4.0 & 42.1 & 15.6 & 34.2 & 8.2 & 44.4 & 5.32 \\
\hline MB 2025900 & -439.2 & 79.0 & 9.1 & 4.0 & 42.1 & 15.6 & 34.2 & 8.2 & 44.4 & 5.32 \\
\hline
\end{tabular}

Step: 5. To aggregate obtained values of weighted indicators to get composite score (table 1.9).

Table: 1.9. Composite Vulnerability Score for Mesh blocks

\begin{tabular}{lcccccc}
\hline Mesh block & Z1 & Z2 & Z3 & Z4 & Z5 & Composite Score \\
\hline MB 2025900 & 79.05 & 3.98 & 15.56 & 8.22 & 5.32 & 112.14 \\
MB 2026201 & 79.03 & 3.98 & 15.56 & 8.22 & 5.32 & 112.11 \\
MB 1985800 & 78.83 & 3.98 & 15.56 & 8.22 & 5.32 & 111.92 \\
MB 1874300 & 33.82 & -0.21 & -5.58 & -5.50 & -1.53 & 21.00 \\
MB 1874204 & 37.33 & -4.55 & -7.76 & -2.98 & -2.68 & 19.36 \\
MB 1874202 & -3.79 & 1.05 & -6.64 & -2.98 & -2.14 & -14.51 \\
MB 1874206 & 2.03 & -4.25 & -6.46 & -3.62 & -2.55 & -14.85 \\
MB 1874400 & -51.18 & -2.30 & -7.34 & -4.35 & -2.30 & -67.47 \\
MB 1874203 & -100.52 & -0.71 & -6.15 & -2.02 & -2.36 & -111.75 \\
MB 1874205 & -154.60 & -1.01 & -6.74 & -3.19 & -2.42 & -167.96 \\
\hline
\end{tabular}

\subsubsection{1.a. Justification for weight and the method used:}

Weighting is the most controversial aspect of a composite index. The very first issue related to weight is its use. There is no consensus in the literature about using weights for vulnerability indicators. Many studies have used either equal weights or no weights for the composite index including United Nations 2000, 2003 as cited in Guillaumont, 2004, 62, Briguglio (2003) and Cutter, Boruff and Shirley (2003). Arguments for not using weight include its simplicity and the subjectivity associated with weighting procedures (Briguglio, 2008). However, a composite index without weight mainly shows the presence of vulnerability indicators, where their mere presence may not necessarily contribute to the actual vulnerability of the place. For example population 
density and poor income both indicate vulnerability in different contexts. A rich neighbourhood in a city however, could have a higher density e.g. a group of apartment houses with say 1000 people, but this does not make it more vulnerable than a poor neighbourhood of about 200 people. But in a composite index without weight, a rich neighbourhood would score higher compared to the poor group because of high density. Even inclusion of another component (i.e. low income), would not put the poor group into a high vulnerability category. This is because either aggregation or the average of two factors would make it score less than some other groups. For example, a middle income group with dense population, which would come out as more vulnerable due to relatively higher values of both indicators, even if it is less vulnerable than the poor group. Also, a high value of a particular indicator such as density could overwhelm lower values of other vulnerability indicators such as the proportion of disabled population or low income population etc. This can be seen in the example of the vulnerability index calculated above. The following tables 1.10 and 1.11 show difference in total vulnerability scores calculated with and without weight.

Furthermore, not all factors contribute equally to produce vulnerability over space. Therefore, there should be some methodology to bring out this relation in order to present true vulnerability, and weighting is one such viable technique.

Table: 1.10. Composite Vulnerability Index without Weight

\begin{tabular}{lcccccc}
\hline Mesh block & Z1 & Z2 & Z3 & Z4 & Z5 & Composite Score \\
\hline MB 1874205 & 858.9 & -2.3 & -18.2 & -13.3 & -20.2 & 804.9 \\
MB 1874203 & 558.5 & -1.6 & -16.6 & -8.4 & -19.6 & 512.2 \\
MB 1874400 & 284.3 & -5.2 & -19.8 & -18.1 & -19.1 & 222.0 \\
MB 1874202 & 21.1 & 2.4 & -17.9 & -12.4 & -17.9 & -24.8 \\
MB 1874206 & -11.3 & -9.7 & -17.5 & -15.1 & -21.3 & -74.7 \\
MB 1874300 & -187.9 & -0.5 & -15.1 & -22.9 & -12.8 & -239.1 \\
MB 1874204 & -207.4 & -10.3 & -21.0 & -12.4 & -22.3 & -273.4 \\
MB 1985800 & -438.0 & 9.1 & 42.1 & 34.2 & 44.4 & -308.3 \\
MB 2026201 & -439.0 & 9.1 & 42.1 & 34.2 & 44.4 & -309.3 \\
MB 2025900 & -439.2 & 9.1 & 42.1 & 34.2 & 44.4 & -309.4 \\
\hline
\end{tabular}

Table: 1.11: Composite Vulnerability Index with Weight

\begin{tabular}{lcccccc}
\hline Mesh block & Z1 & Z2 & Z3 & Z4 & Z5 & Composite Score \\
\hline MB 2025900 & 79.05 & 3.98 & 15.56 & 8.22 & 5.32 & 112.14 \\
MB 2026201 & 79.03 & 3.98 & 15.56 & 8.22 & 5.32 & 112.11 \\
MB 1985800 & 78.83 & 3.98 & 15.56 & 8.22 & 5.32 & 111.92 \\
MB 1874300 & 33.82 & -0.21 & -5.58 & -5.50 & -1.53 & 21.00 \\
MB 1874204 & 37.33 & -4.55 & -7.76 & -2.98 & -2.68 & 19.36 \\
MB 1874202 & -3.79 & 1.05 & -6.64 & -2.98 & -2.14 & -14.51 \\
MB 1874206 & 2.03 & -4.25 & -6.46 & -3.62 & -2.55 & -14.85 \\
MB 1874400 & -51.18 & -2.30 & -7.34 & -4.35 & -2.30 & -67.47 \\
MB 1874203 & -100.52 & -0.71 & -6.15 & -2.02 & -2.36 & -111.75 \\
MB 1874205 & -154.60 & -1.01 & -6.74 & -3.19 & -2.42 & -167.96 \\
\hline
\end{tabular}

The second issue is related to the weighting method. A variety of methodologies have been used in the literature to weight indicators for the composite index. The common weighting methods are revealed weights, econometric model (Guillaumont, 2003, 62-63), multiple regression models, principal component analysis, factor analysis, efficiency frontier, distance to target, expert judgment, analytic hierarchy process, multi-criteria decision approach and endogenous weighting 
(Instituto de Estudios Ambientales [IDEA], 2005, 62-64). However, since there is no consensus over using a particular weighting method (IDEA, 2005, 65), their use is determined by the aim and requirements of the research. In this research, the use of weights based on regression or revealed vulnerability was not feasible for calculating the vulnerability index as the region has not experienced any disaster in recent past. It is also not viable to use an economic model as that would not indicate overall vulnerability. Use of experts' opinions for weight would differ with hazards and the hazardscape they have in mind, which would allow the problem of subjectivity to penetrate, and therefore the expert opinion weighting method has not been used.

Use of correlation for weight is a common method. Both Principal Component Analysis and Factor Analysis use correlation to determine weight for a particular indicator and use the results to identify the few dominant factors that represent overall variation in data and hence describe vulnerability on the basis of a few output indicators. A composite index using these methods, even if it succeeds in highlighting the areas of high vulnerability could not be used to explain underlying factors that cause vulnerability. This is also the main criticism for using correlation for weighting indicators (IDEA, 2005, 62-63). The criticism is valid if the cause of vulnerability is explained on the basis of a composite index based on Principal Component Analysis, as the result only shows the presence of dominant factors that represent a significant pattern in the data, and there may be no inclusion of principal causal factors of actual or overall vulnerability. For example, vulnerabilities from income and fragile sectors of the population, such as children, elderly or disabled people are different, so even if income represents 80 percent of total variation in data, it firstly fails to represent the other 20 percent of variations in data and secondly, to attribute 80 percent of vulnerability to economic factors would be denying the influence of many other operative factors. However, use of correlation for weight is justifiable for a vulnerability index, if it is not used to eliminate or select a few factors over others that also contribute to total vulnerability. It is therefore reasonable to use the correlation for vulnerability indicators in order to represent the interlinked vulnerabilities of a place, and the explanation provided describes the role of input indicators in overall vulnerability rather than claiming to describe the cause of total vulnerability at a place based on few indicators. There are also other reasons that support the use of correlation.

It has been observed that correlations are profuse and pervasive among various vulnerability factors (Sen (1981), Dreze and Sen (1989), Chambers (1989), Swift (1989), Agarwal (1993), Wisner (1993) as cited in Ribot, 1995, 120), even if they are not caused by each other. A vulnerable population at a place exhibits various correlated features, which can contribute to the collapse of many aspects of hazard response leading to the onset of a disaster. In disasters, neither all people die for the same reason nor is one vulnerability aspect sufficient to cause a disaster. It is the presence of varied and interlinked vulnerabilities which cause subsequent collapses and a cumulative loss in the form of a disaster. Correlation is therefore inherent in the vulnerability of a place. In areas where these indicators are not correlated and stand separate from one another, the cumulative impact of a disaster would be less or at least less widespread than those where they are correlated. Unrelated vulnerability indicators therefore indicate either less vulnerability or isolated vulnerability. However, a composite index without weight or equal weight does not recognize this aspect and simply aggregates or takes the average values of all indicators, which may or may not 
Fig: 1.2. A Possible Scenario of Population Characteristics for Composite Index

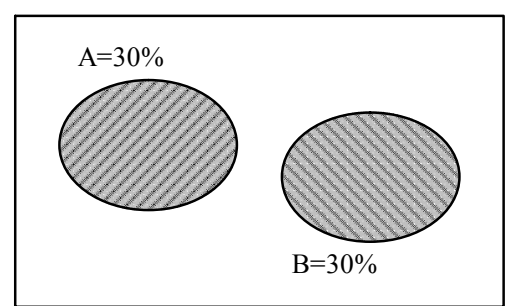

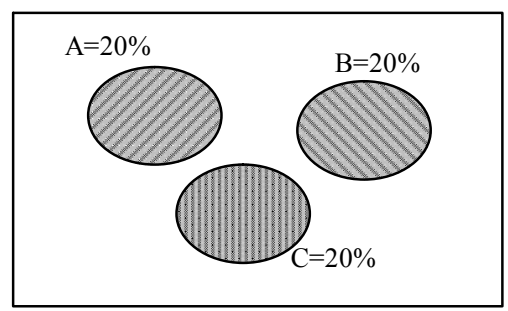

Area: Y

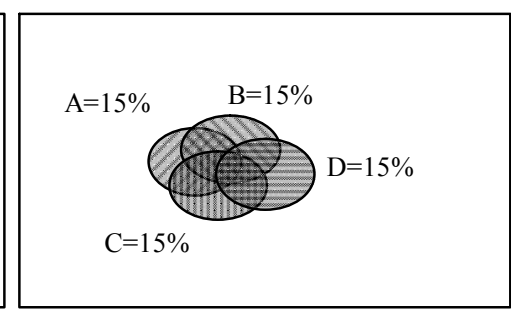

Area: $\mathbf{Z}$

$\mathrm{A}, \mathrm{B}, \mathrm{C}$ and $\mathrm{D}$ are the vulnerability indicators showing percentage value in the given spatial unit.

cause actual vulnerability to a hazard at a place. For example, in figure 1.2, the vulnerability score from summing indicator values for areas $\mathrm{X}, \mathrm{Y}$ and $\mathrm{Z}$ would be same if the index is calculated without any weight or equal weight. But the intensity of vulnerability is not same in all three places, rather it increases from $\mathrm{X}$ to $\mathrm{Z}$. In area $\mathrm{X}$, vulnerability would be less because the groups possessing the two vulnerability features are separate, and the impact of a disaster in this case would be governed more by the nature of the hazard, which could affect one or another section of the population with characteristics A or B. Further, not all people with a particular vulnerability characteristic would be subjected to disaster as vulnerability is often modified by other correlated factors, e.g. not all poor die in any disaster. The case of area $\mathrm{Y}$ would be similar, where disaster

Map: 1.3. Difference in Final Output of Composite Index with and without Weight

A. Composite Index without Weight
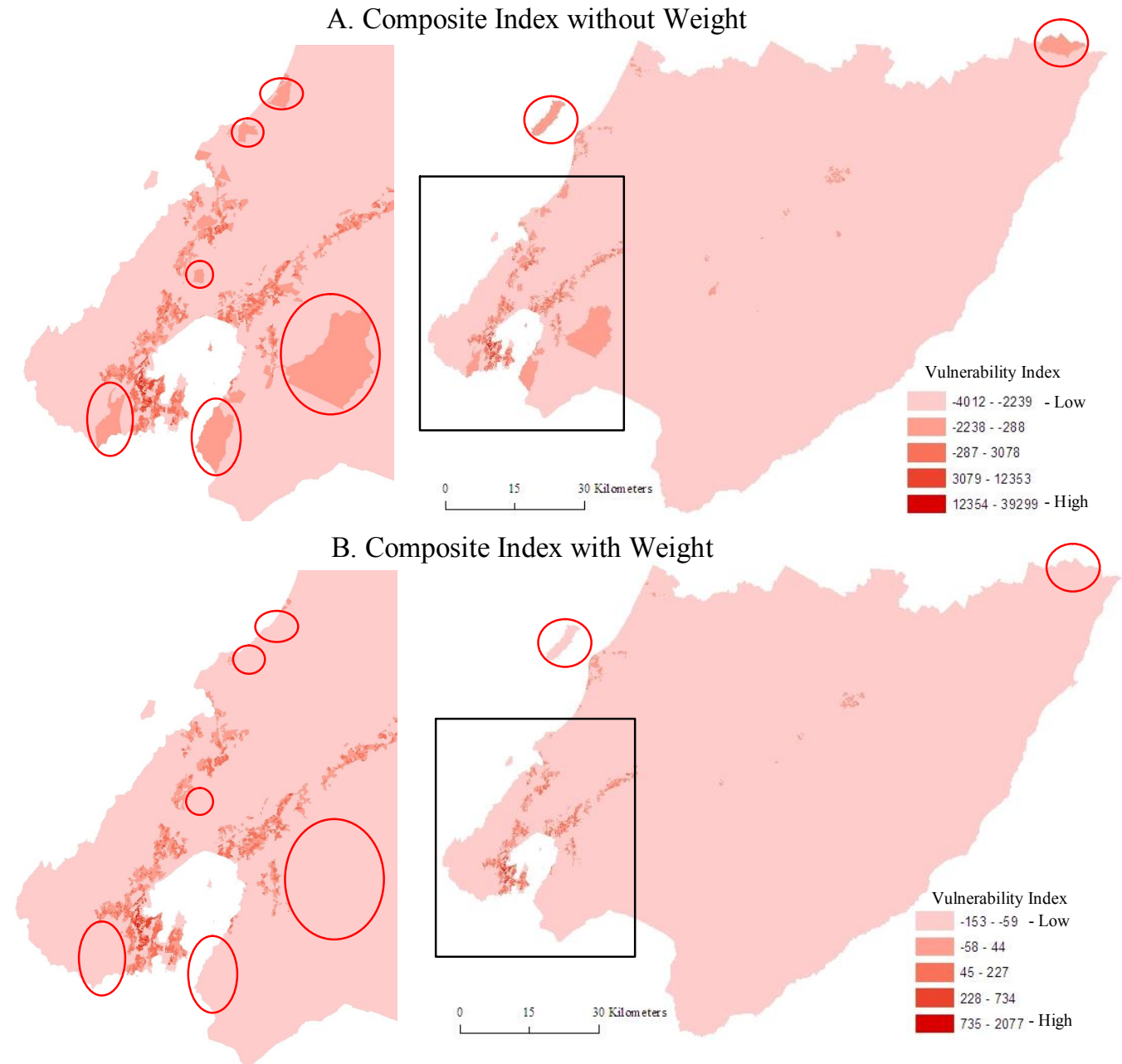

Based on data from Statistics New Zealand, 2006 census

Note: Index is based on maximum imputed value 
outcome would depend on the nature of the hazard, but the possible hazards that could affect the area would be more than in area X. In the case of area Z, on the other hand, correlated vulnerability indicators would cause high vulnerability, and the area could experience disaster because of any or many hazards due to higher vulnerability. The zones of overlaps in area Z, which represents higher vulnerability in reality, get dropped off from the composite index if calculated without weight and therefore it fails to capture true vulnerability.

The difference in the final output of the composite index with and without weight is clear in map 1.3. The map shows that the composite index without weight (Map: 1.3.A) designates many areas (encircled areas) as relatively high vulnerability zones, which do not appear vulnerable if

Map: 1.4. Difference in Final Output of Composite Index with and without Weight
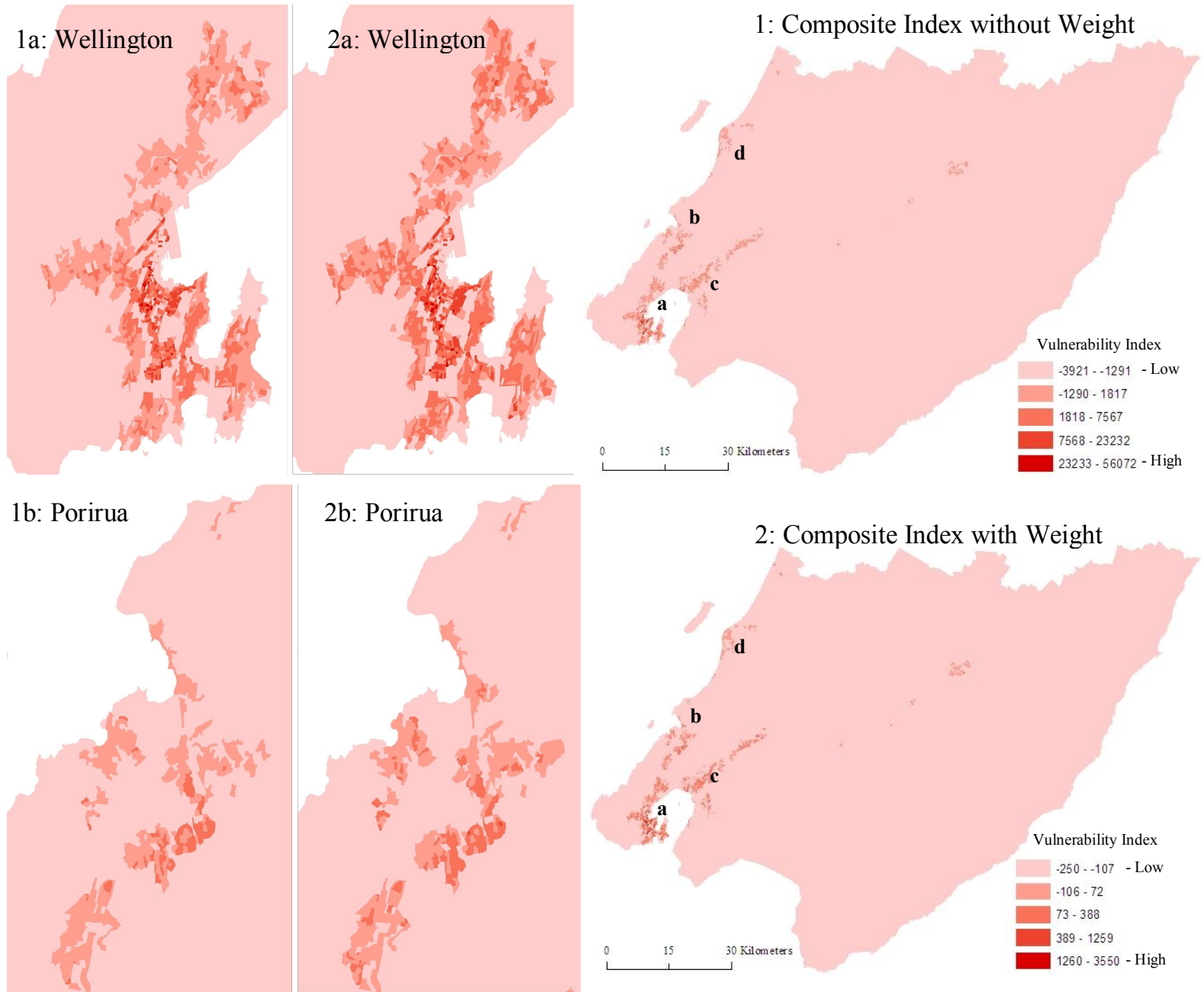

2b: Porirua
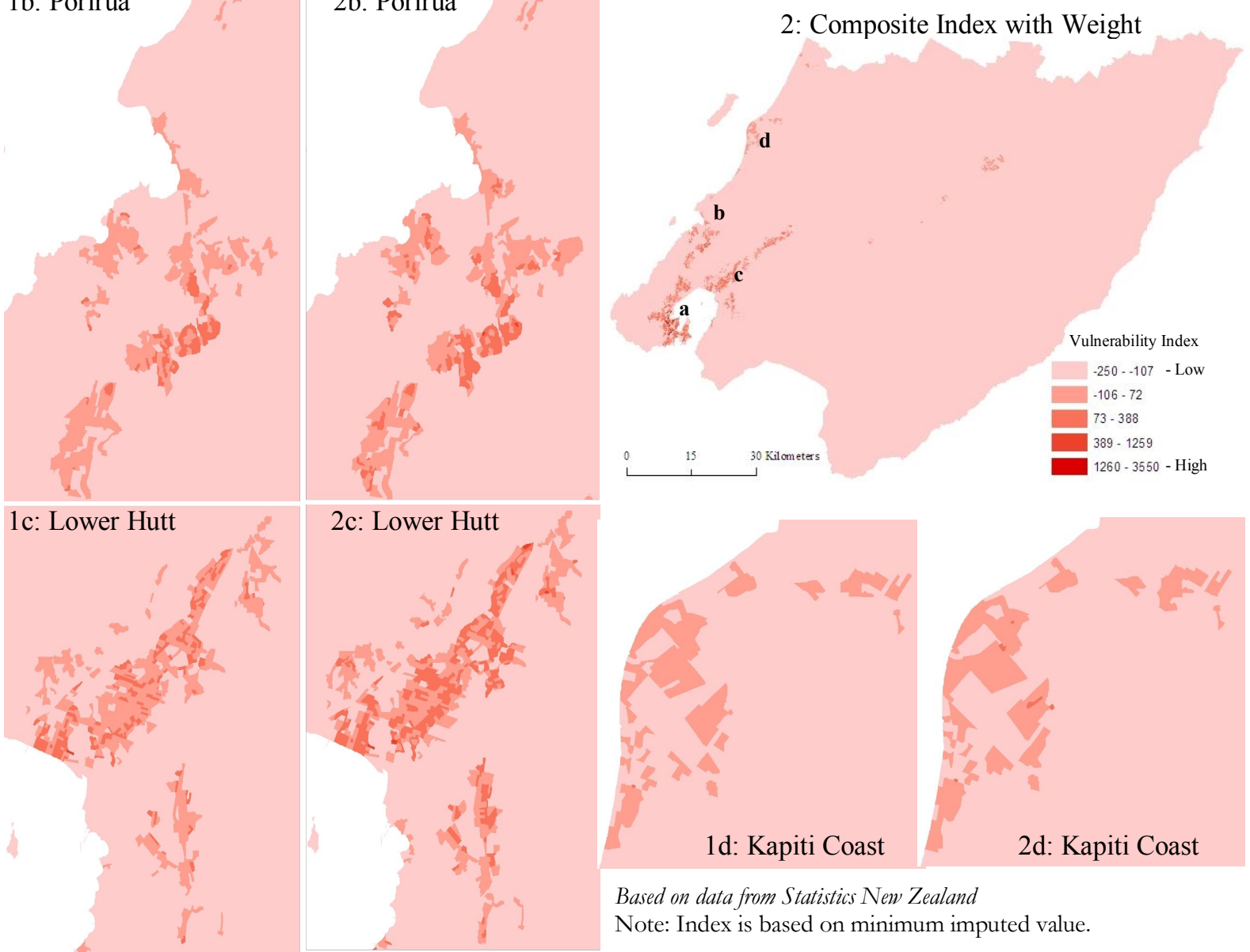

Based on data from Statistics New Zealand

Note: Index is based on minimum imputed value. 
compared with the index produced by using correlation weighting procedure (Map: 1.3.B). The areas, which appeared in without or equally weighted composite index, actually have extremely low population ranging from three to six, and most data of vulnerability indicators for these areas are imputed ones that would be two in most cases, which results in vulnerability on a greater proportion of the population compared to densely populated areas. This is different from what is seen in the example shown above in Table $1.10 \& 1.11$, where many of these areas with low population density do not appear as vulnerable as they did through the weighted method. The reason could be that the index without weight aggregates the overall score and therefore the classification of these areas puts them in higher categories on the basis of natural breaks, while the index based on correlated indicators draws correlations for large numbers of selected indicators, where their combinations in varying proportions affect overall score and their classification accordingly.

A different trend is noted when the composite vulnerability indexes with and without weight are calculated for minimum imputed values. Map 1.4 shows that the composite index without weight dropped out many areas, which appear vulnerable in the composite index calculated through the correlation weighting method. Most of these areas, which are left out in the composite index without weight, are rather densely populated with numbers of other vulnerability features; such as areas in Plimmerton, Pukerua Bay in Porirua, Woburn and Waterloo in Lower Hutt, Waikanae and Paraparaumu Beach in Kapitiu Coast and Wadestown, Lyall Bay in Wellington City etc. This happened again because the index without weight did not respect the connectivity of vulnerability indicators, and it is essentially the connectivity of these factors, which restricts the scope for response and hence produces vulnerability. Thus weighting through correlation not only helps to figure out areas of vulnerability more accurately, but also to comprehend various contributory aspects of it.

Table: 1.12. The Variations in the Final Output Through Maximum and Minimum Imputed Values in Vulnerability Index

\begin{tabular}{|c|c|c|c|c|c|}
\hline Categories & $\begin{array}{l}\text { Categories for } \\
\text { maximum } \\
\text { imputed values }\end{array}$ & $\begin{array}{c}\text { Number } \\
\text { of mesh } \\
\text { blocks }\end{array}$ & $\begin{array}{l}\text { Categories for } \\
\text { minimum } \\
\text { imputed values }\end{array}$ & $\begin{array}{c}\text { Number } \\
\text { of mesh } \\
\text { blocks }\end{array}$ & $\begin{array}{c}\text { Difference in } \\
\text { number of mesh } \\
\text { blocks }\end{array}$ \\
\hline \multicolumn{6}{|c|}{ Demographic } \\
\hline Low & -141 to -9 & 2433 & -236 to -14 & 2443 & 10 \\
\hline Medium & -8 to 337 & 2111 & -13 to 576 & 2101 & 10 \\
\hline High & 337 to 2082 & 110 & 577 to 3555 & 110 & 0 \\
\hline \multicolumn{6}{|c|}{ Social } \\
\hline Low & -6 to 0 & 3284 & -6 to 0 & 2942 & 342 \\
\hline Medium & 1 to 15 & 1235 & 1 to 9 & 1595 & 360 \\
\hline High & 16 to 39 & 135 & 10 to 21 & 117 & 18 \\
\hline \multicolumn{6}{|c|}{ Economic } \\
\hline Low & -6 to 2 & 3931 & -8 to 7 & 4325 & 394 \\
\hline Medium & 3 to 23 & 704 & 8 to 49 & 315 & 389 \\
\hline High & 24 to 91 & 19 & 50 to 167 & 14 & 5 \\
\hline \multicolumn{6}{|c|}{ Composite } \\
\hline Low & -153 to -8 & 2467 & -250 to -14 & 2451 & 16 \\
\hline Medium & -7 to 348 & 2077 & -13 to 592 & 2092 & 15 \\
\hline High & 349 to 2077 & 110 & 593 to 3550 & 111 & 1 \\
\hline
\end{tabular}


However, imputation of maximum and minimum values has resulted in significant difference in scores, especially for social and economic vulnerability (Table: 1.12.). This happened particularly because of mesh blocks with low population, where change in imputed values i.e. from one to two, caused significant changes in the proportion of vulnerable population to the total population of mesh blocks, and hence affected their classification. It is important to note that the classification of vulnerability into low medium and high is based on relative values and classified according to the natural breaks in data.

Importantly, giving weight through correlation is also free from any personal subjectivity. In correlation, weight is not given to a particular indicator for its significance in causing vulnerability, but according to its contribution in total correlation value with respect to other vulnerability indicators, which highlights congregation of interlinked vulnerabilities at a particular place rather than their mere presence. Since vulnerability indicators are very much influenced by other socio-economic factors, their relations are an important aspect that needs to be incorporated in the composite index.

5.2.2. Primary data analysis: After cleaning the primary data from various sources, descriptive statistics and mapping techniques were applied to assist analysis and draw conclusions. In order to compare the response of local people throughout the region and to correlate that with other geophysical characteristics, the location of respondents along with the information provided were geocoded with the help of a geocoding tool in ArcGIS. However, out of 272 questionnaires about 100 could not be plotted automatically because of the errors in the address locations, incomplete addresses, or absence of the street names in the software itself. These addresses were then manually plotted using other information provided by the respondents.

The information provided by these respondents was then compared with hazard characteristics, physical susceptibility of the place and vulnerability of the area in which they are living, in order to see the influences of these elements of hazardscape on the local response. Various statistical techniques including correlation and factor analysis were applied to explore the data and to find if any significant relationships exist in the data. The analysed data were then presented with the help of maps, tables, diagrams and photographs.

\subsection{Limitations}

The research faced some limitations, which are as follows:

1. Data not available: Much data that was required for this research was not available either in reports or in the census. For example, the Census does not collect or record all types of disabilities or provide background information about migrants. Similarly the data given for ethnic composition and occupation were in very broad categories and further details were not available. The unavailability of such data restricted the vulnerability assessment to an 
extent because the indicators selected for the vulnerability index were biased towards the data availability rather than actual factors.

2. Incomplete data or missing information: The data collected from various sources including both primary and secondary were incomplete either in terms of time or space or simply because of missing values. This inhibited the presentation of a holistic picture of hazards for all places in the region with equal precision.

3. Inconsistent data and ambiguities in the available information: The data collected from different sources were inconsistent in themselves as well as with each other. The landslide records collected from GNS, which have been compiled from various sources, including newspapers, books, internet and other sources, often had no geographical reference or the wrong one. A few geographical references were also wrong in the damage data provided by EQC, and when mapped, many points were seen to be lying outside the regional boundary in the sea. Such data were modified and corrected by placing the outlying points manually to their nearest geographical location and interpreted at district level in order to avoid misinterpretation.

4. Noise or human errors: The data collected from various sources also had errors or noise that had to be either corrected or removed from the final data set that is used for the interpretation. For example, in the census data, for nearly 300 mesh blocks, where the population is zero, indicator values were given confidential, which if combined with imputed values for confidential data could have given wrong index values and therefore such data were cleaned before processing the vulnerability index.

5. Other Restrictions: Some data received from various agencies were in categorical form or in other formats, which were difficult to decode or to rearrange according to the thesis requirements. This restricted the possibility of further exploration with the data sets.

6. Sampling restrictions: Since the purposive stratified sampling technique was used for sampling, the number of respondents for large scale (small area) comparisons was very small. This precluded the establishment of statistically significant comparisons and correlations. While this is regrettable in terms of certainty in stated correlations, it has revealed a wide and comprehensive range of conditions.

\subsection{Chapter Outline of Thesis}

The thesis consists of eight chapters addressing various aspects of this research including background, purpose, design, process, findings and concluding remarks.

The first chapter 'Introduction' states the rationale of this research along with its aim, objectives and hypothesis. It describes the study area in brief, and discusses the research methodology in detail along with limitations of the research and thesis organisation. The second 
chapter, entitled 'Hazardscape: A Conceptual Framework', explores the concept of hazardscape and its implications for local response. It provides an overview of the research being done in geography on hazards, hazardscapes and their ecological assessments, and highlights the gaps in theory, which can be addressed by assessing hazardscape of a place.

The three subsequent chapters present the hazardscape of the Wellington Region and focus on various elements of hazardscape (i.e. physical susceptibility, human vulnerability and spatiotemporal occurrence of hazards in the region respectively). The third chapter, 'Physical Susceptibility of the Wellington Region to Natural Hazards', is based on the physical characteristics of Wellington Region, which enhance susceptibility to different hazards in the region. The chapter does not see hazards as the necessary product of natural processes alone. Nature has been significantly modified by human beings and therefore, they have played an important role in inflicting hazards by enhancing the local susceptibility to hazards. The fourth chapter, 'Human Vulnerability to Natural Hazards in the Wellington Region', describes the vulnerability of the region in terms of exposure, fragility and coping capacity. It also looks for the historical, socio-economic and political roots of the problem. The chapter is primarily based on the census data and is supported by both secondary and primary data. The fifth chapter on 'Spatio-Temporal Occurrence of Hazards in the Wellington Region' assesses hazard occurrence in the region over space and time. It encapsulates a variety of hazards ranging from geological, meteorological and hydrological hazards, which have grown in number and intensity as reflected in the damage incurred through them, and highlights the connectivity of various processes in causing damage.

The next two chapters describe the hazard response of the general public and administrative bodies in the region and identify the gaps and factors influencing their response. The sixth chapter, 'Local Response to Hazards in the Hazardscape of the Wellington Region', is mainly based on the primary survey conducted with local people in the region. It describes the general trend of response in the region and identifies the factors influencing hazard response and variations in them over space. It describes how and to what extent elements of hazardscape influence the response to them. The seventh chapter is entitled 'Administrative Response to Harards of the Wellington Region'. This chapter is based on the primary survey conducted with district planners and civil defence officers in the region. However, it is equally dependent on other secondary data sources such as district development plans, policies, local and national reports and hazard management plans in the region. The chapter discusses the current hazard management strategies in the region and highlights their perspectives and shortcomings.

'Synthesis and Conclusion' is the eighth and final chapter of the thesis. It provides the overview of findings from different chapters and presents a holistic picture of hazardscape and response to hazards in the region. It also highlights the shortcomings and gaps, which could be considered for future research. 
Chapter: 2

Hazardscape: The Conceptual Framework

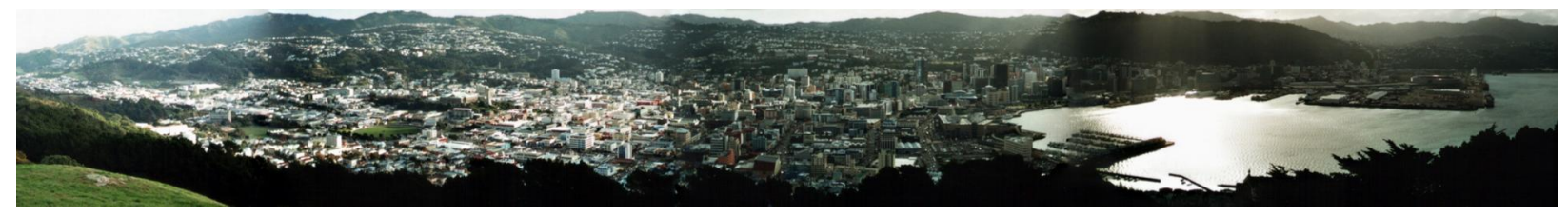


The research on natural hazards gained momentum in the late $20^{\text {th }}$ century due to an increase in both disasters and their awareness (Smith, 1992, 4). In a quest to find explanations, while one set of scholars focused their research on the 'naturalness' of so called natural disasters, others looked for social factors behind their occurrence (Wisner, et. al, 2004, 10). As a result, numerous terms have evolved with multiple interpretations and loose definitions. 'Natural hazard' has been defined in four different ways and is used synonymously for natural events, processes, elements, and risks (Alexander, 1993, 4). Similarly, vulnerability has been attributed a similar meaning to marginality and poverty and is used in contrast to capacity and resilience (Wisner et al, 2004). Response, on the other hand, has been described and classified in multiple ways as involving adjustments, adaptation, mitigation, preparedness, emergency response and recovery. The spontaneous use of these terms with evolving research in the field has not only enriched the lexicon of hazards and disaster studies, but has also enhanced understanding of them and of effective management. One new term in this field is 'hazardscape', which has been frequently used by the scholars and practitioners to introduce the hazards of a place.

\subsection{Definition}

The term hazardscape was first defined by Corson in 1999. With a focus on technological hazards, he defined hazardscape as "the spatial distribution and attributes of human engineered facilities.....that contain or emit substances harmful to humans and environment" (Corson, 1999, 57). Even though this definition is relevant to most technological hazards, it does not fully apply to hazards in general or especially to natural hazards. The following year, Cutter, Mitchell and Scott (2000) used the word hazardscape in their research on place vulnerability of Georgetown County, South Carolina. Though they did not define the term, they used 'hazardscape' interchangeably with 'riskscape'. The dilemma here is that even though both terms hazards and risks are related, they are not the same. This is discussed later in the chapter. Gray (2001) used the word hazardscape to describe the collective areas of risks associated with hazards (Gray, 2001, 35). This definition again interpreted the hazardscape in terms of risk. Mustafa (2005) described hazardscape as an integrative concept, and defined it as both an analytical way of seeing that asserts power and as a socialenvironmental space where the gaze of power is contested and struggled against to produce the lived reality of a hazardous place. He used the term hazardscape as a substitute for natural hazards, which denotes some external nature as the key causative element in the hazardousness and vulnerability of life (Mustafa, 2005, 569-570). In this definition, the author rightly suggests that the hazardscape is an integrative concept, but latter concedes external nature as the prime cause of hazards and vulnerability.

However, a hazardscape neither just simply refers to the hazards of a place nor indicates them to be factors external to the environment. Rather, it demonstrates the ecological perspective of hazards and consequent risks, which build through a constant, implicit and intricate relationship between human beings and the environment in a particular spatio-temporal context. It conveys the underlying fact that hazards were never separate either from people or places. The definition of hazard as an agent (event or process or situation), which can cause damage to life and property (Glade, Anderson \& Crozier, 2005, 782), if assessed carefully, clearly implies that hazards exist not 
only because of unstable characteristics of environmental processes (i.e. when it says agent or process), but also due to physical susceptibility of the place (i.e. situation, which partly implies place characteristics) and human vulnerability (i.e. damage to life and property). Physical susceptibility here characterizes the likelihood of a place to experience natural hazards due to its physical characteristics, while human vulnerability in brief refers to the liability of a community or people to suffer from hazards at a given place (Smith, 1992, 22). Both susceptibility and vulnerability change through time and along with the changing nature and types of hazards, they give a dynamic character to hazardscape. Hazardscape therefore can be defined as a "dynamic scape which reflects the physical susceptibility of a place and vulnerability of human life and assets to various hazards in a given human ecological system".

A hazardscape may contain one or more hazards in addition to varied spatial and population characteristics. Variations in the nature and severity of hazards, physical susceptibility and human vulnerability alter hazardscape across space and time. This implies that a hazardscape would differ from remote to rural to urban places and would change through time (i.e. days, nights, months, years and through generations).

\subsection{The Ecological Perspective}

The use of the ecological approach in geography to study hazards is not new and has been adopted by many scholars in the past. Burton, et al. (1978) used the ecological perspective to make a resource and hazard model, which stated that natural hazards are created due to interaction between humans and the environment, and in order to respond to these hazards humans may seek to modify both natural event systems and their uses of location, livelihood and social organisation (Burton et al, 1978, 20). The model was later used by many scholars with either slight or no modification in successive pieces of research, e.g. Erickson (1986), Smith (1992) and Handmer, (2004). This model adopted a basic idea of an ecological thesis, but instead of having an holistic approach to assess human environment relationships, it viewed the problem from a humanistic point of view i.e. adjustments made by human beings to cope with natural hazards. It did not look for how these adjustments have influenced the environment. The origin of such deviated ecological theory goes back to 1923, when Barrows first defined geography as human ecology. According to his definition, geography as human ecology aims to study the relationships existing between natural environment and human activities, but it views the problem from the standpoint of human adjustment to environment rather than from that of environmental influence (Barrows, 1923, 3). The one way view of the problem restricted geographers' view of how the environment responds to the changes incurred through human activities. They basically looked for how human behaviour could reduce hazards rather than what role human beings play in the hazard creation. If we see the current adjustments to hazards i.e. building codes for earthquake or dams to reduce flooding; although they have reduced the occurrence of minor hazard events, they have increased both the 
risk and vulnerability to high magnitude events. As a result, even after years of research and technological applications, natural hazards are the leading threat to human life and property.

The dissatisfaction with the simply portrayed relationship between human beings and the environment, along with increasing disasters forced the scholars to look at the problem from a different point of view. Subsequently, the ecological model of natural hazards was replaced by vulnerability theories, which looked into human societies for the reason behind disaster occurrence. These studies kept the ecological perspective but took a more sociological point of view in which community was more critical than the natural environment. In the social sciences, especially in sociology, the theory of human ecology was basically developed in the context of the urban society of an industrialised world where the position of the human was predominant over natural factors and nature had little or no role to play in decision making. As a result the study of human ecology focused largely on the community and its human environment (Wirth, 1945, 484; Catton, 1994, 78). The resultant vulnerability theory thus blamed communities for disaster occurrence due to their specific economic, political, social and cultural set up. Although the theory provided a major breakthrough in disaster studies by having a different perspective, it could not provide satisfactory answers to many questions, particularly those related to increased hazards and related risks in developed countries. The reason behind this was that even though the theory adopted the ecological perspective and acknowledged the relationship between human beings and the environment, it also viewed the problem from a humanistic point of view rather than a holistic perspective. Although the environment was considered an important part, the theory mainly focused on the human environment, and the biophysical environment was left out as the source of hazard. The difference between the humanistic perspective of the ecological approach adopted by geographers and sociologists was that the geographers viewed humans as the dominant factor of making adjustments with the environment, while sociologists focused on the human vulnerability in the face of natural hazards. The ecological analysis in geography, along with its adoption by other social sciences including anthropology, sociology and economics, was also criticised for having a static view of ecology (Scoones, I. 1999, 483). Scientists assessed hazards and vulnerability as a constant of the human-environment relationship, and therefore calculated the probability of a hazard occurrence on the basis of existing situations and vulnerability assessed as the product of static factors of race, gender and employment, without linking them with the bigger picture of changing environmental processes. Hazard analysis through the ecological approach, therefore, suffered not only because of the problems associated with the definition and application of the ecological approach in geography but also due to controversies linked to the theory of human ecology studied by sociologists. The misapplication of the ecological approach with its skewed focus on human beings also failed to bridge the gap between hazard research carried out in natural and social sciences.

Despite the problems associated with the theory or application of the ecological perspective, its use to study hazards has been continuously supported and advocated by many geographers including Kates (1971), Wisner et al (1994), Hewitt (1971, 1997), Cutter, Mitchell and Scott (2000), Turner et al (2003). This was due to overall consensus of the fact that the origin of hazards is somewhere linked to interactions between human and environment. However, the aim 
here is not to clarify the already confirmed relationship, but to further extend the approach. Hazard and disaster research has passed through several phases, starting from assessing physical processes and responses to considering vulnerability and resilience. A paradigm shift has also been observed in the methods of assessment i.e. from descriptive to analytical and from single issue focus to holistic assessment. In such situations, hazardscape fulfils the demands of the dual paradigm shift in the subject matter and the method of hazard analysis. Hazardscape from an ecological perspective provides an integrative framework where both human and environmental factors play active roles, and their relationships determine its existence and outlook at a particular place and time. Hazardscape represents those aspects of human ecology which are responsible for hazard creation, their persistence and occurrence at a particular place. Hazardscape would not explain why environmental processes fluctuate in their extremes but where and why these processes turn into hazards and produce disasters. Hazardscape would highlight the human relationship with dominant environmental processes and show how they affect physical susceptibility and human vulnerability which may lead to a disaster. Although these conditions may not help to predict a hazard occurrence at a given time, they can contribute to the understanding of strained relationships between humans and the environment, and therefore, could contribute to reducing the possible damage.

\subsection{Hazardscape and Ecosystem}

The ecosystem is the foundation concept of Human Ecology (Catton, 1994, 76), but at the same time it has been associated with many controversial issues. There are two such issues related to ecosystem which have significant implications for the hazardscape. The first issue concerns the content of ecosystem and questions the validity of the environment as a part of an ecosystem, while the second issue asks what actually constitutes the environment. Tansley, the founder of the concept in Bioecology, defined ecosystem 'in the sense of Physics, including not only the organism complex, but also the whole complex of physical factors forming what we call the environment of the biome-the habitat factors in widest sense' (Tansley, 1935, 299). The term was later adopted in social sciences for the study of human ecology, but it was used in an entirely different context. Hawley, who wrote a detailed theoretical essay of human ecology, defined ecosystem as 'an arrangement of mutual dependence in a population by which the whole operates as a unit and thereby maintains a viable environmental relationship' (Hawley, 1986, 26). His concept of ecosystem basically explains a system without 'environment or eco', which is simply a population system. According to him, population and system are different aspects of the same thing i.e. one being a quantitative aspect of which the other is a substantive aspect (Hawley, 1986, 26). This conception of ecosystem, which was shared by many sociologists of the time, disqualified many ecological principles, which were otherwise applicable to other living beings in their ecosystems (Catton, 1994, 78). The omission of the environment from the ecosystem led human ecology to view humans and the environment as separate entities having their separate systems which 
influence each other, but they are not related. The idea of humans and environment as separate systems is also found in hazard research by geographers, where the environment has often been seen as the source of hazard, and population as a modifier or corrective factor (see Burton et al, 1978). This notion has long directed scientists and researchers to find solutions by taming natural processes, which in some cases has resulted in a continuous increase in the size and extent of hazards. Modification and suppression of natural processes has reduced the likelihood of frequent small hazardous events but increased the risk of extreme events. Vulnerability theory, on the other hand, put more emphasis on community weaknesses by keeping the environment separate. This was also not very useful because in increasingly complex and populous societies, simple empowerment and change in economic systems could not decrease the risks of major environmental hazards.

To find the long term solution to hazard problems, it is important to view humans and the environment as parts of the same system. It would be wrong to blame nature as the source of hazard as it would not be able to produce hazards if population were to be removed from the system. However, it is also true that most damaging forces often translate through environment. Here it is important to note that it is not only the coexistence and interaction of humans and environment that is significant for hazard occurrence, but their interrelatedness in the functioning of ecosystem also influences hazard characteristics. As an ecosystem contains both human beings and the environment which together operate and adapt to its functioning, hazards are therefore an essential characteristic of ecosystem rather than products of the environment or simply human and nature interactions. An ecosystem provides both the background and the context to various environmental hazards. The ecosystem here is therefore used in its classical sense where it not only includes the human community but also the proximate environment.

Another issue is linked with the environment. The meaning and definition of environment has been 'essentially contested' among natural and social scientists (Barry, 2007, 12). In the early hazard research 'nature' was often used synonymous with 'environment' (see Kates, 1971, 438, Burton et al., 1978), which basically referred to the biophysical world separate from human beings, to which humans adapt or exploit for resources. Sociologists, on the other hand, viewed the environment as predominantly human encompassing society, culture, economy, politics, technology and built infrastructure where nature plays little or no role. Both definitions are valid in the sense that they apply the literal meaning of the term environment, which means to surround the object in focus. Nevertheless, they view environment partially. For hazard analysis it is important to consider both views as they project different roles that the environment could play in hazard creation. Environment is a broad term and includes all elements and processes in the surroundings and sets the condition, which influences the existence, characteristics and behaviour of the population under investigation. These elements may range from physical, abiotic, non human elements to biotic and human elements. In order to do a systematic assessment, as Hawley (1984) puts it, environment can be broadly classified into the biophysical and the ecumenical environment. The biophysical environment refers to the natural elements and processes of the environment including landforms, geology, climate, soils, plant and animal life, while the ecumenical environment refers to human elements and comprises the cultures created due to 
interrelationships among human groups (Hawley, 1986, 14). However, since the word ecumenical is often understood in religious context and is not readily acceptable by all, the word human is used in this thesis to represent all the socio-economic, cultural and political aspects of environment. Both biophysical and human environments play a significant role in hazardscape. While the physical environment determines the physical susceptibility of the place, the human environment has a dominant influence on vulnerability and together they not only govern the type of hazards but also the response of the community. This relationship defines the core of the concept of 'hazardscape'.

There are six aspects of ecosystem which are crucial in the understanding of a hazardscape. These are space, process, connectivity, change, uncertainty and scale. Space is the basic requirement for any ecosystem to exist and operate, hence it can be said that every ecosystem engages some space in the universe. A hazardscape, on the other hand, develops in a three dimensional space within an ecosystem as life has not evolved in a vacuum. A hazardscape therefore, is the product of various processes and changes operating in the ecosystem which shape its various characteristics. If we consider earth as a human ecosystem, a hazardscape could be drawn for any geographical location on earth for which $\mathrm{x}$ and $\mathrm{y}$ coordinates can be delimited on the basis of territorial or administrative boundaries while $z$ axis touches the biosphere limits, starting from the interior of the earth to higher up in the atmosphere. The description and details of the hazardscape, however, would depend on the existing state of knowledge, research objectives and awareness of the researcher.

Processes, which also indicate functionality, are another principal characteristic of the ecosystem. They actually give meaning to the ecosystem by interlinking its various elements in a functional order. The relationship between ecosystem and processes is so strong that their evolution reflects the reason behind the existence and characteristics of the two. While ecosystem owes its origin and evolution to the processes of different order, processes on the other hand, have evolved to a significant extent in their number and type with evolution of the ecosystem. The evolution of living conditions on earth is an example of the role of processes and associated changes in the ecosystem. The earth as an ecosystem contains numerous biophysical and human processes, which together determine the environmental conditions at a place that could be both beneficial as well as harmful to the community. Human beings, as the ecosystem community, have to adapt to these environmental processes in order to survive and escape hazards. In the midst of numerous processes, a few are relatively more dominant and play key role in defining hazardscape. Therefore, in order to understand hazardscape, it is important to comprehend these processes. An understanding of them is also significant because their patterned behaviour provides an indication about their future course which may either intensify or weaken the hazardscape.

Another closely related characteristic of the ecosystem is connectivity or linkages. All processes in the ecosystem are interlinked and connected through the flow of energy, matter and information (Wessels, 2006, 44) which facilitate the system's operation. Therefore a functional relationship could be observed among different environmental processes and ecosystem communities, and in between them. Connectivity in the ecosystem can be attributed to the coevolution of the system and its elements, which has also given the system its nested character. As a 
result the diversified communities and environment at lower levels are nested and unified at the higher order of the ecosystem. Connectivity also helps the system to feed back on itself. By being the part of the same ecosystem each part interacts with other parts at different times and in different ways, which allows the system to loop or feed back on itself (Wessels, 2006, 7). The feedback loops help the system to self organise and operate in a meticulous way. Any change in the ecosystem either through its environment or communities is absorbed by the system, which acts as guidance for the future course. However, this also adds to the complexity of the system as parts of the system absorb energy and matter from the environment and grow with time (Wessels, 2006, 11). Besides, connectivity also helps the system to attain some properties, which cannot be explained by the sum of its parts. These are called emergent properties (Wessels, 2006, 9). For example, resilience of a community is not just the sum of its individual resilience, but it is influenced by various social, economic and spatial characteristics of a community that make it important to assess resilience at the community level rather than at the individual level (Adger, 2000, 349).

Connectivity therefore has an important role to play in shaping hazardscape. In the human ecosystem, it can be said that the human environment is superimposed over the biophysical environment and community has nested in the midst of both environments and settlements of different order. This connectivity makes the community vulnerable to any change in the environment or the ecosystem functions. Due to the nested and connected nature of the ecosystem any change at one level gets easily transferred to different levels. A major change in the higher order processes generally proves to be catastrophic for the community at lower order. The connectivity also signifies that the boundaries of the ecosystem are open and permeable. Energy, matter and information are constantly exchanged within and outside the various parts of the ecosystem (Wessels, 2006, 44) even if the general appearance and basic function of the system remains constant for a long period of time. This implies that the boundaries of a hazardscape are essentially permeable, and a hazardscape is not only affected by the hazardscape of nearby areas but also due to overall changes in the ecosystem.

Change is another important characteristic of an ecosystem which signifies its dynamic character. Although an ecosystem and subsequently, the hazardscape are occasionally influenced by outside disturbances, the major changes in an ecosystem and a hazardscape result through internal factors. The source of change could be either the community or environmental processes. The change could vary in speed, direction and size. It could be slow or rapid, forward or backward and small or major, depending on the nature of disturbances and their cumulative effect. While the changes in environmental conditions, especially through biophysical processes, are often slower and abrupt (Wessel, 2006, 17), change in human elements and thus to the human environment are comparatively rapid and spontaneous. The direction of change in processes generally depends on the feedback loops which determine their future course. There are basically two types of feedback loops that operate in a complex system. These are positive and negative feedbacks, where negative feedback maintains the status quo of the system's behaviour, positive feedback amplifies the system's behaviour in a directional accumulative way (Wessels, 2006, 16). A process follows its initial behaviour pattern as long as it can accommodate smaller changes. The processes are 
therefore never stable or uniform, rather they are usually associated with changes of certain order within a particular threshold. However, occasionally processes totally change their direction and behave in a highly unpredictable way. The point at which a process jumps into a new behavioural pattern is known as a bifurcation event (Wessels, 2006, 16). But after adopting an entirely new behavioural pattern the process again starts absorbing changes under a new threshold. This is called dynamic equilibrium. The community in the ecosystem generally adapts to the changes under a particular threshold of environmental processes and when the process fluctuates beyond this threshold, the community experiences a hazard, for example, an earthquake, flood, drought, windstorm etc. A bifurcation event is particularly significant to the hazardscape as drastic change in one process could result in significant changes in other connected processes, which then can produce new hazards to which a community may be caught unaware. A change in the environment is, therefore, particularly significant as it tests the ability of the community to survive the change, and the inability of the community to cope fabricates a hazardscape.

A closely related factor to change that plays an important role in ecosystem and shaping hazardscape is uncertainty. Due to the complexity of the system, sometimes it is hard to forecast when a major change could happen. This is particularly the case with bifurcation events which are hard to predict, as the system retains its status quo until it reaches its bifurcation point (Wessels, 2006, 18-19). Uncertainty about the system behaviour is also associated with other factors such as the current state of knowledge and lack of awareness. Since one is not fully aware of all ecosystem processes, their linkages and behaviour, any probability of a hazard occurrence is generally an uncertainty. This inability has led many scientists to label the system's behaviour, a chaotic process. However, there is evidence that these processes, if examined over a long period of time, are very much predictable (Wessels, 2006, 8). At the local level, uncertainty plays a key role behind the poor hazard response and therefore, it intensifies hazardscape. In hazard theory, hazard is represented by the probability of its occurrence referral to a given magnitude. These are essentially determined through analysis of the historical behaviour of processes which are assumed to be constant in time. The alternative assumption of time is chaos which cannot be used in any sensible way to assist humankind.

Furthermore, ecosystem processes operate at different scales which produce a range of hazards from local flash flooding to global climate change. The issue of scale is significant in both spatial and temporal dimensions as it plays a significant role in shaping the hazardscape. While environment is infinite, a community inhabits and uses a very small fraction of it. Most of the biophysical processes overlap, and are continuous and related globally. As a result, change in one part of the globe may affect other places located at a distance, and the process of transfer of change may involve a time period which may vary from a few seconds to a number of years or much more. Human communities, although started as small and segregated units, soon grew bigger and are now increasingly getting interconnected as a result of economic and political processes. Due to the connectivity of biophysical and human processes and the nested characteristics of the ecosystem, a hazardscape at a place is shaped by processes of a far bigger dimension than those operating at local scale. Processes at different scales also influence the degree and the speed of change, and therefore, they produce hazards of varied scale. Hazards at the local level, produced by 
the interaction between local community and the environmental processes, are generally accommodated or absorbed with less damage, while those of higher order which influence a district or region often exceed the community's capacity and prove to be disastrous. Therefore, it is very important to integrate community behaviour and its relationships with environment at all scales in the ecosystem.

Ecosystem therefore gives an integrative framework to link both humans and the environment to one system and to understand hazardscape from a holistic point of view. The various aspects of ecosystem help to understand the origin, development and complexity of a hazardscape.

\subsection{Elements of a Hazardscape}

A hazardscape portrays the relationships between humans and the environment in the ecosystem, where it exists and changes through time. It represents hazards along with place and people's characteristics that favour hazard occurrence. Hazards, place and people are therefore, three key elements of a hazardscape.

Fig: 2.1. A Venn Diagram of Hazardscape
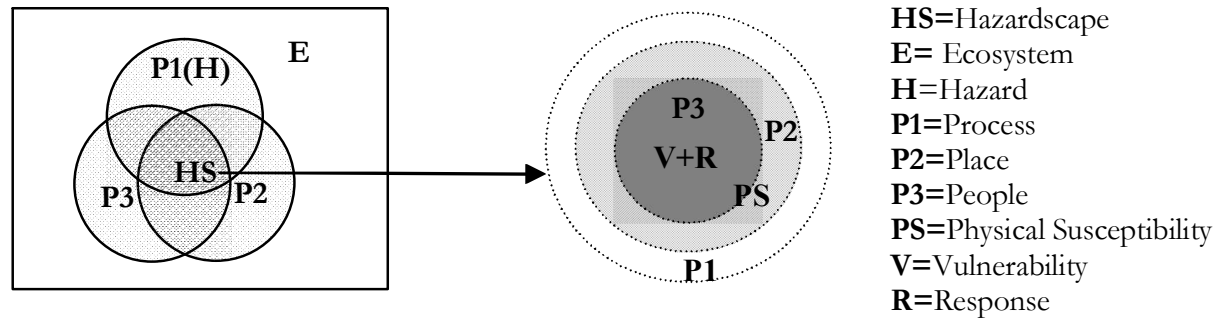

Hazardscape $=$ Process $($ Hazard $)+$ Place $($ Physical Susceptibility $)+$ People (Vulnerability)

While hazards are related to the behaviour of environmental processes, place characteristics determine the physical susceptibility, and people are the factor of vulnerability and response to hazards in the hazardscape.

\subsection{Hazards}

The explanation of hazards has evolved from a concept of 'acts of God' to an attribution as 'environmental hazards', which exist at the interface of natural events and human use systems (Smith, 1992, 10). Burton, et al. (1978) called them negative resources produced during the humannature interaction. But the depiction of humans and the environment as two different systems and their interaction at a place does not explain many hazards, especially those for which such interactions are not visible. For example, a drought at a place signifies a slow change in the biophysical processes which turns into a hazard, through associated sudden changes in the human 
processes, not only for the place that experiences the change, but also for the neighbouring areas which may not be directly affected by the drought. This happens not simply due to interaction of the two systems at a place, but also because of their interrelationships and connectivity as being the parts of the same ecosystem. Since most biophysical processes are connected globally, changes in the environment at one place due to human activities may result in hazards at far distant places. Hazards could even occur due to external disturbances (i.e. their source could lie outside the ecosystem), which can bring major change in biophysical or human processes within the system (for example, meteorites). This theory therefore sees humans and the environment as part of the same ecosystem, where change in either the human or the biophysical environment easily transfers to the other, and the community experiences hazards because it could not cope with the degree of change or a set of changes in different processes. Therefore, the definition of hazards as "extreme fluctuations or deviations in environmental process" (Smith, 1992, 10), which could be dangerous to the community, still applies. Although hazards can occur through changes in both biophysical and human environmental processes, biophysical hazards prove to be more dangerous than those derived from human change. This is because a community generally possesses some idea and control networks for a change in its human processes that helps in early warning and effective management. For example, inflation may drive certain changes in the economy, but since the changes in biophysical processes are generally more sudden, drastic and extensive in nature, the community often lacks the means of control even if it gets warning in advance.

Hazards are the source of risk in the hazardscape, not only due to their uncertainty but also because of enhanced vulnerability of the community. Alexander regarded hazard as the predisaster situation (Alexander, 1993, 7). Pointing to hazards as a necessary element for disaster occurrence is not only relevant but also helps to refine the use of the term for only those events which can cause disaster, as compared to minor events or accidents. Since each hazard varies in its frequency, duration, areal extent, speed of onset, spatial dispersion and temporal spacing (Burton, et. al, 1993, 34), it poses a differential threat over diverse space and different communities. Also, in multiple combinations with other hazards, it transmits variations in the hazardscape, such as an earthquake in hilly areas may also produce landslides, and in soft ground it may cause liquefaction or ground settlement apart from high ground shaking. Hazards may also vary through time with changes in the ecosystem or changing relationships among its factors. For example, an increase in the frequency and magnitude of hazards through climate change. Similarly, changes in the human environment have produced a number of new hazards such as transport and industrial explosions, biochemical hazards etc. Hazards are generally localised in their impact due to their inherent links with the vulnerability of the exposed communities, which often tend to be clustered over space. Hazards are also identified with the place, not only because of the physical characteristics of a place but where the relationship between humans and the environment is strained such as in overpopulated areas or urban clusters. Hazardscape highlights these areas, which represent the zones of threatened ecosystem. 


\subsection{Physical Susceptibility}

Place is the second most important constituent of the hazardscape. It represents the ecological relationship of the community with its environment. Each place holds individuality with its specific location and other physical characteristics such as geology, landforms, climate etc. These physical characteristics of a place can play a key role in turning an environmental process into a hazard. They not only define the nature of a change but also the propensity of a place to experience hazard due to certain changes in the behaviour of environmental processes. They also govern the type and spatial characteristics of hazards. For example, flooding largely depends on the physiography of a place such as a valley floor or flood plain. Place characteristics can also exacerbate the intensity of hazards. For example, earthquakes would be severe across fault lines, and tsunami would cause more damage in low lying productive coastal plains as compared to rocky unused hilly coast. The regular occurrence of a few hazards at certain places signifies the role of physical susceptibility in their recurrence. It is important to note here that a place acquires its physical characteristics through various ongoing environmental processes. While biophysical processes are largely responsible for the intrinsic properties of a place, the human processes can modify its various properties depending on the characteristics of the community that resides at the place.

The overall characteristics of a place therefore can be classified into three categories, which play an active role in triggering natural hazards of varied intensities. These are location, natural biophysical characteristics and human modified conditions. The location of a place in both an absolute and relative sense has an overriding influence on the hazard occurrence. While absolute location is directly responsible for a place to experience hazards, the relative location can make a place susceptible to hazards both directly and indirectly. For example, landslips may not only cause damage on a hill i.e. at its absolute location, but also from run out into adjacent areas. The biophysical characteristics of a place include its physiographic, geological, hydrological, drainage and other spatial characteristics. These characteristics not only make a place susceptible to different hazards, but at times induce amplification of hazards, such as high ground shaking through earthquakes in flood plains due to loose sediment composition. The third characteristic that supercedes the other two characteristics is the human modified characteristics of a place. The biophysical characteristics of places have been largely altered by the human beings for different reasons. This has not only increased the frequency of natural hazards, but has also exposed these places to new hazards, for example, liquefaction of reclaimed land or longer run of tsunami inundation due to the removal of vegetation barriers. Physical susceptibility of a place therefore plays a dominant role in the hazardscape.

Varying susceptibilities to different hazards produce diversity in the hazardscape. Hewitt termed the physical susceptibility of a place as the "intervening conditions of disaster, which intervene between hazard and vulnerable structures" (Hewitt, 1997, 28). Cutter, Boruff and Shirley, put these under the category of biophysical vulnerability (Cutter et al, 2003, 243). However, to tag vulnerability to susceptibility is inaccurate because the biophysical characteristics of a place can only make it susceptible to various changes in environmental processes, not to the degree of damage which is a function of human conditions. Therefore, susceptibility is a more appropriate 
term than vulnerability. Nonetheless, physical susceptibility influences the degree of exposure through the locational characteristics, but the damage through hazards is the function of human vulnerability.

\subsection{Vulnerability}

The existence and intensity of a hazardscape depends mainly on the vulnerability of its inhabitants. Vulnerability has been studied from various perspectives including behavioural, socioeconomic, human ecology, politico-economy, sustainability and climate change (Burton et al, 1993; Birkman, 2006; Patt, et al, 2009, 4). Even though the use of the human ecology approach to study vulnerability has been repeatedly supported by geographers such as Cutter (2000), Bohle (2001), and Turner, et al (2003), it has not been used (as discussed earlier) in its holistic sense. By excluding humans from the ecological system, humans and environment have been considered as two separate systems (Turner, et al, 2003; Millennium Ecosystem Assessment Board, 2005, 146-147). Even if this simplification helps to understand vulnerability to an extent, it fails to explain many complicated situations in the hazardscape, which may enhance other forms of vulnerability. The holistic ecosystem framework, on the other hand, helps to understand and clarify the causes, nature, development and extent of vulnerability in the hazardscape.

Vulnerability has been defined in multiple ways. At present, there are more than 25 definitions that explain the concept and present various methods for its systematic assessment (Birkmann, 2006, 11). The notion of vulnerability has expanded from incorporating concepts of internal risk factors to multidimensional vulnerability encompassing physical, social, economic, environmental and institutional features (Birkmann, 2006, 17). Against a background of an ever increasing range of factors associated with it, vulnerability can be simply defined as the inability of the community to resist damage to life and assets in the situation of hazard occurrence. Though various aspects of vulnerability have been identified and classified in different ways, they have been broadly classified under three dominant categories of exposure, fragility and lack of coping capacity (IDEA, 2005, 105; Cordana, 2006, 195; Birkmamm, 2006a).

Exposure represents the susceptibility of the population to damage by hazards. Although IDEA (2005) used the term exposure along with 'physical susceptibility', exposure is different from physical susceptibility with respect to its focus on people and elements of risk and goes beyond the physical characteristics of a place. Fragility refers to the weakness in the face of initial hazard impacts and is often the main cause of disaster. Absence of coping capacity, on the other hand, is linked with the extended impact of hazard and represents the inability of the community to survive and recover from the hazard impacts.

Vulnerability of a community is contributed to by a number of factors which affect one or more of its various aspects. These include socio-economic as well as socio-cognitive factors such as age, gender, disability, poverty, awareness, knowledge, perception, emotion, fear, faith, self efficacy, 
trust, culture and so on, which may restrict an effective response to hazards (Paton 2003, Finnis, 2006). Vulnerability is rather a complex characteristic of a community. It is not caused by any single factor or set of factors, but varied factors in different combinations. This leads to variations in the vulnerability across different population groups for different hazards over space and time. A person possesses multiple characteristics, which together determine his/her vulnerability to a particular hazard. For example, a person could be elderly, female, poor, disabled and living in the coastal belt of an underdeveloped country. But at the same time she could be knowledgeable, experienced and well aware of her situation. Although not physically strong, her mental capabilities put her out of vulnerable group, because she knows how to cope with sudden natural occurrences such as earthquake or tsunami. However, she may be vulnerable to the recent changes in the environment of which she is unaware. In this case, vulnerability of the woman is low for one hazard but very high for another. Besides, vulnerability is not restricted to any one side of a scale such as being female, elderly, poor, disabled or illiterate. Rather, it is spread on both sides of the scale depending on the nature of hazard. For example, poverty or economic development, a child or elderly, male or female; these all could lead to vulnerability if assessed with respect to different hazards and contexts. However, studies show that communities with a higher proportion of sensitive groups for example, poor, children, elderly, disabled or isolated, suffer more than others as these characteristics not only affect fragility but also the coping capacity after disaster. Besides, in many situations it is these groups that tend to occupy the areas exposed to hazards.

Apart from the population characteristics, vulnerability is strongly contributed to and influenced by environmental conditions, both biophysical and human. Where biophysical processes shape the basic socio-cultural norms related to livelihoods, food and other habits, the human environment governs the systems of production and development along with factors which affect vulnerability to a significant extent such as entitlement, empowerment and political economy (Semple, 1911; Bohle, 2001; Wilhite, 1998 as cited in Birkmann, 2006, 120). In fact, the role of the environment in producing vulnerability at times can be highly significant and could play a more deterministic role than the individual vulnerability itself. For example, sudden financial inflation in an economy can make many households suffer, even if the members of the family are employed and have a regular income. Similarly, low rainfall is not a drought for a poor family living in a city, but it is often the case for farmers living in rural areas. A strong human environment, such as a strong economy, can feed its poor and save them from drought or famine much more effectively than a fragile one. Similarly, fragile and degraded environmental conditions can make a strong community vulnerable to various hazards. Therefore, it is important to assess both community and environmental characteristics with respect to each other rather than assessing them as two separate entities.

Vulnerability is therefore not all about the intrinsic characteristics of a population under normal environmental conditions, but about how these characteristics would behave during an unanticipated change in the environment (Patt, et al., 2009, 4-5). A community is not vulnerable simply because of its any particular characteristics, such as poverty or ethnicity but due to its positionality and characteristics with respect to change in the environment. Age, gender, health, 
ethnicity, disability or incomes do not act as the source of vulnerability in normal conditions, but become so in the face of changed environmental conditions.

Interconnectivity of different environmental processes increases the vulnerability as the sudden change in any environmental process results in change in the behaviour of connected processes. This not only introduces uncertainty into the behaviour of various processes experiencing the change, but also to the consequential vulnerability. This gives vulnerability a dynamic and multidimensional character that changes through time, space, hazard and society. Vulnerability is therefore, subjective to each hazard and relative to different groups and scales of processes. The dynamic and multidimensional character of vulnerability poses problems for its synthesis and analysis. However, a few factors have been consistently reported as contributing to vulnerability in various disaster situations across different societies. The coexistence and correlation of these factors therefore could be used to portray a vulnerability scenario (for further details please refer to the vulnerability index in chapter one). Vulnerability from a hazardscape-ecosystem perspective therefore provides a more coherent, holistic and meaningful explanation.

\subsection{Response}

People are also a major factor of making changes in the ecosystem, and thereby they intensify or modify the local or global hazardscape. People respond to hazards either to produce resources or to avoid damage from them (Burton et al, 1993, 32, 59). The response of people is a two-ways relationship with a hazardscape. It not only modifies hazardscape, but it is also shaped and influenced by the nature and characteristics of the hazardscape (Fig: 2.2).

Fig: 2.2. Relationship Between Hazardscape and Response

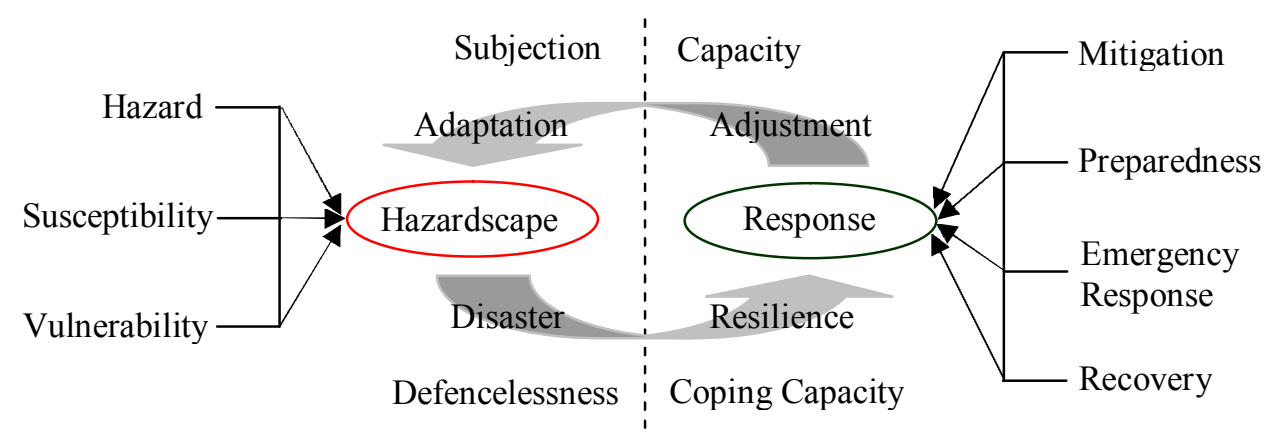

Response is a broad term, which applies to all sorts of actions that are taken by the people, communities or institutions in the ecosystem against natural hazards. It could be classified into four broad categories: mitigation, preparedness, emergency response and recovery. Mitigation basically includes all the efforts and actions from the community to reduce or prevent the hazard occurrence. This would not only mean reducing hazard through engineering solutions but also reducing susceptibility and vulnerability. Hazard susceptibility can be reduced by land use planning, 
while changes in the response behaviour, building types and codes, social development and effective management of people and their resources could reduce vulnerability. It is generally a long term process which is carried out during both pre disaster and post disaster situations (Godschalk and Brower, 1985, 64).

Preparedness refers to all those efforts which a community makes to cope with a hazard that may occur in the future. It includes emergency response planning, warning systems and arrangements of emergency materials to cope with a hazard (Clary, 1985, 20). Emergency response as the third category of overall response refers to the immediate and short term actions, which are practised just after the realisation of hazard (Glade, Anderson \& Crozier, 2005); such as search and rescue, provision of food, shelter and clothing (Clary, 1985, 20). The fourth stage of recovery involves long term reconstruction in the community after a damaging event (Clary, 1985, 20).

All kinds of responses are not only shaped but significantly influenced by the nature and characteristics of a hazardscape. While in a physically active hazardscape, people are more aware of hazards and a range of response methods, a docile hazardscape generates negligent attitudes with slow or no response from people. The nature and possible impacts of hazards, susceptibility, and vulnerability govern the nature and type of response from the community i.e. adjustment, adaptation, accepting loss or denial. The nature and elements of hazardscape therefore, indicate the possible response both in present as well as in future (Paton, 2006).

The hazard characteristics such as magnitude, frequency and aerial extent indicate the physical impact of the hazard, urgency of response and the type and extent of damage, and therefore, they may govern the presence and type of technology or mitigation measures adopted by the community. Speed of onset has a bearing on the preparedness and warning systems, and duration influences the measures taken for various hazards. Spatial dispersion on the other hand, governs the response pattern for adjustments and land use control, while temporal dispersion determines the timing of hazard response (Burton, 1993, 35-36). The predictability and controllability of hazards also influence the preparedness and response of the local community. Similarly, the physical susceptibility of a place through absolute and relative location along with its biophysical and human modified characteristics not only influences the current response, but also the measures and methods adopted by the community over time. Different aspects of vulnerability (i.e. exposure, fragility, and lack of coping capacity) on the other hand, not only govern the hazard impact, but also the response type and ability to respond. While children, elderly and disabled people often have limited capacity to respond effectively at the time of hazard occurrence, poor people in the community may have fewer resources and options for hazard mitigation. It has been noted that economic reasons often prevent the people from adopting adjustment measures and making use of available technology, even if it is widely available (Lindell, et al, 1997, 332). A high degree of exposure for a community puts stress on the carrying capacity and therefore influences the scope of response at the time of disaster and coping capacity in the post disaster situation. Overall hazardscape characteristics (such as the current level of hazard awareness, attitude and perception of hazards along with the response culture at different levels) further govern the applicability and continuation of specific response practices. Clearly, various elements of 
hazardscape are not independent or separate from each other but rather they are affected and influenced by each other. The hazardscape therefore demands a holistic assessment.

Response in a hazardscape includes both short term adjustments and long term adaptations. All four kinds of response start with small adjustments either in behaviour or in the hazardscape and their success over time helps communities adopt them for a longer term, and thus they become adaptations (Burton, et al, 1993, 52). Adaptation is also a preferred option when the cost of adjustment is too high or other options are not available. While adjustments reflect the capacity of the inhabitants to reduce the intensity of hazardscape by making changes in it, adaptation in a sense indicates long term acceptance of living with hazard by absorbing the effects and learning to adapt to hazardous environmental processes. At times, communities have to make further adjustments beyond adaptation, which then may eventually add to further adaptation (Burton, et. al, 1993, 52). The socio-cultural norms and political economic conditions along with the biophysical environment not only govern the choices made by communities between adjustments and adaptation but also the nature of adjustments along with type of adaptation chosen. For example, a tribal community is more likely to adapt, while an industrialised society is more likely to make adjustments with nature. Also, the nature of adjustments differs across different industrialised countries, depending on the social and political preferences. While various adjustments and adaptations decrease the intensity of hazardscape, other responses such as doing nothing, accepting loss or denial of hazards increases the hazardscape intensity.

However, despite all adjustments and adaptations made for the perceived hazards in a hazardscape, hazards remain that may lead to any disaster. The possibility of post mitigation damage is embodied in the concept of residual risk. An event that exceeds the coping capacity of the community may extend the temporal span of disaster. Response in this situation is more focused on the recovery rather than making physical changes in the hazardscape. The speed and extent of recovery marks the resilience of the community. Disasters often engender actions for reducing future vulnerability and building resilience, and thereby, modify the response and consequently, the hazardscape (Burton, et al. 1993, 220). Resilience is an ecological concept, which literally means to bounce back. It has come from the Latin word resiliere, which means 'to jump back' and implies a capability to regain its original state (Paton, 2006, 7). Failure of the community to restore the original state or the state of normalcy after disaster represents a lack of resilience that increases the cumulative loss from disaster.

Continuous response to hazards over time changes the initiating risks threshold in the hazardscape. While mitigation of high frequency low magnitude events changes the threshold of hazards by reducing vulnerability to these events, it subjects the community to a greater risk from less frequent high magnitude hazard events. For example, most high-rise buildings in various cities built with lawful building codes are not vulnerable to small or medium earthquakes, but they are unable to sustain the force of a very high magnitude earthquake. This has put many lives at risk, which would have been otherwise safe if people lived and worked in widespread low-rise buildings. Furthermore, many unsustainable practices such as building on steep slopes or reclaimed land either increase the risks from existing hazards such as landslides, or introduces new risks in the 
hazardscape, for example liquefaction. The response therefore changes the hazardscape over time by modifying the hazard characteristics or by replacing old hazards with a set of new ones.

The two-way relationship between a hazardscape and response brings constant change in both the hazardscape and response, which explains their dynamic nature. These changes can be brought by physical, socio-cultural, economic and political conditions. Therefore, the response is not only governed by population characteristics, but also by both biophysical and human environmental conditions. A holistic assessment of response therefore not only involves assessing hazards at different levels, but their integration and analysis in the context of ecosystem. This also helps to understand sources of uncertainty linked with various environmental processes and their interconnectivity, which ultimately affects response measures.

\subsection{Difference in Hazardscape and Riskscape}

Traditionally, hazard and risk studies have developed separately. The term risk is adopted in the hazard research in order to convey the probability of damage. At times, both terms have been used interchangeably, but the two terms are in fact very different in their perspectives, and they can not be used synonymously.

First of all, there are basic differences in the understandings of these two terms. Risk is often calculated in order to estimate the probability of certain consequences in the case of hazards, but some people view risk as synonymous with the term probability, likelihood or chance e.g. the probability (risk) of an earthquake occurrence. The understanding of risk not only differs between lay public and experts, but also between the natural and social sciences (Vatsa, 2004, 5; Mooney, 2007, 211). This variation in understanding and interpretation by practitioners and their wide audiences make risk communication difficult (Jardine and Hrudey, 2001, 99). The use of the term hazard on the other hand, has been largely confined to disciplines such as geography and geology (Cutter, 2001, 3), where it has been used to represent the incidents that could produce damage (Alexander, 1993, 7). This means that the term carries its seriousness, and can convey the message more effectively.

Hazard and risk are conceptually two distinct terms, which is also the basic reason behind their different methodology. Risk cannot exist by itself, by excluding the hazard. A hazardscape henceforth, does not depend on riskscape, but riskscape builds over a hazardscape (Fig: 2.3). A hazardscape is the function of hazard, susceptibility and vulnerability at a particular place and the severity of these three would bring a specific degree of risk in a particular hazardscape. For

Fig: 2.3. Relationship Between Hazardscape and Riskscape

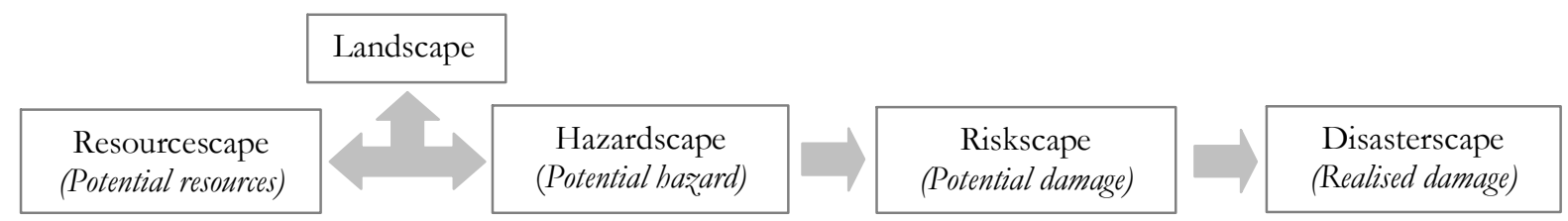


example, in an intense hazardscape, a combination of severe hazard, susceptibility and vulnerability together would result in high risk. However, a less intense hazardscape can also have a high risk due to the excessive concentration of population and resources. Risk calculation also includes the time factor in a different sense than hazardscape. Risk multiplies likelihood of hazard occurrence within a given period of time with vulnerability and elements at risk. As a result, the nearness of hazards in the future i.e. high frequency increases the risk, while the intensity of hazardscape increases with time if the current unsustainable practices continue.

Risk has the disadvantage of being predominantly quantitative. As risk indicates possible outcomes in both positive and negative sense, people compare that value according to their priorities and may not necessarily think about other implications. For example, people voluntarily take some risks such as smoking and driving, where taking such a risk is perceived to provide more advantages than occasional loss; they may not see the relationship of their behaviour with other factors in the ecosystem. In addition, there are some coerced risks, where even if people see high risk, they don't see themselves as having control of the risk, and avoiding such risk is next to impossible. In this situation acceptance means no obligation to spend energy and resources on mitigation. However, a hazardscape refers to the relationship between the people and their environment within the ecosystem, and indicates the consequences of inaction. A hazard in an existing relationship that does not necessarily damage property and life at one point in time can be more widespread in its impact over both time and space. Further, in case of inaction, positive feedbacks of the system may result in a sudden change, which could be devastating for the whole community. White (1988) also suggests that risk analysis fails to include the social structure or social context within which those risks occur (Cutter, 2001, 9).

Hazardscape characterises the existing situation, while riskscape is the probability of damage in the future. Hence management of a hazardscape is more rational and tangible to the human mind than riskscape. Probabilities associated with risk are also difficult to understand. For example, how serious is a risk of 10 percent in 50 years and how much worse a 20 percent risk is in this same period. These are difficult concepts to relate to everyday lives and behaviour. A hazardscape, on the other hand, represents the ongoing situations in the ecosystem, which continuously change and bring changes to its shape. The risk would also change, but because of data constraints it is not feasible or practically possible to calculate the risk for each and every place and for each and every hazard, which again changes through time. Understanding the processes of hazard occurrence in the hazardscape is easier and more reliable, and also indicates what can be done about the future. Risk does not favour its mitigation until it reaches the optimum, while hazardscape favours adjustments before choosing the outcomes.

The understanding of riskscape and hazardscape also has different implications for administrative response to hazards. Risk varies at different levels (i.e. a risk at local level may not be a risk at national level) (Cordana, 2006, 189), which poses constraints on the prioritisation of a risk produced by a particular hazard. Further, risks are often managed within administrative boundaries, while hazards do not necessarily follow such boundaries. In such cases, risk redistribution or management doesn't necessarily either reduce the hazard or prevent a disaster from happening. Besides, risk distribution often involves the diversification of economy or the 
spatial spread of vital resources and infrastructure from specific hazard locations, which is primarily aimed towards the wealth or wealthier people in the community (Manuta, et al, 2006 as cited in Lebel, et al, 2006, 372). It does not take into account the vulnerable population of the community, which occupies the most hazard susceptible zone, and are often the main victims of any disaster. Therefore, it is vital to understand the hazardscape rather than riskscape to plan for hazard response.

It can be concluded that the hazardscape with an ecosystem framework not only provides a holistic approach to study various aspects of hazards, but also connects the loose ends of various theories, concepts and processes, which are essential in the understanding of hazards and finding their solutions. The concept of hazardscape transcends administrative boundaries, and it could be applied across time and space in different context of both developed and developing counties for natural and social hazards. It not only relates to the current hazards in a community with respect to the current environment but also to the changing environmental conditions attributed to climate change and globalisation of the socio-economic and political environments. 
Chapter: 3

Physical Susceptibility of the Wellington Region to Natural Hazards

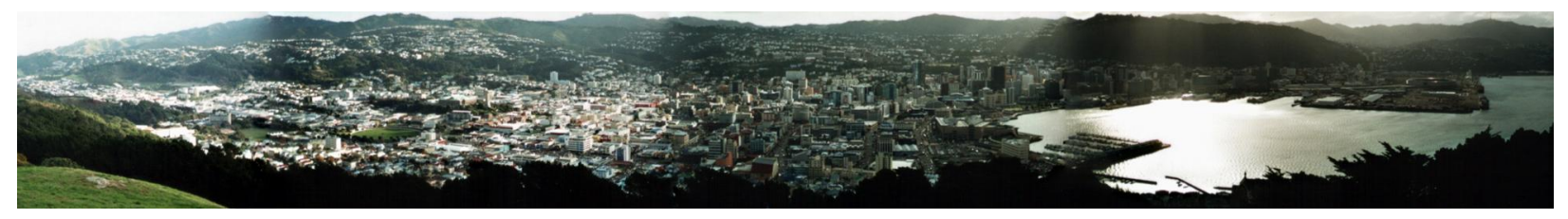


Natural hazards are the extreme fluctuations in the biophysical processes of the environment which are harmful to human life and assets. The intensity of such events depends on the energy released through these processes, while their impact is governed by the susceptibility of a place to accommodate the degree of change. The spatial characteristics of places, which themselves are the product of various environmental processes, have a significant influence on how environmental processes would behave at a particular location. They offer a specific background which conditions the nature of hazards by absorbing or amplifying the impact of any major change. Since each place is unique in its spatial characteristics, their physical susceptibility to hazards differs accordingly. The same is true for the Wellington Region where its diverse physical characteristics bring variations in the nature and spatial dispersion of hazards. They play an active role behind the regular occurrence of extreme events and thus shape the local hazardscape. Location, geology, landforms, climate, drainage, vegetation and soil are a few key physical characteristics, which govern the susceptibility to natural hazards in the region.

\subsection{Location}

The location of a place in the realm of diverse environmental processes plays a significant role in defining its various physical characteristics and resultant susceptibility to extreme natural events. The Wellington Region is located in an active sphere of biophysical processes including tectonic, meteorological and atmospheric processes, which have shaped its susceptibility to a range of natural hazards such as earthquakes, tsunami, cyclones, windstorms, droughts and so on.

The location of the Wellington Region at the edge of the Indo-Australian plate on the Pacific Rim exposes it to active seismic forces from the subduction of the Pacific plate under the Indo-Australian plate. These forces are not only responsible for the current shape and structure of the region but also for various geological hazards such as earthquakes, fault movements, liquefaction,

landslides and

Map: 3.1. Location of the Wellington Region on the Pacific Rim as a Cause for its subsidence, which would have been less frequent and less intense at some other location. The Pacific Rim is also known for its high volcanic activity. However, even though there are many Exposure to Earthquakes and Volcanic Ash Fall
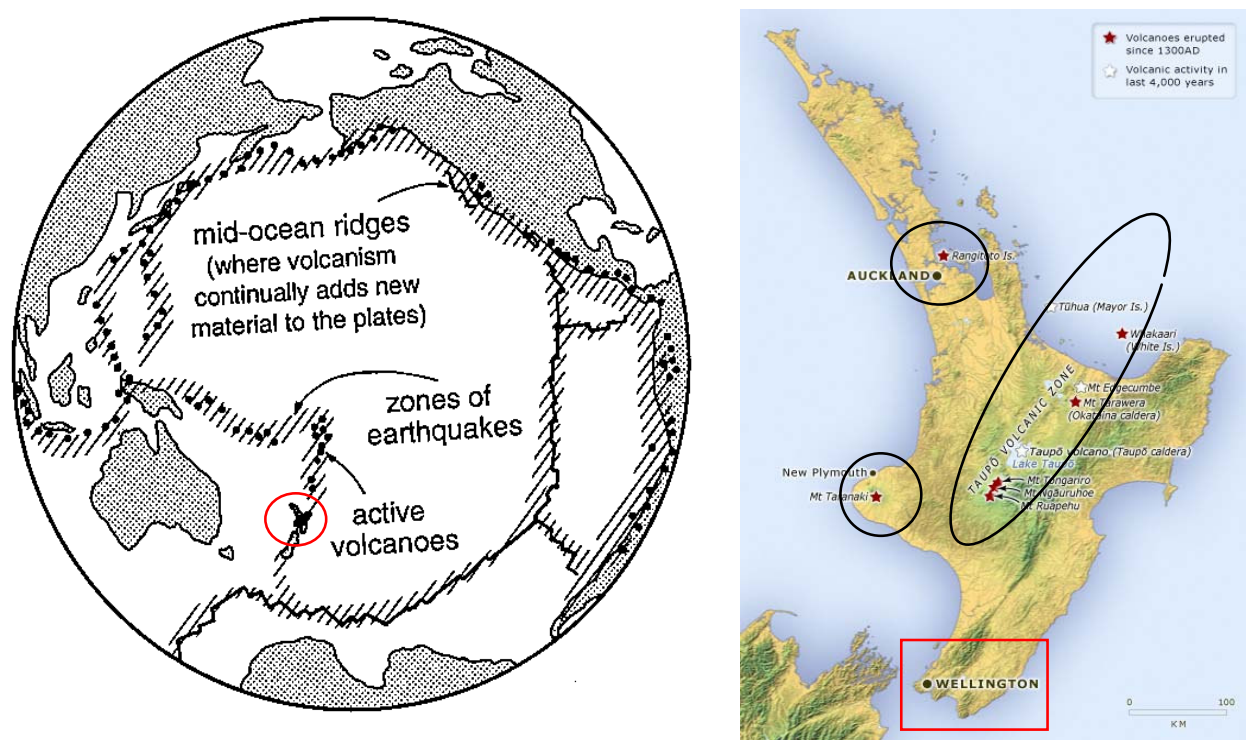

volcanoes in the 
North Island of New Zealand, the relative location of the Wellington Region at its southern tip (Map: 3.1) makes it only susceptible to volcanic ash fall and gas plumes in certain conditions.

Due to high seismic activity at the Pacific Rim, the region is also exposed to both near and distant tsunami. The eastern section of the region facing Pacific Ocean is particularly susceptible to tsunami because of higher tectonic activity on this side. The location next to the plate boundary, where earthquakes are often centred, acts as a source for tsunami that could hit the region within minutes. This would give very little time to evacuate the densely populated low coastal areas of Wellington and Lower Hutt cities. Tsunami in the region could also be produced by submarine landslides on the active Pacific bed, and there is evidence of such incidents in the past. Map 3.2 shows various possibilities of tsunami through earthquakes at different locations on the Pacific Rim that could reach New Zealand. It reveals that the risk for tsunami in the Wellington Region ranges from moderate to high.

Map: 3.2. Tsunami Possibility Scenario for New Zealand and the Wellington Region

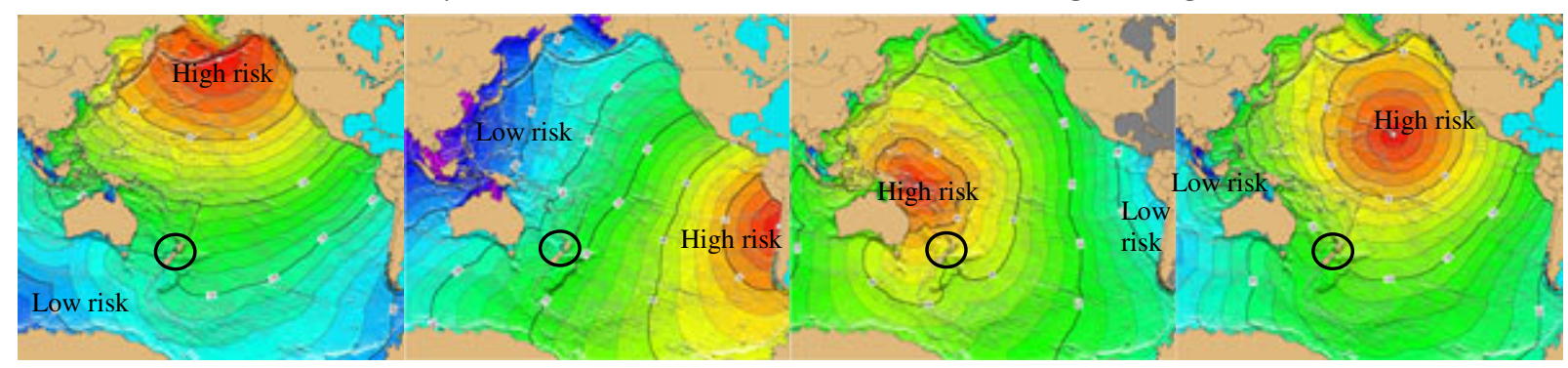

Source: Ministry of Civil Defence and Emergency Management, 2008.

The oceanic proximity of the region also exposes it to vigorous meteorological, atmospheric and hydrological processes, which often produce extreme events. The ocean provides a rich source of moisture, which results in frequent rainfall and hence flash floods and/or landslips in the region. It also exposes the region to various coastal hazards including erosion, flooding and seiche. Its location in the southern hemisphere ocean places it in the "roaring forties" and exposes

Map: 3.3. Relative Location of New Zealand in Relation to Global Winds and Ocean Currents
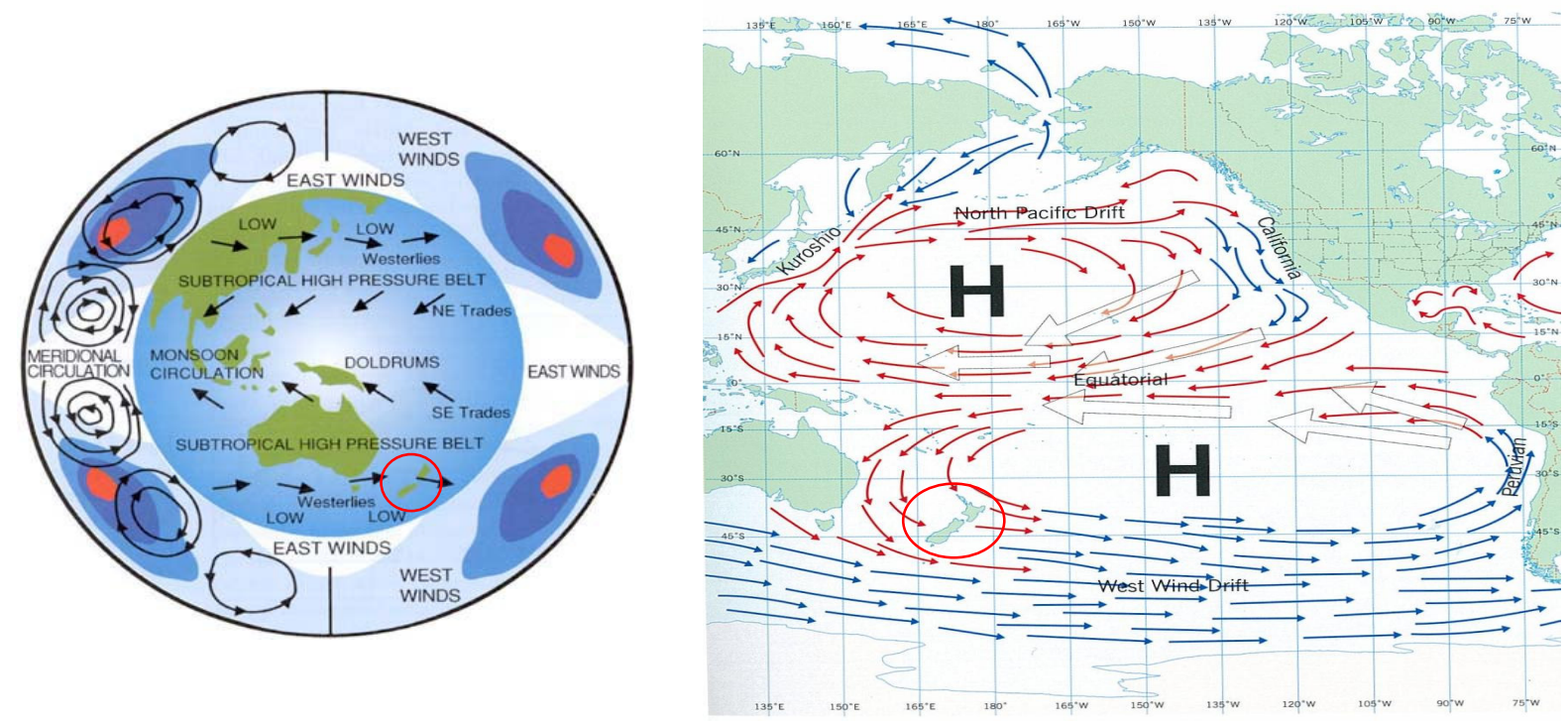

Source: Australian Bureau of Meteorology and Mogil, 2007. 
it to associated high speed winds and gales. The atmospheric processes at a global regional scale bring windstorms, tornadoes and cyclones (Map: 3.3) to the region. The weather conditions associated with La Niña and El Niño events in the Pacific Ocean not only affect the occurrence but also the locations of droughts and cyclones within the region. The Map 3.4 shows the path of subtropical cyclones from the Pacific Ocean that have crossed the region or passed through in close proximity to it. The subsequent heavy rainfall and high winds from these cyclones generate other hazards such as flooding, erosion or landslides in its susceptible parts. At local level, the presence of the Cook Strait in the southwest increases the velocity of winds in the region, particularly in Wellington City. The relative location of various places within the region also affects their susceptibility to various hazards, which are enhanced by the local biophysical conditions such as geology, terrain, climate and so forth. The location of the Wellington Region, therefore acts as a generic source of the region's

Map: 3.4. Cyclone Tracks Within 300km of the Wellington Region (1960-1989)

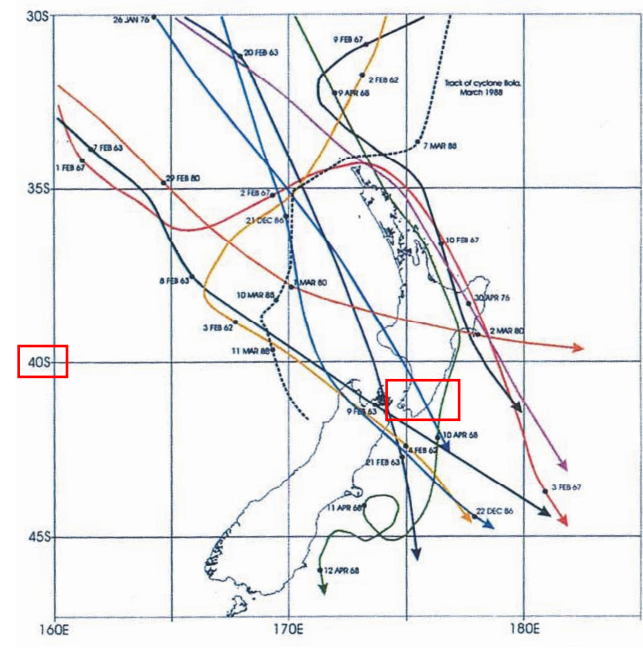

Source: NIWA (1999-2000) as cited in WELA, 2003. susceptibility to various hazards in both absolute and relative sense.

\subsection{Geology}

Rocks and other earth materials have significant influence on the susceptibility of a place to various hazards such as landslides, erosion, liquefaction, ground shaking and subsidence. The rocks in the region range from slightly metamorphosed Greywacke or sandstones to igneous chert or basalt, and sedimentary siltstone, conglomerates or mudstones etc. The bedrocks of the region belong to the Torless complex group which was formed during the Paleozoic to Mesozoic age. The original rock material was eroded from Primeval Australia or Gondwanaland and deposited in the east in the Pacific Ocean about 200 million years ago (Begg \& Mazengarb, 1996, 6; McConchie, 2000a, 11). This was the time when the plate boundary between the Indo-Australian plate and Pacific plate was not so active. As a result the ocean currents separated argillite and sandstone sediments into different strata and arranged them in graded bedding structure (McConchie, 2000a, 11). Active movement during the Pleistocene and subduction of the Pacific oceanic plate under the Indo-Australian continental plate interrupted the depositional processes, and compressed and uplifted the erosion surface to form hill ranges. The pressure was so strong that in places it raised the horizontal beds to stand vertically and resulted in a broken rock formation called mélange (Begg \& Mazengarb, 1996, 6). Subduction also mixed the submarine volcanic and oceanic materials such as basalt, chert, coloured argillite and limestone in the bed rock, which are found in small 
areas of the Torless complex (Begg \& Mazengarb, 1996, 6). The origin and arrangement of rocks however, differ across the region and it is divided into three zones named as Wellington, Rimutaka and the Wairarapa belt.

The Wellington belt covers the area west of the main Rimutaka Range (Zone-I in Map: 3.5) in the region (Begg \& Mazengarb, 1996, 19). The rocks of this section are the oldest ones, having been deposited about 215-205 million years ago in the New Zealand Geosyncline (Begg \& Mazengarb, 1996, 40). Due to intensive heat and pressure from compression, the sediments were mineralised and deformed in a highly complex form. Rocks of this belt are also called Rakaia Terrane. It is dominated by the grey quartzo-feldspathic sandstone mudstone sequence where the proportion of mudstone is highly variable. In the areas of thick sandstone dominated beds, mudstone inter-beds are either thin or absent, while in other areas they contain fragments of mudstone. In areas of equally occurring sequences of sandstone and mudstone, the beds range from centimetres to a metre thick, but dominance of mudstone beds is rare in this belt (Begg \& Johnston, 2000, 20). Sandstone, also called Greywacke, is therefore the main rock of this belt. The strength of this rock depends on the weathering conditions, which implies that it is highly strong in unweathered condition but weaker in the weathered forms. The very closely jointed, shattered or sheared forms also show its reduced strength (Begg \& Mazengarb, 1996, 96). The rock is susceptible to rock fall or rock avalanches, debris fall and scree erosion. In the cut surfaces, it is also susceptible to surficial failure during heavy rainfall (Begg \& Mazengarb, 1996, 96). The Western Hills of Wellington City, Lower Hutt, Upper Hutt and Porirua are particularly susceptible to these types of landslides. Other rocks of the belt include minor conglomerates, red, green and yellow grey mudstone, chert, basalt and very rare limestone (Begg \& Johnston, 2000, 20). Fossils also occur meagrely in Rakaia terrane (Begg \& Johnston, 2000, 20). Most of the rocks are slightly metamorphosed and deformation is restricted to the upper parts due to relatively low temperature at greater depth (Begg \& Mazengarb, 1996, 19). The only location showing the highly metamorphosed rock in the form of low grade schist is the Terawhiti area in Wellington City (Begg \& Mazengarb, 1996, 19). Most of the oceanic rocks are minor in quantity, and are relatively harder. Subsequently, they are more stable as compared to other rock types in the belt. Further, the major rock defects are sub parallel to the predominantly steeply dipping beds, so large bedrock slides are rare in the Wellington Region (Begg \& Mazengarb, 1996, 98).

In places, Greywacke is overlaid by younger sediments or gravels of Quaternary age (Begg \& Mazengarb, 1996, 20). Though they are widespread in the region, the main areas of gravel concentration in this belt are Lower Hutt, Upper Hutt and the Kapiti Coast. In the Hutt Valley the depth of these sediments reaches 300m (CAE, 1991b, 11). These low lying areas are susceptible to liquefaction and lateral spreading due to the loose composition of gravels. While on slopes, due to the clay rich content of most gravel units, silt tends to improve their stability (Begg and Johnston, 2000, 47). The sand dunes of the Kapiti Coast are the other distinct feature of this belt, which contains fine to medium sands of very loose to medium density composition (Begg \& Mazengarb, 1996, 96). It is highly prone to wind and coastal erosion as well as medium to small landslides. Reclaimed land further adds to the range of earth materials in the region. They are the youngest 
formations, which mainly contain mixed clay, silt, sand, gravel or weathered rock materials and their composition ranges from loose to medium density (Begg \& Mazengarb, 1996, 96). These areas are highly susceptible to liquefaction and ground settlement, and in urban areas including Wellington, Lower Hutt and Porirua, a significant amount of infrastructure rests on these reclaimed lands. In addition, there are areas of peat deposition particularly in Lower Hutt, the Eastern Hills and in the Kapiti Coast which are very likely to suffer from fire, shrinkage and subsidence.

\section{Map: 3.5. Rocks of the Wellington Region}

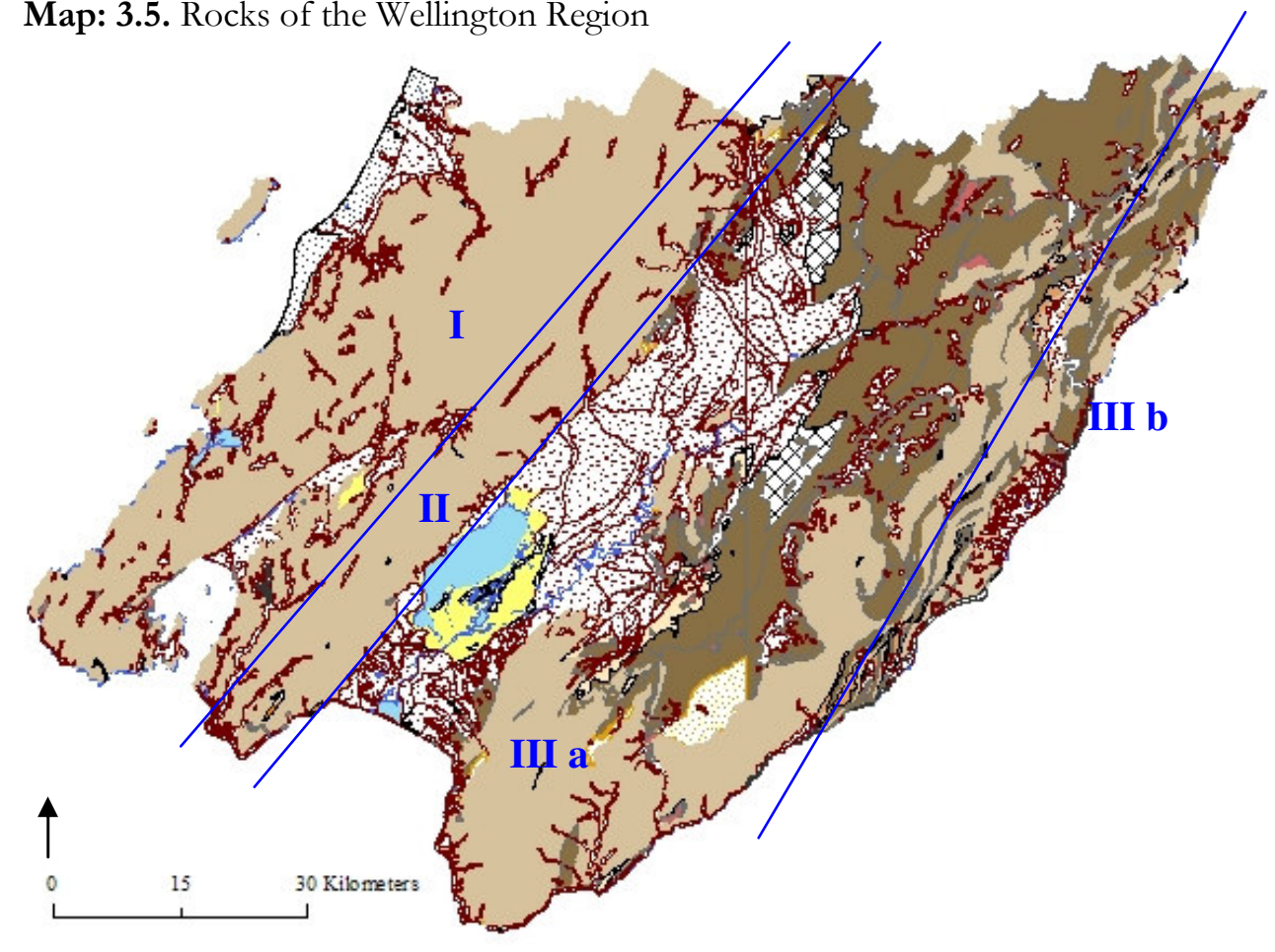

\begin{tabular}{|ll}
\hline & Sandstone \\
\hline & Conglomerates \\
\hline & Sand \\
\hline & Silt \\
\hline & Mudstone \\
\hline & Claystone \\
\hline & Limestone \\
\hline$\square$ & Basalt \\
\hline Breccia & Peat \\
\hline & Coquina \\
\hline
\end{tabular}

Based on data from Wellington Regional Council, 2007

The second belt in the region is the Rimutaka belt, which basically includes the main Rimutaka Range (Zone-II in Map: 3.5). This belt is also called as Pahau terrane, which is similar to Rakaia terrane of Wellington belt and dominated by grey quartzo feldspathic sandstone. The difference between Pahau and Rakaia terrane is that Pahau terrane is slightly less metamorphosed and tends to be lighter in colour and less indurated than the older Greywacke of the Wellington belt. Pahau rocks also contain more carbonaceous matter and slightly more conglomerates (Begg \& Johnston, 2000, 25). The belt contains rocks with variety of metamorphic grades (Begg \& Mazengarb, 1996, 6). It has relatively under-formed blocks of rocks (up to a kilometre in size), which are surrounded by intensely deformed mélange and broken rock formation (Begg \& Mazengarb, 1996, 30). The mélange of this belt contains material from the neighbouring Wellington and Wairarapa belt and oceanic plate (Begg \& Mazengarb, 1996, 41). The oceanic materials include unmetamorphosed Triassic limestone, diamicite and chert, which although forming a minor part of this belt, are widespread. It is the regional extent of its pervasive deformation which separates this belt from Wellington belt (Begg \& Mazengarb, 1996, 30). The age of this belt is uncertain and various theories have been forwarded which suggest deformation after the deposition of the Wairararapa belt (Begg \& Mazengarb, 1996, 42). While the coarser blocks of sandstone in the belt are hard and more resistant, the weathered mixture is susceptible to frequent 
slides. Excavation of steep slopes adds to the frequency to landslides, particularly along the Rimutaka Range road, i.e. State Highway 2, which experiences frequent slides due to both rainfall and earthquakes.

The Wairarapa belt is the third belt of the region (Zone-IIIa and IIIb in the Map: 3.5). The rocks in this belt were deposited during the Jurassic to early Cretaceous period about 145 to 100 million years ago (Begg \& Mazengarb, 1996, 41), which is about 100 million years later than the Wellington belt. The sediments in this zone contain both clastic and oceanic rocks (Begg \& Mazengarb, 1996, 41), which were late additions to the Torless rocks and deformed thereafter (Begg \& Mazengarb, 1996, 19). The belt contains indurated quartzofeldspathic and lithic sandstone and mudstone as the bedrock (Lee \& Begg, 2002, 11). This belt is subdivided into two sub-belts called Western (Zone-IIIa in the Map: 3.5) and Eastern (Zone-IIIb in the Map: 3.5) sub-belts separated by Adams-Tinui Fault (Moore, 1988b as cited in Lee and Begg, 2002, 18).

In the western sub belt, the bedrock belongs to the Pahau group especially in Aorangi Range and north east of Martinborough (Begg \& Johnston, 2000, 25). The bedrock basically contains deformed sandstone and mudstone which are overlain by the sedimentary rocks of Early Cretaceous Mangapurupuru group including oblistormes, mudstone breccia, conglomerates etc, which are finally overlaid unconformably by the sediments of Tinui Group. The coquina and limestone of this belt are loose and soft in nature, even though they are part of recemented hard rock (Beg and Johnston, 2000, 47). However, it has been observed that there are fewer slips per unit area on alluvium, limestone and Mesozoic sandstone than the less permeable mudstone and alternating sedimentary rocks (Crozier et al, 1982, 87). The western central section of this belt, containing the river gravels, swamps and alluvial sediments deposits with higher water content and loose composition depending on the sediment texture, are susceptible to high ground shaking and liquefaction (Lee and Begg, 2002, 54), which was also noticed during the 1855 and 1942 earthquakes.

The eastern sub belt on the other hand, belongs to Glenburn formation, which is partly related to Mangapurupuru group. It also represents the youngest rock group as no rock older than this group has been found in the region (Lee \& Begg, 2002, 19). The dominant rocks are alternating sandstone, mudstone and conglomerates. Some sandstone beds are massive to thick bedded and may rest on eroded base. This is conformably overlain by the Tinui Group. Due to fine sediments deposits of Tinui Group in the upper part, it is hard to differentiate the two distinct zones of eastern and western subgroups (Lee \& Beg, 2002, 18). In the clay rich areas the landslides are more frequent due to active stream down cutting (Lee and Begg, 2002, 51).

Both Glenburn and Pahoa belts are subject to soil creep and earthflows even on gentle slopes and mudstone particularly contributes to such movements (Lee and Begg, 2002, 51; Eyles, 1983 as cited in Glade, 1997, 96). While in the hard section of south east Wairarapa, scree erosion is common, in the north eastern section earth flow erosion is the dominant type of slide (Crozier, 1990, fig 9). Further the density of slides tends to be higher in the soft sediments of Wairarapa areas. In the 1977 storms, the regional density of landslides in the Wairarapa was 98 per square 
kilometre (Crozier, 1986, 171). However, it is also important to notice that the landslides in the sedimentary zone are much shallower than those of metamorphosed areas (Glade, 1997, 96). Thus in Wairarapa belt even though the frequency or density of landslides could be higher during a particular storm, the amount of material eroded through landslides could be much higher in the Wellington and Rimutaka belt. Loess deposits, not shown in the map, are widespread in the south eastern Wairarapa basin and even though they are of relatively strong material, they tend to have

Map: 3.6. Liquefaction and Ground Shaking Susceptibility of the Wellington Region

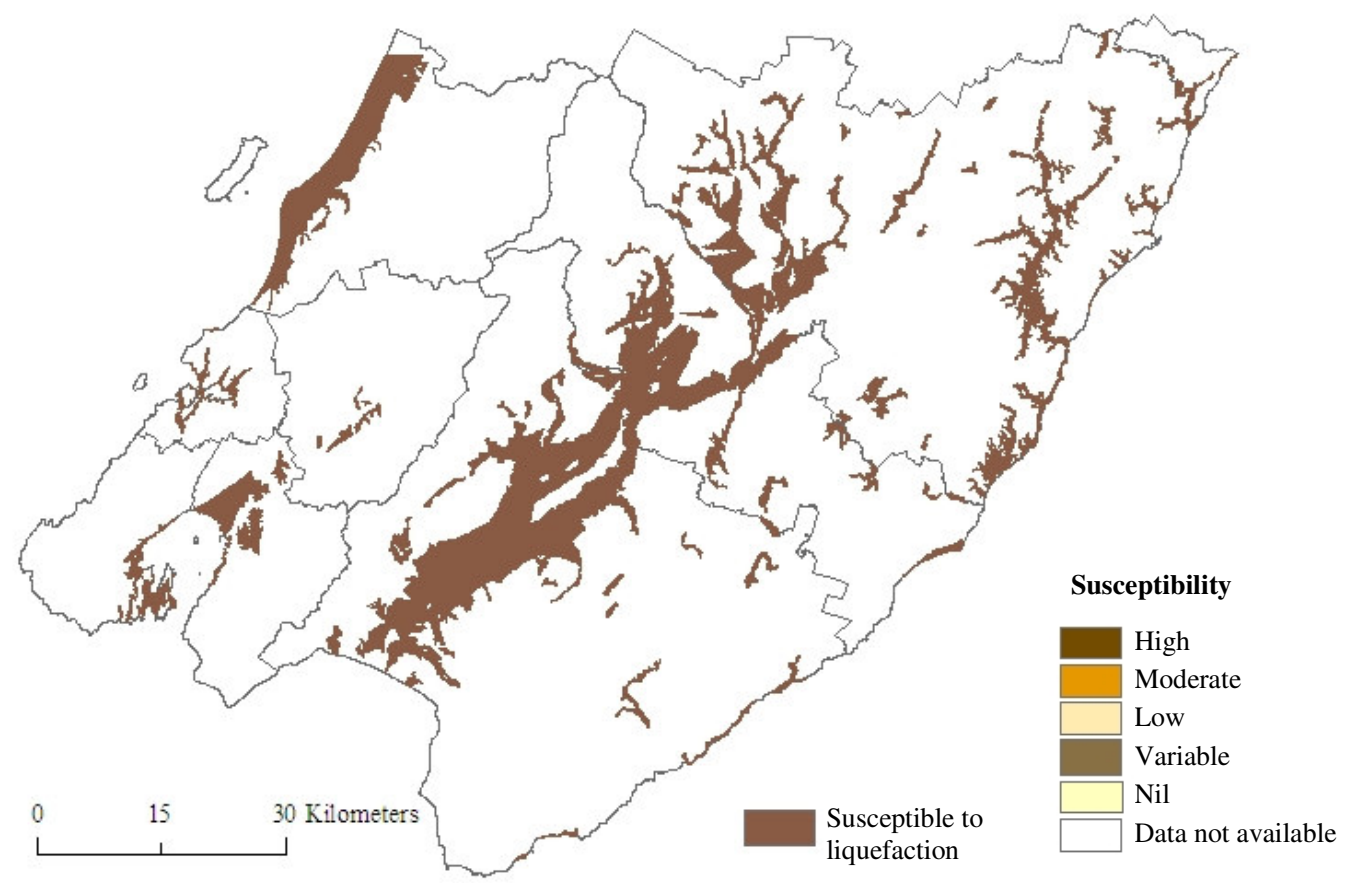

\section{Liquefaction Susceptibility}
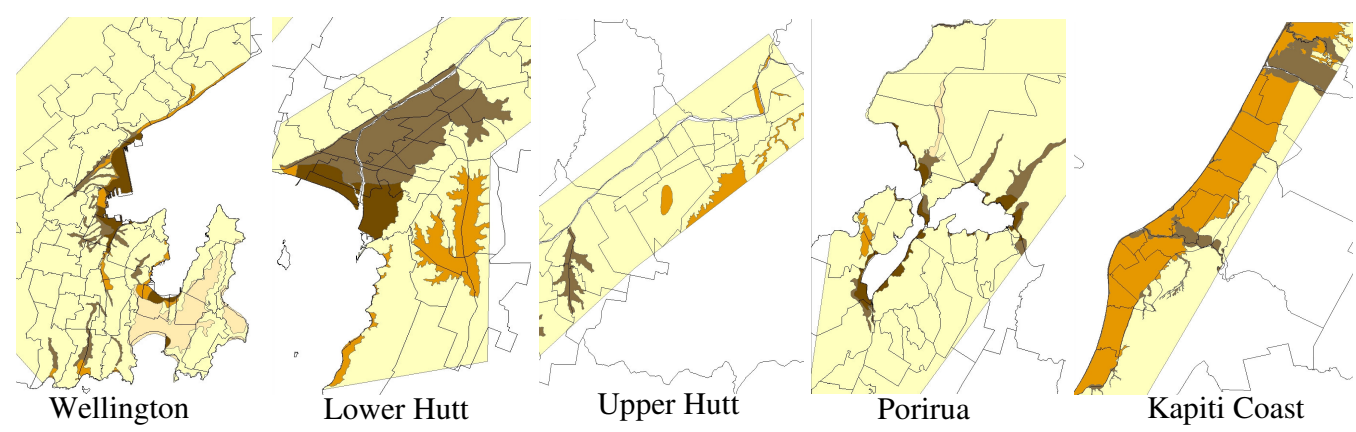

\section{Ground Shaking Susceptibility}

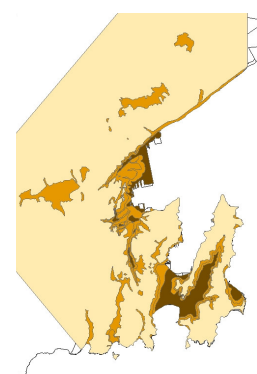

Wellington
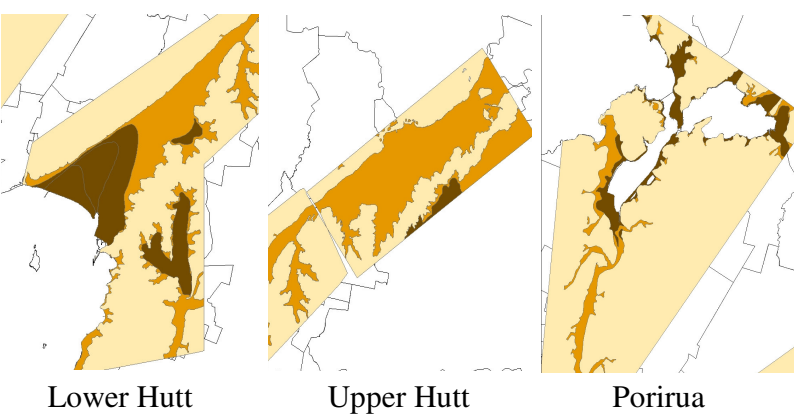

Porirua

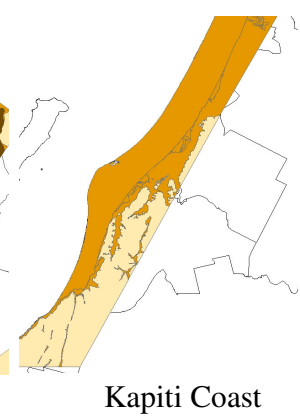


tunnel gully erosion. Further, landslide deposits themselves tend to have less internal strength which could result in further mass movement (Begg and Johnston, 2000, 47).

Across these zones, there is quite an extensive area in the region, which lacks solid bedrock and sits on the piles of soft sediments, and therefore could experience sand boil, liquefaction or higher ground shaking during a major earthquake. Though the Wellington Regional Council has conducted a detailed study of liquefaction and ground shaking in the western part of the region, in the eastern section the information is limited to the areas of soft sediment, which may liquefy. Map 3.6 shows that a wider area in the region is susceptible to liquefaction. However as a hazard, it is more concentrated in the urban areas particularly in Wellington and Hutt City Council where a huge infrastructure sits on the soft ground. The nature and complexity of the hazard is further added to by the physiography or landforms of the region.

\subsection{Physiography}

The landforms of the Wellington region are quite young, and have been largely built in the last 10,000 years (McConchie, 2000a, 9). The overall physiography is primarily structured by the ongoing tectonic process underneath the region. Above it, the climatic and human forces are constantly reshaping it. The resultant landforms are susceptible to a number of hazards including landslips, floods, fault movements, windstorms and drought etc. They can be broadly classified into hills and ranges, basins and lowlands.

The hills in the region vary from the extremely steep and rugged hills of Tararua and Rimutaka Range to the gently sloping rolling hills in the eastern Wairarapa. The highest range in the region is the Tararua Range where the highest peak called Mitre Peak is about $1571 \mathrm{~m}$ high. The Rimutaka Range is the second highest range with the highest peak of $941 \mathrm{~m}$ called Mt Mathews followed by the Orongorongo Range with the maximum height of about $864 \mathrm{~m}$ at the peak, which is called The Peak (MapToaster Topo/NZ 1:250,000 [242] $]^{+}$). The slope

Fig: 3.1. Tectonic Forces Shaping the Wellington Region

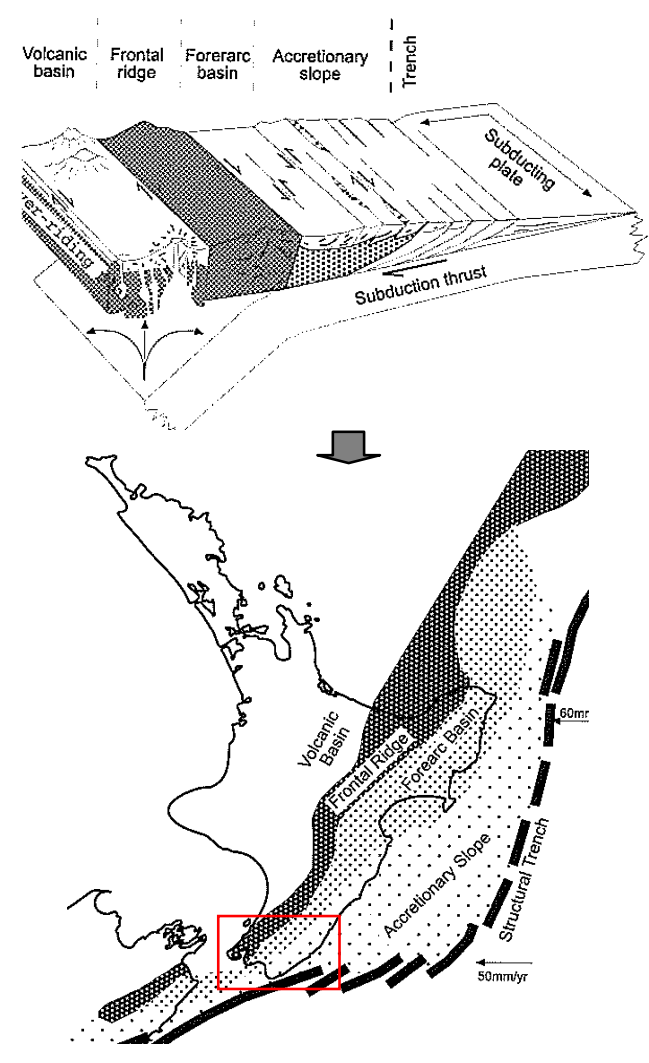

Source: McConchie et al, 2000, 12. and height of these hills and ranges represent the nature of tectonic activities operating beneath the region. The Hikurangi Trough that lies 150 kilometres east of Wairarapa marks the subduction 
zone, where the Pacific Ocean plate is subsiding under the Indo-Australian plate. The angle of subsidence is gentle near the subduction trench but gets very steep below Wellington at a depth of about 25 kilometres (McConchie, 2000a, 12), where the excessive force results in the higher rate of uplift. This zone is called the frontal ridge, and all the highest ranges of the region are located in this zone including Tararua, Rimutaka and Orongorongo Range. Western Hills are the smallest range of this zone with a maximum height of about $495 \mathrm{~m}$ at Hawkins Hill in Wellington. However, it is one of the actively rising ranges of the region along with the Rimutaka Range (Begg \& Mazengarb, 1996, 10). The rate of uplift varies across the region as well as among these ranges. It is estimated to be less the $2 \mathrm{~mm}$ per year in the Tararua Range to more than $4 \mathrm{~mm}$ per year in the Rimutaka Range along the fault axis (Pillans, 1986 as cited in Glade, 1997, 54).

The uplifted higher blocks are then exposed to active climatic processes and thus experience frequent erosion and landslides. It has been observed that areas with higher rate of uplift experience high rates of denudation due to steepened slopes (Crozier, M. J., 1990, 4). Besides, uplift directly affects the availability and amount of erodible material (Glade, 1997, 54). Under the influence of higher uplift and frequent erosion, soils on these slopes are too active to be able to build normal slope catenas (Glade, 1997, 54), which further adds to the landslide susceptibility through stunted vegetation growth. This also has a direct influence on the social and economic development of these areas. Most areas of excessively higher relief and steep slopes have either not been occupied or the development is minimal. However, a larger population resides on the Western Hills in Wellington, Porirua, Lower Hutt and Upper Hutt, and is therefore exposed to frequent landslides due to both atmospheric and seismic activities. Many of these hills have been modified to a significant extent by human beings in order to make space suitable for settlement. While many of the steep hills have been turned into gentle slopes to overlay houses and infrastructure, others have been steepened by cuts and fills to make streets and driveways (McConchie, 2000a, 10), which has increased the susceptibility to landslides (photo: 3.1).

Photo: 3.1. Landslide Susceptibility of Hills in the Wellington Region

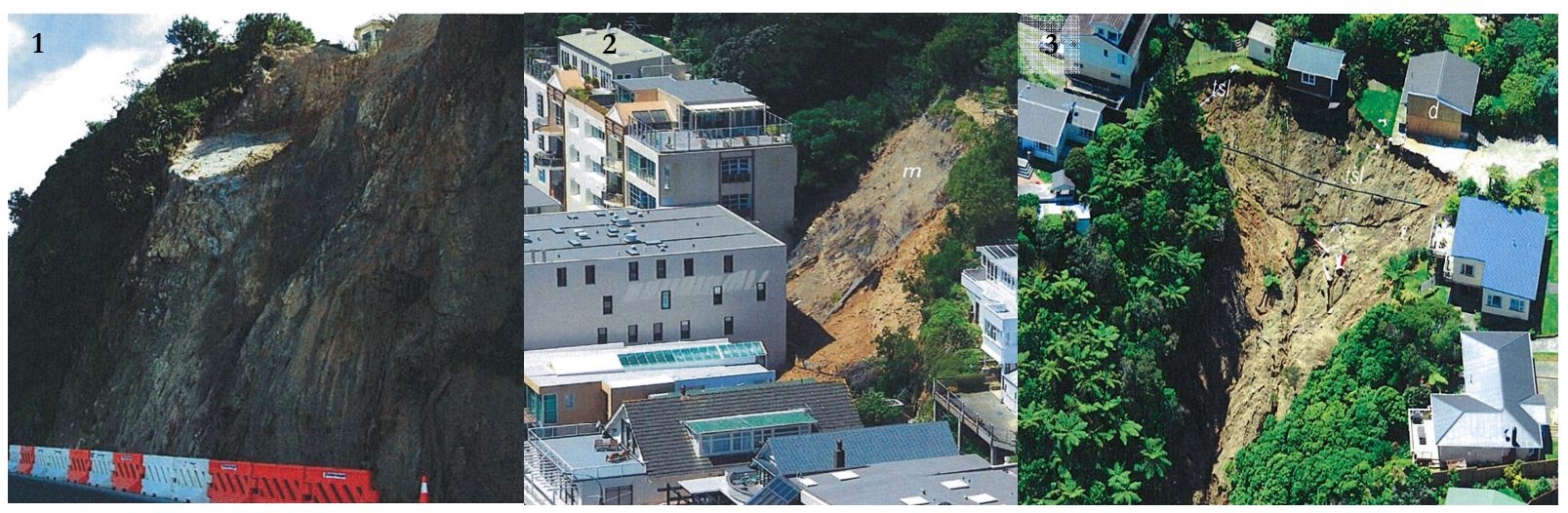

1. Rock fall on excavated slope on State Highway-2, July, 2006.

2. Slope failure in Oriental Bay, August, 2006.

3. Landslide in Kelson, Lower Hutt, August, 2007.

Source: Hancox, et al, 2007, 12, 27, 28.

The ranges at the Frontal Ridge cross the region at a diagonal axis. Due to their excessive height, not only the communication of human beings is difficult across them, but they also create a 
rainfall shadow zone in the east, which receives less rain and faces frequent drought. The hills in the far eastern section of the region are mainly accretion hills with gentle slopes. The average height of these hills ranges from 400 to $500 \mathrm{~m}$ above sea level, and the highest peak is Mount Adams which is $663 \mathrm{~m}$ high and capped by Paleocene mudstone (Lee and Begg, 2002, 7). These hills are prone to landslides and erosion, which bring heavy costs to local farmers (Glade, 1997, $55)$.

Apart from the steep and Photo: 3.2. K-surfaces in Wellington Against the Steep Slopes of the Tararua Range rolling hills, there are uplifted highlands with flat tops, which are known as K-surfaces after MT Kaukau (Cotton 1912, 1957, Eyles, and McConchie, 1992 as cited in Begg \& Mazengarb, 1996, 13). These are the remnants of earlier peneplains, which

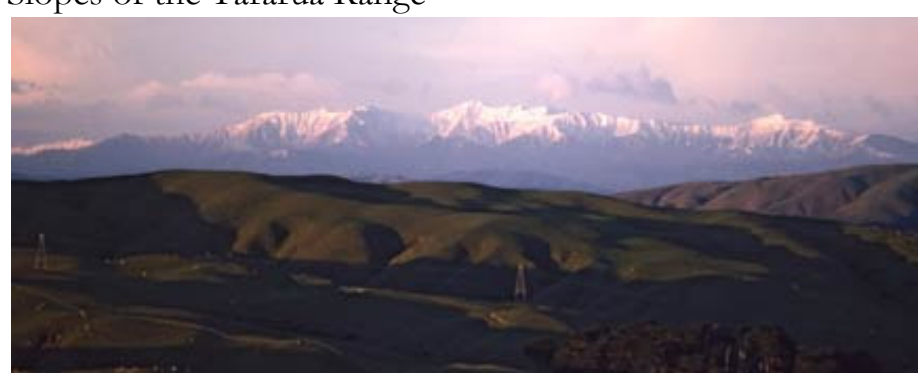

Source: Te Ara, 2008d existed before the uplift during quarternary age (CAE, 1991, 11). Many of such hills can be seen in the west of Wellington Fault. Quartz hill is a good example. However, their flat tops are being readily dissected by active stream erosion, and hence they are degrading fast (Begg \& Mazengarb, 1996, 11).

There are many uplifted blocks which are rising continuously under the tectonic influence. These include the northern margin of Upper Hutt basin (Te Marua area), Taita Gorge between the Lower Hutt and Upper Hutt Basin, and the area between Brooklyn and Miramar peninsula on the

Map: 3.7. Physiography of the Wellington Region

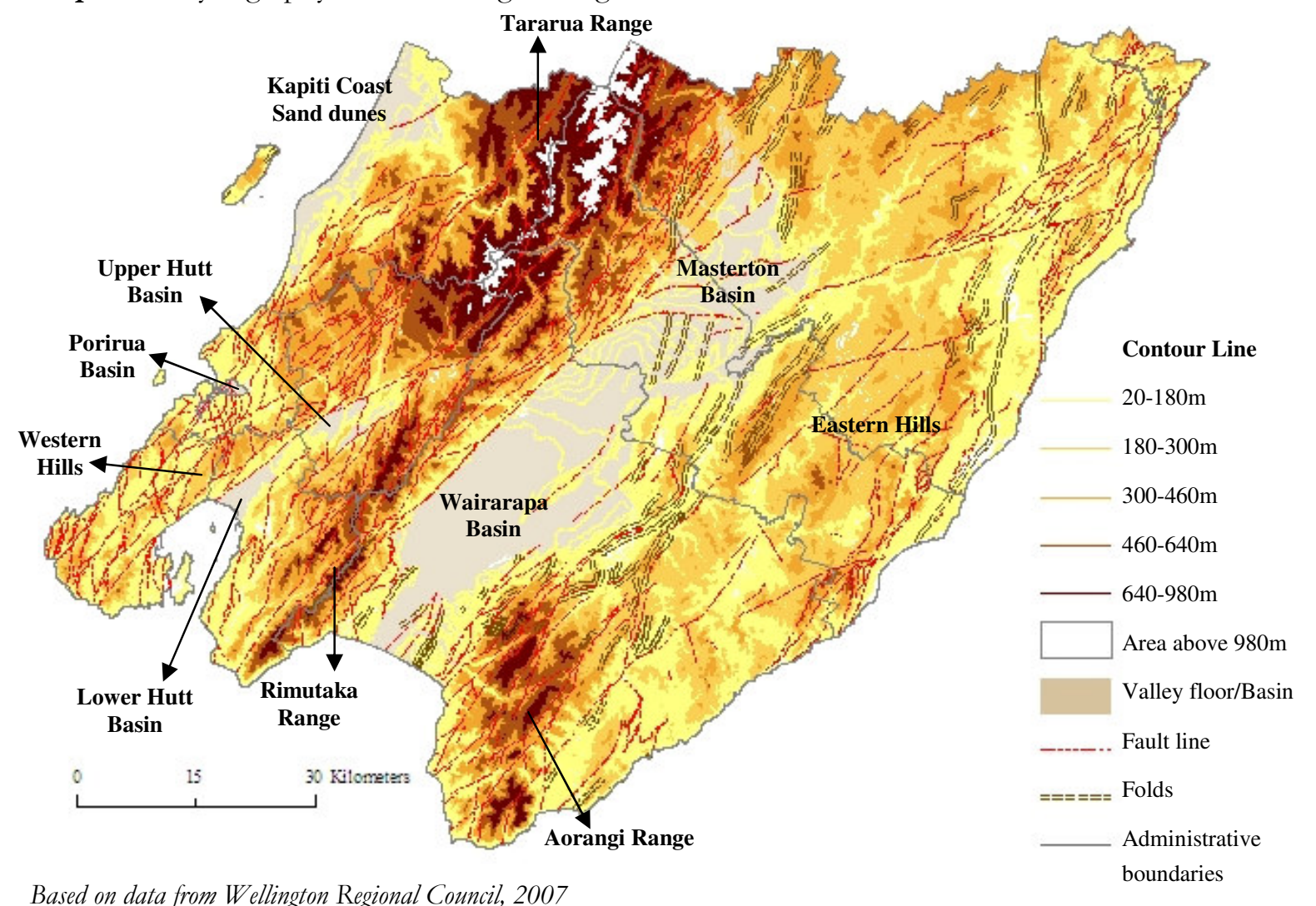


southern edge of Port Nicholson along with Somes and Ward Islands (Begg \& mazengarb, 1996, 10). In the Upper Hutt Basin, a series of river terraces near Emerald Hill have progressively raised the Hutt river Valley floor by a combination of tectonic uplift and river down cutting. The Craigs Flat and Maungaraki, surfaces underlain by gravel from Hutt River have been also elevated above the valley floor by uplift on the western side of Wellington Fault (Begg \& Mazengarsb, 1996, 13). These heightened blocks through intermittent uplift provide new areas of landslide and erosion.

The seismic forces have also produced various deformational features in the region such as faults and folds. Faults are particularly associated with various hazard susceptibilities. The major faults of the region include Wellington, Ohariu, Wairarapa, Pukerua, Masterton and Carterton. These faults are aligned in a north-east to south-west direction and are largely dextral strike slip faults (McConchie, 2000a, 15). Their relative movement shows that the force is higher in the east and decreases towards the west (McConchie, 2000a, 13). However, since uplift is higher immediately west of the major faults, most of the uplifted blocks in the region are tilted towards the west (McConchie, 2000a, 17). The movements along these faults not only make the place susceptible to substantial land displacement, but also to intense ground shaking and land resettlement during earthquakes. The major fault lines also experience surface rupture (WELA, 2007, 21), which could generate further change in the landforms and cause damage to properties during an earthquake. These faults are susceptible to both vertical and horizontal displacement, which can easily destroy or weaken the foundations of overlaid infrastructure. The two faults, which could generate an earthquake of magnitude eight or even higher by their movements are the Wairarapa Fault and the subduction interface also known as Hikurangi Trench (Begg \& Johnston, 2000, 53; Grant, 2005b). The distance to fault and damage often share an inverse relation depending on the location of the epicentre i.e. greater the distance, lesser would be the damage. Besides, there are many faults below sea level that cross the region or pass through the nearby areas (Map: 3.8). The movements or ruptures along these faults could be also seen as a potential source for local tsunami.

The tectonic activity has also produced a number of down faulted basins, which are the main areas of low land or flat land in the region. The major basins in the region include Masterton Basin, Wairarapa Basin, Lower Hutt/Port Nicholson Basin, Upper Hutt Basin, Mangaroa Basin, Porirua Basin, Judgeford Basin, Wainuiomata Basin and Miramar/Evans Bay Sub-basin. Masterton and Wairarapa Basins are located in the forearc basin, where the tectonic force is less severe than at the Frontal Ridge. These basins have been filled by the eroded material from the hills on both sides and have formed the largest plain area in the region. Similarly, the Lower Hutt Basin has been filled by the Hutt River aggradations. Most of the basins in the region are subsiding. The rate of subsidence of Lower Hutt Valley is about $0.6 \mathrm{~mm}$ per year under the influence of combined activity from the Wellington and Wairarapa fault movements (McConchie, 2000a, 20). The active subsidence of the Port Nicholson/Lower Hutt (600m deep) and Upper Hutt basins (400m deep) (Begg \& Mazengarsb, 1996, 6, 10) is a matter of concern as they are densely occupied urban areas. Subsidence along with active river aggradations in the basin would result in the continuous rise of the river bed, reduction in the river flow and hence poor drainage in the area (Begg \& Mazengarb, 
1996, 103). This process in the long run would lead to continuous lowering of house levels and thus increased flooding, which would require constant upgrading of stop banks. The low lying areas in Petone and Wellington harbour would also face enhanced tidal effects and drainage would become difficult (Begg \& Mazengarb, 1996, 103). The inward movement of sea and enhanced marine erosion can also be noticed in Palliser Bay at the southward end of Wairarapa Basin (Baggaley, 1967, 26).

Coastal landforms are also important physiographic features in the region. The coastline of the region is extremely dynamic. It experiences constant uplift and subsidence under tectonic forces along with denudation by marine and atmospheric processes. The differential rates of uplift could be easily noticed on raised platforms of Turakirae Head (Photo: 3.3) or quaternary marine beaches found inland in the region (Begg \& Mazengarb,

1996, 6). One recent change in the coastline occurred during the 1855 earthquake which uplifted a

Photo: 3.3. Changing Coastlines of the Wellington Region

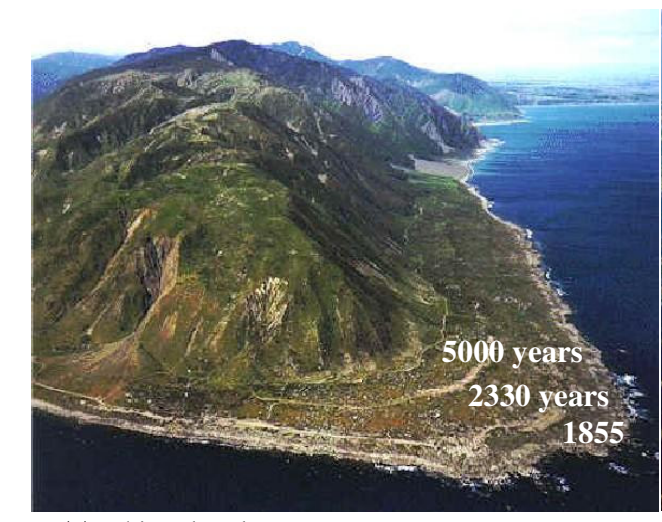

a. Turakirae head Source: GNS, n.d.; Te Ara, $2008 b$

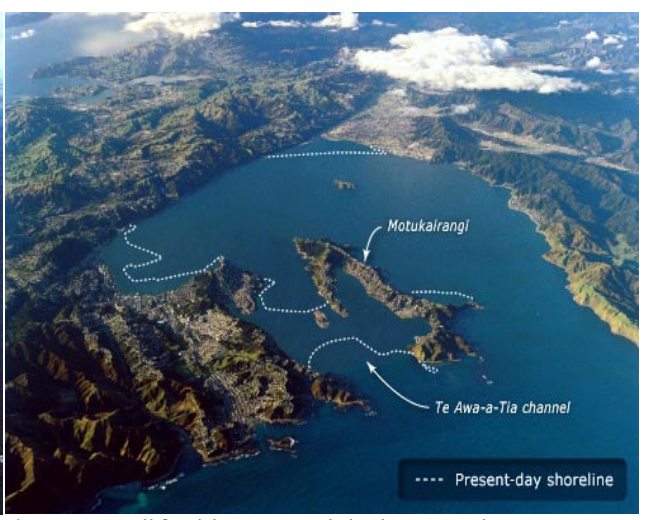

b. Area uplifted in Port Nicholson Basin through intermittent earthquakes.

significant landmass and thus changed the coastline of the region to a significant level including a three metre rise in the Wairarapa coastline and a one to two metre rise in Wellington (Te Ara, 2008a). Photo: 3.2 shows that the Wellington coastline has changed to a significant extent by regular uplift through earthquakes. These changes were superimposed on the earlier changes in the coastal land due to subsidence of Port Nicholson basin which led the sea to intrude about six miles inland (Baggaley, 1967, 26). The sea intrusion then exposed this landmass to marine erosion and Map: 3.8. Bathymetry of the Wellington Region

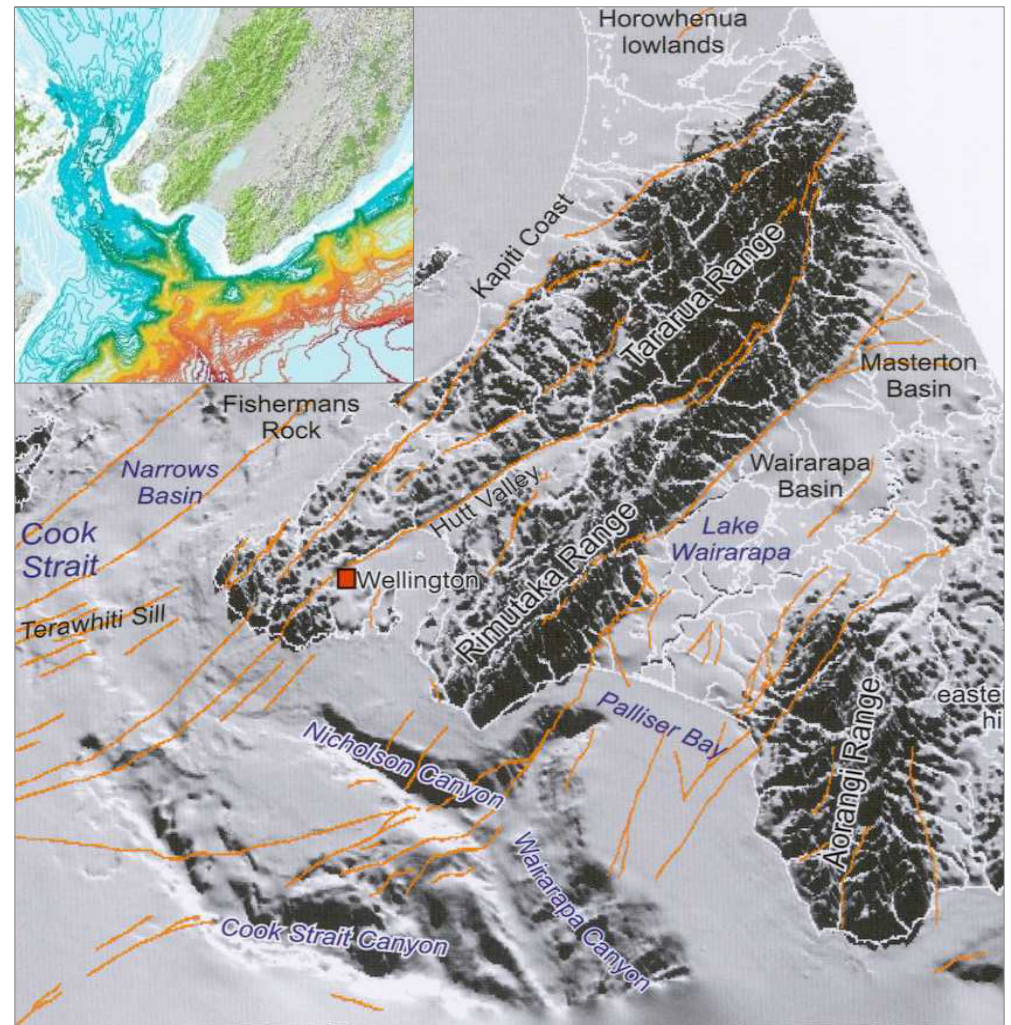

Source: Begg \& Johnston, 2000, 3 and NIW A, 2008 
tsunami. The soft sand dunes at the Kapiti Coast are particularly exposed to erosion and landslides compared to the rocky coastlines at other places.

The bathymetry of the region shows deep canyons in the Cook Strait, which represent the potential source of local tsunami. Numerous landslides scars have been located on the Cook Strait Canyon System along with the Hikurangi Trough and adjacent continental shelf, which do not represent tsunami occurrence but certainly indicate the potential (Carter et al., 1988 as cited in GeoEnvrionmental Consultant, 2001, 18). Further a greater depth in ocean along the region (Map: 3.8) signifies higher amount of water that could be displaced in case of marine landslide or earthquakes. The low lying areas on the coast including Palliser Bay, the Kapiti Coast, Lower Hutt, Wellington and Porirua are likely to be inundated from both near and distant tsunami.

\subsection{Meteorology and Climate}

The Wellington Region is located in an active climatic regime. Its mid-latitude maritime

Fig: 3.2. Mean Monthly Temperature and Rainfall in the Wellington Region

location brings high winds along with frequent rainfall and reduces the contrast of maximum and minimum temperature. Under the Köppen's Climatic Classification Scheme, the region is characterised by $\mathrm{Cfb}$ climate, which denotes a marine climate where average temperature throughout the year does not exceed $22^{\circ} \mathrm{C}$ and the area experiences rainfall throughout the year (Köppen Climatic Classification, 2008). However, despite its small spatial extent there are distinct variations in the climate across the region, which is governed by the local topography that produces varied physical susceptibility to hazards such as floods, droughts, storms, cyclones, windstorms and landslides.

Despite frequent overcast conditions and rain, the region gets long sunshine hours, which vary from 1600 to 1700 hours per year in the Tararuas to more than 2000 hours at exposed areas in both east and west of the Range. The highest mean annual sunshine is recorded at Martinborough i.e. about 2167 hours, which is 51 percent of the total possible sunshine hours. A strong seasonal 
fluctuation is also common between winter and summer, when the sunshine drops from 220 hours in mid summer to 100 hours in winters (Tait et al., 2002, 13-15). On average the eastern part of the region receives more sunshine compared to the west, which leads to high temperature contrast and contributes to regolith erosion and extreme dryness of farmlands especially during summers.

The mean annual temperature of the region is $12.6^{\circ} \mathrm{C}$. The temperature rises above $17^{\circ} \mathrm{C}$ during January and February, which are the warmest months across the region. June on the other hand is the coldest month, when mean temperature drops down to $8.7^{\circ} \mathrm{C}$ throughout the region. The coolest places in the region are Kaitoke in Upper Hutt and Ngaumu Forest in Masterton where the mean annual temperatures are $11.2^{\circ} \mathrm{C}$ and $11.6^{\circ} \mathrm{C}$ respectively. While the low mean annual temperature at Kaitoke station could be attributed to very high rainfall, at Ngaumu Forest it is associated with cooling effect of the forest besides rain. The warmest place in the region is Wellington airport, where the mean annual temperature is about $13.6^{\circ} \mathrm{C}$ followed by Gracefield and Avalon in Lower Hutt, where the mean annual temperatures are higher than $13^{\circ} \mathrm{C}$. The broad spatial arrangement shows that the mean average temperature is lower in the eastern section including South Wairarapa, Carterton and Masterton along with Upper Hutt than the other four districts on the western side of the region including Wellington, Lower Hutt, Porirua and the Kapiti Coast. The reason behind this is high diurnal and seasonal contrast of temperatures in the eastern section due to greater distance from the sea and its leeward location, which reduces the number of overcast days.

The mean daily minimum temperature in the region ranges from $6.13^{\circ} \mathrm{C}$ at Ngaumu Forest to $10.5^{\circ} \mathrm{C}$ at Wellington Airport. The difference in the mean minimum temperature is particularly sharp between the east and west of the middle ranges. While the minimum temperature ranges from $6.13^{\circ} \mathrm{C}$ to $7.04^{\circ} \mathrm{C}$ in the eastern districts of South Wairarapa, Carterton and Masterton, it ranges between $6.86^{\circ} \mathrm{C}$ to $10.5^{\circ} \mathrm{C}$

in the western districts of Wellington, Lower Hutt, Upper Hutt, Porirua and the Kapiti Coast. Also, the extreme minimum temperate is much lower in the east i.e. from $-3.1^{0} \mathrm{C}$ to $-5.0^{\circ} \mathrm{C}$ than the west, where it ranges from $0.6^{\circ} \mathrm{C}$ to $-4.7^{\circ} \mathrm{C}$. The extreme low temperature causes frequent ground frost and screen frost in the region, which is particularly damaging for the eastern farmlands. The low

Map: 3.9. Average Annual Snowfall Days in the Wellington Region

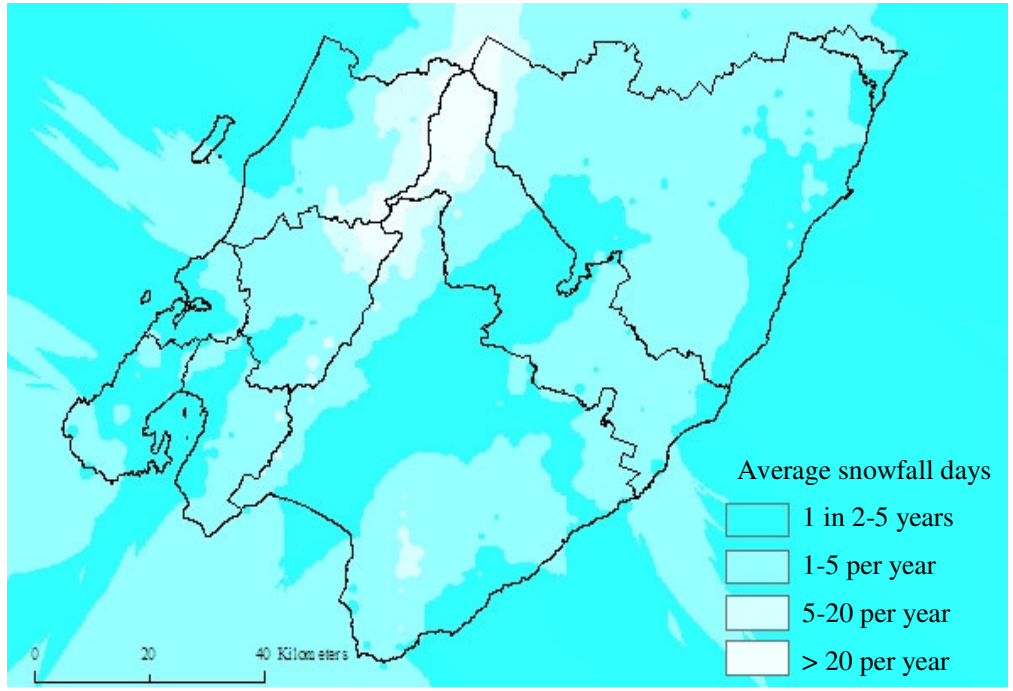

Based on data from WRC, Masterton, \& WELA, 2003, 40 temperature also leads to snowfall, which is largely restricted to the high altitudes in Tararua, Rimutaka and Orongorongo Ranges (Map: 3.9). However, the presence of snow on the ground after falling is rare in the region 
because it melts fast (Tait, et. al., 2002, 93). On average the area below $200 \mathrm{~m}$ from mean sea level experiences snowfall once in two to five years, at $200 \mathrm{~m}$ about once a year, at $600 \mathrm{~m}$ about five times in a year and at $800 \mathrm{~m}$ about 22 days of snowfall in a year (Tait, et. al., 2002, 19). Snowfall in the region is largely led by deep lows or troughs that pass through the region and mainly occurs during winter and early spring season (WELA, 2003, 39).

The upper end of the temperature, on the other hand, results in hot weather, soil moisture deficit and drought. Mean daily maximum temperature in the region is $17^{\circ} \mathrm{C}$ and the average extreme maximum air temperature is $28^{\circ} \mathrm{C}$. The distribution of mean daily maximum temperature shows that the temperature is relatively higher in the eastern districts where it ranges from $17^{\circ} \mathrm{C}$ to $18^{\circ} \mathrm{C}$ than in the western districts where the range is from $15.7^{\circ} \mathrm{C}$ to $17.3^{\circ} \mathrm{C}$. Also, the range of extreme maximum temperature in eastern parts is higher i.e. from $30^{\circ} \mathrm{C}$ to $31^{\circ} \mathrm{C}$ than western districts where it ranges from $26^{\circ} \mathrm{C}$ to $29^{\circ} \mathrm{C}$. The maximum temperature of $32.2^{\circ} \mathrm{C}$ was recorded at Castlepoint on $3^{\text {rd }}$ January, 2004 (National Climatic Centre [NCC], 2005). High heat leads to severe health problems, but in areas of moderate heat, it is the temperature deviation from the normal, which results in serious health problems and even mortality (Tait, et al, 2002, 99). The high risk areas include Masterton City and the Eastern Hills around Gladstone in Masterton, Carterton and South Wairarapa (Tait, et. al., 2002, 100). The higher temperature and its deviation are prominent in the eastern section compared to the western areas, where most areas are located in close proximity to the sea, and winds tend to modify the extreme temperatures (Table: 3.1).

Table: 3.1. Extreme Temperature Deviation from Mean Minimum Winter and Mean Maximum Summer in the Wellington Region

\begin{tabular}{|c|c|c|c|c|c|}
\hline \multirow[t]{2}{*}{ District } & \multirow[t]{2}{*}{ Station Name } & \multirow[t]{2}{*}{$\begin{array}{l}\text { Height } \\
\text { (m) }\end{array}$} & \multirow{2}{*}{$\begin{array}{l}\text { Number } \\
\text { of years } \\
\text { in the } \\
\text { data }\end{array}$} & \multicolumn{2}{|c|}{$\begin{array}{c}\text { Extreme Temperature Deviation from } \\
\text { Average }\end{array}$} \\
\hline & & & & $\begin{array}{l}\text { Minimum Winter } \\
\text { Temperature }\end{array}$ & $\begin{array}{l}\text { Maximum Summer } \\
\text { Temperature }\end{array}$ \\
\hline Porirua & Porirua & 94 & 13 & -12.6 & 8.6 \\
\hline Masterton & Ngaumu Forest & 244 & 39 & -10.4 & 9.8 \\
\hline Carterton & Waingawa & 114 & 86 & -9.8 & 12.0 \\
\hline Upper Hutt & Kaitoke & 223 & 33 & -9.7 & 10.4 \\
\hline Kapiti Coast & Paraparaumu Aero & 5 & 48 & -9.6 & 8.6 \\
\hline Lower Hutt & Lower Hutt,Avalon & 15 & 36 & -8.3 & 10.8 \\
\hline Upper Hutt & Te Marua & 84 & 7 & -8.2 & 7.4 \\
\hline Wellington & Wellington,Kelburn & 125 & 73 & -8.0 & 11.4 \\
\hline Wellington & Wellington Aero & 43 & 39 & -8.0 & 10.0 \\
\hline Lower Hutt & Lower Hutt, Gracefield & 34 & 30 & -7.7 & 10.9 \\
\hline South Wairarapa & Greytown P.O. & 57 & 18 & -7.4 & 11.3 \\
\hline
\end{tabular}

The wind in the region however, not only modifies the temperature extremes, but is also linked with hazards such as severe gales, windstorms, waterspouts, cyclones and anticyclones. The average wind speed in the region is $20 \mathrm{~km} / \mathrm{hr}$, which is largely modified or enhanced by the local terrain, and hence its speed varies throughout the region. It ranges from $10 \mathrm{~km} / \mathrm{hr}$ at Upper Hutt, which is the most sheltered place in the region to $42 \mathrm{~km} / \mathrm{hr}$ at Mt. Kaukau in Wellington (Tait et al., 2002 , 13). Even though the wind is prevalent throughout the year, a slight increase in the wind speed could be noticed during the spring season i.e. from October to January. The dominant wind 
direction is generally northerly between October and January and southerly between May and August. The southerly wind storms generally have higher wind speed but they are often less intensive. Besides, they have low wind gust height compared to northerlies (Tait, et. al, 2002, 87).

High winds are frequent in the region. Average annual days of wind gust of speed more than 50 knots or $93 \mathrm{~km} / \mathrm{hr}$ vary from less than one day in Upper Hutt to nearly three months in Kelburn, Wellington, which is one of the most exposed and densely populated areas in the region (Map: 3.10). Other sheltered areas, which Map: 3.10. Wind Gust of 1 in 142 years Probability in the Wellington Region face nearly one day of

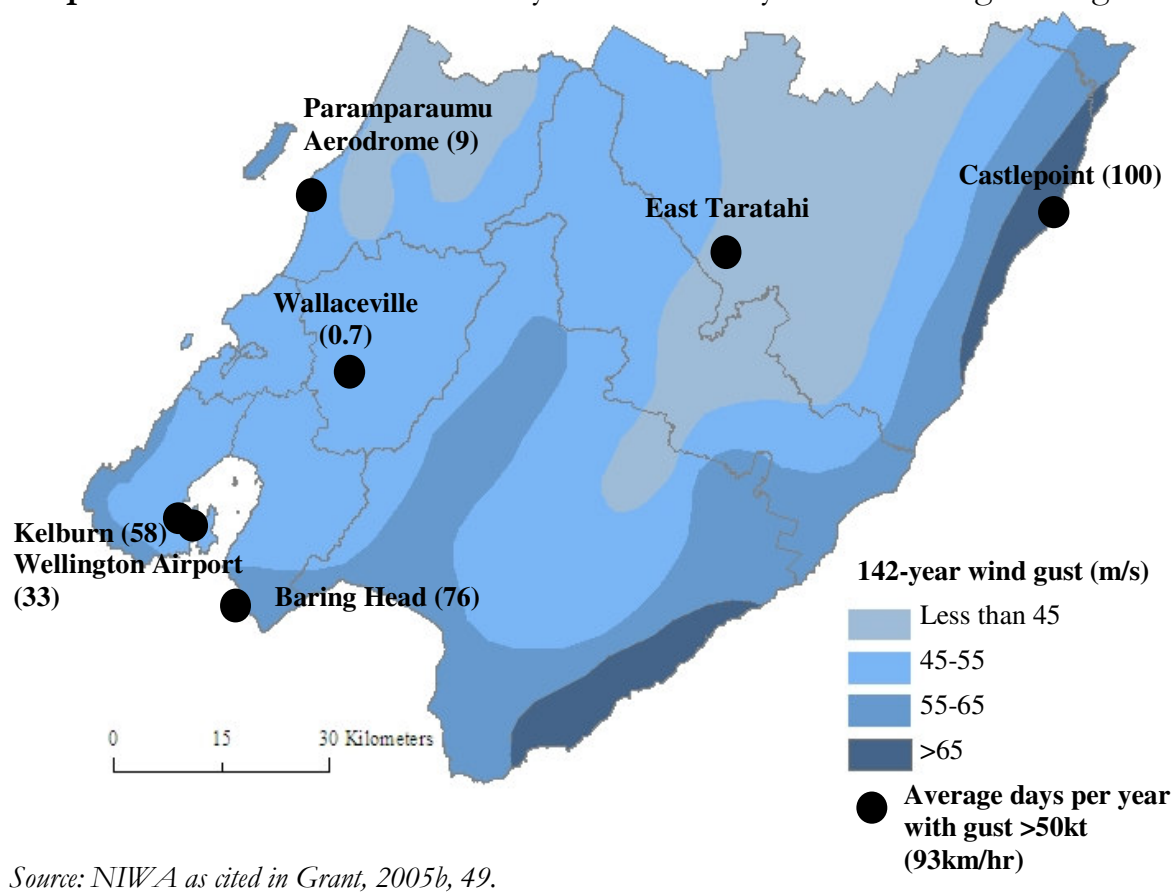
high wind in a year, include Waingawa in Carterton, Ngaumu Forest in Masterton, Avalon and Gracefield in Lower Hutt (CLIFLO, 2007). On average Upper Hutt and Porirua face moderate number of gale days i.e. six to seven days per year. The areas which are most exposed to the windstorms in the region include Mt Kaukau, Kelburn and the Airport in Wellington, Baring Head and Eastbourne in Lower Hutt, Palliser Bay, Featherston and the southeast coast in South Wairarapa and Castlepoint and neighbouring areas in Masterton (WELA, 2003, 29, Grant, 2005b, 45-48). The close proximity of Cook Strait, results in gusty winds in Wellington as the winds are channelled by the central ranges and forced to move up the slope because of the hilly terrain. Tararua Range is a high wind zone in the region, but since it is unpopulated the risk is low. The Range, however, plays an important role in producing high winds at the low ground in its east Wairarapa districts (Porteous et. al, 1999 as cited in Tait, et. al, 2002, 88). Gusty Föhn winds are produced when the strong winds from the west move down from the Ranges. The most frequent wind however in the eastern section is from the northeast, which is relatively lighter (Tait et al., 2002 , 13). Some areas are however more susceptible to high winds than other parts. For example, Castlepoint gets more than 100 days of high winds of speed more than $93 \mathrm{~km} / \mathrm{hr}$. The area adjoining Castlepoint along with the south east coast of the South Wairarapa have susceptibility for wind speed of more than $234 \mathrm{~km} / \mathrm{hr}$ in case of 142 year wind gust event, which could increase to more than $257 \mathrm{~km} / \mathrm{hr}$ in case of 472 year wind gust event that is ten percent higher than the former (Tait et al, 2002, 89). This causes frequent damage in the area. Winds are also the carrier of rain in the region. 
Rainfall is directly associated with hazards including flooding, landslides and drought. The mean annual rainfall of the region ranges from $1200 \mathrm{~mm}$ to $1400 \mathrm{~mm}$ (Tait et al, 2002, 12). However, there is a wide variation in the amount of rainfall received across the region, which is linked to the local topographic characteristics. A greater proportion of rain in the region is orographic. The moisture laden westerlies enter through west and meet the axial range, which crosses the region from south-west to north-east. They produce heavy rainfall in the west of the mountainous zone and the leeward zone in the east tends to be dry. The highest rainfall in the region is received at Tararua Range i.e. about $3200 \mathrm{~mm}$ followed by Rimutaka Range, which receives a mean annual rainfall of about $2400 \mathrm{~mm}$ (Tait et al, 2002, 12). Among the populated segments of the region, the highest rainfall is received at Upper Hutt mainly at Arawhata, Kaitoke and Kaitoke head work station, which receive more than $2000 \mathrm{~mm}$ of rainfall per year (CLIFLO, 2007). The eastern section is the driest part of the region especially Martinborough area in South Wairarapa and the area adjacent to Masterton City receive less than $800 \mathrm{~mm}$ of rainfall (Map: 3.11). Rainfall is also less in the low lying areas of very western sections of the region including western Wellington, Porirua and the Kapiti Coast, where dryness increases towards north and the average annual falls below $1000 \mathrm{~mm}$ per year in Otaki.

Map: 3.11. Mean Annual Rainfall in the Wellington Region

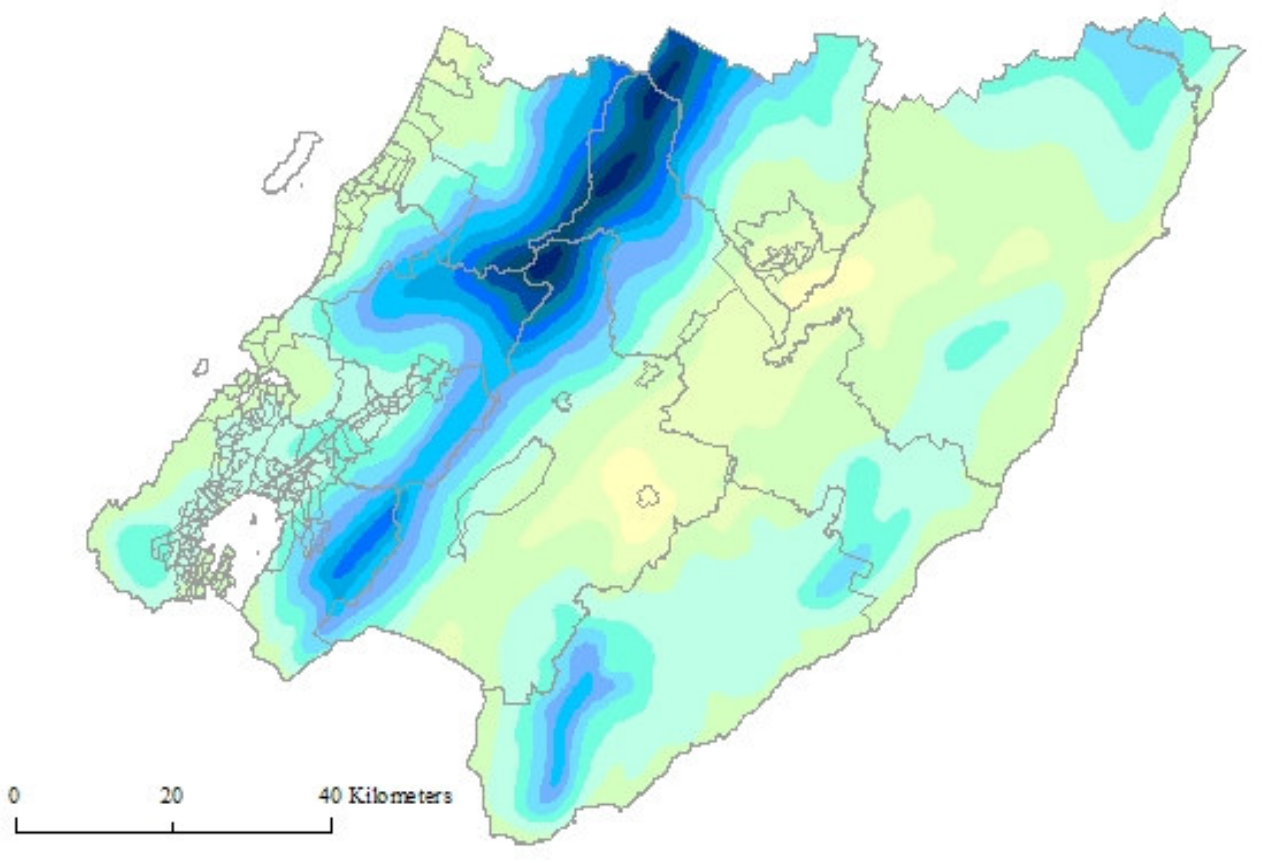

Rainfall (in mm)
Less than 800
$800-1000$
$1000-1200$
$1200-1400$
$1400-1600$
$1600-2000$
$2000-2400$
$2400-2800$
$2800-3200$
$3200-4000$
$4000-4800$
$4800-5600$
$5600-6400$
$6400 \&$ above

Based on data from WELA, 2007 \& Statistics New Zealand, 2007

Hazards such as flooding and landslides in the region largely depend on the intensity and duration of the rainfall. While there are significant variations in the total rainfall across the region, there is less contrast in the number of rain days in the eastern and western districts. For example, while the wettest station (i.e. Arawhata) receives $2327 \mathrm{~mm}$ of rainfall annually in 249 days, the driest station in the east (i.e. Martinborough) receives $799 \mathrm{~mm}$ of rainfall in 217 days. It can be therefore said that the intensity of rainfall in western districts is relatively higher than the eastern ones, which mainly receive the offshoots of various rainstorms which produce heavy rain in the west but lose their intensity and moisture on their way and therefore produce less rain with low intensity in the 
east. It could be also seen as an important reason for frequent floods and landslides in the west while drought and earth flows in the east. This is further supported by the geomorphic features such as steep slopes, V-shaped valleys in western areas compared to gentle slopes and open farm lands in the east. The extreme western section also receives less rain and gets less rainy days. However, since the intensity of rainfall is higher than the east it experiences frequent landslides in higher slopes or on coast. It is important to recognise here that a greater number of landslides are triggered on the modified slopes; therefore rainfall is not the only governing factor of landslide susceptibility in the region. However, rainfall at different stages such as mean hourly, daily, monthly or total precipitation from a rainstorm often bears the strength to trigger landslides or flash floods in the region.

The research shows that most of the landslides in the North Island have been triggered by $10-80 \mathrm{~mm}$ of maximum hourly rain (Glade, 1997, 105). In the Wellington Region the mean maximum hourly rain is $30 \mathrm{~mm}$ based on the data from 16 stations across the region, which indicates a quantity sufficient enough to trigger landslides. The maximum hourly rainfall witnessed at Kelburn, Wellington was $55.7 \mathrm{~mm}$ in June 1988 followed by $36.5 \mathrm{~mm}$ in November 1995 at Baring Head. While there is a record of a landslide in Wellington city in 1988 (Glade, 1997, 360), no such record was found for landslides at Baring Head corresponding to the heavy rainfall recorded at the station. The reason could be attributed to the remoteness of the area and consequently absence of reporting. It has been observed that the daily rainfall required to trigger landslides in the North Island has decreased from $200 \mathrm{~mm}$ in the early $19^{\text {th }}$ century to $50 \mathrm{~mm}$ in 1990 (Glade, 1997, 99). The average maximum rainfall for a day in the region is $184 \mathrm{~mm}$ based on data from 14 stations, which is well beyond the rainfall threshold required to produce landslides. However, their occurrence also depends on other factors such as land use or antecedent climatic or soil conditions. The region received its maximum rain in 24 hours of about $285.6 \mathrm{~mm}$ at Waingawa, Carterton in May 1981, but no landslide was recorded for the day. Cumulative and continuous rain for a few days also increases the chance for landslides. It has been noted that until 1915 a total precipitation of $250 \mathrm{~mm}$ was required to trigger a landslide in North Island, which decreased to $50 \mathrm{~mm}$ in 1975 and less than 100mm afterwards (Glade, 1997, 98-99). Added to this, an increase in the frequency and magnitude of rainfall in New Zealand is noted by Fowler \& Hennessy, 1995 (Glade, 1997, 98), that has further enhanced the landslide susceptibility. The average maximum rainfall in 74 hours for the region is $215 \mathrm{~mm}$ based on data from 14 stations, which is sufficient enough to cause landslides. Maximum rain in 74 hours has been frequently recorded at Wainuiomata Reservoir i.e. 360.3 in March, 1987, 337.8 in May, 1981 and 336.6 in May, 1983, which indicates that the area is more likely to face landslides in the presence of other favourable conditions.

The monthly distribution of the rainfall in the region shows that it receives rainfall throughout the year but the share of winter months is slightly higher than the summer. Months from May to August contribute to near or more than 40 percent of the total rainfall throughout the region. Landslide claim data at the Earthquake Commission shows that the number of claims start rising progressively with the progress of rainy season, which indicates towards the building up of 
antecedent climatic conditions that enhance the landslide susceptibility. Seasonality in terms of maximum and minimum rainfall received at a place is less conspicuous in the extreme west sections of the region i.e. about three percent in areas including Otaki, coastal areas of Paraparaumu and Porirua besides, pockets in the eastern section including Greytown and Woodside Village in South Wairarapa. It is more pronounced in the eastern section especially in Masterton and South Wairarapa where the difference of rainfall between the most wet and dry months is 9-11 percent. The run off in the region varies from very high i.e. 71 percent of the total rainfall at $\mathrm{Mt}$ Holdsworth Lodge and more than 60 percent in high rainfall high areas to less than 30 percent in the low lying dry areas including Martinborough, Baring Head, Otaki and Paraparaumu. In terms of runoff days while high rainfall areas have near or more than 50 percent runoff days of total rain days, in dry areas they form even less than 18 percent of total rain days. The overall generalisation at district level puts South Wairarapa, Porirua, the Kapiti Coast and Masterton as relatively drier than the other four districts of the region.

Besides local rainstorms, migratory cyclones, anticyclones or depression also produce heavy rains in the region. The cyclones generated in warm Equatorial Ocean in south west Pacific often pass through the North Island. They lose some of their intensity on their way, but when they reach New Zealand, they regain their strength from low sea temperature and produce heavy rains, high winds and storm surge (WELA, 2003, 36). The amount of rain from these cyclones has varied from $10 \mathrm{~mm}$ to $136 \mathrm{~mm}$ in Wairarapa (WELA, 2003, 36). The region also receives heavy rainfall from local anticyclones and mid latitude storms. The two frequent directions of storms in the region are north-westerly and easterly. Storms from both directions produce heavy rain but differ in their rainfall patterns (Map: 3.12).

The rainfall pattern through the north-westerly storm indicates heavy rainfall in the Tararua Range, which gradually declines in all directions. The areas which receive least rain include a wider zone in northeast Masterton, southeast of South Wairarapa, Porirua and parts of Lower Hutt along with Wellington. Wellington, however, on the whole receives medium to high rain, which may trigger landslides in its higher slopes. Besides, heavy rain in the Tararua Range, which is the catchment zone for most of the rivers in the region indicates likelihood of flooding especially in

Map: 3.12. Rainfall from 1 in 142 years North-westerly and Easterly Storms in the Wellington Region

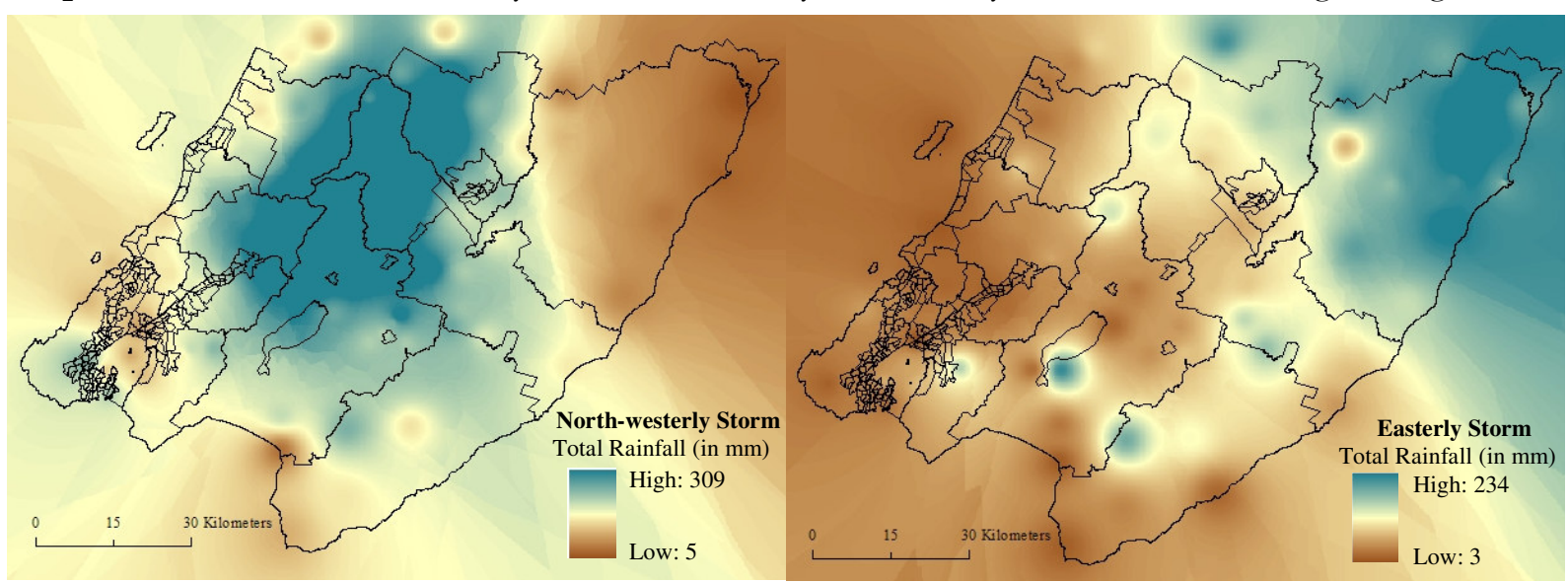

Based on data from WELA, 2007 \& Statistics New Zealand, 2007 
South Wairarapa rivers. The rainfall pattern of easterly storms on the other hand shows an opposite trend. Areas that receive high rain include northeast Masterton and parts of Carterton, South Wairarapa and Lower Hutt. While the heavy rainfall results in earth flow in the soft sedimentary rocks of northeast Masterton, the possibility of landslides in South Wairarapa, Carterton and Lower Hutt cannot be denied. The rainfall from the easterly storm gradually declines towards south and west. These storms are important triggers of landslides in the region. The damage data from the Earthquake Commission shows that the region does not experience maximum landslides in its rainy season i.e. from May to August, but in October, when the frequency of storms is higher.

The region is also susceptible to the scarcity of rainfall which often results in drought conditions. Though there are various measures and definitions of drought, it is defined in New Zealand as a condition of more than $130 \mathrm{~mm}$ of soil moisture deficit, if the area does not get dry at the particular time of the year (National Climate Centre [NCC], February, 2008a, 1). The annual soil moisture deficit in the region ranges from as low as $30 \mathrm{~mm}$ at Mt Holdsworth Lodge in Carterton to as high as $300 \mathrm{~mm}$ at Baring Head in Lower Hutt. Other areas of high soil moisture deficit are Martinborough $(296 \mathrm{~mm})$ in South Wairarapa, Wairarapa Cadet Farm $(279 \mathrm{~mm})$ and Gladstone $(279 \mathrm{~mm})$ in Carterton, Te Oro Oro $(275 \mathrm{~mm})$ in Masterton, Oteranga Bay $(286 \mathrm{~mm})$ and Wellington Airport $(274 \mathrm{~mm})$ in Wellington. The high soil moisture deficit has differential impacts on rural and urban areas. While urban areas could face water shortages and thus restrictions on irrigating gardens or washing cars or windows, in the rural countryside it directly affects agriculture and livestock. All the three eastern districts including South Wairarapa, Masterton and Carterton face high soil moisture deficit, which poses a risk to their rural economy, which depends on pasture farming and vineyards. The temporal expanse of soil moisture deficits in these areas extend to an average of more than 70 days i.e. nearly two and half months, which could result in severe losses for farmers. In general the Wairarapa districts experience more droughts (i.e. at least 15 days of soil moisture deficit of more than $130 \mathrm{~mm}$ per year) than western districts which experience about ten such days per year (Tait et al, 2002, 42). The severe soil moisture deficit also produces extreme or very high fire risk in the region.

Weather-related hazards such as drought and extra-tropical cyclones in the region are also affected by the El Niño and La Niña events in the Southern Oceanic Oscillations in the Pacific Ocean (Grant, 2005b, 24). La Niña condition, which results in stronger easterly or north-easterly flow often leads to less rainfall in western districts of the region and hence low water flow in Otaki, Waikanae, Hutt, Wainuiomata and Orongorongo rivers, while the El Niño conditions of stronger westerly flow often cause drought in the eastern districts of the region (Tait et al, 2002, 17 and Watts, 2005 as cited in Grant, 2005b, 56). There is evidence that suggests that Interdecadal Pacific Oscillation (IPO) is entering in a negative phase, which could result in a weaker westerly flow in the region, with more La Niña years and less El Niño years in the next 20-30 years. It would enhance the probability of the occurrence of extra-tropical cyclones along with water scarcity in the western section of the region (Grant, 2005b, 24). 


\subsection{Drainage and Hydrology}

Hydrological processes not only govern the sustainability of livelihood but also the hazards such as flood, drought and landslides. Wellington Region has plenty of water resources due to its exposure to maritime conditions and elevated catchment areas. The water then travels in the region through surface and sub-surface drainage networks, which determine the direction and quantity of water flow and hence the hydrological status of a particular area.

The region has dense surface drainage in the form of rivers and streams of different orders besides lakes and ponds (Map: 3.13). The direction and speed of surface water flow is largely governed by the alignment of hills and ranges in the region. As a result most of the drainage is moving either towards the east, west or south. A general overview of surface drainage shows that drainage density is relatively higher in the Tararua and Rimutaka Ranges and the areas west of them compared to those in the east. The drainage density also declines sharply near the urban areas, where they have been removed in order to make more space. Most of the valleys in the western section of the region are steep and V-shaped, which result in the faster flow of water than the

Map: 3.13. Surface Drainage in the Wellington Region

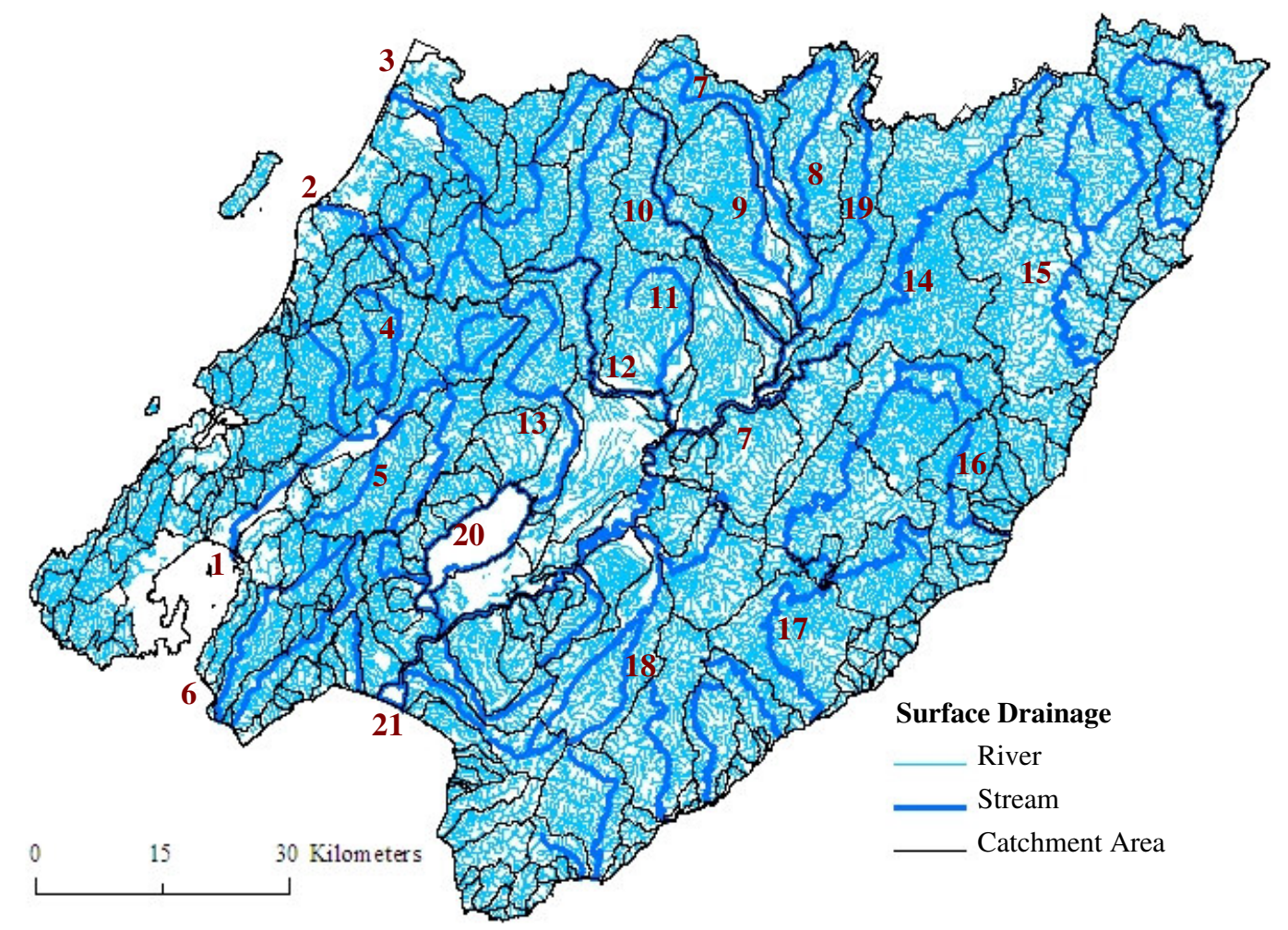

Index

1. Hutt River

2. Waikanae River

3. Otaki River

4. Akatarawa River

5. Mangaroa River

6. Wainuiomata River

7. Ruamahanga River
8. Kopuaranga River
9. Waipoua River
10. Waingawa River
11. Mangaterere River
12. Waiohine River
13. Tauherenikau River
14. Tauweru River

15. Whareama River

16. Kaiwhata River

17. Pahaoa River

18. Huangarua River

19. Whangaehu River

20. Lake Wairarapa

21. Lake Pounui 
gentle slope of eastern Wairarapa. The catchment areas are much smaller near the coast in all directions. A greater proportion of rivers have their catchment in Tararaua Range, and therefore a single storm in the Range could produce flooding in both eastern and western parts of the region (Thompson, 1997 as cited in Tait, et. al, 2002, 31). The rivers in the Wairarapa valley have bigger and wider catchment areas compared to the western districts. As a result the length of the rivers in the east is greater than the west, which is also due to the greater distance from the sea. The Ruamahanga River, located in the east is the largest river of the region. Other major rivers in the east are Tauweru, Kopuaranga, Waipoua, Waingawa, Waiohine, Tauherenikau, Pahaoa, Huangarua, and Whareama River. The major rivers in the western section are Hutt, Otaki, Waikanae, Akatarawa and Mangaroa. Each covers an area of more than 100 square kilometres.

Lakes and ponds are other sources of surface water. The two major lakes of the region are Lake Wairarapa and Pounui, which are located in South Wairarapa. Besides, there are many artificial lakes which are created for dams and agricultural ponds but due to their small size, they are not distinct on the map. The surface drainage network across the region shows that there is a sharp decline in urban areas especially in Wellington, Porirua, Lower Hutt and the Kapiti Coast. The reason could be attributed to the high demand for land in these urban areas, where most of the drainage areas have been used and developed either by removing or modifying the natural drainage system e.g. by underground storm water system.

Rivers in the region experience variable flows throughout the year. This is because they are largely rain fed and their catchment areas have limited storage capacities due to shallow regolith (McConchie, 2000b, 40). As a result they experience flooding during storms and minimum discharge during the intermediate period or in summers, which often accompany drought. The map of flooding zones in

Map: 3.14. Flooding Areas in the Wellington Region

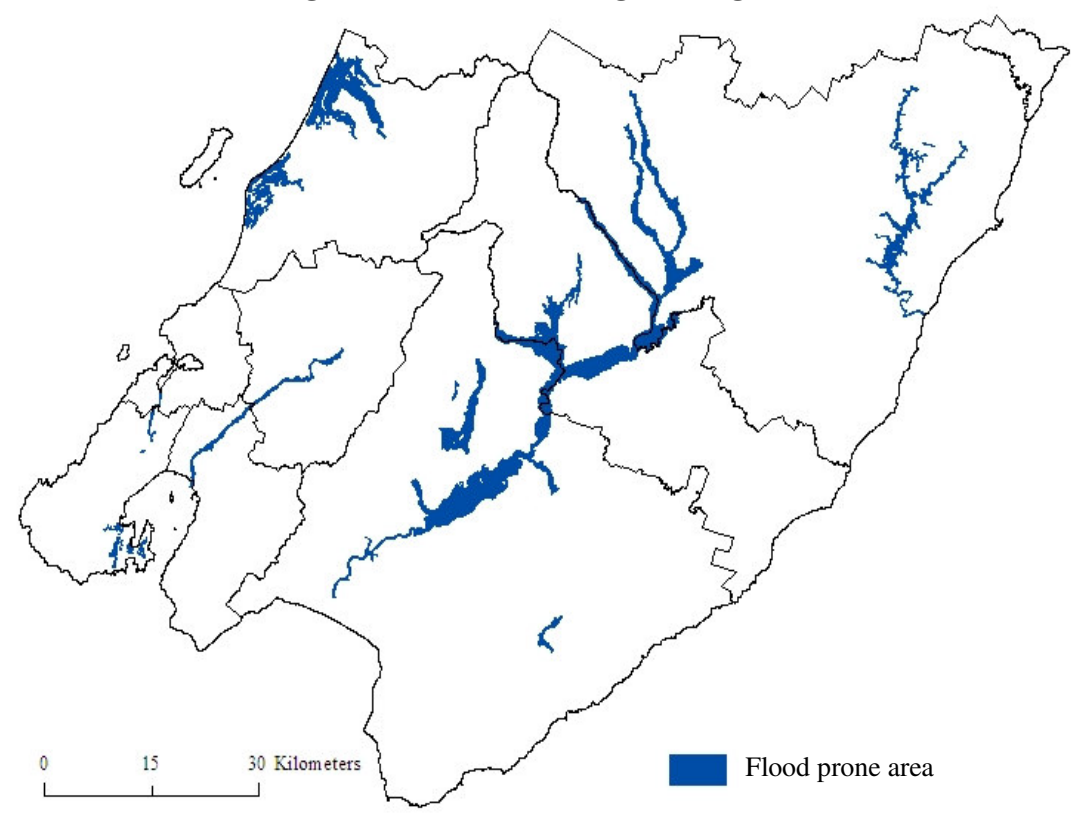

Source: Wellington Regional Council, 2007. the region (Map: 3.14) shows that all the eight district councils experience flooding. However, the flood affected area is wider in the three eastern districts of Wairarapa than the west. The Kapiti Coast is the exception in the western districts, where an extensive portion of the district gets affected by flooding. If the flood zones in the region are compared with the drainage pattern, it also brings out that while there is not much natural drainage in Wellington City, it has a relatively higher proportion of area affected by floods. This is because the natural drainage is blocked and 
the human induced drainage system has limited capacity. Gullies, which allow natural drainage along with rivers and streams and thus reduce flooding and landslides susceptibility by not allowing the groundwater pressure to elevate (Begg \& Johnston, 2000, 47), have been also modified for housing that has resulted in higher flood and landslide susceptibilities.

Groundwater is the other important source of water in the region. The availability of groundwater is closely linked with the topography and geology of the area. Since the shallow regolith in high altitudes retains less soil moisture and the steep slopes help the water to run off quickly, groundwater tends to be less in these areas (McConchie, 2000, 40). Most of the valley basins in the region on the other hand, are filled with highly permeable gravels brought by the rivers from their catchment areas mostly from the Tararua Range, and therefore they have higher groundwater content (Begg, \& Johnston, 2000, 46). The major aquifers in the region are confined to the low lying areas including Hutt Valley, the Kapiti Coast and Wairarapa Valley (Map: 3.15). Other areas of groundwater include Upper Hutt, Mangaroa Valley, Wainuiomata Valley and a section of the eastern Wairarapa coastline (McAlister, 2007, 2). These aquifers are largely recharged by rainfall. The shallow aquifers, which are located above $20 \mathrm{~m}$ in depth, are mainly connected with rivers, streams, springs and wetlands, and thus recharged by them (McAlister, 2007, 9). However, few aquifers are recharged by both rainfall and streams depending on their depth and extent.

The Lower Hutt Basin

has the most abundant groundwater resource. There are three zones of aquifers in this basin. The deepest one named Maera Basal Gravel is located at the depth of $120 \mathrm{~m}$ (Begg, \& Mazengarb, 1996, 92). This aquifer is weakly mineralised and has high content of calcium carbonate and chloride. The presence of carbon-dioxide, methane and nitrogen make it acidic in nature (Begg, \& Johnston, 2000, 45). The

Map: 3.15. Ground Water Zones in the Wellington Region

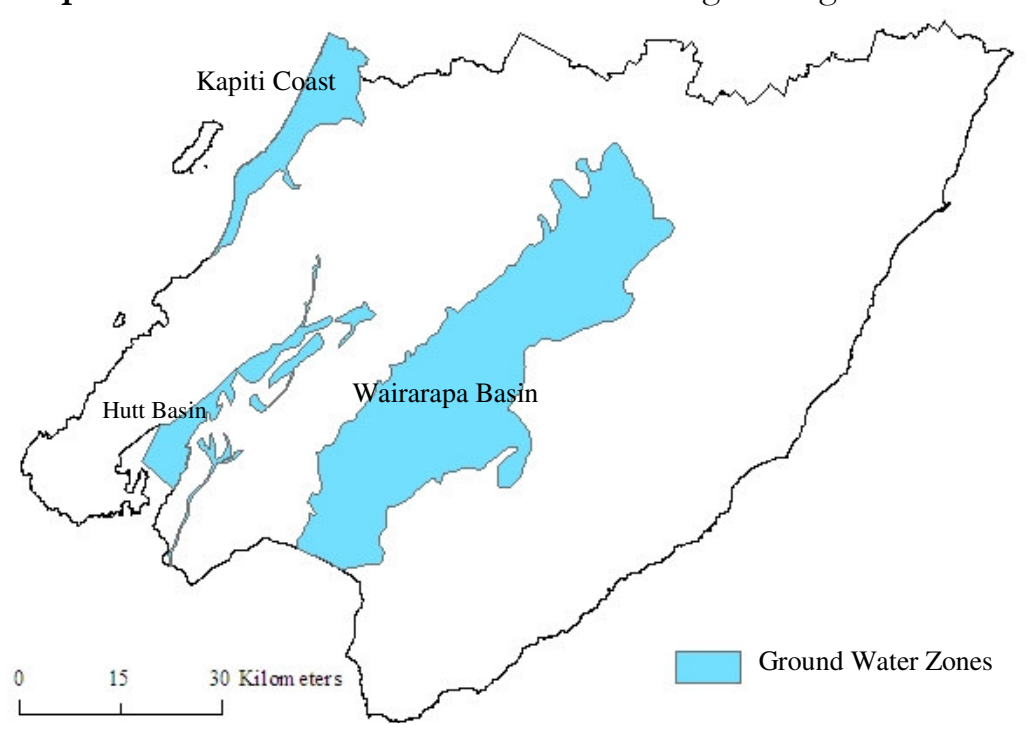

Based on Baker \&o Jones, 2005, 13. intermediate aquifer named Waiwhetu Artesian Gravel lies about 20-30m below ground at Lower Hutt and Petone (Begg, \& Mazengarb, 1996, 91). It is recharged by both rain and by the Hutt River between Avalon and Taita Gorge. It is a confined aquifer and most of the water, which is extracted in the district, comes from this aquifer. Swamps and marine sediments confine this aquifer to the lower part of the valley (Begg, \& Johnston, 2000, 45). As a result extra caution is required to extract the water from this aquifer to avoid the mixing of salt water (Begg, \& Johnston, 2000, 46). The third aquifer is at the surface called Taita Alluvium, which extends from Taita Gorge to Hutt Golf 
Course. It is a semi confined aquifer and rests on the older glacial and interglacial deposits (Begg, \& Mazengarb, 1996, 92).

The Kapiti Coast is the other area in the western section of the region, where a significant amount of land could supply groundwater. The sand dunes of the district provide an unconfined aquifer, which is recharged by both rain and river. However, because of high iron content and low $\mathrm{pH}$ value, the water quality is poor. Further it is easily polluted by effluent and storm water discharge (Begg, \& Johnston, 2000, 46).

In Wellington City limited groundwater can be extracted from areas of low grade greywacke at the depth of about $150 \mathrm{~m}$. The quality of groundwater is generally good in this area except those in volcanic and schist zones where sulphide minerals reduce the water quality (Begg, \& Johnston, $2000,45)$. Groundwater in other areas in the western section especially in alluvium valleys including Upper Hutt, Whitemans Valley, Judgeford, Tawa, Porirua is limited. They provide small quantities of groundwater, which is used for various purposes (Begg, \& Mazengarb, 1996, 90). It is difficult to extract groundwater from Late Cretaceous and Cenozoic rocks that have few planes of weakness in this part of the region (Begg, \& Johnston, 2000, 45).

The Wairarapa Valley floor provides the most extensive area having groundwater potential in the region. It is an unconfined aquifer, which is recharged by the rivers from the Tararua Range and the rain. Besides, the areas of limestone, coquina along with coarse and few shelly sandstones of Miocene and Pliocene age have groundwater potential (Lee \& Begg, 2002, 45 \& Begg, \& Johnston, 2000, 45). At other places, the late Pleistocene-Holocene sediments are mostly finegrained and have low permeability (Begg, \& Johnston, 2000, 46). The groundwater yield in Wairarapa varies with the thickness of gravels along with folding of gravel bed. The yield in the area varies from $1500 \mathrm{~m}^{3} /$ day in Te Ore Ore in Masterton to a few cubic metres per day in Holocene beach sands and thin alluvial deposits at shallow depth (Moore et al, 1992 as cited in Lee \& Begg, 2002, 45).

Groundwater is an important source of water supply for domestic, industrial and agricultural purposes in the region. Wellington City depends on groundwater for 25 percent of its total water supply, which it gets from the Lower Hutt Basin (Begg, \& Mazengarb, 1996, 90). Other districts including Lower Hutt, Upper Hutt and Porirua also use groundwater for many purposes. In Waikanae, the Kapiti Coast District Council uses groundwater as a backup to its surface water supply taken from the Waikanae River (McAlister, 2007, 1). Similarly, the primary supply of water in Carterton and Greytown comes from surface water but groundwater is also used for various purposes. In Wairarapa and other eastern districts, groundwater is often used for irrigation and other farm activities. The demand for groundwater is, however, increasing with time. The demand for groundwater in Wairarapa for irrigation has increased significantly from 200,000 $\mathrm{m}^{3} /$ day in 1996 to $400,000 \mathrm{~m}^{3} /$ day in 2005. This has led to a fluctuation in groundwater level (McAlister, 2007, 9). In the year 2006-07, the Wairarapa aquifers in general showed the largest variations in water levels due to extreme weather and high withdrawal of groundwater (McAlister, 2007, 9). The eastern districts are particularly susceptible to drought. In such a situation, fluctuating groundwater could 
be critical and hazardous for the community. The problem could be further aggravated by the degrading water quality, which would restrict its use for the various domestic and farming practices. The unconfined shallow depth aquifers such as the Wairarapa Basin could get easily contaminated by effluent disposal, sea water intrusions, farming and horticulture inputs including nitrates and phosphates (Lee \& Begg, 2002, 45; McAlister, 2007, 12), which in some cases could constitute health hazards. Availability and purity of groundwater and natural drainage is also influenced by the vegetation and forest cover in the area.

\subsection{Vegetation}

Just one and a half centuries ago Wellington was described by early settlers as a rough country covered with dense forests, bushes and lush green vegetation (McConchie, 2000a, 10). But, at present a major part of the region has been cleared of native vegetation in order to make use of land for different purposes. New plants and vegetation have been introduced to suit the needs of the wider population. The current vegetation and forests therefore, can be broadly classified as indigenous or native and human induced or cultural vegetation.

Map: 3.16. Forests and Vegetation in the Wellington Region

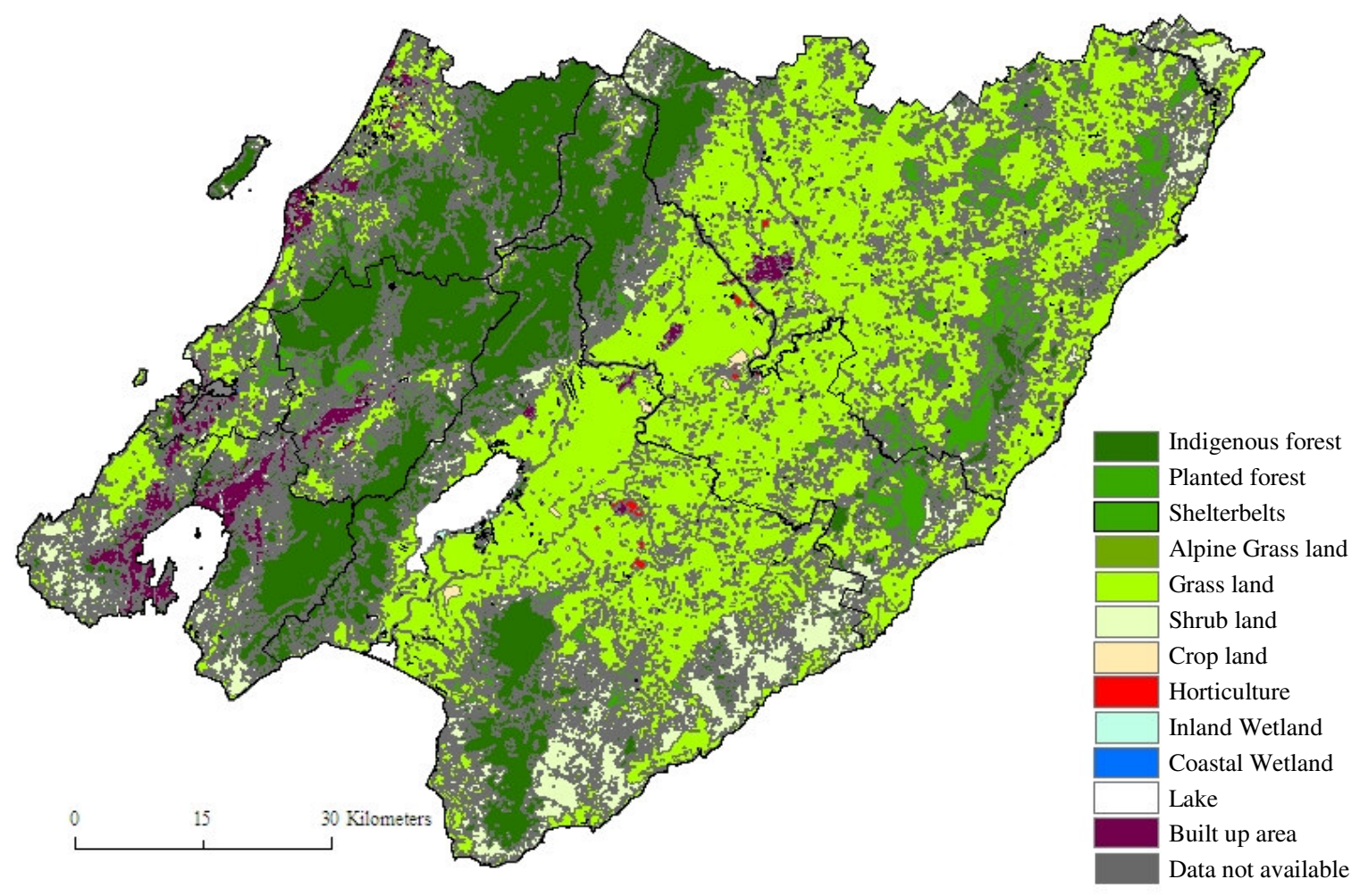

Based on data from Wellington Regional Council, 2007

The indigenous or native vegetation can be categorised under forests, grassland, shrub land, inland wetlands and coastal wetlands (Forme Consulting Group Ltd [FCGL], 1998, 4-5). The native forest types identified by Forest Service Map include Silver Beech, Beech/Kamahi, 
Rimu/Beech/Kamahi, Rimu/Kamahi, Beech Kamahi with Hard or Black Beech in the Tararua Range forests and Podocarp Hardwood, Podocarp Hardwood Beech, Beech, Hardwood and Unidentified bush in Rimutaka Range and Haurangi Range forests (FCGL, 1998, 4-5). The spatial spread of these forests is largely restricted to the high altitude areas of the region, where they are either inaccessible or their use is uneconomical (Map: 3.16).

The natural grassland includes the species such as Alpine Tussock, non pastoral or unenclosed grassland. It is largely restricted to either the high altitudes of Tararua Range or in areas of rough grass basically Tussocks near the east coast in Carterton, which because of small spatial extent are not visible on the map. Natural shrub lands, on the other hand, are more widespread. Shrubs are woody plants of less than $10 \mathrm{~cm}$ in diametre at breast height, and shrub land basically represents those areas with more than twenty percent of woody vegetation including shrub and tree canopy (FCGL, 1998, 4). The main species of shrub land in the region include Manuka, Kanuka, Gorse, Broom, shrub hardwood, and sub-alpine type including Leatherwood and Dracophylum (FCGL, 1998, 4). While sub-alpine shrub land in the region surrounds the alpine grassland of the Tararua Range. Others are mainly concentrated in the Eastern Hills of South Wairarapa, Carterton and Masterton, southern hills of Rimutaka and Orongorongo Range and in south and western hills of Wellington. The inland wetland and coastal wetlands are other native vegetation types of the region. The inland wetlands i.e. the areas inundated by fresh water are dominated by species such as Flax, Willows and Rushes (FCGL, 1998, 5). These are mainly located in South Wairarapa in the area adjoining Lake Wairarapa and Lake Pounui along with the Kapiti Coast, coastal Masterton, Porirua and near the Wainuiomata River in Lower Hutt. Coastal wetlands on the other hand are the areas inundated by saline water and their main species include Succulents and Rushes (FCGL, 1998, 5). They are mainly located in Porirua and at the southeast coast of Lower Hutt.

The human induced or cultural vegetation, on the other hand, include plantation forests, shelterbelts, grassland or pastoral, cropland and horticulture. The plantation forests are those areas which have been planted for commercial use or recently afforested. The vegetation in these forests includes Pinus radiata and Pseudotsuga menziesii. These are specifically the areas of high weed growth and include open and closed Pine canopy along with logged stands (FCGL, 1998, 4). These forests are mainly located on the outer edge of indigenous forests in the Tararua Range and in the Eastern Hills especially in Carterton and Masterton. However, the small patches of plantation forests could be seen in all districts. Shelterbelts, on the other hand, are not forests as such but they do include tree plantation. They mainly involve small patches of land, and are widespread in South Wairarapa, Carterton, Masterton, the Kapiti Coast, Porirua and Upper Hutt.

Grasslands outside the Tararua Range are mainly used for pastoral activities. An extensive area is covered under these grasslands, especially in Masterton, Carterton, South Wairarapa, the Kapiti Coast, Porirua and Wellington, besides small patches in Lower Hutt and Upper Hutt. Other categories of human induced vegetation are cropland and horticulture, which mainly involves orchards and vineyards. Carterton has maximum area under cropland followed by South Wairarapa, the Kapiti Coast and Masterton, while the horticulture activities are more widespread in South Wairarapa followed by Carterton, the Kapiti Coast and Masterton. 
Table: 3.2. Flammability of Vegetation Types by LCDB Classification in the Wellington Region

\begin{tabular}{lll}
\hline Flammability & Vegetation type & Vegetation sub type \\
& & \\
\hline Extreme & Shrub land & Gorse, Manuka, Dracophylum \\
Very High & Grass land & Non-pastoral \\
& Inland Wetland & - \\
& Shrub land & Medium flammability subclass, broom, mix of shrub hardwood/ Gorse \\
& & and Manuka \\
High & Planted forest & - \\
& Shelter belts & - \\
& Coastal Wetlands & - \\
Medium & Scrub land & Low flammability subclass, indigenous shrub and Manuka \\
Low & Indigenous forest & - \\
& Primarily pastoral & - \\
Source: Forme Consulting Group Ltd, 1998, 10 & Primarily horticulture & -
\end{tabular}

Both natural and human induced vegetation have a significant impact on hazard susceptibility especially slope instability, wildfire and drought. They also act as a mitigating factor for flooding and tsunami inundation. Clearing of vegetation and change in its type have had a significant impact on slope stability of the region. Both Maori and European colonisation have contributed to this change. However, while the changes led by the Maori population had a significant impact on vegetation type, their impact was insignificant in terms of slope instability (Glade, 1997, 61) if compared to those led by European colonisation. At Wellington harbour the average rate of sedimentation was increased from $2.1 \mathrm{~mm} /$ year during the Polynesian period to $38.2 \mathrm{~mm} /$ year in the European period (Glade, 1997, 61). This was the result of enhanced erosion due to extensive deforestation and conversion of forests for pasture or other land uses including road, rail or built up areas. In 1991 the forest area had shrunk to 6.2Mha (Poole \& Adams, 1994 as cited in Glade, 1997, 61) from 16.2Mha in pre-European time period (Newsome, 1987 as cited in Glade, 1997, 61). Thomas Glade (1997) in his study of the spatio-temporal occurrence of rainstorm-triggered landslides compared influence of vegetation type on landslide characteristics. The study shows that land use such as forest land, shrub land and grasslands have differential impact on landslide susceptibility. While the forest areas are less susceptible to landslide, the volume eroded during occasional landslides tends to be higher if compared to pasture and shrub land. On the other hand the area under pasture land tends to experience frequent landslides compared to forest and shrub land. Both frequency and volume of soil erosion tends to be less in shrub land due to less human disturbance. However, the landslide density tends to be least in forested areas if assessed over time (Glade, 1997, 93). It can be concluded here that by removing the forest areas from the region, a large part of area is now susceptible to landslides or slope failures as the removal of trees eventually meant decayed roots, which mechanically strengthen the slope and assist in pumping out the soil water to keep the antecedent soil water level low (Crozier, 1990, 7). Forest clearance also had an impact on the runoff rate. Since trees have been removed from the catchment areas, enhanced rate of water flow has been observed from the catchments (Crozier, 1990, 7), which certainly raises the susceptibility to flood and drought simultaneously. 
Another hazard closely related with the vegetation type is wildfire. Even though the initial ignition involves the support of other factors such as slope, temperature, lightning, rainfall or human factors, the vegetation type could govern the nature and intensity of fire. Different vegetation types including forest, grassland, shrub land, pasture and horticulture offer a range of flammability. According to the Land Cover Database [LCDB] classes, the shrub lands have high to extreme flammability, followed by non-pastoral grassland and inland wetlands with very high flammability. Planted forest, shelter belts and coastal wetlands are more susceptible to flames than indigenous forest, while grassland used primarily for pastoral activities along with horticulture including vineyards and orchards have the lowest flammability characteristics (Table: 3.2).

A study of wildfire in the region shows that about 84,000ha (i.e. approximately ten percent of the region) is at high or extreme risk from wildfire (Wellington Regional Council [WRC], 1998b, 27). However, another study puts about 20 percent of the area in the region, which is about 165,5000 ha at extreme risk to wildfire, which includes all areas characterised by gorse and shrub land, vegetation, steep slopes, low rainfall and proximity to people (Grant, 2005b, 53). The areas, which are most at risk, include southern and western edges of Wellington, the eastern Hutt Hills, areas around

Wainuiomata and Eastbourne, eastern foothills of the Rimutaka and the Tararua Ranges, the Cape Palliser coast and parts of the coastal Eastern Hills in three Wairarapa districts (Grant, 2005b, 53). The wildfire or bushfire susceptibility map of the region (Map: 3.17) adds a few other areas to the list Map: 3.17. Bushfire Susceptibility of the Wellington Region

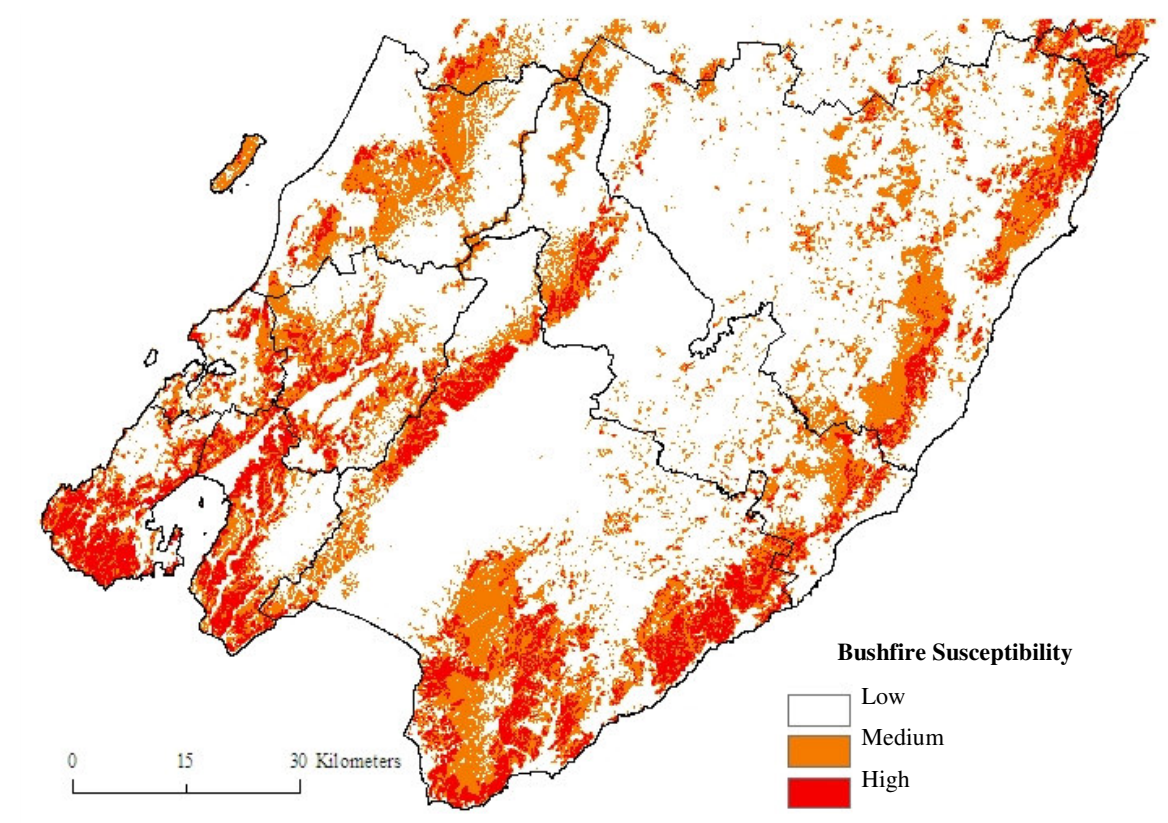
including a significant

Source: Wellington Regional Council, 2007. area in Wellington City, eastern and western Hutt Hills and Aorangi Range. Bushfire in urban areas or their periphery could be more disastrous than rural areas because of large number of people and infrastructure at risk. The presence and growth of vegetation, however to an extent is governed by the soil type. 


\subsection{Soils}

Soils of the Wellington Region are relatively young due to steep slopes and the interrupted processes of soil formation during the glacial and periglacial age. Most of the soils are less than 1000 years old, and very few soils have been aged more than 20,000 years (Glade, 1997, 54-55). Though there are quite a wide range of soils in the region, on a broad scale they can be categorised into nine soil types. These include Brown, Melanic, Allophanic, Recent, Raw, Gley, Organic, Ultic and Pallic. These soils possess differential characteristics (Table: 3.3) and share a close relationship with hazards such as landslide, erosion, liquefaction and drought.

Table: 3.3. Soil Characteristics in the Wellington Region

\begin{tabular}{lccccccc}
\hline Soil type & \multicolumn{7}{c}{ Soil Characteristics } \\
\cline { 2 - 7 } & Permeability & Drainage & $\begin{array}{c}\text { Root } \\
\text { depth }\end{array}$ & Fertility & $\begin{array}{c}\text { Shrink \& } \\
\text { swell }\end{array}$ & $\begin{array}{c}\text { Stability/ } \\
\text { strength }\end{array}$ & Erosion \\
\hline Brown & Moderate & Good & Deep & High & - & $\begin{array}{c}\text { Relatively } \\
\text { stable }\end{array}$ & - \\
Pallic & Slow & Poor to Moderate & Limited & - & - & Low & High \\
Gley & Slow & Poor & Limited & - & - & - & Minimum \\
Ultic & Slow & Poor & Limited & Low & High & Low & Susceptible \\
Melanic & - & - & Deep & High & High & High & - \\
Recent & - & Good & Deep & High & - & - & Susceptible \\
Organic & - & Poor & - & Low & High & Low & - \\
Raw & - & - & - & Low & - & - & High \\
Allophonic & High & Well, moderate, & Very Deep & Limited & High & Weak/Sensitive & Low \\
& \multicolumn{1}{c}{ imperfect } & & & & to disturbance &
\end{tabular}

Brown soil is the most extensive soil type in the Wellington Region. It is formed of sedimentary rocks including greywacke, argillite, schist, sandstone, siltstone or igneous rock such as granite or gneiss, which are rich in silica and non-calcareous material (Molloy, 1988, 137). It generally develops in the moist climate with little or no summer dryness. It is found in all higher areas of the region including the Tararua, Rimutaka and Orongorongo Ranges and the Western Hills along with a wide area in the Eastern Hills of South Wairarapa, Carterton and Masterton (Map: 3.18). Under the New Zealand Soil Classification, Brown soil has six sub-groups including acid, firm, allophonic, mafic, oxidic and sand, and twenty subgroups in the region. The soil provides rich base for vegetation with moderate micro porosity, good drainage and high biological activity, where roots can grow deep (Hewitt, 1998, 51-52). This leads to reduced susceptibility to landslides and erosion, but against the background of dominant rainfall, seismic and human activities, the strength of the soil is rendered ineffective.

The second most dominant soil of the region is Pallic soil. It is located on the gentle slopes mainly in the Eastern Hills, but is also found in the Kapiti Coast, Porirua and Lower Hutt along with Wellington and Upper Hutt, where it is found in minor quantities. This soil is largely derived from the loess or sediments from quartzo-feldspathic rocks (schist or greywacke) (Hewitt, 1998, 90). Its high slaking potential along with slow permeability, perched water table and limited biological activity in terms of root depth (Hewitt, 1998, 89-90), makes it susceptible to frequent water scarcity and erosion. 
Map: 3.18. Soils of the Wellington Region

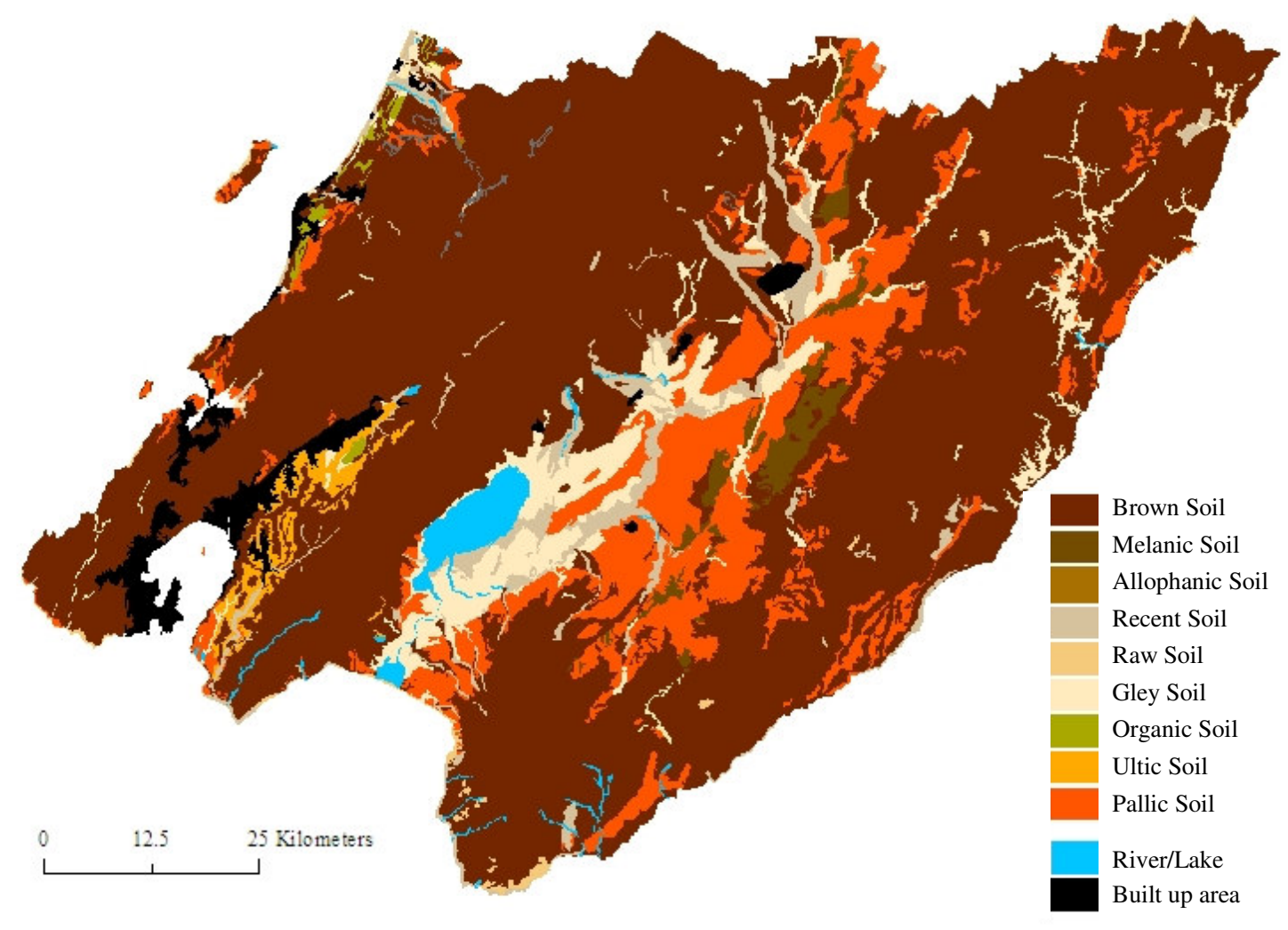

Based on digital data from Landcare Research, Manaaki Whenua \& Hewitt, 1998

Gley soil, the third dominant soil type of the region, is commonly formed in alluvial or colluvial parent materials, where there is either high groundwater or seepage of water. It is therefore, mainly located in the low lying areas of Wairarapa and Masterton Basin along with the Kapiti Coast. It contains a wide range of clay minerals and generally has a high groundwater table. It offers shallow potential rooting depth and has relatively high bulk density with limited movement of components (Hewitt, 1998, 62-63). It is either poorly or very poorly drained and therefore for agriculture this soil needs to be artificially drained. Though the soil is less prone to erosion, it is susceptible to liquefaction.

Ultic soil in the region is largely concentrated in the eastern sections of the Hutt Valley. It is Yellow Ultic soil with clayey characteristics as they develop in clayey weathering products of siliceous sediments or acid igneous rocks. It has slow permeability and except for a few cases it is either moderately or imperfectly drained. The soil is strongly weathered and subjected to compaction during the winter season, which leads to livestock treading damage. It has less strength and tends to be dispersible (Hewitt, 1998, 123-124), and hence it is prone to erosion and landslides.

Melanic soil is present in the Eastern Hills of Carterton, South Wairarapa and Masterton. The soil is generally known for its well developed structure, very dark A horizon and relatively high resistance to structural damage under heavy cropping unless organic matter is reduced significantly. However, it is subject to high shrink and swell, which may result in erosion. The soil material is sticky and plastic and fertility is higher with deep rooting - except for shallow soil on rock or soil affected by high water table (Hewitt, 1998, 74-75). 
Recent soil, as the name suggests, are located in the areas of newly formed soil or young landscape of fluvial or aeolian or on steep slopes, and accordingly they are named as Fluvial, Sandy and Orthic Recent soil respectively (Hewitt, 1998, 114-116). Fluvial Recent soil occur in sediments deposited by flowing water, mainly in the flooding areas, and hence it is largely concentrated along the dominant streams in the Wairarapa Basin, Wainuiomata River in Lower Hutt, Otaki and Waikanae River in the Kapiti Coast along with other small streams across the region. Sandy recent soil are found in areas of aeolian and alluvial sand deposits and it is mainly found in the areas attached with the Fluvial Recent soil in Wairarapa Basin and the Kapiti Coast. Orthic Recent soil, which occur on eroded land or where sediments have been deposited by slope processes, are restricted in the southern and eastern parts of the Eastern Hills in South Wairarapa, Carterton and Masterton. Recent soil are generally characterised by weak soil development with fresh to moderately weathered gravels. They generally have good drainage with high potential for deep rooting and fertility. However, they are susceptible to erosion, sedimentation (Hewitt, 1998, 111112) and liquefaction.

The organic soil found in the region is Humic Organic soil, which forms in very wet sites or in sites which are artificially drained. The peat material of Humic Organic soil is hard to identify due to their extreme decomposition (Hewitt, 1998, 84). This soil is mainly found in the Kapiti Coast and Upper Hutt. Mineral soil material is commonly present but organic soil material is dominant. The soil is also characterised by less bulk density and low bearing strength, which requires special design of foundation for building construction. The soil also has high shrinkage potential, which makes it susceptible to erosion. The high total available water capacity and deficiency in common nutrients such as nitrogen, phosphorous, sulphur and the trace elements copper, selenium and molybdenium makes it unsuitable for crops and pasture. It is also known for poor drainage (Hewitt, 1998, 80-81).

Raw soil is generally found in the areas where the formation of topsoil is restricted due to rockiness or active erosion or deposition (Hewitt, 1998, 106). It lacks distinct topsoil development or fluid at a shallow depth. It contains fresh and weakly weathered material and thus shows the inherited mineralogy. It is characterised by low fertility and thus has sparse vegetation and is susceptible to active erosion (Hewitt, 1998, 106-107).

In a small area in the northern part of the Kapiti Coast, Orthic Allophanic soil is found. It is a permeable soil without any barrier to deep penetration of roots, but generally has low fertility. The drainage varies from well to moderate or imperfect drainage. It is characterised by low erosion but has high shrinkage potential. It is sensitive to external disturbance and can lose strength (Hewitt, 1998, 41-42), and therefore, it is highly susceptible to liquefaction.

The details of soil type are not available for built up areas of the region. In the built up areas, the role of soil as a triggering factor to hazards is restricted mainly to landslides and erosion. In the rural districts of Wairarapa, the role of soil for hazards such as drought is more important, where it could enhance the effect of water scarcity. 


\subsection{Connectivity of the System and Susceptibility to Hazards}

The susceptibility to hazards is clearly not governed by a single factor or process. It is rather linked with the combinations of factors discussed above, which are the product of local, regional, global and universal biophysical processes, which together modify, build and rebuild the local susceptibility. The connectivity of various processes thus introduces various complexities and intricacies in the local susceptibility to hazards (Fig: 3.3).

Fig: 3.3. Connectivity of Various Processes and Hazards Susceptibility in the Wellington Region

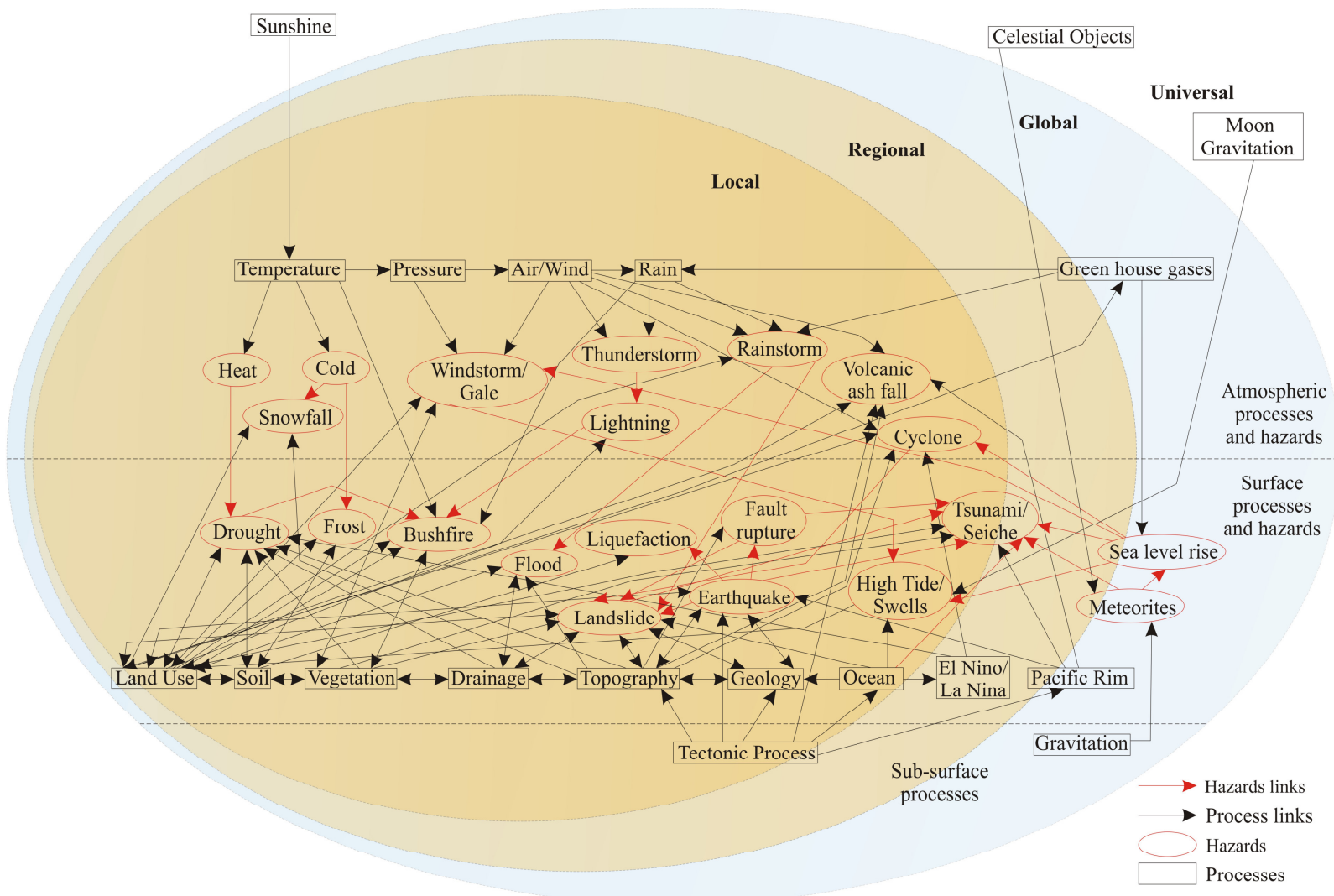

Though earthquakes are produced by the tectonic processes operating underneath the region, their impact is amplified by the surface features such as fault alignments, geological characteristics including bedrock and earth material along with location and land use, which often results in other associated hazards such as fault rupture, liquefaction, landslide and tsunami. Tectonic processes are also responsible for the volcanic activity. However, due to the southward location of the region, it only receives ash fall and minor tephra, which get further modified by the wind direction and wind speed. Likewise the extent of tsunami inundation is not only governed by mere location of a place on a coastal front but also by the denudation processes that ensure low elevation flat land and geological processes that dictate the location of the fault lines along with vegetation cover, which is ultimately linked to the climate, soil and land use.

Similarly, the susceptibility to landslides is determined by the uplift and seismic activities through tectonic processes, slope and contour formation through geomorphic processes, rainfall, surface and groundwater through hydrological processes along with vegetation and soil through biological processes. 
Plate: 3.1. Varied Landslide Susceptibility of the Wellington Region

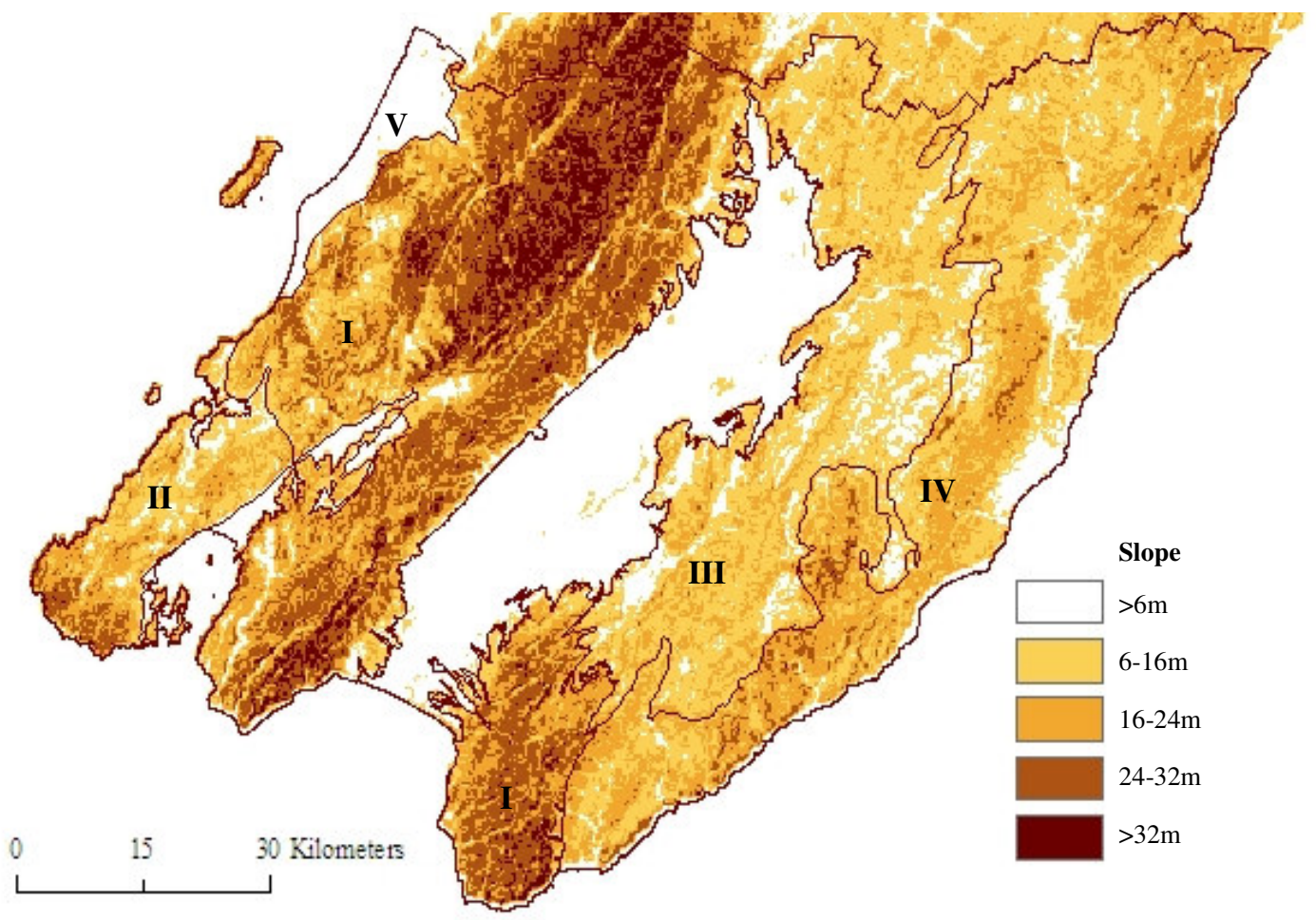

\begin{tabular}{|c|c|c|c|}
\hline Zone & Topography & Rock & Climate \\
\hline I & Steep slope & $\begin{array}{l}\text { Greywacke/ } \\
\text { Sandstone }\end{array}$ & $\begin{array}{l}\text { Heavy } \\
\text { rain }\end{array}$ \\
\hline II & $\begin{array}{l}\text { K-surfaces, } \\
\text { moderate } \\
\text { slope }\end{array}$ & $\begin{array}{l}\text { Greywacke/ } \\
\text { Sandstone }\end{array}$ & $\begin{array}{l}\text { Moderate } \\
\text { rain }\end{array}$ \\
\hline III & Gentle slope, & $\begin{array}{l}\text { Mudstone, } \\
\text { Coquina, } \\
\text { Loess }\end{array}$ & Dry area \\
\hline IV & $\begin{array}{l}\text { Moderate } \\
\text { slope }\end{array}$ & $\begin{array}{l}\text { Greywacke, } \\
\text { Mudstone }\end{array}$ & $\begin{array}{l}\text { Moderate } \\
\text { rain }\end{array}$ \\
\hline
\end{tabular}

Type of Landslide and Erosion

Dominant: Rock fall/avalanche, debris fall/

avalanche, scree erosion, sheet erosion.

Slight: Soil slip erosion, gully erosion

Dominant: Debris slide/flow, rock fall/slide, scree erosion, sheet erosion, soil slip erosion.

Slight: Gully erosion

Dominant: Deep earth slip, earth flow (shallow), tunnel gully erosion, soil slip erosion.

Slight: Gully erosion

Dominant: Scree erosion, deep seated earth flow, shallow earth slips, sheet erosion, soil slip erosion, gully erosion, slump erosion.

Slight: Wind erosion

V Gentle slope Sand dunes Dry area Dominant: Wind erosion, coastal erosion

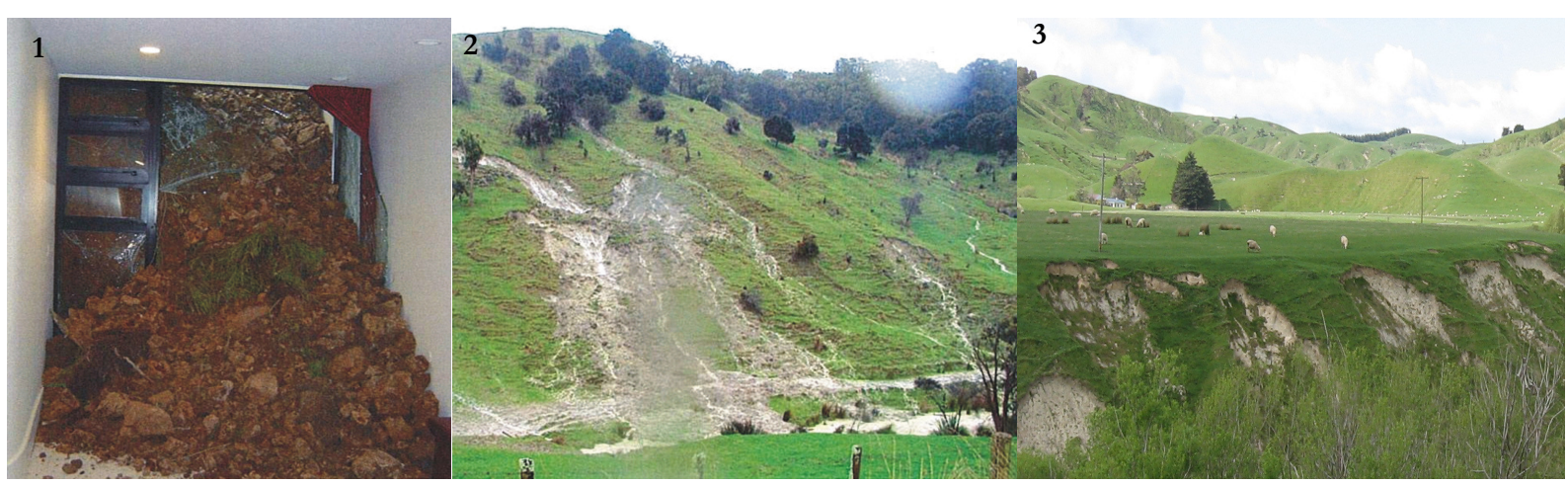

1. Debris flow in Oriental Bay, August, 2006

2. Shallow regolith soil slide/flow in Wainuioru, Masterton, July, 2006.

3. Earth flow in Masterton, 2007.

Based on Crozier, 1990, 8; Eyles, 1983, 15-17; Begg \& Mazengarb, 1996, 96; digital data from Wellington Regional Council, 2007; Hancox, et al, 2007, 7, 28 and Field Survey, 2007 
The varied combination of these biophysical processes not only determines the basic susceptibility to landslides but also produces variations in the nature of landslides and erosion (Plate: 3.1). Plate: 1 shows that even though a wider area in the region is susceptible to landslides (i.e. area with more than $6 \mathrm{~m}$ of slopes), due to variations in the local physical characteristics, the nature of hazard differs across the region. While the higher areas in the region (Zone-I) are susceptible to rock fall/avalanche, debris fall/avalanche and scree erosion, the $\mathrm{K}$ surfaces in the Western Hills (Zone-II) are susceptible to debris slide/flow, rock slide/fall along with scree erosion, sheet erosion and soil slip erosion. While the hazard is less in Zone-I due to absence of human habitation, it is significant in the later due to the densely built Western Hills. Zone-III is the area of gentle slope which is susceptible to deep earth slips and shallow flows, while the Eastern Hills in Zone-IV is susceptible to deep seated creeping earth flow and shallow earth slips. Though slips and erosion in these two zones produce less damage to housing and other infrastructure, they cause extensive damage to pasture farming. The photographs in plate-1 also portray the nature of hazards across the region. The sand dunes of the Kapiti Coast in Zone- $\mathrm{V}$, in spite of having a low relief suffer from wind and coastal erosion owing to their location, loose composition and strong winds.

Meteorological processes also generate a range of hazards in the region including frost, snowfall, windstorm, gale, lightening, thunder, heavy rain and bushfire. The hazards related to temperature e.g. snowfall, frost and heat are often modified by the local land use and vegetation along with topography. Similar is the case for hazards associated with winds. The intensity of windstorm is not only linked with the local meteorological conditions such as temperature and pressure but also with the local topography such as slope, which forces the winds to move up and the location on the windward or leeward side of a hill. As a result the intensity of windstorm is particularly high in the windward exposed areas such as Kelburn and Wellington Airport in Wellington City, Baring Head in Lower Hutt and Castlepoint in Masterton. However, to an extent, the speed of the wind is modified by the natural vegetation or human induced shelterbelts, but its impact largely depends on the subsequent land use. Similarly, bushfire depends on the vegetation type and hence soil and climate along with the meteorological conditions such as temperature and lightning, besides topography and land use. The very high areas of the region are, however, not susceptible to bushfire because of high rainfall (Map: 3.19).

Hydrological hazards such as flood and droughts are again modified by meteorological, tectonic and geomorphologic processes along with human land use. Floods in the region are often generated by the frequent and heavy rainfall through rainstorms from oceanic neighbourhood, which is supported by the hilly terrain that allows faster flow of water and gets further prompted by the shallow human induced drainage system, which has been created after blocking the natural drainage in order to reclaim land for urban uses. This is particularly the case in Wellington City. 
Map: 3.19. Hazard Susceptibility of the Wellington Region
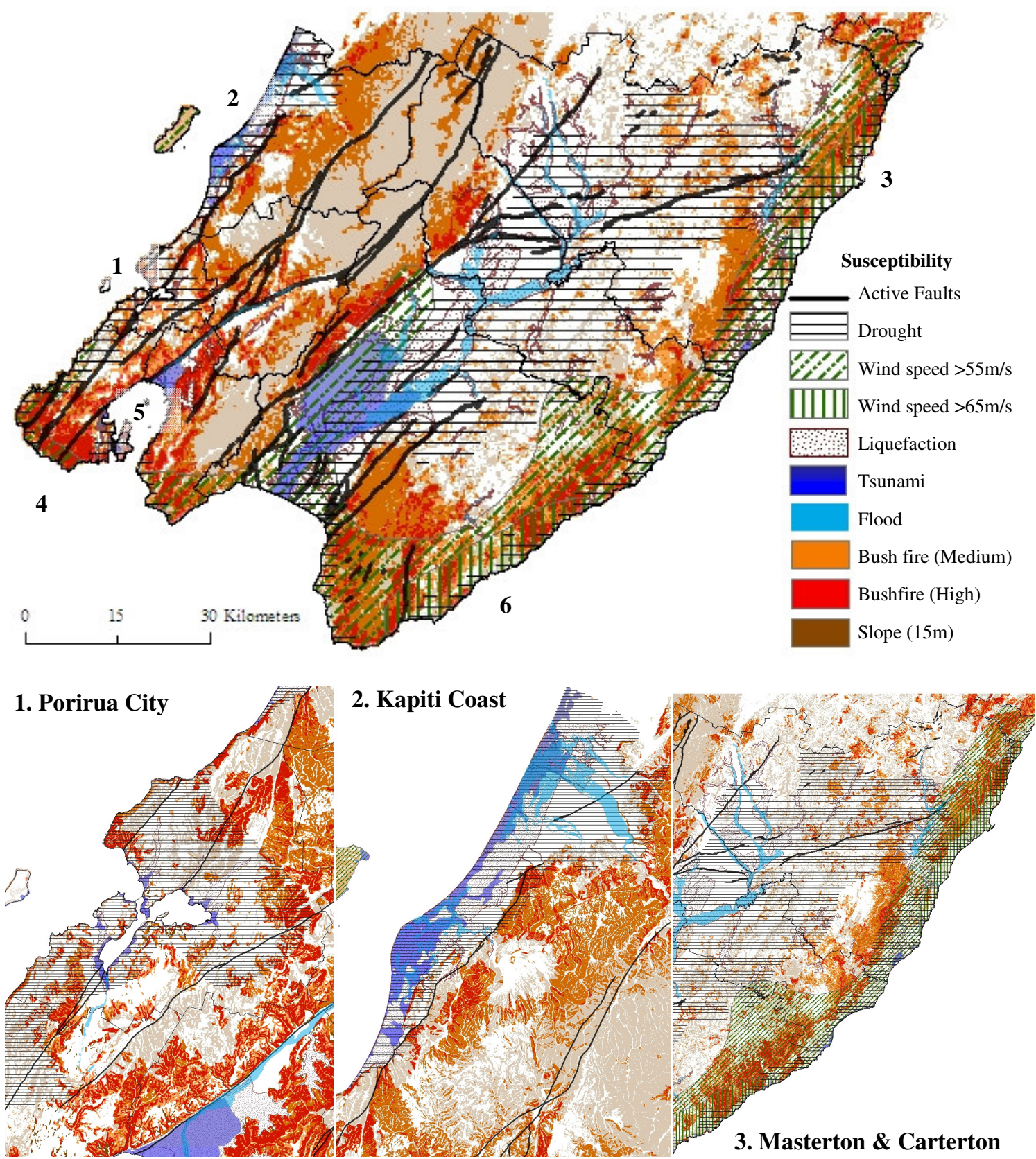

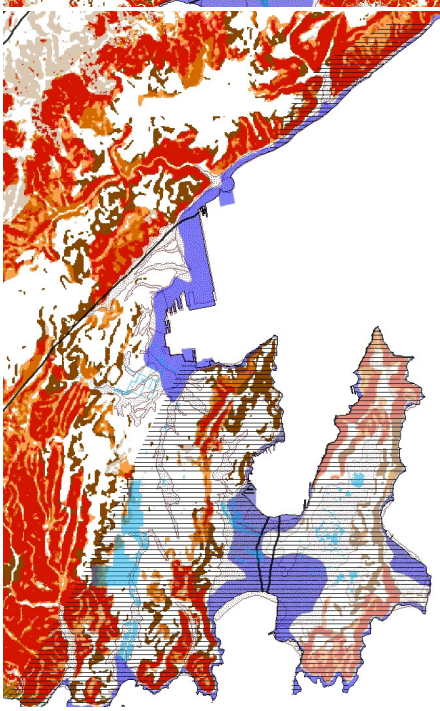

4. Wellington City

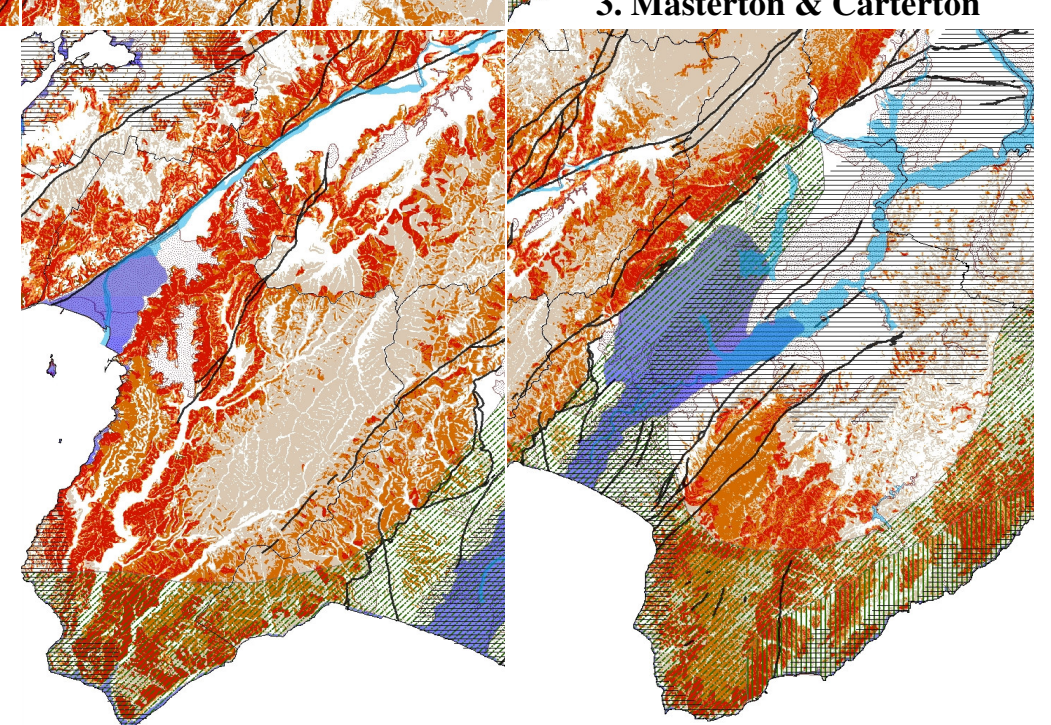

5. Lower Hutt \& Upper Hutt 6. South Wairarapa

Based on digital data from Wellington Regional Council, WELA, CLIFLO, GNS, 2007 
Drought on the other hand is more widespread in the rural districts of Wairarapa, besides the Kapiti Coast and some areas in Porirua and western Wellington. The hazard is primarily contributed to by the rainfall distribution, but gets strengthened by the other meteorological features including temperature and sunshine hours along with vegetation type, soil and land use.

Various regional, global and universal processes also play an active role in the local hazards. The regional processes that frequently affect the region is the higher seismic activity of the Pacific Rim that often shake the region and bring tsunami along with meteorological hazards such as extra tropical cyclones from the tropical Pacific Ocean. The El Niño and La Niña events in Southern Oceanic Oscillations in the Pacific further enhance the possibility of drought and extra-tropical cyclones in the region that get modified by the local meteorological conditions, which eventually regulate the path of cyclones or spatial extent of drought in the region along with local topography and vegetation cover. The global rise of green house gases in the atmosphere is linked with sea level rise and increase in the frequency of many meteorological and hydrological hazards in the region. The universal events that create the susceptibility to hazards linked with high tides from gravitational pull of moon, meteorites as well as hazards linked with temperature from sun.

Connectivity, however, is not only apparent in the process of hazard creation but also among the various hazards. For example, earthquakes are often associated with fault rupture, liquefaction, landslides, fire and tsunami; cyclone with heavy rain, flood and landslide; lightning with bushfire; windstorms with sea swell and so on (Fig: 3.3). The connectivity of the system therefore results into the multiple hazard susceptibility at a place. A simple overlay map of various hazard susceptibility of the region (Map: 3.19) shows that most of the built up areas in the region are exposed to a number of hazards. For example, four major cities in the western section of the region including Wellington, Lower Hutt, Upper Hutt and Porirua are exposed to fault rupture, liquefaction, tsunami, flooding and bushfire. A wider area in three rural districts of South Wairarapa, Carterton and Masterton is exposed to drought, bushfire, flooding, liquefaction and landslides. The map also depicts that most hazards are spread across the administrative boundaries, which not only require regional planning but also an active and well planned and coordinated response from Local Territorial Authorities.

The susceptibility of the region to hazards has been modified and enhanced by human land use to a significant extent. The construction of infrastructure such as roads, footpath or subways creates impervious cover, which often results in high runoff and therefore flash floods in the cities. The cuts in the steep slopes result in landslides, which could be often observed in hilly sections of urban areas in the western parts of the region. The relationship between human activities and hazards is also true other way round i.e. human activities and land uses are modified by hazards as well. For example, the construction of Wellington Airport and State Highway-2 could have been only possible after the uplift though 1855 earthquake.

This chapter fulfils the first objective of the thesis and explains the physical susceptibility of Wellington Region as an important component of hazardscape that influence hazard response, and in turn, is shaped by them. However, in spite of higher susceptibility of a place to extreme events, 
the presence of human vulnerability is critical in hazard creation, which is discussed in the following chapter. 
Chapter: 4

Human Vulnerability to Natural Hazards in the Wellington Region

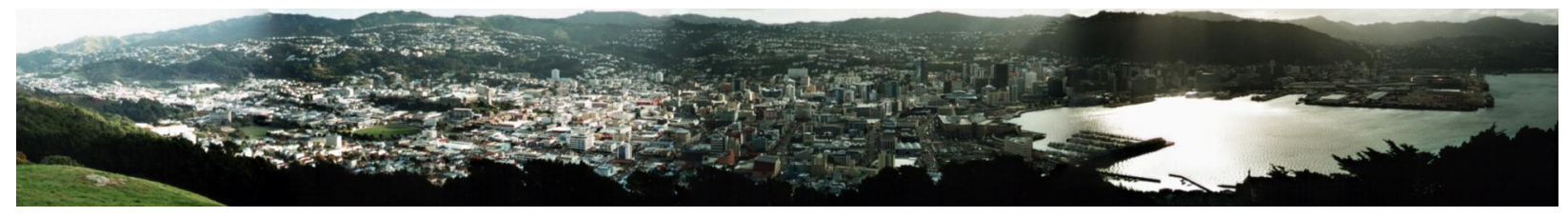


Human vulnerability is an important cause of hazard occurrence. Though everyone is vulnerable to one or another situation, vulnerability to hazards means weakness against any environmental change that could produce a disaster. Environmental change here refers to a sudden change in any environmental process either biophysical or ecumenical that could destabilise order and cause significant damages to a community. Therefore, vulnerability of a community is directly linked to environmental conditions where ecumenical processes (such as demographic, social, cultural, economical or political) build, intensify and modify vulnerability, while biophysical processes place external stress and expose the local vulnerability. Vulnerability of a community can be depicted through various demographic, socio-cultural, economic and political characteristics such as population distribution, growth, urbanisation, household type, ethnicity, income, employment, land use etc. The diverse combinations of these factors produce variations in vulnerability over space and time. This chapter looks into variations in different aspects of vulnerability in the hazardscape of the Wellington Region.

\subsection{Demographic Vulnerability}

No disaster could occur without population, and therefore demographic characteristics of a place i.e. population distribution, structure and change play a critical role in producing vulnerability by affecting exposure, response and coping capacity.

\subsubsection{Population Distribution}

The Wellington Region shares 11 percent of the total population of New Zealand. More than 90 percent of its population live in four cities and one district council located in the western section of the region. About forty percent of the total population live in Wellington and another 22 percent in Lower Hutt. The other three councils in this part including Porirua, the Kapiti Coast and Upper Hutt share ten percent of the total population each (Table: 4.1). Despite being bigger in spatial extent, the three eastern districts contribute less than nine percent of the region's total population. As a result even though a hazard could occur anywhere, disaster vulnerability through exposure is higher in western urban areas compared to the eastern rural belt.

Table: 4.1. Population Distribution in the Wellington Region (2006)

\begin{tabular}{lccc}
\hline Local Territorial Authority & $\begin{array}{c}\text { Total } \\
\text { population }\end{array}$ & $\begin{array}{c}\text { Percent } \\
\text { population }\end{array}$ & $\begin{array}{c}\text { Percent population change } \\
\text { (1996-2006) }\end{array}$ \\
\hline Wellington City & 179,466 & 39.97 & 13.79 \\
Lower Hutt City & 97,701 & 21.76 & 1.9 \\
Porirua City & 48,546 & 10.81 & 4.12 \\
Kapiti Coast District & 46,200 & 10.29 & 19.74 \\
Upper Hutt City & 38,415 & 8.56 & 4.62 \\
Masterton District & 22,626 & 5.04 & -0.57 \\
South Wairarapa District & 8,889 & 1.98 & -0.54 \\
Carterton District & 7,098 & 1.58 & 4.18 \\
Wellington Region & $\mathbf{4 4 8 , 9 5 6}$ & $\mathbf{1 1 . 1 4 *}$ & $\mathbf{5 . 9 1}$ \\
\hline
\end{tabular}

Based on Census 2006, Statistics New Zealand

* Percent population of New Zealand.

Within districts, there are further variations in population distribution depending on the availability of flat land or area under moderate slopes. Local topography has therefore played a key 
Map: 4.1: Population Density in the Wellington Region (2006)

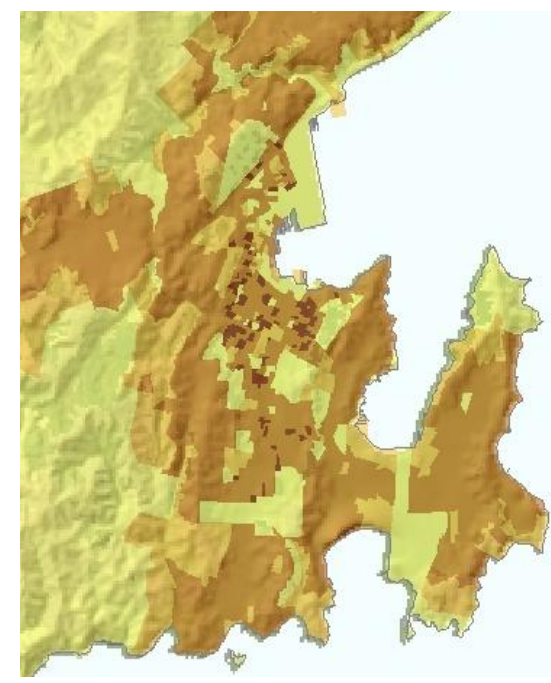

Based on Census 2006, Statistics New Zealand.

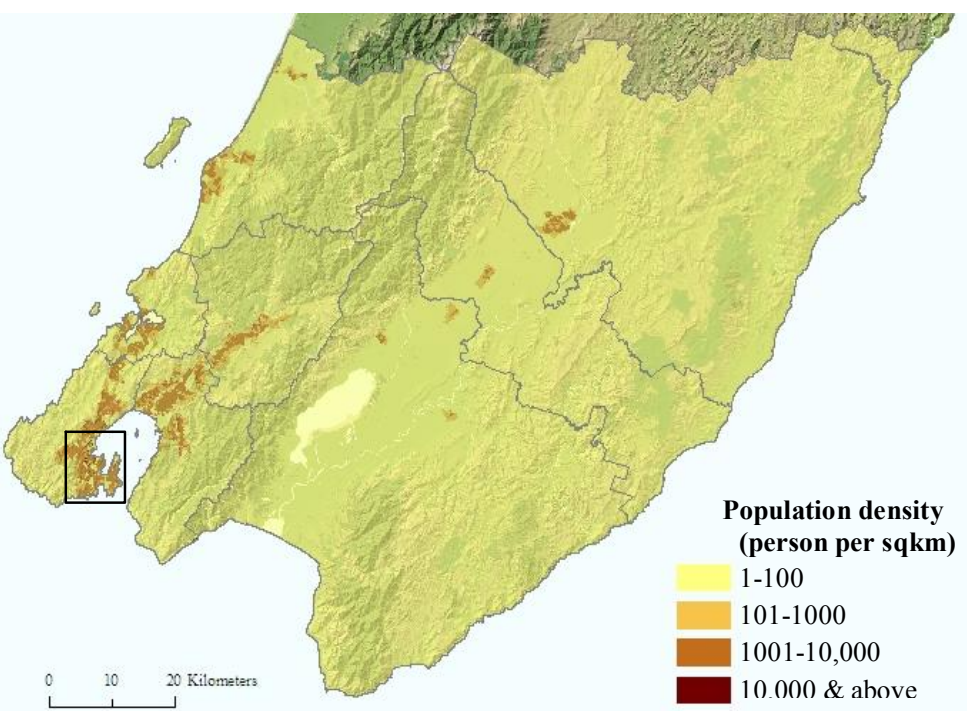
(person per sqkm) $1-100$ $10.000 \&$ above

role in the location of settlements along with associated factors such as presence of a harbour, close proximity to sea or a sea view. Limited available flat areas in the western section are mainly occupied by Central Business Districts [CBDs]. Population density declines significantly as one moves away from city centres (Map: 4.1). Since most of these flat areas have high physical susceptibility to natural hazards, dense population has enhanced the hazard exposure.

Hazard exposure is determined by three critical factors i.e. hazard, nature and characteristics of place and population. While a few hazards affect highly specific zones such as flooding, landslides, fault movement, liquefaction and tsunami, a few others affect relatively wider areas with less spatial specificity i.e. windstorms, drought, rainstorm, lightning or thunderstorm, and the rest have even more widespread impact over space, for example volcanic ash fall or hazards for which it is hard to predict their path such as cyclones or tornadoes. It is easier to plot exposed areas for hazards having specific spatial manifestation than those with widespread impacts. It can be said that areas exposed to location specific hazards are susceptible to a greater number of

Map: 4.2. Population Distribution in Relation to Earthquake Related Hazards (2006)
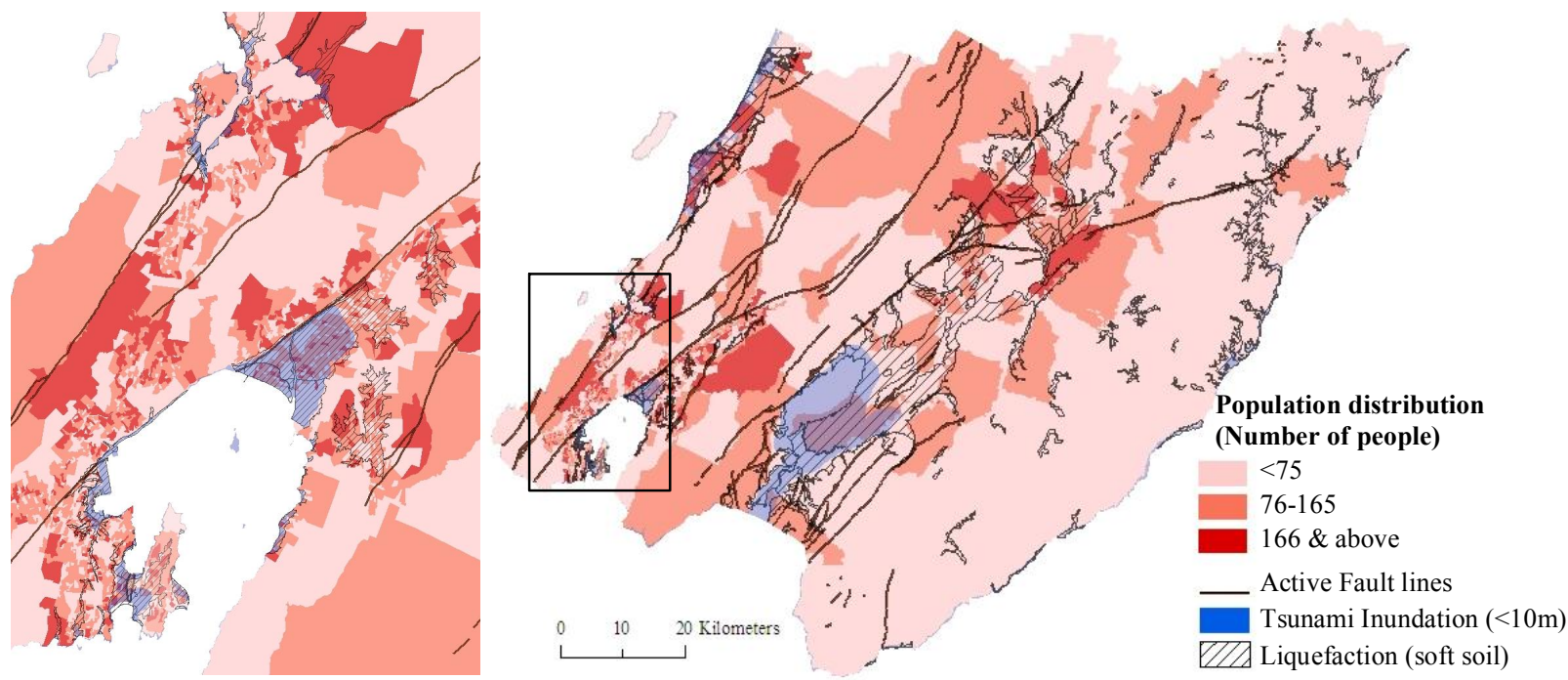

Based on Census 2006, Statistics New Zealand; Wellington Regional Council, Wellington and Masterton. 
hazards compared to those which are subject to non-location specific hazards. This affects vulnerability not only in terms of hazard exposure, but also influences the response and coping capacity of people as they tend to be more negligent to hazards that are not fixed to specific locations. Map: 4.2 shows the exposure of population in the Wellington Region to earthquake related hazards such as fault movement, tsunami and liquefaction, while Map 4.3 depicts exposure to a range of meteorological and hydrological hazards. Both maps reflect that dense population living in urban areas are exposed to most of these hazards, and therefore face greater vulnerability compared to less populated rural areas.

Map: 4.3. Population Distribution in Relation to Flood, Drought and Windstorm (2006)
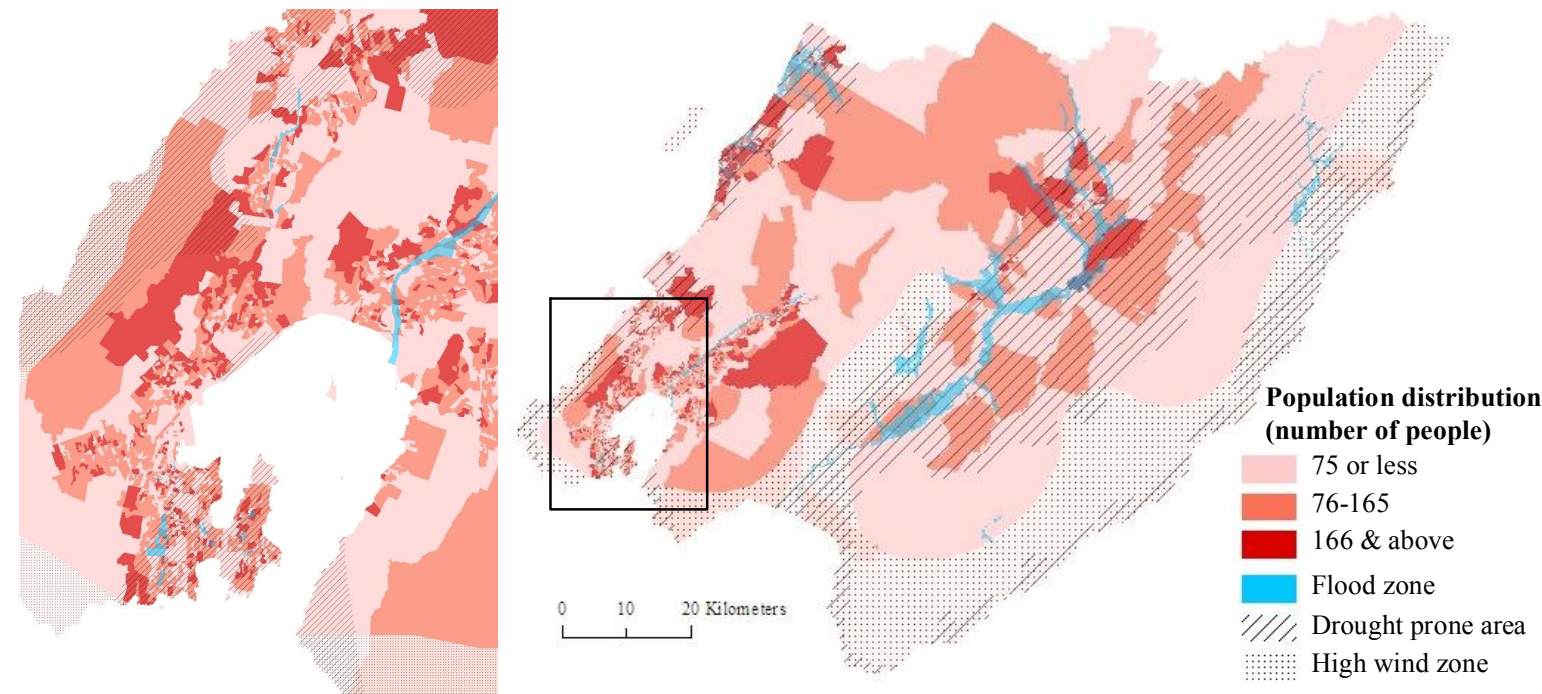

Based on Census 2006, Statistics New Zealand; Wellington Regional Council, Wellington and Masterton.

Hazard exposure changes through time with associated changes in population distribution. The data at district level show that the western section of the region is rapidly growing with highest population growth at the Kapiti Coast (20 percent) followed by Wellington (14 percent). The eastern section, on the other hand, is experiencing negative growth at Masterton ( -0.57 percent) and South Wairarapa (-0.54 percent). Carterton is the only district in the eastern section that has experienced a growth of about four percent during 1996-2006 (Table: 4.1).

Map: 4.4: Population Growth in the Wellington Region (1996-2006)
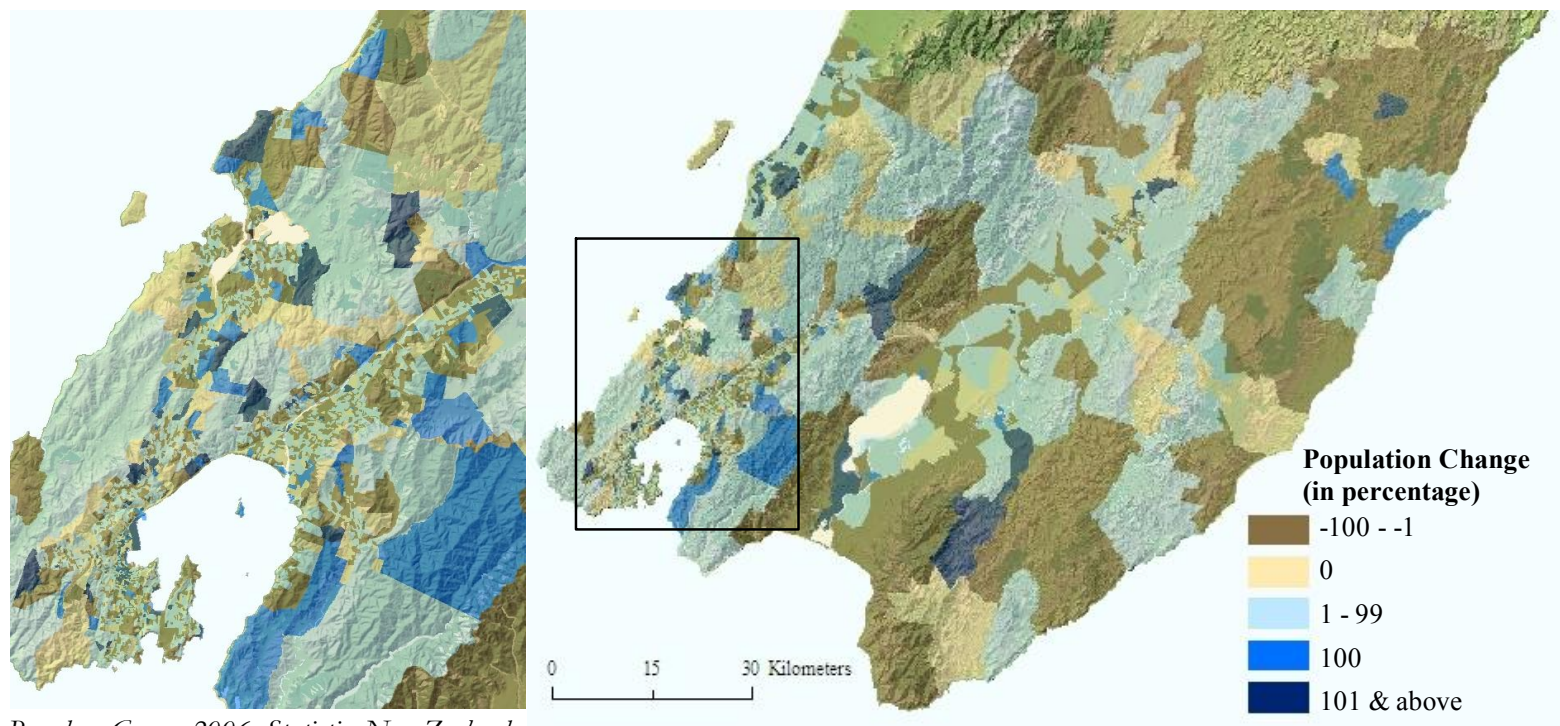

Based on Census 2006, Statistics New Zealand 
A further assessment of population change at mesh block level highlights local changes in spatial distribution of population in the region. While most of the rural areas in the east are experiencing a decline in population, excessive population growth has mainly occurred in newly built sub-urban areas of the western section (Map: 4.4). Significant growth has caused population sprawl in more fragile areas having higher physical susceptibility to hazards such as steep slopes or areas in very close proximity to the sea. It has been also observed that often newly built areas lack the social service networks (Heinz Centre for Science, Economics and the Environment (2000), Morrow (1999) and Puente (1999) as cited in Cutter, et al, 2003, 248), which is partly due to lower population density, and hence low public demand. High physical susceptibility along with insufficient social and service networks produce vulnerability in these newly built areas. If such areas get disconnected they could face severe impacts. The people in these areas tend to be more self-sufficient and could manage isolation at least for a few days. However, if they get injured, rescue could be delayed due to higher demands of services by city dwellers. In Map: 4.4, the areas with hundred percent growth mainly represent entirely new sections that have emerged in the ten years between 1996 and 2006. These areas possess many new households, which are more exposed to hazards firstly because they may not be fully aware of the local environment and secondly because they may have to bear the cost of all damages unless their insurance covers all the hazards.

Areas with even higher growth are mainly the areas which were established before 1996 but experienced momentous growth between 1996 and 2006. Many of these areas are located in hazard susceptible zones. Their growth is favoured by allied benefits in the form of better connectivity and availability of services which exceeded the risk associated with natural hazards. Twenty five mesh blocks throughout the region experienced more than 1000 percent growth of which 18 are located in Wellington city, four in the Kapiti Coast and one in Porirua, Masterton and Lower Hutt each. Highest growth has been experienced by MB2072413 in the Endeavour area of the Northern Ward, Porirua, which experienced a total growth of 9,150 percent (i.e. from 6 to 555 people) during 1996-2006, followed by MB1998406 (6,300 percent) in Maungakotukutuku, Paraparaumu Ward in the Kapiti Coast and MB2085202 (3,200 percent) in Raroa, Onslow-western Ward in Wellington. Excessive growth has mainly occurred in urban areas which intensifies existing vulnerability. Though help is readily available in urban areas administrative, rapid growth puts extra pressure on available resources. This could enhance disaster impact through shortage of services and the resultant chaos and social tension provoked at the time of adversity. The region has not experienced any significant disaster in the recent past, and infrequent individual hazards that have affected individual households or families hardly seem to have any significant influence on population distribution and sprawl over the region. Other demographic characteristics such as age, sex and disability further modify local vulnerability and play a critical role in determining the fragility, coping capacity and resilience of the community.

\subsubsection{Women}

The literature suggests that disaster impacts are often severe on women. They not only suffer because of less physical strength, but their recovery period is also slow due to various socioeconomic and cultural reasons (Blaikie et al (1994), Enarson and Morrow (1998), Morrow and 
Phillips (1999), Fothergill (1996), Peacock, Morrow and Gladwin (1997, 2000), Hewitt (1997), Cutter (1996) as cited in Cutter, Boruff and Shirley, 2003, 246). At national level, a difference has been observed in the physical and socio-economic characteristics between men and women, and women from various ethnic groups. Women in New Zealand are more likely to be less qualified, working part time, engaged in low paid work, especially in sales and services, and therefore earn less than men. The severity of economic vulnerability further tends to be higher in Maori and Pacific women, who are more likely to be unqualified and engaged in elementary occupations (Statistics New Zealand \& Ministry of Women's affair, 1998).

Table: 4.2. Demographic Characteristics Associated with Vulnerability in the Wellington Region (2006)

\begin{tabular}{lcccccc}
\hline $\begin{array}{l}\text { Local Territorial } \\
\text { Authority }\end{array}$ & Female & $\begin{array}{c}\text { Children } \\
(<5 \text { Years) }\end{array}$ & $\begin{array}{c}\text { Old } \\
\mathbf{( > 6 5} \\
\text { Years) }\end{array}$ & $\begin{array}{c}\text { Live on } \\
\text { Sickness } \\
\text { Benefit }\end{array}$ & $\begin{array}{c}\text { Use NZ } \\
\text { Sign } \\
\text { Language }\end{array}$ & $\begin{array}{c}\text { Usual residence } \\
\text { overseas five } \\
\text { years before }\end{array}$ \\
\hline Carterton District & 50.7 & 6.6 & 15.0 & 1.8 & 0.3 & 4.0 \\
Kapiti Coast District & 53.5 & 5.7 & 23.3 & 1.5 & 0.7 & 5.3 \\
Lower Hutt City & 51.2 & 7.6 & 10.9 & 1.7 & 0.6 & 6.2 \\
Masterton District & 51.9 & 6.2 & 16.8 & 2.2 & 0.6 & 3.6 \\
Porirua City & 51.3 & 8.7 & 7.9 & 1.7 & 0.6 & 5.6 \\
South Wairarapa District & 50.4 & 6.4 & 16.3 & 1.7 & 0.6 & 4.1 \\
Upper Hutt City & 50.3 & 6.7 & 12.5 & 1.2 & 0.6 & 5.0 \\
Wellington City & 51.6 & 6.2 & 8.4 & 1.2 & 0.5 & 12.2 \\
Wellington Region & 51.5 & 6.8 & 11.5 & 1.5 & 0.6 & 8.1 \\
\hline Bayyyyy
\end{tabular}

Based on Census 2006, Statistics New Zealand

Throughout the region, there is a higher proportion of female population than male. It is highest in the Kapiti Coast (54 percent) and lowest in Upper Hutt (51 percent). At mesh block level there are quite a few mesh blocks where female composition is 100 percent. These include MB1879200 and MB1881500 in Otaki, the Kapiti Coast, MB1916201 in Te Marua, Upper Hutt, MB1956900 in Naenae North and MB2021700 in Homedale West in Lower Hutt, MB2132400 in Willis Street-Cambridge

Terrace, MB2097900 in

Map: 4.5. Female Population in the Wellington Region (2006)

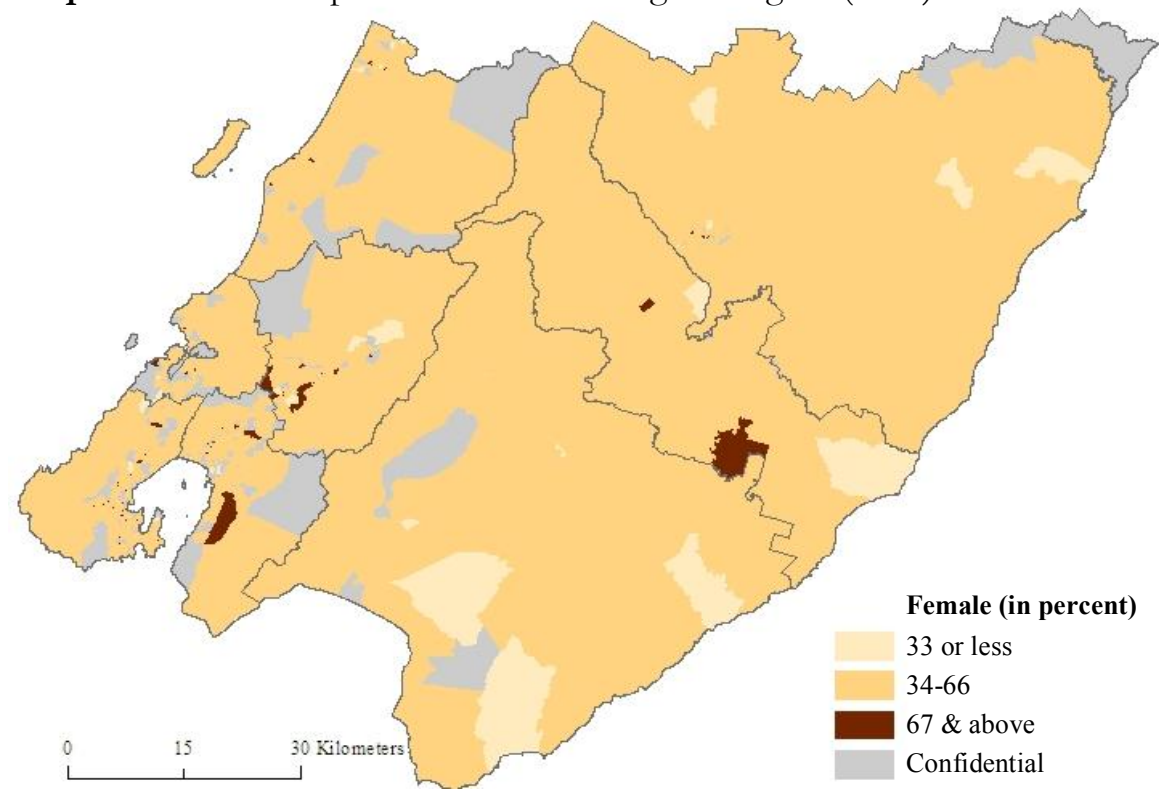

Based on Census 2006, Statistics New Zealand

Ngaio, MB2111600 in Karori East, MB2121300 in Thorndon-Tinakori Road, MB2129100 in Lambton and MB2169402 in Newtown East in Wellington and MB2237800 in Masterton West, Masterton. Most of these mesh blocks have a very low population ranging from three to twelve, 
which could be seen as the main reason for entire female population composition. It is not possible to classify all Census data according to male and female population and therefore, it is difficult to portray a detailed picture of female vulnerability in the region.

\subsubsection{Children}

Vulnerability from age not only governs fragility which affects hazard response, but also resilience because of mobility and other care requirements (Cutter, Mitchell and Scott, 2000, O' Brien and Mileti, 1992, Hewitt 1997, Ngo 2001 as cited in Cutter, Boruff and Shirley, 2003, 246). Children less than five years of age depend entirely on their parents or elders for livelihood and support. They are, therefore, extremely vulnerable to most natural hazards. The child population of the region is about seven percent of the total. At district level, it ranges from 5.7 percent in the Kapiti Coast to 8.7 percent in Porirua. The range is wider at mesh block level. In a few mesh blocks, it is even more than 20 percent of the total population. These include MB2053804 (30 percent) in Ranui Heights and

MB2041900

percent) in Titahi Bay South in Porirua, MB1891200

percent) in Map: 4.6. Children Less Than Five Years in the Wellington Region (2006)

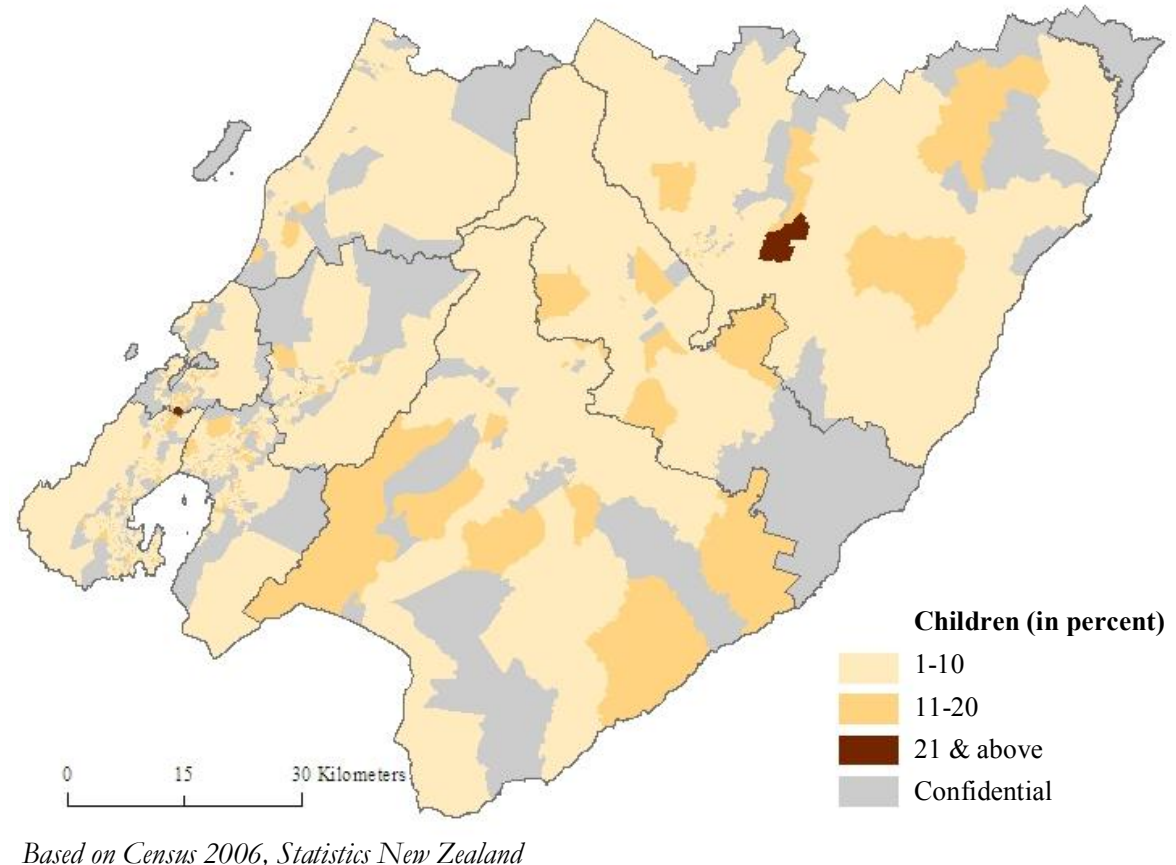

Brentwood, Upper

Hutt, MB2254102 (22 percent) in Whareama, Masterton, MB2180001 (23 percent) and MB2181202 (24 percent) in Kilbirnie West and MB2086724 (23 percent) in Churton in Wellington. Nowhere in the region does the child population exceed thirty percent at mesh block level. However, it is important to note that since population size varies significantly across mesh blocks, percentages do not necessarily reflect the magnitude of potential risk. In MB2053804, where the child population is nearly 30 percent, the actual number of children is 30, while in MB2086724, where they form 23 percent of the total population, their number is 78 . The highest number of children, on the other hand, is located in MB2003512 in Paraparaumu Beach South, the Kapiti Coast, where their total number is 735 , and they form only 14 percent of the total population in the mesh block.

\subsubsection{The Elderly}

Elderly people stand at the other end of age spectrum. Their vulnerability is linked to the physical and in some cases mental incapability to deal with hazards (Cutter, Mitchell and Scott, 2000, O’ Brien and Mileti, 1992, Hewitt 1997, Ngo 2001 as cited in Cutter, Boruff and Shirley, 
2003 , 246). The total elderly population of age more than 65 years is 11.5 percent in the Wellington Region. This is nearly five percent higher than the children population. The highest proportion of elderly population in the region as well as in the country resides in the Kapiti Coast district (23.3 percent) (Statistics New Zealand, 1998a, 38). The district also has the highest women population, and therefore it is likely that more elderly in the district are women. In the 1996 Census, there were about 132 women per 100 men of age above 65 years as women in New Zealand live longer than men (Statistics New Zealand \& Ministry of Women Affairs, 1998, 14). This suggests an even high vulnerability of elderly population attributed to both physical and economic fragility. Porirua, on the other hand, shares the minimum elderly population $(7.9$ percent).

In

MB1883704

Waikanae East, a hundred percent of the population is above 65 years of age, while in few other mesh blocks including

MB1940403 in Taita North, Lower Hutt, MB2004101 in

Raumati Beach, MB2003505

Paraparaumu Beach South and MB1883804 in
Map: 4.7. Elderly Population of Age 65 or More Years in the Wellington Region

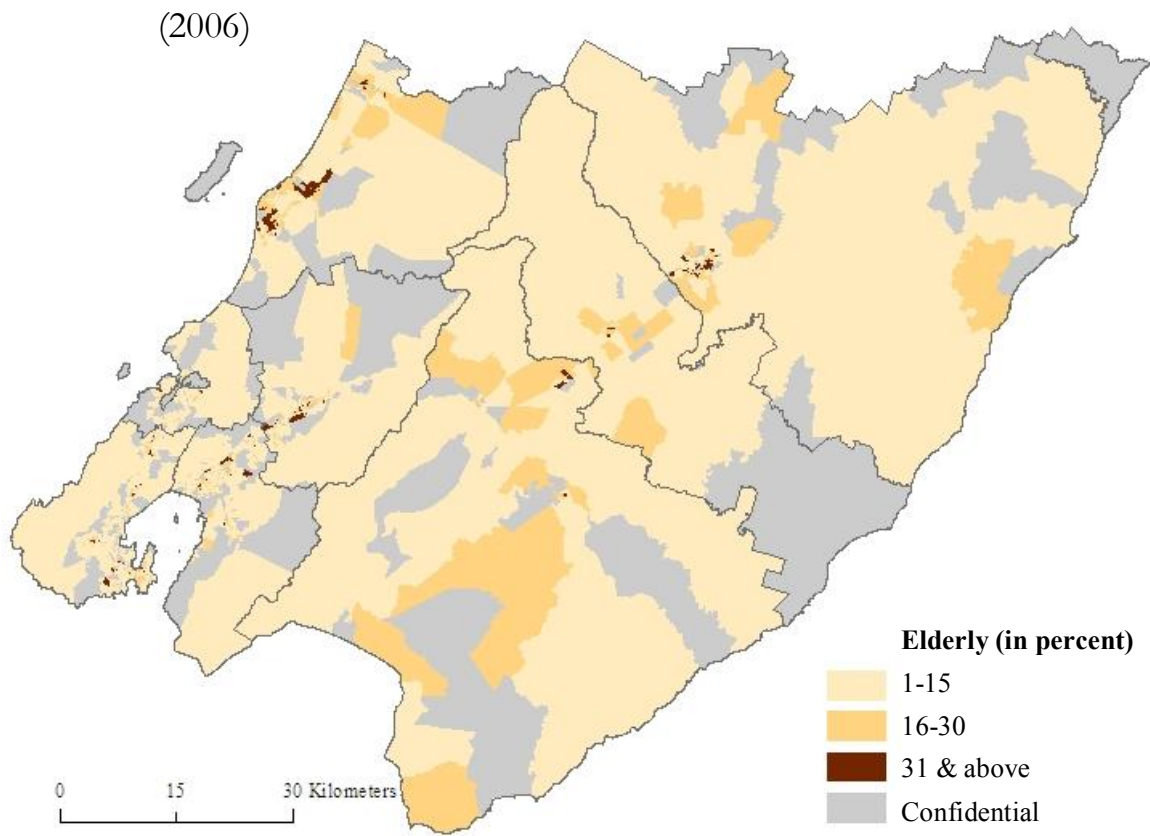

Based on Census 2006, Statistics New Zealand

Waikanae Park, the Kapiti Coast, MB2171300 in Berhampore and MB2083900 in Raroa in Wellington, and MB1903100 in Heretaunga Park, Upper Hutt, the elderly population is more than 90 percent. Many of these mesh blocks are retirement villages. The vulnerability of these mesh blocks is particularly high because the population in these areas is considerable i.e. ranging from 60 to 261 and widespread. This would require significant amount of time to evacuate all people from these areas, and the problem would get further compounded in the absence of local help from young individuals. The excessive concentration of an elderly population in the Kapiti Coast could be attributed to its relatively calm weather conditions, particularly in Waikanae, and accessibility to basic day-to-day services as mentioned by the respondents during field work. This subtle environment incubates hazard conditions by inviting more and more old people. An old female respondent expressed her fear that no one would come to know if she dies tomorrow, and hers would not be the first case as it has happened in the past with a neighbour. Her fear was genuine and shows the grim reality of her vulnerability. It would be wrong to expect such people to listen to an alarm warning and run in case of a tsunami. Also, one could not entirely depend on the memory 
of civil defence organisations, when there is no such description of job for age specific or other vulnerabilities in their job list.

\subsubsection{Disabled}

Physical disability creates vulnerability by restricting effective response. However, since there are no such data in the census, inferences for this aspect had to be drawn from other indicators for which data are available, such as the number of a population living on the sickness benefit and people who use New Zealand Sign Language. While the first indicator includes all sorts of disability that can prevent a person from work, the latter indicate disability by being deaf and dumb. However, there are a range of other disabilities, which, even though they allow a person to work in normal conditions, could affect hazard response to a significant extent such as blindness. Since such people may not be part of any of these categories, a complete picture of vulnerability through disability could not be produced.

People on sickness benefit are distributed widely throughout the region. The region has 1.5 percent of its total population living on sickness benefit. Across districts, the proportion of population receiving sickness benefit ranges from 1.2 percent in Wellington and Lower Hutt to 2.2 percent in Masterton. At mesh
Map: 4.8. Population Living on Sickness Benefit in the Wellington Region (2006)

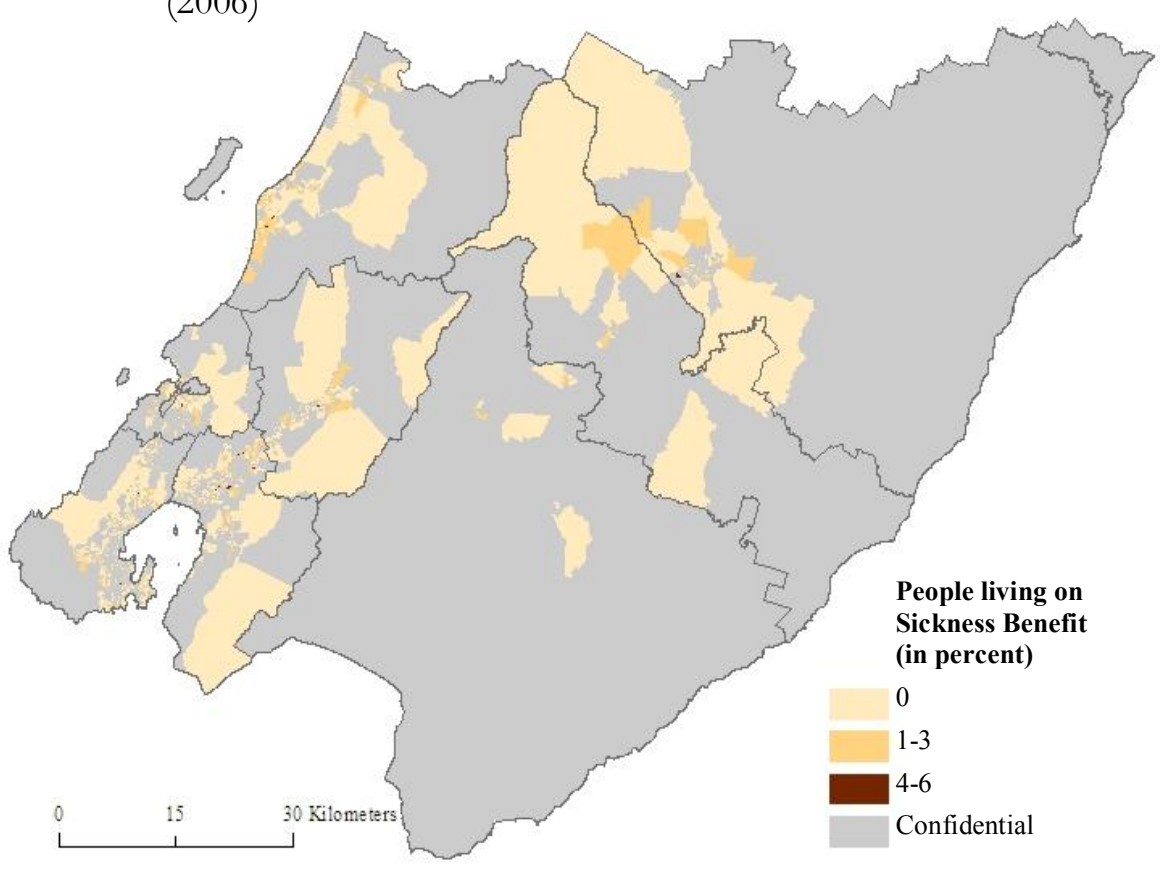

Based on Census 2006, Statistics New Zealand

Map: 4.9. Population Using NZ Sign Language in the Wellington Region (2006)

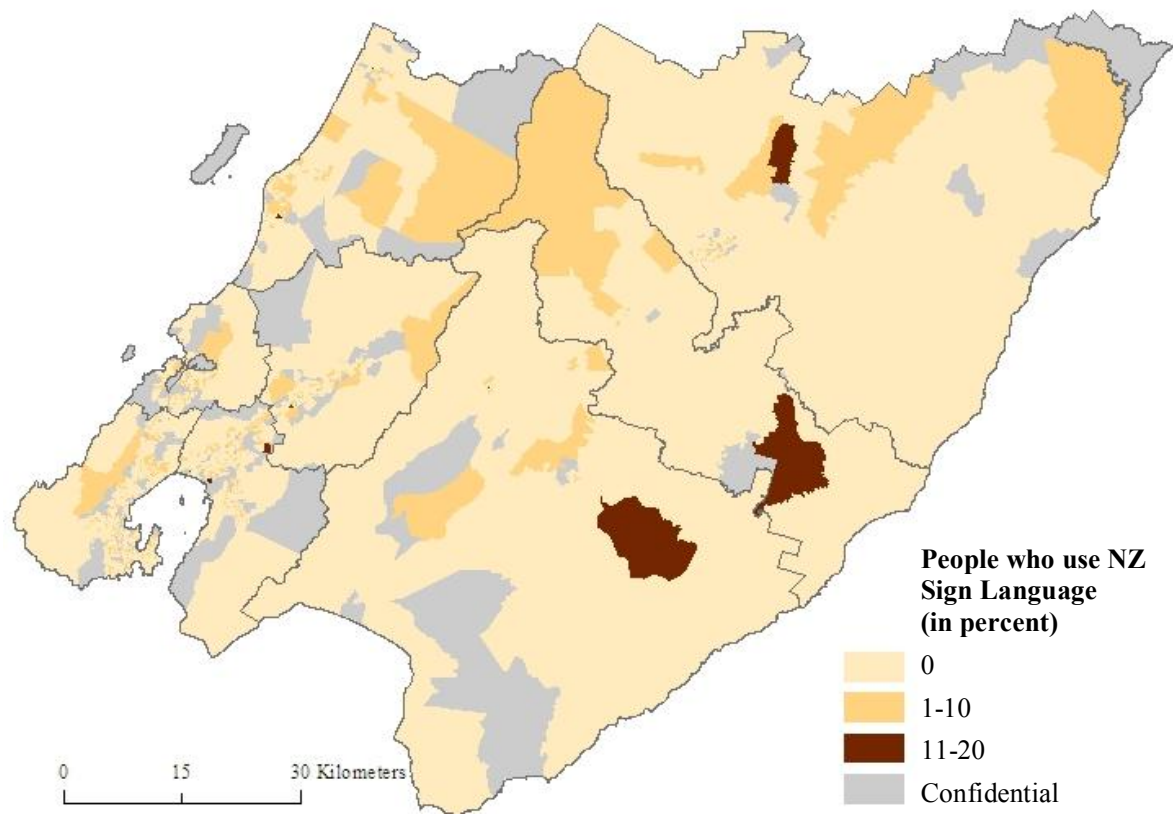

Based on Census 2006, Statistics New Zealand 
block level the highest percentage of such population is found in MB1927200 in Manuka in Lower Hutt, where they form six percent of the total population. In MB1951000 in Epuni East, Lower Hutt and MB2081000 in Johnsonville North, Wellington, five percent of the total population lives on sickness benefits. The vulnerability of these people is not only linked to their physical disability but also to economic vulnerability as often their earning is limited due to disability. The absence of savings could undermine their coping capacity to a significant extent.

The percentage of people who use New Zealand Sign Language is 0.6 in the region. It is highest in the Kapiti Coast (0.7 percent) and lowest in Carterton (0.3 percent). The highest percentage of such population lives at MB2033500 in Petone Central, Lower Hutt (20 percent) followed by MB1877600 in Otaki, the Kapiti Coast, MB1926500 in Manuka, Lower Hutt, MB2254301 in Kopuaranga, Masterton and MB2274000 in Martinborough, South Wairarapa, each with 17 percent of such population. The number of such people in all these mesh blocks is only three. The highest number of people who use sign language is in MB1941900 in Boulcott, Central Ward in Lower Hutt i.e. 12 out of 141 people where they form 8.5 percent of total population, which again shows that percentages do not essentially present the true picture.

\subsubsection{Movement for Migration and Tourism}

Demographic vulnerability is also produced by movement of people in and out of the region. Migration in the region occurs at different levels i.e. migration of people within the region, from other parts of New Zealand and from overseas. The frequent movement of people over space is often associated with unawareness about local hazards and various possible response methods, which may not necessarily create vulnerability in terms of fragility, but could affect the immigrant's response and resilience to hazards. Since detailed data about migrations in the region are not available, inferences have been drawn from Census data, which indicates those who have lived zero years at their current residence along with those who lived overseas five years prior to Census 2006.

Map: 4.10. Population Living for Less than One Year at their Current Residence in the Wellington Region (2006)
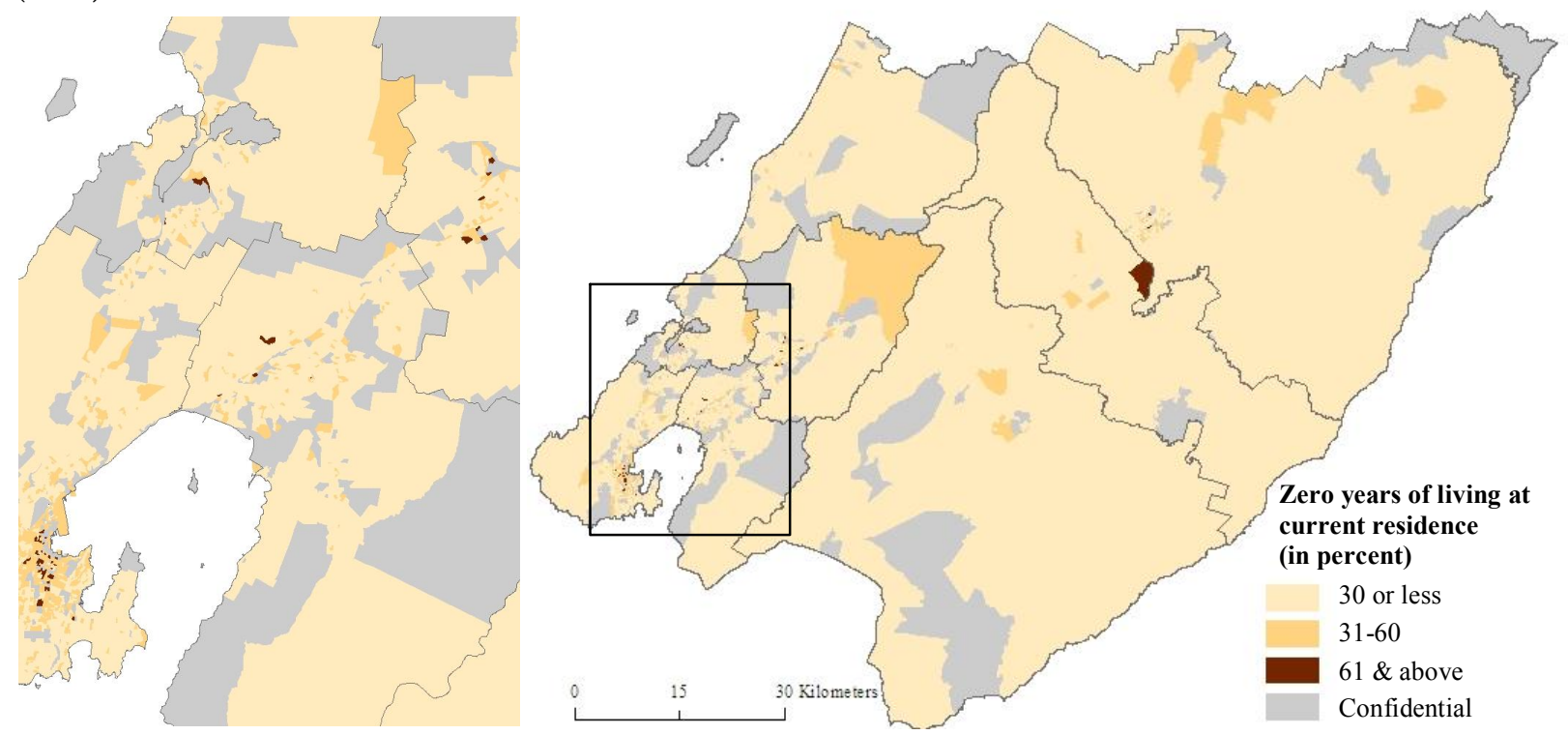
The data for people who lived zero years at their current residence is not available at district level. At mesh block level, in MB1899400 in Trentham South and MB1903705 in Riverstone Terraces in Upper Hutt and MB2057902 in Ascot Park, Porirua, the entire population is new. These areas are newly developed areas and the vulnerability of residents in these mesh blocks therefore would vary depending on their earlier place of residence i.e. either from the district itself or from the region or another part of New Zealand or a country overseas. The movement is high in central city areas, especially in Wellington, which is a tourist hub and hundreds of international people visit the city for work, education and recreational purposes.

While people from within New Zealand or within the Wellington Region would have some degree of awareness about local hazards, people from overseas may face a total setback if met with hazards in an unknown environment. Nearly eight percent of the region's population lived overseas five years prior to the Census 2006. The proportion of such population ranged from four percent in Carterton to about 12 percent in the Wellington. At the mesh block level, the highest immigrant population lives in MB1900500 in Trentham South, Upper Hutt, where it makes up 75 percent of total population. In MB2157000 in Aro Street-Nairn Street, MB2134800 Willis Street-Cambridge Terrace and MB2123900 in Lambton in Wellington and MB1900600 in Trentham South, Upper Hutt, more than 50 percent of total population are immigrants. A major proportion of immigrant population in both Wellington and Upper Hutt consists of students, who come for higher education at universities or institutes located in both cities.

Map: 4.11. Population Living Overseas Five Years Ago in the Wellington Region (2006)
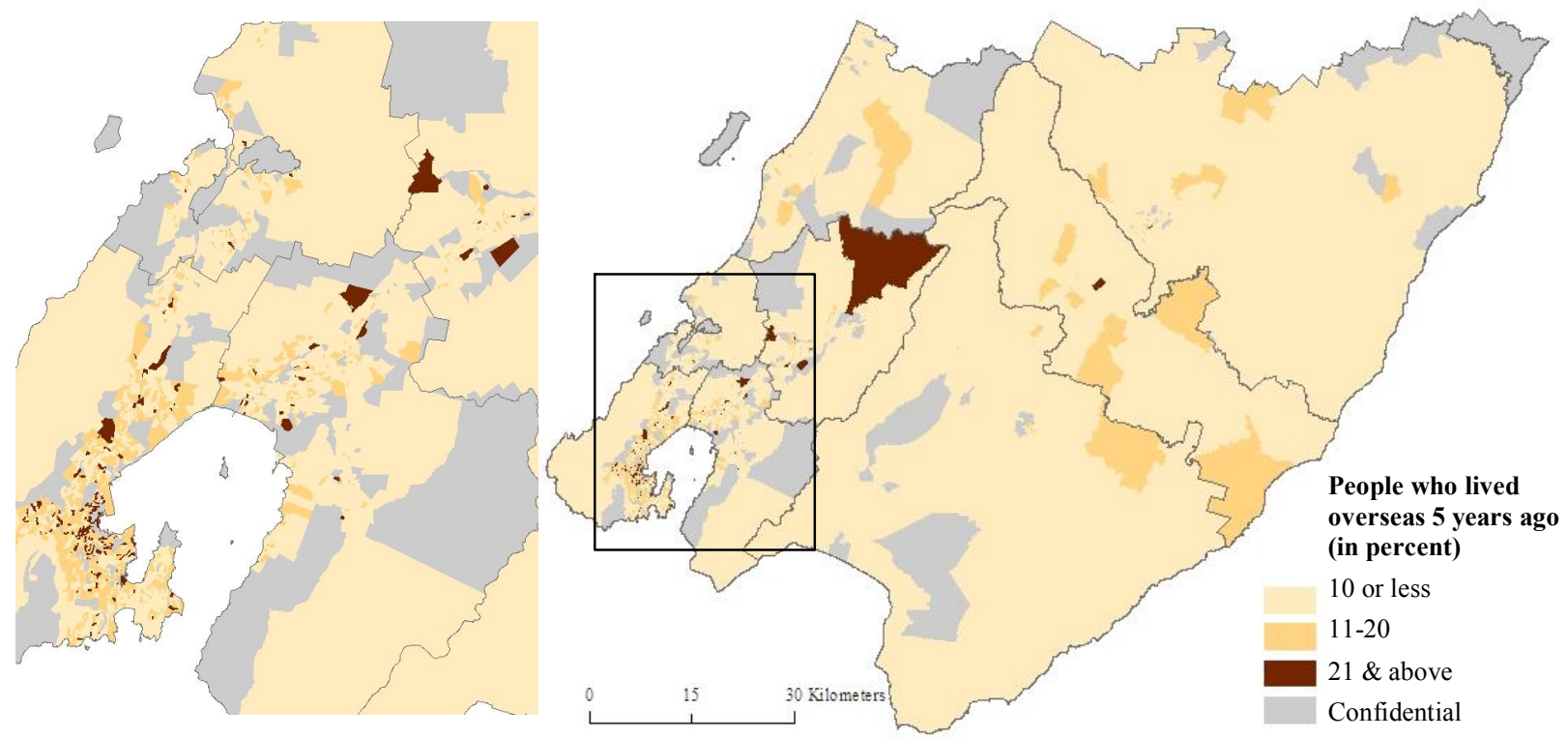

Based on Census 2006, Statistics New Zealand

The perception, awareness and therefore response of an immigrant population to a significant extent are based on their response to hazards in their home country, where they may or may not be exposed to significant natural hazards. Whereas people from Japan, Indonesia or parts of America are likely to be more aware of earthquakes and related hazards along with how to respond to them, such awareness could be limited in people from other countries that are not exposed to frequent earthquakes. 
Plate: 4.1. Demographic Vulnerability Index of the Wellington Region (2006)
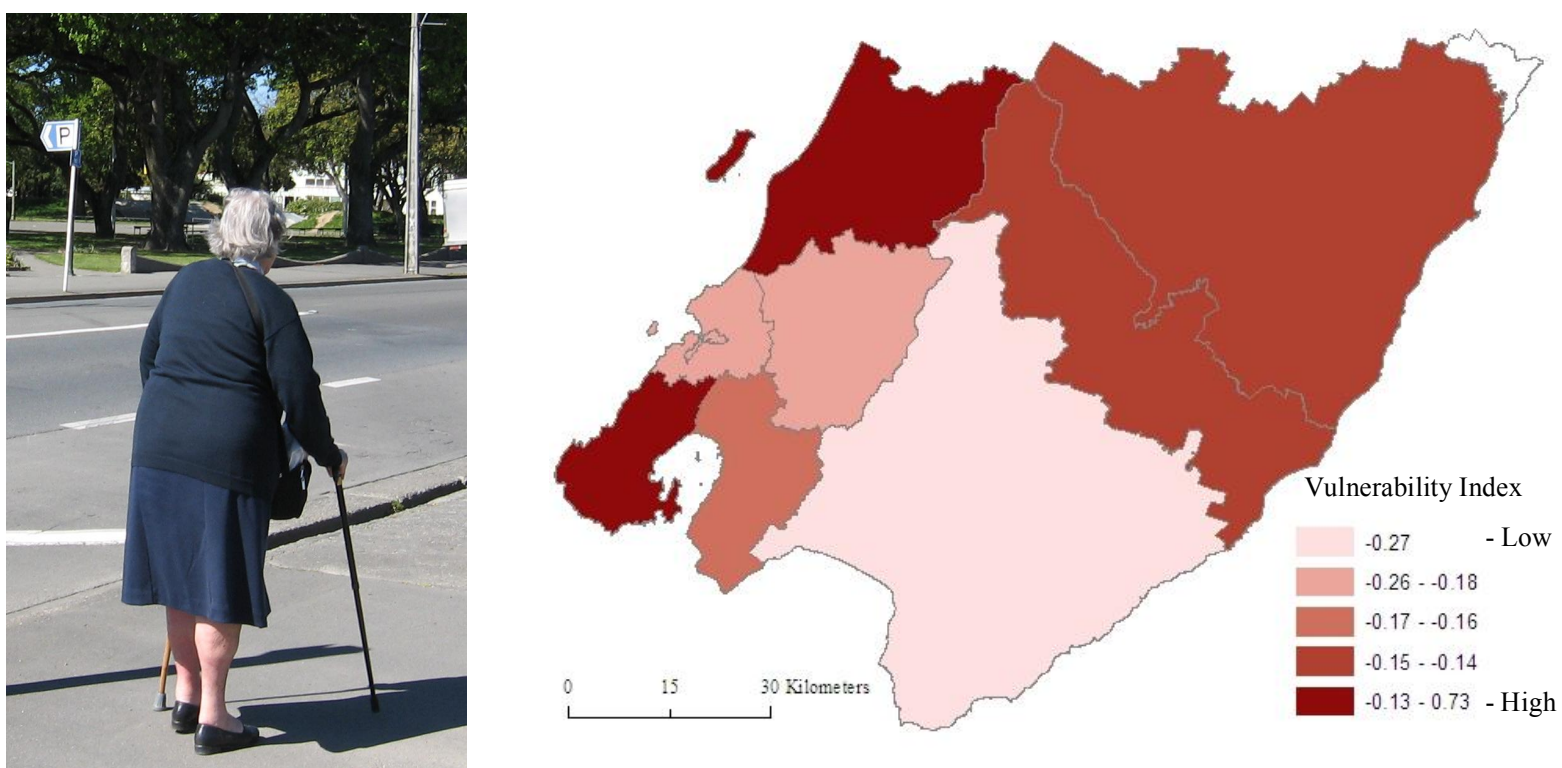

1. Vulnerability Index Based on Maximum Imputation Value

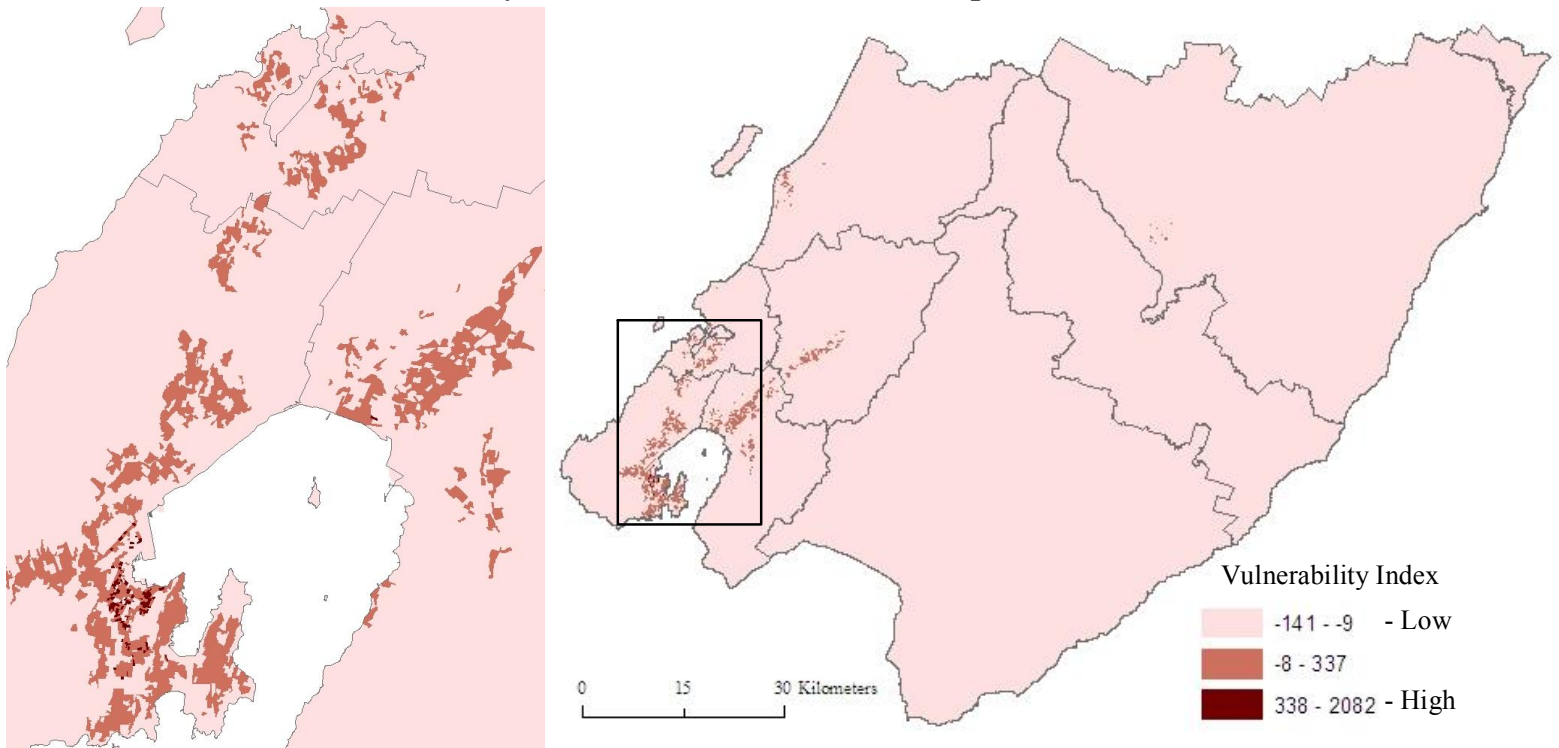

2. Vulnerability Index Based on Minimum Imputation Value

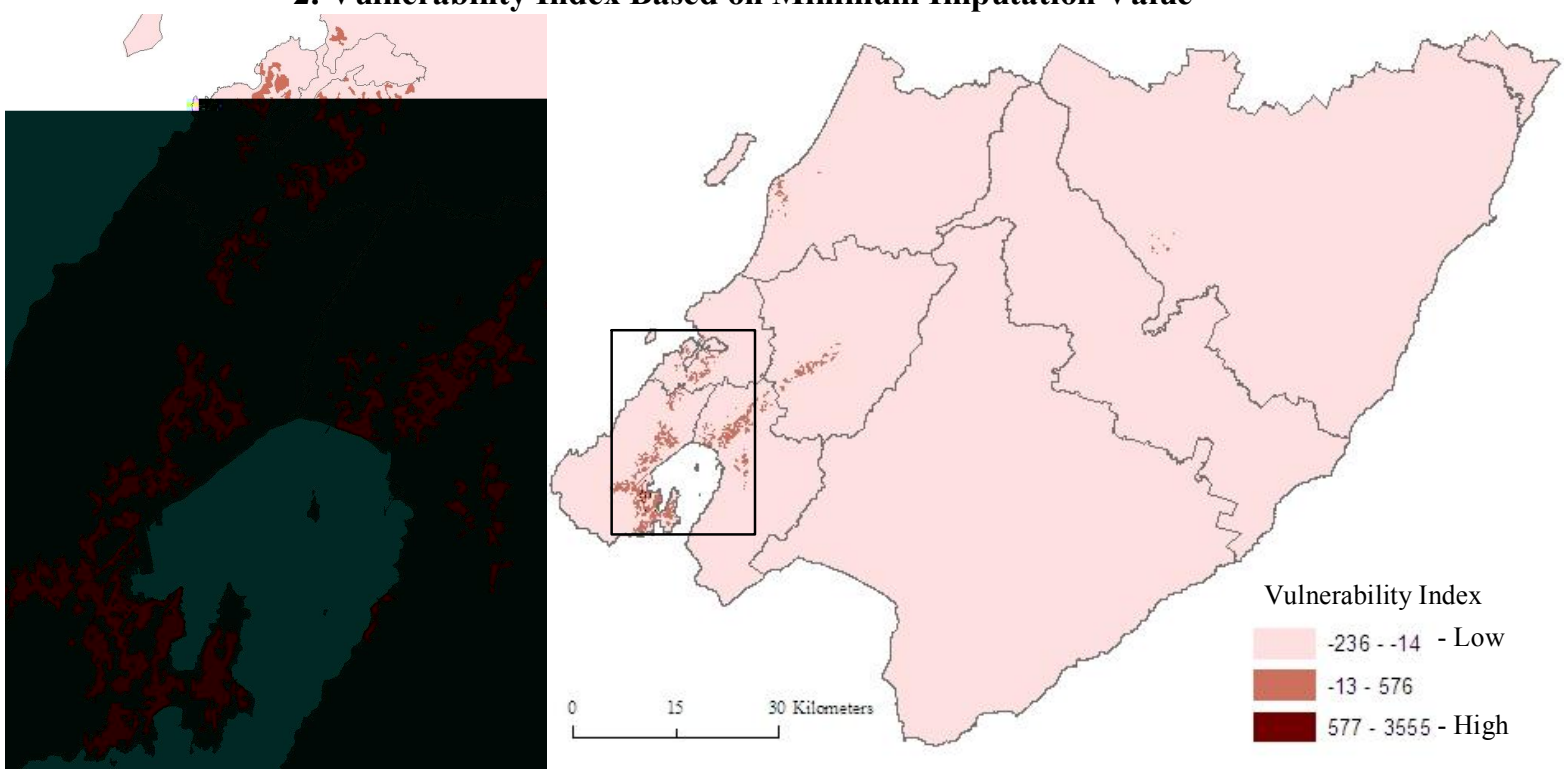

Based on Census 2006, Statistics New Zealand; field work photograph 
Further, the response culture differs among countries exposed to similar kinds of hazards. However, immigration data for the region are not accessible with country specific details. Nevertheless, some information could be extracted from the ethnic composition of the region, which is discussed in detail in the following section of social vulnerability. But classifications such as 'Asian' or people of 'Pacific' origins are very broad and people within the same category may share entirely different experiences depending on their country of origin.

Besides long term immigration, short term visits and tourism represent other important factors of vulnerability within the region. The region attracts a large number of international tourists. According to tourism statistics, there were about 676,900 international visitor nights in Wellington city from March 2006 to February 2007, which was about a one percent increase over 2006. The monthly figure of international visitor nights for February 2007 was 89,620 in Wellington alone (Wellington Tourism Statistics, 2007), which indicates a large number of people being exposed to hazards for a short period. Most of these tourists largely stay in the city central hotels, where they are exposed to earthquakes and tsunami along with various climatic hazards. Their unawareness about local hazards and hazard response adds to the local vulnerability.

\subsubsection{Demographic Vulnerability Index}

Plate 4.1 shows overall demographic vulnerability of the region based on factors including population density, women, children, elderly and disabled population, who live on sickness benefit and who use NZ sign language along with migrant population who lived overseas five years before Census 2006. The methodology for the vulnerability index has been discussed in chapter one. The data show Wellington and the Kapiti Coast as the two most vulnerable districts. These two districts share many common characteristics such as high population growth along with significant female, elderly and overseas population. At mesh block level, the overall result for demographic vulnerability calculated by using maximum and minimum imputed value does not show much difference in the final output. The vulnerability map at mesh block level shows that almost all the most vulnerable mesh blocks are located in Wellington city, except one from Lower Hutt i.e. MB2029400 in Wilford area in Harbour Ward. Those located in Wellington are largely spread in and around the city centre mainly in Lambton Ward (93 mesh blocks), Southern Ward (15 mesh blocks) and one mesh block in Eastern Ward i.e. 2178102 in Kilbirnie East. The most vulnerable mesh block in the region is MB2128800 in Lambton in Lambton Ward in Wellington. The vulnerability in this mesh block is mainly caused by a very high population density i.e. about 43,045 people per sq $\mathrm{km}$ along with unawareness related with short stay in the area. The median age of population in this mesh block is 18 and about 94 percent of total population (i.e. 162) has lived zero years in the current residence and 15 percent population is from overseas. The composition basically indicates a high concentration of students in this mesh block, who keep changing each year. 


\subsection{Social Vulnerability}

Social vulnerability characterizes those aspects of a community that limit the options for individual response and resilience to natural hazards. These include family type, family size, education, language and ethnicity. The role of these indicators, although governed by local conditions, are also modified by ecumenical processes operating at community, district, regional, national or global level.

\subsubsection{Family}

The family is the basic unit of the social system and it may influence vulnerability to a significant extent. A family is often seen as relatively more vulnerable compared to a single individual as the response of an individual within a family to hazard is often influenced by the state of other members. The emotional and economic interdependence could play a determinant role in response and resilience of family members. While a couple without children would be able to respond effectively, a family with large number of dependents or children may suffer with resilience and recovery problems (Blaikie et al (1994), Morrow (1999), Heinz Centre for Science, Economics and Environment (2000) and Puente (1999) as cited in Cutter et al, 2003, 248). Often it has been observed that emotional attachments of people to a place or house or objects create problems during evacuation. The region has about 118,000 families, of which 60 percent have children (Table: 4.3).

Table: 4.3. Family Structure in the Wellington Region (2006)

\begin{tabular}{|c|c|c|c|c|c|}
\hline \multirow{2}{*}{$\begin{array}{l}\text { Local Territorial } \\
\text { Authority }\end{array}$} & \multicolumn{4}{|c|}{ Family structure (data in percent) } & \multirow{2}{*}{$\begin{array}{l}\text { Females with } \\
\text { four or more } \\
\text { children }\end{array}$} \\
\hline & $\begin{array}{c}\text { Total } \\
\text { Families }\end{array}$ & $\begin{array}{l}\text { Couple without } \\
\text { children }\end{array}$ & $\begin{array}{l}\text { Couple with } \\
\text { child(ren) }\end{array}$ & $\begin{array}{c}\text { One parent } \\
\text { with child(ren) }\end{array}$ & \\
\hline Kapiti Coast District & 13134 & 50.0 & 33.3 & 16.7 & 15.8 \\
\hline Porirua City & 12669 & 29.1 & 46.3 & 24.6 & 12.9 \\
\hline Upper Hutt City & 10380 & 37.5 & 43.8 & 18.7 & 13.9 \\
\hline Lower Hutt City & 26313 & 34.8 & 44.7 & 20.6 & 17.9 \\
\hline Wellington City & 44496 & 42.4 & 43.2 & 14.4 & 15.0 \\
\hline Masterton District & 6180 & 43.5 & 38.5 & 18.0 & 6.7 \\
\hline Carterton District & 2013 & 46.3 & 40.8 & 13.0 & 16.9 \\
\hline South Wairarapa District & 2520 & 50.4 & 37.3 & 12.4 & 17.1 \\
\hline Wellington Region & 117705 & 40.0 & 42.4 & 17.6 & 11.3 \\
\hline
\end{tabular}

Based on Census 2006, Statistics New Zealand

Single parents are particularly vulnerable to hazards. They not only have to manage both occupational and domestic work, but they are also responsible for saving their children during a disaster. However, the severity of the hazard and the age of children play a crucial role in single parents' vulnerability. In New Zealand, most single parent families are headed by women (about 83 percent in 1996 Census as cited in Statistics New Zealand, 1998c, 14). On the whole, the region has about 18 percent of single parent families. The proportion of such families is highest in Porirua i.e. about 25 percent and lowest in South Wairarapa i.e. 12 percent. Though such families are distributed in both rural and urban areas, they are more common in urban areas. In MB2045600 in Cannons Creek North, Eastern Ward of Porirua and MB2169901 in Newtown East, Southern Ward of Wellington, single parents form 100 percent of the family composition of the mesh block. The reason behind broken families could be attributed to low socio-economic status linked to low 
Map: 4.12. Single Parent Families in the Wellington Region (2006)
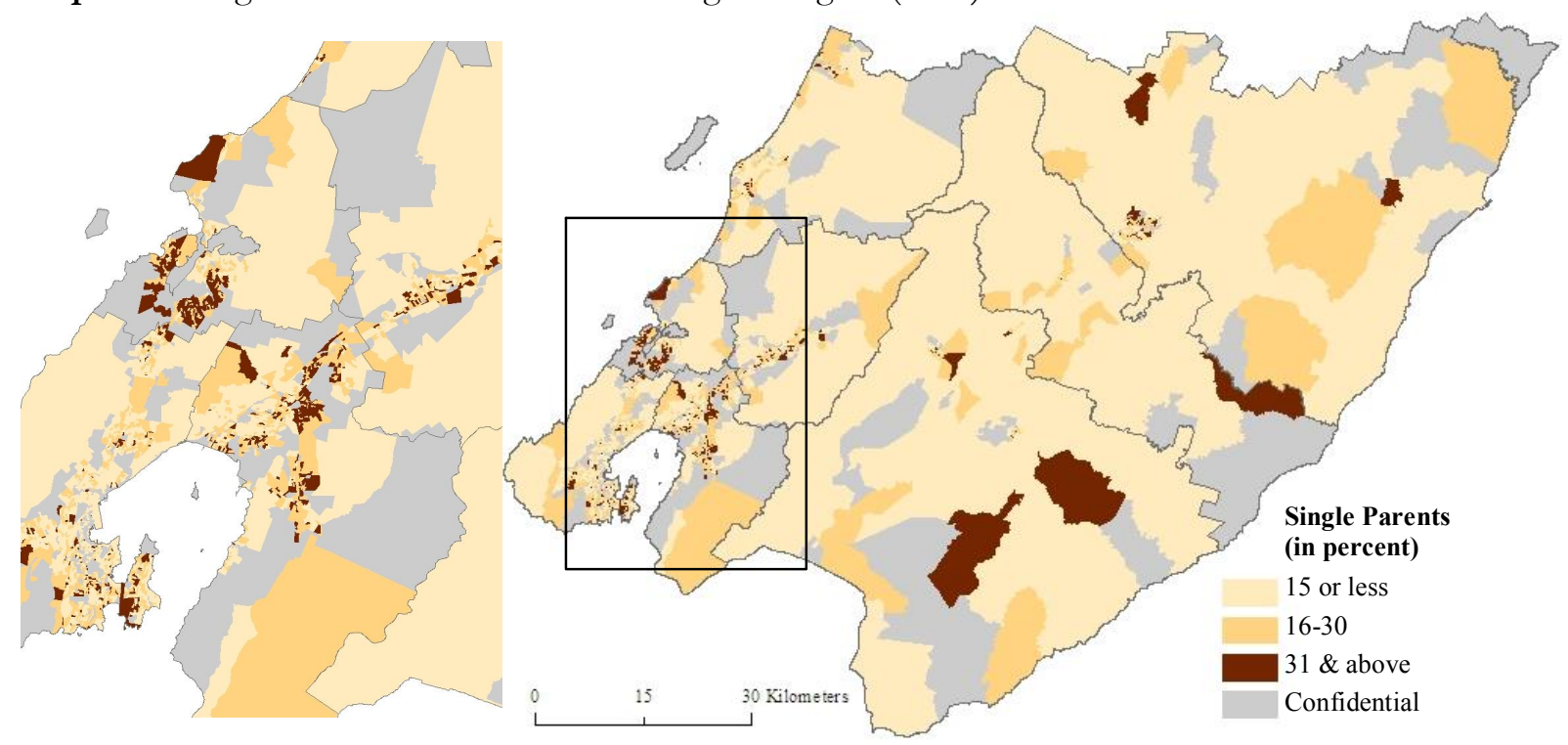

Based on Census 2006, Statistics New Zealand

income. The median income for both of these mesh blocks is confidential and they have a high population dependent on one or other kind of government benefits or allowance i.e. about 41 percent in MB2045600 and 31 percent in MB2169901. Both of these mesh blocks have significant proportion of unqualified people i.e. about 16 percent and 15 percent respectively. Besides, a much higher percentage of people i.e. 66 percent and 70 percent of population respectively use English as second language. While in MB2045600, this is attributed to high Maori (33 percent) and Pacific (42 percent population), MB2169901 has mixed population composition i.e. European (53 percent), Maori (eight percent), Pacific (eight percent), MELAA (23 percent) and other (eight percent). Overall both of these mesh blocks have six families each with a total population of 36 and 39 respectively and none of families has children of less than five years of age. While this reduces physical vulnerability, economic vulnerability remains, which could affect resilience and recovery of the affected population.

The number of children within a family is a critical issue. Though such data are not given in the Census, it does tell about females above 15 years of age, who bear four or more children, who may or may not be part of a family. The region has 11 percent of such females, and the highest percentage of such females is in Masterton (18 percent) and the least in Wellington ( 7 percent). The distribution of females with four or more children is higher in rural and suburban areas. The percentage is consistently high in three rural districts of Masterton (17.9 percent), South Wairarapa (17.1 percent) and Carterton (16.9 percent).

Mesh blocks with high share of female having four or more children include MB2013902 (67 percent) in Glendale, Wainuiomata Ward, Lower Hutt, MB2258200 (50 percent) in Carterton, Carterton Urban Ward, Carterton District and MB2058102 (45 percent) in Ascot Park, Eastern Ward, Porirua. A high percent of such females could be associated with particular socio-cultural set up e.g. Maori and Pacific families tend to have more children compared to others (see Table: 4.7). Most of these mesh blocks have significant Maori and Pacific population e.g. in MB2013902, 41 percent of the population is Maori and another 14 percent are Pacific, while in MB2258200, 25 
Map: 4.13. Females Having Four or More Children in the Wellington Region (2006)
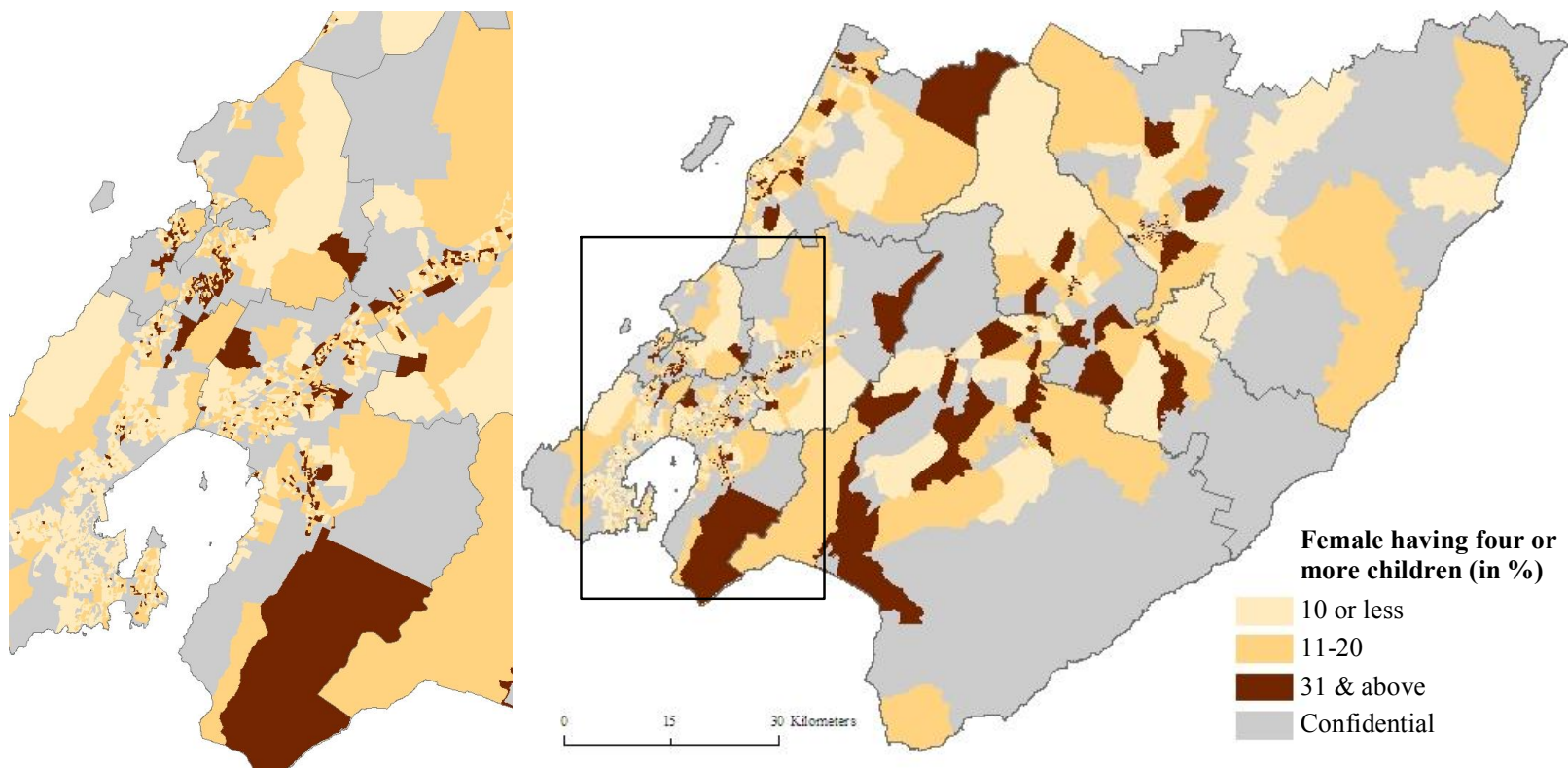

Based on Census 2006, Statistics New Zealand

percent are Maori and in MB2058102, 35 percent are Maori and another 50 percent are Pacific. Large numbers of children not only indicate a larger and highly dependent population but also indicate the work profile of the female population, which is more likely to be busy with household work rather than being engaged in economic activities, a situation which could affect the coping capacity of families during a disaster.

\subsubsection{Household Composition}

Household composition may also influence vulnerability to an extent. Household composition in the region varies from one-family households to a number of families sharing one house, one or multi person household or a household for which it is hard to identify the nature of composition. Household composition influences decision making not only for real time hazard response but also for mitigation and recovery.

Table: 4.4. Household Composition in the Wellington Region (2006)

\begin{tabular}{|c|c|c|c|c|c|}
\hline \multirow{2}{*}{$\begin{array}{l}\text { Local Territorial } \\
\text { Authority }\end{array}$} & \multicolumn{5}{|c|}{ Household composition (in percent) } \\
\hline & $\begin{array}{c}\text { One-family } \\
\text { household (with or } \\
\text { without other } \\
\text { people) }\end{array}$ & $\begin{array}{l}\text { Two or more family } \\
\text { household (with or } \\
\text { without other } \\
\text { people) }\end{array}$ & $\begin{array}{l}\text { Other Multi- } \\
\text { Person } \\
\text { Household }\end{array}$ & $\begin{array}{l}\text { One Person } \\
\text { Household }\end{array}$ & $\begin{array}{c}\text { Household } \\
\text { Composition } \\
\text { Unidentifiable }\end{array}$ \\
\hline Kapiti Coast District & 66.2 & 1.3 & 2.4 & 28.6 & 1.6 \\
\hline Porirua City & 72.1 & 4.9 & 3.6 & 16.8 & 2.7 \\
\hline Upper Hutt City & 69.7 & 1.9 & 3.0 & 24.7 & 0.7 \\
\hline Lower Hutt City & 68.3 & 2.9 & 4.1 & 23.7 & 0.9 \\
\hline Wellington City & 62.0 & 1.8 & 9.8 & 24.6 & 1.7 \\
\hline Masterton District & 66.4 & 1.5 & 3.3 & 27.8 & 1.0 \\
\hline Carterton District & 71.1 & 0.9 & 2.3 & 23.7 & 1.8 \\
\hline $\begin{array}{l}\text { South Wairarapa } \\
\text { District }\end{array}$ & 67.2 & 1.2 & 2.4 & 27.3 & 2.0 \\
\hline Wellington Region & 65.9 & 2.2 & 6.0 & 24.4 & 1.5 \\
\hline
\end{tabular}


Map: 4.14. Household Composition in the Wellington Region (2006)
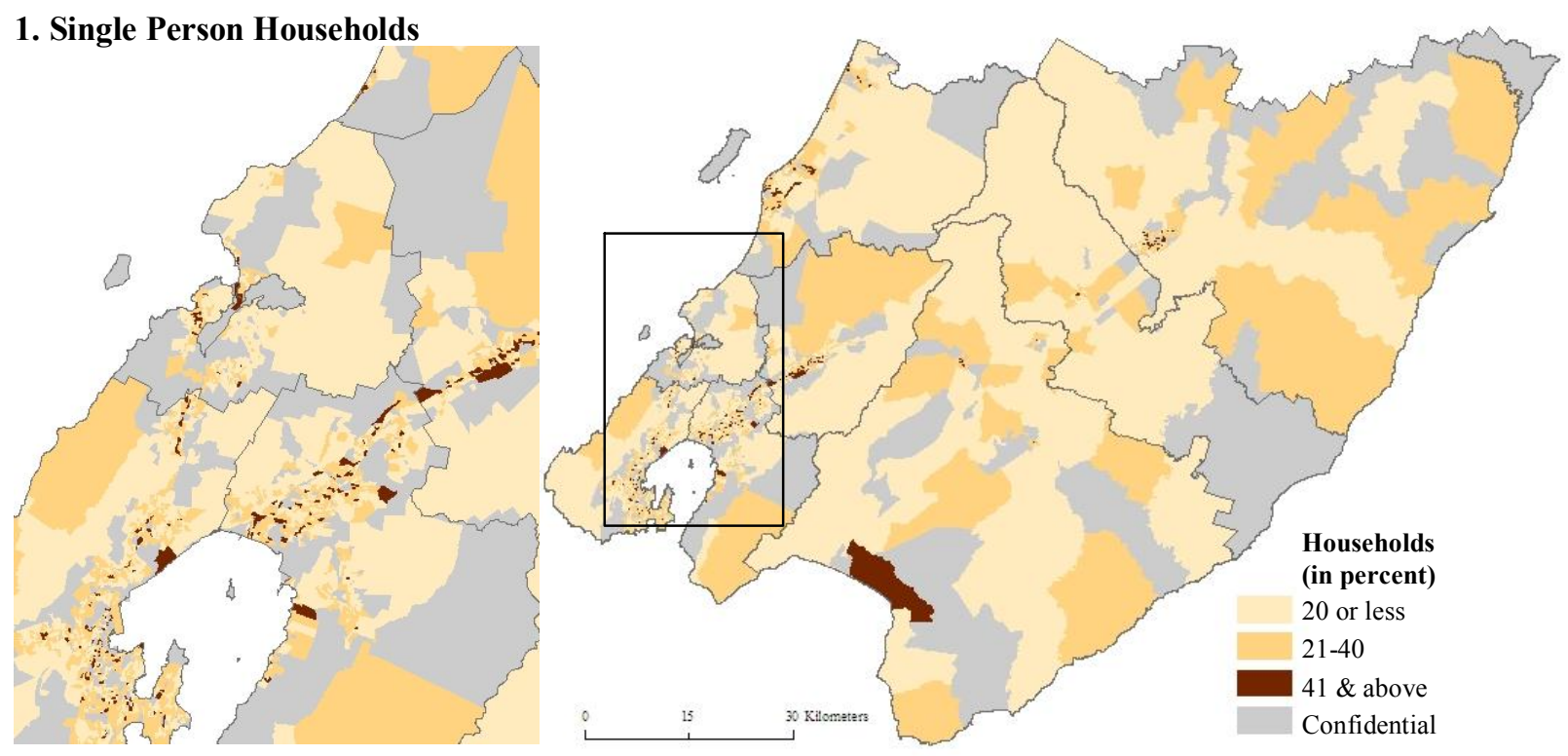

\section{Family Households}
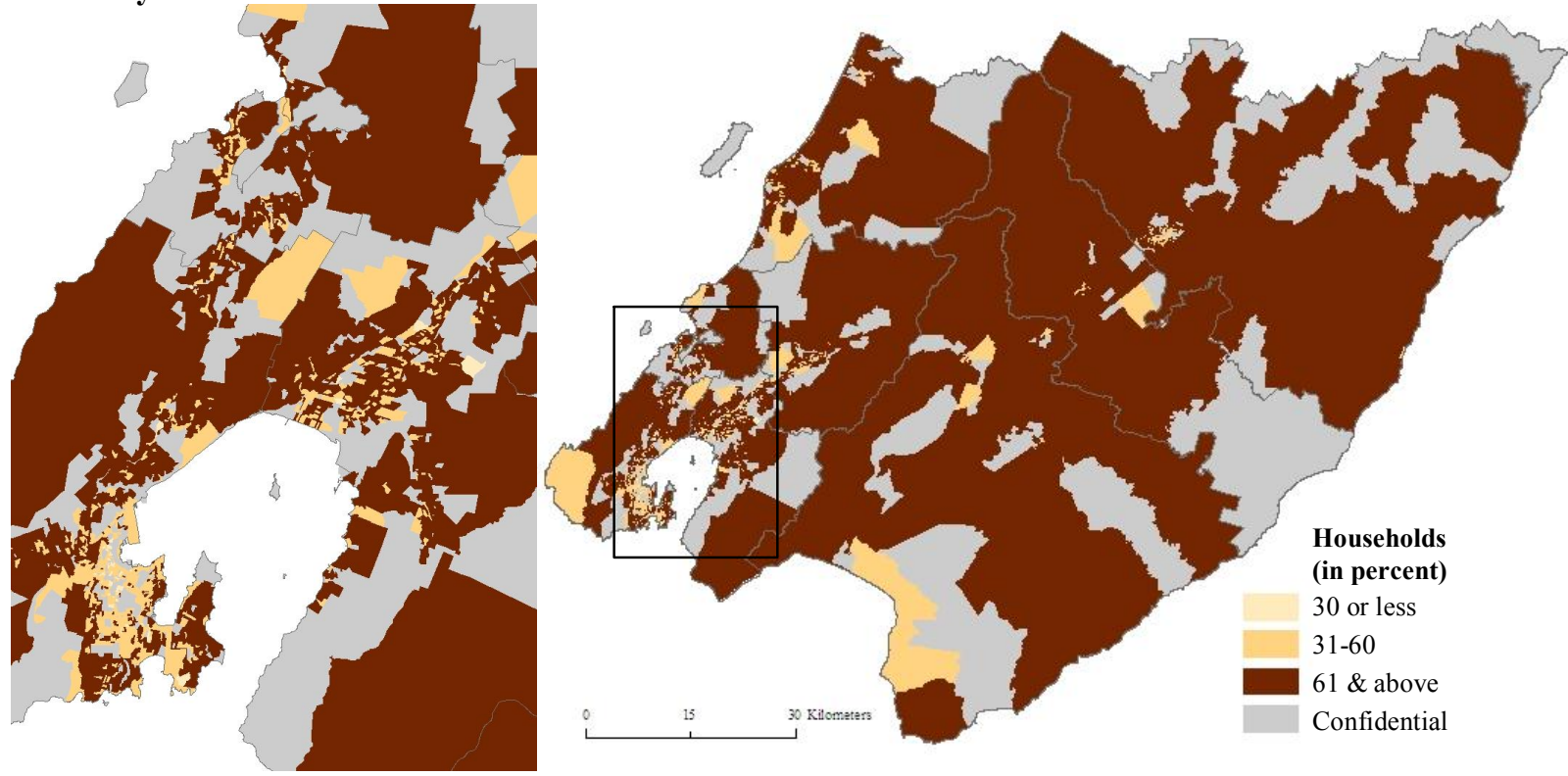

3. Multi-Person Households
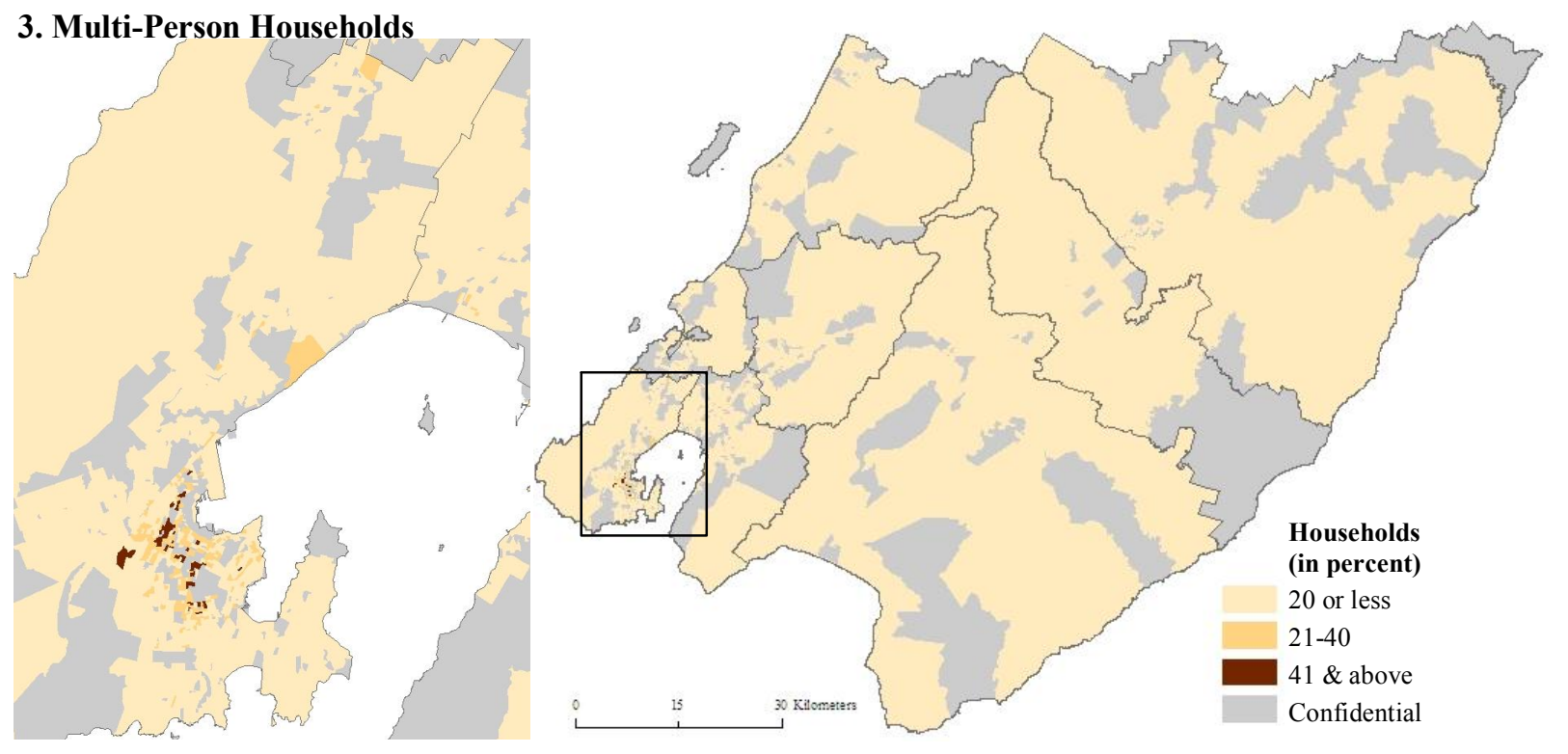

Based on Census 2006, Statistics New Zealand 
About 90 percent of total households in the region are either one family unit or one person households, where household decisions are less likely to experience any conflicts (Table: 4.4). In multi-person or multi-family households on the other hand, shared decision making could put many issues on hold because of varying interests and needs. This could influence hazard mitigation decisions, which could indirectly increase vulnerability of occupants. In terms of spatial distribution, it is clear that while family households are widespread in the region, one person households are mainly concentrated in the urban areas and multi-person households are specifically dominant in Wellington (Map: 4.14). This could be attributed to the short stay of a large population in the city, who would not necessarily buy a house and in the case of students, they may not be able to afford the rent of a complete house for just themselves.

\subsubsection{Education}

Lack of education could limit the awareness and understanding of hazards, which subsequently influences hazard response and recovery (Heinz Centre for Science, Economics and the Environment , 2000 as cited in Cutter, Boruff \& Shirley, 2003). It is also linked with economic opportunities and income that could get reduced at the time of scarcity or after the disruption of existing occupational activity, and therefore may increase the consequent impact of a disaster.

While a majority of the population in the region possesses some educational qualification, about 14 percent of people do not have any educational qualification. The percentages of such people are consistently high in the three rural districts of Masterton (23.4 percent), Carterton (23 percent) and South Wairarapa (21 percent). In rural areas, these people could find work on farms or other related activities, where educational qualifications are not required. The proportions of such people are least in Wellington (nine percent). In the other four cities and district councils of the western section including Porirua, Lower Hutt, Upper Hutt and the Kapiti Coast, population without qualification is around 17.5 percent on the average.

Map: 4.15. Population without Educational Qualification in the Wellington Region (2006)
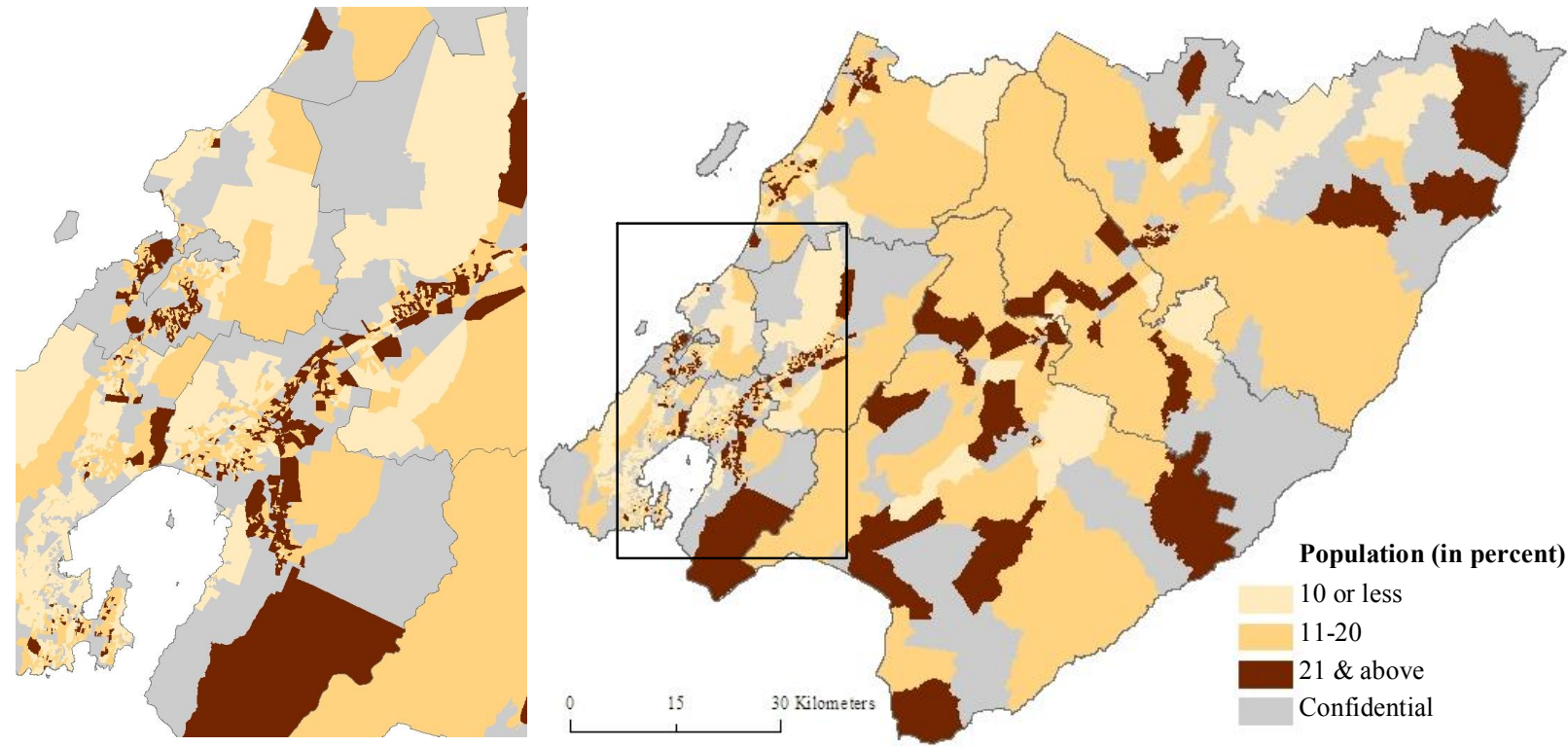

Based on Census 2006, Statistics New Zealand 
At mesh block level, the trend is nearly opposite and most of the mesh blocks with a high percentage of non qualified people are located in urban areas. These include MB1940403 (65 percent) in Taita North, Northern Ward, Lower Hutt, followed by MB1961100 (63 percent) in Naenae North, Eastern Ward, Lower Hutt and MB2168300 (62 percent) in Newtown East, Southern Ward, Wellington city. In urban areas, these people would be more likely to be engaged in blue collar elementary occupations, which do not require any qualification.

\subsubsection{Language Barrier}

Language can also act as a barrier in hazard response and recovery (Cutter, Boruff \& Shirley, 2003). From the vulnerability perspective, not to be able to speak English in an English speaking country may not only restrict economic opportunities but could also put up barriers to understand hazard warnings and communicating basic needs in a post disaster situation. The Census does not record such data, but it records the most common language used by people in New Zealand. English is the main language for nearly 93 percent of population and for another 20 percent of the population it is not the only common language even though they may use it for communication. It is difficult to extract the data for the population that finds it hard to understand and communicate in English but clearly there are people who could not communicate in English. This is observed during primary survey conducted for this research, when about six people refused to talk and participate because of their inability to communicate in English. Many of these people are family dependents, refugees or seasonal labourers, who may have come to Wellington due to any socioeconomic reasons, and are not very comfortable with the language. The problem associated with non English speaking people would differ for different ethnic groups, especially the immigrants.

The region has nearly 20 percent of population whose first language is not English. They are mainly concentrated in Wellington, Lower Hutt and Porirua (Table: 4.5).

Table: 4.5. Main Language Spoken in the Wellington Region (2006)

\begin{tabular}{|c|c|c|c|c|c|}
\hline \multirow[t]{2}{*}{ Local Territorial Authority } & \multicolumn{5}{|c|}{ Main Language of Population (in percent) } \\
\hline & English & Mäori & Samoan & Other & $\begin{array}{c}\text { English Not the First } \\
\text { Language }\end{array}$ \\
\hline Masterton District & 94.7 & 4.5 & 0.9 & 4.6 & 9.9 \\
\hline Carterton District & 94.5 & 1.9 & 0.2 & 4.9 & 7.1 \\
\hline South Wairarapa District & 93.8 & 2.6 & 0.3 & 5.3 & 8.2 \\
\hline Upper Hutt City & 94.1 & 3.3 & 1.3 & 8.0 & 12.5 \\
\hline Kapiti Coast District & 94.3 & 3.8 & 0.4 & 6.6 & 10.8 \\
\hline Lower Hutt City & 92.9 & 4.8 & 4.9 & 12.5 & 22.2 \\
\hline Porirua City & 89.5 & 5.5 & 10.1 & 9.9 & 25.6 \\
\hline Wellington City & 92.2 & 2.2 & 2.2 & 19.3 & 23.7 \\
\hline Wellington Region & 92.6 & 3.5 & 3.2 & 13.3 & 20.0 \\
\hline
\end{tabular}

At the mesh block level, in MB2053804 in Ranui Heights, Eastern Ward, Porirua, English is not the only most common language for the entire population of about 30. MB1900500 (92 percent of 36) in Trentham South, Upper Hutt, MB2216200 (88 percent of 126) in Strathmore Park, Eastern Ward, MB1988202 (88 percent of 26) in Tawa South and MB1989200 (85 percent of 117) in Tawa Central, Northern Ward in Wellington city are other mesh blocks with significant 
Map: 4.16. Population for Whom English May Not Be the First Language in the Wellington Region (2006)
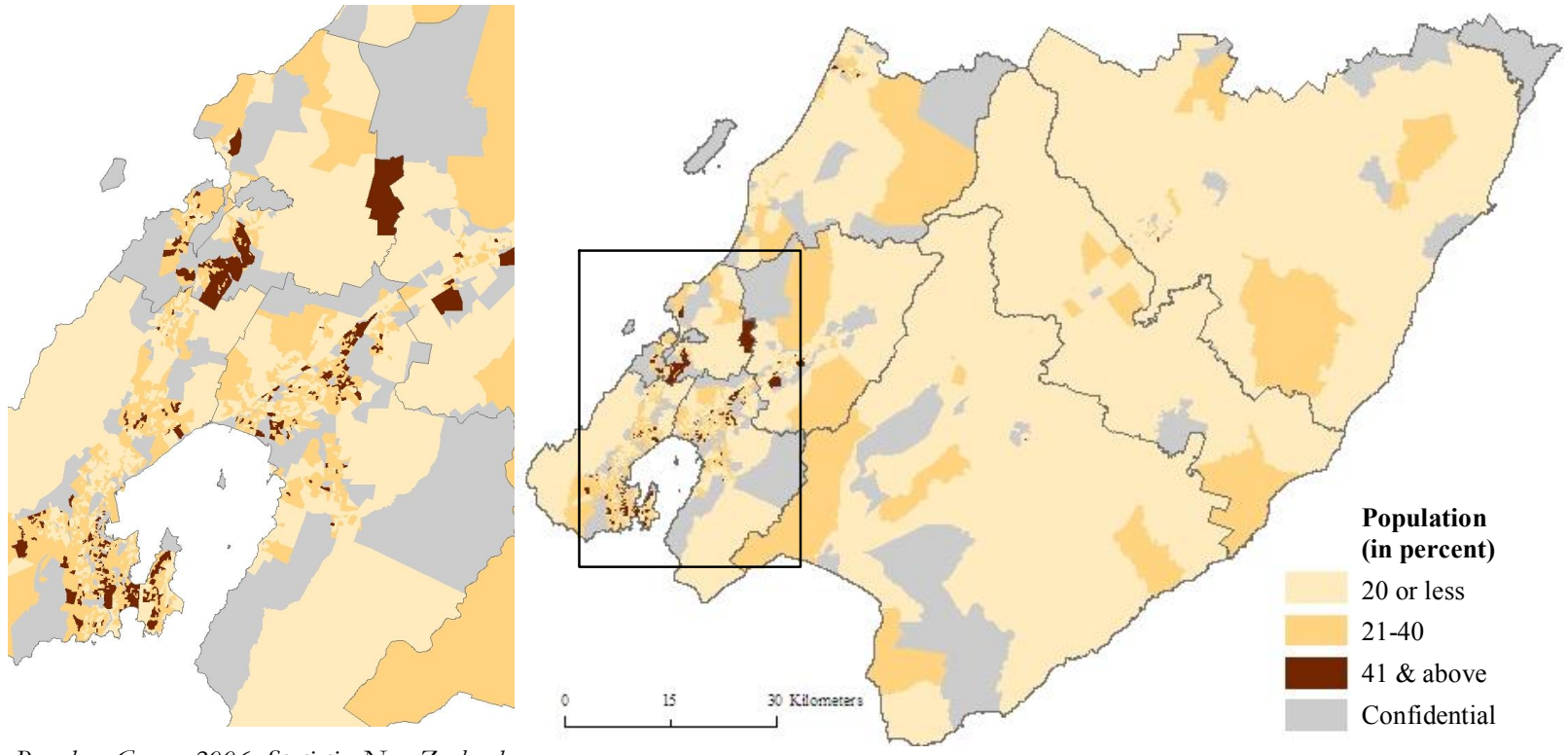

Based on Census 2006, Statistics New Zealand

proportion of population for whom English is not the most common language. For most of these mesh blocks the data on ethnicity are confidential except one MB1900500 in Trentham South, Upper Hutt population, where about 75 percent of the population is Asian and eight percent is Maori and European each.

\subsubsection{Ethnicity}

Ethnicity itself does not produce vulnerability. However, certain socio-economic characteristics associated with different ethnic groups influence vulnerability to disaster. It has been noted that in a diverse society, different ethnic groups tend to assert their differences, which could result in conflict primarily because of economic reasons (Gomez, 2008, 1). Disaster often results in economic crises and in such situations, ethnic differences could fabricate social biases and prejudice, which could make coping difficult for one section of the community or another. It is not that a particular ethnicity is associated with all social injustice, but often it is the minorities of any ethnic group who feel more segregated and separated, which results in mental and emotional stress. Ethnicity is also linked with barriers to culture and language, which affects recovery and resilience (Pulido (2000), Peacock, Morrow and Gladwin (1997, 2000), Bolin with Stanford (1998) and Bolin (1993) as cited in Cutter et al, 2003, 246).

Table: 4.6. Ethnic Composition in the Wellington Region (2006)

\begin{tabular}{lcccccc}
\hline \multirow{2}{*}{\begin{tabular}{l} 
Author Territorial \\
\cline { 2 - 7 }
\end{tabular}} & European & Maori & Pacific & Asian & MELAA & Other \\
\hline Carterton District & 80.3 & 9.6 & 1.5 & 1.1 & 0.3 & 11.7 \\
South Wairarapa District & 77.6 & 12.3 & 1.6 & 1.6 & 0.2 & 12.5 \\
Kapiti Coast District & 76.9 & 11.9 & 2.1 & 2.3 & 0.2 & 12.9 \\
Masterton District & 75.9 & 16.5 & 2.7 & 1.6 & 0.3 & 11.9 \\
Upper Hutt City & 73.6 & 13.5 & 4.3 & 4.0 & 0.6 & 12.1 \\
Wellington City & 67.6 & 7.4 & 5.0 & 12.7 & 2.0 & 10.2 \\
Lower Hutt City & 63.4 & 16.7 & 10.3 & 8.6 & 1.1 & 9.8 \\
Porirua City & 54.0 & 19.9 & 25.3 & 4.3 & 0.5 & 8.5 \\
Wellington Region & $\mathbf{6 7 . 5}$ & $\mathbf{1 2 . 3}$ & $\mathbf{7 . 7}$ & $\mathbf{8 . 1}$ & $\mathbf{1 . 2}$ & $\mathbf{1 0 . 5}$ \\
\hline
\end{tabular}


The region has significant ethnic diversity. The European population is dominant with 68 percent of total population followed by Maori (12 percent), Asian (8.1 percent), Pacific (7.7 percent), Middle Eastern, Latin American and African population [MELAA] (1.2 percent) and the other ethnicity, which is a new category introduced in the Census 2006 and refers to New Zealanders form nearly ten percent. Besides Maori-the local ethnic group, Pacific, MELAA and Asian groups could be classified as relatively more vulnerable because of foreign language, less income and international status, which could result in social biases during disaster. The ethnic distribution of population shows that most minority groups except Maori are mainly concentrated in urban area especially in Wellington, Porirua, Lower Hutt and Upper Hutt. The reason could be associated with low income, which implies nearness to the work and other services along with cheap housing.

Map: 4.17. Ethnic Composition in the Wellington Region (2006)

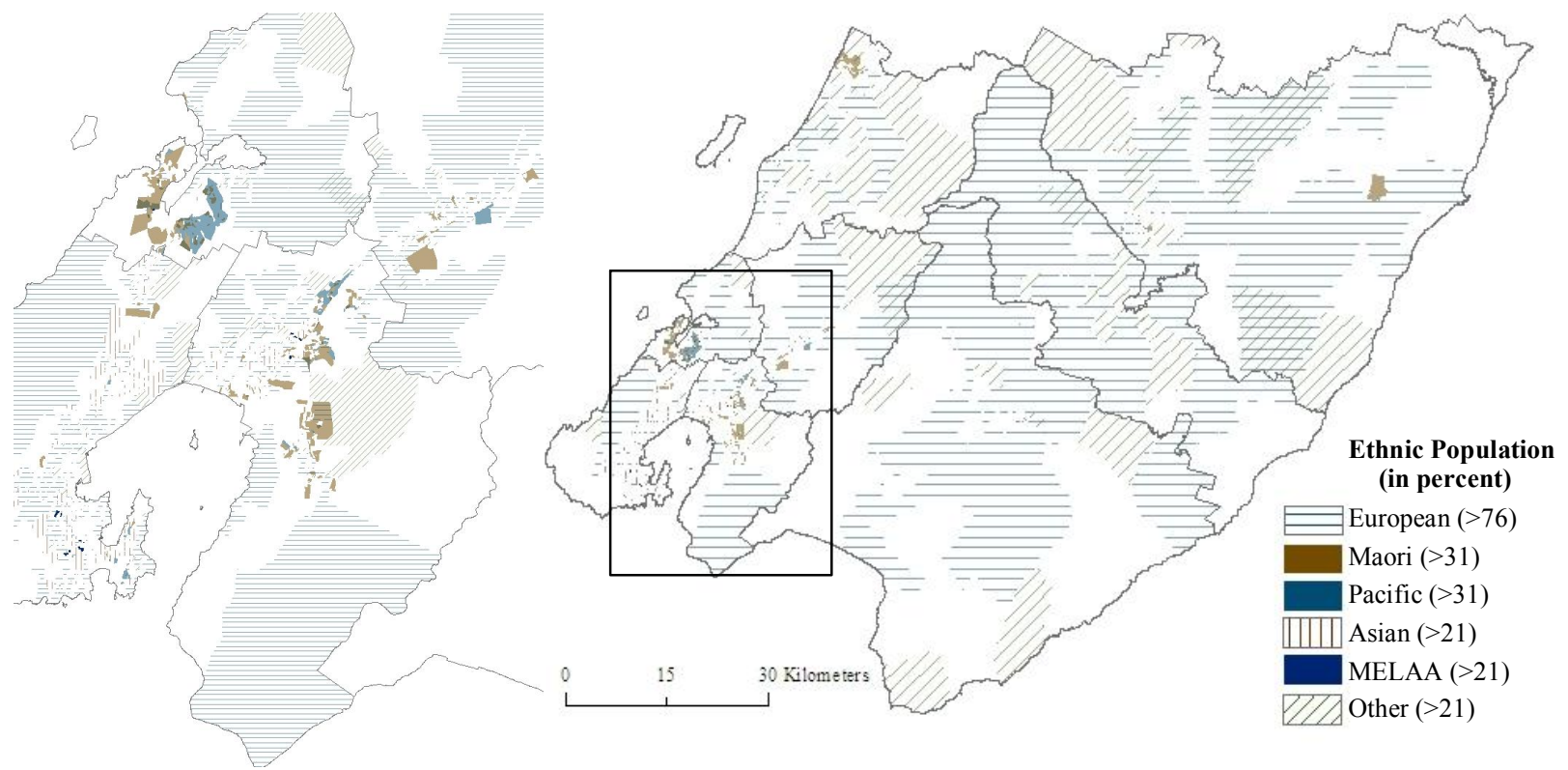

Based on Census 2006, Statistics New Zealand

Segregation of ethnic groups is more clearly defined at the mesh block level. Mesh blocks including MB2188601 in Island Bay West, MB2191702 in Island Bay East, MB2179500 and MB2180101 in Kilbirnie West, MB2103001 in Wilton-Otari, MB2089900 in Te Kainga, and MB2187801 in Happy Valley-Owhiro Bay in Wellington, MB2069103 Mana-Camborne, MB2070000 in Paremata-Postagate in Porirua, MB1983400 and MB1984600 in Eastbourne, MB1918901 in Belmont, MB1940402 in Taita North and MB1927002 in Manuka in Lower Hutt, MB1874300 in Waikanae Beach, MB2000904 in Paraparaumu Beach North in the Kapiti Coast and MB2252100 in Lansdowne in Masterton have hundred percent European population. Against these MB2048900, MB2048900 and MB2047900 in Cannons Creek North, MB2063400, 2062802, MB2061600 and MB2063000 in Cannons Creek East, MB2060400, MB2059300, MB2060700 and MB2061000 in Waitangirua in Porirua, MB1900500 in Trentham South, Upper Hutt and MB1948600 in Avalon East in Lower Hutt have less than ten percent European population. The Maori population, on the other hand, is more dominant in MB1976102 (94 percent) and 
MB1976300 (75 percent) in Waiwhetu North, Lower Hutt and in MB2066800 (72 percent) in Plimmerton in Porirua.

A significant proportion of the Pacific community is located in Porirua. The mesh block with a dominant Pacific community is MB2206700 in Miramar South, Wellington with 90 percent of Pacific people. Besides, 17 mesh blocks in Waitangirua, Eastern Ward, two in Cannons Creek North, Eastern Ward, eleven in Cannons Creek East, Eastern Ward, one in Cannons Creek South, Eastern Ward, and one in Ascot Park, Eastern Ward in Porirua have 70 percent or more Pacific population. Asian population, on the other hand, is more concentrated in Wellington and Lower Hutt. The highest Asian population is located in MB2134800 (80 percent) in Willis StreetCambridge Terrace in Lambton Ward, Wellington followed by MB1900500 (75 percent) in Trentham South, Upper Hutt, MB2157000 (67 percent) in Aro Street-Nairn Street in Wellington, MB1979301 (65 percent) in Waiwhetu South in Moera in Lower Hutt.

MELAA population is mainly located in Wellington, Lower Hutt and Porirua. At mesh block level their concentration is more in MB1948600 (52 percent) in Avalon East, Lower Hutt, MB2166100 (45 percent) and MB2166200 (40 percent) in Newtown East in Wellington. A high concentration of the population who identify themselves as New Zealanders are mainly located in MB2067801 (56 percent) in Plimmerton, Porirua, MB1983700 (50 percent) in Eastbourne, Lower Hutt and MB1882513 (42 percent) in Otaki Forks, the Kapiti Coast.

Table 4.7 shows vulnerability characteristics of different ethnic groups in the region drawn on the basis of the dominance of specific ethnic population at the mesh block level. Dominance of a specific ethnic group in a mesh block has been defined if the mesh block has 60 percent or more population of a particular ethnic community. However this criterion could not be used for all groups because MELAA and other ethnic groups only formed slightly more than 50 percent in mesh blocks of their majority. Therefore for them 50 percent of the population is taken as the limit for defining their dominance in the mesh block. However, overall characteristics drawn on this basis are generalised as another 40-50 percent of the total population of selected mesh blocks may not belong to the same ethnic group and further, vulnerability would vary at household and individual level.

According to the data (Table: 4.7), Europeans could be classified as least vulnerable across various ethnic groups. European vulnerability in the region is mainly linked to age. They have the highest share of population above 65 years of age (about 12 percent), along with single person households (22 percent). Elderly people living alone could be more severely affected by hazard than any other group because of their physical incapability and absence of help in the household.

Vulnerability of the Maori population, on the other hand, is contributed to by a set of factors. Maori have maximum share of people with no qualification (27 percent), females with four or more children (26 percent) and workers engaged in agriculture (five percent). Besides they also have significant proportion of family households ( 74 percent) and single parents (43 percent) as they are less likely to be not married and more likely to live in de facto relationships (Statistics New Zealand, 1998d, 33), workers in elementary occupation (22 percent), which is linked to less qualification, besides population living on pension, allowance or benefits ( 26 percent). These 
Table: 4.7. Population Characteristics of Ethnic Groups in the Wellington Region (2006)

\begin{tabular}{|c|c|c|c|c|c|c|}
\hline \multirow{2}{*}{$\begin{array}{c}\text { Population Characteristics at Mesh block } \\
\text { level }\end{array}$} & \multicolumn{6}{|c|}{ Ethnic Groups } \\
\hline & European & Maori & Pacific & Asian & MELAA & Other \\
\hline Proportion of population (lower limit in percent) & 60 & 60 & 60 & 60 & 50 & 50 \\
\hline Number of mesh blocks & 2985 & 13 & 78 & 4 & 1 & 2 \\
\hline Average population per mesh block & 112 & 94 & 108 & 86 & 75 & 29 \\
\hline Average density & 2,727 & 2,543 & 4,180 & 5,545 & 5,185 & 1,283 \\
\hline Average Median Income (NZD) & 27,116 & 18,185 & 15,587 & 9,425 & 12,100 & $C^{*}$ \\
\hline \multicolumn{7}{|l|}{ Average proportion per mesh block (in percent) } \\
\hline Ethnic Population & 76 & 69 & 68 & 71 & 52 & 53 \\
\hline Female & 52 & 50 & 51 & 45 & 56 & 58 \\
\hline Children of less than five years & 6 & 8 & 10 & 1 & 12 & 0 \\
\hline Elderly of age 65 or more & 12 & 9 & 5 & 4 & 4 & 10 \\
\hline Zero years of living at current residence & 23 & 20 & 19 & 41 & 20 & 21 \\
\hline Lived overseas five years ago & 8 & 2 & 6 & 54 & 12 & 10 \\
\hline Single Parents & 15 & 43 & 36 & 3 & 50 & 17 \\
\hline Females with four or more children & 9 & 26 & 22 & 1 & 10 & 0 \\
\hline No qualification & 13 & 27 & 21 & 4 & 20 & 0 \\
\hline English not a first language & 19 & 35 & 61 & 70 & 68 & 11 \\
\hline No source of income & 4 & 6 & 8 & 22 & 6 & 0 \\
\hline Population living on benefit/pension/allowance & 23 & 26 & 21 & 14 & 36 & 0 \\
\hline Unemployed & 2 & 5 & 6 & 5 & 8 & 11 \\
\hline Engaged in elementary occupation & 8 & 22 & 24 & 10 & 50 & 0 \\
\hline Engaged in agriculture, fishing or forestry & 3 & 5 & 1 & 0 & 0 & 0 \\
\hline Living in one or two rooms & 2 & 1 & 0 & 17 & 0 & 0 \\
\hline Living in one bedroom & 5 & 6 & 1 & 17 & 0 & 0 \\
\hline Dwelling not owned & 27 & 42 & 55 & 24 & 83 & 13 \\
\hline No access to motor vehicle & 9 & 16 & 18 & 16 & 17 & 13 \\
\hline No access to telecommunication & 1 & 6 & 5 & 2 & 17 & 0 \\
\hline Family households & 66 & 74 & 73 & 33 & 100 & 30 \\
\hline Multi person households & 6 & 8 & 4 & 7 & 0 & 10 \\
\hline Single person households & 22 & 18 & 10 & 9 & 0 & 10 \\
\hline
\end{tabular}

Based on Census 2006, Statistics New Zealand

$\mathrm{C}^{*}=$ Confidential

characteristics produce low income and high economic vulnerability, which could intensify during a disaster, and affect coping capacity to deal with disaster impacts.

Although the Pacific population is not visible on the extreme end of vulnerability scale, they are vulnerable to a disaster in many ways. They closely resemble Maori in terms of vulnerability characteristics, but are relatively more vulnerable than the latter. They have a significant proportion of single parents (36 percent), females with four or more children (22 percent), population with no qualification (21 percent), population engaged in elementary occupation (24 percent), no source of income (eight percent), children less than five years old (10 percent). Besides this about 55 percent of the population in these mesh blocks do not own their dwelling and about 18 percent of households do not have access to a motor vehicle, which is the highest across all ethnic groups. Their vulnerability is also contributed to by the fact that they are not native, and therefore, they may not be as familiar with the local environment as Maori, who have been living here for generations.

The Asian population faces a different kind of vulnerability. Mesh blocks with dominant Asian population have a minimum female population (45 percent), minimum child population with less than five years of age (one percent), minimum elderly population (four percent) and minimum 
single parents (three percent). The population composition however differs significantly among Asians from different countries. While the population contrast between male and female has been observed at a maximum in the Filipino and Thai population, the Chinese composition more closely relates to New Zealand because of a long history of residence in the country (Statistics New Zealand, 1998b, 21). Asian vulnerability is high in economic terms i.e. they have minimum medium income i.e. 9,425 NZD (which again differs across the country of origin i.e. minimum income was noted for Korean, Thai and Iranian and maximum for Sri Lankan, Japanese and Malay in 1996 as cited in Statistics New Zealand, 1998b, 87), a significant population with no source of income (22 percent), the highest proportion of population living in one to two rooms or in one bedroom houses i.e. 17 percent in each category, which results in the highest density of population in these mesh blocks i.e. 5,545 person per sq $\mathrm{km}$ and causes vulnerability through exposure. Asian dominant mesh blocks also have the highest proportion of people who have less than one year in their current houses (41 percent), population who lived overseas five years ago (54 percent) and population for whom English is not the first language $(70$ percent). This results in vulnerability through unawareness and problems in communication. A significant Asian population, particularly in Wellington city comprises students, who come for education, who are new, unaware about local hazards and lack a social network.

People of MELAA origin on the other hand, face severe vulnerability. Since the source areas are more likely to be in conflict, the population from these countries is likely to be largely refugees, which is apparent in their socio-economic characteristics. The mesh block with dominant MELAA population has the highest proportion of single parents (50 percent), population engaged in elementary occupation (50 percent), population who do not own a dwelling (83 percent) and population with no access to telecommunication (17 percent). Besides this the mesh block also shows some other vulnerability indicators such as a noteworthy population with no qualification (20 percent), population with no source of income (six percent), unemployed population (eight percent), population with no access to motor vehicle (17 percent), population dependent on pension, benefits or allowance (30 percent) and a significant population (68 percent) for whom English is not the first language. Almost all households in this mesh block are family households, which indicate that these families may find it hard to recover from disaster impact because of low income and family dependency.

Other ethnic group in the Census is a new category, which mainly includes the people who identify themselves as New Zealanders. It does not necessarily represent one ethnic group as the people in this category could be European, Maori or from any other ethnic group having New Zealand citizenship. The mesh blocks dominated by this population have the highest female composition (58 percent), unemployed population (11 percent) and multi person households (10 percent), besides a significant elderly population (10 percent). These mesh blocks have no female population with four or more children, or without any source of income and minimum family households (30 percent) across ethnic groups. This group is vulnerable because of its elderly female population, who may require external assistance for disaster response and recovery. 
Plate: 4.2. Social Vulnerability Index of the Wellington Region (2006)
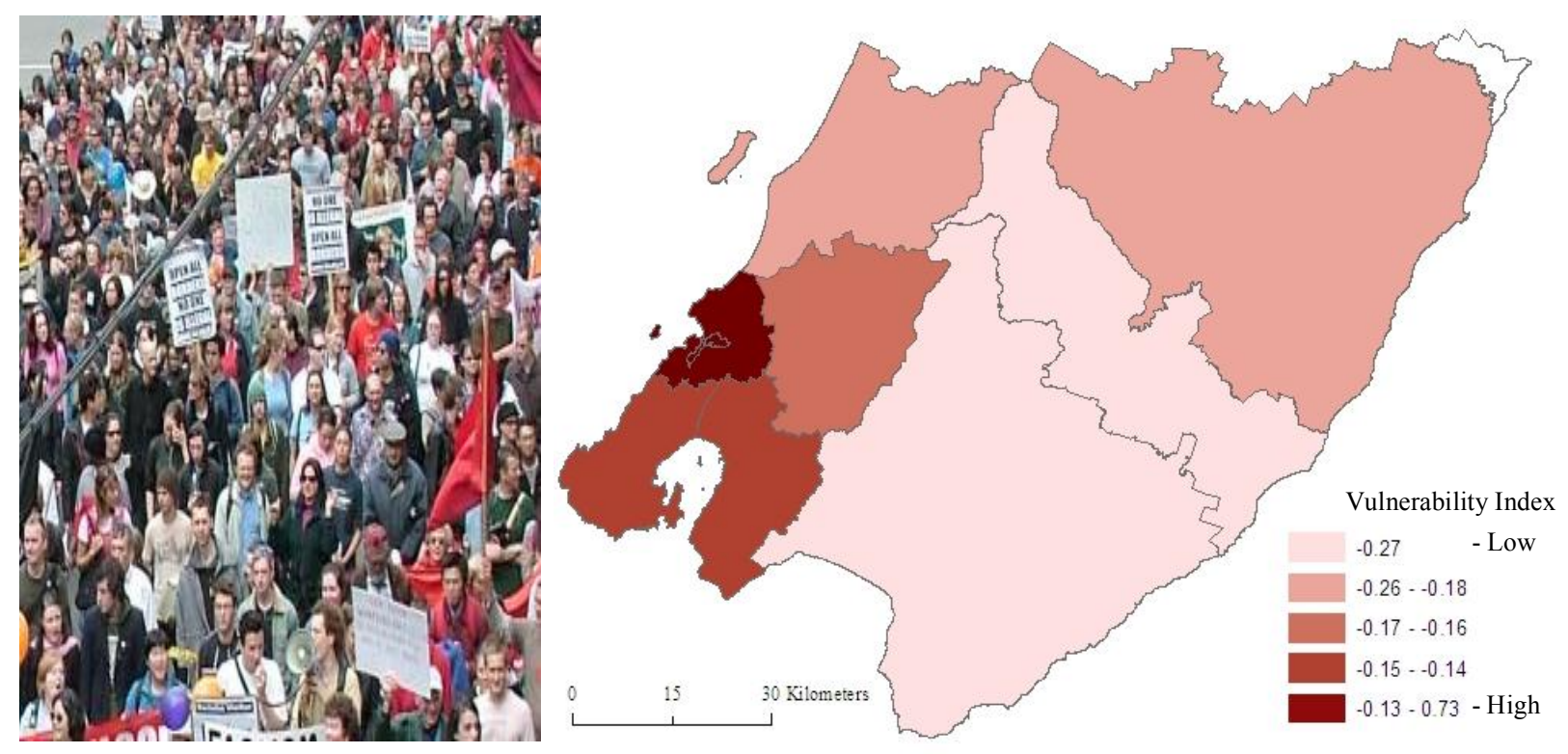

1. Vulnerability Index Based on Maximum Imputation Value

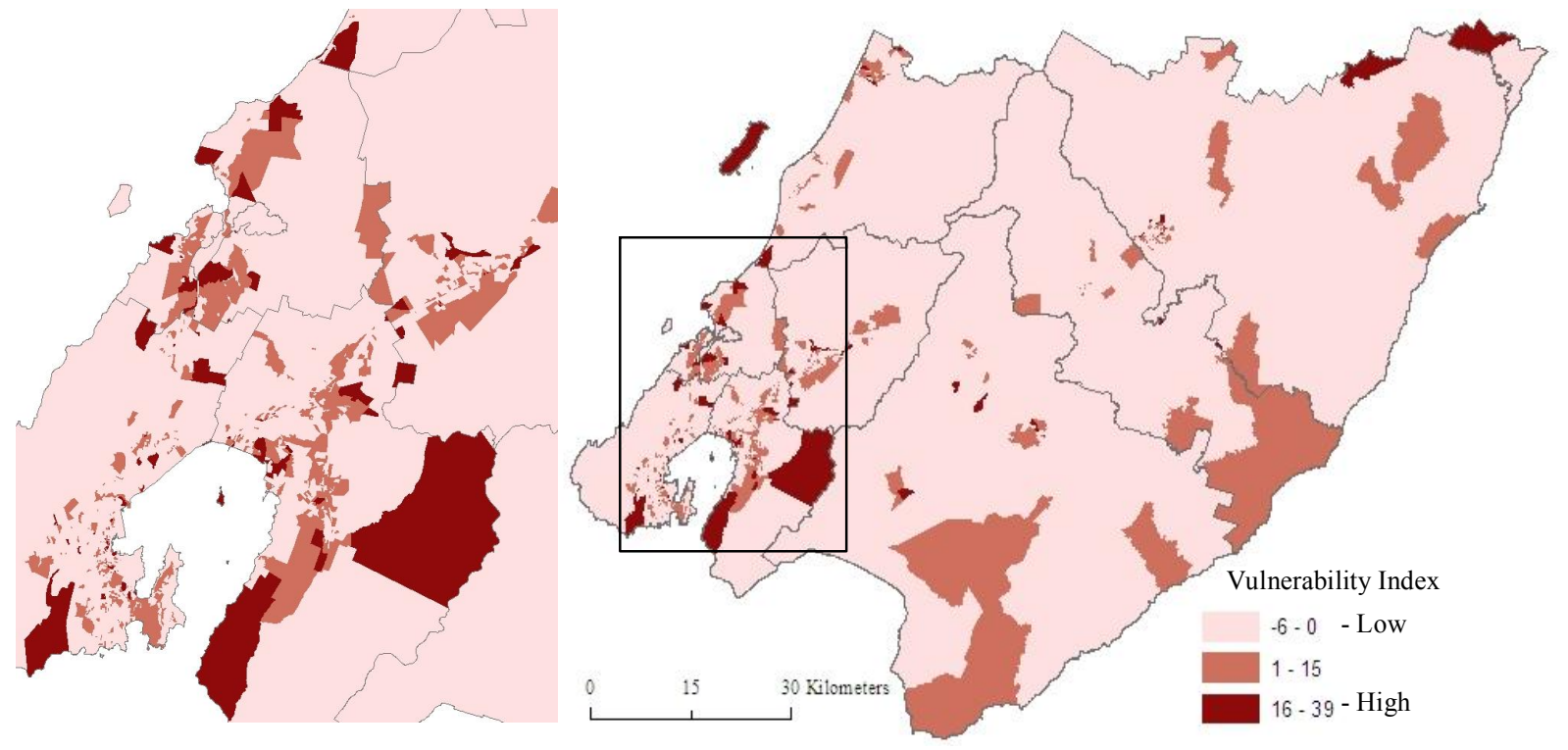

2. Vulnerability Index Based on Minimum Imputation Value

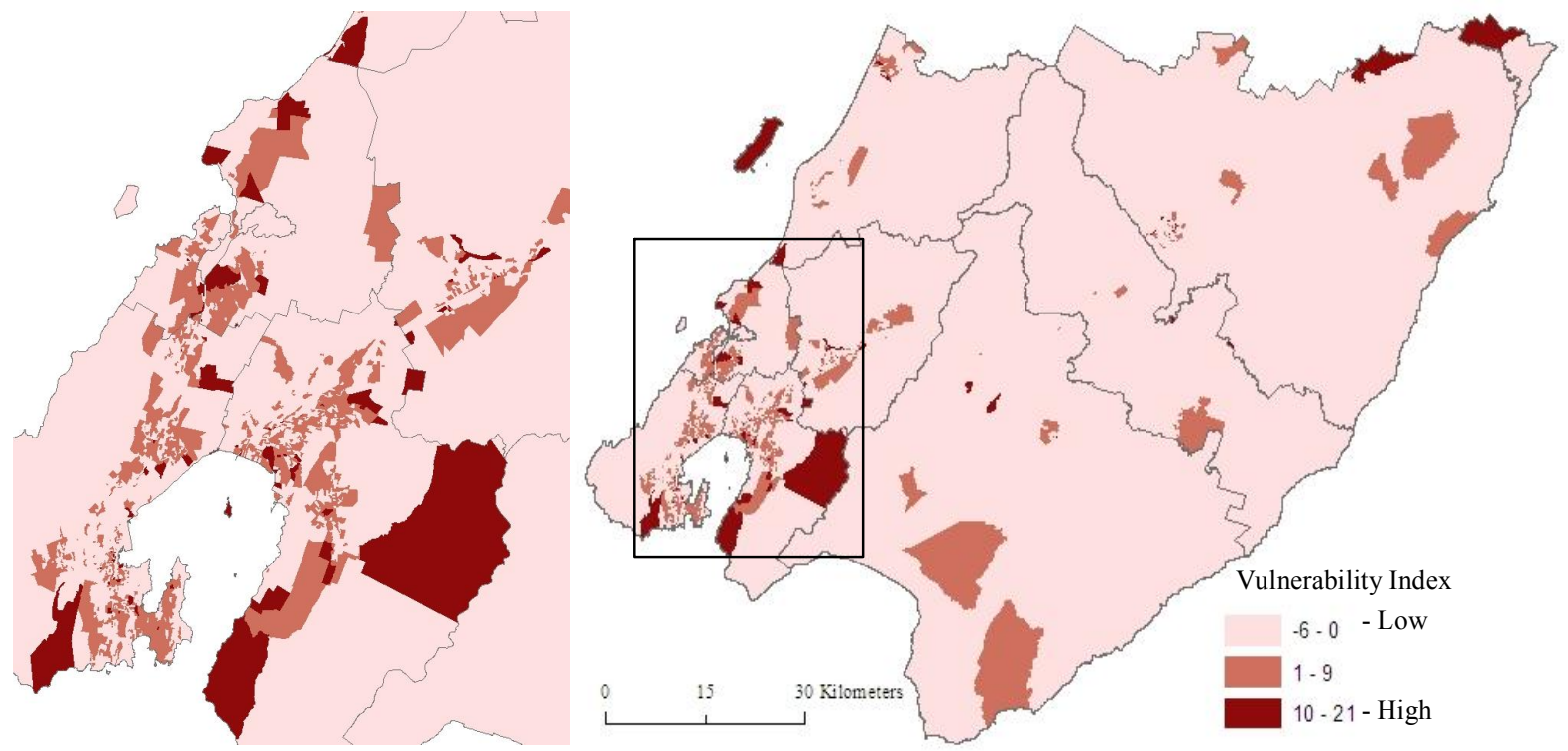

Based on Census 2006, Statistics New Zealand; wmw.scoop.co.nz 
The ethnic categories as named by Census, do not necessarily represent total diversity and cannot be taken as the rigid units for people's vulnerability and response, because there are lots of variations at local level, which are induced by race, culture, religion and other factors, which indirectly affect vulnerability by affecting response.

\subsubsection{Social Vulnerability Index}

The aggregated social vulnerability index of the region based on family type, education, language and ethnicity (see chapter 1) puts Porirua as the most vulnerable district, followed by Wellington and Lower Hutt. Vulnerability Index calculated at mesh block level shows 135 mesh blocks by using maximum imputed values and 117 mesh blocks by using minimum imputed values in the most vulnerable category. Though these mesh blocks are distributed throughout the region, a significant proportion of them i.e. nearly one fifth or more are in Wellington city.

The district-wise distribution of these mesh blocks based on minimum imputed values shows 38 in Wellington, 30 in Lower Hutt, 13 in Porirua, 11 in Masterton, ten in Upper Hutt, eight in the Kapiti Coast and four in South Wairarapa. The distribution on the basis of maximum imputed values include 41 in Wellington, 32 in Lower Hutt, 18 in Porirua, 14 in Masterton, 11 in Upper Hutt, ten in the Kapiti Coast, six in South Wairarapa, two in Carterton and one in Masterton. Mesh blocks which scored highest value on the vulnerability scale include MB2136900 in Willis Street-Cambridge Terrace and MB2116802 in Makara-Ohariu in Wellington, MB1906300 in Upper Hutt Central and MB1914000 in Maoribank in Upper Hutt, MB2268400 in Featherston, South Wairarapa, MB1930500 in Tawhai, MB2027000 in Esplande and MB 1981000 in Gracefield, Lower Hutt, MB2053000 in Porirua Central and MB2053200 in Paekakariki Hill in Porirua, MB1881402 and MB1883203 in Otaki and MB 2009702 in Paekakariki in the Kapiti Coast. The index calculated by using minimum imputed value adds two more mesh blocks to the list. These include MB1961100 in Naenae North and MB1940403 in Taita North from Lower Hutt.

\subsection{Economic Vulnerability}

Economic vulnerability not only affects coping capacity of an individual and the community during a disaster, but it also governs the temporal extent of a disaster along with the nature of the response and degree of resilience. Various indicators of economic vulnerability include employment, income, housing and access to means of communication.

\subsubsection{Employment \& Occupation}

Employment is an important indicator of economic vulnerability. According to the 2006 Census, about 51 percent of the population in the Wellington Region is employed full time, 14 percent is employed part time and for another three percent, work status is unidentifiable (Table: 4.8). For those who are employed full time, their vulnerability is determined by their occupation. 
Occupation is not only an important determinant of income, which affects coping capacity and resilience, but it also governs the exposure to hazards especially those related to primary activities.

Table: 4.8. Work Status in the Wellington Region (2006)

\begin{tabular}{lcccc}
\hline Local Territorial Authority & \multicolumn{4}{c}{ Population (in percent) } \\
\cline { 2 - 5 } & $\begin{array}{c}\text { Employed } \\
\text { Full-time }\end{array}$ & $\begin{array}{c}\text { Employed } \\
\text { Part-time }\end{array}$ & $\begin{array}{c}\text { Dependent } \\
\text { population }\end{array}$ & $\begin{array}{c}\text { Work status } \\
\text { Unidentifiable }\end{array}$ \\
\hline Kapiti Coast District & 41 & 14 & 42 & 3 \\
Porirua City & 50 & 13 & 33 & 4 \\
Upper Hutt City & 51 & 14 & 33 & 2 \\
Lower Hutt City & 52 & 14 & 33 & 2 \\
Wellington City & 55 & 15 & 27 & 3 \\
Masterton District & 45 & 16 & 37 & 2 \\
Carterton District & 49 & 16 & 33 & 2 \\
South Wairarapa District & 50 & 15 & 32 & 3 \\
Wellington Region & 51 & 14 & 32 & 3 \\
\hline
\end{tabular}

Based on Census 2006, Statistics New Zealand

New Zealand Standard Classification of Occupations (1999) categorises nine types of occupations based on skill requirements. These include Legislators, Administrators and Managers; Professionals; Technicians and Associate Professionals; Clerks; Service and Sales Workers; Agriculture and Fishery Workers; Trade Workers; Plant and Machine Operators and Assemblers and Elementary Occupations including residuals. The first four categories of this occupational classification represent high-paid white collar jobs, which provide security in terms of earnings, which enable savings and hence better coping capacity against natural hazards. The vulnerability increases with a shift towards blue collar jobs, which represent less paid work and hence less

Fig: 4.1. Occupational Structure of the Wellington Region (2006)

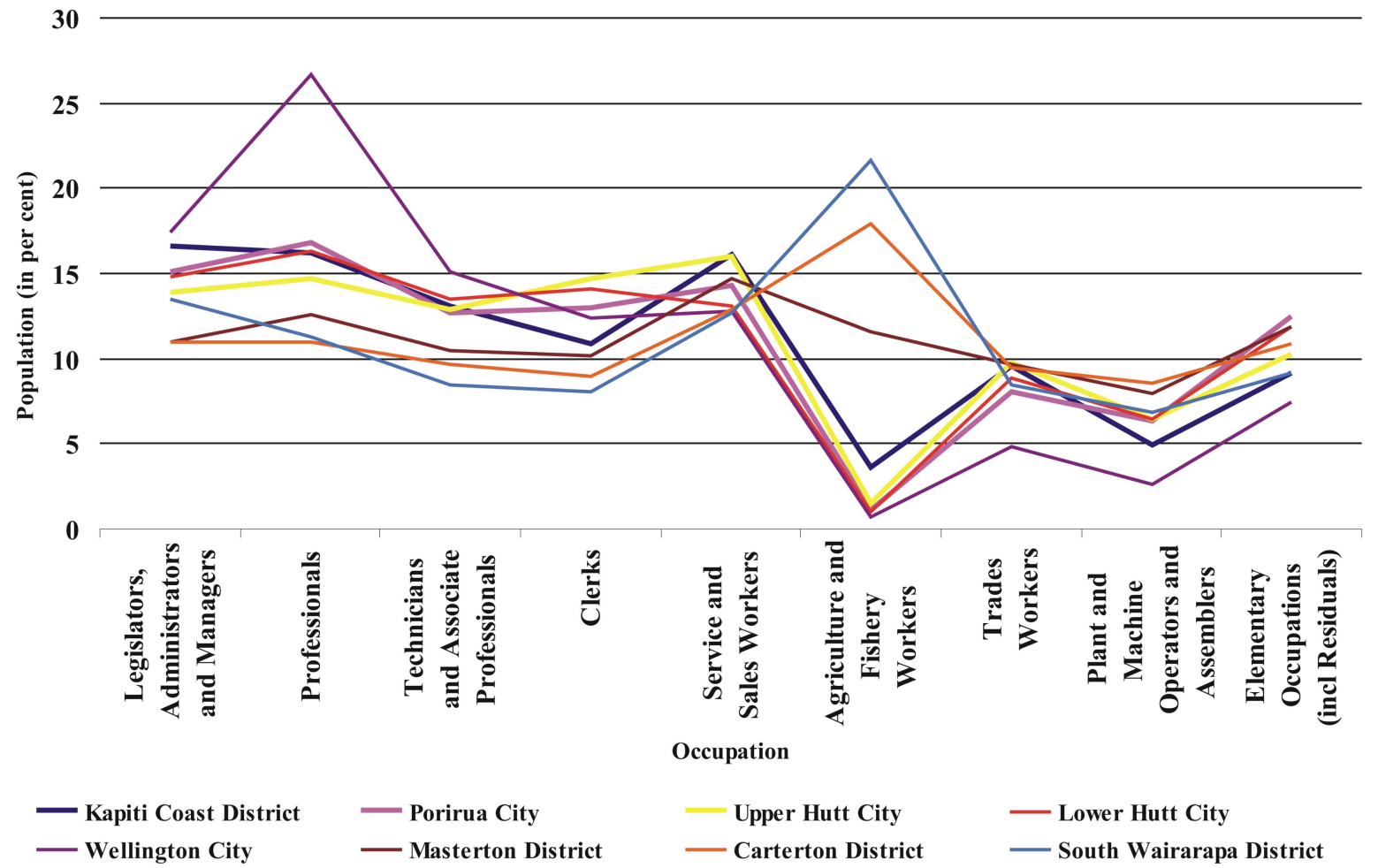


savings, which reduces coping capacity and resilience from disaster. Since Wellington is the capital of New Zealand, concentration of workers in highly paid white collar jobs including legislation, administrators, managers, professionals and semi professionals is greater than other territorial authorities in the region (Fig: 4.1). The workers in agriculture and fishery occupations on the other hand, are more dominant in rural districts of South Wairarapa, Carterton and Masterton. Occupations, which are directly affected by hazards, are Agriculture and Fisheries, Service and Sale workers and workers in Elementary Occupations.

Census classification of Agriculture and Fishery workers also refers to market farmers and crop growers, fruit growers, gardeners and nursery growers, market-oriented animal producers, mixed livestock producers, poultry producers, apiarists, crop and livestock producers, other agriculture workers, forestry and related workers, fishery workers and trappers (Statistics New Zealand, 1999, 31-32). While agriculture and pasture workers are exposed to climatic and hydrological hazards such as frost, hailstorm, flood, drought, along with tsunami, which could result in sea water intrusion in farmland, forest workers are exposed to bushfires and fishery workers to a hazardous combination of windstorm and sea surge. Disruption in income from hazards results in degradation of assets and savings and therefore, further affects the long-term coping capacity and resilience of workers. The region has two percent of the population engaged in Agriculture and Fisheries. The percentage of these workers is highest in South Wairarapa (22 percent) followed by Carterton (18 percent) and Masterton (12 percent) and least in Wellington ( $<1$ percent). At mesh block level, a clear divide can be seen between east and west in map 4.18. In most city centres even less than five percent of workers are engaged in this sector and the proportion varies from 6 to 25 percent in adjoining suburban hinterland. In the western section of the region, only the Kapiti Coast has two mesh blocks with more than 25 percent of Agriculture and Fishery workers. In the eastern section of the region, on the other hand most mesh blocks have more than 25 percent of Agriculture and Fishery workers except urban centres and adjoining areas. The proportion of such workers is highest in MB2254701 (73 percent), followed by MB2229902 (71 percent) in Whareama, Rural Ward in Masterton. Also in mesh blocks including MB2271000, MB2272901, MB2276901 and MB2276701 
in Kahutara and MB2275800 in Tututrumuri in South Wairarapa and MB2255500 in Whareama in Masterton, such workers vary from 60 to 70 percent of total workers.

Since New Zealand is a tourist destination and most tourists visit Wellington on their way to the North or South Island, 'services and sales' is an important occupational group in the region. However, Census data on service and sales workers include a range of workers within and outside the tourism industry. These include travel attendants and guides, housekeeping and restaurant services workers, cooks, waiters and bartenders, personal care workers, other personal services workers, child care workers, funeral directors, fire fighters, police, prison guards, other protective service workers, armed forces, salespersons and demonstrators, street vendors, fashion and other models (Statistics New Zealand, 1999, 29-30). About 14 percent of workers in the region are engaged in Services and Sales occupations. At district level the proportion of these workers is highest in the Kapiti Coast i.e. about 16 percent, and lowest in South Wairarapa i.e. 12.6 percent.

Map: 4.19. Sales and Services Workers in the Wellington Region (2006)

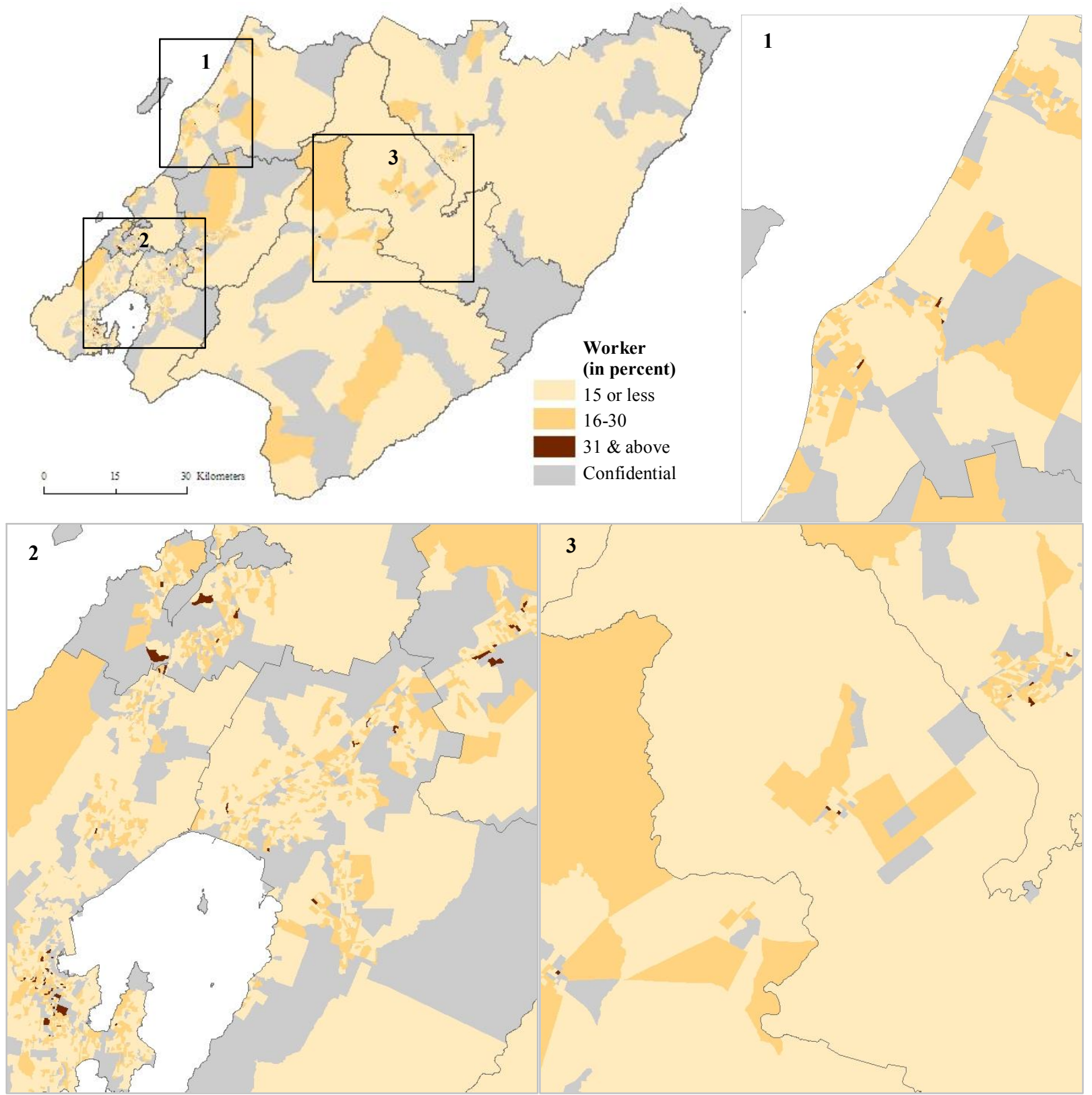


The share of these workers in the total workforce is also low in Wellington i.e. 12.8 percent, but due to bigger population size the actual population engaged in these occupations would be higher than in South Wairarapa. The distribution of these workers at mesh block level shows that they are mainly concentrated in cities and adjoining areas (Map: 4.19).

Since occupational classification includes a wide range of workers in the 'services and sales' industry, income differs significantly within this occupational group, depending on the type of work. Though such data are not available at mesh block level, inferences could be drawn on the basis of other related characteristics. The percentage of services and sales workers is highest in MB1898000 (75 percent) in Heretaunga-Silverstream in Upper Hutt. Total population of this mesh block is 87 with median family income of 79,000 NZD and no family earns less than 20,000 NZD annually, which indicates a higher income group within services and sales sector. Other mesh blocks of high concentration of services and sales workers include MB1883706 (63 percent) in Waikanae East in the Kapiti Coast and MB1900300 (55 percent) and MB1900400 (53 percent) in Trentham South in Upper Hutt. The median individual income within these mesh blocks are 20,800 NZD, 3,400 NZD, and 44,000 NZD respectively, which shows low to moderate income. In Wellington city, the highest concentration of such workers is in Lambton Ward especially in MB2153300 (53 percent) and MB2153100 (46 percent) in Kelburn, MB2128400 (50 percent), MB2128800 (50 percent) in Lambton area with median income of 4,000 NZD, 3,700 NZD, 3,300 NZD and 7,100 NZD which is well below the amount an individual would require annually to survive. These areas have high concentration of students, who are enrolled at universities or other educational institutes, and work in the Service and Sale industry on a part time basis and provide cheap labour.

Another category which is largely influenced by hazards is 'elementary occupations', which mainly involves labourers and related elementary service workers such as building caretakers and cleaners, messengers and doorkeepers, refuse collectors and related labourers, packers and freight handlers, labourers along with those for whom response was unidentifiable, or response was

Map: 4.20. Workers in Elementary Occupations in the Wellington Region (2006)
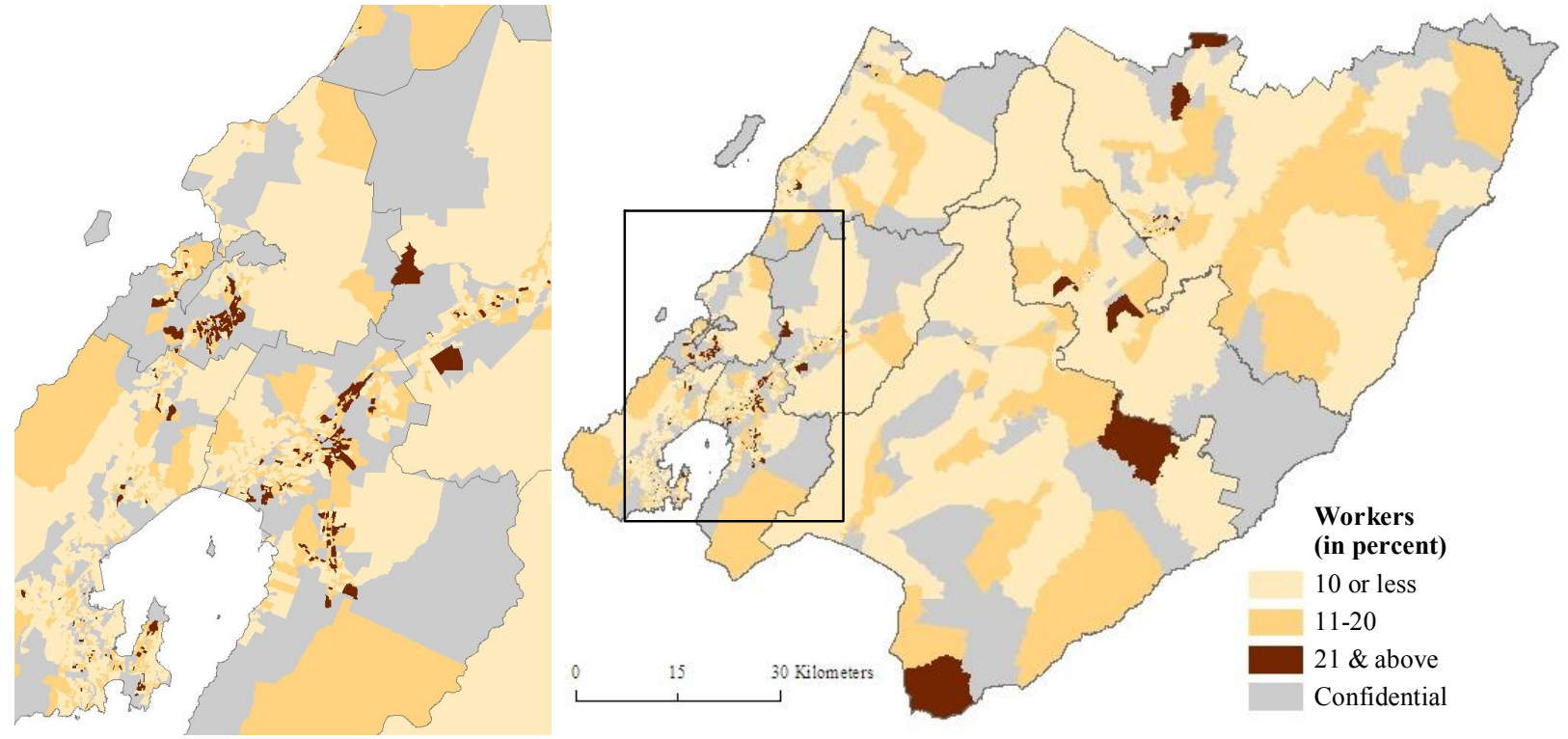

Based on Census 2006, Statistics New Zealand 
outside the scope or not stated (Statistics New Zealand, 1999, 41). Because of low income and hence less savings, workers in this category may suffer severely in a post-disaster situation. The region has about ten percent of its population engaged in elementary occupations. The proportion of these workers is highest in Porirua (13 percent), followed by Lower Hutt and Masterton with 12 percent each, Carterton (11 percent), Upper Hutt (ten percent), the Kapiti Coast and South Wairarapa each with nine percent and Wellington with seven percent.

At mesh block level in MB1900700 in Trentham South area in Upper Hutt, about 82 percent of population is engaged in elementary occupations. It is followed by MB1966700 in Hutt Central, MB2026700 in Esplanade in Lower Hutt, MB2062300 in Cannons Creek East in Porirua each with 57 percent of workers engaged in elementary occupations and in MB2048300 in Cannons Creek North in Porirua with 56 percent of such workers. In addition, there are six other mesh blocks including MB1948600 and MB1949300 in Avalon East, MB1959400 in Naenae North in Lower Hutt MB2048200 in Cannons Creek North and MB2049700 in Cannons Creek South in Porirua and MB2082600 in Johnsonville South in Wellington, where 50 percent of total workers are engaged in elementary occupations. All of these mesh blocks are located in urban areas, where people are located close to their workplace, and it is easier to find regular work.

Vulnerability further increases for those who work part time. The region has about 14 percent of population which works part time. These could include women and the elderly because of their other family responsibilities or physical inability to work full time. The category also includes students, both domestic and international, who could not work full time because of statutory limitations. The percentage of such people is highest in Masterton and Carterton, each with 16 percent of such workers and minimum in Porirua with 13 percent of such workers.

\subsubsection{Dependent and Unemployed Population}

The third category is that of dependent population, which basically includes the unemployed and those outside the labour force i.e. children and elderly population. The region has about 32 percent dependent population. The highest percentage of the dependent population is in the Kapiti Coast i.e. 42 percent followed by Masterton with 37 percent and the lowest is in Wellington i.e. 27 percent. On the regional scale, about three percent of the population is unemployed. Unemployment is least in South Wairarapa i.e. 1.6 percent and highest in Porirua (3.5 percent) followed by Lower Hutt (3.1 percent), Wellington (2.9 percent), Upper Hutt (2.6 percent), Masterton (2.4 percent), the Kapiti Coast (2.2 percent) and Carterton (1.8 percent). At mesh block level it is maximum in MB2132400 (33 percent) in Willis Street-Cambridge Terrace in Lambton Ward in Wellington followed by MB2023202 (25 percent) in Homedale East, Wainuiomata, Lower Hutt, MB2132500 (25 percent) Willis Street-Cambridge Terrace and MB2128400 (24 percent) in Lambton in Lambton Ward, Wellington. In addition, there are seven other mesh blocks in Wellington, five in Porirua, four in Lower Hutt, three in Upper Hutt, two in Masterton and one in the Kapiti Coast, where 15-20 percent of population were unemployed during the 2006 Census. 
Map: 4.21. Unemployed Population in the Wellington Region (2006)
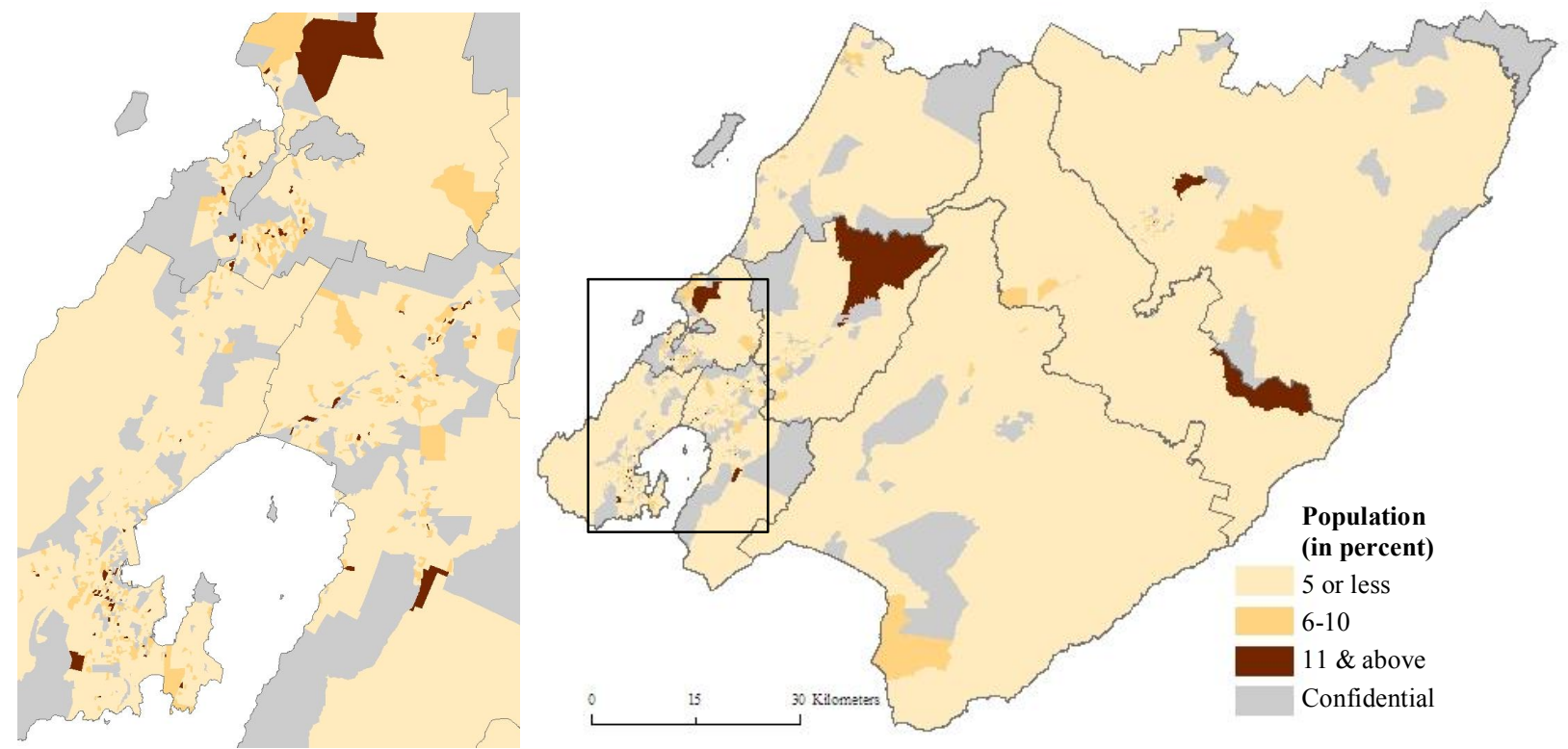

Based on Census 2006, Statistics New Zealand

The unemployed population along with the population outside the labour force such as the elderly or population with disabilities depends on government for income through benefits, allowance or pensions. Nearly a quarter of the population depends on pension (15.6 percent), benefits ( 6.5 percent) and allowances (1.8 percent). The percentage of people dependent on these benefits varies from as low as 20 percent in Wellington to as high as 38 percent in the Kapiti Coast. However, there are variations in the region depending on the type of benefits.

'New Zealand Superannuation and Veteran Pensions' are for people aged 65 years or more. It varies from 11,443 NZD for each partner per annum in case of a couple to 15,485 NZD for a single person living alone (NZ Superannuation, 2008). About 22 percent of the population in the the Kapiti Coast depends on these pensions, which is due to a high concentration of elderly people in the district. Percentage of such people is least in Porirua i.e. seven percent, which signifies a young demographic characteristic of the district. At mesh block level the highest concentration of people with 'NZ Superannuation or Veterans Pension' is in MB1940403 (96 percent) in Taita

Table: 4.9. Population Living on Benefits, Pension or Allowances in the Wellington Region (2006)

\begin{tabular}{|c|c|c|c|c|c|c|c|}
\hline \multirow{2}{*}{$\begin{array}{l}\text { Local } \\
\text { Territorial } \\
\text { Authority }\end{array}$} & \multicolumn{7}{|c|}{ Population (in percent) } \\
\hline & $\begin{array}{c}\text { NZ Super- } \\
\text { annuation or } \\
\text { Veterans Pension }\end{array}$ & $\begin{array}{c}\text { Other Super., } \\
\text { Pensions, } \\
\text { Annuities }\end{array}$ & $\begin{array}{c}\text { Unemploy- } \\
\text { ment } \\
\text { Benefit }\end{array}$ & $\begin{array}{c}\text { Domestic } \\
\text { Purposes } \\
\text { Benefit }\end{array}$ & $\begin{array}{r}\text { Invalids } \\
\text { Benefit }\end{array}$ & $\begin{array}{c}\text { Student } \\
\text { Allowance }\end{array}$ & $\begin{array}{c}\text { Other Govt } \\
\text { Benefits/ Pension } \\
\text { /Payments }\end{array}$ \\
\hline Kapiti Coast & 21.6 & 5.9 & 2.1 & 2.6 & 2.2 & 0.8 & 2.5 \\
\hline Porirua & 6.8 & 2.0 & 3.6 & 3.2 & 1.7 & 1.4 & 2.4 \\
\hline Upper Hutt & 11.5 & 3.1 & 2.3 & 2.4 & 1.9 & 0.9 & 2.5 \\
\hline Lower Hutt & 9.8 & 2.6 & 2.8 & 2.7 & 1.8 & 1.2 & 2.4 \\
\hline Wellington & 7.3 & 2.7 & 3.0 & 1.1 & 1.1 & 2.9 & 2.2 \\
\hline Masterton & 15.7 & 2.7 & 1.7 & 2.8 & 3.0 & 0.8 & 2.7 \\
\hline Carterton & 13.9 & 2.5 & 1.4 & 2.2 & 1.9 & 0.8 & 2.5 \\
\hline $\begin{array}{l}\text { South } \\
\text { Wairarapa }\end{array}$ & 15.1 & 2.7 & 1.7 & 2.2 & 1.8 & 0.6 & 2.3 \\
\hline $\begin{array}{l}\text { Wellington } \\
\text { Region }\end{array}$ & 10.3 & 3.0 & 2.8 & 2.1 & 1.6 & 1.8 & 2.3 \\
\hline
\end{tabular}


North, Lower Hutt followed by MB2168300 (92 percent) in New Town East, Wellington and MB1883704 (90 percent) in Waikanae East in the Kapiti Coast, which represent pockets of a high density of elderly population.

The population dependent on other superannuation, pension and annuities is again highest in the Kapiti Coast i.e. six percent and least in Porirua i.e. two percent. All mesh blocks with more than a quarter of the population dependent on these pensions are located in the Kapiti Coast. These include MB1875001 (33 percent) in Waikanae West, MB1883704 (30 percent) in Waikanae East, MB2003505 (28 percent) in Paraparaumu Beach South, MB2004101 (28 percent) in Raumati Beach and MB1883804 (28 percent) in Waikanae Park in the Kapiti Coast.

The unemployment benefit is provided by the department of labour, which provides a job finding service for the population of working age i.e. above 18 years old (Unemployment Benefit, 2008a). Unemployed population of age 20-24 especially men are more likely to get Unemployment Benefit (Unemployment Benefit for 20-24 year-olds, 2008) than other groups such as women, who are more likely to get other benefits. Unemployment Benefit is paid on a weekly basis and varies from 122.77 NZD net for a single person living at home of 18-19 years of age to 263.78 NZD net for a sole parent (Unemployment Benefit, 2008b). At district level, the concentration of population dependent on unemployment benefits is highest in Porirua (3.6 percent) followed by Wellington (three percent) and lowest in Carterton (1.4 percent). At mesh block level, the proportion of population living on 'Unemployment Benefits' is highest in MB2159800 (20 percent) in Aro StreetNairn Street in Lambton Ward, followed by MB2145700 (19 percent) in Mt Cook-Wallace street in Wellington along with MB2047800 in Cannons Creek North in Porirua, MB2167600 in Newtown East, MB2164901 in Newtown West in Wellington and MB2037100 in Elsdon-Takapuwahia in Porirua each with 18 percent of such population. Also, about five other mesh blocks in Lower Hutt, four in Wellington and three in Porirua have more than 15 percent of the population dependent on Unemployment Benefits.

'Domestic Purpose Benefits', on the other hand, are chiefly given to solo parents mainly single mothers more than 18 years old responsible for a child of less than 18 years without any partner (either parent or someone else). The current amount i.e. on $1^{\text {st }}$ October 2008 is 304.93 NZD a week before tax. They can also get accommodation support depending on family circumstances (Policy Quickies: Domestic Purposes Benefit, 2008). At district level, the highest proportion of the population dependent on domestic purpose benefits resides in Porirua (3.2 percent) followed by Masterton (2.8 percent) and least in Wellington (1.1 percent). At mesh block level such population is highest in MB2046300 (18 percent) in Cannons Creek North in Porirua, followed by MB1957100 (16 percent) in Naenae South in Lower Hutt and MB20242100 (15 percent) in Titahi Bay South in Porirua. Besides these, about 12 mesh blocks in Lower Hutt (eight in Eastern Ward, three in Northern Ward and one in Wainuiomata Ward), ten mesh blocks in Porirua (six in Western Ward and four in Eastern Ward), three in Urban Ward of Masterton and one each in Martinborough Ward of South Wairarapa and Paekakariki-Raumati Ward of the Kapiti Coast, have eleven to fourteen percent of the population living on domestic purpose benefits. 
Map: 4.22. Population Dependent on Benefits, Pension or Allowances for Income in the Wellington Region (2006)
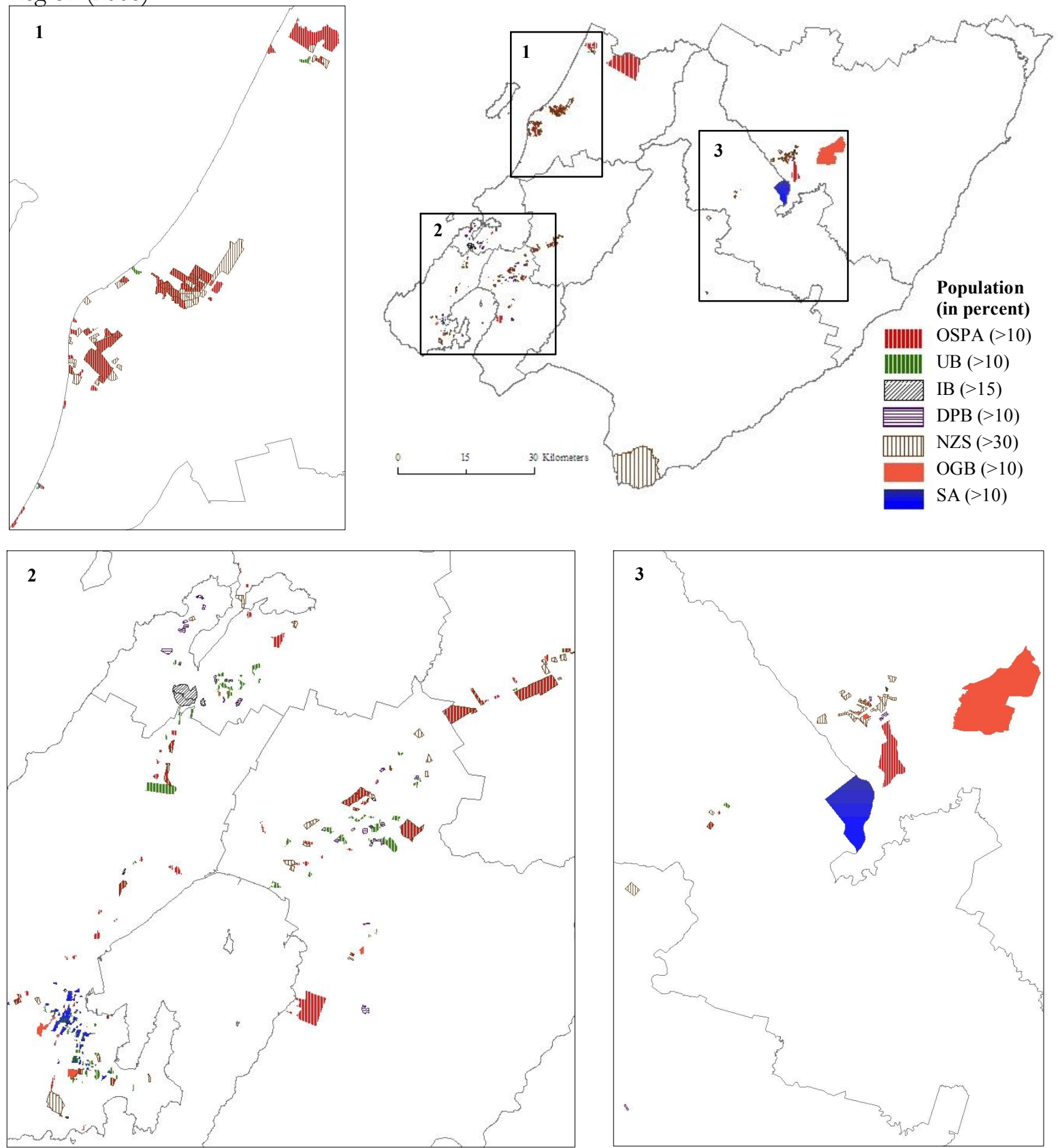

Based on Census 2006, Statistics New Zealand

Invalid benefits are given to those people who can do limited work due to sickness, injury or disability. Benefit rates vary from 186.28 NZD net per week for single person of age of 16-17 years to 302.40 NZD net per week for a sole parent with a hospital rate of 33.73 NZD as on $1^{\text {st }}$ October 2008 (Invalid's Benefit, 2008). The region has nearly 1.6 percent population dependent on invalid benefits, which varies from 1.1. percent in Wellington city to as high as three percent in Masterton. Although people living on Invalid Benefits are distributed widely in all urban areas, their concentration is high in MB2157800 (29 percent) in Aro Street-Nairn Street in Wellington closely followed by MB2051302 (28 percent) in Ranui Heights, MB2053104 (27 percent) in Porirua Central in Porirua, MB2082600 (25 percent) in Johnsonville South in Wellington and MB1949300 (24 percent) in Avalon East in Lower Hutt. In the rest of the mesh blocks it is less than 20 percent. In Masterton, where the proportion of population dependent on invalid benefits is highest, such 
population is widespread throughout the district, and in none of its mesh blocks exceeds 20 percent.

Student allowance is given on weekly basis for full time students who are either New Zealand citizens, permanent residents or refugees. Criteria and amount of allowance varies with age and family circumstances (Student Allowances, 2008). The region has nearly two percent of the population dependent on student allowance which varies from 0.6 percent in South Wairarapa, which is a rural district to nearly three percent in Wellington city. Mesh blocks with more than ten percent of people living on student allowance are mainly concentrated in Wellington along with one in Carterton. In Wellington the concentration of such people are high in Lambton Ward especially MB2157000 (33 percent), MB2158700 (25 percent) and MB2157400 (25 percent) in Aro Street-Nairn Street, MB2123900 (22 percent) in Lambton, MB2157100 (20 percent) in Aro StreetNairn Street and MB2145300 (20 percent) in Mt Cook-Wallace Street.

The region has about 1.5 percent of people dependent on Sickness Benefits. Sickness Benefits are mainly given to sick, disabled or pregnant women who cannot work or work less because of their inability. The highest population dependent on sickness benefit is in Masterton and the lowest in Wellington and Lower Hutt i.e. 1.2 percent each. The amount provided by the government varies from 122.77 NZD net per week for a single person of 18-19 years old living at home to 263.78 NZD net per week to a solo parent (Sickness Benefit, 2008). The details of distribution of such population at mesh block level have been discussed in the demographic vulnerability under the disability section.

Besides, the region has about 2.3 percent of the population dependent on 'Other Government Benefits, Pensions or Payments'. The proportion of such population does not vary much across the region. It is highest in Masterton (2.7 percent) and lowest in Wellington (2.2 percent). At mesh block level, the concentration of people living on Other Government Benefits, Payments or Pensions is highest in MB2171100 (23 percent) in Berhampore in Wellington, followed by MB2238300 (19 percent) and MB2237400 (18 percent) in Masterton West, Masterton, MB2156500 (17 percent) and MB2156600 (15 percent) in Mitchell town in Lambton Ward, Wellington. Though income through these benefits varies, in most cases it is likely to be low income, which is given with an aim for survival rather than savings. Therefore, any disaster could undermine the coping capacity of these individuals.

\subsubsection{Income}

Income is an important indicator of vulnerability as it enables an individual or a community to cope and recover from loses (Cutter, Mitchell \& Scott (2000), Burton, Kates and White (1993), Blaikie et al. (1994), Peacock, Morrow and Gladwin (1997, 2000), Hewitt (1997), Puente (1999) and Platt (1999) as cited in Cutter et al. 2003, 246). The median income of the region is 28,000 NZD, which varies throughout the region from minimum 21,700 NZD per annum in Masterton to 32,000 NZD in Wellington city (Table: 4.10). The population with no income is the most vulnerable group as lack of income could enhance the post-disaster effects on exposed individuals. Although, this population relies on government welfare, but scarcity of income is likely to influence hazard preparedness and response. The 2006 Census shows that nearly four percent of people in 


\begin{tabular}{|c|c|c|c|c|c|c|c|}
\hline \multirow{2}{*}{$\begin{array}{l}\text { Local Territorial } \\
\text { Authority }\end{array}$} & \multirow{2}{*}{$\begin{array}{l}\text { Percent } \\
\text { populatio- } \\
\text { n with no } \\
\text { Source of } \\
\text { Income }\end{array}$} & \multicolumn{3}{|c|}{ Individual Income Characteristics } & \multicolumn{3}{|c|}{ Family Income Characteristics } \\
\hline & & $\begin{array}{l}\text { Median } \\
\text { Income in } \\
\text { NZD }\end{array}$ & $\begin{array}{c}\text { Poverty } \\
\text { level } \\
(60 \% \\
\text { of median } \\
\text { income in } \\
\text { NZD) }\end{array}$ & $\begin{array}{c}\text { Percent } \\
\text { population } \\
\text { earning } \\
\text { less than } \\
10,000 \$\end{array}$ & $\begin{array}{l}\text { Median } \\
\text { Income } \\
\text { in NZD }\end{array}$ & $\begin{array}{c}\text { Poverty } \\
\text { level } \\
(60 \% \text { of } \\
\text { median } \\
\text { income } \\
\text { in NZD) }\end{array}$ & $\begin{array}{c}\text { Percent } \\
\text { populatio } \\
\text { n earning } \\
\text { less than } \\
20,000 \$\end{array}$ \\
\hline Kapiti Coast District & 3.3 & 23,000 & 13,800 & 12.9 & 54,900 & 32,940 & 6.6 \\
\hline Porirua City & 4.5 & 26,300 & 15,780 & 13.9 & 65,300 & 39,180 & 8.3 \\
\hline Upper Hutt City & 4.4 & 26,900 & 16,140 & 13.7 & 65,000 & 39,000 & 5.8 \\
\hline Lower Hutt City & 4.1 & 27,300 & 16,380 & 13.9 & 65,800 & 39,480 & 7.1 \\
\hline Wellington City & 3.9 & 32,500 & 19,500 & 15.3 & 87,000 & 52,200 & 5.2 \\
\hline Masterton District & 3.3 & 21,700 & 13,020 & 13.8 & 49,500 & 29,700 & 7.7 \\
\hline Carterton District & 3.7 & 22,200 & 13,320 & 14.4 & 53,000 & 31,800 & 7.2 \\
\hline South Wairarapa District & 2.8 & 24,100 & 14,460 & 13.2 & 54,600 & 32,760 & 7.7 \\
\hline Wellington Region & 3.9 & 28,000 & 16,800 & 14.4 & 69,200 & 41,520 & 6.4 \\
\hline
\end{tabular}

Based on Census 2006, Statistics New Zealand

the region did not have any source of earning at the time of data collection. The percentage varies from 2.8 percent in South Wairarapa to 4.5 percent in Porirua. The concentration of such a population is higher in urban areas including Wellington, Lower Hutt, Upper Hutt, Porirua and Masterton CBD.

Map: 4.23. Population with No Source of Income in the Wellington Region (2006)

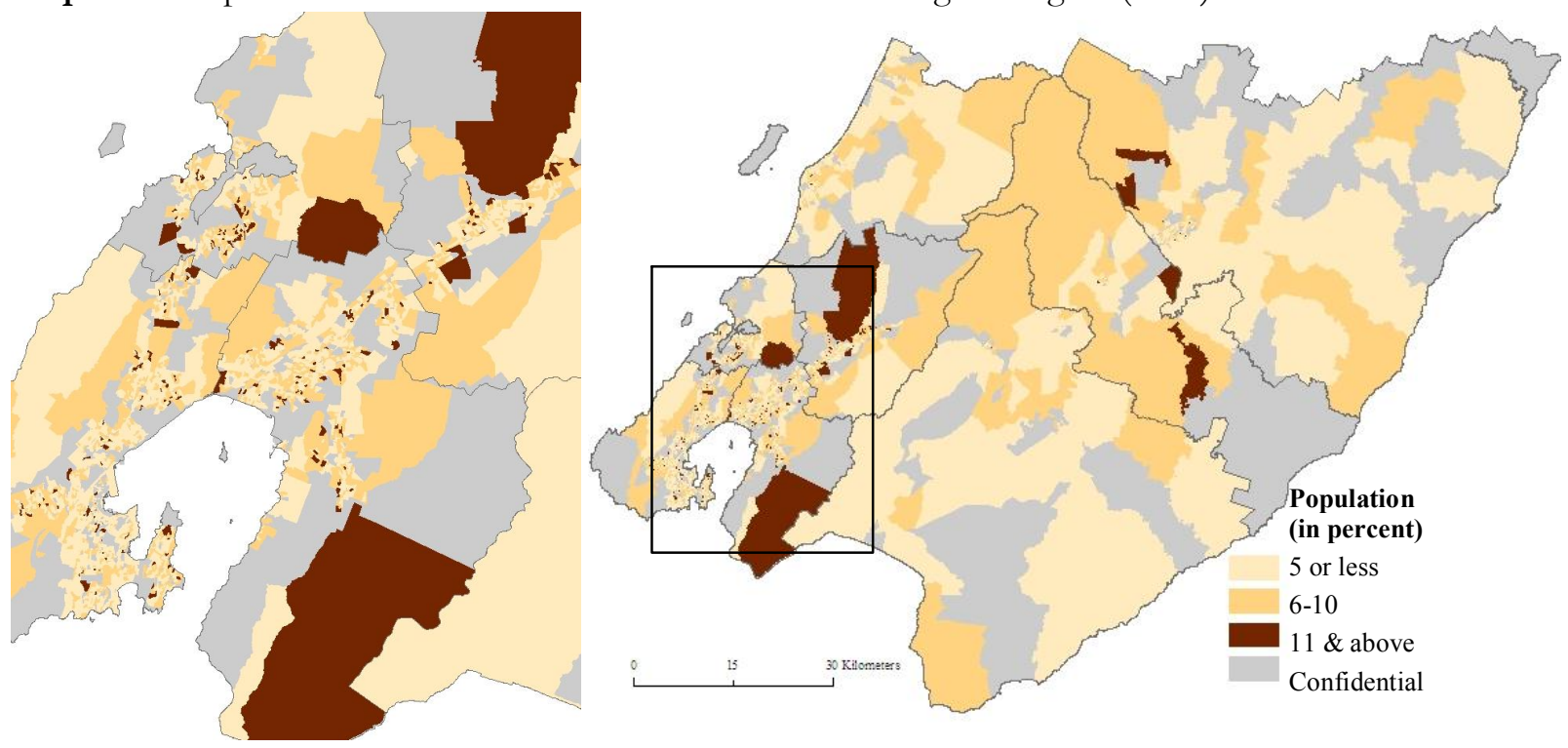

Based on Census 2006, Statistics New Zealand

The highest proportion of population without any source of income is found in MB1900500 in Trentham South, Upper Hutt with 33 percent followed by 25 percent in MB1900700 in Trentham South, Upper Hutt and 22 percent in MB2134800 in Willis StreetCambridge Terrace in Lambton Ward of Wellington. Besides, MB2145300 in Mt Cook-Wallace Street, MB2155300 in Kelburn, MB2099000 in Wadestown in Wellington, MB1898400 in Heretaunga-Silverstream in Upper Hutt and MB2070902 in Paremata-Postgate, MB2037100 in Elsdon-Takapuwahia and MB2063400 in Cannons Creek East in Porirua, each having about 20 percent of population with no source of income. 
Map: 4.24. Income Characteristics in the Wellington Region (2006)

\section{Individual Income Less than 10,000 NZD}

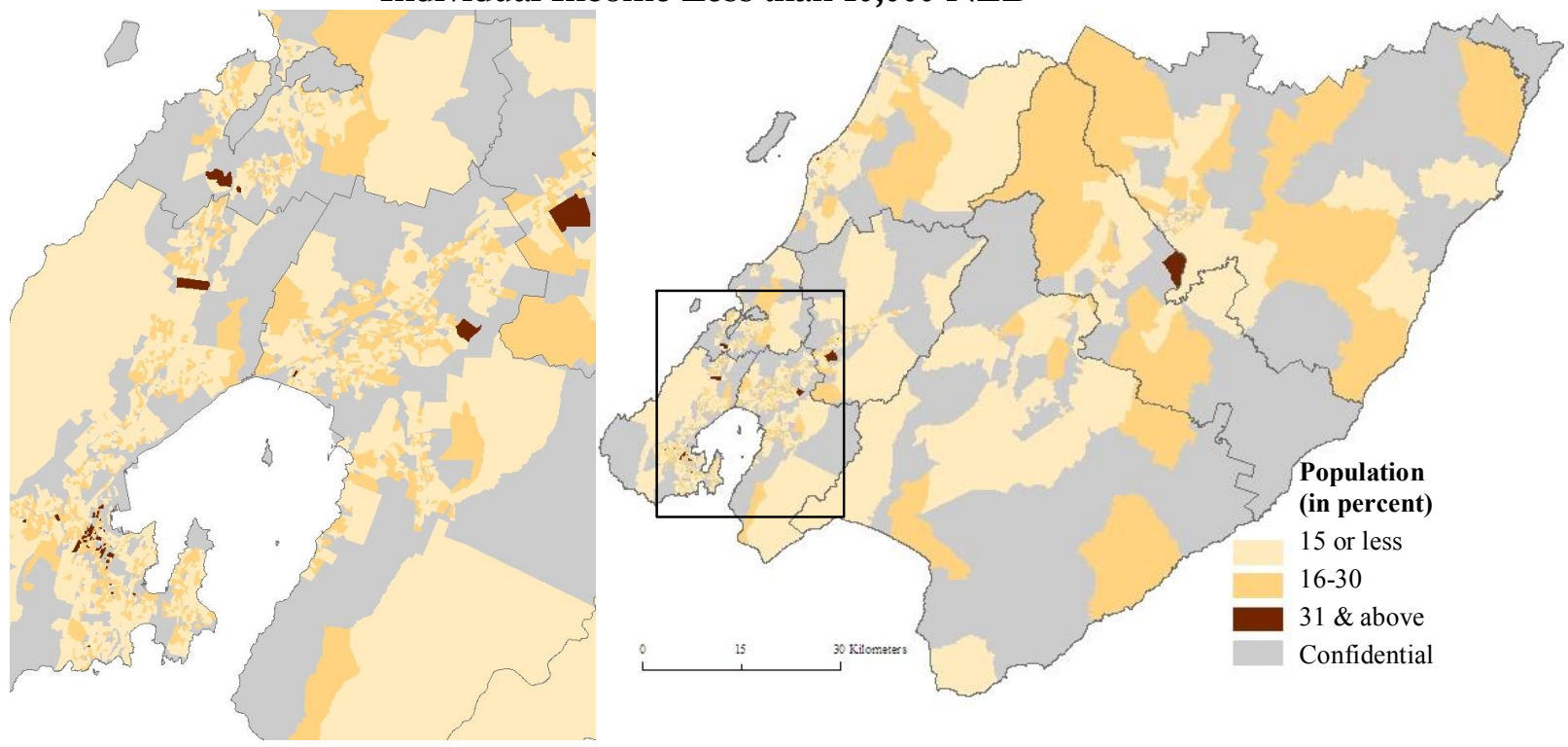

Family Income Less than 20,000 NZD
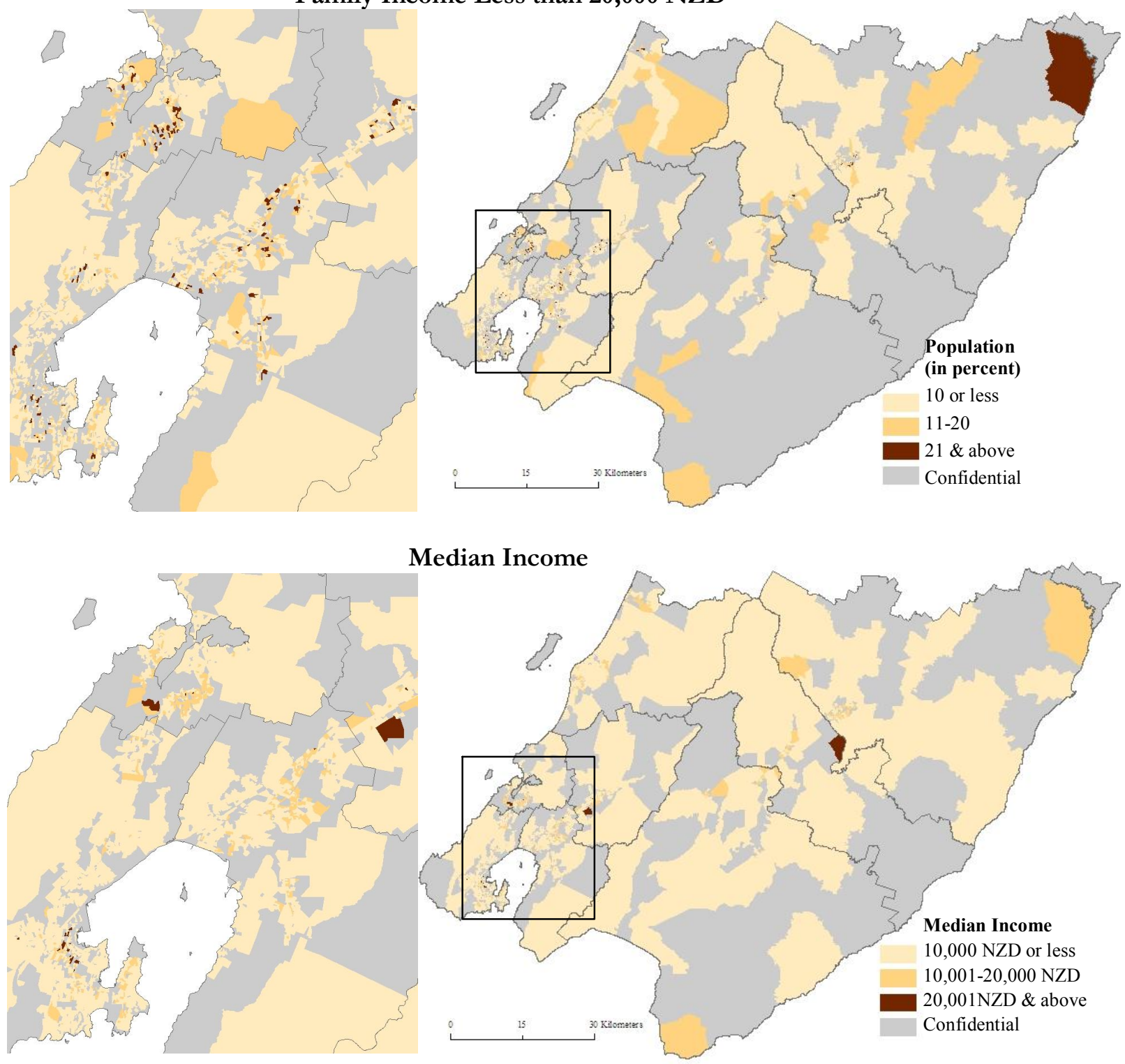

Based on Census 2006, Statistics New Zealand 
Low income, on the other hand, builds vulnerability first by restricting hazard mitigation and by affecting their coping capacity. People with less income tend to have fewer savings, which also slows down their recovery after a disaster. Although there is no absolute poverty line for the country, poverty has been estimated through various measures including income. Stephens, et al. (1995) used relative poverty threshold as 60 percent of the median equivalent household disposable income or expenditure. Since the Census provides gross income data in categorical form for each mesh block, it is difficult to calculate the disposable income after tax to get the percentage of people living below poverty threshold. Therefore, the proportion of individuals having gross income of less than 10,000 NZD and family gross income less than 20,000 NZD were taken as the population having very low income. This level is considered on the basis of ENZ living cost calculator in New Zealand. According to this calculator a family living a frugal standard of life i.e. basic living with few treats or entertainment, buying cheap and second hand good, running a cheap car around 5000 miles $(8,000 \mathrm{~km})$ each year would require a minimum sum of 26,000 NZD per annum (ENZ 2009). Since the income range given in the Census is for less than 20,000 and 2030,000, people living in the household of income of less than 20,000 NZD and individual earning less than 10,000 NZD are considered to be in the population of very low income group. The data show that nearly one sixth of the total population of the region earns less than 10,000 NZD per year.

The highest proportion of population earning less than 10,000 NZD lives in the Wellington city. At mesh block level, the concentration of such people is high in MB2153300 (84 percent), MB2153100 (63 percent) in Kelburn, MB2128800 (83 percent), MB2128400 (82 percent), MB2129700 (74 percent), MB2123900 (63 percent) in Lambton, MB2131600 (68 percent) in Willis Street-Cambridge Terrace and MB2144500 (64 percent), MB2145600 (61 percent), MB214300 (61 percent) in Mt Cook-Wallace Street. All of these mesh blocks are located in the Lambton Ward of Wellington, which is CBD area and primarily occupied by students, who live and work in close proximity to the universities. Besides these, there are about seven percent of families in the region, who survive on less than 20,000 NZD of annual income. The share of such families ranges from five percent in Wellington to eight percent in Porirua. Highest concentration of the family earning less than 20,000 NZD is in MB2134800 (62 percent) in Willis Street-Cambridge Terrace and MB2144500 in Mt Cook-Wallace Street (50 percent) both in Lambton Ward in Wellington. These are followed by MB21633 (44 percent) in Newtown West, Wellington, MB1976900 (43 percent) in Waiwhetu North, Lower Hutt and MB2146500 (43 percent) in Mt Cook-Wallace Street in Lambton Ward in Wellington.

The lowest median income at mesh block level is found at MB1900700 in Trentham South, Upper Hutt with 700 NZD medium income per annum. The mesh block has a day time population of 477, in which 25 percent has no source of income, 30 percent earn less than 5,000 NZD per year, six percent are unemployed, 18 percent depend on one or other government benefit, allowance or pension, 25 percent population has no qualification and nearly 30 percent are engaged in elementary occupations. There are about 18 mesh blocks in Wellington city, where median income is less than 10,000 NZD per annum out of which 17 are in Lambton Ward. Porirua has about three such mesh blocks, Lower Hutt, Upper Hutt and Carterton each has one. The mesh blocks with 
lowest medium income are MB2128800 (3,300 NZD), MB2128400 (3,700 NZD), MB2129700 (3,800 NZD) in Lambton, MB2153300 (4,000 NZD) in Kelburn in Wellington.

\subsubsection{Housing}

Housing is another indicator of economic vulnerability, which not only reflects coping capacity but also exposure to many hazards such as earthquakes, flooding and windstorms, which directly affect vulnerable houses and hence the residents. Various aspects of housing such as dwelling density, size and ownership portray different kinds of vulnerability.

Table: 4.11. Vulnerability Linked with Housing in the Wellington Region (2006)

\begin{tabular}{lcccccc}
\hline $\begin{array}{l}\text { Local Territorial } \\
\text { Authority }\end{array}$ & \multicolumn{5}{c}{ Population with following housing characteristics (in percent) } \\
\cline { 2 - 7 } & $\begin{array}{c}\text { Dwelling } \\
\text { density }\end{array}$ & $\begin{array}{c}\text { Living in } \\
\text { one room }\end{array}$ & $\begin{array}{c}\text { Living in } \\
\text { two rooms }\end{array}$ & $\begin{array}{c}\text { Living in } \\
\text { one } \\
\text { bedroom }\end{array}$ & $\begin{array}{c}\text { Dwelling } \\
\text { not owned } \\
\text { by residents }\end{array}$ & $\begin{array}{c}\text { Median } \\
\text { Weekly Rent } \\
\text { Paid (\$) }\end{array}$ \\
\hline Kapiti Coast District & 26.1 & 0.4 & 1.1 & 4.3 & 22.9 & 200.5 \\
Porirua City & 84.4 & 0.2 & 0.9 & 2.8 & 34.4 & 170.5 \\
Upper Hutt City & 26.2 & 0.3 & 1.1 & 3.7 & 25.3 & 175.2 \\
Lower Hutt City & 93.9 & 0.4 & 1.6 & 5.4 & 31.1 & 190.3 \\
Wellington City & 233.4 & 1.1 & 3.0 & 11.0 & 37.4 & 270.2 \\
Masterton District & 3.9 & 0.3 & 1.3 & 4.2 & 27.7 & 150.1 \\
Carterton District & 2.3 & 0.2 & 0.8 & 3.4 & 22.3 & 150.4 \\
South Wairarapa District & 1.5 & 0.5 & 0.6 & 3.2 & 25.2 & 145.0 \\
Wellington Region & $\mathbf{2 0 . 8}$ & $\mathbf{0 . 7}$ & $\mathbf{1 . 9}$ & $\mathbf{7 . 0}$ & $\mathbf{3 2 . 1}$ & \\
\hline
\end{tabular}

Based on Census 2006, Statistics New Zealand

Dwelling density is linked to population concentration and quality of life. The average dwelling density in the region is 20.8 dwellings per square kilometre [sqkm], which varies from as low as 1.5 dwellings per sqkm in rural South Wairarapa to as high as 233.4 dwellings per sqkm in Wellington city. This certainly does not represent the true picture as significant areas in these districts are not inhabited. However, it does represent sharp contrast (though at a subdued level) of dwelling density across the districts, which may produce higher risk to a disaster in densely built areas.

Map: 4.25. Dwelling Density in the Wellington Region (2006)
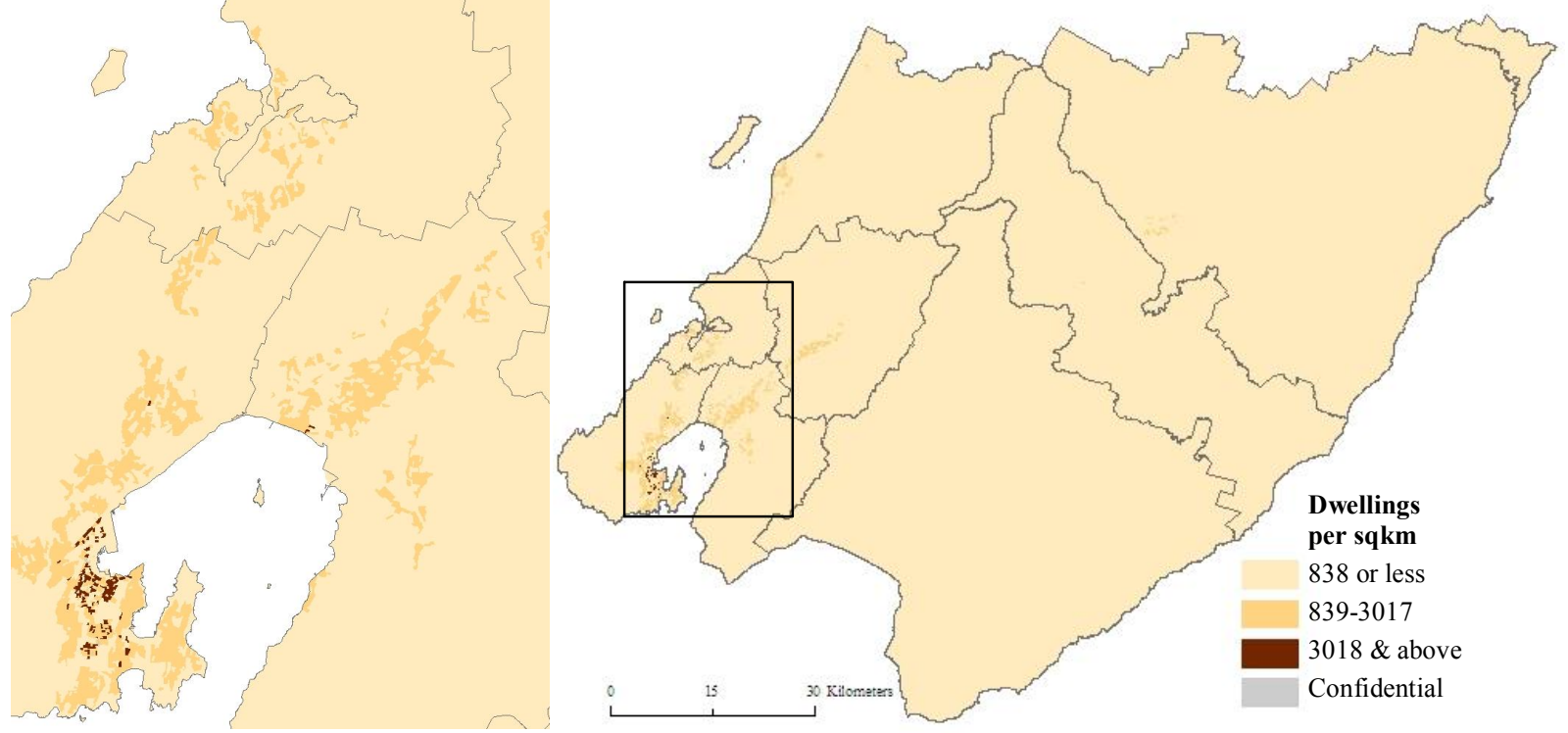

Based on Census 2006, Statistics New Zealand 
The contrast at mesh block level is more distinct. A major proportion of the region has a rural character with a minimum dwelling density. The density is conspicuously high in cities especially in Wellington, where density in CBD and adjoining areas marks more than 3018 dwellings per sqkm. High density in the city centre is contributed to by high population growth and associated apartment living (Wellington City Council, 2007). This enhances vulnerability through exposure and limits coping capacity due to increased pressure on services and infrastructure.

The highest dwelling density is in MB2126500 (27,026 dwellings per sqkm) followed by MB2126400 (22,418 dwellings per sqkm) and MB2129000 (22,018 dwellings per sqkm) in Lambton area of Wellington city. Besides these, Lambton Ward has three more mesh blocks with more than 10,000 dwellings per sqkm and 42 mesh blocks with more than 5,000 dwellings per sqkm, which make this ward the most densely built area in the region. Southern Ward is the second most densely built with four mesh blocks with more than 10,000 dwellings per sqkm, in which two are located in Newtown East and two in Newtown West. This ward also has three other mesh blocks with more than 5000 dwellings per sqkm, in which two are located in Berhampore and one in Newtown East. Besides Eastern Ward has two mesh blocks one in Kilbirnie West i.e. MB2179101 and other in Kilbirnie East i.e. MB2178102 with dwelling density of more than 5,000 dwellings per sqkm. The high density of dwellings is also an indicator of the size of houses.

House size is often linked to affordability of both house and transport costs to and from work, which results in high dwelling density in urban areas, where a high proportion of the population share limited space. In order to indicate vulnerability relating to house size, three categories have been included from the 2006 Census data i.e. people living in one room, two rooms and one bedroom houses. About one percent of the population in the region lives in one room. The highest proportion of this population lives in Wellington i.e. 1.1 percent and minimum in Carterton and Porirua. At mesh block level, the highest proportion of such population lives in MB1966700 in Hutt Central, Lower Hutt, where more than 55 percent of the total population lives in one room dwelling. This is followed by MB2131600 in Willis Street-Cambridge Terrace in Wellington city with 50 percent of such population. Besides these, in eight other mesh blocks of Lambton Ward about 20 to 35 percent of population lives in one room housing and in one mesh block i.e. MB1911700 of Emerald Hill, Upper Hutt 20 percent of its population lives in one room. This shows that data at district level present a more generalised picture and isolated areas of higher vulnerability could be located out of the most vulnerable district.

The region has about two percent of the population living in two room houses. The share of such population is highest in Wellington city (three percent) and lowest in South Wairarapa (0.6 percent). At mesh block level, the highest proportion of such population lives in MB2082600 in Johnsonville South (53 percent) followed by MB2179101 (39 percent) in Kilbirnie West and MB2178102 (36 percent) in Kilbirnie East in Wellington city and MB1956200 (35 percent) in Naenae North in Lower Hutt. 
Map: 4.26. Distribution of Population According to House Size in the Wellington Region (2006)

\section{Population Living in One Room}

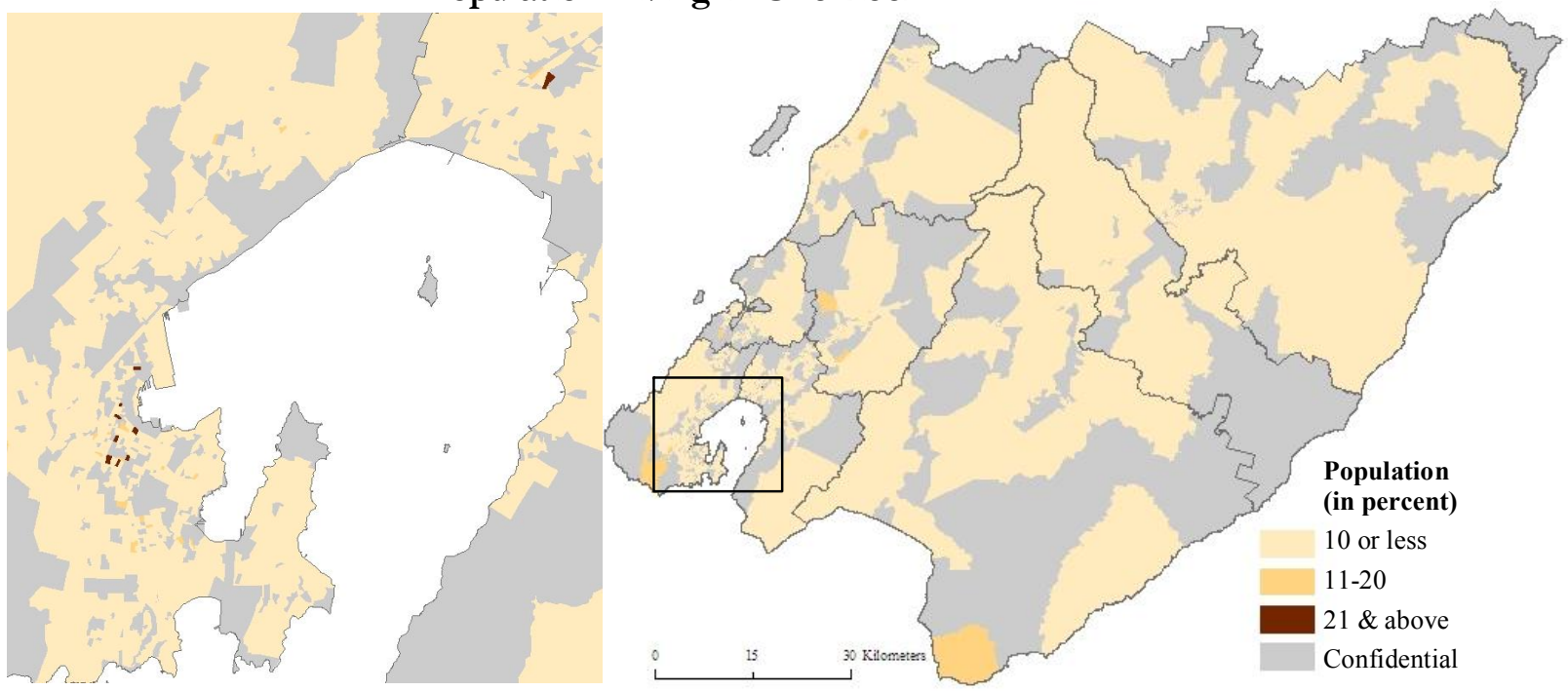

Population Living in Two Rooms

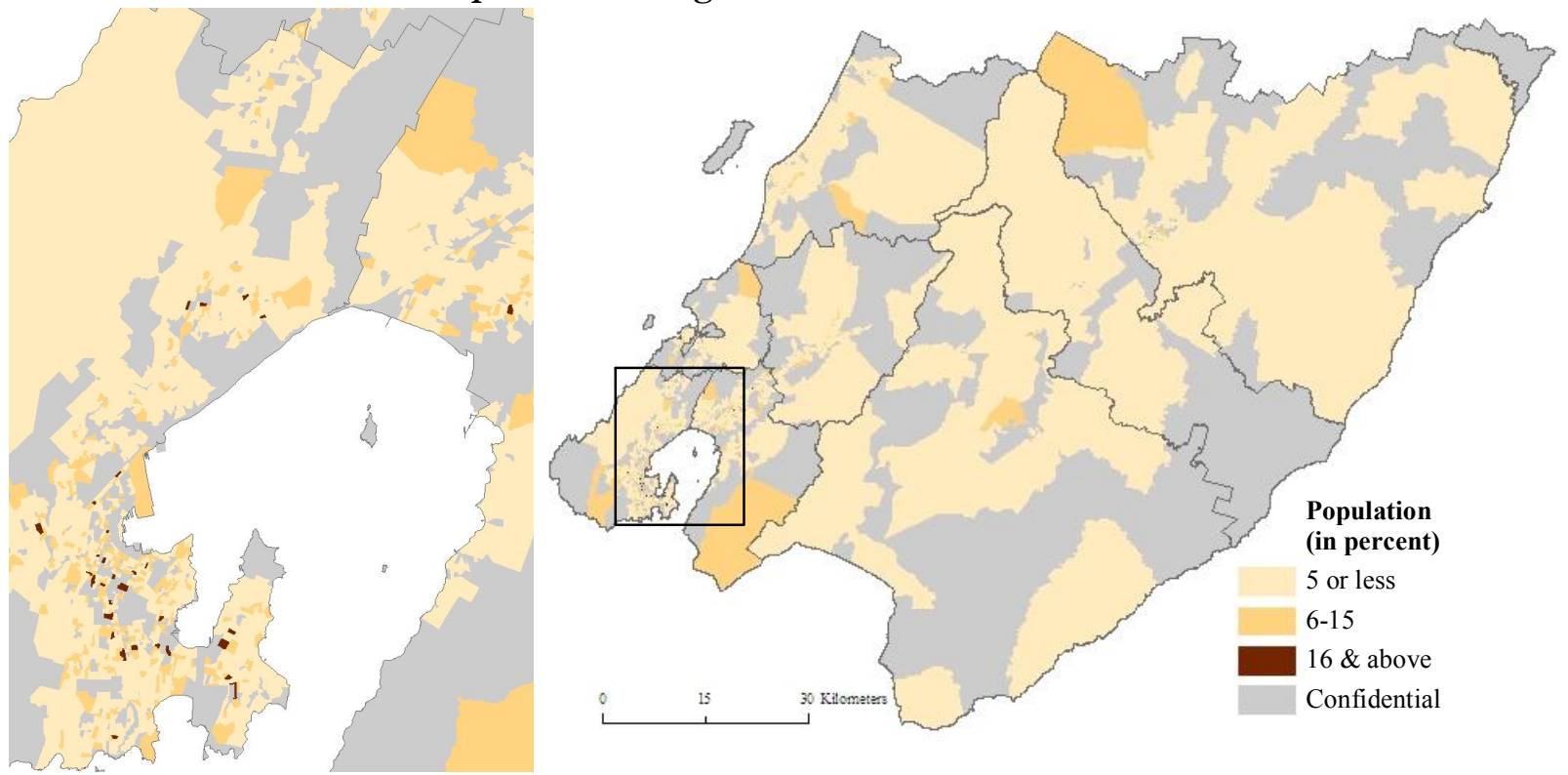

Population Living in One Bedroom

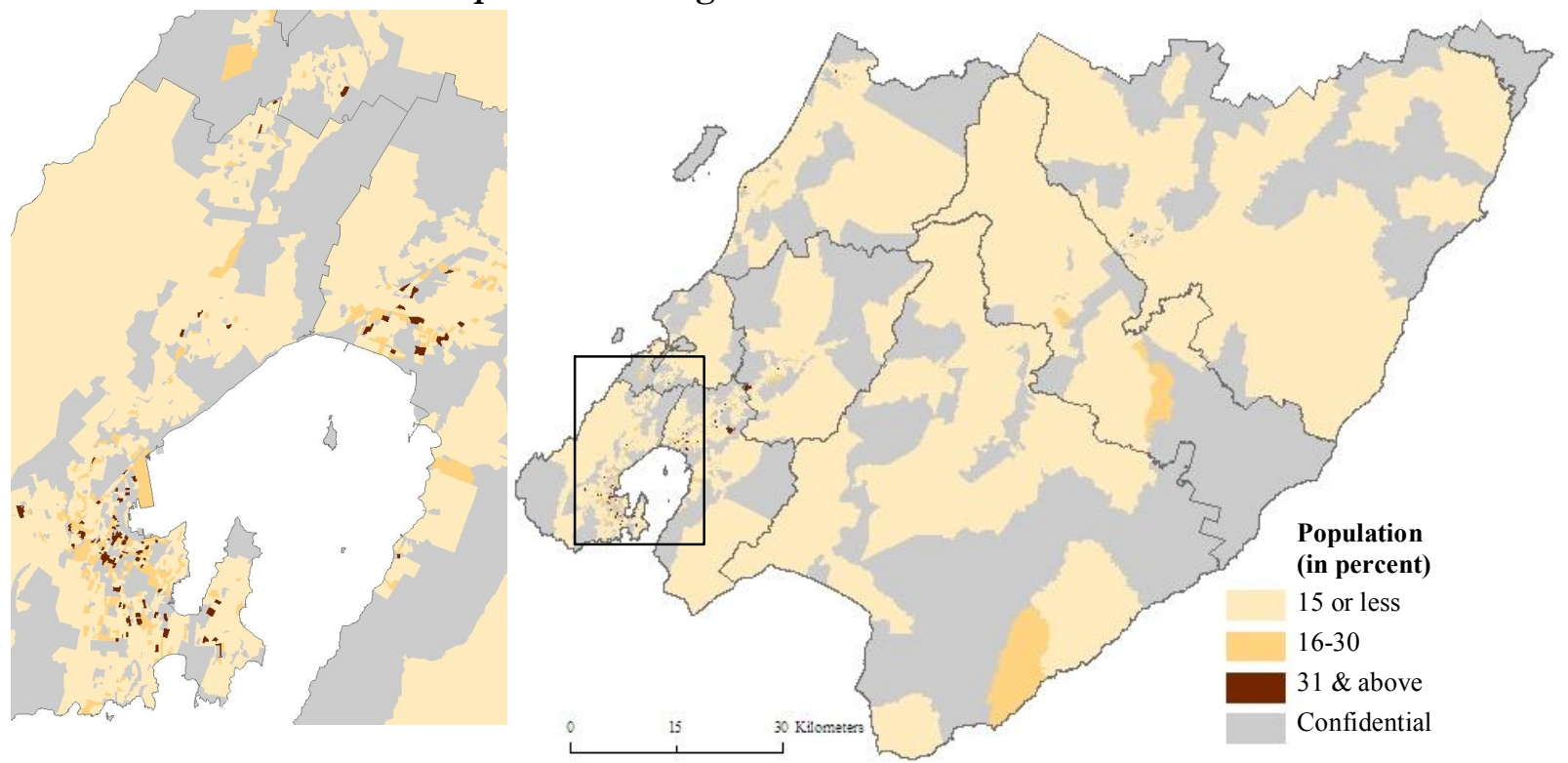

Based on Census 2006, Statistics New Zealand 
One bedroom houses are common in the region. About seven percent of the total population lives in a one bedroom house, which varies from 2.8 percent in Porirua to 11 percent in Wellington. Distribution of such population at mesh block level shows that high proportion of population living in one bedroom does not live in city centres but in suburbs and are mainly concentrated in Wellington, Lower Hutt and few mesh blocks of Upper Hutt, Porirua, the Kapiti Coast and Masterton. The concentration of such houses is very low in rural areas. The highest

Map: 4.27. Population Living in Dwelling Not Owned by Them in the Wellington Region (2006)

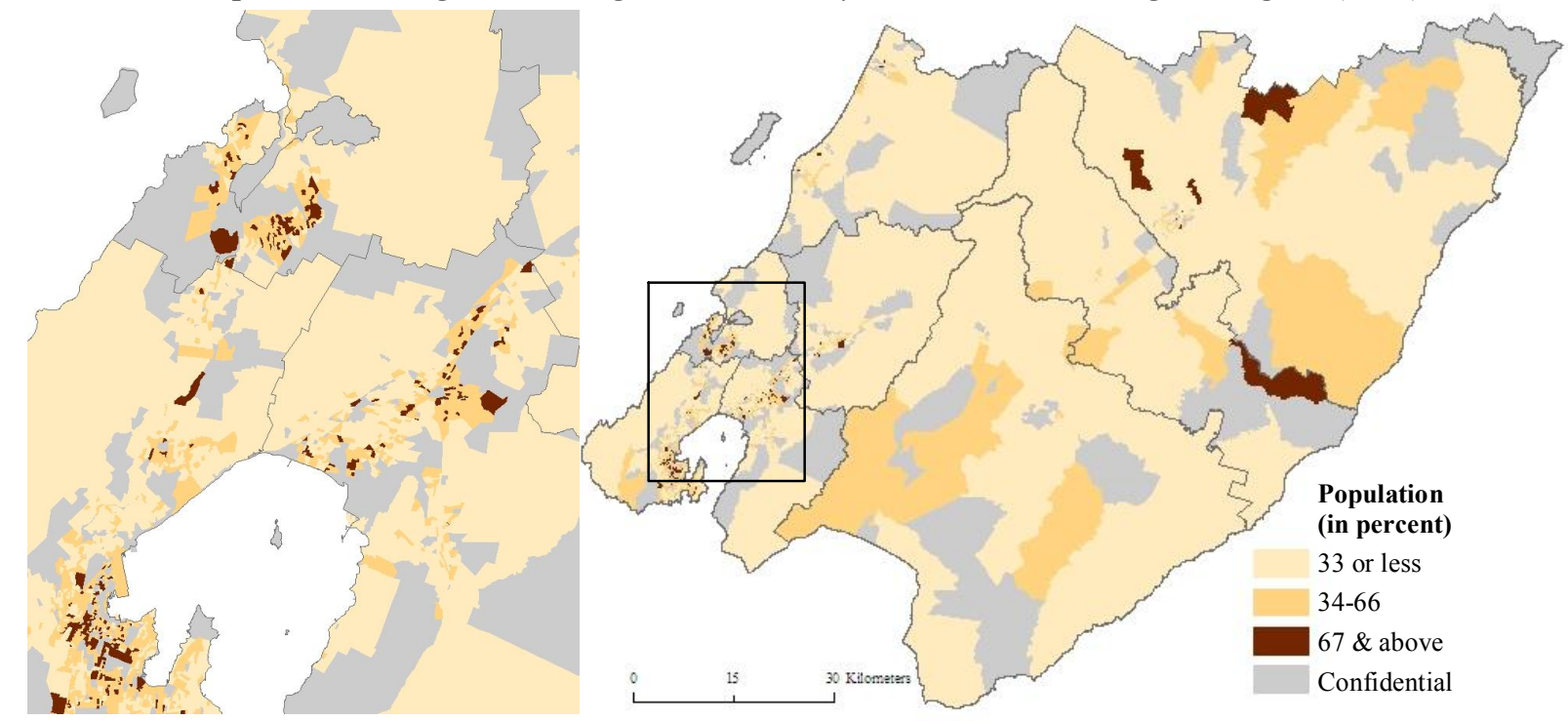

Based on Census 2006, Statistics New Zealand

proportion of one bedroom houses is in MB2129000 (89 percent) in Lambton area followed by MB2131600 (82 percent) in Willis Street-Cambridge Terrace, MB2082600 (79 percent) in Jonshonville South, MB2163300 (75 percent) in Newtown West, MB2159500 (75 percent) in Aro Street-Nairn Street in Wellington, MB1966400 (73 percent) in Hutt Central in Lower Hutt and MB1881100 (71 percent) in Otaki in the Kapiti Coast.

Another vulnerability characteristic of housing is linked with ownership. The rented houses Map: 4.28. Median Rent in the Wellington Region (2006)
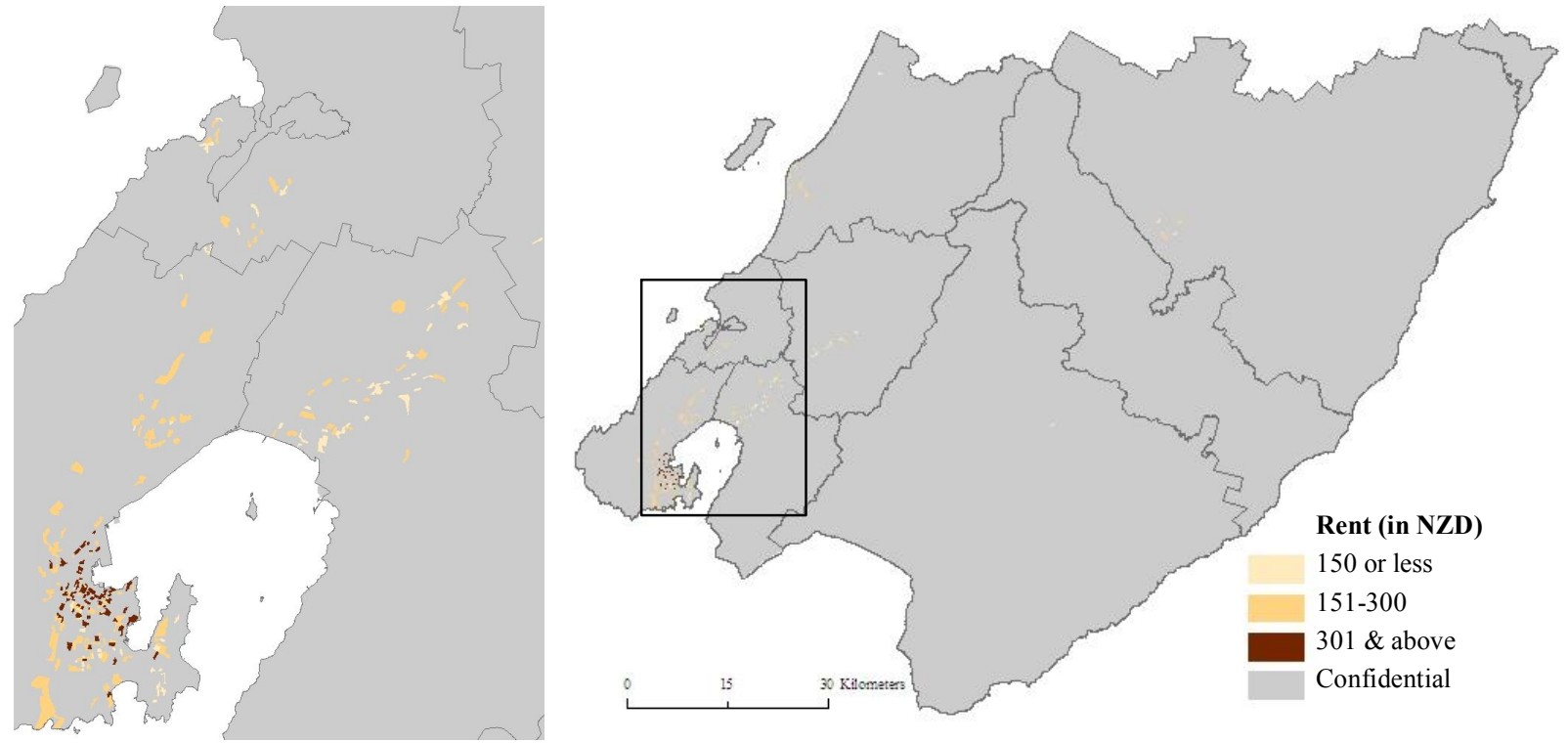
tend to be less well-maintained than those occupied by owners. The region has a very high percentage of rented properties (>32 percent). It is highest in Wellington (37.4 percent) and lowest in Carterton (22.3 percent). Mesh blocks including MB2142700 in Mt Victoria West, MB2136600 in Willis Street-Cambridge Terrace, MB2168700 in Newtown East, MB2126100 in Lambton, MB2119400 and MB2119700 in Thorndon-Tinakori Road, MB2145700 in Mt Cook-Wallace Street, MB2157500 in Aro Street-Nairn Street in Wellington, MB2060001 in Waitangira and MB2049800 Cannons Creek South in Porirua, MB1977100 in Waiwhetu North in Lower Hutt and MB1890702 in Brentwood, MB1898000 in Heretaunga-Silverstream and 1900400 in Trentham South in Upper Hutt have 100 percent dwellings on rent. Besides these, about 46 mesh blocks in Wellington, 14 in Porirua, 10 in Lower Hutt and one each in Upper Hutt and Masterton have about 80-92 percent of dwellings on rent.

The amount of rent also demonstrates housing conditions. The median rent for the region varies from 145 NZD in South Wairarapa per week to 270 NZD in Wellington. The picture at mesh block level is quite different. The minimum median rent for the region is given for MB1936600 i.e. 62 NZD in Taita South in Lower Hutt followed by MB1881600 (63 NZD) in Otaki, the Kapiti Coast, MB2129000 (63 NZD) in Lambton, Wellington and MB2246800 (64 NZD) in Ngaumutawa in Masterton. Besides these, in about 13 mesh blocks in Wellington, ten in Lower Hutt, four in Porirua and one in the Kapiti Coast, the rent varies from 70 NZD to 100 NZD. Given the median rent for most of these cities are much higher, a rent less than 100 NZD could be attributed to poor quality housing.

\subsubsection{Means of Communication}

Access to means of communication is another important indicator of vulnerability. No access to telecommunication and a motor vehicle represents a low level of income and resilience. A major disaster such as an earthquake could easily destroy public means of transport and other communication lines, which may take days to months to restore. In such a situation people without any motor vehicle could face hardship and their coping capacity could be undermined because of limited options for movement and communication.

Table: 4.12. Vulnerability Linked with Communication in the Wellington Region (2006)

\begin{tabular}{lcc}
\hline Local Territorial Authority & \multicolumn{2}{c}{ No access to communication means (in percent) } \\
\cline { 2 - 3 } & Telecommunication & Motor Vehicle \\
\hline Kapiti Coast District & 1.1 & 8.5 \\
Porirua City & 2.2 & 10.5 \\
Upper Hutt City & 1.4 & 9.5 \\
Lower Hutt City & 2.0 & 11.1 \\
Wellington City & 1.3 & 13.5 \\
Masterton District & 2.1 & 10.0 \\
Carterton District & 1.5 & 5.9 \\
South Wairarapa District & 1.8 & 5.6 \\
Wellington Region & $\mathbf{1 . 6}$ & $\mathbf{1 1 . 3}$ \\
\hline
\end{tabular}

Based on Census 2006, Statistics New Zealand

About 1.6 percent of the population in the region has no access to telecommunication systems. This varies from as low as 1.3 percent in Wellington to 2.2 percent in Porirua. The mesh block data show that such population is mainly concentrated within or near urban areas. The mesh 
blocks with higher concentration of such people include MB1940200 (29 percent) in Taita North, MB1966700 (27 percent) in Hutt Central along with MB2029400 in Wilford, MB1957400 MB1956300 in Naenae North in Lower Hutt, MB2063100 in Cannons Creek and MB2072708 in Inlet-Porirua harbour in Porirua; MB1995400 in Linden in Wellington and 1915900 in Cloustonville in Upper Hutt, each with 25 percent of such population.

Map: 4.29. Population without Access to Telecommunications in the Wellington Region (2006)
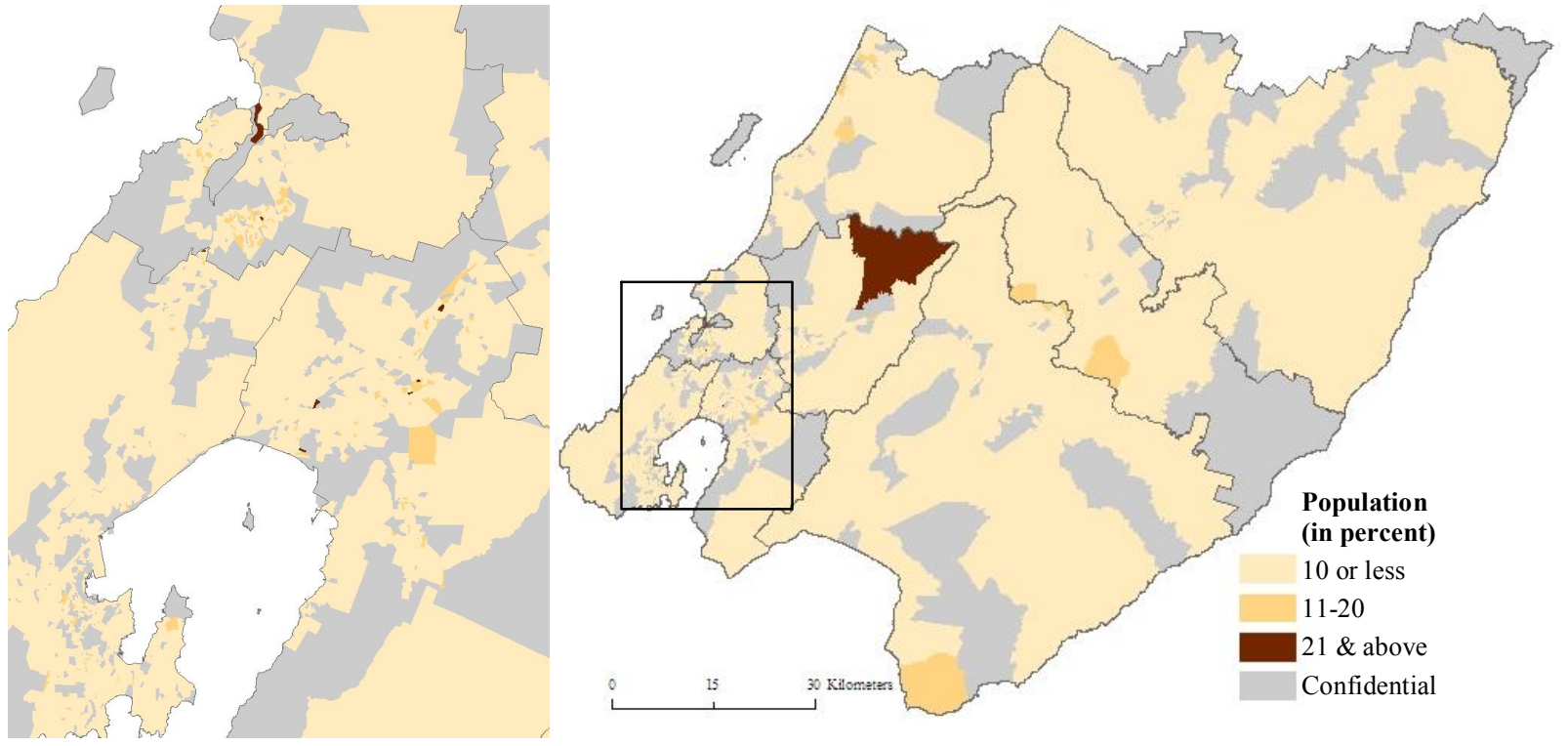

Based on Census 2006, Statistics New Zealand

The population without access to a motor vehicle is more widespread in the region. About 11 percent of the total population of the region has no access to a motor vehicle, which varies from 5.6 percent in South Wairarapa to 13.5 percent in Wellington. The low proportion of people without motor vehicles in South Wairarapa could be attributed to the rural character of the district, where people are spread over greater distances and the poor public transport system makes a motor vehicle a necessity for residents. In urban areas, with better public services and close

Map: 4.30. Population with No Motor Vehicle in the Wellington Region (2006)
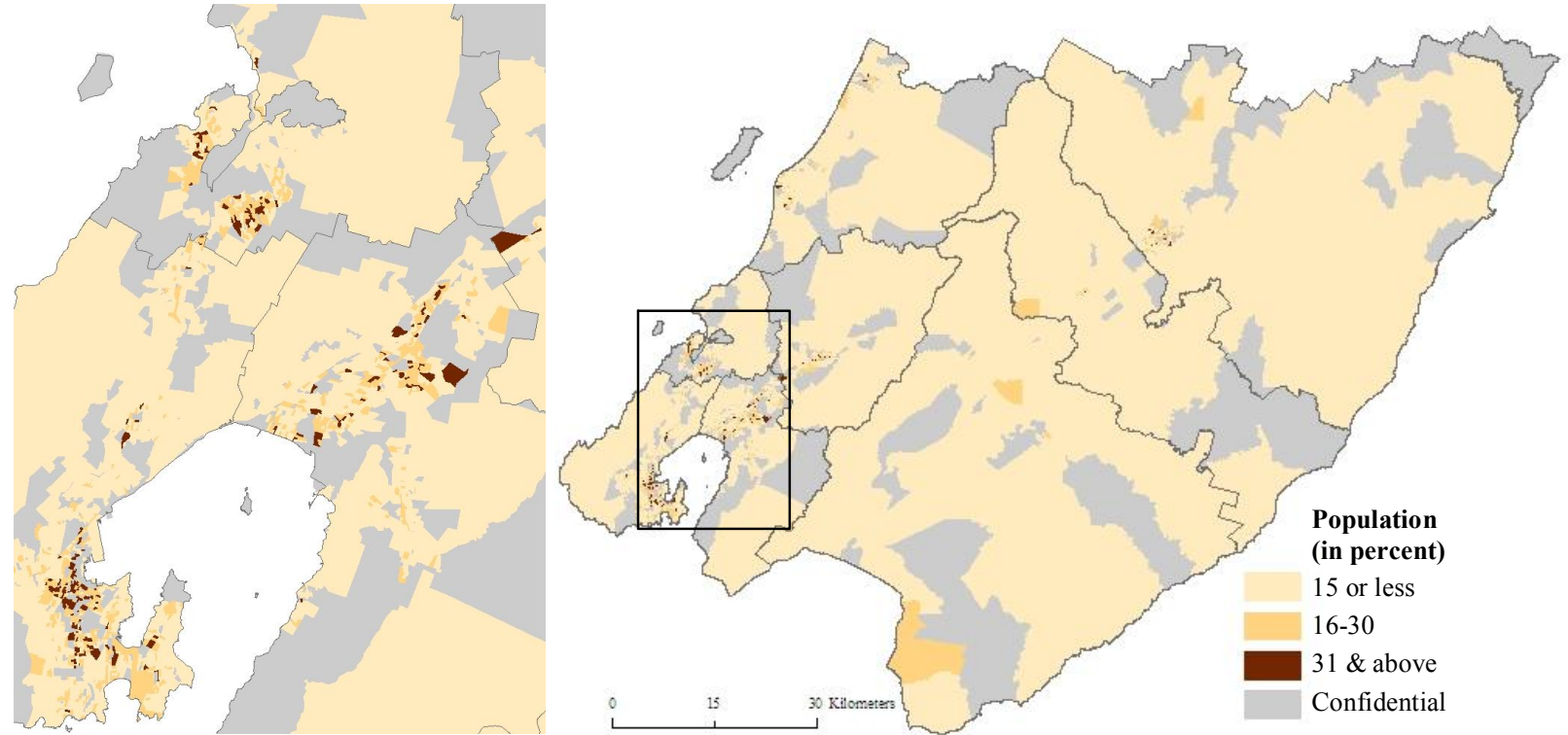

Based on Census 2006, Statistics New Zealand 
Plate: 4.3. Economic Vulnerability Index of the Wellington Region (2006)
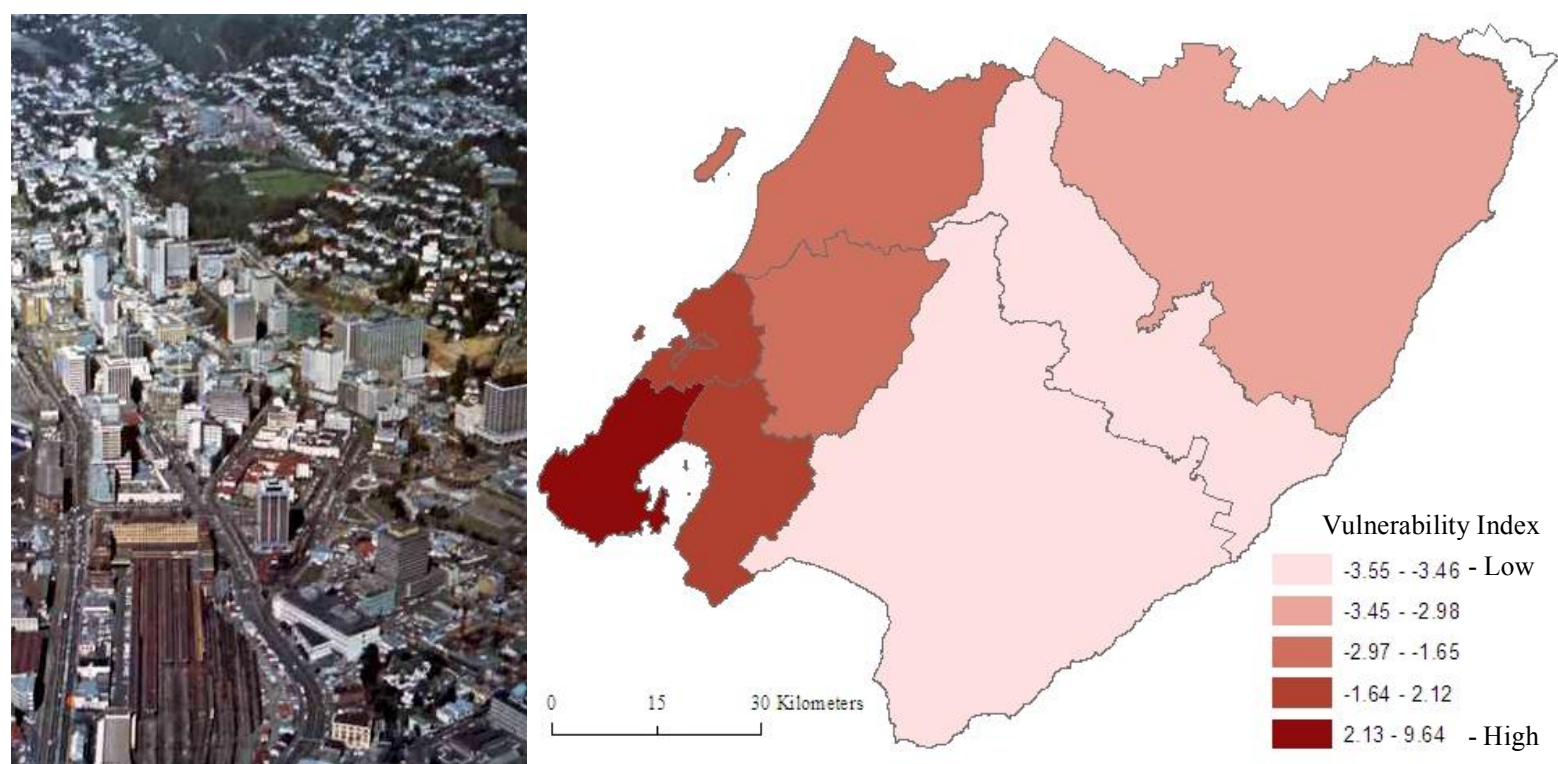

1. Vulnerability Index Based on Maximum Imputation Value

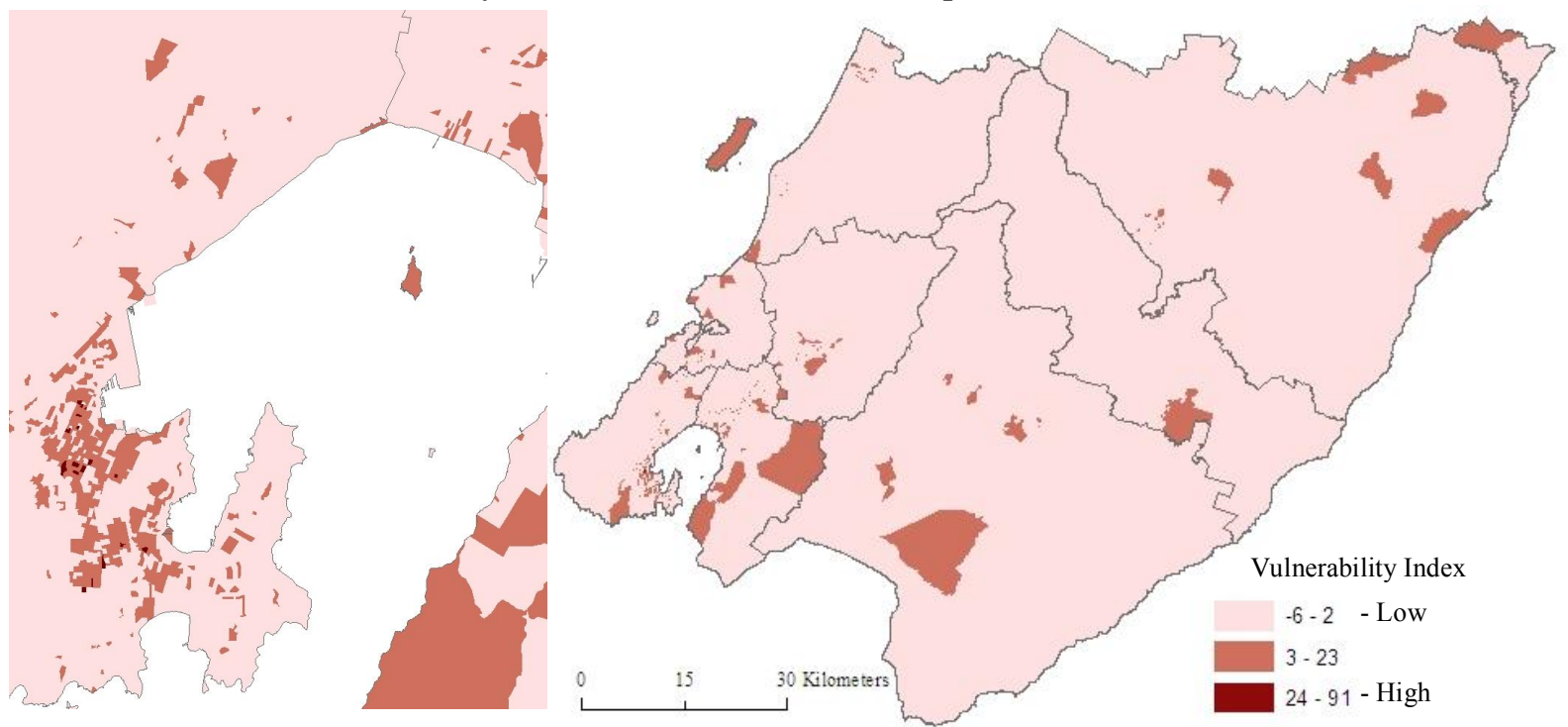

2. Vulnerability Index Based on Minimum Imputation Value

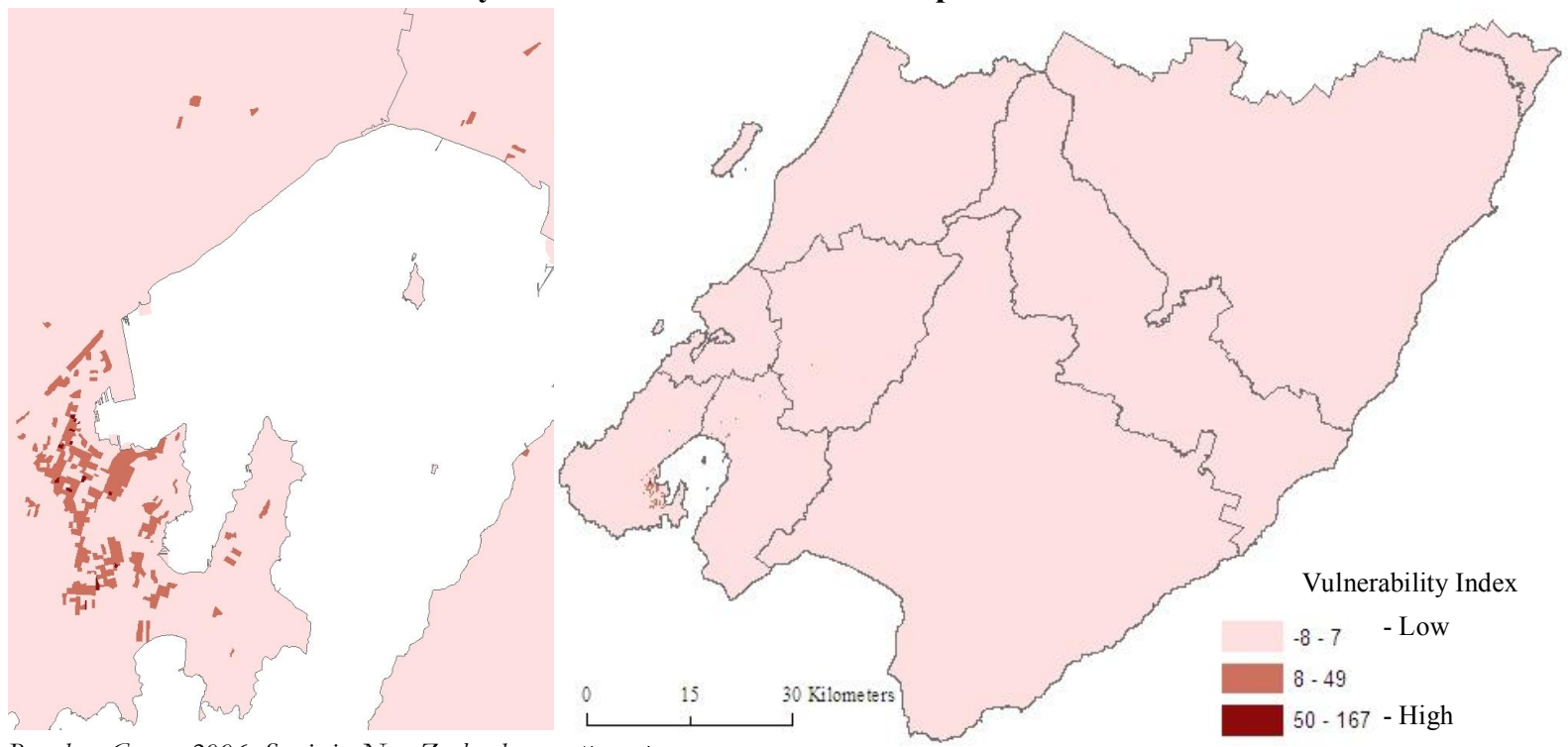

Based on Census 2006, Statistics New Zealand; www.flatrock.org.nz. 
proximity to work and other facilities, the absence of a motor vehicle is understandable. At mesh block level, higher concentration of such people are in MB2131800 (80 percent) in Willis StreetCambridge Terrace, MB2123900 (79 percent) in Lambton in Wellington and MB1961100 (70 percent) in Naenae North in Lower Hutt. Besides these, there are about 29 mesh blocks in Wellington, four in Porirua, three in Lower Hutt, two in Masterton and one in Upper Hutt, where 50 percent or more population has no motor vehicle.

\subsubsection{Economic Vulnerability Index}

The overall economic vulnerability index of the region highlights Wellington city as the most vulnerable district within the region, followed by Lower Hutt and Porirua (Plate: 4.3). All the most vulnerable mesh blocks (19 on the basis of maximum imputed values and 14 on the basis of minimum imputed values) in the region are located in Wellington. A further classification at ward level shows that about 13 most vulnerable mesh blocks are located in Lambton Ward, five in Southern Ward and one in Eastern Ward.

The economic vulnerability at individual level is often affected by the changes in economy at national or global scale. New Zealand is an island nation and its relatively small economy makes it vulnerable to regional and global changes. History shows that past global economic depressions led to severe economic consequences for the country. The economic depression in 1885-1892, made many people move out of New Zealand. About 125,000 people left of which most went to Australia and a few to North America. New Zealand's worst depression was in the late 1930s (Naumann, 2000, 13). The incidents in late 1980s and 1990s suggest that such incidents affect the most economically vulnerable group (Howden-Chapman et al., 2005), which mainly include poor, less skilled and those with less savings. Global changes often lead to changes in the local economy. The economic restructuring of New Zealand in the 1980s enhanced the economic vulnerability by increased unemployment, decrease in income and welfare along with working conditions for the vulnerable sections of the society including working class Maori and Pakeha, women, a population dependent on welfare benefits, public health and education (Poata-Smith, 1997, 177). In the current global economic recession (2008), the New Zealand stock exchange index fell by 37 percent since May 2007 and the NZD fell by 35 percent against the USD since its February 2008 high (Jensen, 2008,11). The country's commodity export especially linked with dairy and tourism has recently experienced slumps and is facing uncertainty about its growth in the near future (Jensen, 2008, 11). In addition, unwinding household indebtedness is also going to affect housing industry and debt reduction is likely to have a long-term impact on household spending (Jensen, 2008 , 2). Thus global conditions often produce vulnerability at the local level, which if met with unanticipated environmental changes or hazards, may then produce disaster, and it is the vulnerable population that is more likely to be affected by both social and natural changes.

\subsection{Infrastructure Vulnerability}

The state of infrastructure not only represents the exposure and fragility but also influences the coping capacity and recovery during and after hazard occurrence. The infrastructure here refers 
to buildings, means of transport such as roads, railway lines, airport or ferry, electricity, telecommunications, water supply, gas, drainage, sewage, storm water system etc. Most of these types of infrastructures are vulnerable to most geological and climatic hazards, which could not only disrupt the services they provide, but could also cause a disaster through themselves.

\subsubsection{Buildings}

Buildings are the basic infrastructure of any settlement. They are an important indicator and potential source of human vulnerability. The vulnerability arising from buildings are determined by their type, age and use. Although, there is no such dataset available for all buildings in the region, New Zealand Heritage and local governments list old heritage buildings, which highlight just a few vulnerability aspects of buildings in the Wellington Region. New Zealand Heritage records about 760 historical places mainly buildings or other constructed features in the Wellington Region. A major share of these buildings is located in Wellington city (nearly 55 percent). The distribution of historic buildings in other districts include 11 percent in South Wairarapa, eight percent in Lower Hutt, Masterton and Porirua each, five percent in the Kapiti Coast, three percent in Carterton and two percent in Upper Hutt. In rural districts like Masterton, Carterton and South Wairarapa, significant proportion of historical places are linked with agriculture and horticulture assets and stable, which are mainly no longer in use. Besides, there are a number of other buildings which do not extend vulnerability to visiting people such as garden gates, roads, pit and pa etc. The buildings which could have been vulnerable including banks, administrative buildings, educational and health services are mostly either not in use or has been transformed for residential or civic purposes. Heritage buildings which are still in use are mainly residential, and are distributed throughout the region. Since the list from New Zealand Heritage does not provide a very detailed account of buildings' characteristics, the list prepared by the Wellington City Council was consulted for further analysis.

On a vulnerability scale, buildings in Wellington city are broadly classified into four categories in this research. The first category includes those that invite large numbers of people for a short stay, and are medium to high-rise (two or more stories such as theatres, cinema, educational institutes such as universities, schools or libraries, hospitals and hotels etc). These buildings play an important role in social communication, and by attracting large crowds, they pose a high risk during a disaster. Any damage to these buildings in case of a major earthquake or tsunami could take hundreds of lives at once.

The Wellington City Council Heritage Inventory 1995 and 2001 identifies about eight heritage theatres, cinema and downstage theatres in Wellington. Five in eight of these buildings were made before 1925, one before 1950, one after that and for the last one, the year of construction is not known. The main structural materials of these old buildings include concrete for four, reinforced concrete for one, masonry for two and timber for one building. Most of these buildings are old and deteriorating, and their total risk has been mitigated by placing limits on the number of people they accommodate. For example, the original seating of Paramount theatre was for 1200 people on two levels, which is now reduced to 450 (Boffa Miskell Ltd \& Cochran, 2001). Yet, their old age and structural material pose significant vulnerability to people, who often visit 
them. Out of eight, only three buildings are stated to be in good condition and details are not given for the other five.

Vulnerable hospital buildings also fall in the first category as their vulnerability not only puts the lives of admitted patients at risk but also affects the coping capacity of the community by disrupting services they provide. Wellington city heritage list includes about three hospitals, two rehabilitation centres, one medical clinic and one dental clinic, which all were built before 1950 i.e. one before 1900, two before 1925 and four before 1950. Three out of seven buildings are made of concrete, one from masonry and the other three from timber.

The heritage educational buildings in Wellington city include four schools, five colleges, four libraries, three university buildings, one institute, one lab and one education board building. Five of these buildings were built before 1900, ten before 1925 and five from 1926-1953. Many of these buildings are at high risk, and the students and the people who visit these institutes may or may not be aware of all hazards. Of 20 educational buildings labelled as heritage, one was noted in poor and two in fair condition. For 12 buildings, details of their strength are not given. Only five buildings were classified as being in good condition. The two oldest buildings in the city are Government building, which is now used for the Law School by Victoria University of Wellington and Queen Margaret College Tower Building. Both buildings were constructed in 1876 and are in regular use.

Another set of buildings in the first category consists of hotels and other short term accommodation. The Council identifies about twelve hotels in their heritage list in which one is recognised to have earthquake risk, one is in poor, two in fair to good and three in good condition. For another five, strength details are not given. Most of these hotels are old as two were constructed before 1900, six from 1901-1925, and the other four before 1950. Since tourism is an important industry in Wellington, the vulnerability of these buildings could put many people at risk and affect the industry both in the short and long term, if a disaster occurs. Besides big hotels, there are number of other buildings, which provide accommodation to local and international tourists. The local council records 27 such buildings that fall in the heritage category, in which one has earthquake risk, two are in poor to fair condition, nine in fair to good condition, nine in good to excellent condition and for the other six conditions are not stated. Only four of 27 buildings are made of timber, and the rest are concrete and masonry buildings, which make them susceptible to collapse during a major earthquake.

Category two of building vulnerability include those buildings, which invite regular users for a relatively long stay and are medium to high-rise i.e. more than two stories such as apartment housing, offices, retails, factories, banks, administrative buildings etc. These buildings again accommodate a large number of people. However, the people visiting or living in these buildings are expected to be more familiar with buildings and hazard response. But the risk through exposure is still high due to the presence of large numbers of people in these buildings. The Wellington City Council lists 31 apartments or flats or residential buildings with two or more stories. Of these buildings only six are made of timber and the rest are of concrete and masonry, and therefore they are susceptible to earthquake damage, which could result in massive casualties if the disaster 
happens at night. The other set of buildings, which are mainly used for office work besides warehouse and industrial purposes, could face greater damage if earthquake occurs during day time. The council records about 136 such buildings in which only 13 buildings are made of timber, and 27 buildings, which are used for heavy warehouse and industrial purposes are all concrete and masonry structures.

The third category of buildings includes those which are purely residential and are of medium to low height. Though timber is widely used for most houses, many of the old houses have brick chimneys, which are susceptible to collapse during an earthquake. The council records 175 heritage houses, which are old and are in a relatively more fragile condition than the rest. Only 58 buildings are in good to excellent condition, and for the rest, strength varies from earthquake susceptible to poor and fair to good conditions.

Other buildings invite both people familiar and unfamiliar with the venues for short stays and are not high rise. These include cafes, pubs, and restaurants which fall into category four, as their structural vulnerability pose least risk to the guests. Such old buildings in Wellington city include retail, café, shops or commercial buildings (41), churches or chapels (33), community buildings (12), club or clubrooms (13), historic places (3), museum or galleries (5), crematoriums (2), a mission (1), a monastery (1), sheds/shelters/Gazebos/observatories (34) and seven unspecified buildings.

\subsubsection{Infrastructure for Transport and Communication}

Infrastructure for transport in the region including rail, road and air is vulnerable to a number of geological hazards such as fault displacement, uplift, subsidence or ground settlement etc. The vulnerability of such infrastructure is linked to exposure and fragility not only in terms of economic loss and disruption of related services, but also by putting coping capacity of connected districts at risk. The roads and railway lines in Wellington are often disrupted, closed or damaged by landslides and toppling. The damage from these hazards has been discussed in Chapter 5 on spatio-temporal occurrence of hazards in the region. Road and railways lines along with the Wellington airport are also vulnerable to liquefaction and ground settlement on reclaimed areas along with tsunami and sea surge. The Wellington Ferry Terminal is also likely to be affected by the Wellington fault movement because of its close location. Thorndon area is particularly vulnerable as the three services including rail, road and ferry meet at a very short distance from the Wellington Fault. Besides these main links, bridges along with underground tunnel are also vulnerable to earthquake and fault movement (CAE, 1991b, 26).

Interconnectivity is an important aspect of vulnerability associated with transport links. Roads and railway routes in the region are insufficiently interconnected. For example, the SH2 is the only road connection between Wellington to Lower Hutt, and Wellington to other Eastern districts, and any damage at critical locations could isolate people on either side. The situation is the same for the railway route, which is less diversified. The restricted road and rail connections could reduce the speed of recovery and could add to losses during a disaster (CAE, 1991b, 1). At local level there are number of places in the region, which have only one access route, which could create a major problem for evacuation in case of tsunami warning, when people would try to get 
out of a place and more likely all together and would get caught up in traffic jams. The problem could particularly arise in the low lying coastal areas of the Kapiti Coast. In Paekakariki while a few people saw the Kapiti Island as a protection against any major tsunami event, they feared for evacuation situation due to only exist route from their houses which may face heavy traffic jam.

Power and telecommunication lines in the region mainly follow the same route as that of road and railway lines and are vulnerable to earthquake, windstorms, lightening and volcanic ash

Map: 4.31. Vulnerable Infrastructure in the Wellington Region

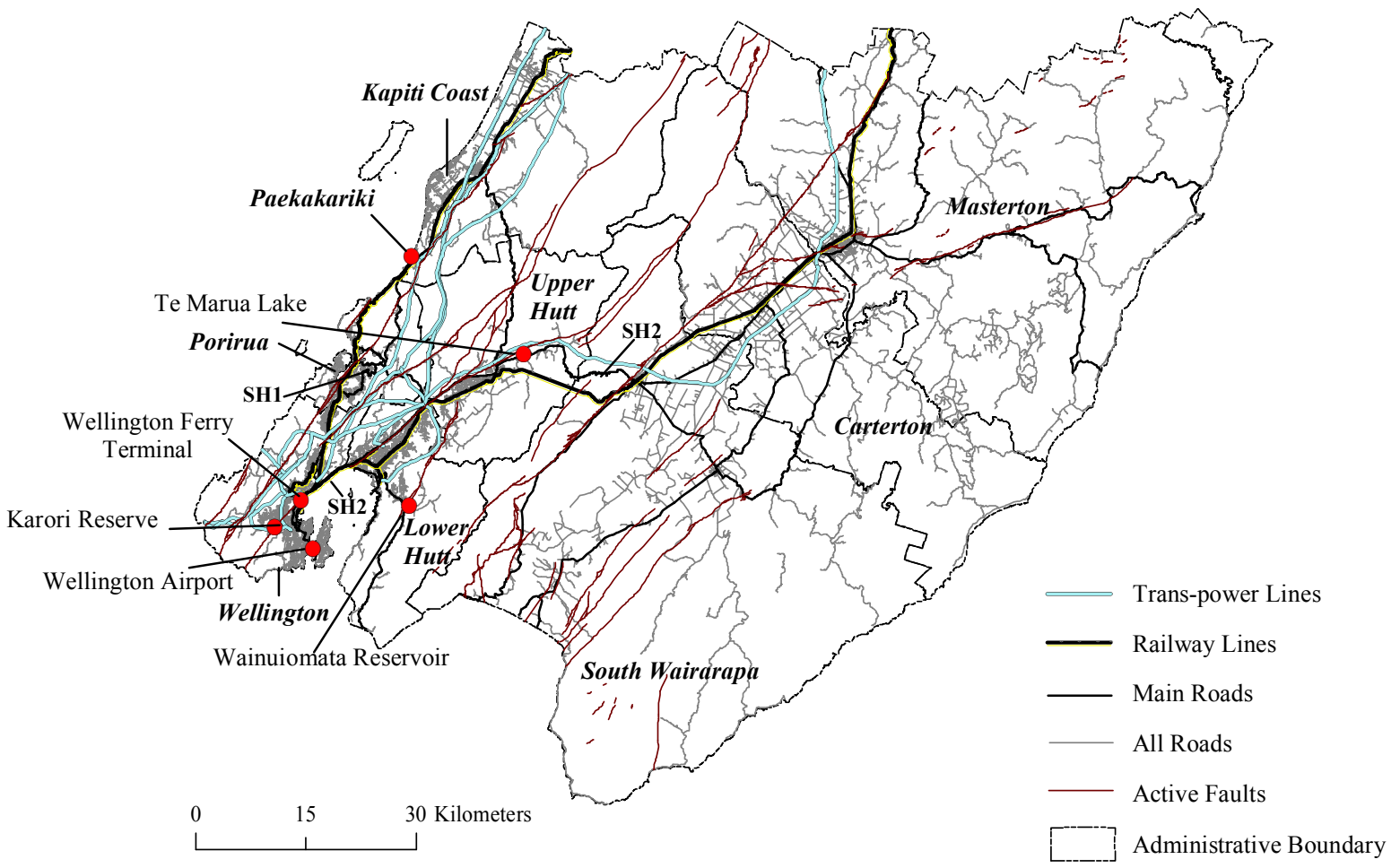

Based on data from Wellington Regional Council, 2007

fall. The disruption of power and telecommunication could hamper the disaster response and could increase disaster loss. The CAE report 1991 finds that Wellington city could experience a complete loss of power during a major earthquake event. Older substations in the region could face major damage and transformers are susceptible to toppling. The vulnerability of the power lines is also about their recovery and coping capacity as there are not enough supply of spare cables and required parts, and it could take up to a year to restore the damaged system to its pre-quake level (CAE, 1991b, 25). The lines, transformers and substations close to fault lines are particularly vulnerable. Similarly the telecommunication and broadcasting in the region could be disrupted for several days after the event as the broadcast transmitters and aerials are susceptible to damage depending on their location. The Radio New Zealand House, which is located close to the fault line, may suffer severe damage and it could take months to recover (CAE, 1991b, 26).

\subsubsection{Gas, Water and Sewerage System}

Gas and water supply along with drainage including sewage and storm water system are vulnerable to earthquakes and related hazards. Many of these infrastructures such as Te Marua water supply lakes near the fault are built to survive the effects of fault movement, but the connecting pipelines, which often pass through fault lines are vulnerable to geological hazards. This 
could result in disruption of services. Many main pipelines also pass through old and vulnerable bridges, and hence are more vulnerable to earthquake and other related hazards. The vulnerable structures in the region include the main pipe line at Te Marua, where it crosses the fault line, and Paremata Bridge from where main branch water passes is vulnerable to liquefaction and ground settlement along with Wainuiomata and Orongorongo mains and Petone Foreshore. Besides, two Karori lakes and associated facilities are located on Wellington Fault (CAE, 1991b, 24), which have now been decommissioned.

In case of sewage supply most pumping stations have no back up power supply. The Ngaio Gorge aqueduct could fail during an earthquake and pipelines through reclaimed land may suffer damage due to liquefaction. Besides, overflows could discharge into the storm water system, which may end up in Wellington harbour. It is also noted that mechanical and electrical plants are vulnerable to shaking and internal flooding (CAE, 1991b, 24-25). Many of the older drains are made of bricks, which could be damaged by liquefaction and flooding. The Horokiwi, Ngauranga and Ngaio streams are vulnerable to landslides which could result in disruption of main road links (CAE, 1991b, 25).

The gas supply lines in the region often cross the fault line i.e. in Wellington at Raroa Road and in Hutt Valley at two locations, and they are therefore vulnerable to damage from fault movement. The liquefaction also poses significant risk to these pipelines especially in areas such as Sea View. The cast iron/lead jointed pipe system in south of Wellington CBD and around the waterfront will be badly affected by ground shaking (CAE, 1991b, 25). The coastal infrastructure could also face damage from tsunami and sea surge. The infrastructure vulnerability in the region could extend the disaster impact over spatial and temporal scales.

\subsection{Administrative and Political Vulnerability}

Political processes at different scale i.e. local, regional, national or global over time generate vulnerability at the local level. In the Wellington Region, influences of such processes could be witnessed in the varying vulnerability across local administration and various socio-economic groups.

Historical development and current administrative arrangements influence the funding distribution across districts. In the $19^{\text {th }}$ century, the aim of the British Crown was to establish a political power and to use local resources. As a result, provincial governments were formed to suit the rough landscape with scattered population (Memon, 1993, 28). Initially, the country was divided into two provinces in 1846, which were later subdivided into six in 1852 (Kelleher, 1991, 333-334). The Wellington Provincial Government was established in 1853 (Patterson, 2000, 161). The province included a major part of southern North Island (see Map: 4.26) along with Chatham Island (Department of Land and Survey, 1969, 1). The subdivision of the region was very broad 
and the current Wellington Region was occupied by two districts named Port Nicholson and Wairarapa and East Coast (Map: 4.32).

Map: 4.32. The Wellington Province (1870) and the Wellington Region (2009)

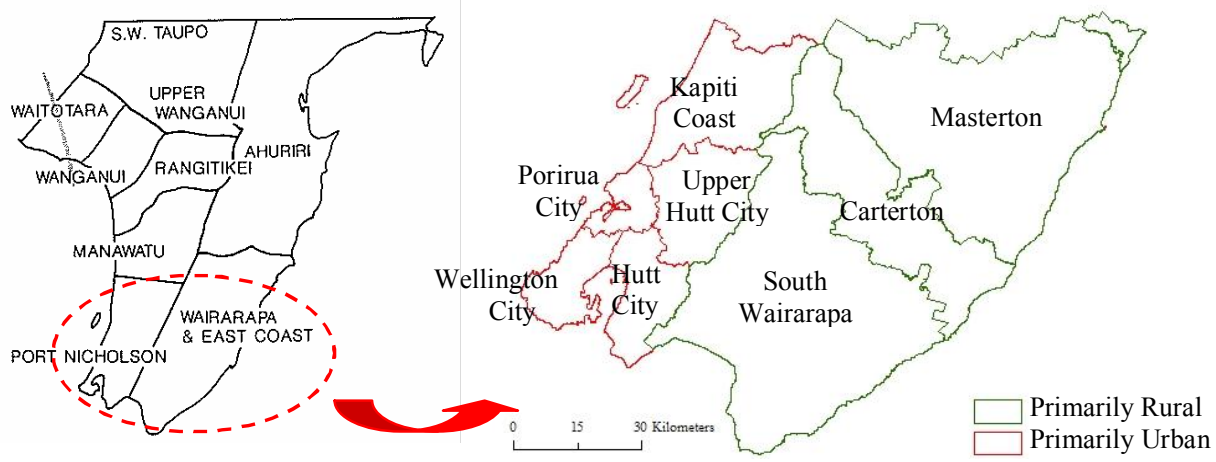

Based on Patterson, 2000, 162; Census 2006, Statistics New Zealand

The end of provincial government in 1876 further subdivided the region in to various local authorities. The boroughs, local boards and the road boards were reorganised for local governance (Bagnall, 1976, 306). The Wellington Region experienced several changes in the administrative boundaries of local government, but due to lack of consistent details, they could not be presented. The region attained its current shape (Map: 4.32) as late as 1989, when the Kapiti Coast district was formed by carving out areas from Upper Hutt and Manawatu (Kapiti Coast District Council, 2009).

The end of provincial government changed the power distribution in New Zealand along with the region. It gave enhanced supremacy to the central government with the power of decisionmaking for resource exploitation for economic growth and development at the local level (Hearn, 1982 as cited in Memon, 1993, 29). The role of local governments was marginal, though they were responsible for a number of important functions including land use planning, and water and soil management (Memon, 1993, 27). This power continued to grow over time. Since 1970s, the economic growth and resource use are seen more as national issues rather than regional or local concerns. This resulted to adoption of policies that apply to all localities irrespective of their physical, social or economic differences (Memon, 1993, 26-27). Differences at the local level are however, distinct and visible in both vulnerability and response aspects. At the local level, political power is determined by the distribution of population and nature of settlement (rural or urban). The eastern section of the region by and large remained rural, and politically quiet. The western section, on the other hand, has been more politically active ever since the shifting of capital from Auckland to Wellington in 1865 (Wellington, 2009). The political motivation, urban growth and development have consequently affected the administrative response to hazards and associated vulnerability (see chapter seven).

Political processes also influence vulnerability across ethnic groups and economic classes. First generation Maori arrived in New Zealand in the 13 ${ }^{\text {th }}$ century (Stevens, 1990, 246 as cited in Easther, 1991, 21). Over centuries of occupation, Maori were well-aware and adapted to the active biophysical environment and hazards in the country. There is evidence of Maori settlement abandonment and migration from the coast to inland because of seismic activity and tsunami incidents in $15^{\text {th }}$ century (Goff and McFadgen, 2003, 616). The vulnerability of Maori settlements 
before the arrival of Europeans was therefore mainly due to exposure rather than coping capacity or lack of resilience.

The European colonisation of Wellington in 1839 led to subsequent development of the current administrative system. Since the country was sparsely populated by Maori, the new settlers had to buy legal rights. Subsequently, Treaty of Waitangi was signed on $6^{\text {th }}$ February, 1840 between 500 Maori Chiefs and the British Crown, which annexed New Zealand to the latter. However, the treaty at the same time guaranteed Maori the possession of their land without any reservation (Kawharu, 1989 as cited in Patterson, 2000, 156; Keenan, 2008, 218). The subsequent scale of migration in New Zealand was beyond the imagination of local tribes. In 1840 Maori population exceeded Europeans by nearly 70 to 1 ; the proportion was equal after 20 years, and fell to a mere 4.5 percent by 1921 (Memom and Cullen, 1991 as cited in Memon, 1993, 22). Large scale immigration broke the traditional Maori subsistence economic system and led to the development of a mercantile economy based on commodity export (Memon, 1993, 22).

Maori people were not only exposed to a new economic and political system but also to a new language, food and lifestyle in the new European dominant society. The changed socioeconomic and administrative set up marginalised Maori in all respects. There was no Maori representation in the administration of Wellington Province until 1867, when four special seats were specially formed for them (Keenan, 2008, 219). Maori were also not directly involved in project initiation and planning as officials at higher level were exclusively Pakeha (European) (Mahuta et al 1985 as cited in Memon, 1993, 34). Lack of political influence further did not allow them to censure decisions on resource exploitation (Memon, 1993, 29). The negligence of colonial power towards Maori autonomy because of economic and political reasons resulted in continuous marginalisation of the community (Keenan, 2008, 219), which increased their economic vulnerability over time both in terms of coping capacity and disaster resilience.

The collapse of subsistence economy forced the community to sell their labour to survive in the new economy. A significant working class emerged from the community during the economic boom from 1945 to 1975 (Poata-Smith, 1997, 174). The rapid development of the country and exploitation of resources for development led to several breaches of the Waitangi Treaty. It also happened partly because the treaty had different understanding between Maori community and the Government (Naumann, 2000, 21). The economic collapse in the mid-1970s subsequently generated a political movement for racial equality based on historical, social and economic grievances (Poata-Smith, 1997, 175). This led to the development of the Treaty of Waitangi Act in 1975, establishing the Waitangi Tribunal to hear Maori claims against the Crown (Keenan, 2008, 222). However, the powers of the Tribunal were limited and did not satisfy Maori concerns until 1985, when the Waitangi Amendment Act allowed the tribunal to make recommendations for even older claims until 1840 (Memon, 1993, 34). The task of the tribunal was to assess the case and if valid to then make recommendations to the government, which would finally decide the issue (Keenan, 2008, 222). This generated some confidence in the community, but it benefited only certain section of the community. Similarly, the policy of biculturalism, which helped the middle class Maori population to achieve higher positions, shifted the cost to the 
vulnerable working class. About one fifth of Moari working class were made redundant within two years from March 1987 and March 1989 after the establishment of the policy of biculturalism (Te Puni Kokiri, 1993, 41 as cited in Poata-Smith, 1997, 177).

Even today, a significant proportion of the Maori population occupy low socio-economic positions and their interests, values and traditional methods have been compromised for development by the government for resource allocation and management (Memon, 1993, 22). However, after a significant immigration of other ethnic communities from different parts of the world including, Pacific, Asian, MELAA, New Zealand is rather a multi-cultural place (Keenan, 2008, 223), and Maori are not the only ethnic group at the bottom level of vulnerability scale (see Table: 4.13). Along with Maori, these people share socio-economic vulnerability and lack political voice, which poses significant challenges to local authorities to manage their vulnerability in order to avoid future disaster.

The colonisation of New Zealand was itself part of globalisation. Political decisions in New Zealand and subsequently in the region have also been affected by the global and local economic changes. The economic recession after the mid 1970s increased economic and political pressure to bring changes in government. The restructuring of the economy led to a shift from a welfare state to an open economy, where many important political decisions were governed by business interests rather than actual needs at local level (Memon, 1993, 32). The reduction in welfare enhanced the vulnerability of those who depended on it i.e. poor, unemployed, sick, women, solo parents and therefore the gap between rich and poor (Poata-Smith, 1997, 177).

\subsection{Composite Vulnerability}

Overall vulnerability is the output of various demographic, socio-cultural, economic and political processes. However, it is difficult to give all ecumenical characteristics of a community some value to feed into the composite index. Those characteristics, which could have been added such as demographic, social and economic, show that Wellington city is the most vulnerable district in the region (Plate: 4.4). Porirua, Lower Hutt, the Kapiti Coast, Upper Hutt, Masterton, South Wairarapa and Carterton follow it in descending order. Therefore a gradient can be observed for vulnerability, which is centred on densely populated and built up urban areas and declines towards the rural periphery over widespread physical susceptibility of the region.

At mesh block level about 109 mesh blocks through maximum imputed values and 110 mesh blocks through minimum imputed values fall under the category of the most vulnerable areas. Almost all of these mesh blocks are located in Wellington city except one i.e. MB2029400, which is located in Wilford, Lower Hutt. The most vulnerable mesh block in the region is MB2128800 in Lambton followed by MB2166200 in Newtown West in Wellington. 
Plate: 4.4. Composite Vulnerability Index of the Wellington Region (2006)
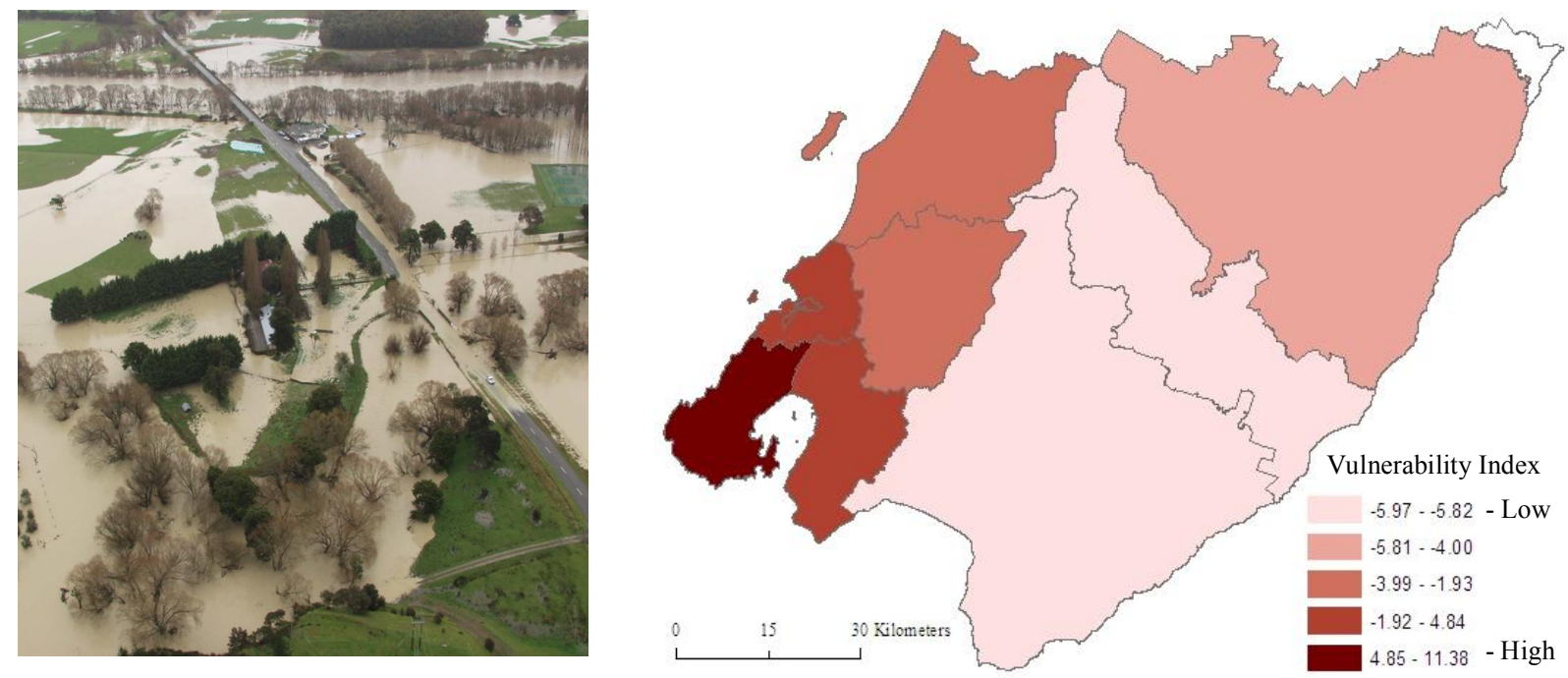

1. Vulnerability Index Based on Maximum Imputation Value

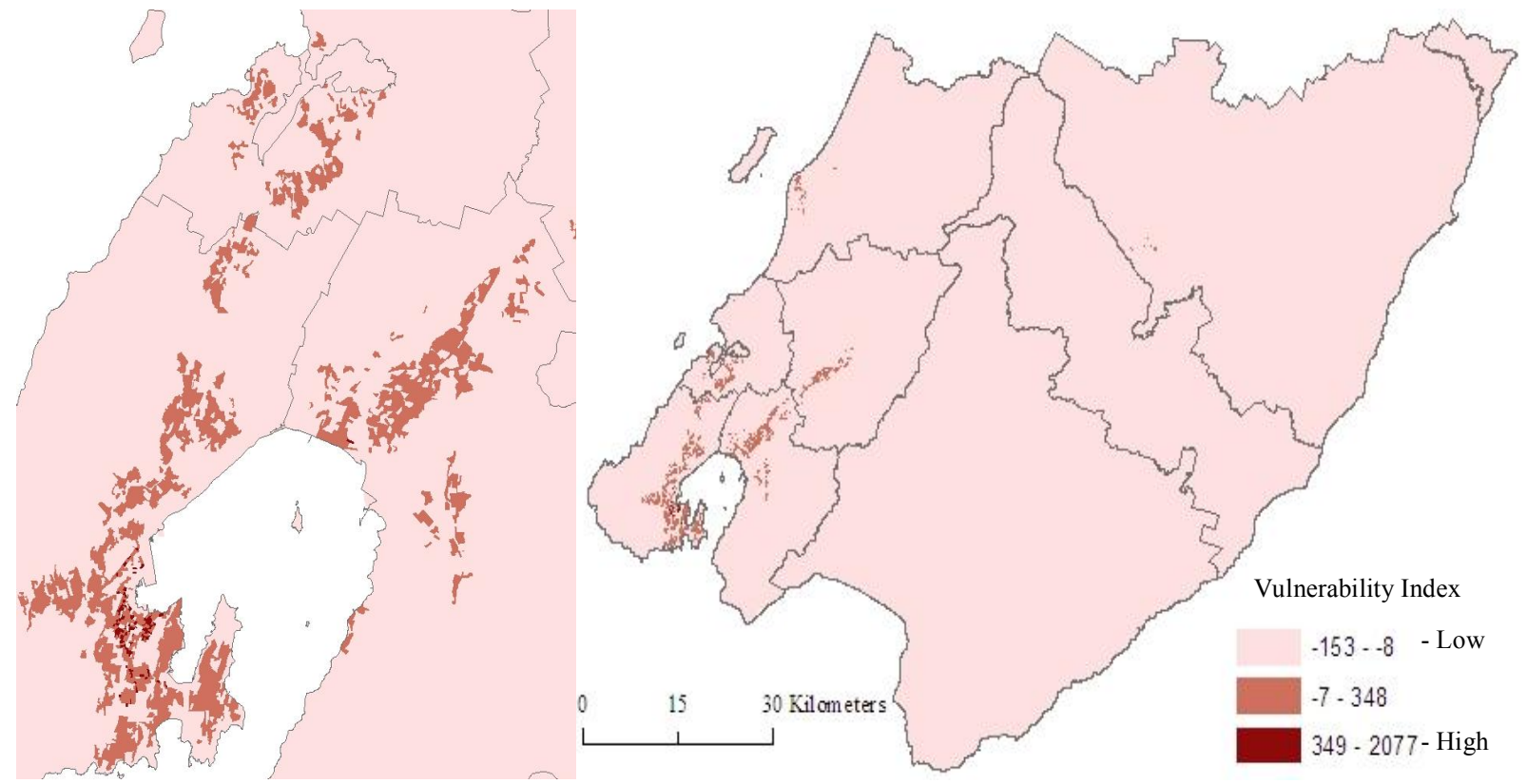

2. Vulnerability Index Based on Minimum Imputation Value

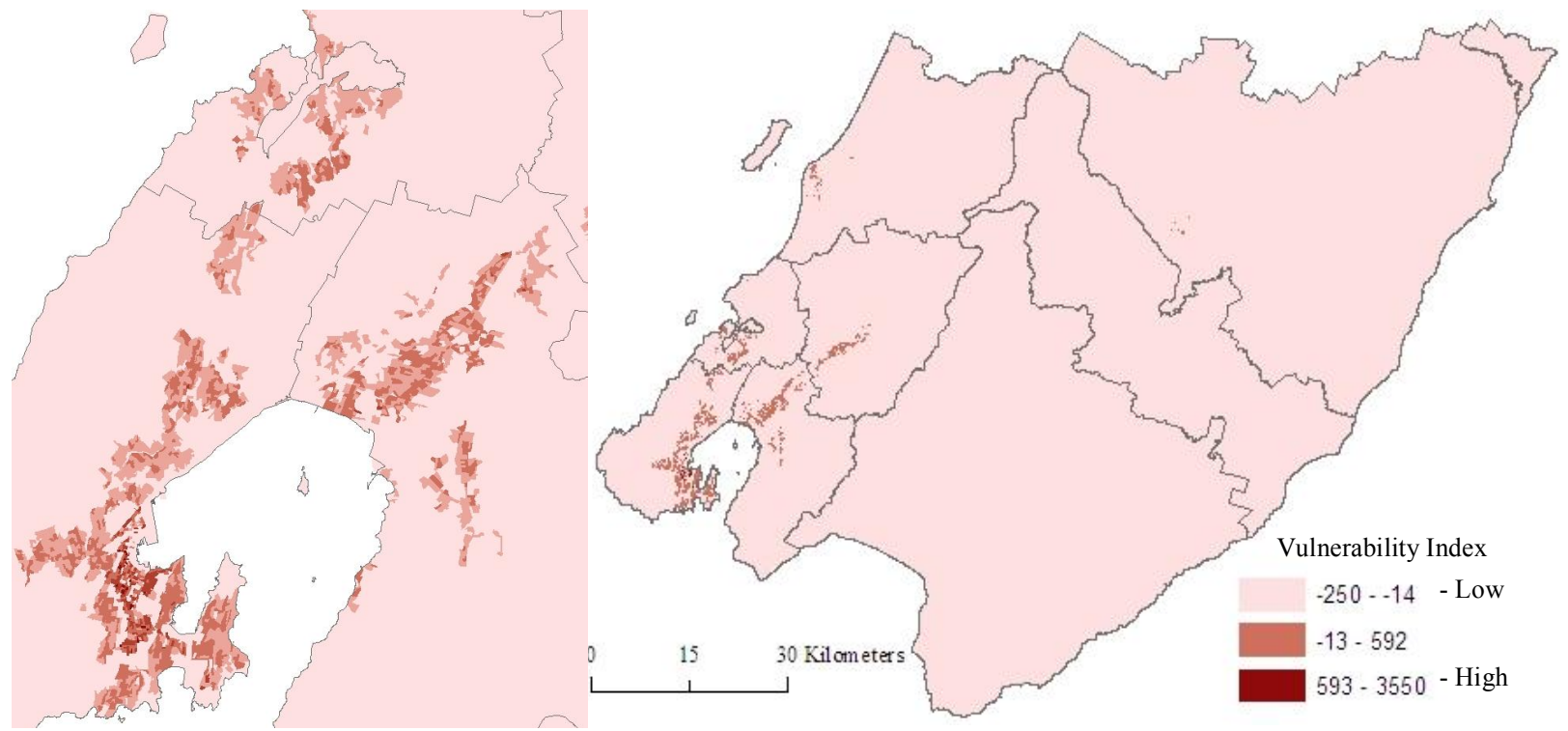

Based on Census 2006, Statistics New Zealand; GWRC (2009c) 
The vulnerability map highlights concentration of high vulnerability in specific areas, indicating that vulnerable population tend to locate in close proximity to each other, which in turn generates spatial expression of vulnerability. Concentration of 93 most vulnerable mesh blocks in Lambton Ward and 15 of such mesh blocks in Southern Ward of Wellington emphasize this aspect. It could also be interpreted the other way round i.e. areas of high vulnerability bear certain socio-economic conditions, which encourage the congregation of vulnerable population. In either case, the congregation of vulnerable people results in segregation of these people over space, which further enhances vulnerability at the local level. For example, high proportion of old people in MB1940402 (95 percent) in Taita North, Lower Hutt, MB2004101 (92 percent), MB2003505 (92 percent), MB1883804 (91 percent) in Raumati Beach, Paraparaumu Beach; single parents in MB2045600 (100 percent) in Cannons Creek North, Porirua and MB2169901 (100 percent in Newtown East, Wellington; non qualified people in MB1940403 (65 percent) in Taita North, Lower Hutt, MB1961100 (63 percent) in Naenae North, Lower Hutt, MB2168300 in Newtown East, Wellington; Workers in elementary occupation in MB1900700 (82 percent) in Trenthan South, Upper Hutt; population with individual income less than 10,000 NZD in MB2153300 (84 percent) in Kelburn, MB2128800 (83 percent) and MB2128400 (82 percent) in Lambton, Wellington; Maori in MB1976102 (94 percent) in Waiwhetu North, Lower Hutt; Pacific in MB2206700 (90 percent) in Miramar South, Wellington; Asian in MB2134800 (80 percent) in Willis Street-Cambridge Terrace, Wellington; MELAA in MB1948600 (52 percent) in Avalon east, Lower Hutt. The localisation of vulnerability within the region bears significant consequences for hazard response as most people in the community would be facing similar kinds of problems, which could enhance the disaster impact.

Further analysis of vulnerability in the region shows that vulnerability pattern varies on different spatial scales. The vulnerability index at the mesh block, area and district level show distinct patterns (Plate: 4.5). For example, in demographic vulnerability index at district level even though the Kapiti Coast appears as the most vulnerable district along with Wellington, at area level none of its area is as vulnerable as parts of Wellington and Porirua. Furthermore at the mesh block level, the number of mesh blocks with medium vulnerability in the Kapiti Coast is not as high as other districts such as Lower Hutt and Upper Hutt. Similarly in the social vulnerability index, Porirua is the most vulnerable district but at area and mesh block level, spatial extent and number of areas of high vulnerability are more in Wellington and Lower Hutt. The reason is partly associated with the distribution of population, which directly affects the proportion of vulnerable population to the total and hence their categorisation in high or low vulnerability over space.

The vulnerability pattern also varies for economic and composite vulnerability. For example, while Masterton looks medium vulnerable at district level, at area level its vulnerability is confined to its city centre and Tararua district, which gets further reduced to only city centre at the mesh block level. In Carterton and South Wairarapa few rural areas are rather more vulnerable but because of small population size, they are not visible on mesh block and district level. This points out that though collective vulnerability is more dominant in highly populated urban areas, it is the individual vulnerability, which is prevalent in suburban or rural areas with less population concentration.The variations across scales could also be witnessed for individual indicators, which 
Plate: 4.5. Variations in Vulnerability Index on Different Spatial Scales in the Wellington Region (2006)
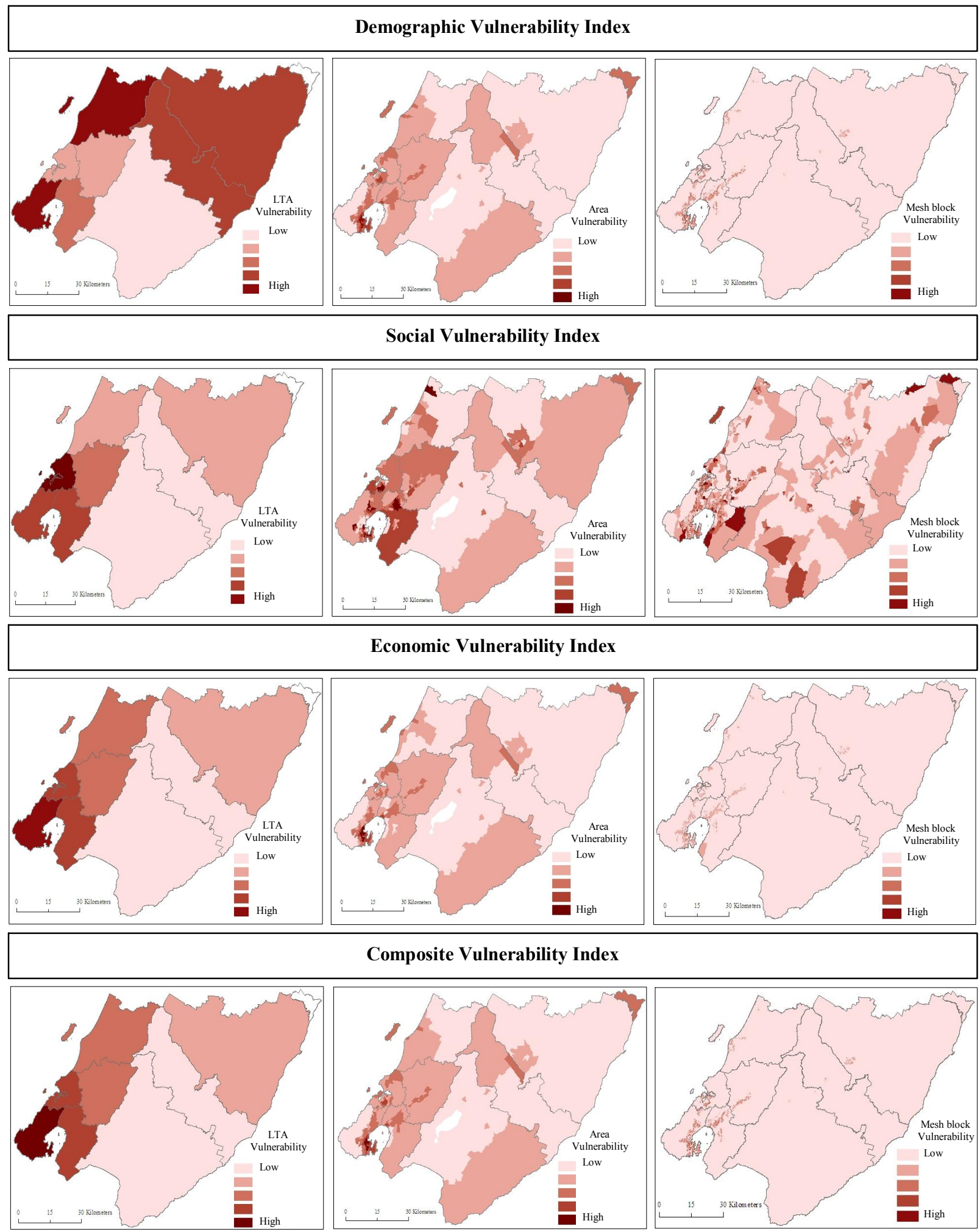

Based on Census 2006, Statistics New Zealand; wmw.gw.govt.nz

signify changing cause of vulnerability over space. For example, at the district level the highest proportion of the population living in one room is concentrated in Wellington i.e. 1.1 percent, but at the mesh block level, it is found in MB1966700 in Hutt Central, Lower Hutt, where 55 percent of its population (49) lives in one room. The comparison of the mesh blocks with higher concentration of population living in one room in MB1966700 (55 percent) in Lower Hutt Central 
and MB2131600 (50 percent) in Lambton Ward of Wellington shows difference in the cause and characteristics of vulnerability. In Lower Hutt mesh block (MB1966700) one room dwellers are mainly local people, which is indicated by the fact that the people who lived overseas five years before the 2006 Census were less than 7 percent of its total population. The mesh block also portrays high socio-economic vulnerability i.e. population not qualified ( 21 percent), having low median income (18300 NZD), high Maori population (35 percent) and high percentage of population (57 percent) engaged in blue collar elementary labour jobs. In MB2131600 of Lambton Ward, Wellington one room dwellings are mainly used by international population as the population who lived overseas five years ago is more than 80 percent of its total population. They are likely to be international students, who live and work in close proximity to universities and have low income as apparent in the low median income (4,400 NZD) of the mesh block along with low percentage of non qualified population (two percent) and those in elementary labour jobs (12 percent). Their vulnerability is different from the previous group. The vulnerability of students is more transitional as their socio-economic conditions and awareness level are likely to change through time, which would reduce their vulnerability over time, which is less likely to happen for other groups. This also highlights the spatial aspect of vulnerability.

Despite the fact that the current vulnerable population living in Lambton Ward would later get out of the vulnerability sphere, the spatial spread of vulnerability in the area would continue to exist and the current students would only be replaced by newcomers. They will again have the same vulnerability characteristics linked with unawareness and socio-economic characteristics. Similarly, vulnerability in the Kapiti Coast is related to the excessive concentration of elderly female population (Statistics New Zealand \& Ministry of Women Affairs, 1998, 15). In this case again the current set of elderly population is likely to be replaced by a new generation of elderly population and hence despite the population change, spatial vulnerability will continue to exist. Vulnerability in Porirua, on the other hand, is linked to the presence of indigenous population of Maori and migrated Pacific community having high socio-economic vulnerability, high child population living with single parents and low income. This emphasises the varying patterns and causes of vulnerability throughout the region.

It can therefore be said that a spatial approach to vulnerability reduction is essential. It is further enforced by the spatial interdependence of different city and district councils in the region. Wellington city act as the main service centre for the whole region and employs a significant proportion of population from various parts of the region. The collapse of Wellington CBD and resultant disconnectivity through fault movement could produce a significant loss to its urban and rural hinterlands.

Finally, it can be concluded that vulnerability in the Wellington Region is prevalent and varied. Since the response of people are often modified and governed by various vulnerabilities, dominant patterns of vulnerability over space open the scope for effective response management. 
Chapter: 5

Spatio-Temporal Occurrence of Hazards in the Wellington Region

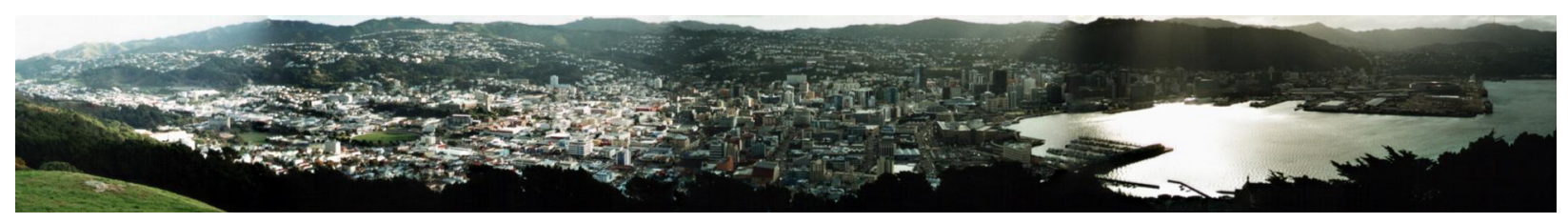


The presence of hazards in the environment has always been felt by the settlers of the Wellington Region. However, the history of hazard occurrence is brief due to the region's late colonisation and a lack of detailed records. The region was first colonised by Polynesians in 1080AD (McGlone, 1983 as cited in Glade, 1997, 60). In this initial phase of settlement either no records of hazards were formed or they did not eventually last. The only evidence of hazard occurrence in this phase is the ones, which are embedded in archaeological sites. In the second phase, Maori came in about 1250AD (McGlone, 1983 as cited in Glade, 1997, 61). Their records of hazards on the other hand are oral, and mention major events but are less certain about the rest. Europeans colonised the region in 1839 and their records of hazards started in 1840. Initially not all hazards were recorded due to unawareness and lack of need, but with the settlement expansion and growing complexities of hazardscape, the records improved significantly in the late $20^{\text {th }}$ century. However, the availability of information differs with the nature and type of hazards.

\subsection{Geological Hazards}

As indicated in chapter three, the Wellington Region is exposed to a range of geological hazards including earthquakes, liquefaction, fault displacements, landslides and tsunami. Most of these hazards can be associated with each other in time and space, and therefore the history of these hazards is often interconnected.

\subsubsection{Earthquakes}

In the geological setting of the Wellington Region, earthquakes are frequent. At times they are associated with liquefaction, fault displacement, landslides or tsunami. Maori called them rū whenua, which generate when their god Rūaumoko/Rūamoko (Photo: 5.1) walks (Explore Te Ara: The Encyclopedia of New Zealand [Te Ara], 2008e). They have also been attributed to Taniwha, which is a dragon like monster. A Maori legend tells the story of a taniwha that travelled north from Porirua to Te Aute in Hawke's Bay, and left a trail of destruction (Te Ara, 2008a). It is also noted by Maori that a big earthquake named Haowhenua/Hau-Whenua (the land destroyer) around 1460AD raised the sections of Wellington's coastline and the island of Motukairangi was joined to the mainland, which is now called Miramar Peninsula (Te Ara,

Photo: 5.1. Earthquake god Rūaumoko

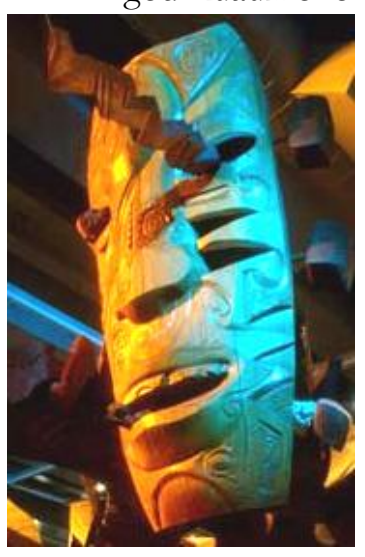

Source: Te Ara, 2008a 2008b; CAE, 1991b, 13) (see Photo: 3.4b).

The records from 1840 to 2008 show that the region has experienced about 40,246 earthquakes in 169 years (Table: 5.1). However, the numbers are not complete because for a long period of time only major earthquakes could be recorded, which were either felt by local residents or some change was evident in the landscape. No information is available on the magnitude for nearly 97 percent of earthquakes recorded from 1840 to 1860. The earthquake records therefore show a gradual shift in the nature and availability of both data and technology, and can be divided into three different phases. In the first period from 1840 to 1923, because of the absence of 
advanced technology, only higher magnitude earthquakes could be recorded. As a result all the recorded earthquakes in this phase were above four in magnitude. In the second phase from 1924 to 1965 , advances in technology helped to record earthquakes of a magnitude above two. A trend of earthquake occurrence emerged, wherein more than 99 percent of earthquakes that hit the region ranged between two to six in magnitude. The third phase started from 1966, when it became possible to record earthquakes of magnitude just above zero. The data recorded in this phase further clarified the established trend from the former data. It showed that more than 99 percent of the earthquakes that occurred in the region were below four in magnitude. The overall records reflect that about 58 percent of the recorded earthquakes that hit the region since 1840 to 2008 were between 2-4 magnitudes. The region has only experienced ten earthquakes of $>6$ magnitude that account for 0.02 percent of recorded earthquakes.

Apart from magnitude, the factor that indicates the energy released through an earthquake Table: 5.1. Magnitude of Earthquakes Recorded in the Wellington Region (1840-2008)

\begin{tabular}{|c|c|c|c|c|c|c|c|}
\hline \multirow[b]{2}{*}{ Year } & \multicolumn{6}{|c|}{ Magnitude } & \multirow[b]{2}{*}{ Total } \\
\hline & $\begin{array}{c}0.000- \\
1.999\end{array}$ & $\begin{array}{c}2.000- \\
3.999\end{array}$ & $\begin{array}{c}4.000- \\
5.999\end{array}$ & $\begin{array}{l}6.000- \\
7.999\end{array}$ & $\begin{array}{c}8.000 \& \\
\text { above }\end{array}$ & Not given & \\
\hline $1840-1860$ & 0 & 0 & 0 & 3 & 1 & 139 & 143 \\
\hline 1861-1881 & 0 & 0 & 0 & 0 & 0 & 0 & 0 \\
\hline 1882-1902 & 0 & 0 & 0 & 1 & 0 & 1 & 2 \\
\hline 1903-1923 & 0 & 0 & 2 & 1 & 0 & 0 & 3 \\
\hline 1924-1944 & 0 & 89 & 101 & 3 & 0 & 20 & 213 \\
\hline 1945-1965 & 0 & 213 & 117 & 1 & 0 & 0 & 331 \\
\hline 1966-1986 & 3660 & 3704 & 89 & 0 & 0 & 0 & 7453 \\
\hline $1987-2007$ & 12716 & 19106 & 139 & 0 & 0 & 0 & 31961 \\
\hline 2008 & 13 & 125 & 2 & 0 & 0 & 0 & 140 \\
\hline Total & 16389 & 23237 & 450 & 9 & 1 & 160 & 40246 \\
\hline
\end{tabular}

is its depth. The earthquake records from 1840 to 2008 show that about 64 percent of total earthquakes have occurred at a depth of less than 30 kilometres, about 97 percent at 60 kilometres and more than 99 percent at a depth of 90 kilometres (Table: 5.2). The number of earthquakes drastically decreases below the depth of 90 kilometres. Until now only 0.06 percent of the total number of earthquakes has occurred below 90 kilometres and only 0.005 percent at a depth greater than 150 kilometres.

Table: 5.2. Depth of Earthquakes Recorded in the Wellington Region (1840-2008)

\begin{tabular}{|c|c|c|c|c|c|c|c|c|}
\hline \multirow[b]{2}{*}{ Year } & \multicolumn{7}{|c|}{ Depth (in Kilometres) } & \multirow[b]{2}{*}{ Total } \\
\hline & $\leq 30$ & $\begin{array}{c}30.00- \\
59.99\end{array}$ & $\begin{array}{c}60.00- \\
89.99\end{array}$ & $\begin{array}{l}90.00- \\
119.99\end{array}$ & $\begin{array}{l}120.00- \\
149.99\end{array}$ & $\begin{array}{l}150.00- \\
179.99\end{array}$ & $\begin{array}{c}180.00 \& \\
\text { below }\end{array}$ & \\
\hline $1840-1860$ & 143 & 0 & 0 & 0 & 0 & 0 & 0 & 143 \\
\hline $1861-1881$ & 0 & 0 & 0 & 0 & 0 & 0 & 0 & 0 \\
\hline $1882-1902$ & 2 & 0 & 0 & 0 & 0 & 0 & 0 & 2 \\
\hline $1903-1923$ & 3 & 0 & 0 & 0 & 0 & 0 & 0 & 3 \\
\hline 1924-1944 & 196 & 14 & 3 & 0 & 0 & 0 & 0 & 213 \\
\hline $1945-1965$ & 218 & 107 & 5 & 0 & 0 & 0 & 1 & 331 \\
\hline 1966-1986 & 4479 & 2722 & 246 & 5 & 1 & 0 & 0 & 7453 \\
\hline $1987-2007$ & 20721 & 10376 & 844 & 11 & 8 & 1 & 0 & 31961 \\
\hline 2008 & 81 & 54 & 5 & 0 & 0 & 0 & 0 & 140 \\
\hline Total & 25843 & 13273 & 1103 & 16 & 9 & 1 & 1 & 40246 \\
\hline
\end{tabular}

Based on data from Geonet, 2008 
Fig: 5.1. Magnitude and Depth of Earthquakes Recorded in the Wellington Region (1840-2008)

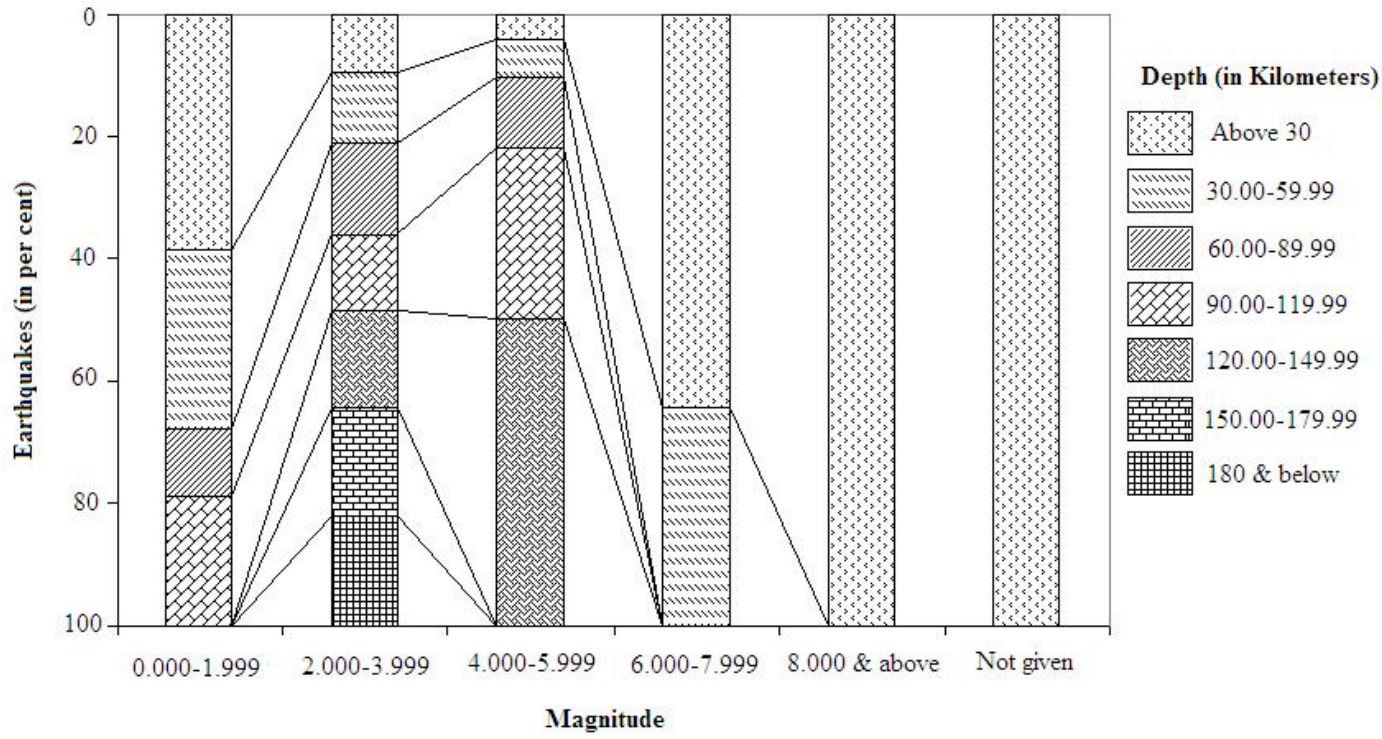

Based on data from Geonet, 2008

The relationship between magnitude and depth is crucial as together they determine the impact of an earthquake on the surface. The data show that maximum earthquakes occurred at a shallow depth of about 30 kilometres (Fig: 5.1). The comparison of earthquake magnitude and depth shows that none of the bigger earthquakes of magnitude nine or more on the Richter scale have occurred below 60 kilometres from the earth's surface. The deepest earthquakes, which generated below 150 kilometres were 2-5 in magnitude.

The spatial distribution of earthquakes shows that most of the shallow earthquakes occur along the Rimutaka and Tararua Ranges (Map: 5.2). These are earthquakes which occur in the Indo-

Map: 5.1. Distribution of High Magnitude Earthquakes and Density of Shallow and Deep Earthquakes in the Wellington Region (1840-2008).

Shallow Earthquakes $(<30 \mathrm{~km})$

Deep Earthquakes $(\geq 30 \mathrm{~km})$
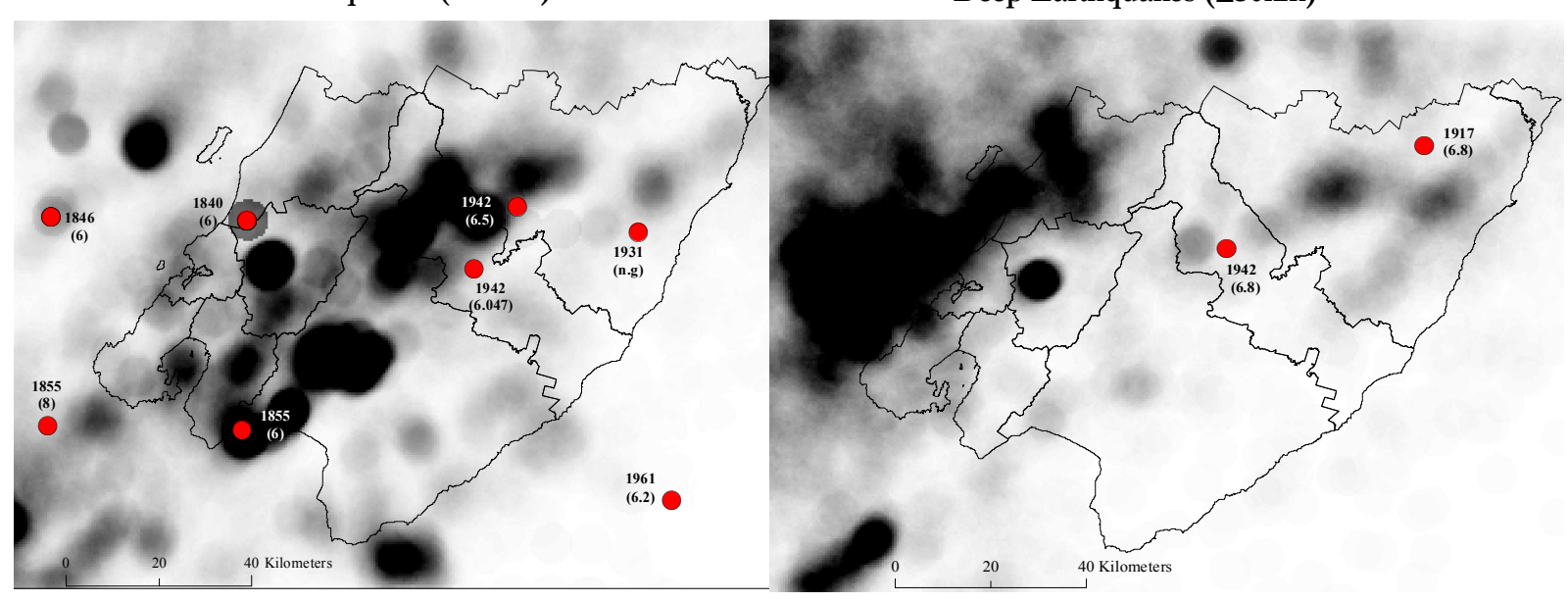

Earthquake Density

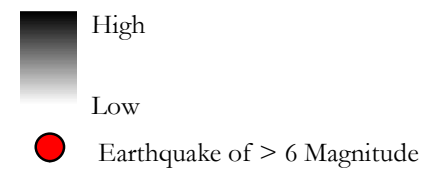

Total Number of Earthquakes: 40246

Total Shallow Earthquakes: 25843 (64\%)

Total Deep Earthquakes: 14403 (36\%)

Based on data from Geonet, 2008 
Australian plate due to its expansion. Most of the high magnitude earthquakes, which caused damage in the region, have occurred in this zone. Deeper earthquakes have occurred more on the western edge of the region. These earthquakes are related to the subduction of the Pacific plate beneath the Indo-Australian plate (Grant, 2005a, 3). The districts most affected by these earthquakes include the Kapiti Coast, Porirua and Upper Hutt. Surprisingly, the central part of the Upper Hutt district is affected by both shallow and deep earthquakes, which could be an issue of concern as the district does not have its own civil defence emergency management service as noted during the field survey. The location of earthquakes is also worth noting as it has been observed that moderate to big earthquakes generally happen in the areas which experience a high rate of smaller earthquakes (Frankel, 1995 as cited in Stirling et al, 1998, 361). Dark patches in the sea bed as shown in Map 5.2 are of particular concern as they could be the source areas of local tsunami particularly near Wellington harbour, the Kapiti Coast, Palliser Bay and south east of South Wairarapa. Since most earthquakes are generated in shallow depth, they are likely to engender local tsunami in the future.

Map: 5.2. Hazards Associated with Historical Earthquakes in the Wellington Region.

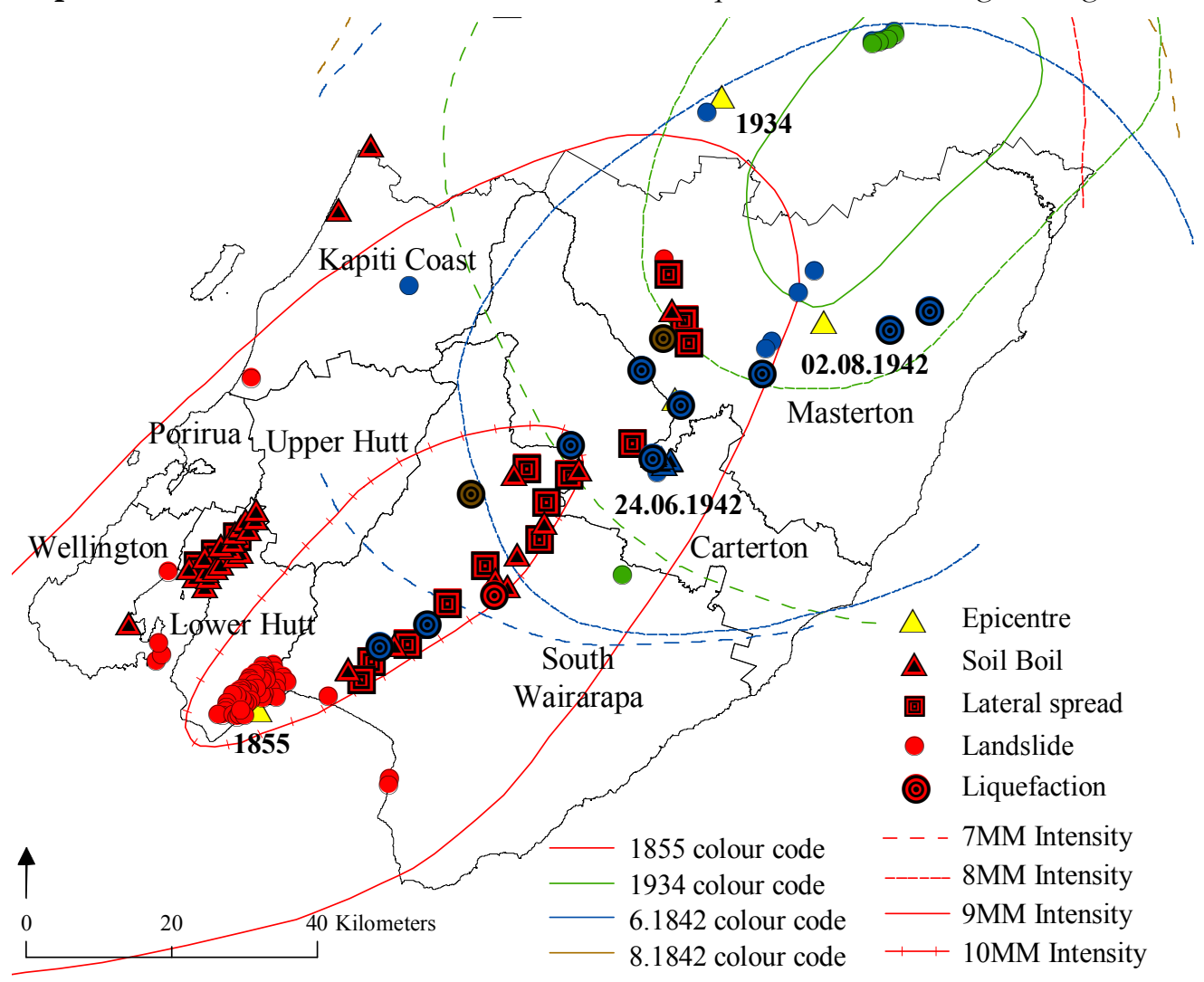

Based on data from Wellington Regional Council, 2007

The distribution of high magnitude earthquakes in the region also shows a spatial pattern. The Table: 5.3 shows that most of the damaging earthquakes have had their epicentre located in the vicinity of Wairarapa, and they were all generated at shallow depth.

According to the recorded history of earthquakes, the Wellington Region experienced its biggest earthquake on 23 January, 1855. It was also the biggest recorded earthquake in New Zealand (Wellington Engineering Lifeline Association [WELA], 2003, 9). The earthquake was more than eight in magnitude on the Richter scale, and had MMX-MMIX shaking intensity. It was 
Table: 5.3. Damaging Earthquakes in the Wellington Region (1840-2008)

\begin{tabular}{|c|c|c|c|c|c|}
\hline Year & $\begin{array}{l}\text { Depth in } \mathrm{Km} \text {. } \\
\text { from crust }\end{array}$ & Magnitude & Name & Area affected & Loss \\
\hline January 3,1855 & 25 & $8.2(\max .=10)$ & Wairarapa & All Region & $\begin{array}{l}7 \text { - } 9 \text { killed, } 5 \text { injured } \\
\text { and infrastructure } \\
\text { damage }\end{array}$ \\
\hline June 24, 1942 & 12 & $7.2(\max .=8+)$ & Wairarapa & All Region & $\begin{array}{l}1 \text { killed, } 2 \text { injured and } \\
\text { infrastructure damage }\end{array}$ \\
\hline August 2, 1942 & 40 & $7(\max .=8)$ & Wairarapa & All Region & Infrastructure damage \\
\hline December 2, 1942 & n.g. & 6 & Wairarapa & $\begin{array}{l}\text { Masterton, } \\
\text { Wellington }\end{array}$ & Infrastructure damage \\
\hline
\end{tabular}

Based on Geonet, (2008a)

associated with a displacement of the Wairarapa fault, which moved vertically up to six metres and horizontally about 13 metres. It lifted and tilted about $5,000 \mathrm{~km}^{2}$ of the adjoining western section of Rimutaka Range (WELA, 2003, 9 and Te Ara, 2008b). The intense ground shaking caused fissures in Wairarapa (Grapes, 2000 as cited in WELA, 2003) and Hutt valley (Te Ara, 2008a). It created numerous landslides and produced a tsunami of about 2-3 metres in Wellington harbour and nine metres in Palliser Bay (Official's Committee for Domestic and External Security [ODESC], 2007, 26).

Besides physical impacts on the landscape, this earthquake also had significant socioeconomic consequences. About seven to nine people were reported dead. One person died in Wellington due to chimney collapse and five or more Maori people were killed in the Wairarapa due to the collapse of a whare (Te Ara, 2008a). In addition, about five people were injured and there was massive damage to infrastructure. Nearly all chimneys in the Wellington area collapsed (ODESC, 2007, 26) along with several brick buildings. Single storey wooden houses survived though they suffered damage from falling chimneys or damaged foundations (Te Ara, 2008a). The damage was less with respect to earthquake intensity, which could be attributed to low population density.

A century later the region was hit by two consecutive earthquakes on the $24^{\text {th }}$ of June and $2^{\text {nd }}$ of August, 1942, which were centred near Masterton (Photo:5.2). In the first earthquake one person died in the Welling suburb of Kelburn because of coal gas escaping from a fractured pipe. In the Wellington Central Business District [CBD], a large amount, of concrete fell and several buildings collapsed (Roger, 1996, 124-125). There was widespread damage to infrastructure including telephone lines, roads and railway lines. Brick buildings were badly damaged, walls

Photo: 5.2. Earthquake Damage in Masterton (24 June, 1942)

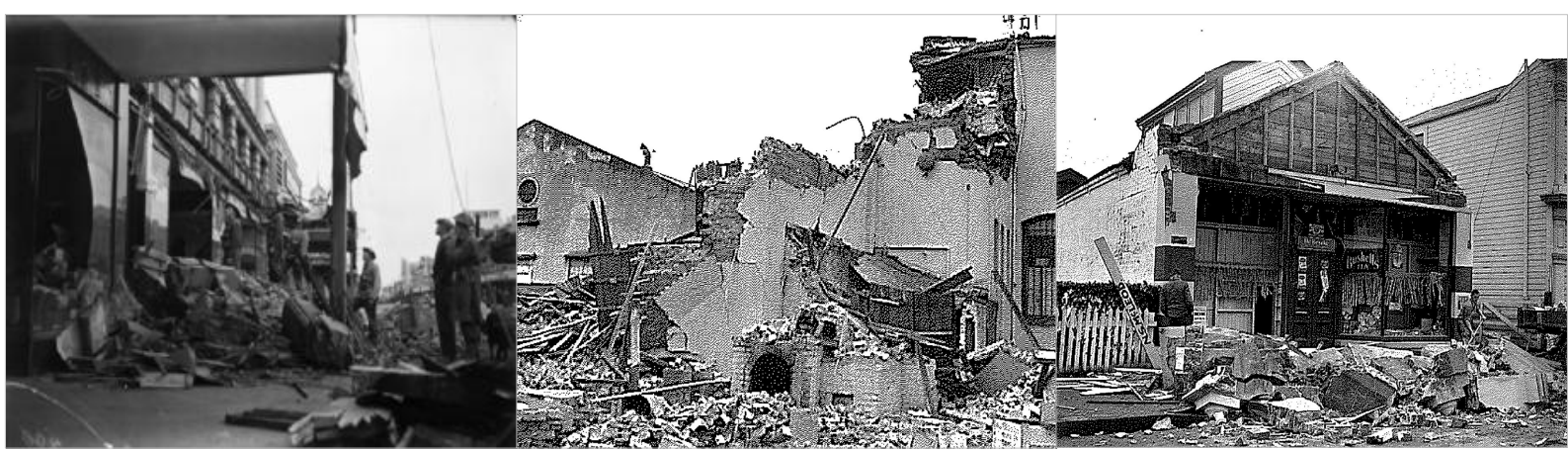

Source: Turnbull Library as cited in Rogers, 1996, 128 and bttp:/ / www.wcl.govt.nz/wellington/ earthquakes.html 
cracked, windows were shattered, brick and concrete masonry came down. Timber buildings survived but again lost their brick chimneys, and in a few houses foundations were moved due to intense ground shaking. According to official figures about 5,000 houses, 10,000 chimneys and 100 city buildings were damaged (Grayland, 1957 as cited in Rogers, 1996, 125). In the Wairarapa Farmers Co-operative Association Building, a 40,000-gallon water tower toppled over and damage occurred to other significant buildings such as post office and the large Bullick and Blackmore store, which lost its front (Rogers, 1996, 130).

The second earthquake was also felt extensively. Within the Wellington CBD, Manners street (between Cuba and Willis streets) was closed for several months because of the dangerous state of the buildings (Rogers, 1996, 131). The army was called for assistance with demolition and clean up. It is estimated that the combined economic cost of the two earthquakes amounted to more than two million pounds (Rogers, 1996, 124). The overall damage pattern in the region shows that damage was greater in city centres compared to residential areas.

The region has not faced any major earthquake since 1942, however it has experienced a range of smaller earthquakes, which resulted in significant damage. The Earthquake Commission [EQC] recorded 369 earthquakes from 1996 to 2007, which generated about 4,750 damage claims throughout the region. It is important to note that many of the earthquakes, which produced damage in the region, were centred outside the region. This is also the reason behind the difference in the number of earthquakes recorded in the region by Geonet (website that records geological hazards and maintained by Institute of Geological and Nuclear Sciences [GNS]) and the number represented by the claims in the EQC records. For the total of 369 earthquakes, EQC paid about $5,014,880$ NZD.

A comparison of damage with earthquake magnitude shows that most earthquakes produced damage except those below two in magnitude (Table: 5.4). It is also observed that the average number of claims, serving here as an indicator for damage per earthquake, do not follow a linear pattern. For example, the maximum number of claims per earthquake was made for 6.0 to 6.9 magnitude rather than those above it. Similarly, the average loss from 2.0 to 2.9 magnitude earthquakes is nearly twice the damage from 3.0 to 3.9 magnitude earthquakes and the loss from 6.0 to 6.9 magnitudes is 3.6 times higher than those from 7.0 to 7.9 magnitude earthquakes. The reason is partly related to the depth and distance from the epicentre that determine the damage from a particular earthquake.

Table: 5.4. Damage Distribution and Magnitude of Earthquakes in the Wellington Region (1996-2007)

\begin{tabular}{lccccc}
\hline Magnitude & $\begin{array}{c}\text { Number of } \\
\text { Earthquakes }\end{array}$ & $\begin{array}{c}\text { Total claims } \\
\text { made }\end{array}$ & $\begin{array}{c}\text { Number of } \\
\text { claims per } \\
\text { earthquake }\end{array}$ & $\begin{array}{c}\text { Total damage } \\
\text { paid (in NZD) }\end{array}$ & $\begin{array}{c}\text { Average damage } \\
\text { per earthquake } \\
\text { (in NZD) }\end{array}$ \\
\hline $1.0-1.9$ & 0 & 0 & 0 & 0 & 0 \\
$2.0-2.9$ & 5 & 9 & 2 & 33,334 & 6,667 \\
$3.0-3.9$ & 135 & 420 & 3 & 517,115 & 3,830 \\
$4.0-4.9$ & 101 & 532 & 5 & 685,686 & 6,789 \\
$5.0-5.9$ & 38 & 2,810 & 74 & $2,953,298$ & 77,718 \\
$6.0-6.9$ & 6 & 519 & 87 & 561,278 & 93,546 \\
$7.0-7.9$ & 4 & 99 & 25 & 102,768 & 25,692 \\
Not given & 80 & 358 & 4 & 181,310 & 2,266 \\
\hline
\end{tabular}


The lowest magnitude of earthquake for which a damage claim was made is 2.2 , which hit the region on July, 26, 2000. The claim was made by a Wellington resident, but no money was paid by the EQC. The lowest magnitude of earthquake for which the EQC paid out the claim was for 2.7, which occurred on July, 26, 2005. The depth of this earthquake was 12 kilometres and the claim was made from Lower Hutt. The commission paid 27,257.67 NZD for damage to the claimant's house. The highest magnitude of earthquake for which the EQC paid out claims for was of 7.6 magnitude and occurred at Raoul Island at the depth of 150 kilometres. About nine people made claims of which six were paid 21,459 NZD. The comparison of the amount of money paid by the EQC for the highest and the lowest magnitude earthquakes shows that the loss was higher from the lowest magnitude earthquake that occurred at low depth. This indicates that depth could play an even more crucial role than the magnitude of the earthquake.

Table: 5.5. Damage Claims Distribution and Depth of Earthquakes in the Wellington Region (1996-2007)

\begin{tabular}{lcccccc}
\hline $\begin{array}{l}\text { Depth of } \\
\text { Earthquake (in } \\
\text { Kilometres) }\end{array}$ & $\begin{array}{c}\text { Number of } \\
\text { Earthquakes }\end{array}$ & $\begin{array}{c}\text { Mean } \\
\text { magnitude }\end{array}$ & $\begin{array}{c}\text { Total claims } \\
\text { made }\end{array}$ & $\begin{array}{c}\text { Number of } \\
\text { claims per } \\
\text { earthquake }\end{array}$ & $\begin{array}{c}\text { Total money } \\
\text { paid (in } \\
\text { NZD) }\end{array}$ & $\begin{array}{c}\text { Average money } \\
\text { paid per } \\
\text { earthquake (in } \\
\text { NZD) }\end{array}$ \\
\hline 30 and less & 161 & 3.9 & 2,247 & 14 & $2,744,377$ & 17,046 \\
$31-60$ & 85 & 4.2 & 1,414 & 17 & $1,333,296$ & 15,686 \\
$61-90$ & 20 & 4.6 & 105 & 5 & 126,525 & 6,326 \\
$91-120$ & 8 & 5.2 & 58 & 7 & 40,965 & 5,121 \\
$121 \&$ more & 14 & 6.2 & 563 & 40 & 605,291 & 43,235 \\
Not given & 81 & Not given & 360 & 4 & 184,336 & 2,276
\end{tabular}

Table 5.5 shows that while mean magnitude of earthquakes increases with increasing depth, the total amount of claims generated by shallow earthquakes is far greater than those from deeper situated high magnitude earthquakes. The relationship became further clearer when damage claims from the specific magnitude of earthquake is compared with their specific depth. Figure 5.2 clearly shows that the damage drops significantly for all magnitudes of earthquake with depth. This indicates that even a very small magnitude of earthquake could produce significant loss depending on its location and depth.

A comparison of the number of claims with the damage paid by the EQC shows that about 96 percent of the total earthquakes resulted in 25 or less claims, about three percent generated 26-100 claims and less than two percent generated more

Fig: 5.2. Damage Claims, Depth and Magnitude of Recorded Earthquakes in the Wellington Region (1996-2007)

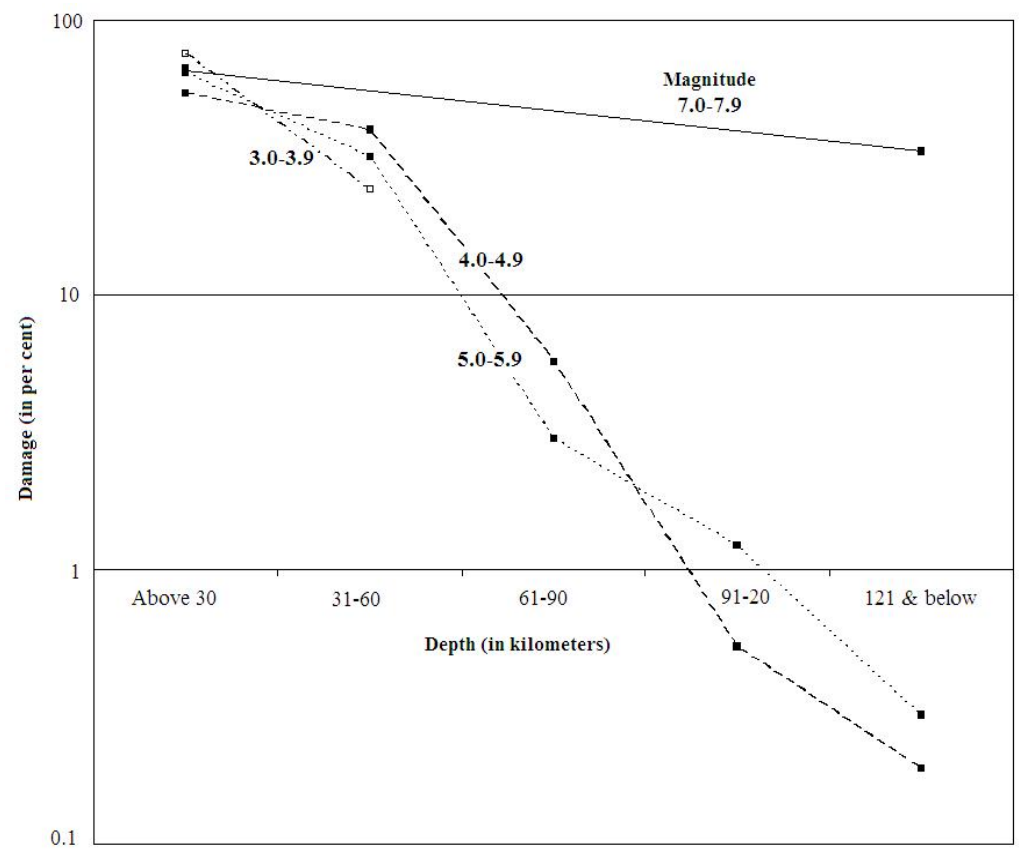

Based on data from Earthquake Commission, 2007 
than hundred claims (Table: 5. 6).

Table: 5.6. Number of Claims and Earthquake Characteristics in the Wellington Region (1996-2007)

\begin{tabular}{lccccccc}
\hline $\begin{array}{l}\text { Number of } \\
\text { claims }\end{array}$ & $\begin{array}{c}\text { Number } \\
\text { of Earth- } \\
\text { quakes }\end{array}$ & $\begin{array}{c}\text { Mean } \\
\text { Magnitude }\end{array}$ & $\begin{array}{c}\text { Mean } \\
\text { Depth }\end{array}$ & $\begin{array}{c}\text { Mean Damage/ } \\
\text { Earthquake (in } \\
\text { NZD) }\end{array}$ & $\begin{array}{c}\text { Damage } \\
\text { Paid (in } \\
\text { NZD) }\end{array}$ & $\begin{array}{c}\text { Damage } \\
\text { paid (in } \\
\text { percent) }\end{array}$ & $\begin{array}{c}\text { Districts } \\
\text { affected/ } \\
\text { Earthquake }\end{array}$ \\
\hline 25 and less & 353 & 3.2 & 33.2 & 4,633 & $1,635,591$ & 32 & 2 \\
$26-50$ & 7 & 4.9 & 80.4 & 44,079 & 308,550 & 6 & 6 \\
$51-100$ & 3 & 6.1 & 73.0 & 58,624 & 175,871 & 3 & 6 \\
$101-200$ & 2 & 5.8 & 102.0 & 228,068 & 456,136 & 9 & 8 \\
$201-400$ & 1 & 6.3 & 245.0 & 105,893 & 105,893 & 2 & 8 \\
$401-800$ & 2 & 5.5 & 30.0 & 467,882 & 935,763 & 19 & 8 \\
801 and above & 1 & 5.5 & 30.0 & $1,416,986$ & $1,416,986$ & 28 & 8 \\
\hline
\end{tabular}

Based on data from Earthquake Commission, 2007

The yearly distribution of damage shows that the region experiences loss from earthquakes every year (Fig: 5.3). Fewer earthquakes and less damage in 1996 and 2007 are because of incomplete data, while high damage in the 2005 is associated with the occurrence of six earthquakes of magnitude five and
Fig: 5.3. Earthquake Claims and Money Paid by the EQC in the Wellington Region (1996-2007)

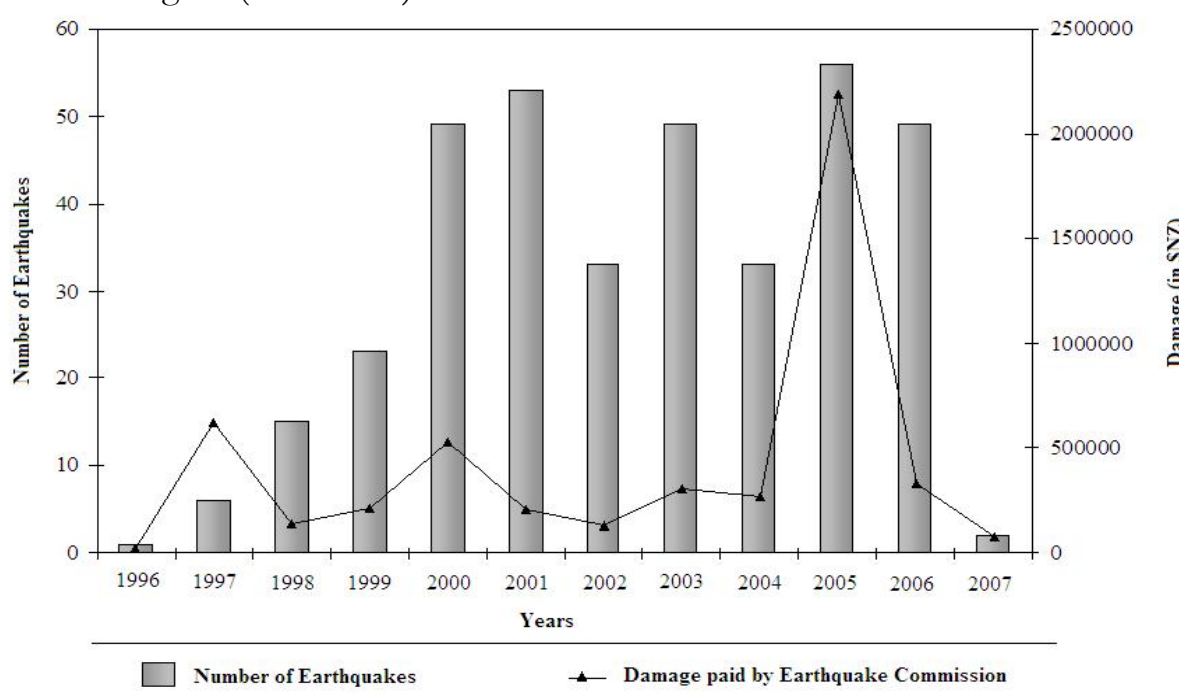

Based on data from Earthquake Commission, 2007

more. The damage in the region therefore appears to be linked with the number and characteristics of the earthquakes. It is difficult to relate the damage to changing vulnerability conditions as the temporal extent of data is very short and lacks detail.

Table: 5.7. Earthquake Characteristics and Money Paid by the Earthquake Commission (1996-2007)

\begin{tabular}{lccccccc}
\hline $\begin{array}{l}\text { Total Money paid } \\
\text { by the EQC } \\
\text { (NZD) }\end{array}$ & $\begin{array}{c}\text { Number of } \\
\text { Earthquakes }\end{array}$ & $\begin{array}{c}\text { Percent of } \\
\text { Earthquakes }\end{array}$ & $\begin{array}{c}\text { Mean } \\
\text { Magnitude }\end{array}$ & $\begin{array}{c}\text { Mean } \\
\text { Depth }\end{array}$ & $\begin{array}{c}\text { Total } \\
\text { claims } \\
\text { made }\end{array}$ & $\begin{array}{c}\text { Percent of } \\
\text { claims } \\
\text { made }\end{array}$ & $\begin{array}{c}\text { Percent of } \\
\text { claims paid }\end{array}$ \\
\hline None & 144 & 39.0 & 2.3 & 23 & 344 & 7 & 0 \\
less than 1000 & 44 & 11.9 & 3.6 & 37 & 140 & 3 & 34 \\
$1001-10,000$ & 125 & 33.9 & 3.7 & 35 & 597 & 13 & 49 \\
$10,001-100,000$ & 49 & 13.3 & 4.4 & 62 & 883 & 19 & 55 \\
$100,001-1000,000$ & 6 & 1.6 & 5.3 & 90 & 1767 & 37 & 51 \\
1000,001 \& above & 1 & 0.3 & 5.5 & 30 & 1016 & 21 & 59 \\
\hline
\end{tabular}

Based on data from Earthquake Commission, 2007

Table 5.7 compares damage paid by the EQC with earthquake characteristics. It shows a consistent relationship between damage paid by the Commission and increase in the magnitude of earthquakes. While the highest proportion of earthquakes (39 percent) were of low magnitude and the EQC did not have to pay out any claims for them, for the second highest proportion of 
earthquakes (34 percent) with a mean magnitude 3.7, the EQC paid between 1,000 NZD and 10,000 NZD. The data show that the EQC paid $>1 \mathrm{~m}$ NZD for a single earthquake which recorded 21 percent of the total claims made over ten years. It was a 5.5 magnitude earthquake of shallow depth that generated 1,016 claims, 59 percent of which were paid by the EQC.

The spatial distribution of damage corresponds with distribution and density of population. Map: 5.3 shows that most of the claims were made from the densely populated urban areas compared to the rural districts of

Map: 5.3. Earthquake Claims Made to the EQC in the Wellington Region (1997-2006)

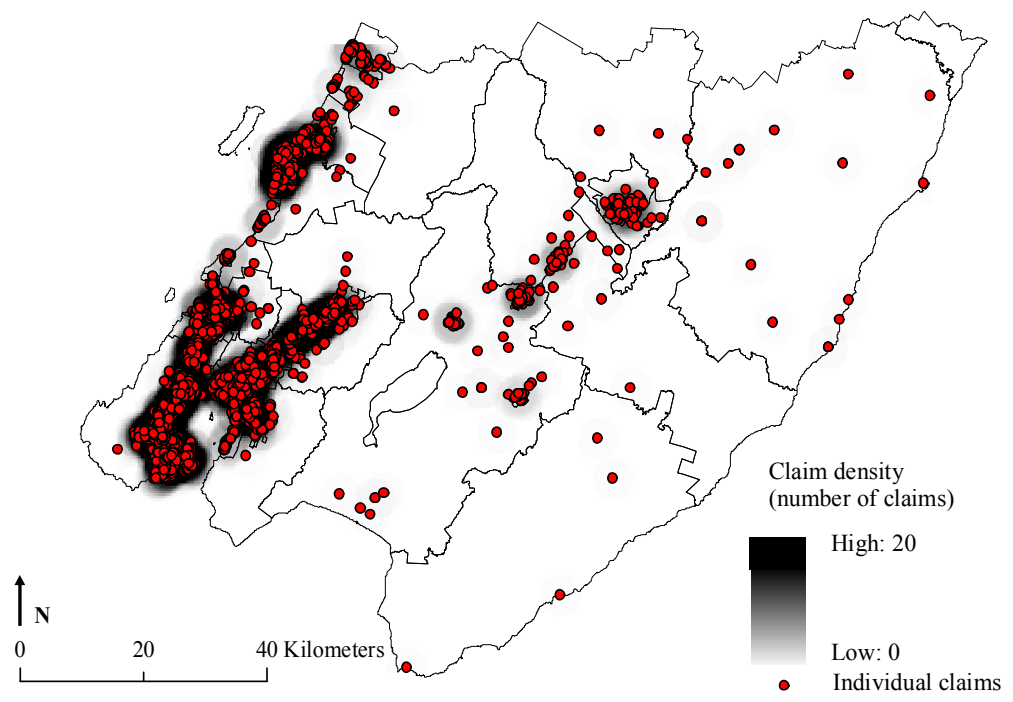

Carterton, South

Wairarapa or Masterton.

Table: 5.8. Earthquake Damage Claims Made at the EQC in the Wellington Region (1996-2007)

\begin{tabular}{lccc}
\hline $\begin{array}{l}\text { Local Territorial } \\
\text { Authorities }\end{array}$ & Total Claims made & $\begin{array}{c}\text { Percentage total } \\
\text { claims }\end{array}$ & $\begin{array}{c}\text { Percent times area affected in 369 } \\
\text { earthquakes }\end{array}$ \\
\hline Wellington City & 1783 & 38 & 60 \\
Lower Hutt City & 933 & 20 & 42 \\
Kapiti Coast & 819 & 17 & 46 \\
Upper Hutt City & 507 & 11 & 30 \\
Porirua City & 393 & 8 & 28 \\
Masterton & 146 & 3 & 15 \\
South Wairarapa & 121 & 3 & 11 \\
Carterton & 48 & 1 & 5 \\
\hline
\end{tabular}

Based on data from Earthquake Commission, 2007

Table: 5.8 shows that the largest proportion of claims (38 percent) was made from Wellington City followed by Lower Hutt City and the Kapiti Coast, and the lowest from Carterton (one percent). In total Wellington City was affected by 221 out of 369 earthquakes, followed by the Kapiti Coast and Lower Hutt, which were affected by 170 and 155 events respectively.

More than 90 percent of claims were paid for any kind of damage to dwellings followed by three percent for damage to land and two percent for damage to contents. This does not total 100 percent as for a few claims the details of damage types were not given. While highest loss of contents was recorded in Masterton, the highest damage to houses occurred in Lower Hutt and the highest land damage occurred in Wellington followed by South Wairarapa and Porirua (Table: 5.9). 
Table: 5.9. Money Paid by the EQC for Earthquake Claims in the Wellington Region (1996-2007)

\begin{tabular}{lrcccc}
\hline $\begin{array}{l}\text { Local Territorial } \\
\text { Authorities }\end{array}$ & $\begin{array}{c}\text { Total money } \\
\text { paid (in NZD) }\end{array}$ & $\begin{array}{c}\text { Percentage of } \\
\text { total money paid }\end{array}$ & \multicolumn{2}{c}{ Money paid by EQC (in percent) } \\
\cline { 4 - 6 } & & & Contents & Dwelling & Land \\
\hline Wellington City & $1,659,181$ & 33 & 0 & 91 & 9 \\
Lower Hutt City & 867,336 & 17 & 2 & 97 & 1 \\
Kapiti Coast & $1,352,396$ & 27 & 2 & 86 & 1 \\
Upper Hutt City & 368,207 & 7 & 2 & 95 & 0 \\
Porirua City & 387,951 & 8 & 10 & 93 & 5 \\
Masterton & 125,323 & 2 & 1 & 86 & 3 \\
South Wairarapa & 120,034 & 2 & 1 & 93 & 6 \\
Carterton & 154,363 & 3 & $\mathbf{2}$ & 92 & 4 \\
Total & $\mathbf{5 , 0 3 4 , 7 9 0}$ & $\mathbf{1 0 0}$ & & $\mathbf{9 2}$ & $\mathbf{3}$ \\
\hline
\end{tabular}

Based on data from Earthquake Commission, 2007

Fig: 5.4. Damage Claims from Different Magnitudes of Earthquakes Made to the EQC in the Wellington Region (1996-2007)
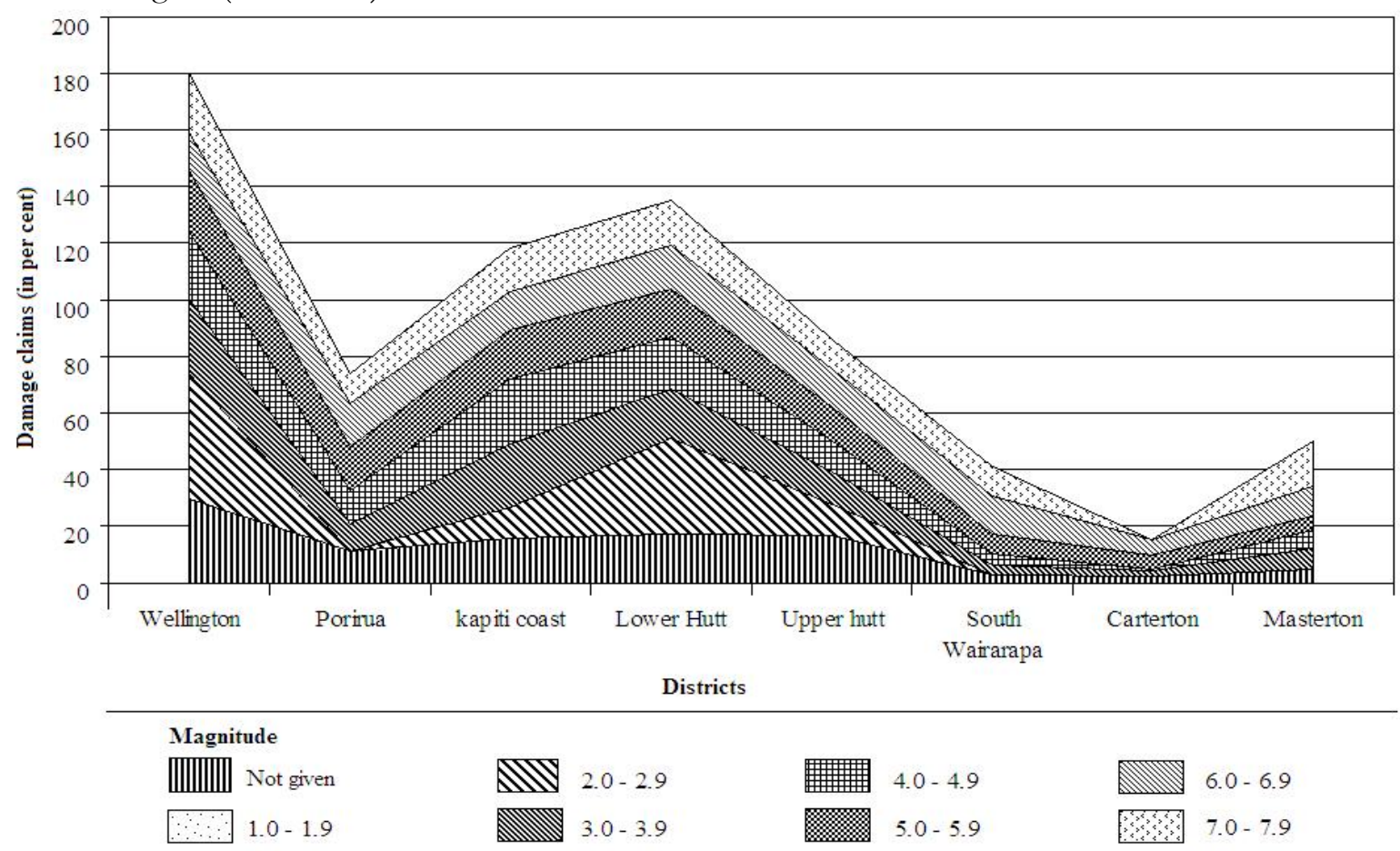

Based on data from Earthquake Commission, 2007

Figure 5.4 compares the damage claims from various districts with magnitude of earthquakes. The sum for individual districts is not equal to one hundred percent because it shows the percentage of each district affected by a certain magnitude of earthquake. The figure highlights that the damage based on the claims made from earthquake of low magnitude (i.e. 2.0-2.9) was more widespread in urban areas (i.e. Wellington, Lower Hutt City and the Kapiti Coast) compared to rural areas (i.e. Carterton, South Wairarapa or Masterton). It also shows an inverse relationship between the proportion of claims and earthquake magnitude in urban areas, which is not true for the rural districts, i.e. in South Wairarapa and Masterton, where damage increases with increasing magnitude. The reason could be attributed to the high population density of urban areas, where a significant proportion of infrastructure and resources are located either on hills or on reclaimed land i.e. soft soil that tends to exacerbate ground shaking. 
Fig: 5.5. Damage Claims and Depth of Earthquakes in the Wellington Region (1996-2007)
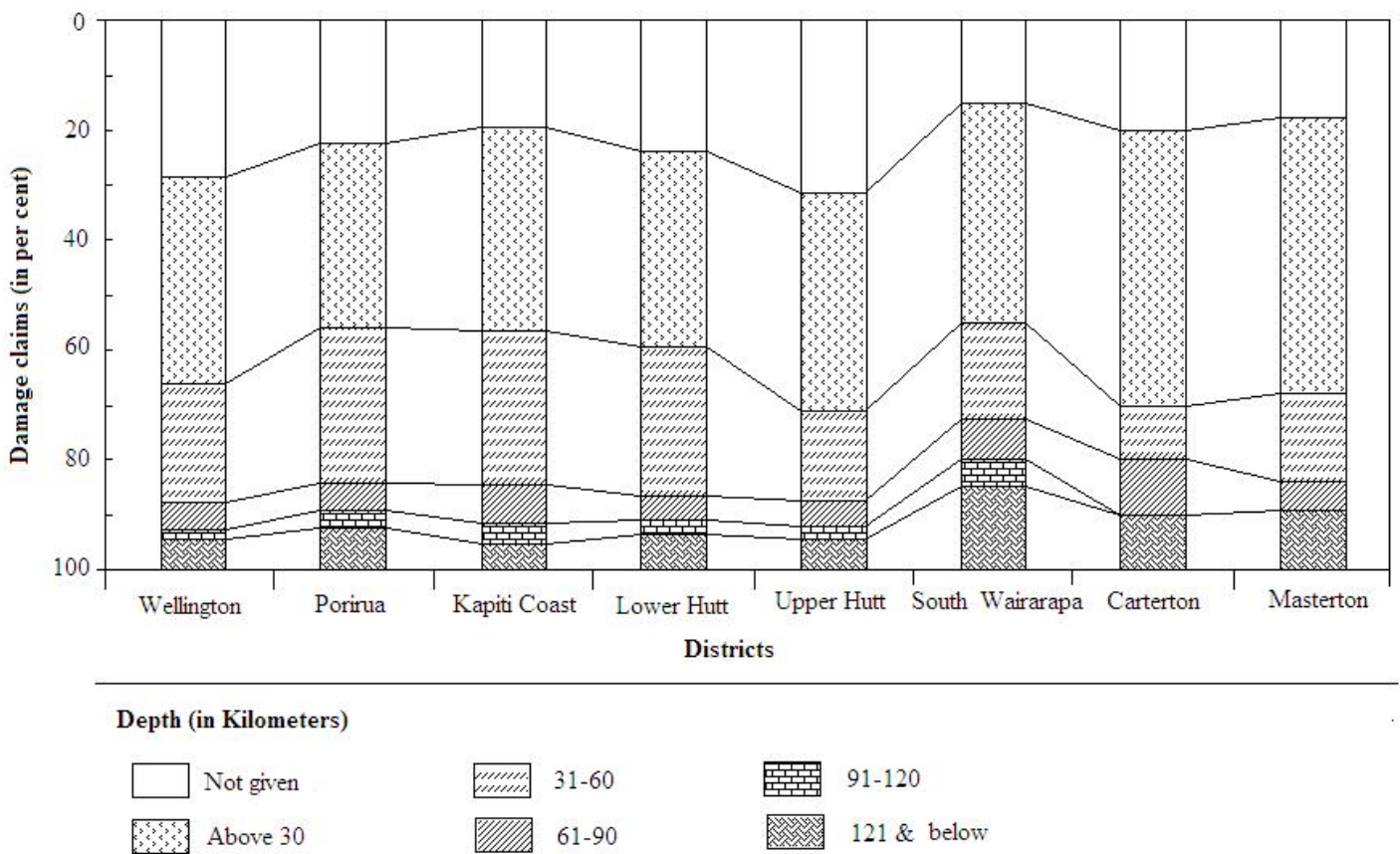

Based on data from Earthquake Commission, 2007

Figure 5.5 supports the evidence that most areas in the region suffered highly from shallow earthquakes rather than those originating at a greater depth. The impacts of deeper earthquakes were highest in South Wairarapa followed by Masterton and Carterton, and the impacts are relatively low for most urban areas. The data also indicate that damage tends to be more widespread for deeper earthquakes compared to shallow earthquakes. The earthquakes that generated below 120 kilometres often affected four or more districts, while those between 91 to 120 kilometres

Fig: 5.6. Distribution of Money Paid by the EQC in the Wellington Region (1996-2007)

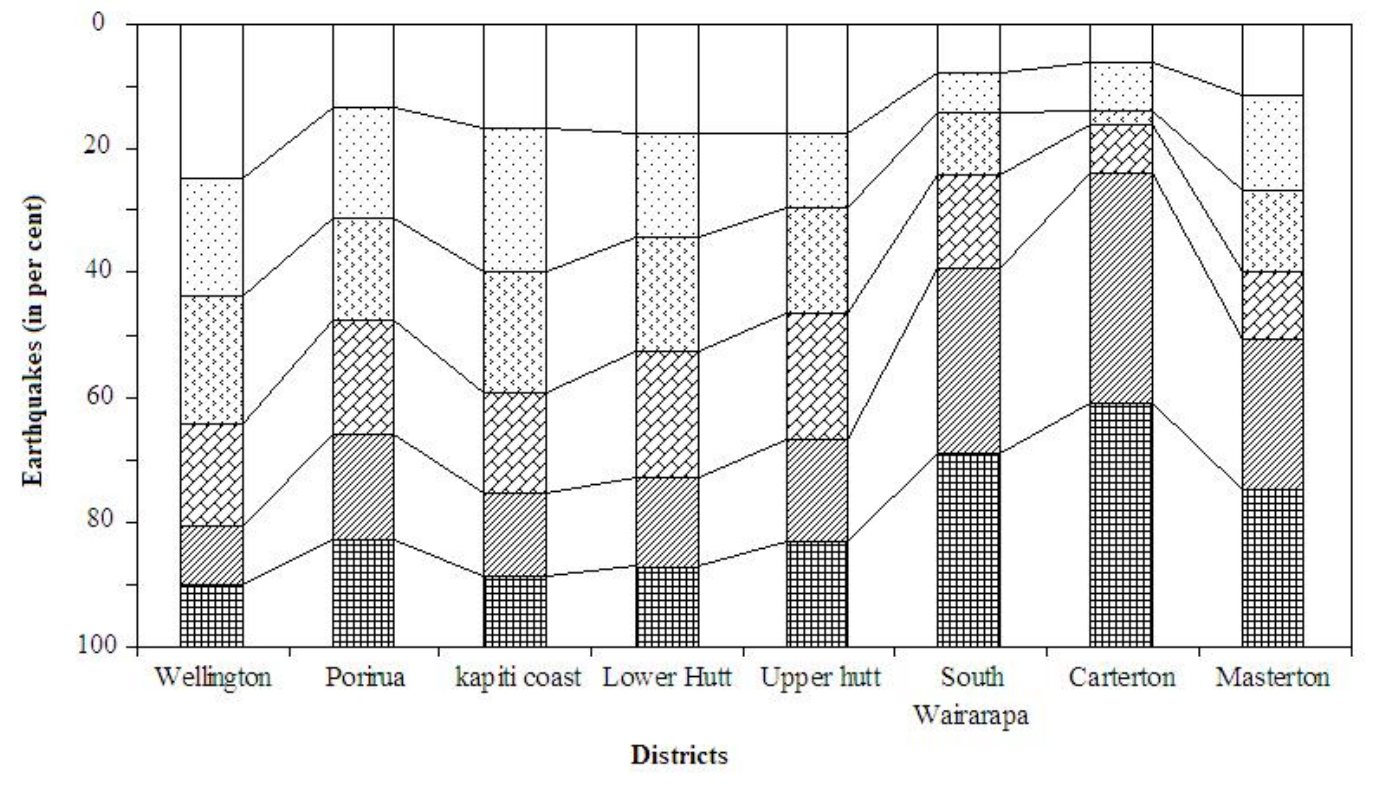

Damage Paid (in SNZ)

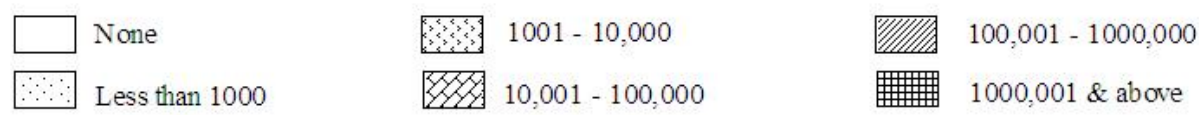


affected three districts and those above them affected two or less.

The spatial distribution of damage across the region (Fig: 5.6) shows that a higher proportion of claims made from urban areas were of less monetary value, while a greater proportion of claims made from the three rural districts (i.e. Carterton, South Wairarapa and Masterton) involved high costs.

Another aspect of earthquake hazard is its probability of occurrence in the future. The seismic history of New Zealand indicates that it should experience 10-20 five magnitude earthquakes along with one six magnitude earthquake each year, and one seven magnitude earthquake in each decade (ODESC, 2007, 19). Since Wellington is located in one of the highest seismic activity zones of the country, the average probability of earthquake occurrence is likely to be higher than many other parts of New Zealand. However, the available data tell a different story.

Table: 5.10. Frequency of Earthquakes in the Wellington Region

\begin{tabular}{lcccc}
\hline $\begin{array}{l}\text { Earthquake } \\
\text { Magnitude }\end{array}$ & \multicolumn{2}{c}{ Earthquake Occurred in 169 years*1 } & Earthquakes that produced damage in 12 years*2 \\
\cline { 2 - 5 } & Number & $\begin{array}{c}\text { Frequency } \\
\text { per year }\end{array}$ & Number & $\begin{array}{c}\text { Frequency } \\
\text { per year }\end{array}$ \\
\hline $8.000-8.999$ & 1 & 0.01 & 0 & 0.00 \\
$7.000-7.999$ & 0 & 0.00 & 4 & 0.33 \\
$6.000-6.999$ & 9 & 0.05 & 6 & 0.50 \\
$5.000-5.999$ & 38 & 0.22 & 38 & 3.17 \\
$4.000-4.999$ & 412 & 2.44 & 101 & 8.42 \\
$3.000-3.999$ & 2,458 & 14.54 & 135 & 11.25 \\
$2.000-2.999$ & 20,779 & 122.95 & 5 & 0.42 \\
Total & $\mathbf{2 3 , 6 9 7}$ & $\mathbf{1 4 0 . 2 2}$ & $\mathbf{2 8 9}$ & $\mathbf{2 4 . 0 8}$ \\
\hline
\end{tabular}

Based on Geonet, and Earthquake Commission, 2007

$* 1=$ Geonet $* 2=\mathrm{EQC}$

The earthquake records of the region for 169 years from Geonet, show that the region has experienced an average of one magnitude-six earthquake in every 19 years and a magnitude-five earthquake in every four years. In addition, the region has experienced two magnitude-four, 15 magnitude-three and 123 magnitude-two earthquakes per year (Table: 5.10). The 12 year damage data from the EQC show that the region has experienced damage from an earthquake of magnitude-seven in every three years and from magnitude-six in every two years. The damages from low magnitude earthquakes have been rather more frequent in the region. In the past 12 years, the region has experienced damage from three magnitude-five, eight magnitude-four, and 11 magnitude-three earthquakes per year. The frequency of damage from magnitude-two earthquake is similar to that of magnitude-six or seven, which indicates that the probability of hazards differ from that of geophysical events.

The other data from the GNS give the probability of earthquake occurrence on the basis of its shaking intensity on the Modified Mercalli [MM] Scale. According to this data, the probability of an MM7 earthquake varies between 40 to 670 years, MM8 from 120 to 32,940 years; MM9 from 320 to 99,990 and MM10 from 1180 to 500,000 years. 
Map: 5.4. Probability of 7, 8, 9 and 10MM Earthquakes in the Wellington Region

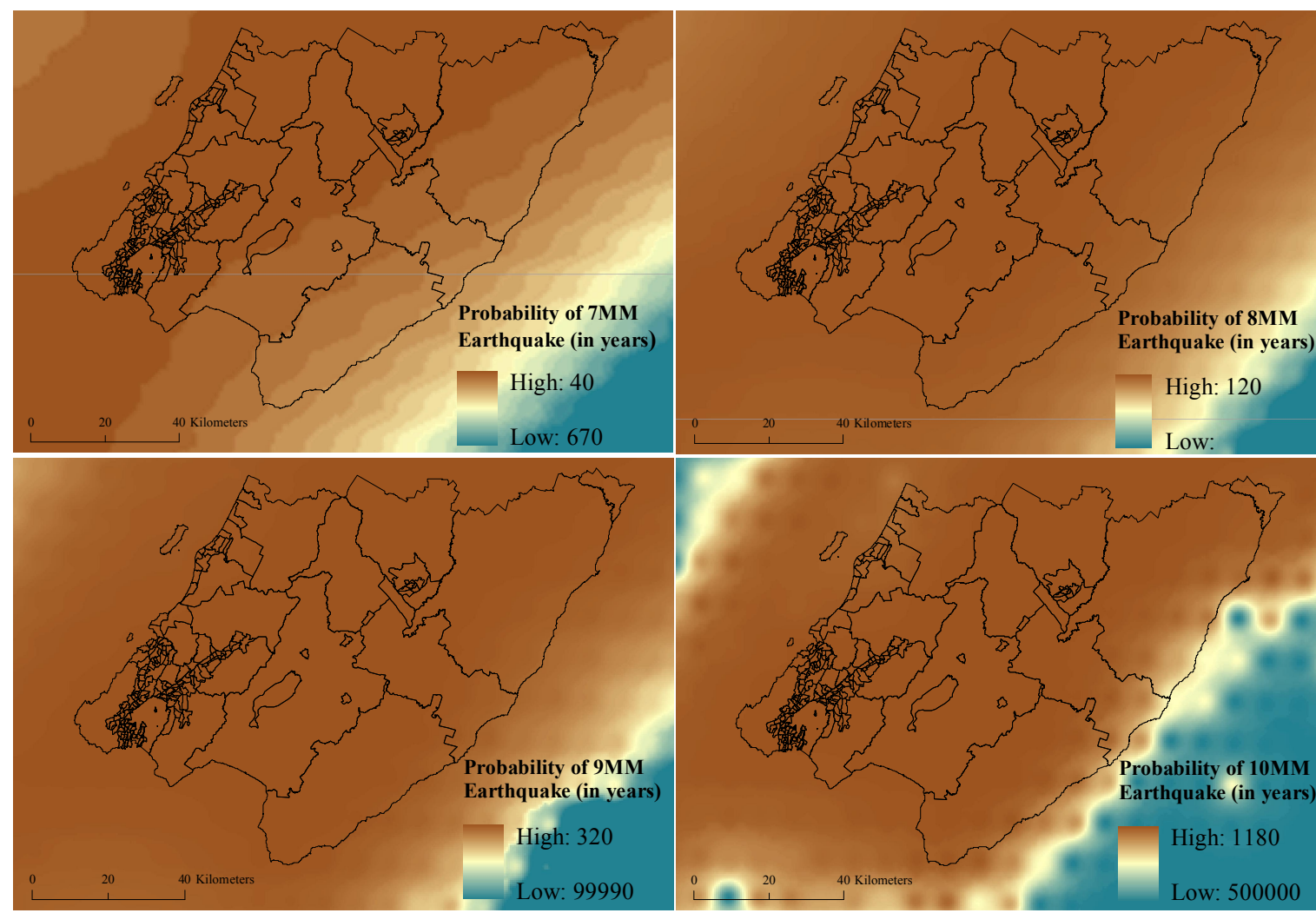

Based on data from GNS Science, 2007

Table: 5.11. Probability of Earthquakes of Seven or More Magnitude from Faults in the Wellington Region

\begin{tabular}{|c|c|c|c|c|c|}
\hline Fault & $\begin{array}{c}\text { Slip rate } \\
(\mathrm{mm} / \text { year })\end{array}$ & $\begin{array}{c}\text { Estimated single } \\
\text { event displacement } \\
\text { (m) }(\mathrm{h}=\text { horizontal; } \\
\mathrm{v}=\text { vertical) }\end{array}$ & $\begin{array}{c}\text { Recurrence } \\
\text { Interval (years) }\end{array}$ & $\begin{array}{l}\text { Time since } \\
\text { Last event } \\
\text { (years) }\end{array}$ & $\begin{array}{l}\text { Estimated } \\
\text { magnitude }\end{array}$ \\
\hline Awatere & $6-8$ & 4-7 (h) & $<1000-1300$ & 149 & $7.5-7.8$ \\
\hline Wairau & $3-5$ & 5-7 (h) & $1000-2300$ & $>800$ & $7.2-7.7$ \\
\hline Northern Ohariu & $1-3$ & $3-3.5$ & $1000-4000$ & $<4000$ & 7.3-7.7 \\
\hline Gibbs & $?$ & $1.5(\mathrm{v})$ & $?$ & $<10,000$ & $\sim 7$ \\
\hline Shephard Gully & $0.8-1.4$ & $3.5-4(h)$ & $2500-5000$ & $>1060$ & 7.6 \\
\hline Ohariu & $0.7-2$ & $3-5(h)$ & $1500->5000$ & 1060-1140 & 7.6 \\
\hline Otaki Forks & c.1 & $2.5-3.3(\mathrm{~h})$ & $<4000-9000$ & $?$ & 7.3-7.6 \\
\hline Wellington & $6-7.6$ & $3.5-5(h)$ & $500-770$ & $335-485$ & 7.6 \\
\hline Whitemans V. & 0.1 & 3 & $15,000-20,000$ & $<10,000$ & 7 \\
\hline Wairarapa & $5.9-10$ & $9-13.5(\mathrm{~h})$ & $1160-1880$ & 140 & $8.0-8.3$ \\
\hline Saunder Road & $?$ & $?$ & 3000 & $?$ & 7.3 \\
\hline Mokomui & $?$ & $?$ & 2000 & $?$ & 7.0 \\
\hline Carterton & $?$ & $?$ & 1000 & $?$ & 7.0 \\
\hline Otaraia & $?$ & $?$ & 10000 & $?$ & 7.2 \\
\hline Dry River & $?$ & $?$ & 5000 & $?$ & 7.3 \\
\hline Flat Point & $?$ & $?$ & 10000 & $?$ & 7.0 \\
\hline Palliser & $?$ & $?$ & 2000 & $?$ & 7.4 \\
\hline Mataikona & $?$ & $?$ & 2700 & $?$ & 7.1 \\
\hline Uruti & $?$ & $?$ & 3300 & $?$ & 7.5 \\
\hline Pahaoa & $?$ & $?$ & 3300 & $?$ & 7.4 \\
\hline Subduction Interface & 58 & $?$ & 2500 & $?$ & 8.2 \\
\hline
\end{tabular}

Source: Begg \& Johnston, 2000, 53; Grant, 2005b, 5; McConchie, 2000, 13, WELA, 2003, 8

Map 5.4 shows that except for MM7 earthquakes, which have a relatively higher probability in the western section of the region, the probability of occurrence of higher intensity earthquakes (i.e. $>M M 7$ ) is the same throughout the region. 
A comparison of the data about the magnitude of previous earthquakes and their shaking intensity portrays a different picture. Looking at the two consecutive earthquakes that hit the region in 1942; they were of nearly magnitude seven on the Richter scale and produced MM8 and MM10 shaking on the $24^{\text {th }}$ of June and the $2^{\text {nd }}$ of August respectively. If one considers that magnitude seven can produce such high shaking of eight to ten on the Mercalli scale, then the calculated probability from the data cannot be taken as accurate and a major earthquake can be expected very soon.

The region is also due for a big earthquake from the Wellington Fault movement, which was last displaced about 300-350 years ago and close to its recurrence time i.e. 485 to 783 years (Van Dissen and Berryman, 1990 as cited in CAE, 1991a, 14). However, this is not the only fault, which has the potential to produce a high magnitude earthquake. There are numerous other faults within and outside the region including one at the subduction zone that further raises the probability of high magnitude earthquakes in the region (Table: 5.11).

The region suffered significant economic loss in the 1942 earthquakes despite having sparse population and infrastructure. A major earthquake in today's hazardscape of the region could result in about 3,000-4,000 casualties including 200-300 deaths, and economic loss of more than 10 billion NZD (ODESC, 2007, 26). This is an estimate, and the situation could be totally different depending on the event's characteristics and people's response.

\subsubsection{Landslides}

The processes which are responsible for frequent landslides in the region, are tectonics through earthquakes and fault movements, meteorological processes through heavy rainfall, cyclones and storms, and anthropogenic processes through slope modification. While there are detailed accounts of tectonic and rainfall induced landslides, there is less information about human influenced landslides, wherein human activities affect pre-conditions. The anthropogenic cause of landslides is generally not recorded because the foremost visible trigger often tends to be either an earthquake or heavy rain.

Seismic forces are important triggers for landslides in the region. Although earthquakes have been frequent, significant landslides have been mainly generated in major historical incidents. Hancox, et al. (1997) identified about 20 landslides of size less than $1,000 \mathrm{~m}^{3}-1000,000 \mathrm{~m}^{3}$ since

Table: 5.12. Characteristics of Earthquake-Induced Landslides in the Wellington Region

\begin{tabular}{lcc|cc}
\hline \multicolumn{2}{c|}{ Earthquake Characteristics } & \multicolumn{2}{c}{ Landslide Characteristics } \\
\hline Name & Date & $\begin{array}{c}\text { Magnitude } \\
\text { (Maximum) }\end{array}$ & $\begin{array}{c}\text { Number of individual slides } \\
\text { (size) }\end{array}$ & $\begin{array}{c}\text { Area of Superficial Landslides } \\
\text { (square kilometres) }\end{array}$ \\
\hline Wairarapa & 03.01 .1855 & $8.2(10)$ & $\mathbf{5 4}\left(\right.$ Big: $\left.100,000-10,000,000 \mathrm{~m}^{3}\right)$ & 77.3 \\
and $\mathbf{7}\left(\right.$ Small: $\left.<100,000 \mathrm{~m}^{3}\right)$ & 1017.7 \\
Pahiatua & 05.03 .1934 & 7.6 & $\mathbf{1}\left(\right.$ Small: $\left.<100,000 \mathrm{~m}^{3}\right)$ & 129.3 \\
Masterton & 24.06 .1942 & $7.2(8+)$ & $\mathbf{2 0}\left(\right.$ Small: $\left.<100,000 \mathrm{~m}^{3}\right)$ & \\
Masterton & 02.08 .1942 & $7(8)$ & & \\
\hline
\end{tabular}

Based on Hancox et al., 1997, 15; Geonet and data from Wellington Regional Council, 2007 
1840, which were initiated by ground shaking of more than seven magnitude on Modified Mercalli scale (Hancox, et. al, 1997, 17). However, data from the Wellington Regional Council differ in the number of landslides, and the overall data from different sources present the following picture (Table: 5.12).

Photo: 5.3. Gold's Slide: Earthquake-Induced Landslide in Wellington (1855)

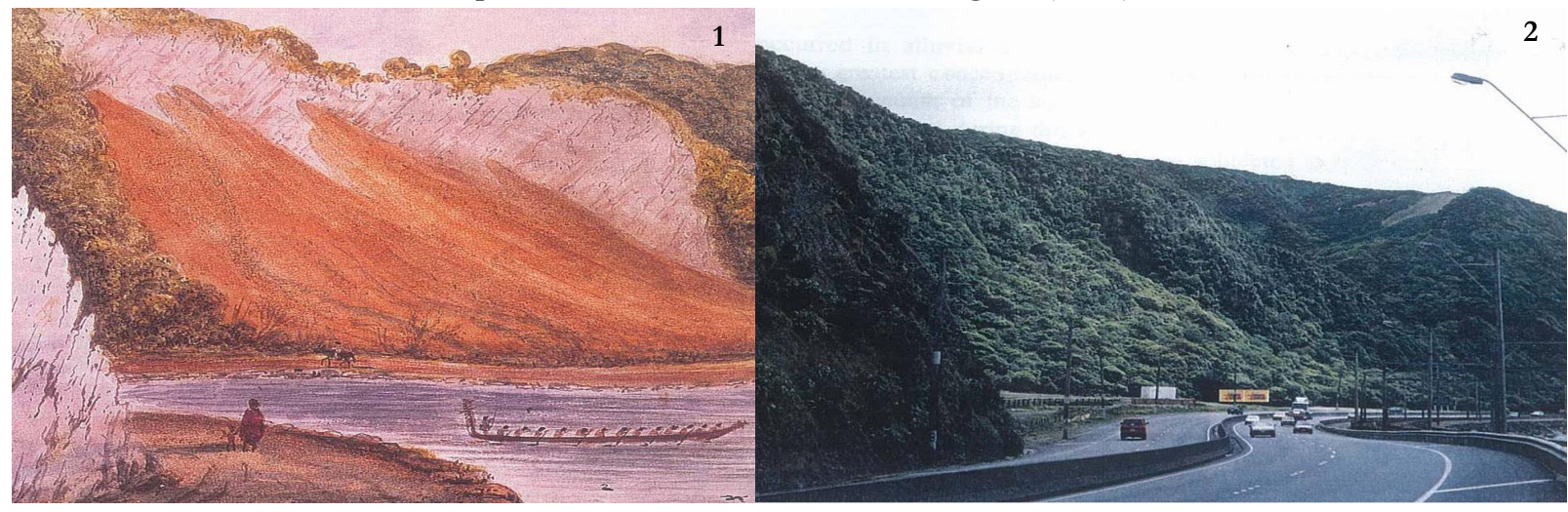

1. As Drawn Soon After Earthquake

2. Current

Source: Turnbull Library as cited in Hancox et al, 1997.

The 1855 earthquake produced landslides over an area of about $135,000 \mathrm{~km}^{2}$ and blocked most of the major roads and rivers in the region (Goff \& McFadgen, 2003, 619, Te Ara, 2008b). Areas which were significantly affected included South Wairarapa, Wellington, Lower Hutt, Masterton and to an extent the Kapiti Coast. The Orongorongo Ranges experienced numerous landslides, especially the ranges within 10-15km of the epicentre (Hancox et al, 1997, 24). Since the region was not highly populated at the time, it is very likely that many of the landslides were not reported. The type of landslides varied from superficial landslides to rock avalanches and their size from few cubic metres to more than $10,000,000 \mathrm{~m}^{3}$. The biggest landslide occurred in Bruce's Lake i.e. about $83 \mathrm{~km}$ northwest of the epicentre in Masterton in which about $10,800,000 \mathrm{~m}^{3}$ of material (mainly tertiary sandstone) fell down. The second biggest landslide occurred in Mukamuka stream in South Wairarapa, which was $5,000,000 \mathrm{~m}^{3}$ in size. Besides, 27 other landslides of more than $200,000 \mathrm{~m}^{3}$ in size occurred in this earthquake. The lithology of most of these landslides involved Greywacke that suggests that eve the hardest rock in the region is susceptible to break and fall during intense shaking. One of the most common and well known landslide is that of Gold's Slide (Photo: 5.3) which occurred in Wellington, about $23 \mathrm{~km}$ away from the epicentre and eroded $300,000 \mathrm{~m}^{3}$ of material (Hancox, et. al, 1997, 25). In total about 61 landslides were recorded across the region in which 54 were major and seven were small to moderate. A large area was affected by superficial landslides, i.e. about $77.3 \mathrm{~km}^{2}$, especially in Masterton and the Rimutaka hills between Lower Hutt and South Wairarapa.

The next earthquake that produced landslides in the region had the epicentre Pahiatua, a neighbouring district in 1934. The earthquake was of 7.6 in magnitude, and resulted in a number of small landslides of $<10,000 \mathrm{~m}^{3}$ in the periphery of its epicentre. One small landslide occurred in South Wairarapa along with superficial landslides over a wider area of about $1017.7 \mathrm{~km}^{2}$ in Carterton and Masterton (Map: 5.5). 


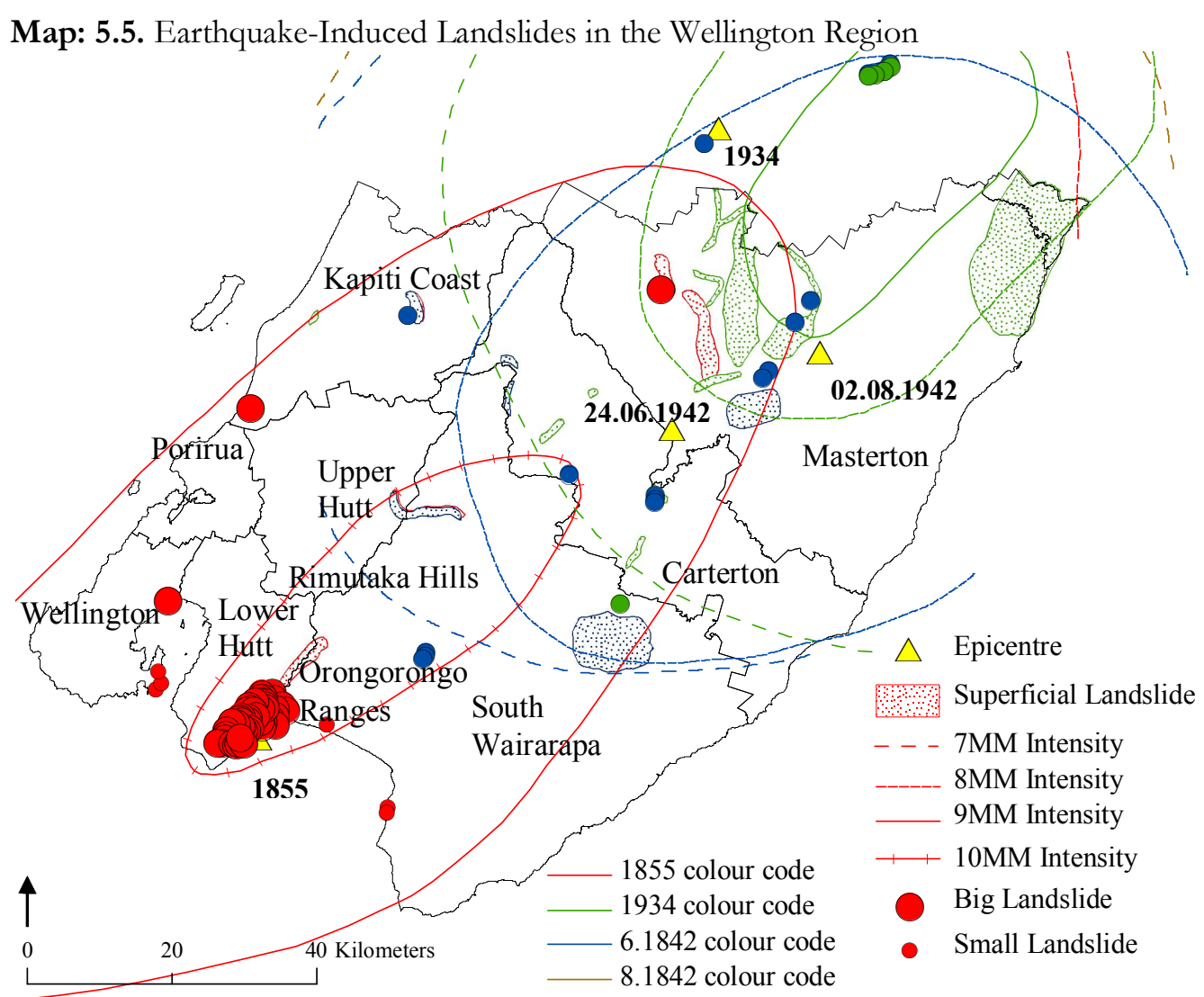

Based on data from Wellington Regional Council, 2007

The earthquake of $24^{\text {th }}$ June 1942 in Masterton produced minor but widespread landslides over $3700 \mathrm{~km}^{2}$ across the region. Some moderate to small landslides were recorded in Greywacke in the southern Tararua Range, southeast of Otaki. In addition, small debris and rock falls were reported in Wellington city, the Kapiti Coast between Plimmerton and Paekakariki, the Western Hutt road and the Rimutaka hill road. The landslide at Plimmerton blocked both lines on the main trunk railway line (Hancox, et. al, 1997, 40). The second earthquake on $2^{\text {nd }}$ August 1942 turned out to be less damaging and produced few moderate to small landslides in Wairarapa. In both earthquakes about 19 small to moderate landslides occurred across the region along with superficial landslides over an area of about $129.3 \mathrm{~km}^{2}$.

Hancox, et al, 1997 correlated the magnitude of earthquakes with landslide distribution in New Zealand and found that no area would be affected by a landslide from an earthquake of up to magnitude $[\mathrm{M}]$ four. From M5 about $100 \mathrm{~km}^{2}$ of area would be affected, while from M6 about $500 \mathrm{~km}^{2}$, from M7 about $2000-3000 \mathrm{~km}^{2}$, from M7.8 about $8000 \mathrm{~km}^{2}$ and from M8.2 up to 20,000km of area is likely to experience landslides (Hancox, et. al, 1997, 56).

Landslides are also predominantly caused by rainfall. Thomas Glade (1997) compiled records of rainfall induced landslides in New Zealand from 1860 to 1995. Glade assessed the landslides at regional scale that were classified according to weather forecast districts. Under this classification the current Wellington Region was divided into two regions. While the western section of the region with the five districts of Wellington, Lower Hutt, Upper Hutt, Porirua and the Kapiti Coast was classified as the Wellington Region, the eastern section with the three districts of South Wairarapa, Carterton and Masterton was named the South Wairarapa Region. According to 
this data the first rainfall induced landslide was recorded in the South Wairarapa in 1880, and in the Wellington Region in 1911 (Glade, 1997, 75). The absence of landslide records before this time could be attributed to the lack of need and isolated settlement pockets. The study shows that in the Wellington Region rainstorm induced landslides occurred in 36 out of 85 years, while in the South Wairarapa Region they occurred in 13 out of 116 years (Glade, 1997, 75). Therefore, the frequency of rainfall induced landslide years in the western section was higher (on an average once in every 2.3 years) as compared to the eastern section (once in nearly nine years). Also, the average frequency of storms in the Wellington Region (once in one and half years) is much higher than the South Wairarapa Region (i.e. once in seven and half years), and subsequently, the ratio of return period of landslide triggering storms is short in the Wellington Region (0.64 years) as compared to the South Wairarapa Region (i.e. 0.94 years) (Glade, 1997, 75). These statistics indicate a high frequency of landslide incidents in the western sections of the current Wellington Region as compared to its eastern parts. The data also show that a significantly higher number of landslides and storms occurred in the Wellington Region during 1932-1941 (Table: 5.13).

Table: 5.13. Rainfall Induced Landslide Years in the Wellington Region (1880-1995)

\begin{tabular}{lcccccccc}
\hline Years & \multicolumn{4}{c}{ Wellington } & \multicolumn{3}{c}{ Wairarapa } \\
\cline { 2 - 9 } & $\begin{array}{c}\text { Percentage } \\
\text { of years } \\
\text { with } \\
\text { landslide }\end{array}$ & $\begin{array}{c}\text { Place } \\
\text { affected } \\
\text { (no.) }\end{array}$ & $\begin{array}{c}\text { Storms Return period Landslide } \\
\text { (no.) }\end{array}$ & $\begin{array}{c}\text { Place } \\
\text { of landslide } \\
\text { producing } \\
\text { storm (years) }\end{array}$ & $\begin{array}{c}\text { Sears (\%) } \\
\text { affected } \\
\text { (no.) }\end{array}$ & $\begin{array}{c}\text { Rerms } \\
\text { (no.) }\end{array}$ & $\begin{array}{c}\text { Return period } \\
\text { of landslide } \\
\text { producing } \\
\text { storm (years) }\end{array}$ \\
\hline 1920 and Before & 20 & 1 & 2 & 5.00 & 2 & 1 & 1 & 40.00 \\
$1921-1940$ & 65 & 1.4 & 18 & 1.11 & 20 & 1.25 & 5 & 4.00 \\
$1941-1960$ & 45 & 1.2 & 13 & 1.54 & 20 & 1 & 4 & 5.00 \\
$1961-1980$ & 30 & 1.5 & 14 & 1.43 & 10 & 1.5 & 3 & 6.67 \\
1981 and After & 40 & 1.16 & 7 & 2.14 & 10 & 1 & 2 & 10.00 \\
\hline
\end{tabular}

Based on Glade, 1997, 70

The reason behind the highest frequency of storms witnessed during this decade is not clear. However, it strongly indicates the likelihood of such occurrence in the future with perhaps even higher intensity under the influence of climate change. Further, most of the storms in the region have had localised impacts affecting one or two localities. However, in today's context due to increased population density even a localised impact could result in significant damage.

The landslide records for the period from 1996 to

Map: 5.6. Rainfall Induced Landslides in the Wellington Region

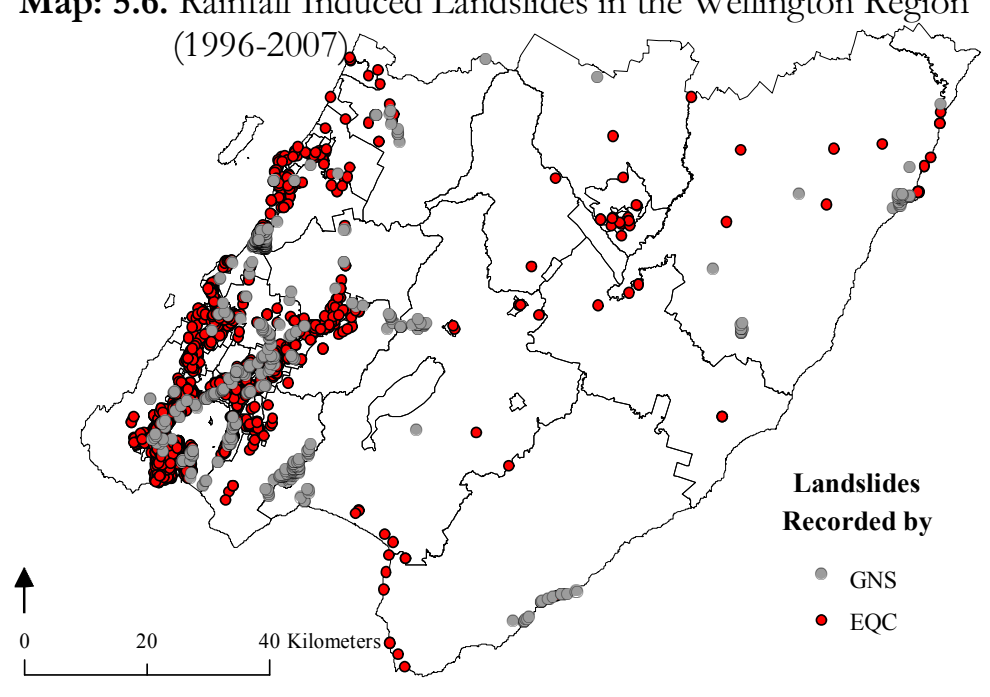

Based on data from GNS and EQC, 2007 
2007 were collected from the EQC and the GNS. Despite representing the same time and area, the data from the two institutes differ in their context due to different vested interest. While the EQC maintains the landslide records with respect to the damage claims made and compensation paid to individuals, the GNS records of landslides are mainly for research purposes. Both data complement each other as the EQC records show even the slightest loss due to landslides at an individual level, which may not be regarded significant or recorded for research purpose by the GNS. The latter institution records landslide events that occurred either in remote areas or those that caused damage to public resources for which individuals may not have necessarily made claims and which are missing in EQC records. Therefore both data were combined to get a holistic picture. However, there were a few cases that have been reported in both datasets, but since they represent different aspects of the landslides and are hard to segregate, they were retained in the data for further analysis. Since the data were collected in 2007, the landslide record for this year is not complete. Also the cause of landslide is not clear in the EQC data, therefore it has been assumed that they occurred as a result of rainfall. Data from GNS on the other hand are classified according to the main trigger of landslides, and this section only includes landslides triggered by rain.

Data from the EQC show that the region has experienced 121 days of landslides in the past 12 years, in which 2,781 claims were for property damage. The latter figure could have been taken as the number of landslides, but it is avoided because there is a high possibility that more than one family may have suffered the damage from one landslide. Data from the GNS show that the region experienced 510 rainfall induced landslide incidents from 1996 to 2006. The main reason behind the difference is that many

Fig: 5.7. Landslide Incidents in the Wellington Region (1996-2007)

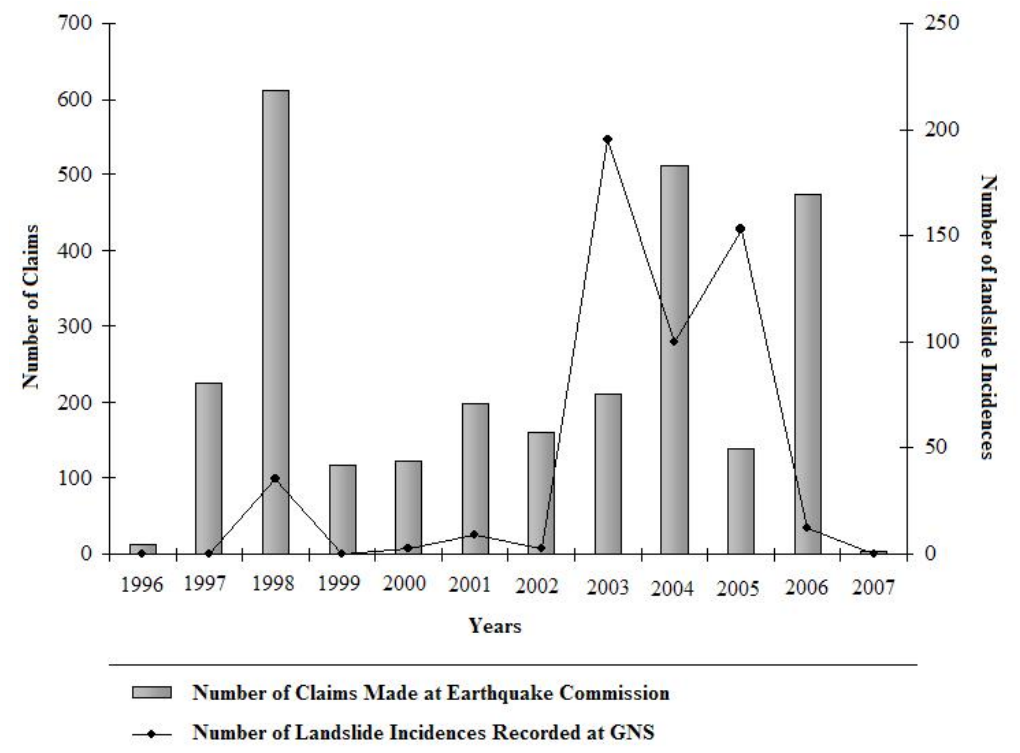

Based on data from EQC and GNS, 2007

landslides may not have caused damage to individual properties, and therefore were not registered by the EQC. The number further decreases as the EQC does not cover commercial properties. Although frequency of landslides reported in two sources does not relate well, their combination shows a general trend of rising landslide occurrence in the recent past (Fig: 5.7). Increased frequency of landslides could be attributed to enhanced awareness, improved recording and augmented susceptibility to landslides due to human activities such as slope excavation and deforestation along with population growth and rising variability in climatic conditions.

Landslide records from GNS show that although most of the incidents involved single landslides, a noteworthy proportion (i.e. about nine percent of the total incidents) involved more than one landslide at a time (Table: 5.14). 
Table: 5.14. Landslide Incidents in the Wellington Region (1996-2006)

\begin{tabular}{lccccccc}
\hline Local Territorial & Number of & \multicolumn{5}{c}{ Number of slips at a time (percent of incidents) } \\
\cline { 3 - 7 } Incidents & $\mathbf{1}$ & $\mathbf{2 - 5}$ & $\mathbf{6 - 1 0}$ & $\mathbf{> 1 0}$ & Several & Unknown \\
\hline Kapiti Coast & 184 & 96 & 0 & 0 & 0 & 3 & 1 \\
Lower Hutt City & 128 & 97 & 2 & 0 & 0 & 2 & 0 \\
Upper Hutt City & 50 & 80 & 6 & 0 & 4 & 10 & 0 \\
South Wairarapa & 46 & 83 & 2 & 4 & 2 & 9 & 0 \\
Wellington City & 44 & 82 & 0 & 0 & 0 & 18 & 0 \\
Masterton & 40 & 85 & 0 & 0 & 0 & 10 & 5 \\
Porirua City & 18 & 72 & 0 & 0 & 0 & 28 & 0 \\
Total & $\mathbf{5 1 0}$ & $\mathbf{9 1}$ & $\mathbf{1}$ & $\mathbf{0}$ & $\mathbf{1}$ & $\mathbf{7}$ & $\mathbf{1}$ \\
\hline
\end{tabular}

Based on data from GNS, 2007

For the period from 1996 to 2006, the maximum number of landslides was recorded in the Kapiti Coast (184) followed by Lower Hutt (128) and Upper Hutt (50). Here the data deviate significantly from EQC records, which show that in 121 days of landslides, Wellington was most affected (i.e. about 96 percent of total occurrence) followed by Lower Hutt (70 percent), Porirua (50 percent) and the Kapiti Coast and Upper Hutt 30 percent each. Masterton was affected in about 19 percent of total occurrences, while South Wairarapa and Carterton were affected in 10 percent of the total incidents. The differences could be explained on the basis of type and location of landslides and whether or not they caused damage that resulted in a claim.

Table: 5.15. Landslide Incidents and their Spatial Extent in the Wellington Region (1996-2006)

\begin{tabular}{lcccccc}
\hline Local Territorial & \multicolumn{5}{c}{ Radius in meters (number of incidents) } \\
\cline { 2 - 7 } Authorities & $\mathbf{1 0}$ and less & $\mathbf{1 1 - 1 0 0}$ & $\mathbf{1 0 1 - 1 0 0 0}$ & $\mathbf{1 0 0 1 - 1 0 0 0 0}$ & $\mathbf{1 0 0 0 1} \mathbf{~ a b o v e ~}$ & Not given \\
\hline Kapiti Coast & 64 & 75 & 39 & 3 & 2 & 1 \\
Lower Hutt City & 2 & 108 & 10 & 6 & 0 & 2 \\
Upper Hutt City & 9 & 22 & 6 & 10 & 0 & 3 \\
South Wairarapa & 4 & 33 & 1 & 7 & 6 & 0 \\
Wellington City & 7 & 22 & 7 & 4 & 1 & 1 \\
Masterton & 0 & 35 & 0 & 5 & 0 & 0 \\
Porirua City & 0 & 9 & 4 & $\mathbf{4 1}$ & $\mathbf{5}$ & $\mathbf{7}$ \\
Total & $\mathbf{8 6}$ & $\mathbf{3 0 4}$ & $\mathbf{6 7}$ & $\mathbf{8}$ & $\mathbf{1}$ & $\mathbf{1}$ \\
Percent & $\mathbf{1 7}$ & $\mathbf{6 0}$ & $\mathbf{1 3}$ &
\end{tabular}

Based on data from GNS, 2007

Characteristics of these slides further shed light on the general nature of landslides in the region. Table 5.15 shows that only 17 percent of the total landslides were below $10 \mathrm{~m}$ in radius. Large numbers of landslides (304) were between 10-100m in radius i.e. significant enough to cause collapse of one or more houses. Another 22 percent were bigger than $100 \mathrm{~m}$, i.e. large enough to cause serious damage at a community level if occurring in a residential area. Such landslides were common in Porirua (50 percent) along with South Wairarapa and Wellington, 32 percent each. One percent of the total landslides were greater than $10,000 \mathrm{~m}$ in radius indicating a huge mass movement, experienced twice in the Kapiti Coast and South Wairarapa and once in Lower Hutt, Wellington and Masterton. Such landslides pose a significant threat to infrastructure and resources in urban areas due to high population density.

In terms of total material eroded from these landslides, it is found that about 96 percent of the total landslides that hit the region were small in size i.e. less than $1000 \mathrm{~m}^{3}$ (Table: 5.16 ). Only 
Table: 5.16. Landslide Size in the Wellington Region (1996-2006)

\begin{tabular}{|c|c|c|c|c|}
\hline \multirow{2}{*}{$\begin{array}{l}\text { Local Territorial } \\
\text { Authorities }\end{array}$} & \multicolumn{4}{|c|}{ Size (percent Landslides) } \\
\hline & $\begin{array}{c}\text { small } \\
\left(\text { less than } 1000 \mathrm{~m}^{3}\right)\end{array}$ & $\begin{array}{c}\text { Medium } \\
\left(1000-100,000 \mathrm{~m}^{3}\right)\end{array}$ & $\begin{array}{c}\text { Large } \\
\left.\text { (more than } 100,000 \mathrm{~m}^{3}\right)\end{array}$ & $\begin{array}{l}\text { Not given or } \\
\text { Unknown }\end{array}$ \\
\hline Kapiti Coast & 98 & 1 & 0 & 1 \\
\hline Lower Hutt City & 98 & 2 & 0 & 1 \\
\hline Masterton & 95 & 5 & 0 & 0 \\
\hline Porirua City & 100 & 0 & 0 & 0 \\
\hline South Wairarapa & 93 & 7 & 0 & 0 \\
\hline Upper Hutt City & 88 & 6 & 0 & 6 \\
\hline Wellington City & 98 & 2 & 0 & 0 \\
\hline Total & 96 & 3 & 0 & 1 \\
\hline
\end{tabular}

three percent were medium and an even smaller share of large landslides occurred. The cause behind the only large landslide, which occurred on $8^{\text {th }}$ March 1999 in Whatarangi Cliffs, South Wairarapa was anthropogenic i.e. slope excavation.

Table: 5.17. Materials Eroded Through Landslides in Wellington Region (1996-2006)

\begin{tabular}{lcccc}
\hline Local Territorial & \multicolumn{4}{c}{ Type of material (percent of incidents) } \\
\cline { 2 - 5 } Authorities & Coarse Soils & Fine Soils & Rock & Unknown \\
\hline Kapiti Coast & 33 & 5 & 6 & 56 \\
Lower Hutt City & 31 & 25 & 39 & 5 \\
Masterton & 0 & 88 & 0 & 13 \\
Porirua City & 6 & 28 & 6 & 61 \\
South Wairarapa & 52 & 9 & 24 & 15 \\
Upper Hutt City & 14 & 32 & 26 & 28 \\
Wellington City & 9 & 20 & 34 & 36 \\
Total & 27 & 22 & 20 & 32 \\
\hline
\end{tabular}

Based on data from GNS, 2007

The data about the type of debris moved through landslides are only 55 percent complete. However they indicate, only one percent of the eroded material was 'blocky' and 54 percent was 'chaotic'. The blocky landslides largely occurred in the Kapiti Coast, Lower Hutt and South Wairarapa, while chaotic landslides were widespread throughout the region. A more detailed classification of the type of material shows that maximum number of landslides involved coarse soils (27 percent) followed by fine soil ( 22 percent) and rock ( 20 percent) (Table: 5.17$)$. It links to the variations in the geological composition and therefore differences in the nature of landslides. While in Masterton about 88 percent of the total slides involved fine soils, in Wellington a higher percentage of landslides (34 percent) involved rocks.

Table: 5.18. Type of Landslide Movements in the Wellington Region (1996-2006)

\begin{tabular}{|c|c|c|c|c|c|c|c|}
\hline \multirow{2}{*}{$\begin{array}{l}\text { Local } \\
\text { Territorial } \\
\text { Authorities }\end{array}$} & \multicolumn{7}{|c|}{ Type of Movement (percent of landslide) } \\
\hline & Fall & Flow & Topple & Translational slide & Rotational slide & Subsidence & Unknown \\
\hline Kapiti Coast & 1 & 6 & 1 & 20 & 0 & 0 & 73 \\
\hline Lower Hutt City & 5 & 52 & 0 & 32 & 2 & 0 & 9 \\
\hline Masterton & 0 & 68 & 0 & 20 & 0 & 0 & 13 \\
\hline Porirua City & 11 & 0 & 0 & 28 & 28 & 0 & 33 \\
\hline South Wairarapa & 4 & 70 & 0 & 11 & 0 & 0 & 15 \\
\hline Upper Hutt City & 6 & 2 & 0 & 54 & 0 & 0 & 38 \\
\hline Wellington City & 5 & 0 & 0 & 59 & 2 & 2 & 32 \\
\hline
\end{tabular}


Most of the slides in the region were translational slides ( 29 percent) followed by flow (27 percent) and fall (three percent) (Table: 5.18). While none of the landslides involved creep, the only incident of toppling was witnessed in the Kapiti Coast and of subsidence was recorded in Wellington. Fall of debris or rock material was rather widespread in the region with the exception of Masterton and Carterton, where soft sediments on gentle slopes tend to flow rather than fall. A significant number of rotational slumps were noticed in Porirua and a few in Lower Hutt and Wellington.

Table: 5.19. Landslide Triggers in the Wellington Region (1996-2006)

\begin{tabular}{lccc}
\hline Local Territorial & \multicolumn{3}{c}{ Trigger (percent of incidents) } \\
\cline { 2 - 4 } Authorities & Rainfall & Prolonged Rainfall & Intense rainfall \\
\hline Kapiti Coast & 17 & 3 & 80 \\
Lower Hutt City & 2 & 19 & 80 \\
Masterton & 0 & 0 & 100 \\
Porirua City & 11 & 0 & 89 \\
South Wairarapa & 2 & 2 & 96 \\
Upper Hutt City & 0 & 30 & 70 \\
Wellington City & 14 & 11 & $\mathbf{7 5}$ \\
Total & $\mathbf{8}$ & $\mathbf{1 0}$ & $\mathbf{8 2}$ \\
\hline
\end{tabular}

Based on data from GNS, 2007

Though rainfall acted as the main trigger of most of these landslides, the nature of rainfall also had a significant influence on landslide occurrence. The data show that about 82 percent of the landslides in the region occurred due to intense rainfall followed by ten percent due to prolonged rainfall. The remaining eight percent were simply associated with rainfall (Table: 5.19). The intensity of rainfall plays a critical role in landslide occurrence in the region. Since the region has a humid climate, frequent rainfall tends to remove loose material, and therefore intense rainfall is necessary for landslides (Hancox, et. al, 1997, 55). While incidents of landslide due to intense rainfall were widespread and common in all districts, landslides due to prolonged rainfall were significant in Upper Hutt, Lower Hutt and Wellington. In the Kapiti Coast a noticeable 17 percent of landslides were reported to be associated with rainfall followed by Wellington (14 percent) and Porirua (11 percent). In Masterton all landslides occurred due to intense rainfall, followed by South Wairarapa where 96 percent of landslides were caused by intense rain.

The monthly distribution of damage given in the EQC records also confirms the role of rainfall as a triggering factor. It shows that maximum claims were made in the winter season, when the region receives

Fig: 5.8. Monthly Landslide Damage Claims Made to the EQC (19962007)

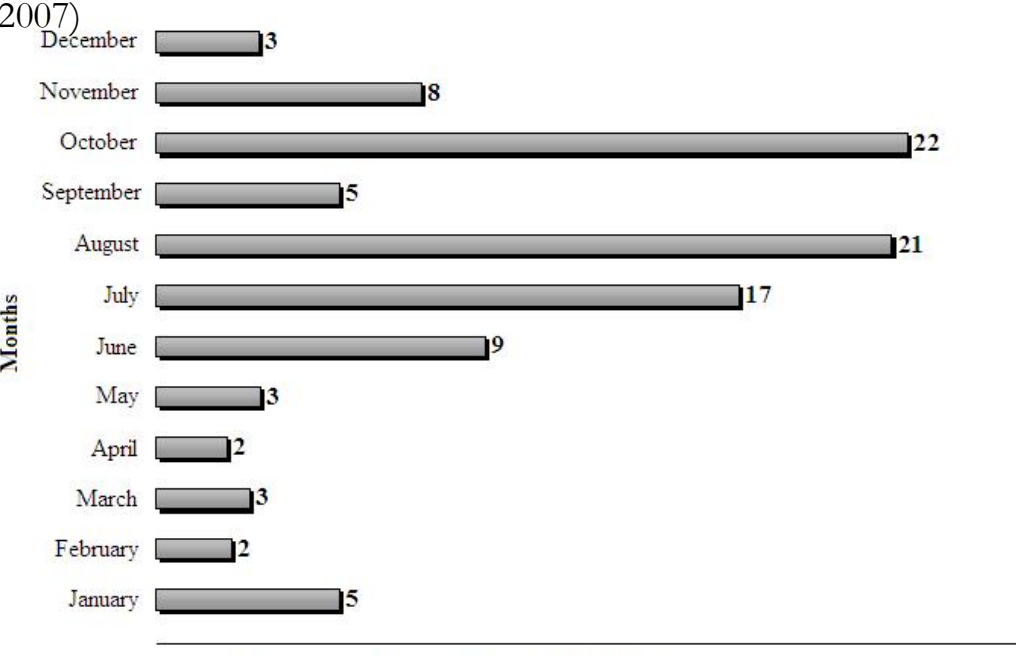

Per cent of claims made at Earthquake Commission 
the most rain. The proportion of claims was highest in the months of October (22 percent) followed by August (21 percent), July (17 percent), June (nine percent) and November (eight percent) (Fig: 5.8). Other months contributed to 23 percent of total claims where individual monthly share was five percent or less. The highest number of claims was made in October 1998, when a number of storms affected various parts of the region. In this month about 295 claims were lodged from six out of eight districts in the region with no claim from Masterton or Carterton. About 146 claims were paid, totalling of 651,072 NZD.

Even though rainfall acts as the main trigger, it is the preconditions, which play an important role in landslide occurrence. In 1974, one of the wettest years recorded in the region, Wellington City experienced 1149 landslides, in which only two landslides occurred on natural slopes and the rest occurred on modified slopes associated with cuts and fills (Eyles, Crozier \& Wheeler, 1978, 58, 61). However, preconditions are not always set by humans. A storm on October $7-10^{\text {th }}, 1974$ produced $61 \mathrm{~mm}$ of rain in $24 \mathrm{hrs}$ and $109 \mathrm{~mm}$ in $72 \mathrm{hrs}$, and caused 46 landslides in the Brooklyn, Mornington and Kingston areas of Wellington City, which eroded a volume of about $161 \mathrm{~m}^{3}$. The same area was again affected by another similar storm in terms of rainfall characteristics (60mm in $24 \mathrm{hrs}$ and $115 \mathrm{~mm}$ in $72 \mathrm{hrs}$ ) on $15-17^{\text {th }}$ July, 1976. This only produced nine landslides that eroded $24 \mathrm{~m}^{3}$. The significant drop in the number of incidents and the volume of material eroded in 1976 was due to event resistance and lower antecent rainfall, i.e. $413 \mathrm{~mm}$ rainfall in the preceding four months, which was as high as 656mm in 1974 (Eyles, Crozier \& Wheeler, 1978, 59; Crozier, 1986, 176).

Table: 5.20. Secondary Causes of Landslides in the Wellington Region (1996-2006)

\begin{tabular}{lccccccccc}
\hline $\begin{array}{l}\text { Local } \\
\text { Territorial } \\
\text { Authorities }\end{array}$ & $\begin{array}{c}\text { Excavation } \\
\text { of slope }\end{array}$ & fill & $\begin{array}{c}\text { stream } \\
\text { diversion }\end{array}$ & $\begin{array}{c}\text { River } \\
\text { erosion at } \\
\text { slope toe }\end{array}$ & $\begin{array}{c}\text { permeability } \\
\text { contrast }\end{array}$ & $\begin{array}{c}\text { weathered } \\
\text { material }\end{array}$ & $\begin{array}{c}\text { Jointed/ } \\
\text { fissured } \\
\text { material }\end{array}$ & $\begin{array}{c}\text { Ground } \\
\text { water } \\
\text { flow }\end{array}$ & $\begin{array}{c}\text { Not } \\
\text { given/ } \\
\text { unknown }\end{array}$ \\
\hline Kapiti Coast & 21 & 0 & 1 & 23 & 1 & 0 & 0 & 0 & 55 \\
Lower Hutt City & 29 & 2 & 1 & 1 & 2 & 7 & 2 & 1 & 56 \\
Masterton & 13 & 0 & 0 & 0 & 0 & 0 & 0 & 0 & 88 \\
Porirua City & 67 & 0 & 0 & 0 & 0 & 11 & 0 & 0 & 22 \\
South Wairarapa & 30 & 0 & 0 & 0 & 0 & 0 & 0 & 0 & 70 \\
Upper Hutt City & 62 & 0 & 0 & 6 & 2 & 14 & 0 & 0 & 16 \\
Wellington City & 77 & 0 & 0 & 0 & 0 & 0 & 11 & 0 & 11 \\
Total & $\mathbf{3 4}$ & $\mathbf{0}$ & $\mathbf{1}$ & $\mathbf{9}$ & $\mathbf{1}$ & $\mathbf{4}$ & $\mathbf{1}$ & $\mathbf{0}$ & $\mathbf{5 0}$ \\
\hline
\end{tabular}

Based on data from GNS, 2007

Data from the GNS also records secondary causes associated with rainfall induced landslides (Table: 5.20). They range from natural factors such as river erosion, permeability contrast, weathering, joints or fissures in rocks and ground water flow to human induced changes such as slope excavation, fills, stream diversion etc. About 34 percent of landslide incidents were associated with excavated slopes in contrast to 15 percent of incidents which were associated solely with natural factors. One percent of slides involved stream diversion as a secondary trigger, while the incidents in which fill was noted as a causative factor were negligible.

The damage from landslides in the region is an issue of concern. Although none of the records show any deaths from landslides during 1996-2007, one injury was reported from a landslide in Sunshine Bay, Eastbourne, Lower Hutt on $24^{\text {th }}$ October, 2006. It was a small 
translational slide, which was triggered by intense rain along with permeability contrast and human modified slope. It also damaged a house. Landslides have often caused household evacuation. Many houses have been evacuated due to landslides either on a precautionary basis or due to enhanced risk of the house collapsing. Due to a landslide in Paekakariki on $3^{\text {rd }}$ of October, 2003 about 20 houses were evacuated. It was a medium sized landslide, which affected $2.5 \mathrm{~km}$ of area, and buried cars and a local motel. Even though the slide was caused by intense rain, slope excavation was also noted as a secondary cause. Another landslide in Russo Terrace, Eastbourne on $23^{\text {rd }} \mathrm{July}$, 2006, led to the evacuation of 25 houses. It destroyed one house completely and threatened several others. It was a small slide of $100 \mathrm{~m}$ radius, and was triggered by prolonged rainfall. In Wellington, in three separate incidents, about seven houses were evacuated. The data show that evacuations of houses were concentrated in specific localities compared to house collapse or economic damage, which was widespread both spatially and temporally.

In the twelve years of the EQC records, about 2,781 claims were made for the damage from landslides, 55 percent of which were paid. The maximum number of claims was made in the year 1998 when 610 claims were registered for damage, of which 295 were paid. Fig: 5.9. Landslide Claims Paid by the EQC (1996-2007)

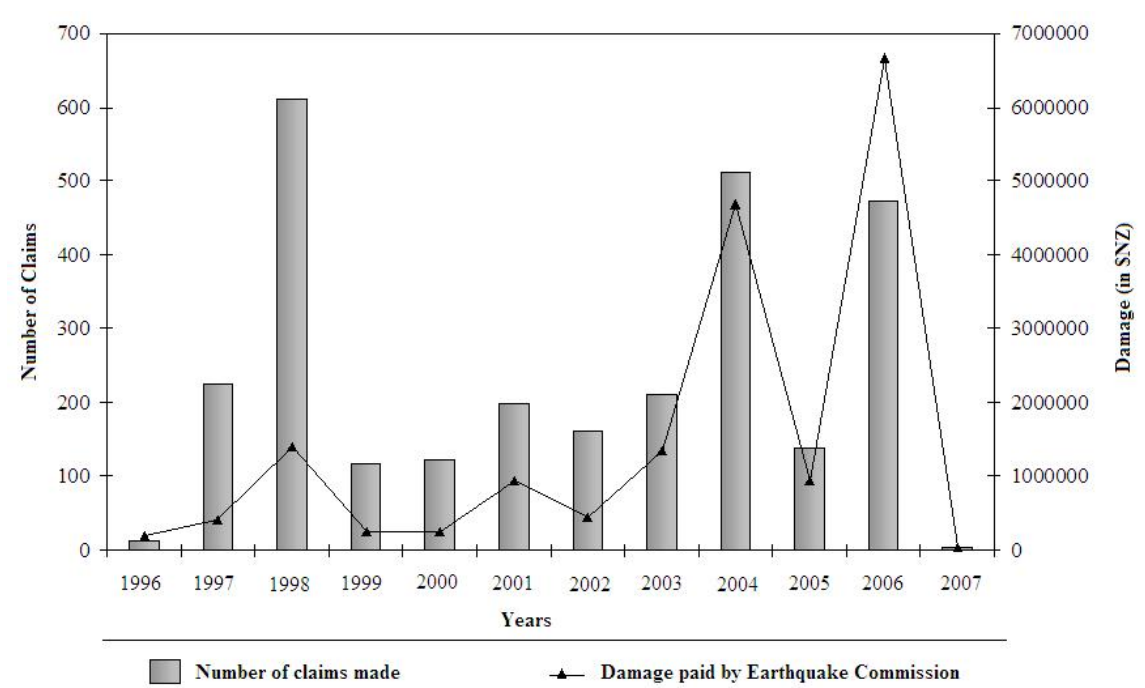
Almost all districts were affected by landslides Based on data from Earthquake Commission, 2007 except Carterton, and the EQC paid a total of about 1.4million NZD for the damage. This was, however, not the maximum amount that the EQC paid for loss due to landslides. The pay out was greatest in 2006, when about 473 claims were made of which 353 were compensated for. The total pay out for damage was about 6.7million NZD, which is about five times higher than 1998 damage paid by the EQC. The data show that while the claims are fluctuating over the years with the number of storm incidents (e.g. higher claims during storms in October 1998, February 2004, and July 2006), the damage paid by the EQC is consistently rising in relation to the number of claims made. This could be partly attributed to inflation along with population growth. The sharp decline in damage in the year 2007 is due to incomplete data (Fig: 5.9).

Table: 5.21. Number of Claims and Landslide Characteristics in the Wellington Region (1996-2007)

\begin{tabular}{lccccc}
\hline Claims & $\begin{array}{c}\text { Landslide } \\
\text { days }\end{array}$ & $\begin{array}{c}\text { Percent of } \\
\text { Landslide days }\end{array}$ & $\begin{array}{c}\text { Percent } \\
\text { claims made }\end{array}$ & $\begin{array}{c}\text { Percent of } \\
\text { damage paid }\end{array}$ & $\begin{array}{c}\text { Average number of } \\
\text { districts affected per day }\end{array}$ \\
\hline 10 and less & 70 & 58 & 12 & 8 & 1 \\
$11-100$ & 44 & 36 & 44 & 41 & 3 \\
101 and above & 7 & 6 & 44 & 69 & 5 \\
\hline
\end{tabular}

Based on data from Earthquake Commission, 2007 
The classification of claims made at the EQC shows that about 60 percent of the landslide days produced ten or less claims while only six percent of total landslide days produced more than 100 landslide claims, which registered 44 percent of total claims made over 12 years. The EQC paid nearly 70 percent of the total amount claimed for these seven landslide days. The data also show that most landslides are localized in nature, which either affected a district or its part (Table: 5.21).

The distribution of damage paid by the EQC shows that out of 121 days of landslides, the three major landslide days accounted for a damage of more than one million dollars (Table: 5.22). In these three days of landslide damage, on an average seven districts were affected each day. The money paid for these three days exceeded 40 percent of the total damage paid by the Commission over 12 years. Most of this money was paid for land loss followed by damage to dwellings. Another 22 percent of incidents cost more than 100,000 NZD to 1000,000 NZD, in which about 1433 claims were made and 52 percent of them were paid. These days again indicate widespread landslides in the region affecting four to five districts on an average and contribute 46 percent of the total damage paid by the Commission for landslide damage. For 12 percent of landslides, in which 36 claims were made, EQC did not pay out the damage.

Table: 5.22. Money Paid by the EQC for Landslide Damages in the Wellington Region (1996-2007)

\begin{tabular}{lccccccccc}
\hline $\begin{array}{l}\text { Money paid } \\
\text { (NZD) }\end{array}$ & $\begin{array}{c}\text { Number of Percent of Average } \\
\text { landslide } \\
\text { days }\end{array}$ & $\begin{array}{c}\text { Total } \\
\text { incidents }\end{array}$ & $\begin{array}{c}\text { Percent } \\
\text { districts } \\
\text { affected }\end{array}$ & $\begin{array}{c}\text { Totaims } \\
\text { made }\end{array}$ & $\begin{array}{c}\text { Percent } \\
\text { made } \\
\text { claims } \\
\text { paid } \\
\text { claims } \\
\text { paid }\end{array}$ & $\begin{array}{c}\text { Total } \\
\text { Money } \\
\text { paid }\end{array}$ & $\begin{array}{c}\text { Percent } \\
\text { Money paid }\end{array}$ \\
\hline None & 15 & 12 & 3 & 36 & 1 & 0 & 0 & 0 & 0 \\
Less than 1000 & 6 & 5 & 4 & 23 & 1 & 7 & 0 & 4302 & 0 \\
$1001-10,000$ & 22 & 18 & 3 & 100 & 4 & 43 & 3 & 93144 & 1 \\
$10,001-100,000$ & 48 & 40 & 4 & 606 & 22 & 337 & 20 & 1793577 & 12 \\
$100,001-1000,000$ & 27 & 22 & 5 & 1433 & 52 & 862 & 52 & 6711732 & 46 \\
1000,001 and above & 3 & 2 & 7 & 583 & 21 & 422 & 25 & 6091460 & 41 \\
\hline
\end{tabular}

Based on data from Earthquake Commission, 2007

From 1996-

2007 the EQC has paid about 17 million NZD for damage due to landslides. About 51 percent of the total cost was paid for the land, 32 percent for dwelling and one percent for content loss. Figure 5.10 shows that damage from landslides has significantly increased over the
Fig: 5.10. Type of Landslide Damage Claims Paid by the EQC (1996-2007)

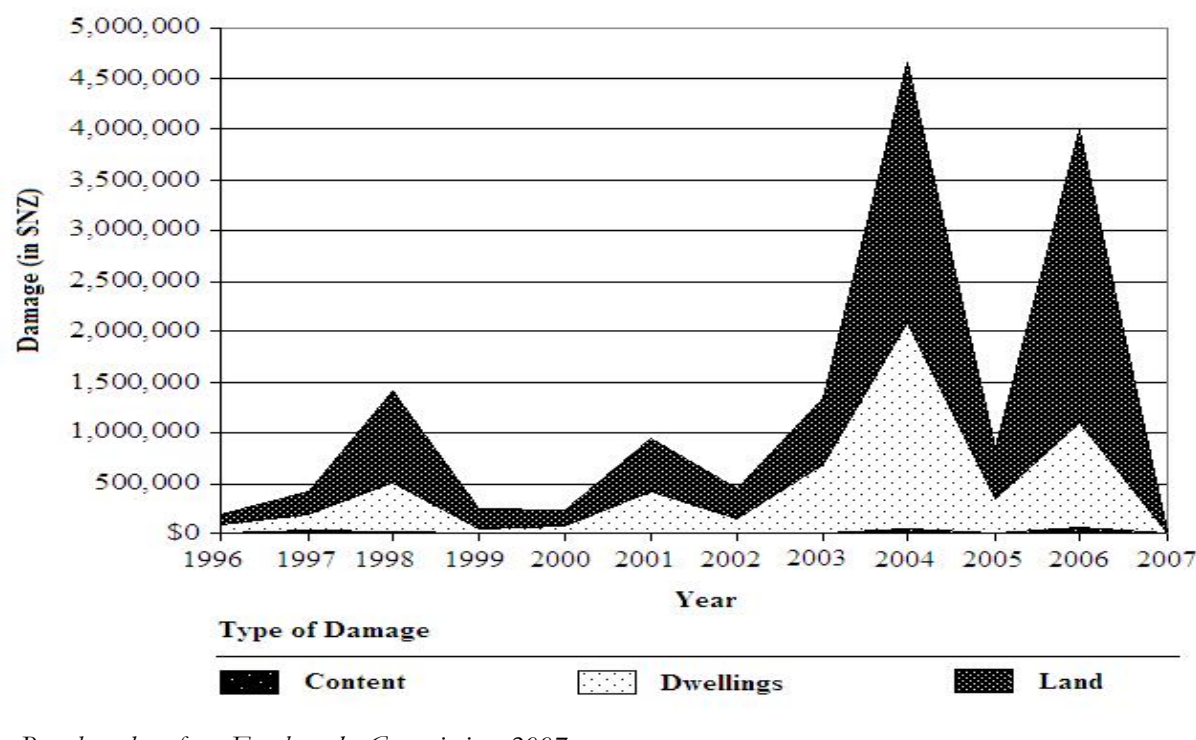

Based on data from Earthquake Commission, 2007 
past few years

The spatial distribution of claims made at the EQC shows (Map: 5.7) that the highest number of claims were registered for Wellington city where more than 1600 claims were made over 12 years. Wellington is followed by Lower Hutt and Porirua City where about 550 and 300 claims were lodged respectively. The minimum number of claims (eight) was registered

Map: 5.7. Landslide Claims Made to the EQC in the Wellington Region (1997-2006)

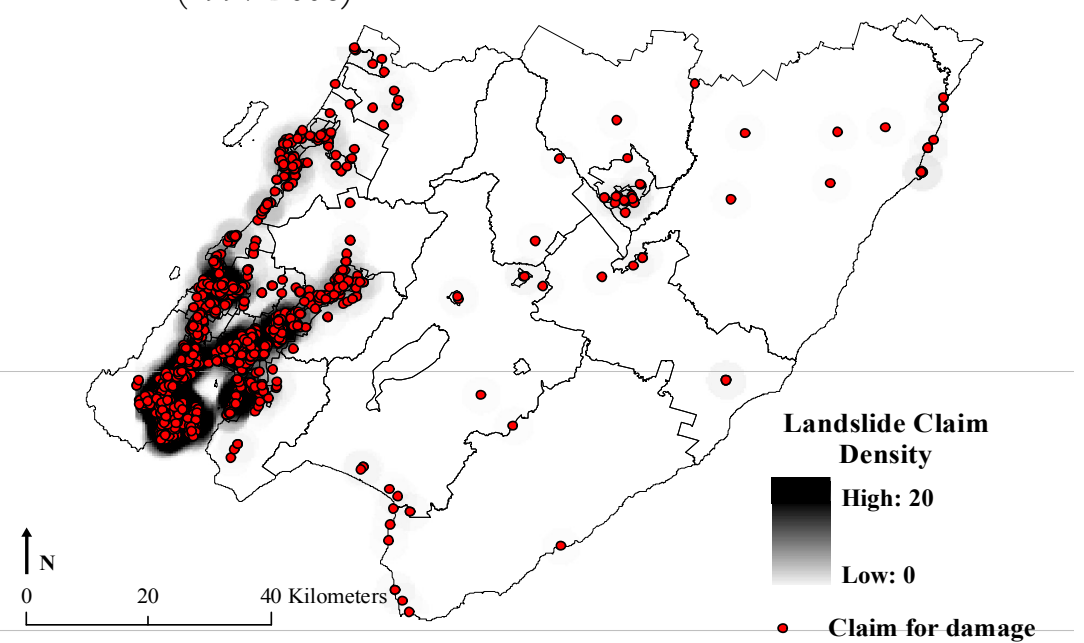

Based on data from Earthquake Commission, 2007 in Carterton.

The EQC paid the highest number of claims in Wellington city i.e. about 9.7million NZD, which was more than half of the total claims (55 percent) paid in the region (Table: 5.23). The second highest amount was paid in Lower Hutt (i.e. 5.5million NZD). These two districts together constituted more than 87 percent of the total claims paid in the region. Porirua accounted for nine percent of the total claims. Apart from these three cities, the other five districts accounted for three percent of the total claims. The description of damage type shows that the maximum share of land loss was paid in the Kapiti Coast ( 89 percent), and South Wairarapa (87 percent), while maximum damage to dwellings was experienced in Carterton (50 percent) and maximum content loss occurred in Upper Hutt (about five percent).

Table: 5.23. Money Paid by the EQC for Landslide Damages in LTAs (1996-2007)

\begin{tabular}{lrcccc}
\hline $\begin{array}{l}\text { Local Territorial } \\
\text { Authorities }\end{array}$ & $\begin{array}{c}\text { Total money } \\
\text { paid (NZD) }\end{array}$ & $\begin{array}{c}\text { Percentage of } \\
\text { money paid }\end{array}$ & \multicolumn{3}{c}{ Damage paid by EQC (in percent) } \\
\cline { 5 - 6 } & 44379.79 & 0.3 & Contents & Dwellings & Land \\
\hline Carterton & 154420.35 & 0.9 & 0 & 50 & 50 \\
Kapiti Coast & 5513754.30 & 31.5 & 2 & 39 & 89 \\
Lower Hutt City & 48966.86 & 0.3 & 0 & 0 & 51 \\
Masterton & 1640044.90 & 9.4 & 0 & 37 & 51 \\
Porirua City & 96126.01 & 0.5 & 0 & 13 & 87 \\
South Wairarapa & 314465.90 & 1.8 & 5 & 37 & 52 \\
Upper Hutt City & 9706714.60 & 55.4 & 0 & 27 & 50 \\
Wellington City & $\mathbf{1 7 , 5 1 8 , 8 7 2 . 7 1}$ & $\mathbf{1 0 0 . 0}$ & $\mathbf{1}$ & $\mathbf{3 2}$ & $\mathbf{5 1}$ \\
Total & & &
\end{tabular}

Based on data from Earthquake Commission, 2007

Note: The type of damage does not sum up 100 percent for a few districts the necessary details were not available for all claims made.

House damage due to landslide is more common in the region than any other hazards. Record at the GNS show that about nine houses were destroyed due to landslide incidents in the past 11 years throughout the region (Table: 5.24). Loss of assets or damage to infrastructure was more widespread in terms of time and space. Personal asset damages involved loss of cars, walkways, driveways, car parks and damage to garages and fence. In the rural areas of Masterton 
Table: 5.24. Personal Damages Due to Landslides in the Wellington Region (1996-2006)

\begin{tabular}{lcccccc}
\hline Local Territorial & $\begin{array}{c}\text { Number of } \\
\text { Authorities }\end{array}$ & \multicolumn{5}{c}{ Damage (number of incidents) } \\
\cline { 3 - 6 } & evacuated & House & $\begin{array}{c}\text { Loss of } \\
\text { assets }\end{array}$ & $\begin{array}{c}\text { Slips on } \\
\text { farms }\end{array}$ & $\begin{array}{c}\text { Pasture loss } \\
\text { Farm tracks buried or } \\
\text { damaged by slips }\end{array}$ \\
\hline Kapiti Coast & 20 & 0 & 1 & 1 & 0 & 0 \\
Lower Hutt City & 25 & 6 & 6 & 0 & 0 & 0 \\
Masterton & 0 & 0 & 0 & 0 & 27 & 8 \\
Porirua City & 0 & 1 & 0 & 0 & 2 & 0 \\
South Wairarapa & 0 & 0 & 2 & 0 & 0 & 0 \\
Upper Hutt City & 1 & 0 & 0 & 0 & 0 & 0 \\
Wellington City & 7 & 2 & 1 & 0 & 0 & $\mathbf{8}$ \\
Total & $\mathbf{5 3}$ & $\mathbf{9}$ & $\mathbf{1 0}$ & $\mathbf{1}$ & $\mathbf{2 9}$ & \\
\hline
\end{tabular}

Based on data from GNS, 2007

and South Wairarapa, major area of damage to private resources occurred on farms where slips resulted in pasture loss or farm tracks being buried under debris.

Besides individual damage, landslides have also been responsible for damage to public assets in the region (Table: 5.25). The most common forms include damage to transport infrastructure and traffic disruption. State highways that pass through the steep hills are frequently affected by landslides. State Highway-2 which passes through six districts of the region has been reported to be blocked in Wellington, Lower Hutt, Upper Hutt and South Wairarapa along with State Highway-1, which was reported to be blocked in both districts it passes through, i.e. Porirua and the Kapiti Coast, and State Highway 58 in Porirua.

Table: 5.25. Transport Damages from Landslides in the Wellington Region (1996-2006)

\begin{tabular}{lccccc}
\hline Local Territorial & \multicolumn{2}{c}{ Transport damage (number of incidents) } & $\begin{array}{c}\text { Percent of total } \\
\text { landside incidents }\end{array}$ \\
\cline { 2 - 5 } & $\begin{array}{c}\text { Highway } \\
\text { partially/fully } \\
\text { blocked }\end{array}$ & $\begin{array}{c}\text { Road } \\
\text { partially/fully } \\
\text { blocked }\end{array}$ & $\begin{array}{c}\text { Lanes/street } \\
\text { blocked }\end{array}$ & $\begin{array}{c}\text { Railway line } \\
\text { blocked }\end{array}$ & \\
\hline Kapiti Coast & 2 & 10 & 7 & 3 & 12 \\
Lower Hutt City & 5 & 9 & 1 & 0 & 12 \\
Masterton & 0 & 4 & 0 & 0 & 10 \\
Porirua City & 5 & 5 & 0 & 0 & 56 \\
South Wairarapa & 3 & 8 & 1 & 0 & 46 \\
Upper Hutt City & 2 & 16 & 5 & 0 & 34 \\
Wellington City & 4 & 11 & 0 & 0 & 46 \\
\hline
\end{tabular}

Based on data from GNS, 2007

Blockages of roads have been reported more frequently than those of highways or local streets. This might be due to the fact that not all street blockages have been reported. Rail routes have also been reported blocked several times. In the Kapiti Coast, the main train line has been blocked three times in the past 11 years due to slips. Overall transport hazards have been experienced most frequently in the western urban districts of Porirua (56 percent), Upper Hutt (46 percent) and Wellington (34 percent) compared to rural districts of Carterton ( 0 percent), Masterton (10 percent) and South Wairarapa (26 percent).

Landslides often remove the vegetal cover and increase the susceptibility for future slides in the exposed ground. This results in longitudinal impacts in terms of enhanced risk to houses or to other resources due to landslides in the neighbourhood. Photo: 5.4 depicts one such situation, 
where debris flows not only damaged the houses located in the gully but also forced the occupants to abandon them because of increased future risk of such incidents (Hancox, et al, 2007, 32).

A few landslides in the region have been triggered by factors other than rainfall or earthquake. These include geological factors such as stress release and anthropogenic use of explosives. So far three landslides are reported to have occurred due to stress release, one in

Photo: 5.4. Damage to Houses in Eastbourne from Debris Flow (October, 2006)

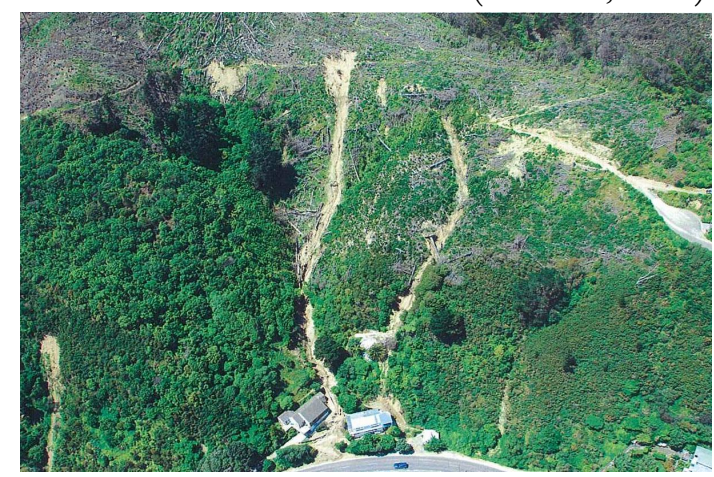

Source: GNS Photo D200-2657, 26Nov06 as cited in Hancox, et al, 2007, 32

the Kapiti Coast and two in Wellington City. However, anthropogenic causes, such as slope excavation were also noted at these sites. The slides varied in radius from $100-3000 \mathrm{~m}$, but all involved chaotic material of rocks and coarse soil and were translational in nature. The damage from these slides involved closure of State Highway-1 and rail route, damage to a house and an apartment building. One landslide was caused by explosives in Wellington on $14^{\text {th }}$ January, 2004. It was a small landslide of five metres in radius. Eroded material consisted of rocks which smashed into a nearby house. Objects from shelves inside the house were also dislodged and broken. In addition, there are a number of landslides for which the trigger is not clear. The number of such slides in GNS records is 64. Most of these landslides were associated with anthropogenic causes such as excavated slopes, and for one slide a geological cause was noted, that is, jointed and fissured material. But for others no such records found. Most of these landslides were small in size, except three medium size and one large size landslide. Damage from these landslides varied from damages to houses, roads and infrastructure along with blocked roads, traffic disruption, train derailment and the evacuation of houses.

It can be concluded that landslides in the region vary in their nature as well as in the type of damage they produce. Whereas rock fall, debris avalanche, scree erosion, riparian erosion and bed load transport are more common in the western part of the region in high altitude ranges, the eastern section is characterized by deep seated earth flow, debris flow and regolith slide along with slumping (Crozier, 1990, 7-8). Also, the material eroded differs across the region, i.e. commonly hard rocks in the west and weathered rocks and soil in the east. A spatial trend is also seen in the type of damage experienced in the region. The western urban districts experienced damage to property and infrastructure loss along with traffic jams, delays, house collapse etc. In the rural Wairarapa districts damage was linked to loss of pasture and farm tracks. Furthermore, superficial landslides were observed more in the eastern hills, particularly during severe earthquakes.

\subsubsection{Tsunami}

Tsunami is the other geophysical hazard for which the region is highly susceptible. There is evidence of regular tsunami occurrences in the region in the past. Palaeo records indicate that tsunami occurred in the region in 1200-1220AD (before Maori settlement), 950AD, 500AD, 
200AD, 2500BP, 3000-3200BP and 4800-5000BP (GeoEnvironmental Consultants, 2001, 22). But since there was no human occupation in the Region, these incidents are not regarded as hazards. A few tsunami occurred during the $15^{\text {th }}$ century affecting many parts of the region (GeoEnvironmental Consultants, 2001, 22). There is evidence that tsunami occurrence at this time may have affected coastal Maori settlements in many ways especially at Okoropunga, at Palliser Bay and at Te Ikaamaru Bay, where tsunami related sand deposits have been found. This has been identified a reason for the consequent abandonment of the coastal areas by Maori communities (Goff \& McFadgen, 2003, 613-616). Moreover, it is important to mention that abandonment of coastal areas was a practical solution during the $15^{\text {th }}$ century, but is not an option in today's context where both infrastructure and people are firmly established and tend not to move even though the risk is clear and obvious.

Tsunami have been reported more frequently in the recent past. Since 1840, about four locally generated tsunami and twelve distant tsunami have affected various parts of the region. The biggest tsunami in the region was produced by the 1855 earthquake. The highest wave was recorded at Te Kopi, Palliser Bay. It was of about ten metres high, and washed away the whares and the materials for shipment from the coast (GeoEnvironmental Consultants, 2001, 90; WELA, 2003, 26). During the incident one Maori village also appeared to have been ruined (Goff \& McFadgen, 2003, 619). The impact was severe on the community as tsunami destroyed most of the food sources including terrestrial, lacustrine as well as marine. Devegetated slopes, sediments in streams and salt water inundation of gardens along with the loss of canoes further aggravated the situation (Goff \& McFadgen, 2003, 619). In Wellington Harbour the height of the tsunami wave was estimated to be about 3-5m causing flooding on Lambton Quay (Glimmer and Stanton, 1990 and Downes et al, 2000 as cited in GeoEnvironmental Consultants, 2001, 15).

Table: 5.26. Tsunami Affected Areas in the Wellington Region (1840-2000)

\begin{tabular}{|c|c|c|c|c|c|c|c|c|c|c|c|c|c|c|c|}
\hline \multirow[t]{2}{*}{ Tsunami } & \multirow[t]{2}{*}{ Date } & \multicolumn{12}{|c|}{ Place } & \multirow[b]{2}{*}{$\begin{array}{l}\text { Max. } \\
\text { height of } \\
\text { tsunami } \\
\text { wave in } \\
\text { the } \\
\text { Region } \\
\text { (m) }\end{array}$} & \multirow{2}{*}{$\begin{array}{c}\text { Place of Maximum } \\
\text { height of tsunami wave } \\
\text { in the Region }\end{array}$} \\
\hline & & 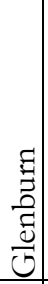 & 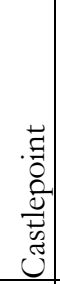 & 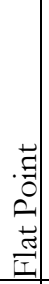 & 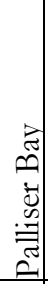 & 苟 & 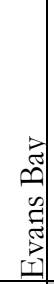 & 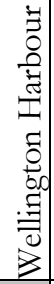 & $\begin{array}{l}0 \\
0 \\
0 \\
0 \\
0\end{array}$ & 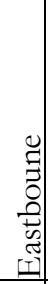 & 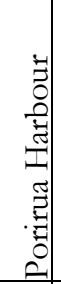 & 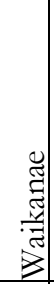 & $\frac{2}{2}$ & & \\
\hline \multirow{4}{*}{$\begin{array}{l}\text { Local } \\
\text { generated } \\
\text { tsunami }\end{array}$} & $16-19.10 .1948$ & & & & & & & & & & & & & 1 & \multirow{4}{*}{$\begin{array}{l}\text { Lambton quay } \\
\text { Te Kopi, Palliser Bay } \\
\text { Wellington } \\
\text { South Wairarapa }\end{array}$} \\
\hline & 23.01.1855 & & & & & & & & & & & & & $9-10$ & \\
\hline & 07.04 .1870 & & & & & & & & & & & & & $<0.5$ & \\
\hline & 13.04.1882 & & & & & & & & & & & & & ? & \\
\hline \multirow{10}{*}{$\begin{array}{l}\text { Distant } \\
\text { generated } \\
\text { tsunami }\end{array}$} & 15.08.1868 & & & & & & & & & & & & & 1 & Lyall bay and Evans Bay \\
\hline & 11.05.1877 & & & & & & & & & & & & & 2 & Lyall bay and Evans Bay \\
\hline & 21.09.1897 & & & & & & & & & & & & & 1 & Wellington \\
\hline & 12.11.1922 & & & & & & & & & & & & & $<0.5$ & At most places \\
\hline & 04.09 .1923 & & & & & & & & & & & & & 0 & Wellington \\
\hline & 02.04 .1946 & & & & & & & & & & & & & 1 & Wellington \& Wairarapa \\
\hline & 06.11 .1952 & & & & & & & & & & & & & $?$ & Wellington \\
\hline & $24-25.05 .1960$ & & & & & & & & & & & & & 2 & Wairarapa Coasts \\
\hline & 29.03 .1964 & & & & & & & & & & & & & $?$ & Wellington \\
\hline & 15.10.1994 & & & & & & & & & & & & & $<0.1$ & Wellington \\
\hline
\end{tabular}


Table 5.26 shows that tsunami waves were higher in local tsunami than distant ones. A tsunami generated by a high magnitude earthquake has the potential to affect all coasts of the region. However, while there are warning systems available for distant tsunami, no such measures are available to recognize a locally generated tsunami. The response time tends to be much shorter for locally generated tsunami compared to a distant one, which further increases the vulnerability to local tsunami. Strong ground shaking could be an indicator of local tsunami, but it has been observed that earthquakes along the subduction zone could produce devastating tsunami without causing significant tremors (Darienzo, 2005, 117). Therefore, it can be said that risk from local tsunami in the region is considerably higher than risk of distant tsunami. The data show that Wellington Harbour has been affected by all the local and distant tsunami. This could be attributed to detailed research of the area. It also indicates a higher susceptibility and probability of tsunami occurrence in Wellington city, which is the most densely populated and busiest area of the region.

Other factor to note is the greater heights of tsunami waves at Palliser Bay, Lyall Bay and Evans Bay, which indicate that bay areas tend to amplify tsunami wave heights (GeoEnvironmental Consultants, 2001, 21). During the 1855 earthquake, the height of tsunami was ten metres in Palliser Bay, about four metres in Evans Bay and about two to three metres in Wellington Harbour near the current CBD (GNS, 2008a). In the two other distant tsunami incidents of 1868 and 1877, wave heights were highest in Evans Bay and Lyall Bay. The reason could be attributed to their low lying, flat topography, which acts as a gateway for tsunami, where surrounding waves tend to get centred leading to an increase in the height of waves. The semi-enclosed area also holds the water for longer hours, which further enhances the risk (Downes, et. al, 2000 as cited in GeoEnvironmental Consultants, 2001, 10). The risk is relatively higher in Evans Bay and Lyall Bay than in Palliser Bay as the previous two are densely populated areas.

Tsunami run up on land is another factor to analysis. Most of the bays and low lying areas not only face higher tsunami waves, but waves tend to reach further inland in these zones compared to hilly areas. During the $15^{\text {th }}$ century, tsunami water was moved about $200 \mathrm{~m}$ inland and over 10masl in Kapiti Island, where salt water inundation was noticed. In Palliser Bay cobbles were found up to one kilometre inland along with wave inundation being sited over $20.5 \mathrm{~km}$ inland (Goff et al, 1998 in Goff \& McFadgen, 2003, 618). Contemporary evidence suggests that tsunami run up has occurred inland at Lyall Bay, which at one time extended across Rongotai Isthmus (GeoEnvironmental Consultants, 2001, 21).

Future occurrence of tsunami in the region is clearly possible. While Okal et al (1990) have established that there is no risk of tsunami in the South Pacific Ocean from earthquake of magnitude less than $7.3 \mathrm{Mw}$, in New Zealand the bigger tsunamis have been caused by earthquake of magnitude 6.0 (de Lange and Hull, 1994 \& in press as cited in GeoEnvironmental Consultants, $2001,6)$. This means that the region is exposed to tsunami even from low magnitude earthquakes. It has been noted that tsunami earthquakes do occur along the Hikurangi Trough (Kelsey, et. al, 1998 as cited in GeoEnvironmental Consultants, 2001, 6). The return period of tsunami in Wellington Port is 728 years for wave height of 5 meters and 84 years for wave height of 5-10 metres (GeoEnvironmental Consultants, 2001, 13). The hotspots in the region identified by 
GeoEnvironmental Consultants (2001) include Riversdale or Castlepoint, Palliser Bay (particularly its north east corner), Wellington Harbour, Porirua Harbour and the Kapiti Coast (GeoEnvironmental Consultants, 2001, 14). K. Berryman (2005) studied the tsunami risk for New Zealand and calculated tsunami risk for four local councils including Wellington, Lower Hutt, Porirua and the Kapiti Coast (Table: 5.27). The study highlights that even a very low tsunami height could result in injuries, deaths and destruction of infrastructure in the region. The minimum height of a tsunami waves causing death and injuries is about $1.6 \mathrm{~m}$ on the Kapiti Coast followed by Lower Hutt $(2.3 \mathrm{~m})$, Porirua $(3 \mathrm{~m})$ and Wellington $(3.3 \mathrm{~m})$. However, the maximum damage from the minimum wave height would occur in Wellington where about 26 people could die and another 330 could be injured.

Table: 5.27. Probability of Tsunami Occurrence in the Wellington Region

\begin{tabular}{|c|c|c|c|c|c|}
\hline \multicolumn{2}{|c|}{ Hazard Characteristics } & \multicolumn{4}{|c|}{ Local Councils Exposed to Tsunami } \\
\hline & & Wellington & Lower Hutt & Porirua & Kapiti Coast \\
\hline \multirow[t]{2}{*}{ Wave Height (m) } & $\operatorname{Min}^{1}$ & 3.3 & 2.3 & 3 & 1.6 \\
\hline & $\operatorname{Max}^{2}$ & 17.4 & 12.1 & 8.7 & 8.4 \\
\hline \multirow[t]{2}{*}{ Return period (yrs) } & $\operatorname{Min}^{1}$ & 100 & 100 & 200 & 100 \\
\hline & $\operatorname{Max}^{2}$ & 2500 & 2500 & 2500 & 2500 \\
\hline \multirow[t]{2}{*}{ Cost (NZDm) } & $\operatorname{Min}^{1}$ & 1200 & 210 & 270 & 50 \\
\hline & $\operatorname{Max}^{2}$ & 9500 & 4300 & 1200 & 2400 \\
\hline \multirow[t]{2}{*}{ Deaths } & $\operatorname{Min}^{1}$ & 26 & 3 & 6 & 1 \\
\hline & $\operatorname{Max}^{2}$ & 13000 & 4600 & 510 & 1200 \\
\hline \multirow[t]{2}{*}{ Injuries } & $\operatorname{Min}^{1}$ & 330 & 120 & 100 & 64 \\
\hline & $\mathrm{Max}^{2}$ & 9900 & 6500 & 1400 & 3800 \\
\hline
\end{tabular}

Based on Berryman, 2005, 71-92

Notes: $1=$ Minimum that can result in death; $2=$ Maximum that is studied;

All values are based on the 84 percentile of uncertainty.

Wellington would be affected very badly by the highest tsunami wave height studied (i.e. 17.4 metres), which could kill about 13,000 people, injure another 9900 and may cost up to 9,500 million NZD. This although seems to be a conservative estimate, yet it indicates a massive damage. The death scenario for a 2500 years event is significant in all four councils, even if the wave height is not as high as in the Kapiti Coast ( 8.4 metres) and Porirua (8.7 metres). This implies high vulnerability to tsunami in the region.

\subsubsection{Volcanic Ash fall}

Due to a distant south location from volcanic ash fields of the North Island, the region is only susceptible to volcanic ash fall. Volcanic ash fall refers to all particles of less than $2 \mathrm{~mm}$ in diameter that are aerially ejected from a volcano (Neall, et. al, 1999 as cited in Patterson, 2001, 4). These particles could travel hundreds of kilometres in the air depending on height of vent, wind direction and speed (Neall, et. al, 2001, 4), and could prove hazardous to human lives and properties.
Photo: 5.5. Eruption at Ruapehu (1996)

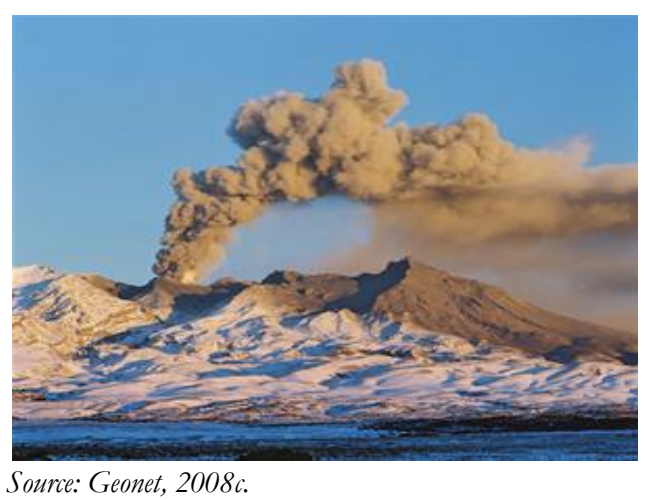


The region could receive ash fall from Ruapehu, Ngauruhoe, Tongariro, Taranaki (Egmont), Taupo and Okataina volcano near Rotorua. Most of these volcanoes are located in the north of the region, except Taranaki (Egmont) volcano, which is located in the northwest. An assessment of wind directions with the location of these volcanoes shows that due to less frequent northerly winds, it is less likely that the region would face ash fall from northern volcanoes. Nonetheless, the likelihood is high for receiving ash fall from Taranaki because of high frequency of northwest winds at both the surface and upper atmosphere level (Paterson, 2001, 4). Wind direction also determines the susceptibility and thickness of volcanic ash fall. However, such details are not available for the past incidents.

Map: 5.8. Dominant Wind Directions and Relative Location of the Wellington Region to Volcanic Fields

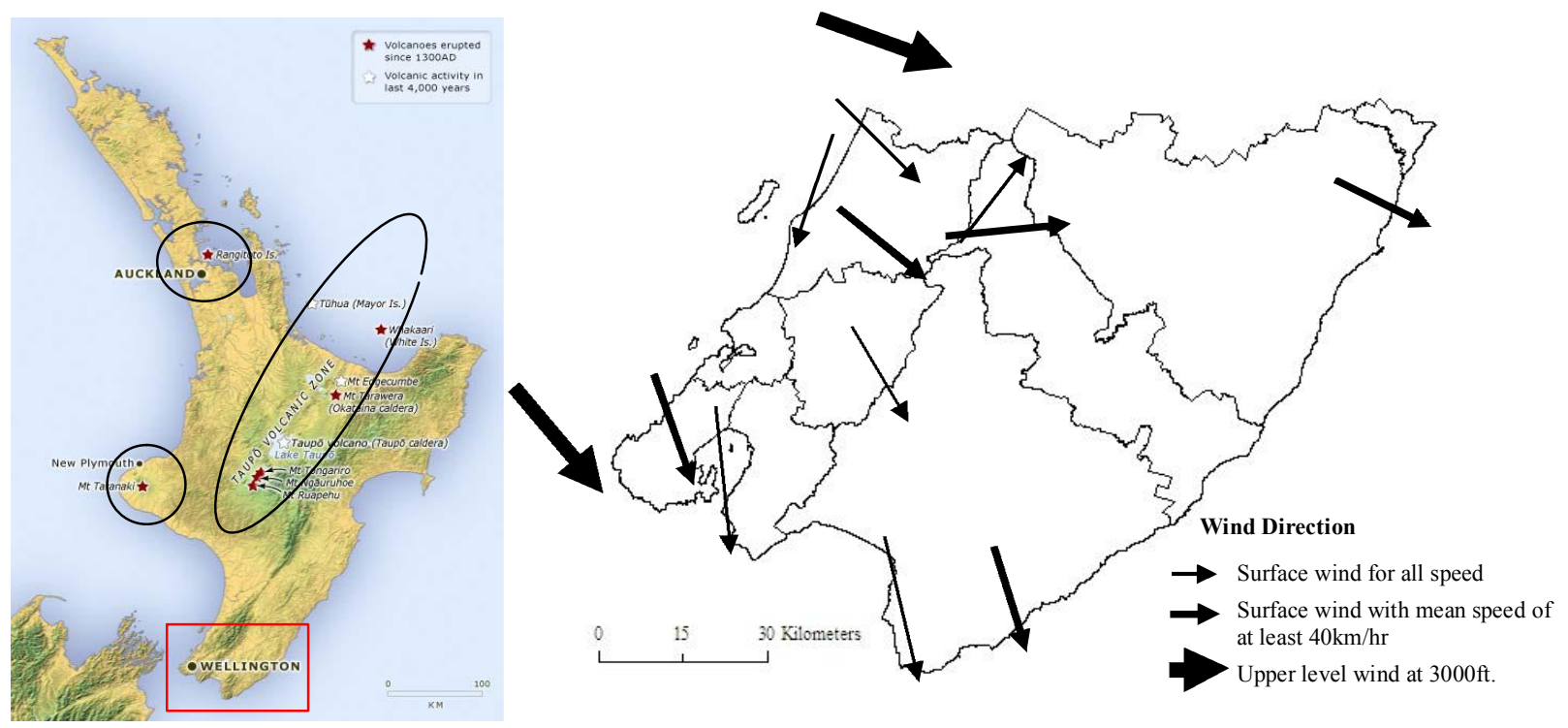

Based on image from Te Ara, 2008g and NIWA 1999-2000 as cited in Paterson, 2001, fig: 1.

Though no detailed work has been done on volcanic ash fall in the Wellington Region, a few studies have recorded occurrences in the region (Patterson, 2001, 3). A layer of Tephra has been observed in the geological beds of the Wairarapa, which dates back to 10,000 to two million years ago, i.e. of Pleistocene age (Patterson, 2001, 3). The most recent layer was formed by the Taupo eruption 22,500 years ago and was named as Kawakawa Tephra (Shane, et. al, 1995 as cited in Paterson, 2001, 3). The layer is thin $(<30 \mathrm{~mm})$, but it is assumed that it could be $>60 \mathrm{~mm}$ when deposited as preserved layers tend to be only 50 percent of the original thickness (Paterson, 2001, 3; Scott, et al., 1998 as cited in Paterson, 2001, 3). The absence of geological records of ash fall in the period since eruption of Kawakawa could be due to their subsequent erosion and may not necessarily mean absence of volcanic ash fall (Paterson, 2001, 3). The various intermittent eruptions at Mt Ruapehu in 1861, 1895, 1945, 1995 and 2007 often resulted in volcanic ash fall in the Wellington Region, even if the thickness of the layers could not be measured. The last eruption at Ruapehu occurred on September, 25, 2007 and since it was explosive, the ash did not reach a wider area as it did in 1996 (Geonet, 2008), when many people in the region experienced 'smoke' in the air or fine ash on their car windows. 
Table: 5.28: Possible Thickness of Volcanic Ash Fall in the Wellington Region

\begin{tabular}{|c|c|c|c|c|}
\hline Volcano & $\begin{array}{c}\text { Eruption Volume in } \\
\mathrm{km} 3\end{array}$ & $\begin{array}{c}\text { Frequency of } \\
\text { occurrence (in years) }\end{array}$ & Ash Thickness & $\begin{array}{l}\text { Possible thickness in } \\
\text { Wellington Region }\end{array}$ \\
\hline Ruapehu, & $0.05-0.15$ & $20-500$ & $1 \mathrm{~mm}$ & $0-1 \mathrm{~mm}$ \\
\hline Ngauruhoe & $0.05-0.15$ & $100->200$ & $1 \mathrm{~mm}$ & $0-1 \mathrm{~mm}$ \\
\hline Tongoriro & $0.05-0.15$ & $1000-10,000$ & $1 \mathrm{~mm}$ & $0-1 \mathrm{~mm}$ \\
\hline Taranki (Egmont) & 0.1 & $1300-1600$ & $1-5 \mathrm{~mm}$ & $1.5 \mathrm{~mm}$ \\
\hline Taupo & $0.5-10$ & $1300-5000$ & $1 \mathrm{~mm}$ & $1-500 \mathrm{~mm}$ \\
\hline Okataina & $1-10$ & $1500-2000$ & $1 \mathrm{~mm}$ & $1-300(?) \mathrm{mm}$ \\
\hline
\end{tabular}

Table 5.28 shows that the region could receive as little as $0.1 \mathrm{~mm}$ to $500 \mathrm{~mm}$ of volcanic ash fall. The source of most thick ash fall would be Taupo, and the frequency of its eruption indicates a relatively imminent occurrence as the last eruption occurred in 181AD (GNS as cited in Lake Taupo New Zealand, 2009). Though there is no current sign of its eruption, and future eruption is assumed to be small to medium in size, nothing could be said with certainty as volcanoes are still not well understood (Froggatt, 2009).

Table: 5.29: Possible Impacts of Volcanic Ash Fall in the Wellington Region

\begin{tabular}{|c|c|c|c|c|c|}
\hline \multirow{2}{*}{$\begin{array}{l}\text { Possible } \\
\text { Impacts of } \\
\text { Ash fall }\end{array}$} & \multicolumn{5}{|c|}{ Ash fall thickness } \\
\hline & $<1 \mathrm{~mm}$ & $1-5 \mathrm{~mm}$ & $5-100 \mathrm{~mm}$ & $100-300 \mathrm{~mm}$ & $>300 \mathrm{~mm}$ \\
\hline Water Supply & $\begin{array}{c}\text { possible } \\
\text { contamination }\end{array}$ & $\begin{array}{l}\text { limited or } \\
\text { cut supply }\end{array}$ & $\begin{array}{l}\text { cut or limited } \\
\text { supply }\end{array}$ & $\begin{array}{l}\text { cut or limited } \\
\text { supply }\end{array}$ & cut or limited supply \\
\hline $\begin{array}{l}\text { Electrical and } \\
\text { telephone }\end{array}$ & & $\begin{array}{l}\text { may be cut } \\
\text { especially } \\
\text { low voltage } \\
\text { system }\end{array}$ & $\begin{array}{c}\text { may be cut } \\
\text { especially low } \\
\text { voltage system }\end{array}$ & $\begin{array}{l}\text { Cut due to falling } \\
\text { branches and } \\
\text { shortening of lines }\end{array}$ & $\begin{array}{l}\text { Loading and possible } \\
\text { breakage of power and } \\
\text { telephone lines }\end{array}$ \\
\hline Air transport & close & close & close & close & $\begin{array}{l}\text { Unusable until track } \\
\text { cleared }\end{array}$ \\
\hline Road transport & & visibility & halted & halted & $\begin{array}{l}\text { Unusable until track } \\
\text { cleared }\end{array}$ \\
\hline Rail transport & & & halted & halted & $\begin{array}{l}\text { Unusable until track } \\
\text { cleared }\end{array}$ \\
\hline House damage & $\begin{array}{l}\text { minor } \\
\text { abrasion }\end{array}$ & $\begin{array}{l}\text { minor } \\
\text { damage to } \\
\text { equipments }\end{array}$ & $\begin{array}{c}\text { weaker } \\
\text { structure } \\
\text { would collapse }\end{array}$ & $\begin{array}{c}\text { Large flat roofs if } \\
\text { not cleared would } \\
\text { collapse, if ash is } \\
\text { wet }\end{array}$ & Major roof collapses \\
\hline Crop \& & & crop & burial of & pasture destroyed & Heavy destruction of \\
\hline Vegetation & & damage & $\begin{array}{l}\text { pasture and } \\
\text { low plants }\end{array}$ & & vegetation \\
\hline Livestock & & $\begin{array}{c}\text { stressed } \\
\text { due to lack } \\
\text { of feed }\end{array}$ & & & Killed \\
\hline Aquatic life & & & & suffocation & Killed \\
\hline Human health & $\begin{array}{l}\text { Irritant to } \\
\text { lungs and eyes }\end{array}$ & & & & $\begin{array}{c}\text { May face severe health } \\
\text { problems e.g. cancer, } \\
\text { which may lead to later } \\
\text { deaths }\end{array}$ \\
\hline
\end{tabular}

Based on Neall, et al, 1999, 25-26

The impacts of volcanic ash fall may range from contamination of water supply, traffic and flight disruption, minor damage to houses and crops, to health effects such as irritation in the lungs and eyes due to ash fall thickness of less than $5 \mathrm{~mm}$. Serious health implications leading to deaths along with destruction of pasture, vegetation, livestock and aquatic life are expected if the ash fall layer exceeds $300 \mathrm{~mm}$ in thickness (Table: 5.29). Thus volcanic hazards in the region are possible and pose serious threats to local communities. 


\subsection{Meteorological and Climatic Hazards}

The Wellington Region is also exposed to a range of meteorological and climatic hazards including frosts, snowfall, heat waves, windstorms, cyclones, lightning, thunderstorms, hailstorms and rainstorms. These hazards can be grouped according to their main driving force i.e. temperature, wind or rainfall. Damage from these hazards is either poorly reported or often associated with the consequent hazard such as landslides, flood or drought. As a result, a true (hazard) scenario is not available for most of these hazards.

\subsubsection{Frosts, Snowfall and Heat Waves}

High fluctuations in temperature, either positive or negative, prove hazardous to communities, especially where the livelihoods are closely linked to primary modes of production. Hazards associated with cold temperatures are snowfall and frost, while those with hot temperatures include heat waves and droughts. While no heat wave has been reported in the region, since drought is primarily associated with the availability of water, it is discussed in following section of hydrological hazards.

Significant temperature drops over night result in ground and screen frost. While the western districts of the region experience fewer than 30 days of ground frost annually, in the eastern districts, the number of such days exceeds 80. Because of the data paucity for wider areas in the eastern district, a detailed picture of variations in ground frosts cannot be drawn (Map: 5.9). However, ground frost is particularly bad for crops and

Map: 5.9. Average Annual Ground Frost Days and Screen Frost Days in the Wellington Region

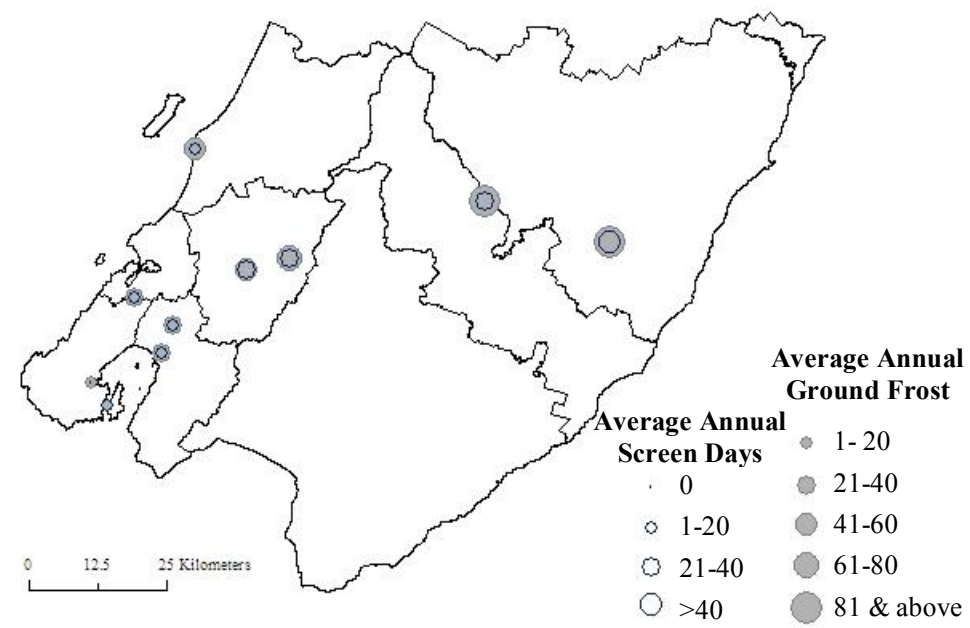

Based on data retrieved from CliFlo, NIW A, 2007 other plantations in this part of the region. In the western urban areas of the region ground frost is related to transport hazards due to slippery roads. The region experiences fewer days of screen frosts if compared to the number of ground frost days. The eastern districts of the region experience the maximum number of screen frost days (20-40 or more days per year) compared to western districts ( $0-40$ days per year). The regional differences in the number of frost days are related to high temperature differences between day and night in the eastern parts compared to the western section.

Reports of damage from these incidents are incomplete and scattered, and therefore, annual loss from these hazards is not clear. On July $4^{\text {th }} 2001$, Wallaceville in Upper Hutt 
experienced severe frost, when the temperature fell below $-5.7^{0} \mathrm{C}$. The incident froze native Punga trees (Tait, et al., 2002, 97). It was however, not the most intense frost the area has experienced. One such frost occurred on June $28^{\text {th }} 1975$ when the temperature was about $-5.9^{0} \mathrm{C}$ (Tait, et al., 2002 , 95). However, the damage data for this incident is not available.

The region is also exposed to snowfall, which occurs in the largely unpopulated high altitude zones. Since most observatories are located in valley areas, true records of snowfall occurrences are not available (WELA, 2003, 39). Nevertheless, the National Climate Centre [NCC] has recorded hazardous snowfalls in the region from 2000 to 2007 in National Climate Summary Reports. The reports mention about 13 snowfall incidents in the past seven years, 12 of which occurred on the Rimutaka Hill Summit, where 67 percent of the total incidents led to road closure. The Orongorongo Range was also affected three times, along with Kaitoki and Kapiti Hills, which were affected once. Since depth of snowfall is not measured in New Zealand (Tait, et al, 2002, 20), data is again not available for most incidents. However, in two separate incidents, depth of snowfall was reported to be about $35 \mathrm{~cm}$ and $20 \mathrm{~cm}$ on the Rimutaka Hill road. About 30 percent of snowfall incidents occurred in June, 15 percent in August, September and October each, and the remaining incidents were scattered throughout April, July and November.

\subsubsection{Windstorms, Tornadoes, Water Spouts, Cyclones and Sea Surges}

The region experiences a range of wind related hazards including high winds, gales, tornadoes, water spouts, cyclones and sea surges. Due to a lack of details about the spatio-temporal occurrence of these hazards, it is hard to categorise these events.

The speed of windstorms is critical in hazard occurrence. On 11 September 1880 several carriages of a train passing through the Rimutaka Range were blown over and two passenger carriages were derailed by a severe gale. During the incident three children died and 21 people were injured (GNS, 2008c). The exact wind speed is not known, but it certainly represents an extreme force associated with gale winds in the region. It has been noted that wind speed of $50-120 \mathrm{~km} / \mathrm{hr}$ could damage trees and more than $120 \mathrm{~km} / \mathrm{hr}$ could overwhelm old houses and farm buildings (WELA, 2003, 29). Wind speed records show that these limits are often crossed by winds in the region. The highest wind speed of $207 \mathrm{~km} / \mathrm{hr}$ was recorded at the Hau Nui Wind Farm in southern Martinborough. At Castlepoint a wind speed of $183 \mathrm{~km} / \mathrm{hr}$ was recorded on 18-19 $9^{\text {th }}$ October, 1998 (Grant, 2005, 46). Another incident occurred on the $4^{\text {th }}$ of June, 2004 at mount Kaukau and Baring Head, when the instrument taking measurements broke down showing $183 \mathrm{~km} / \mathrm{hr}$ of wind speed (Grant, 2005, 48). The average speed of winds at Castlepoint $(122-183 \mathrm{~km} / \mathrm{hr}$ ) bears enough capacity to harm old infrastructure and buildings. The same is true for Beacon Hill where wind speed ranged from 145-166km/hr (Grant, 2005, 45-48). In urban areas damage from wind could occur at a speed just above $100 \mathrm{~km} / \mathrm{hr}$. Significant damage in the region has been recorded at wind speeds of $132 \mathrm{~km} / \mathrm{hr}$ at Kelburn, Wellington on 18-20 November, 1996, when many roofs, windows, power lines and outdoor furniture were destroyed. During the incident an elderly women was also blown over and injured (Grant, 2005, 45). 
Records of windstorms from 19962004 in Grant (2005b) and from 2005-2007 in the Climate Summary Reports from NCC show that the region has faced 170 severe wind events in the 12 years between 1996 and 2007. In terms of dominant wind direction, 54 percent were from the northwest, 31 percent from the south, seven percent from the west, the remaining three percent was not mentioned. About 66 percent of total events caused economic loss or property damage in the region, but monetary estimates of the total loss are not given. The data show that out of 170 cases, about 35 percent involved property damage such as loss of roofs or broken roofs, windows and outdoor furniture (Fig: 5.11). Transport or traffic disruption was another major problem, and reported in 44 percent of cases. All modes of transport were affected including water, air and road in 25, 11 and eight percent of hazard incidents respectively. The most dangerous impact was observed on the Rimutaka Range road, where in five percent of cases, truck or vehicles were blown over. Power cuts were another major problem, which occurred in 10 percent of cases. In two percent of cases people got blown over or injured, showing the most immediate impact on human life.

The areas most frequently affected by these incidents are Wellington City (48 percent), South Wairarapa (28 percent), Masterton specifically at Castlepoint and Mount Bruce (21 percent), Rimutaka Range (11 percent), Lower Hutt at Eastbourne (five percent) and the Kapiti Coast (four

Photo: 5.6. Damage from the Wahine Storm (10 April, 1968)

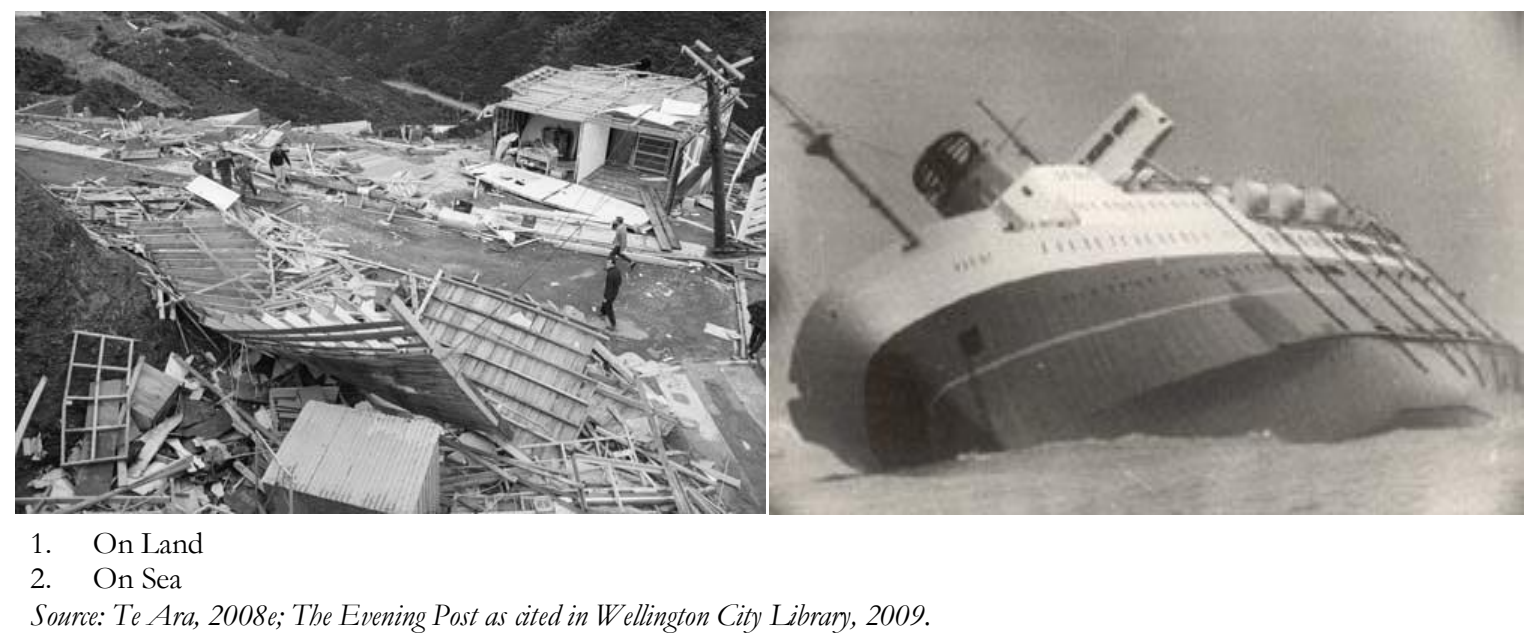


percent). Upper Hutt and Carterton were least affected as they are relatively sheltered. For another two percent of cases, the area affected by severe winds was not given (NCC, 2005-2007, Grant, 2005, 45-48).

Many of the severe wind incidents in the region were associated with other hazards including sea surges, hail, lightning, waterspouts, snow and scrub fires. Sea surge was the most common associated hazard which was found in nine percent of total cases. The height of sea surge associated with severe wind ranged from 5 to $14.4 \mathrm{~m}$ in height, and often led o the closure of the Inter-Island ferry services. Although, not enough data is available about the damage due to sea surge, history provides some evidence. On 29 March 1888, the Wellington train got stranded between Wellington and Petone, as waves generated from southerly storms removed the railway bed and sleepers for about $1.5 \mathrm{~km}$ from behind and ahead of the train. This required about $300 \mathrm{men}$ to repair the service over six days (GNS, 2008d). Another example is the Wahine storm, which is discussed later. In 1.2 percent of cases, wind was associated with lightning, which often affected the region's power supply. In 1.2 percent of cases between 1996 and 2007, severe wind ignited several scrub fires. In nearly three percent of cases hail occurred, which damaged crops. Thunderstorm and snow fall were also observed in 1.2 percent of cases, additional to sleet that was reported with 0.6 percent of total cases.

The most damaging combination was winds with waterspout or local tornado, which were noted in 5.3 percent of cases. The most frequent location of these waterspouts was off the Kapiti Coast, Otaki, Waikanae and once in Wellington Harbour. They have resulted in property damage and one incident destroyed the conservatory at Waikanae on 31 May, 1998. Flight and ferry services in Wellington often affected by events originated far away. For example, Wellington airport was closed for many hours during the Greymouth tornado on $10^{\text {th }}$ March, 2005 (NCC, 2005).

High speed winds also occur in the region due to cyclonic depressions, and can cause widespread damage. Tropical cyclone track data suggest that central New Zealand, that is the Wellington Region could be affected by cyclones of tropical origin once in every three to six years (Tait, et al., 2002, 115). The most significant examples of high speed wind hazard was the cyclone of February 1936 and the Wahine storm that occurred on April 1968 (Ta Ara, 2008c; Tait, et al., 2002, 113). The cyclone of February 1936 proved disastrous in the North Island causing flooding and landslides at different places. There was damage to infrastructure and about two people died due to hypothermia in the Tararua Ranges (Te Ara, 2008c). The Wahine storm was caused by the ex-tropical cyclone Gisele, which crossed the North Island to the east of Cape Palliser (Tait, et al., 2002, 113). It was not an extreme event as the wind speed was $110 \mathrm{~km} / \mathrm{hr}$ at Wellington Harbour, when the Inter-Island ferry was entering the region (Tait, et. al, 2002, 19). The ship could not cope with the combination of high wind speed and a sea surge of height $10 \mathrm{~m}$ having short horizontal wavelengths, and ran onto Barret reef. About 51 people lost their lives in the incident. The storm caused massive damage inland as well. People lost their houses (Photo: 5.6) and damage to infrastructure such as power lines was also widespread. The cost of damage from this storm including the loss of the Wahine is estimated to be around 150million NZD in today's context (NIWA, 2000 as cited in Tait, et al., 2002, 114). The damage from the incident shows that even a 
moderate intensity windstorm can be proved devastating if the region is unprepared for such events.

\subsubsection{Hails, Lightning, Thunderstorms and Rainstorms}

Another set of meteorological hazards are related to rain such as hail, lightning, thunderstorms and rainstorms. Hail and lightning often come through convective storms passing through the region (Tait, et. al., 2002, 102). Since the updraft is not vigorous in small storms, the size of hail is small and by the time hailstones reach the ground, they have melted and therefore cause less damage. Most hail in the region is produced in small storms (Tait, et al., 2002, 103). The spatio-temporal occurrence of hail in the region show that the western districts are affected more frequently than the eastern districts of South Wairarapa, Carterton or Masterton, except the areas adjacent to the Tararua and Rimutaka Ranges (Map: 5.10). Castlepoint is an exception in the eastern section, which gets 2-4 days of hail annually. The Wellington suburb of Kelburn received hail most frequently in the region, i.e. nine days annually, followed by Wellington airport with seven days and Te Marua in Upper Hutt with six days of hail per annum.

Even though damage data from hail is not available, a few incidents have been evaluated. A violent hailstorm on $7^{\text {th }}$ January 2001 in Masterton caused significant damage to roofs, orchards, vineyards and seasonal crops grown in the region. The hailstones were of golf ball size that filled the gutters, dented vehicles, damaged windscreens and killed many birds. The storm lasted for 1020 minutes, and because of large drift, hail was piled about a metre on the surface after the storm (Tait, et al., 2002, 108-109).

Lightning in the region frequently affects power and transmission lines. Risk of lightning flashes to the ground is measured through ground flash density per square kilometre per year, which is denoted by Ng. The distribution of flash density across the region shows that it is high in the western region, especially on the Kapiti Coast and in Upper Hutt and Wellington (Map: 5.10). While the Kapiti Coast faces six days of lightning along with Kelburn in Wellington, such incidents are negligible or absent in a major section of all three eastern districts. Frequency could be higher in the Tararua Ranges but because of inadequate data, it

Map: 5.10. Lightning and Hail Days in the Wellington Region

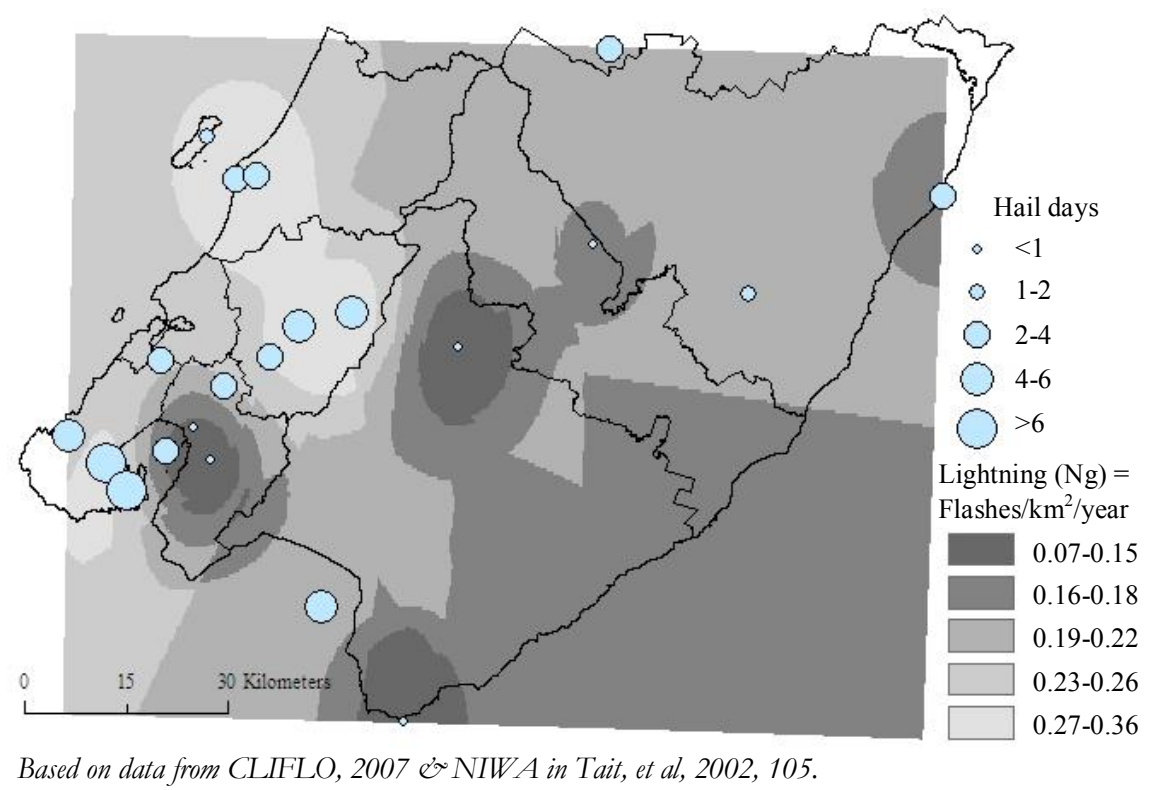


cannot be proved (Tait, et al., 2002, 111).

Another related hazard is thunderstorm. The distribution pattern of thunderstorm days shows (Fig: 5.11) that the north western section of the region, especially the Tararua Ranges, experiences a high number of thunderstorms days per year along with part of Upper Hutt, Porirua and to an extent Kelburn, Wellington. The eastern section including Masterton, Carterton, and South Wairarapa, except the areas close to the Tararaua Range, have less thunder days. Lower Hutt has the minimum number of thunder days in the region. The Climate Summary Reports from 2000 to June, 2008 show that the region had four thunderstorms in eight years, three of which resulted in flooding that affected housing, roads and farms. A thunderstorm in Porirua in 2003 affected six

Map: 5.11. Average Annual Thunder Days in the Wellington Region

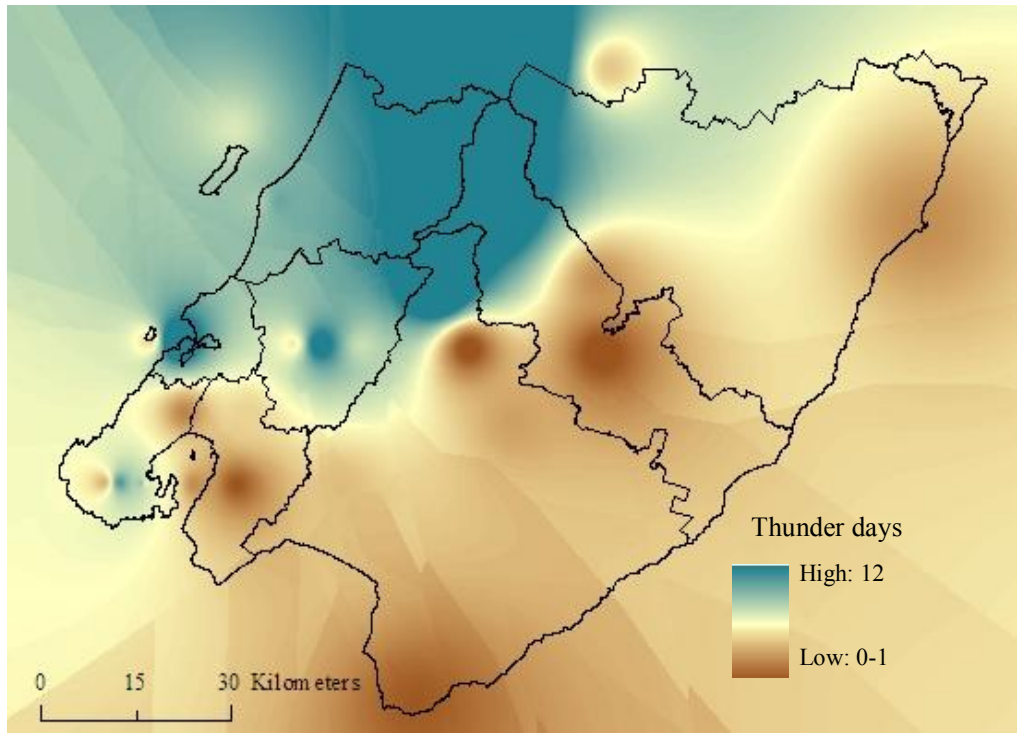

Source: WELA \& Wellington Regional Council, 2007.

households, when the houses were damaged by falling trees during storms (Personal Communication with Civil Defense Officer, Porirua, 2007).

The region is also affected by frequent rainstorms. Heavy rain in the region is brought by both easterly and westerly storms (WELA, 2003, 29). Though there is no consistency in data about the number of rainstorms hitting the region, data from various sources indicate that the number of storms hitting the region is very high. The Climate Summary Reports (2000-2008) show that the region experienced about twenty four incidents of heavy rain, of which four were associated with thunderstorms and three with windstorms, frontal systems and lightning. Out of 24 incidents, 21 resulted in flooding and landslides. Damage included flooding in houses, shops and on roads, breached banks, mudslides, slips and traffic disruptions. In four cases 526 people were evacuated for safety reasons.

Data from the EQC (2002-2006) include flooding incidents due to storms. In combination with the data on landslide claims paid by the EQC for the same time period, this provides an estimate of damage due to storms in the region. The data show that the region experienced about 39 storms in four years which produced claims of $6,774,000$ NZD due to flooding and about 13,069,000 NZD due to landslides. These figures however, do not depict the true reflection of damage because many claims were not paid by EQC and many damages may not have been filed for claim because the EQC does not pay for all damage types to all sectors. The number of claims shows that about 1030 people were affected by flooding and another 1279 people were affected by landslides during the storm months (Table: 5.30). Wellington was affected most frequently as flood claims were made in 82 percent and landslide claims in 97 percent of storm incidents. Flooding and 
landslide incidents were also higher in Lower Hutt and Porirua. The data show that three eastern districts including South Wairarapa, Masterton and Carterton made minimum claims for damage for both flooding and landslides.

However, a few storms proved more damaging and a few months experienced more storms, which enhanced the damage. The Wellington Region experienced about three storms in February 2004, which caused extensive flooding in all districts. In Lower Hutt about 1500 people were evacuated because of flooding which caused extensive damage to houses, businesses, roads etc (Personal communication with Civil Defence Officer, Lower Hutt, 2007). About 783 people made

Table: 5.30. Damage Claims Due to Rainstorms in the Wellington Region (2002-2006)

\begin{tabular}{|c|c|c|c|c|c|c|c|c|c|c|c|c|c|c|c|c|c|c|c|c|c|}
\hline \multirow[b]{3}{*}{ ear } & \multirow[b]{3}{*}{ 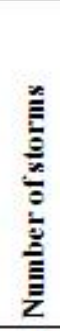 } & \multicolumn{10}{|c|}{ Flood } & \multicolumn{10}{|c|}{ Landside } \\
\hline & & \multicolumn{10}{|c|}{ Area affected } & \multirow[b]{2}{*}{ 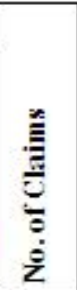 } & \multirow[b]{2}{*}{ 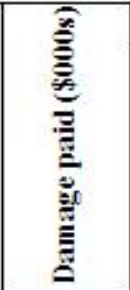 } & \multicolumn{8}{|c|}{ Area affected } \\
\hline & & 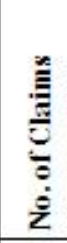 & 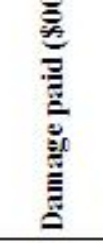 & 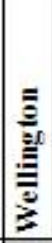 & 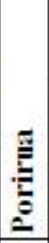 & 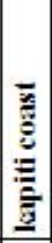 & 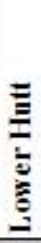 & 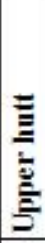 & 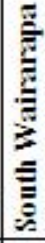 & 类 & 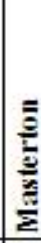 & & & 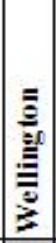 & 产 & 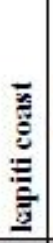 & 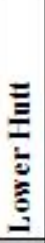 & 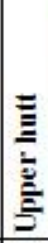 & 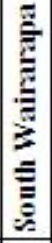 & 产 & 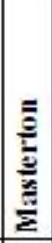 \\
\hline Jul, 2002 & 1 & 2 & 1.8 & & & & & & & & & 34 & 103.9 & & & & & & & & \\
\hline Aug, 2002 & 1 & 2 & 7.8 & & & & & & & & & 22 & 51.6 & & & & & & & & \\
\hline Sep, 2002 & 1 & 1 & 1.9 & & & & & & & & & 11 & 18.6 & & & & & & & & \\
\hline Nov, 2002 & 1 & 1 & 1.4 & & & & & & & & & 4 & 6.3 & & & & & & & & \\
\hline Dec, 2002 & 1 & 1 & 0 & & & & & & & & & 10 & 48.6 & & & & & & & & \\
\hline Apr, 2003 & 1 & 1 & 0 & & & & & & & & & 1 & 0 & & & & & & & & 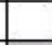 \\
\hline Jun, 2003 & 1 & 11 & 14.1 & & & & & & & & & 25 & 130.3 & & & & & & & & \\
\hline Jul, 2003 & 1 & 2 & 1.5 & & & & & & & & & 14 & 158.2 & & & & & & & & \\
\hline Sep, 2003 & 1 & 1 & 0 & & & & & & & & & 21 & 117.7 & & & & & & & & \\
\hline Oct, 2003 & 1 & 23 & 86.4 & & & & & & & & & 119 & 780.7 & & & & & & & & \\
\hline $\operatorname{Jan}, 2004$ & 1 & 4 & 6.6 & & & & & & & & & 14 & 41.5 & & & & & & & & \\
\hline Feb, 2004 & 3 & 783 & 5858 & & & & & & & & & 38 & 384.8 & & & & & & & & \\
\hline Mar, 2004 & 1 & 7 & 264.6 & & & & & & & & & 11 & 77.8 & & & & & & & & \\
\hline Apr, 2004 & 1 & 1 & 0 & & & & & & & & & 5 & 37.8 & & & & & & & & \\
\hline Jul, 2004 & 1 & 4 & 4.7 & & & & & & & & & 62 & 630.6 & & & & & & & & \\
\hline Aug, 2004 & 1 & 10 & 1.6 & & & & & & & & & 272 & 2,767 & & & & & & & & \\
\hline Sep, 2004 & 1 & 6 & 8. & & & & & & & & & 34 & 185.1 & & & & & & & & \\
\hline Oct, 2004 & 1 & 2 & 2.8 & & & & & & & & & 10 & 97.9 & & & & & & & & \\
\hline Nov, 2004 & 1 & 2 & 18.3 & & & & & & & & & 7 & 114.7 & & & & & & & & \\
\hline Dec, 2004 & 1 & 4 & 7.8 & & & & & & & & & 6 & 44.6 & & & & & & & & 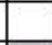 \\
\hline $\operatorname{Jan}, 2005$ & 1 & 49 & 125.9 & & & & & & & & & 50 & 232 & & & & & & & & \\
\hline Feb, 2005 & 1 & 1 & 0 & & & & & & & & & 2 & 18.9 & & & & & & & & \\
\hline Mar, 2005 & 1 & 22 & 82.4 & & & & & & & & & 28 & 222.1 & & & & & & & & \\
\hline Apr, 2005 & 1 & 8 & 13.6 & & & & & & & & & 6 & 14.1 & & & & & & & & \\
\hline May, 2005 & 1 & 2 & 0.7 & & & & & & & & & 10 & 141.6 & & & & & & & & \\
\hline Jul, 2005 & 1 & 3 & 3. & & & & & & & & & 19 & 192.3 & & & & & & & & \\
\hline Aug, 2005 & 1 & 1 & 21.4 & & & & & & & & & 7 & 51.9 & & & & & & & & \\
\hline Sep, 2005 & 1 & 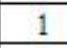 & 7.4 & & & & & & & & & 3 & 7.5 & & & & & & & & \\
\hline Oct, 2005 & 1 & 2 & 1.8 & & & & & & & & & 3 & 13.5 & & & & & & & & \\
\hline Nov, 2005 & 1 & 1 & 0 & & & & & & & & & 2 & 0.8 & & & & & & & & \\
\hline Mar, 2006 & 1 & 7 & 1.2 & & & & & & & & & 6 & 0 & & & & & & & & \\
\hline Jul, 2006 & 1 & 2 & 66 & & & & & & & & & 140 & 899.90 & & & & & & & & \\
\hline Aug, 2006 & 1 & 15 & 10 & & & & & & & & & 171 & $3,583.20$ & & & & & & & & \\
\hline Sep, 2006 & 1 & 5 & 9.2 & & & & & & & & & 21 & 108.3 & & & & & & & & \\
\hline Oct, 2006 & 1 & 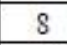 & 16 & & & & & & & & & 30 & 346.6 & & & & & & & & \\
\hline 2006 & 1 & 10 & 19.4 & & & & & & & & & 55 & 421.6 & & & & & & & & \\
\hline Dec, 2006 & 1 & 2 & 12 & & & & & & & & & 6 & 17 & & & & & & & & \\
\hline Total & 39 & 103 & 6774 & 30 & 17 & 11 & & 10 & 5 & 3 & & 127 & 13,069 & 36 & 23 & 8 & & 13 & 4 & 3 & 9 \\
\hline
\end{tabular}

Based on data from EQC, 2007 
damage claims and the Commission paid claims of 5,858,000 NZD. Landslide claims were made from Wellington, Porirua, Lower Hutt and Upper Hutt, but they were not as widespread as flooding. In terms of landslides, the most damaging storms were October 2003 (claims-119; damage-780,700 NZD), August 2004 (claims-272; damage- 2,767,000 NZD), July 2006 (claims-140; damage-1,899, 900 NZD) and August 2006 (claims-171; damage-3, 583, 200 NZD) storms.

The data show that most of the damaging storms often involved either the presence of two depressions or the convergence of two moist air streams. For example, the December 1976 storm involved the convergence of two moist streams, one from the north and the other from the south over the Hutt Valley and resulted in extensive flooding, about 900 landslides in the area and an estimated damage cost of 20million NZD (Poole, 1983, 104). Similarly, the storm on October 2003 in Paekakariki involved the convergence of a northeasterly and a northwesterly front. The storm caused extensive flooding in Paekakariki, in which 30 families were affected and 12 houses were damaged along with hotels, shops and other infrastructure (Personal communication with Civil Defence Officer, the Kapiti Coast, 2007). The January 2005 storm involved the convergence of a northwesterly with a southwesterly flow and caused both flooding and landslides in the region (Watts, 2003, 1-2; Watts, 2005, 1). Similarly, the storm of July 2006 involved two lows, which were activated one after the other and caused massive damage (Watts \& Gordon, 2006, 1). Thus convergence of two storms has proved more damaging for the region, and the western districts have higher susceptibility for such conditions compared to the east.

\subsubsection{Bushfires}

Bushfire is another hazard, which is closely related to meteorological conditions such as low rainfall, high temperature, lightning and solar radiation. Though bushfires have been identified as significant hazard in the region (Wellington Regional Council [WRC], 1998, 27) the damage data from bushfires are not readily available. The region experiences frequent bushfires due to thunderstorm, lightning or extremely dry conditions associated with high temperatures especially from November to March (Grant, 2005(b), 51).

Over the ten year period from July 1995 to June 2005, about 1544 bushfire incidents occurred in the region affecting 1460 hectares of land (Grant, 2005(b), 51). Fig: 5.12 shows that the region has experienced between 50 to more than 200 bushfires each year since 1995 to 2005. Large numbers of fire incidents in 1997-98, 2000-01 and 2002-03 have been attributed to hot and dry summers (Grant 2005 b, 51). The

Fig: 5.12. Area Affected by Bushfire in the Wellington Region (1995-2005)

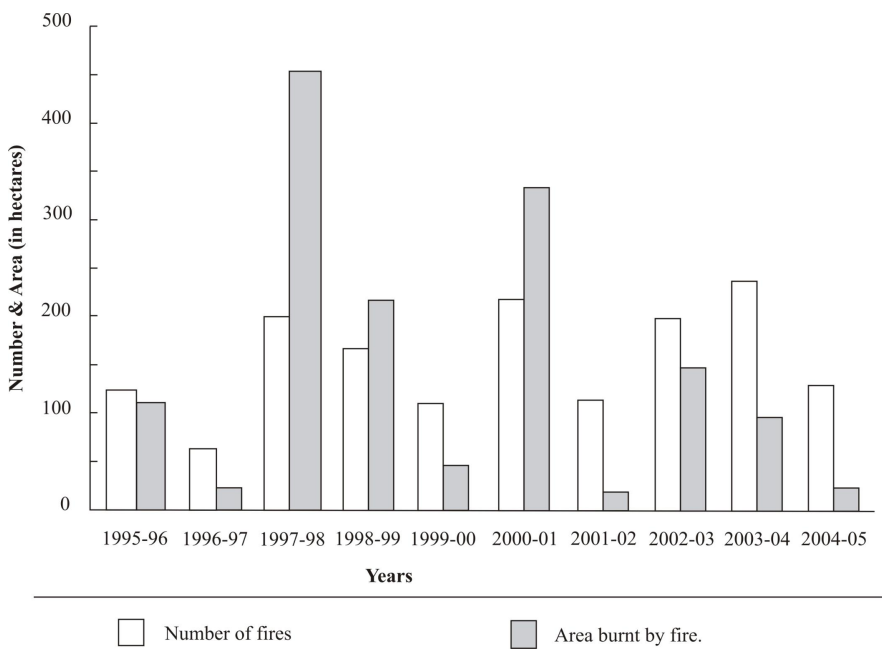

Source: National Rural Fire Authority as cited in Grant, 2005b, 52. 
areas affected by wildfire have varied significantly compared to the number of fires. On a yearly basis, the area affected by bushfire has varied from just more than 20 ha to about 450 ha depending on the season and the location of the bushfires. In recent years an increasing number of fires were cases of arson. In January 2001

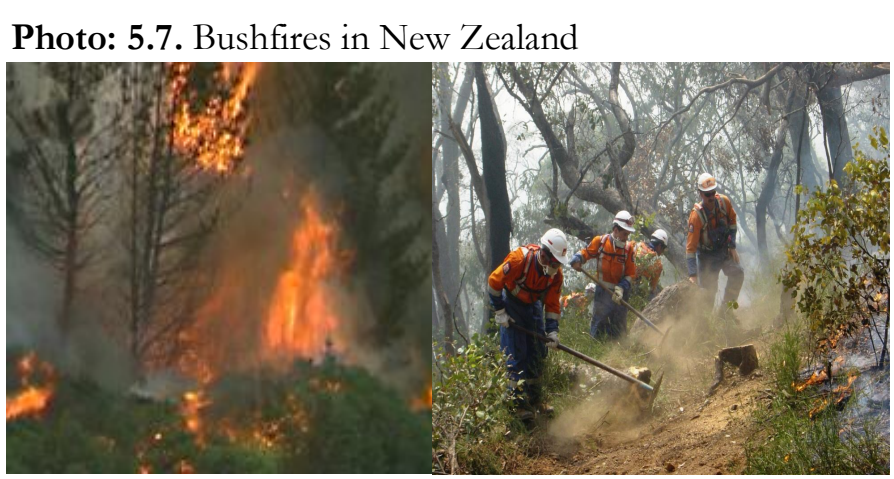

Source: Rural Fire Authority, 2008.

three out of four fires were noted to be caused by arson (Tait, et. al, 2002, 117).

The distribution of bushfires across the region shows that the maximum number of wildfires has been experienced in Masterton, Porirua and South Wairarapa (Fig: 5.13). The maximum area was affected in Wellington followed by South Wairarapa, the Kapiti Coast, Porirua and Lower Hutt. While the cause in urban areas is often related to arson, in rural Wairarapa, the reason is linked to land under shrubs and dry climatic conditions. Both Upper Hutt and Carterton experienced the minimum number of bushfires, which could be

Fig: 5.13. Area Affected by Bushfire in Local Territorial Authorities of the Wellington Region (1995-2005)

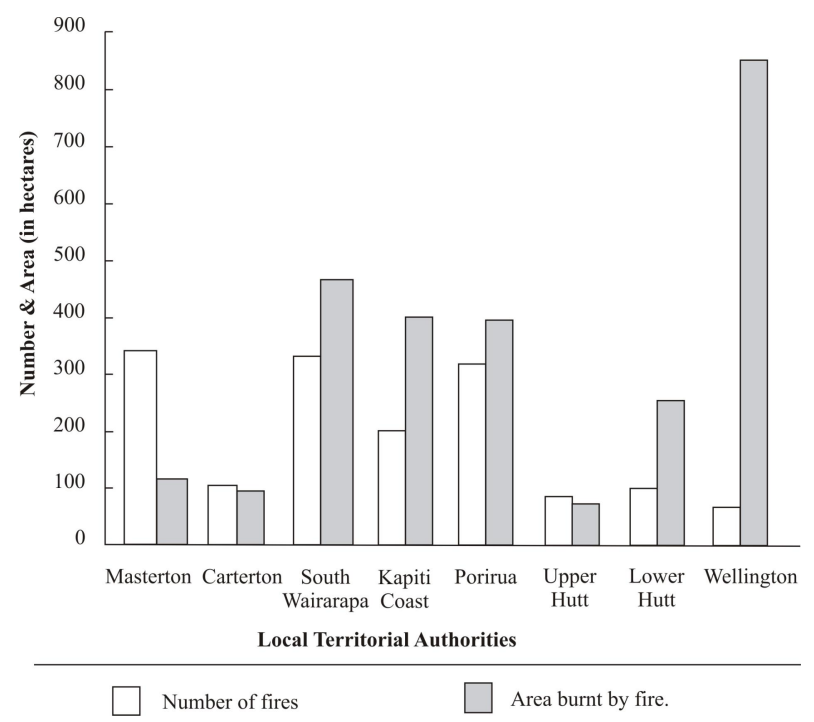

Source: National Rural Fire Authority as cited in Grant, 2005b, 52. attributed to high rainfall in the former, and land use under pasture in the latter case.

\subsection{Hydrological Hazards}

The most frequent hydrological hazards of the region are flood and drought. Though they are mainly triggered by meteorological processes, human activities play a significant role in converting them into hazards.

\subsubsection{Flooding}

The region is dissected by numerous rivers and streams, which often flood during heavy rain or storms. However, flooding in some rivers proves more hazardous than others due to their specific location and nearby settlements. The rivers that frequently result in flood damage in the region are the Hutt, Wainuiomata, Otaki, Waikanae and Ruamahanga rivers. 
Flooding is one of the longest experienced hazards in the region. The floodplain which was the first to become densely populated is that of the Hutt River. Early settlers in the region occupied this area for its characteristics such as flat land, availability of fresh water and communication viability through the harbour. However, they suffered significant damage due to frequent floods in the area. Consequently, many of the settlers migrated to either Wellington or to higher ground to avoid flooding (McConchie, 2000b, 48). The records of flooding of the Hutt River from 1840 to 1990 show that the river caused about 141 flood incidents in 151 years. The number of floods could be even higher as it very likely that many of the small flood incidents before 1930 may not have been recorded (Easther, 1991, 151). However, these records suggest that during this period the Hutt River flooded almost every second year. The data show that in 29 percent of flood incidents the river rose five feet or more above its normal level, and in ten percent of incidents the river level was ten feet above its normal level. The maximum rise was about 17 feet above normal level at Lower Hutt on 3 April 1931. The observed (and in few cases estimated) river flows in the recorded flood incidents show that the river flow crossed 1000cumecs about 28 times in 151 years. Since these details are not available for all floods it is hard to plot them in order to assess trends. The type of damage mentioned in these floods include water and mud in houses, farms, gardens, damage to river banks and bridges, loss of livestock, injuries and several deaths. About nine people lost their lives in the flood of 1858 and two old men and a child lost their lives in the flood of 1878 and 1880 respectively. Migration was also observed in the initial floods but not reported afterwards. Logs and timber in the river was also one of the major problems during the $19^{\text {th }}$ century floods but such incidents were not reported later. Similarly livestock loss was more frequent in the $19^{\text {th }}$ Century. Thus a change could be witnessed in the nature of damage due to flooding in the Hutt Valley, which is associated with the urbanisation of the valley floor. The most damaging flood incidents of

Table: 5.31. Flood Damages in the Wellington Region (1840-1990)

\begin{tabular}{|c|c|c|c|c|c|}
\hline Year & River/Lake & $\begin{array}{c}\text { River } \\
\text { discharge }\end{array}$ & $\begin{array}{l}\text { Maximum river } \\
\text { flow/height }\end{array}$ & $\begin{array}{c}\text { Area } \\
\text { Affected }\end{array}$ & Damage \\
\hline Winter 1849 & Hutt & $\sim 1000 \mathrm{~m} 3 / \mathrm{s}$ & - & Hutt Valley & 180 Sheep lost. \\
\hline Winter 1855 & Hutt & $\sim 1500 \mathrm{~m} 3 / \mathrm{s}$ & 2 feet & Hutt Valley & $\begin{array}{l}300 \text { sheep lost; destroyed Hutt bridge and } \\
\text { large areas of crops. }\end{array}$ \\
\hline Jan, 1858 & Hutt & $\sim 2000 \mathrm{~m} 3 / \mathrm{s}$ & - & Hutt Valley & $\begin{array}{l}9 \text { people lost their life in Taita; heavy stock } \\
\text { and crop loss. }\end{array}$ \\
\hline 1878 & Hutt & $\sim 1500 \mathrm{~m} 3 / \mathrm{s}$ & - & Hutt Valley & $\begin{array}{l}2 \text { old men died; flood swept the valley } \\
\text { from side to side. }\end{array}$ \\
\hline Mar, 1880 & Hutt & $\sim 900 \mathrm{~m} 3 / \mathrm{s}$ & - & Hutt Valley & $\begin{array}{l}1 \text { child swept to his death and farmland } \\
\text { flooded. }\end{array}$ \\
\hline 1893 & Hutt & $\sim 2000 \mathrm{~m} 3 / \mathrm{s}$ & - & Hutt Valley & River bank burst and stock loss. \\
\hline Apr, 3, 1931 & Hutt & $\sim 1400 \mathrm{~m} 3 / \mathrm{s}$ & 17 feet & Hutt Valley & $\begin{array}{l}\text { The Manor Park Bridge and Haywarc } \\
\text { suspension bridge were swept away. }\end{array}$ \\
\hline 1939 & Hutt & $\sim 1600 \mathrm{~m} 3 / \mathrm{s}$ & 9 feet & Hutt Valley & $\begin{array}{l}\text { Isolated Houses, blocked roads, damaged } \\
\text { bridge and large number of stocks } \\
\text { drowned. }\end{array}$ \\
\hline 1947 & Ruamahanga & $\sim 2044 \mathrm{~m} 3 / \mathrm{s}$ & $\begin{array}{c}11^{\prime} 6 " \text { in Lake } \\
\text { Wairarapa }\end{array}$ & $\begin{array}{l}\text { Lower } \\
\text { Wairarapa } \\
\text { Valley }\end{array}$ & $\begin{array}{l}5000 \text { sheep and } 300 \text { cattle lost their lives } \\
10,000 \text { acres of farmland inundated; stop } \\
\text { banks were burst along with infrastructure } \\
\text { loss. }\end{array}$ \\
\hline Feb, 1955 & Hutt & $\sim 1250 \mathrm{~m} 3 / \mathrm{s}$ & $\sim 45000 \mathrm{~m} 3 / \mathrm{s}$ & Upper Hutt & 17 houses flooded. \\
\hline Jan, 1962 & Hutt & $\sim 1280 \mathrm{~m} 3 / \mathrm{s}$ & $\sim 47000 \mathrm{~m} 3 / \mathrm{s}$ & Upper Hutt & $\begin{array}{l}3 \text { houses and a shop flooded in Upper } \\
\text { Hutt. }\end{array}$ \\
\hline
\end{tabular}

Based on Easther, 1991, McConchie, 2000, 49, WELA, 2003, 47 
the Hutt River occurred in 1849, 1855, 1858, 1878, 1880, 1893, 1898, 1931, 1939, 1955 and 1962 which shows that the damage from flood was more frequent in the $19^{\text {th }}$ century than in the $20^{\text {th }}$ century (Table: 5.31). This could be attributed to the development and placement of stopbank protection against flooding, which although decreased the loss of livelihood, it increased the monetary cost involved in protecting the areas.

In recent years (1995-2005), the Hutt River flooded in October 1997, October 1998, October 2000, October, 2003, February, 2004, August, 2004 and January, 2005. The most severe incident occurred in January 2005, which had a return period of 25 years. There was severe damage to the flood protection work on the river, which cost more than 591,500 NZD. During the flood about 10 properties were affected in Lower Hutt and four homes were evacuated in Upper Hutt (Grant, 2005b, 21). The major damage due to flooding in the Valley was caused by a flood in October 1997, having a return period of 3-10 years. The damage to flood protection work due to this incident was 789,500 NZD. Two deaths, severe erosion of river banks at Manor Park and evacuation of a house in Upper Hutt were reported (Grant, 2005b, 20).

Flooding in Wainuiomata also caused serious damage in Lower Hutt. In recent years the river flooded in October 1997, October 2000, June and October 2003, February and August 2004 and March 2005. The flood in February 2004 had a return period of 30 years. It blocked roads and two houses were evacuated in Wainuiomata.

In the eastern section, the Ruamahanga River is the main source of flood damage, especially in South Wairarapa. However, data about the flood incidents in this river are not consistent. The most damaging event was in 1947, which flooded the Lower Wairarapa Valley. Stop banks of the River along with that of Lake Wairarapa were overwhelmed by the water level, which reached more than 11.6 feet above normal level. Areas including Pukio Basin and Kahutara were inundated, and people had to be rescued. A few houses were isolated due to water and were supplied with food by aeroplane. A large number of stock (about 5000 sheep and 300 cattle) was lost, causing a major loss to the rural economy of the region (WELA, 2003, 47). In recent years, the river flooded in April 1991, October 1998, February 2004 and March 2005. The flood on April 1991 is also called Tinui flood. During the flood, houses, shops, a church and a local hotel were inundated and communication system disrupted for 12 hours. The incident also led to widespread road damage (WELA, 2003, 49). The highest flood was that of February 2004 when the river flow reached 1900 $\mathrm{m}^{3} / \mathrm{sec}$. The return period of this event was 50 years, and it resulted in extensive damage in the region, though details are not available. In July 2006 flooding in Ruamahanga affected all three districts. About 80 people in South Wairarapa and 19 families in Carterton were directly affected. In addition, many families were evacuated, and the damage involved sewage contamination along with housing and road damage (Personal communication with Civil Defence Officers of South Wairarapa, Carterton and Masterton, 2007).

In the Kapiti Coast district flood damage is often caused by the Otaki and Waikanae Rivers. In Otaki River, damaging floods occurred in 1854, 1904, 1906, 1920, 1925, 1926, 1931, 1936 and 1940 (Wellington Regional Council, 1998, 12). Since damage details are not available, it is difficult to compare the loss over time and across the region. In Waikanae River, the most damaging incidents occurred in 1924 that washed away the local crematory and in February 1955, flooding 
damaged the houses located on its floodplain (Wellington Regional Council, 1997, 13-14). Both Otaki and Waikanae Rivers often flood due to the same storm. Recent floods in the region from 1995 to 2005 from Grant (2005b) show that both rivers flooded due to storms about five times that include October 1997, October 1998, October 2000, February 2004 and January 2005 storms. In October 1998 on $20^{\text {th }}-21^{\text {st }}$ and $28^{\text {th }}$ of October, a civil defence emergency was declared due to high flood water levels. On the $20^{\text {th }}-21^{\text {st }}$ of October about 13 homes were evacuated in Waikanae and houses and schools were flooded in Otaki. Houses were also evacuated in Paramparamau and Paekakariki because of water and sewerage problems. On the $28^{\text {th }}$ of October 40 people were evacuated from Waikanae and State Highway-1 was closed as a bridge was washed out in Otaki. One person died in Waikanae River while assessing his property on the river bank (Grant, 2005b, 20).

Data about recent flood occurrences are scattered. The EQC records about 39 storm incidents from 2002 to 2006, which caused river flooding in the region. In these 39 incidents more than a thousand people made claims in which about 572 people were paid a total sum of $6,774,174$ NZD. Table 5.32 shows that the region experienced 5 to 12 floods every year, with an average of about eight floods per year. However, not all floods are damaging, which is clear in the fluctuations in the number of claims made each year. The data reveal that the maximum number of claims was made in 2004, when 824 people made claims. About 57 percent of claimants were paid by the EQC. The damage in this flood accounted for 91 percent of the total damage paid by the Commission over five years.

Table: 5.32. Flood Damages in the Wellington Region (2002-2006)

\begin{tabular}{cccccc}
\hline Year & $\begin{array}{c}\text { Number of } \\
\text { floods }\end{array}$ & $\begin{array}{c}\text { Total } \\
\text { claims } \\
\text { made }\end{array}$ & $\begin{array}{c}\text { Percentage of } \\
\text { claims paid }\end{array}$ & Total damage paid & $\begin{array}{c}\text { Percentage of Total } \\
\text { Damage }\end{array}$ \\
\hline 2002 & 5 & 7 & 57 & 12890.5 & 0.2 \\
2003 & 5 & 38 & 45 & 102021.62 & 1.5 \\
2004 & 12 & 824 & 57 & 6172881.82 & 31.1 \\
2005 & 10 & 90 & 52 & 256749.66 & 3.8 \\
2006 & 7 & 71 & 51 & 229629.99 & 100.0 \\
Total & 39 & 1030 & 56 & 6774173.59 & 100.0 \\
\hline
\end{tabular}

Based on data from Earthquake Commission, 2007

A further classification of the damage claims made across the region shows that in 77 percent of total floods, the number of damage claims was ten or less (Table: 5.33). Only in one flood incident the number of claims was more than 100, which was the February flood of 2004. In this flood 741 claims were made from all eight district councils and 427 claims were paid by the EQC. This flood accounted for 86 percent of total claims paid by the EQC over five years.

Table: 5.33. Flood Damage Claims Made to the EQC in the Wellington Region (2002-2006)

\begin{tabular}{lccccc}
\hline $\begin{array}{l}\text { Total claims } \\
\text { made }\end{array}$ & $\begin{array}{c}\text { Number of } \\
\text { floods }\end{array}$ & $\begin{array}{c}\text { Number of } \\
\text { floods }\end{array}$ & $\begin{array}{c}\text { Average number of } \\
\text { district affected }\end{array}$ & $\begin{array}{c}\text { Total damage } \\
\text { paid (NZD) }\end{array}$ & $\begin{array}{c}\text { Percent of } \\
\text { damage paid }\end{array}$ \\
\hline 10 and less & 30 & 77 & 2 & $435,922.21$ & 6 \\
11 - 100 & 8 & 21 & 5 & $542,729.36$ & 8 \\
101 and above & 1 & 3 & 8 & $5,795,522$ & 86 \\
Total & 39 & 100 & 8 & $6,774,173.6$ & 100 \\
\hline
\end{tabular}


The data show that the total cost paid by the EQC per flood varied from none to more than one million dollars. For most floods the EQC paid between 1000 NZD to 10000 NZD, however, for a single flood in February 2004, it paid >1 million NZD (Table: 5.34). The EQC paid about 5,795,522 NZD in total including 51,401 NZD for contents, 2,642,805 NZD for dwellings and 3,001,316 NZD for land damage.

Table: 5.34. Money Paid by the EQC for Flood Damages in the Wellington Region (2002-2006)

\begin{tabular}{|c|c|c|c|c|c|c|c|}
\hline $\begin{array}{l}\text { Total Damage } \\
\text { paid by EQC } \\
(\mathrm{NZD})\end{array}$ & $\begin{array}{l}\text { Number } \\
\text { of floods }\end{array}$ & $\begin{array}{c}\text { Average } \\
\text { number of } \\
\text { district } \\
\text { affected }\end{array}$ & $\begin{array}{c}\text { Total } \\
\text { number of } \\
\text { claims made }\end{array}$ & $\begin{array}{l}\text { Percent of } \\
\text { claims made }\end{array}$ & $\begin{array}{l}\text { Percent of } \\
\text { claims paid }\end{array}$ & $\begin{array}{c}\text { Total damage } \\
\text { paid }\end{array}$ & $\begin{array}{c}\text { Percent of } \\
\text { damage } \\
\text { paid }\end{array}$ \\
\hline None & 6 & 1 & 6 & 1 & 0 & 0 & 0 \\
\hline less than 1000 & 1 & 2 & 2 & 0 & 0 & 700.75 & 0 \\
\hline $1001-10,000$ & 16 & 2 & 57 & 6 & 4 & 69922.11 & 1 \\
\hline $10,001-100,000$ & 12 & 4 & 153 & 15 & 13 & 412493.84 & 6 \\
\hline $100,001-1000,000$ & 3 & 4 & 71 & 7 & 8 & 495534.87 & 7 \\
\hline 1000,001 and above & 1 & 8 & 741 & 72 & 75 & 5795522.00 & 86 \\
\hline Total & 39 & 8 & 1030 & 100 & 100 & 6774173.60 & 100 \\
\hline
\end{tabular}

Based on data from Earthquake Commission, 2007

The spatial distribution of floods across the region shows that Wellington was affected more than any other district (Map: 5.12 \& Table: 5.35). However, the nature of flooding in the district was not due to any stream or river (as most of them have been blocked or built up), but due to the inability of the drainage system to cope with heavy water flow (Photo: 5.8). The second most affected district was Lower Hutt,
Map: 5.12. Flood Claim Made to the EQC in the Wellington Region (2002-2006)

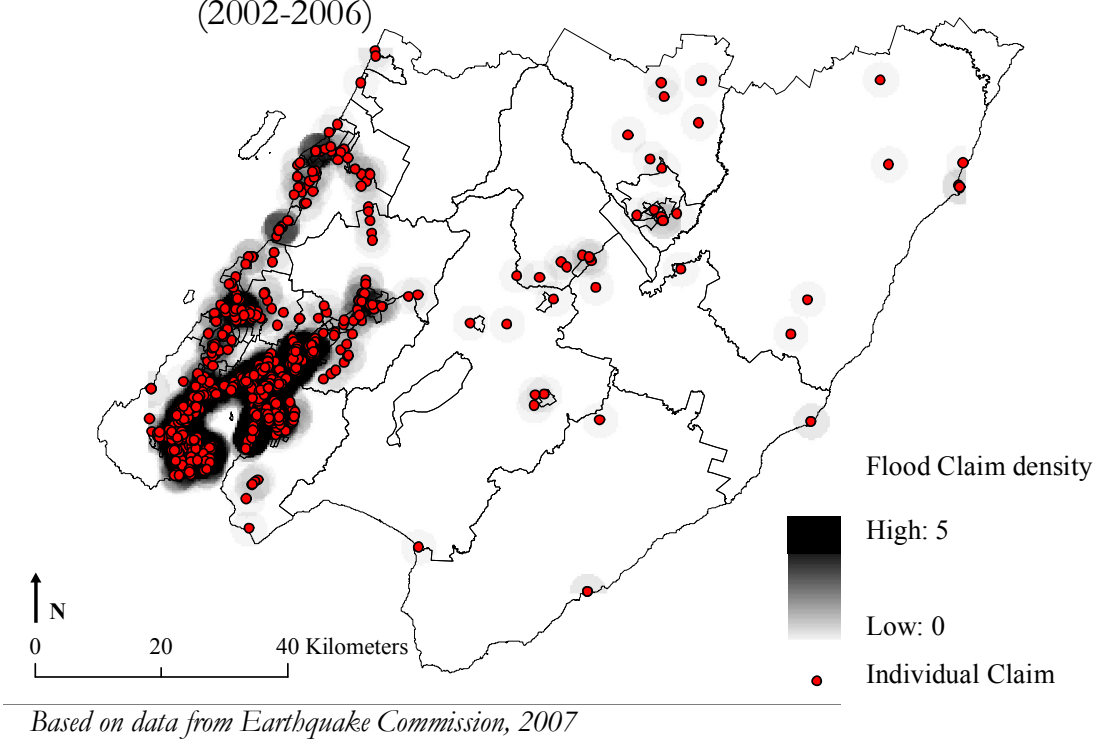

Table: 5.35. Claims Made to the EQC for Flood Damages in the Wellington Region (2002-2006)

\begin{tabular}{lccccc}
\hline $\begin{array}{l}\text { Local Territorial } \\
\text { Authorities }\end{array}$ & $\begin{array}{c}\text { Number of times } \\
\text { area affected }\end{array}$ & $\begin{array}{c}\text { Percent times } \\
\text { area affected }\end{array}$ & $\begin{array}{c}\text { Number of } \\
\text { Claims }\end{array}$ & $\begin{array}{c}\text { Percentage of } \\
\text { claims }\end{array}$ & $\begin{array}{c}\text { Percentage of } \\
\text { claims paid }\end{array}$ \\
\hline Wellington City & 32 & 82 & 311 & 30.2 & 59 \\
Lower Hutt City & 23 & 59 & 445 & 43.2 & 60 \\
Porirua City & 18 & 46 & 82 & 8.0 & 52 \\
Kapiti Coast & 13 & 33 & 69 & 6.7 & 52 \\
Upper Hutt City & 12 & 31 & 79 & 7.7 & 33 \\
Masterton & 7 & 18 & 24 & 2.3 & 38 \\
South Wairarapa & 5 & 13 & 11 & 1.1 & 55 \\
Carterton & 4 & 10 & 9 & 0.9 & 22 \\
Total & $\mathbf{3 9}$ & $\mathbf{1 0 0}$ & $\mathbf{1 0 3 0}$ & $\mathbf{1 0 0}$ & $\mathbf{5 6}$ \\
\hline
\end{tabular}

Based on data from Earthquake Commission, 2007 
where frequent flooding is often associated with flooding of the Hutt River. The damage and hence the number of claims tend to be higher in this district. Other urban areas of the region including Porirua, the Kapiti Coast, Upper Hutt and Masterton experienced damage (in order of severity from greatest to least). The minimum claims were made from Carterton and South Wairarapa. This is because the EQC does not pay for damage to crops. As a result, despite these areas having the major rivers, the claims are far less than western

Photo: 5.8. Flooding in Kilbernie, Wellington (November, 1994)

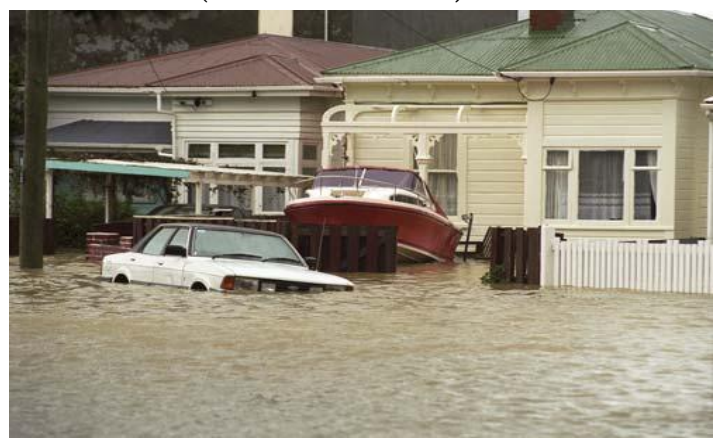

Source: Te Ara, 2008d. urban areas, where the number and size of rivers are small.

The damage distribution across the region shows that the maximum damage by floods was in Lower Hutt, which accounted for more than 62 percent of total damage paid by EQC followed by Wellington City with 22 percent of the total damage (Table: 5.36). EQC paid the maximum amount of money for land damage (55 percent) followed by damage to dwellings (42 percent) and the minimum for content loss (one percent). While land damage claims were high in Carterton, claims for dwelling damage formed the largest share in Lower Hutt and content damage claims in Wellington. The nature of flood damage varies across the region. While the rural eastern sections suffer damage to farms and the loss of livestock, in urban areas the damage is predominantly related to housing and shops along with disruption of main transport channels.

Table: 5.36. Money Paid by the EQC for Flood Damages in the Wellington Region (1996-2007)

\begin{tabular}{|c|c|c|c|c|c|}
\hline \multirow{2}{*}{$\begin{array}{l}\text { Local } \\
\text { Territorial } \\
\text { Authorities }\end{array}$} & \multirow{2}{*}{$\begin{array}{c}\text { Total money } \\
\text { paid (in NZD) }\end{array}$} & \multirow{2}{*}{$\begin{array}{l}\text { Percentage of } \\
\text { total money paid }\end{array}$} & \multicolumn{3}{|c|}{ Percentage share of damage paid } \\
\hline & & & Contents & Dwelling & Land \\
\hline Lower Hutt City & $4,214,450$ & 62.21 & 1 & 53 & 46 \\
\hline Wellington City & $1,502,266$ & 22.18 & 2 & 23 & 64 \\
\hline Porirua City & 435,659 & 6.43 & 0 & 32 & 67 \\
\hline Kapiti Coast & 312,793 & 4.62 & 0 & 16 & 84 \\
\hline Upper Hutt City & 224,790 & 3.32 & 0 & 18 & 82 \\
\hline Masterton & 43,817 & 0.65 & 0 & 2 & 98 \\
\hline South Wairarapa & 37,613 & 0.56 & 0 & 35 & 65 \\
\hline Carterton & 2,788 & 0.04 & 0 & 0 & 100 \\
\hline Total & $6,774,175$ & 100.00 & 1 & 42 & 55 \\
\hline
\end{tabular}

Based on data from Earthquake Commission, 2007

The claims paid by the EQC certainly do not represent the total damage from floods as the Commission does not cover all types of flood damage. Records show that at times, a major flood can cause damage worth tens of millions of dollars, for example, the damage from the 1979 storm through flooding and landslips was estimated to be 30million NZD (Salinger, 1998, 125-153). It destroyed many houses in Pinehaven, Stokes Valley, and Petone. Transport including road and rail was badly disrupted and damaged (Salinger, 1998, 125-153). One major impact of flood is that of damage to flood protection measures, which require consistent rebuilding and strengthening before and after flood events. Records of major floods from 1995-2005 by Metservice, show that in six flooding incidents, the region has suffered a total damage of about 4,936,000 NZD to flood 
protection measures. Maximum damage was experienced along the Hutt River, i.e. about 3,078,000 NZD, followed by Otaki (1,055,000 NZD) and then Waikanae River (519,000 NZD). Wellington watercourse suffered damage of about 225,000 NZD in two flood incidents (Table: 5.37). The table also suggests that it is not always the most extreme event, which causes significant damage. For example, the maximum damage to flood protection work along the Hutt River was not caused by an event of 25 years return period but by an event having a return period of 12 years. In fact the damage from an event of three to ten years of return period was greater than 25 years return period.

Table: 5.37. Flood Protection Works Damages from Flooding in the Wellington Region

\begin{tabular}{|c|c|c|c|c|c|c|c|}
\hline \multirow[t]{2}{*}{ Year } & \multirow[t]{2}{*}{ Date } & \multicolumn{6}{|c|}{ Flood protection work damage estimates in 1000 NZD (Return period of flood) } \\
\hline & & $\begin{array}{l}\text { Hutt } \\
\text { River }\end{array}$ & $\begin{array}{l}\text { Otaki } \\
\text { River }\end{array}$ & $\begin{array}{l}\text { Waikanae } \\
\text { River }\end{array}$ & $\begin{array}{c}\text { Waitohu } \\
\text { River }\end{array}$ & $\begin{array}{c}\text { Kapiti } \\
\text { Watercourse }\end{array}$ & $\begin{array}{c}\text { Wellington } \\
\text { Watercourse }\end{array}$ \\
\hline 1997 & 4 Oct & $790(3-10)$ & $75(1)$ & $10(3)$ & - & - & - \\
\hline 1998 & $20-21 \& 28$ Oct & $1376(12)$ & $442(10)$ & $156(28)$ & $25(14)$ & - & - \\
\hline 2000 & 2 Oct & $245(6-10)$ & $187(6)$ & $97(5)$ & $25(7)$ & - & - \\
\hline 2004 & 11-19 Feb & 75 (4) & $136(5)$ & - & - & 4.5 (?) & 210 (?) \\
\hline 2005 & 5-6 Jan & $592(25)$ & $215(10)$ & $256(80)$ & - & 4.5 (?) & 15 \\
\hline Total & & 3078 & 1055 & 519 & 50 & 9 & 225 \\
\hline
\end{tabular}

Based on Met Services, Greater Wellington Records as cited in Grant, 2005b, 20

The region also gets flash floods from smaller rainfall events that result in surface flooding. Surface flooding data (1996-2004) in Grant (2005b) show that the region has experienced about 56 flash floods in 46 small rainfall events. Out of these flash floods, Wellington experienced the maximum of 52 percent of the total flash floods, followed by the Kapiti Coast ( 22 percent), Lower Hutt (17 percent) and Wairarapa (nine percent). For six percent of flash floods the area was not specified and another six percent were experienced in the Tararua Ranges and Upper Hutt.

\subsubsection{Droughts}

Drought is the other hydrological hazard in the Wellington Region. The region has experienced many severe droughts in the past, but records of droughts are highly fragmented and inconsistent. Data retrieved from CliFlo, NIWA for 29 stations throughout the region, show that drought conditions (soil moisture deficit $=>130 \mathrm{~mm}$ ) at most stations did not last more than a month (Table: $5.38)$.

In only five percent of cases, drought extended for more than a month, and none of the stations had soil moisture deficits for more than two months. Drought conditions are mainly observed in December, January and February. Sixty three percent of total droughts were recorded in January followed by 33 percent in December and four percent in February. The data show that Wellington had maximum drought incidents followed by Carterton, Masterton, Lower Hutt and South Wairarapa. For the Upper Hutt stations, soil moisture deficits have not been provided in the dataset. However, this district gets the maximum rainfall in the region and is therefore less likely to experience severe drought conditions. Minimum droughts occurred in Porirua followed by the Kapiti Coast.

In terms of spatial coverage, the January 1988 drought affected the largest area in the region including the six districts of Wellington, Lower Hutt, the Kapiti Coast, South Wairarapa, Carterton 
and Masterton. This is followed by the 1987 and 1955 droughts, which affected five districts and the 1978 and 1954 droughts, which affected four districts across the region. Most droughts (56 percent) affected three districts or less.

Table: 5.38. Soil Moisture Deficits in the Wellington Region (1933-2000)

\begin{tabular}{|c|c|c|c|c|c|c|c|c|c|c|c|c|}
\hline \multirow[t]{2}{*}{ Year } & \multicolumn{3}{|c|}{ Month } & \multicolumn{9}{|c|}{$\begin{array}{l}\text { Local Territorial Authorities Affected } \\
\text { (Soil Moisture Deficit }>130 \mathrm{~mm} \text { ) }\end{array}$} \\
\hline & 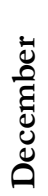 & & 苞 & 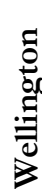 & 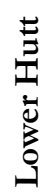 & 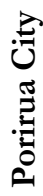 & 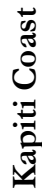 & 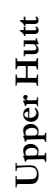 & 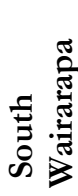 & & 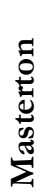 & Total \\
\hline 1933 & $\sqrt{ }$ & & & $\sqrt{ }$ & & & & & & & & 1 \\
\hline 1934 & $\sqrt{ }$ & & & $\sqrt{ }$ & $\sqrt{ }$ & $\sqrt{ }$ & & & & & & 3 \\
\hline 1946 & & & $\sqrt{ }$ & & & & & & & & $\sqrt{ }$ & 1 \\
\hline 1954 & & $\sqrt{ }$ & & $\sqrt{ }$ & & & & & $\sqrt{ }$ & $\sqrt{ }$ & $\sqrt{ }$ & 4 \\
\hline 1955 & & $\sqrt{ }$ & & $\sqrt{ }$ & $\sqrt{ }$ & & & & $\sqrt{ }$ & $\sqrt{ }$ & $\sqrt{ }$ & 5 \\
\hline 1957 & & $\sqrt{ }$ & & $\sqrt{ }$ & $\sqrt{ }$ & & & & & & $\sqrt{ }$ & 3 \\
\hline 1961 & $\sqrt{ }$ & & & $\sqrt{ }$ & $\sqrt{ }$ & & & & & & & 2 \\
\hline 1965 & & $\sqrt{ }$ & & $\sqrt{ }$ & & & & & & & & 1 \\
\hline 1970 & & $\sqrt{ }$ & & & & & & & $\sqrt{ }$ & $\sqrt{ }$ & $\sqrt{ }$ & 3 \\
\hline 1970 & $\sqrt{ }$ & & & $\sqrt{ }$ & & & & & & & & 1 \\
\hline 1973 & & $\sqrt{ }$ & & & & & & & $\sqrt{ }$ & $\sqrt{ }$ & $\sqrt{ }$ & 3 \\
\hline 1974 & & $\sqrt{ }$ & & $\sqrt{ }$ & $\sqrt{ }$ & & $\sqrt{ }$ & & & & & 3 \\
\hline 1974 & $\sqrt{ }$ & & & & & & & & $\sqrt{ }$ & & & 1 \\
\hline 1978 & & $\sqrt{ }$ & & & $\sqrt{ }$ & & & & $\sqrt{ }$ & $\sqrt{ }$ & $\sqrt{ }$ & 4 \\
\hline 1979 & & $\sqrt{ }$ & & $\sqrt{ }$ & $\sqrt{ }$ & & & & & $\sqrt{ }$ & & 3 \\
\hline 1982 & & $\sqrt{ }$ & & $\sqrt{ }$ & $\sqrt{ }$ & & & & & . & & 2 \\
\hline 1983 & & $\sqrt{ }$ & & $\sqrt{ }$ & $\sqrt{ }$ & & & & & $\sqrt{ }$ & & 3 \\
\hline 1985 & & $\sqrt{ }$ & & & & & & & & $\sqrt{ }$ & & 1 \\
\hline 1986 & $\sqrt{ }$ & & & & & & $\sqrt{ }$ & & & & & 1 \\
\hline 1987 & & $\sqrt{ }$ & & $\sqrt{ }$ & $\sqrt{ }$ & & & & $\sqrt{ }$ & $\sqrt{ }$ & $\sqrt{ }$ & 5 \\
\hline 1988 & & $\sqrt{ }$ & & $\sqrt{ }$ & $\sqrt{ }$ & & $\sqrt{ }$ & & $\sqrt{ }$ & $\sqrt{ }$ & $\sqrt{ }$ & 6 \\
\hline 1988 & $\sqrt{ }$ & & & & & & & & & $\sqrt{ }$ & $\sqrt{ }$ & 2 \\
\hline 1997-98 & $\sqrt{ }$ & $\sqrt{ }$ & & & & & & & & $\sqrt{ }$ & $\sqrt{ }$ & 2 \\
\hline Total & 8 & 15 & 1 & 14 & 11 & 1 & 3 & - & 8 & 12 & 11 & 60 \\
\hline
\end{tabular}

Based on data from CliFlo, 2007

The station that experienced the highest number of droughts was Baring Head in Lower Hutt, which experienced soil moisture deficit of $>130 \mathrm{~mm}$ in ten out of 55 years on records, i.e. one drought every 5.5 years. In Carterton at Wairarapa Cadet farm and Ngatapa in Wainuioru valley, drought occurred every 6.5 years and in Masterton at Ngaumu forest, the recurrence period of drought has been 6.57 years. In South Wairarapa at Martinborough station, drought was recorded in seven out of 48 years, which highlights a frequency of one drought in 6.86 years. The average of all stations in a district, however, hides the local extremes and portrays a different picture. It shows that the minimum mean return period of drought in the region has been recorded for Masterton, which experiences drought once in every five years. This is followed by Carterton, Wellington and Lower Hutt with return periods of 5-6 years. South Wairarapa faces drought once in every eight 
years. The maximum return period is for Porirua, which is once in 38 years followed by the Kapiti Coast with 18 years (Table: 5.39).

Table: 5.39. Mean Return Period of Droughts in the Wellington Region

\begin{tabular}{lcccc}
\hline $\begin{array}{l}\text { Local Territorial } \\
\text { Authorities }\end{array}$ & Years of Data & Number of Years & Years of Soil Moisture Deficit & Mean return period \\
\hline Masterton & $1948-2000$ & 53 & 11 & 4.81818 \\
Carterton & $1940-2001$ & 61 & 12 & 5.08333 \\
Wellington City & $1928-2000$ & 73 & 14 & 5.21429 \\
Lower Hutt City & $1940-2000$ & 61 & 11 & 5.54545 \\
South Wairarapa & $1940-2000$ & 61 & 8 & 7.625 \\
Kapiti Coast & $1948-2000$ & 53 & 3 & 17.6667 \\
Porirua City & $1931-1968$ & 38 & 1 & 38 \\
Upper Hutt City & - & - & - & - \\
\hline Based on data from CliFlo, 2007 & &
\end{tabular}

The drought frequency map (Map: 5.13) is not complete due to inadequate data, however, it highlights some significant variations in drought occurrence throughout the region. The map shows that drought frequency is not the same for all parts of the districts. Some areas face more droughts than others. While Lower Hutt is one of most drought affected districts, high frequency of droughts is restricted to the southern parts of Orongorongo and Rimutaka Range. It is lowest in the central parts of the district, where the

Map: 5.13. Drought Frequency in the Wellington Region

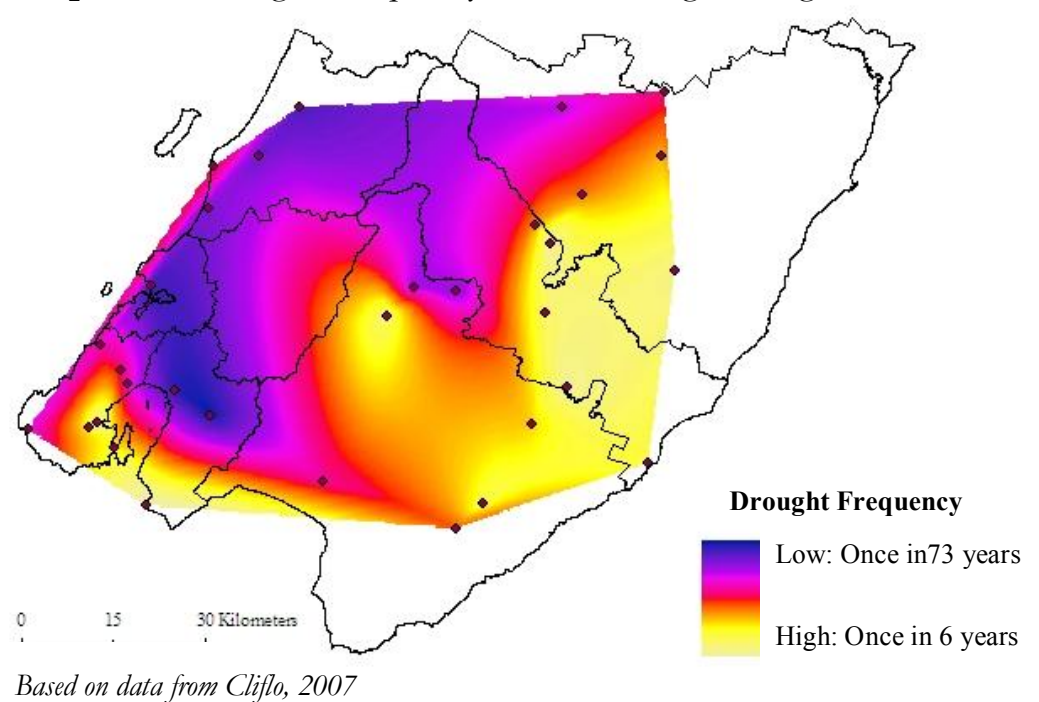
mean return period of droughts is among the lowest, that is, once in 73 years. Similarly, the eastern sections of Wellington, Carterton, Masterton and South Wairarapa, experience more frequent droughts than their western parts. The map for the Kapiti Coast is not complete, but the northern part of the district experiences relatively more frequent droughts than southern and western districts.

The literature on droughts in the region presents a rather more extreme picture (Table: 5.40). This could be partly due to different sources and stations of data coverage. Literature shows that the western parts of the region, including Wellington, Porirua, the Kapiti Coast and Hutt Valley faced droughts in 1934-1936, 1939, 1970, 1971-72, 1972-73, 1973, 1974-1975 and in 2001. These areas generally experience drought during La Niña years. The most severe drought in this part occurred in 2001, which was a La Niña year. The drought affected all five districts in this section. However, the intensity was much higher in Wellington and the Kapiti Coast, where the period of 
soil moisture deficit was extended over four and two months respectively. It resulted in water restrictions for garden and agricultural purposes. The impact of drought on farmers was severe. They lost crops and in some cases were forced to sell their stock. One farmer in Ohariu Valley in Wellington sold 300 stock and sent 1300 sheep to other parts of the North Island (Tait, et. al, 2002, 47). On Somes Island, more than 6000 new plants died. Drought also resulted in frequent bushfires due to less moisture and high temperatures. About 250 scrub fires occurred between October 2000 and February 2001 in the region. A high risk of bushfires also led to the closure of Somes Island for public use. In the Kapiti Coast, schools and swimming pools were closed in order to conserve water

Table: 5.40. Soil Moisture Deficits during Droughts in the Wellington Region (1934-2008)

\begin{tabular}{lcc}
\hline Year & Months & Area affected (Days of soil moisture deficit (>130mm)) \\
\hline $1934-1936$ & Nov-Feb & Kelburn, Wellington (60) \\
1939 & Feb-Apr & Kelburn, Wellington (45) \\
1943 & Jan-Apr & Masterton, Bagshot station (65) \\
1970 & Jan-Mar & Wallaceville (39), Paekakariki (31), Paraparaumu airport (46), Waikanae \\
1971 & Feb-Apr & waterworks (40) \\
$1971-1972$ & Dec-Mar & Maungaraki (21) \\
$1972-1973$ & Dec-Mar & Orongorongo station (36) \\
1973 & Jan-Mar & Wellington Airport (61), Maugaraki (24), Wallaceville (35), Masterton Bagshot \\
$1974-75$ & Dec-Mar & station (65), \\
1978 & Jan-Mar & Paramparaumu airport (73), Waikanae Waterworks (61), Masterton Bagshot \\
1982 & Jan-Mar & Station (69) \\
$1997-1998$ & Dec-Mar & East Taratahi (74), Wellington airport (67), Masterton Bagshot Station (68) \\
2001 & Jan-May & Kelburn (79), Wellington airport (122), Maungaraki (26), Wallaceville (47), \\
& & Paekakariki (22), Paramparumu airport (58), Waikanae Waterworks (22), \\
& & Orongorongo Station (53), Masterton, Bagshot station (23), East Taratahi (12) \\
$2002-2003$ & - & Wairarapa (?), Kapiti Coast (?) \\
$2007-2008$ & Dec-Mar & Wairarapa (?), Kapiti Coast (?) \\
\hline Based on Tait, et al, 2002, 49, Grant, 2005b \& NIWA Climate Centre, 2007, 2008
\end{tabular}

(Tait, et. al, 2002, 47). It was the most severe drought in Wellington City. The second most severe historic drought in Wellington occurred in 1934-1935, when soil moisture deficit was experienced for nearly two months. However, there is no record of its impacts. The city also experienced one and a half months of dry spells in 1939 and 1982.

Drought frequency reported in the literature shows that the Kapiti Coast is one of most drought prone area in the western districts. It not only experiences drought during La Nina events but also in El Nino periods, which mainly affect eastern Wairarapa districts. The district was severely affected by droughts in 1970, 1974-75, 1978, 2001, 2002-2003 and 2007-08. The most severe drought in the Kapiti Coast district occurred in 1978, when the period of soil moisture deficit $(>130 \mathrm{~mm})$ extended over nearly two and half months at Paramparaumu Airport and two months at Waikanae Waterworks station. Porirua is relatively less affected by the drought over the years, but this could also be due to very poor information availability about the district. Upper Hutt, the least drought prone area in the region was affected by drought in 1970, 1973, and 2001 and in all three cases the period of soil moisture deficit in the district extended over a month. However, information about drought impact is not available. 
Droughts in the eastern districts including South Wairarapa, Carterton and Masterton are more frequent, but records are incomplete because of the late establishment of rainfall recording stations. These districts generally experience drought during El Niño years, and few well known droughts in this section occurred in 1943, 1972-73, 1978, 1997-98, 2002-03 and 2007-08. Since a wide area in this section is rural and dominated by farming activities, impacts of drought are more severe. Farmers are often forced to sell their livestock due to water and food scarcity. The 1997-98 drought was one of the most severe droughts in this part. It was ranked as the driest period in the eastern hills since 1906 (WRC, 1998b, 48). This drought also affected parts of the western districts including Wellington airport, where soil moisture deficit extended for more than two months. The area most affected by this drought was the eastern and central Wairarapa, which experienced soil moisture deficit $(>130 \mathrm{~mm})$ for three and a half months (Grant, 2005b, 55). It forced farmers to sell their livestock, and water restrictions for domestic and agricultural purposes were imposed. The 1972-73 drought was the second most severe drought and the districts experienced soil moisture deficit for about two months. The recent droughts of 2002-03 and 2007-08 again severely affected eastern Wairarapa districts. The river flows in the Wairarapa during 2007-08 drought were among the lowest in records especially in the Ruamahanga, Waingawa and Waiohine Rivers, which experienced a slightly higher flow than in the years 1978 and 1985 (WRC, 2008a). The Regional Council records this as one of the most severe droughts in the Wairarapa in past few decades and formed a committee to help farmers

Photo: 5.9. Drought in South Wairarapa (2008)

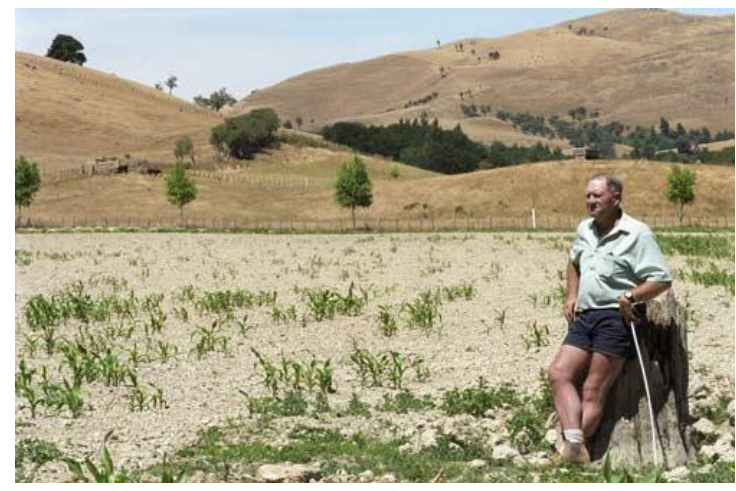

Source: Te Ara, $2008 f$. to cope with the impacts of the drought (WRC, 2008a).

Overall, drought patterns in the district show that even though the frequency of drought is higher in Lower Hutt in the western section of the region, Wellington City and the Kapiti Coast are the other two most frequently drought affected districts in this part. The three eastern districts of South Wairarapa, Carterton and Masterton face even more frequent and severe impacts of drought because of their higher economic dependence on farming activities. The area affected by droughts over the period shows that the boundary of the east and west is not distinct in all droughts. Often one section of the region is more affected along with some areas in other parts. Middle ranges, effects of El Nino and La Nina events along with local topographical and geological characteristics play an important role in shaping drought occurrence. 


\subsection{Connectivity of Processes and Changing Hazard Frequency}

Due to connectivity of ecosystem processes, communities at the local level often experience a change in hazard frequency, which is likely to be augmented in the face of climate change. The percentage change in the average annual rainfall for 1978-98 compared to the preceding 21 years for the Wellington Region shows that the eastern parts of the Wairarapa districts has experienced a four to eight percent rise in its drier years compared to western parts, which have experienced a change from -4 to +4 percent (Ministry for the Environment [MfE], 2004), which indicates higher variability in rainfall rather than steady increase or decrease. On the other hand, projected average rainfall change for the Wellington Region shows that the region could experience a rise in rainfall from 0 to 10 percent in western sections of the region, compared to a fall in rainfall (about five percent) in eastern Wairarapa districts during summer. The changes are going to be even more drastic during winter season, when the western part of the region could experience a rise in rainfall from 0 to 20 percent, while the eastern districts could experience a fall from 0 to -20 percent. An increase in rainfall in the western districts would certainly enhance the current frequency of floods and landslides, and a decrease in rainfall in the eastern section would have a significant impact on drought conditions, which is likely to increase manifolds due to the associated change in the temperatures.

The CLIMPACTS system developed for New Zealand predicts about $0.80^{\circ} \mathrm{C}$ to $0.90^{\circ} \mathrm{C}$ temperature change in the Wellington Region per degree of global warming (Kenny et. al. 1995, 888). The projection from the Ministry for the environment shows that the region is going to experience an increase in temperature from -1.2 to 3.7 degree Celsius in summer and 0.4 to 4.0 degree Celsius in winter till 2080 (MfE, 2004). Low temperatures and longer episodes of high temperatures could severely affect the rural economy of Wairarapa districts which largely depend on farming, and are very likely to face increased drought periods. Besides, average wind speed and stronger winds have also been predicted to increase from slightly to double of their current characteristics by 2080 (MfE, 2004). Sea level rise in Wellington Harbour in the past 100 years has been $17.8 \mathrm{~cm}$, and it is likely to increase by an additional $0.16 \mathrm{~m}$ by 2100 , which could exacerbate the effects of coastal hazards especially erosion or coastal landslips along with inundation during storm surges (GWRC, 2007, 2). Rise in rainfall, temperatures, wind speed along with sea level rise could enhance the hazards in the western Wellington Region, where most of its cities are inhabited in the coastal zones and infrastructure is exposed to coastal hazards.

A spatio-temporal assessment of hazards in the region finds the following. First, the damage from hazards has not always been caused by the most extreme events. For example, the Hutt River protection works were most severely affected by an event of a recurrent period of 12 years rather than one of twenty five years or more. Similarly, the average damage caused by an earthquake of magnitude two is nearly twice that of magnitude three, and damage from magnitude six earthquakes 
is more than three and half times higher than damage from magnitude seven earthquakes. The Wahine Storm presents another example, which was not the most severe windstorm, but it certainly proved most costly with 51 lives and a damage of 150million NZD. Therefore, hazards do not always share a linear relationship with the intensity of geophysical events.

Damage data also show that hazards in the region have actually expanded over time irrespective of any major change in the physical environment. The modified physical susceptibility has allowed hazards to occur even in those places, where they have minimum natural susceptibility. Flooding in Wellington City caused by blocked and narrow drains is a good example. The nature, impact and intensity of hazards differ across the region depending on population density and land use. While western urban areas have suffered frequent house and infrastructure damage from earthquakes, landslides and flooding, damage from drought and bush fire to pasture and farming assets is more dominant in the eastern rural districts. It is also noted that in urban areas the threshold of events causing damage tends to be lower compared to rural areas. All these facts indicate an increased human role in the creation of hazards and building hazardscape.

The hazardscape gets further complicated when changes to the local environment interrupt ecosystem processes. Interconnectivity of processes in ecosystems plays an important role in feedback systems, and links hazards over space. This is visible in flood incidents of Upper Hutt, which is situated in the catchment zone of the Hutt River, where the main role of the river is water collection and erosion rather than flooding. However, the limitation of the River throughout its course through stop banks, forces it to keep its water level high, and the new water in the absence of free space floods its upper reaches. Connectivity of processes also results in the connectivity of different hazards, which has been observed in the concurrence of earthquakes with tsunami and landslides, windstorm with sea surge, drought with rural fire etc. Furthermore, all ecosystem processes do not always follow the same path. The area affected by the Wahine Storm shows that high speed winds occurred in those areas, which are generally not affected by southern winds (Tait, et. al, 2002, 91). This is because the system allows process deviations in order to keep its balance at a higher level. Therefore, deviation of a process is part of ecosystem functioning, and even if it is not common, it is real. This enhances vulnerability in hazardscapes through negligence and unawareness, and bears significant implications for hazard responses. 
Chapter: 6

Local Response to Hazards in the Hazardscape of the Wellington Region

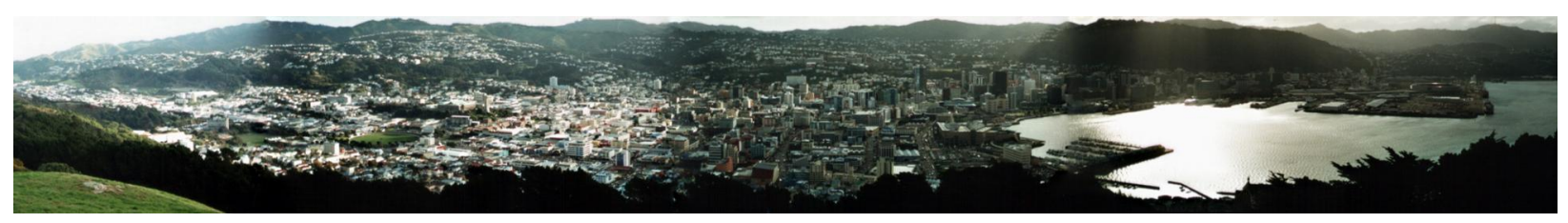


As pointed out in the conceptual framework, the response to hazards shares a two-way relationship with hazardscape (see Fig: 2.2). As a result, variations in hazard response can be observed over space as being influenced by the nature and characteristics of hazardscape. This chapter presents the overall response of people to natural hazards in the Wellington Region, and illustrates the variations in the local response influenced by the hazardscape characteristics. It is important to note here that since the sample was selected through the non-random purposive stratified sampling method, no statistical tests of significance have been made. Instead, the aim has been to assess the range and variety of responses to elucidate trends and indicate relationships between response and aspects of hazardscape.

\subsection{Overview of Hazard Response in the Wellington Region}

The local response to hazards varies from long term adaptation to short term adjustments which are aimed at hazard mitigation, preparedness, emergency response and recovery. Since the region has not experienced any disaster in recent years, emergency response and recovery are restricted to minor hazard events, which have affected either one or a few individuals. Therefore, most hazard response in the region can be classified under hazard mitigation and preparedness for disaster.

Photo: 6.1. Hazard Mitigation Measures Adopted for Houses in the Wellington Region
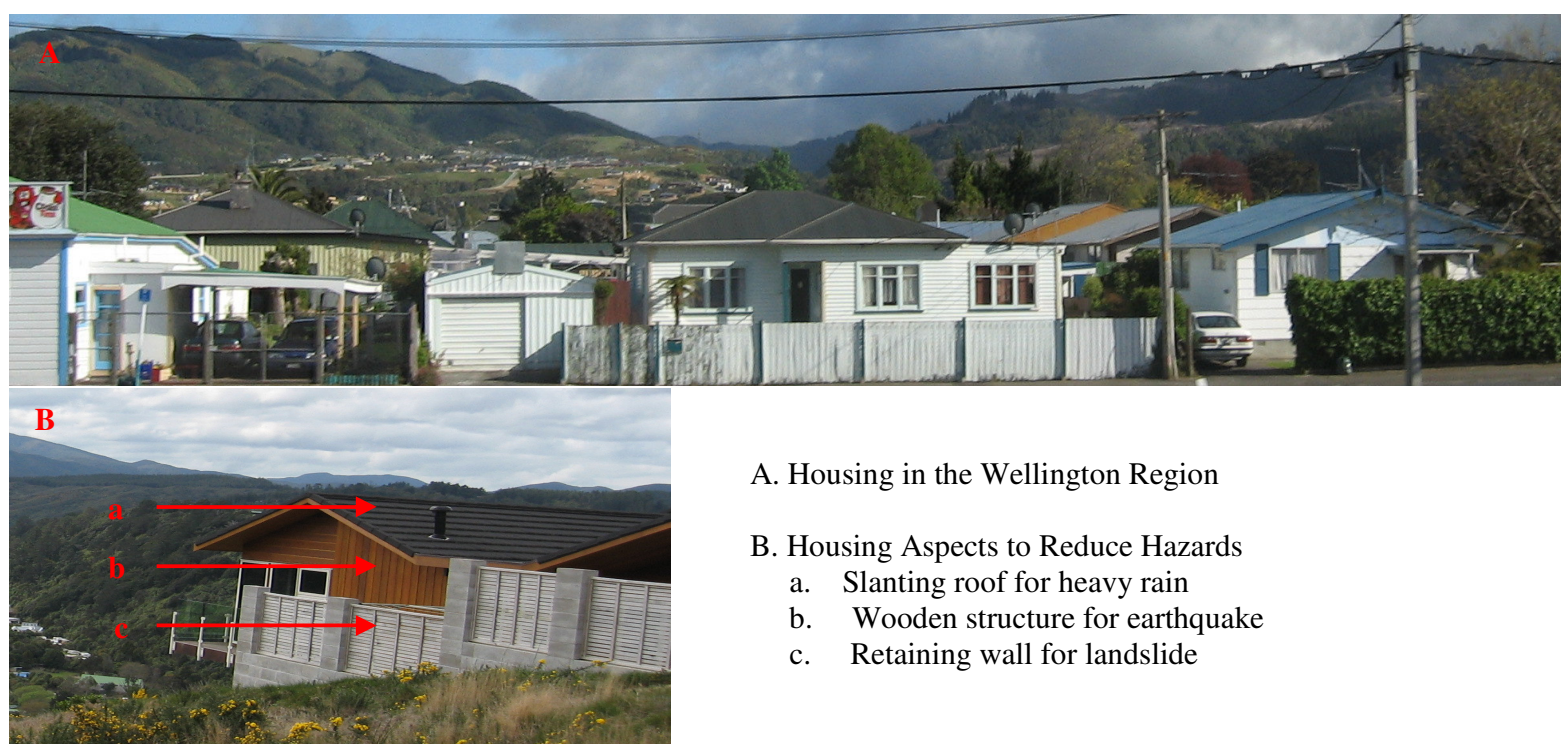

A. Housing in the Wellington Region

B. Housing Aspects to Reduce Hazards

a. Slanting roof for heavy rain

b. Wooden structure for earthquake

c. Retaining wall for landslide

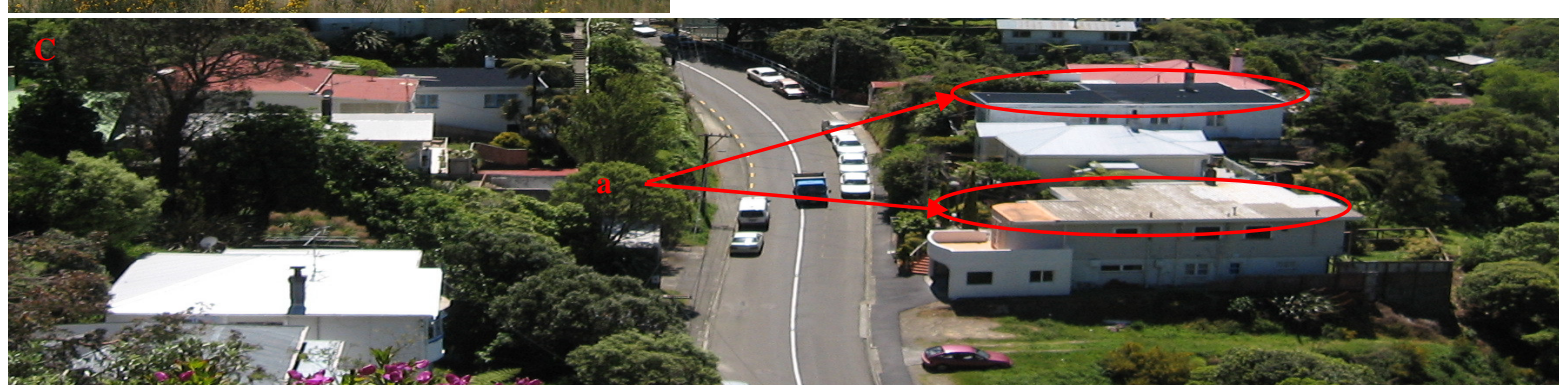

Compromised Adaptations:

C. a. Flat roof

D. a. Brick house

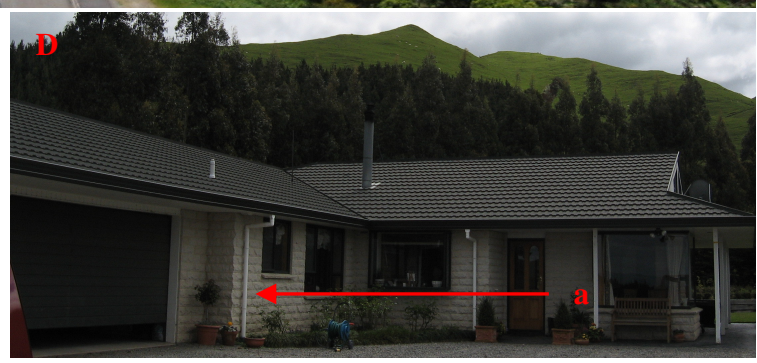


Individual response to reduce hazards in the region can be observed in housing, mitigation, and safety measures taken along with routine behaviour. A few noticeable adaptations in houses of the region include wooden structures and reinforcing of chimneys for earthquakes, the slanting roofs for heavy rain and retaining walls for landslides (Photo: 6.1.B). However, these practices are less obvious in individual cases especially in newly built houses (Photo: 6.1.C \& D). The reason could be attributed to modern technology that has over the years incorporated improved building standards and material as well as the individual's own preferences and capacity that influence the decision of adopting any particular measure.

In addition to long term adaptations, people have also made various short term adjustments in their houses to reduce hazards. The adjustments described in the following sections are based on the questionnaire survey conducted with the local people. The respondents were asked whether they had made any specific adjustments in their houses to reduce damage from natural hazards. Nearly 34 percent of the total respondents said that they had. However, the type of adjustments they made varied significantly. Only one percent of the total 272

Fig: 6.1. Adjustments Made by Respondents In or Outside their Houses to Reduce Hazards

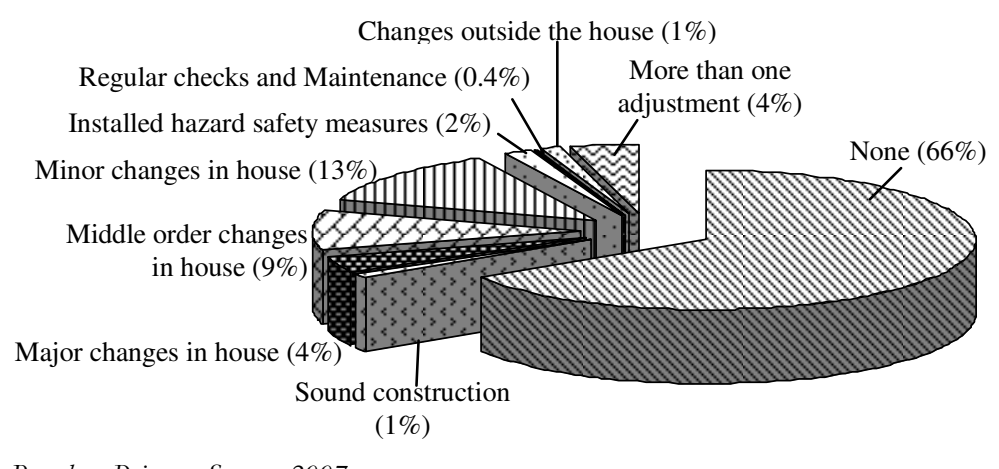

Based on Primary Survey, 2007

respondents said that they had specially built a strong house or made sure that they bought a strong house that could cope with natural hazards (Fig: 6.1). About four percent of the respondents had made major changes to their house such as strengthening the foundations or roof, raising the floor level, building a basement, installing boreholes or reconstructing the weaker section of the house. Nine percent of respondents had made middle order changes in their houses such as replacing roof tiles, stabilising the chimney, improving drainage or preventing leaks etc. More respondents (13 percent) had made minor changes such as window glazing or secured things in house such as furniture, windows, water cylinder etc. Two percent of respondents mentioned that they have installed hazard safety measures such as fire extinguisher, smoke detectors, alarm system, sprinkler system, or installed a bore or motor pump

Fig: 6.2. Hazard Safety Measures Adopted by Respondents

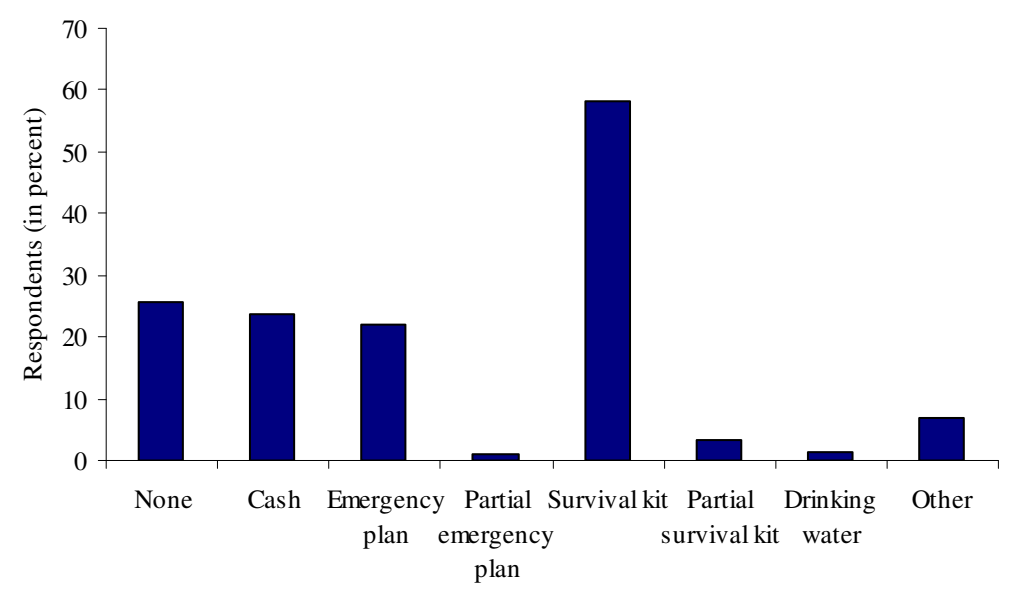

Based on Primary Survey, 2007 for drought or a pipe network for storm water. Another one percent of respondents made 
adjustments outside their houses such as planting or removing trees to avoid damage from high winds, or had built stop banks to avoid flood or a sea wall for protection against coastal erosion. Only four percent of respondents made more than one of the above mentioned adjustments in their house to reduce hazards. The main fnding, however is that by far the largest proportion of respondents (66 percent) had done nothing in this respect.

However, on the question of adopting safety measures, a large proportion (74 percent) replied yes. A survival kit is the most common safety measure adopted by the people (Fig: 6.2). About 58 percent of respondents had survival kits, and another five percent had either stored drinking water or had partial or unorganised survival kits. About 24 percent of respondents had cash at home while another

22 percent had an

Fig: 6.3. Contents of Survival Kit Stored by Respondents Who Said to emergency plan. Nearly 12 percent of the respondents said they have taken other safety measures such as having secured furniture in the house, built a protection wall, have emergency materials or worked on trees outside their house. Although a larger proportion of respondents said that they have a survival kit, a difference was observed in the contents Have Made Survival Kit

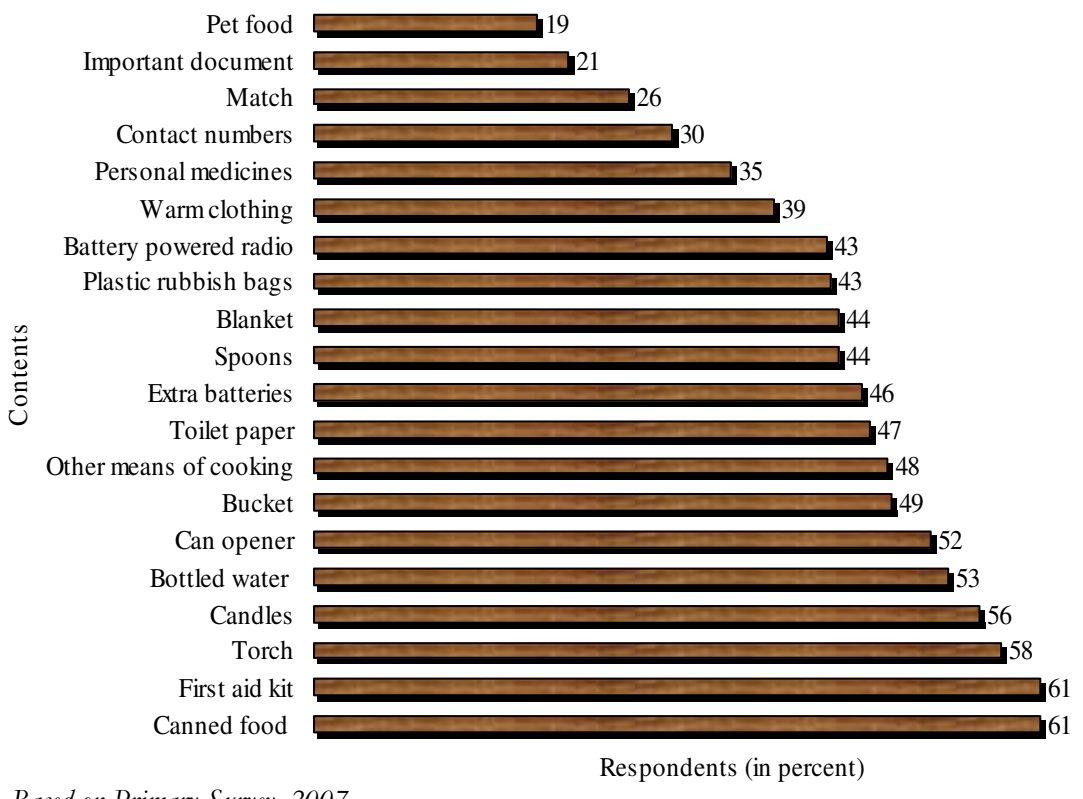
they stored (Fig: 6.3).

Insurance is another significant hazard safety measure, which is widely adopted in the region for recovery. This is because hazard insurance is readily available to people who take fire insurance. Nearly 80 percent of the respondents therefore had house insurance for natural hazards. Temporary stay and rented accommodations were the prime reasons behind either not having insurance or lack of awareness about hazard insurance. About 84 percent of respondents had insurance for contents, while four percent of respondents had insurance for their farm land or assets and 0.7 percent had insurance for livestock. The smaller number of respondents with farm or livestock insurance could also be attributed to their small representation in the total sample size. Besides, the general insurance for hazards from the Earthquake Commission [EQC] does not cover the loss of farming products or livestock, and the insurance from other companies is found too expensive by respondents.

Respondents were also asked about their preparedness levels for different hazards. The data show that only three percent of respondents thought that they were very prepared for any hazards. Nearly 21 percent perceived themelves to be fairly prepared, while 13 percent of respondents found themselves to be less prepared to deal with any kind of hazards. About 24 
percent of respondents said that they are not at all prepared, and about 35 percent of respondents believed that they are not exposed to any of the mentioned hazards.

\subsection{Variations in Response to Hazards and Influences of the Hazardscape}

The following sections assess the variations in hazard response in the region with respect to hazardscape characteristics. These include hazards, physical susceptibility, human vulnerability and overall hazardscape characteristics.

\subsubsection{Influences of Hazard Characteristics}

A significant variation is observed in the response of local people to different hazards, which is closely linked with the nature and characteristics of these hazards in the region. The respondents were asked about the hazards for which they took safety measures. The highest proportion of respondents (39 percent) mentioned earthquakes (Fig: 6.4). The reason could be attributed to high frequency, potential damage and high awareness about earthquakes in the region. About eight percent of respondents took safety measures for flooding. The relatively low number of respondents could be linked with limited spatial spread of this hazard in the region. Nearly three percent of respondents had taken measures for bushfire and windstorm, which can be attributed to minor or no damage experienced by the respondents from these hazards. The two percent of respondents who took safety measure for drought were mainly farmers, who are directly and frequently affected by the hazard. Less than one percent of respondents had taken measures for cyclone or tsunami or landslide, which could be attributed to lack of controllability over these hazards along with their infrequent occurrences. None of the respondents mentioned volcanic ash fall because they do not see this hazard to be life threatening or causing significant damage to them. Likewise few respondents mentioned specific impacts due to any hazard as a reason to keep safety

Fig: 6.4. Hazards for Which Safety Measures Taken by Respondents

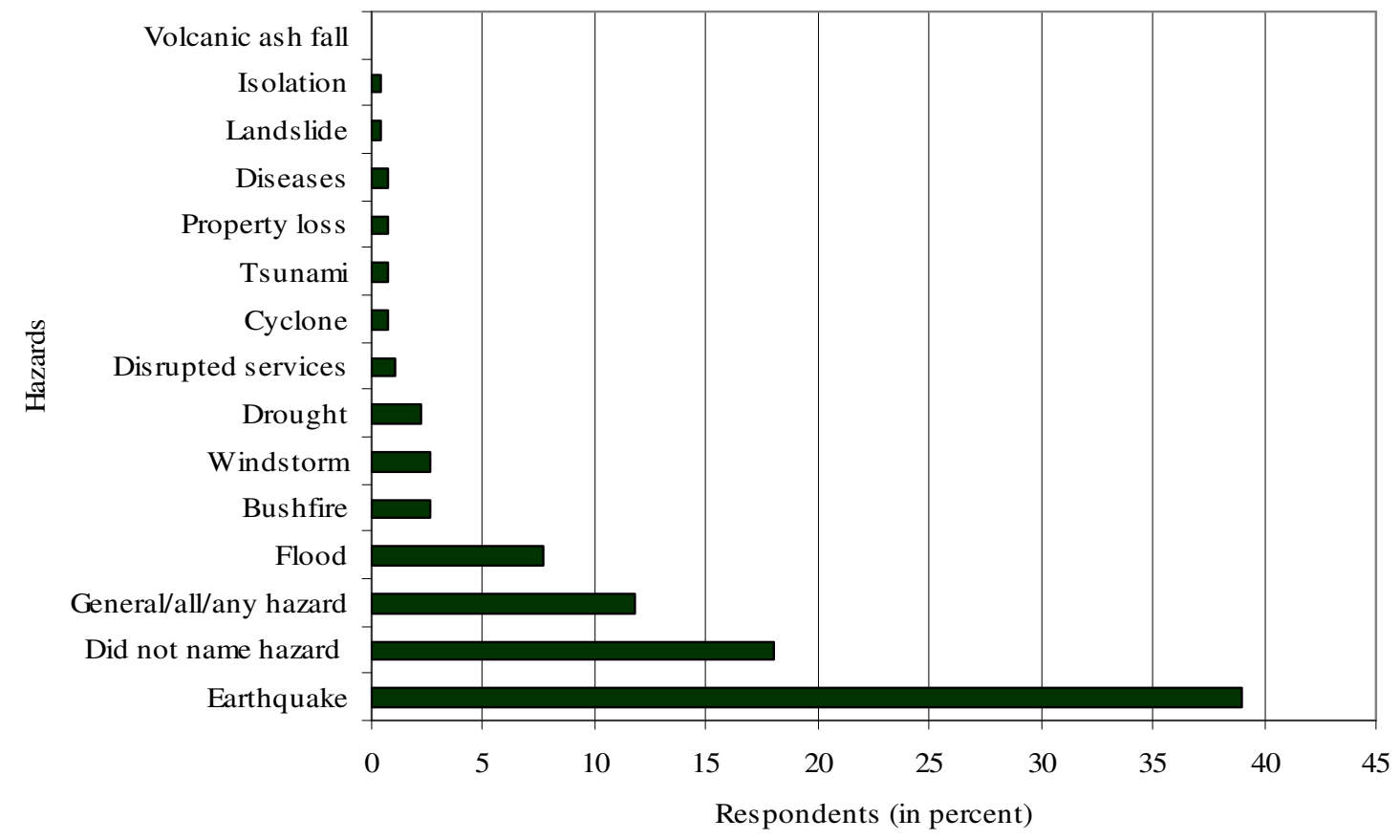


measures such as disruption of services (1.1 percent), diseases (0.7 percent) and isolation (0.4 percent).

Since there is one common insurance policy provided by EQC for all hazards, preparedness could not be assessed separately for each hazard type at the individual level. However, the difference in the preparedness level of respondents suggests some links with the nature and characteristics of hazards in the region (Fig: 6.5). More respondents said that they are

Fig: 6.5. Hazards Preparedness of Respondents

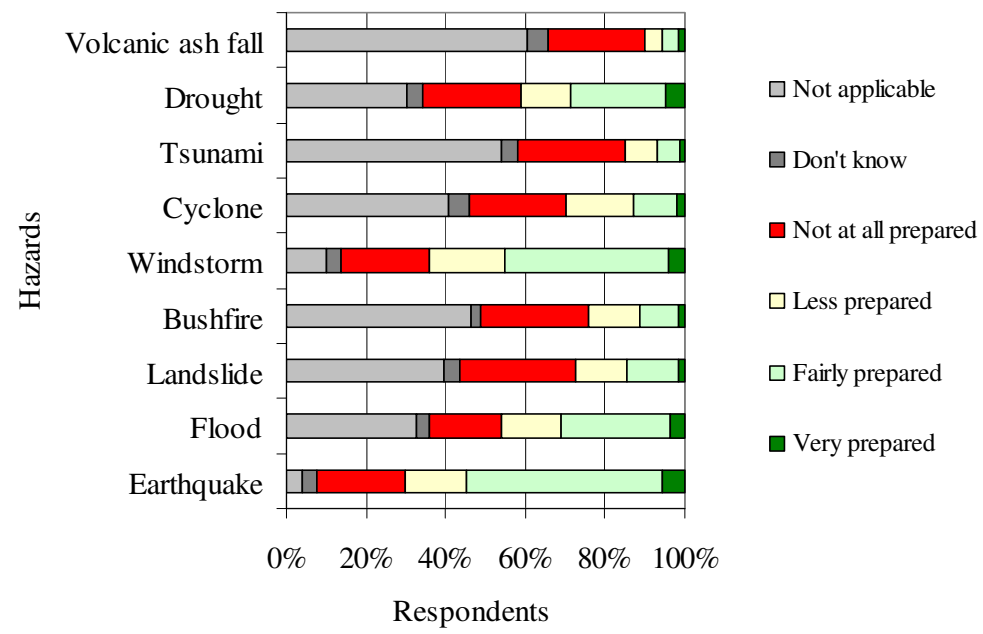

Based on Primary Survey, 2007 fairly or very prepared for earthquake, windstorm, flood and drought, which could be attributed to their regular occurrence in the region. On the other hand, very few respondents claimed to be prepared for the volcanic ash fall or tsunami as they do not perceive themselves to be exposed to these hazards due to their irregular occurrence, and minor or no damage through them in the past.

The variations in the local response for different hazards are linked with both inherent and modified hazard characteristics. These characteristics can be classified into three groups on the basis of their main governing factor i.e. time, space or damage. Since each hazard characteristic influences response in different ways and to a varied extent, the following paragraphs assess the influences of these characteristics separately on the local response to hazards in the region.

\subsubsection{Time Specific Hazard Characteristics}

The hazard characteristics having time as the main component include frequency, duration, speed of onset, temporal spacing and predictability. They not only shape the perception of hazard occurrence but also the vulnerability and response to hazards.

6.2.1.1. a. Frequency: Hazards, by their nature as the source of disaster, are highly infrequent, low probability events (Lindell et al, 1997, 331). However, a few low magnitude events which occur more frequently, not only make the community aware and encourage response, but also shape the nature of adjustments and adaptations for these hazards.

Fig: 6.6. Recorded Frequency of Hazards and Response in the Wellington Region

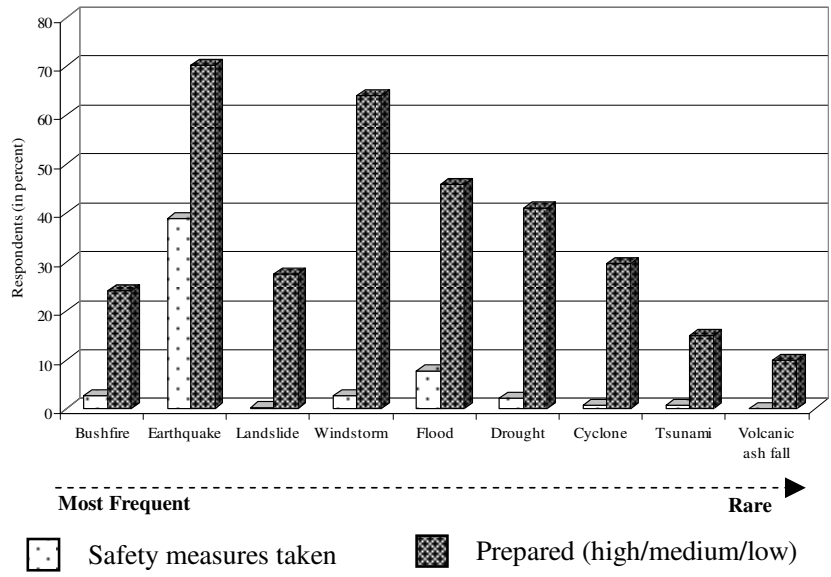

Based on Primary Survey, 2007 
In order to see the influence of frequency of hazards on response, the secondary data of hazard occurrence in the past 10 years (as described in Chapter-5), are compared with the hazard wise response from the people i.e. the proportion of respondents who took safety measures and those who perceived themselves to be fairly or very prepared for different hazards (Fig: 6.6.). The comparison shows that except for bushfire and landslide, the proportion of respondents who perceived themselves to be prepared declines gradually with declining hazard frequency. It is important to note that the frequency of earthquakes could be higher than the bushfire occurrences, but as hazard earthquakes have been recorded less than bushfires. The reason for less preparedness for bushfire among people could be associated with the location of bushfire occurrences i.e. either in remote areas or on public property, which although registered by the administration, may not have concerned the individual respondents. On the other hand, less preparedness for landslides could be due to either non exposure or because of unawareness about any specific preparedness measure for this hazard. The safety measures taken by the respondents for individual hazards show less correlation with frequency. The reason could be partly associated with the perceived potential damage from various hazards along with the perceived relevance of safety measures for different hazards.

Table: 6.1. Hazard Frequency as Perceived by Respondents at their Place of Residence

\begin{tabular}{|c|c|c|c|c|c|c|c|c|c|}
\hline \multirow[t]{2}{*}{ Frequency } & \multicolumn{9}{|c|}{ Hazard Occurrence (percent respondents) } \\
\hline & \multicolumn{8}{|c|}{ Earthquake Flood Landslide Bushfire Windstorm Cyclone Tsunami Drought } & \multirow{2}{*}{$\begin{array}{c}\begin{array}{c}\text { Volcanic } \\
\text { ash fall }\end{array} \\
0\end{array}$} \\
\hline Once in a month & 4 & 1 & 1 & 0 & 16 & 0 & 0 & 0 & \\
\hline Once in $2-6$ months & 5 & 3 & 2 & 0 & 5 & 0 & 0 & 1 & 0 \\
\hline Once in $7-12$ months & 20 & 13 & 5 & 2 & 35 & 1 & 0 & 12 & 0 \\
\hline Once in $2-5$ years & 10 & 12 & 8 & 3 & 7 & 2 & 0 & 18 & 0 \\
\hline Once in $6-10$ years & 5 & 5 & 4 & 2 & 3 & 2 & 0 & 5 & 0 \\
\hline Once in $11-20$ years & 7 & 3 & 3 & 1 & 2 & 1 & 0 & 1 & 0 \\
\hline More than 20 years & 4 & 0 & 0 & 0 & 0 & 1 & 1 & 0 & 2 \\
\hline Never experienced & 7 & 2 & 5 & 6 & 3 & 8 & 8 & 5 & 6 \\
\hline Not applicable & 8 & 47 & 49 & 63 & 11 & 60 & 74 & 42 & 78 \\
\hline Don't know & 30 & 15 & 23 & 22 & 17 & 24 & 16 & 15 & 13 \\
\hline
\end{tabular}

Based on Primary Survey, 2007

In order to assess the perception of hazard frequency at the local level, respondents were also asked about the occurrences of different hazards at their place of residence. The most frequent hazard observed by the respondents was windstorm followed by earthquake, flood, drought and landslide (Table: 6.1). The comparison of perceived hazard frequency by respondents with the proportion of respondents who took safety measures, and those who perceived themselves to be fairly or very prepared for different hazards

Based on Primary Survey, 2007
Fig: 6.7. Perceived Hazard Frequency and Response in the Wellington Region

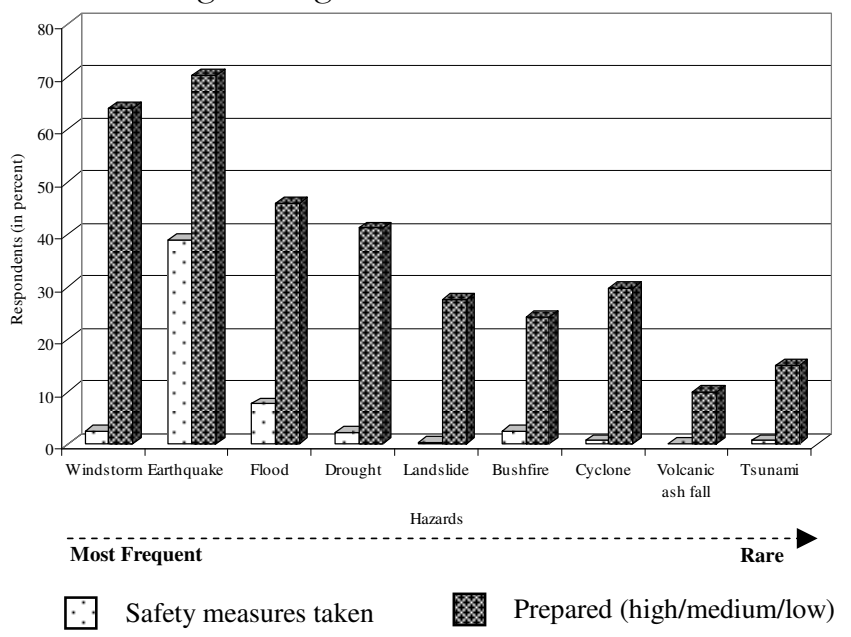


safety measure is very small, the proportion of those who considered themselves prepared was high.

Fig: 6.8. Proximity of Hazards in Future as Perceived by Respondents in the Wellington Region

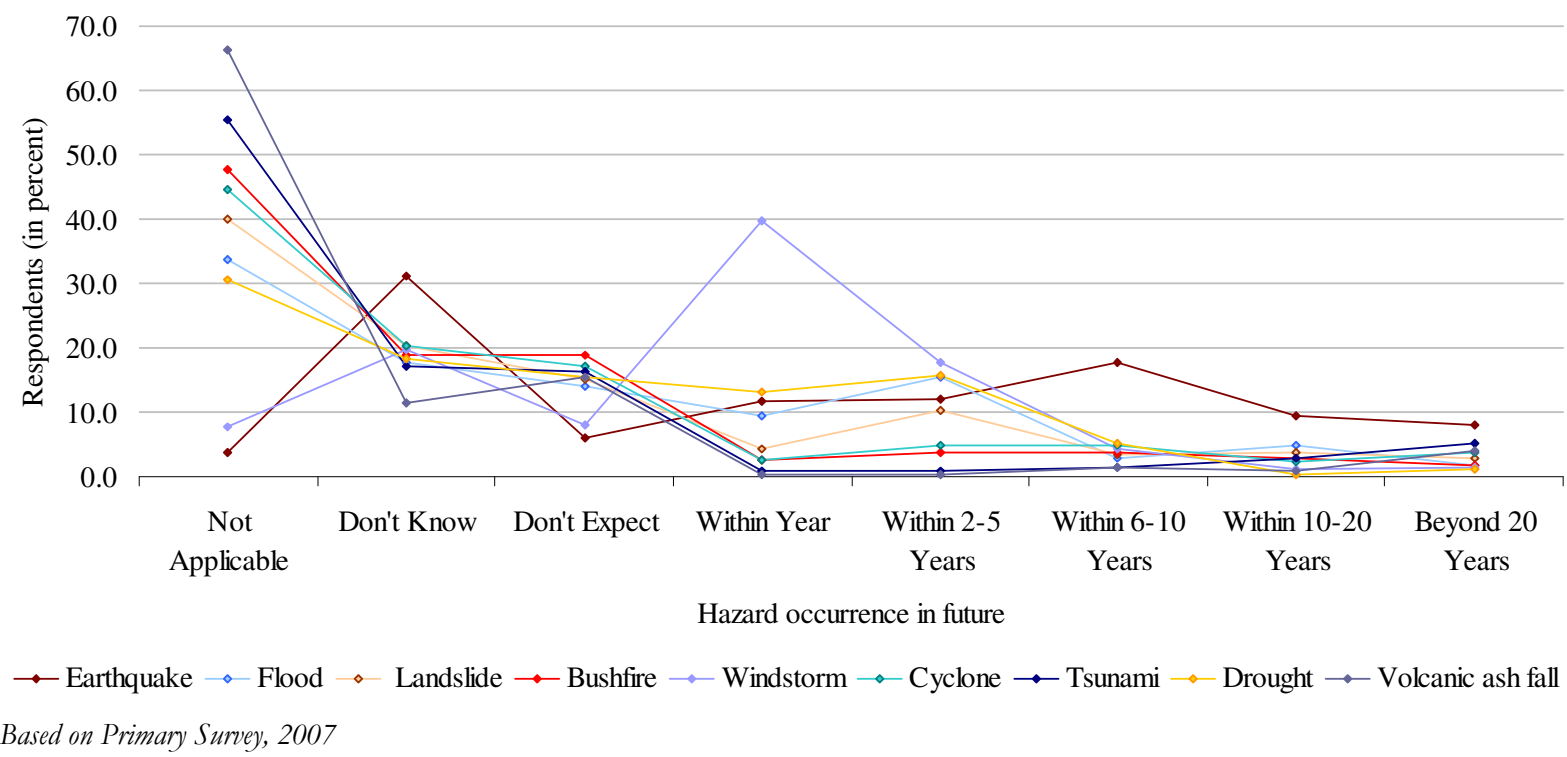

Respondents of this research were also asked about how near they see hazard occurrence in future. The data show that most respondents, even if they recognise that Fig: 6.9. Perceived Proximity, Speed of Onset of they are exposed to a particular hazard, find it difficult to locate a hazard in their future. The perceived proximity of different hazards by respondents indicates a close link with the magnitude of hazards they perceived. While respondents see small magnitude events as occurring in the near future i.e. within a year or within 2-5 years especially windstorm, drought, earthquake and flood, they locate bigger events such as a major earthquake, tsunami or volcanic ash fall at a distant future (Fig: 6.8). The relation of perceived proximity of hazards in future with response pattern indicates that respondents are more prepared for those hazards which they could perceived occuring in their near future (Fig: 6.9).

6.2.1.1. b. Speed on Onset: Speed of onset has been recognised as an important hazard characteristic having a relationship to response (see Burton, et al, 1993, 34). The Hazards and Response in the Wellington Region
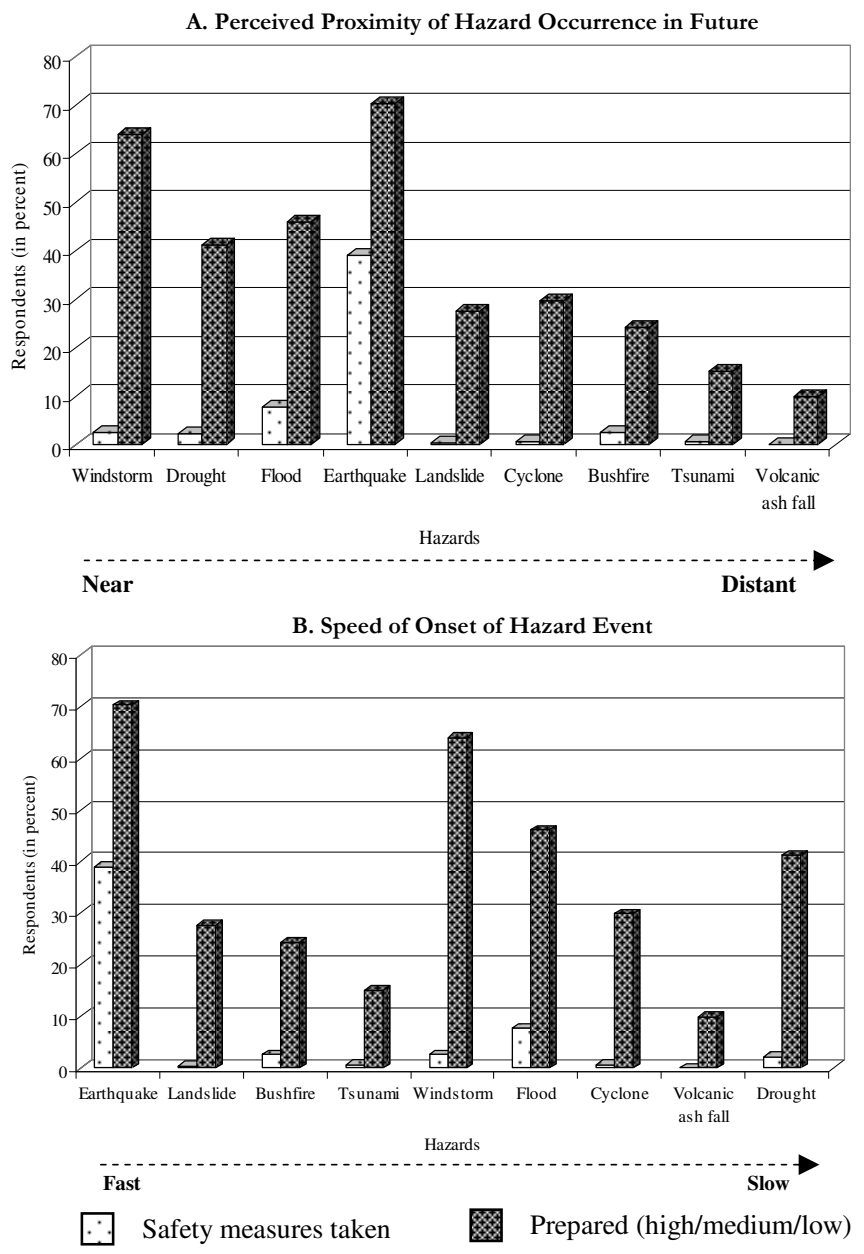
overlay of hazard response in the region over speed of onset does not show any linear relationship 
between the two (Fig: 6.9.B). Both the fastest hazard i.e. earthquake and the slowest hazard i.e. drought have high response rate compared to others hazards such as landslide, bushfire, tsunami, cyclone and volcanic ash fall. This could be partly because the speed of hazard onset has a greater influence on real time response compared to mitigation and preparedness, and therefore is more of a concern for civil defence authorities.

6.2.1.1. c. Duration: Duration refers to the length of time over which a hazard persists (Burton, 1993, 34). Duration of a hazard may vary with each single incident and therefore it is difficult to arrange them in a definite order. Therefore, they have been broadly arranged on the basis of general trend. However, the overlay of local response over duration scale of hazards does not show a consistent relationship (Fig: 6.10.A). This is again because duration of hazards has a higher influence on the real time response compared to mitigation. Further, it is very likely to be extended because of local ecumenical factors or social conditions at the time of disaster, which are difficult to predict and plan for in advance.

\subsubsection{1. d. Temporal Spacing: The} sequence of hazard events depicts their temporal spacing (Burton et al, 1993, 35). The comparison of temporal spacing and hazard response in the region show that, on a broad scale, the response in the region is influenced by the temporal spacing of hazards. The preparedness to hazards declines from the regular events to random hazard events, except for earthquake, which is an outlier (Fig: 6.10.B) in this case. The reason could be attributed to the nature of this hazard, which despite being random in time, occurs with a regular frequency in the region.

6.2.1.1. e. Predictability: Nearly 40 percent of the respondents find unpredictability of the hazard as the main factor of their vulnerability. However, their response does not seem to be influenced significantly by the predictability of hazards (Fig: 6.10.C). There is high preparedness and response to hazards with high predictability such as

Fig: 6.10. Duration, Temporal Spacing, Predictability of Hazards and Response in the Wellington Region
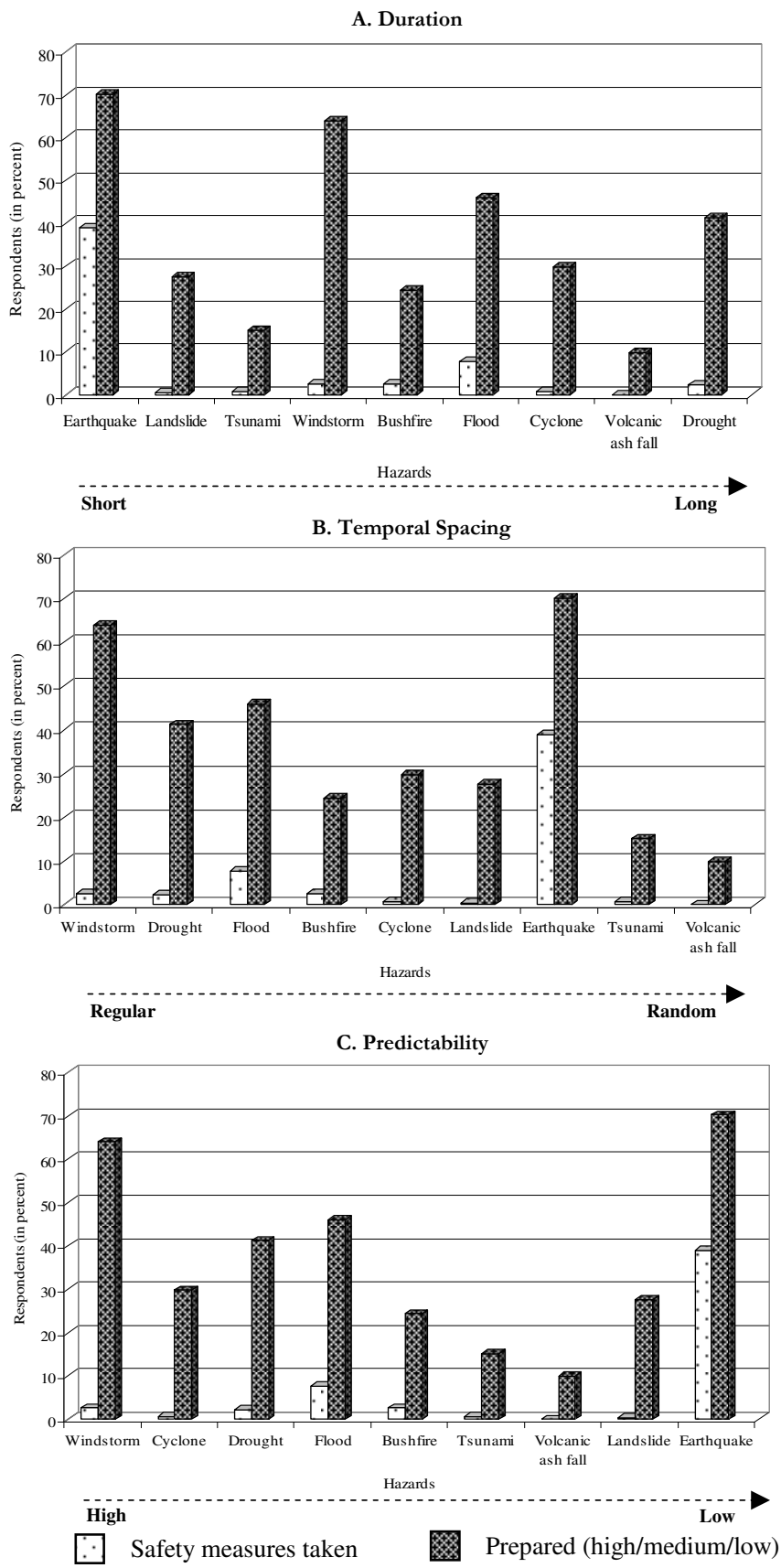

Based on Primary Survey, 2007 
windstorm or flood, along with hazard that are less predictable i.e. earthquake. In summary, the only time specific hazard characteristic that has a constant relationship with response is frequency of occurrence.

\subsubsection{Space Specific Hazard Characteristics}

The two hazard characteristics which are related to space are the areal extent and spatial dispersion of hazards. These characteristics are also related to the magnitude and duration of hazards, and therefore influence both mitigation and emergency response.

6.2.1.2. a. Areal Extent: Areal extent of hazards is another important hazard characteristic that could influence overall response (Burton, 1993, 34). However, when the response is overlain on the areal extent of different hazards in the region, it indicates a general trend of increase in response for more extensive hazards, but does not show a definite relationship (Fig: 6.11). This is because for hazards such as volcanic ashfall, which may cover the

Fig: 6.11. Areal Extent of Hazards and Response in the Wellington Region

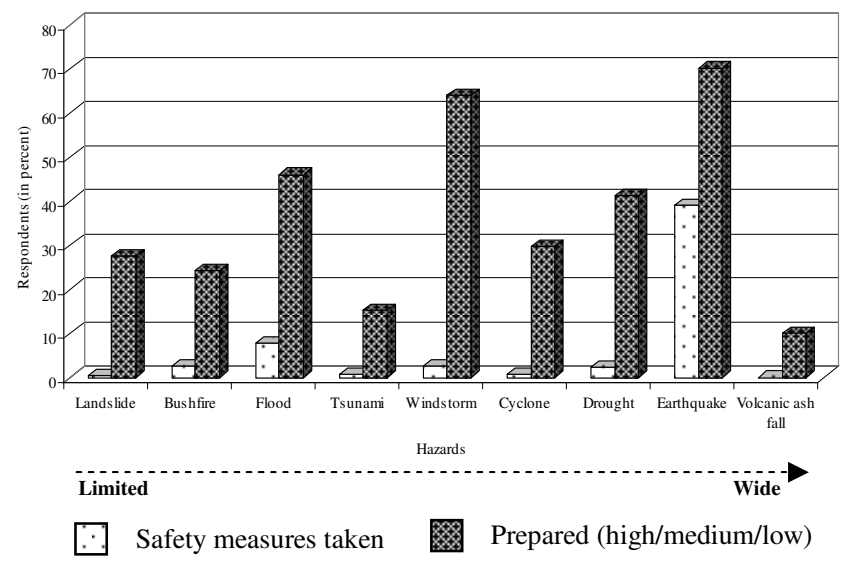

Based on Primary Survey, 2007 region to the widest extent, most of the respondents did not believe themselves to be exposed to this hazard. The same reason applies for cyclone, while for tsunami and drought fewer people were directly influenced by them.

6.2.1.2. b. Spatial Dispersion: Spatial dispersion highlights the distribution of hazard pattern over space (Burton et al, 1993, 35). On a very broad level it could be generalised that the response to hazard increases with the wider dispersion of hazards in the region (Fig: 6.12). The fluctuating response for outliers i.e. cyclone and volcanic ash fall, could be attributed to their infrequent occurrences, which build the perception of nonexistence of these hazards for the majority of respondents.
Fig: 6.12. Spatial Dispersion and Response in the Wellington Region

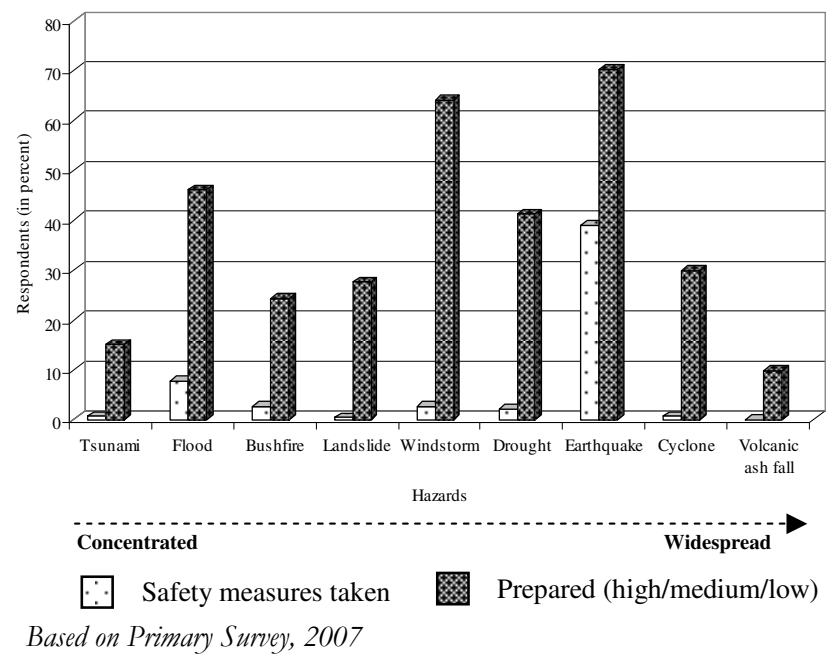

\subsubsection{Damage Specific Hazard Characteristics}

The third governing factor of hazards is damage or social costs. Damage related hazard characteristics include the nature of regular damage from hazards, available protection, 
controllability of the hazardous event, potential damage or risk from hazards and intensity of the hazards.

6.2.1.3. a. Problems and Damage from Hazards: In order to assess the problems resulting from hazards in the region, respondents were asked to what extent they find various hazards to be problematic to them. Most respondents found windstorms to be the most problematic hazard followed by droughts and floods (Table: 6.2). Earthquakes were mentioned as problematic by 15 percent of the total respondents. Windstorm was also highest in the extent of problems and the highest proportion of respondents labelled it beyond control and highly problematic. Other hazards that were seen as out of human control include earthquake, landslide and tsunami. Flood and drought were mainly seen as highly problematic. On the other hand, the least problematic hazard in the region is volcanic ash fall from which no one faced problems at any time.

Table: 6.2. Problems from Hazards in the Wellington Region

\begin{tabular}{lcccc|ccc}
\hline Hazards & \multicolumn{3}{c|}{$\begin{array}{c}\text { Problems from Hazards } \\
\text { (percent respondents) }\end{array}$} & \multicolumn{3}{c}{$\begin{array}{c}\text { Extent of Problems } \\
\text { (percent respondents) }\end{array}$} \\
\cline { 2 - 8 } & $\begin{array}{c}\text { Not } \\
\text { Applicable }\end{array}$ & $\begin{array}{c}\text { Don't } \\
\text { Know }\end{array}$ & No & Yes & Problematic & $\begin{array}{c}\text { Highly } \\
\text { Problematic }\end{array}$ & $\begin{array}{c}\text { Out of } \\
\text { Control }\end{array}$ \\
\hline Earthquake & 7.0 & 9.6 & 68.8 & 14.7 & 12.5 & 1.8 & 0.4 \\
Flood & 46.3 & 5.5 & 27.2 & 21.0 & 15.4 & 5.5 & 0.0 \\
Landslide & 46.7 & 5.9 & 35.3 & 12.1 & 10.7 & 1.1 & 0.4 \\
Bushfire & 56.6 & 7.0 & 31.3 & 5.1 & 4.4 & 0.7 & 0.0 \\
Windstorm & 10.3 & 4.8 & 37.1 & 47.8 & 39.3 & 7.7 & 0.7 \\
Cyclone & 53.3 & 8.8 & 33.8 & 4.0 & 3.3 & 0.7 & 0.0 \\
Tsunami & 65.4 & 5.9 & 26.1 & 2.6 & 2.2 & 0.0 & 0.4 \\
Drought & 37.5 & 5.5 & 29.4 & 27.6 & 21.3 & 6.3 & 0.0 \\
Volcanic ash fall & 73.9 & 4.8 & 21.3 & 0.0 & 0.0 & 0.0 & 0.0 \\
\hline
\end{tabular}

Based on Primary Survey, 2007

The comparison of the degree of problem through hazards with response shows that more respondents are prepared and have taken safety measures for those hazards that they see as being out of control or highly problematic compared to those which are less problematic (Fig: 6.13). The data show that the degree of damage spread, i.e. concentrated to individual or widespread effect on community, also has a significant influence on the hazard response. For example, more respondents have responded to hazards which can cause high individual loss compared to those hazards for which the damage is widespread or diffused throughout the community (Fig: 6.14.A). Landslide, drought and cyclones are outliers because fewer respondents were directly exposed to these hazards.

6.2.1.3. b. Controllability: The response is also poorly related with the controllability of hazards in the region. A relatively high proportion of respondents said that they are prepared for flooding (a
Fig: 6.13. Problems from Hazards and Response in the Wellington Region

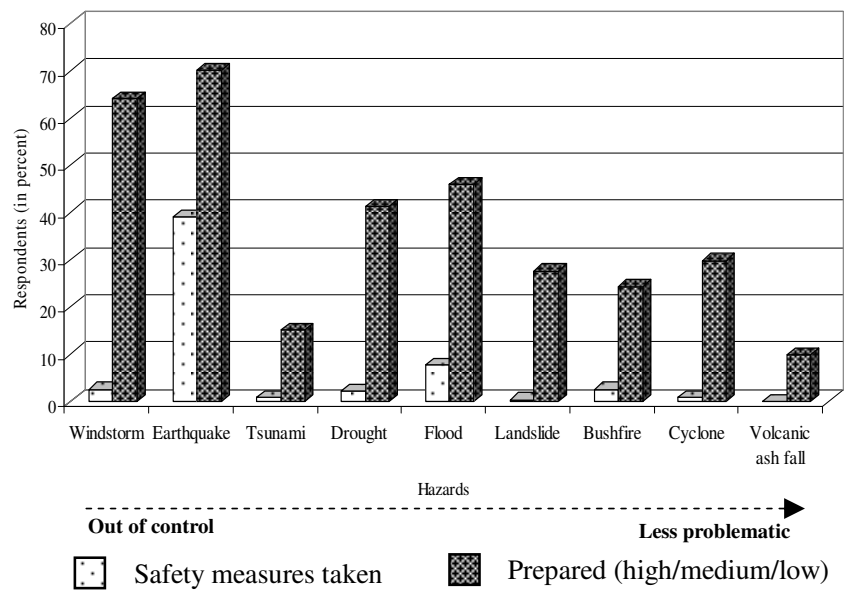

Based on Primary Survey, 2007 
highly controlled hazard) and earthquake (one of the least controlled hazards) (Fig: 6.14.B). Also, a poor relationship is noted between the proportion of respondents who took safety measures and controllability of hazards.

\subsubsection{3. c. Available Protection: The} comparison of people's response with available protection either through adaptation (earthquake proof buildings) or through administration (flood control works) shows a weak relationship (Fig: 6.14.C). The data show that on a very broad level people are relatively more prepared for the hazards for which protection measures are available compared to those hazards for which there are less protection measures. This also indicates a high risk perception of hazards for which protection measures are available.

6.2.1.3. $d$. Risks: The overall risks from various hazards have been calculated by the Wellington Regional Council in order to plan the emergency response to hazards in the region. The overlay of individual responses over calculated risks shows a close relationship (Fig: 6.14.D). The risk calculated for the CDEM plan does not mention cyclone and windstorm separately but gives a risk value for storms that include rain, wind and lightning. Therefore, the risk of storms is used to position cyclone and windstorm on the risk scale. Another outlier is tsunami. The CDEM plan uses two different risk values for near and distant tsunami. For the risk scale used in this research, the hazard is put in the high risk category, as most people would be caught unaware if a tsunami is generated by a local earthquake. The response to this hazard is low as most respondents either
Fig: 6.14. Damage, Controllability, Protection \& Risks from Hazards and Response in the Wellington Region
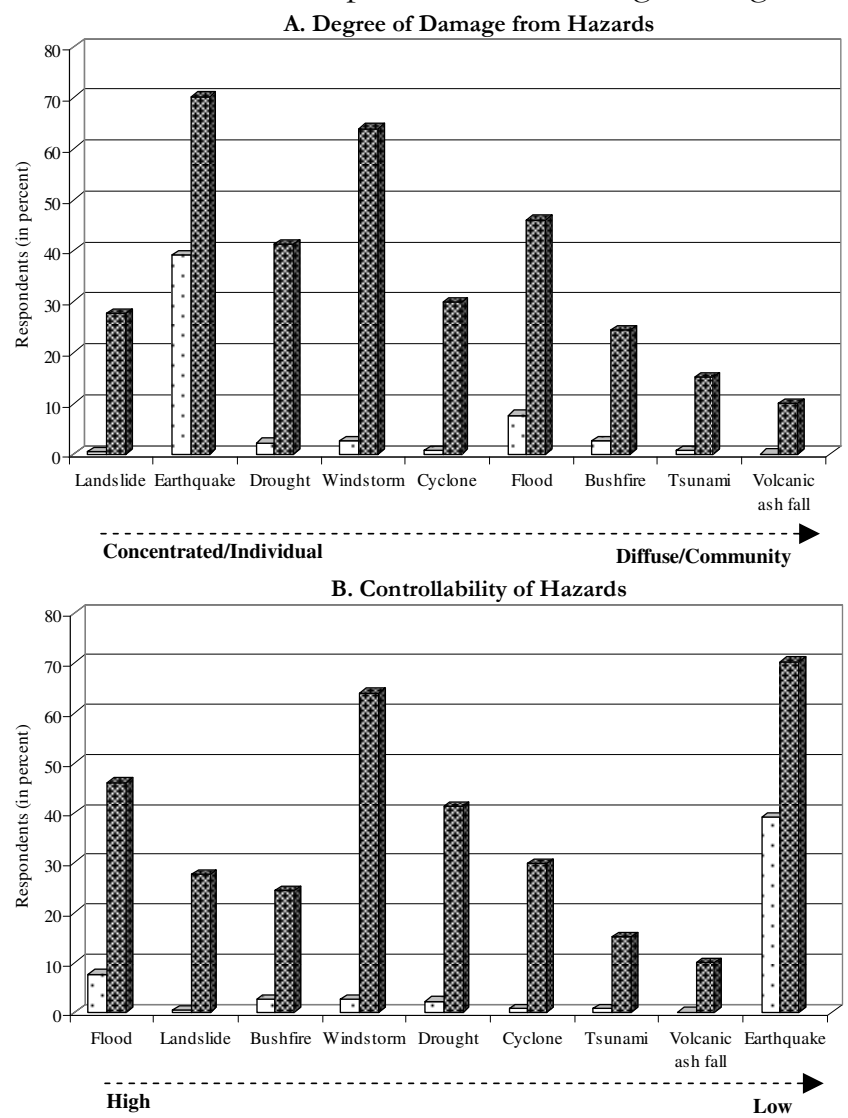

C. Available Protection from Hazards

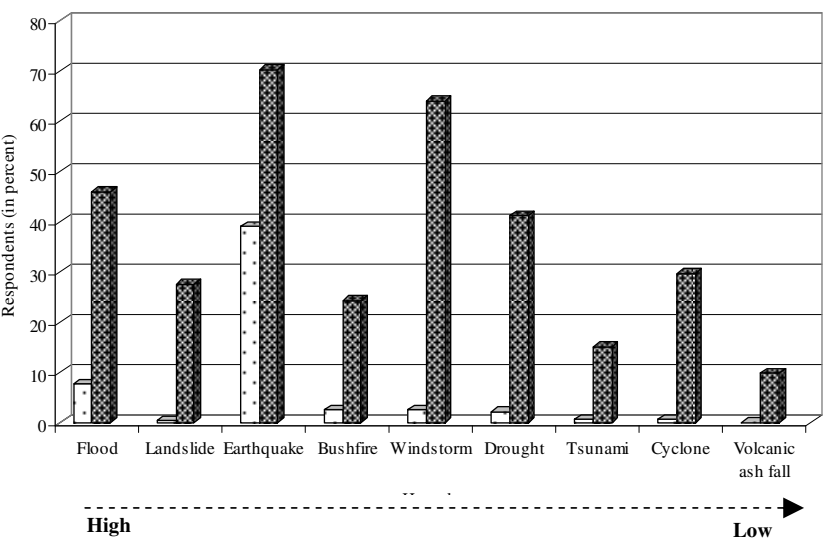

D. Calculated Risk by Wellington Regional Council from Hazards

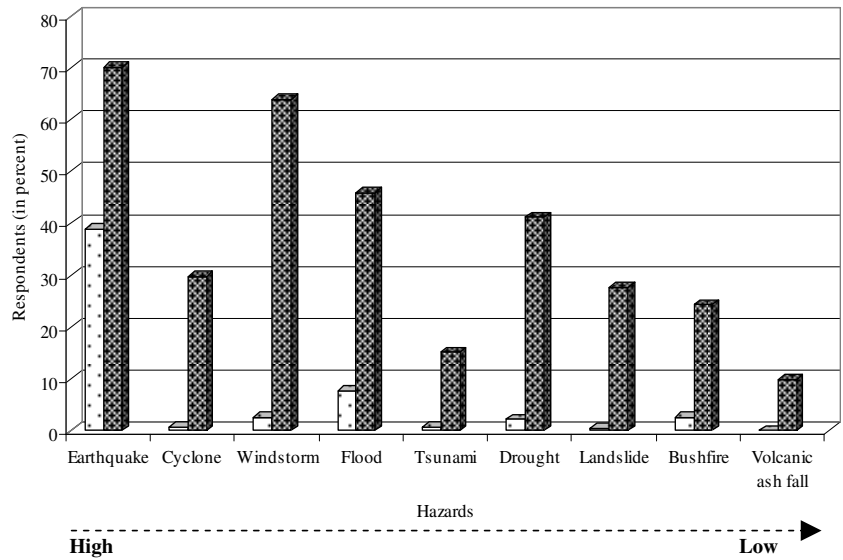

Safety measures taken

Prepared (high/medium/low)

Based on Primary Survey, 2007 
perceived it to be of low risk perhaps because of where they live or they do not think that they could do much about it.

Fig: 6.15. Potential Damage from Hazards as Perceived by Respondents

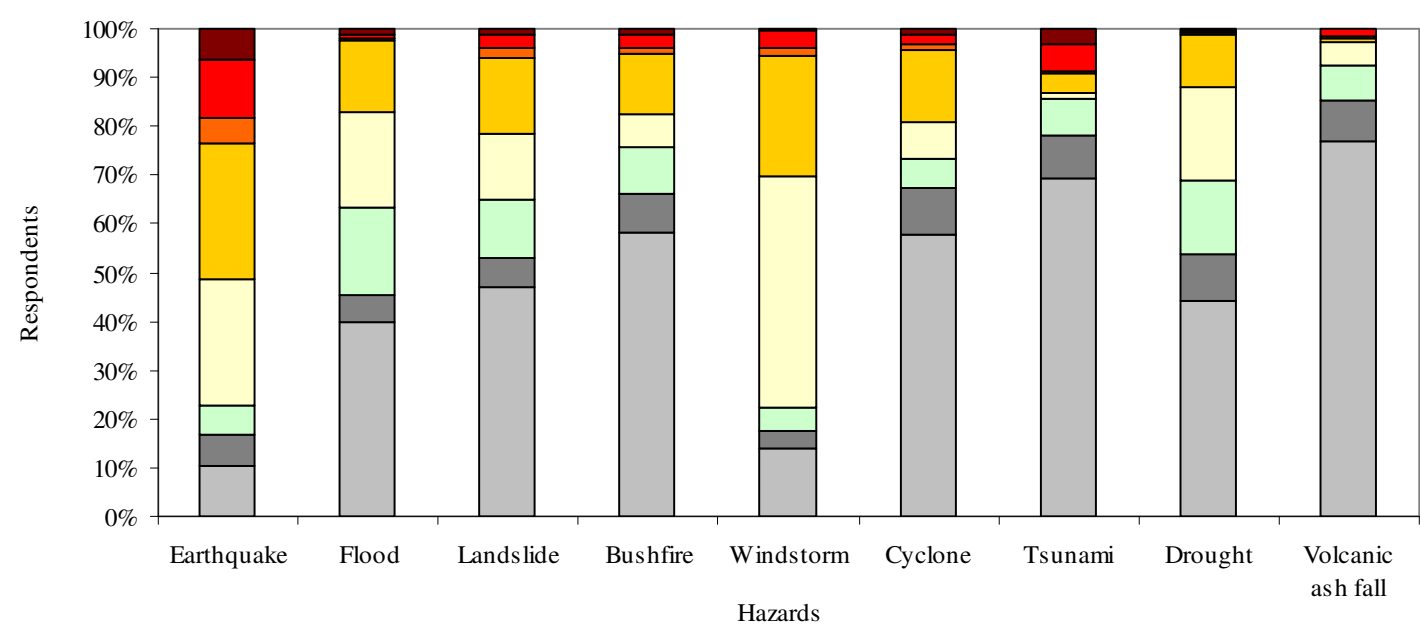
$\square$ Not Applicable
$\square$ Don't Know
$\square$ Significant Property Damage $\square$ Physical Injuries
$\square$ Not Harmful
$\square$ Life Threatening
$\square$ Minor Damage
- Total Destruction

Based on Primary Survev, 2007

The response of local people is also compared with the perceived potential damage from different hazards (Fig: 6.15). However, it does not show as close a relationship as does the calculated risk from the Wellington Regional Council (Fig: 6.16 \& Fig: 6.14). Though the region is exposed to various hazards, very few respondents see these hazards as life threatening or causing total destruction. Earthquakes are perceived as the most dangerous hazard, which explains why the highest proportion of

Fig: 6.16. Perceived Risks from Hazards and Response in the Wellington Region

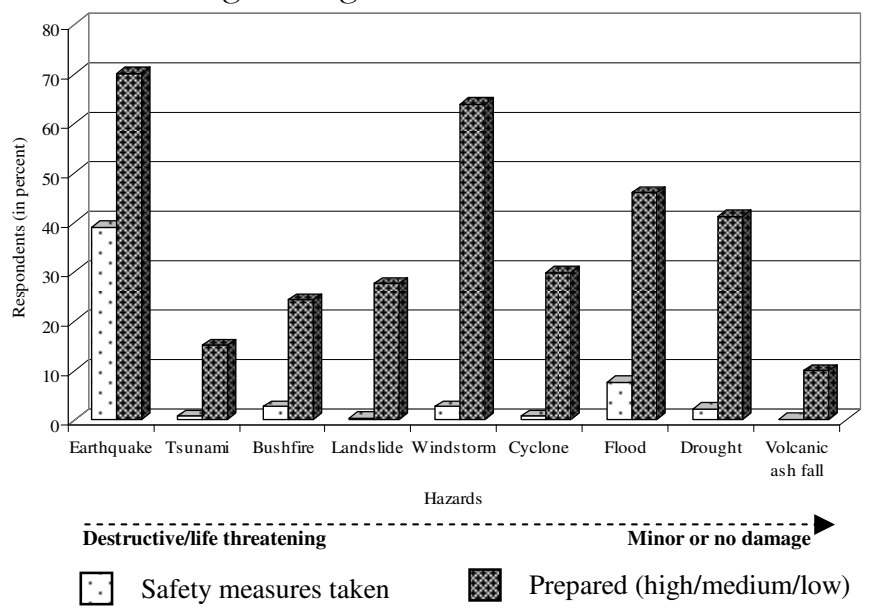

Based on Primary Survey, 2007 respondents has taken safety measures for this hazard. Tsunami, on the other hand, is perceived to be the second most dangerous hazard. However, due to its low frequency, most respondents perceive it to be of low risk. Windstorms are also perceived to be life threatening, but most people believe them to cause mainly minor to significant property damage. As a result, even though very few respondents have taken safety measures, a high proportion of them believe themselves to be prepared for this hazard. A significant proportion of respondents found drought to be not applicable to them, and a relatively equal share identified it as not harmful or causing minor or significant property damage. Very few respondents see this hazard as potentially damaging to physical health or life. As a consequence, a high proportion of respondents perceived themselves to be prepared for drought. Safety measures have mainly been taken by those respondents who are directly affected by this hazard, such as farmers. 
6.2.1.3. e. Intensity: Following Burton et al (1993) and Hewitt and Burton (1971), hazards in the region are also plotted on an intensive and pervasive scale. However, the scale is modified by including modified hazard characteristics along with inherent physical characteristics. High intensity hazards here represent the hazards with low frequency, short duration, small areal extent, fast speed of onset, concentrated spatial dispersion, random temporal spacing, poor controllability, poor available protection, diffuse nature of regular damage, poor predictability and high risk, while low intensity hazards represent the other end of the spectrum for these characteristics. The scale shows that tsunami and earthquake are the most intensive hazards in the region. The overlay of response on intensity scale shows that except for earthquake which is an outlier in this case, the response level increases for less intensive hazards in the region (Fig: 6.17).

Fig: 6.17. Intensity of Hazards and Response in the Wellington Region

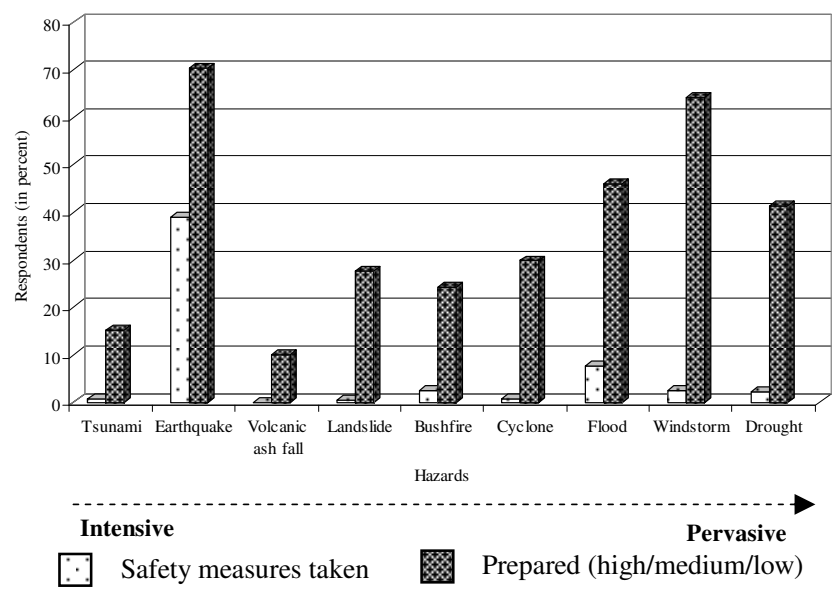

Based on Primary Survey, 2007

Therefore, it can be said that the response pattern in the region is not completely governed by any particular hazard characteristics, but is influenced by a number of them. The hazard characteristics which have influenced the response more dominantly include hazard frequency, temporal spacing, problems and regular damage from hazards and potential risk. Preparedness appears to increase markedly as both the level of risk and the intensity of hazard declines for a range of hazards.

\subsubsection{Influences of Physical Susceptibility}

Physical characteristics of a place not only govern the nature and propensity of hazards, but subsequently influence the perception and response of the local community as well. The following paragraphs describe the influences of varied physical susceptibilities on hazard occurrence, perception and response to different hazards in the Wellington Region.

\subsubsection{Geology}

The nature of rocks and other materials dominantly influence the felt

Fig: 6.18. Problems Experienced from Earthquakes in Areas Susceptible to Liquefaction in the Wellington Region

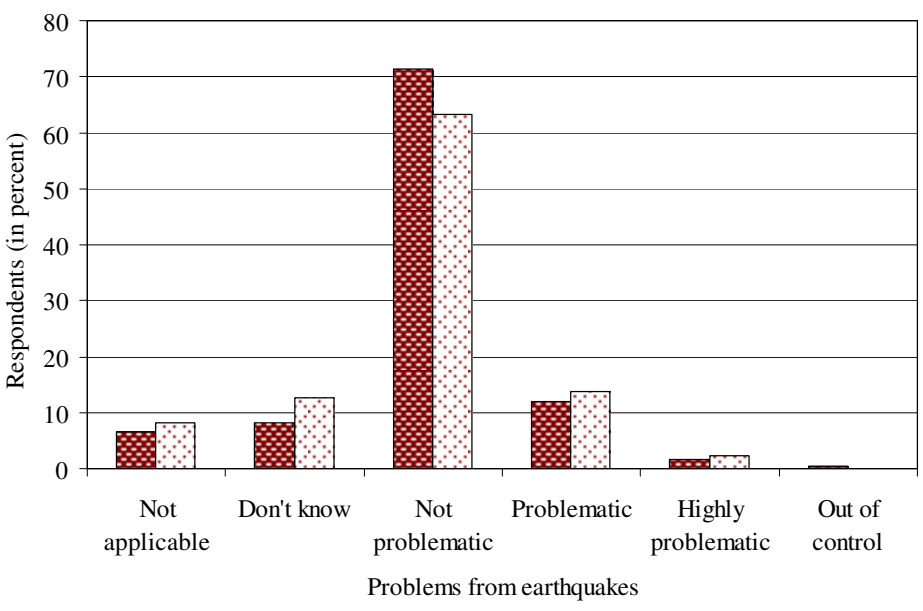

⿴囗大 Respondents not living on soft ground $\square$ Respondents living on soft ground

Based on Primary Survey, 2007 and data from Wellington Regional Council, 2006 
intensity of earthquakes and associated hazards such as liquefaction, ground shaking, ground settlement and landslides. In order to gain a measure of this influence on hazard response, the respondents were classified into two groups i.e. the respondents who lived on soft ground and those who lived outside this zone. Areas of soft ground in the region are mainly low lying flood plains and coastal areas, and they are susceptible to liquefaction and high ground shaking along with ground settlement during earthquakes (see Fig: 3.6). About 32 percent of the total respondents lived in such areas. The assessment of data show that the susceptibility to Fig: 6.19. Perceived Frequency of Earthquakes in Areas Susceptible to Liquefaction

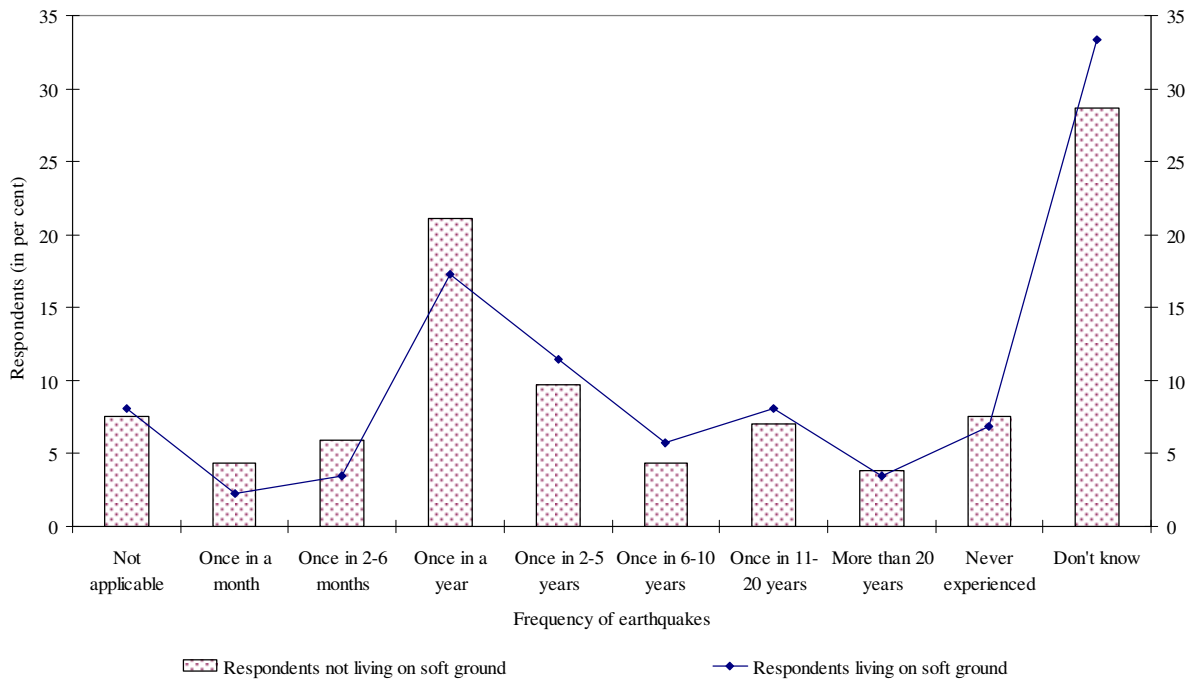

Based on Primary Survev, 2007 and data from Wellington Regional Council, 2006

Fig: 6.20. Proximity of Earthquake Occurrence in Future as Perceived by Respondent Living in Areas Susceptible to Liquefaction in the Wellington Region

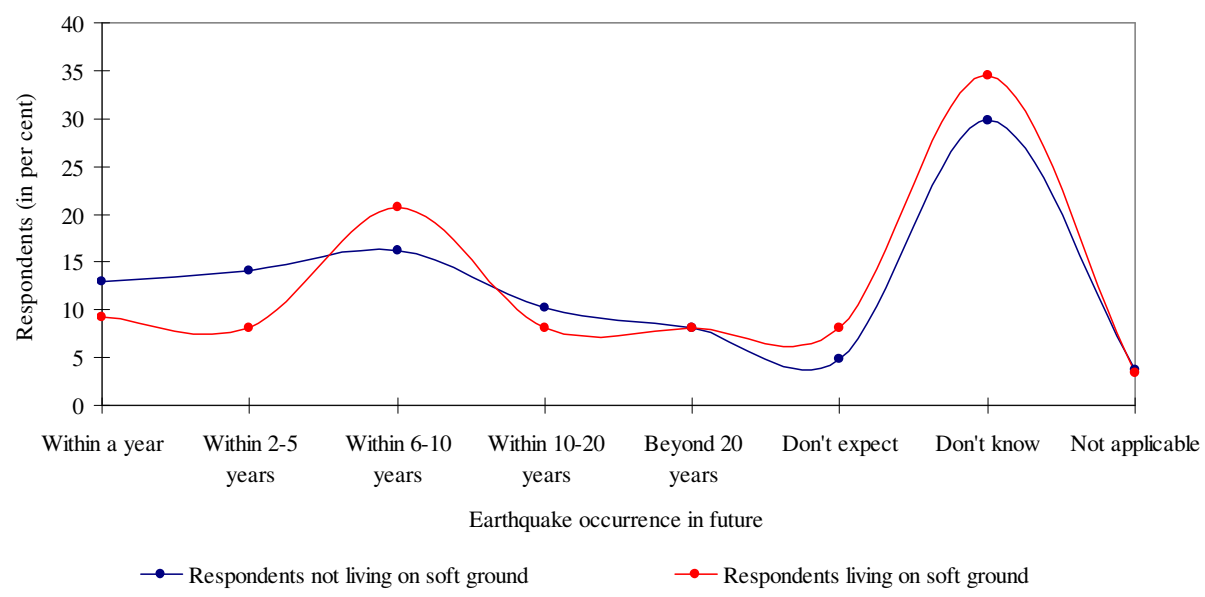

liquefaction however, did not make much Based on Primary Survey, 2007 and data from Wellington Regional Council, 2006

difference for the perception of earthquake exposure. Compared to 87.4 percent of the respondents who are living on soft ground, 87.6 percent of respondents who lived outside the liquefaction zone perceived themselves to be exposed to earthquakes. The reason behind a high proportion of respondents perceiving earthquakes throughout the
Fig: 6.21. Potential Damage Perceived from Earthquakes in Areas Susceptible to Liquefaction in the Wellington Region

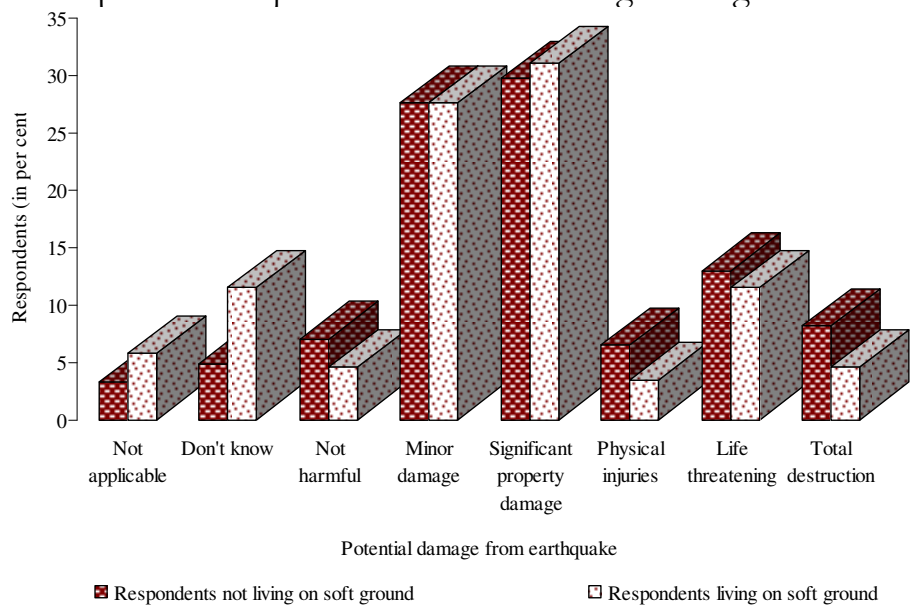

Based on Primary Survey, 2007 and data from Wellington Regional Council, 2006 
region could be attributed to high awareness and an active campaign of the Wellington Regional Council [WRC] about earthquake preparedness. Figure 6.18 shows that the ground conditions have little influence on people's perception of earthquake problems.

Figure 6.19 and figure 6.20 show that the people not living on soft ground have experienced earthquakes more frequently and think they will occur sooner in future than those people living on soft ground. This is a surprising result given the fact that soft ground amplifies the earthquake shaking. Fig: 6.21 shows that the respondents living on soft ground compared to those who are not living

on soft ground consider

earthquakes less harmful and less likely to cause physical injuries, death and total destruction.

Figure

6.22.A shows that respondents living on soft ground feel relatively safe and are not as worried about earthquakes as those who are not living on soft ground. Fig 6.22.B shows that while a smaller proportion of respondents living on soft ground are most afraid earthquakes, a relatively higher proportion of them fear flood, tsunami, drought or sea surge compared to those who are not living on soft ground.

The comparison of the awareness of respondents about hazard information provided by local governemnts shows that while a lower proportion of respondents living on soft ground
A. Perceived Feeling of Well-being against Earthquake

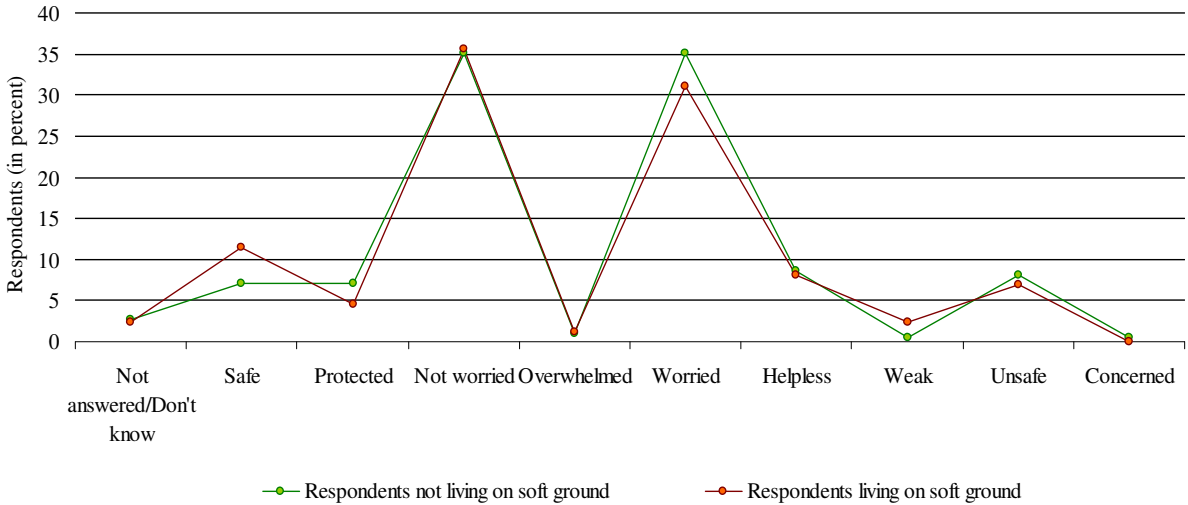

B. Most Feared Hazard

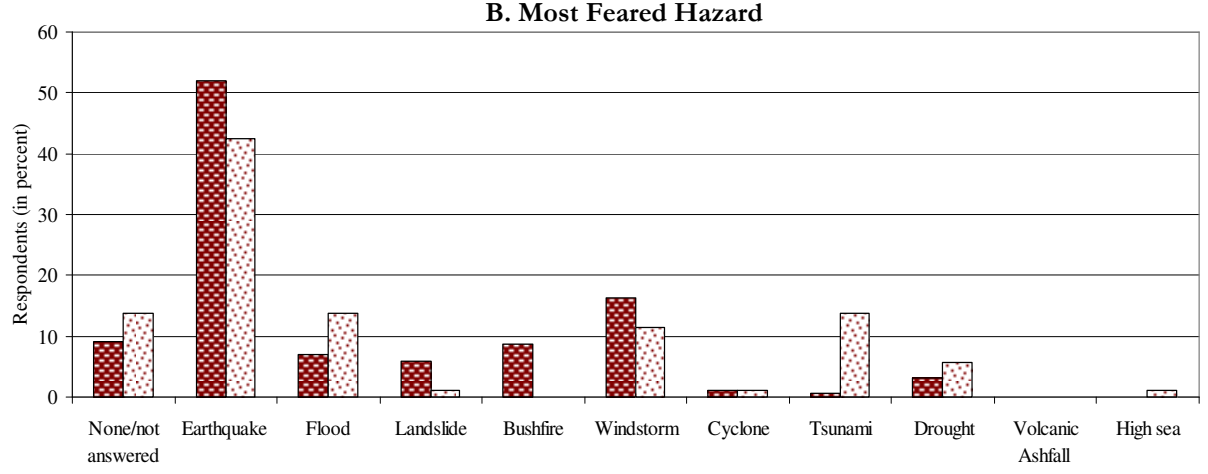

C. Awareness of Hazard Information Provided By Local Council

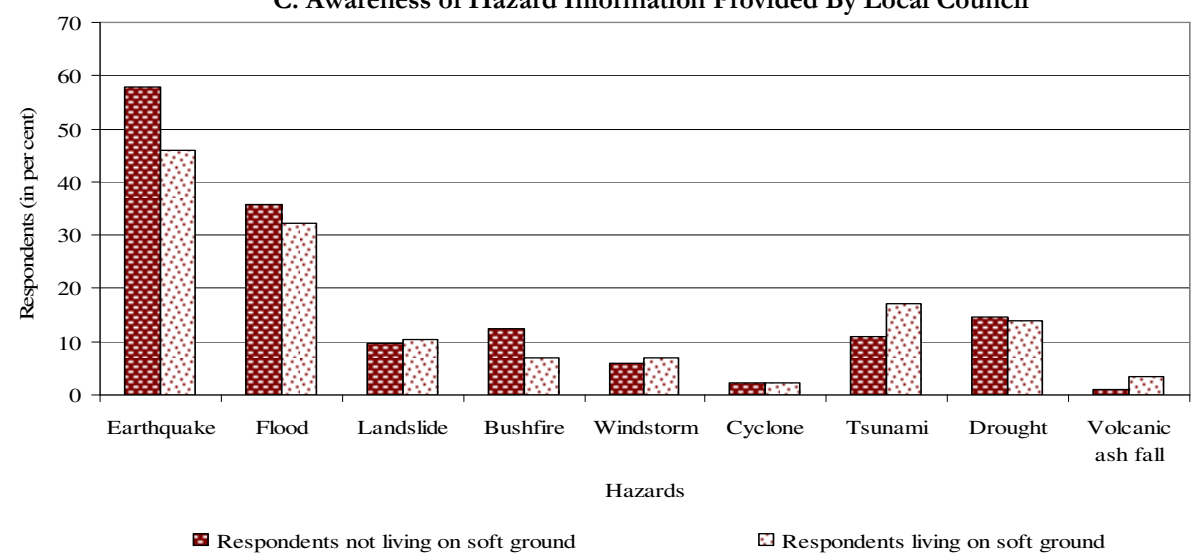

Based on Primary Survey, 2007 and data from Wellington Regional Council, 2006 
received information on earthquakes, floods, droughts and bushfires, a relatively high proportion of them received information about tsunami, landslide, windstorm and volcanic ash fall. An equal proportion of them received information about cyclones (Fig: 6.22.C). This mainly indicates that most of the respondents living on soft ground are located close to the coast, where both administration and local populations are also concerned about surface hazards along with liquefaction and ground settlement.

Fig: 6.23. Hazard Awareness of Respondent When First Settled at the Current Place of Residence

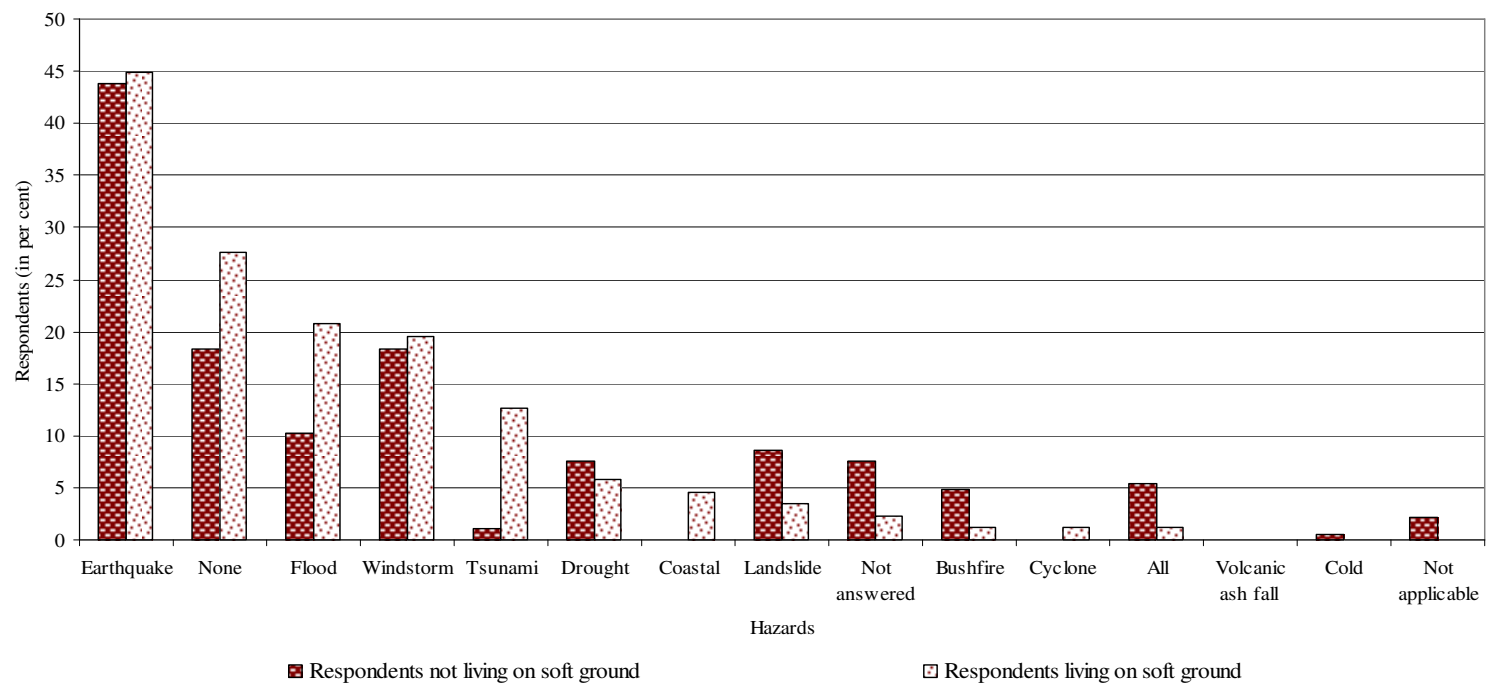

Based on Primary Survey, 2007 and data from Wellington Regional Council, 2006

The respondents were also asked about the hazards they were aware of when they first moved into their current house. A high proportion of the respondents living on soft ground named earthquake, no hazard, flood, windstorm and tsunami along with coastal hazards such as erosion or waves (Fig: 6.23). Less than six percent of the respondents mentioned drought, landslide and bushfire respectively. Despite being aware of a number of hazards, only 26 percent of the respondents in liquefaction zones said that they took any measure to cope with known hazard compared to 30 percent who lived in the areas not susceptible to liquefaction.

The comparison of mitigation measures taken by the respondents shows that a greater proportion of respondents living in liquefiable areas have either not taken any measures or took fewer measures compared to the respondents who lived outside soft ground or liquefaction zone (Fig: 6.24). Fig: 6.24. Hazard Mitigation Measures Taken by Respondent Living in Areas Susceptible to Liquefaction When First Moved into the House

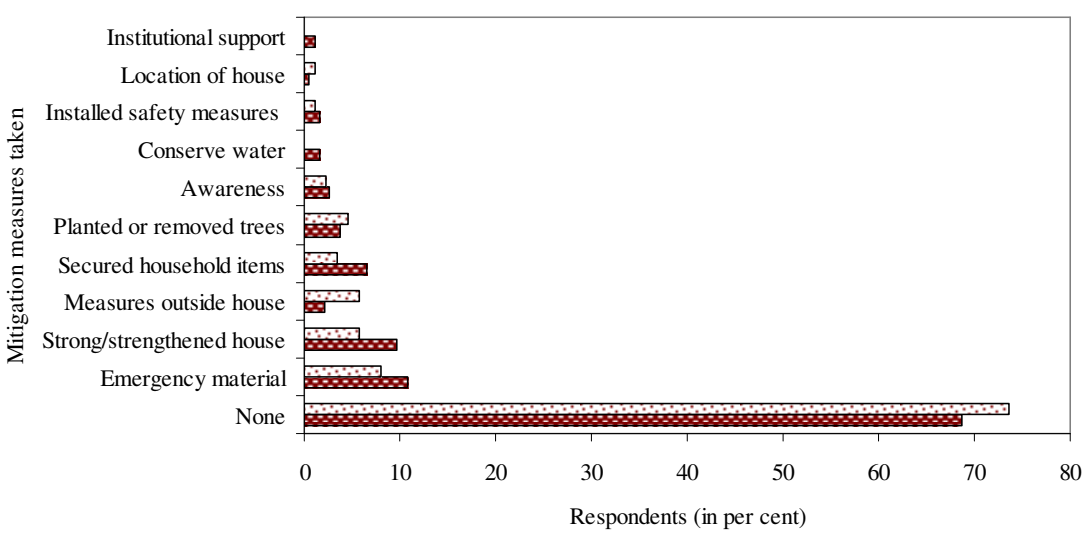

Although small in absolute numbers, a higher proportion of respondents living in liquefaction zone carefully selected the 
location of their residence, and constructed safety measures outside their house such as stop banks or sea walls or built pumps for ground water extraction or planted or removed trees to protect their house. A small proportion of them looked for institutional support, built or strengthened their house or stored emergency material or water. These measures indicate that earthquake is not the only concern for the respondents living on soft ground despite of their susceptibility to a high ground shaking and liquefaction. The respondents have taken measures for flood, drought and sea surge, which are viewed to occur closer in space and time.

A nearly similar percentage of respondents living in liquefiable areas (31 percent) and those who lived outside this zone (32 percent) said that they considered possible hazards at the time of purchasing or renting the house. While compared to 30 percent of the respondents living in liquefiable areas, 36 percent of those not living in such areas said that they have made changes to their house. Also a relatively higher proportion of respondents living on soft ground did not take any safety measures but they did keep cash or made emergency plans for possible disaster scenarios. A relatively small proportion of them kept a complete or partial survival kit compared to the respondents not living on soft ground (Fig: 6.25.A). When respondents were asked for which hazard did they took safety measures, a relatively lower proportion of respondents living in liquefiable zone named earthquake compared to those who lived outside of this zone (Fig: 6.25.B). A higher proportion of respondents on soft ground rather said that they took safety measures for all hazards, flood, tsunami, drought, cyclone, isolation or not for any specific hazard compared to the respondents who did not live on soft ground. This shows that the response to earthquakes is
Fig: 6.25. Types of Safety Measures for Hazards Taken by Respondent Living on Soft Ground
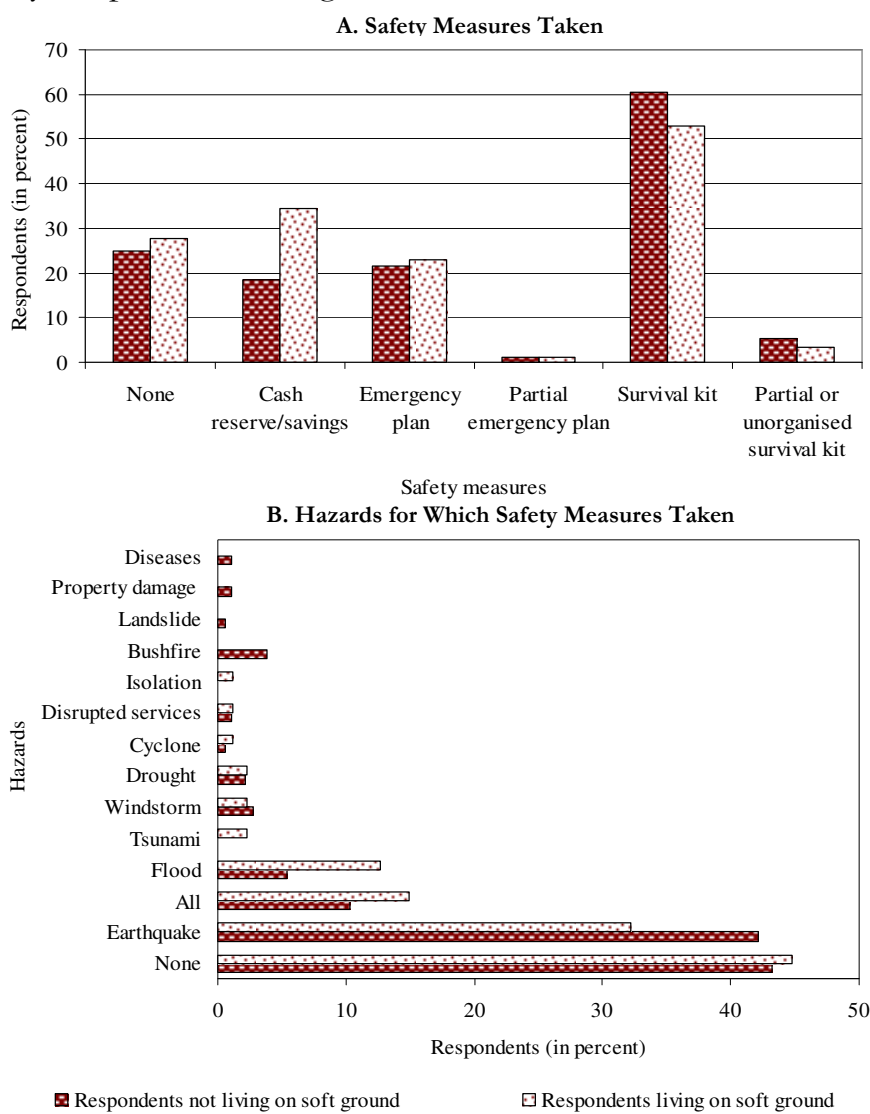

Based on Primary Survey, 2007 and data from Wellington Regional Council, 2006

Fig: 6.26. Perceived Earthquake Preparedness of Respondents Living on Soft Ground

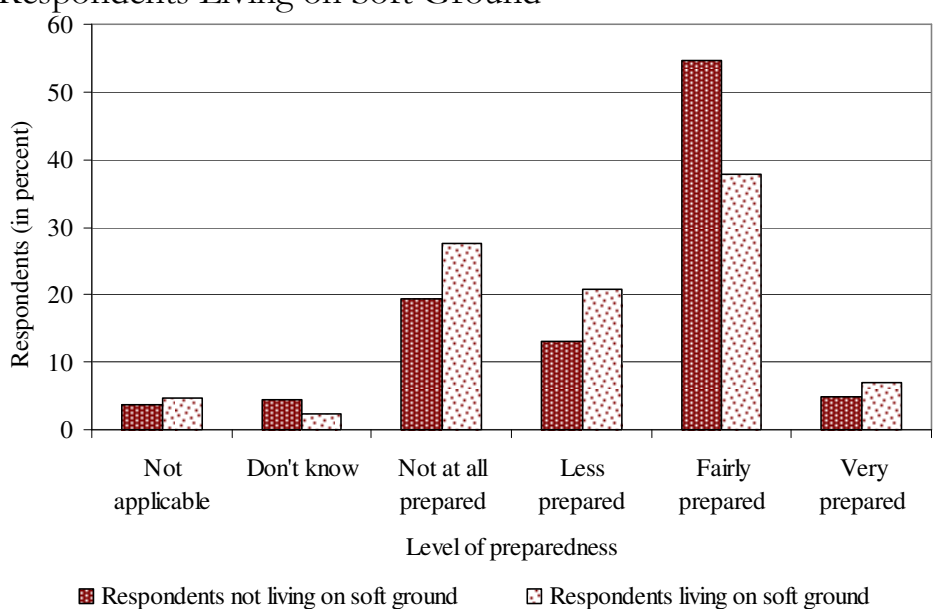

Based on Primary Survey, 2007 
influenced by the exposure of the respondents living in liquefaction zone to a number of other hazards such as flooding, drought and tsunami which require a different nature of planning and response.

The effect of location and hazard susceptibility is also visible in the perceived preparedness of respondents for earthquakes (Fig: 6.26). The data show that a higher proportion of respondents living on soft ground perceived themselves to be either not at all prepared or less prepared for earthquakes as compared to respondents not living on soft ground. This correlates with the hazards for which they took safety measures for (Fig: 6.25). It is observed that a higher proportion of respondents on soft ground find themselves to be more prepared for flood, drought, tsunami and cyclone, for which they have taken safety measures. On the other hand, respondents living outside the soft areas took safety measures for earthquakes and perceived themselves to be fairly prepared for them.

Therefore, while the location on the soft ground suggests that people should be more concerned about earthquakes that could cause excessive ground shaking, liquefaction or ground settlement, and thus a significant damage to their property and assets, the results of this survey are different. The data show that the respondents living on soft ground are relatively less worried about earthquakes compared to those who do not live on soft ground, and subsequently they have taken relatively less measures and are less prepared for earthquakes than the latter group. While a high awareness and preparedness for earthquake throughout the region could be attributed to active campaign of WRC, a relatively low preparedness for earthquakes in the respondents living on soft ground could be attributed to the nature of information provided by WRC for earthquake preparedness, which does not place much emphasis on associated hazards such as liquefaction.

\subsubsection{Physiography}

Physiographic features also influence hazard occurrence, and slope angle is a key physiographic element of hazard susceptibility. Slope influences the nature, and occurrence of many hazards

Fig: 6.27. Perceived Hazard Exposure of Respondents Living at Different Slope Angles

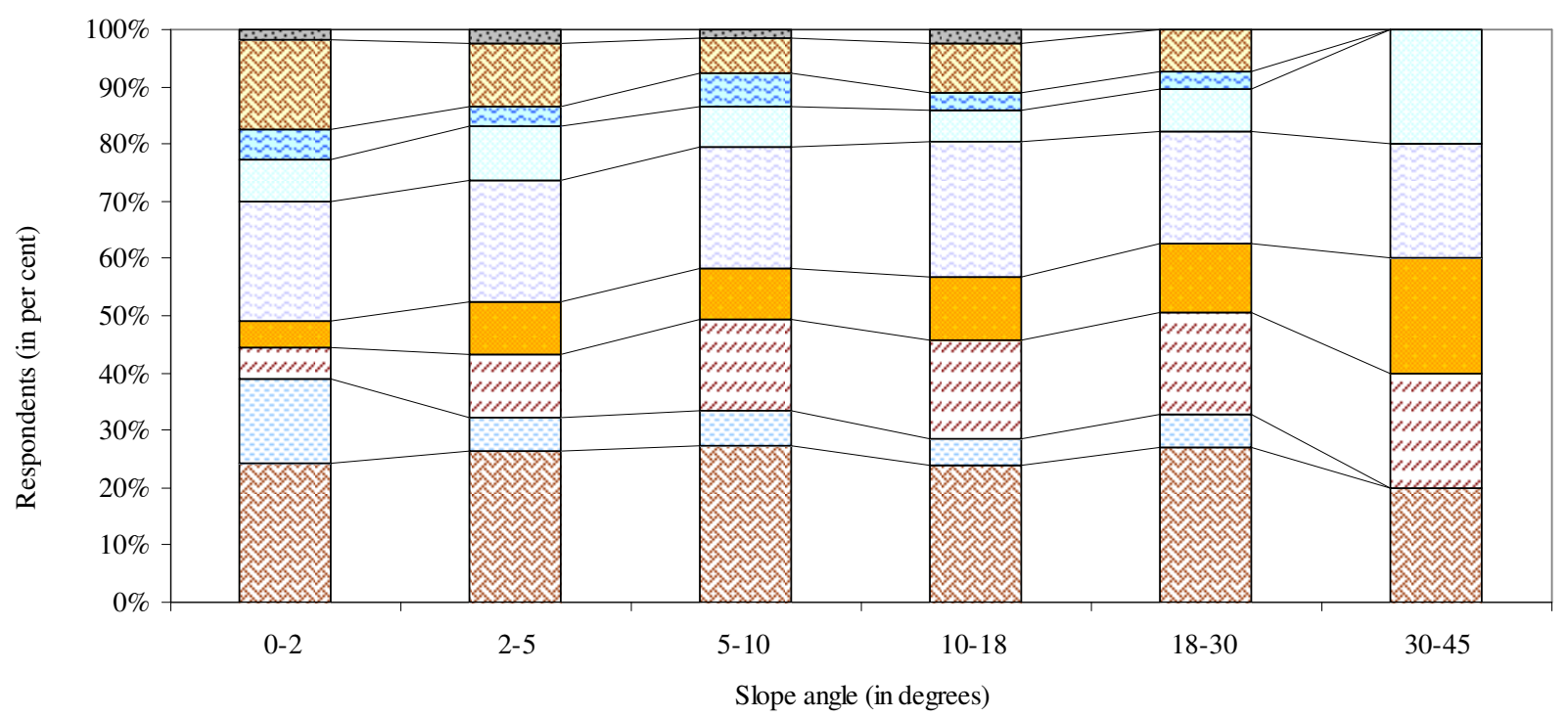

Earthquake $\square$ Flood $\square$ Landslide $\square$ Bushfire $\square$ Windstorm $\square$ Cyclone $\square$ Tsunami $\quad \square$ Drought $\quad$ Volcanic ash fall Based on Primary Survey, 2007 and data from Wellington Regional Council, 2006 
including landslides, windstorm, bushfire, flood, tsunami and drought. The data show that the proportion of respondents who perceive themselves to be exposed to landslides, bushfire and to an extent cyclones rises with the increase in slope angle (Fig: 6.27). The perception of exposure to bushfire with increasing slope angle is mainly linked to the presence of more trees on slopes. The respondents living on steep slopes have planted trees to avoid landslides, which leads to the fear of bushfire during summer.

The perception of exposure to windstorm and earthquakes is rather general across all slope angles (Fig: 6.27). Slope also makes less difference for the perception of exposure to volcanic ash fall. While some respondents living on gentle $\left(0-5^{0}\right)$ or moderate slopes $\left(5-18^{0}\right)$ perceived an exposure to volcanic ash fall, none of the respondents from moderately steep (10-18 $)$ to steep slopes $\left(>18^{\circ}\right)$ perceived such exposure. Although flood and tsunami are hazards of gentle slope, the respondents from moderate $\left(5-18^{\circ}\right)$ to moderately steep slopes $\left(10-18^{\circ}\right)$ and steep $\left(18-30^{\circ}\right)$ also perceived themselves to be exposed to these hazards. While the respondents living on moderate to steep slopes experience flooding due to inadequate drainage, droughts on high slope angles mainly occur due to faster run off and long intermittent period between rainfall events. Tsunami on moderate slopes is mainly perceived due to close proximity to sea, where waves could easily reach significant heights.

The

proportion of respondents who faced problems through hazards at different slope angle does not portray any specific relationship (Fig: $\quad$ 6.28.A). However, a high proportion of respondents living on very gentle slopes $\left(0-2^{9}\right)$ find hazards to be highly problematic and the highest proportion of respondents who find problems to be
Fig: 6.28. Problems from Hazards to Respondents Living across Slopes

A. Extent of Problems from hazards across Slope

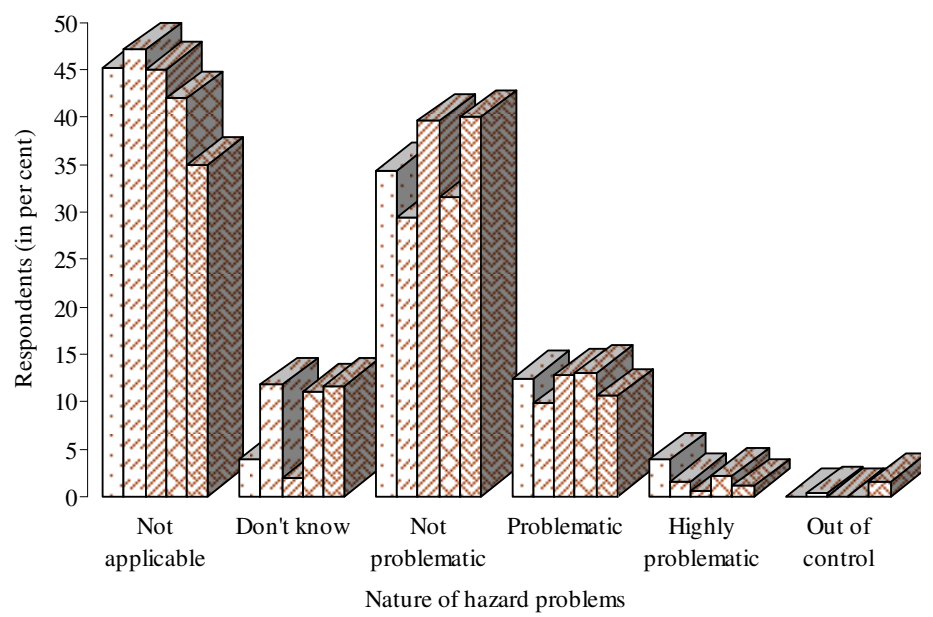

$\square$ 0-2 degree $\square$ 2-5 degree $\square 5$-10 degree $\square$ 10-18 degree $\square$ More than 18 degree

B. Problems from Types of Hazards across Slopes

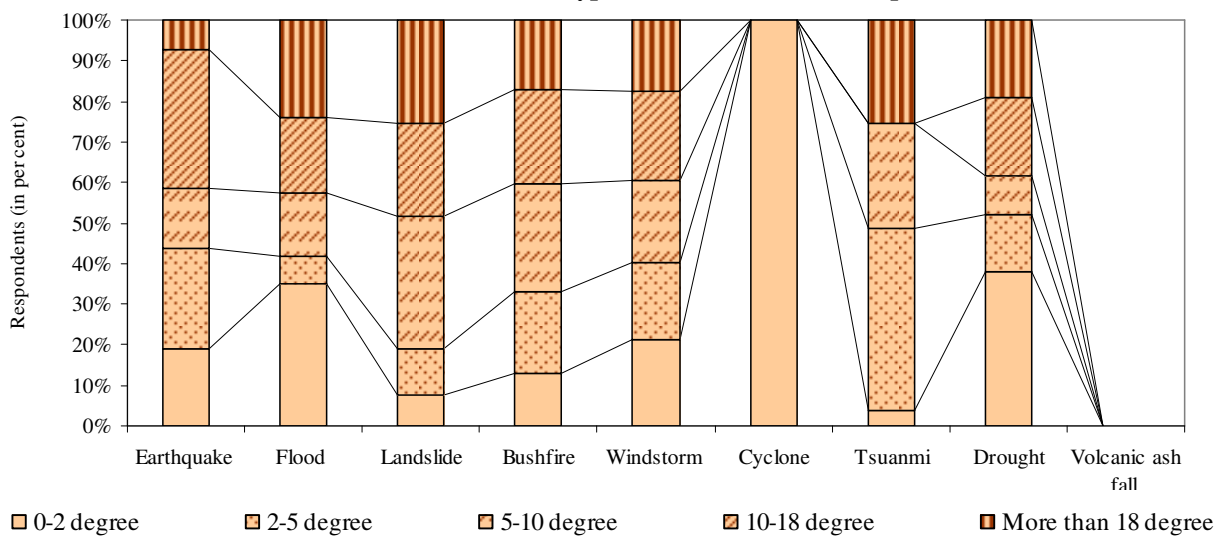

Based on Primary Survey, 2007 and data from Wellington Regional Council, 2006 
out of control were living on steepest slopes $\left(>18^{\circ}\right)$. As noted in Fig: 6.27, the perception of cyclone exposure increases with the increase in slope angle, but a high proportion of respondents who found cyclone to be problematic were from very gentle plains, i.e. four from the Kapiti Coast, two each from Carterton, Masterton and South Wairarapa and one from Wellington. The problems from windstorms are experienced across all slopes. Although in general the proportion of respondents who faced problems from landslide and bushfire increasing with increase in slope angle (Fig: 6.28.B), more respondents from moderate slopes experienced problems with these hazards compared to respondents living in other areas. A high proportion of respondents living on gentle plains found flood and drought to be problematic compared to tsunami, which is dominantly found to be problematic by the respondents living on moderately gentle slopes $\left(2-5^{0}\right)$. The reason behind this difference is the distance from coast, which strongly affects the perception of tsunami.

The frequency of hazards in the region also shows variations across slope angles. The data show a constant rise in the proportion of respondents, who face hazards at least once in a month with increasing slope angle (Fig: 6.29.A). On the other hand, a declining trend can be observed for

Fig: 6.29. Frequency of Hazards Experienced by Respondents Living on Different Slope Angles

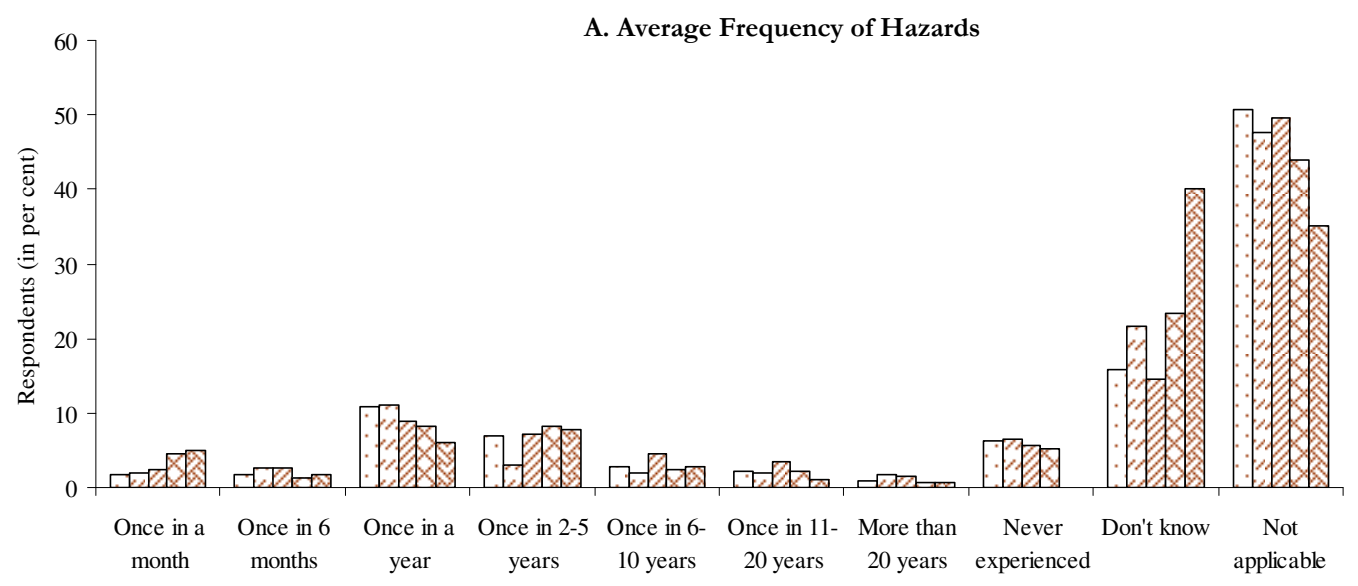
Frequency

$$
\square \text { 0-2 degree } \square \text { 2-5 degree } \square \text {-10 degree } \quad \text { More than } 18 \text { degree }
$$

B. Frequency of Different Type of Hazards

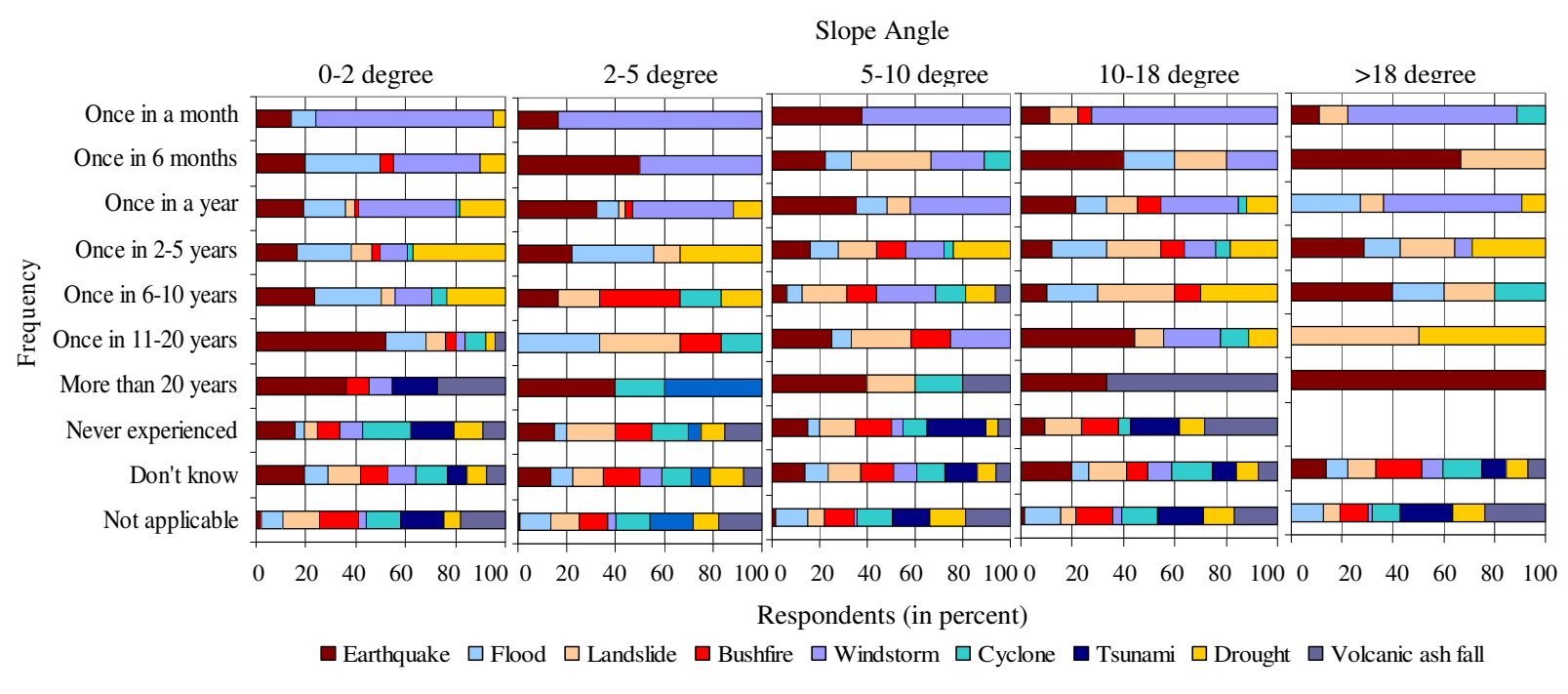

Based on Primary Survey, 2007 and data from Wellington Regional Council, 2006 
the proportion of respondents who face hazards within a year with increasing slope angle. The overall trend indicates that while the highest proportion of respondents either found the hazards to be not applicable or did not know their frequency; the respondents who mentioned the frequency, a relatively high proportion of them mentioned hazards to occur in five years than those who viewed it distant in future.

The data also show a significant variation in the type of hazards people face across the slope angles. While windstorm is the most frequent hazard across all slopes along with earthquakes, respondents on gentle slopes face flood and those on moderate to steep slopes face landslides at least once in a month (Fig: 6.29.B). While respondents on moderately steep slopes (10-18 ${ }^{9}$ reported frequent bushfires, those on steep slopes $\left(>18^{\circ}\right)$ did not report any bushfire. Cyclones are intermittently reported at all slopes, however, they are reported to be more frequent by the respondents living on moderate to steep slopes compared to those who live on gentle slopes. Opposite to this, drought and flood are reported more frequently in areas of low slope angles compared to those on moderate or steep slopes.

Fig: 6.30. Hazard Occurrence in Future as Perceived by Respondents Living on Different Slope Angles

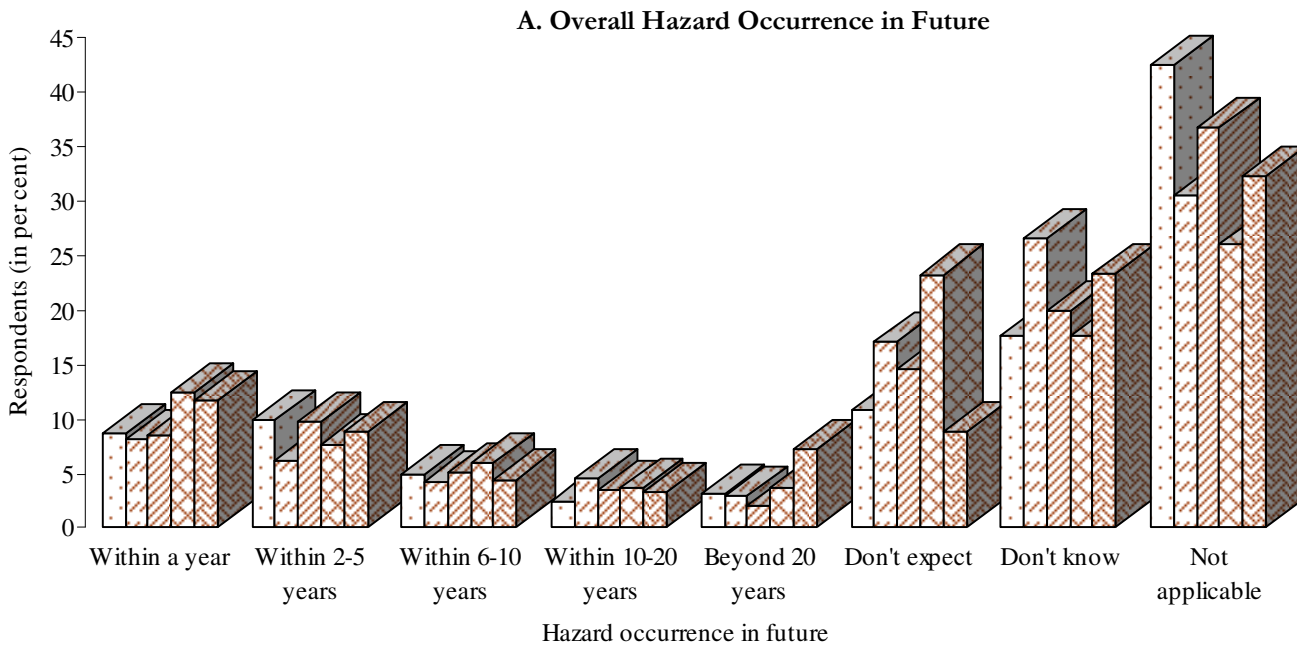

$\square$ 0-2 degree $\square$ 2-5 degree $\square$-10 degree $\square$ 10-18 degree $\quad$ More than 18 degrees

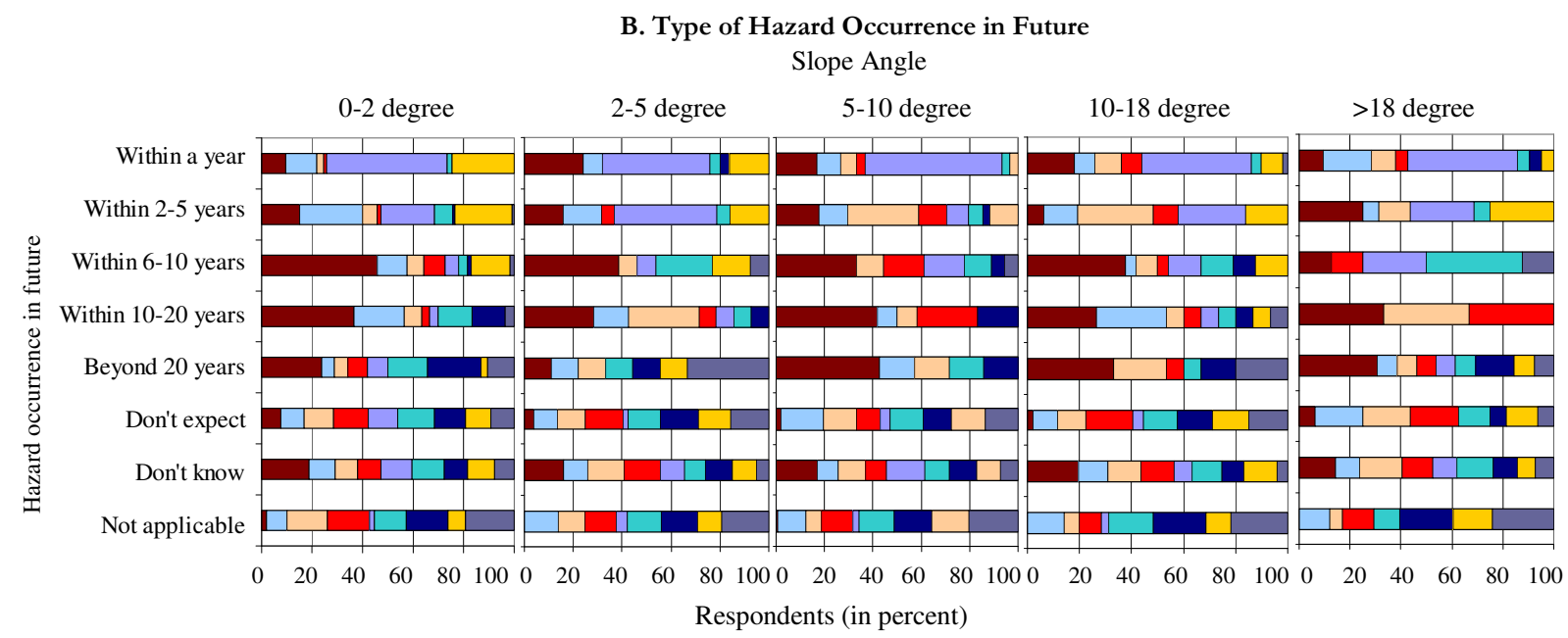

$\square$ Earthquake $\square$ Flood $\square$ Landslide $\square$ Bushfire $\square$ Windstorm $\square$ Cyclone

- Tsunami $\square$ Drought $\square$ Volcanic ash fall 
No consistent relationship is observed in the trend for perception of respondents for hazard occurrence in future with their location on different slope angles. However, at a very broad level it can be said that a high proportion of respondents living on moderately steep and steep slopes perceived a hazard to occur within a year compared to those living on either gentle or moderate slopes (Fig: 6.30.A).

The type of hazards perceived in the near future show that while the respondents on steep slopes don't face bushfire and drought very often, they perceive it to occur within a year (Fig: 6.30.B). Similarly, those on gentle slopes, although they said that they don't face cyclone very often, perceive it to be closer in the future i.e. within a year or two to five years. Earthquakes and windstorms are perceived to occur in the near future by respondents across all slope angles, while all respondents perceived volcanic ash fall in the distant future.

A general trend can be observed in the extent to which potential danger is perceived by the respondents with increasing slope angle (Fig: 6.31.A). While more respondents on gentle and

Fig: 6.31. Potential Danger from Hazards Faced by Respondents Living on Different Slope Angles

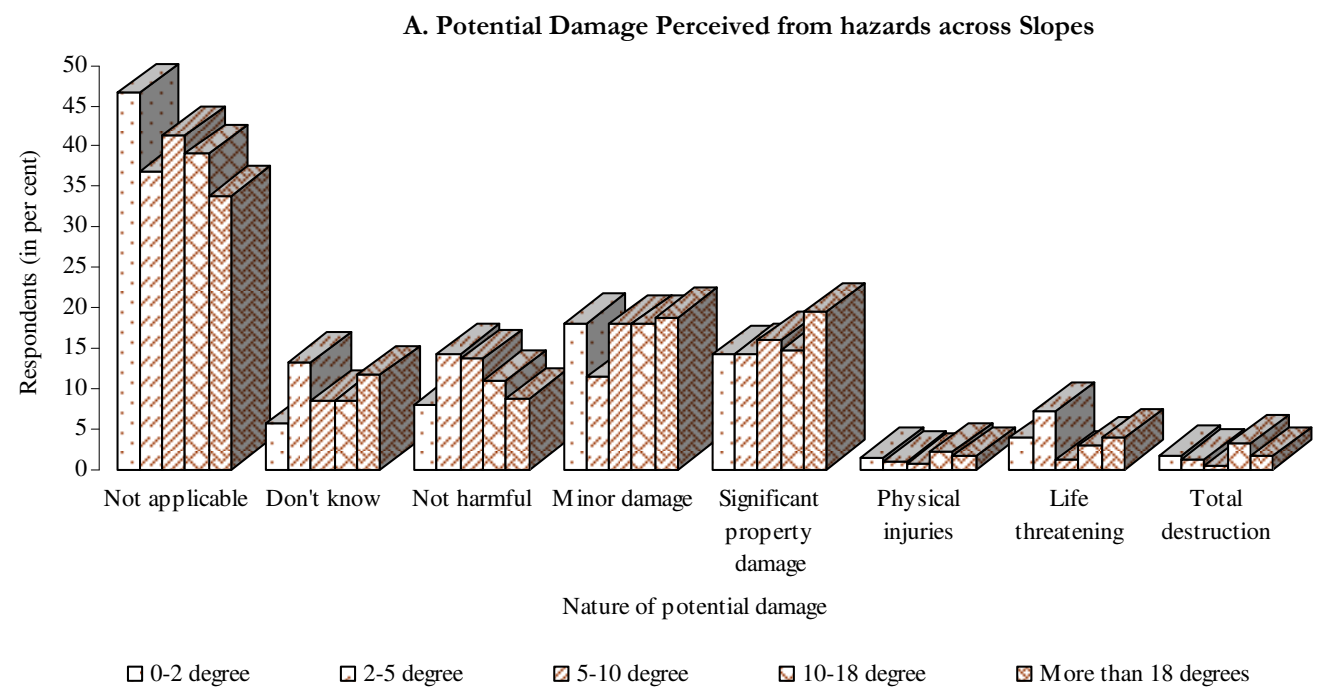

B. Potential Damage Perceived from Types of Hazards across Slopes

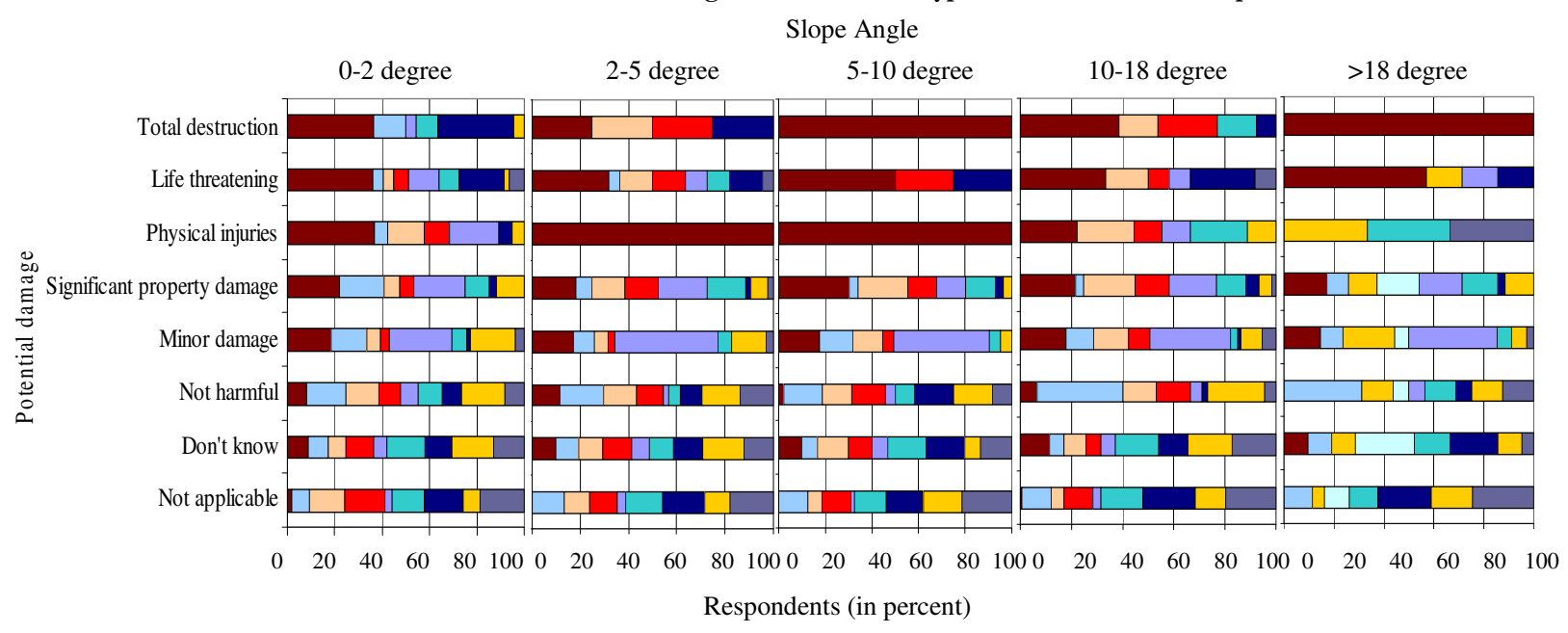

Earthquake $\square$ Flood $\square$ Landslide $\square$ Bushfire $\square$ Windstorm $\square$ Cyclone $\square$ Tsunami $\square$ Drought $\square$ Volcanic ash fall 
moderately gentle slopes perceive hazards as not harmful or causing minor damage, a relatively high proportion of respondents living on moderately steep and steep slopes perceive them to cause

Fig: 6.32. Perceived Situation against Hazards of Respondents Living on Different Slope Angles

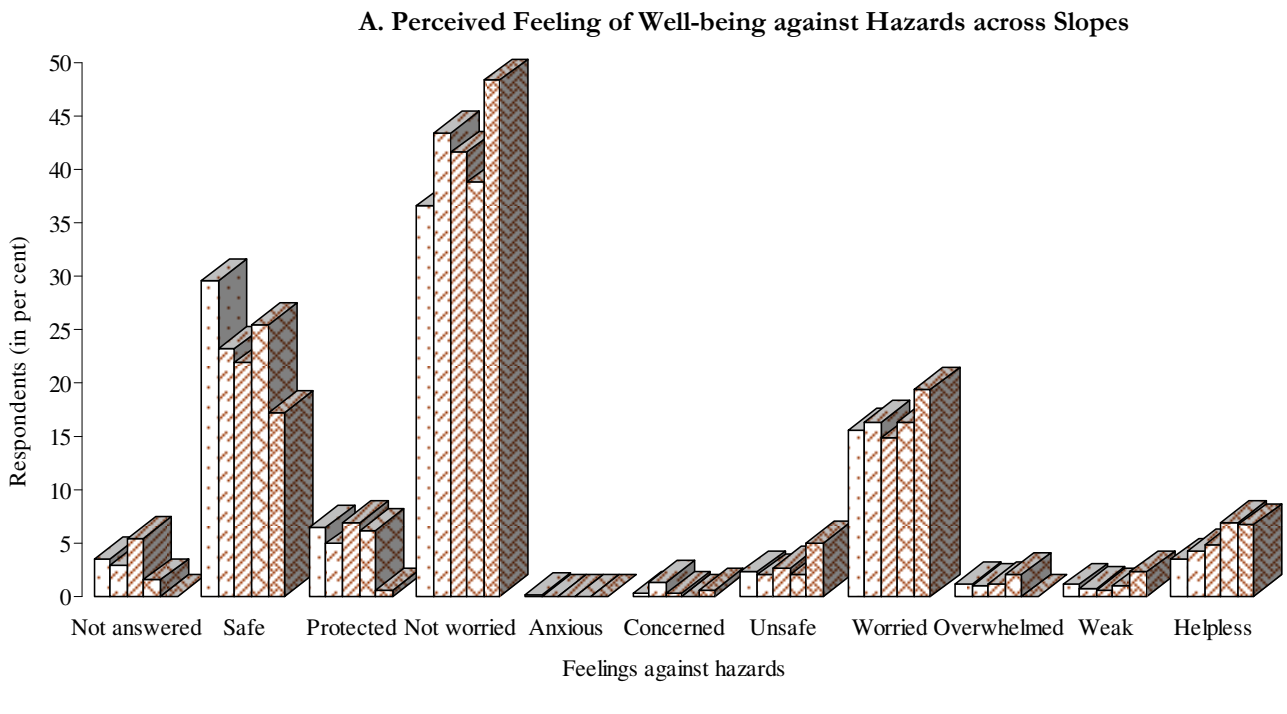

$\square$ 0-2 degree $\square$ 2-5 degree $\square$ 5-10 degree $\quad \square$ More than 18 degrees

B. Perceived Feeling of Well-being against Types of Hazards across Slopes

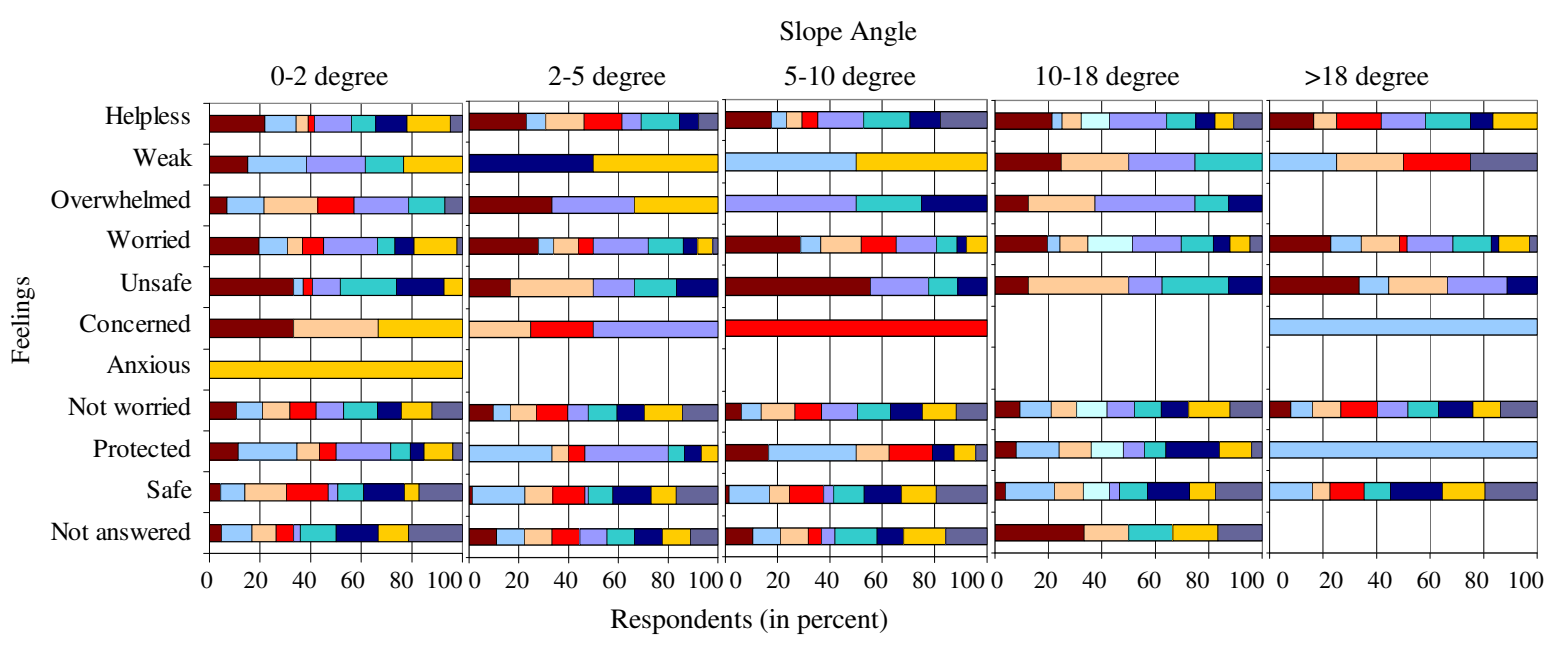

घ Earthquake $\square$ Flood $\square$ Landslide $\square$ Bushfire $\square$ Windstorm $\square$ Cyclone $\square$ Tsunami $\square$ Drought $\square$ Volcanic ash fall

Based on Primary Survey, 2007 and data from Wellington Regional Council, 2006

significant property damage. The perception of physical injuries is also high among respondents living on moderately steep $\left(10-18^{0}\right)$ to steep slopes $\left(>18^{0}\right)$. However, the perception of hazards as life threatening is dominant in the respondents on moderately gentle slopes $\left(2-5^{0}\right)$ followed by those on gentle slopes $\left(<2^{9}\right)$, but the perception of total destruction is again high in the respondents living on moderately steep and steep slopes.

The potential danger perceived from different types of hazards also varies for respondents living on different slope angles. While the respondents living on gentle slopes perceive a number of hazards being able to cause total destruction, those on moderate to steep slopes predominantly see earthquakes causing total destruction (Fig: 6.31.B). The fear of landslides and bushfire causing disaster is more dominant in the moderately gentle $\left(2-5^{0}\right)$ and moderately steep (10-18 $)$ slopes. Tsunami is seen as life threatening and destructive by the respondents living on gentle to 
moderately gentle slopes. Cyclones are mainly seen as an agent of destruction by respondents living on either very gentle or moderately steep slopes, while windstorm is perceived to cause total destruction by a few of respondents living on gentle slopes. Most respondents from other slopes mainly find windstorm causing minor or significant property damage, and very few respondents see it as life threatening. The fear of flood, on the other hand, is more dominant on gentle slopes for causing significant damage, while the perception of drought for severe damage is found in the respondents living on steep slopes.

The overall perceived feeling of well-being against hazards relates more closely to the location of respondents at different slope angles (Fig: 6.32.A). While more respondents living on gentle slopes felt safe from various hazards, the proportion of such respondents decreases with increasing slope angle. The trend is the opposite for the proportion of respondents who felt unsafe, worried or helpless against hazards, as the number of such respondents increases with the increasing slope angle. The proportion of respondents who were not worried about any hazard also increases with increasing slope angle. However, it is clear that they know they are neither safe nor protected from most of the hazards. On the other hand, it is difficult to relate the perceived situation of respondents to different types of hazards, and it does not show a clear trend (Fig: 6.32.B).

Fig: 6.33. The Most Feared Hazard by Respondents Living on Different Slope Angles

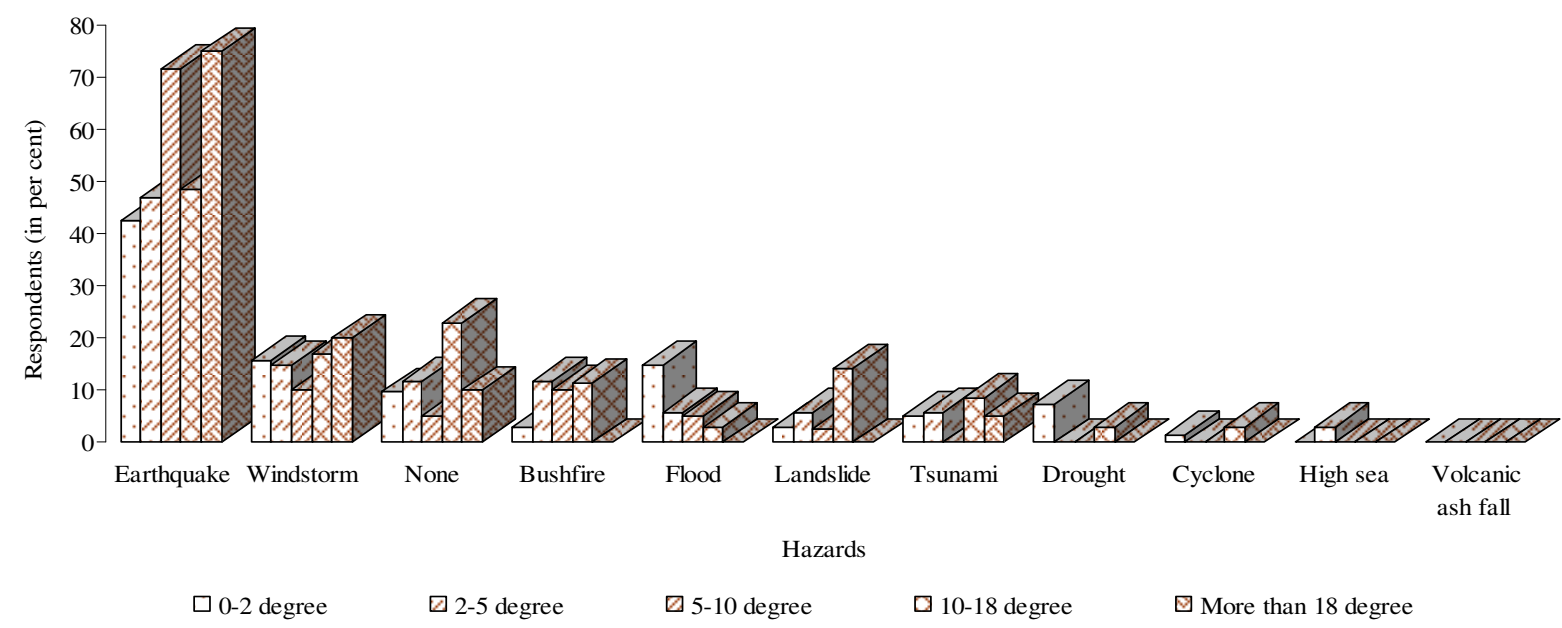

Based on Primary Survey, 2007 and data from Wellington Regional Council, 2006

The most feared hazards of respodents do not match consistently with slope angles for all hazards (Fig: 6.33), but there is a very general trend of increase in the proportion of respondents who fear earthquake with increasing slope angle. The windstorm is the second most feared hazard but as with many other hazards, there is not a clear relationship with slope angle. The only hazard, for which a steady relationship is evident, is flood as a consistent decline in noted in the proportion of respondents who feared flood with increasing slope angle.

The awareness of the respondents about the hazard information provided by the local councils also shows some variations with respect to slope angle, even though there is not any definite trend for each hazard (Fig: 6.34.A). Information on earthquakes is provided across all slope angles, and a higher proportion of respondents on the moderately steep and steep slopes 
Fig: 6.34. Awareness of Hazard Information Provided by the Local Council to Respondents across Slopes

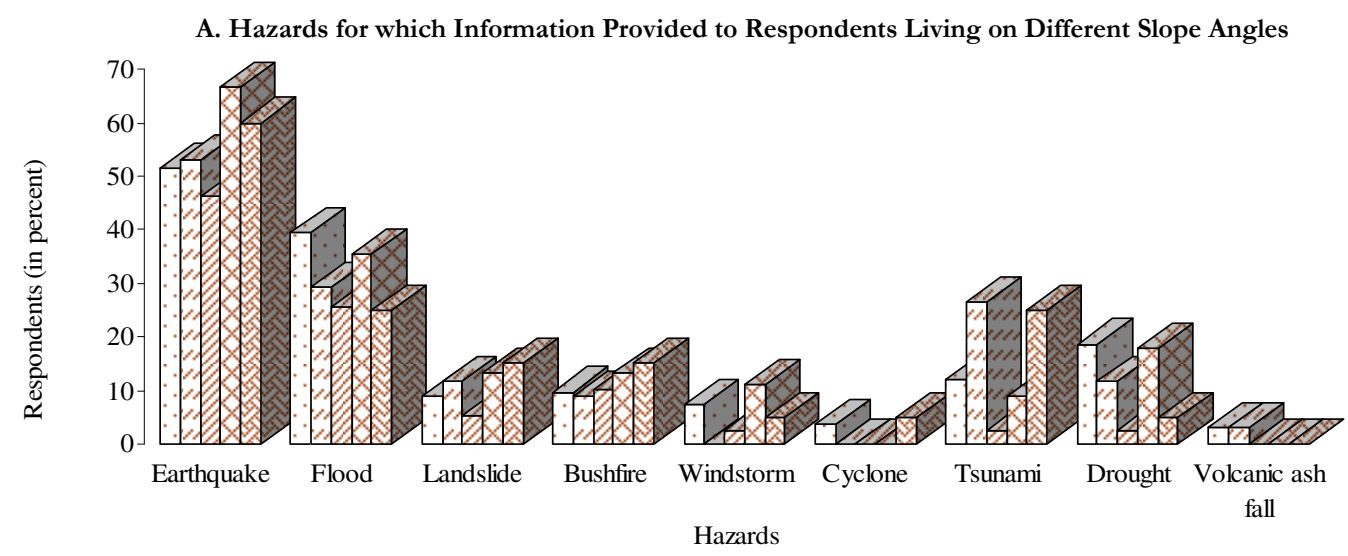

$\square$ 0-2 degree $\square 2-5$ degree $\square 5$-10 degree $\quad$ 10-18 degree $\otimes$ More than 18 degree

B. Number of Hazards for which Information Provided to Respondents Living on Different Slope Angles

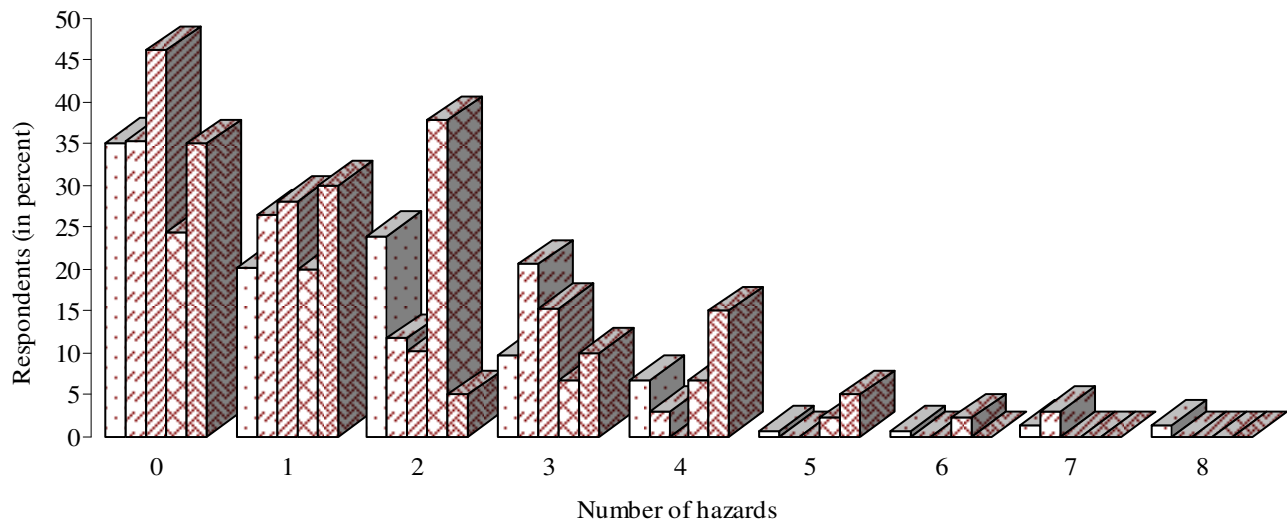

$\square$ 0-2 degree $\square$ 2-5 degree $\square 5$-10 degree $\square$ 10-18 degree $⿴$ More than 18 degree Based on Primary Survey, 2007 and data from Wellington Regional Council, 2006

mentioned receiving information compared to those on moderate or gentle slopes. A general increasing trend is observed with increasing slope angle for the information provided by local council for landslides and bushfires. On the other hand, a decreasing trend is noted for flood and drought information to the respondents on gentle slopes compared to those living on steep slopes.

Fig: 6.35. Hazard Awareness When First Settled at the Current Place of Residence of Respondents Living on Different Slope Angles

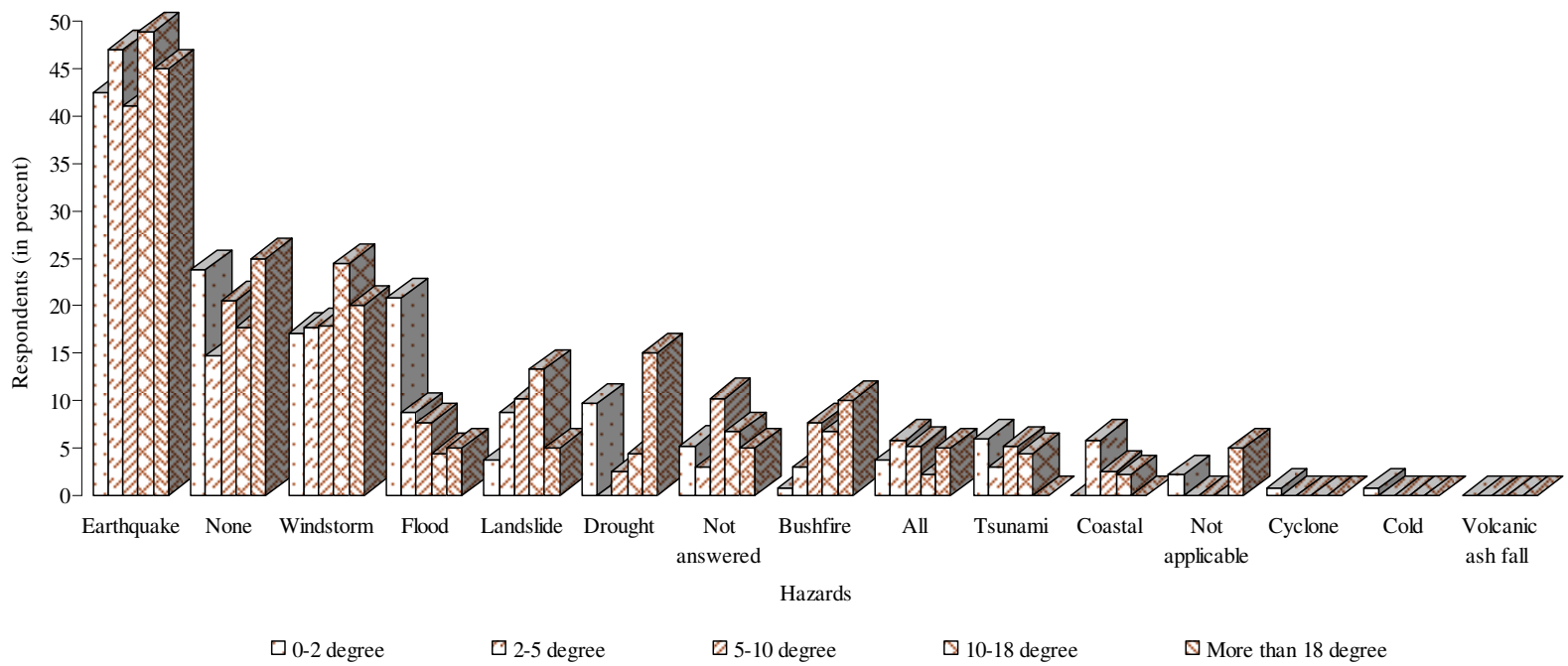


There is no clear trend for information provided for other hazards. The trend is also not consistent with the number of hazards for Fig: 6.36. Hazards Considered and Mitigation Measures Taken by the which information is provided by local council across different slope angles (Fig: 6.34.B). However, none of the respondents from high slope angles mentioned Respondents across Slopes When They First Settled at Current Residence

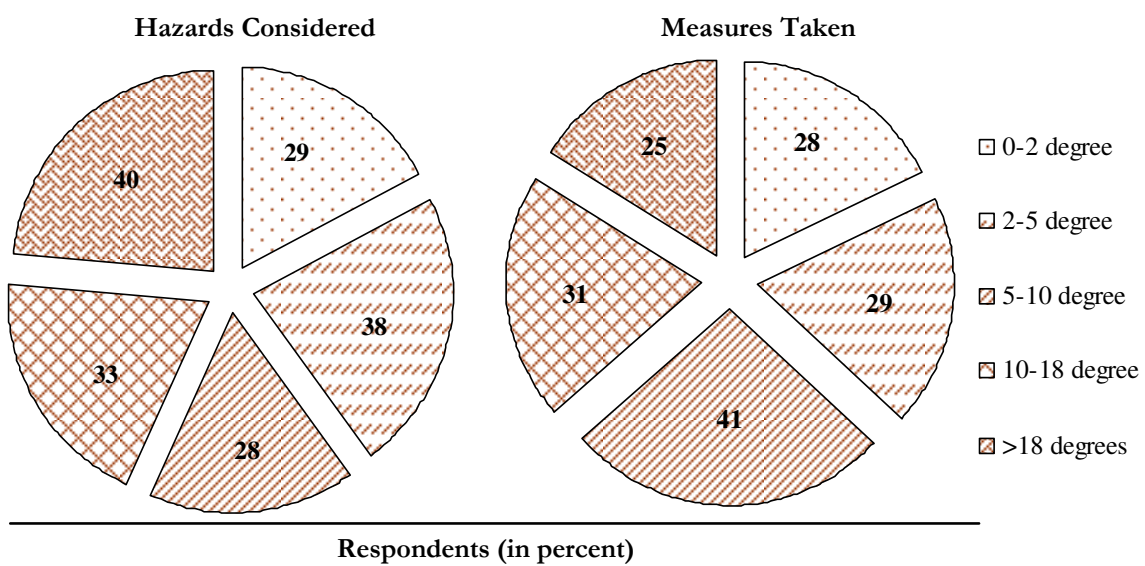

receiving

Based on Primary Survey, 2007 and data from Wellington Regional Council, 2006

information about seven or more hazards.

When respondents first settled at their current residence, most of them were aware of either earthquake or windstorm or no hazard, irrespective of their location on any specific slope angle (Fig: 6.35). The hazards for which a general trend could be witnessed for awareness with respect to slope angle include flood, which shows a declining trend with increasing slope angle and bushfire which shows the reverse trend. Other hazards show no distinctive trend.

While the highest proportion of respondents living on steep slope $\left(>18^{0}\right) \quad$ enquired about hazard when they first settled in their current residence, a smaller proportion of these respondents took mitigation measures (Fig: $\quad$ 6.36). In contrast, while respondents living on moderate slopes

Fig: 6.37. Type of Hazard Mitigation Measures Taken and Changes Made by the Respondent Living on Different Slope Angles When First Moved into Current Residence

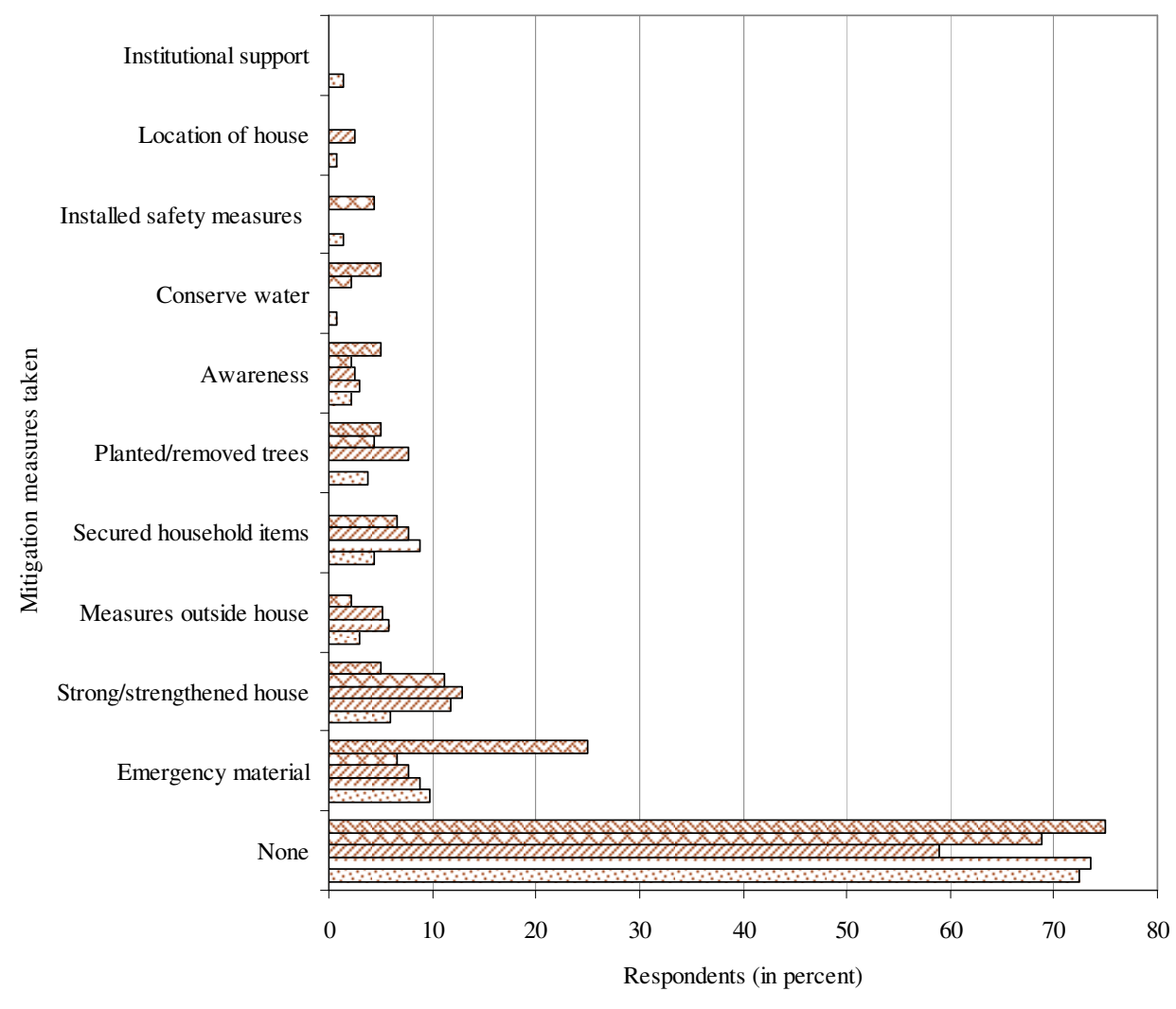

ㅂ. 0-2 degree

2-5 degree 
(5-10 $)$ have the lowest inquiry rate of all, they had highest proportion of those taking mitigation measures. Only 1.5 percent of respondents living on gentle slopes had to move away from their house due to hazards compared to nine percent of respondents from moderately steep slopes who shifted their house because of hazards. The shifts on gentle slopes were associated with landslide and swampy ground; while those on moderate slope were associated with flooding and landslide.

The survey results show that most repondents did not take any measures for natural hazards when they first moved into their residence. The type of hazard mitigation measures taken by the respondents portrays a difference across slopes, but does not follow a clear pattern (Fig: 6.37). The data show that the proportion of respondents having emergency material declines with increasing slope angle, except for steep slope category where it rises sharply. Nearly 25 percent of respondents living on steep slopes have stored emergency material compared to less than 10 percent of respondents on any other slope angle. The respondents on steepest slope also topped in conserving water, and getting information to enhance their awareness about hazards.

Fig: 6.38. Safety Measures Taken by Respondents across Slopes

A. Type of Safety Measures Taken by Respondents Living on Different Slope Angles
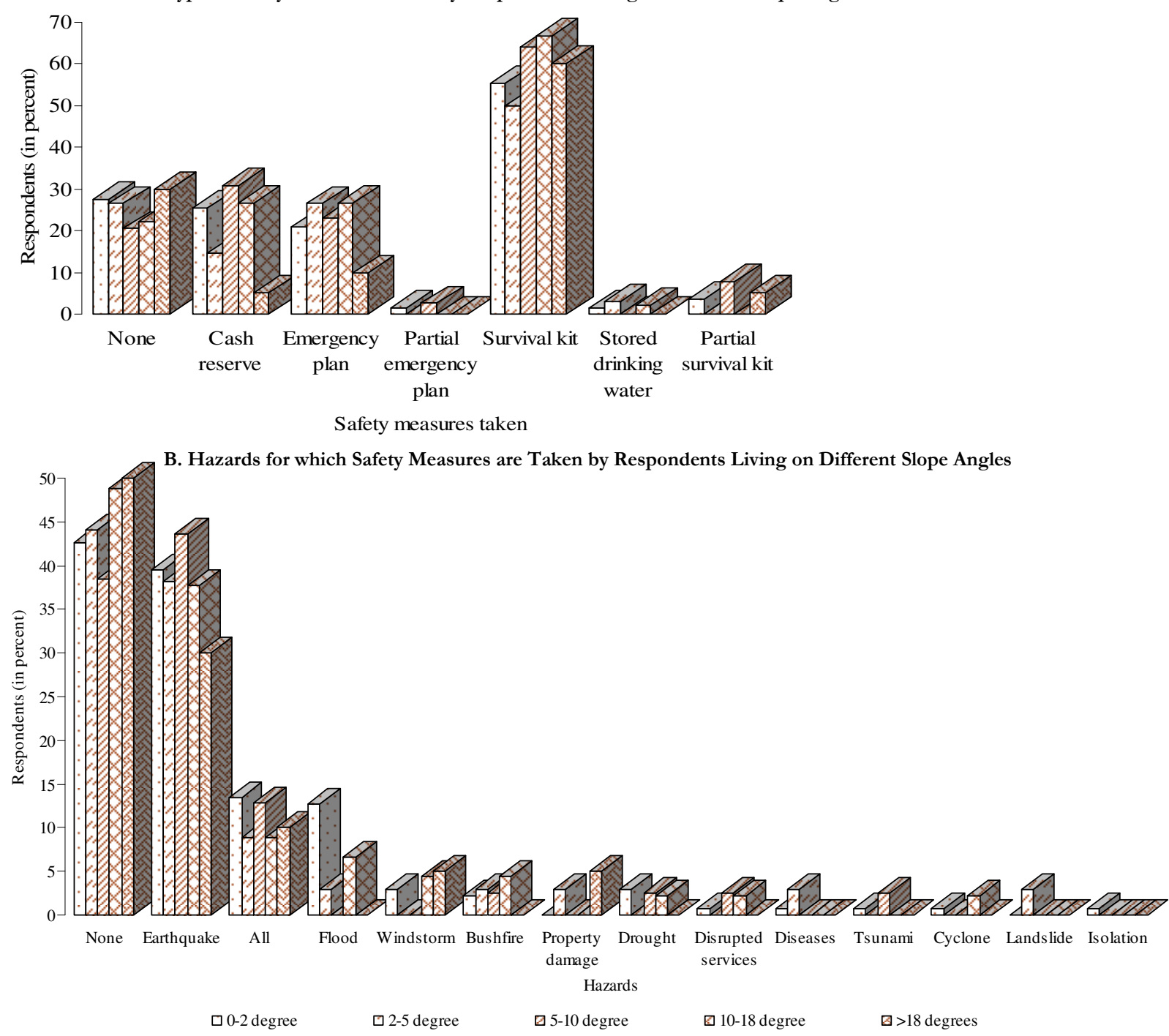

Based on Primary Survey, 2007 and data from Wellington Regional Council, 2006 
Figure 6.38.A shows a greater proportion of respondents living on moderate or steep slopes secured the survival kit as a safety measure than those living on gentle slopes. However, the overall data show that irrespective of the slope angle, survival kits are the most favoured safety measure followed by having cash reserves, an emergency plan. Slope angle of residence appears to have only a minor and inconsistent influence on the type of safety measure adopted.

Turning to the type of hazards to which people have responded to (Fig: 6.38.B), the first thing to note is that most respondents (except for those living on moderate slopes of $5-10^{\circ}$ ) have taken the safety measures for none of the mentioned hazard. The second highest proportion of respondents took measures against earthquake. Against the trend of no hazard, which increased with slope angle, the proportion of respondents who took safety measures for earthquakes declines with increasing slope angle except for those on moderate slopes. In general the proportion of respondents who took safety measures for flood, drought or all hazards also tended to decline with increasing slope angle, but the relationship is not consistent. Similarly, not consistent but a reverse trend is witnessed for windstorm, bushfire and property damage.

Fig: 6.39. Perceived Hazard Preparedness Levels of Respondents across Slopes in the Wellington Region

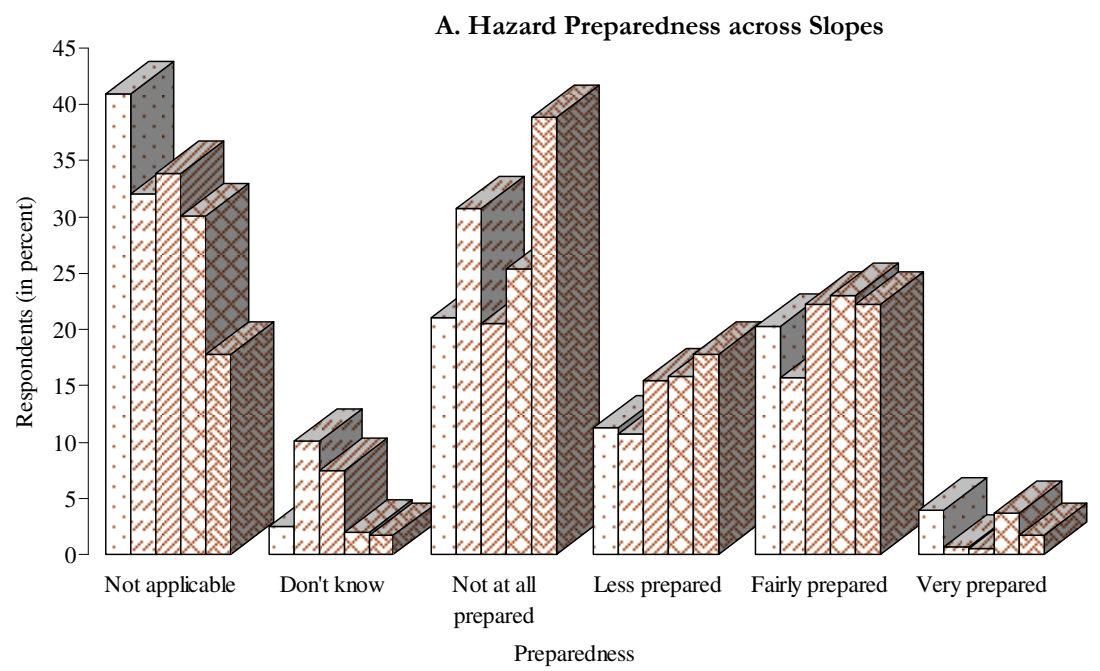

$\square$ 0-2 degree $\square$ 2-5 degree $\square$ 5-10 degree $\square$ 10-18 degree $\quad$ More than 18 degrees

B. Preparedness for Different Hazards across Slopes

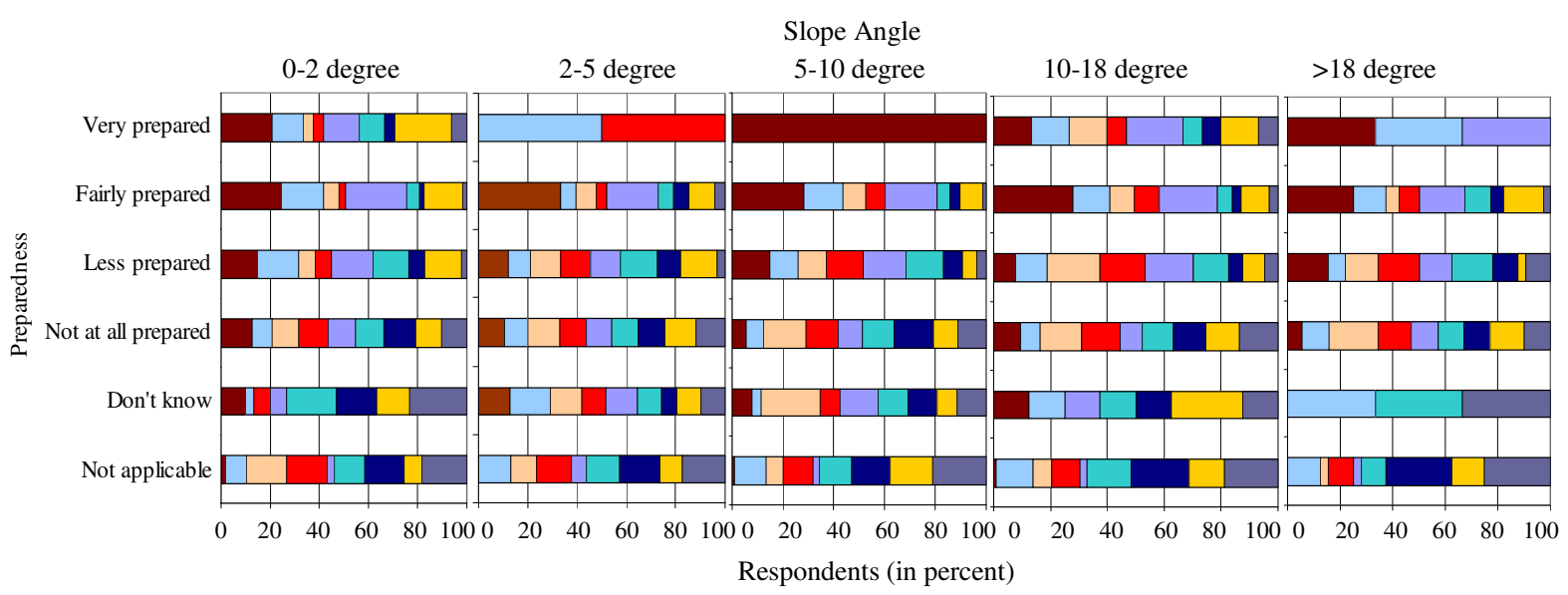

$\square$ Earthquake $\square$ Flood $\square$ Landslide $\square$ Bushfire $\square$ Windstorm $\square$ Cyclone

Tsunami $\square$ Drought $\square$ Volcanic ash fall 
The proportion of respondents who perceived themselves to be not at all prepared for any hazard in general increases with slope angle and a similar trend exists for those who are less prepared (Fig: 6.39.A). The highest percentage of respondents, who are very prepared for any hazard mainly live on gentle slopes followed by those on moderately steep and steep slopes. The differentiation of preparedness for different types of hazards shows that the respondents on moderate slopes are very prepared only for earthquakes, on moderately gentle slope for flood and bushfire, and on steep slopes for earthquakes, floods and windstorms (fig: 6.39.B). The respondents on gentle and moderately steep slopes perceive themselves to be very prepared for all hazards. Therefore, it can be said that although slope has some influence on both perception and response to hazards, the relationship is not consistent.

\subsubsection{Area Below $10 \mathrm{~m}$ Contour}

About 19 percent of the total respondents (52/272) lived in the area below 10m contour line i.e. areas considered to be susceptible to tsunami. Out of these 52 respondents, nearly 37 percent did not perceive themselves to be exposed to tsunami. These respondents were mainly from the Kapiti Coast (7), Lower Hutt (5), South Wairarapa (5) and Wellington (2). This could be attributed to the

Fig: 6.40. Problems and Frequency of Tsunami in Susceptible Areas in the Wellington Region

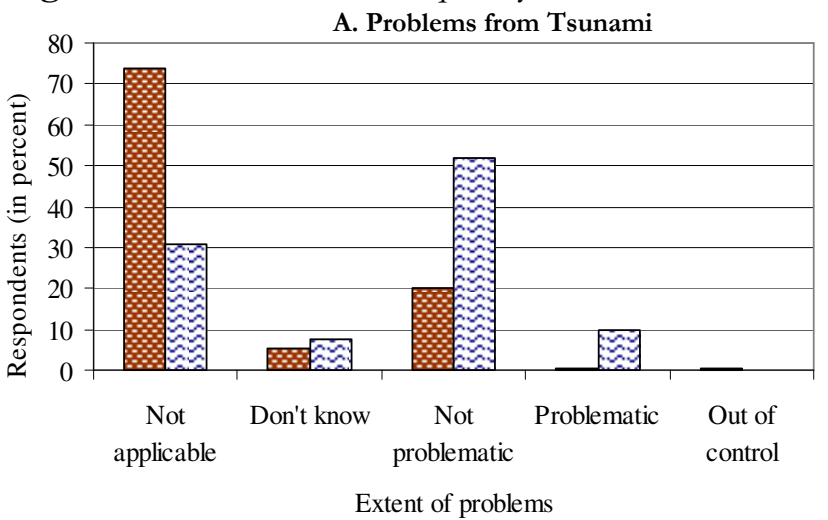

圆 Respondents not living in tsunami susceptible zone
B. Frequency of Tsunami

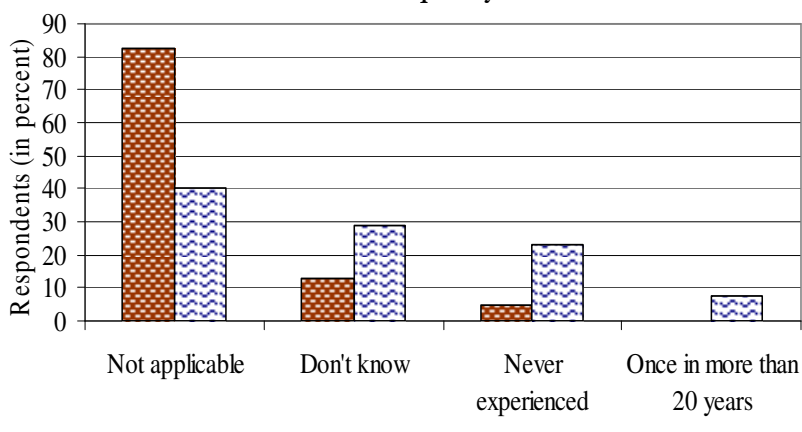

Frequency

Based on Primary Survey, 2007 and data from Wellington Regional Council, 2006

distance from the coast Fig: 6.41. Tsunami Occurrence in the Future as Perceived by especially in the South Wairarapa, and lack of awareness among respondents about their hazard suceptibility. Against this, about five percent of the respondents who lived outside this zone perceived themselves to be exposed to tsunami primarily because of Respondent in Susceptible Areas in the Wellington Region

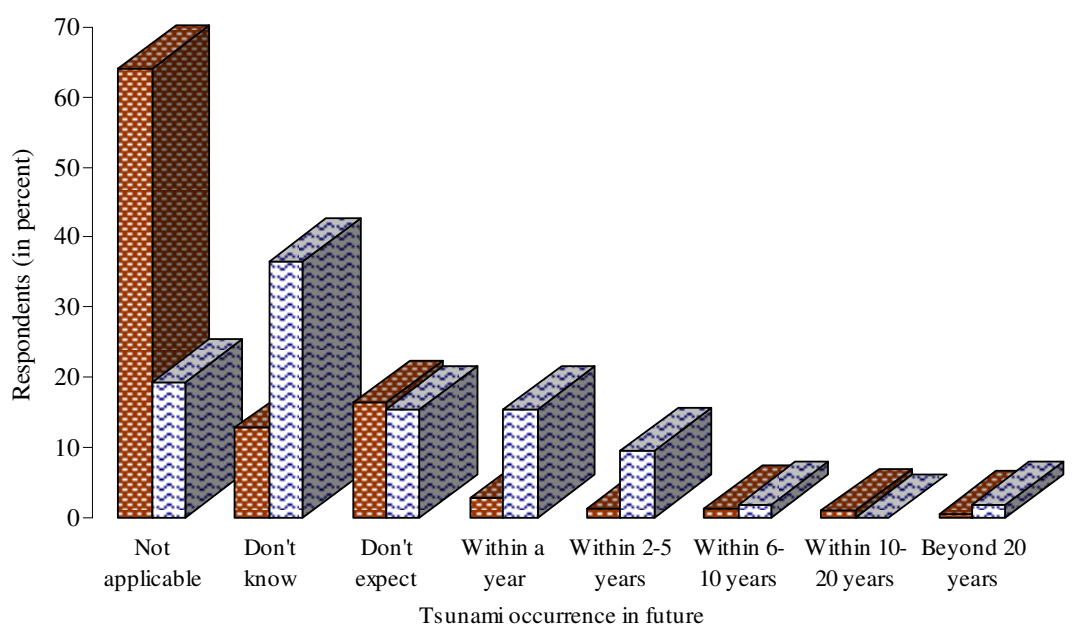

Based on Primary Survey, 2007 and data from Wellington Regional Council, 2006 
their close proximity to the coast.

Since the region has not experienced a tsunami since 1965, the hazard is not problematic for most of the respondents. However, ten percent of respondents found it to be problematic (Fig: 6.40.A). The reason could be attributed to recent global events such as the Boxing Day Tsunami (2004) that has enhanced the awareness and fear of this hazard. On the other hand, respondents living outside of this susceptibility zone primarily believe the hazard to be not applicable to them or it is not problematic for them. Since none of the respondents had experienced a tsunami, most respondents found it hard to tell its frequency, and they said that it was not applicable to them, they didn't know or they had never experienced it (Fig: 6.40.B). A few respondents who believed it to occur once in more than 20 years were aware of the history of tsunami in the region.

The data show that a higher proportion of respondents living in areas below $10 \mathrm{~m}$ contour expect a tsunami to occur in the future as compared to those who lived outside of this zone (Fig: 6.41). While many respondents in this zone could not tell how soon they could expect a tsunami, nearly 20 percent expect a tsunami to occur within a year and another 10 percent within 2-5 years. Further, a high proportion of respondents living in tsunami

Fig: 6.42. Perceived Potential Damage, Feeling of Well-being against Hazard and Most Feared Hazard by Respondents in Susceptible Areas
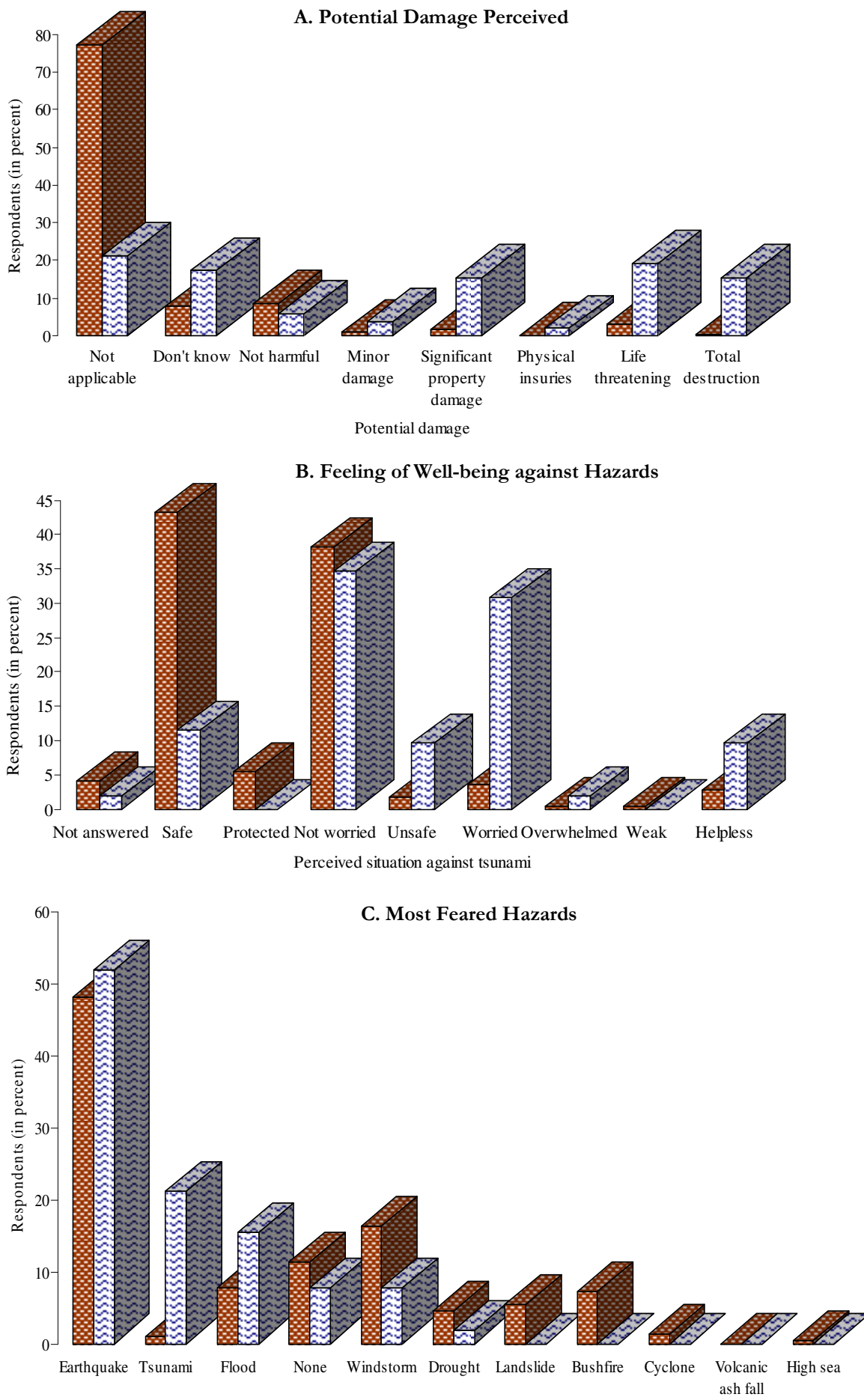

Respondents not living in tsunami susceptible zone $₫$ Respondents living in tsunami susceptible zone Based on Primary Survey, 2007 and data from Wellington Regional Council, 2006 
susceptible zones perceived a tsunami capable of causing significant property damage (Fig: 6.42.A).

Since most respondents in tsunami susceptible areas could see the possibility of tsunami occurrence and high potential risks, a higher proportion of these respondents felt unsafe, worried, overwhelmed or helpless as compared to those who lived outside this zone (Fig: 6.42.B). However, a significant proportion were not worried about tsunami, primarily because they don't see themselves to be exposed to it and secondly, because of their belief that they could not do much about it and therefore they are not worried. Respondents living outside the tsunami zone primarily felt either safe, not worried or protected.

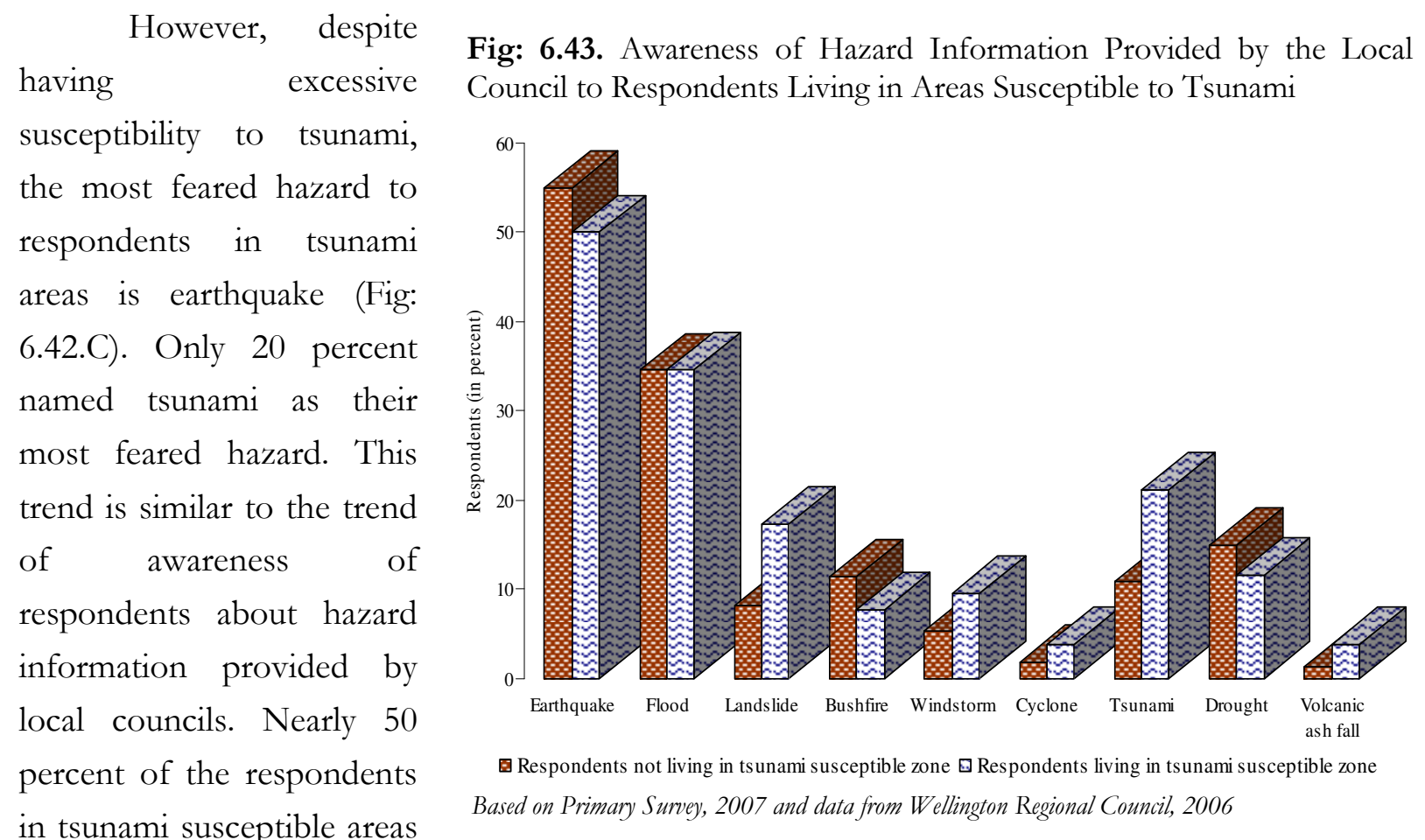

said that they are given information about earthquake as compared to 20 percent of respondents who said to have received information about tsunami (Fig: 6.43). Also, more respondents from the

Fig: 6.44. Hazard Awareness When First Settled at the Current Place of Residence of Respondents in Areas Susceptible to Tsunami

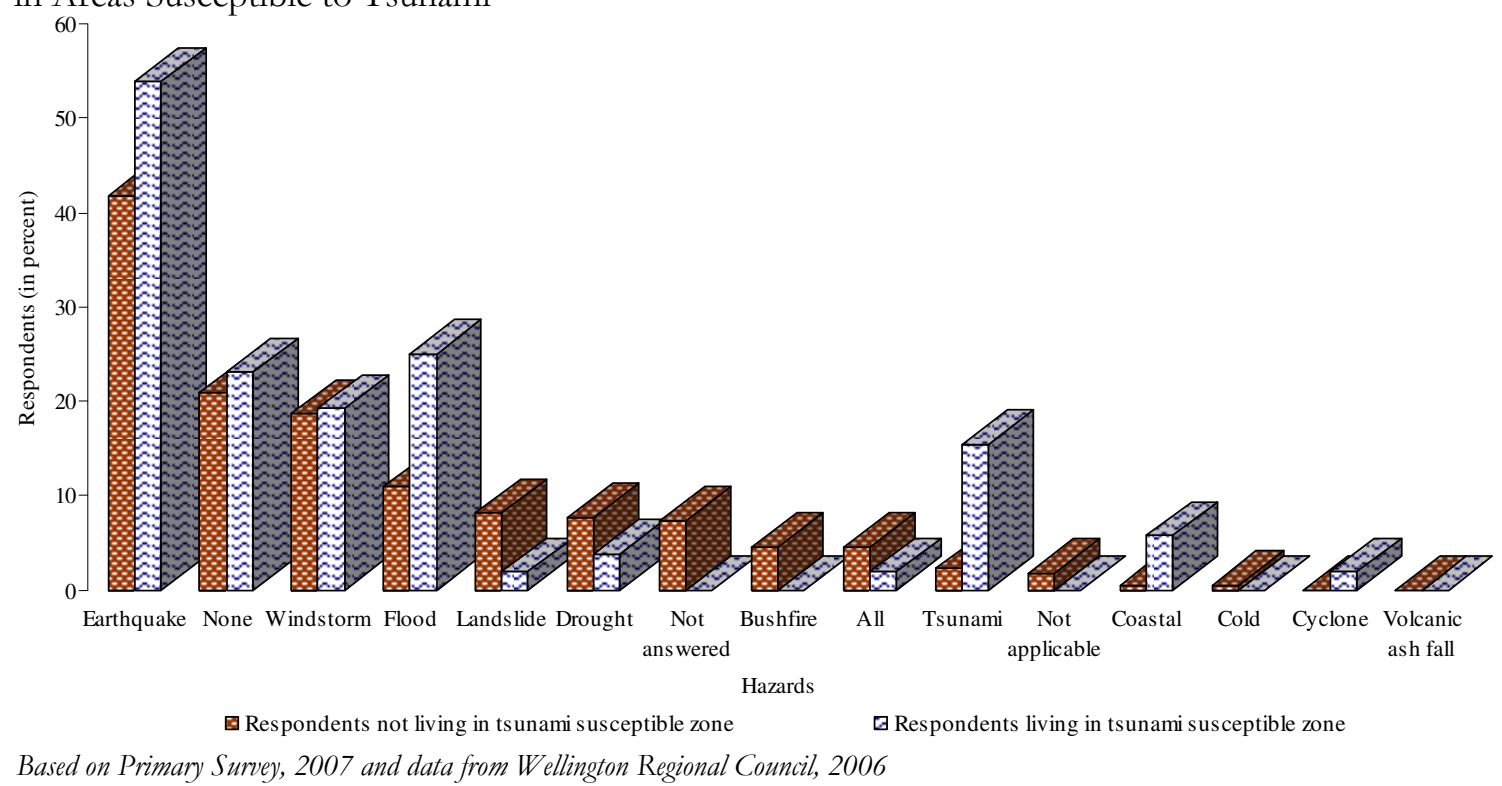


areas below $10 \mathrm{~m}$ contour were aware of earthquakes, flooding, windstorms or no hazard as compared to tsunami (Fig: 6.44).

There is not a great difference in the proportion of respondents who considered hazards when they first moved into their house in the tsunami susceptible zone (33 percent) compared with those who live outside this zone (31 percent). Also a small difference is noted in the proportion of respondents who took mitigation measures for hazards in tsunami susceptible zones (29 percent) as compared to those who live outside the tsunami susceptible area (30 percent). However, more respondents in tsunami susceptible areas took mitigation measures that involved changes outside of their house i.e. planting or removing trees or building a sea wall, conserving water, and choosing location of the house
Fig: 6.45. Hazard Mitigation Measures and Safety Measures Taken by Respondents Living in Areas Susceptible to Tsunami A. Mitigation Measures Taken

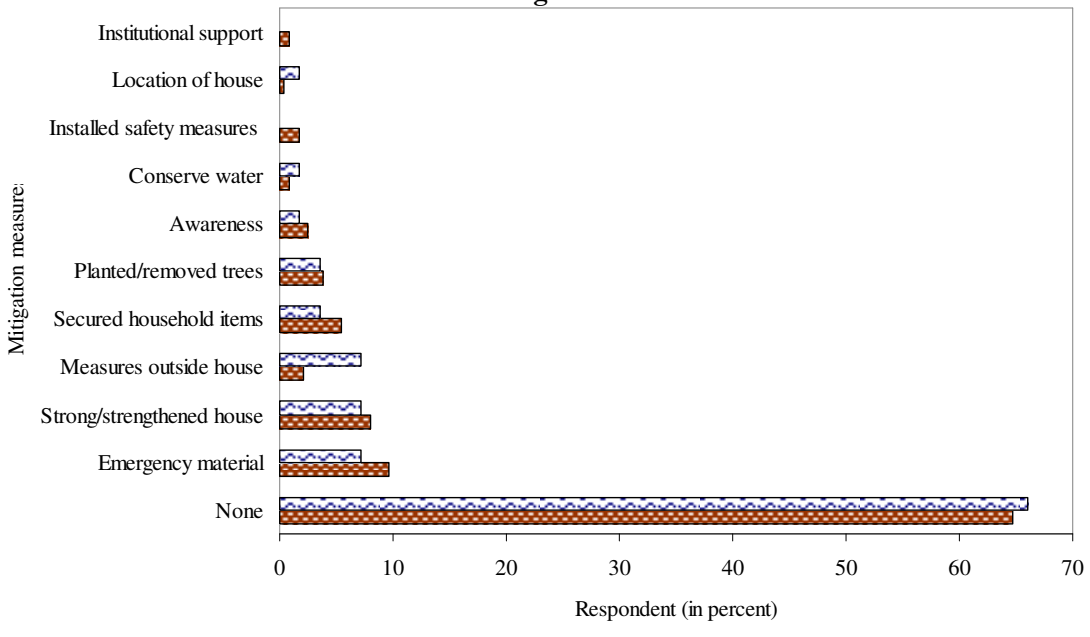

B. Safety Measures Taken

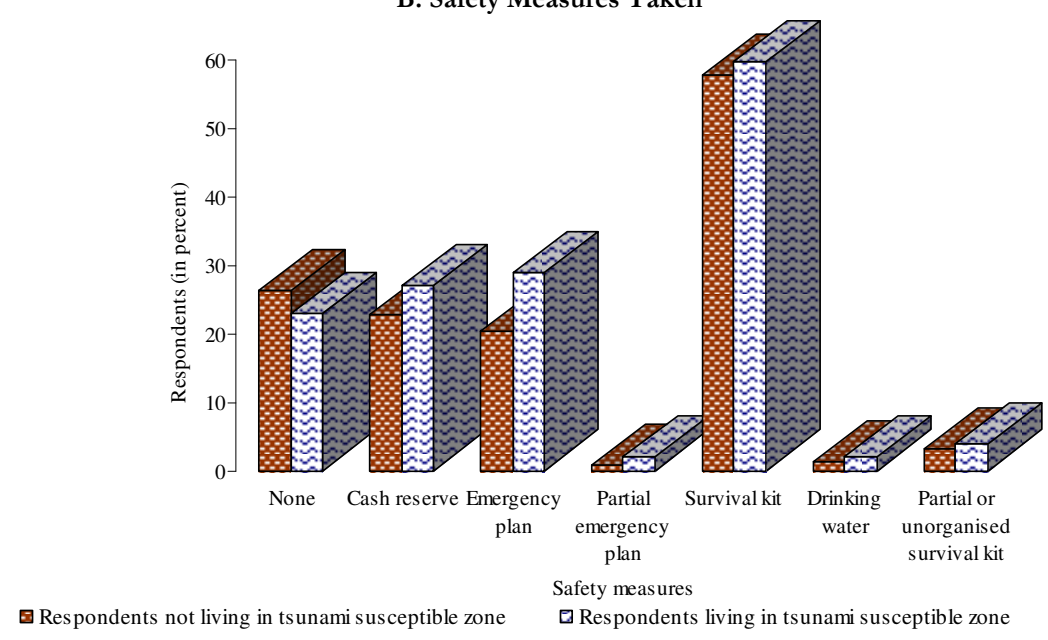

Based on Primary Survey, 2007 and data from Wellington Regional Council, 2006

Fig: 6.46. Hazards for Which Safety Measures Taken by Respondents in Areas Susceptible to Tsunami

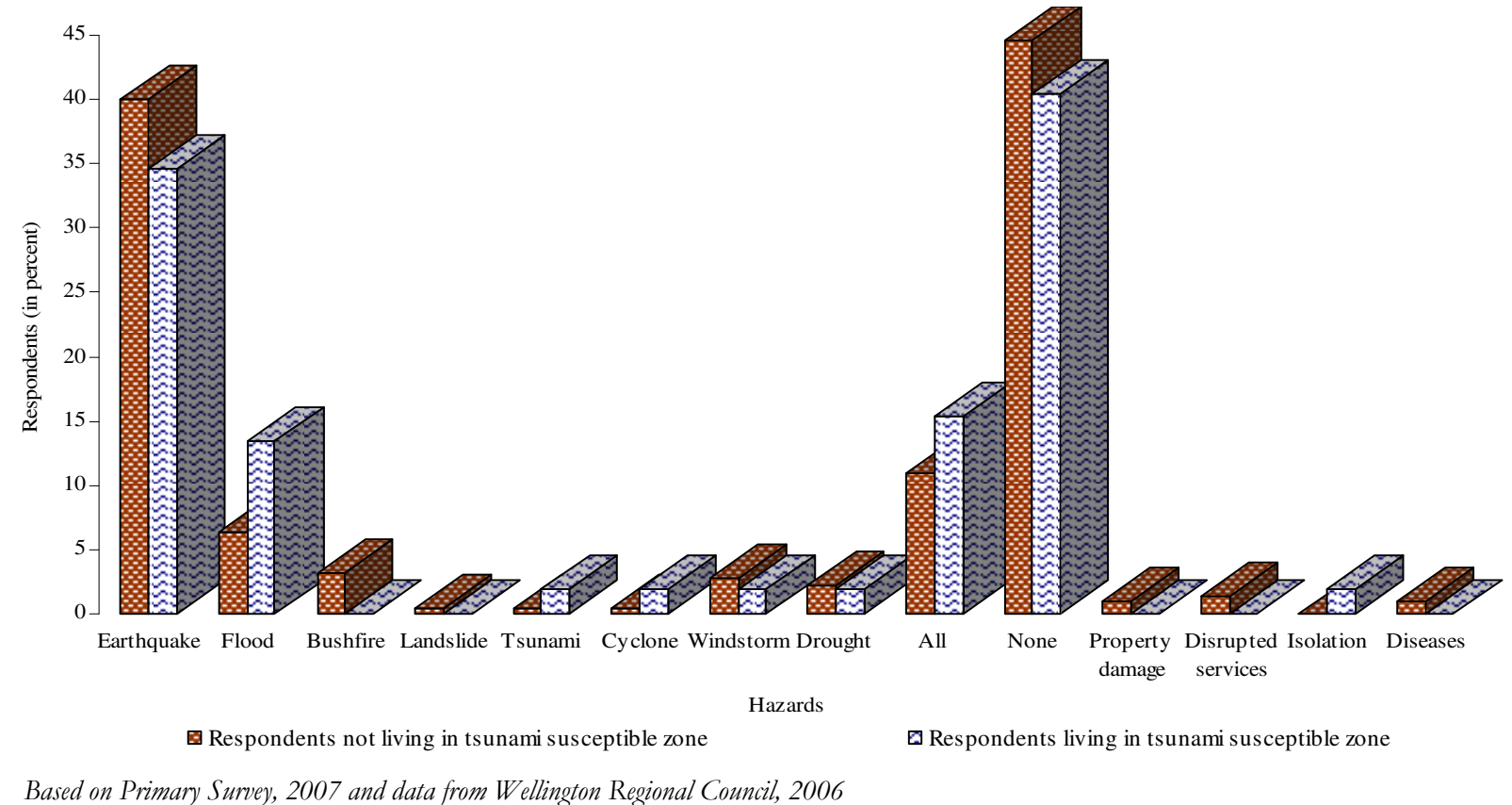


(Fig: 6.45.A). Also, a higher proportion of them took safety measures as compared to the respondents living outside the tsunami susceptibility zone (Fig: 6.45.B).

The highest proportion of respondents said that they took safety measures for none of the hazards, followed by those who took them for earthquake, flood or for all hazards (Fig: 6.46). Less than five percent of respondents took these hazard safety measures for tsunami, but their relative proportion is higher than the respondents who live outside the tsunami susceptible area.

A major proportion of respondents living in tsunami susceptible areas found that they were not at all prepared for tsunami (Fig: 6.47). However, more respondents in these areas responded as either less, fairly or very prepared to tsunami compared to the respondents who lived outside the susceptible zone. Therefore, a distinct difference can be noted in the perception and response to tsunami in the respondents living in area susceptible to tsunami as compared to those living outside this zone.
Fig: 6.47. Perceived Preparedness for Tsunami by Respondents Living in Areas Susceptible to Tsunami

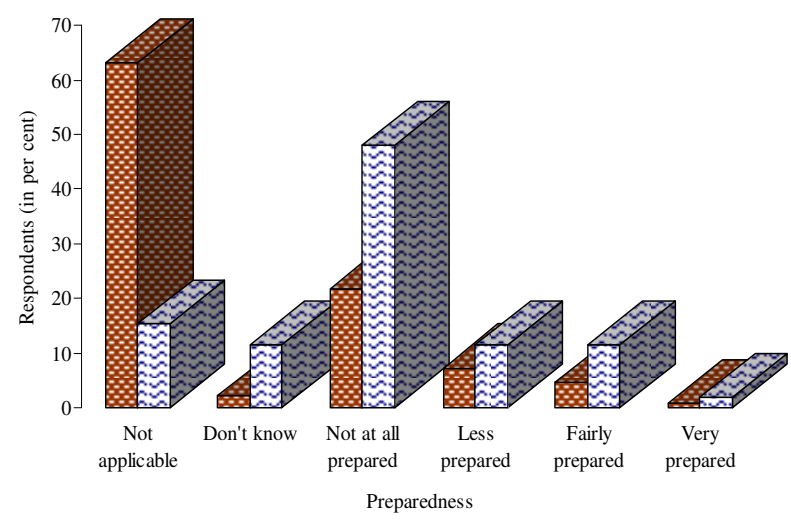

圆 Respondents not living in tsunami susceptible zone 0 Respondents living in tsunami susceptible zone

Based on Primary Survey, 2007 and data from Wellington Regional Council, 2006

\subsubsection{Distance from Fault}

Distance from a fault could play a crucial role behind the impact of an earthquake, and therefore, the response to it. In order to assess the influences of distance from faults on hazard response, the sample was classified into six distance categories. The classified data show that even though there is not a significant difference, a relatively high proportion of respondents who lived close to the fault perceived themselves to be exposed to earthquakes compared to those who lived at a distance (Fig: 6.48). However, a decline in proportion is also witnessed for those who lived closest to the fault i.e. within $150 \mathrm{~m}$. The reason could be attributed to the small sample size (i.e. four) in this zone. The only respondent who did not perceive himself to be exposed to earthquake was an elderly person. It is worth noting that he shifted to his current house

Fig: 6.48. Perceived Exposure to Earthquake by Respondents Living at Varied Distance from Fault

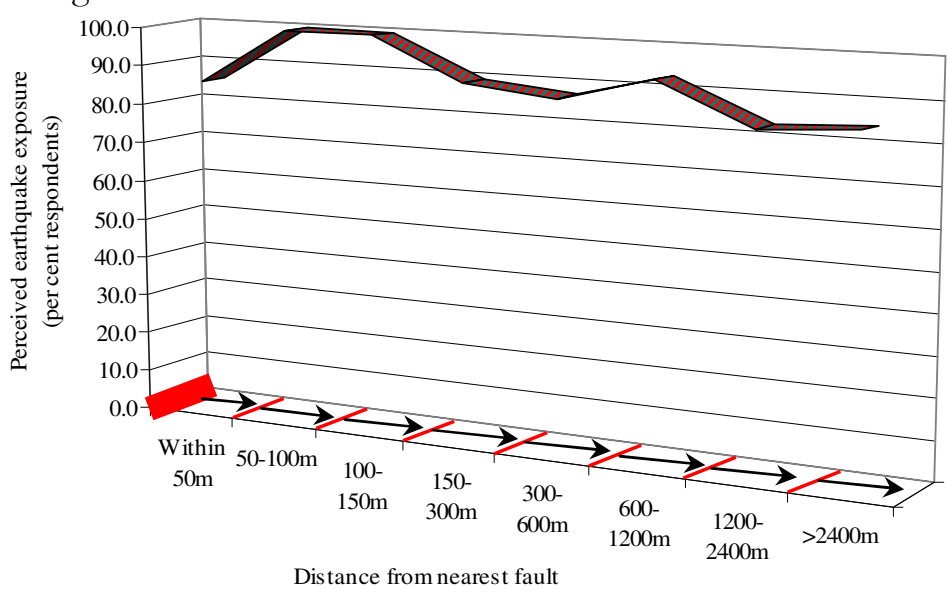

Based on Primary Survey, 2007 and data from Wellington Regional Council, 2006 after retirement when he had to sell his previous house in order to get medical treatment. He 
bought the current house at a cheap price. Because of his age the respondent was not able to speak or hear properly, and his exposure to the hazard did not worry him. Fatalism has been noted as a major factor in response, especially for those most exposed to hazards (Crozier et al, 2006).

The data show that the proportion of the respondents who experienced any kind of problem through earthquakes tended to increase with distance from the fault (Fig: 6.49.A). On the other hand, those who lived close to the fault experienced more frequent earthquakes compared to those who were located at a greater distance (Fig: 6.49.B). The current frequency has not influenced the future expectancy of earthquakes by the respondents. While a significant proportion of respondents from each zone expect an earthquake to occur within a year, the highest proportion of respondents who expect an earthquake to occur in 6-10 years lived within $150 \mathrm{~m}$ of distance from any fault (Fig: 6.49.C). Here again it is possible that two factors dictate the perception and response of those most exposed i.e. fatalism (not having control) and the blasé effect (experiencing numerous events without any serious consequences) (Tobin and
Fig: 6.49. Problems, Frequency, Proximity in the Future, Potential Damage and Perceived Feeling of Well-being against Earthquake by the Respondents Living at Varied Distance from Fault
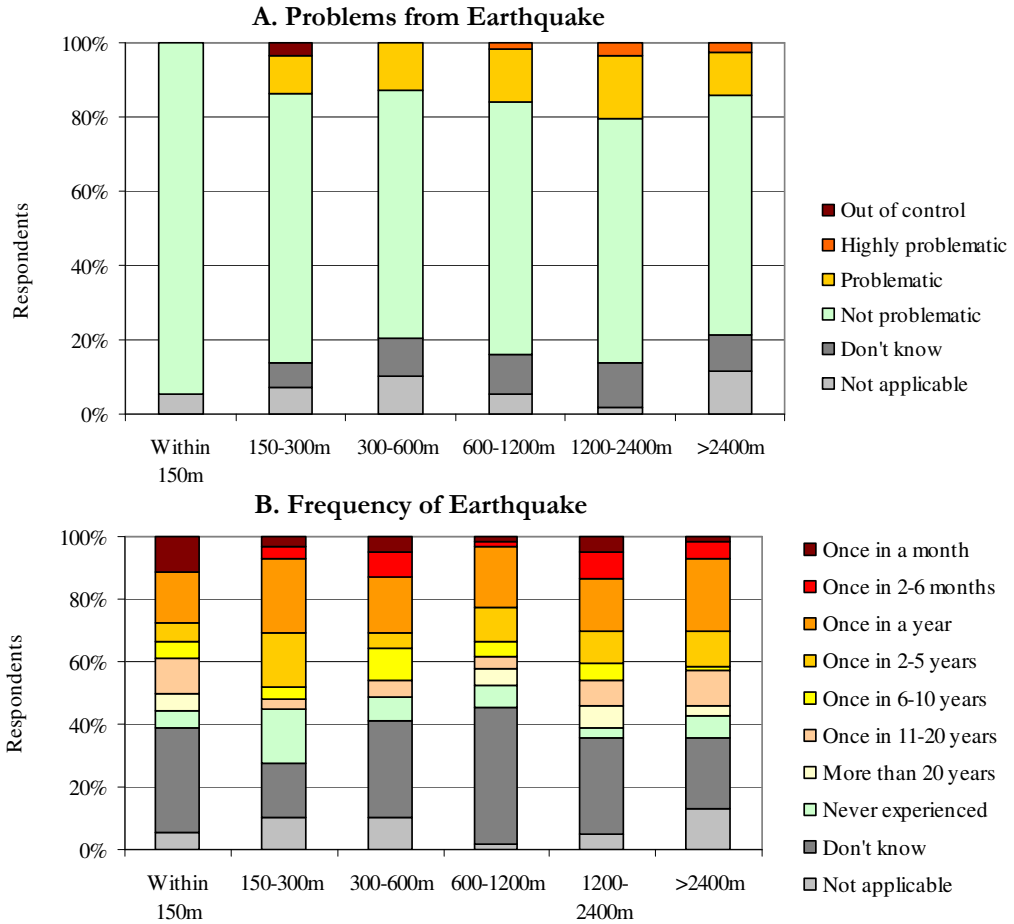

Once in a month

Once in 2-6 months $\square$ Once in a year $\square$ Once in 2-5 years 口 Once in 6-10 years $\square$ Once in 11-20 year $\square$ More than 20 years $\square$ Never experienced $\square$ Don't know $\square$ Not applicable

C. Proximity of Earthquake Occurrence in Future

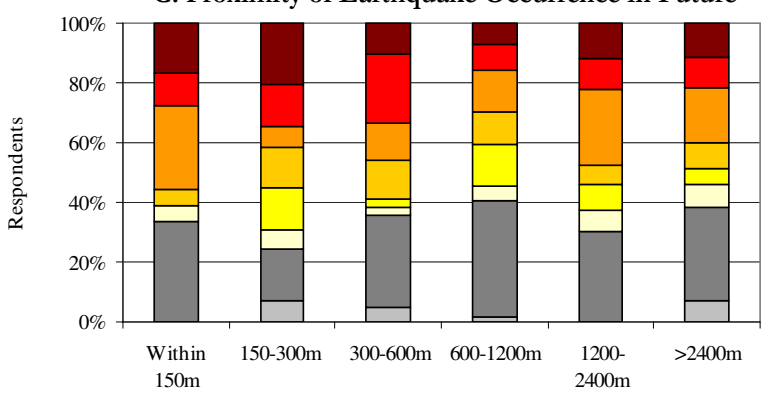

- Within a year

Within 2-5 years $\square$ Within 6-10 years Within 10-20 years $\square$ Beyond 20 years $\square$ Don't expect $\square$ Don't know $\square$ Not applicable

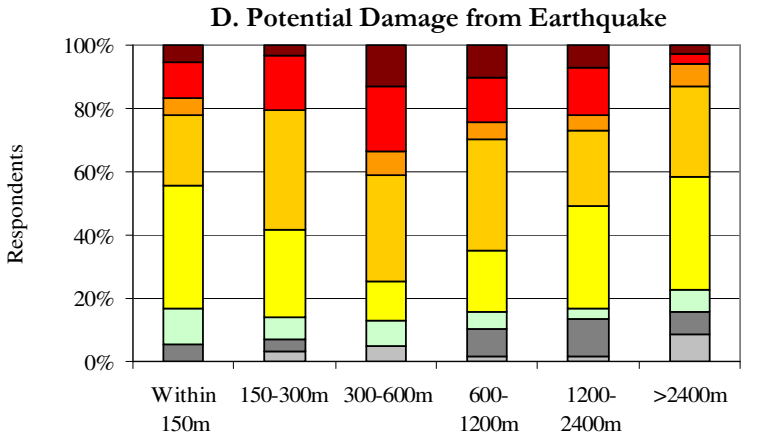

Total destruction $\square$ Life threatening $\square$ Physical injuries $\square$ Significant property damage $\square$ Minor damage $\square$ Not harmful $\square$ Don't know $\square$ Not applicable

E. Perceived Felling of Well-being against Earthquake

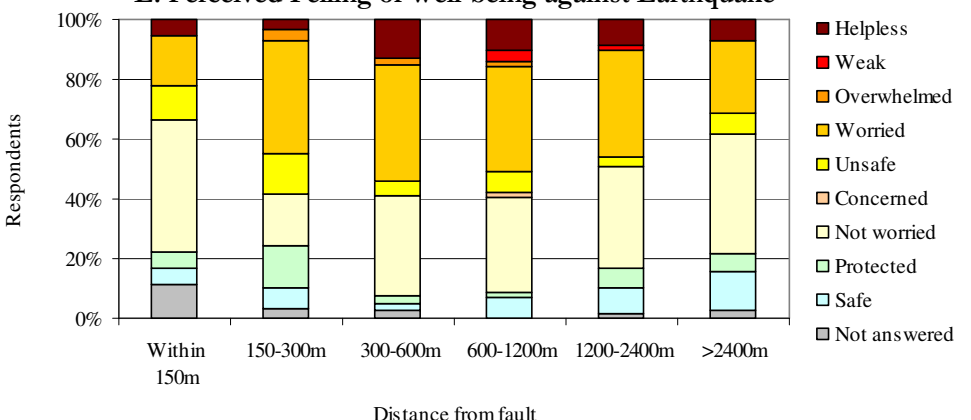

Based on Primary Survey, 2007 and data from Wellington Regional Council, 2006 
Montz, 1997).

The trend of potential damage perceived by respondents from earthquakes shows a curve pattern (Fig: 6.49.D). A low proportion of respondents living either close or distant to faults perceived earthquakes to be destructive as compared to respondents who lived between $300 \mathrm{~m}$ and $1200 \mathrm{~m}$ of distance from any fault. A similar pattern is also noted for how the respondents perceived their situation against earthquakes (Fig: 6.49.E). The highest proportion of respondents who felt helpless against earthquakes were located at a medium distance (within 300$600 \mathrm{~m}$ from fault) followed by those who lived about 600$1200 \mathrm{~m}$ of distance from any fault. The highest proportion of respondents who felt safe from earthquakes lived at a distance of more than $2400 \mathrm{~m}$ from the fault.

A clear decline is noted in the proportion of respondents with increasing distance from fault, who feared most from earthquakes (Fig: 6.50.A). In contrast, the awareness of hazard information provided by the local council does not have a good correlation with the distance from fault (Fig: 6.50.B). This may indicate that the consideration of spatial susceptibility is not effectively

Fig: 6.50. Most Feared Hazard, Hazard for Which Information Provided by Local Council and Hazard Awareness of Respondents When they First Moved into House, at Varied Distance from Fault

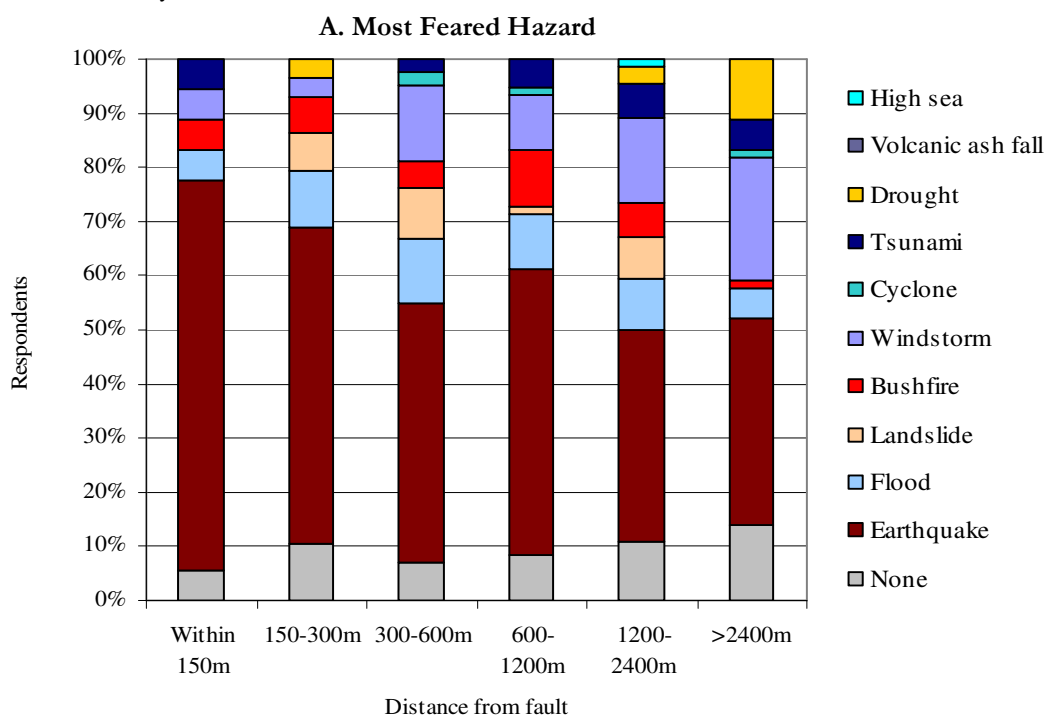

B. Awareness of Hazard Information Provided by Local Council

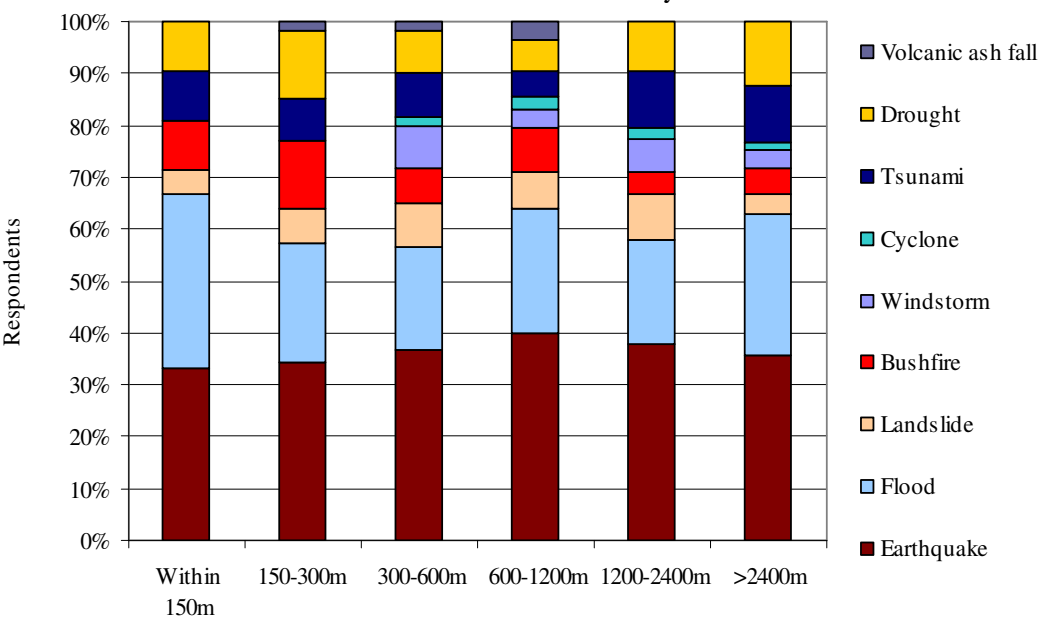

Distance from fault

C. Hazard Awareness When First Moved in Current Residence

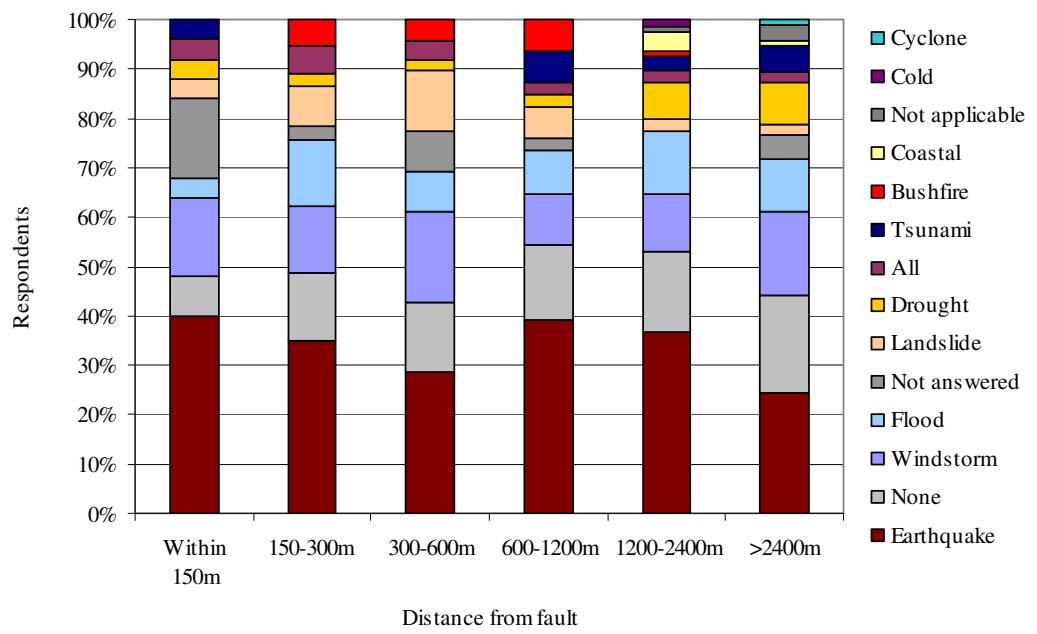

Based on Primary Survey, 2007 and data from Wellington Regional Council, 2006 
targeted in the government response.

Although the highest proportion of respondents living within $150 \mathrm{~m}$ of the fault line were aware of earthquakes when they first moved in their current residence, there is no consistent declining trend in this awareness with the distance from the fault (Fig: 6.50.C). The comparison of initial hazard awareness (Fig: 6.50.C) with the most feared hazard (Fig: 6.50.A) shows that with time hazard perception of respondents has become more focused.

The data also show that the location not only influences the perception, but also modifies the response. It is noted that the highest proportion of respondents who considered and took measures for hazard mitigation lived very close to the fault (Fig: 6.51). Besides, the increasing trend of shifting houses with increasing distance from the
Fig: 6.51. Hazard Consideration and Mitigation Measures Taken by Respondents When First Moved into House, with Distance from Fault

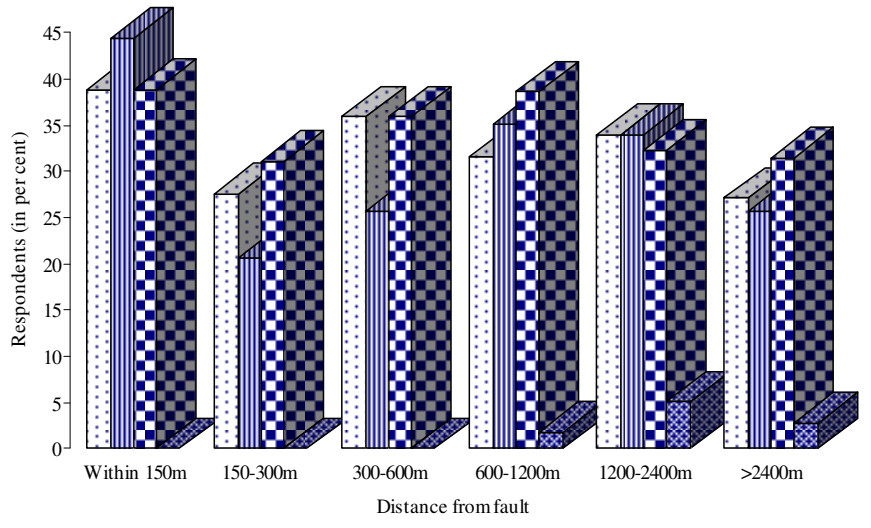

$\square$ Considered about hazards $\mathbf{m}$ Measurment taken $\square$ Changes made in house $\square$ Shifted house

Based on Primary Survey, 2007 and data from Wellington Regional Council, 2006

Fig: 6.52. Hazard Mitigation Measures Taken by Respondents When First Moved in the House, with Distance from Fault

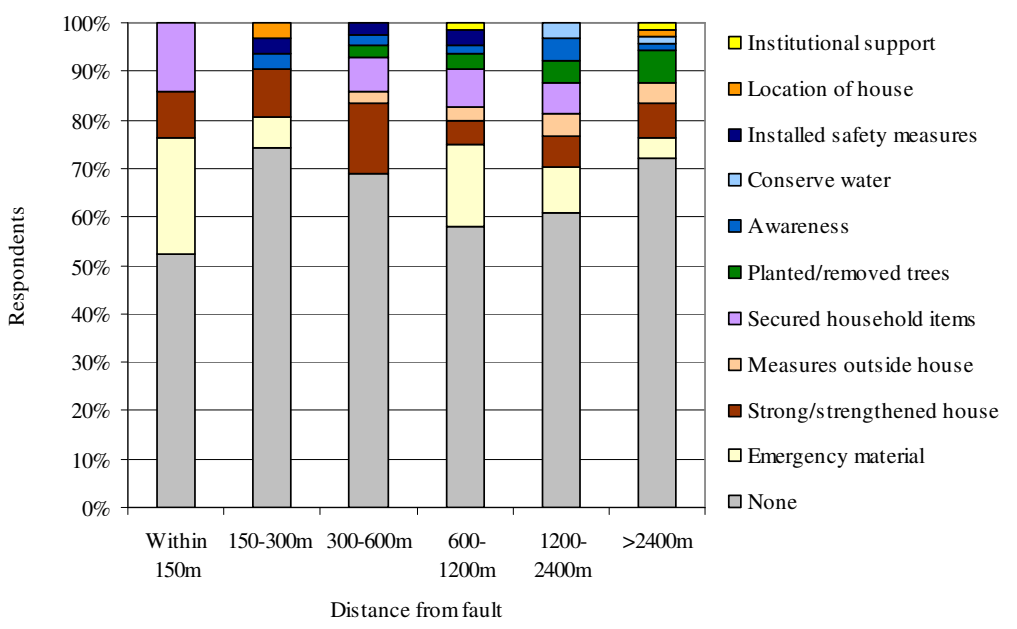

Based on Primary Survey, 2007 and data from Wellington Regional Council, 2006

Fig: 6.53. Type and Hazards for Which Safety Measures Taken by Respondents Living at Varied Distance from Fault
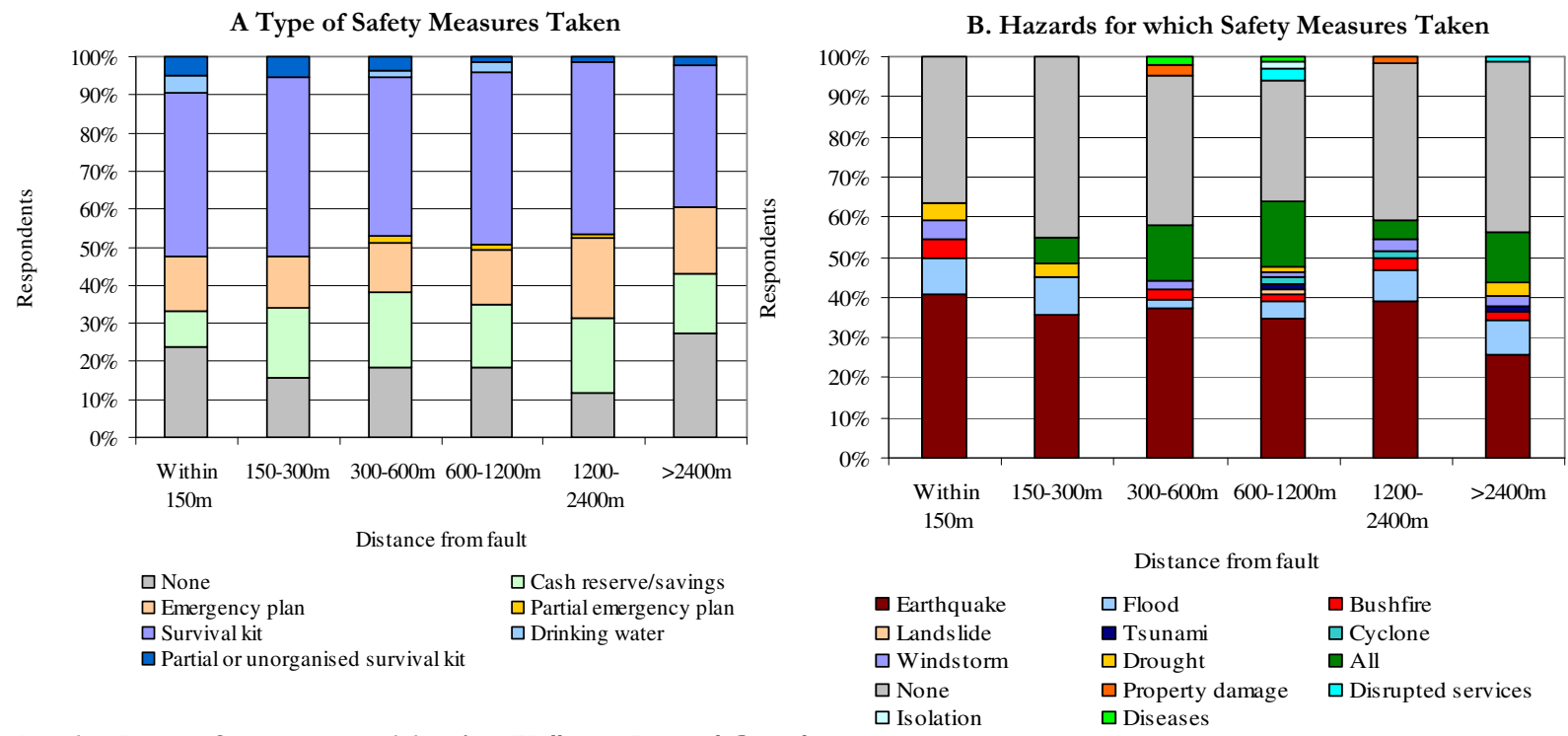

Based on Primary Survey, 2007 and data from Wellington Regional Council, 2006 
fault shows that faults have played little or no role behind decision to shift house due to hazards.

The data show that the highest proportion of respondents who stored emergency material lived within 150m of the fault (Fig: 6.52). The two common measures taken (i.e. strengthening or building safe houses and securing household items) did not consistently decline with the distance from fault, but found to be adopted by a high proportion of respondents who lived within $600 \mathrm{~m}$ of distance from the fault. In terms of the type of safety measures taken, a general trend can be observed in declining proportion of respondents having complete or partial survival kits with the increasing distance from the fault (Fig: 6.53. A). The proportion of respondents who took safety measures for earthquakes also declines with increasing distance

Fig: 6.54. Hazard Preparedness of Respondents Living at Varied Distance from Fault

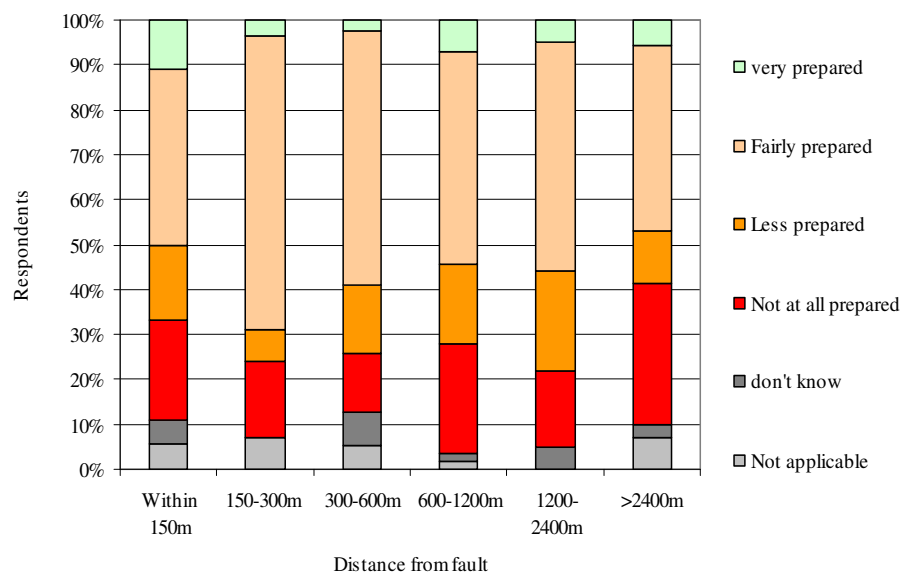

Based on Primary Survey, 2007 and data from Wellington Regional Council, 2006 from the fault, even though it remains a dominant hazard for which mitigation measures have been taken in the region.

Also, more respondents living close to the fault said they were very prepared for earthquakes compared to those who lived at a distance (Fig: 6.54). In keeping, the proportion of respondents who are not at all prepared for earthquakes increases with increasing distance from the fault. Therefore, it can be said that location of respondents with respect to faultlines has influenced the response to this hazard.

\subsubsection{Rainfall}

The main variations in the rainfall throughout the region are related to a range of hazards including flooding, landslides, drought and bushfire. In order to assess the influences of rainfall variation, the sample is again reclassified on the basis of the location of respondents in various rainfall Zones. The data show that a high proportion of respondents living in lower rainfall areas $(<1000 \mathrm{~mm}) \quad$ perceived themselves to be exposed to both flood and drought (Fig: 6.55). This is particularly true for eastern rural districts, where the rivers bring water from the remote catchment areas of the Tararua Ranges that

Fig: 6.55. Hazard Exposure in Rainfall Zones

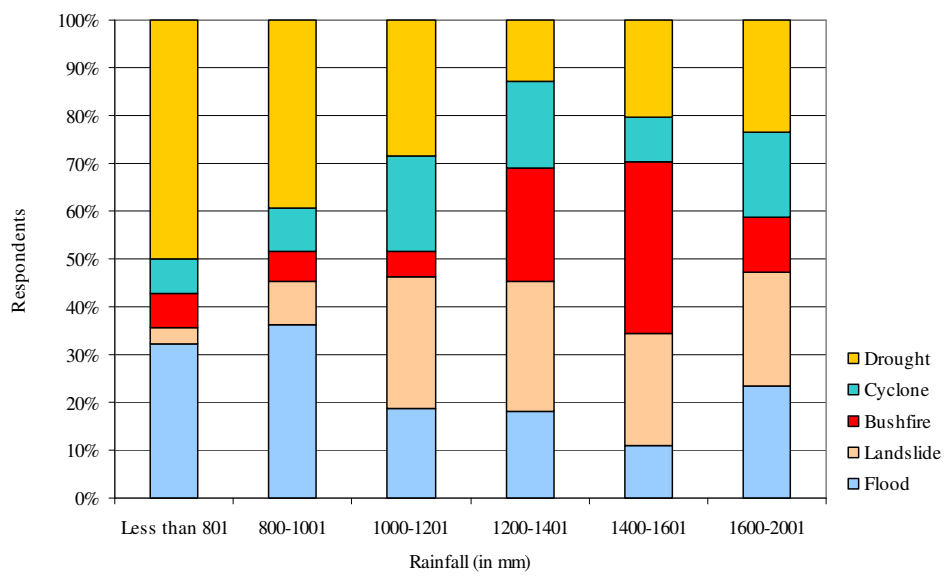

Based on Primary Survey, 2007 and data from Wellington Regional Council, 2006 
receive frequent and heavy rainfall throughout the year. The areas receiving high rainfall are also exposed to both flood and drought. While the reason for flood in these areas could be attributed to vulnerable drainage systems, rapid runoff and high population pressure for water in hilly areas often causes water scarcity and restrictions on water use that people perceive as drought. The proportion of respondents exposed to landslides increases with increasing rainfall. Also, more respondents in moderate or high rainfall areas perceived themselves to be exposed to cyclones than those who lived in low rainfall areas. The proportion of respondents who perceived themselves to be exposed to bushfire first increases with rainfall and then declines for the highest rainfall zone, but remains greater than those who lived in the lower rainfall area. The reason could be attributed to the presence of forests and recurrent water scarcity due to rapid runoff in high rainfall zones.

Fig: 6.56. Problems Faced Through Hazards in Rainfall Zones

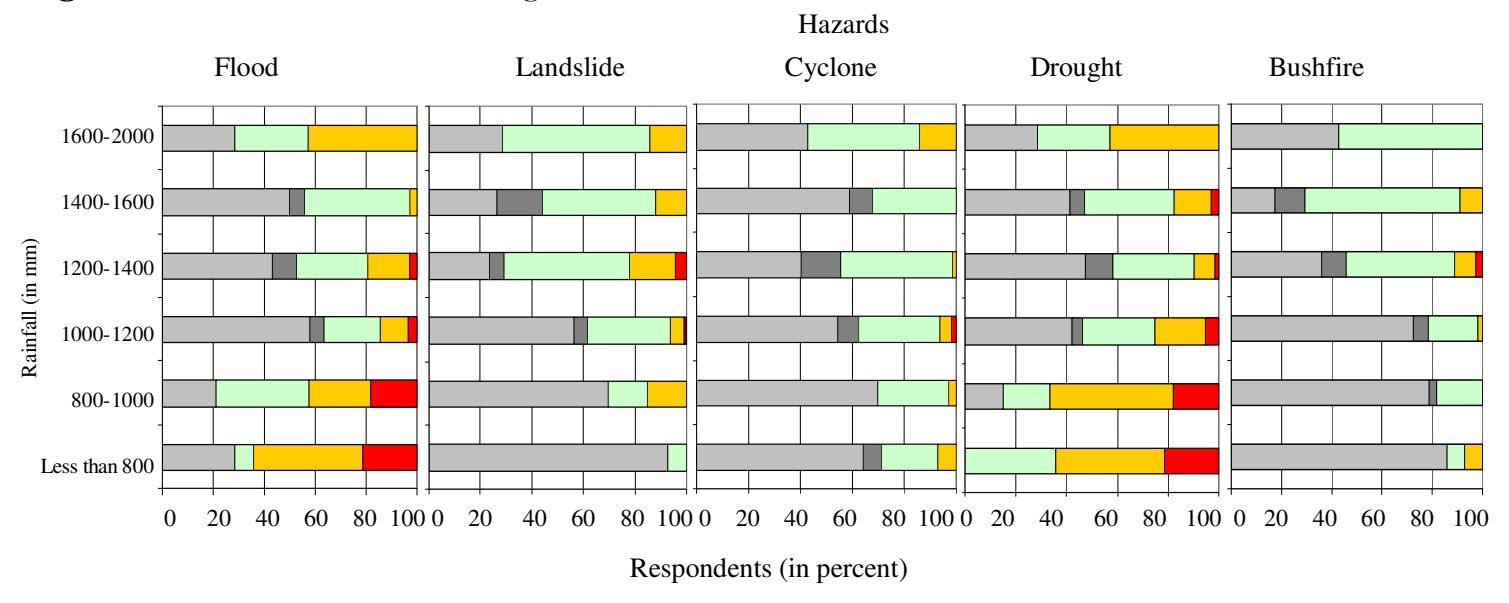

$\square$ Not applicable $\quad \square$ Don't know $\quad \square$ Not problematic $\quad \square$ Problematic $\quad \square$ Highly problematic $\quad \square$ Out of control

Based on Primary Survey, 2007 and data from Wellington Regional Council, 2006

In terms of problems faced, more respondents living in low rainfall areas found flood to be highly problematic and their proportion declines gradually with the increasing rainfall (Fig: 6.56). Landslides on the other hand, are more problematic to the respondents living in mid rainfall zones $(1200-1400 \mathrm{~mm})$. The reason could be attributed to the fact that occurrence of landslides is also

Fig: 6.57. Frequency of Hazards in Rainfall Zones

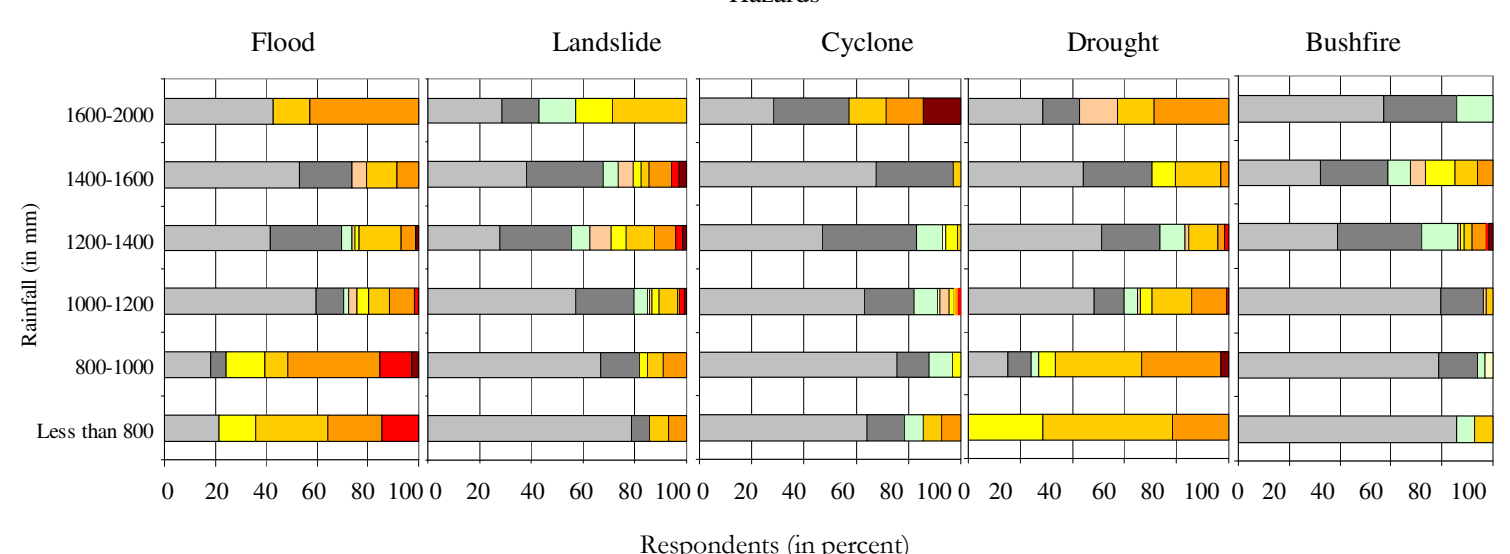
$\square$ Not applicable
$\square$ Don't know
$\square$ Never experienced
$\square$ More than 20 years
$\square$ Once in 11-20 years
$\square$ Once in 6-10 years
$\square$ Once in 2-5 years
$\square$ Once in a year
$\square$ Once in 2-6 months
- Once in a month 
governed by a number of other factors such as slope angle, deforestation, cuts or modified slopes. Besides, most urban development in the region lies within this rainfall class. Drought, as expected, is more problematic in the low rainfall zone. Even though the high rainfall areas face regular water scarcity (Fig: 6.57), the hazard is not highly problematic in this zone (Fig: 6.56). Similarly, even

Fig: 6.58. Perceived Future Occurrence, Potential Damage and Feeling of Well-being against Hazard by Respondents in Rainfall Zones

A. Perceived Future Occurrence of Hazards
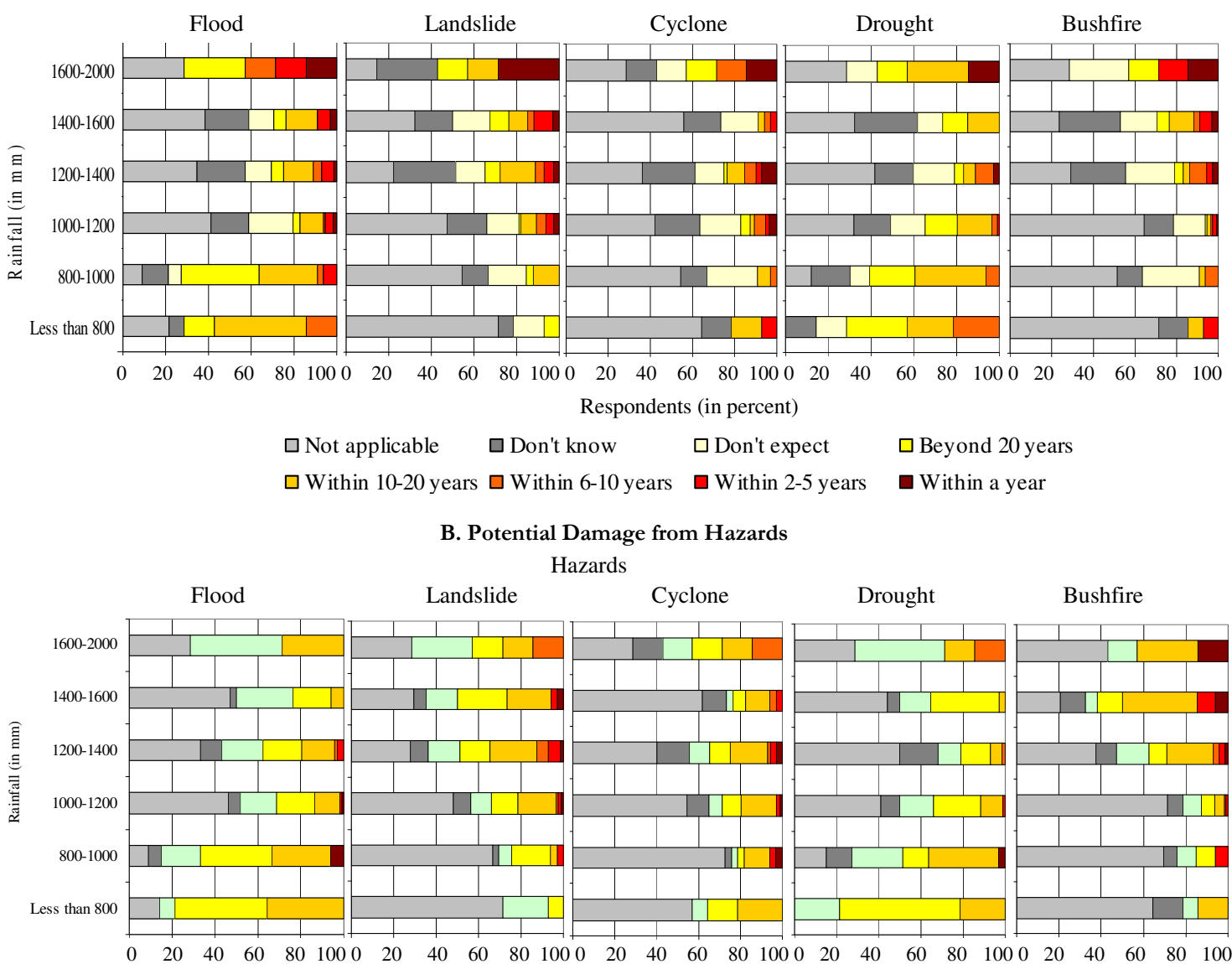

Respondents (in percent)
$\square$ Not applicable
$\square$ Don't know
$\square$ Not harmful
$\square$ Minor damage
$\square$ Significant property damage $\square$ Physical injuries
$\square$ Life threatening
$\square$ Total destruction

C. Perceived Feeling of Well-being against Hazards Hazards

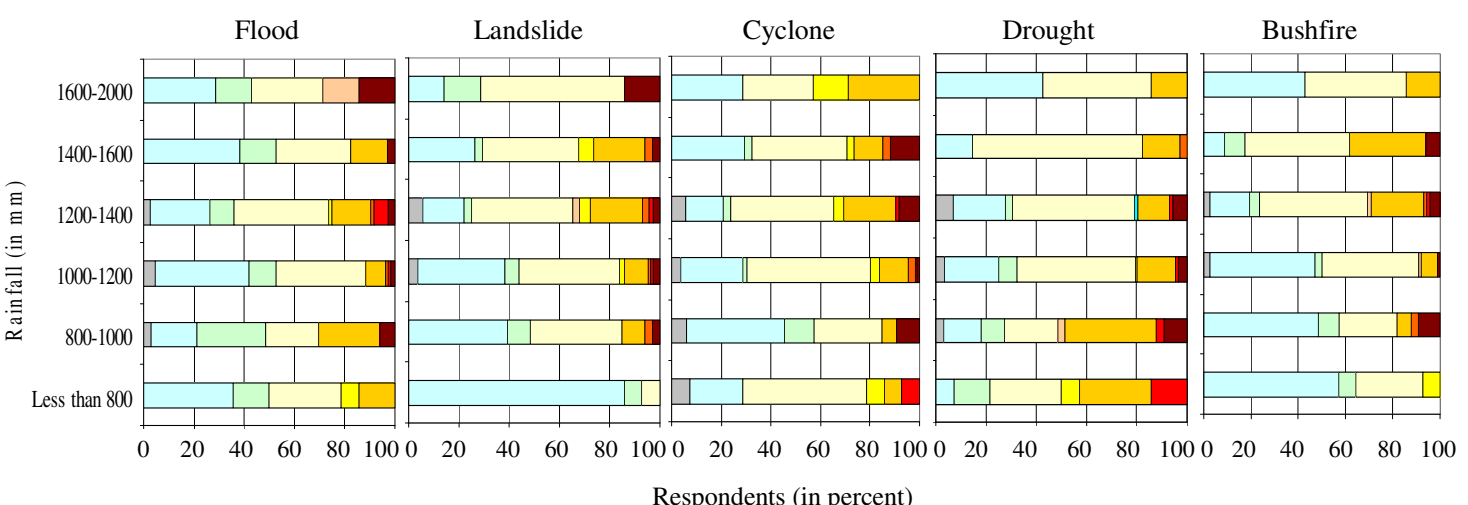

$\square$ Not answered $\square$ Safe

$\square$ Unsafe $\square$ Worried $\square$ Overwhelmed $\square$ Weak

$\square$ Concerned

Based on Primary Survey, 2007 and data from Wellington Regional Council, 2006 
though cyclones are noted to be highly frequent in high rainfall zones (Fig: 6.57), the problems from cyclones are perceived to be more problematic in 1000-1200mm rain zone.

The problems from both droughts and cyclones represent the impact on critical economic resources as water scarcity and erosion cause significant loss to farmers. Bushfires on the other hand, are noted to be highly problematic and frequent in the populated $1200-1400 \mathrm{~mm}$ rainfall zone which perhaps indicates a human cause behind hazard occurrence rather than natural susceptibility.

Despite the low frequency of most hazards in high rainfall zones, a high proportion of respondents perceived flood and landslides to occur within a year and feel helpless aginst these hazards, even if they did not see these hazards to be either life threatening or causing total destruction (Fig: 6.58.A. B. \& C). These hazards are perceived to be more damaging in medium rainfall zones. Similarly, even though bushfires are not frequent in high rainfall zones, they are seen as destructive and respondents were worried and felt helpless against the hazard because of a high vegetation cover in their surroundings. Drought and cyclones were also perceived to occur in the near future by the respondents in high rainfall zones and were seen as potentially destructive by the respondents who lived in medium and low rainfall zones.

The analysis of most feared hazards across various rainfall zones shows that while in low rainfall areas more
Fig: 6.59. Most Feared Hazard, Awareness of Hazard Information Provided by the Local Council and Hazard Awareness When Respondents First Moved in Their House, in Rainfall Zones
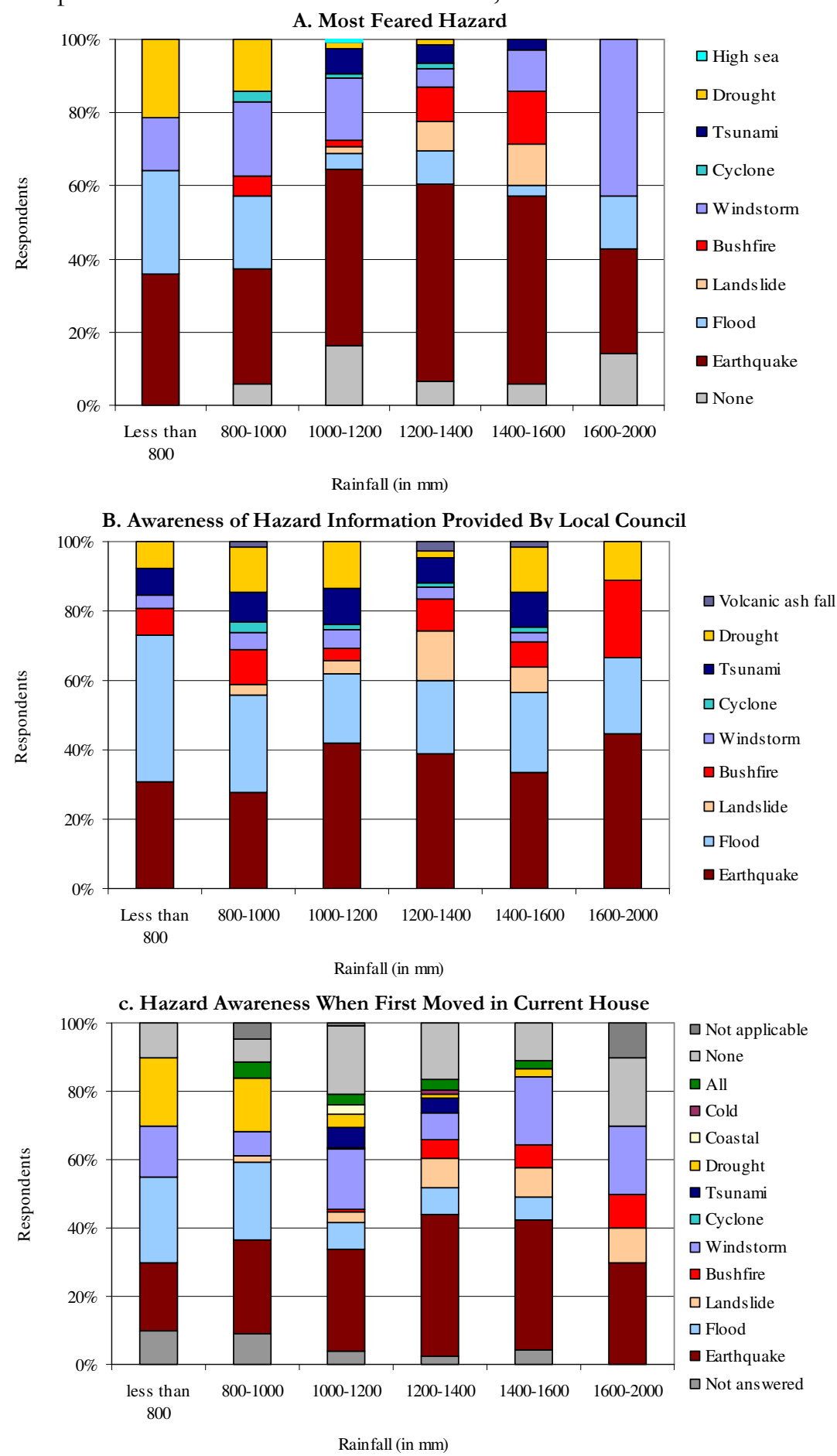

Based on Primary Survey, 2007 and data from Wellington Regional Council, 2006 
respondents feared earthquakes, flooding, windstorm and droughts, in very high rainfall zones the respondents feared more of windstorms, earthquakes and flooding (Fig: 6.59.A). The fear of bushfire was high in lowmedium, medium to medium-high rainfall areas.

In terms of awareness of information provided by the local council, again there is less difference with respect to the rainfall pattern (Fig: 6.59.B). A high proportion of respondents living in high rainfall areas said that they received information about bushfires that may have possibly made them to perceive their susceptibility to bushfires with significant potential damage despite its low frequency.

The awareness of the respondents when they first moved into their current house shows a mixed influence of both the most feared hazard and the awareness of information provided by the council in their residential area (Fig: 6.69.C). While the respondents living in low rainfall areas were more aware of earthquakes, flooding, droughts or windstorms, the respondents living in high rainfall zones knew about earthquakes, windstorms, landslides and bushfires.

Fig: 6.60. Response to Hazards by Respondents in Rainfall Zones
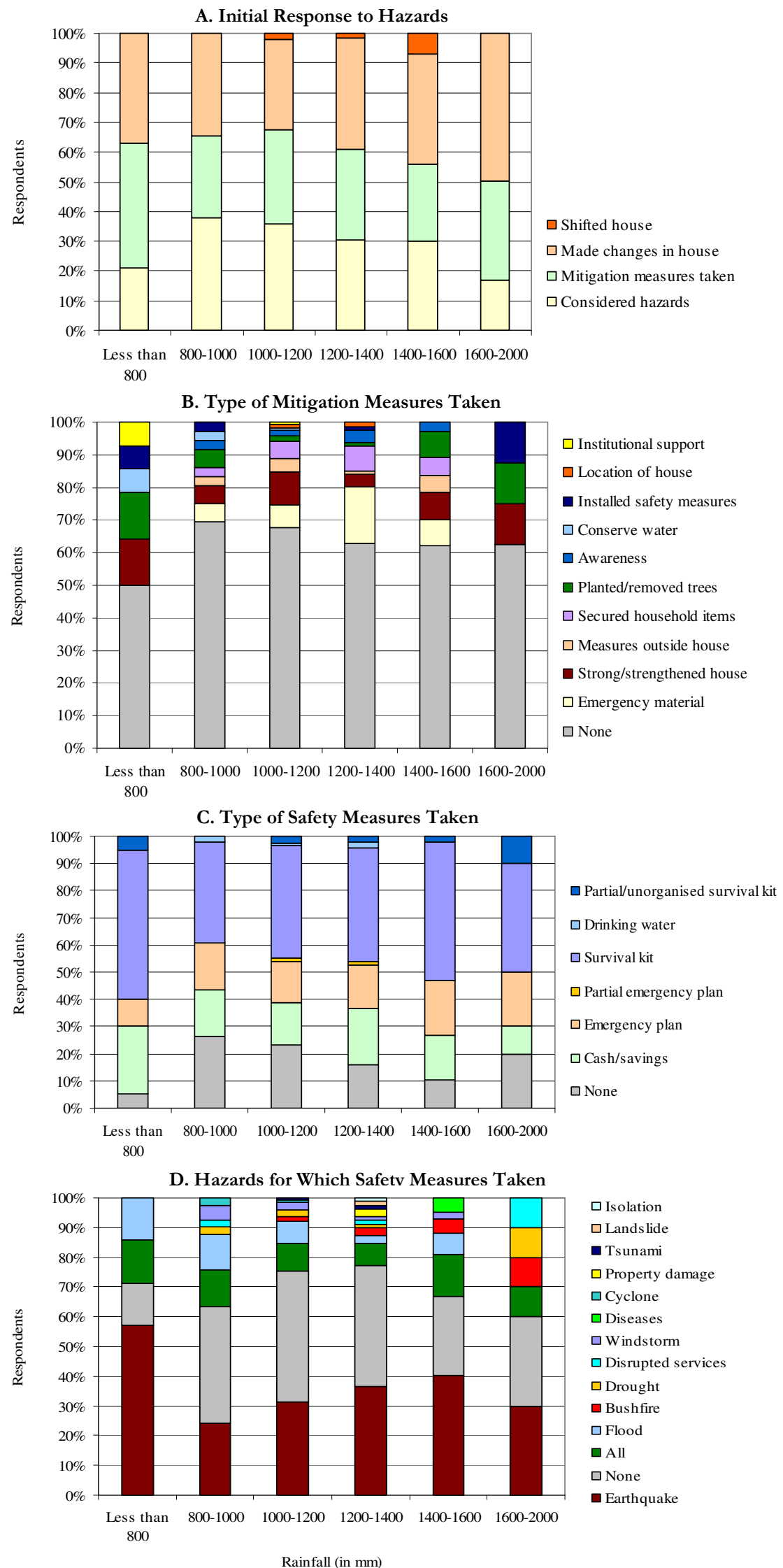

Based on Primary Survey, 2007 and data from Wellington Regional Council, 2006 
The respondents in all rainfall categories considered hazards when they first moved into their current house (Fig: 6.60.A). However, an increasing trend is witnessed in the proportion of respondents with increasing rainfall areas, who made changes to their house. A few respondents who moved house because of hazards were mainly located in moderate to high rainfall areas, which closely indicate their causes of movement, as being flood, damp ground and landslides.

Fig: 6.61. Hazard Preparedness of Respondents in Rainfall Zones

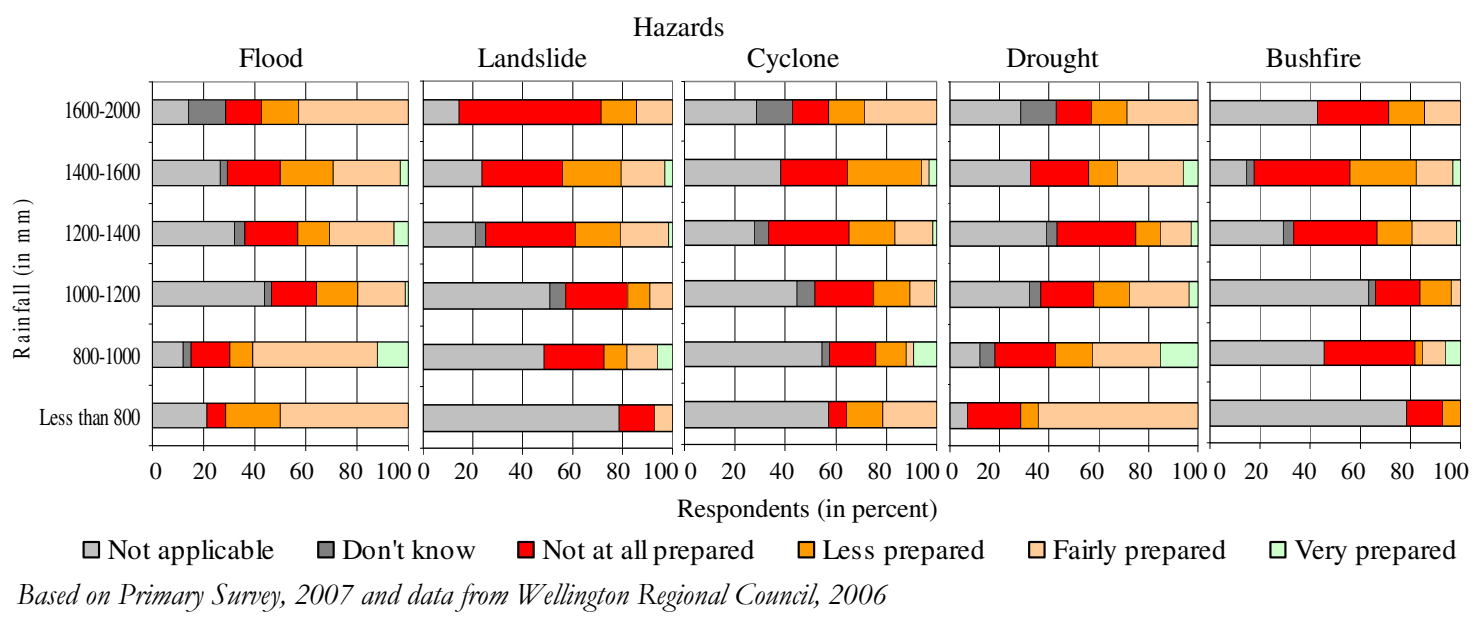

There is however, no consistent pattern in the type of mitigation measures adopted by respondents across different rainfall zones (Fig: 6.60.B). More respondents in low rainfall areas depended on the institutional support for hazard mitigation i.e. flood warning and insurance and took safety measures for hazards compared to those living in high rainfall areas (Fig: 6.60). The comparison of hazards for which safety measures were taken by respondents shows a correlation to flood frequency across different rainfall zones, but not for other hazards (Fig: 6.60.D). The highest proportion of respondents took safety measures for drought in high rainfall areas, which does not relate to its real frequency, but may relate to the perceived proximity of drought occurrence in the future. The comparison of preparedness across different rainfall zones shows that more respondents living in low rainfall areas are prepared for flood and drought (Fig: 6.64) compared to those from high rainfall areas. This shares a close relationship with actual frequency and susceptibility for these hazards.

\subsubsection{Floodplain}

About four percent of the total respondents (10/272) live in the 100 year flood susceptible zone of the region. The small number of respondents in this category means that generalisation can not be made. However, the results are included here for completeness and can be considered indicative only. Out of these 10 respondents, two respondents did not perceive themselves to be exposed to flood. An equal proportion of respondents in the flood zone found the hazard to be either not problematic, problematic or highly problematic i.e. three each. Only one person said that flooding is not applicable to him (Fig: 6.62.A). Frequency of flooding experienced by the respondents living on a floodplain also varied significantly (Fig: 6.62.B). While two respondents claimed to have experienced flooding once in a year, one said that it occurs once in every 2-5 years. However, none of the respondent living in floodplain perceived flooding to occur in coming five years (Fig: 6. 
Fig: 6.62. Problems, Frequency, Proximity in the Future and Potential Danger Perceived from Flood in the 100 Year Floodplain
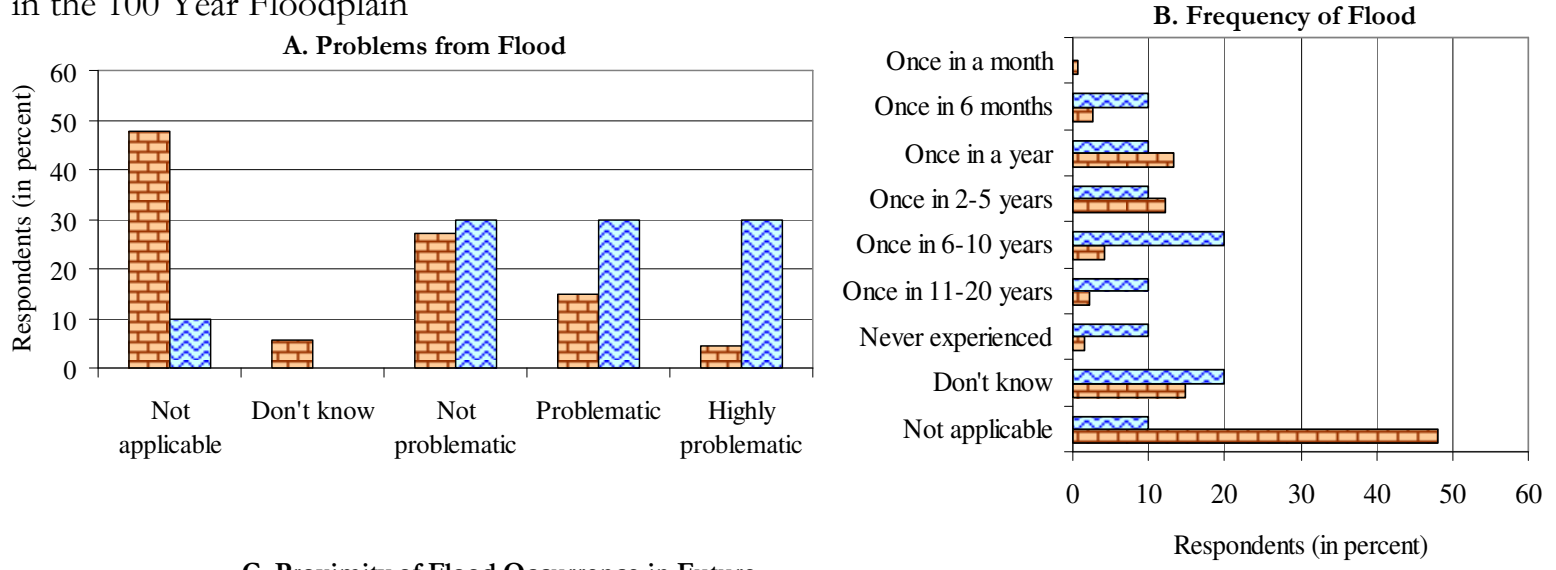

C. Proximity of Flood Occurrence in Future
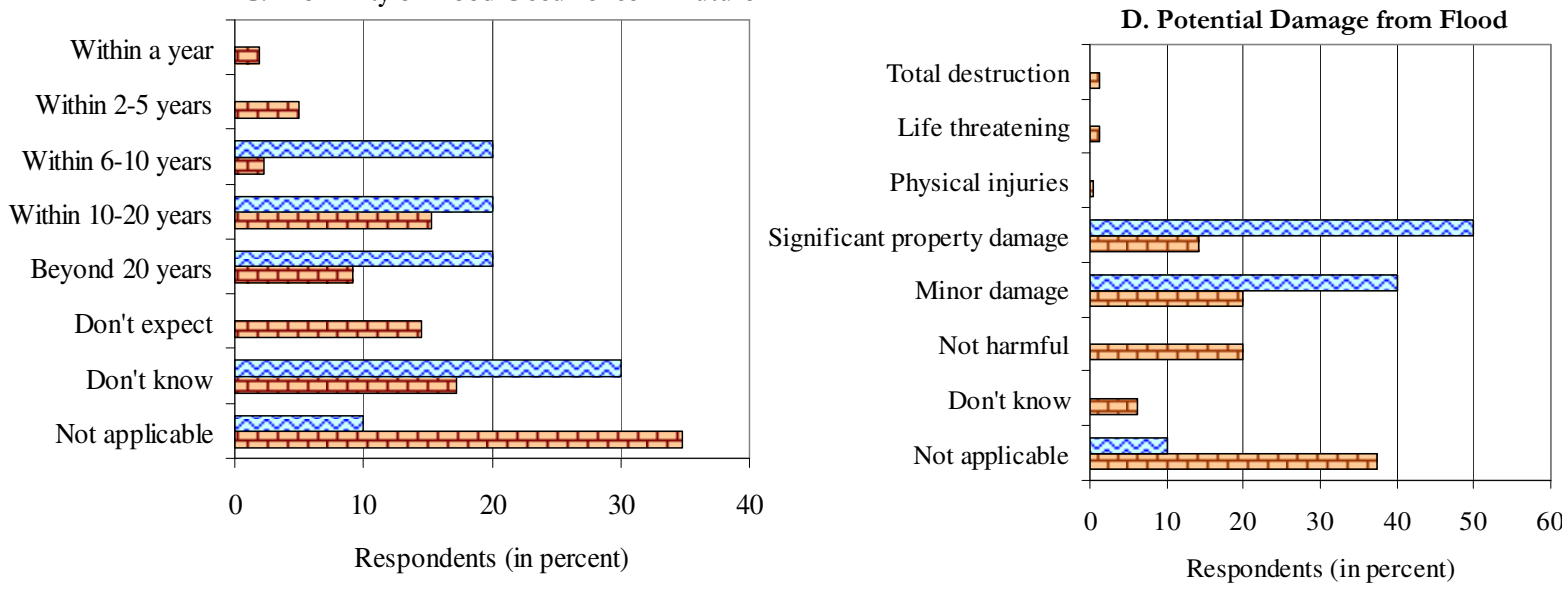

$\square$ Respondents not living in flood zone $\square$ Respondents living in flood zone

Based on Primary Survey, 2007 and data from Wellington Regional Council, 2006

62.C). Most of them either were not sure or perceived it to occur after five years, but none of them said that they did not expect it. Five respondents living on the floodplain believed that the flooding may cause significant property damage, while four perceived it to cause a minor damage (Fig: 6.62.D). On the other hand, the respondents, who perceived flooding to cause physical injuries, life threatening or devastating, lived outside the floodplain.

Fig: 6.63. Perceived Feeling of Well-being against Flood and the Most Feared Hazard in the 100 Year Floodplain
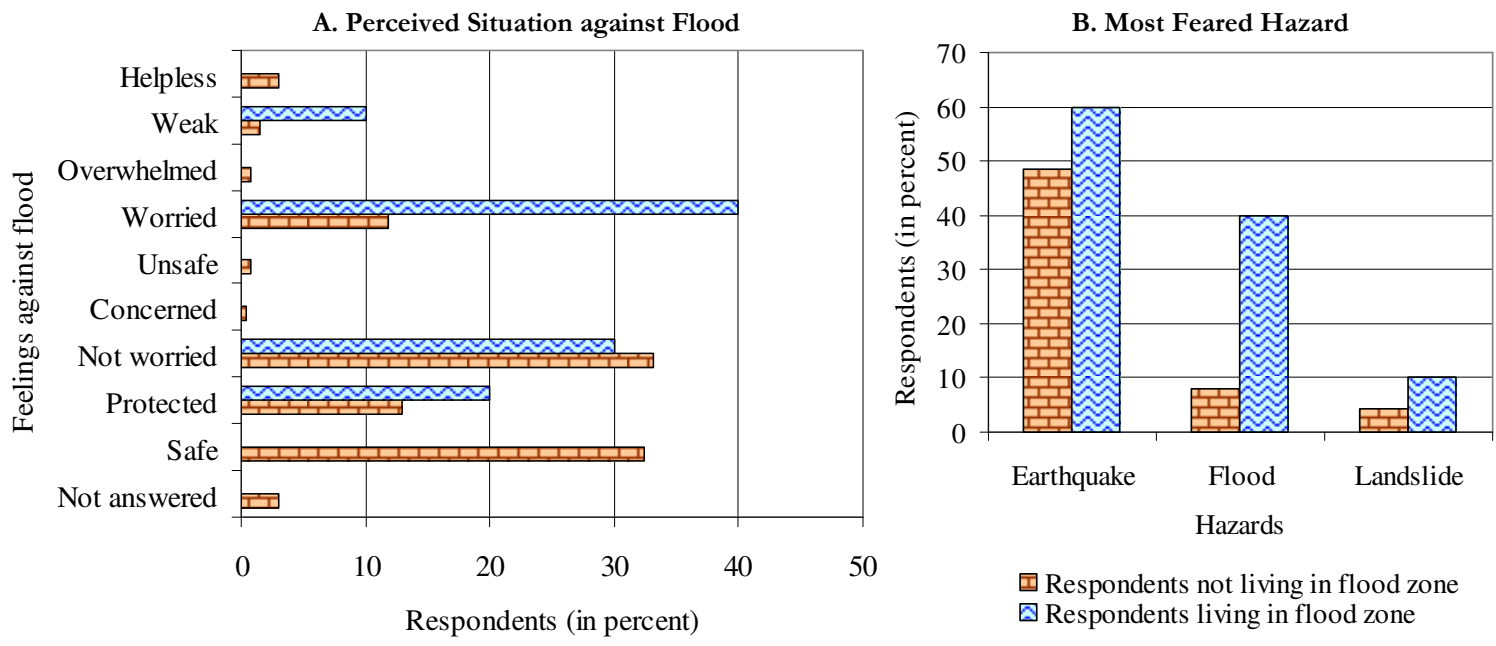

田 Respondents not living in flood zone Q Respondents living in flood zone 
While three respondents were not worried about flood, four felt worried and one respondent felt weak against the prospects of a flooding (Fig: 6.63). The reason can be attributed to perceived significant property damage from the hazard. The respondents who lived outside the floodplain mainly felt safe or not worried, except a few, who either felt worried or helpless in facing flooding.However, the most feared hazard in the floodplain is earthquake followed by flooding and landslides (Fig: 6.63.B).
Fig: 6.64. Awareness of Hazard Information Provided by Local Council to Respondent Living in the Floodplain

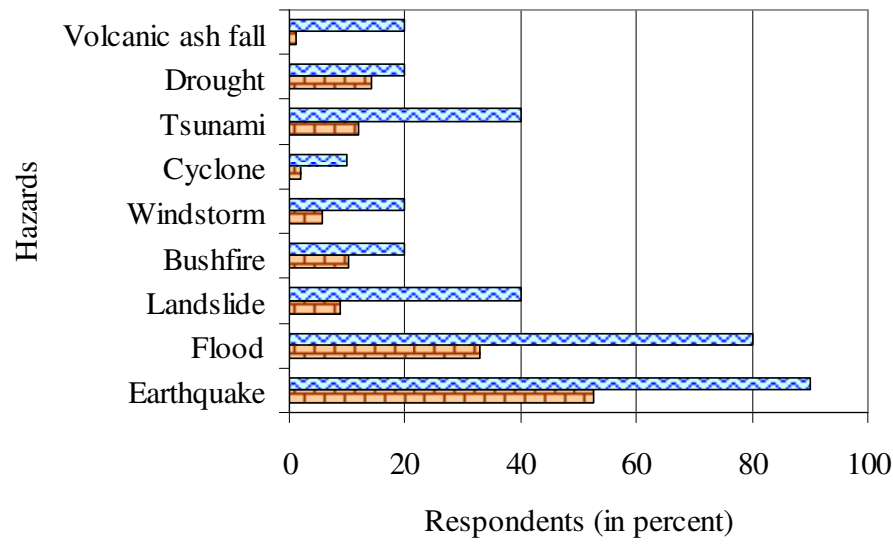

$\square$ Respondents not living in flood zone $\quad$ Respondents living in flood zone Based on Primary Survey, 2007 and data from Wellington Regional Council, 2006

Fig: 6.65. Hazard Awareness and Response by Respondents When First Settled into the House, in the Floodplain

A. Hazard Awareness

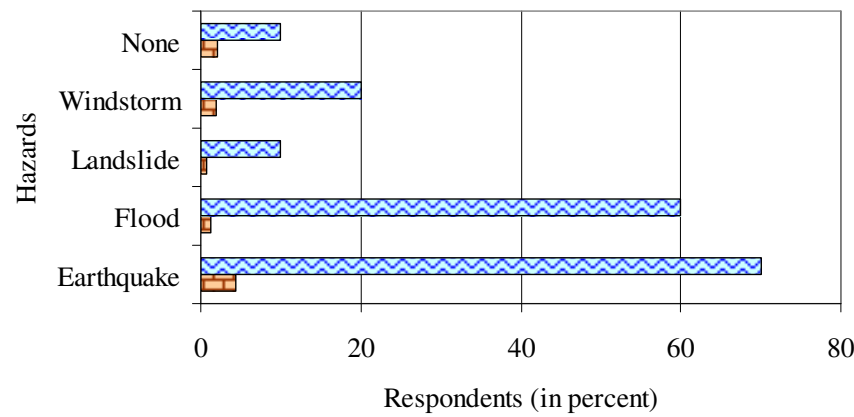

$\boxminus$ Respondents not living in flood zone

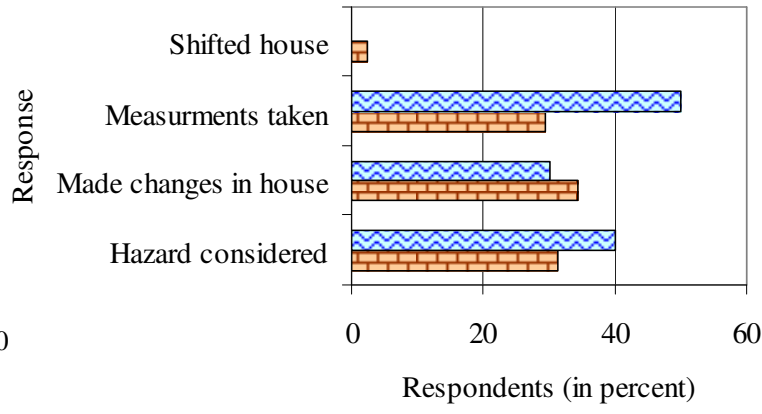

$\vee$ Respondents living in flood zone

Based on Primary Survey, 2007 and data from Wellington Regional Council, 2006

This is closely related with the trend of awareness of hazard information provided by the local council. The highest proportion of respondents said that they received information for earthquakes followed by those who received information for flooding and landslides (Fig: 6.64). The consistency for the type of hazards for which information is received and perceived fear suggests that the government response could play an effective role in influencing local perception and response.

Also, most of the respondents on the floodplain, when they first moved into their current house, were aware of earthquakes and flooding (Fig: 6.65.A). The data show that a relatively high

Fig: 6.66. Hazard Mitigation Measures Taken by Respondents When First Moved into the House, in the Floodplain

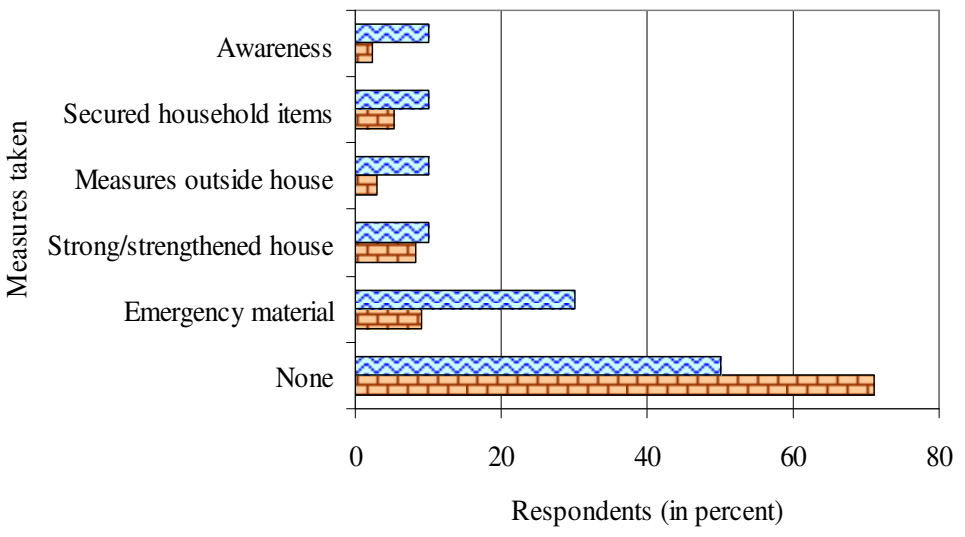

$\Xi$ Respondents not living in flood zone $\square$ Respondents living in flood zone Based on Primary Survev, 2007 and data from Wellington Regional Council, 2006 
proportion of respondents on the floodplain considered the hazard and took mitigation measures when they first moved to their current residence (Fig: 6.65.B).

The data also show that a relatively high proportion of respondents living on the floodplain took all kinds of mitigation measures including storing emergency material, strengthening the house, securing household items, constructing safety measures outside the house such as stop banks, and planting trees and enhancing their awareness about hazards (Fig: 6.66) as compared to those who lived outside the floodplain. Also, a relatively higher proportion of these respondents took safety measures including having spare cash, an emergency plan or survival kit compared to

Fig: 6.67. Type and Hazards for Which Safety Measures Taken by Respondents Living in the Floodplain

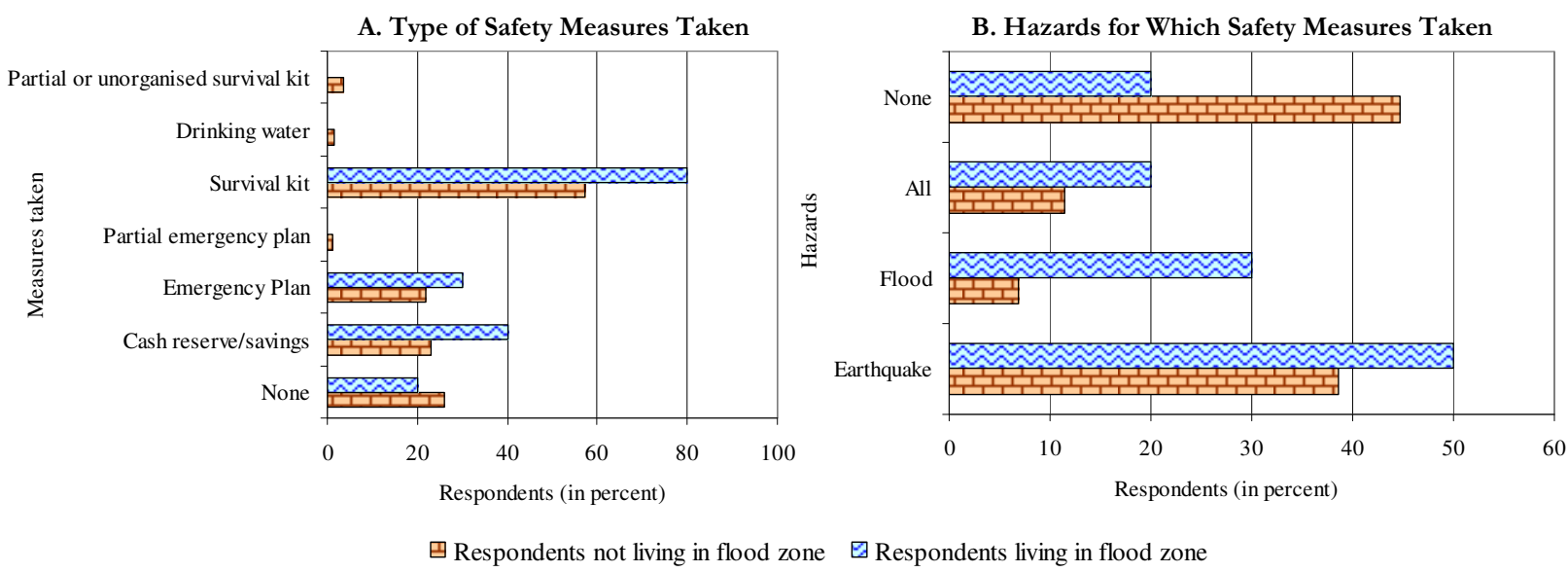

Based on Primary Survey, 2007 and data from Wellington Regional Council, 2006

the other respondents (Fig: 6.67.A).

While five of ten respondents took these measures for earthquake, three took these measures for flood, a higher proportion as compared to respondents who lived outside the floodplain (Fig: 6.67.B).

Also a high preparedness level is witnessed with respect to flooding among the residents of the floodplain compared to those who lived outside the floodplain (Fig: 6.68). While one

Fig: 6.68. Hazard Preparedness of Respondents Living in the Floodplain

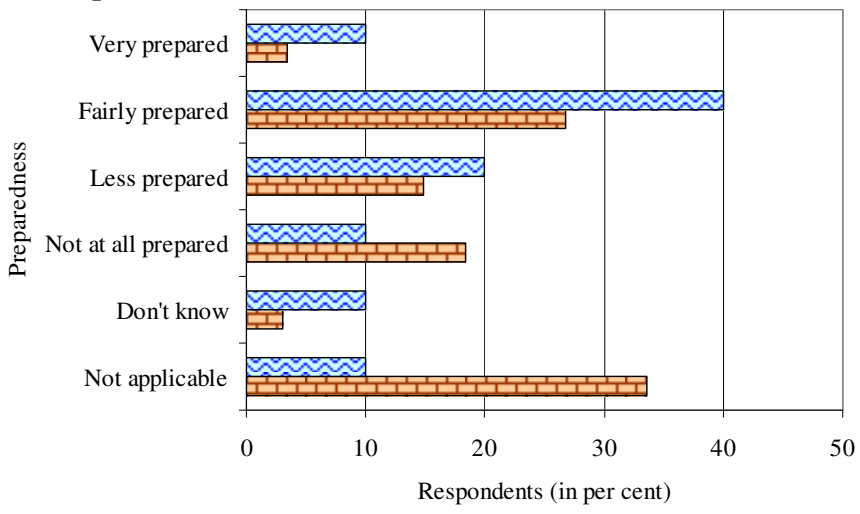

$\Xi$ Respondents not living in flood zone $\mathrm{G}$ Respondents living in flood zone Based on Primary Survey, 2007 and data from Wellington Regional Council, 2006 respondent was very prepared, four other respondents perceived themselves to be fairly prepared for flood, which indicates a higher proportion, compared to the respondents who lived outside the floodplain. However, as mentioned earlier, a small sample size in the floodplain could negate the importance of the observed differences.

\subsubsection{Wind Speed}

Wind is related to many hazards including windstorms, volcanic ash fall, bushfires and drought. The comparison of perception of hazard exposure with the location of respondents in different wind speed zones (see Map: 3.10) highlights a positive correlation for bushfire and volcanic ash fall 
(Fig: 6.69). The perception of both hazards is high in the high wind speed zone. The perception of windstorm exposure on the other hand, shows less correlation with increasing wind speed zone. However, at a very broad level, it can be said that more respondents in high wind speed zones perceived themselves to be exposed to windstorm than those who lived in lower wind speed zones. The perception of cyclone exposure does not bear any particular trend to areas of increasing wind speed.

A greater proportion of respondents living in areas of high wind speed consider windstorms to be more problematic as

Fig: 6.69. Hazards Exposure in Wind Speed Zones of 142 Year Wind Gust

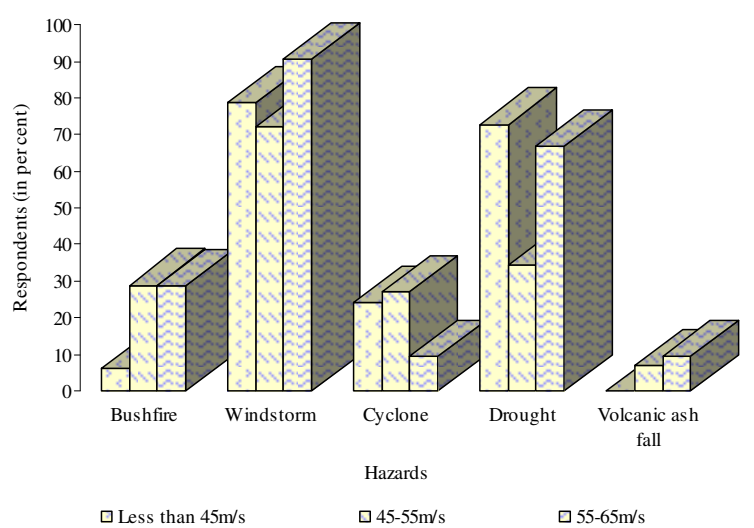

Based on Primary Survey, 2007 and Grant, 2005 compared to those who lived in low wind speed zones, but such trend is not observed for other hazards (Fig: 6.70.A). Similarly, a high frequency of windstorms is reported by a greater proportion respondents living in high wind speed zones compared to those who lived in low wind speed zone, but such trend is not observed for any other hazards (Fig: 6.70.B). For bushfire, however, a declining trend is noted in the proportion of respondents who perceived the hazard to be not applicable to them with wind speed zones.

Fig: 6.70. Perceived Problems and Frequency of Hazards in Wind Speed Zones (142 Year Wind Gust)

A. Problems from Hazards

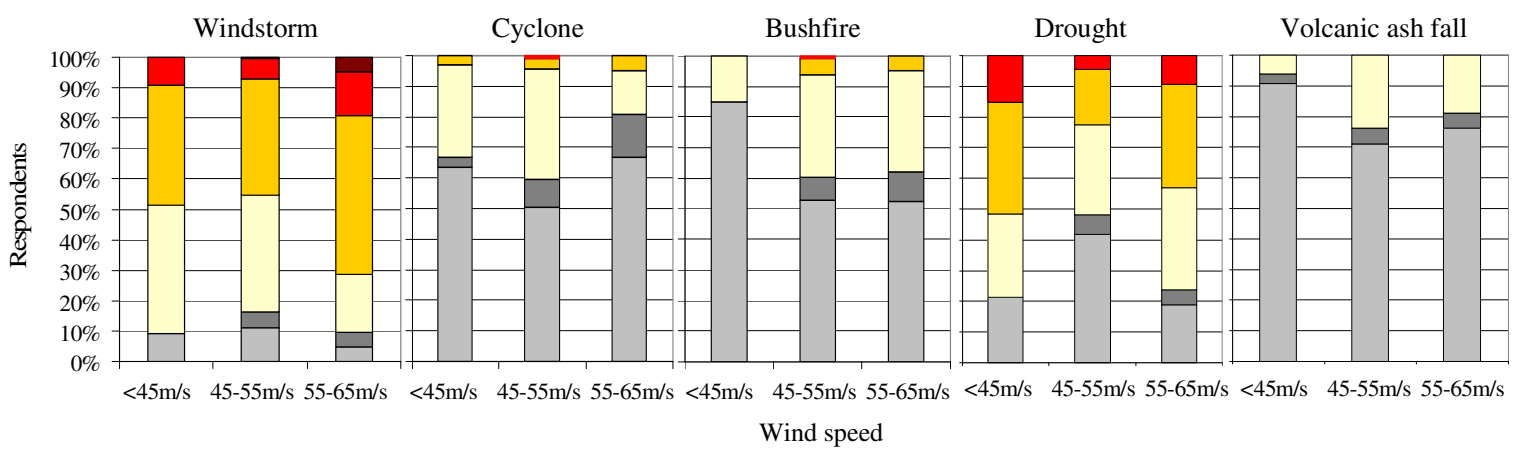

$\square$ Not applicable $\square$ Don't know $\square$ Not problematic $\square$ Problematic $\square$ Highly problematic $\square$ Out of control

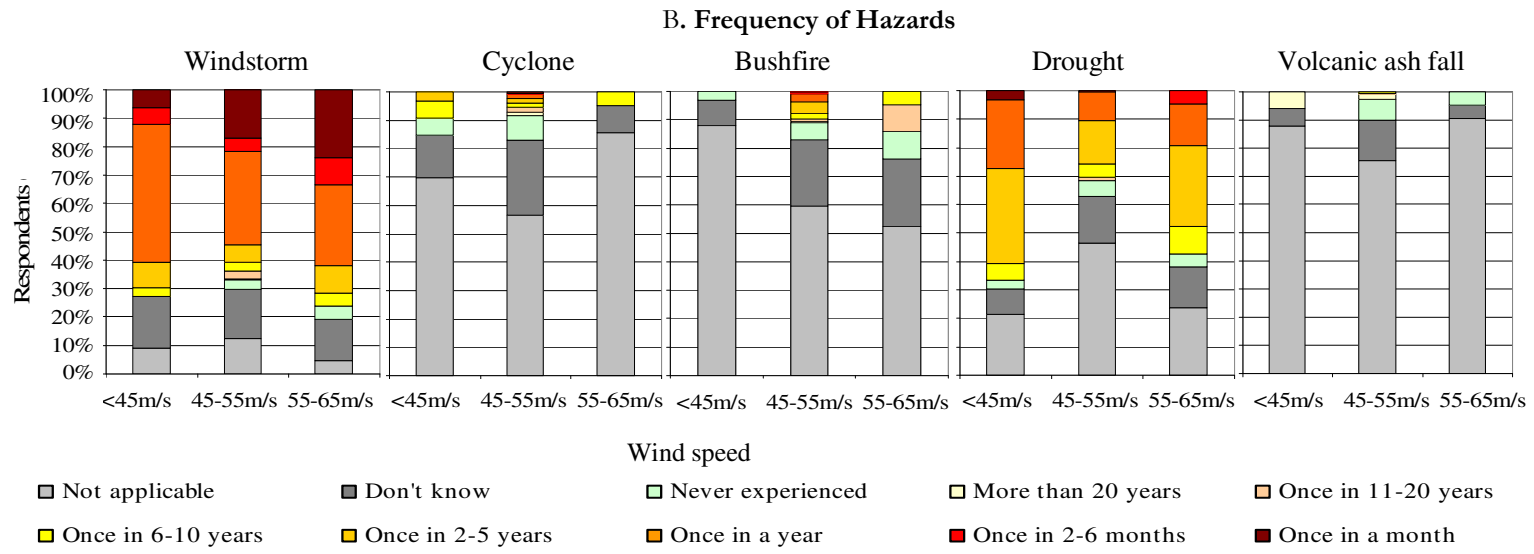

Based on Primary Survey, 2007 and Grant, 2005 
Fig: 6.71. Frequency, Proximity of Hazard Occurrence, Potential Damage and Perceived Situation against Hazards by Respondents in Wind Speed Zones (142 Year Wind Gust)
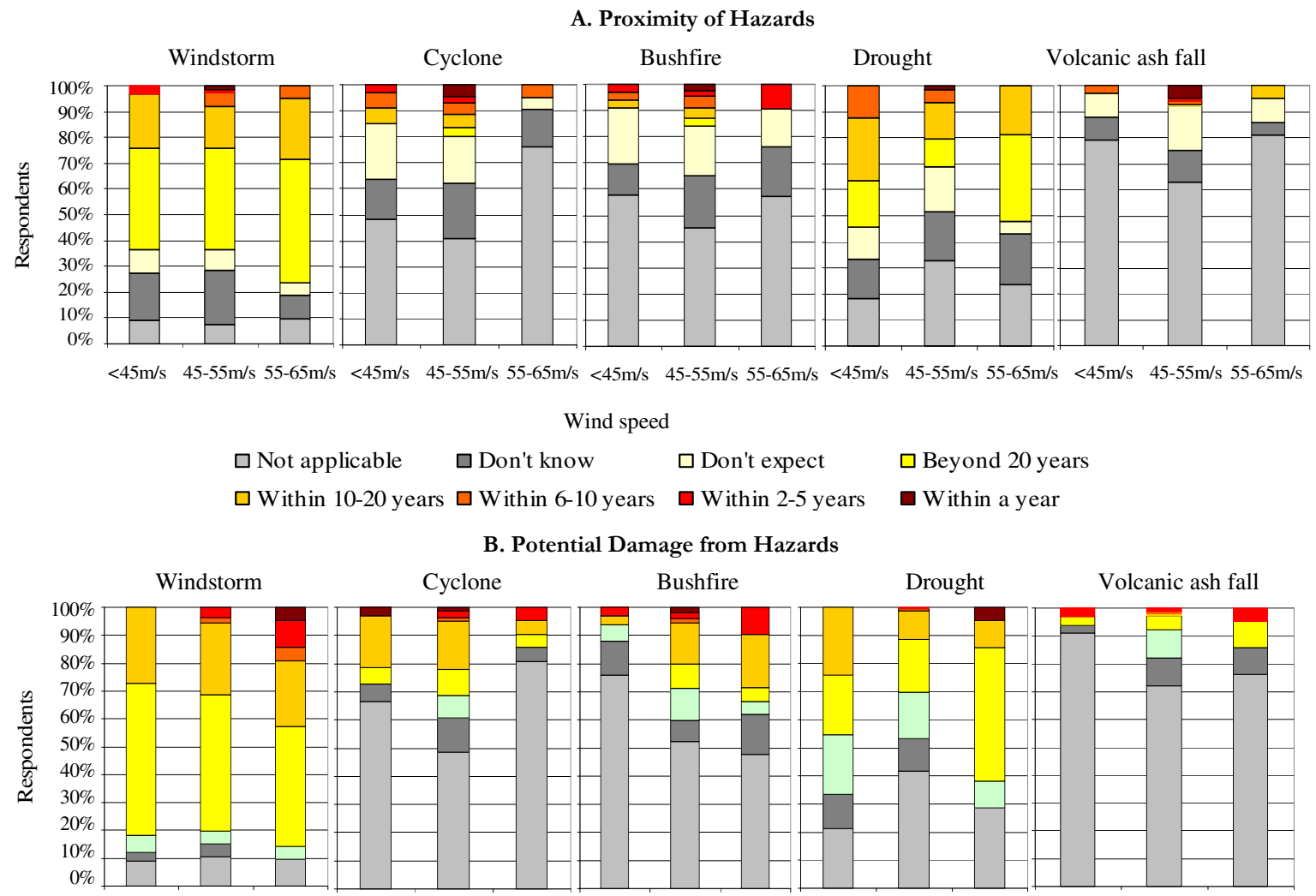

$<45 \mathrm{~m} / \mathrm{s} \quad 45-55 \mathrm{~m} / \mathrm{s} \quad 55-65 \mathrm{~m} / \mathrm{s} \quad<45 \mathrm{~m} / \mathrm{s} \quad 45-55 \mathrm{~m} / \mathrm{s} \quad 55-65 \mathrm{~m} / \mathrm{s} \quad<45 \mathrm{~m} / \mathrm{s} \quad 45-55 \mathrm{~m} / \mathrm{s} \quad 55-65 \mathrm{~m} / \mathrm{s} \quad<45 \mathrm{~m} / \mathrm{s} \quad 45-55 \mathrm{~m} / \mathrm{s} \quad 55-65 \mathrm{~m} / \mathrm{s} \quad<45 \mathrm{~m} / \mathrm{s} \quad 45-55 \mathrm{~m} / \mathrm{s} \quad 55-65 \mathrm{~m} / \mathrm{s}$ Wind speed
$\square$ Not applicable
$\square$ Don't know
$\square$ Not harmful
$\square$ Minor damage
$\square$ Significant property damage $\square$ Physical injuries
$\square$ Life threatening
- Total destruction

C. Perceived Feeling of Well-being against Hazards

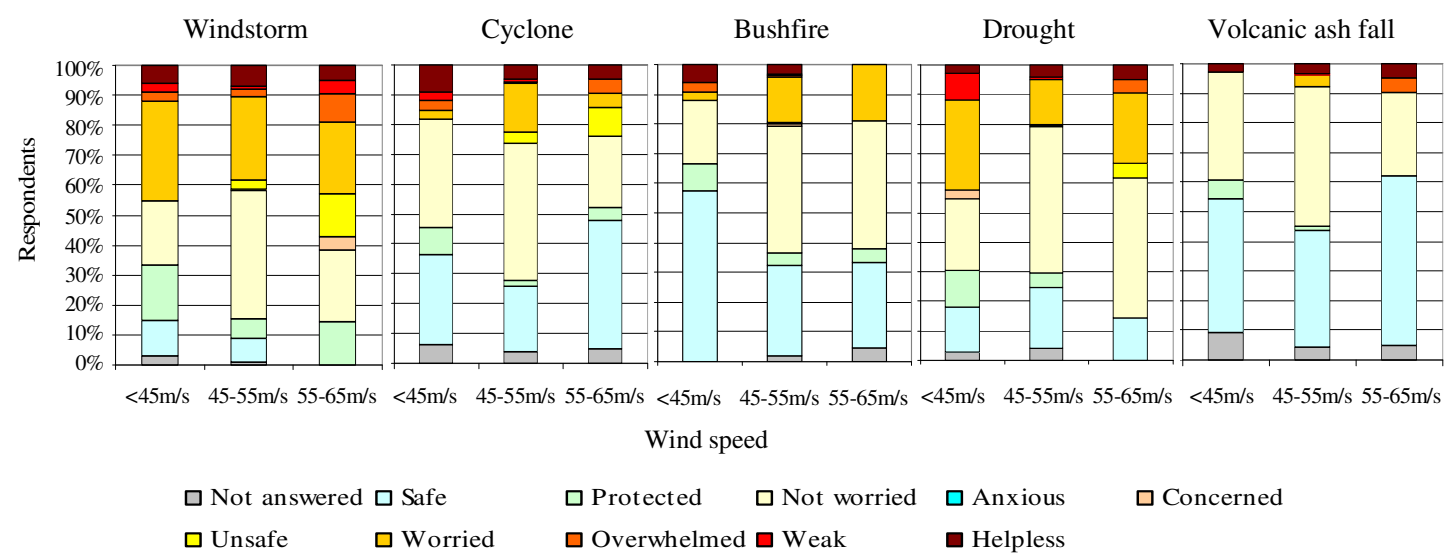

Based on Primary Survey, 2007 and Grant, 2005

The number of respondents who perceived windstorms to occur at some time in the future increases with the wind speed zone. However, more respondents living in low and mid wind speed zones perceived it to occur in the near future than those who lived in the high wind speed zone (Fig: 6.71.A). The greater variability in the perception of respondents in the mid wind zone could be attributed to a high sample size in this zone compared to other two zones. In terms of potential damage from hazards, a positive trend is noted in the proportion of respondents who perceived a greater threat from windstorm with increasing wind speed zones (Fig: 6.71.B). A greater potential 
Fig: 6.72. Most Feared Hazard and Awareness of Hazard Information Provided by the Local Council to Respondents in Wind Speed Zones
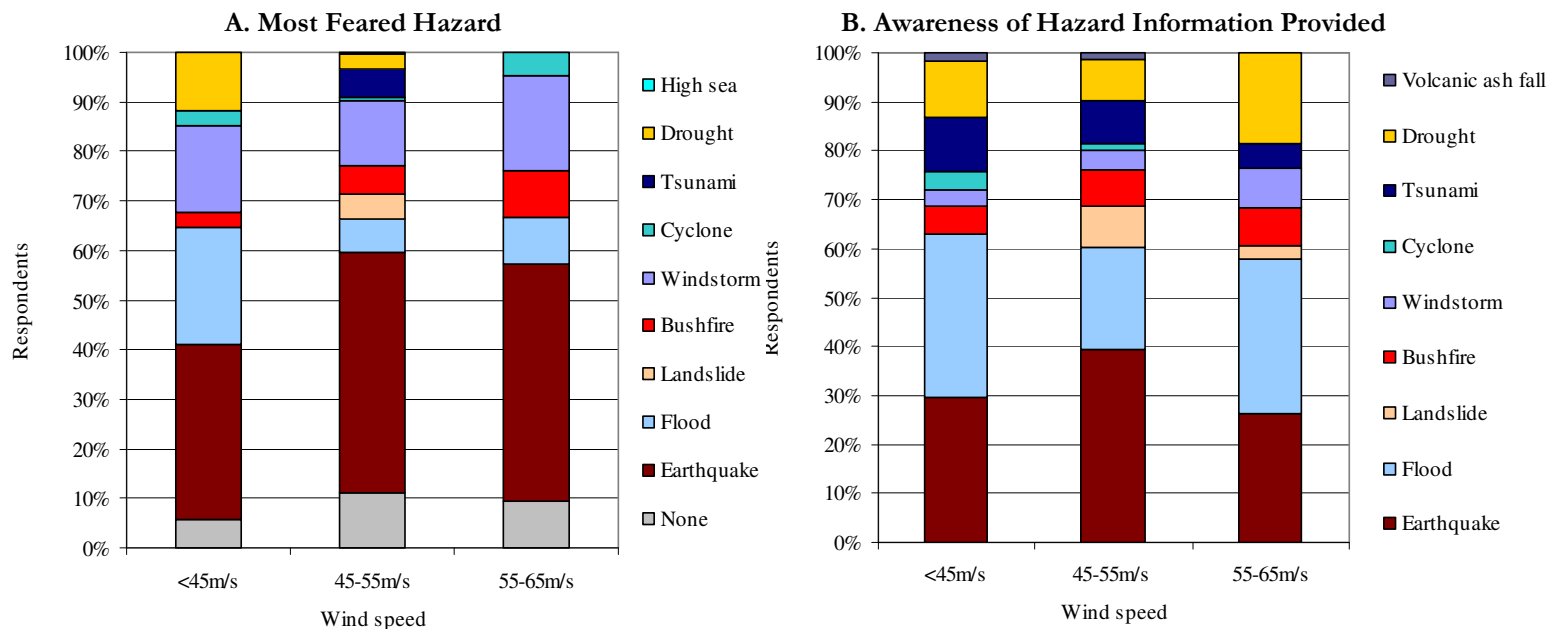

Based on Primary Survey, 2007 and Grant, 2005

threat from drought and volcanic ash fall is also perceived in the high wind speed zone. For bushfire and cyclone, though there are variations in the perception over space, there is no definite relationship with wind

Fig: 6.73. Hazard Consideration, Measures Taken by Respondent When First Moved into the House, in Wind Speed Zones

speed zones. The proportion of respondents who felt helpless increases with wind speed zone for drought and volcanic ash fall, while a decreasing trend is witnessed for windstorm, cyclone and bushfire (Fig: 6.71.C). However, a greater proportion of respondents perceived themselves to be unsafe or in a more uncomfortable situation against windstorms in the high wind speed zone than in other

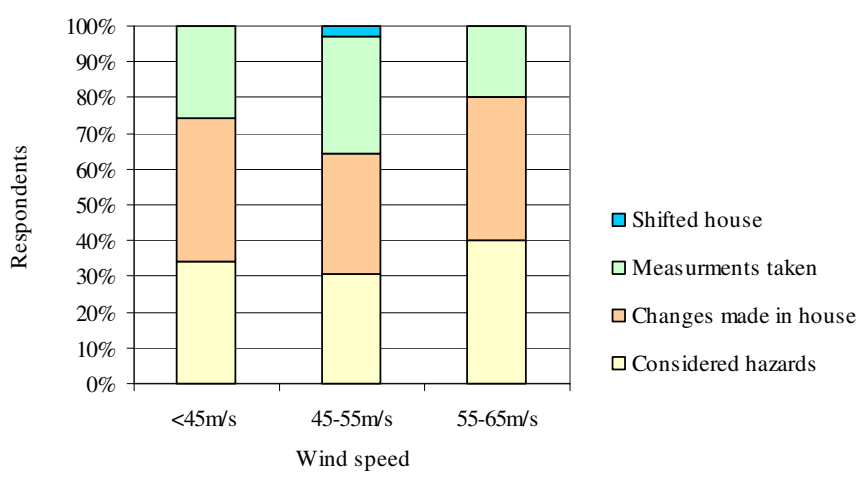

Based on Primary Survey, 2007 and Grant, 2005 zones.

Fig: 6.74. Hazard Awareness and Mitigation Measures Taken by Respondents When First Moved into the House, in Wind Speed Zones
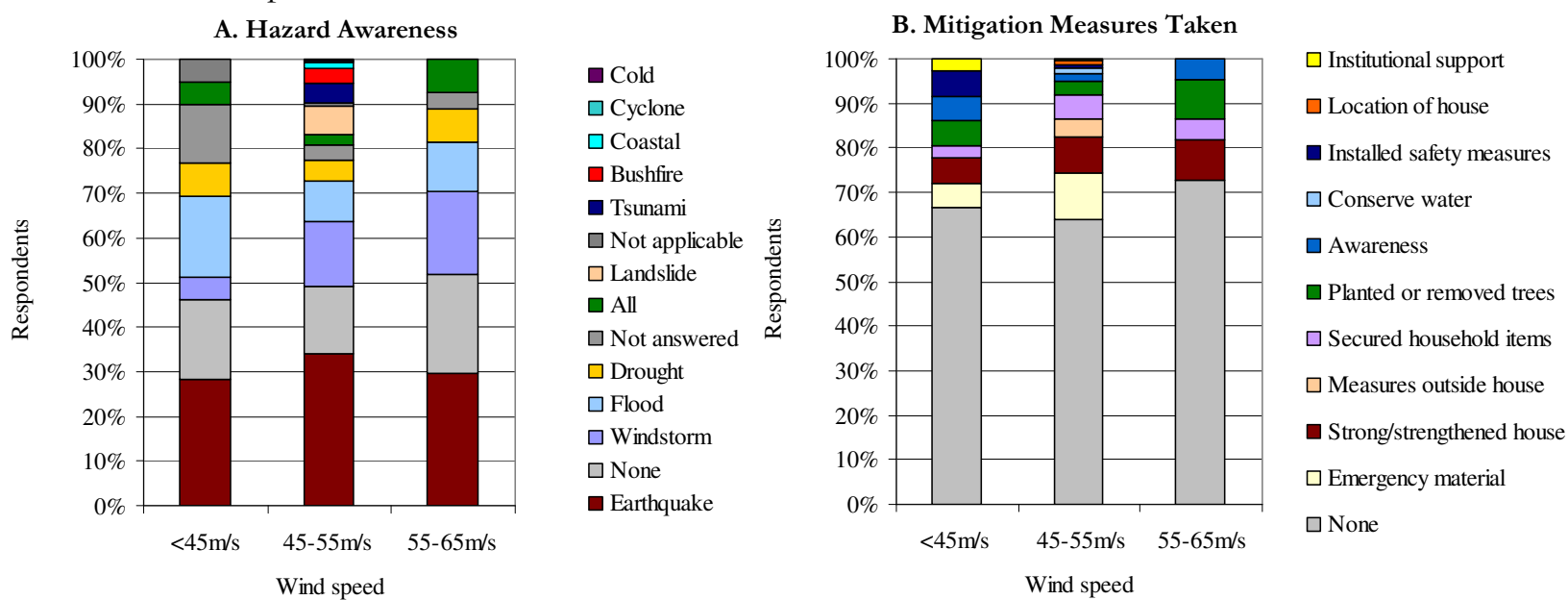

Based on Primary Survey, 2007 and Grant, 2005 
Even though windstorm is not the most feared hazard for a greater proportion of respondents in all wind speed zones, the highest proportion of respondents who feared windstorm most were from high wind speed zone (Fig: 6.72.A). Further, a positive trend is witnessed for the proportion of respondents who feared bushfire with increasing wind speed, and a negative trend is observed for drought. This is opposite to the trend of awareness of information provided for drought in different wind speed zones as the highest proportion of respondents in high wind speed zone said to have received information about the hazard (Fig: 6.72.B). This indicates that it is not only the information given that influences the people's perception, but the personal experience of hazards also plays a dominant role.

Fig: 6.75. Types and Hazards for Which Safety Measures Taken by Respondents in Wind Speed Zones
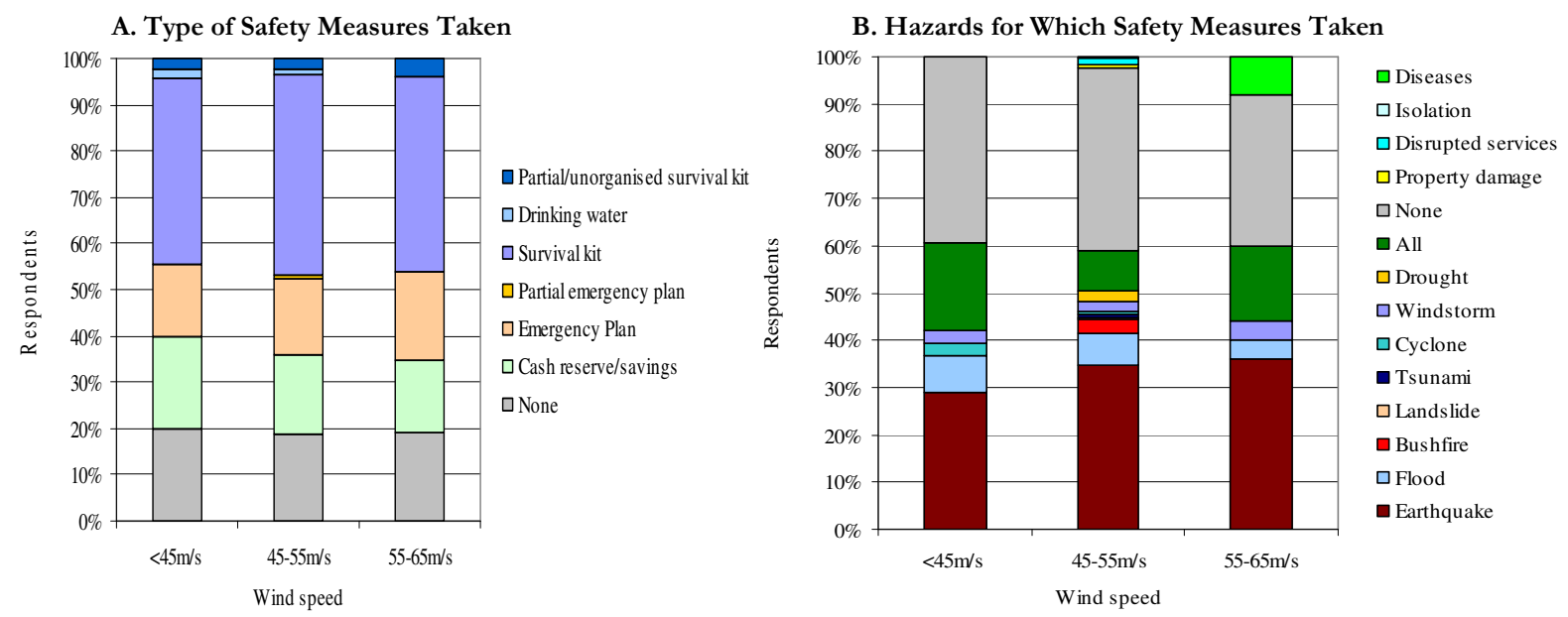

Based on Primary Survey, 2007 and Grant, 2005

The initial consideration and response to hazards, when respondents first moved into their house, does not correlate well with the varying wind speed zones (Fig: 6.73). However, an increasing trend is observed in the proportion of respondents who were aware of windstorm with areas of increasing wind speed (Fig: 6.74.A). A similar trend is also noted for those who opted for a strong house or strengthened their house once they moved in (Fig: 6.74.B). Further, the highest proportion of respondents who planted or removed trees to avoid damage from the windstorm were from the high wind speed zone.

Variations can be also observed in the safety measures taken by the respondents in

Fig: 6.76. Preparedness of Respondents in Wind Speed Zones (142 Year Wind Gust)

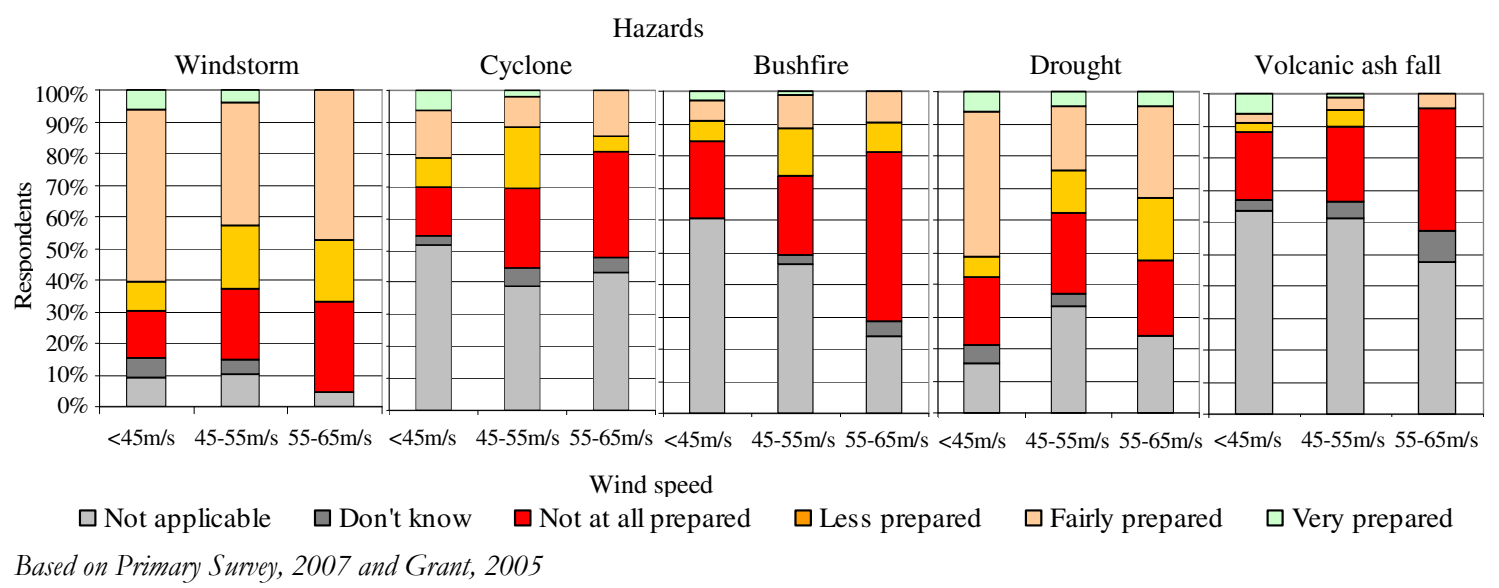


different wind speed zones, but the difference is not distinct (Fig: 6.75. A). However, the highest proportion of respondents who took safety measures for windstorms was from the high wind speed zone (Fig: 6.75.B).

In terms of preparedness, the proportion of respondents who are not at all prepared for windstorm, cyclone, bushfire and volcanic ash fall increases with increasing wind speed zones, while it decreases for the proportion of respondents who perceived themselves to be very prepared these hazards with increasing wind speed zones (Fig: 6.76). This is a revealing result which shows that even though respondents in high wind speed zone have taken measures, they do not perceive themselves to be very prepared. The reason could be attributed to perceived lack of control over these natural hazards.

\subsubsection{Bushfire Susceptibility}

Bushfire susceptibility is governed by a number of factors including vegetation, rainfall, slope and lightning. The comparison of perceived bushfire exposure with actual bushfire susceptibility from the Wellington Regional Council shows significant variations (Fig: 6.77). While a greater proportion of respondents living in high to extreme bushfire zones perceived themselves to be exposed to bushfire, a considerable proportion of respondents who lived in very high bushfire susceptibility zone did not perceive themselves to be exposed to the hazard. On the other hand, many respondents who did not live in the bushfire susceptible zone perceived themselves to be exposed to the hazard. Since there was only one respondent who was

Fig: 6.77. Perceived Exposure to Bushfire vs. Susceptibility

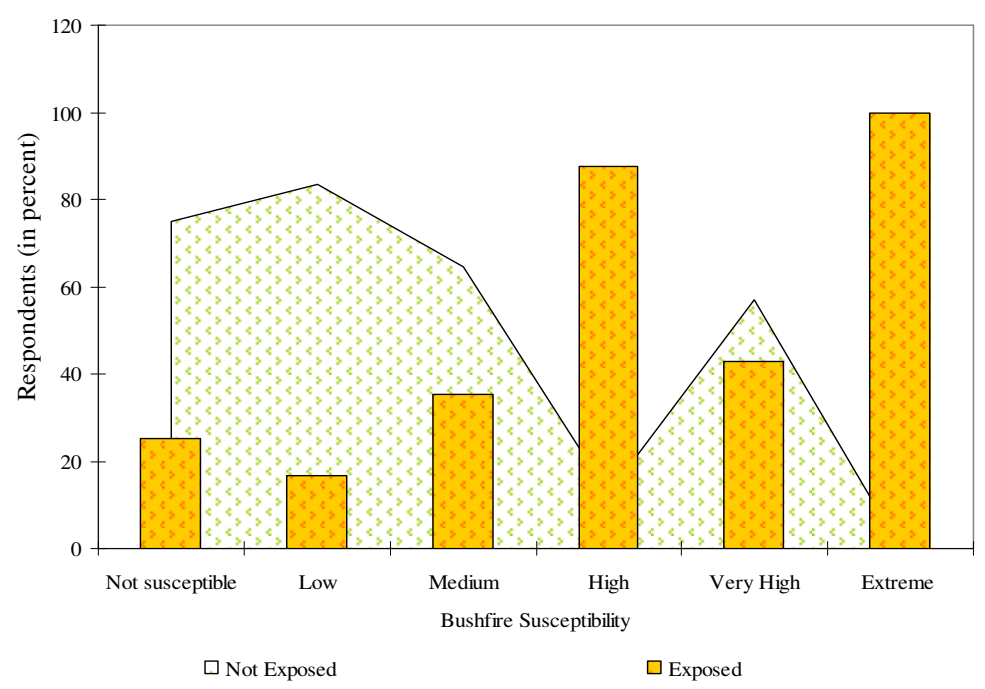

Based on Primary Survey, 2007 and data from Wellington Regional Council, 2006

Fig: 6.78. Perceived Problems and Frequency of Bushfire in Susceptible Areas
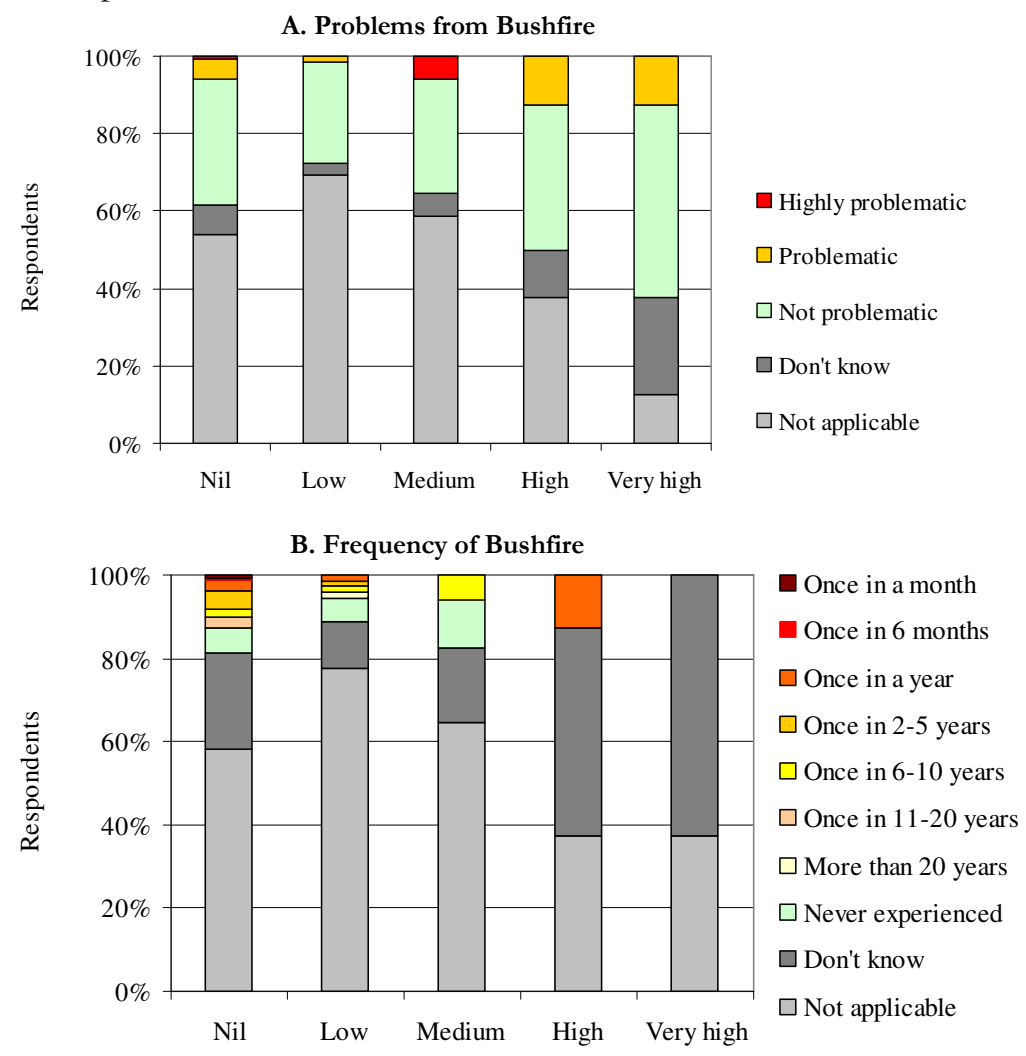

Based on Primary Survey, 2007 and data from Wellington Regional Council, 2006 
living in the extreme bushfire susceptibility zone, this category is merged with very high bushfire susceptibility zone for further analysis in order to get a better representation.

Bushfire has been found problematic by the respondents in all categories irrespective of their level of susceptibility (Fig: 6.78.A). The hazard has been found most problematic in the medium bushfire susceptibility zone followed by the areas which fall outside the susceptible zones. In these areas bushfires are likely to be human induced as also mentioned by the respondents.

The data show that most respondents found it difficult to tell the average frequency of bushfire in their residential area (Fig: 6.78.B). However, bushfires are reported to be most frequent in areas not categorised as susceptible to bushfires followed by the areas of high and low susceptibility respectively.

The perceived proximity of bushfire relates to frequency to some extent (Fig: 6.79.A). Some unexpected results emerge from this analysis. While respondents living in very high bushfire susceptibility zone either perceived it to occur in a period of more than 20 years or didn't expect it, the respondents who lived outside the bushfire zone, along with those in medium and high bushfire susceptinility zones perceived it to occur within a year. None of the respondents from the very high susceptibility zone considered bushfires to be either life
Fig: 6.79. Perceived Future Occurrence, Potential Damage, Feeling of Well-being and Most Feared Hazards in Areas Susceptible to Bushfire
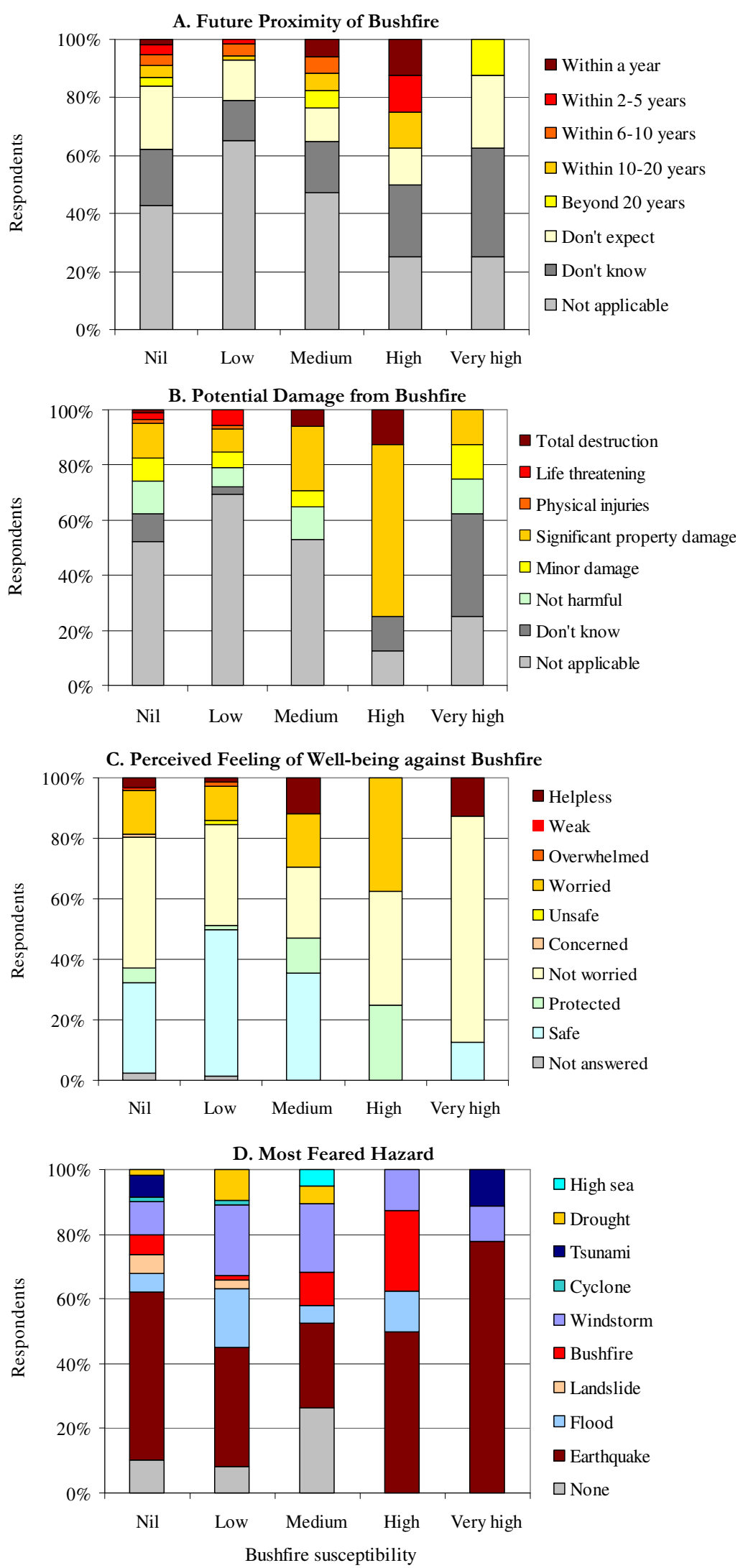

Based on Primary Survey, 2007 and data from Wellington Regional Council, 2006 
threatening or devastating (Fig: 6.79.B). However, a few respondents living in high and medium susceptibility zones and in areas outside the bushfire susceptibility zone could see the potential of total devastation through bushfires. Some respondents living in areas of low bushfire susceptibility could see it as life threatening but not devastating.

The perceived feeling of well-being when faced with the possibility of bushfires varies in different susceptibility zones but does not show a clear trend (Fig: 6.79.C). Interestingly, a major proportion of respondents in the very high bushfire susceptibility zone are not worried about the hazard. Also, the proportion of respondents who feel safe is nearly equal to those who feel helpless. However, the proportion of respondents who feel safe against bushfire declines with the increasing bushfire susceptibility.

The highest proportion of respondents who fear most from bushfire lived in the high bushfire susceptibility zone, and none of the respondents in the very high bushfire susceptibility zone feared most from bushfire (Fig: 6.79.D). Awareness of the information provided by the council about hazards also does not vary significantly across different bushfire susceptibility

Fig: 6.80. Awareness of Hazard Information Provided by the Local Council, Hazard Consideration, Awareness and Mitigation Measures Taken by Respondents When They First Moved into the House in Bushfire Susceptible Areas
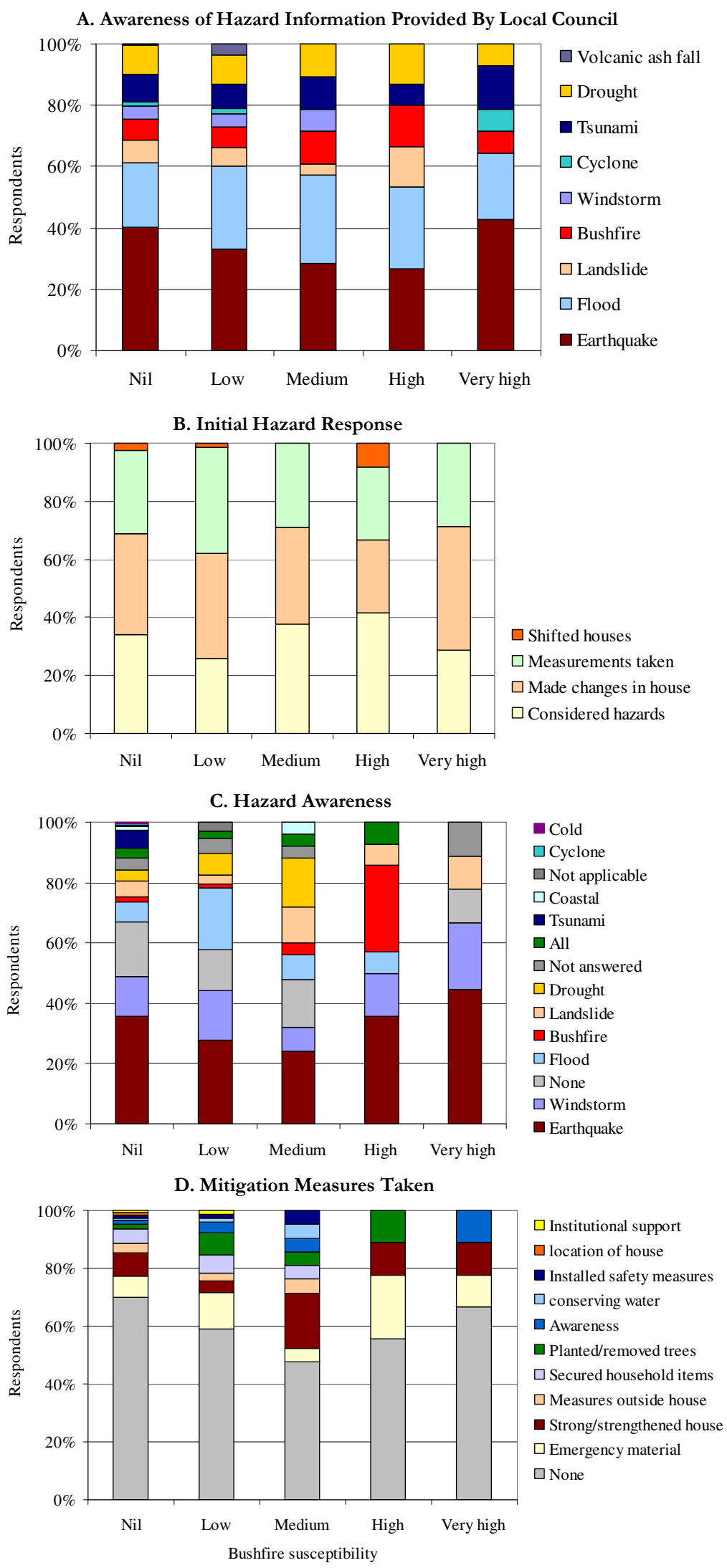

Based on Primary Survev, 2007 and data from Wellington Regional Council, 2006 
zones (Fig: 6.80.A). The proportion of respondents who said that they have received information about bushfire is nearly the same in areas which are not susceptible, less susceptible or very highly susceptible to bushfire. More respondents in medium and high susceptibility zones said that they received information about bushfire than those in other zones.

The initial response of respondents when they first moved into their current house also does not show any significant pattern with respect to increasing bushfire susceptibility (Fig: 6.80.B). None of the respondents in the high bushfire zone knew about this hazard when they first moved into their house. The highest proportion of respondents who knew about bushfires was from the high bushfire zone followed by medium, low and areas not susceptible to bushfires (Fig: 6.80.C). Also, the mitigation measures taken by the respondents do not show any significant relationship with bushfire susceptibility (Fig: 6.80.D). However, a high response is seen from the respondents living in medium bushfire susceptibility zone in 'planted or removed trees' category which could be aimed at reducing bushfire susceptibility besides controlling the damage from windstorm. Similarly, there is no clear trend of safety measures taken by the respondents across bushfire susceptibility

Fig: 6.81. Type and Hazards for Which Safety Measures Taken by Respondents in Bushfire Areas

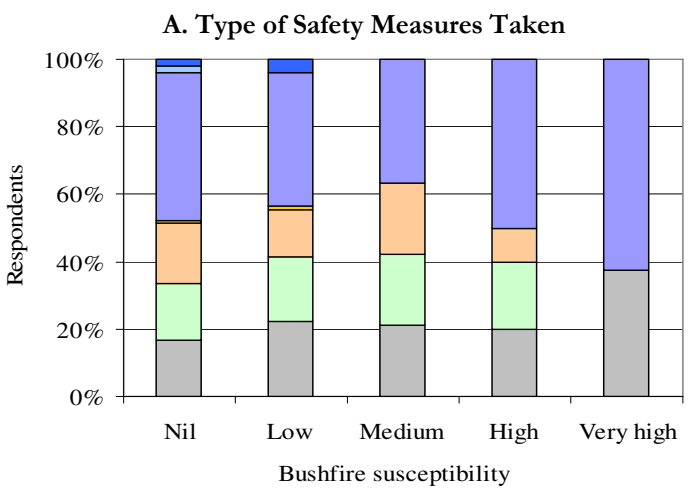

$\begin{array}{ll}\square \text { None } & \square \text { Cash reserve/savings } \\ \square \text { Emergency Plan } & \square \text { Partial emergency plan }\end{array}$

$\square$ Survival kit

$\square$ Partial/unorganised survival kit

Based on Primary Survey, 2007 and data from Wellington Regional Council, 2006

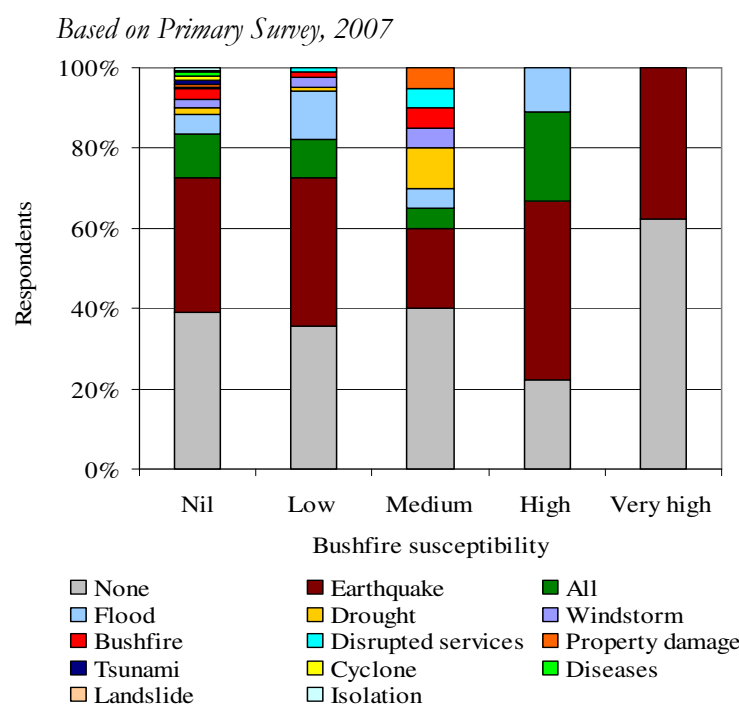

zones (Fig: 6.81.A). None of the respondents have made any emergency plan in the very high bushfire susceptibility zone. A survival kit is the common measure taken across all susceptible areas. None of the respondents from high or very high bushfire susceptibility zones mentioned bushfire as the reason for taking safety measures (Fig: 6.81.B).

The data show that the preparedness for bushfire is less in high bushfire susceptibility zones (Fig: 6.82). The highest proportion of respondents who are not at all prepared for this hazard were living in the very high bushfire

Fig: 6.82. Perceived Hazard Preparedness of Respondents in Bushfire Susceptible Areas

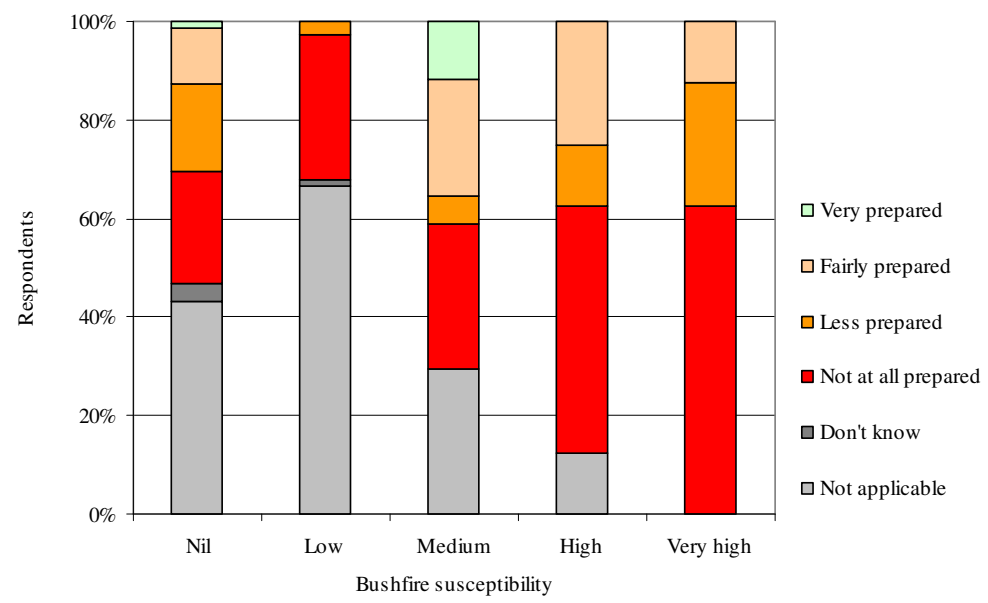

Based on Primary Survey, 2007 and data from Wellington Regional Council, 2006 
susceptibility zone and their proportion declines with the declining susceptibility for this hazard. The highest proportion of respondents who perceived themselves to be very prepared for bushfires lived in the medium susceptibility areas, followed by those who lived outside the bushfire susceptibility zone.

Therefore, it can be concluded that physical susceptibility plays a relatively dominant role behind the perception and response of people for a few hazards such as flooding, tsunami and windstorms, compared to others i.e. liquefaction, cyclones or bushfires. The perception and response for earthquakes on the other hand, is high throughout the region despite of some variations that can be noted along with the distance from fault. High awareness and response to earthquake could be attributed to active government response, which is more general throughout the region in terms of information provided to local people, and does not vary with respect to variations in the physical susceptibilities over space.

\subsubsection{Influences of Human Vulnerability}

As discussed in Chapter-2, various aspects of vulnerability i.e. hazard exposure, fragility and lack of coping capacity influence response in different ways and to different extents.

\subsubsection{Exposure}

The perception of hazard exposure is significant for response, and the perceived exposure is often different from the actual exposure. While nearly 88 percent of the respondents found themselves to be exposed to earthquakes, only six percent of them believed that they are exposed to volcanic ash fall (Fig: 6.83.A). This is contrary to the actual susceptibility and exposure to these hazards, wherein the impact of earthquake is often location specific (e.g. fault rupture along faults, liquefaction in floodplain, tsunami on coasts etc.),

Fig: 6.83. Perceived Type and Number of Hazard Exposure by Respondents at Their Residence
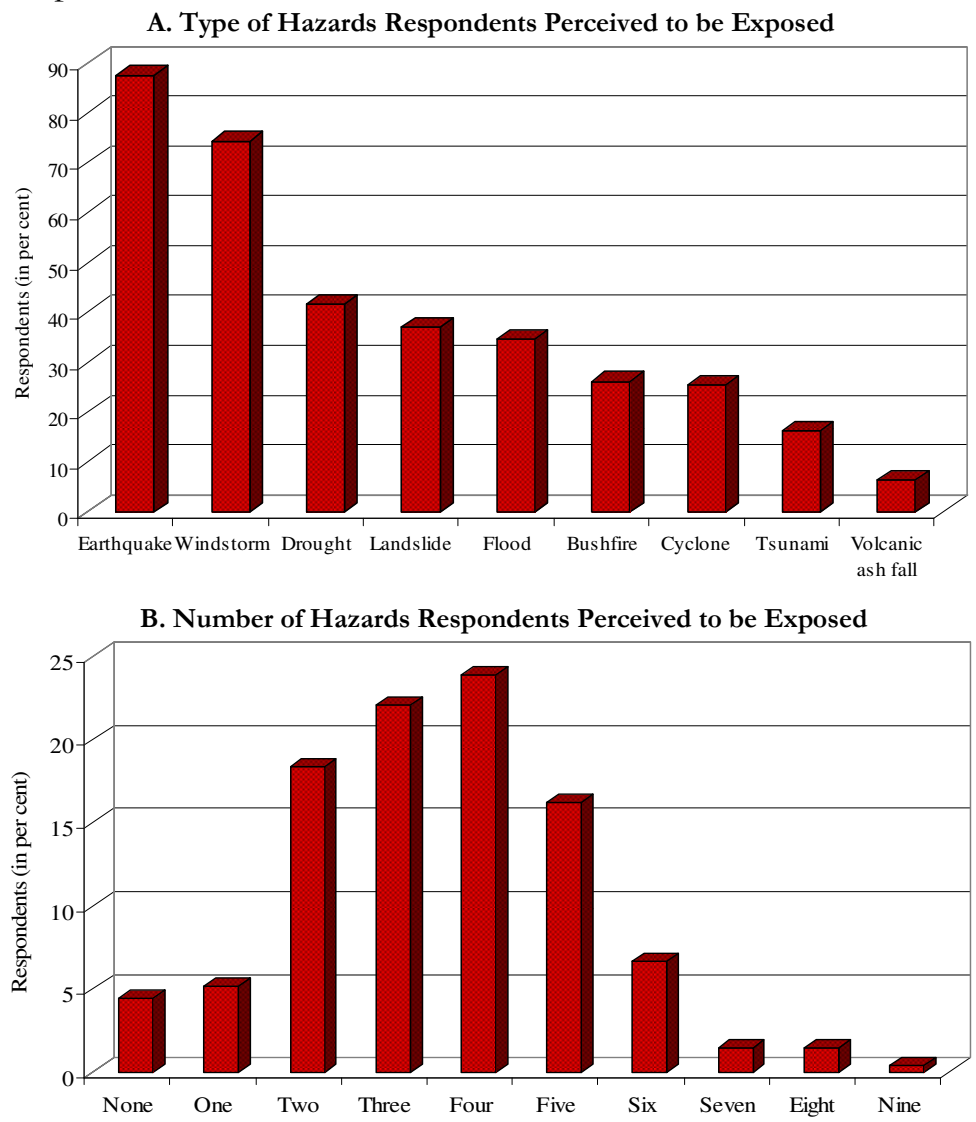

Based on Primary Survey, 2007 the region is throughout susceptible for volcanic ash fall. More than 70 percent of the respondents 
found themselves to be exposed to windstorms, while 30-40 percent named droughts, landslides and flooding. High awareness of these hazards is contributed by their frequent occurrences and regular damage. A gradual decline in the perception of exposure for bushfire (26 percent), cyclone (25 percent), and tsunami (16 percent) reflects on the decline in the frequency of these hazards along with regularity of associated damage. In terms of number of hazards, about a quarter of respondents said that they are exposed to 1-3 hazards, about 60 percent of them said to be exposed to 3-5 hazards and nearly 10 percent found themselves to be exposed to 6-9 hazards at their place of residence. Only four percent of the respondents said that they are not exposed to any hazard (Fig: 6.83.B).

The respondents were asked which area or locality in their district will be most affected in Fig: 6.84. Areas Perceived to be Most and Least Exposed to Hazards by Respondents
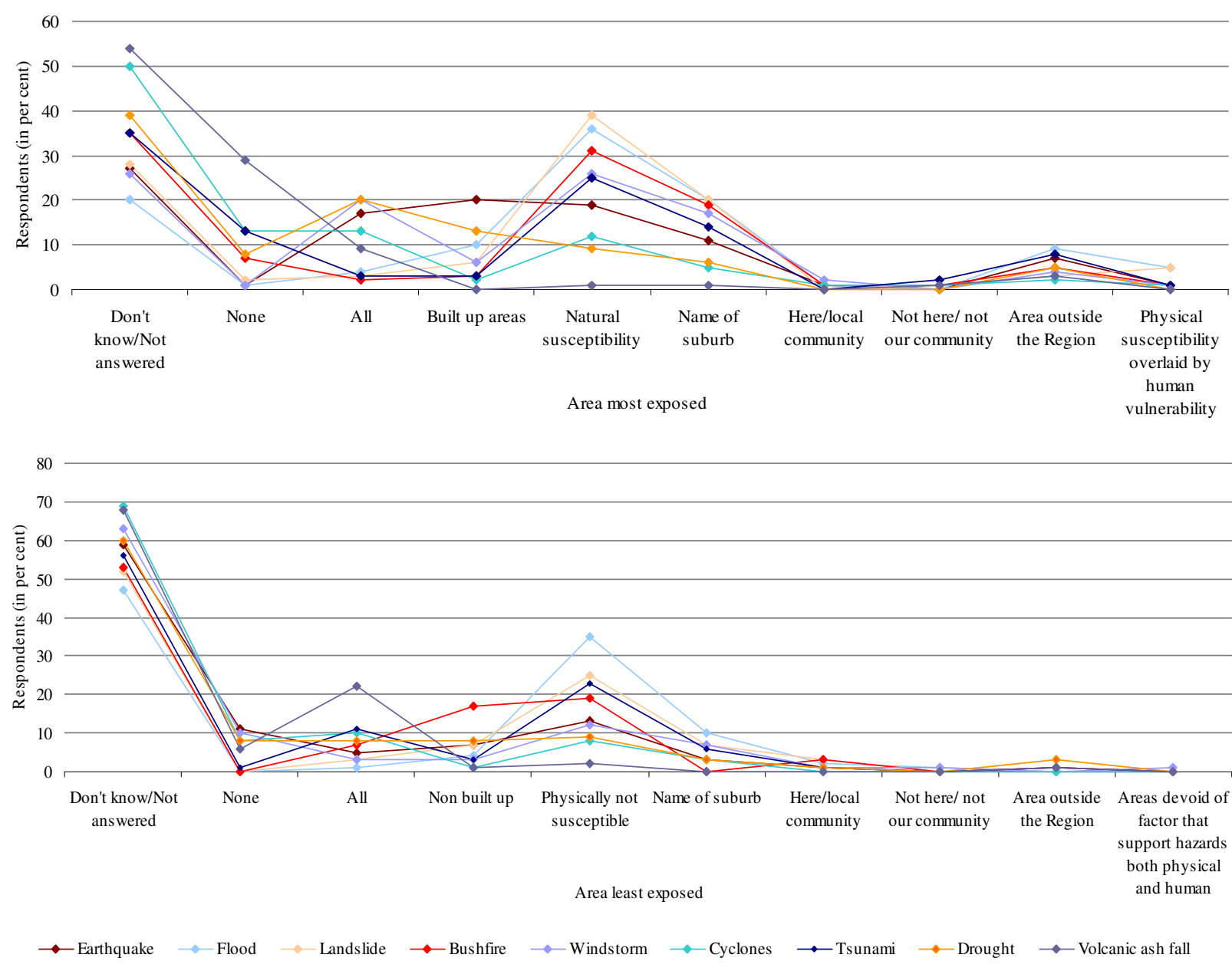

Based on Primary Survey, 2007

the case of the nine mentioned hazards. They were also asked who they think will be most affected by their most feared hazard. The perceived cause of exposure by the respondents not only varied for different areas and people, but also for themselves. At the area level, most respondents found physical susceptibility to be the main cause of hazard exposure rather than human vulnerability (Fig: 6.84). However, they see a different level of influence of physical susceptibility for different hazards. While one percent of the respondents believed physical susceptibility to be the causative factor behind the exposure to volcanic ash fall, nearly forty percent found it to be the cause for landslides. Twenty percent of the respondents could name the suburbs they thought are the most 
susceptible to hazards, and nearly ten percent named the suburbs they thought are least susceptible particularly for the location of specific hazards such as flood and landslides. About twenty percent of the respondents found the built up areas to be the cause for exposure to earthquake damage.

Table: 6.3. People Perceived to be Affected by the Most Feared Hazard of Respondents

\begin{tabular}{|c|c|c|c|c|c|c|}
\hline \multirow{3}{*}{$\begin{array}{l}\text { Individual/group } \\
\text { likely to be } \\
\text { affected }\end{array}$} & \multicolumn{6}{|c|}{ Scale of Affect (percent respondents) } \\
\hline & \multirow[b]{2}{*}{ Not answered } & \multicolumn{5}{|c|}{ Most affected-----------------------------------------------Least affected } \\
\hline & & 1 & 2 & 3 & 4 & 5 \\
\hline Family & 22 & 53 & 15 & 5 & 4 & 1 \\
\hline Yourself & 12 & 42 & 28 & 10 & 6 & 2 \\
\hline Neighbours & 20 & 31 & 16 & 20 & 13 & 1 \\
\hline Friends & 28 & 21 & 11 & 18 & 14 & 7 \\
\hline Community & 67 & 21 & 3 & 1 & 5 & 4 \\
\hline Other & 98 & 2 & 0 & 0 & 0 & 0 \\
\hline
\end{tabular}

Based on Primary Survey, 2007

Fig: 6.85. Reasons Perceived by the Respondents for Being Affected by Their Most Feared Hazard

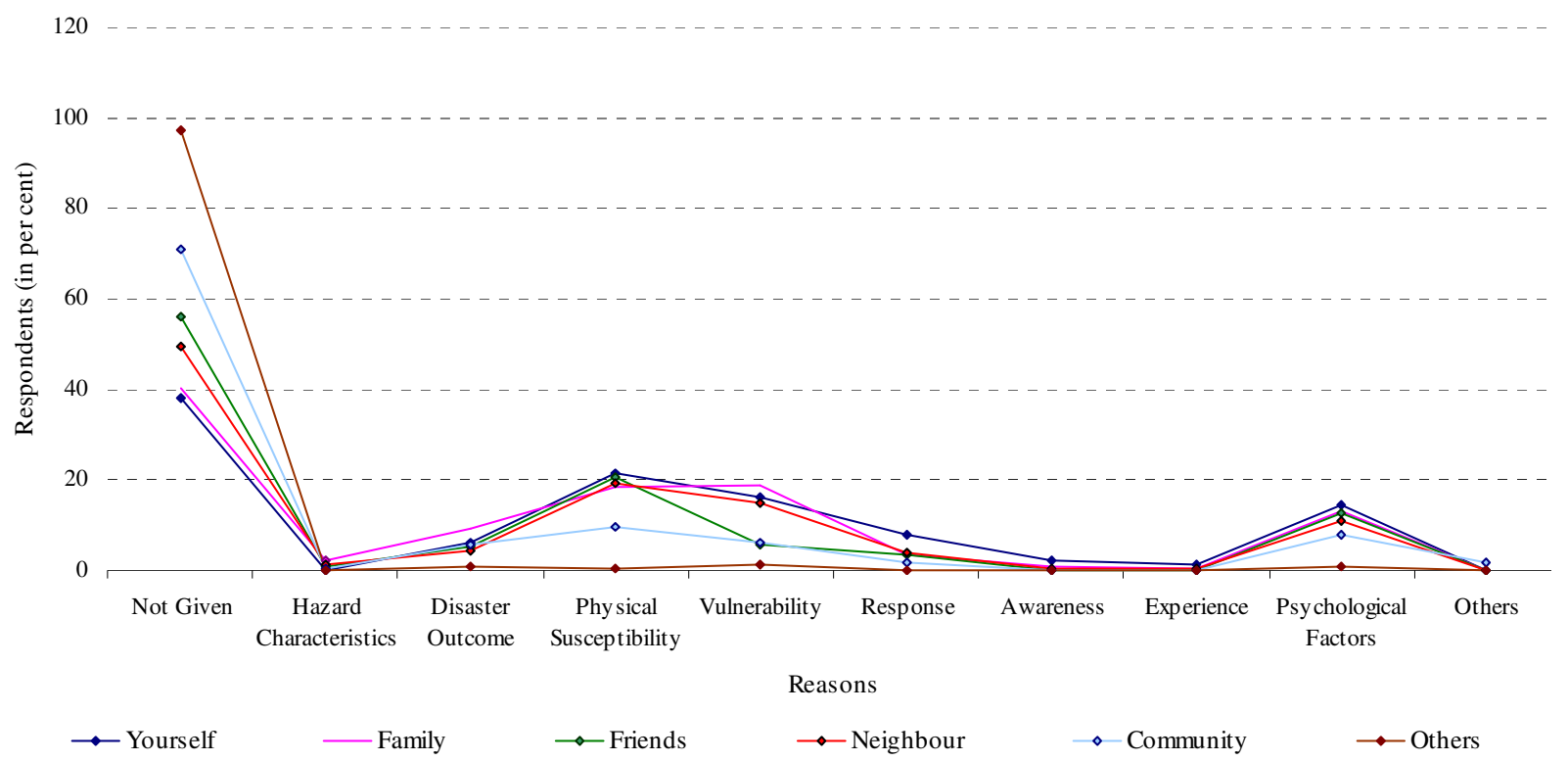

Based on Primary Survey, 2007

The reason and extent of hazard exposure as seen by the respondents for other groups of people and themselves also differed significantly. Most respondents saw their family to be most affected by their most feared hazard followed by themselves and then their neighbours (Table: 6.3). They see friends and community to be less affected compared to those who are likely to reside closer to them. Few respondents also mentioned pets who would be most affected as there would not be much help available for them. The reasons perceived for the vulnerability of respondents and the people around them varies from hazard characteristics, disaster outcome, susceptibility, vulnerability, nature of response, awareness, experience and psychological conditions of the possible victims (Fig: 6.85). However, the most common reason given by the respondents were physical susceptibility, vulnerability and psychological conditions such as stress, concern, fear, worries, hope or fatalism. The perceived disaster outcome is also a noted reason for the fear behind the particular outcome. The hazard characteristics in terms of their frequency, magnitude and intensity are viewed less significant as compared to the susceptibility to hazard as the cause of 
vulnerability. Poor response in the form of preparedness and warning was also given as the reason influencing the real time response of the individuals.

It is also noted that the perception of exposure varies with the respondents' age, gender, ethnicity, occupation, education and the composite vulnerability of the area in which they live. While the percent of respondents who perceived themselves to be exposed to earthquakes, windstorms, tsunami and volcanic ash fall is nearly same for all age groups, it decreases with age for bushfire, landslide and flood and increases for drought and cyclone (Fig: 6.86).

While an equal proportion of Fig: 6.86. Hazard Exposure Perceived in Age Groups

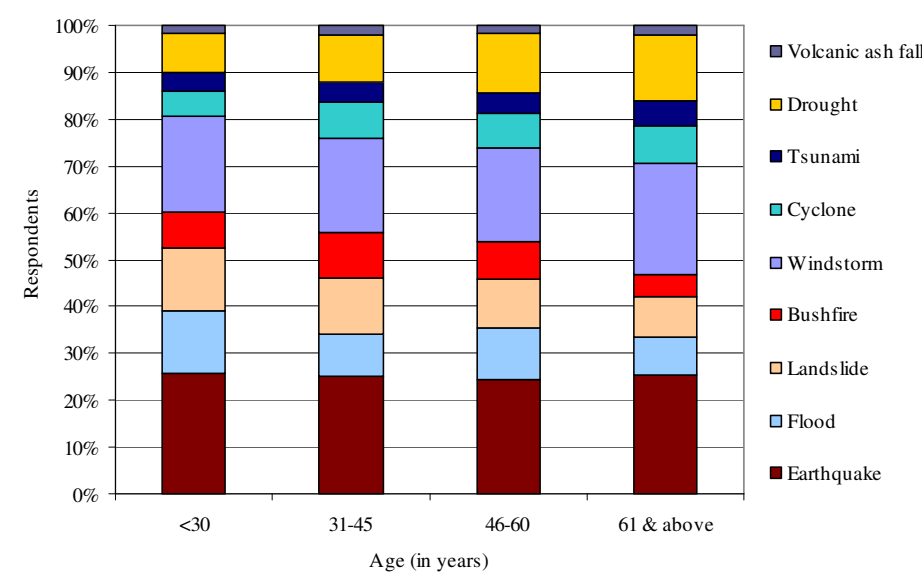

Based on Primary Survey, 2007 male and female respondents perceived themselves to be exposed to earthquakes, more women perceived themselves to be exposed to flooding, windstorms, droughts and tsunami, and relatively more men perceived themselves to be exposed

Fig: 6.87. Perception of Hazard Exposure vs. Gender

landslides, bushfires, cyclones and volcanic ash fall (Fig: 6.87).

However,

differences are small in most cases and given the nature of sampling may not be general throughout the community.

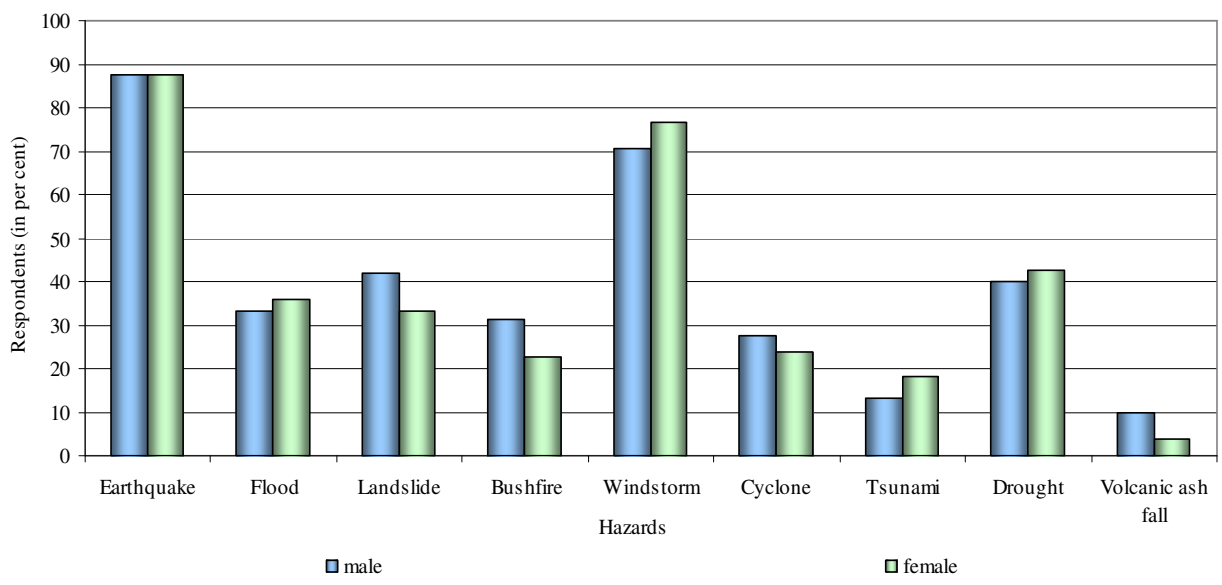

Based on Primary Survey, 2007

Fig: 6.88. Perception of Hazard Exposure vs. Ethnicity

Also, a few similarities and differences are noted in the perception of hazard exposure among different ethnic groups (Fig: 6.88). While the perception of hazard exposure is

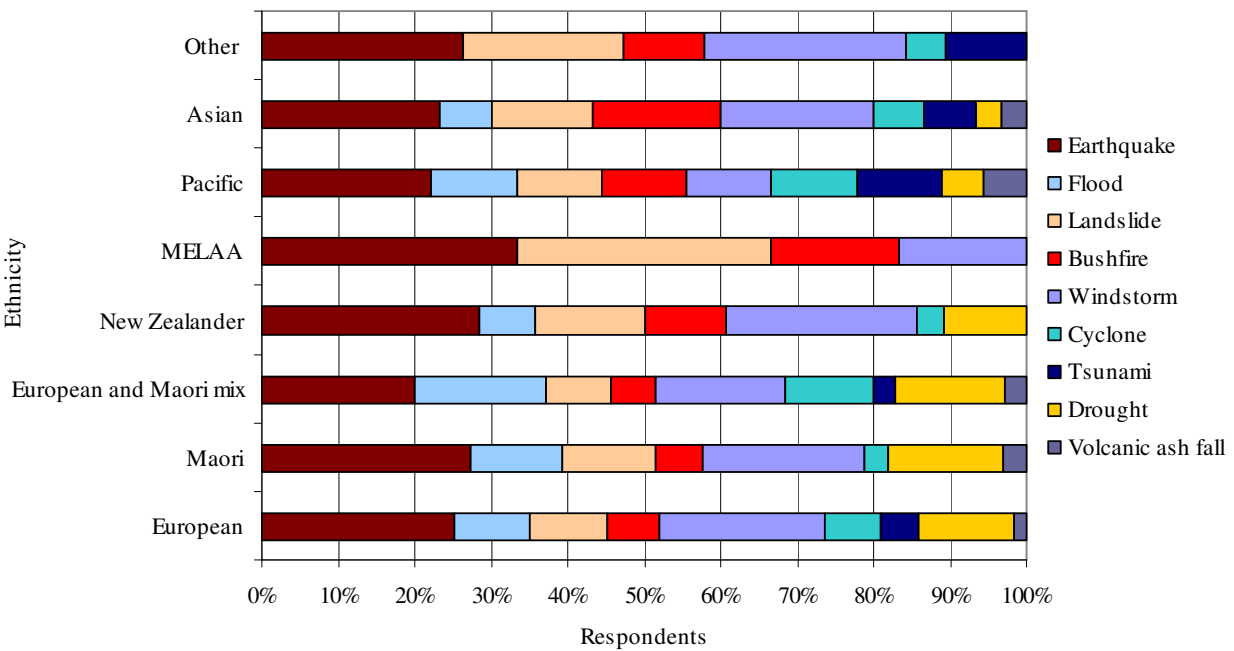


similar for European and European-Maori group, a similarity is also witnessed for Maori and New Zealander groups. However, none of the New Zealanders perceived themselves to be exposed to volcanic ash fall. Note that the ethnicity of those who list themselves as New Zealanders is not known. There is also some similarity in the perception of hazard exposure in Pacific and Asian groups. However, the Pacific group felt more exposed to flood, cyclone, tsunami and volcanic ash fall, while a high proportion of Asians perceived themselves to be exposed to windstorms, bushfires and landslides. The respondents in Middle Eastern and Latin American and African [MELAA] group perceived themselves to be exposed to only four hazards i.e. earthquake, landslide, bushfire and windstorms. The respondents from the other group which mainly consists of Americans, English and Australians did not perceive themselves to be exposed to either droughts or volcanic ash fall. The reason could be attributed to their length of stay in the region and occupation.

Fig: 6.89. Perception of Hazard Exposure vs. General Education and Hazard Education of Respondents

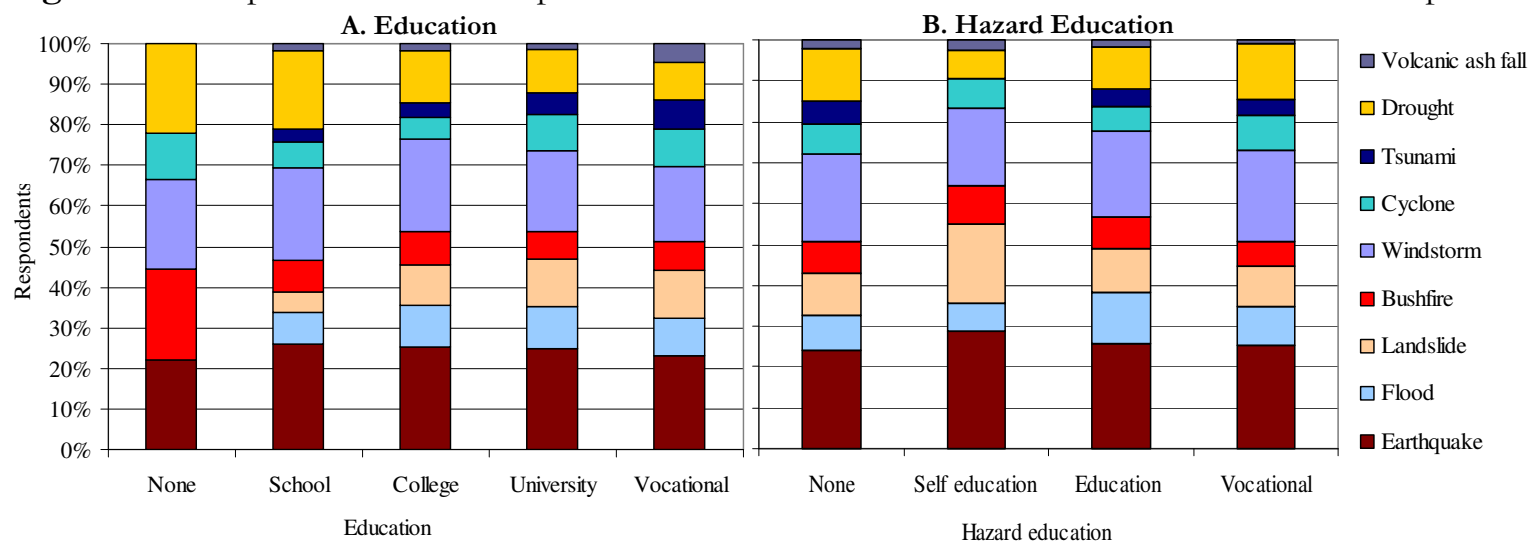

Based on Primary Survey, 2007

The data show that general education has played a more important role in the perception of hazard exposure in the region than hazard education (Fig: 6.89). A consistent rise could be seen in the proportion of respondents who perceived a number of hazards with the level of educational qualification (Fig: 6.89. A). On the other hand, irrespective of the source of hazard education,

Fig: 6.90. Perception of Hazard Exposure vs. Occupation of Respondents

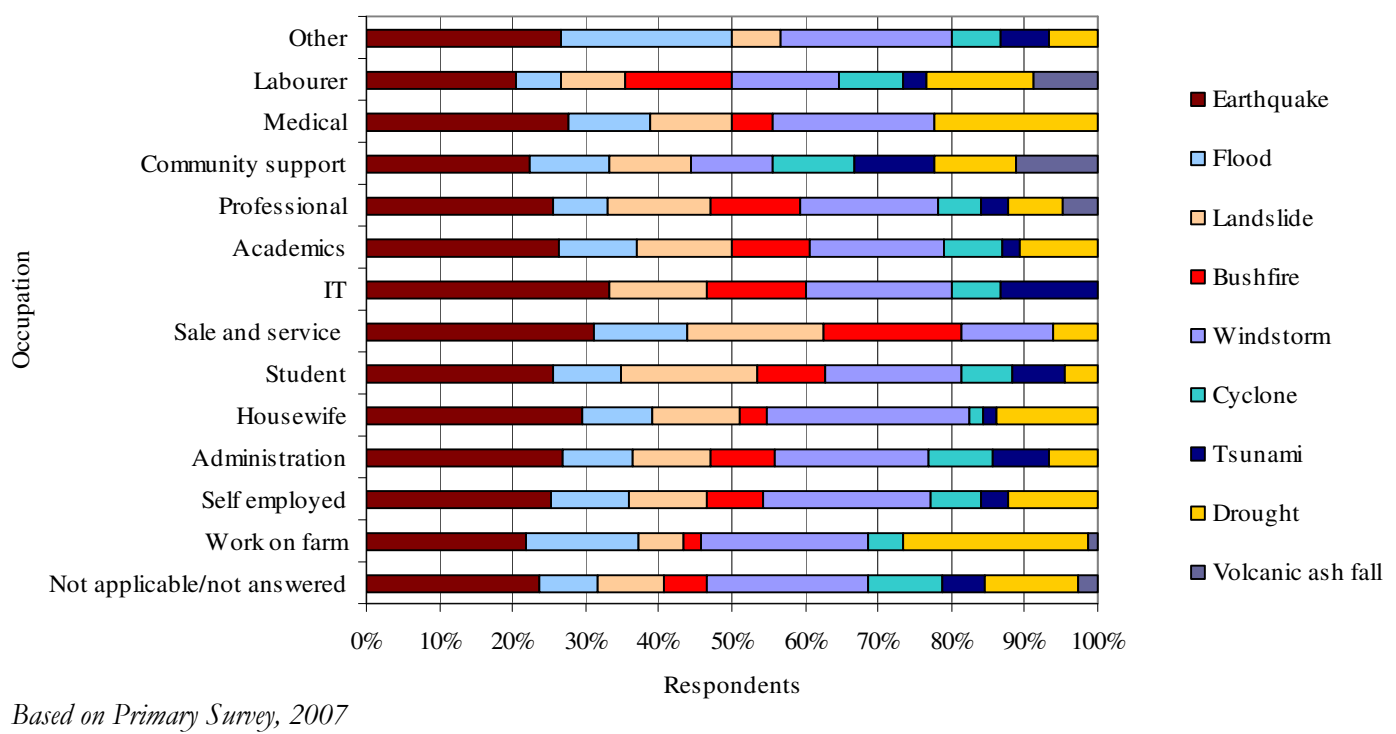


respondents from all categories could identify a range of hazards they perceived themselves to be exposed to (Fig: 6.89. B). The only group, which perceived its exposure to a less number of hazards, was the self education group which did not find itself to be exposed to tsunami.

The perception of hazard exposure also differs in different occupation groups (Fig: 6.90). For example, while a higher proportion of respondents working on farms perceived themselves to be exposed to droughts, respondents working in the information technology [IT] sector did not perceive themselves to be exposed to either drought or volcanic ash fall. In fact most of the occupational groups who worked in an office environment (except for professionals) did not perceive exposure to volcanic ash fall, which is dominantly identified by the respondents who work in an open environment such as labourers, community support workers or those who work on farms.

Fig: 6.91. Perception of Hazard Exposure vs. Time of Stay in New Zealand, Current Area or House

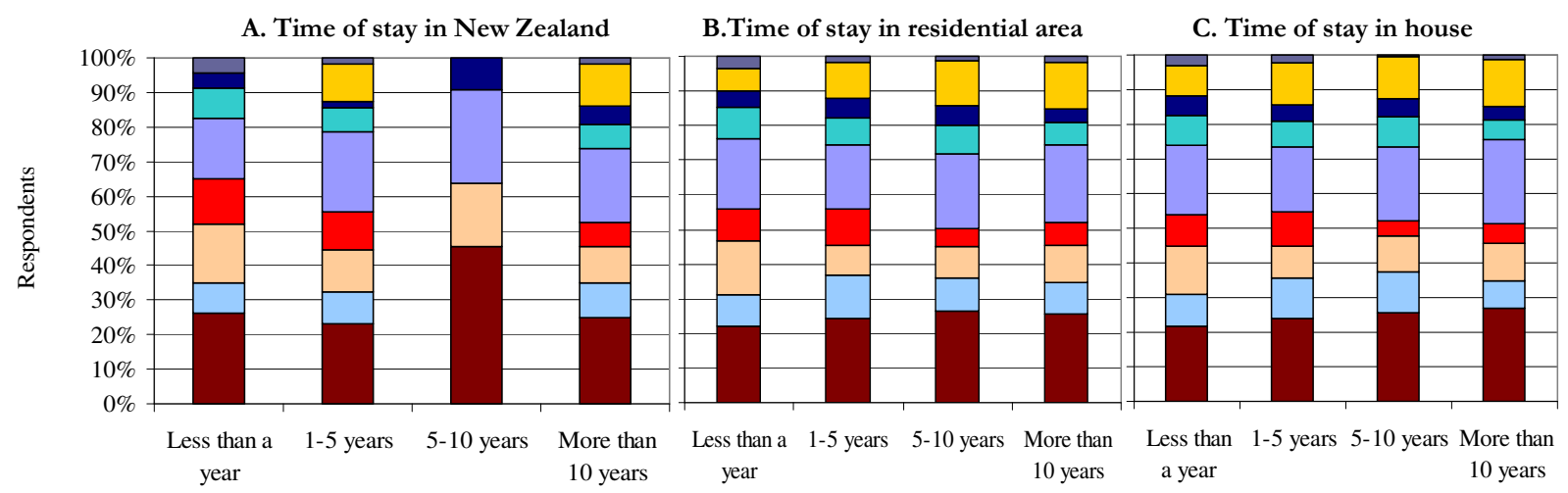

$\square$ Earthquake $\square$ Flood $\square$ Landslide $\square$ Bushfire $\square$ Windstorm $\square$ Cyclone $\square$ Tsunami $\square$ Drought $\square$ Volcanic ash fall Based on Primary Survey, 2007

The variation in the perception of exposure was also noted with the length of stay in New Zealand, but was less obvious with the length of stay in their current residential area or house. Fig: 6.91 shows that even the respondents who have lived 5 to 10 years in New Zealand may not be aware of all hazards in the region.

Variations are also noted in the perception of hazard exposure with respect to the location

Fig: 6.92. Perception of Hazard Exposure vs. Composite Vulnerability Index Score

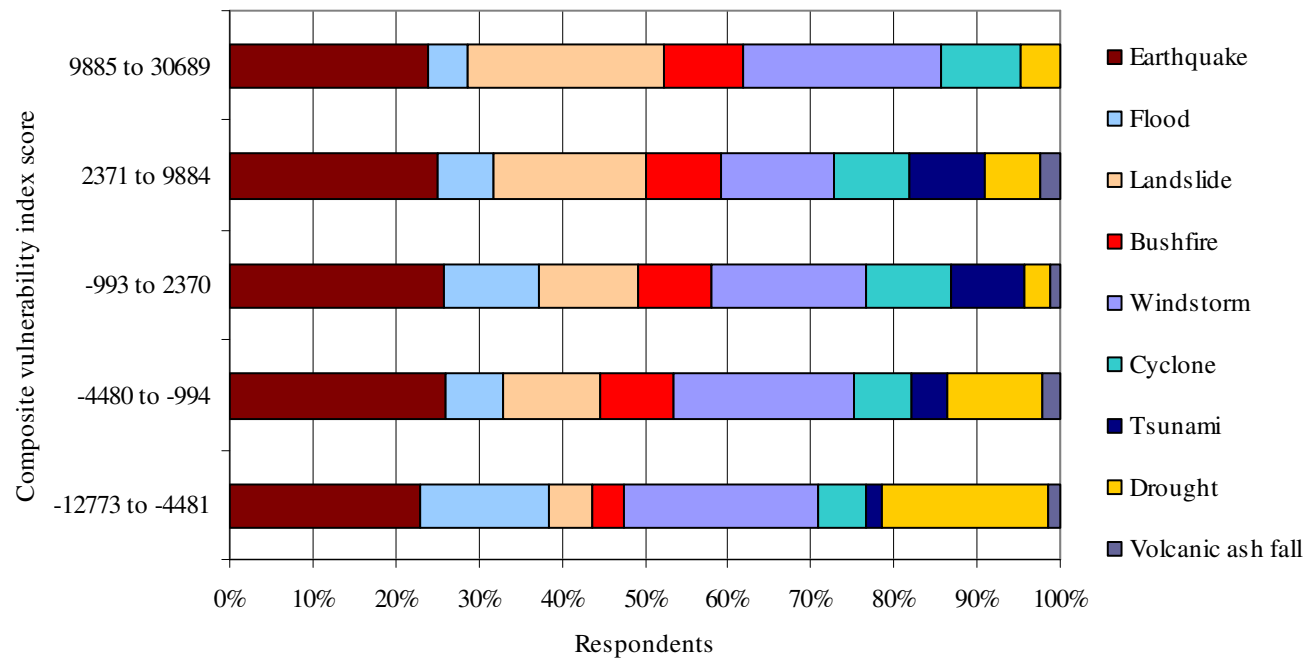


of respondents in different vulnerability groups at the area level (Fig: 6.92). While an increasing proportion of respondents living in high vulnerability groups perceived themselves to be exposed to landslides and bushfires, a decreasing trend is observed for flooding and droughts. The respondents in very high vulnerability areas did not perceive themselves to be exposed to volcanic ash fall. High vulnerability areas are mainly located in Wellington City, where a significant proportion of the population is international, and therefore likely to be unaware of this hazard in the absence of a volcano in close proximity.

Fig: 6.93. Response to Vulnerability through Hazard Exposure

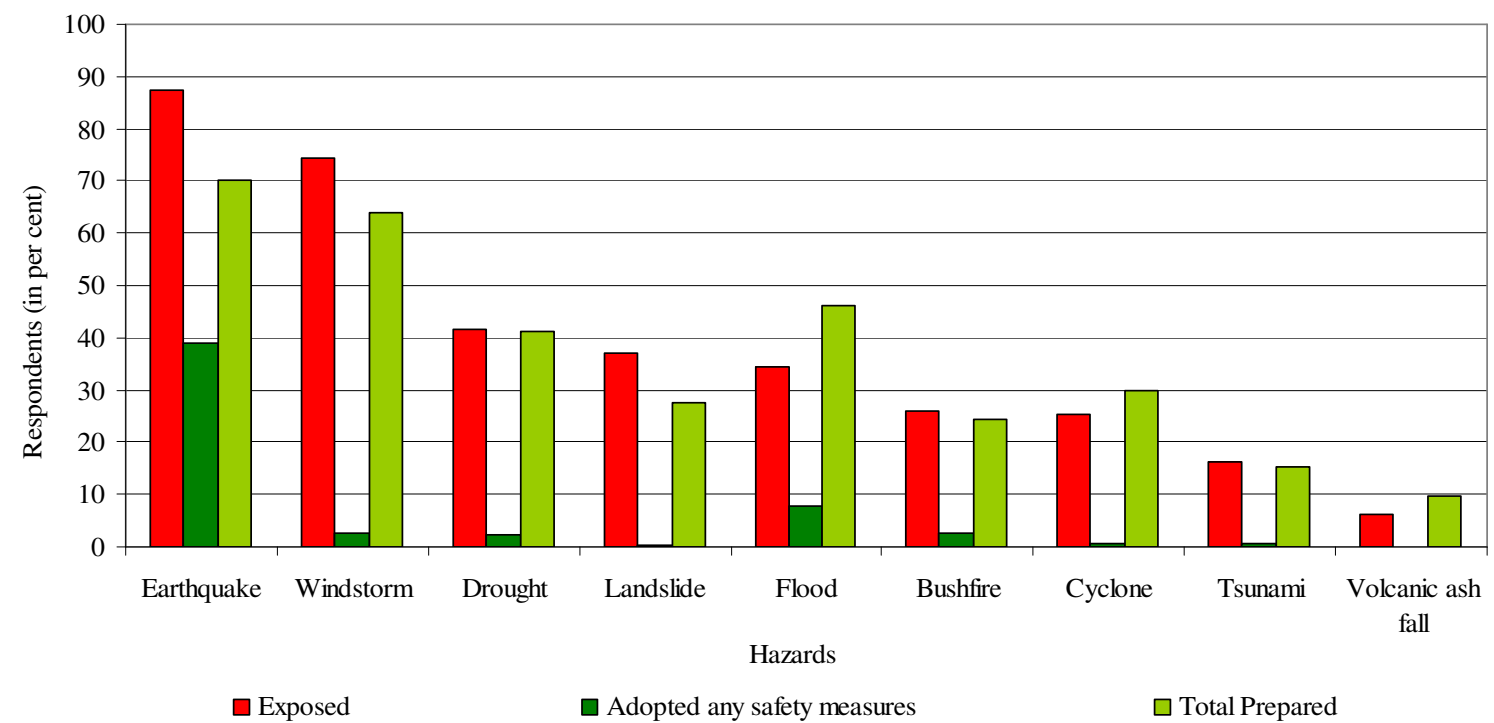

Based on Primary Survey, 2007

The comparison of exposure to safety measures taken by the respondents shows that while a significant proportion of respondents have taken safety measures for earthquakes, very few have taken them for flooding, bushfires, windstorms, droughts, cyclones and tsunami (Fig: 6.93). None of the respondent took any measures for volcanic ash fall. However, despite not taking any safety measures, many respondents felt themselves to be prepared for these hazards. The reason could be associated with the high frequency of less damaging hazard events, which has made the people feel capable enough to cope with the hazard, or although prepared in terms of planned behaviour, they

Fig: 6.94. Exposure to Number of Hazards vs. Number of Hazards for Which Safety Measures Taken and Hazard Preparedness of Respondents

A. Safety Measures Taken

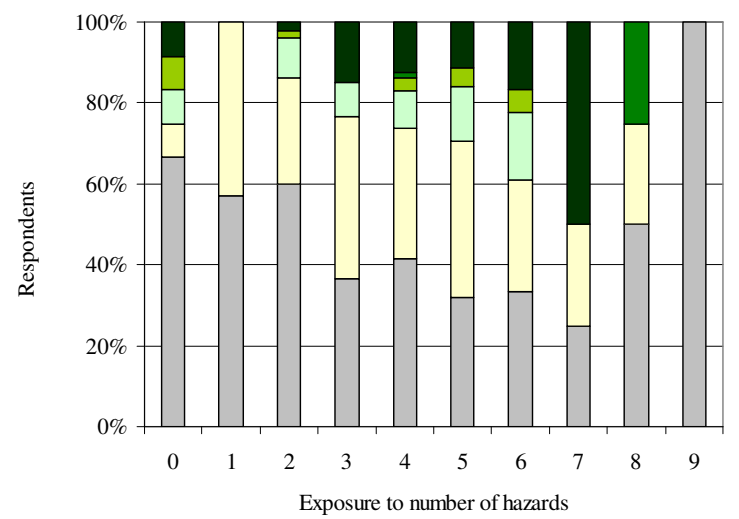

B. Preparedness

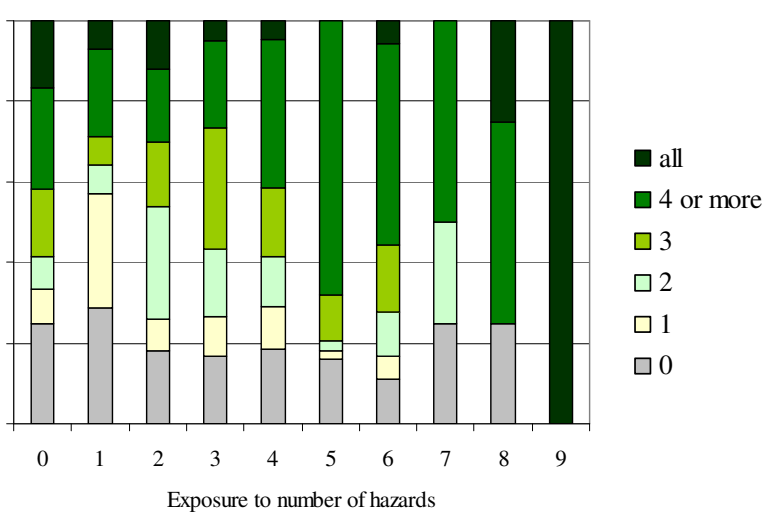


are unaware of which physical safety measures are available or would be effective.

The comparison of the number of hazards that respondents perceived to be exposed to with the number of hazards for which safety measures have been taken (Fig: 6.94.A) and the number of hazards for which respondents perceived themselves to be prepared (Fig: 6.94.B), shows that while a significant proportion of respondents have not adopted any safety measures for any hazard, most of the respondents perceived themselves to be prepared for most hazards.

\subsubsection{Fragility and Coping Capacity}

A number of factors govern the vulnerability of the local community by affecting their fragility and coping capacity. The respondents were asked that to what extent they think the given factors have affected their vulnerability. Itf is important to note that an overwhelming proportion of the respondents saw unpredictability of the hazards to be the dominant factor of their vulnerability (Table: 6.4). However, unpredictability of hazards is a characteristic of hazard event rather than a vulnerability characteristic of the respondents.

Table: 6.4. Factors Influencing the Vulnerability of Respondents in the Region

\begin{tabular}{|c|c|c|c|c|c|}
\hline \multirow[t]{2}{*}{ Factors Influencing Vulnerability } & \multicolumn{5}{|c|}{ 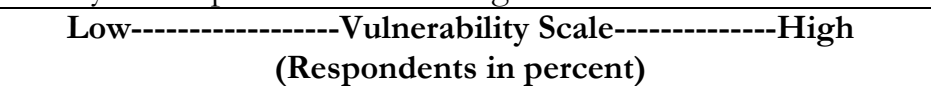 } \\
\hline & $0.1-1.0$ & $1.1-2.0$ & $2.1-3.0$ & $3.1-4.0$ & $4.1-5.0$ \\
\hline Unpredictability of hazards & 12.1 & 8.5 & 18.0 & 20.2 & 37.9 \\
\hline Lack of knowledge about hazards & 27.2 & 20.2 & 26.5 & 13.2 & 8.1 \\
\hline Having children & 9.6 & 2.2 & 8.5 & 7.4 & 7.7 \\
\hline Financial constraints & 39.3 & 17.6 & 19.5 & 5.5 & 7.4 \\
\hline Being old & 11.0 & 6.3 & 5.1 & 4.4 & 6.6 \\
\hline Don't know what to do & 32.4 & 19.5 & 20.6 & 13.2 & 6.3 \\
\hline Being disabled & 5.5 & 1.1 & 1.5 & 2.2 & 5.1 \\
\hline Lack of family support & 52.9 & 12.5 & 10.7 & 5.1 & 4.0 \\
\hline Fear & 38.2 & 19.1 & 18.4 & 9.2 & 3.7 \\
\hline Being a women & 37.1 & 5.9 & 7.7 & 2.6 & 2.9 \\
\hline Lack of local community support & 46.3 & 18.4 & 11.8 & 4.0 & 2.9 \\
\hline Being new to the place & 8.8 & 2.2 & 6.3 & 3.3 & 1.5 \\
\hline Being a migrant & 16.2 & 2.9 & 1.5 & 0.4 & 0.7 \\
\hline Being part of specific group & 5.5 & 1.1 & 0.7 & 0.4 & 0.4 \\
\hline Language barrier & 6.3 & 1.1 & 0.0 & 0.4 & 0.0 \\
\hline Short term stay at current place & 5.1 & 0.7 & 1.5 & 0.4 & 0.0 \\
\hline
\end{tabular}

Based on Primary Survey, 2007

Only eight percent of the respondents saw lack of knowledge as a factor which highly affects their vulnerability. The proportion of respondents futher declines for other factors. Five to eight percent of respondents believed that having children, financial constraints, being elderly, or not knowing what to do could affect their vulnerability to a greater extent.

However, the perception of the cause of vulnerability differed at individual level. The data show that nearly 20 percent of elderly respondents perceived that their age enhances their vulnerability for an effective response and coping capacity to a disaster (Fig: 6.95.A). A high proportion of young respondents (less than 30 years of age) found that unpredictability and lack of knowledge are the main factor of their vulnerability. It is also noted that the proportion of respondents who viewed financial constraints and do not know what to do during disaster as factors of vulnerability is higher in the young group as compared to other groups. The difference in the perceived influences of factors on vulnerability is also noted between male and female 
respondents (Fig: 6.95.B). A few factors that women perceived more to influence their response to disaster included uncertainty of hazards, being a woman, having children, fear and lack of family or community support. More men on the other hand, perceived that being elderly, having a disability and being part of any specific group could highly affect their vulnerability. While a high proportion of respondents having three or more children perceived that having children highly affects their

Fig: 6.95. Perceived Level of Effect of Different Factors on Vulnerability of Respondents
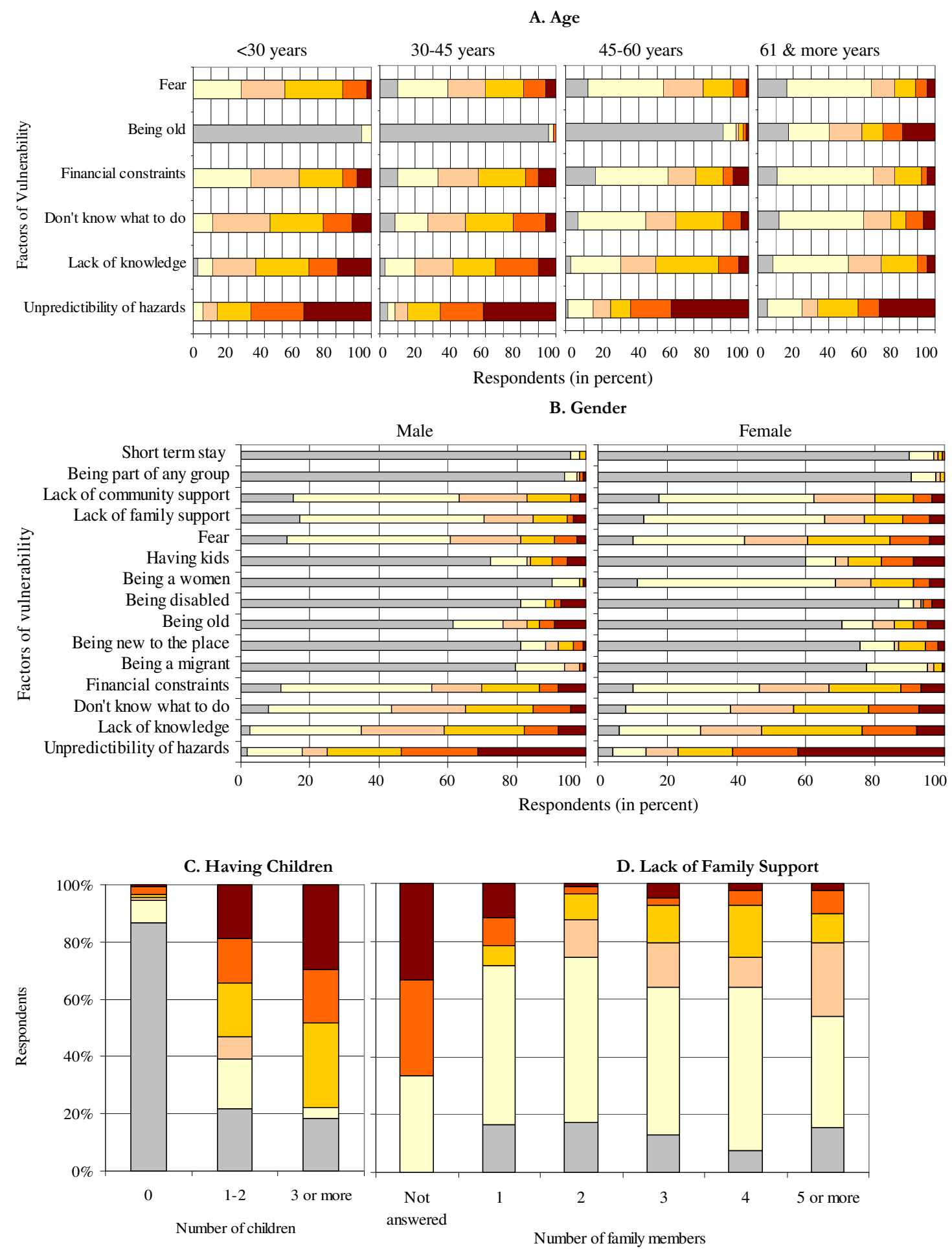
$\square 0$
$\square 1$
$\square 2$
$\square 3$
$\square 4$

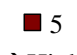

Effect on vulnerability 
vulnerability (Fig: 6.95.C), more respondents living alone perceived that lack of family support could affects their vulnerability to a greater extent (Fig: 6.95.D).

The role of education behind the perception of vulnerability is also noticeable (Fig: 6.96.A). More respondents without education perceived unpredictability of hazards, lack of knowledge about hazards and how to respond as factors affecting their vulnerability highly as compared to those who were educated. The respondents with vocational education perceived these factors having low effect on their vulnerability. On the other hand, there was less difference in the

Fig: 6.96. Perceived Effects of Factors on Vulnerability vs. Education and Religion of Respondents

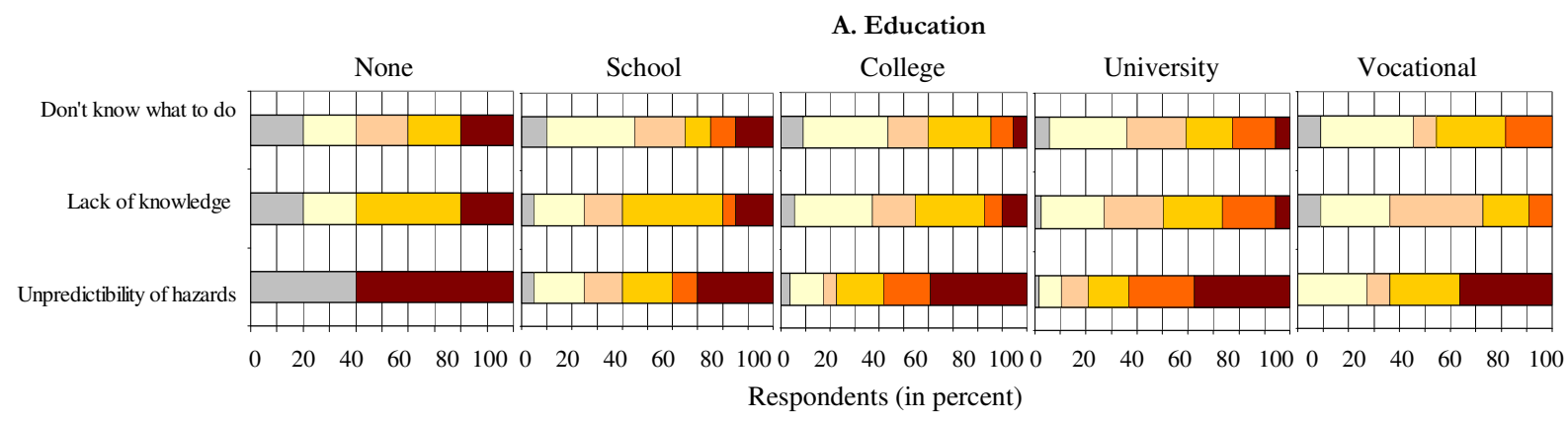

B. Hazard education
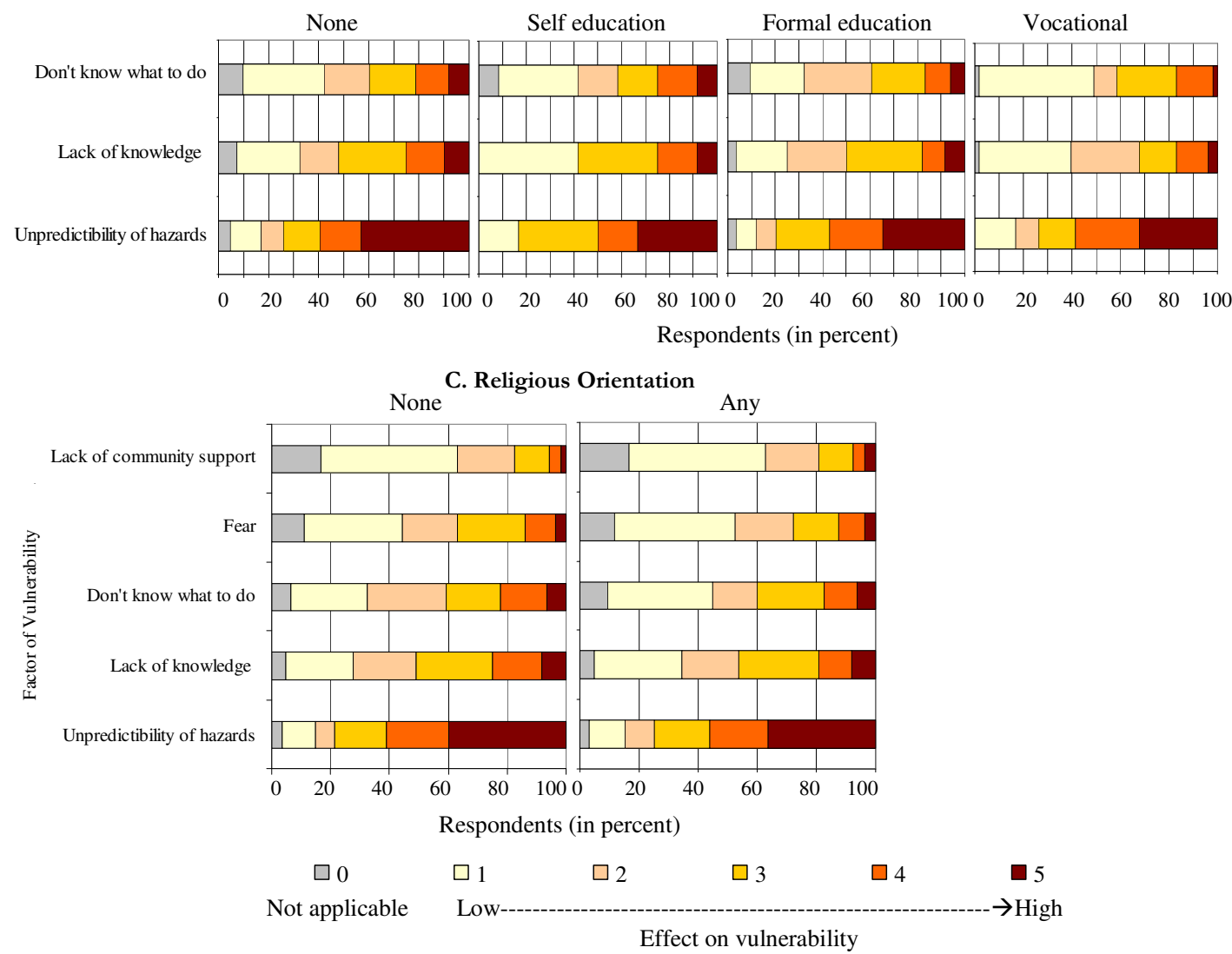

Based on Primary Survey, 2007

perceived factors of vulnerability between the respondents having no hazard education and those with formal hazard education (Fig: 6.96.B). The respondents with vocational hazard education perceived less influence of unpredictability of hazards, lack of knowledge about hazards and how to respond to their vulnerability.

In the absence of sufficient respondents from different religious groups, the comparison of perceptions is made between those who follow any religion and those who do not. However, the 
comparison does not show any significant difference (Fig: 6.96.C). The unexpected finding is that more respondents who follow a religion find lack of community support as a factor that could highly affect their vulnerability as compared to those who do not follow any religion. The reason could be that even though there are church communities, they may not be necessarily from the same residential area in which respondents lived. However, a lesser proportion of this group finds uncertainty to affect their vulnerability, which could be attributed to their faith in the acts of God.

An important factor of vulnerability is financial constraints. While a very small proportion of respondents who are unemployed see this factor as affecting their vulnerability to a high level, the respondents who are employed part time find it to be an important cause of their vulnerability (Fig: 6.97.A). Also a difference can be noted among the respondents engaged in different occupational groups and their perceived factor of vulnerability.

A greater proportion of workers in the community support groups, information technology (IT) and students perceived financial constaints to be a factor that highly affects their vulnerability, while the respondents in blue collar jobs or other work found it to affect their vulnerability at a low or moderate level (Fig: 97.B). The reason could be attributed to the associated uncertainty of work either in the part time employment, work in information technology sector, community support work or student jobs that make them vulnerable to financial constraints.

Fig: 6.97. Perceived Effects of Financial Constraints on Vulnerability of Respondents vs. Their Work Status, Occupation and Income
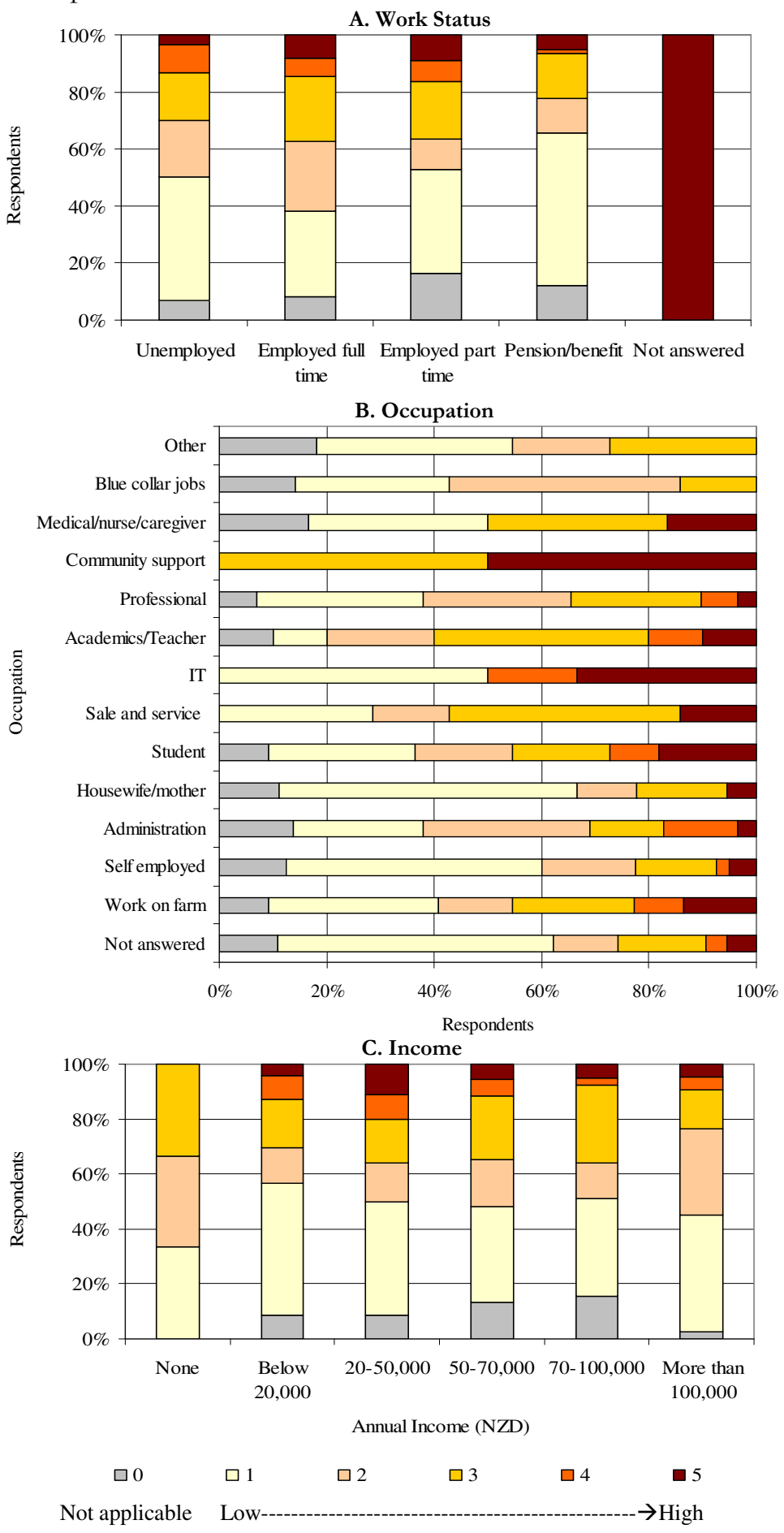

Based on Primary Survey, 2007 
While the respondents with no income perceived that financial constraints affect their vulnerability to a low or moderate level, more respondents earning between 20,000-50,000 NZD found financial constraints to affect their vulnerability to a high level (Fig: 97.C). The latter group also includes the respondents who live on pensions or benefits. This could be because, even though their annual income is slightly above $20,000 \mathrm{NZD}$, it is considered too low to support them through additional adversity.

Fig: 6.98. Perceived Effects of Time of Stay in New Zealand on Vulnerability of Respondents

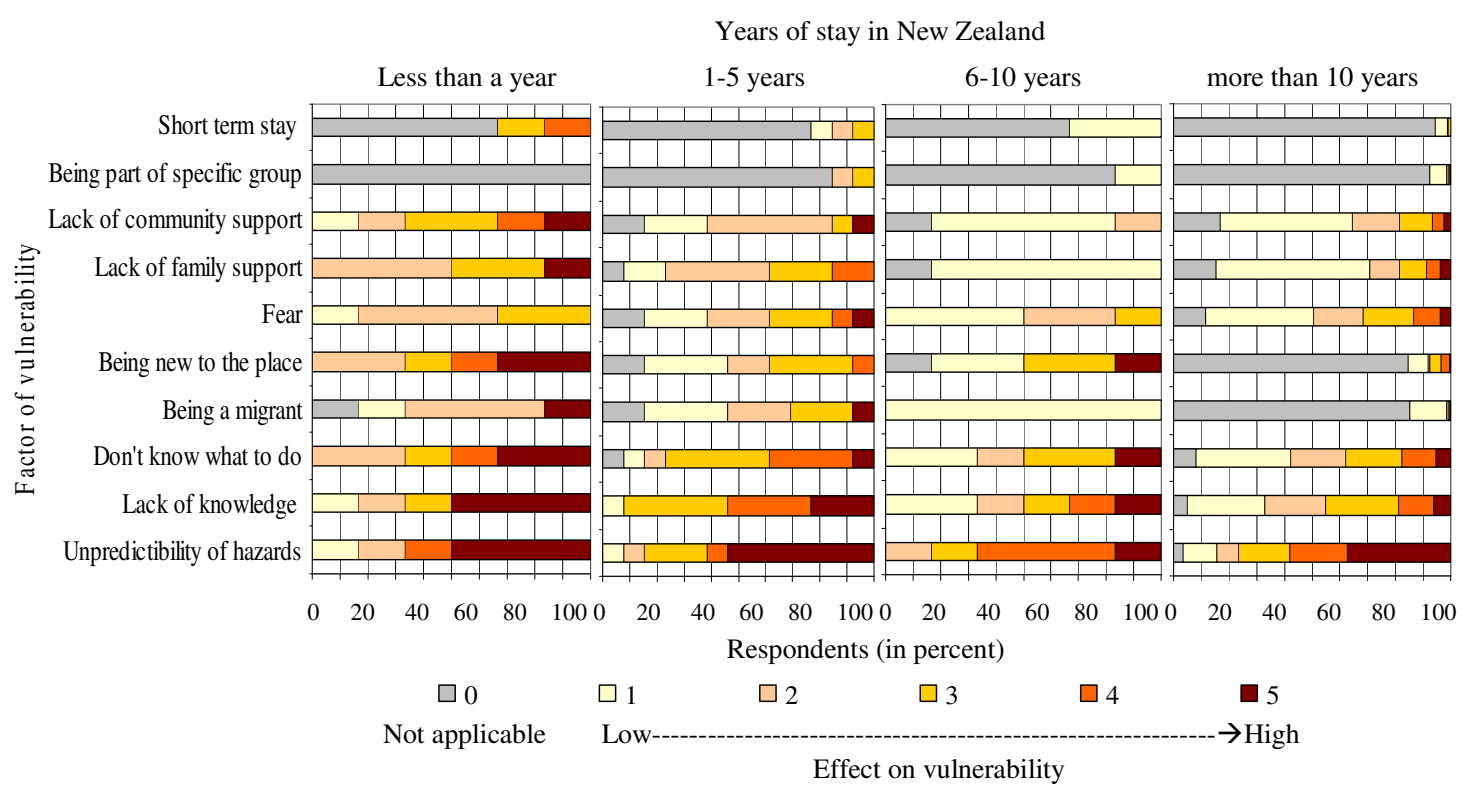

Based on Primary Survey, 2007

The perception of the vulnerability factors also differs between migrants and residents of the region (Fig: 6.98). A declining trend can be noted in the proportion of respondents who have

Fig: 6.99. Perceived Effects of Factors on Vulnerability of Respondents Living in Vulnerable Areas

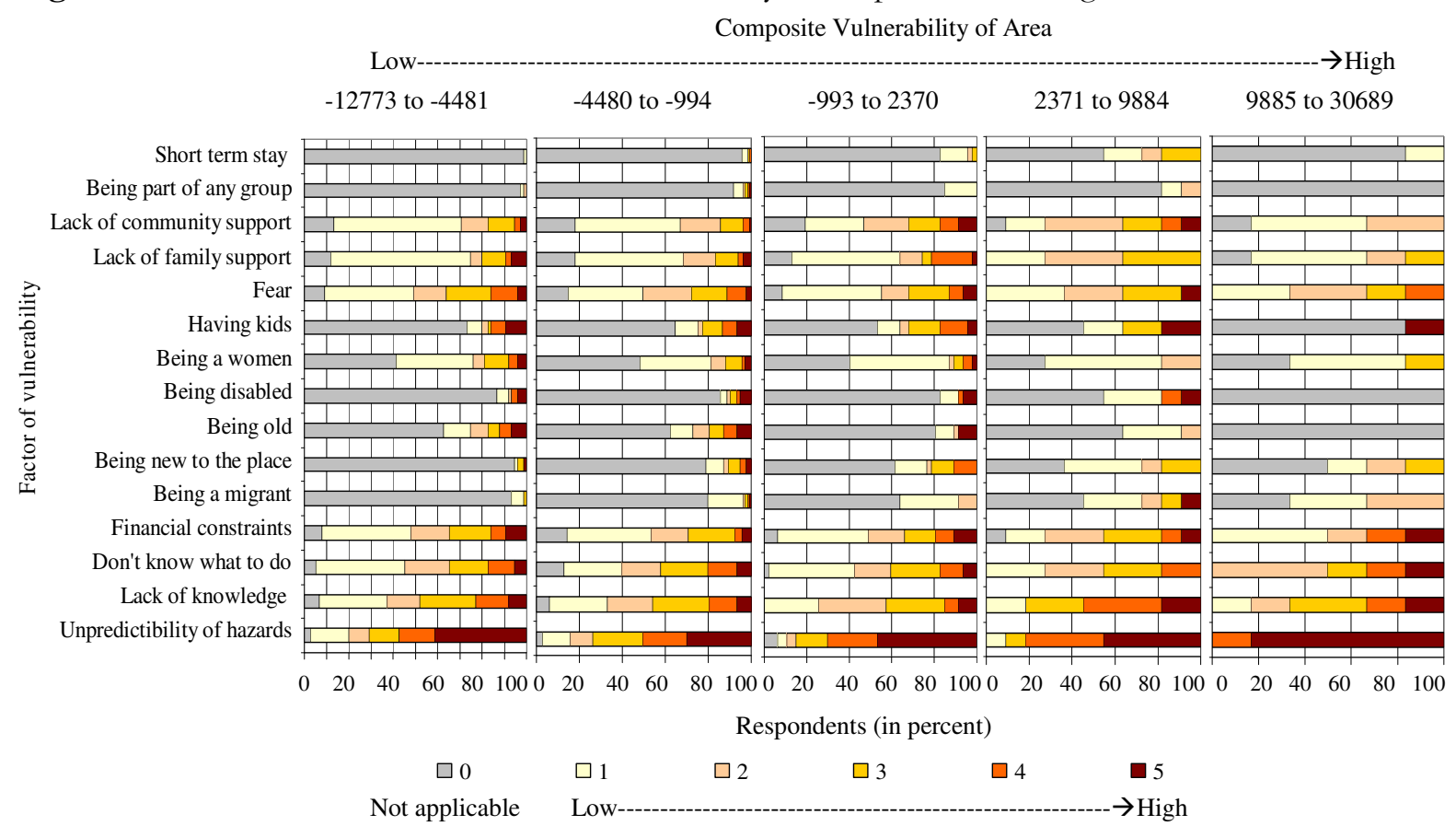


just arrived in the country and perceived unpredictability, lack of knowledge and not knowing what to do as the factors that highly affect their vulnerability as compared to those who have lived longer in New Zealand. A significant proportion of new migrants also find that being a migrant, lack of family and community support affect their vulnerability to a greater extent compared to others. In fact a few respondents who have lived more than 10 years in the country still believe that being a migrant highly affects their vulnerability. The short term stay was viewed as a factor that affects vulnerability from a moderate to high level by respondents who have lived for less than a year, to a moderate level by those who have lived 1-5 years, and to a negligible extent by those who have lived 5-10 years in New Zealand.

The difference in perceived vulnerability factors is also noted in the respondents living in areas of different vulnerability levels (Fig: 6.99). A higher proportion of respondents living in high vulnerability zones perceived unpredictability, lack of knowledge about hazards and how to respond, financial constraints and having children as factors that highly affect their vulnerability as compared to those who lived in less vulnerable areas.

Both actual vulnerability and the perception of vulnerability have significant implications on hazard response in the region. A difference can be observed in the response of the respondents not only from different socio-economic backgrounds but also from the areas of different vulnerability levels.

Although the initial response of the respondents when they first moved into their house shows fewer differences between male and female respondents, a significant difference is noted due to education, ethnicity, occupation and length of stay in the country (Table: 6.5). It can be observed that while only 20 percent of the respondents with no education tried to find out about

Table: 6.5. Characteristics of Respondents and Response to Hazards

\begin{tabular}{|c|c|c|c|c|}
\hline \multirow[t]{2}{*}{$\begin{array}{l}\text { Respondents } \\
\text { Characteristics }\end{array}$} & \multicolumn{2}{|c|}{$\begin{array}{l}\text { Considered hazards at the time of } \\
\text { purchase or renting house } \\
\text { (Respondents in percent) }\end{array}$} & \multicolumn{2}{|c|}{$\begin{array}{l}\text { Changes made in house to prevent or reduce } \\
\text { damage from any natural hazards } \\
\text { (Respondents in percent) }\end{array}$} \\
\hline & Highest & Lowest & Highest & Lowest \\
\hline Gender & Male (34) & Female (30) & Male (35) & Female (34) \\
\hline Age & $46-60$ years $(38)$ & 61 and above (29) & $46-60$ years $(45)$ & $31-45$ years $(23)$ \\
\hline Education & University (40) & None (20) & University (40) & None $(0)$ \\
\hline Hazard education & Vocational (49) & Self education (25) & Vocational (49) & None (25) \\
\hline Ethnicity & Other (66) & $\operatorname{MELAA}(0)$ & Maori (55) & MELAA (0) \\
\hline Religion & None (35) & Any (29) & Any (38) & None (27) \\
\hline Family size & 5 or more $(41)$ & $4(21)$ & $2(44)$ & $1(14)$ \\
\hline Occupation & Academics (70) & $\begin{array}{c}\text { Community support } \\
(0)\end{array}$ & Blue collar job (71) & $\begin{array}{l}\text { Community support } \\
\text { and students }(0)\end{array}$ \\
\hline Work status & $\begin{array}{c}\text { Employed full time } \\
\text { (38) }\end{array}$ & Unemployed (23) & Employed part time (46) & Unemployed (13) \\
\hline $\begin{array}{l}\text { Annual Income } \\
\text { (NZD) }\end{array}$ & $\begin{array}{c}70,001-100,000 \\
(44)\end{array}$ & Less than $20,000(17)$ & $70,001-100,000(44)$ & Less than $20,000(26)$ \\
\hline $\begin{array}{l}\text { Ownership of } \\
\text { house }\end{array}$ & Owned (35) & Not owned (20) & Owned (40) & Not owned (12) \\
\hline $\begin{array}{l}\text { Year of residence } \\
\text { in New Zealand }\end{array}$ & $\begin{array}{c}\text { Less than a year } \\
\text { (33) }\end{array}$ & $1-5$ years $(8)$ & $5-10$ years $(67)$ & Less than a year $(0)$ \\
\hline $\begin{array}{l}\text { Year of residence } \\
\text { in area }\end{array}$ & $5-10$ years $(38)$ & $\begin{array}{c}\text { More than } 10 \text { years } \\
(31)\end{array}$ & More than 10 years (41) & Less than a year (17) \\
\hline $\begin{array}{l}\text { Year of residence } \\
\text { in house }\end{array}$ & $1-5$ years $(35)$ & $5-10$ years $(27)$ & $5-10$ years $(39)$ & Less than a year (17) \\
\hline
\end{tabular}


the hazards when they first rented or purchased their house, none of them made any changes in their house to avoid or to reduce damage from natural hazards.

Similarly the response (i.e. considering hazard at the time of shifting house and making changes in the house to reduce hazards) was also noted low from students and those who work for community support or NGOs. Only 13 percent of the unemployed respondents made changes in their house compared to 46 percent of those who were employed part time. A lesser proportion of the respondents made changes in their house who either moved to New Zealand from any other country or to the local area or current residence within a year as compared to those who have lived longer either in the country, area or residence. This indicates that migration could have significant implications for hazard mitigation and response.

The overall composite vulnerability scores of the area also correlated with some significant differences in the local response. While the highest proportion of respondents living in the moderately low vulnerability zone considered hazards during the purchase or renting house, the lowest proportion of respondents from the high vulnerability zones considered natural hazards when moving to their house (Fig: 6.100). The trend is similar to the changes made in houses to reduce damage from natural hazards. It closely follows that the act of moving house to avoid hazards which was predominant in the least vulnerable zone. None of the respondents from the most vulnerable zone reported to have moved house because of natural hazards, which could be attributed to few choices available to them because of their low socio-economic conditions as compared to the less vulnerable group of respondents.

Fig: 6.100. Response to Hazards by Respondents Living in Vulnerable Areas

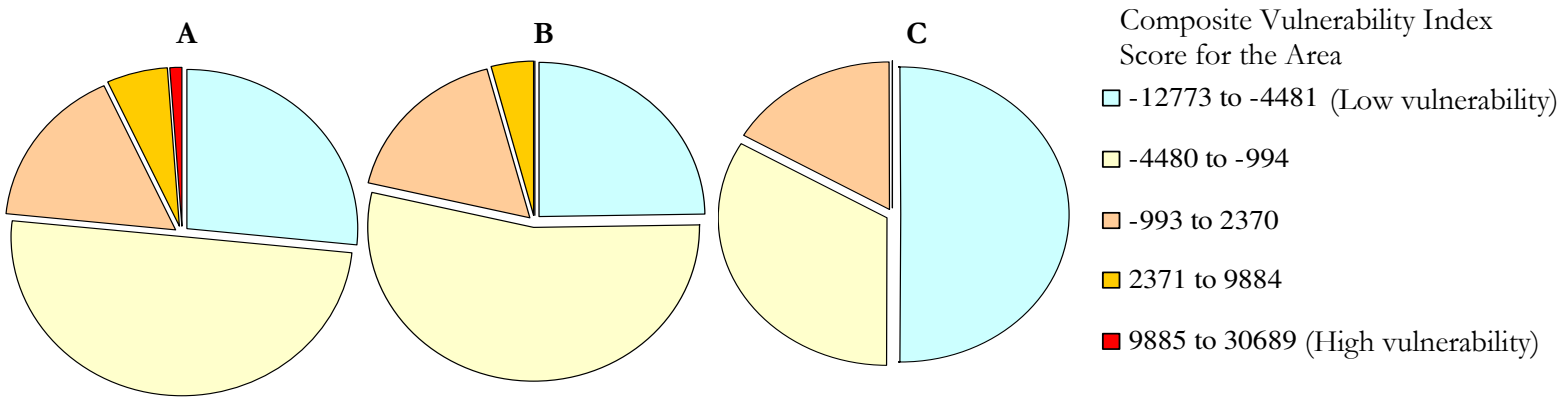

A. Considered hazards during renting or purchase of house

B. Made changes in house in order to prevent or reduce damage from any natural hazard

C. Shifted house because of hazard

Based on Primary Survey, 2007

A difference is also noted in the type of measures taken by the respondents depending on their length of stay either in the country, local area or house (Fig: 6.101). It is very clear that those who just recently moved to the country did not take any mitigation measure for natural hazards (Fig: 6.101.A). On the other hand, the respondents who recently moved either to the area or to the house took very limited and basic measures, such as buying a strong house, securing household items or having emergency materials. However, with the increase in time of stay both the proportion of respondents and the type of measures taken by the respondents has increased. It shows that time may play a critical role behind the understanding of hazardscape and adopting appropriate measures for hazard mitigation. 
Differences are also noted for other mitigation measures taken by the respondents from different socio-economic and vulnerability groups. While more male respondents had adopted mitigation measures, a greater variety is observed in the mitigation measures taken by female respondents (Fig: 6.102.A). Also, the dominant measures taken by the different gender varied. While more male respondents took measures such as building a strong house or constructing measures outside the house such as stop banks, putting in bore holes and extra drainage, a high proportion of female respondents secured household items, stocked emergency materials, planted or removed trees and arranged institutional support such as being on the warning list or having hazard insurance.

In terms of age, a high proportion of respondents of 45-60 years had adopted a number of measures, while a low proportion of the young respondents had adopted any kind of mitigation measure (Fig: 6.102.C). The mitigation measures taken by different ethnic groups also showed variations (Fig: 6.102.B). The highest variety of mitigation measures were taken by the European community followed by Maori and 'the Other group' that refers to Australian, English or American, who do not classify them as Europeans. The respondents who identify themselves as New Zealanders had taken very few measures, while the respondents who were both European and Maori showed the poorest response along with MELAA and Pacific groups. Asians took few basic mitigation measures such as having emergency material and getting information to enhance their hazard awareness. The ownership of house has also influenced the mitigation measures

Fig: 6.101. Duration of Stay in New Zealand, Residential Area and House, and Measures Adopted by Respondents
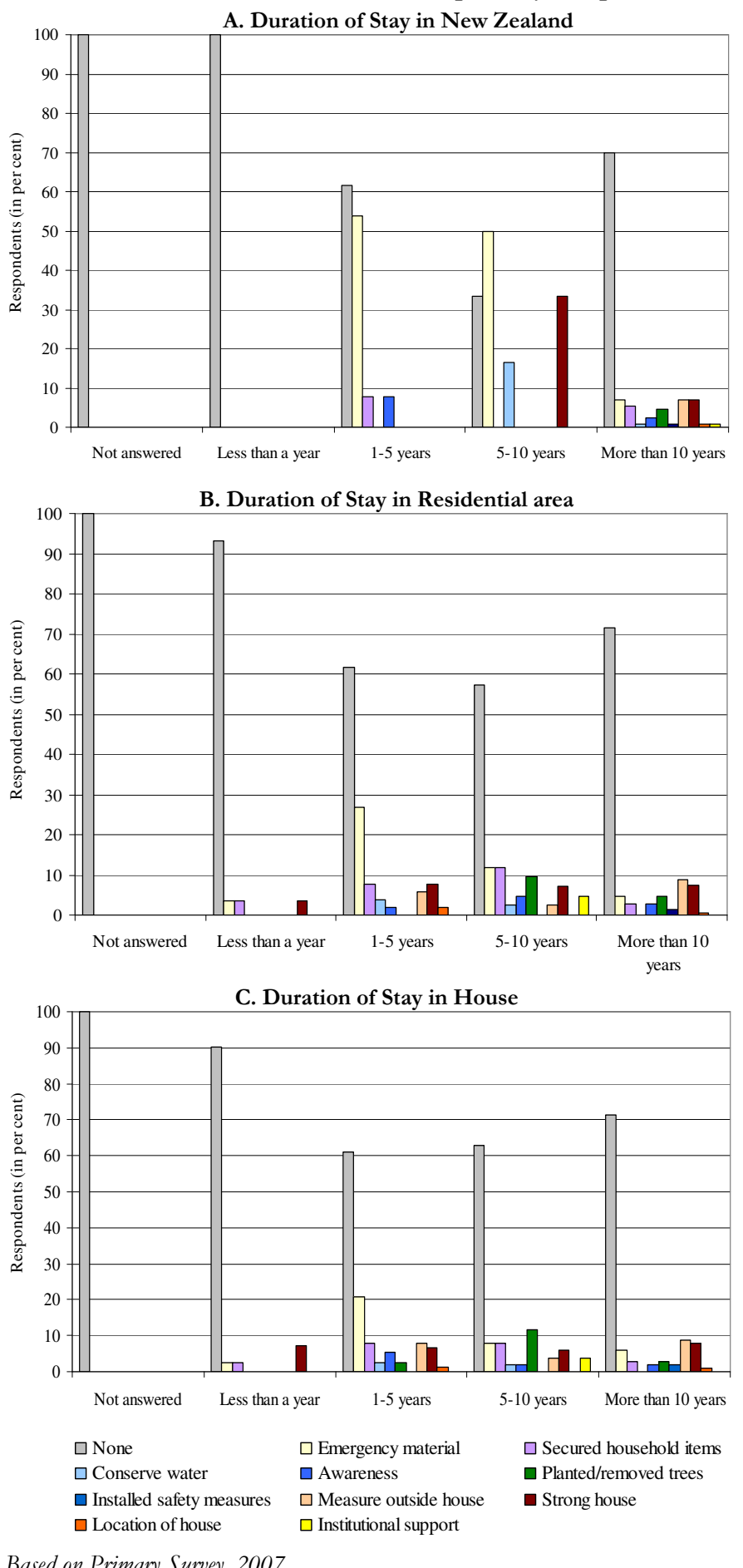

Based on Primary Survey, 2007 taken by respondents (Fig: 6.102.D). More respondents who owned their house took the mitigation measures for hazards compared to those who did not. 
Fig: 6.102. Gender, Ethnicity, Age, Education, Hazard Education, Ownership of House, Work Status, Income, Occupation and Mitigation Measures Adopted by Respondents

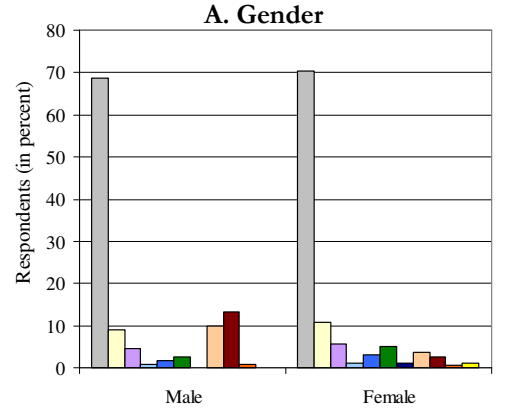

C. Age
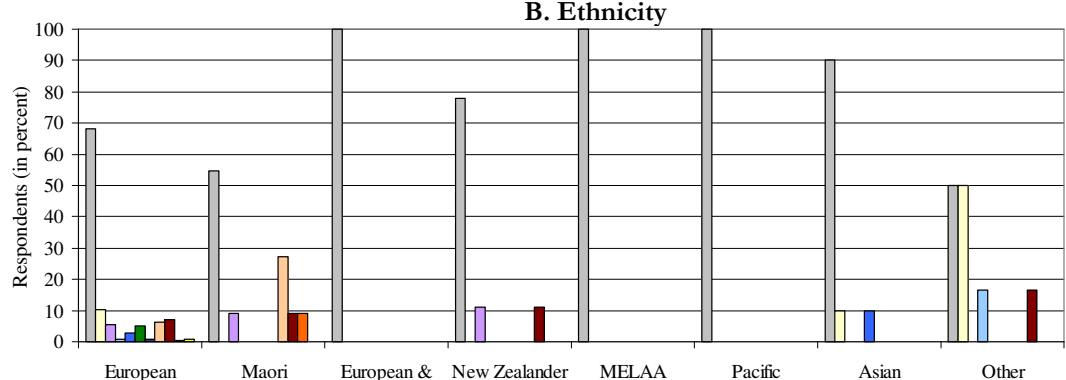

D. Ownership of House
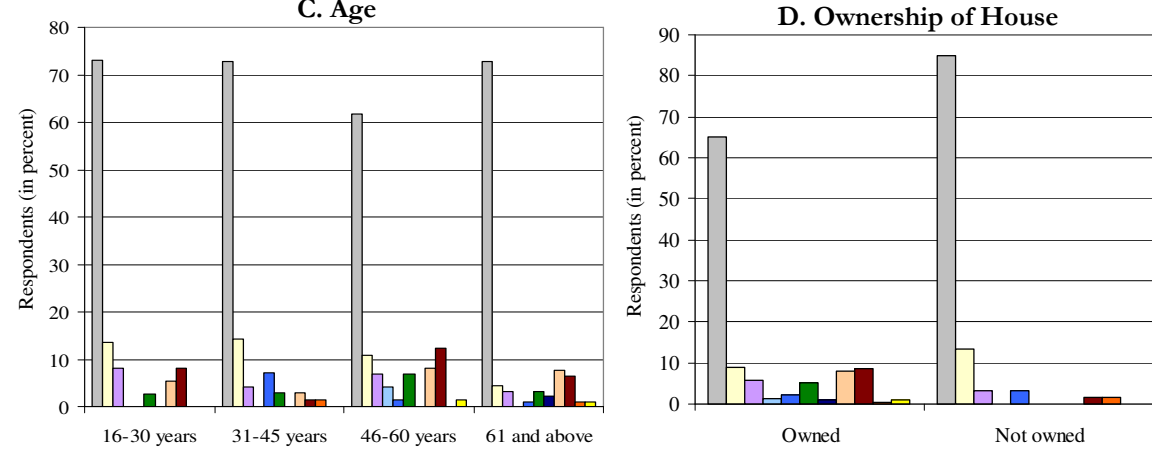

$\square$ Institutional support

$\square$ location of house

- Installed safety measures

$\square$ conserving water

๑ Awareness

口 Planted/removed trees

$\square$ Secured household items

$\square$ Measures outside house

- Strong/strengthened house

$\square$ Emergency material

$\square$ None

F. Hazard Education
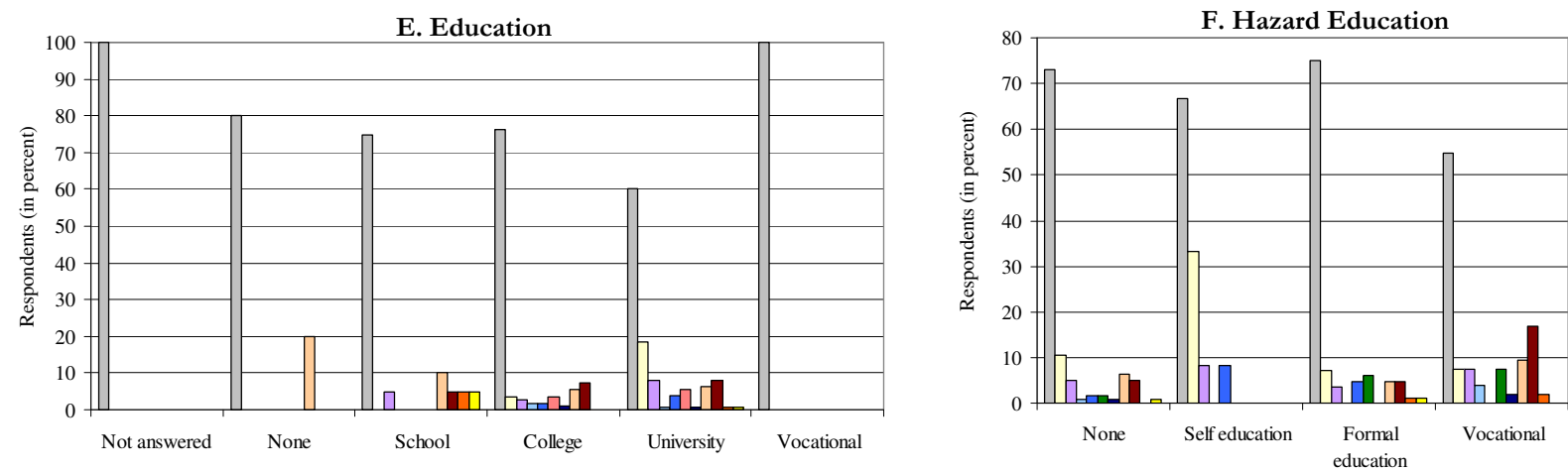

G. Work Status
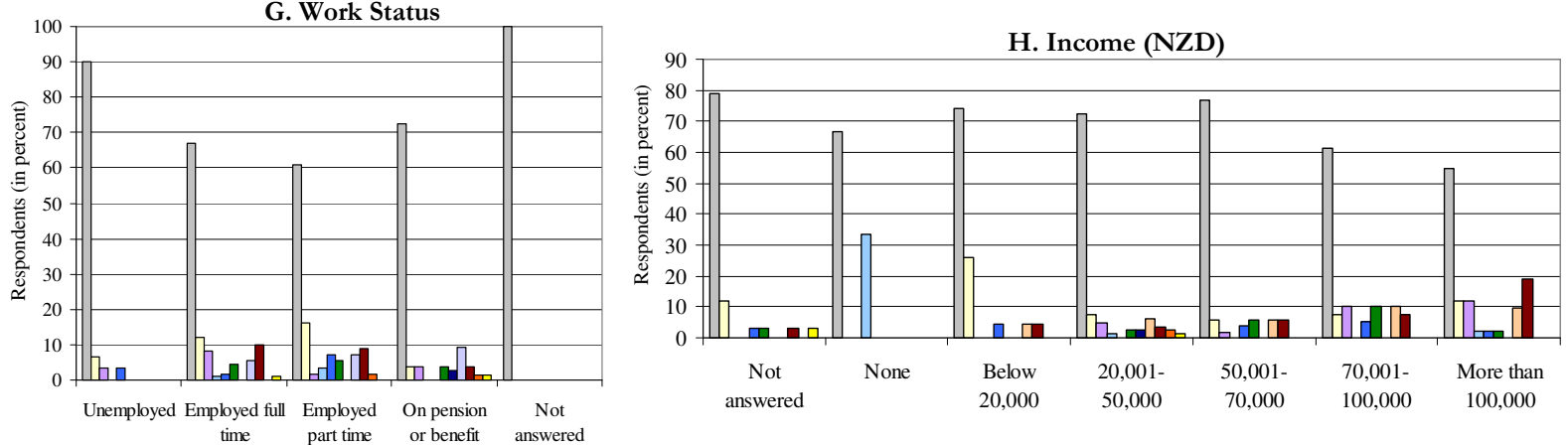

I. Occupation

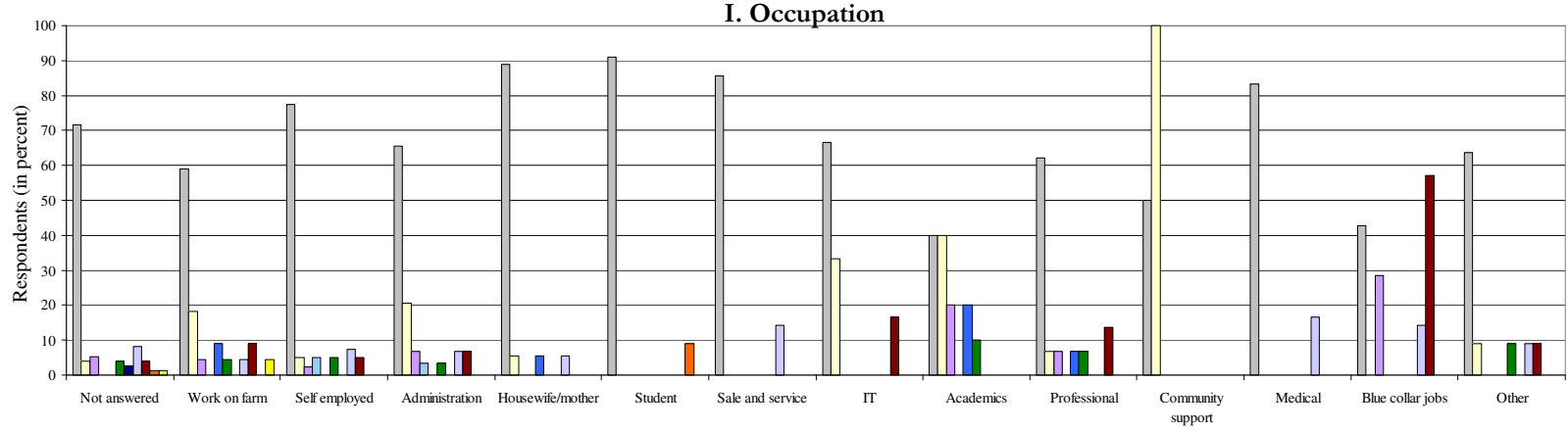

Based on Primary Survey, 2007 
Education has also affected the adoption of mitigation measures (Fig: 6.102.E). The respondents having no formal educational qualification mainly constructed the measures outside their house, such as putting in drainage or bore holes or constructed stop banks, which indicate towards farming background. The respondents with vocational qualification also did not take many mitigation measures. On the other hand, the classification of respondents on the basis of source of hazard education showed a different trend (Fig: 6.102.F). The respondents with vocational training for hazards i.e. either for civil defence or other official training had adopted a number of mitigation measures along with those who had hazard awareness through formal education. The response of respondents with self education about hazards was restricted to having emergency material, securing household items and enhancing their awareness about hazards. In terms of occupation, poor response is observed from students and the respondents who were working in sale and service sector, or for community support, or if they are in the medical profession (mainly nurse or care giver) (Fig: 6.102.I). Those with no education rather adopted a range of measures. The influence of work status and income was also clear on the measures taken by the respondents (Fig: 6.102.G \& H). The respondents who were unemployed took the least type of measures along with those who had no source of income.

The overall effect of these vulnerability factors is also observed in the response of respondents living in areas of different vulnerability levels. A declining trend can be observed in the variety of mitigation measures taken by the respondents from areas of low level of vulnerability to high vulnerability zones

Fig: 6.103. Measures Taken for Natural Hazards by Respondents Living in

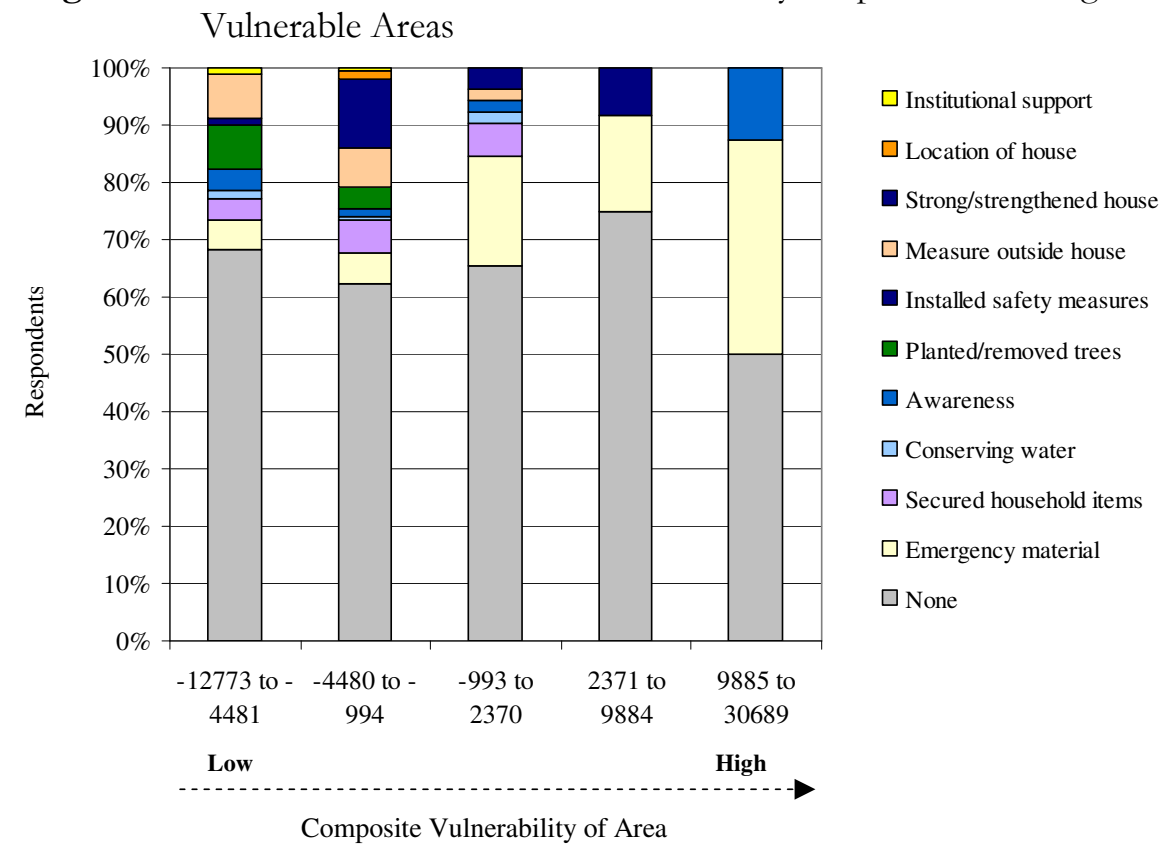

(Fig: 6.103). However, more respondents from the high vulnerability zones said they had stored emergency material and gathered information to enhance their awareness about hazards as compared to the respondents from low vulnerability areas. The measures taken by respondents such as measures taken outside the house i.e. building sea wall or retaining wall along with planting or removing trees declines with the increasing vulnerability level.

The variations are also observed in the types of changes that respondents made within their houses across gender, age, ethnicity, education, employment and income groups (Fig: 6.104). While a high proportion of male respondents made major changes in their house, the response of female participants was inclined towards minor changes and securing household items besides placing the 
Fig: 6.104. Gender, Ethnicity, Age, Number of Family Members, Education, Hazard Education, Work Status, Income, Occupation and Changes Made in House to Reduce Hazards by Respondents

A. Gender
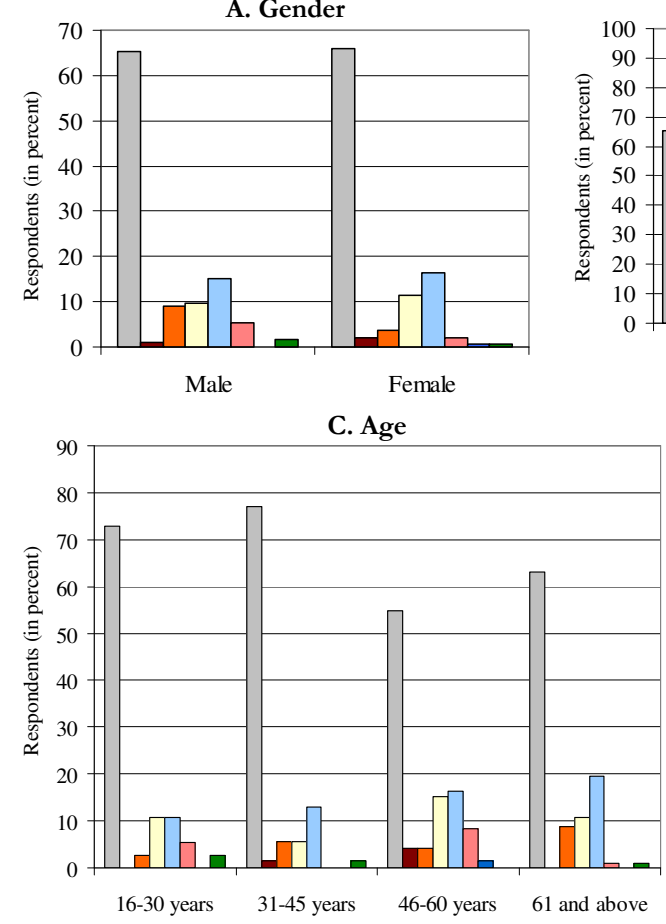

E. Education

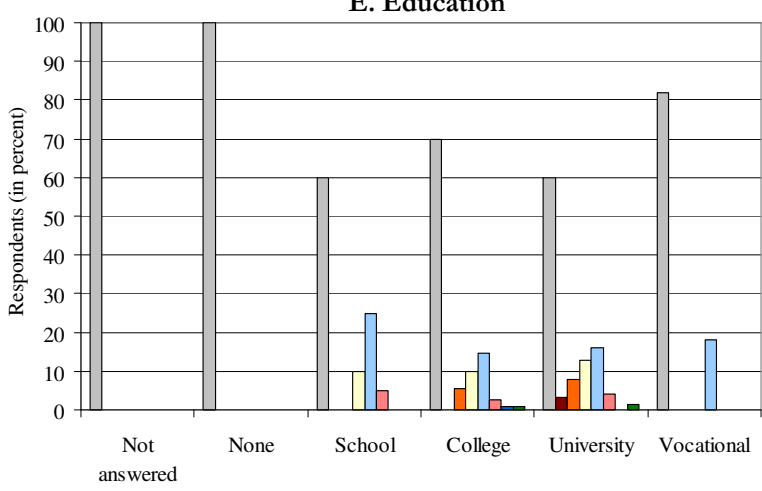

G. Work Status
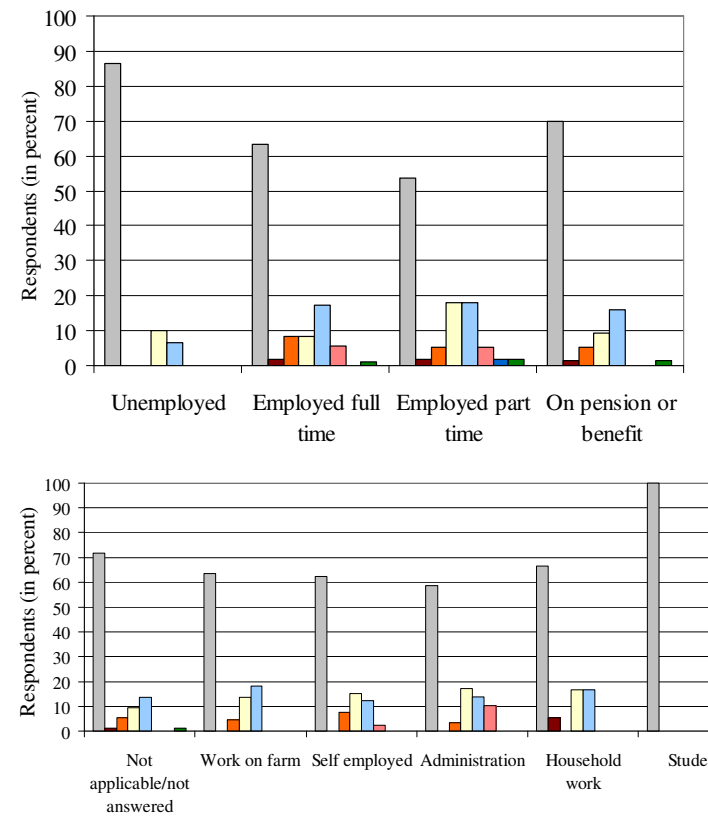

B. Ethnicity

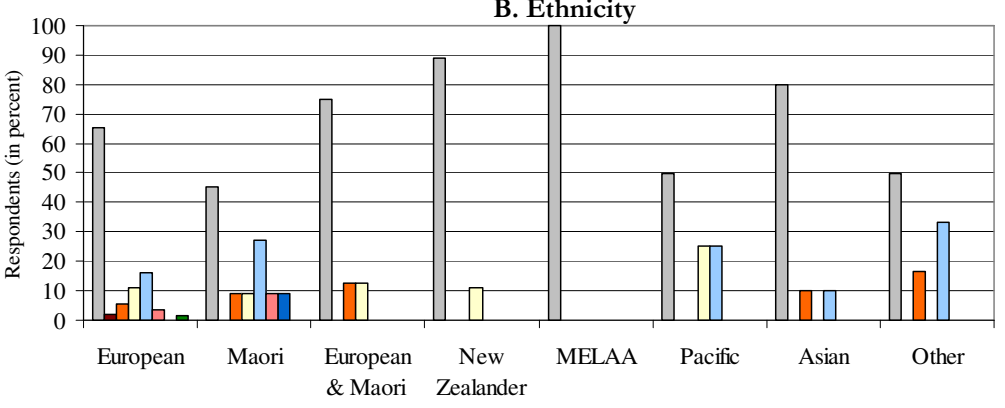

D. Number of Family Members

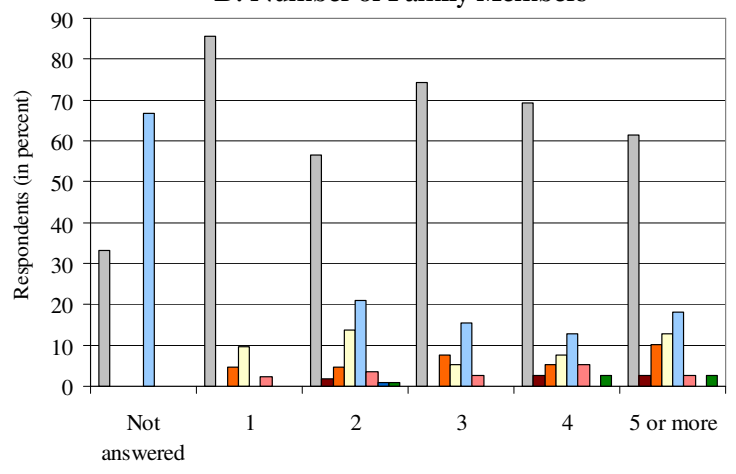

F. Hazard Education

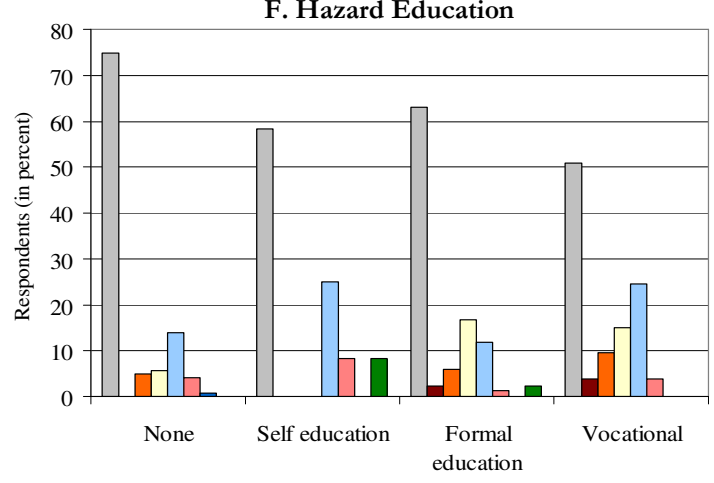

H. Income (NZD)

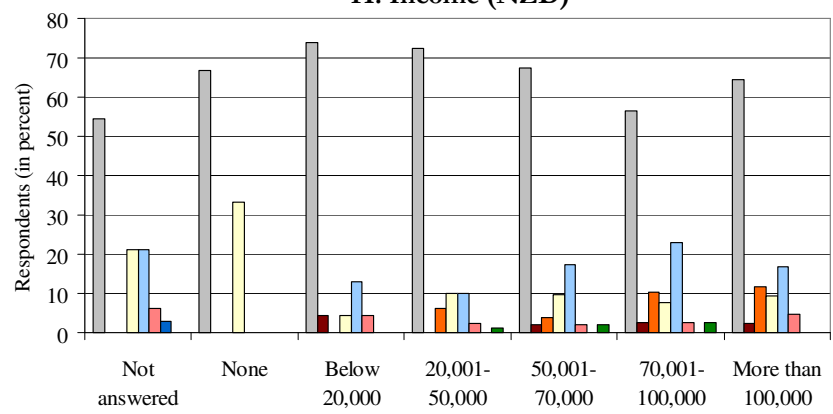

I. Occupation

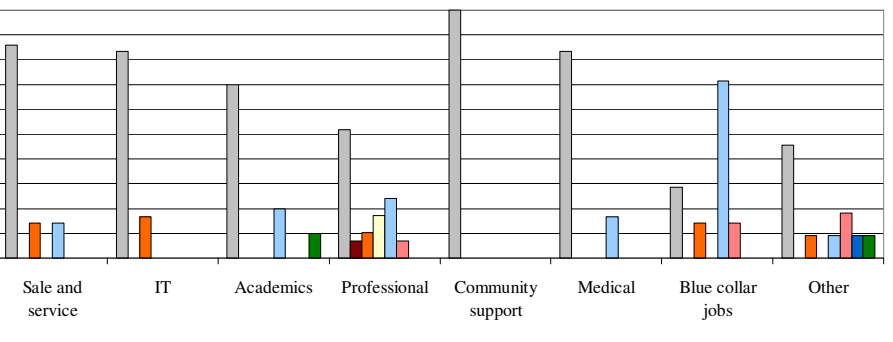

$\square$ Not answered $\square$ Build a safe/strong house $\square$ Major changes $\square$ Minor changes $\square$ Secured/fixed household items $\square$ Imroved security $\square$ Regular checks and maintenance $\square$ Planted or removed trees Based on Primary Survey, 2007 
emphasis on choosing a strong house or strengthening the existing one (Fig: 6.104.A). Among ethnic groups, while respondents from MELAA group did not make any change in their house to avoid hazards, New Zealanders made only minor changes. The European and Maori groups, on the other hand made a range of changes compared to other ethnic groups (Fig: 6.104.B).

Age of respondents has also influenced the nature of changes made by the respondents (Fig: 6.104.C). The young respondents did not emphasise choosing strong houses, and only a very small proportion of them made any major changes in their houses. The more proactive group was that between 46-60 years of age who made a range of changes in their houses. In general, an increasing trend can be observed in the proportion of respondents who secured household items with increasing age. It is also observed that the single respondents made less changes in their house compared to those who had families (Fig: 6.104.D). A high proportion of respondents with more family members (four or more) made a number of changes in their house. Education also played a significant role. While the respondents with no qualification made no change in their house, respondents having university qualifications made a number of changes and those with vocational training only secured the

Fig: 6.105. Type and Degree of Changes Made in Houses and Insurance Taken by Respondents Living in Vulnerable Areas

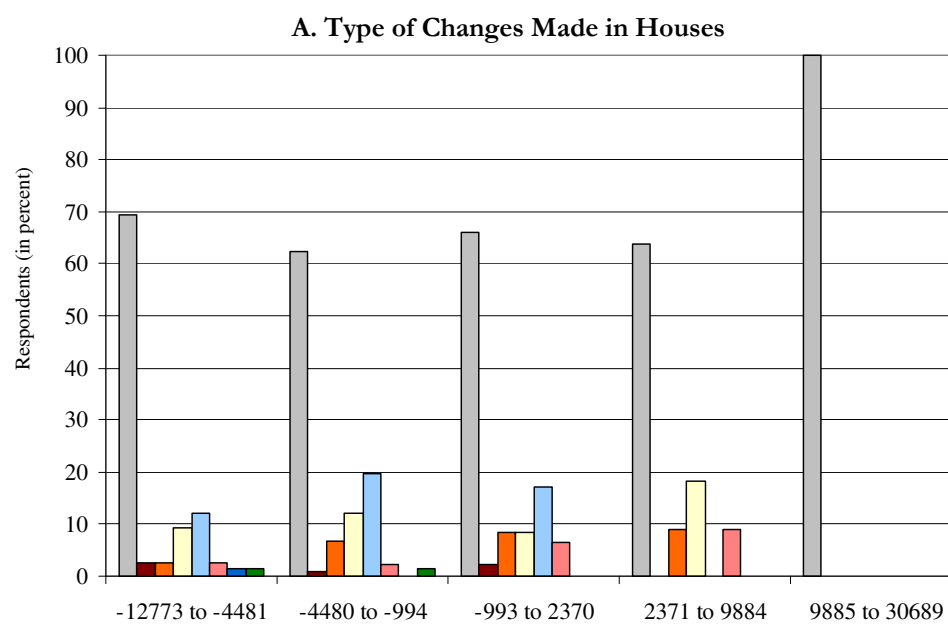

$\square$ Not answered

Build a safe/strong house $\square$ Major changes $\square$ Minor changes $\square$ Secured/fixed household items $\square$ Imroved security

$\square$ Regular checks and maintenance

$\square$ Planted/removed trees

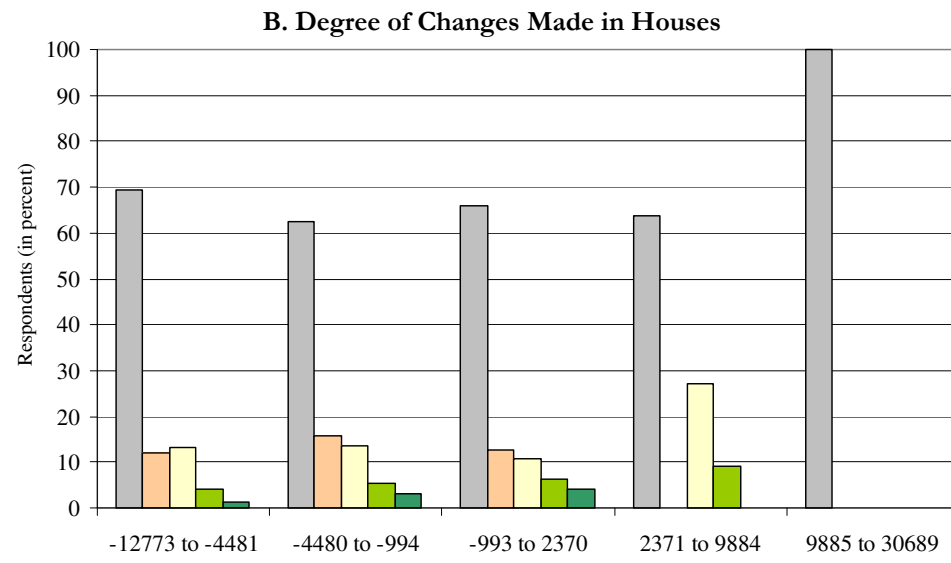

$\square$ None

$\square$ Low

$\square$ Medium

$\square$ High

$\square$ Very high

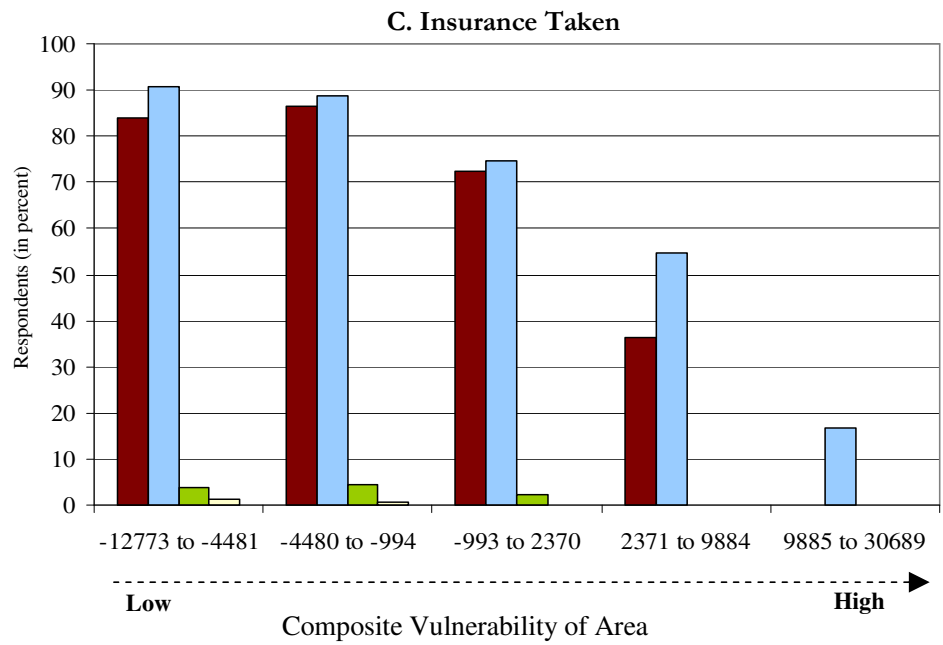


Fig: 6.106. Gender, Age, Education, Hazard Education, Number of Children, Family Members, Work Status, Ethnicity, Religious Orientation, Income, Years of Stay in New Zealand and Current Area vs. Safety Measures Adopted by Respondents

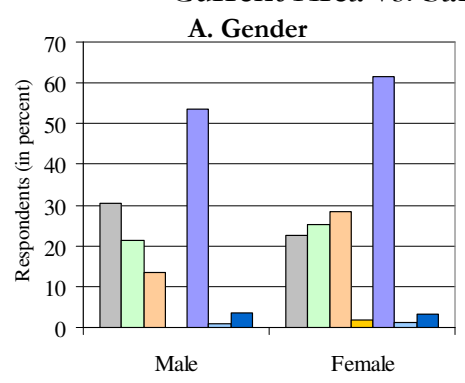

C. Education

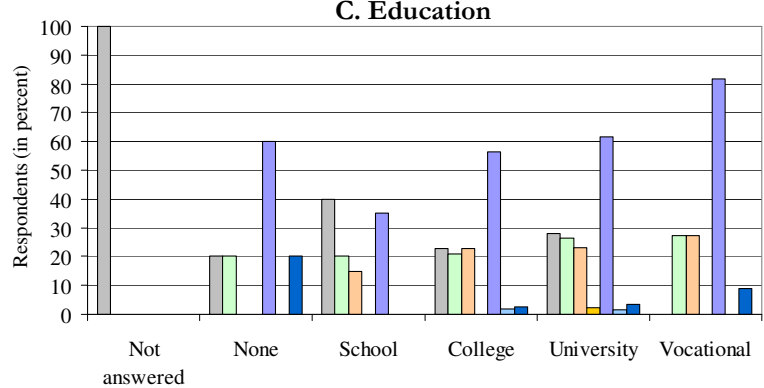

E. Number of Children

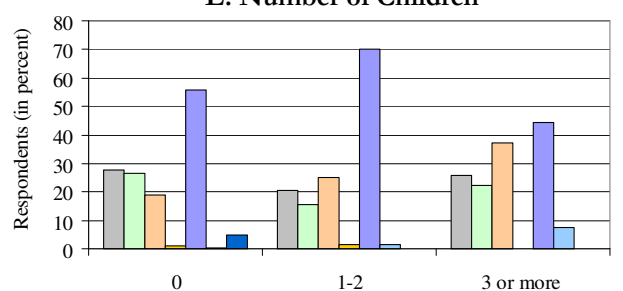

G. Ethnicity

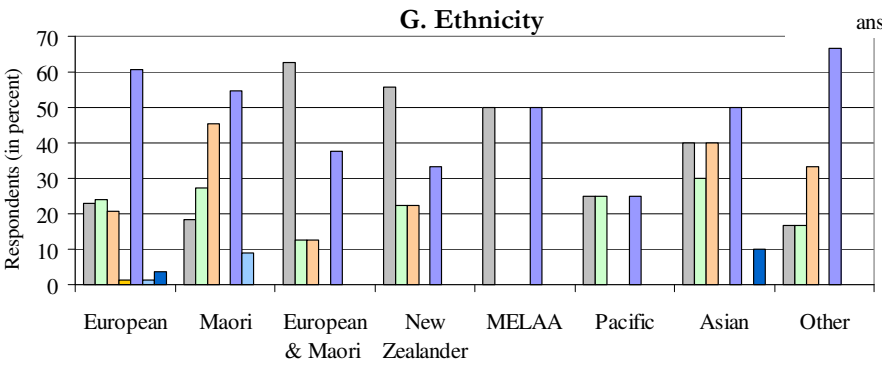

I. Work Status

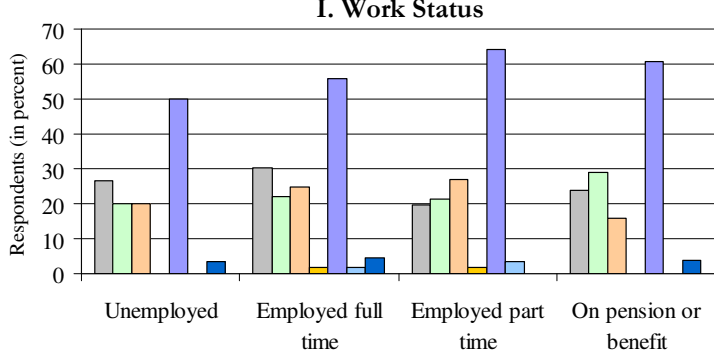

K. Years of Stay in New Zealand

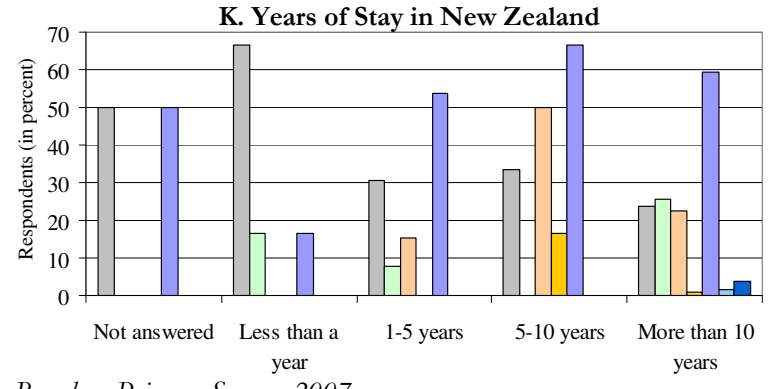

Based on Primary Survey, 2007
B. Age

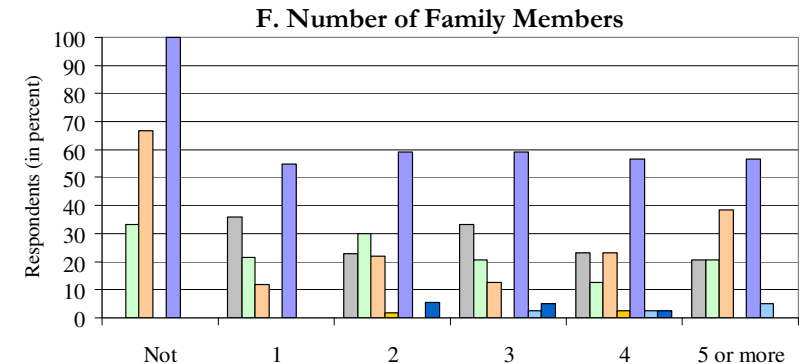

H. Religious Orientation

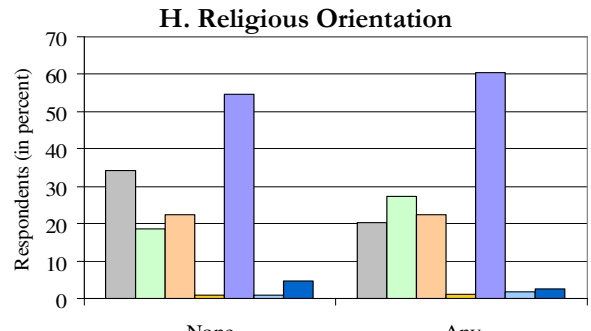

J. Income (NZD)

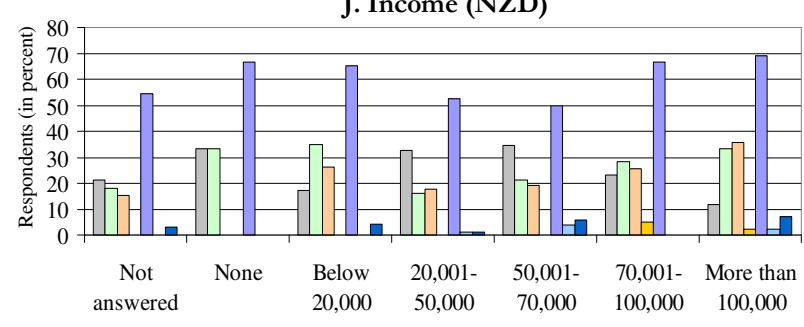

L. Years of Stay in Current Area

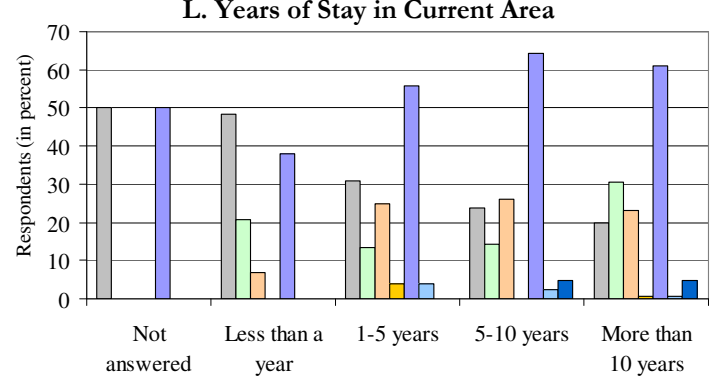


Fig: 6.107. Gender, Age, Education, Hazard Education, Occupation, Income, Ethnicity, Years of Stay in New Zealand and Current Area vs. Hazards for Which Safety Measures are Adopted by Respondents
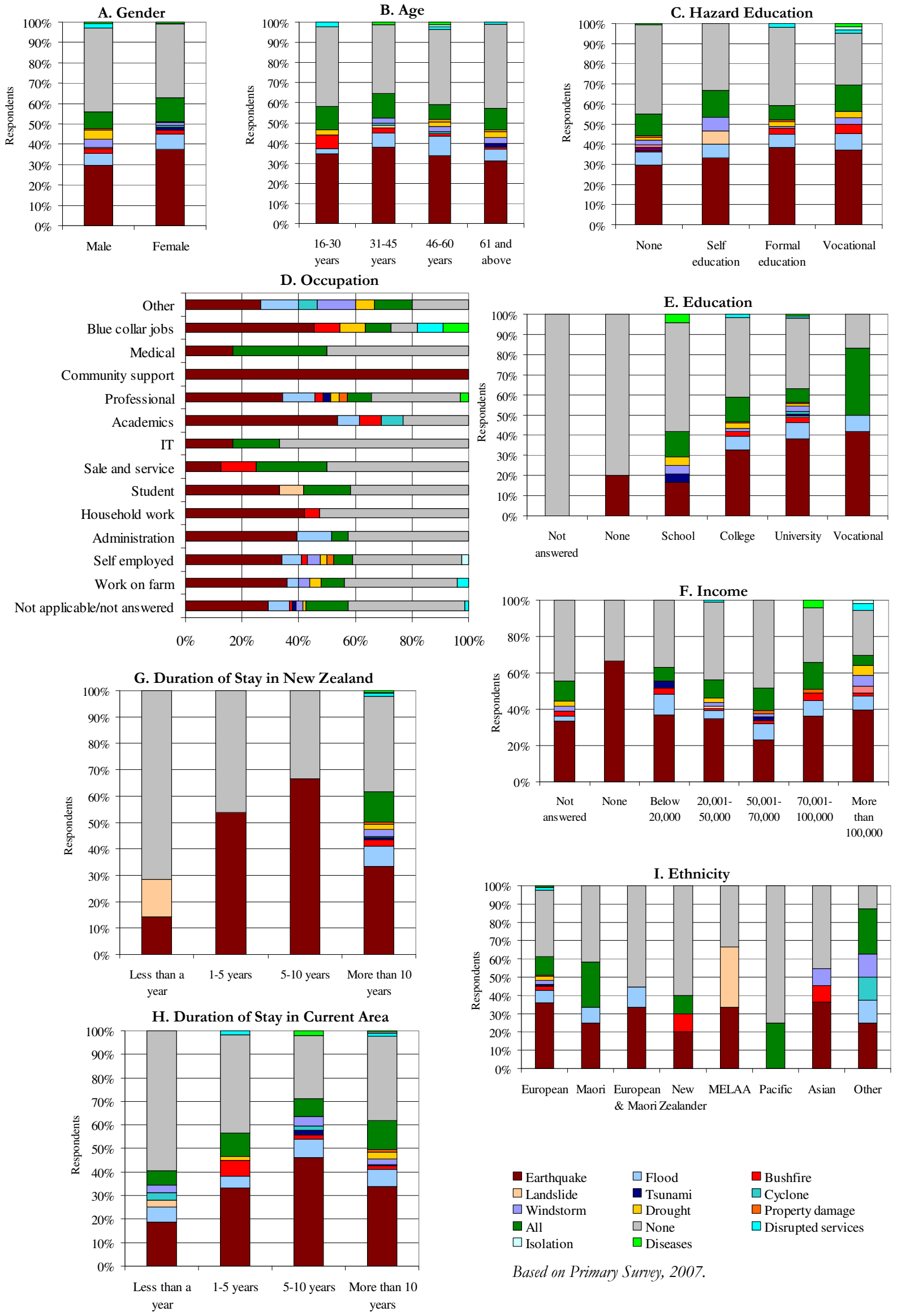

Based on Primary Survey, 2007. 
household items (Fig: 6.104.E). In terms of hazard education, the best response was noted from the respondents with civil defence or other hazard related training (Fig: 6.104.F).

Those with self education did not make significant structural changes in their house, but they secured household items, improved security by installing alarms and planting or removing trees outside the house.

Economic factors also played a significant role (Fig: 6.104.G, H \& I). The unemployed and the respondents with no income only made minor changes to their houses, while students and community support respondents made no changes in their house. The respondent who made maximum changes in their houses to reduce hazards were professionals followed by those working in administration or those who were self employed.

The influence of vulnerability on response is also visible at the area level. While a range of changes were made to houses by the respondents living in low vulnerability areas, those in high vulnerability zones did not make any change to their houses. A declining trend can be observed in the level of effort made to reduce hazards in their houses from the respondents living in low to moderate vulnerable zones to those who lived in the high vulnerability areas (Fig: 6.105.A \& B). A declining trend is also clear in the proportion of respondents who have taken insurance for their house and contents from the areas of low vulnerability towards high vulnerability zones (Fig: 6.105.C).

In addition, differences are also noted in the safety measures taken by the respondents, such as having cash, an emergency plan or survival kit, with respect to their socio-economic and vulnerability characteristics (Fig: 1.106). The data show that more female respondents have adopted the safety measures either having cash, emergency plan or survival kit compared to the male respondents. The comparison of safety measures taken by respondents in different age groups shows that a low proportion of young respondents ( $<30$ years of age) have kept cash or a survival kit than older age groups. On the other hand, none of the elderly respondents ( $>65$ years of age) had an emergency plan. The respondents without formal education also did not have any emergency plan, while an increasing trend is noted in the proportion of respondents who had secured survival kits with increasing hazard education. It is also noted that while the highest proportion of respondents with one to two children had survival kits, a greater proportion of respondents with three or more children had made an emergency plan.

Across different ethnic groups, the respondents from MELAA group only had the survival kit, while a low proportion of Pacific respondents had kept cash along with a survival kit. It was also observed that respondents with religious belief had taken more safety measures compared to those who did not follow any religion. The role of economic factors was also noted as a small proportion of unemployed respondents had taken safety measures, while none of the respondents without income had made an emergency plan. A higher proportion of respondents with high income had taken all the mentioned safety measures. Time of stay in New Zealand and the current residential area has also influenced the safety measures taken by the respondents. While a very small proportion of respondents had cash or survival kits if they were in the country for less than a year, none of these respondents had made an emergency plan when they were very new to their residential area. 
The safety measures taken by the respondents also differed for different hazards (Fig: 6.107). While male respondents had taken measures for a range of hazards, female respondents had mainly taken measures for earthquake, flood, all or none of the mentioned hazards. It was also observed that with increasing age the proportion of respondents who took safety measures for earthquake declines, while it increases for those who did not take safety measures for any particular hazard. This is opposite to the trend of education or hazard education of respondents for taking safety measures which indicates an overriding influence of experience over education. Whereas the proportion of respondents who took measures for earthquake increased along with both normal and hazard education, it declined for those respondents who took measures for none of the mentioned hazards. The hazards for which safety measures have been taken by respondents also differed in various occupation and income groups. While the respondents in community support group only took measures for earthquakes, those in professional work took safety measures for a range of hazards. This is also related to income. While the respondents with no income took safety measures for earthquakes or no hazard, the highest variation in the number of hazards was observed in the high income group. Among various ethnic groups, while Pacific respondents took measures for either all or none of the hazards, the MELAA group took measures for earthquakes, landslides or no hazards, and the respondents with European and Maori mix ethnicity took measures for earthquake, floods or no hazards. The influence of time of stay in New Zealand was more dominant for the hazards for which measures were taken by the respondents as compared to the time of stay in the current residential area.

Fig: 6.108. Type and Hazards for Which Safety Measures Taken by Respondents Living in Vulnerable Areas

A. Type of Safety Measures Taken

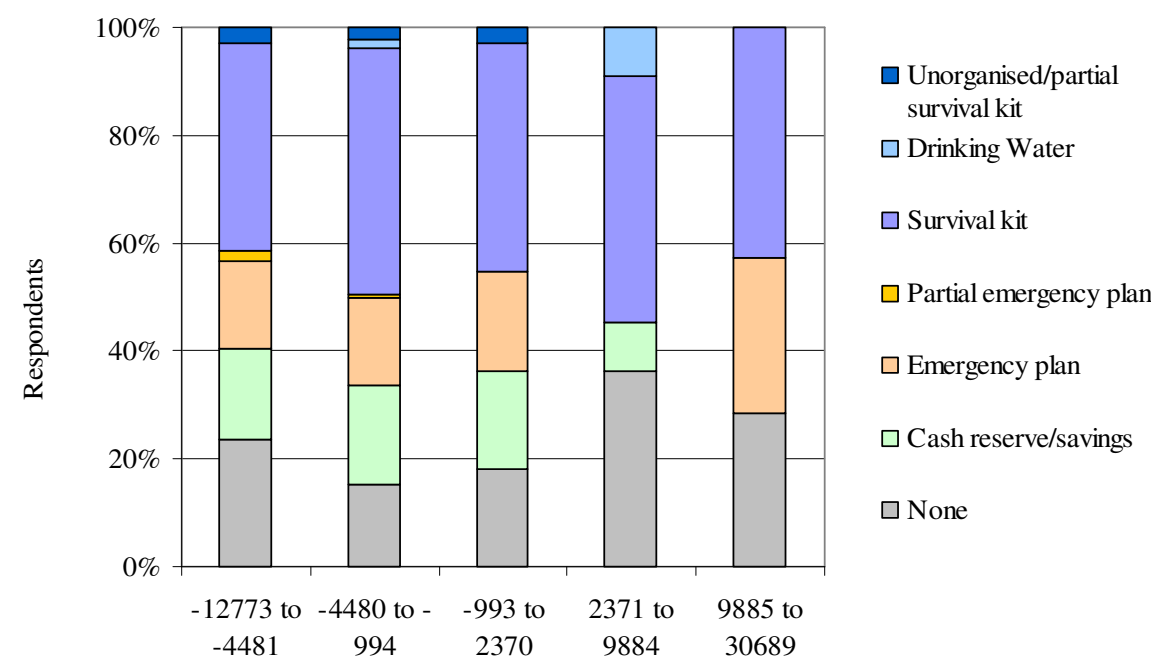

B. Hazards for Which Safety Measures Taken

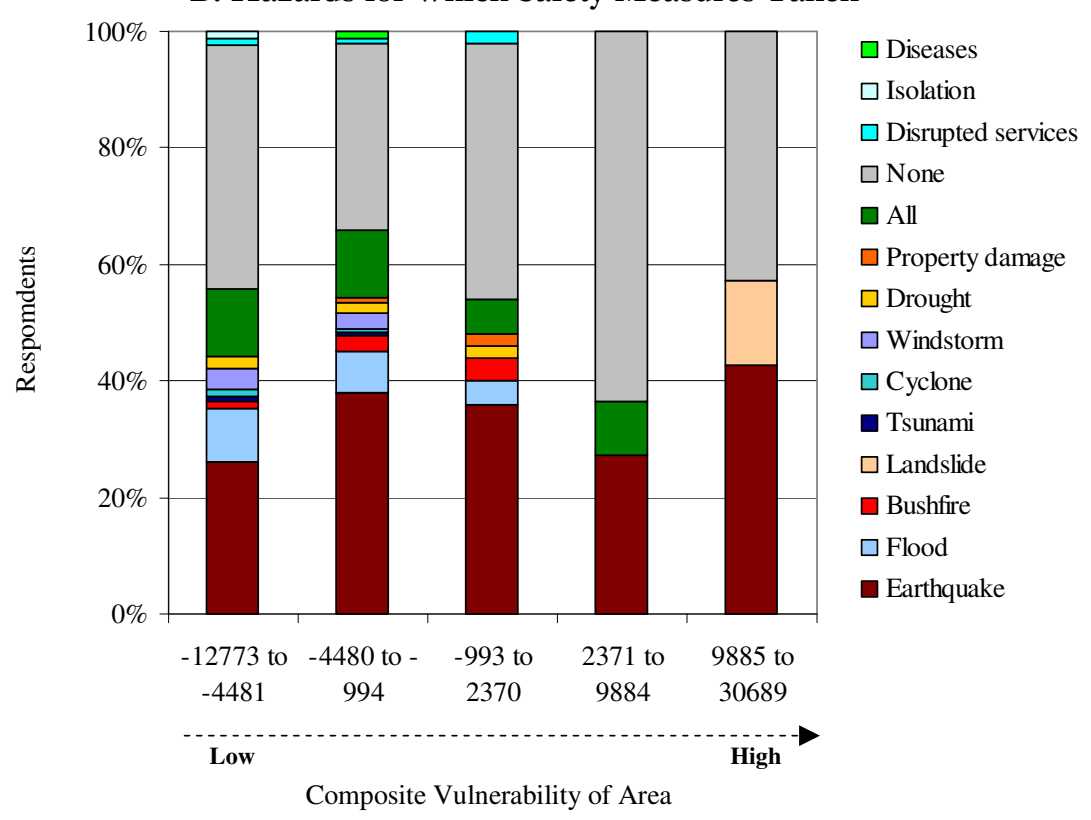

Based on Primary Survey, 2007 
Fig: 6.109. Gender, Age, Hazard Education and Education vs. Preparedness of Respondents
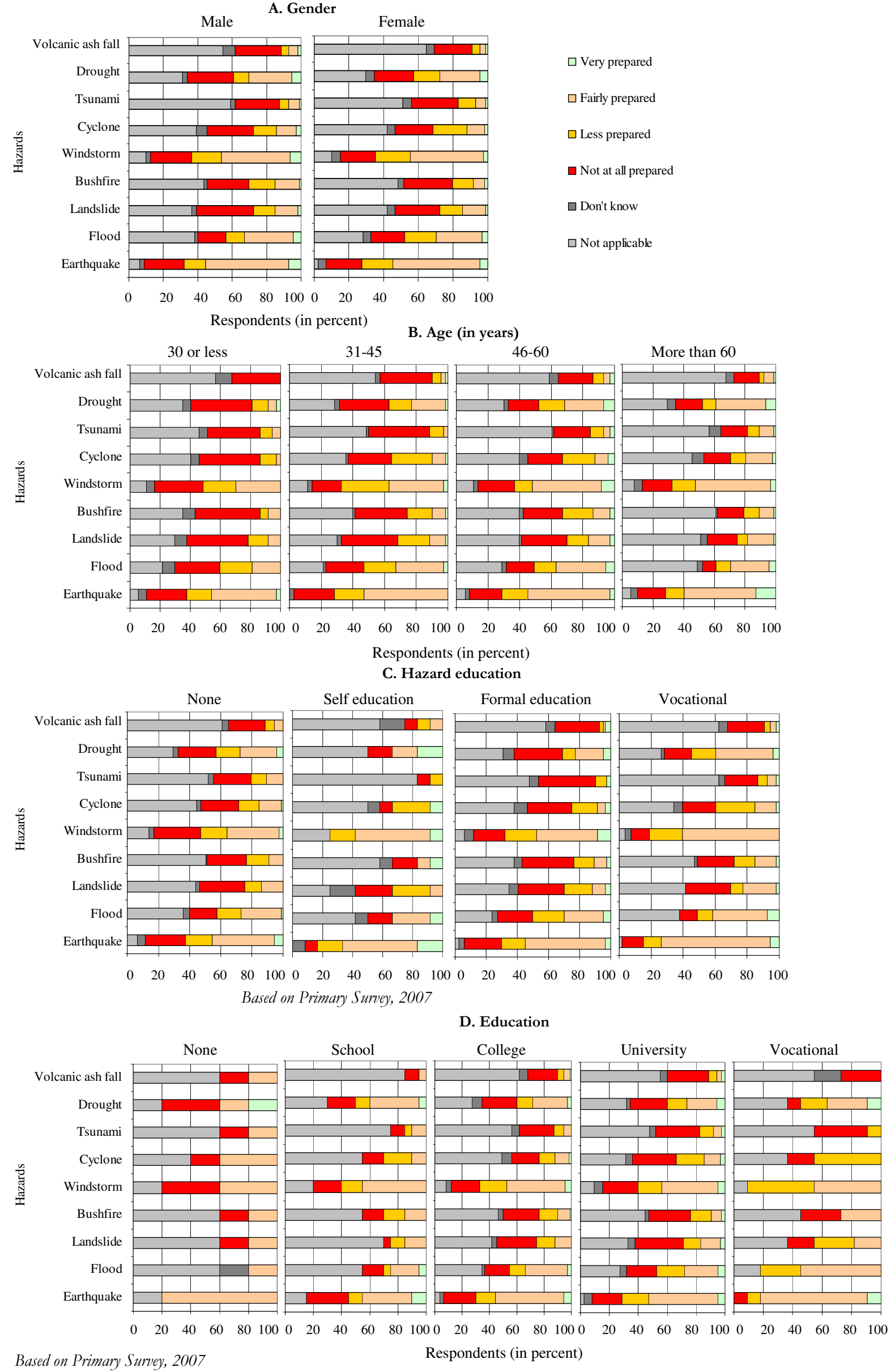
With respect to the vulnerability variations over space, a declining trend is observed in the types of safety measures taken by the respondents living in low vulnerability areas to those who lived in high vulnerability zone (Fig: 6.108.A). In general, the proportion of respondents who have not taken any measure for hazards increases with the increasing vulnerability. Also, the proportion of respondents who have kept cash for the hazard situation decreases with areas of increasing vulnerability. On the other hand, the proportion of respondents who had kept a survival kit for hazards is nearly the same for all zones. However, the purpose in terms of type of hazards for which they had taken safety measures differed across different vulnerability zones. While the safety measures in the highest vulnerability zone were mainly taken for earthquakes, landslides or for none of the mentioned hazards, in the second highest vulnerability zone, they were taken for earthquakes, all or for none of the mentioned hazard. In the moderate or low vulnerability zones, respondents have mentioned a greater range of hazards and the proportion of respondents who took safety measures for none of the mentioned hazard were relatively less than those who lived in high vulnerability zones.

The difference is also observed in the preparedness level of respondents across different socio-economic and vulnerability groups (Fig: 6.109). A high proportion of male respondents perceived themselves to be very prepared for all hazards as compared to the female respondents.

Fig: 6.110. Ethnicity vs. Preparedness of Respondents to Hazards

\section{Ethnicity}
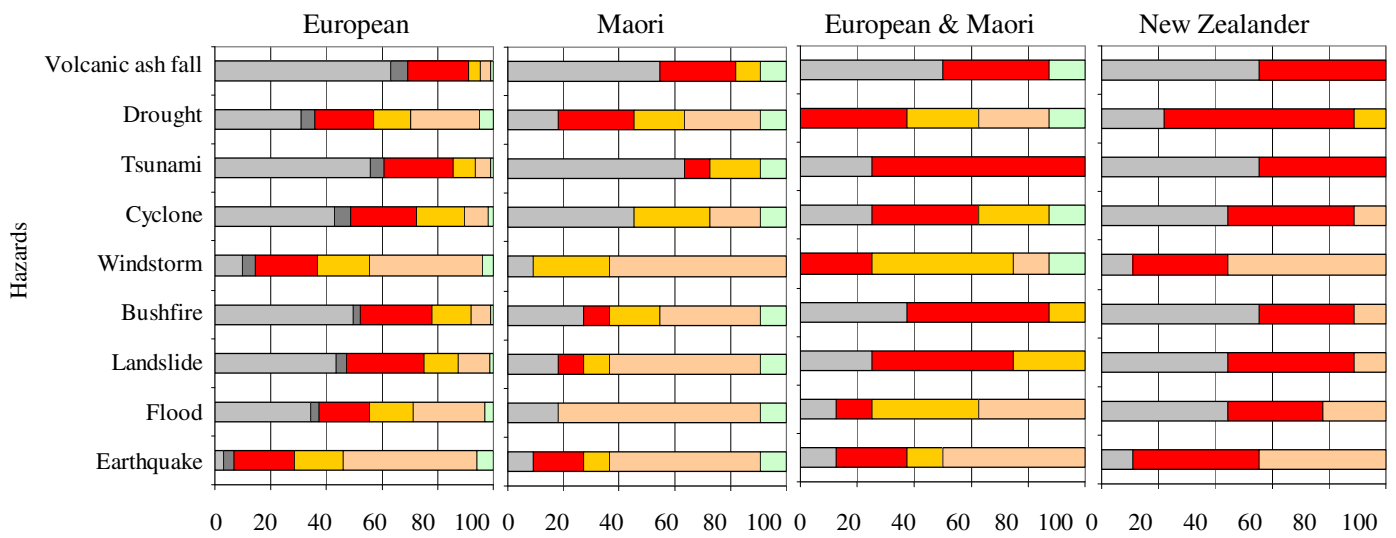

Respondents (in percent)
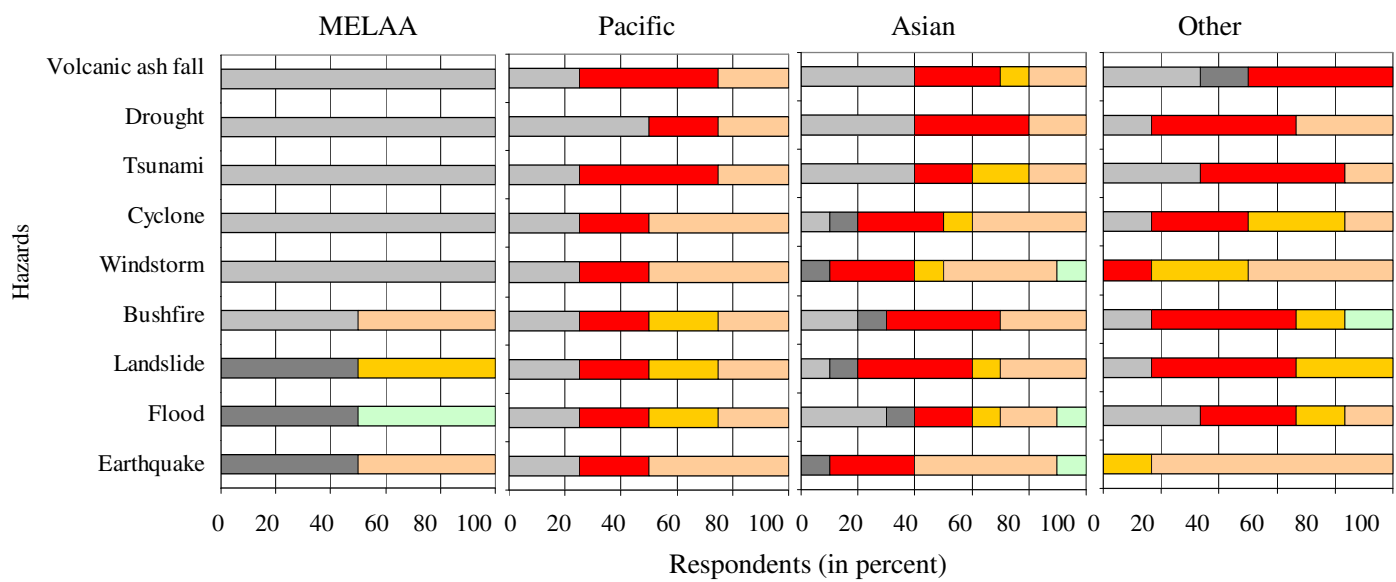

Respondents (in percent)

$\square$ Not applicable $\square$ Don't know $\square$ Not at all prepared $\square$ Less prepared $\square$ Fairly prepared $\square$ Very prepared 
Also, a smaller proportion of male respondents felt not at all prepared as compared to the female respondents. In terms of age, while the young respondents of less than 30 years did not find themselves to be very prepared for most hazards except earthquake and drought, a high proportion of middle age respondents (46-60 years) found themselves to be prepared for most hazards. The perception of very high preparedness for earthquakes is noted high in elderly respondents.

Education has also influenced the perception of preparedness among respondents. A high proportion of respondents with no educational qualification found themselves to be either fairly prepared or not at all prepared for most hazards. The only hazard for which the respondents from this group perceived themselves to be very prepared was drought. Most of these respondents also found most of the hazards to be not applicable to them. A share of respondents with university qualifications, on the other hand, perceived themselves to be very prepared for all hazards. The data show that the highest proportion of respondents with self education about hazards found themselves to be very prepared for most hazards followed by those with formal education, vocational training for hazard management and those without any hazard education.

The effect of ethnicity is also observed on the preparedness level of respondents (Fig: 6.110). Most respondents from the MELAA group found most of the hazards to be not applicable for them or they did not know about them. Their preparedness level was least among all ethnic groups. On the other hand, the highest proportions of respondents who perceived themselves to be very prepared for all hazards were from the Maori group followed by the European-Maori group. None of the Pacific respondents perceived themselves to be very prepared for any hazard, though a significant proportion of them perceived themselves to be fairly prepared for all hazards. Simiarly, though a high proportion of Asian respondents also perceived themselves to be fairly or very prepared for earthquake, the majority of them were either not at all prepared for most hazards or perceived hazards to be not applicable to them.

Fig: 6.111. Religious Orientation and Ownership of House vs. Preparedness of Respondents
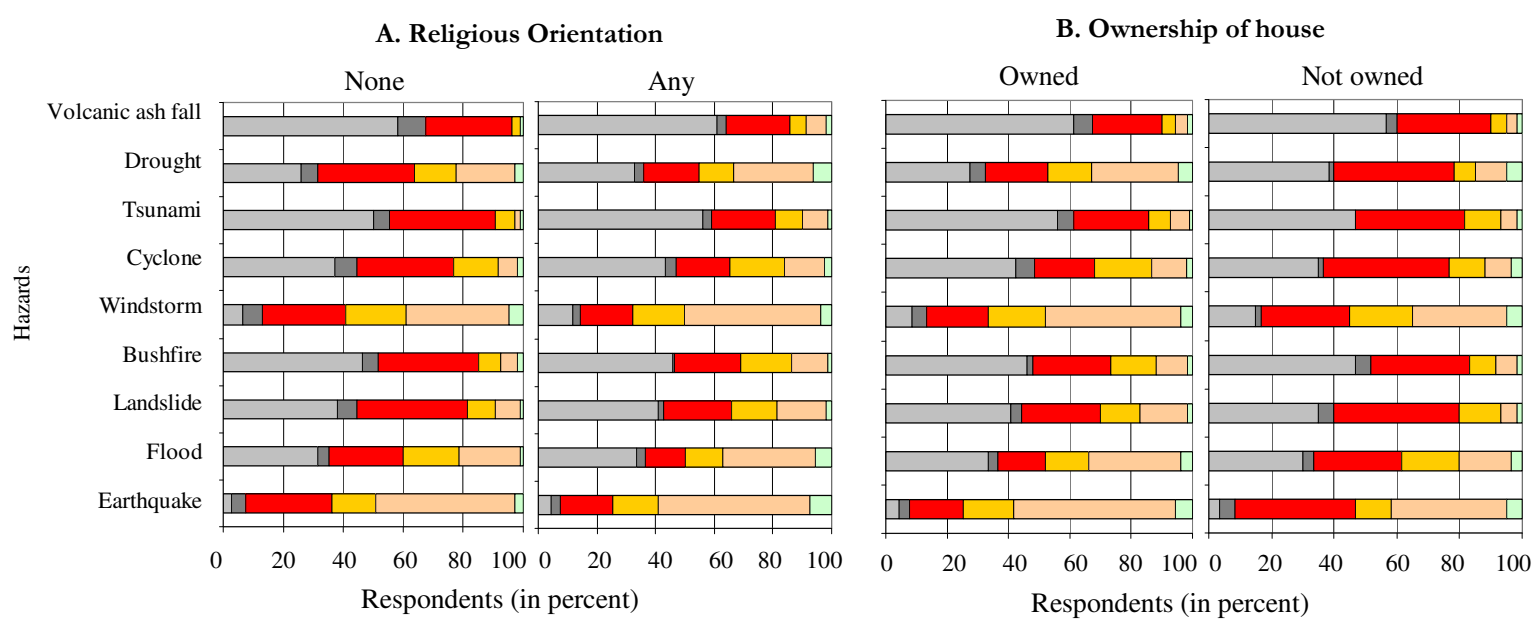

$\square$ Not applicable $\square$ Don't know $\square$ Not at all prepared $\square$ Less prepared $\square$ Fairly prepared $\square$ Very prepared

Based on Primary Survey, 2007

Religious orientation has also influenced the perception of preparedness to an extent. A greater proportion of respondents having religious belief perceived themselves to be very prepared 
for all hazards as compared to those who do not follow any religion (Fig: 6.111.A). The perception of preparedness level is also noted to vary with the economic conditions of respondents. While a higher proportion of respondents who owned their house were found to be very prepared for earthquakes and flooding, a greater proportion of respondents who did not own their house were very prepared for windstorms and cyclones (Fig: 6.111.B). Also a high proportion of respondents who did not own house were not at all prepared for any hazard as compared to those who owned their house. The influence of work status is also noted in the perception of preparedness. None of the respondents who were unemployed found themselves to be very prepared for any hazard (Fig: 6.112.A). The highest proportion of respondents who found themselves to be very prepared were either employed part time or they were living on pension or benefits. The change in the preparedness level to hazards however, does not show any clear trend across different income groups even though differences can be observed. The respondents without any income mostly perceived themselves to be either not at all prepared or less prepared. None of these respondents without any income claimed to be very prepared for any hazard. The highest proportion of the respondents who find them to be very prepared earned less than 20,000 NZD. A very few respondents in moderate (50,000-70,000 NZD) and high income group (more than 100,000 NZD) found themselves to be very prepared (Fig: 6.112.B).

Fig: 6.112. Work Status and Annual Income vs. Preparedness of Respondents

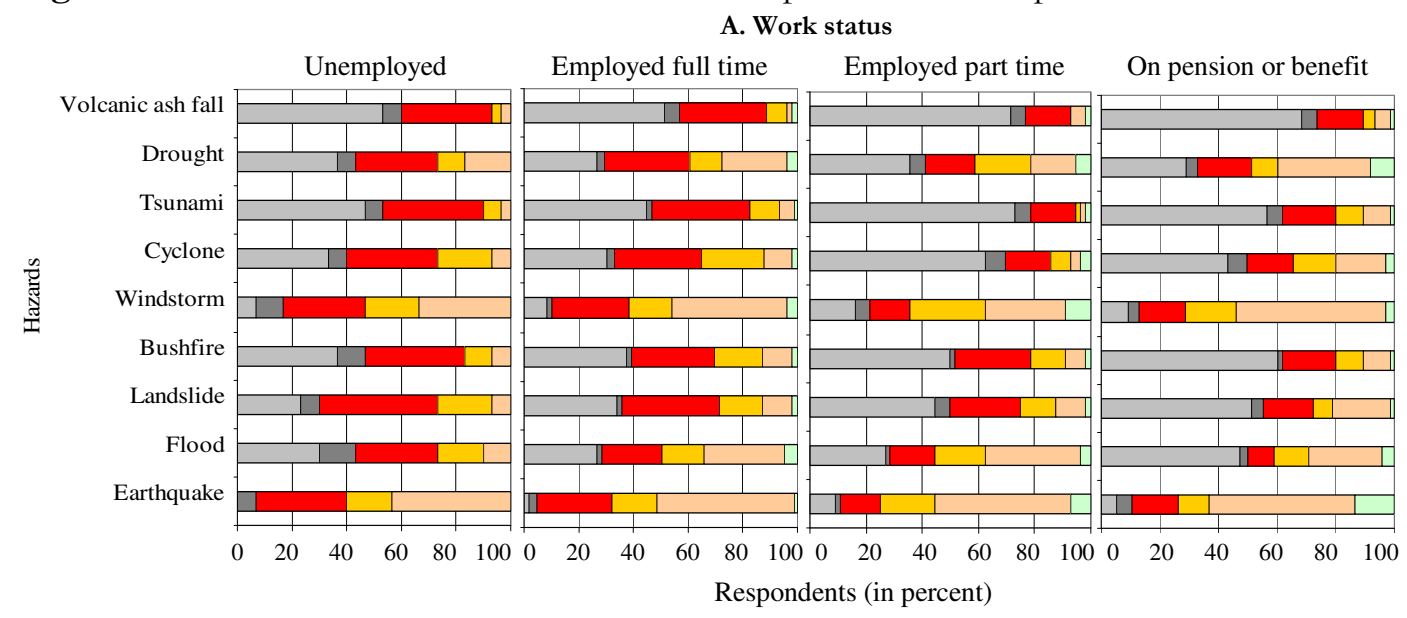

B. Annual Income (NZD)

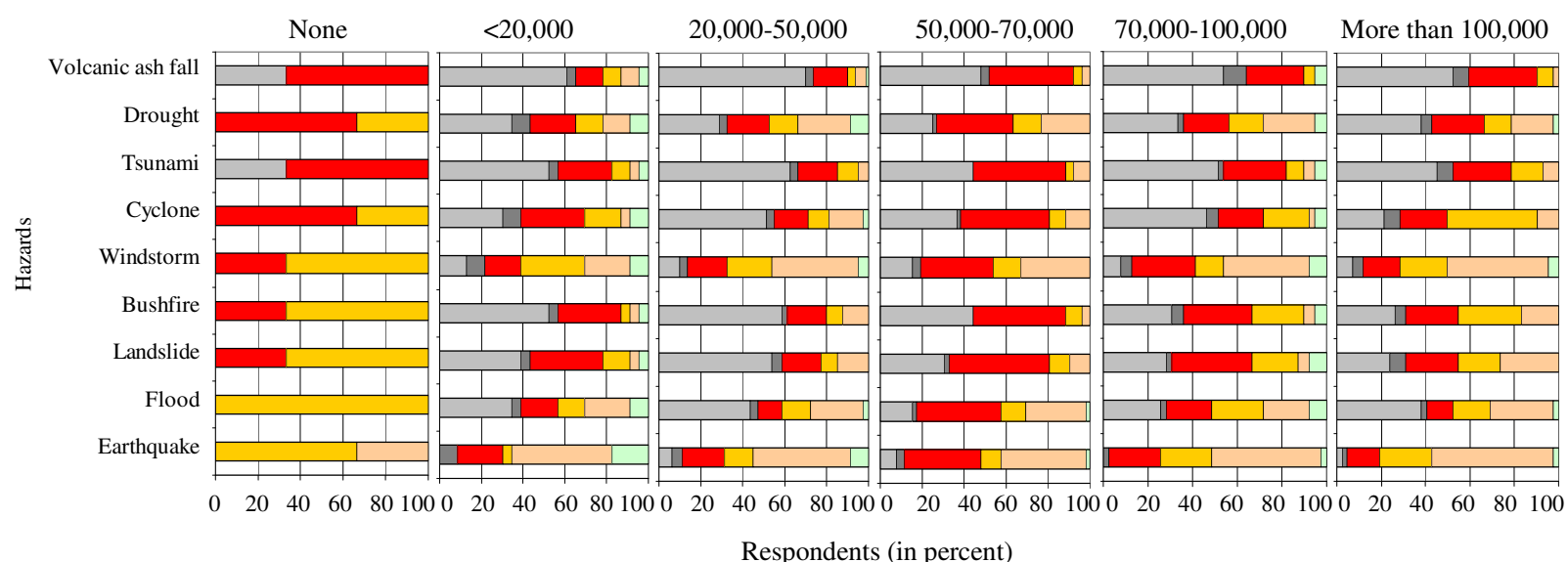

$\square$ Not applicable $\square$ Don't know $\square$ Not at all prepared $\square$ Less prepared $\square$ Fairly prepared $\square$ Very prepared

Based on Primary Survey, 2007 
The perception of preparedness also differed among respondents on the basis of having children and the number of children they had (Fig: 113.A). A higher proportion of respondents without children perceived themselves to be very prepared for a number of hazards compared to those who had children. On the other hand, a high proportion of respondents with three or more children perceived themselves to be not at all prepared for most hazards. Contrary to this, a high proportion of respondents with more than five family members perceived themselves to be very prepared for hazards compared to those who are either living alone or have small families (Fig: 113.B).

Fig: 6.113. Number of Children and Family Members vs. Preparedness of Respondents
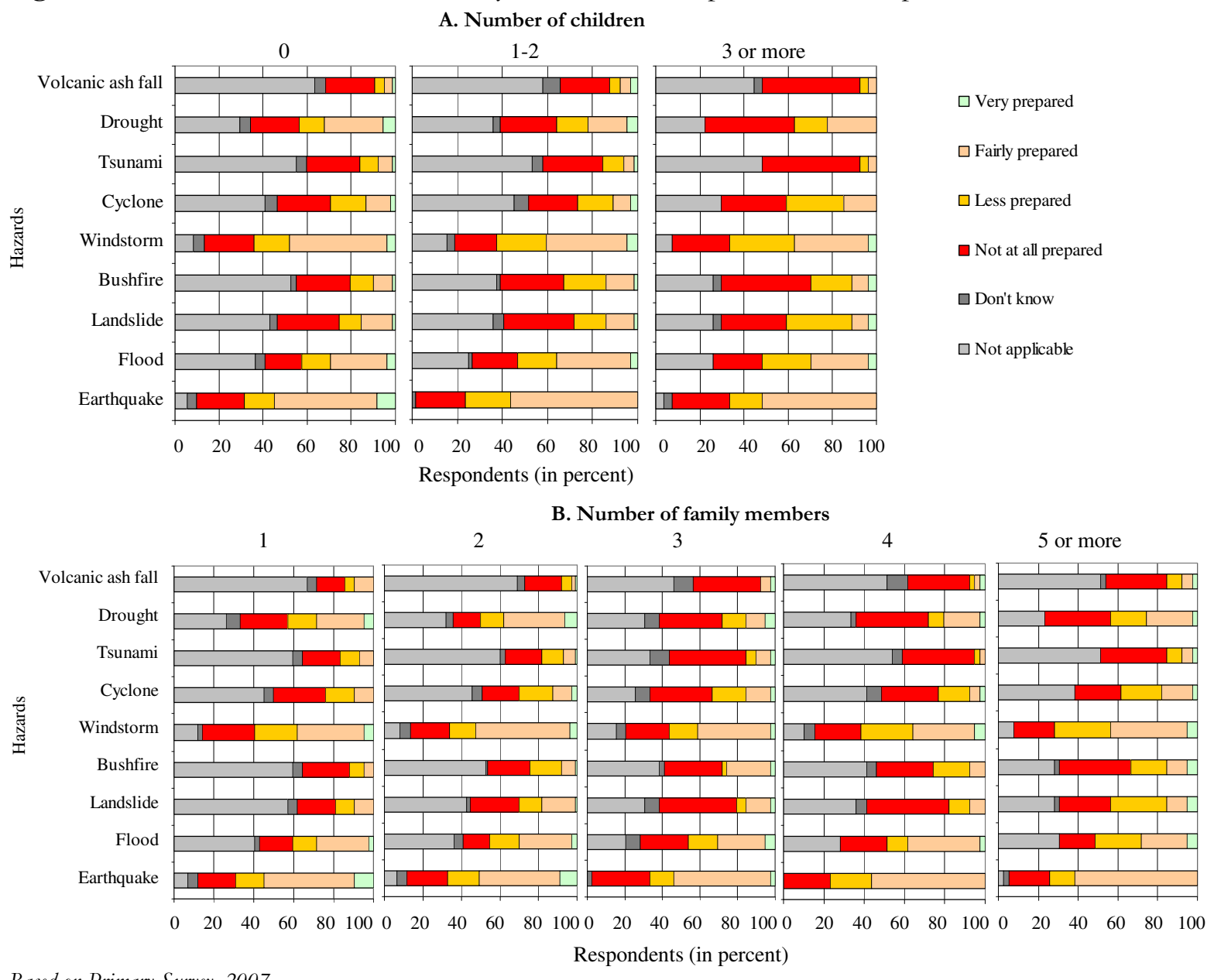

Based on Primary Survey, 2007

Time of stay either in New Zealand, current residential area or in the current house has also influenced the perceived preparedness level of respondents (Fig: 6.114). The highest proportion of respondents who perceived themselves to be not at all prepared has lived in the country for less than a year. The proportion of such respondents declines significantly in the group of population who have lived 5-10 years in the country and increases again for those who have lived longer in New Zealand. The reason for sharp decline could be associated with lack of any hazard experience during 5-10 years of stay in the country, while the increase among those who have lived here longer could be associated with their better awareness of the potential risks from natural hazards. Similarly, a high proportion of respondents, either new to their residential area or within their house, perceived themselves to be not at all prepared for any hazard. 
Fig: 6.114. Preparedness of Respondents and Time of Stay in New Zealand, Residential Area and Current Houses
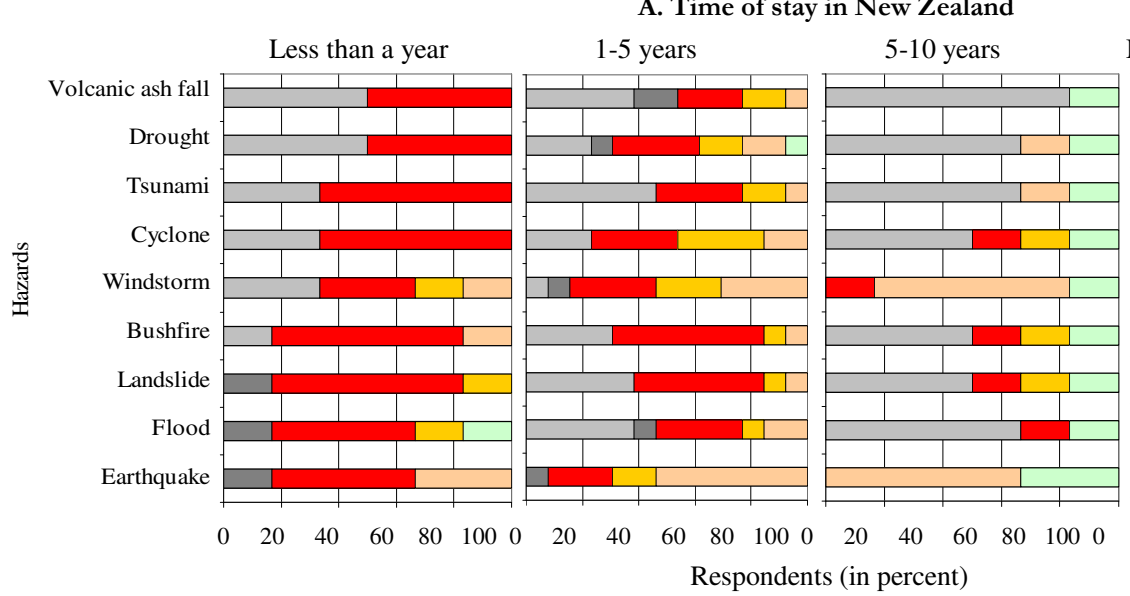

More than 10 years

B. Time of stay in current area
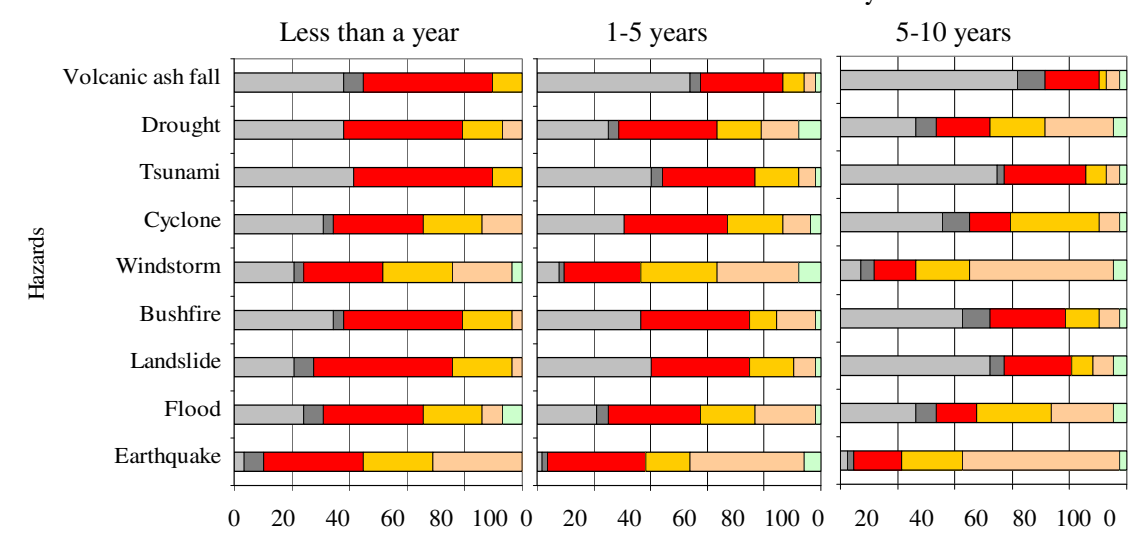

More than 10 years

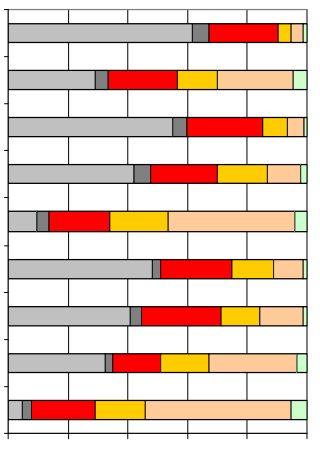

$\begin{array}{lllll}20 & 40 & 60 & 80 & 100\end{array}$

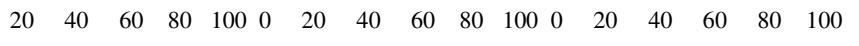

Respondents (in percent)

C. Time of stay in current house

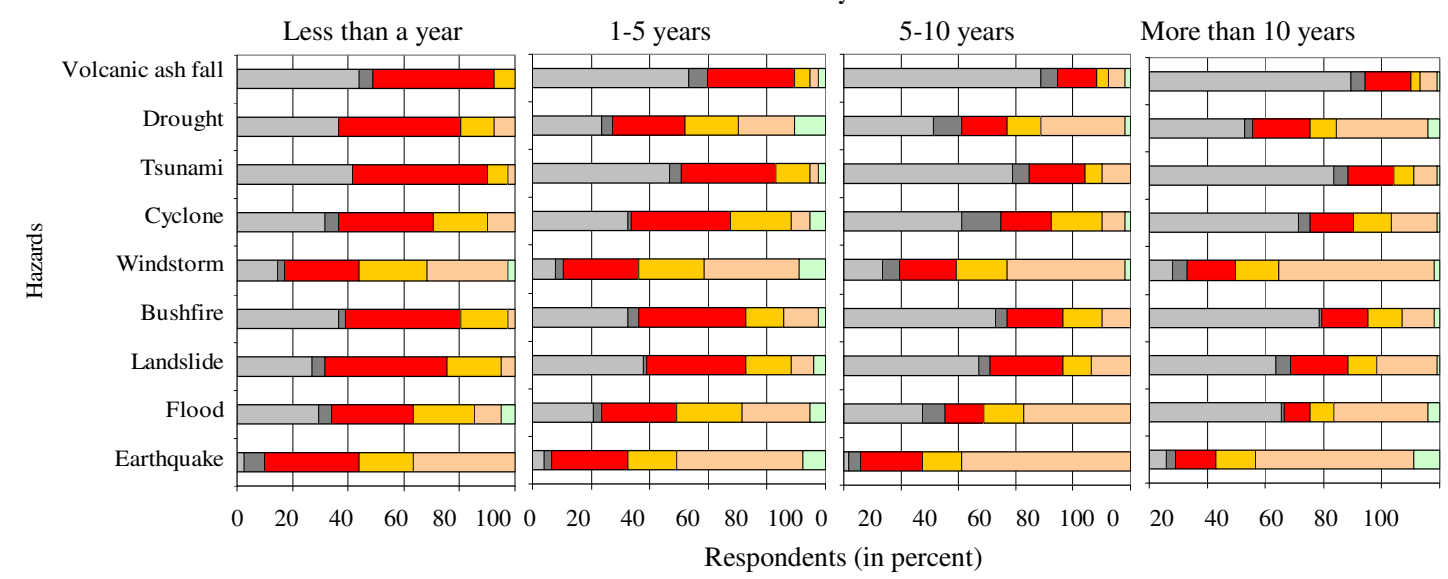

$\square$ Not applicable $\square$ Don't know $\square$ Not at all prepared $\square$ Less prepared $\square$ Fairly prepared $\square$ Very prepared

Based on Primary Survey, 2007

Not a clear relationship is observed between the perceived preparedness level and the location of respondents in differential vulnerability zones (Fig: 6.115). The highest proportion of respondents who were not at all prepared for any hazard lived in the moderate vulnerability zone and their share decreased with areas of both high and low vulnerability. This could be attributed to the previous finding that even though the respondents have not taken safety measures, they perceived themselves to be prepared for most hazards. However, a difference is noted in the 
number and type of hazards for which respondents perceived themselves to be prepared (Fig: 6.116). While the respondents living in low vulnerability areas perceived themselves to be very prepared for a number of hazards, those in high vulnerability areas perceived themselves to be very prepared for earthquakes and flooding, and those in the second highest vulnerability zone did not perceive themselves to be very prepared for any hazard.
Fig: 6.115. Hazard Preparedness of Respondents in Vulnerable Areas

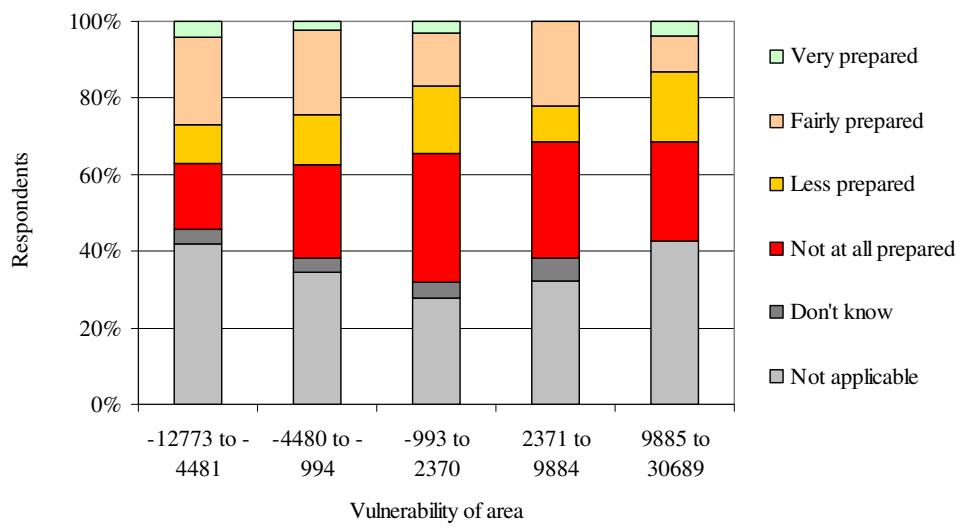

Based on Primary Survey, 2007

Fig: 6.116. Preparedness of Respondents Living in Vulnerable Areas

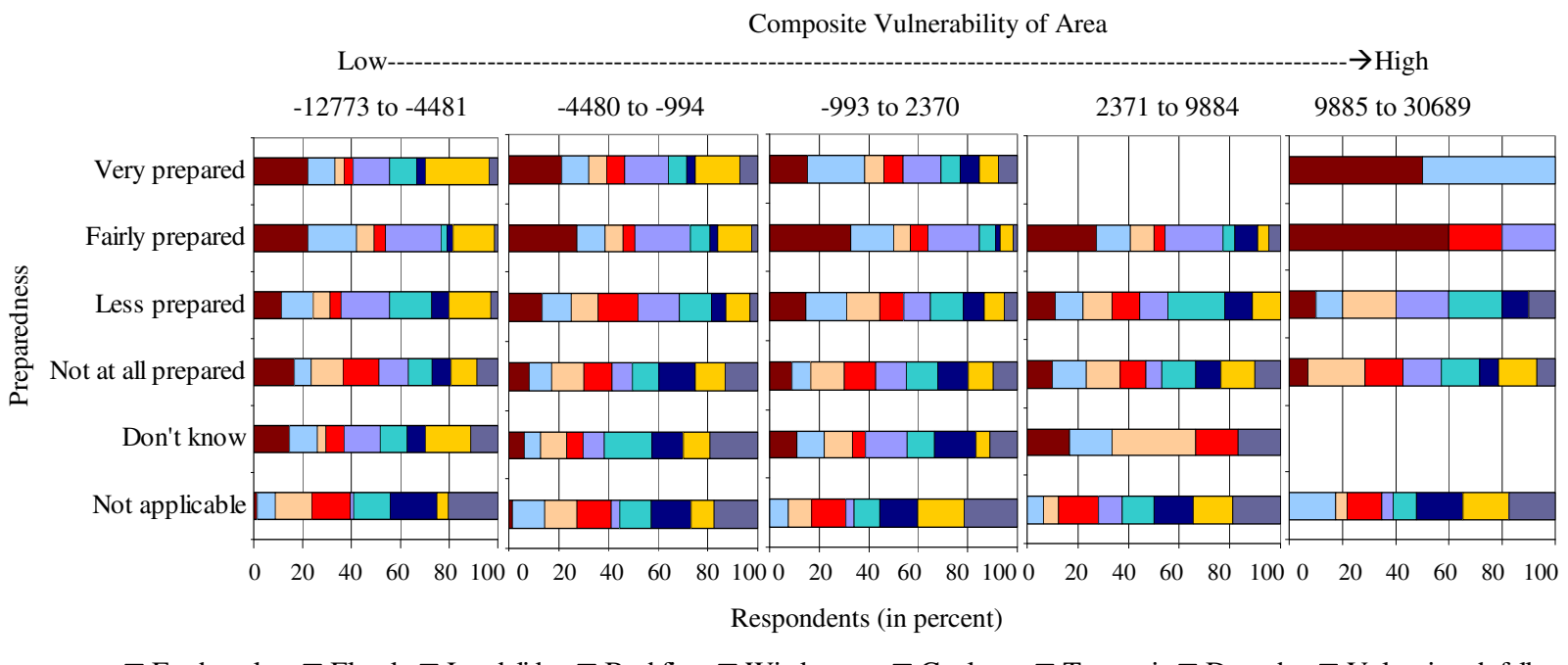

$\square$ Earthquake $\square$ Flood $\square$ Landslide $\square$ Bushfire $\square$ Windstorm $\square$ Cyclone $\square$ Tsunami $\square$ Drought $\square$ Volcanic ash fall Based on Primary Survey, 2007

Therefore, it can be concluded that vulnerability of respondents not only influences their perception but also their response in terms of type of mitigation and safety measures taken by them along with their perceived preparedness level against hazards. Most respondents perceived hazard characteristics or physical susceptibility to be the prime cause of their vulnerability, and did not mention their own vulnerability until they had to score the factors related to individual vulnerability (i.e. age, gender or knowledge of hazards etc.) for their influence on the respondents' capacity and response. Most of the respondents who possessed these characteristics recognised the role of vulnerability factors in influencing their response to hazard. Not recognising the individual vulnerability not only influences the response to hazards, but also intensifies the hazardscape, as despite being vulnerable and having made poor response to hazards most respondents perceived themselves to be prepared for most hazards. 


\subsubsection{Influences of Overall Hazardscape}

Apart from the individual characteristics, the response in the region is also modified by the nature of overall hazardscape. Overall characteristics of hazardscape are more than the sum of its individual characteristics. They are the product of ongoing direct and indirect response to hazards at different levels, Fig: 6.117. Hazard Exposure Perceived by Respondents in LTAs

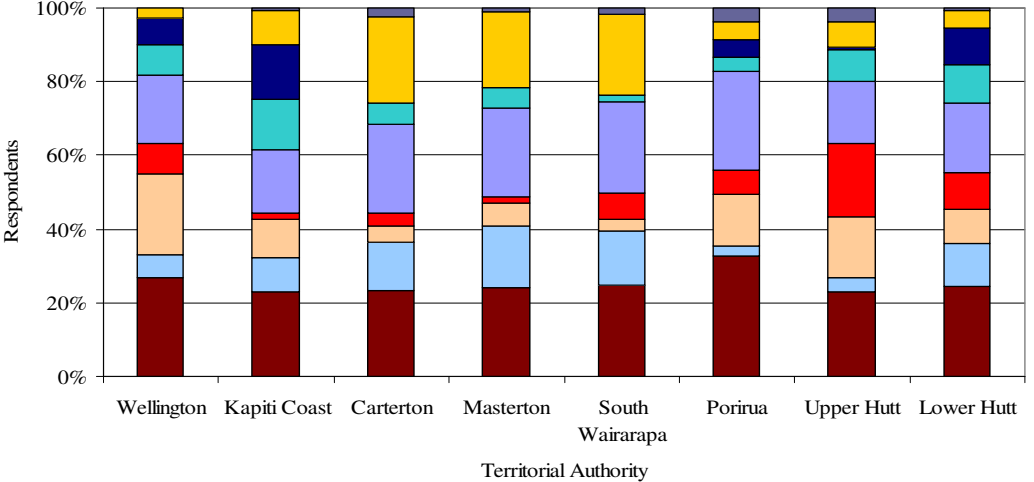

Earthquake $\square$ Flood $\square$ Landslide $\square$ Bushfire $\square$ Windstorm $\square$ Cyclone $\square$ Tsunami $\square$ Drought $\square$ Volcanic ash fall Based on Primary Survey, 2007 which also change its individual characteristics over time i.e. hazards, susceptibility and vulnerability. These characteristics again not only determine the perception of the local people, but also influence their response. The influences of overall hazardscape can be viewed in the hazard characteristics, perception and response at district level.

Fig: 6.118. Problems from Hazard Faced by Respondents in LTAs

City Councils

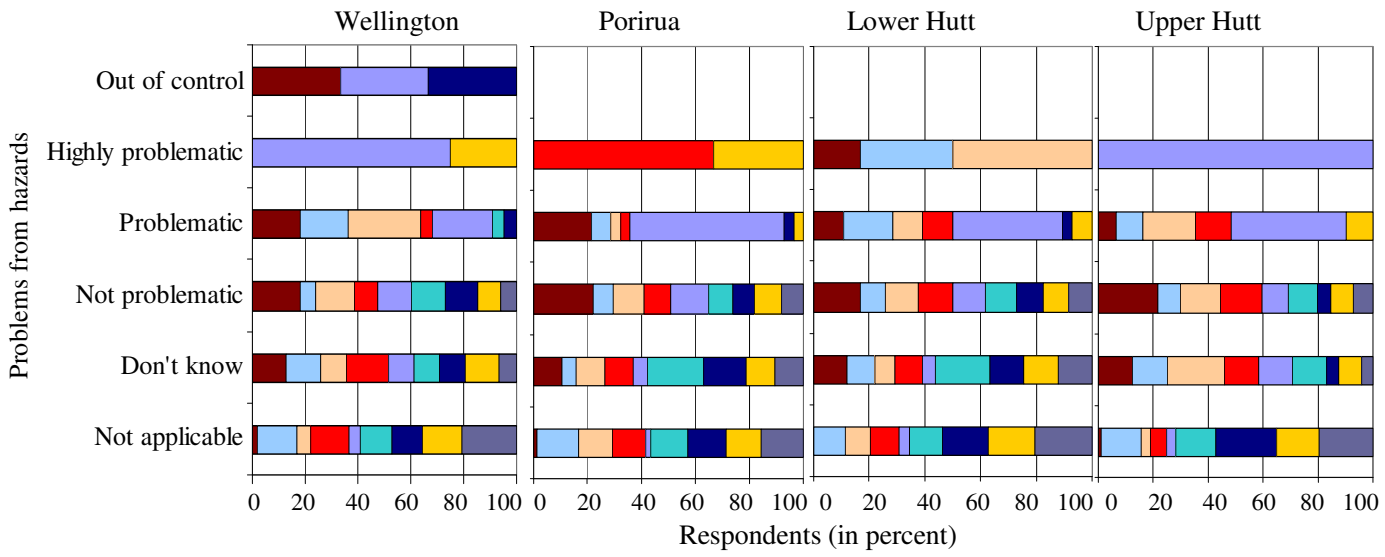

District Councils

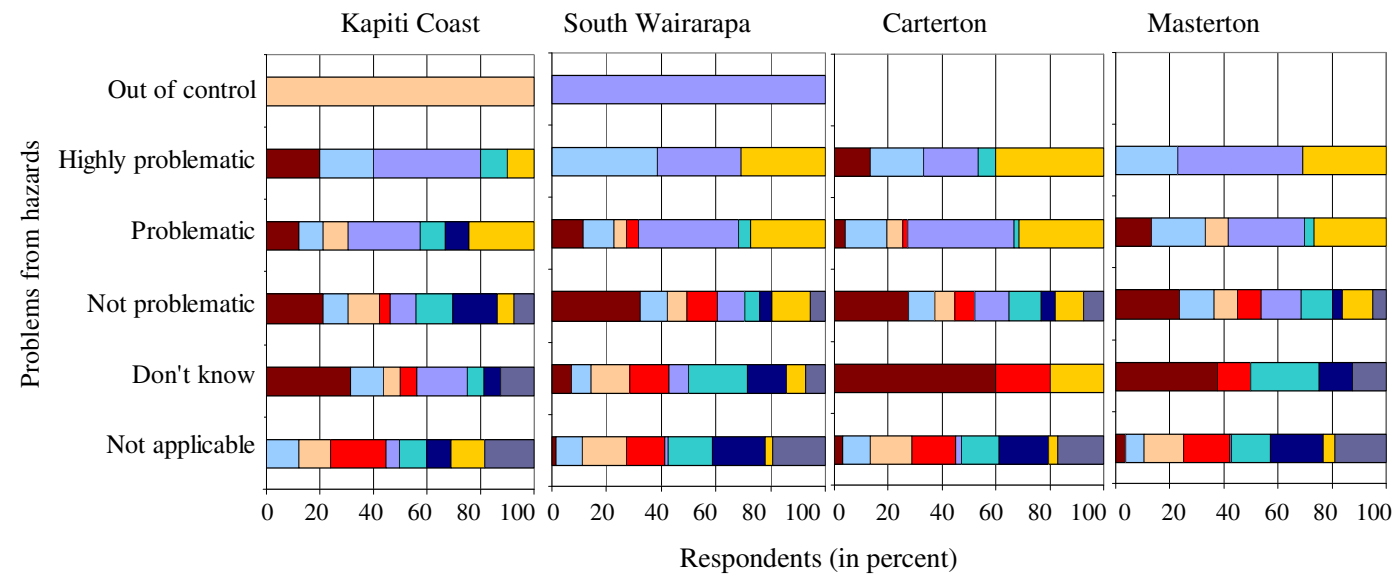

घEarthquake $\square$ Flood $\square$ Landslide $\square$ Bushfire $\square$ Windstorm $\square$ Cyclone $\square$ Tsunami $\square$ Drought $\square$ Volcanic ash fall 
A variation can be observed in the number and type of hazards that respondents perceived themselves to be exposed in different districts (Fig: 6.117). More respondents in the rural districts i.e. South Wairarapa, Carterton and Masterton perceived themselves to be exposed to droughts and flooding attributed to their direct dependence on farming. A high proportion of respondents from urban areas on the other hand, perceived greater threat from earthquakes, landslides, tsunami, bushfires and windstorms that put their life and properties at high risk. The same reason can also be given for not perceiving the tsunami risk in South Wairarapa or perceiving high risk from bushfires in Upper Hutt.

The problems faced through hazards in different districts also show variations that indicate towards the overall characteristics of hazardscape in these districts (Fig: 6.118). While in Wellington City respondents found earthquakes, windstorms and tsunami to be out of control, in the Kapiti Coast landslides/coastal slips and in South Wairarapa windstorms were perceived to be out of control. In other districts none of the mentioned hazards was perceived to be out of control. However, a number of hazards were found to be highly problematic in all districts. The hazards which have been highly problematic in most districts are windstorms (except for Porirua and Lower Hutt) and drought (except for Lower Hutt and Upper Hutt). The intensity of both hazards is reported to be higher in rural areas as compared to cities. Flooding is reported as highly

Fig: 6.119. Frequency of Hazards as Experienced by Respondents in LTAs
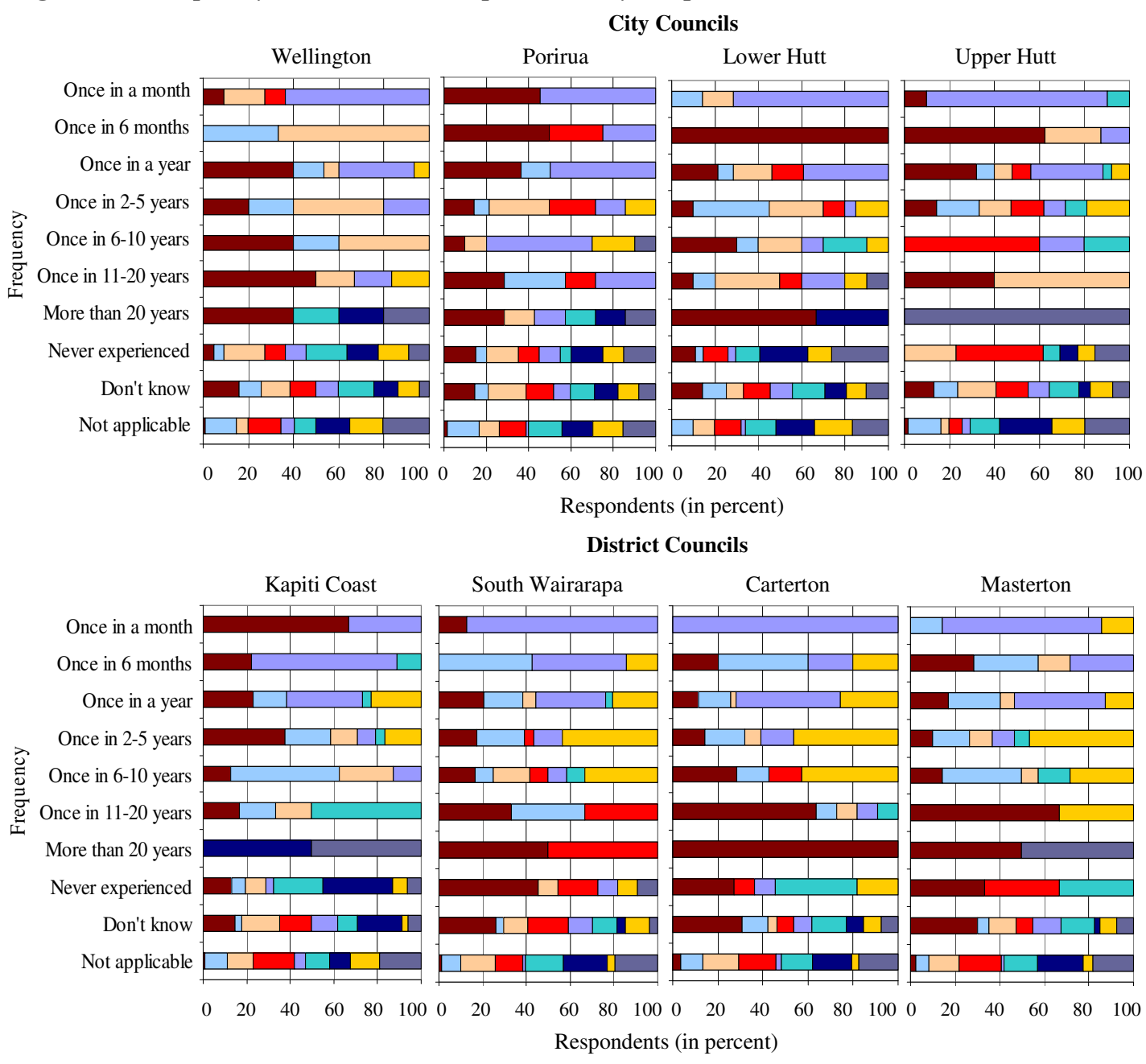

$\square$ Earthquake $\square$ Flood $\square$ Landslide $\square$ Bushfire $\square$ Windstorm $\square$ Cyclone $\square$ Tsunami $\square$ Drought $\square$ Volcanic ash fall Based on Primary Survey, 2007 
problematic in all the four district councils along with Lower Hutt City. Bushfires on the other hand, are perceived to be highly problematic in Porirua.

The most frequent hazard of the region across all the local councils is windstorm (Fig: 6.119). While flooding is more frequent in the three rural districts, fewer respondents found it problematic in these districts. This indicates the frequent occurrence of low magnitude flooding that reminds respondents about the presence of hazard. On the other hand, earthquakes, landslides and bushfires are found more frequent in western districts where both susceptibility and vulnerability to these hazards are high. In contrast to the observed frequency of hazards, respondents perceived more types of hazards to occur in the near future i.e. within a year (Fig: 6.120). There is also a difference in the type of hazards perceived in the near future between city and district councils. The respondents from cities perceived relatively more types of hazards to occur wthin a year as compared to those who lived in rural areas. While bushfire is perceived to occur within a year in all city councils, none of the respondents from the rural district councils perceived this hazard to occur within a year irrespective of their susceptibility. Drought is perceived

Fig: 6.120. Proximity of Hazards in the Future as Perceived by Respondents in LTAs
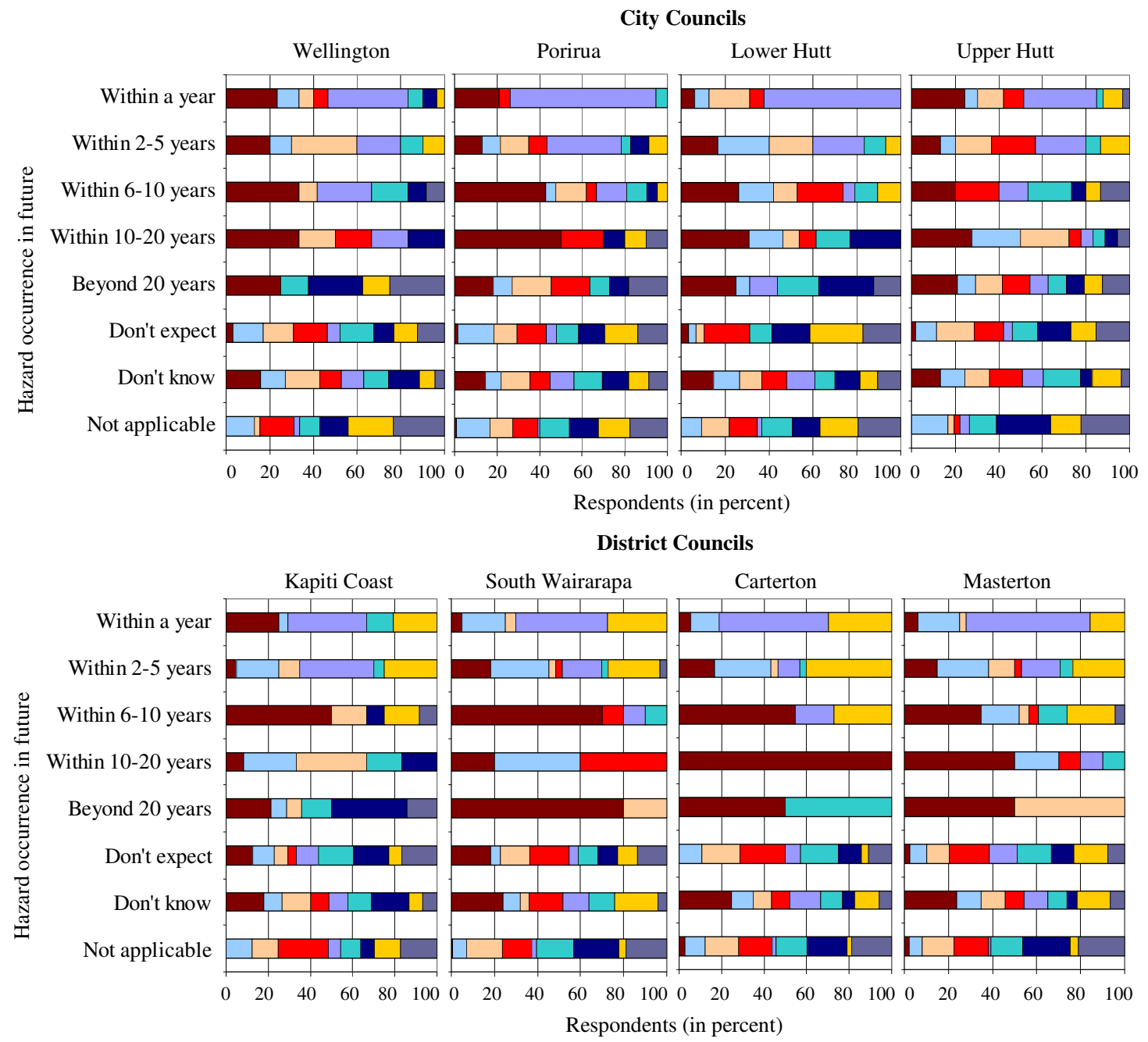

$\square$ Earthquake $\square$ Flood $\square$ Landslide $\square$ Bushfire $\square$ Windstorm $\square$ Cyclone $\square$ Tsunami $\square$ Drought $\square$ Volcanic ash fall Based on Primary Survey, 2007 
to occur within a year in all district councils along with Upper Hutt City Council which is the highest rainfall receiving area in the region.

The potential threat perceived from hazards also varied among city and district councils (Fig: 6.121). While earthquakes are seen as predominantly dangerous in all districts, tsunami are perceived destructive in Wellington, Lower Hutt and the Kapiti Coast, landslides in Wellington, Porirua and Upper Hutt, and bushfires in Upper Hutt and Wellington. Droughts are perceived as destructive only in South Wairarapa. It can be noted here that despite the high frequency and regular problems through windstorm and drought, the potential threat perceived from these hazards is low and perceived by fewer respondents compared to other hazards.

Fig: 6.121. Potential Damage from Hazards as Perceived by Respondents in LTAs
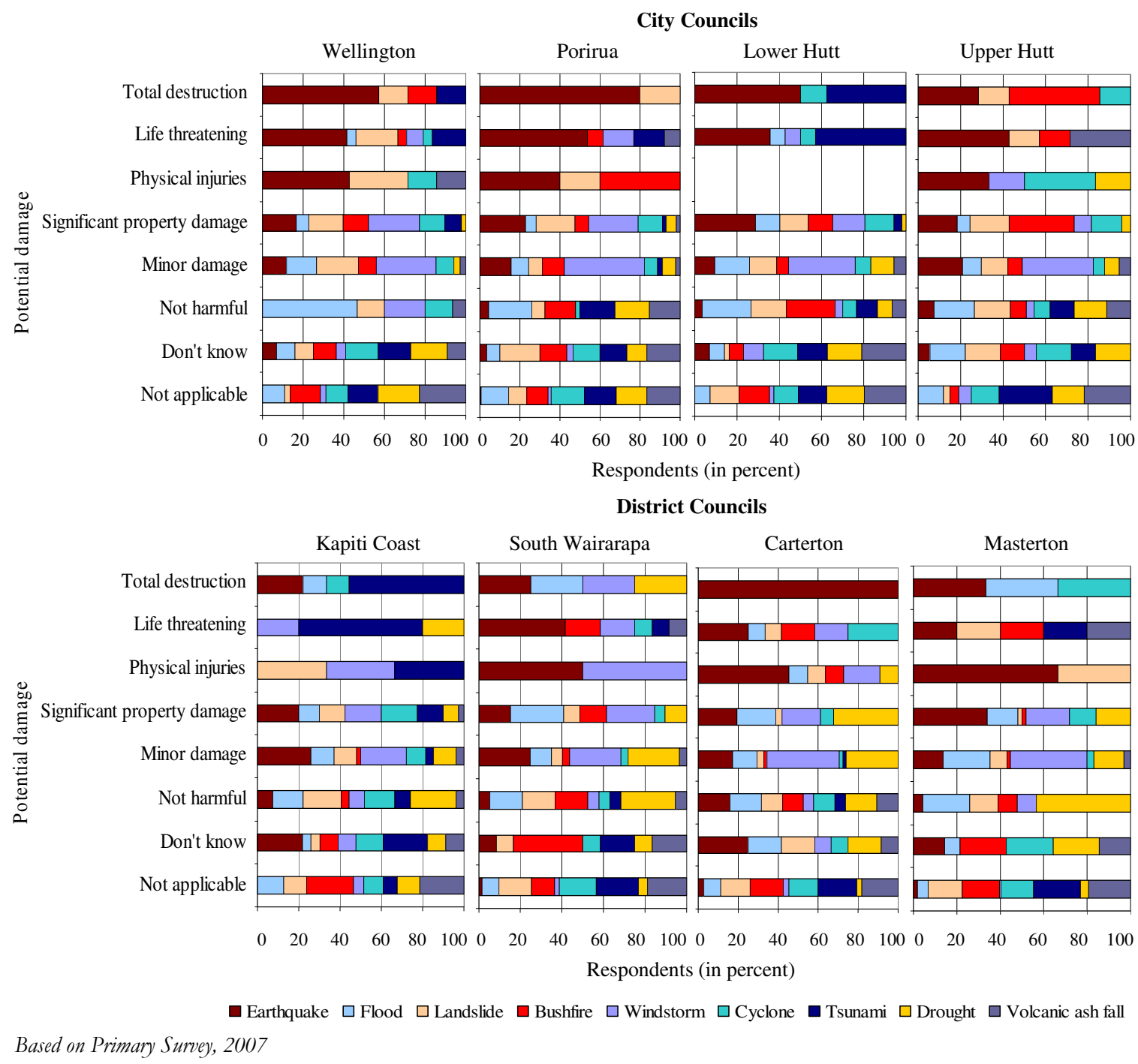

The potential threat perceived from any hazards is also closely linked with the perceived feeling of well-being in the face of future hazard occurrence (Fig: 6.122). Although most respondents were not worried about all hazards, there was a set of respondents who were worried about most hazards. Respondents also perceived themselves to be helpless against a number of hazards as they could not see how to reduce these hazards. However, they felt weak against a smaller number of hazards except for the respondents from Wellington who perceived themselves 
Fig: 6.122. Perceived Feeling of Well-being against Hazards Perceived by Respondents in LTAs City Councils

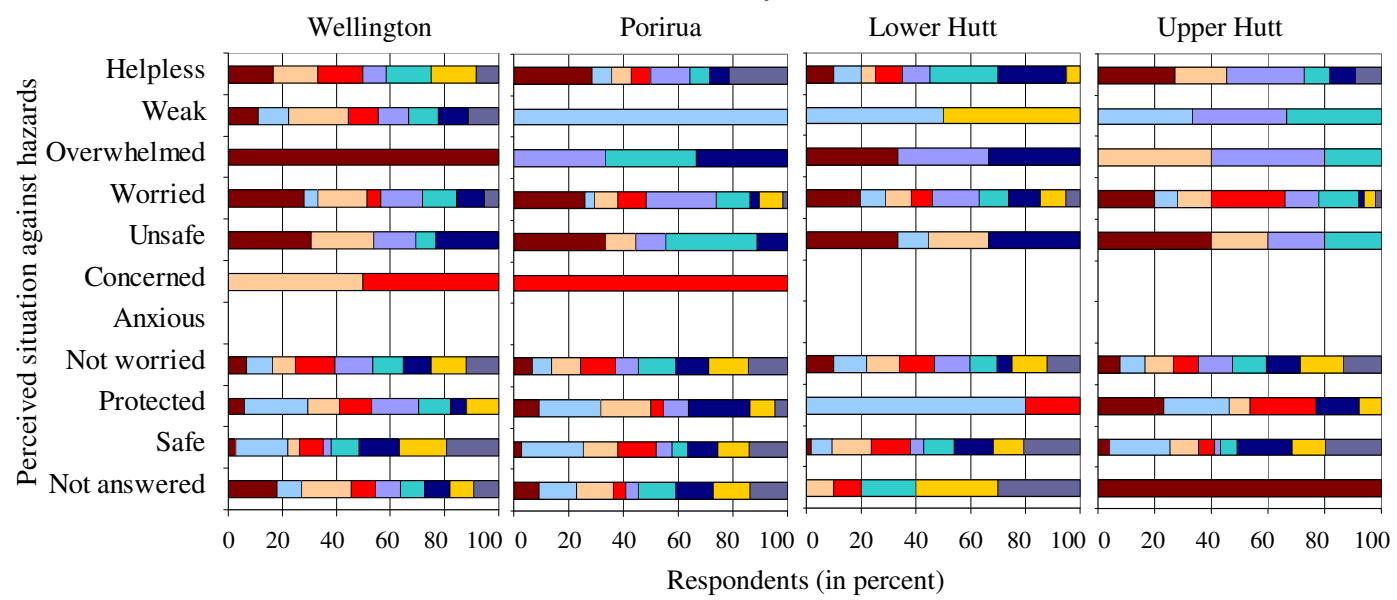

District Councils

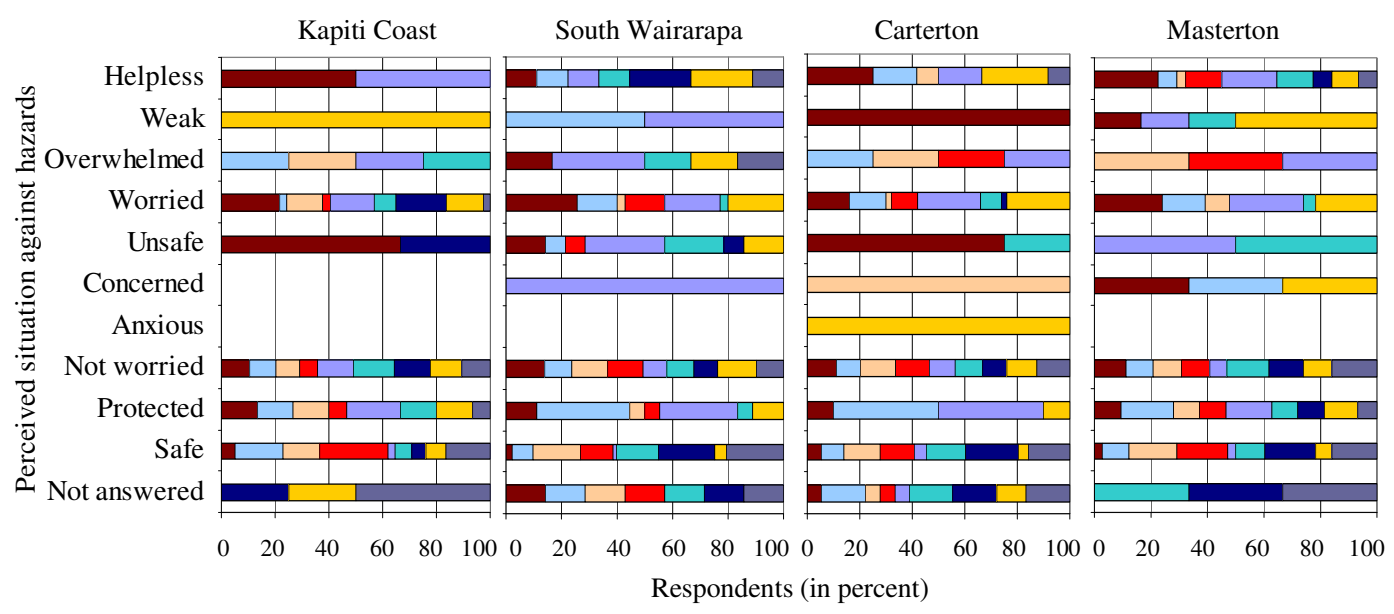

$\square$ Earthquake $\square$ Flood $\square$ Landslide $\square$ Bushfire $\square$ Windstorm $\square$ Cyclone $\square$ Tsunami $\square$ Drought $\square$ Volcanic ash fall

Based on Primary Survey, 2007

to be weak against most hazards. The feeling of weakness is however, less closely linked with the frequency or problems experienced through these hazards. The feeling of weakness in Porirua is noted against flooding, in Lower Hutt against flooding and drought, in Upper Hutt against flooding,

windstorms and cyclones, in the Kapiti Coast against drought, in Carterton against earthquakes, in South Wairarapa against flooding and windstorms, and in Masterton against earthquakes, drought, cyclones and windstorms.

Fig: 6.123. Most Feared Hazards by Respondents in LTAs

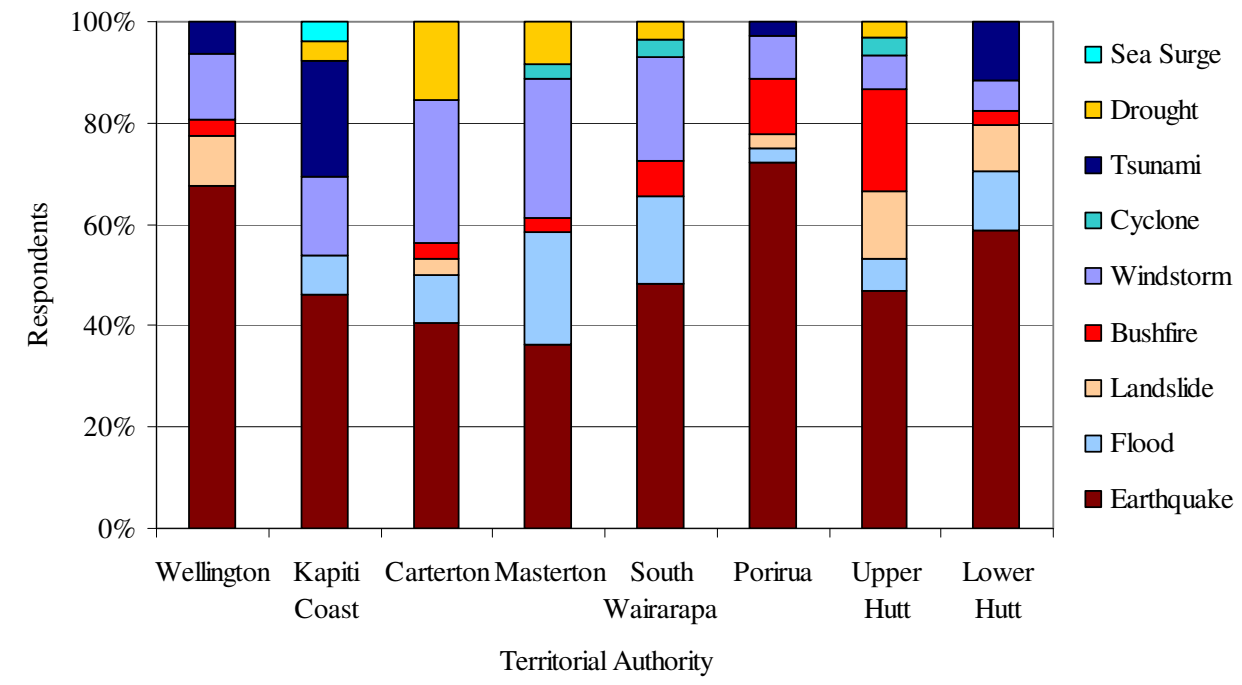


The most feared hazard in all districts was earthquakes irrespective of their varying susceptibility or vulnerability (Fig: 6.123). However, for other hazards a significant variation is seen across different districts. For example, drought is noted as most feared hazard in Carterton, bushfires in Upper Hutt, and tsuanami in the Kapiti Coast. Windstorms are noted as the most feared hazard in the three eastern rural districts compared to western city councils. The perception of fear and perceived feeling of well-being is generally influenced by the hazard information that respondents get from various sources. The data show that radio is the dominant source of hazard information in the region followed by television, newspaper, local council and internet (Table: 6.6).

Table: 6.6. Main Source of General Hazard Information for Respondents

\begin{tabular}{lcccccc}
\hline \multirow{2}{*}{$\begin{array}{c}\text { Local Territorial } \\
\text { Authorities }\end{array}$} & \multicolumn{6}{c}{ Source of hazard information (percent of respondents) } \\
\cline { 2 - 7 } & Radio & TV & Newspaper & Local Council & Internet & Other \\
\hline Carterton & 64 & 54 & 15 & 21 & 10 & 15 \\
Masterton & 61 & 31 & 33 & 17 & 3 & 14 \\
South Wairarapa & 55 & 26 & 19 & 23 & 6 & 13 \\
Lower Hutt & 55 & 36 & 39 & 21 & 6 & 6 \\
Kapiti Coast & 52 & 45 & 35 & 26 & 19 & 13 \\
Porirua & 43 & 57 & 32 & 11 & 11 & 8 \\
Upper Hutt & 39 & 45 & 21 & 18 & 24 & 15 \\
Wellington & 28 & 38 & 31 & 19 & 19 & 16 \\
Total & 50 & 42 & 28 & 19 & 12 & 13 \\
\hline Based on Primary Survey, 2007 & & & & & &
\end{tabular}

Radio is the most widely used for hazard information in the three eastern districts of the Wellington Region which are primarily rural. On the other hand, radio is least used for hazard information by respondents in Wellington City. The popularity of television for hazard information is relatively consistent throughout the region. It is however, used to a minimum in South Wairarapa (26 percent) and maximum in Porirua (57 percent), which could be attributed to a farming lifestyle in the first and family households with a number of children in the latter case. Newspapers are the leading source of hazard information in Lower Hutt (39 percent) and they are least used in Carterton

percent). Local councils are noted as the source of hazard information for nearly 20 percent of the respondents from Carterton, South Wairarapa, Lower Hutt and the

Fig: 6.124. Awareness of Respondents for Hazard Information Provided by Councils in LTAs

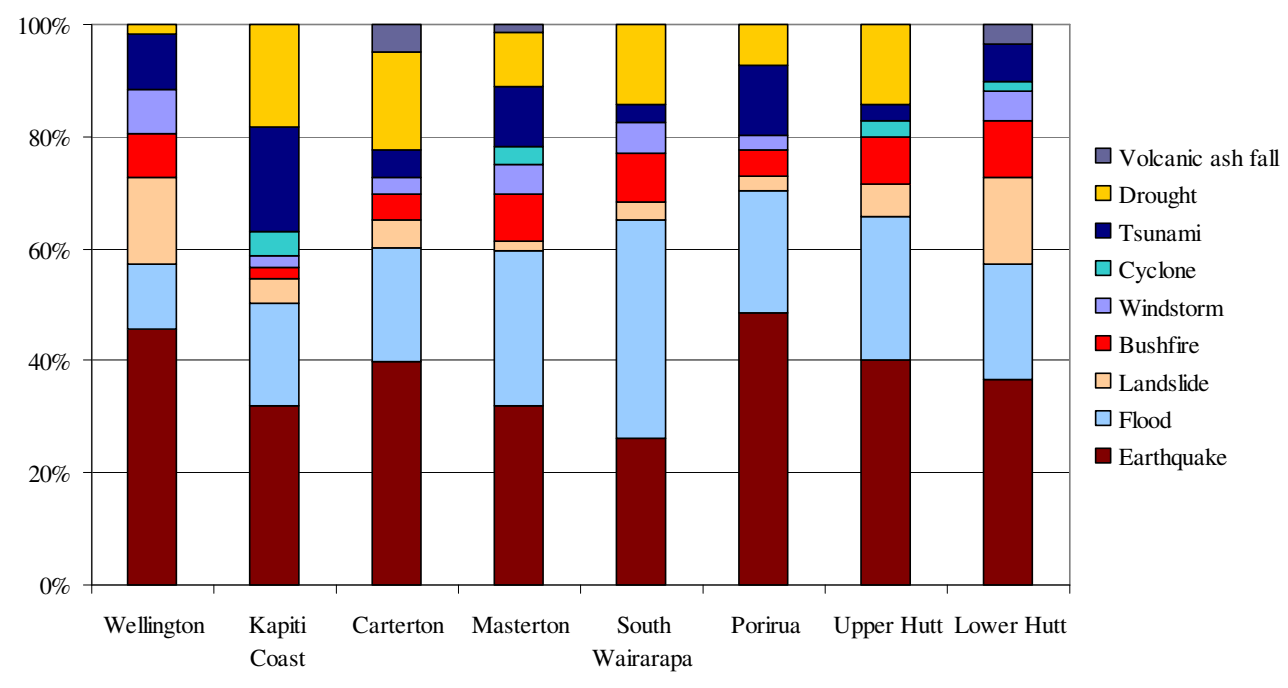

Based on Primary Survey, 2007

Kapiti Coast and for less than 20 percent for the respondents from Wellington, Upper Hutt, Masterton and Porirua. More than 20 percent of respondents in Upper Hutt used the internet as 
their prime source of hazard information, while less than ten percent respondents used internet in Carterton, Masterton, South Wairarapa and Lower Hutt.

About 13 percent of respondents mentioned other sources of hazard information. These included yellow pages or phone book (6 percent), pamphlets in the mails, schools, word of mouth, text for 1.1 percent each, past experience or neighbours for 0.7 percent and university teaching and research, getting around, met services phone, general knowledge or other government agencies for 0.36 percent of respondents.

Awareness of respondents about information provided by the local council not only varied in different districts but also for different hazards (Fig: 6.124). The highest proportion of respondents from most district and city councils mentioned to have received information about earthquakes (54 percent) and flooding (35 percent). Nearly 75 percent of respondents in Wellington City received information about earthquakes followed by 64 percent in Lower Hutt and Masterton each. About 71 percent respondents in South Wairarapa received information about

Fig: 6.125. Hazard Awareness and Mitigation Measures Taken by Respondents When First Moved into the House
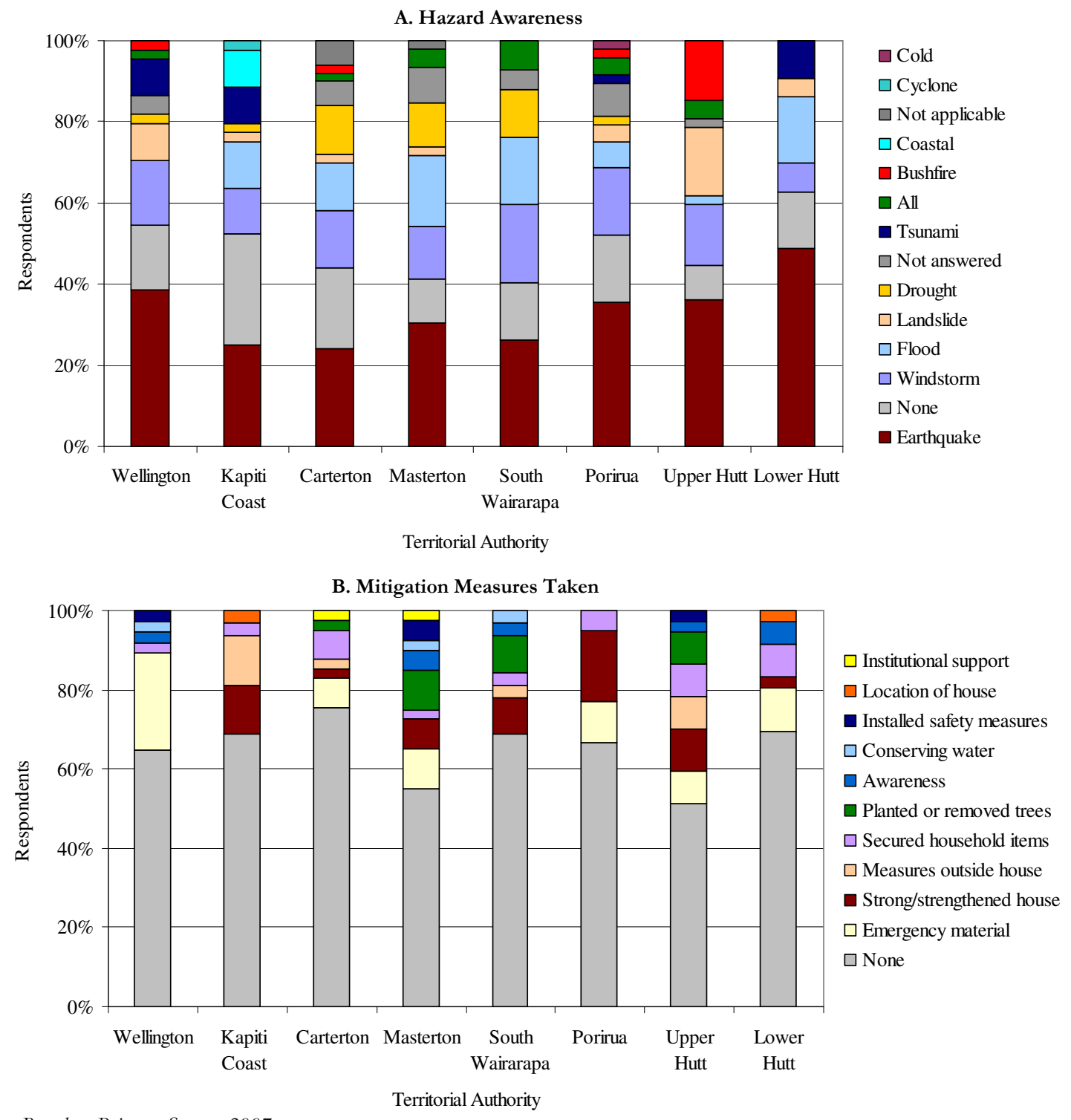
flooding followed by 56 percent in Masterton and 36 percent in Lower Hutt. Information about landslides are received more widely by the respondents living in Lower Hutt and Wellington, about bushfires in Lower Hutt, South Wairarapa, Masterton and Wellington, about windstorms in Masterton, South Wairarapa, Wellington and Lower Hutt, about tsunami in the Kapiti Coast and Masterton, and about droughts in South Wairarapa and the Kapiti Coast. Only two percent of the respondents said that they received hazard information about cyclones and volcanic ash fall. While the cyclone information is received in Lower Hutt, Upper Hutt, Masterton and the Kapiti Coast, information about volcanic ash fall is said to be received in Lower Hutt, Masterton and Carterton. The only district in which information is said to be received by respondents about all hazards is Masterton. In Lower Hutt, Carterton and the Kapiti Coast, information is received for eight out of nine mentioned hazards, and in other districts respondents received information for seven out of nine mentioned hazards.

Although a major proportion of respondents did not take any measure despite their awareness, the measures taken by others differ significantly in different district and city councils

Fig: 6.126. Type and Hazards for Which Safety Measures Taken by Respondents
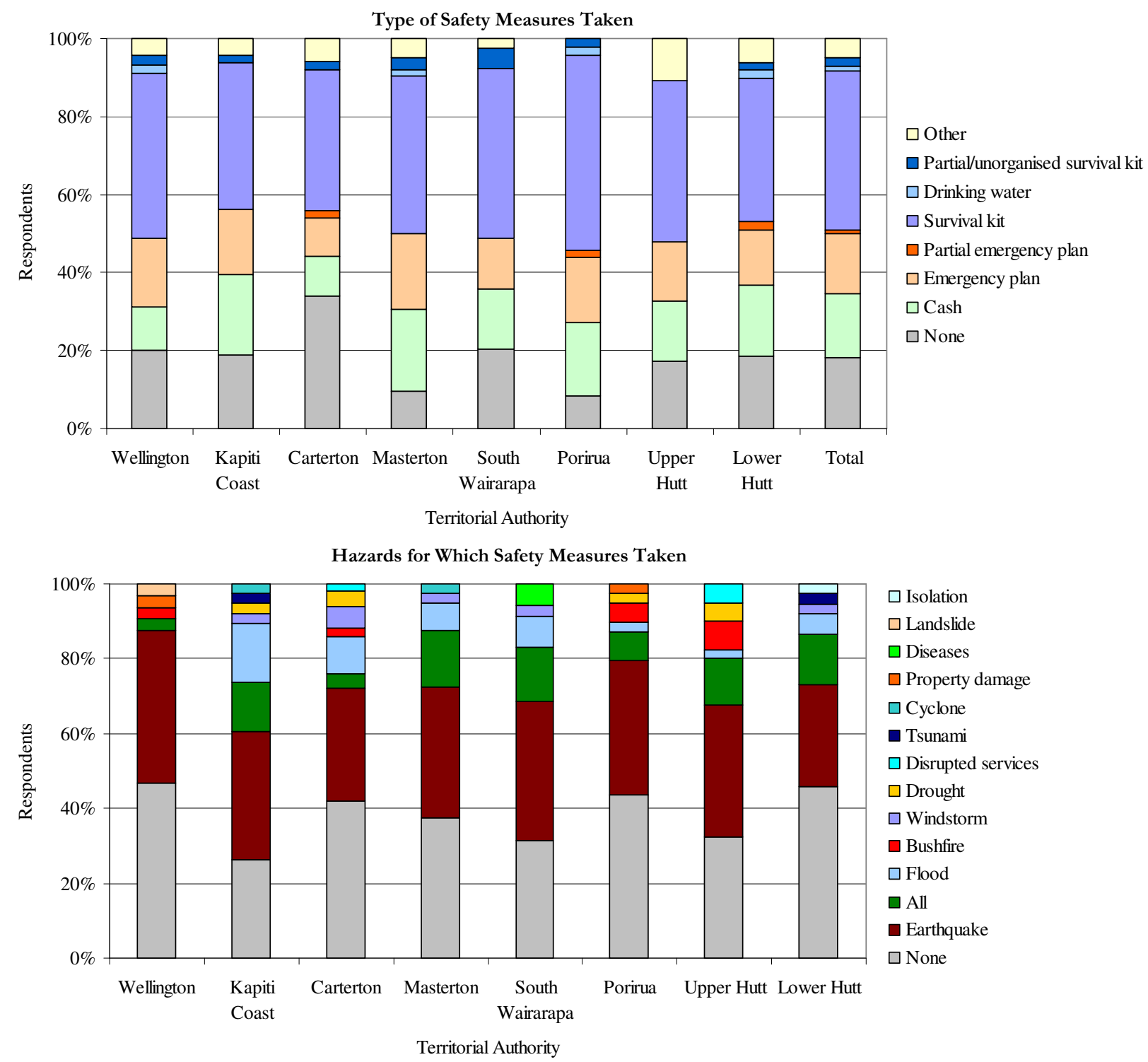
(6.125). None of the respondents from Wellington City mentioned choosing a strong house or strengthening of their house as a mitigation measure adopted by them. The reason could be attributed to the fact that more than 50 percent of the respondents $(17 / 32)$ did not own their house as the population in a city is more likely to move away rather than living there for a long period of time. Also, housing in Wellington is relatively expensive compared to other city and district councils in the Region. Location of house was only taken into consideration by a few respondents living in the Kapiti Coast and Lower Hutt. Absence of locational choices in cities could be attributed to their high susceptibility to one or more hazards compared to the rural areas where the decision of living is governed by the lifestyle and occupation. The highest proportion of respondents from Wellington City had stored emergency materials, which can be attributed to an active campaign for survival kits in the City. Besides, it is the easiest method to be prepared for hazards. Planting or removing trees to avoid hazards was more prominent in the three eastern districts along with Upper Hutt. The reason could be attributed to the fact that most of the householders are residents and they own the property. In cities such as Porirua and Wellington respondents mentioned that the bush around their house is the responsibility of the local council and they could not do much about it to reduce the damage. Institutional support was mainly mentioned by the respondents in the rural areas chiefly for flood alarm and insurance.

There is less variation in the safety measures taken by respondents across the districts (Fig:

Fig: 6.127. Preparedness of Hazards by Respondents in LTAs

\section{City Councils}
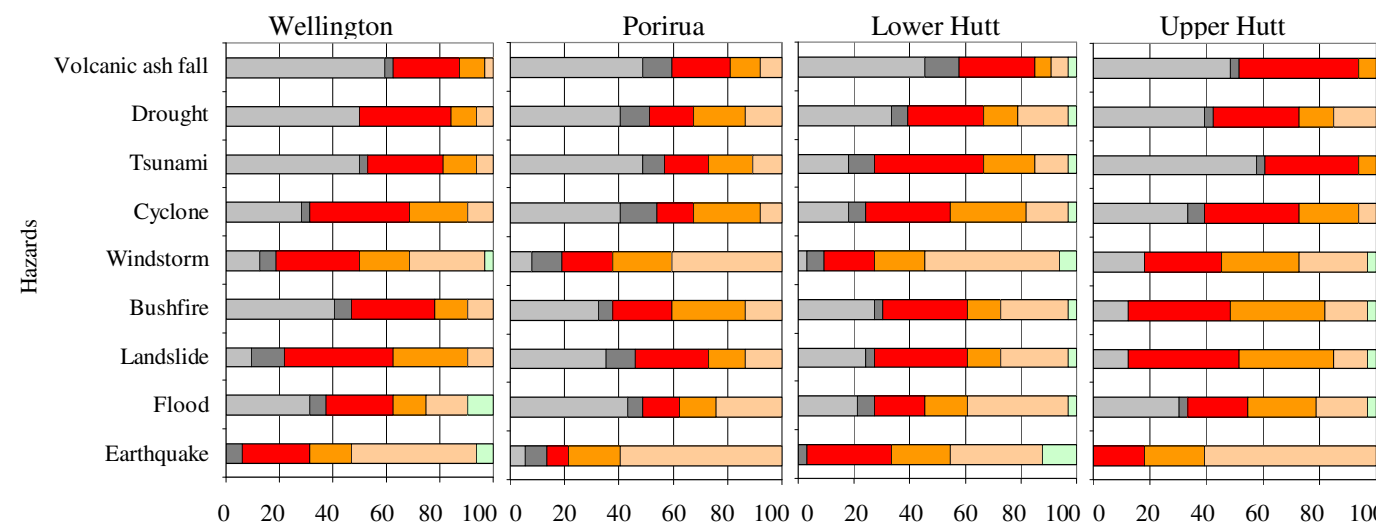

Respondents (in percent)

District Councils

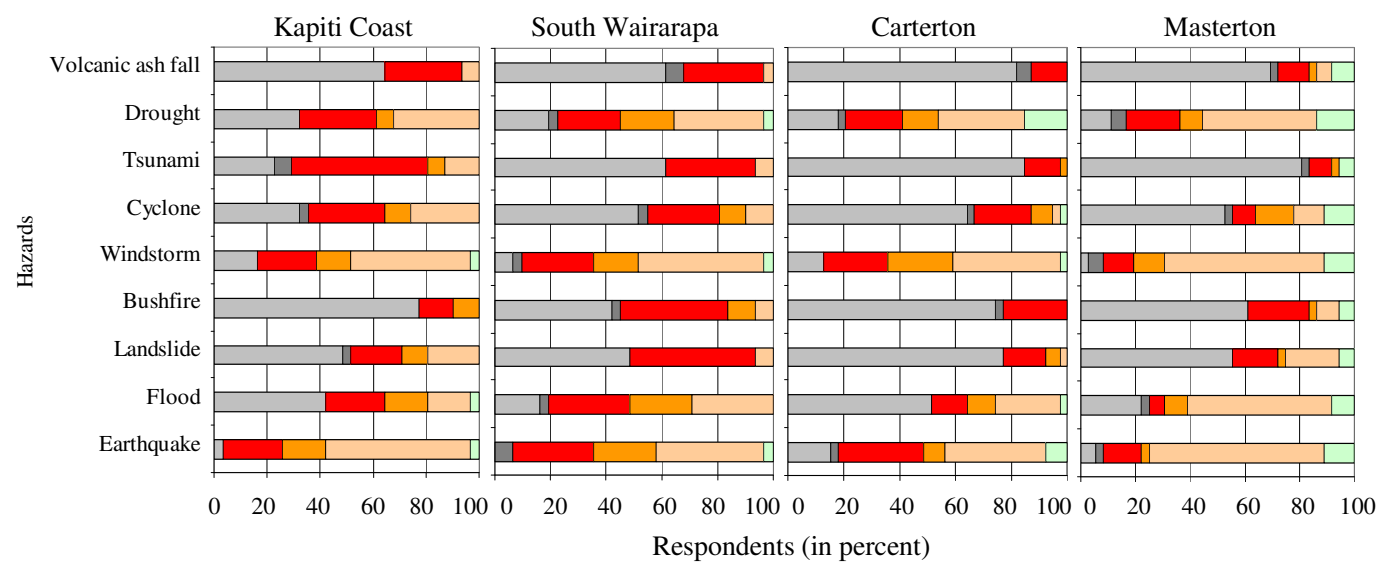

$\square$ Not applicable $\square$ Don't know $\square$ Not at all prepared $\square$ Less prepared $\square$ Fairly prepared $\square$ Very prepared 
6.126.A). However, a greater difference is observed across districts in hazards for which respondents took safety measures (Fig: 6.126.B). While in Wellington City most respondents took measures for earthquake or no hazards, the dominant hazards for which respondents took measures in the Kapiti Coast included earthquakes, floods and none of the mentioned hazards. The safety measures for bushfires were mainly taken in Upper Hutt and Porirua, while for isolation in Lower Hutt, diseases in South Wairarapa, and disrupted services in Upper Hutt and Carterton. The dominance of response for no hazard, earthquake and all hazards throughout the region show that most respondents were not very specific about hazards while taking safety measures. It can be argued that the measures taken by them are influenced by the response culture of the region (i.e. most people have adopted measures for hazards about which they hear and talk in day to day life with each other and see others to have adopted particular measures) rather than a thoughtful process at individual level.

The variations can also be observed in the preparedness level of different hazards (Fig: 6.127). While in Masterton and Lower Hutt many respondents perceived themselves to be very prepared for all hazards, in Porirua none of the respondents perceived themselves to be very prepared for any hazard. The highest proportion of respondents were prepared for earthquakes, windstorms, droughts and volcanic ash fall in Masterton, floods, bushfires, landslides and tsunami in Lower Hutt, and for cyclones in the Kapiti Coast.

The overall hazardscape characteristics that produce variations in the response at local level include awareness, perception, experience, response culture, effectiveness of safety measures and trust in the response agencies. The description of these characteristics of overall hazardscape is derived from the analysis of the response of total respondents throughout the region.

\subsubsection{Awareness}

Awareness of hazards, response measures and agencies could influence the overall response to hazards to a significant extent. The awareness varied in the region for different hazards. While nearly 88 percent of respondents perceived themselves to be exposed to earthquake, less than six percent of respondents perceived their exposure to volcanic ash fall.

Local and international migration is an important cause of lack of awareness in the region. A significant proportion of respondents (i.e. 21 percent) said that they were not aware of any hazard when they first moved into their current house (Fig: 6.128). Another 59 percent of the
Fig: 6.128. Hazard Awareness of Respondents When First Settled at the Current Residence

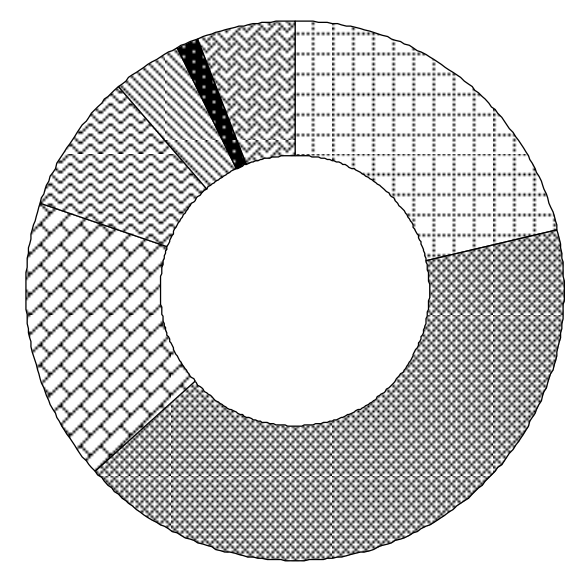

\section{Hazards Known}

None

One

QX7 Two

栄 Three

M. All

Not applicable

Not answered/don't know 
respondents knew about one or two hazards. Only four percent of the total respondents said that they knew about all hazards. The initial awareness also varied for the types of hazards. While nearly 44 percent of the respondents knew about earthquakes, 21 percent knew about windstorms, 14 percent knew about floods and five to seven percent of respondents were aware of tsunami, drought and landslides. Only four percent of the respondents knew about bushfires and less than two percent of them mentioned coastal hazards, cold and cyclone each. None of the respondents mentioned about volcanic ash fall.

Respondents were also asked whether they want any information about hazards from their local council. While 61 percent of respondents said no, another 25 percent did not answer the question. In 14 percent of respondents who chose to answer, nearly 13 percent wanted information on hazards they were exposed to. About three percent wanted to know what to do, how to respond and where to go in case of tsunami or any other hazard occurrence. One percent of respondents also wanted to know about the roles and responsibilities of civil defence organisations, hazard susceptibility of their own location, risk areas of the region, methods to reduce their vulnerability and things required to survive during a hazard.

Awareness of response measures and agencies could also influence the hazard response. Respondents were asked whether they knew the location of their nearest civil defence centre. Only 42 percent of the respondents said that they knew, but many wrongly perceived the location of their nearest civil defence centre as their city or district council office.

\subsubsection{Perception}

The influence of perception of hazard and response measure was also noted on the response in the Wellington Region. The most feared hazards in the region are earthquakes and windstorms (Fig: 6.129). These are also the two hazards for which most respondents took safety measures. Against these two, many of the other significant hazards

Fig: 6.129. Most Feared Hazard by Respondents at Their Residence

underestimated including tsunami or volcanic ash fall. The response is also influenced by the perception of respondents towards their feeling of wellbeing against hazards.

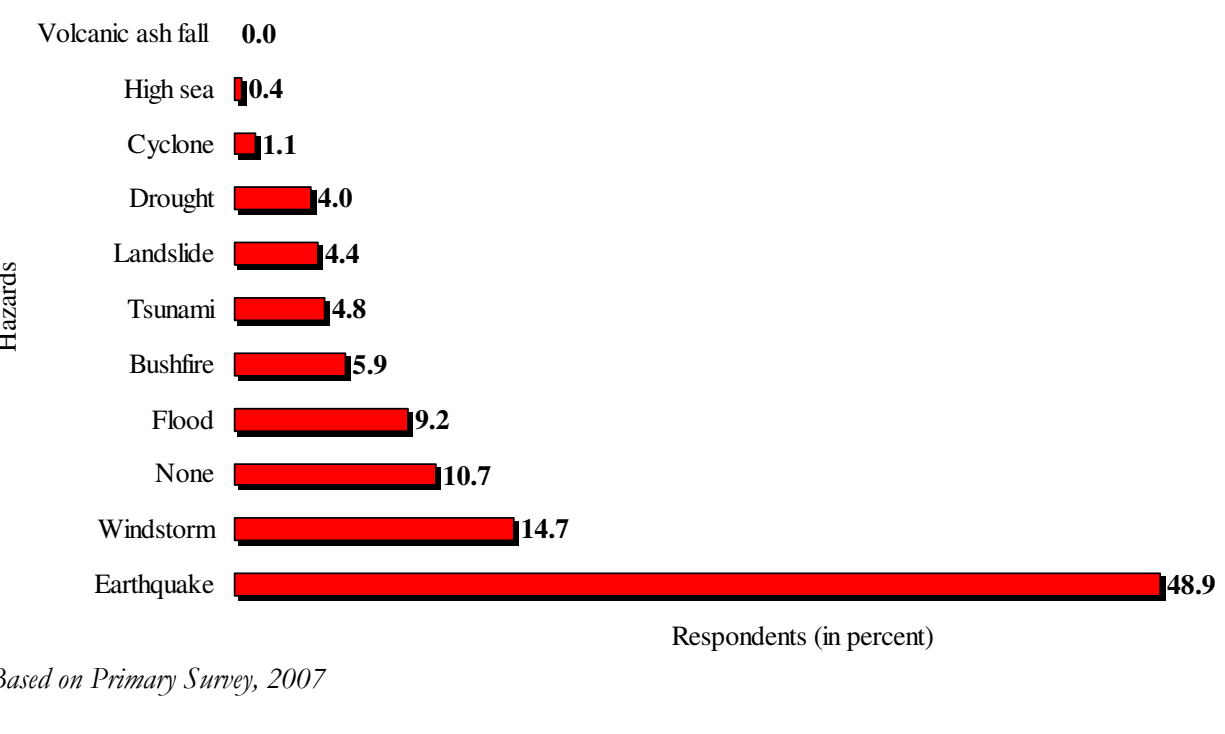

While on average nearly 40 percent of respondents were not worried about any hazard, for those who were worried, their level of concern differed significantly for different hazards (Table: 
6.7). About 32 percent of the respondents were worried about earthquakes compared to 3.3 percent of respondents who were worried about volcanic ash fall. On the other hand, the highest proportion of respondents felt safe from volcanic ash fall followed those who felt safe from tsunami and landslides. Nearly nine percent of the respondents felt helpless against earthquake followed by seven percent against windstorms and five percent against cyclones. Less than two percent of respondents felt weak against any kind of hazard and except for windstorms an equal percentage of respondents felt being overwhelmed by various hazards.

Table: 6.7. Perceived Feeling of Well-being against Hazard by Respondents

\begin{tabular}{|c|c|c|c|c|c|c|c|c|c|c|c|}
\hline \multirow[t]{2}{*}{ Hazards } & \multicolumn{11}{|c|}{ Perceived Feeling of Well-being Against Hazards } \\
\hline & $\begin{array}{c}\text { Not } \\
\text { Answered }\end{array}$ & Safe & Protected & $\begin{array}{c}\text { Not } \\
\text { Worried }\end{array}$ & Anxious & Concerned & Unsafe & Worried & $\begin{array}{c}\text { Over- } \\
\text { whelmed }\end{array}$ & Weak & Helpless \\
\hline Earthquake & 2.6 & 8.1 & 5.5 & 33.8 & 0.0 & 0.4 & 7.0 & 32.0 & 1.1 & 1.1 & 8.5 \\
\hline Windstorm & 1.1 & 7.7 & 8.8 & 38.6 & 0.0 & 0.7 & 3.3 & 28.3 & 3.3 & 1.5 & 6.6 \\
\hline Cyclone & 4.0 & 24.6 & 3.3 & 43.0 & 0.0 & 0.0 & 3.7 & 13.6 & 1.5 & 1.1 & 5.1 \\
\hline Drought & 3.7 & 19.5 & 5.5 & 46.0 & 0.4 & 0.4 & 0.7 & 17.6 & 0.4 & 1.8 & 4.0 \\
\hline Landslides & 2.9 & 31.6 & 5.1 & 38.2 & 0.0 & 0.7 & 2.6 & 13.2 & 1.8 & 0.7 & 2.9 \\
\hline Flood & 2.9 & 31.3 & 13.2 & 33.1 & 0.0 & 0.4 & 0.7 & 12.9 & 0.7 & 1.8 & 2.9 \\
\hline Bushfire & 1.8 & 33.8 & 4.8 & 40.1 & 0.0 & 0.7 & 0.4 & 14.0 & 0.7 & 0.4 & 3.3 \\
\hline Tsunami & 3.7 & 37.1 & 4.4 & 37.5 & 0.0 & 0.0 & 3.3 & 8.8 & 0.7 & 0.4 & 4.0 \\
\hline $\begin{array}{l}\text { Volcanic } \\
\text { ash fall }\end{array}$ & 5.1 & 41.2 & 1.8 & 44.5 & 0.0 & 0.0 & 0.0 & 3.3 & 0.4 & 0.4 & 3.3 \\
\hline
\end{tabular}

The response was also affected by the cause of hazards as perceived by the respondents. More than 40 percent of the respondents perceived most hazards as natural processes except for bushfires which are predominantly perceived to be caused by human negligence (Fig: 6.130). The hazards such as windstorms, cyclones and volcanic ash fall are seen more as nature's fury. Perception of hazards as an act of God fades as one could see more control or a human role behind their occurrence such as in bushfires, landslides, droughts and flooding. The role of the Government and technological failure has also been perceived as the cause for flooding and landslides occurrences. Few respondents could not mention any of these as they saw a combination

Fig: 6.130. Primary Cause of Hazards as Perceived by Respondents

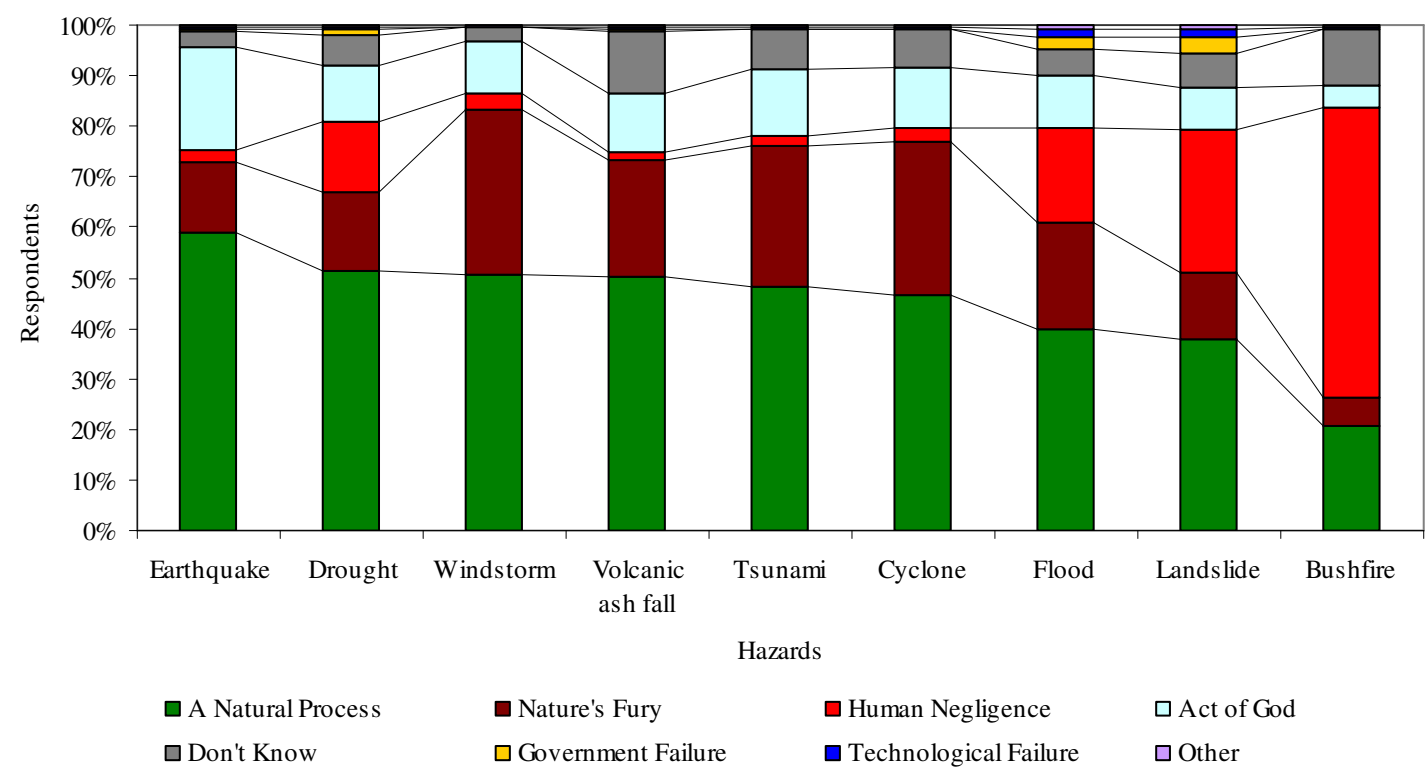

Based on Primary Survey, 2007 
of factors responsible for a hazard occurrence.

The perception of the possibility of hazard mitigation may also play a significant role in hazard response. In order to identify the perception of hazard mitigation in the region, the respondents were asked whether it is possible to reduce damage from the mentioned natural hazards. While more than 50 percent of the respondents could see the possibility of mitigating flooding, landslides, earthquakes and bushfires, 24-45 percent could see such possibility for droughts, windstorms, tsunami and cyclones and only nine percent could see it for volcanic ash fall (Table: 6.8).

Table: 6.8. Perceived Possibility of Reduction of Potential Damage from Different Hazards

\begin{tabular}{lccc}
\hline Hazard & \multicolumn{3}{c}{ Possibility of Hazard Reduction (Respondents in percent) } \\
\cline { 2 - 4 } & Yes & No & Don't know/Not answered \\
\hline Flood & 70 & 16 & 14 \\
Landslide & 64 & 23 & 13 \\
Earthquake & 59 & 32 & 9 \\
Bushfire & 56 & 23 & 21 \\
Drought & 45 & 38 & 17 \\
Windstorm & 36 & 51 & 13 \\
Tsunami & 26 & 49 & 25 \\
Cyclone & 24 & 53 & 24 \\
Volcanic ash fall & 9 & 58 & 32 \\
\hline
\end{tabular}

Based on Primary Survey, 2007

Although a significant proportion of respondents could not give any reason for their particular thinking, the reason given by others varied to a greater extent (Table: 6.9). The most widely accepted hazard mitigation measures among respondents were engineering works i.e. either by strengthening the house or building, reinforcement, shock foundation, retention walls, dams, stream diversion, sand bags, drainage maintenance, irrigation, protective measures, improved water system or sea protection etc. These measures were mainly suggested for floods, earthquakes, windstorms and landslides. The second commonly perceived mitigation method for hazards was changing individual behaviours especially for droughts, flooding, bushfires, earthquakes and windstorms. These included being proactive, not cutting trees, planting trees, reducing arson, securing household items, glazing windows, conserving water, not wasting water, rainwater harvesting and using grey water etc. Land use planning or controlling land use and using fire breaks were suggested for floods, landslides and bushfires respectively. Monitoring, forecasting and warnings were also suggested as the options for mitigating all hazards but mainly for tsunami and cyclones. Considering locations or relocation were seen as mitigative actions for flooding and landslides. Laws, regulations, policies and guidelines along with awareness, knowledge and educating people were seen significant for earthquakes and bushfires. Preparedness was mentioned for earthquakes, drought and floods. Few individual suggestions included effective hazard management services such as fire fighting and civil defence services, not enhancing hazard exposure i.e. by avoiding overpopulation, not cutting into hill sides, less gravel removing, controlling deforestation and by reducing human interference in nature. A few respondents also suggested effective emergency response to reduce hazard impacts such as evacuation, quick communication and early response mainly for tsunami, droughts, bushfires, earthquakes and 
Table: 6.9. The Reason behind Particular Thinking on the Possibility of Hazard Reduction
Reason
Respondents (in percent)

$\overline{\text { Earthquake Flood Landslide Bushfire Windstorm Cyclone Tsunami Drought Volcanic }}$ ash fall

\begin{tabular}{|c|c|c|c|c|c|c|c|c|c|}
\hline Reason Not Given & 27.9 & 30.5 & 32.4 & 42.6 & 45.6 & 57.4 & 55.1 & 46.0 & 68.8 \\
\hline $\begin{array}{l}\text { Don't Know or } \\
\text { Nothing that I Know }\end{array}$ & 0.0 & 0.0 & 0.0 & 0.0 & 0.4 & 0.4 & 0.7 & 0.4 & 0.7 \\
\hline \multicolumn{10}{|c|}{ Yes } \\
\hline $\begin{array}{l}\text { Mitigation through } \\
\text { Engineering Works }\end{array}$ & 25.0 & 39.7 & 13.2 & 1.8 & 13.2 & 8.1 & 1.8 & 4.0 & 2.6 \\
\hline $\begin{array}{l}\text { By Changing Human } \\
\text { Behaviour }\end{array}$ & 16.9 & 4.0 & 20.6 & 18.8 & 11.0 & 4.4 & 1.5 & 21.7 & 0.4 \\
\hline By Land Use Planning & 2.2 & 8.1 & 10.3 & 10.3 & 4.0 & 1.1 & 1.5 & 2.6 & 0.4 \\
\hline $\begin{array}{l}\text { Monitoring, Forecasting } \\
\text { and Warning }\end{array}$ & 2.2 & 3.3 & 2.2 & 2.9 & 2.9 & 6.6 & 11.8 & 2.2 & 2.9 \\
\hline Location or Relocation & 1.8 & 10.3 & 8.5 & 1.8 & 0.4 & 0.4 & 6.6 & 0.0 & 1.1 \\
\hline $\begin{array}{l}\text { Laws, Regulations, } \\
\text { Policies and Guidelines }\end{array}$ & 6.6 & 0.7 & 0.7 & 4.8 & 2.6 & 2.2 & 0.7 & 1.5 & 1.5 \\
\hline Preparedness & 9.2 & 2.2 & 0.4 & 0.7 & 1.5 & 1.1 & 0.7 & 4.4 & 0.7 \\
\hline $\begin{array}{l}\text { Awareness, Knowledge } \\
\text { and Education }\end{array}$ & 4.0 & 1.5 & 1.1 & 6.3 & 1.8 & 1.1 & 1.1 & 2.2 & 0.7 \\
\hline $\begin{array}{l}\text { Effective Hazard } \\
\text { Management Services }\end{array}$ & 0.7 & 0.4 & 0.4 & 4.0 & 0.0 & 0.4 & 0.4 & 0.7 & 0.0 \\
\hline $\begin{array}{l}\text { By Not Enhancing } \\
\text { Hazard Exposure }\end{array}$ & 0.4 & 0.4 & 4.0 & 0.0 & 0.0 & 0.0 & 0.0 & 0.7 & 0.0 \\
\hline By Effective Response & 0.7 & 0.7 & 0.0 & 0.7 & 0.0 & 0.4 & 1.5 & 0.7 & 0.4 \\
\hline $\begin{array}{l}\text { Research and } \\
\text { Investigations } \\
\end{array}$ & 0.0 & 0.0 & 2.9 & 0.4 & 0.0 & 0.0 & 0.4 & 0.0 & 0.0 \\
\hline $\begin{array}{l}\text { By Changing } \\
\text { Perception }\end{array}$ & 0.4 & 0.4 & 0.4 & 0.4 & 0.4 & 0.4 & 0.4 & 0.4 & 0.4 \\
\hline Insurance & 0.0 & 0.0 & 0.0 & 0.7 & 0.0 & 0.0 & 0.0 & 0.4 & 0.0 \\
\hline There is Always a Way & 0.0 & 0.4 & 0.0 & 0.0 & 0.0 & 0.0 & 0.0 & 0.0 & 0.0 \\
\hline $\begin{array}{l}\text { By Reducing Human } \\
\text { Vulnerability }\end{array}$ & 0.0 & 0.0 & 0.0 & 0.0 & 0.0 & 0.0 & 0.0 & 0.0 & 0.0 \\
\hline
\end{tabular}

Yes But....

\begin{tabular}{lccccccccc}
\hline $\begin{array}{l}\text { Depends on Hazard } \\
\text { Characteristics }\end{array}$ & 1.8 & 0.7 & 0.4 & 0.0 & 1.1 & 1.1 & 0.7 & 0.4 & 0.0 \\
\hline $\begin{array}{l}\text { Phenomenal Cost and } \\
\text { Low Benefit }\end{array}$ & 0.0 & 0.0 & 0.7 & 0.0 & 0.0 & 0.0 & 0.0 & 0.0 & 0.0 \\
\hline
\end{tabular}

\begin{tabular}{|c|c|c|c|c|c|c|c|c|c|}
\hline \multicolumn{10}{|c|}{ No } \\
\hline Fatalism & 5.9 & 2.6 & 4.0 & 2.9 & 11.0 & 10.7 & 9.2 & 5.9 & 8.5 \\
\hline Natural Cause & 3.3 & 2.2 & 2.9 & 2.6 & 4.0 & 4.4 & 4.4 & 3.7 & 4.8 \\
\hline $\begin{array}{l}\text { Uncertainty in Space } \\
\text { and Time }\end{array}$ & 2.2 & 1.5 & 1.8 & 0.7 & 1.8 & 1.8 & 1.8 & 1.1 & 0.7 \\
\hline Small Threat & 0.4 & 0.0 & 0.0 & 0.7 & 0.4 & 1.1 & 2.2 & 1.8 & 3.7 \\
\hline Act of God or Luck & 1.5 & 0.0 & 0.0 & 0.0 & 1.5 & 1.5 & 1.5 & 1.5 & 1.1 \\
\hline $\begin{array}{l}\text { Global Warming or } \\
\text { Climate Change }\end{array}$ & 0.4 & 1.1 & 0.4 & 0.4 & 0.7 & 0.4 & 0.7 & 1.1 & 0.4 \\
\hline High Susceptibility & 0.7 & 0.0 & 0.0 & 0.0 & 0.4 & 0.4 & 0.0 & 0.0 & 0.4 \\
\hline $\begin{array}{l}\text { Lack of Knowledge and } \\
\text { Awareness }\end{array}$ & 0.0 & 0.0 & 0.4 & 0.4 & 0.0 & 0.4 & 0.0 & 0.0 & 0.4 \\
\hline $\begin{array}{l}\text { Don't Think or Worry } \\
\text { About it }\end{array}$ & 0.4 & 0.0 & 0.0 & 0.0 & 0.0 & 0.0 & 0.0 & 0.4 & 0.4 \\
\hline $\begin{array}{l}\text { It is Difficult or Not } \\
\text { Easy to Protect }\end{array}$ & 0.0 & 0.0 & 0.0 & 0.0 & 1.1 & 0.0 & 0.0 & 0.0 & 0.0 \\
\hline Not from Arsonist & 0.0 & 0.0 & 0.0 & 0.7 & 0.0 & 0.0 & 0.0 & 0.0 & 0.0 \\
\hline
\end{tabular}

Based on Primary Survey, 2007

flooding. Research and investigations were mainly suggested for landslides, while insurance for bushfires and droughts. While a respondent suggested that by changing the perception one could 
better control hazards, another was thoughtfully optimistic that there is always a way to find solutions to such problems. However, no one suggested that hazards could be reduced by reducing human vulnerability.

A few other respondents were hopeful, but their hope was conditional. They said that hazards could be reduced but it always depends on the nature of hazards or their characteristics, such as strength or severity. A respondent also saw that there is a possibility of landslide reduction but there is phenomenal cost involved compared to the benefit. This is an important barrier of hazard reduction in the region that leads to enhanced vulnerability.

The reasons behind not being able to see the possibility of hazard mitigation include fatalism especially for windstorms, cyclones and tsunami, and nature as the cause mainly for volcanic ash fall, tsunami and cyclone. Uncertainty of hazards in space and time was also seen as a barrier for most hazards but mainly for earthquakes, landslides, windstorms, cyclones and tsunami. A few respondents perceived only a small threat from hazards such as volcanic ash fall, tsunami, droughts, cyclones, windstorms, bushfires and earthquakes, and therefore they did not explore the mitigation possibilities for these hazards. Many other respondents perceived hazards as an act of God which also inhibited them to explore the possibilities of hazard mitigation. Change in the environment through climate change or global warming was also perceived as a barrier for hazard mitigation along with the lack of knowledge and awareness especially for landslides, bushfires, cyclones and windstorms. A few respondents did not see the possibility of mitigating hazards because they did not think about hazards or the presence of hazards did not worry them. For bushfires, a respondent could not see any possibility of mitigating them as he believed that bushfires are essentially caused by arsonists.

\subsubsection{Past Experiences}

The region has not experienced any disaster in the recent years. As a result individual experiences of minor hazard events influence the perception and response to hazards in the region. Respondents were asked whether they had experienced any significant damage due to any natural hazards. About 23 percent of respondents (64) said that they have experienced damage from one or more natural hazards. Most of the respondents recalled recent incidents, which affected them in one or more ways, and very few respondents could recall the hazards in the distant past (Table: 6.10). The oldest hazard remembered by a respondent is that of the 1942 earthquake, which caused panic in the Wellington City, and personally the respondent experienced cracks in the roof and damages from a shifted chimney. The respondent felt nervous for a couple of days and could not

Table: 6.10. The Year of Hazard Experienced by Respondents

\begin{tabular}{lcc}
\hline Year of Hazard Occurrence & Number of Respondents & Percent of Respondents \\
\hline Before 1970 & 2 & 3 \\
$1971-1980$ & 2 & 3 \\
$1981-1990$ & 1 & 2 \\
$1991-2000$ & 4 & 6 \\
2001 \& after & 45 & 68 \\
Can't remember & 1 & 2 \\
Not answered & 11 & 17 \\
Total & 66 & 100 \\
Based on Primary Survey, 2007 & &
\end{tabular}


sleep properly. Another family member of the respondent was stressed for nearly eight hours after the incident. Another early event, i.e. before 1970, recalled by a respondent was that of the Wahine storm. Because of strong winds the whole area (Carterton) was cut off and the respondent was separated from family as she was on a visit to her friend. She described the dismal picture of the conditions following the event. On her way back home she saw uprooted power poles and trees lying on roads. There was no power or telephone for nearly three weeks. They had to cook food on an open fire. Her neighbours also suffered the same conditions. They had to adjust to the adverse conditions, but they helped and supported each other. The respondent also lost her barn in the storm which uplifted its roof and destroyed its structure. The intensity of the event made the respondent to believe that one cannot be prepared for such events because nothing much could be done about them. In other words, she felt a sense of fatalism resulting from her experience of a high magnitude event.

The analysis of hazards mentioned by the respondents with respect to the damage they caused show that old hazards mentioned by respondents were mainly high magnitude events that affected the respondent to a significant extent besides having implications for the wider community. The experience of recent hazards ranged from mere realisation of the presence of hazards in the environment to substantial property damage.

Fig: 6.131. Damage Experienced from Hazards by Respondents

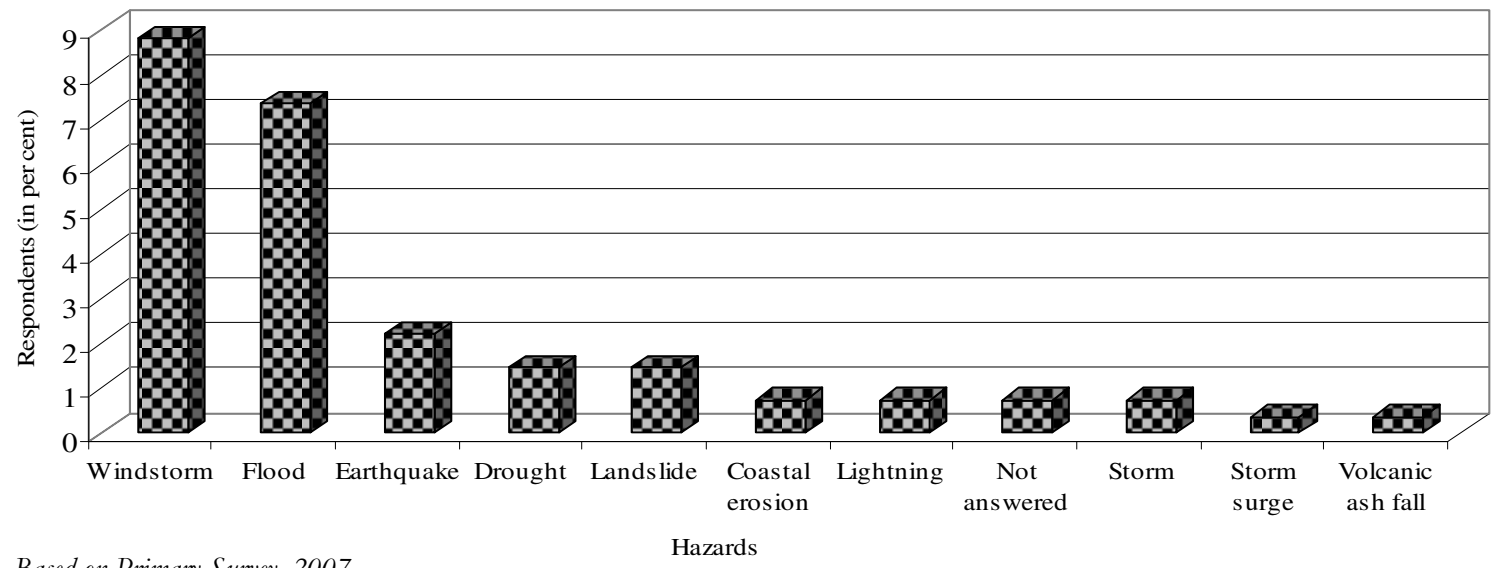

Based on Primary Survey, 2007

The damage experienced from different types of hazards shows that highest number of respondents (24) faced one or other kind of damage from wind followed by 20 respondents who faced damage from flood (Fig: 6.131). Six respondents had experienced damage from earthquake and four each from droughts and landslides. Coastal hazards, lightning and storms each affected two respondents in separate cases. Storm surge and volcanic ash fall were also mentioned by two respondents. Two other respondents did not name any hazard but stated that their past experience had influenced their preparedness to hazard over time.

Respondents also mentioned a range of damage through hazards (Table: 6.11). While frequent winds in the region caused minor to significant damage to households, substantial damage was reported from landslides, floods and windstorms. Damage to household assets was mainly caused by windstorms, flooding and earthquakes. In terms of property damage outside the house 
or loss of fences are frequently caused by windstorms and flood. Respondents also lost land outside their house due to landslides. Damage reported by farmers was mainly 'significant to substantial' in nature and included loss of bridges, stop banks, stock and crops. Such damage was caused by floods and droughts.

Table: 6.11. Type and Extent of Damage Experienced by Respondents

\begin{tabular}{|c|c|c|c|c|c|c|}
\hline \multirow[t]{2}{*}{ Type of Damage } & \multirow{2}{*}{$\begin{array}{l}\text { Number of } \\
\text { Respondents }\end{array}$} & \multirow{2}{*}{$\begin{array}{c}\text { Percent of } \\
\text { Respondents }\end{array}$} & \multicolumn{4}{|c|}{ Extent of damage (percent respondents) } \\
\hline & & & $\overline{\text { None }}$ & $\begin{array}{c}\text { Minor/ } \\
\text { Insignificant }\end{array}$ & Significant & Substantial \\
\hline House damage & 15 & 5.5 & 0 & 20 & 53 & 27 \\
\hline $\begin{array}{l}\text { Property damage but type } \\
\text { not specified }\end{array}$ & 10 & 3.6 & 0 & 0 & 100 & 0 \\
\hline Damage to assets & 9 & 3.3 & 0 & 56 & 33 & 11 \\
\hline Damage on farm & 9 & 3.3 & 11 & 0 & 67 & 22 \\
\hline Damage outside house & 7 & 2.6 & 0 & 0 & 100 & 0 \\
\hline No damage & 7 & 2.6 & 0 & 0 & 0 & 0 \\
\hline Loss of trees/shrubs & 5 & 1.8 & 0 & 100 & 0 & 0 \\
\hline Not answered & 5 & 1.8 & 0 & 0 & 0 & 0 \\
\hline
\end{tabular}

Based on Primary Survey, 2007

A few respondents did not report any damage but they felt stressed because of awareness of hazards, either by going through a dry spell or by having flood water within their property. In many cases the damage generated emotional and mental stress besides financial loss (Table: 6.12). However, financial loss was reported more frequently than emotional and mental stress. Hazards such as floods and windstorm also caused isolation which was more common in rural areas where farms and stock often got isolated because of these hazards.

Table: 6.12. Type and Effects of Damage Experienced by Respondents

\begin{tabular}{lcccccc}
\hline Type of Damage & Number of & Percent of & \multicolumn{4}{c}{ Effects } \\
\cline { 5 - 7 } & Respondents & Respondents & Financial & Mental & Emotional & Isolation \\
\hline House damage & 15 & 5.5 & 100 & 7 & 13 & 0 \\
Damage outside house & 7 & 2.6 & 100 & 14 & 14 & 0 \\
Damage to assets & 9 & 3.3 & 100 & 11 & 11 & 0 \\
Damage on farm & 9 & 3.3 & 89 & 22 & 0 & 11 \\
Loss of trees/shrubs & 5 & 1.8 & 0 & 0 & 0 & 0 \\
Property damage but type & 10 & 3.7 & 100 & 0 & 0 & 0 \\
not specified & 7 & 2.6 & 0 & 29 & 0 & 14 \\
No damage & 5 & 1.8 & 0 & 0 & 0 & 0 \\
Not answered & & &
\end{tabular}

Based on Primary Survey, 2007

About 70 percent of the respondents who experienced hazards attributed nature as the prime cause of damage. Another 19 percent did not answer the question, and only 11 percent of the respondents perceived vulnerability of the infrastructure or assets as the main cause of damage. About 15 out of 64 respondents said that they had received some sort of warning before the hazard occurrence. The highest number of respondents had received warning for flooding (7), followed by strong winds (4), droughts (2) and one for landslide and volcanic ash fall each. However, about 49 respondents said that they did not receive a warning, and seven respondents did not answer this question. The reason for not receiving warning is mainly associated with the nature of hazard as for many geological hazards such as earthquakes or landslides, warnings are not available. 
Table: 6.13. Coping Strategies Adopted by Respondents for hazards

\begin{tabular}{lcc}
\hline Coping Strategies & Number of Respondents & Percent of Respondents \\
\hline Replace damaged article/content & 8 & 12.5 \\
Got Insurance company to pay for the damage & 8 & 12.5 \\
Called fire brigade/civil defence/district council for help & 5 & 7.8 \\
Got help of friends or family & 3 & 4.7 \\
Reduce exposure & 3 & 4.7 \\
Stay at home/wait for hazard to reduce & 2 & 3.1 \\
Clean the damage & 2 & 3.1 \\
Nothing & 2 & 3.1 \\
Shifted contents/stock to safe place & 2 & 3.1 \\
Evacuation & 2 & 3.1 \\
Being prepared for hazard & 2 & 3.1 \\
Faced the consequences & 1 & 1.6 \\
Listen to radio & 1 & 1.6 \\
Not to panic & 1 & 1.6 \\
Sell the stock & 1 & 1.6 \\
Strengthened the vulnerable assets & 1 & 1.6 \\
Warned other people & 1 & 1.6 \\
Not answered & 19 & 29.7 \\
\hline
\end{tabular}

Based on Primary Survev, 2007

In order to survive when faced with hazards respondents adopted various coping strategies (Table: 6.13). These coping strategies not only differed according to the type of hazard but also with the nature of damage. They could be broadly classified in the following categories:

1. Bear the consequences: A common coping strategy of most respondents who experienced the hazard was to bear the damage or repair the damage. Nearly 17 percent mentioned to have accepted the loss. This response has mainly been engendered by the regular damage from frequent low magnitude events which caused minor or insignificant damage such as loss of household assets or plants by windstorm or flooding in backyard.

2. Insurance: Since insurance is readily available to households for natural hazards, it is another most common coping strategy. About 13 percent of respondents who experienced damage relied on their insurance cover to cope with the damage.

3. Seek help: Another 13 percent of respondents managed the impact of hazards by seeking help either from hazard management agencies i.e. fire brigade or civil defence organisation and local council (7.8 percent) or from family and friends (4.7).

4. Reduce Vulnerability: About 10 percent of the respondents chose to reduce their vulnerability i.e. reducing hazard exposure ( 4.7 percent) by shifting things within house or within the property ( 3.1 percent), reducing fragility by strengthening the windows (1.6 percent), or by selling the stock (1.6 percent) to cope with scarce situation.

5. Do nothing: Few respondents also choose to do nothing, but this happened primarily because the damage they experienced was either very minor or there was no damage.

6. Evacuation: Two respondents also had to evacuate their house. Both of these evacuations were caused by landslides. The first landslide occurred at the coastal property in the Kapiti Coast District when a part of the respondent's house fell into the sea and they had to make arrangements for another house. The second landslide occurred in the western hills in Lower Hutt. In this case, the respondents had to live in a motel for a few days, until the 
house was declared safe by the council engineers. Needless to say both incidents caused financial, mental and emotional stress.

7. Preparedness: Two respondents said that they coped as a result of their preparedness to these hazards i.e. by having enough food and other required items within the house.

8. Appropriate response attitude and behaviour: Respondents also mentioned that being alert, not panicking, listening to radio and warning each other helped them to cope with hazards.

The respondents who experienced hazards were also asked if any cultural or traditional practice helped them to cope with hazards (Table: 6.14). Nearly 78 percent of the respondents did not answer the question. About six percent of respondents who experienced hazards said that they do not have any cultural practice to avoid natural hazards. Only 16 percent of respondents could identify any traditional practices. These included seeking spiritual support, praying and depending on family, friends and community for support. Other methods were selling stock early in summer to avoid loss from drought, keeping streams clear to avoid flooding, and self reliance for effective response.

Table: 6.14. Cultural or Traditional Methods Adopted by Respondents to Deal with Hazards

\begin{tabular}{lcc}
\hline Cultural/Traditional Methods & Number of Respondents & Percent of Respondents \\
\hline None & 4 & 6.3 \\
Prayers/Faith/spiritual support & 3 & 4.7 \\
Family and friends support & 3 & 4.7 \\
Community support & 1 & 1.6 \\
Carry certain number of stock in summer & 1 & 1.6 \\
Keeping streams clean & 1 & 1.6 \\
Self Reliance & 1 & 1.6 \\
Not answered & 50 & 78.1 \\
\hline
\end{tabular}

Based on Primary Survey, 2007

The respondents were also asked if they learnt any lessons from their past experiences (Table: 6.15). Though the term vulnerability is not mentioned by many respondents, hazard experience made them aware of the fragility of their life and assets. About 17 percent of the respondents learnt to reduce vulnerability by building protection for hazards, by regular checking and maintenance of property and by reducing their hazard exposure.

Table: 6.15. Lessons Learnt by Respondents who Experienced Hazards

\begin{tabular}{lcc}
\hline Lessons Learnt & Number of Respondents & Percent of respondents \\
\hline Reduce vulnerability & 11 & 17.2 \\
Response behaviour & 10 & 15.6 \\
Preparedness & 8 & 12.5 \\
Hazard Characteristics & 7 & 10.9 \\
Reliance on others & 4 & 6.3 \\
None & 4 & 6.3 \\
\hline
\end{tabular}

Based on Primary Survey, 2007

About 16 percent of the respondents learnt about how to respond at the time of hazard occurrence. Their learnt response behaviours include being vigilant and alert about hazard conditions (1), 'do not panic' (1), react quicker (1), do not go outside, or stay inside the house in 
case of windstorm (2), evacuate or shift livestock at safer places (1), respond to hazard as the situation demands (1). One respondent also said 'I know what to do now'.

About 13 percent of respondents said their hazard experience forced them to be prepared for future ones. While most meant general preparedness (5), one respondent had a plan and two others learnt to be prepared by securing household items in place. A few other respondents just labelled their experience to hazard characteristics such as 'hazards happen' (2), 'nature will do what it wants' i.e. to say hazards are natural (2), 'nothing much you could do about them' (1) and hazards are 'unpredictable' (1). One respondent said that the last experience made him think about hazards.

Hazard experience also taught people about the reliability of other agencies. While two respondents lost their trust in the council, one respondent said that the local council is useful but did not give details. Another respondent said that he looked for spiritual protection. About four respondents said they did not learn anything from their past experience. Another 16 respondents who experienced damage from hazards did not mention if they had learnt any lessons from their past experience. It can be assumed that they did not learn any lesson from past damages.

Table: 6.16. Number of Times Hazards Experienced by Respondents

\begin{tabular}{lcc}
\hline Number of times affected by hazards & Number of Respondents & Percent of Respondents \\
\hline Once & 23 & 35.9 \\
Twice & 9 & 14.1 \\
$3-5$ times & 7 & 10.9 \\
6-10 & 2 & 3.1 \\
$>10$ & 2 & 3.1 \\
At times/Many Times/Often & 9 & 14.1 \\
Every year & 3 & 4.7 \\
Every 2-5 years & 2 & 3.1 \\
Not answered & 6 & 9.4 \\
\hline
\end{tabular}

Based on Primary Survey, 2007

The number of times a particular hazard is experienced by the respondents also varied significantly i.e. from once in a lifetime to more than 10 times or every year (Table: 6.16). While maximum respondents (36 percent) experienced hazards once, about 14 percent faced them twice and 11 percent had faced them three to five times. About three percent of respondents experienced hazards 6-10 times and another three percent experienced them more than 10 times. The frequency of hazard experience also gives an indication of the intensity of hazards and response in the region. About 14 percent of respondents could not give any number, but they faced hazards regularly. The hazard experienced every year or many times mainly refers to windstorms. Since the frequency of flooding and drought experienced by respondents in rural Wairarapa is once in every 2-5 years, many respondents had experienced these hazards a number of times. Major events such as earthquake, landslide and in some cases flooding, drought or windstorm have been mainly

Table: 6.17. Influences of Hazard Experience on Preparedness of Respondents

\begin{tabular}{lcc}
\hline Influence on Preparedness & Number of respondents & Percent of respondents \\
\hline None & 24 & 38 \\
Increase in preparedness & 29 & 45 \\
Can't prepare for hazards & 3 & 5 \\
Not answered & 8 & 13 \\
\hline
\end{tabular}

Based on Primary Survey, 2007 
experienced once.

Hazard experience has influenced the preparedness of respondents in different ways, but not for all (Table: 6.17). While for 38 percent of the respondents their past experiences did not affect their preparedness level, about 45 percent of respondents noted an increase in their preparedness level. Another five percent realised that they can not be prepared for all hazards, and 13 percent did not answer this question.

The respondents were also asked whether their past experience has influenced their coping strategies. Although 61 percent of respondents said no, about 31 percent believed that their coping strategies are influenced by their past experiences (Table: 6.18). The nature of influence varied from knowing a procedure to cope (5), improvement in the methods to cope with hazard (4), acceptance of hazard (3), methods of response i.e. being prepared (2), being realistic (2), respond early (1), awareness of their vulnerability (1), awareness of their capacity to cope (1), staying calm (1) or by strengthening the bonds in the family (1).

Table: 6.18. Influences of Hazard Experience on Coping Strategy of Respondents

\begin{tabular}{lcc}
\hline Influence on Coping Strategy & Number of Respondents & Percent of Respondents \\
\hline No influence & 39 & 60.9 \\
Know the procedure to cope & 5 & 7.8 \\
Improved or influenced in positive way & 4 & 6.3 \\
Acceptance of hazard & 3 & 4.7 \\
Be prepared & 2 & 3.1 \\
Be realistic & 1 & 1.6 \\
Early response & 1 & 1.6 \\
Know about vulnerability & 1 & 1.6 \\
Know about capacity to cope & 1 & 1.6 \\
Stay calm & 1 & 1.6 \\
Strengthened sense of reliance on extended family & 1 & 1.6 \\
Not answered & 5 & 7.8 \\
\hline
\end{tabular}

Based on Primary Survey, 2007

Not many people mentioned any influence of past experience on their recovery methods (Table: 6.19). A few respondents repeated their answers. While 66 percent of respondents did not find any influence, about three percent said their experience has influenced their recovery positively, but they did not mention any method. One respondent said he learnt to work with the community to recover from hazards, while another respondent said as time passes people recover and normalcy returns. One respondent felt cynical about insurance claims as he could not claim for storm damage to his roof and property.

Table: 6.19. Influences of Hazard Experience on Recovery of Respondents

\begin{tabular}{lcc}
\hline Influence on Recovery & Number of Respondents & Percent of Respondents \\
\hline None & 42 & 65.6 \\
Good/positively & 2 & 3.1 \\
Work in community level & 1 & 1.6 \\
Cynical about insurance claim & 1 & 1.6 \\
Time passes and normalcy returns & 1 & 1.6 \\
Not answer & 17 & 26.6 \\
\hline
\end{tabular}

Based on Primary Survey, 2007 
Table: 6.20. Influences of Hazard Experience on Vulnerability of Respondents

\begin{tabular}{lcc}
\hline Influence on vulnerability & Number of Respondents & Percent of Respondents \\
\hline No & 44 & 68.8 \\
Feeling of vulnerability & 4 & 6.3 \\
Awareness of vulnerability & 3 & 4.7 \\
Increase in exposure & 1 & 1.6 \\
Reduced vulnerability & 1 & 1.6 \\
Don't know & 1 & 1.6 \\
Not answered & 10 & 15.6 \\
\hline
\end{tabular}

Based on Primary Survey, 2007

While about 69 percent of respondents did not find any influence of past experiences on their vulnerability, one person was not sure (Table: 6.20). Four respondents got the feeling of vulnerability from their past hazard experience and three respondents said they are now more aware of their vulnerability. One respondent said that hazard occurrence has increased his exposure, while another believed his vulnerability has been reduced but did not mention how.

Table: 6.21. Influences of Hazard Experience on Thinking of Respondents about Hazards

\begin{tabular}{lcc}
\hline Influence on Thinking about Hazards & Number of Respondents & Percent of Respondents \\
\hline None & 34 & 53.1 \\
Awareness & 7 & 10.9 \\
Accept nature & 5 & 7.8 \\
Not answered & 5 & 7.8 \\
Accept the vulnerability & 3 & 4.7 \\
Some influence & 2 & 3.1 \\
Don't think about it & 1 & 1.6 \\
Decision of where to live & 1 & 1.6 \\
It's unpredictable & 1 & 1.6 \\
Know what to expect & 1 & 1.6 \\
Move away & 1 & 1.6 \\
Reluctance to accept & 1 & 1.6 \\
Thankful to be alive & 1 & 1.6 \\
Can manage most things & 1 & 1.6 \\
\hline Based on Primary Survey, 2007 & &
\end{tabular}

Past experiences have also changed the thinking of respondents about hazards in many ways (Table: 6.21). While seven respondents said they are now more aware of hazards, five respondents now recognized them as natural processes. Another three respondents said they accepted their vulnerability in the face of hazards. While for a few respondents their experience has influenced their decision making about where to live or whether to move away from an area prone to hazards, others were were thankful to be alive. For some respondents their past experience was insignificant to the extent that they either don't think about hazards or reluctant to accept the hazard. A few other respondents believed that they can manage most things on their own.

\subsubsection{Response Culture}

The general trend of response at a place also influences response to a significant extent at different levels i.e. at Individual, community and administrative level.

6.2.4.4.1. Response at Individual Level: As highlighted in the previous discussion, not everyone has responded to hazards in the same way. When the respondents were asked whether they considered possible hazards when they first moved into their house, only 32 percent said yes. 
The classification of these responses on the basis of the degree of effort expended to make changes in their house to avoid hazards, shows that while a greater proportion of respondents have not made any effort to reduce hazards at their house, an equal proportion of respondents have put in low and medium levels of effort (Fig: 6.132). A low level of effort here refers to the activities or adjustments which involve less intense changes in or around the house such as

Fig: 6.132. Degree of Efforts Made by Respondents to Reduce Hazards in the Wellington Region Very High/Proactive $(3 \%)$

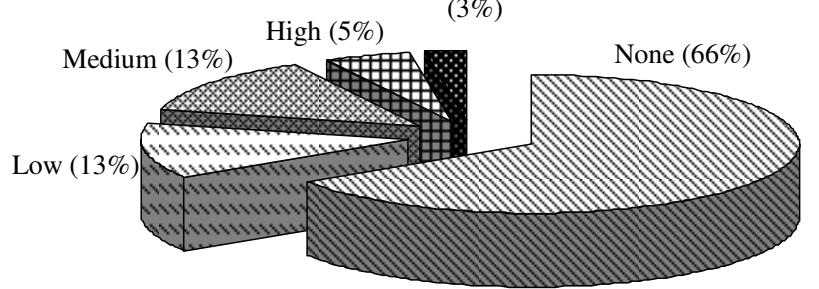

Based on Primary Survey, 2007 securing household items, fixing the water cylinder, windows and cabinets to walls along with regular checks and maintenance. Medium level of effort refers to significant adjustments in or around the house but does not include any major construction work. A high level of effort on the other hand, includes strengthening or structural adjustments in the house. Only five percent of respondents said they had made high level of effort and three percent were proactive adopting more than one adjustment of a medium or high level of effort. The hazards for which maximum respondents have taken measures are earthquakes and windstorms.

There are a few common mitigation measures that respondents took for all hazards such as choosing a strong house, having hazard insurance, storing emergency material and gathering information for hazard awareness. The common measures adopted for windstorms in the region include planting shelter belts or trees to reduce wind speed, removing trees in very close proximity of house to reduce indirect damage and securing household items. Careful selection of house location, improving drainage and seeking institutional support i.e. making sure the name of the household is on the flood warning list were the common mitigation strategies for flooding, while securing household items and reinforcing chimneys were mentioned repeatedly for mitigating earthquakes. For landslides, common response included building retaining walls, choosing right location for housing and planting trees. Conserving water, storing water and putting in bore holes for private water supply were found frequent response to drought, and sprinkler system were mentioned to reduce bushfires.

Compared to mitigation measures, a significant proportion of respondents (74 percent) had adopted safety measures for the real time response such as having cash, an emergency plan, survival kit or storing drinking water. However, about 18 percent of respondents could not name the hazard for which they have taken these measures and another 12 percent of respondents said they took safety measures for all hazards. This may be because these respondents did not see themselves to be exposed to any or all hazards. However, due to high awareness about the safety measures, people have taken such measures.

It is also noted that even though many respondents did not adopt either mitigation or safety measures, they perceived themselves to be prepared for most hazards. The reason could be attributed to the underestimation of potential risk or they did not know what they could do to be prepared. About 24 percent of respondents were not at all prepared for any hazard. These 
respondents were asked for the reasons for not being prepared to various hazards. Reasons given by respondents (as listed in Table 6.22) highlight the role of various aspects of hazardscape. These are as follows:

Table: 6.22. Reasons for Not Being Prepared for Hazards Category Percent of Respondents

$\overline{\text { Earthquake Flood Landslide Bushfire Windstorm Cyclone Tsunami Drought Volcanic Total }}$ ash fall

\begin{tabular}{|c|c|c|c|c|c|c|c|c|c|c|}
\hline Apathy & 11.40 & 18.01 & 19.12 & 23.16 & 17.28 & 21.69 & 21.32 & 20.96 & 18.38 & 19.04 \\
\hline $\begin{array}{l}\text { Distance from } \\
\text { hazard in } \\
\text { space }\end{array}$ & 4.04 & 26.10 & 22.79 & 23.16 & 4.78 & 14.34 & 26.84 & 15.81 & 30.88 & 18.75 \\
\hline Not applicable & 4.04 & 16.91 & 20.59 & 24.26 & 5.15 & 20.22 & 23.53 & 11.03 & 28.31 & 17.12 \\
\hline Prepared & 27.94 & 12.13 & 7.72 & 2.94 & 21.69 & 5.15 & 2.21 & 15.81 & 1.47 & 10.78 \\
\hline Not answered & 6.99 & 6.25 & 7.35 & 8.46 & 7.35 & 7.35 & 7.35 & 6.25 & 8.09 & 7.27 \\
\hline $\begin{array}{l}\text { Lack of } \\
\text { knowledge }\end{array}$ & 5.51 & 6.62 & 6.25 & 6.25 & 12.13 & 1.84 & 9.93 & 8.46 & 6.99 & 7.11 \\
\hline Lack of time & 14.71 & 6.25 & 6.25 & 4.41 & 8.82 & 5.15 & 4.78 & 2.57 & 1.84 & 6.09 \\
\hline $\begin{array}{l}\text { Cost of } \\
\text { preparedness }\end{array}$ & 12.13 & 5.88 & 3.68 & 2.57 & 4.41 & 2.94 & 2.21 & 5.88 & 1.10 & 4.53 \\
\hline $\begin{array}{l}\text { I can bear the } \\
\text { damage }\end{array}$ & 6.25 & 3.31 & 3.68 & 1.47 & 10.66 & 3.31 & 0.37 & 10.29 & 1.10 & 4.49 \\
\hline Laziness & 8.09 & 4.04 & 2.94 & 2.57 & 3.68 & 3.68 & 3.68 & 2.57 & 2.21 & 3.72 \\
\hline Optimism & 1.84 & 0.74 & 0.74 & 0.74 & 0.37 & 11.76 & 1.10 & 0.74 & 0.00 & 2.00 \\
\hline Fatalism & 1.10 & 0.37 & 1.47 & 1.10 & 2.57 & 2.21 & 1.84 & 1.10 & 0.37 & 1.35 \\
\hline $\begin{array}{l}\text { Hazard never } \\
\text { occurred }\end{array}$ & 1.47 & 0.37 & 1.10 & 0.37 & 1.84 & 1.47 & 1.10 & 0.74 & 1.10 & 1.06 \\
\hline $\begin{array}{l}\text { Preparedness } \\
\text { with fatalism }\end{array}$ & 1.47 & 0.74 & 1.10 & 0.74 & 1.10 & 1.10 & 0.74 & 1.10 & 0.74 & 0.98 \\
\hline $\begin{array}{l}\text { Distance in } \\
\text { time: } \\
\text { Uncertainty }\end{array}$ & 2.21 & 0.37 & 0.74 & 0.74 & 1.10 & 0.74 & 0.37 & 1.10 & 0.74 & 0.90 \\
\hline $\begin{array}{l}\text { Will respond } \\
\text { on the event }\end{array}$ & 0.74 & 0.37 & 0.00 & 1.10 & 1.10 & 1.10 & 0.74 & 0.74 & 0.74 & 0.74 \\
\hline $\begin{array}{l}\text { Physically } \\
\text { incapability }\end{array}$ & 0.74 & 0.00 & 0.37 & 0.37 & 0.74 & 0.74 & 0.37 & 0.74 & 0.00 & 0.45 \\
\hline $\begin{array}{l}\text { Can't perceive } \\
\text { hazard } \\
\text { occurrence }\end{array}$ & 0.37 & 0.37 & 0.37 & 0.37 & 0.37 & 0.37 & 0.37 & 0.37 & 0.74 & 0.41 \\
\hline Denial & 0.74 & 0.00 & 0.00 & 0.00 & 0.74 & 0.00 & 0.00 & 0.00 & 0.00 & 0.16 \\
\hline $\begin{array}{l}\text { Property is } \\
\text { not owned }\end{array}$ & 0.00 & 0.37 & 0.00 & 0.37 & 0.00 & 0.00 & 0.00 & 0.00 & 0.37 & 0.12 \\
\hline $\begin{array}{l}\text { Mentally } \\
\text { prepared }\end{array}$ & 0.74 & 0.00 & 0.00 & 0.00 & 0.00 & 0.00 & 0.00 & 0.00 & 0.00 & 0.08 \\
\hline Feel safe & 0.37 & 0.00 & 0.00 & 0.00 & 0.00 & 0.00 & 0.00 & 0.00 & 0.00 & 0.04 \\
\hline
\end{tabular}

Based on Primary Survey, 2007

Hazard characteristics and occurrence: Hazard characteristics and occurrences have influenced perceived preparedness level of respondents both directly and indirectly. The influences of hazard characteristics are noted in various reasons given by the respondents for not being prepared. While more than 20 percent respondents were perceived to be prepared for earthquakes and windstorms, less than three percent were prepared for tsunami and volcanic ash fall which closely follows the trend of frequency of these hazards in the region. However, the high frequency of windstorms and earthquakes in the region is a reason for being prepared for some and not being prepared for 
others. This is because although low magnitude earthquakes and windstorms are frequent, the region has not experienced any major event in decades. This gives an important reason to many people for not being prepared for these hazards. For moderately frequent hazards such as flood and drought 12-16 percent of respondents were prepared. About one percent of respondents said that they are not prepared because a hazard never occurred. This reason was mainly given for windstorm (1.8 percent) and earthquake (1.5 percent), but also mentioned for landslides, tsunami and volcanic ash fall. Nearly one percent of respondents did not prepare because of uncertainty associated with hazard occurrence or they don't expect a hazard in near future, especially earthquake (2.2 percent), windstorm (1.1 percent) and drought (1.1 percent).

The nature of hazards also influences the reasons for certain responses such as 'I can bear the damage' which leads to denial of the need for being prepared. Nearly 4.5 percent of respondents said they can bear the damage particularly those from windstorms (11 percent), droughts (10 percent) and earthquakes ( 6.25 percent). It is very likely that these respondents were thinking about the minor loss from these hazards as they have seen or experienced in the past. About 0.16 percent of respondents declined for preparedness as they could not see any reason to be prepared for hazards such as earthquakes and windstorms.

Another 0.7 percent of respondents said that they did not prepare for hazards because they will respond to the event as the situation demands. This response was more common for bushfire, windstorm and cyclone as compared to earthquake, flood, tsunami, drought and volcanic ash fall. This thinking could again be attributed to hazard characteristics as in both minor and major hazard events, respondents did not think that they could do something about them and therefore they could not see any reason why should they be prepared for these hazards. While the numbers related to each type of response given above are low, they serve to indicate the wide variety of answers given.

Physical susceptibility: Location and physical characteristics of a place have also played a significant role in lack of preparedness. It is the second most common reason given for not being prepared for any hazard, after apathy. About 19 percent of the respondents see the physical distance from a hazard in space as the main reason for not being prepared, especially for hazards such as flood, landslides and volcanic ash fall. While the susceptibility for flood and landslide varies significantly across the region, the region overall is exposed to volcanic ash fall. Physical susceptibility is also linked with the reasons stating 'can't perceive hazard occurrence'. About 0.4 percent of respondents could not perceive hazard occurrence because of the distance, especially for volcanic ash fall.

Another reason for not being prepared that links to physical susceptibility is that hazard is seen as not applicable to the respondents. About 17 percent of the respondents said the hazard is not applicable for them, mainly volcanic ash fall (28 percent), bushfire ( 24 percent), tsunami (24 percent), landslide (21 percent) and cyclone (20 percent). Since susceptibility of volcanic ash fall and cyclone is general, this reason therefore indicates lack of awareness for these hazards.

Vulnerability: Vulnerability is another important reason for not being prepared. Various forms of vulnerability either in terms of physical incapability, economic vulnerability or lack of awareness or 
knowledge hinder effective response to hazards. Lack of knowledge about hazards was the main reason for not being prepared, for nearly seven percent of respondents, mainly for windstorm (12 percent), tsunami (9.9 percent) and drought ( 8.5 percent). The cost of preparedness was a barrier for nearly 4.5 percent of respondents. It dominantly affected the preparedness for earthquake (12 percent), followed by flood and drought for six percent of respondents for each hazard. Physical incapability either because of old age or disability has also affected preparedness. Besides, some respondents could not prepare for hazards such as flooding, bushfires and volcanic ash fall because the property (i.e. house or bushes in the surroundings) was not owned by them. These respondents mainly believed that the responsibility of hazard reduction either lies with the owner or the local council. A few other respondents could not prepare because of lack of time, which indicates their busy schedule either with office or household work, which enhances their vulnerability to hazards.

Overall hazardscape: The data show that besides the individual components of hazardscape, the overall characteristics of hazardscape also govern the response by influencing the attitude, perception and adoption of particular response type.

- Apathy: Apathy is the most common reason for not being prepared for nearly 19 percent of respondents, mainly for hazards such as bushfires (23 percent), tsunami (21 percent), droughts (21 percent), landslides (19 percent), flooding (18 percent) and volcanic ash fall (18 percent). The reason behind the existence of apathy towards preparedness for hazards could be attributed to their irregular occurrence, minor damage and socio-economic well being of respondents along with the availability of effective hazard management services i.e. civil defence organisation, fire and police services etc.

- Laziness: Laziness was the prime factor of non preparedness for nearly four percent of respondents especially for earthquake ( 8 percent) followed by flood, windstorm, cyclone and tsunami.

- Feel Safe: A few respondents said that they feel safe and therefore they did not prepare. This reason was mainly given in context of earthquake. The mitigation measures adopted by local councils such as building act for earthquakes and flooding also make people to feel safe against these hazards.

- Optimism: Nearly two percent of respondents were optimistic that a hazard would never occur for them, or they do not expect a hazard occurrence at their place. This feeling is found to be more dominant for cyclones (12 percent) followed by earthquakes ( 2 percent) and tsunami (1 percent). For floods, landslides, bushfires, windstorms and drought, less than one percent of respondents were optimistic that hazard would not affect them.

- Fatalism: A few respondents also did not prepare because of their fatalistic attitude about hazards, that no preparedness could save them at the time of major disaster.

- Preparedness with fatalism: A few other respondents though prepared for most hazards, still had a degree of fatalism. Their thoughts were based on the feeling that there is only so much one can do about these hazards, or they are prepared as much as they could have; or they could not be more prepared than the extent they already have. Such a response was more common for earthquakes. 
- Mentally Prepared: A few other respondents said that they are mentally prepared for the hazards, again especially for earthquake. This could be attributed to both optimistic and fatalistic views, where respondents either see little or too much damage. Both optimism and fatalism are the product of overall hazardscape that is related to the nature of response methods available, as well as the perception and attitude of the community.

6.2.4.4.2. Hazard Safety Measures at Work Place: Respondents were also asked if they have any hazard safety measures at their work place. Nearly 51 percent did not answer the question, 21 percent said no and another 8 percent said they are either retired or work from home or on farm (Table: 6.23). Only 20 percent of total respondents were aware of one or other kind of safety measures available at their work place.

Table: 6.23. Availability of Hazard Safety Measures at the Workplace of Respondents

\begin{tabular}{lcc}
\hline Availability of Hazard Safety Measure at Work Place & $\begin{array}{c}\text { Number of } \\
\text { Respondents }\end{array}$ & $\begin{array}{c}\text { Percent of } \\
\text { Respondents }\end{array}$ \\
\hline Yes & 55 & 20 \\
No & 56 & 21 \\
Don't know & 138 & 51 \\
Not Applicable & 23 & 8 \\
Total & 272 & 100 \\
\hline
\end{tabular}

Based on Primary Survey, 2007

The safety measures again varied from having a survival kit to a full fledged civil defence team and emergency plan. While a number of workplaces are well organised, a few other give safety measures only in the form of insurance cover or health and safety policy. Many of the workplaces have emergency teams and volunteers, and they do regular drills or train the staff for emergency. Having equipments or instruments for any specific hazard is also common and nearly six percent of respondents said their workplace have them (Table: 6.24).

Table: 6.24. Type of Hazard Safety Measures at Workplace of Respondents

\begin{tabular}{lcc}
\hline Hazard Safety Measure at Work Place & $\begin{array}{c}\text { Number of } \\
\text { Respondents }\end{array}$ & $\begin{array}{c}\text { Percent of } \\
\text { respondents }\end{array}$ \\
\hline Emergency team/ volunteers/training/drills & 17 & 6.3 \\
Instruments (including fire extinguisher/sprinkler system/protective & 16 & 5.9 \\
clothing/fire drills/ fire safety equipment etc)/infection & & \\
control/earthquake sensors/alarm/ warning) & & 3.7 \\
Emergency kit/first aid/stored water & 10 & 3.3 \\
Plans and Policy & 9 & 1.8 \\
Safe Building (Location and construction) & 5 & 1.5 \\
Secured items & 4 & 1.5 \\
Outer protection stop banks, flood protection etc.. & 4 & 1.5 \\
Regular check and maintenance & 4 & 1.1 \\
Education and Awareness & 3 & 0.4 \\
Insurance & 1 & $\mathbf{2 6 . 8}$ \\
Total & 73 & \\
\hline
\end{tabular}

Based on Primary Survey, 2007

The presence of an emergency or first aid kit is also reported by four percent of respondents. But since the offices are not liable for safety from natural hazards, they do not enforce it or have it for all their staff. Other measures adopted by many workplaces include securing items such as shelves or computers, hazard education programmes and regular checks and 
maintenance. Nearly two percent of respondents said that their office building is safe because of safe location and strong construction. Farmers, on the other hand, said they have stop banks and trees to protect the damage from flooding and windstorms respectively.

6.2.4.4.3. Hazard Mitigation Measures taken at Community Level: Awareness and response for hazard mitigation at community level is limited. While about 76 percent of respondents were not aware of any hazard mitigation measures taken at community level, another 13 percent said no such measure is taken by their community. Only 11 percent of respondents said yes and the measures mentioned by them varied significantly (Table: 6.25 ).

Table: 6.25. Type of Hazard Safety Measures at the Community Level in the Wellington Region

\begin{tabular}{lcc}
\hline Type of Measure & $\begin{array}{c}\text { Number of } \\
\text { Respondents }\end{array}$ & $\begin{array}{c}\text { Percent of } \\
\text { Respondents }\end{array}$ \\
\hline Institutional services: Civil defence office/fire brigade/red cross & 9 & 3.3 \\
Flood control: Flood bank construction/flood control/raised houses/water & 9 & 3.3 \\
control/drainage along the road/1 check the banks and keep the stuff out & & 2.9 \\
from bank & & 0.7 \\
Education and Awareness/meetings/posters/phonebook/civil defence & 8 & 0.7 \\
handbook/education at school & 2 & 0.7 \\
Fire risk control, cutting trees & 2 & 0.4 \\
Survival kit for neighbours/at schools & 2 & 2 \\
Emergency teams/community response in previous flood & 1 & \\
Early warning & & \\
\hline Based on Primary Survey, 2007 & &
\end{tabular}

The most common measure at community level as identified by respondents was the presence of organisations such as civil defence or the fire brigade. It is important to note that since these organisations are not operated by the community itself, they can not be taken as community response. The second common measure was flood control which again at times has been done in association with administrative help, and is mainly noted in the rural districts. Education and Awareness is the third most common response identified at the community level. Other responses at this level as mentioned by respondents include fire risk control, survival kits for schools and neighbours, and emergency team and group work during past hazard incidents. But such cases of community work are mentioned by very few respondents.

6.2.4.4.4. Administrative Response: Local councils and the Wellington Regional Council share the responsibility for hazard mitigation and response. They provide hazard information to local people that influence the perception and response of the local community. About 35 percent of respondents said they did not receive any information about any particular hazard. On the other hand, about 23 percent of respondents received information for one hazard, 21 percent for two hazards, 11 percent for three hazards, six percent for four hazards and one percent for five, six, seven and eight hazards each.

Besides the specific hazard information, about four percent of the respondents said that they received information about how to be prepared for natural hazards, while three percent said they received general information about natural disaster from the local council. Another two percent of respondents said that they do not remember seeing any information or do not think that they have ever received hazard information from local council. Nearly two percent of the respondents said that they have not received any hazard information recently or at least not in the 
last six months. A few respondents mentioned receiving information about pandemic and water restrictions. Individual respondents mentioned that they have seen information about coastal erosion, water contamination by bacteria, possum poisoning, or about tsunami on coast but did not receive that information at home.

\subsubsection{Effectiveness of Response Measures and Trust in Response Agencies}

Trust in mitigation measures and response agencies have also influenced the hazard response in the region.

6.2.4.4.1. Insurance: Insurance is an important measure for hazard recovery. While nearly 17 percent of the respondents said that they have claimed on insurance due to natural hazards, about 23 percent of them were not fully satisfied with their insurance claims. For two respondents, who gave details, the reason for their dissatisfaction was heavy loss of property and insufficient pay back from the insurance company. The causes of damage in these cases were windstorm and landslips. One reason of dissatisfaction was inflation in the price of damaged product for which insurance company paid the old price.

6.2.4.4.2. Trust in Response Agencies for Hazard Information during Emergency: In order to assess trust in the response agencies, respondents were asked to rank various agencies in a

Fig: 6.133. Agency Trusted by Respondents for Hazard Information

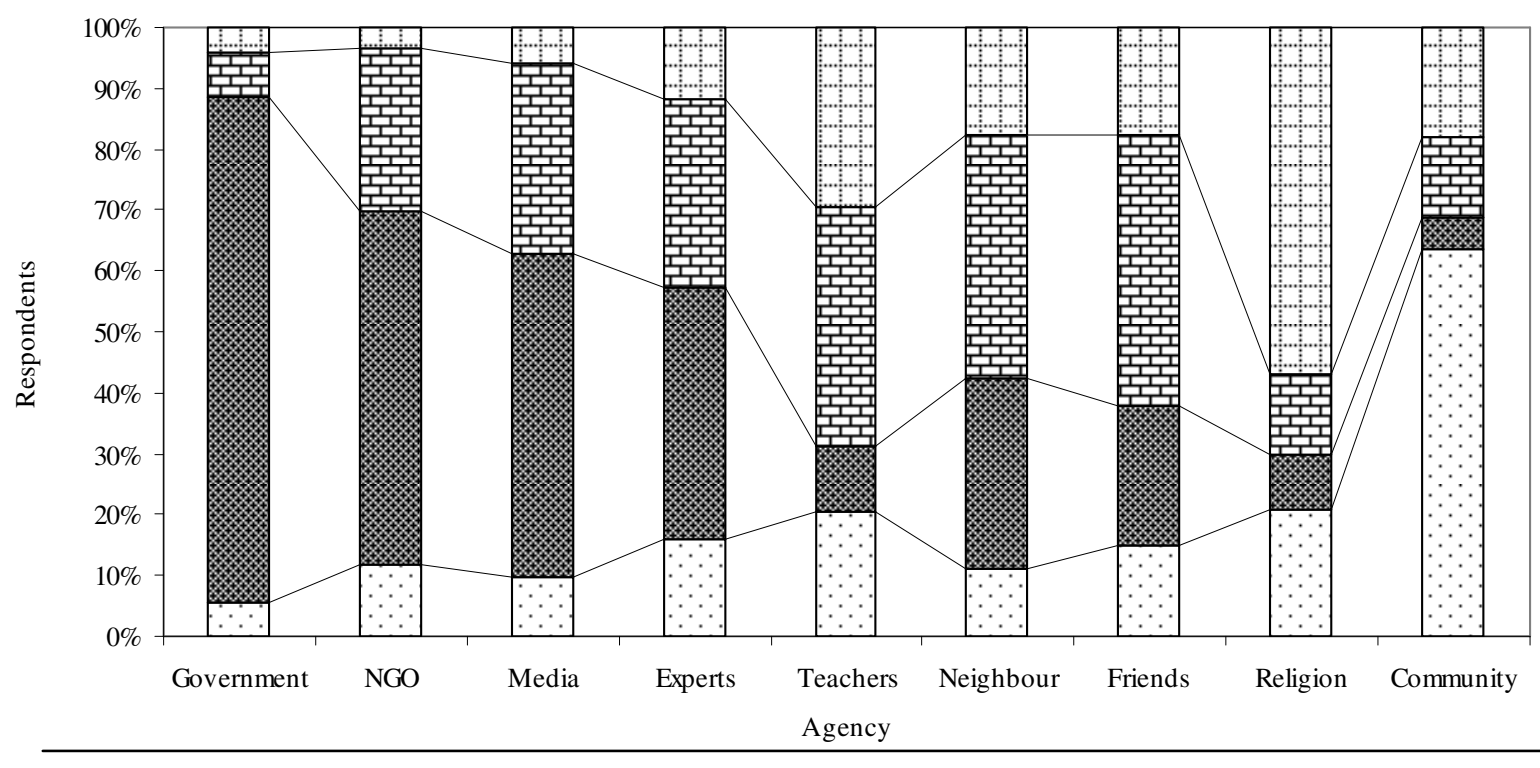

Don't Know/Not Answered

Most Trusted

臣 Trusted

Less Trusted

Based on Primary Survey, 2007

Fig: 6.134. Agency Most Trusted by Respondents

decreasing order of their trust for the information these agencies would provide at the time of hazard occurrence. The data show that Local government is the most trusted agency for hazard information (83 percent) followed by NGO (58 percent), media (53 percent) and hazard experts (42

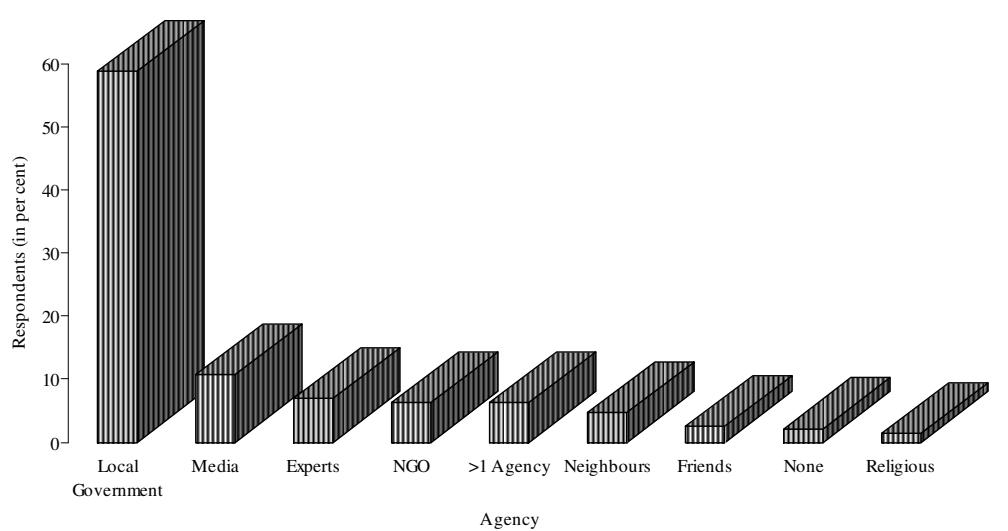


percent) (Fig: 6.133). Against these less than 10 percent of the residents highly trusted religious institutes such as church or temple authority (nine percent) or community (five percent) for hazard information. These two agencies along with teachers are rather less trusted by most respondents. The lower level of trust in religious institutes is attributed to lack of belief or faith along with the suspicion for the hidden interests or agenda behind their help. Other agencies such as neighbours and friends, even if not ranked on top, are trusted by a significant proportion of respondents.

Table: 6.26. Reason for Trust in the Most Trusted Agency

\begin{tabular}{lcc}
\hline Reason for Trust & Number of Respondents & Percent of Respondents \\
\hline Informed & 68 & 25.0 \\
Professional and trained & 58 & 21.3 \\
Responsible for the job & 56 & 20.6 \\
Not answered/ don't know & 30 & 11.0 \\
Source of information & 22 & 8.1 \\
Local knowledge & 19 & 7.0 \\
Reliability/confidence & 15 & 5.5 \\
Available and accessible & 14 & 5.1 \\
Experienced & 7 & 2.6 \\
Live together & 7 & 2.6 \\
Government power and network & 6 & 2.2 \\
Rational and unbiased & 6 & 2.2 \\
Can interrogate or get back to them & 5 & 1.8 \\
More in contact and know them & 5 & 1.8 \\
Concerned and helping attitude & 5 & 1.8 \\
Have Faith/ belief & 3 & 1.1 \\
Access to resources, equipments and process & 3 & 1.1 \\
Word of mouth & 1 & 0.4 \\
Well known & 1 & 0.4 \\
\hline
\end{tabular}

Based on Primary Survey, 2007

About 59 percent of respondents ranked local government as the topmost trusted agency for hazard information and the reasons mainly included their profession, responsibility and information base (Fig: 6.134 \& Table: 6.26). About 29 percent of the respondents ranked media on the top for the most trusted agency as they are the source of reliable information which is more readily available. Another 19 percent ranked hazard experts as the top most trusted agency because of their knowledge and expertise. NGOs and Neighbours were most trusted by 17 percent and 13 percent of respondents respectively. The reasons for most trust in NGOs mainly include their experience and presence at hazard situations along with their concerned and helping attitude, while that of neighbours include their presence during the hazard event which they are also likely to experience, more contact or simply because respondents know them. Only seven percent of respondents ranked friends and three percent ranked religious institutes such as church or temples as the most trusted group mainly because they know them or trust them. While about six percent of respondents did not rank any

Fig: 6.135. Agency Least Trusted by Respondents

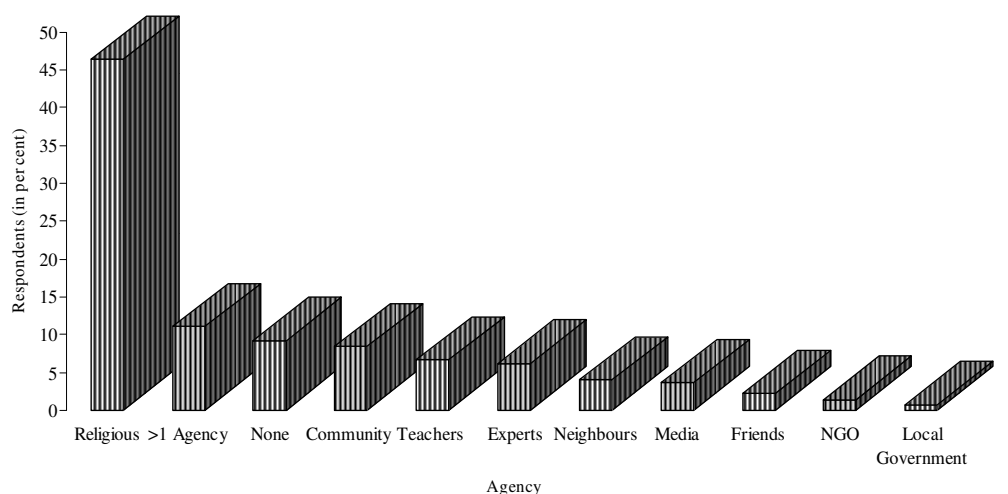

Based on Primary Survey, 2007 
agency as most trusted, another 17 percent ranked more than one agency as the most trusted ones. The various reasons given by the respondents are summarised in the Table: 6.26. Against this, nearly 46 percent of respondents had least trust in religious authority either because they do not follow any religion or they simply do not trust their intentions (Fig: 6.135 \& Table: 6.27).

Table: 6.27. Reason for Lack of Trust in the Least Trusted Agency

\begin{tabular}{lcc}
\hline Reason for Lack of Trust & Number of Respondents & Percent of Respondents \\
\hline Not answered/no reason/don't know & 56 & 20.6 \\
Lack of knowledge & 49 & 18.0 \\
No expertise & 45 & 16.5 \\
Not religious/don't have religion/atheist & 35 & 12.9 \\
Inaccessibility & 17 & 6.3 \\
sensationalising the information & 14 & 5.1 \\
Irrelevant/Not equipped to help/Incompetence & 10 & 3.7 \\
Don't trust them/don't believe them/not reliable & 9 & 3.3 \\
Don't know them & 9 & 3.3 \\
Biased/underlying reasons or interest/hidden agenda & 9 & 3.3 \\
Rumours/Word of mouth & 8 & 2.9 \\
Not a choice/don't like them & 6 & 2.2 \\
Lack of experience & 4 & 1.5 \\
Not an information source for hazards & 4 & 1.5 \\
Misleading information & 3 & 1.1 \\
May induce panic & 2 & 0.7 \\
They are basic & 2 & 0.7 \\
They will not help you & 1 & 0.4 \\
Ignorance & 1 & 0.4 \\
scattered & 1 & 0.4 \\
Doesn't happen & 1 & 0.4 \\
Not many around here & 1 & 0.4 \\
\hline Based on Primary Survey, 2007 & &
\end{tabular}

Nearly 11 percent named more than one agency as the least trusted agency and another nine percent did not name any agency as the least trusted. Seven to eight percent of respondents had least trust in teachers and local community, while six percent put hazard experts in the least trusted agency and another four had least trust in neighbours and media each. Two percent or less of respondents have less trust in friends or non-governmental organisations or local government. Various reasons of least trust or lack or trust in different agencies are given in the table 6.27, which suggests that while most respondents preferred not to answer this question, it is the lack of knowledge and expertise which dominate the reason for least trust.

Finally, it can be concluded that various factors and characteristics of hazardscape influence and produce variations in the local response to hazards. While the frequency, potential risk and regular damage are important characteristics of hazards that have influenced the local response, variations in the perception and response to hazards are also influenced by varying physical susceptibility and human vulnerability at individual and area level. Similarly, variations in the hazard response are also noted with respect to the overall hazardscape characteristics. These results 
therefore confirm the proposed hypothesis that hazardscape produces variations in the local response to hazards throughout the region. However, this could not be said with a statistical significance because the data was collected through a non random sampling method which restricted the scope for applying statistical tests. 
Chapter: 7

Administrative Response to Hazards in the Wellington Region

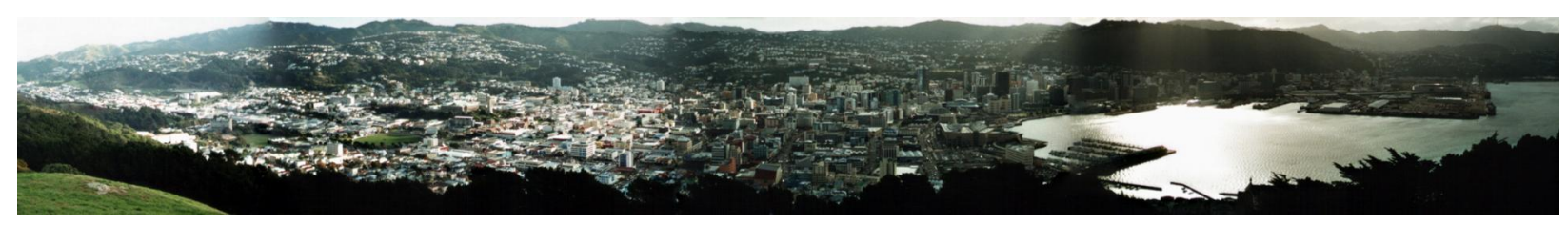


Administrative response here refers to the actions taken by a government set up at local, regional or national level. This chapter presents the overview of the administrative response to hazards in the Wellington Region and analyses the local variations with respect to the hazardscape.

\subsection{Overview of Administrative Response in the Wellington Region}

Administrative response in the region has seen significant changes since its inception in the late $19^{\text {th }}$ century. During the initial period of colonisation, the response to natural hazards was primarily from the affected community. Therefore, the nature of the response was mainly reactive in which migration was favoured for mitigation. The severe earthquakes of 1849 and 1855 made many colonisers move back to their original country (McConchie et al, 2000, 1). Also, many early settlers either moved to Wellington or to the high grounds due to frequent flooding in the Hutt Valley (Easther, 1990, 27). The administrative response mainly came into the picture after the establishment of the regional government in 1852 and then the central government in the late $19^{\text {th }}$ century (Te Ara, 2009). In the beginning, the nature of the administrative response was ad-hoc and impact based and mitigation measures were mainly adopted for frequent hazards such as floods, fires and earthquakes.

The damage from the two severe earthquakes that hit the North Island in the early $20^{\text {th }}$ century (1929 \& 1931) brought some significant changes in the administrative response. Acts and statutes were developed for an organised response to natural hazards (Fig: 7.1). Also the focus of the response was extended to include early mitigation and post disaster recovery. From 1977 onwards the administrative response entered into a new phase through Town and Country Planning Act that stressed planning for hazard mitigation. It also shifted the focus of the administrative response from individual to multiple dominant hazards of an area. This led to subsequent changes in other acts including the Local Government Act and Civil Defence Act, which also shifted their focus from individual to multiple hazards.

Hazard planning received a major boost from the Resource Management Act (1991), which emphasised planning for all hazards at a place. This was the first major step towards integrated hazard management planning at the national level. The act gave regional councils and territorial authorities the responsibility to plan for hazard mitigation consistent with the Regional Policy Statement. The integrated management of hazards however, came into force with the Civil Defence and Emergency Management [CDEM] Act (2002), which asked the local territorial authorities to join and prepare a Regional Civil Defence Group Plan. It also aimed to include all aspects of hazard response including reduction, readiness, response and recovery. The Guide to National Civil Defence and Emergency Management Plan asked to adopt the Australian and New Zealand Risk Management Standard (AS/NZS 4360: 2004) in order to determine risks and manage them. AS/NZS 4360 is a generic guide for managing risks, which can be applied to a range of situations. It highlights the process of risk management and its various elements i.e. communication and consultation, establishing the context, identifying, analysing, evaluation and treatment of risks along with monitoring and review of the process (Standard New Zealand, 2004). This framework is adopted for CDEM planning in order to integrate legislation, policies and services across central government and other sectors to achieve 4Rs (MCDEM, 2009, 4). 
The objectives of the Integrated Emergency Management System, as defined by Britton including the formation of partnerships between the different levels of resource owners, both vertically (between levels of government) and horizontally (between different agencies and the public-private sector), and focusing on hazard analysis, capability maintenance, and emergency response and recovery requirements (Britton, 2001, 45), were clearly adopted through these acts.

The uniformity of response in space is another component of the integrated approach, which mainly aims for an even distribution of standardised response services throughout the region leaving no area either under-served or over-served. However, at territorial local authority level, variations can be observed for different response measures. The following sections describe the variations in administrative response at the local level aimed for hazard mitigation, preparedness, emergency response and recovery.

7.2. Administrative Response for Hazard Mitigation in the Wellington Region
Fig: 7.1. Administrative Response in the Wellington

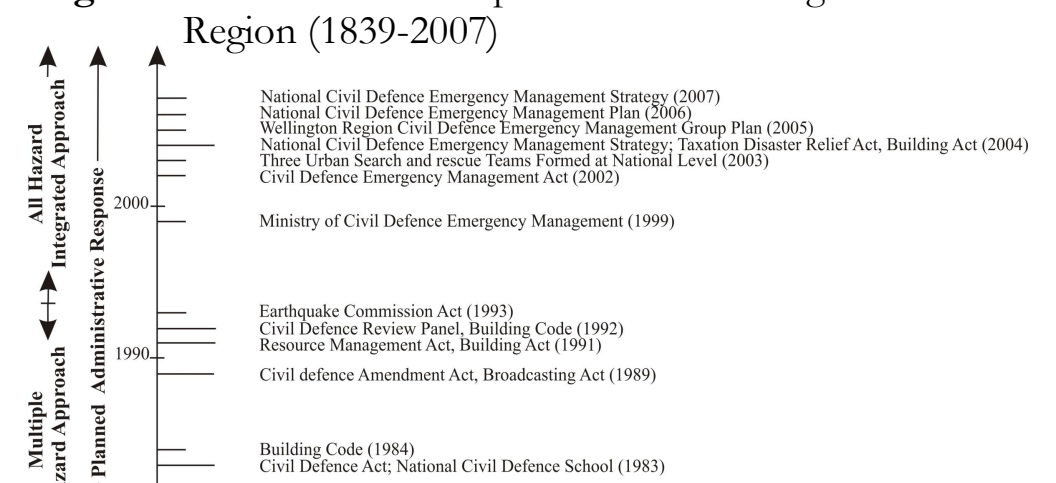

Civil Defence Amendment Act (1979)

Town and Country Planning Act, Forest and Rural Fire Act (1977)

Building Code (1976)
Fire Service Act, Civil Defence Amendment Act (1975)

Civil Defence Amendment Act (1971)

Civil Defence Amendment Bill (1968)

Government Action in a Major Disaster (1966)

Building Code (1965)

National Civil Defence Committee (1964)
Ombudsman Inquiry, Civil Defence Planning Guide for Local Authorities (1963) Civil Defence Act (1962)

Ministry of Civil Defence (1959)

Government Action in a Major Emergency (1954)
Local Authorities Emergency Powers Act (1953)

Fire Service Act (1949)

Forest and Rural Fires Act (1947)

Earthquake Commission (1945)

Soil Conservation and River Control Act (1941)

Emergency Precautions Schemes (1939)

Building Code (1935)

Public Safety Conservation Act (1932)

River Board Act, Fire Brigade Act (1908)

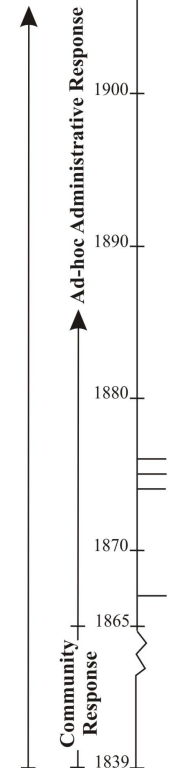
Municipal Corporation Act (1876
Wellington Rivers Act (1875)

Municipal Corporation Act (1867)

Based on Acheson, 1968; mmw.teara.govt.n₹; wmw.legislation.govt.n₹, Becker, J. et al, 2000; www.civildefence.govt.nz. 
The National CDEM Strategy, which defines 4Rs of New Zealand's integrated approach to CDEM, uses the term reduction for hazard mitigation. It defines reduction as "identifying and analysing long-term risks to human life and property from hazards; taking steps to eliminate these risks if practicable, and, if not, reducing the magnitude of their impact and likelihood of their occurring" (Department of Internal Affairs [DIA], 2007, 5). A range of measures have been taken in the region to reduce natural hazards. These include plans and policies, structural engineering measures and non-structural public information and awareness programs.

\subsubsection{Plans \& Policies}

Plans are essential instruments of hazard mitigation at the territorial authority level. This is because they are not only based on the local details, but are also implemented at this level. There are mainly three plans that deal with hazard mitigation by controlling land use and development at the district level. These include the City/District Development Plan, Annual Plan and Long-term Community Development Plan.

The territorial authorities are required to have a holistic district plan for the sustainable development of the area under their control. These plans incorporate information about the nature and type of hazard mitigation measures to be adopted in districts that further assist the Regional Planning Statement for hazard reduction (Regional Policy Statement for Wellington Region, 1995, 6). For eight city and district councils in the region, there are six city/district development plans, as there is one combined district plan for three Wairarapa districts of South Wairarapa, Carterton and Masterton. The variations in these six plans are observed not only in terms of the types of hazards they mention, but also the rules they have adopted to reduce hazards.

Table: 7.1. Natural Hazards Mentioned in the District Development Plans of the Wellington Region

\begin{tabular}{|c|c|c|c|c|c|c|c|c|c|c|}
\hline \multirow{2}{*}{$\begin{array}{l}\text { Territorial } \\
\text { Local } \\
\text { Authorities }\end{array}$} & \multicolumn{10}{|c|}{ Hazards } \\
\hline & Earthquake & Flood & Landslide & Cyclone & $\begin{array}{l}\text { Coastal } \\
\text { hazard }^{1}\end{array}$ & Tsunami & Drought & Windstorm & Bushfire & $\begin{array}{l}\text { Volcanic } \\
\text { Ash fall }\end{array}$ \\
\hline Wellington & $\sqrt{ }$ & $\sqrt{ }$ & $\chi$ & $\chi$ & $\chi$ & $\chi$ & $\chi$ & $\chi$ & $\chi$ & $\chi$ \\
\hline Porirua & $\sqrt{ }$ & $\sqrt{ }$ & $\sqrt{ }$ & $\chi$ & $\chi$ & $\sqrt{ }$ & $\chi$ & $\sqrt{ }$ & $\chi$ & $\chi$ \\
\hline Kapiti Coast & $\sqrt{ }$ & $\sqrt{ }$ & $\chi$ & $\chi$ & $\sqrt{ }$ & $\chi$ & $\chi$ & $\chi$ & $\chi$ & $\chi$ \\
\hline Lower Hutt & $\sqrt{ }$ & $\sqrt{ }$ & $\sqrt{ }$ & $\chi$ & $\sqrt{ }$ & $\sqrt{ }$ & $\chi$ & $\chi$ & $\chi$ & $\chi$ \\
\hline Upper Hutt & $\sqrt{ }$ & $\sqrt{ }$ & $\sqrt{ }$ & $\chi$ & n.a. ${ }^{2}$ & n.a. ${ }^{2}$ & $\chi$ & $\chi$ & $\chi$ & $\chi$ \\
\hline S. Wairarapa & $\sqrt{ }$ & $\sqrt{ }$ & $\sqrt{ }$ & $\chi$ & $\sqrt{ }$ & $\sqrt{ }$ & $\chi$ & $\chi$ & $\chi$ & $\chi$ \\
\hline Carterton & $\sqrt{ }$ & $\sqrt{ }$ & $\sqrt{ }$ & $\chi$ & $\sqrt{ }$ & $\sqrt{ }$ & $\chi$ & $\chi$ & $\chi$ & $\chi$ \\
\hline Masterton & $\sqrt{ }$ & $\sqrt{ }$ & $\sqrt{ }$ & $\chi$ & $\sqrt{ }$ & $\sqrt{ }$ & $\chi$ & $\chi$ & $\chi$ & $\chi$ \\
\hline
\end{tabular}

Based on District Plans of Wellington, Lower Hutt, Upper Hutt, Kapiti Coast, Porirua and Proposed Combined W airarapa District Plan.

Notes: 1. Coastal hazard: erosion, sedimentation, inundation by storm surge or tsunami.

2. Not applicable.

Table 7.1 shows that while earthquakes and floods are considered in all district plans, many hazards have not been covered in these plans despite the high susceptibility in the respective districts. For example, although Wellington city is highly exposed to windstorm, tsunami and landslides, these hazards have not been identified in its development plan. The two busiest shopping streets of the city including Lambton Quay and Courtney Place are located within a distance of few hundred metres from the coast. A local tsunami without warning can take hundreds of lives at a time. Similarly, landslides have not been mentioned, even though the densely occupied hills in the city are susceptible to frequent rock or debris fall during heavy rain or major 
earthquakes. Besides, even though the city does not experience regular drought, bushfire or volcanic ash fall, many of its areas are highly susceptible to them.

A similar trend is observed for other districts. The Lower Hutt city development plan does not mention mitigation measures for tsunami, windstorm and bushfire, irrespective of the high susceptibility of the city. The Porirua plan, on the other hand, identifies the highest number of hazards and has specific policies for allied hazards such as ground shaking, liquefaction, slope failure, tsunami and high winds. However, it does not discuss many frequent hazards such as bushfire, tidal flooding, coastal hazards and droughts. The district plan for the Kapiti Coast also does not include drought, strong wind and bushfire. Landslips in the district are mainly restricted to the coastal areas and therefore, they are covered under erosion and coastal hazards in the plan.

Although the land-locked Upper Hutt is safe from coastal hazards and tsunami, it is exposed to severe windstorm and bushfire, which are not discussed in the hazard section of its city development plan. Similarly, the three eastern districts of Wairarapa face regular damage from drought, cyclone and windstorms, but they are not mentioned in the proposed combined plan for these districts.

Besides, variations are also observed for the rules adopted in different districts to reduce hazards. The Ministry for the Environment produced guidelines in 2003 for the development of land close to the active faults (Grant, 2005, 12). It was recommended that any new building be set back 20 metres from a known active fault. Henceforth, most of the district plans control the land use within 20 metres of an active fault. While three Wairarapa districts of the region totally control and restrict the location of any building within 20 metres of the fault line, other districts have chosen it to be a discretionary activity, where buildings may exist given the proper engineering solutions are taken. Further, the rule does not apply to existing residential households, who will be the major victims in case of fault rupture. Also, though hazard like liquefaction is mentioned in the development plan of Porirua, no rules or guidelines have been suggested for reducing this hazard. The plan only asks to build in a way that does not increase the already existing hazard.

The mitigation responsibility for landslides mainly lies with the local people. This can be attributed to the nature of this hazard, which often affects individual households. Although most plans have rules regarding control on earthworks that guide future development so as to avoid the hazard areas, they do not suggest how that will reduce the existing risk from landslide.

Further, though many of the district plans mention tsunami, they do not clearly outline the mitigation methods for this hazard. The only district that has some rules for land use control with respect to tsunami is Lower Hutt. However, these rules do not apply for all coastal areas of the city. Other areas which are at high risk of tsunami include Wellington and the Kapiti Coast, but their development plans do not specify this hazard for mitigation measures. The building restrictions in the foreshore area of the Kapiti Coast and Wairarapa districts mainly apply for minor coastal hazards rather than bigger tsunami events.

For windstorm, the Building Act (1991) asks buildings to be strengthened according to the heavy wind gusts. Porirua district plan identifies the issue, but it does not have any policy to reduce 
the hazard at the local level. Similarly, for a number of hazards no rule or separate policy has been developed. For such hazards general policies apply. As identified by the Regional Civil Defence Plan (2005), lack of information about these hazards and possible consequences are major reasons behind the absence of hazard specific policies. Policies for flood and earthquake on the other hand, are clear and detailed compared to other hazards. The reason could be attributed to their frequent occurrence and potential risk through them.

Territorial authorities are also required to develop a Long-term Community Plan and Annual Plan under Local Government Act, 2002. Both of these plans are related. Long term community development plans are applied on a yearly basis through annual plans. Hazard mitigation in Long-term plans for most districts is mainly restricted to flood mitigation either by identifying or locating the flood prone areas or by providing flood protection through river management or storm water management. Other hazards are therefore not specifically dealt with in the long term planning of the region.

\subsubsection{Structural Measures}

Structural measures are physical structures or works which are built to control natural hazards. There is a range of structural measures that have been implemented for hazard mitigation in the region. They have been most extensively used for flood control. The common structural measures used for flood in the region include stop banks, river alignment, bank edge protection, rocks or vegetation placement for river control, raised houses or roads, bridge lengthening and gravel extraction.

The region is divided into two parts for flood management, which are managed by different authorities. While for five territorial authorities in the west, the Greater Wellington Regional Council [GWRC] is responsible for the flood management, there are Operations departments for the flood protection in three Wairarapa districts. The nature of work done and information available in these areas therefore differs accordingly. Under the Greater Wellington Regional Authority, flood management plans have been produced for major rivers including Hutt, Waikanae and Otaki. These plans state the design and nature of work to be carried out in 40 years for flood protection against a one in 100 year flood event (Grant, 2005, 25). The measures applied in these plans such as stop banks, gravel extraction, river design, river training or realignment aim to control the river path. The reason is the densely populated urban floodplains of these rivers, where any change in river course could cause serious damage to the local economy. In the Wairarapa districts, the strategy for managing rivers has been rather different from the very beginning of the river management activity. This is again because of the nature of land use and to an extent the size of the river. Instead of river control, development schemes were preferred in the eastern parts of the region, which aim for managing catchment areas of smaller rivers in the rural districts that experience severe erosion problems (Acheson, 1968, 62). At present there are four river schemes operating in this area. They include the Upper Ruamahanga Scheme, Waipoua Scheme, Waiohine Scheme and Lower Wairarapa Valley Development Scheme (GWC, n.d, 89).

Another structural hazard mitigation method, for which variations can be observed across the district and city councils in the region, is the relocation or strengthening of the existing 
infrastructure. In the primary survey of this research, district planners and civil defence officers were asked whether any changes have been made in the location of any significant institutions or services to reduce the damage from hazards. The two districts where civil defence offices have been relocated to reduce hazard include Wellington and Porirua. In both cities the Civil Defence Emergency Management [CDEM] offices have been shifted away from the city centres in order to avoid damage from a major earthquake. In the Kapiti Coast, a new Emergency Operation Centre [EOC] has been built for CDEM use and is resistant to hazards such as earthquake, flood, cyclone and tsunami. The civil defence officers and district planners were also asked about the hazard resistance of the building in which they currently work. Compared to 71 percent of the civil defence officers, only 14 percent of the district planners believed that their current office building is hazard resistant. About 29 percent of the district planners were not sure and the other 43 percent said that their building is not resistant to any hazard.

\subsubsection{Non-structural Measures}

Public education is an important non-structural method of hazard mitigation in the region. Information about hazards is mainly provided by the GWRC, and at local council level, civil defence officers coordinate the distribution. GWRC provides hazard information through various channels including television, radio, pamphlets, posters and yellow pages. In addition, the Rural Fire Authority and Earthquake Commission [EQC] also provide information to the local people about relevant hazards. Although the given information is an important source of hazard awareness, a large part of this information deals with how to be prepared for hazards rather than the methods to reduce them.

In the scheduled questionnaires and interviews, the civil defence officers and district planners were asked whether the local population has been provided information about the nine mentioned hazards. While a high proportion of civil defence officers named a range of hazards, very few district planners could
Fig: 7.2. Hazard Information Given to Local People in the Region as Mentioned by Civil Defence Officers and District Planners

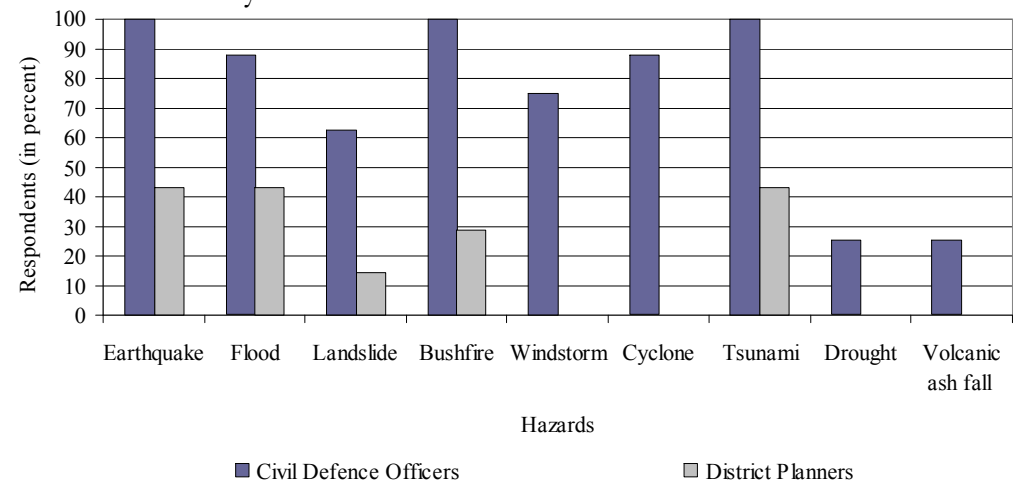

Based on Primary Survey, 2007

Table: 7.2. Hazard Information Provided to Local Population as Mentioned by Civil Defence Officers

\begin{tabular}{|c|c|c|c|c|}
\hline \multirow[t]{2}{*}{$\begin{array}{l}\text { Territorial } \\
\text { authorities }\end{array}$} & \multirow{2}{*}{$\begin{array}{c}\text { Number of hazards for } \\
\text { which information } \\
\text { provided }\end{array}$} & \multicolumn{3}{|c|}{$\begin{array}{l}\text { Type of Hazard Information Provided } \\
\text { (percent of total hazards) }\end{array}$} \\
\hline & & Hazard characteristics & Vulnerability & How to respond \\
\hline Masterton & 9 & 100 & 100 & 100 \\
\hline South Wairarapa & 8 & 0 & 100 & 100 \\
\hline Wellington & 7 & 100 & 100 & 100 \\
\hline Hutt Valley & 7 & 86 & 86 & 86 \\
\hline Carterton & 7 & 0 & 100 & 100 \\
\hline Kapiti Coast & 5 & 100 & 100 & 100 \\
\hline Porirua & 3 & 100 & 100 & 33 \\
\hline
\end{tabular}


answer this question with confidence. None of district planners throughout the region mentioned windstorm, cyclone, drought or volcanic ash fall (Fig: 7.2). The reason behind high differences in the answers of civil defence officers and district planners is that district planners are not directly linked with the process of distributing hazard information to the local people. However, since their work involves hazard planning, their awareness about hazards and related information is essential.

Table: 7.2 shows the number of hazards and type of hazard information provided to the local people in the region, as mentioned by the civil defence officers. The data show that in Masterton information about all nine hazards is given to the local people. In Porirua on the other hand, the information is only provided for earthquakes, bushfires and tsunami, which mainly dealt with hazard characteristics and vulnerability of local people. The only hazard for which information is provided about how to respond is earthquakes. The hazard information provided in South Wairarapa or Carterton mainly dealt with the vulnerability of people and how to respond to hazards, but did not focus on hazard characteristics.

The respondents were also asked what percentage of the local population they think are aware about the nine mentioned hazards. A considerable variation is noted in the public awareness for the number of hazards as perceived by the civil defence officers (Fig: 7.3). The data show that for most hazards (i.e. 6 or more out of 9), public awareness is perceived high (i.e. $>60 \%$ ) in

Fig: 7.3. Hazard Awareness of Local Population as Perceived by Civil Defence Officers

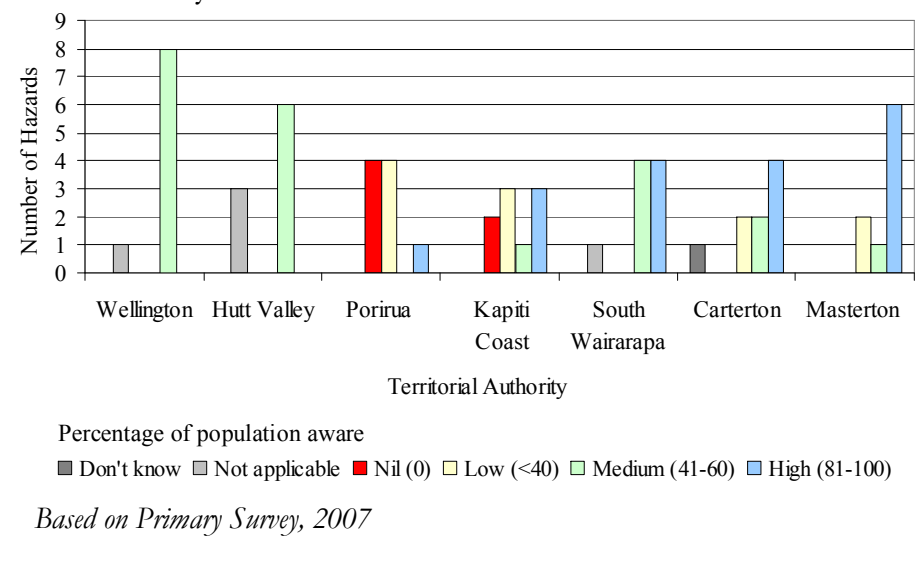
Masterton, medium (40-60\%) in Wellington and low $(<40 \%)$ in Porirua.

A greater variation is also noted in the perceived public awareness of hazards by district planners and civil defence officers (Fig: 7.4). While civil defence officers ranked public awareness from medium to high categories for most hazards, district planners were either not sure or they

Fig: 7.4. Public Awareness of Hazards as Perceived by Civil Defence Officers and District Planners

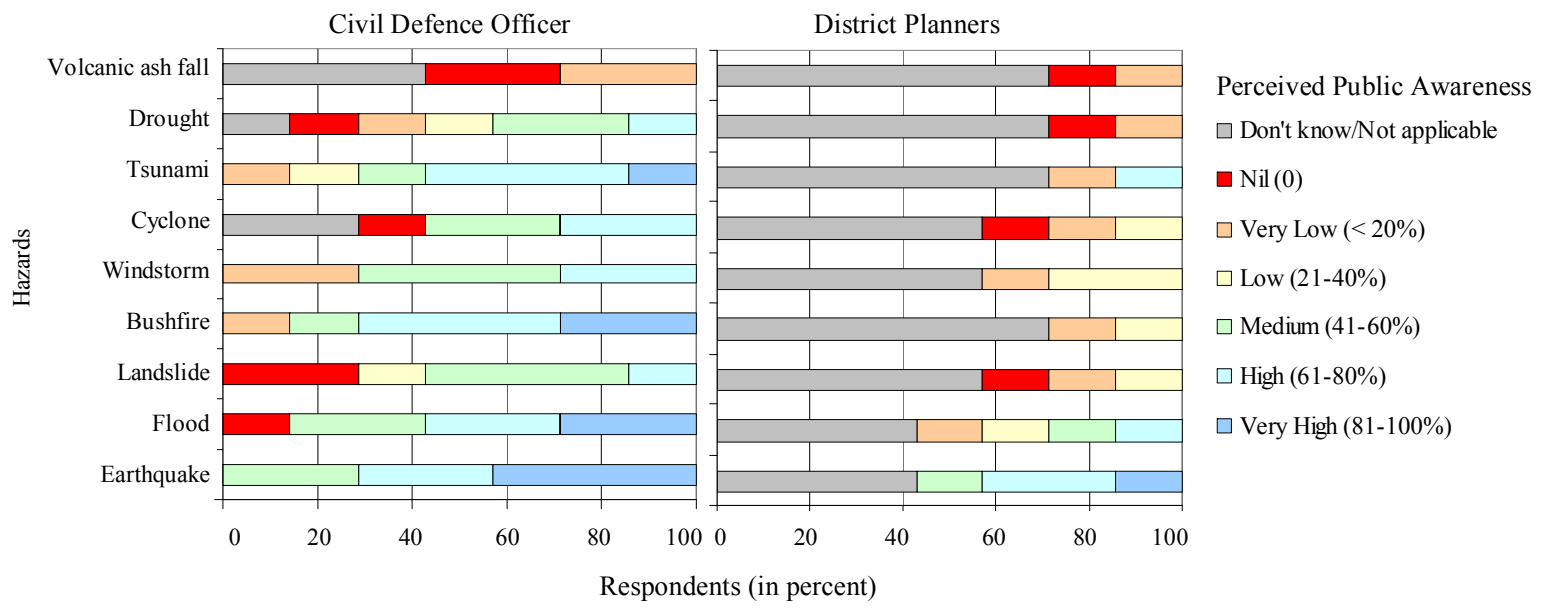


found many hazards to be inapplicable to their districts. However both groups of officers perceived medium to high public awareness for earthquakes and low to poor for volcanic ash fall throughout the region.

In order to know the overview of hazard mitigation work by the administration, the civil defence officers and district planners were also asked about the type of work that has been done in their respective city or district to control or reduce hazards. The data show that while all respondents agreed that there has been work done to mitigate earthquakes and flooding hazards, none of the officers were sure about any work related to volcanic ash fall (Fig: 7.5). A variation can also be noted in the type of work done with respect to different hazards. The work mentioned by civil defence planners and district officers is also closely related to their current profession. For example, while district planners emphasised land use control through city/district development plans along with restriction on resource use such as use of fire or water restrictions, many civil defence officers mentioned evacuation plans, which was not mentioned by any district planner.

Fig: 7.5. Types of Work Done to Reduce Different Hazards as Mentioned by Civil Defence

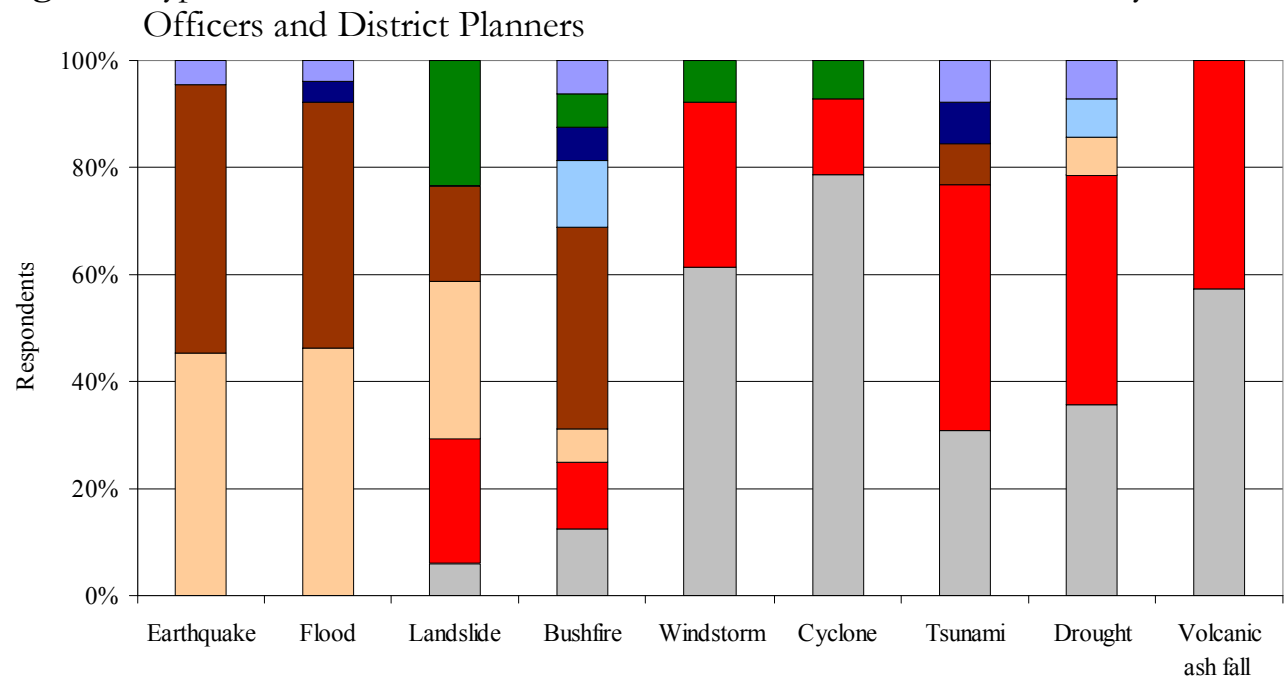
Hazards

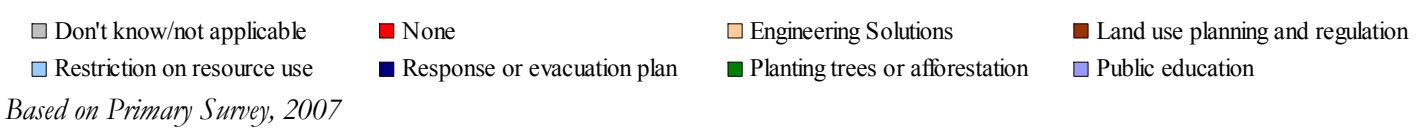

The types of mitigation works mentioned by civil defence officers and district planners indicate that most of these measures either focus on the source of hazard or the physical susceptibility. None of the respondents mentioned any work that reduces vulnerability of the

Table: 7.3. Work Done in Territorial Authorities to Reduce Individual Vulnerability to Hazards

\begin{tabular}{lccc}
\hline Works done & \multicolumn{3}{c}{ Response in percent } \\
\cline { 2 - 4 } & Civil Defence Officers & District planners & Total \\
\hline Public education & 71 & 0 & 36 \\
Land use control & 0 & 29 & 14 \\
Identifying hazard & 0 & 14 & 7 \\
Warning & 0 & 29 & 14 \\
Don't know & 0 & 14 & 7 \\
Not answered & 29 & 29 & 36 \\
\hline
\end{tabular}


people in terms of fragility or coping capacity.

The respondents were also asked specifically whether any work has been done to reduce individual vulnerability. It was rather a difficult question to answer for many respondents. While about 43 percent of officers did not answer this question, civil defence officers mainly mentioned public information and awareness, the district planner named hazard identification, land use control and warning systems as the measures taken by the administration to reduce public vulnerability (Table: 7.3 ).

The data thus show that there is a lack of understanding about the concept of vulnerability. Although public education empowers people with knowledge about hazards and response, it does not reduce vulnerability based on physical or socio-economic conditions. Similarly, land use control modifies the susceptibility and reduces the hazard exposure, but it does not reduce either the fragility or lack of coping capacity. Also, although identifying hazard or warning system modifies hazard response, it has less implication for vulnerability reduction.

\subsection{Administrative Preparedness for Hazards in the Wellington Region}

Preparedness is another form of hazard response. The National and the Wellington Region CDEM plans use the term readiness for preparedness. The National CDEM Strategy defines readiness as "developing operational systems and capabilities before an emergency happens; including self help and response programmes for the general public and specific programs for emergency services, lifeline utilities and other agencies" (DIA, 2007, 5). Various hazard preparedness measures adopted in the region include plans and policies, public education programs, emergency stocks and disaster exercises.

\subsubsection{Plans and Policies}

The city/district development plans in the region mainly focus on hazard mitigation rather than preparedness. The only plan that considers public preparedness, is the Proposed Combined Wairarapa District Development Plan, which has a policy to "raise awareness and educate people about the risks of natural hazards, and prepare them for the occurrence of natural hazard events through the provision of information and advice" (Proposed Combined Wairarapa District Plan, 2006, 77). Long-term community development plans of districts, on the other hand, place more emphasis on preparedness. However, the area of focus for hazard preparedness differs throughout the region. Whereas the Upper Hutt plan aims for all four aspects of hazard preparedness i.e. coordination, public education, exercises and professional development, the South Wairarapa plan emphasises public education and exercises. Both Masterton and Wellington's long-term plans focus on coordination and public education, however in Wellington city, the public education program is only restricted to schools and businesses. In Carterton, its long-term plan asks to organise sufficient resources to respond to any natural hazard, while in the Kapiti Coast it recognises the need for better coordination in civil defence response. The long-term plan of Lower Hutt, on the other hand, does not talk about preparedness. However, it is difficult to measure the preparedness 
achieved through long-term community development plans because even though they mention the budget for CDEM activities, they do not provide the details for the preparedness activities carried out in respective districts.

Although there is a common CDEM plan for all cities and districts in the region, which talks about the preparedness of administration and local people for natural hazards, the respondent officers were asked if there is any hazard specific plan for CDEM in their respective city/district. A greater variation is noted among districts regarding such plans (Fig: 7.6). While the officers from Wellington city mentioned hazard specific plans for six different hazards, three plans each were mentioned in the Kapiti Coast, South Wairarapa and Carterton district. On the other hand, no plan is reported from Hutt Valley i.e. Lower Hutt and Upper Hutt, Porirua and Masterton. The highest number of plans was made for earthquake (4) followed by flood (3), bushfire (2), tsunami (2), drought (2), landslide (1) and volcanic ash fall (1). The officers were also asked if the CDEM or hazard specific plans consider vulnerability of local population through age, gender, disability, etc. It was clear from their answers that CDEM plans do not focus on specific vulnerabilities, but are

Fig: 7.6. Hazard Specific Plans as Mentioned by Civil Defence Officers and District Planners

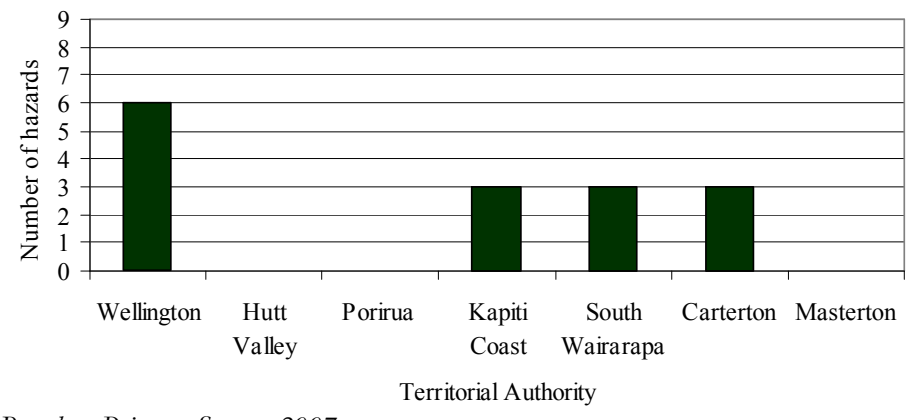

Based on Primary Survey, 2007 general for all.

Fig: 7.7. CDEM Plan for the Staff in the Office of Civil Defence Officers and District Planners

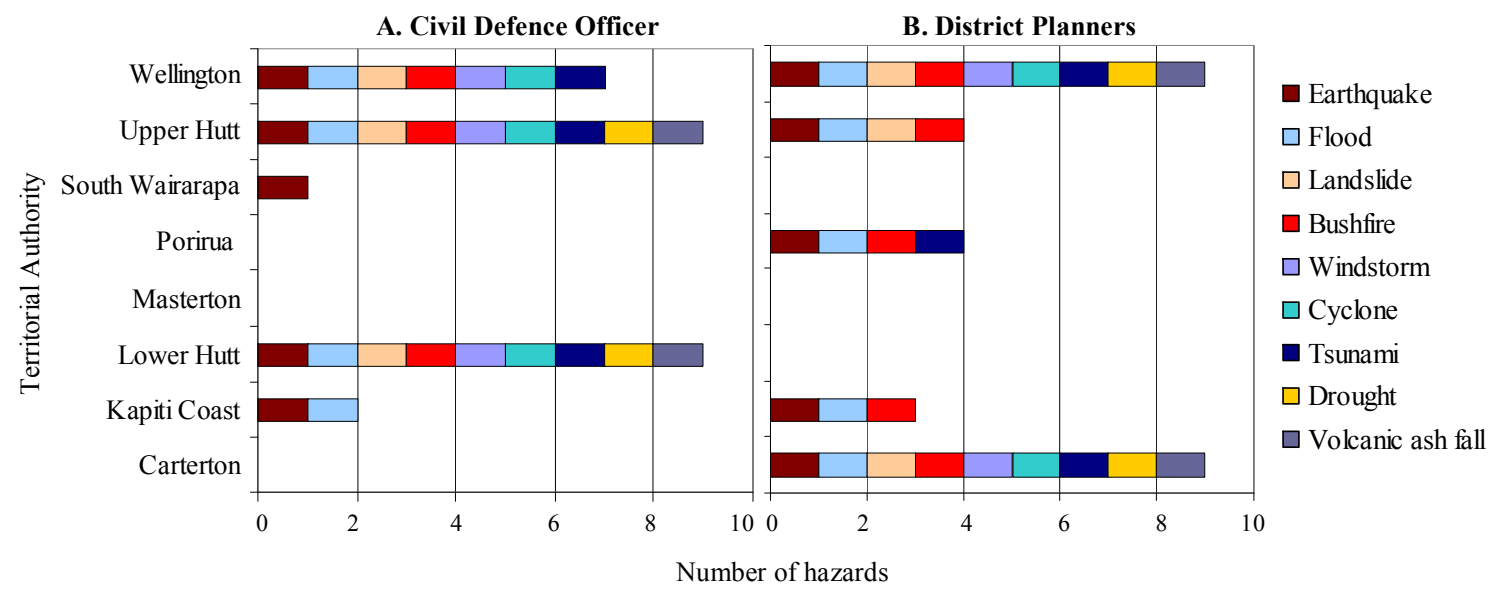

Based on Primary Survey, 2007

The civil defence officers and district planners were also asked if there is any CDEM plan for the safety of employees of their organisation. While the CDEM office of Hutt Valley mentioned having plans for all hazards, no such plan was reported from Porirua, Masterton, and Carterton except for the health and safety policy, which is adopted throughout the region (Fig: 7.7A). District Planners from Wellington city and Carterton on the other hand, reported to have 
emergency plan for all hazards, but no such plan was mentioned in South Wairarapa, Masterton and Lower Hutt (Fig: 7.7B).

\subsubsection{Emergency Stock}

Emergency stock is an important aspect of disaster preparedness. Both regional and local councils have emphasised the preparedness of local people by asking them to store emergency materials or survival kits for at least three days. In order to know the preparedness of the local councils, the civil defence officers were asked whether their respective city or district administration has stored emergency resources for any particular disaster. While Carterton and Masterton districts did not have any emergency stock, the South Wairarapa district administration has stored first aid kits for flood and earthquake victims. Porirua and the Kapiti Coast, on the other hand, have an emergency supply of water for nearly 5000 and 2000 people respectively. In Porirua, while the water is stored for earthquakes, in the Kapiti Coast it is stored for floods. The Wellington CDEM office, on the other hand, has stored food, sewage facility and power supply for its staff, which could sustain 50 people for nearly a month. The CDEM office of Lower and Upper Hutt has stored food and other material for an emergency through any hazard. The material stored can sustain about 20-30 people for nearly five days. In total while five out of seven civil defence offices mentioned having a survival kit for the employees of their organisations, only three out of seven district planners are noted to have survival kits in their office.

\subsubsection{Emergency Exercises}

The National Civil Defence Plan Order $(2005,46)$ asks for civil defence emergency management exercises as a means by which the operational capability of agencies, the CDEM groups and their partners, such as lifeline utilities, may be tested in relation to civil defence emergency management. The disaster scenarios conducted by the territorial authorities of the region in the past five years show that both the number of exercises and the type of hazards for which they have been performed differ throughout the region (Table: 7.4). The data show that all the disaster exercises have been performed either for earthquakes, floods or tsunami.

Table: 7.4. Disaster Scenario Conducted in the Wellington Region (2003-2007)

\begin{tabular}{lcccc}
\hline City or District Councils & \multicolumn{3}{c}{ Disaster Scenario } & \multirow{2}{*}{ Total } \\
\cline { 2 - 4 } & Earthquake & Flood & Tsunami & \\
\hline Wellington & 5 & 0 & 0 & 5 \\
Lower and Upper Hutt & 3 & 5 & 1 & Not answered \\
Porirua & 1 & 0 & 1 & 6 \\
Kapiti coast & 0 & 6 & 0 & 2 \\
South Wairarapa & 0 & 2 & 0 & 5 \\
Carterton & 4 & 0 & 1 & 5 \\
Masterton & 4 & 0 & 1 & $\mathbf{3 4 +}$ \\
Total & $\mathbf{1 7}$ & $\mathbf{1 3}$ & $\mathbf{4}$ &
\end{tabular}

The highest number of disaster exercises in the region has been performed for earthquakes. In Wellington city all the five disaster scenarios were conducted for earthquakes which can be attributed to the high susceptibility of the city. However, in Carterton and Masterton districts, four out of five exercises were performed for earthquakes, even though the risk from earthquake is low 
compared to other parts of the region. The reason could be partly attributed to the overall high emphasis on earthquake preparedness throughout the region, besides the exposure of these districts to significant damage through disrupted services and loss of communication. On the other hand, the highest disaster scenario for flood has been conducted in the Kapiti Coast (6) followed by Hutt Valley (5) and South Wairarapa (2). All of these districts are susceptible to frequent flooding and experience regular damage through them. Individual tsunami disaster scenarios have been conducted in Hutt Valley, Porirua, Carterton and Masterton, but many other areas which are at high risk, such as Wellington, the Kapiti Coast and South Wairarapa, did not practice any disaster exercise for tsunami. Moreover, these disaster scenarios mainly involved the trained staff and emergency management officers and local people were not involved.

The civil defence officers and district planners were also asked to what extent they think the district administration is prepared to deal with hazards. The data show that while a high proportion of civil defence officers (80 percent) perceived administration to be moderately or well prepared for most hazards, many district planners were either not sure or perceived it to be moderately or poorly prepared for most hazards. Only 19 percent of the district planners believed that the administration was well prepared. The highest preparedness level was perceived in Wellington, followed by Hutt Valley, the Kapiti Coast and South Wairarapa (Fig: 7.8).

In terms of hazards, the highest preparedness level was perceived for earthquakes followed by floods and bushfires, and minimum for volcanic ash fall. When respondents were asked about the barriers of total preparedness for hazards in their respective districts, a high proportion of officers (5/14) mentioned financial costs and lack of coordination followed by four officers who found lack of staff to be the main reason. Unwillingness and lack of knowledge and lack of awareness are also pointed out as barriers to full preparedness.

Fig: 7.8. Administrative Preparedness to Deal with Hazards in Local Councils as Perceived by Civil Defence Officers and District Planners

\begin{tabular}{|c|c|c|c|c|c|c|c|c|c|}
\hline \multirow{2}{*}{$\begin{array}{l}\text { Territorial } \\
\text { Authorities }\end{array}$} & \multicolumn{9}{|c|}{ Hazards (Preparedness Level) } \\
\hline & Earthquake & Flood & Landslide & Bushfire & Windstorm & Cyclone & Tsunami & Drought & $\begin{array}{c}\text { Volcanic } \\
\text { ash fall }\end{array}$ \\
\hline & \multicolumn{9}{|c|}{ As Perceived By Civil Defence Officers } \\
\hline \multicolumn{10}{|l|}{ Carterton } \\
\hline \multicolumn{10}{|l|}{ Hutt Valley } \\
\hline \multicolumn{10}{|l|}{ Kapiti Coast } \\
\hline \multicolumn{10}{|l|}{ Masterton } \\
\hline \multicolumn{10}{|l|}{ Porirua } \\
\hline \multicolumn{10}{|c|}{ South Wairarapa } \\
\hline \multicolumn{10}{|l|}{ Wellington } \\
\hline & \multicolumn{9}{|c|}{ As Perceived By District Planners } \\
\hline \multicolumn{10}{|l|}{ Carterton } \\
\hline \multicolumn{10}{|l|}{ Kapiti Coast } \\
\hline \multicolumn{10}{|l|}{ Lower Hutt } \\
\hline \multicolumn{10}{|l|}{ Porirua } \\
\hline \multicolumn{10}{|c|}{ South Wairarapa } \\
\hline \multicolumn{10}{|l|}{ Upper Hutt } \\
\hline \multicolumn{10}{|l|}{ Wellington } \\
\hline \multicolumn{10}{|l|}{ Scale } \\
\hline $\begin{array}{l}\text { Extent of } \\
\text { Preparedness }\end{array}$ & $\begin{array}{l}\text { Don't Know/Not } \\
\text { applicable/Not } \\
\text { answered }\end{array}$ & $\begin{array}{c}\text { Not } \\
\text { prepared at } \\
\text { all }\end{array}$ & $\begin{array}{c}\text { Poorly } \\
\text { prepared }\end{array}$ & $\begin{array}{c}\text { Moderately } \\
\text { prepared }\end{array}$ & Well Prepared & & & & \\
\hline
\end{tabular}


The respondents were also asked to what extent they think that district administration is prepared for the safety of its own employees. Again while a high proportion of civil defence officers perceived the administration to be well prepared, nearly fifty percent of the district planners found it to be either moderately or poorly prepared (Fig: 7.9).

Fig: 7.9. Administrative Preparedness for Employees as Perceived by Civil Defence Officers and District Planners

Civil Defence Officers

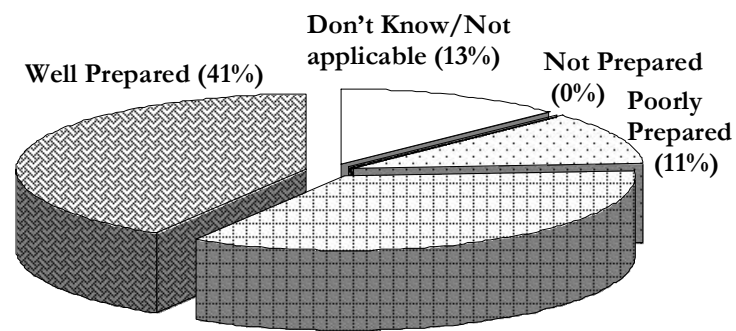

Moderately Prepared (35\%)
District Planners

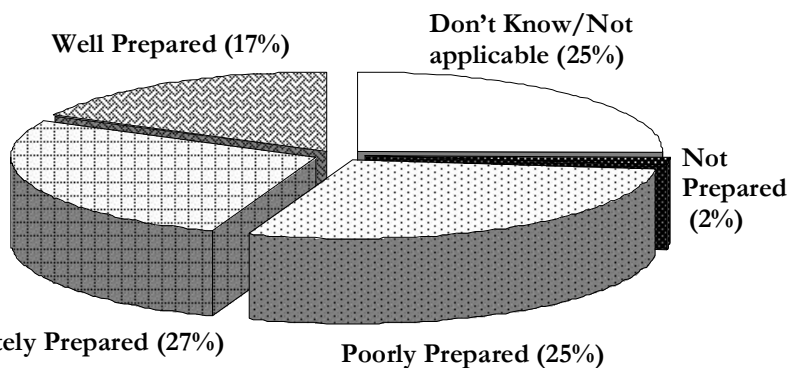

Based on Primary Survey, 2007

The barriers mentioned by the officers behind the shortcomings in administrative preparedness for its employees included financial problems, lack of staff and lack of coordination as noted by five officers along with unwillingness, which is mentioned by two officers. However, three officers did not see any barrier, two officers did not answer the question and another two could not specify any particular reason.

\subsubsection{Public Information for Preparedness}

Public awareness for hazards and response measures has been emphasised in CDEM planning for preparedness at both regional and national level. However, at the local level, variations are noted in the information given to local people. While information about

Photo: 7.1. Hazard Preparedness Brochures Provided by the Greater Wellington Regional Authority earthquakes is provided in all districts with a guideline for how to respond to the hazard, only one district provided information for

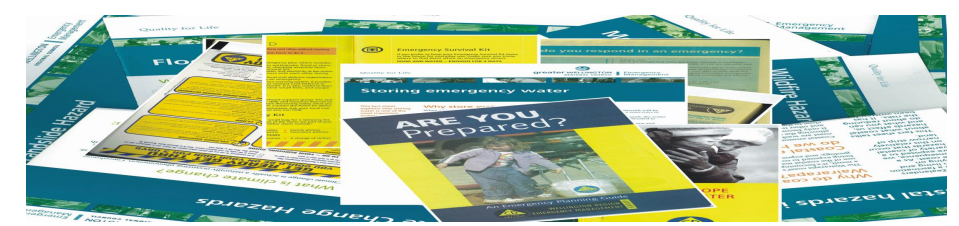
drought and two districts for volcanic ash fall (Table: 7.5).A few other significant hazards have also been left out in many districts irrespective of their high physical susceptibility such as flood and

Table: 7.5. Hazard Information Provided to Local People as Mentioned by Civil Defence Officers

\begin{tabular}{|c|c|c|c|c|c|c|c|c|c|}
\hline Local city/ & & & & & Hazards & & & & \\
\hline $\begin{array}{l}\text { district } \\
\text { councils }\end{array}$ & Earthquake & Flood & Landslide & Bushfire & Windstorm & Cyclone & Tsunami & i Drought & $\begin{array}{c}\text { Volcanic } \\
\text { ash fall }\end{array}$ \\
\hline Wellington & $\sqrt{ }$ & $\sqrt{ }$ & $\sqrt{ }$ & $\sqrt{ }$ & $\sqrt{ }$ & $\sqrt{ }$ & $\sqrt{ }$ & $x$ & $\chi$ \\
\hline Porirua & $\sqrt{ }$ & $\chi$ & $\chi$ & $\sqrt{ }$ & $\chi$ & $\chi$ & $\sqrt{ }$ & $\chi$ & $\chi$ \\
\hline Kapiti Coast & $\sqrt{ }$ & $\sqrt{ }$ & $\chi$ & $\chi$ & $\chi$ & $\sqrt{ }$ & $\sqrt{ }$ & $x$ & $\chi$ \\
\hline Hutt Valley & $\sqrt{ }$ & $\sqrt{ }$ & $\sqrt{ }$ & $\sqrt{ }$ & $\sqrt{ }$ & $\chi$ & $\chi$ & $\chi$ & $\chi$ \\
\hline South Wairarapa & $\sqrt{ }$ & $\sqrt{ }$ & $\sqrt{ }$ & $\sqrt{ }$ & $\sqrt{ }$ & $\sqrt{ }$ & $\sqrt{ }$ & $\chi$ & $\chi$ \\
\hline Carterton & $\sqrt{ }$ & $\sqrt{ }$ & $\sqrt{ }$ & $\sqrt{ }$ & $\sqrt{ }$ & $\sqrt{ }$ & $\sqrt{ }$ & $\chi$ & $\sqrt{ }$ \\
\hline Masterton & $\sqrt{ }$ & $\sqrt{ }$ & $\sqrt{ }$ & $\sqrt{ }$ & $\sqrt{ }$ & $\sqrt{ }$ & $\sqrt{ }$ & $\sqrt{ }$ & $\sqrt{ }$ \\
\hline
\end{tabular}


Fig: 7.10. Proportion of Local People Prepared for Hazards as Perceived by Civil Defence Officers and

District Planners

\begin{tabular}{|c|c|c|c|c|c|c|c|c|c|}
\hline \multirow{3}{*}{$\begin{array}{l}\text { Territorial } \\
\text { Authority }\end{array}$} & \multicolumn{9}{|c|}{ Preparedness of Local People for different hazards } \\
\hline & Earthquake & Flood & Landslide & Bushfire & Windstorm & Cyclone & Tsunami & Drought & $\begin{array}{l}\text { Volcanic } \\
\text { ash fall }\end{array}$ \\
\hline & \multicolumn{9}{|c|}{ As Perceived by Civil Defence Officers } \\
\hline \multicolumn{10}{|l|}{ Carterton } \\
\hline \multicolumn{10}{|l|}{ Kapiti Coast } \\
\hline \multicolumn{10}{|l|}{ Hutt Valley } \\
\hline \multicolumn{10}{|l|}{ Masterton } \\
\hline \multicolumn{10}{|l|}{ Porirua } \\
\hline \multicolumn{10}{|l|}{ South Wairarapa } \\
\hline \multicolumn{10}{|l|}{ Wellington } \\
\hline & \multicolumn{9}{|c|}{ As Perceived by District Planners } \\
\hline \multicolumn{10}{|l|}{ Carterton } \\
\hline \multicolumn{10}{|l|}{ Kapiti Coast } \\
\hline \multicolumn{10}{|l|}{ Lower Hutt } \\
\hline \multicolumn{10}{|l|}{ Porirua City } \\
\hline \multicolumn{10}{|l|}{ South Wairarapa } \\
\hline \multicolumn{10}{|l|}{ Upper Hutt } \\
\hline \multicolumn{10}{|l|}{ Wellington } \\
\hline \multicolumn{10}{|l|}{ Scale } \\
\hline Proportion of & Don't & $0 \%$ & $1-20 \%$ & $21-40 \%$ & $41-60 \%$ & $61-80 \%$ & $81-100 \%$ & & \\
\hline Local People & know/Not & None & Very Low & Low & Medium & High & Very High & & \\
\hline Perceived to be & applicable/ & & & & & & & & \\
\hline Prepared & Not answered & & & & & & & & \\
\hline
\end{tabular}

landslide in Porirua, landslide in the Kapiti Coast and tsunami in Lower Hutt.

Besides, even though most of the territorial authorities claimed to have provided information about tsunami, the sign posts of tsunami have been put up only at the eastern coast of Masterton, Carterton and South Wairarapa that inform people about how to respond in case of a big earthquake (Grant, 2005, 21). In urban areas like Wellington, Lower Hutt, the Kapiti Coast and Porirua, where the risk is very high, such measures are not found. Wellington City Council has, however, prepared a separate guide for "Be Ready for an Emergency", which details what to do

Fig: 7.11. Extent to Which Local People are Perceived to be Prepared for Different Hazards by Civil Defence Officers and District Planners

\begin{tabular}{|c|c|c|c|c|c|c|c|c|c|}
\hline \multirow{3}{*}{$\begin{array}{l}\text { Territorial } \\
\text { Authority }\end{array}$} & \multicolumn{9}{|c|}{ Preparedness of Local People for different hazards } \\
\hline & Earthquake & Flood & Landslide & Bushfire & Windstorm & Cyclone & Tsunami & Drought & $\begin{array}{c}\text { Volcanic } \\
\text { ash fall }\end{array}$ \\
\hline & \multicolumn{9}{|c|}{ Civil Defence Officers } \\
\hline \multicolumn{10}{|l|}{ Carterton } \\
\hline \multicolumn{10}{|l|}{ Hutt Valley } \\
\hline \multicolumn{10}{|l|}{ Kapiti Coast } \\
\hline \multicolumn{10}{|l|}{ Masterton } \\
\hline \multicolumn{10}{|l|}{ Porirua } \\
\hline \multicolumn{10}{|l|}{ South Wairarapa } \\
\hline \multicolumn{10}{|l|}{ Wellington } \\
\hline & \multicolumn{9}{|c|}{ District Planners } \\
\hline \multicolumn{10}{|l|}{ Carterton } \\
\hline \multicolumn{10}{|l|}{ Kapiti Coast } \\
\hline \multicolumn{10}{|l|}{ Lower Hutt } \\
\hline \multicolumn{10}{|l|}{ Porirua City } \\
\hline \multicolumn{10}{|l|}{ South Wairarapa } \\
\hline \multicolumn{10}{|l|}{ Upper Hutt } \\
\hline \multicolumn{10}{|l|}{ Wellington } \\
\hline Scale & & & & & & & & & \\
\hline $\begin{array}{l}\text { Extent to which } \\
\text { Local People are } \\
\text { Perceived to be } \\
\text { Prepared }\end{array}$ & $\begin{array}{c}\text { Don't } \\
\text { know/Not } \\
\text { applicable/ } \\
\text { Not answered } \\
\end{array}$ & $\begin{array}{c}\text { Not } \\
\text { prepared at } \\
\text { all }\end{array}$ & $\begin{array}{c}\text { Poorly } \\
\text { prepared }\end{array}$ & $\begin{array}{c}\text { Moderately } \\
\text { prepared }\end{array}$ & $\begin{array}{c}\text { Well } \\
\text { Prepared }\end{array}$ & & & & \\
\hline
\end{tabular}


and how to be prepared for hazards including fire, bushfire, earthquake, tsunami, storm, pandemic, flood and technological hazard.

The officers were asked about what proportion of the local population they think is prepared to deal with hazards. The data show that while civil defence officers perceived a high proportion of the local population to be prepared for most hazards, most of the district planners were either not sure or they found it to be less than 40 percent (Fig: 7.10). Carterton is the only district where preparedness level of the local population is perceived to be high by its district planner. The reason could be attributed to infrequent hazard occurrence and low potential risk in the district.

In terms of extent of public preparedness perceived by officers, while a high proportion of civil defence officers (62 percent) believed that the population in their respective district is moderately prepared, a major share of district planners (45 percent) perceived the local people to be poorly prepared (Fig: 7.11).

The community preparedness survey of the region for 2007, on the other hand, shows a steady increase in the preparedness level from 2004 onwards in terms of storing food, water and emergency equipment (Table: 7.6.). This indicates that the perception of Civil Defence Officers aligns more closely with the actual preparedness than District Planners.

Table: 7.6. Community Preparedness Level in the Wellington Region

\begin{tabular}{lccc}
\hline Emergency Preparedness Measure & \multicolumn{3}{c}{ Percentage of prepared people } \\
\cline { 2 - 4 } & $\mathbf{2 0 0 4}$ & $\mathbf{2 0 0 5}$ & $\mathbf{2 0 0 6}$ \\
\hline Food supplies & 61 & 65 & 70 \\
Water supplies & 68 & 69 & 71 \\
Equipment supplies & 69 & 69 & 75 \\
Plan & 31 & 26 & 27 \\
\hline Based on Blakeley, 2007, 2-3 & &
\end{tabular}

However, it is important to note that still a significant proportion of people i.e. about 40 percent on an average have not adopted all preparedness measures. Both civil defence officers and district planners mainly see unwillingness and financial costs behind the lack of preparedness among local people.

\subsection{Administrative Arrangements for Emergency Response in the Wellington Region}

The National CDEM Strategy defines emergency response as actions taken immediately before, during and directly after an emergency to save lives and protect property and to help communities to recover (DIA, 2007, 5). The various measures taken in the region for emergency response include plans, warning systems, response resources and alternative services.

\subsubsection{Plans}

For emergency response, there is a Wellington Region CDEM Group Plan, which is followed by all territorial authorities of the region. The plan is generic in nature, which provides strategic issues, 
objectives and an operational framework to achieve an integrated hazard response throughout the region. Although the prime responsibility of managing hazards at local level lies with civil defence officers, most of them denied having their own plan with specific details of hazards in the district. Rather, they follow the Standard Operating Procedures (SOP), which is common for all hazards and emergencies.

The civil defence officers in the region were asked whether they have any evacuation plan to avoid hazards. The three districts which mentioned having such plans include Wellington, the Kapiti Coast and South Wairarapa. While Wellington has an evacuation plan for earthquake and flooding, the Kapiti Coast has it for flooding and South Wairarapa for earthquake, flooding, landslide, bushfire, tsunami and drought. Absence of evacuation plans in a number of districts, particularly for hazards such as tsunami, where a well-planned evacuation could save thousands of lives, enhances the vulnerability to disaster. The response time after a tsunami warning tends to be very short i.e. a few minutes to few hours. It may be sufficient for an individual to move out of the vulnerable location, but it would be too short to evacuate thousands of people living on the coast. During the Primary Survey it was noted that many of the coastal areas have one way streets, which may not handle heavy traffic at the time of evacuation, and could block the traffic and people could go nowhere. This was also a concern from respondents living in the Kapiti Coast next to the sea. Also, when local people are not aware of any evacuation ground, the last minute rush could result in traffic chaos and more people may rush to the same place, which may not be able to shelter all. Fear of the unknown intensity of hazard, could further enhance the chaos. Therefore, absence of an evacuation plan could be seen as a major shortcoming of administrative response. The district planners, on the other hand, were asked if there was any evacuation plan for the employees of their organisations. The three planners that mentioned having an evacuation plan were from Wellington, the Kapiti Coast and Carterton.

\subsubsection{Warning Systems}

Warning systems are the other important need of the real time response. For major hazards, warning information is first available at the Greater Wellington Regional Council [GWRC], which then forwards this information to Territorial Authorities, who warn people if required. The resources available to warn the people however differ in different councils. While major cities of the region including Wellington, Lower Hutt and Upper Hutt have a range of warning systems including sirens, public address systems, and websites, the smaller places such as Porirua and Carterton depend on media such as radio and television for public warnings. Other arrangements particular to certain districts include a siren in the coastal areas of Masterton for tsunami, satellite phones in South Wairarapa for floods and a helicopter public warning system in Wellington.

\subsubsection{Staff and Other Resources}

The number and capacity of civil defence staff often has a significant influence on the emergency response. A wide variation is noted in the staff capacity of the civil defence organisations throughout the region. While there is eight full time staff along with 50 trained staff at the Wellington CDEM office, there is a single part-time civil defence officer at the Carterton district council. In other districts, the number of civil defence staff ranges from two to four. The variation 
in the staff capacity of civil defence organisations reflects both frequency of hazard damage and potential risk. As discussed in chapter 5, while Wellington city has experienced maximum damage from earthquakes, landslides and flooding in past 10 years, Carterton district faced minimum damage.

A significant variation is also noted in the number of civil defence centres in different local councils. The highest number of civil defence centres are located in Wellington (30), followed by Hutt Valley i.e. both Lower Hutt and Upper Hutt (50), 12 in Porirua, 7 in the Kapiti Coast, 11 in Carterton, 5 in urban areas of Masterton and 4 in South Wairarapa. These centres work as both welfare centres as well as information networks for hazards.

\subsubsection{Alternative Arrangements}

Many services are likely to fail during disasters due to damage to infrastructure and loss of communication. In such a situation the question arises of alternative available services. The civil defence officers and district planners in the region were asked whether any alternative arrangements had been made for significant services such as council office, CDEM office, hospital, telecommunication, transport, electricity, gas supplies or for any other services to meet the disaster situation. The response to this question again differed throughout the region. The local authorities that have made alternative arrangements for civil defence operations for disaster include the Kapiti Coast, Hutt Valley including Lower Hutt and Upper Hutt, South Wairarapa, Carterton and Masterton. The list does not include the two urban areas of Wellington and Porirua, which are most likely to be adversely affected by a major earthquake. In Wellington, lifelines services are legally asked to make alternative arrangements and the process is in progress, while in Porirua there is an alternative arrangement for water to the hospital. In South Wairarapa a number of such arrangements have been made including a temporary hospital, temporary shelters and satellite phones at civil defence office at Martinborough along with mobile operational units with all essential services. In Masterton, there is an alternative option for hospital. The overall list of alternative arrangements across the region therefore is not continuous and shows a fragmented pattern of arrangements depending on the availability of resources. Availability of more alternative services in rural districts could be reasoned on the ground of scale of requirements. While a mobile operational unit could be sufficient for a smaller population of South Wairarapa, it would be of little help in case of major disaster if that occurs in Wellington.

\subsection{Administrative Response for Recovery in the Wellington Region}

The National CDEM Strategy defines recovery as "the coordinated efforts and processes to bring about the immediate, medium-term and long-term holistic regeneration of a community following a civil defence emergency" (DIA, 2007, 5). At territorial authority level, however, very few measures were noted to have been taken for recovery. Even though district councils are required to make a plan for recovery, not every district has a plan. At the local level, recovery issue 
has been mainly neglected. District development plans do not have either any objective or policy for disaster recovery. The long-term plans for the districts however do mention recovery planning but do not go in depth or provide details. In June 2002 the Ministry of Civil Defence released the detailed document on 'Preparing a Recovery Plan: information for local authorities'. It describes the task and responsibilities for the local authorities regarding recovery planning, which involves transition from response, managing structure, community involvement, impact assessment, data management, central government involvement, public information, rehabilitation, restoration and assistance, implementation of reduction measures, financial management, reporting and managed withdrawal. However, planning at the local level for recovery is mainly missing. The scheduled questionnaires and interviews conducted in the districts throughout the region show that very few districts have made any kind of recovery plan. The districts which claimed to have a recovery plan include Porirua for earthquakes, the Kapiti Coast for earthquakes and floods, and South Wairarapa for earthquakes, floods, landslide, bushfire, tsunami and drought. These plans do not specify any explicit measures for specific vulnerabilities, and they are generic in nature. The local councils which have recovery plans for their employees include Wellington and Carterton for all hazards along with Porirua which has plans for earthquake, flood and local tsunami.

\subsection{Factors Influencing the Administrative Response to Hazards in the Wellington Region}

The administrative response to hazards in the region is influenced by various biophysical and ecumenical processes operating at the local, regional, national or global scale. These processes have also shaped and modified the hazardscape of the region over time. The following paragraphs discuss the few key factors that have played a significant role in shaping the administrative response.

\subsubsection{Hazard Characteristics and Occurrence}

Hazard occurrence provides the natural trigger for response. Frequency and intensity of hazards further establish the seriousness that governs the nature and type of response measures adopted by the administration. Many of the initial acts and legislation for hazard response were formed after major hazard incidents that caused significant damage in New Zealand. For example, the first earthquake related act i.e. Public Safety Conservation [PSC] Act was formed just after two major earthquakes that hit the North Island in 1929 at Murchison and in 1932 at Napier. These earthquakes generated riots in the respective cities, which subsequently led to the establishment of the PSC act in 1932 (MCDEM, n.d.). Subsequent major developments in earthquake response took place after 10 years, when two other earthquakes hit Wellington and Wairarapa in the early 1940s. The consequent rise in public demand led the government to extend its role in recovery, and subsequently the National Commission for Earthquake and War Damage was established 
(MCDEM, n.d.). Similarly, the frequent occurrence of floods in New Zealand during the 1920s and 1930s provided the impetus for flood legislation (Roche, 1994, 43).

Fig: 7.12. Hazard Characteristics in the Region as Perceived by Civil Defence Officers and District Planners

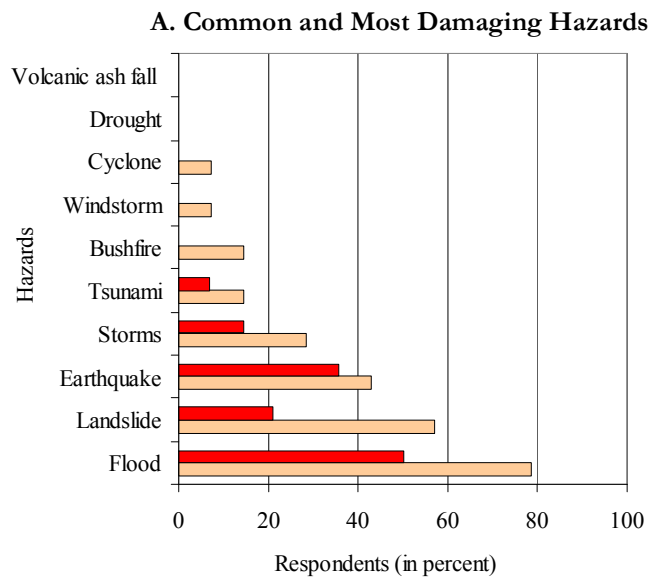

$\square$ The common hazard $\quad$ Most damaging hazard

C. Hazard Frequency

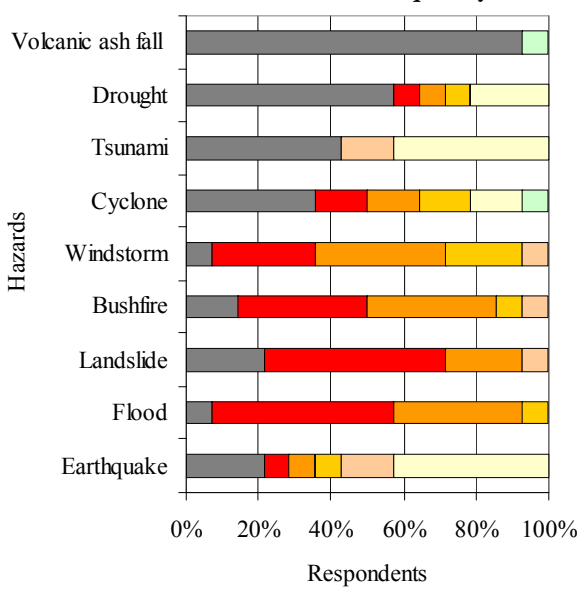

E. Hazard Occurrence in Future

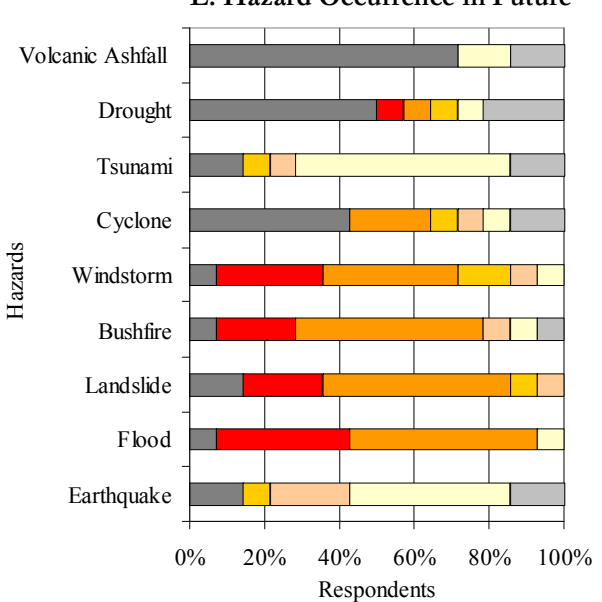

Based on Primary Survey, 2007
B. Frequency of CDEM Services Required

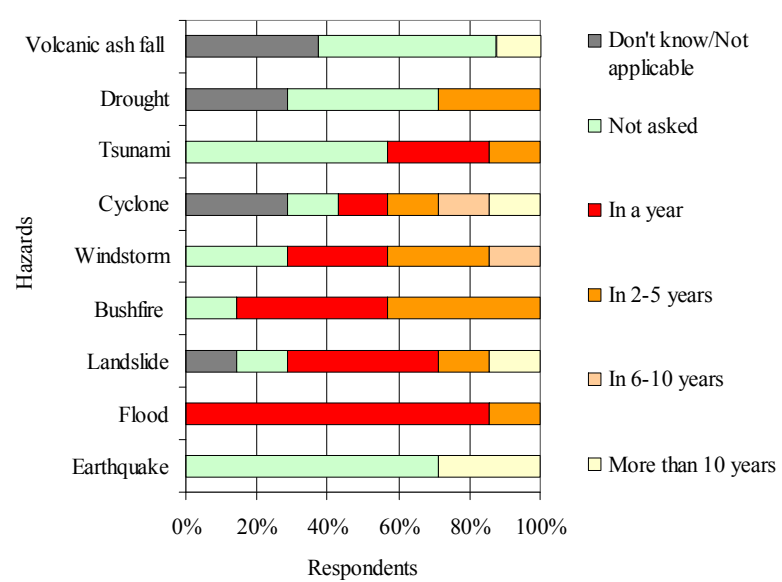

D. Problems from Hazards

$\square$ Don't know/Not applicable/Not answered

W Within a year

$\square$ In 2- 5 years

$\square$ In 6-10 years

$\square$ In 10-20 years

$\square$ Beyond 20 year

$\square$ Never occurred

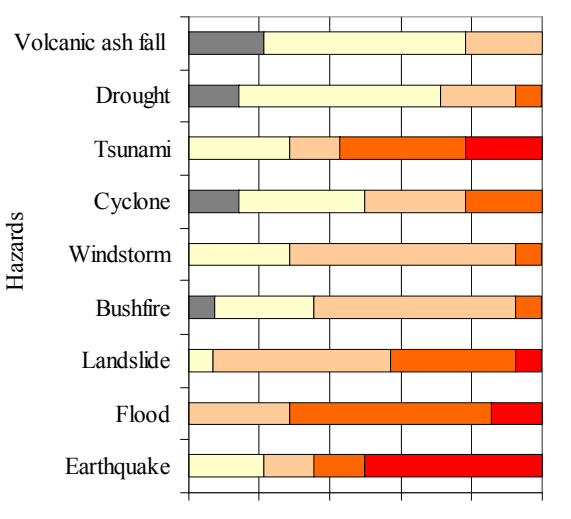

$\square$ Don't know/Not applicable/Not

answered

$\square$ Not problematic

$\square$ Problematic

$\square$ Highly problematic

$\square$ Most serious

Respondents

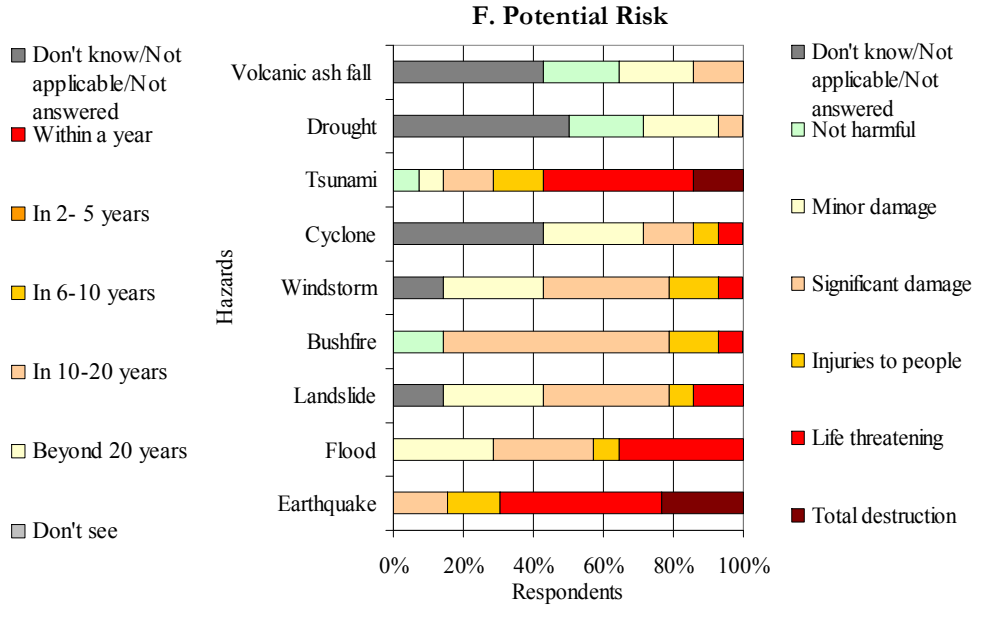

The influence of hazard occurrence is also noted in the current response to hazards. The civil defence officers and district planners were asked whether they experienced any hazard that required CDEM operation and if any lessons were learnt from these incidents. Three districts reported to have experienced emergencies that created alerts at district level in recent years i.e. Lower Hutt, the Kapiti Coast and South Wairarapa. In October-2003 an emergency was declared in 
Paekakariki in the Kapiti Coast District Council that affected 12 houses, hotels and shops. Nearly 20-30 people were affected and civil defence response was activated, welfare centres were opened and recovery work done. Even though the incident did not bring any major changes in the current planning, it made the civil defence team realise that there should be more involvement of local people in civil defence matters. In Lower Hutt, flooding in 2004 resulted in significant damage to houses, business, roads and bridges, and affected nearly 1500 people. Since the event was of big magnitude and affected a greater population in the city, it led to changes in the welfare plan of the city as specified by the civil defence officer of Hutt Valley. Another civil defence emergency was activated in June 2006 in South Wairarapa due to flooding. It affected all parts of the district and widespread damage occurred to houses, roads, bridges and other infrastructure. In total three bridges were damaged and a road near the coast was washed out. Besides, sewage problems were reported in Greytown and Martinborough area. It made the district officials realise that there was a lack of help. However, no lessons were learnt from the incident. The reason could be partly attributed to the lack of significant public demand in the district due to the sparsely populated rural hinterland.

The officers in the region were asked about various characteristics of hazards in their districts. The most common and damaging hazards perceived by the civil defence officers and district planners were floods, landslides and earthquakes (Fig: 7.12). Although landslides are more common, earthquakes are perceived to be more damaging by most officers. Even though most officers did not experience any emergency through earthquake and perceived it to be of low frequency, they found it to be most serious, life threatening and to be able to cause total destruction. The reason for the high perceived threat and concern could be attributed to historical evidence of damage through them. The lack of such evidence for tsunami explains its low significance on the administrative priority list even though officers could see it as highly problematic and a high potential threat. Floods on the other hand are both frequent and damaging in the region. At the same time it also carries a high potential threat, which makes it of high priority in the administrative response. Volcanic ash fall and drought, on the other hand, are perceived to be of lower risk compared to other hazards, which explains the reason for minimum efforts made in the region to reduce these hazards.

\subsubsection{Physical Characteristics}

Physical characteristics of the region have influenced both physical susceptibility and the response to hazards. One major geographical barrier in the uniform response throughout the region is the Rimutaka Range that divides the region into two parts i.e. east and west. The administrative division of the region along this physical barrier first took place in 1870, when the region was divided into two provincial districts namely Port Nicholson, and Wairarapa and East Coast. The division induced many differences in the socio-economic development across this boundary that further influenced the hazard response measures adopted in these segregated parts.

The very first hazard response that was designed along the line of this physical barrier was the establishment of Regional Water Boards, which were made under Soil and Water Conservation Act (1941) for flood mitigation. The two regional boards were later merged in 1989 to form the 
Greater Wellington

Regional Council.

However, various

functions including hazard

response measures have

continued to be divided

and of different standards

even after the unification.

For example, the research

and investigations for

hazards have been

conducted more in-depth

for the western section

compared to the east. An

assessment of detailed

seismic analysis of the

region was only carried out for the four western districts, leaving out three districts of eastern

Wairarapa (Fig: 7.13.A). The reason could be attributed to high potential damage in the west compared to the eastern section.

Similarly, even though the flood problem is more widespread in the east, due to high risk to

$$
\text { properties, }
$$

mitigation measures are more dominant in the west. The division is also apparent in preparedness and response capacities of civil defence. While civil defence services in the western section are relatively more active and prepared, those in eastern parts face resource
Fig: 7.13. The Wellington Region: East \& West Divide

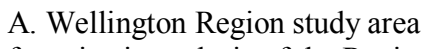
for seismic analysis of the Region
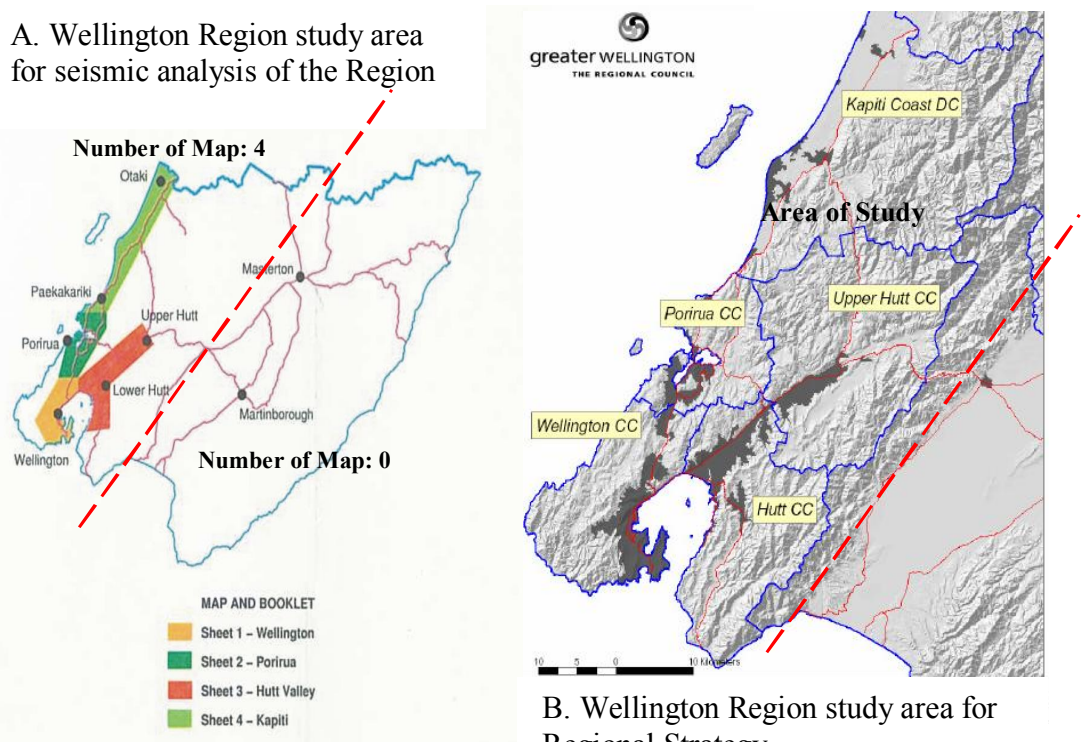

B. Wellington Region study area for Regional Strategy.
Source: Seismic Hazard Map Series, Combined Earthquake hazard Map, 1996, Sheet4; wnw.wrs.govt.nz

Fig: 7.14. Areas Most and Least Susceptible to Hazards as Perceived by Civil Defence Officers and District Planners
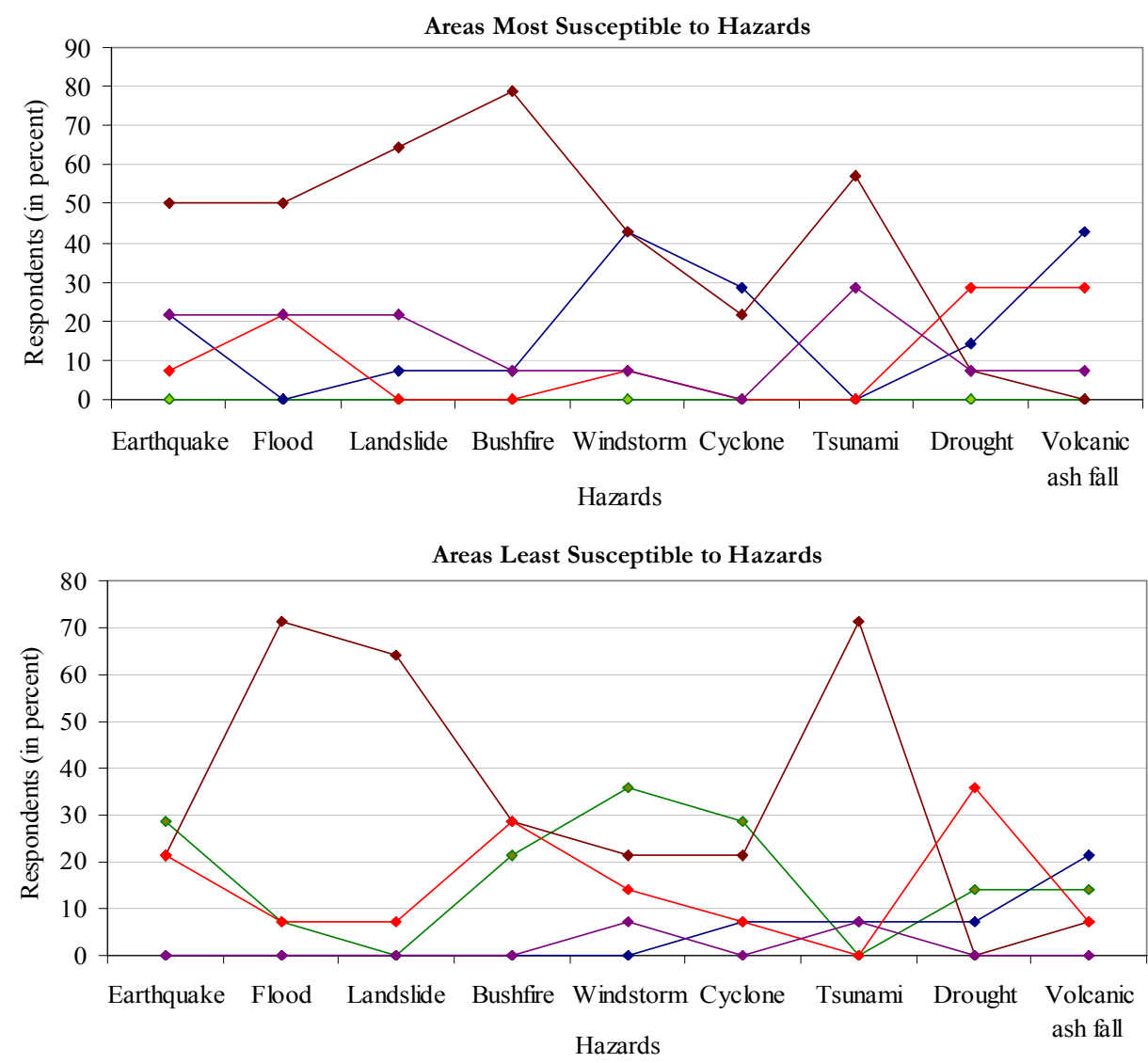

$\multimap$ None $\rightarrow-$ All $\rightarrow-$ Physically Susceptible $\rightarrow-$ Vulnerable $\rightarrow$ Particular suburb 
and financial constraints.

The recent developments in hazard response show that the effect of this divide is ongoing. Many of the current facilities and services tend to build along this division. For example, while the four urban city councils in the west including Wellington, Lower Hutt, Porirua and the Kapiti Coast have separate district plans, the new district development plan for the three district councils in the east is a combined one. Another example is the project plan for the Wellington Regional Strategy (2007), in which the main focus of development is concentrated in the western section instead of the whole region (Fig: 7.13.B). In this strategy the Kapiti Coast, Porirua, Wellington, Lower Hutt, Upper Hutt and the Wellington Regional Council, are the main stakeholders leaving the three eastern districts of Wairarapa aside, which will work as strategic partners rather than as stakeholders. Besides, many other response groups are divided along this line. For example, there are separate engineering lifeline groups across the Rimutaka Range such as Wellington Lifelines Group (WeLG) and the Wairarapa Engineering Lifelines Association (WELA) and separate flood management institutions operating through two branch offices of the Wellington Regional Council, with different strategies.

When the officers were asked about the areas that would be most affected by the occurrence of natural hazards, both civil defence officers and district planners pointed to the areas where physical susceptibility play the dominant role behind the occurrence of hazardous events (Fig: 7.14). The effect of this perception can be seen in the type of mitigation measures adopted in the district, which mainly focus on the land use and engineering solutions that further modify the physical susceptibility to hazards.

\subsubsection{Rural Urban Divide}

Physical characteristics have also resulted in a rural-urban divide in the region. While the western areas of Rimutaka Range are due to their close proximity and networks developed into the urban centre, the eastern areas due to gentle topography primarily used for farming and therefore remained rural. This subsequently produced a difference in the methods and measures of hazard response. Due to a small economy and less exposed population, rural areas tend to receive less attention and therefore they have less mitigation measures compared to their urban counterparts. This has been seen in the region in both a historical and current context. For example, the Municipal Corporation Acts of 1867 and 1876 only contained provisions for the urban areas to adopt fire control measures leaving the rural counties aside (The Encyclopaedia of New Zealand, 1966). In the current context, whereas most of the rivers of the western section have been tamed for flood control, many of the streams have not even been studied in rural Wairarapa districts. Besides, though most of the acts and policies require all district or city councils to adopt measures for hazard mitigation, the mitigation measures, particularly those related to land use control, are more stringent in semi urban or rural areas rather than urban centres. This is because urban areas tend to attract more investment because of bigger markets and fetch higher prices than the rural areas. Therefore, many of the long-term mitigation measures are compromised for the sake of development or due to the high economic cost involved in bringing changes in the already 
established areas. For example, building construction along fault lines is a controlled activity in rural Wairarapa districts, but it is discretionary in urban parts of the Wellington Region.

\subsubsection{Hazard Perception and Fatalism}

Perception has also played a key role in influencing hazard response. The perception evolves and is influenced by the characteristics of the hazardscape. While frequent hazard occurrences build awareness and help people perceive possible damage and mitigation options, the risk from infrequent hazards is often poorly estimated and therefore is not effectively responded to. For example, while a number of measures have been taken in the region for low magnitude frequent hazards such as storms and flood, the bigger events such as Wellington fault rupture or local tsunami have been poorly responded to (Table: 7.8). Most of the high risk hazards have been long considered as an 'Act of God not only by people but to an extent by the administration as well. One example is the National Commission, which was initially established to provide compensation for war damage, but it soon extended the compensation to earthquakes and other hazards for the reason of random and unpredictable damage as caused by 'Acts of God' (Eriksen, 1986). However, the administration soon realised that this principle does not apply to all hazards, especially to the discrete events such as flood and coastal erosion, and therefore withdrew them from disaster funding (Erikson, 1986).

The perception of hazards or disasters as an 'Act of God' is also linked with the fatalism i.e. the perception that not much could be done to reduce the risk from natural hazards, and society has to bear the damage. This attitude is persistent in administrative perception, and partly contributed to by lack of awareness, information and knowledge about these hazards. Many of the policies and plans in the region clearly depict that the risk induced in the current development is undeniable and hazards or disasters are inevitable. A few examples are as follows:

"Issue-2: For the major natural hazards in the Wellington Region, such as flooding and earthquakes, it is not practicable to eliminate risks entirely. The aim should be to ensure that the level of risk is understood and acceptable. However, acceptable levels of risk are generally unknown." (Regional Policy Statement for Wellington Region, 1995, 194)

"The available responses to drought (pg-57),...tsunami (pg-15),... severe winds (pg-49) etc are limited as the event itself cannot be modified..." (Grant, 2005).

Both the statements are not truthful. While it may not be possible to calculate the total risk and acceptable risk, it is certainly possible to reduce hazards to avoid disaster. The statement rather permits the development to occur in the areas of risk given that the occupant understands the risk. The second statement that events cannot be modified is also not entirely true. The severity of drought largely depends on the intensity of water use, which can be reduced significantly through well managed catchments and its sustainable land use. Similarly, windstorm and tsunami as hazards could well be managed through land use planning and shelter belts. Flood and landslide are other hazards which have been intensified in the region through human activities, and at the same time, they have been quite well managed for small frequent hazards. 
A degree of

fatalism is also observed in most of the district planners and civil defence officers that in the case of major a hazard event, nothing much can be done except to face the results. There is an unquestionable agreement about the occurrence of severe earthquakes in the region, irrespective of the fact that the
Fig: 7.15. Extent to Which Potential Damage from Hazards can be Reduced as Perceived by Civil Defence Officers and District Planners

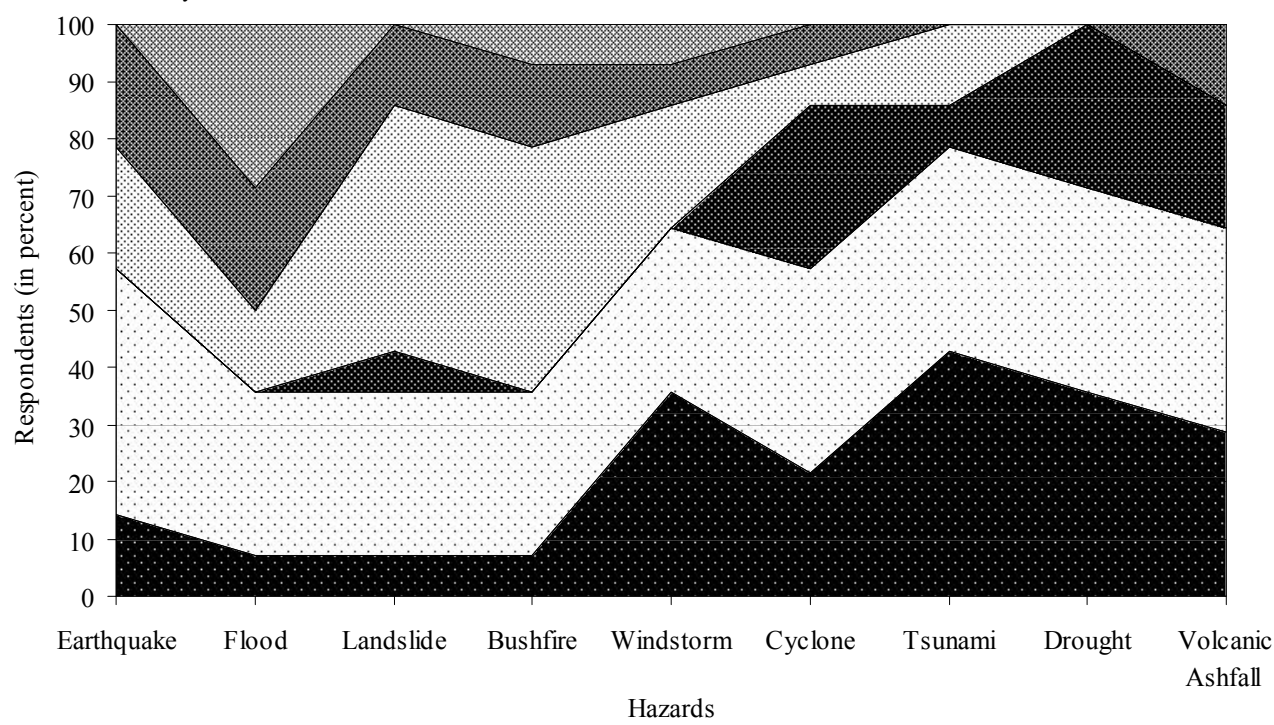

Extent to which potential damage can be reduced

Not possible $\quad[$ Don't know Not applicable Less than 20 21-40 图 41-60

Based on Primary Survey, 2007

hazard varies significantly across the region. The data from the primary survey conducted with civil defence officers and district planners of the region show that on average nearly 22 percent of officers $(3 / 14)$ believe that it is not possible to reduce the possible damage from a potential hazard. The highest number of officials has this fatalism for tsunami (6) followed by drought (5) and volcanic ash fall (4), which could be taken as the reason for less mitigation actions for these hazards in the region. On an average about 33 percent (4/14) of officers said they do not know whether it is possible to reduce the potential damage from hazards. It is also important to note that none of the officers believed that more than 50 percent of potential damage could be reduced in the case of any of the natural hazards (Fig: 7.15). This also shows unawareness in administration of the fact that it has been proved that disasters are social constructs, and many of the natural hazards are either human induced or intensified by them. Therefore, the solutions for reducing hazards and consequent damage rest with human communities. A statement from administration that risks cannot be reduced influences the perception of local people along with their response, and therefore needs to be corrected.

\subsubsection{Economic Viability}

Economic reasons play a dominant role in various aspects of administrative hazard response from establishing legislation or acts, to making plans and policies to bring changes to land use and response behaviour. The Forest Act, which came in 1874 from a conservation point of view but also had mitigation implications for flood and erosion, was repealed in the early $20^{\text {th }}$ century due to economic reasons (Robinson et. al., 2000, 318). Similarly in 1950s a mere plotting of fault lines faced severe backlash from the various sections of society including citizens, builders, real estate companies, and local bodies because of perceived threat of control on land use and development (Stevens, G. 2005, 26-27). 
Adoption of a particular response measure depends to a significant extent on its economic viability. Mitigation options for many hazards have been largely avoided due to the higher cost involved. The Resource Management Act (1991) gives power to both regional and local authorities to plan for hazard mitigation in certain areas. However, the selection of a particular plan at the local level does not depend on its treatment of hazard but on its economic reasons of profit and loss, which ultimately decides the type and the amount of work to be done (Regional Coastal Plan, 2000, 2). Further, the implementation of existing mitigation measures also loses its stringency on the grounds of economic development of precious city land. Since it is very costly to superimpose land use zoning on existing developments, land use policies have been less emphasised in urban Wellington compared to rural districts of Wairarapa or other less populated district/city councils. At times, economic reasons also force the administration to compromise on the rules made for hazard mitigation or to even deny the existence of a hazard, even if they know it. The Wellington district plan map is a good example. The map only shows a partial fault line, which suddenly ends at the harbour instead of continuing along the National Highway-1 (Fig: 7.16.A). The land use control measures such as identification and imposition of
Fig: 7.16. Incomplete Wellington Fault Line in the Wellington District Plan

A. Wellington Fault Line in Wellington District Plan

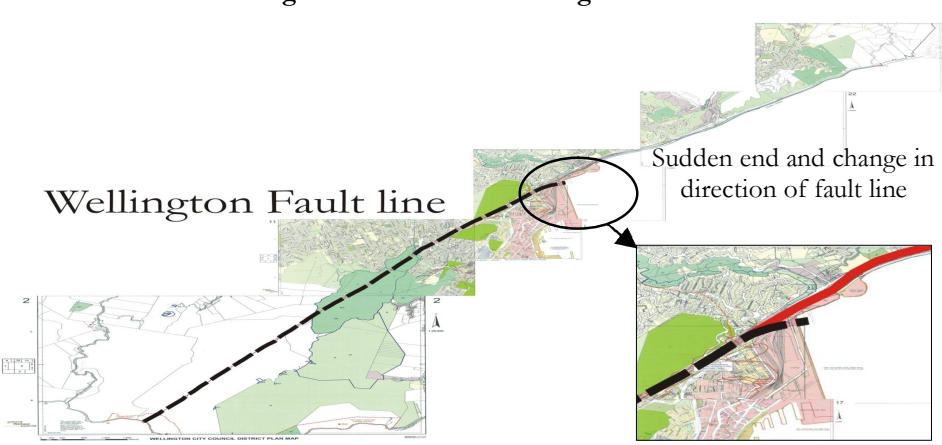

B. Wellington Fault Line in National Hazardscape Report (2006)

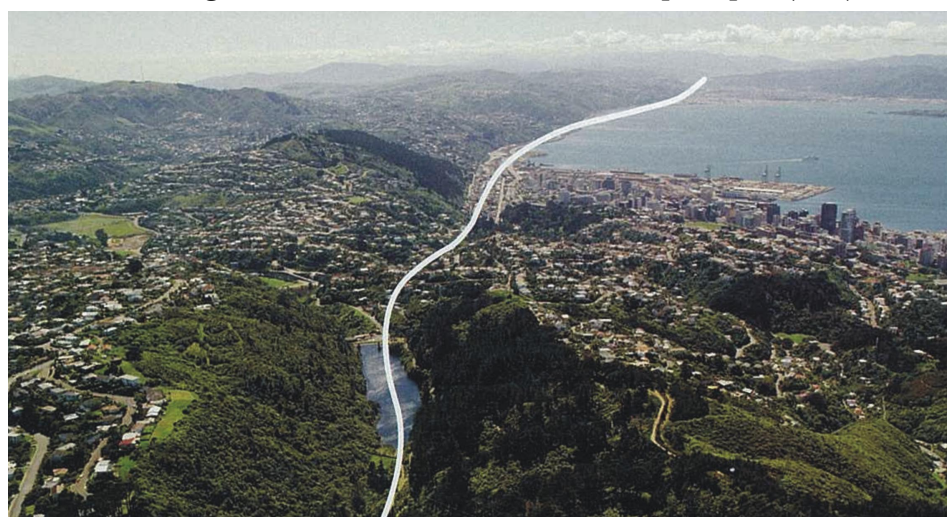

C. The Historic Gold Slide on Wellington Fault during 1855 Earthquake

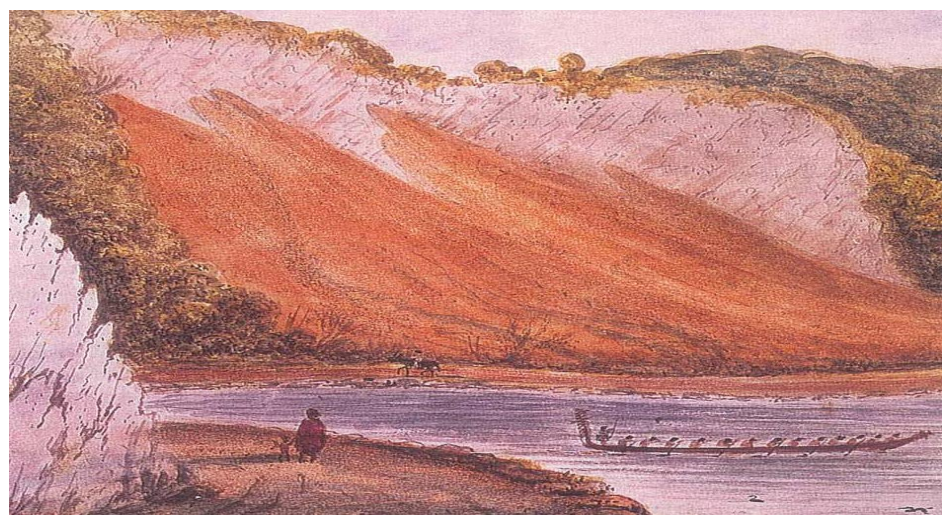

Based on Wellington City Council (n.d.), National Hazardscape Report, 2007, 26 and Turnbull Library as cited in Hancox et al, 1997

Fig: 7. 17. Finance as a Barrier to Reduce Potential Damage

Volcanic ash fall

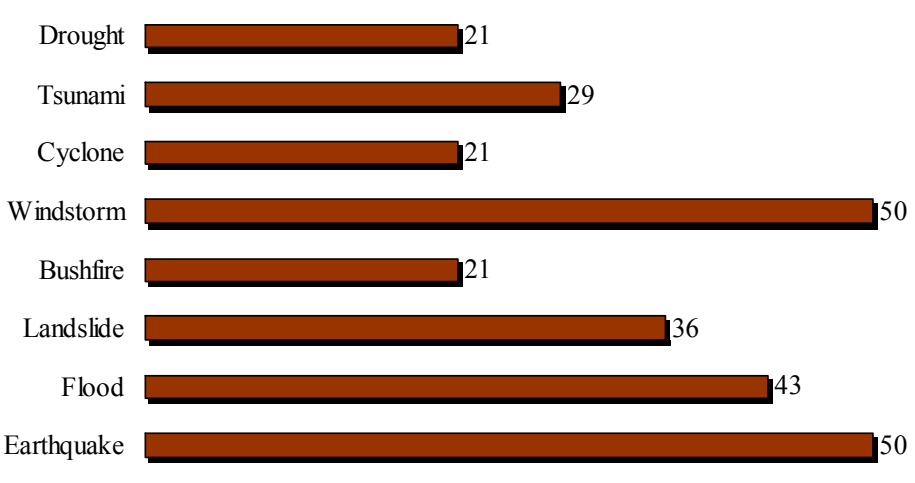

Respondents (in percent)

Based on Primary Survey, 2007 
fault zone rules tend to have some side effects on the economic conditions of the residents such as a decrease in property price, which has been proved true for the Wellington fault zone (Ministry for the Environment [MfE], n.d.b). People ask for compensation and in such cases the administration has to compromise, and the reason often given is the uncertainty linked to the available knowledge and to the occurrence of hazard event. The question to be asked here is what is more significant, economic growth or sustainable development, because even though the occurrence of earthquake is an uncertainty, the historic Gold Slide on the Wellington fault during 1855 earthquake clearly highlights the high susceptibility to a major rock failure. The frequent occurrence of earthquakes in the area further confirms such a possibility. Further it has been noted that major earthquakes often occur in the areas of frequent earthquakes. A clear depiction of Wellington faultline could influence the decisions of future land owners, who may choose other areas to live.

When the officers in the region were asked about the barriers to reduce potential danger from hazards, a high proportion (31 percent) of officers saw financial constraints as a major barrier. The highest number of officers saw it as an important barrier for mitigating earthquake (7), windstorm (7), flood (6) and landslide (5) (Fig: 7.17), where mitigation involves a change in land use. Planting trees or creation of a shelter belt though could help to stabilise slopes and could reduce erosion and slips, but such measures are compromised as they involve high economic costs.
Fig: 7.18. Financial Constraints as a Barrier to Public and Administrative Preparedness as Perceived by Civil Defence Officers and District Planners

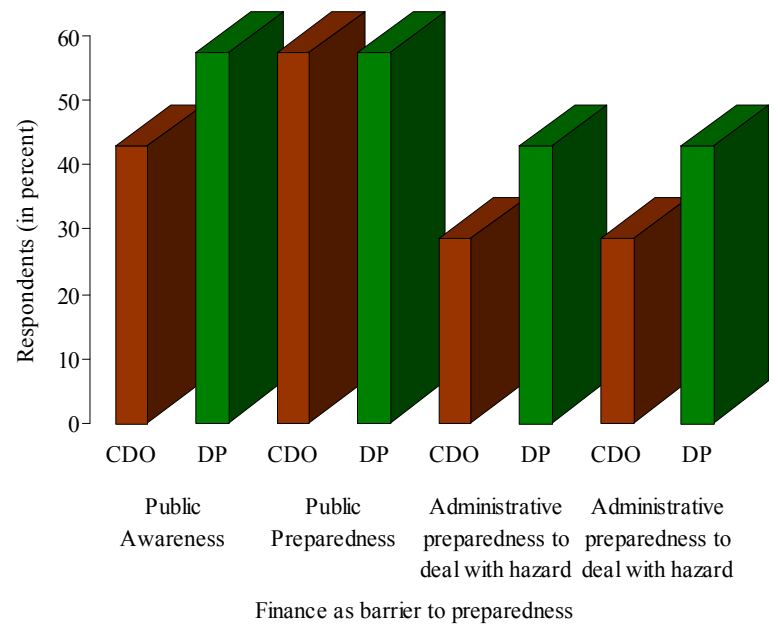

CDO- Civil Defence Officers DP- District Planners

Based on Primary Survey, 2007

Economic reasons was also seen as a major barrier to public awareness and preparedness, however, a greater proportion of district planners saw it for administrative preparedness to deal with hazards compared to civil defence officers (Fig: 7.18). The presence of finance governs the availability of civil defence facilities and services, and it can be seen as an important reason behind the inconsistency of these facilities across the region. Where Wellington has elaborate civil defence facilities, in rural districts of Wairarapa, it is much more limited. Shortage of staff is one critical indicator of financial constraints. Most of the civil defence organisations in the region are run by a few full time staff (Table: 7.7) supported by a number of volunteers. The issue is serious in the districts, where the civil defence officers

Table: 7.7. Staff in Civil Defence Emergency Management Offices in the Wellington Region

\begin{tabular}{lc}
\hline Number of staff & Number of Districts \\
\hline 5 and above & 1 \\
$3-4$ & 4 \\
$1-2$ & 3 \\
\hline
\end{tabular}


have been appointed on a part time basis, e.g. in Carterton and South Wairarapa district councils. There could be a specific time for civil defence officers to operate, but disasters are largely associated with uncertainly and their occurrence is often sudden. While both civil defence officers (2) and district planners (2) found shortage of staff as a major barrier in public awareness and preparedness for natural hazards along with administrative preparedness to deal with hazards both in district as well as in its own compound; three district planners $(>40 \%)$ believed that shortage of staff is a critical reason for them to be not prepared to deal with hazards in their offices.

Further, most of the local civil defence offices depend on regional and central government for financial and other assistance. As a result their strategies for hazard response at times reflect the national concern better than local requirements. For example, in three districts of Wairarapa, where a major population is exposed to drought, only one district has a drought management plan. On the other hand, while a relatively small community is exposed to tsunami in these districts, all the three districts have taken response measures for the hazard. The higher national and regional concern for tsunami can be seen as the major thrust for implementation of tsunami measures in the area. The opposite is true for fewer drought measures in the region as drought has been given lower priority in emergency management at higher levels.

\subsubsection{Political Motivation}

Political decisions often play a crucial role in the adoption of hazard response measures by the administration. At the local level, political decisions are governed by public demand and support, which determines the type of response activities along with their progress. The administrative history of hazard response contains many incidences that highlight the significant role of public demand behind the establishment of hazard specific measures. For example, continuous political support for earthquakes in New Zealand in general and the Wellington Region in particular, is attributed to the public concern over the issue governed by frequent earthquake incidences (Walker, 1999, 4). The riots that occurred because of great depression fuelled the concern for public safety which is noted to be very low in the two major earthquakes of Murchison and Napier in 1929 and 1932 respectively. This led the government to establish the Public Safety Conservation Act in 1932 (MCDEM, n.d.). Similarly the rise in demand for insurance policies after the 1942 earthquake led the government to establish the Earthquake and War Damage Act in 1944 (Britton, 1981, 386). The Forest Act, which was repealed for economic development on public demand in the early 20th century, was revived after large scale public interest expressed in the later part of the $20^{\text {th }}$ century. Often local politics use the public demand for their favour instead of hazard mitigation. Since mitigation options are often costly, long term and generate less public support, local leaders tend to downplay them (Godschalk and Brower, 1985, 70). They rather support less time consuming engineering solutions which can provide fast public relief and more visible structures e.g. stop banks, compared to behavioural changes for which implications are not easy to see in a shorter time frame. This could be also noted in the context of the Wellington Region, where a significant amount of money is invested every year for flood control measures through stop banks, but less is visible in terms of land use planning through long term mitigation measures. 
At a regional level, the politics develop the capability to enforce a major change into legislation or a political decision. In early days of government in Canterbury Provincial Council, frequent floods and excessive number of victims forced the politicians to promote legislation for regional flood protection works. As a result in 1868 Canterbury Rivers Bill was introduced in the house of Representative, which later passed and further paved the way for other bills including the Wellington Rivers Act in 1875 (Roche, 1994, 22). At the regional level the political decision favours economic development and decisions are often biased towards urban areas, which is very clearly visible in the mitigation measures taken across the region. Here, political decisions could also be detrimental to the hazard mitigation and may exacerbate the problem. For example, the initial colonisation of the Wellington Region led to deforestation, water pollution, erosion and environmental degradation, and thus facilitated development of the local hazardscape.

Politics at the national level could enforce a major change in the response method adopted at the regional or local level. The effect of overall change in the politico-economy of New Zealand can be easily seen in the hazard response at the local level. The Earthquake Commission, which used to insure all properties against hazards in the mid $20^{\text {th }}$ century under the egalitarian national ideology of collective response, removed the insurance for non-residential properties under the current neoliberal principle of individualism in the late $20^{\text {th }}$ century (Hay, 1996, 34). The effect of this profit based ideology can also be seen in the change of policy from the payment for restoration to compensation loss by the Ministry for Agriculture and Forestry for the Cyclone Bola farm assistance programme (Parr, 1994, 301). It was done to encourage people to sell their land in order to achieve land aggregation for higher economic development, but the policy failed to achieve its aim as it was not very well developed (Parr, 1994, 306-307). However, in the case of either success or failure, the implication of this policy change had less to do with hazard mitigation. It was rather aimed at economic growth and shifting damage burden from the administration to individuals. This is also the reason behind the excessive emphasis on public preparedness in current hazard management systems than mitigation for most hazards, which is well adopted in the Wellington Region. At times, national political decisions are influenced by international concern or demand for global response.

\subsubsection{Globalization and Connectivity of Biophysical and Human Processes}

The world is getting increasingly interconnected and the administrative response at the local level is not only influenced by the changes in the global biophysical processes such as climate change but also by changes in ecumenical processes especially those linked with hazard response.

Globalisation of ecumenical processes has affected the hazard response at the local level in different ways, i.e. from the transfer of information and technology to the adoption of plans and policies at the national or regional level. Planning and legislation in New Zealand has long been influenced by the British legislation and administration (MCDEM, n.d.). Therefore, most of the initial hazard response acts of the $20^{\text {th }}$ century such as Public Safety Conservation Act (1932), Emergency Precaution Schemes (1939) and National Commission for Earthquake and War Damage (1944) focused primarily on war rather than on natural hazards, even though the scenario for the two countries on these issues were entirely different. 
Further, the current concept of integrated civil defence and emergency management is an important outcome of globalisation of hazard response. The concept of civil defence first came out in the 1940s out of the Second World War and Korean War in the 1950s (Britton, 2001, 44) and it was promptly applied in New Zealand along with various other nations. With the end of World War-II, nuclear threat took over the focus of civil defence. However, with the changing scenario of hazard occurrence in other parts of the world, the focus of civil defence gradually shifted towards the natural hazards. This resulted in the development of comprehensive emergency management in the late 1970s, which later led to an integrated emergency management system (Britton, 2001, 45). The integrated management approach was first adopted in United Stated in the early 1980s, from where it slowly diffused to other nations (Godschalk and Brower, 1985, 64, 71). However, it received a boost in the late 1980s, when the United Nations declared the 1990s as the 'International Decade for Natural Disaster Reduction (IDNDR)'. Under this programme, by the end of the 1990s all countries were asked to have fundamental outputs that would create a framework within which effective emergency management outcomes could be developed (Britton, 2001, 44). It encouraged countries to undertake a comprehensive risk assessment of hazards integrated into national development plans, mitigation plans for long term disaster prevention, preparedness, community awareness and ready access to warning systems by people who were most at risk at global, national or local levels (Britton, 2001, 44). New Zealand experienced various significant changes in the civil defence framework during this decade. It was first initiated with 1991 Law Commission's 'Final Report on Emergencies', which recommended the review of emergency powers and functions in New Zealand, and led to the establishment of the Civil Defence Review Panel to review the system. The subsequent reports of 1995 'Report of the Emergency Task Force and 1996 'Review of Disaster Recovery Preparedness', brought the government consensus on the adoption of a comprehensive emergency management approach which was also focused for all hazard and integrated approach (Jensen, 1998, 27).

At the end of the decade in October 2000, the Inter-agency task force summarised the role of IDNDR in the promotion of an integrated, multi-sectoral approach to disaster reduction in the context of national development plans. In order to continue the commitment, the International Strategy for Disaster Reduction (ISDR) was introduced with the objective to foster enhanced integration across multi-disciplines and multi-sectional relationship, management of risk instead of protection against hazards and integration of ongoing risk prevention strategies to sustainable development plans by various stakeholders through partnership activities (Britton, 2001, 45). In the line of corresponding developments in New Zealand the CDEM Act came in 2002, which fostered the integrated emergency management planning at the regional and national level. Further, in order to show the development on this front an edition of Tephra (1994) was published as a National Report of New Zealand' that was specially prepared for the IDNDR Mid term review and the 1994 World Conference on Natural Disaster Reduction by MCDEM.

Besides this overall approach, many research and technological innovations have also been imported across the globe for hazard mitigation and response. In New Zealand various methodologies have been imported from different nations considering their value and worth in the local context. For example, the construction of a storage basin into which peak flows can be 
discharged was favoured in New Zealand after noting its easy maintenance and successful use in Italy (Roche, 1994, 20). Similarly, the modern earthquake engineering solutions that developed in the late 1950s or 1960s in California were quickly adopted in New Zealand by local scientists in the background of similar earthquake scenarios (Walker, 1999, 4).

Hazard incidence in other countries also helped to raise the concern at the local level. The 1989 Loma Preita earthquake in California led to a period of reviews, reports and workshops in New Zealand on the effectiveness of emergency management in the country (Britton, 2001, 49). The Long-term Community Development Plan of the region also recognises the fact that recent disaster events in New Zealand and overseas have helped to raise the profile of emergency management (GWRC, n.d, 79). The Boxing Day tsunami in south Asia boosted the administrative preparedness to tsunami in Waitakere, where a tsunami siren system was installed for public safety (Text Box: 1). Such

Text Box: 7.1. An Influence of International Hazard Event

Waitakere Tsunami Siren Sytem Operational
Monday, 7 April 2008, 5:25 pm
Press Release: Waitakere City
"Following the disastrous Indian Ocean 2004 Boxing Day tsunami
and a more recent tsunami scare, my council agreed to put a siren
warning system in place as a matter of priority. As far as we are
concerned, public safety is not negotiable and that includes the
threat of any tsunami," Harvey says.

Source: wnw.scoop.co.nz measures have yet to be adopted in the Wellington Region.

Besides ecumenical processes, changes in biophysical processes (such as climate change) also influence the administrative response to hazards at the local level. Climate change would not only affect hazard occurrence, but also the susceptibility and vulnerability of people by affecting human health, energy supply, change in bio-ecology or eco-tone, migration and population change. The enhanced effect of climate change in the Pacific would induce a chain of migration, through which more people are likely to immigrate to New Zealand. This would enhance the burden on current civil defence and emergency management services. However, the Greater Wellington Regional Council has prepared a draft provision of the policies, objectives and methods by taking climate change into considerations for the Regional Policy Statement. It is yet to be adopted.

\subsection{Shortcomings of Administrative Response with Respect to the Hazardscape of the Wellington Region}

Although administrative response to hazards in the region focuses on all aspects of hazard management i.e. reduction, readiness, response and recovery, a number of shortcomings are noted with respect to the overall hazardscape. The following paragraphs discuss the few major shortcomings in current administrative response.

\subsubsection{Lack of Detailed Hazard Management Plan at the Local Level}

As noted earlier in this chapter, although there is an integrated CDEM plan at the regional level, there is no detailed plan for hazard response at the district level. The only detailed plan available at 
this level is the district development plans, which cover hazard mitigation issues for selective natural hazards. The detailed plan for either the management of local hazards, resources, response personnel or volunteers, recovery or evacuation, has not been made in all districts of the region. Various objectives of the Wellington Region CDEM Group Plan could be constrained in the absence of detailed local plans. For example, the regional plan identifies the need for consulting emergency managers in the local district planning and therefore has an objective (19E), which requires that emergency management organisations are given the opportunity to participate in the development of long-term plans (Wellington Region Emergency Management Group [WREMG], $2005,29)$. However, since the emergency organisations in the region do not have any local plans about the hazardscape of their districts, their input would be mainly restricted to the operational and impact based response rather than suggesting any detailed mitigation measures. Further, it is difficult to assess the implementation of long-term plan objectives related to civil defence in the absence of a local civil defence plan stating aims or objectives in the long term. Another objective (19G) of the plan is to make sure that individuals and businesses have adequate insurance (WREMG, 2005, 29). Though the plan strategies are at the regional level, it again requires planning at the local level in order to monitor its implementation and effectiveness. The regional plan also aims to build a synergy between the CDEM Groups and the rural fire management structures in its objective (20K) (WREMG, 2005, 32). Though this could help to manage small hazards, without a local plan it may result in chaos during a disaster. This is because even though everyone would know their role and responsibility through Standard Operating Procedures, lack of local strategy could reduce the effectiveness of their presence and would rather induce disorder at the local level. An advance collaborative planning at the local level is therefore critical for the integration and management of various aspects of hazard response, but it is missing in the current system.

\subsubsection{A Generalised Approach}

The treatment of hazard is generic in most of the acts, plans and policies adopted in the region. The dominant hazard management acts such as the Resource Management Act, Civil Defence Act and Local Government Act apply to all hazards. Most of hazard specific policies are mainly restricted to earthquake and flood. Generalisation is further pronounced at the regional level. The Wellington Region CDEM Group Plan (2005) though identifies various kinds of hazards in the region, the calculation and treatment of risk is generalised at this level. The plan does not have any map of the region showing either low or high risk areas or the areas with different types or levels of vulnerabilities. Further, the objectives and policies of the plans are based on various strategic issues linked with hazard reduction, readiness, response and recovery, which are again common for most hazards, and do not relate to the type and variations of hazards or risks at the local level.

The specificity of the hazard is also restricted at the district level. Only three out of eight district councils have hazard specific plans. While hazard specific plans signify the concern for dominant hazards in the district, general hazard plans reduce the urgency for specific hazard management along with the set of others. Beside, the Standard Operation Procedures followed by the local civil defence organisations in the region for emergency response are general without having hazard specific details. Although this brings a uniformity of hazard response across the 
region at a macro level, it fails to build standardization in terms of effectiveness of services at the local level.

\subsubsection{Bias Towards the Type of Hazards}

Few hazards in the region have been discussed, studied and responded to more than the others. The assessment of district development plans shows that there are many hazards which have not even been mentioned despite having high susceptibility to these hazards. While most district plans in the region have detailed discussion, maps and rules in place for flood and fault rupture, very few plans discuss windstorm, tsunami, landslides and coastal hazards. Drought, bushfire and volcanic ash fall, on the other hand, have not been included as potential hazards in any of the district plans.

The assessment of development of acts and statutes over time also shows that response has been tilted towards the frequent hazards such as earthquake, flood and fire that were the source of regular damage within and outside the region (Fig: 7.20.A). Even though other hazards were later included in hazard acts, their treatment remained generalised.

\subsubsection{Bias Towards Hazards over Disasters}

There is emphasis on the prevention of hazards in the region rather than disasters. Most of the responses largely focus on more frequent and low magnitude hazards, rather than less frequent high magnitude hazards that may turn into disasters. For example, an earthquake prone building policy has been adopted at the territorial authority level. The policy allows buildings to be erected with protective measures for a moderate intensity earthquake in the land use restriction zones, where their vulnerability to high magnitude events is permitted. Besides, many other plans, such as Regional Coastal/Soil/Water plan or Regional Policy Statement, mainly aim to reduce the frequent hazards such as flood, storm surge or erosion and there is less emphasis on major events such as tsunami.

Similarly, building on a floodplain is a controlled or discretionary activity across the region depending on the use, floor level and location of the building. To build in a flood prone area, the lowest habitable floor level should be high enough to face a one in 50 year flood (Grant, 2005, 29). Though this reduces the exposure to frequent floods, it enhances the potential for large magnitude events, which may result in a disaster. The floodplains especially in cities are densely occupied. Most of the flood protection schemes in the region have been adopted for an event of one in 100 year probability. Although this again has reduced the occurrence of frequent floods in the floodplain, it has increased the potential risk for an event of greater magnitude, which may have less probability but has an increasing possibility in the changing biophysical conditions (i.e. rising river bed and climate change) and socio-economic conditions (i.e. increased floodplain occupancy due to population growth).

Stop banks are one of the most favoured flood protection measures in the region. The first stop bank in the Wellington Region was built in Petone in 1894. The subsequent flood of 1898 further boosted the construction of extensive higher stop banks between 1900 and 1906 (WRC in Waugh, Freestone, and Lew, 1997, 30). The number and size of stop banks therefore grew with every intensive flood event, which raised the demand for their control. Stop banks were also 
Map: 7. 1. Existing and Proposed Stop Banks at the Otaki River

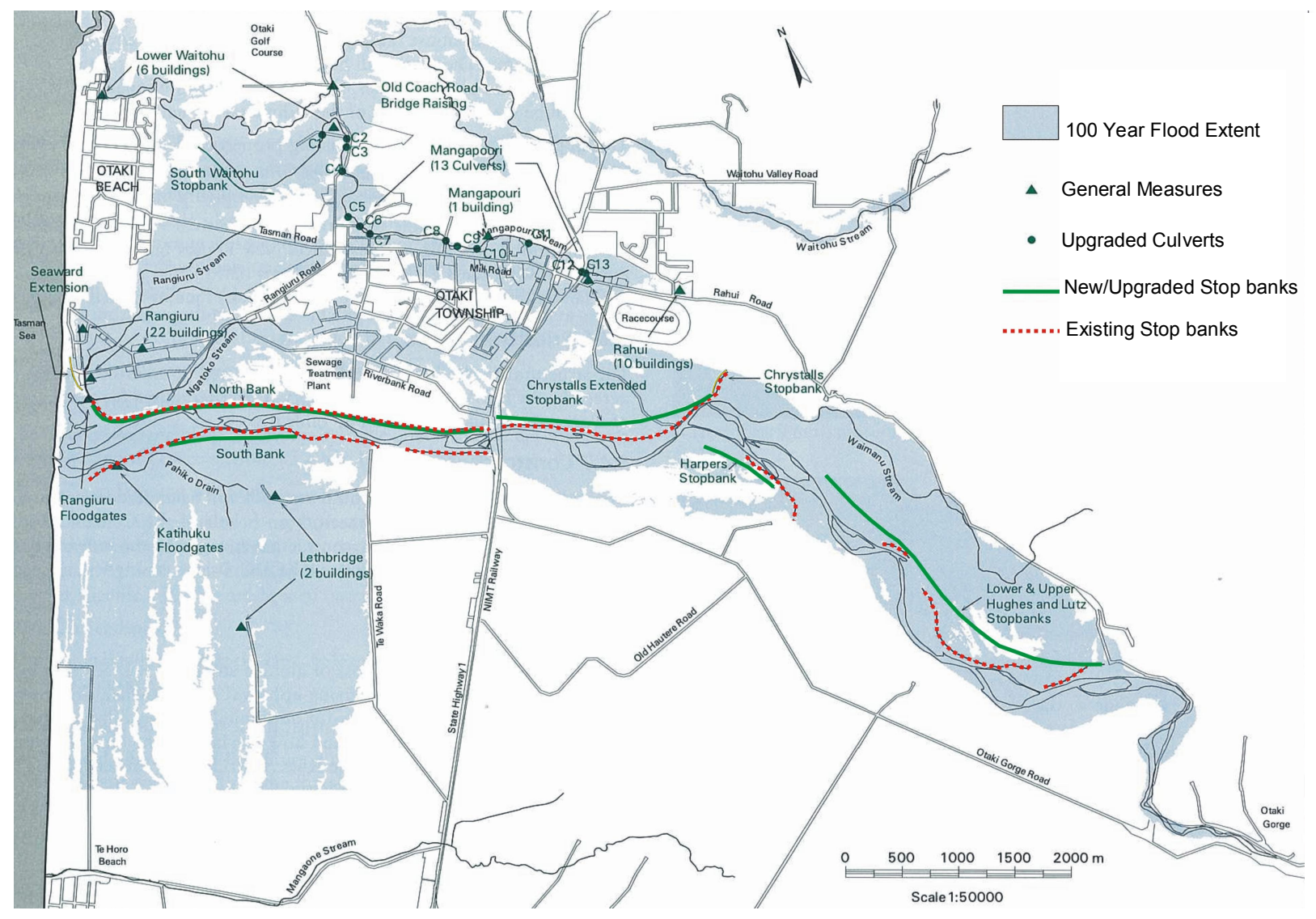

Source: Otaki Flood Plain Management Plan, 1998, 33

supported by evolving legislation and policies, which put public protection from flood before any other ecological issue. On Hutt River in 96 years from the beginning of the first stop bank construction in 1894 to 1990, 11 new stop banks were constructed, four raised, three reconstructed and five others were either flattened, reshaped, regraded, protected or repaired (Easther, 1990, 5). Similarly, most of the other rivers in the urban areas including Waikanae and Otaki River are highly controlled by stop banks. However, since these stop banks have limits to control excess water, they do not reduce the hazard from a high magnitude flood event. Map 7.1 clearly shows that even after the restriction of the Otaki River by a number of stop banks, the surrounding areas are still susceptible to a one in 100 year flood event. It is therefore clear that these stop banks are neither permanent structures nor could provide permanent solutions to flood problems. However, the trend of stop bank construction is ongoing. According to a study, in ten years from 1994 onwards, about 16 new stop banks have been made or are on their way to completion on six major rivers of the region (Grant, 2005, 27).

Similarly, sea walls have been adopted as a significant structural measure to control coastal hazards. Although sea walls in the Kapiti Coast district have effectively reduced the number of slips along the coast, they offer little protection for major hazards such as tsunami due to their short width.

The assessment of WREMG clearly shows that the current efforts made to deal with higher risk hazards especially earthquake on Wellington fault or locally generated tsunami are of low to medium order compared to low risk hazards such as storms or flooding for which higher order 
Table: 7.8. Current Level of Effort for the Identified Hazards and Risk in the Wellington Region

\begin{tabular}{lllll}
\hline $\begin{array}{l}\text { Current } \\
\text { Efforts }\end{array}$ & $\begin{array}{l}\text { Management } \\
\text { Difficulties }\end{array}$ & Rank & Hazards & Risk \\
\hline High & Low & 1 & None & ----- \\
\hline $\begin{array}{l}\text { Medium - } \\
\text { High }\end{array}$ & Low - Medium & 2 & $\begin{array}{l}\text { Storms (rain/wind/hail/lightening) } \\
\text { Droughts (water deficit and extreme heat effect) } \\
\text { Rural fire (urban rural interface) }\end{array}$ & $\begin{array}{l}\text { High } \\
\text { Medium } \\
\text { Medium }\end{array}$ \\
\hline $\begin{array}{l}\text { Medium - } \\
\text { High }\end{array}$ & Medium - High & 3 & $\begin{array}{l}\text { Storm surge and coastal erosion (affecting multiple parts } \\
\text { of coastline) } \\
\text { flooding of high magnitude in Hutt River i.e. one in 440 } \\
\text { year event } \\
\text { landslides with multiple incidents, isolating the Region } \\
\text { and affecting an urban area }\end{array}$ & High \\
& & & $\begin{array}{l}\text { Tsunami distant source } \\
\text { Volcanic ash from Taranaki eruption }\end{array}$ & Medium \\
& & & $\begin{array}{l}\text { Earthquake-Wellington fault event } \\
\text { Locally generated tsunami }\end{array}$ & Medium \\
\hline $\begin{array}{l}\text { Low - } \\
\text { Medium }\end{array}$ & Low-High & 4 & Low \\
\hline Low & High & 5 & None & High \\
\hline Based on WREMG, 2006 & & & High \\
\hline
\end{tabular}

efforts have been made. The efforts made for local tsunami is minimum in the region despite having high susceptibility. There is neither any alert system nor evacuation plan for local tsunami. However, it is not only the coastal areas which are exposed to tsunami but also the areas along the major rivers, which extends the risk to a wider zone.

\subsubsection{Bias Towards Response Type}

Even though a range of methods have been adopted in the region to reduce the hazards, few aspects of hazard response have been dealt with more vigorously than others. For example, a range of acts have been developed at national and regional level over time that mainly deal with hazard mitigation compared to a limited number of acts that emphasised hazard preparedness or recovery (Fig: 7.19).

The response at the local level on the other hand is tilted towards preparedness and real time response. The local and regional civil defence offices place excessive emphasis on public awareness for hazard preparation. The information thus provided to the government talks about an emergency plan, emergency survival kit and how to respond rather than how to mitigate them. Most of the suggested measures help to cope with the impact of a high magnitude hazard rather than avoiding its initial occurrence. The work done by administration for disaster recovery at the local level is limited. Even though there is a guide for territorial authorities to make a recovery plan, it has not been made in most districts.

\subsubsection{Focus on Risks from Hazards Rather than the Hazardscape}

In addition hazard response is primarily based on the risk from hazards, rather than understanding of hazards as part of the hazardscape. In urban areas, even the most hazard prone areas have been built up by taking moderate precautionary measures. Planning for hazard mitigation is mainly done by the district planners, whose expertise and responsibilities lie in other fields (Godschalk and Brower, 1985, 70). This is a major reason that mitigation at local level is lagging behind and compromised for the sake of economic development. Besides, due to lack of understanding by district planners about all hazard issues, there is less emphasis on either modifying the hazard event 
or reducing the vulnerability of the community. Further, the adopted structural measures have rather enhanced the susceptibility and exposure to major changes in the biophysical processes.

Fig: 7.19. Acts for Hazard Response in the Wellington Region (1840-2008)

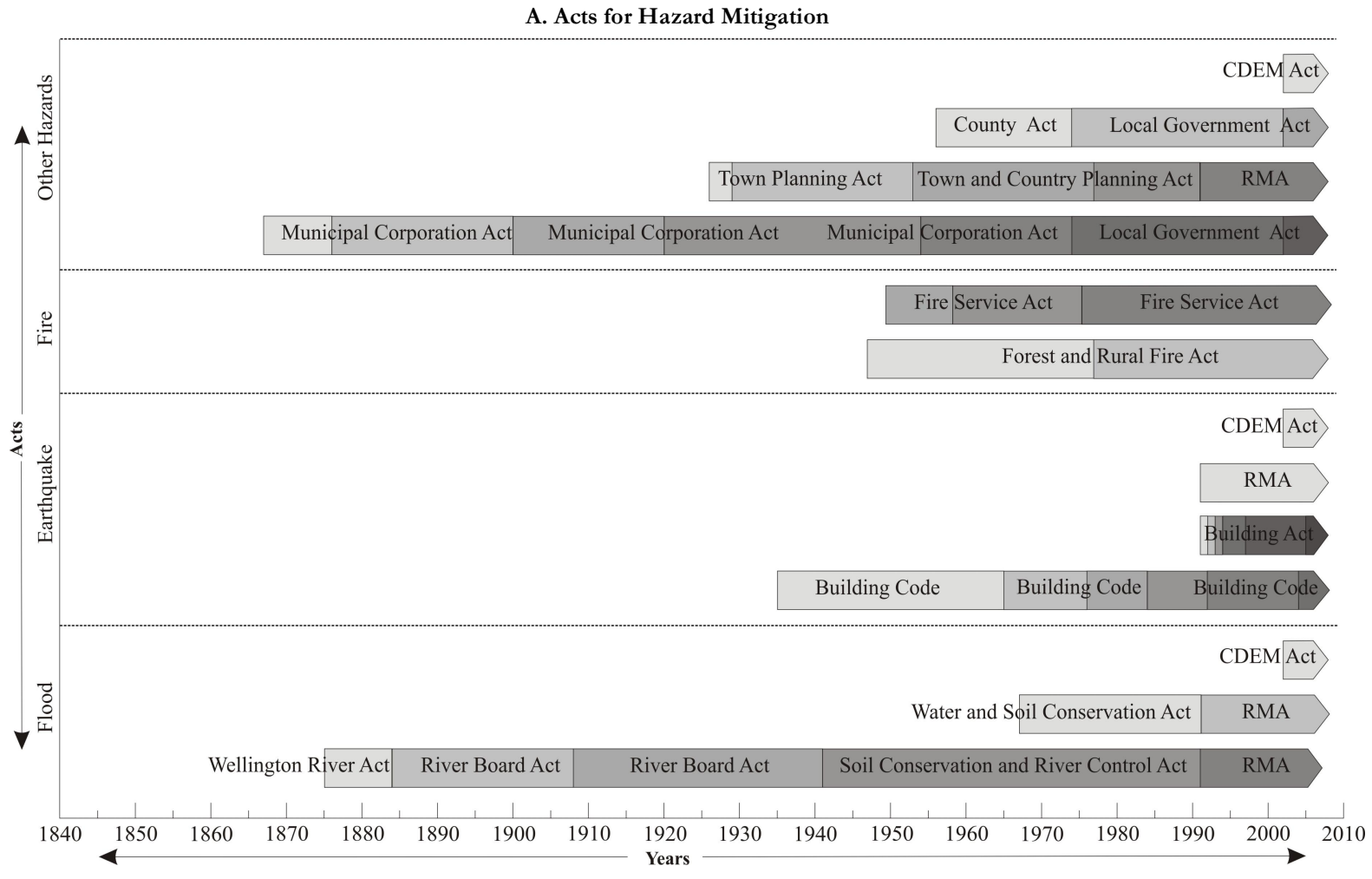

B. Acts for Hazard Preparedness

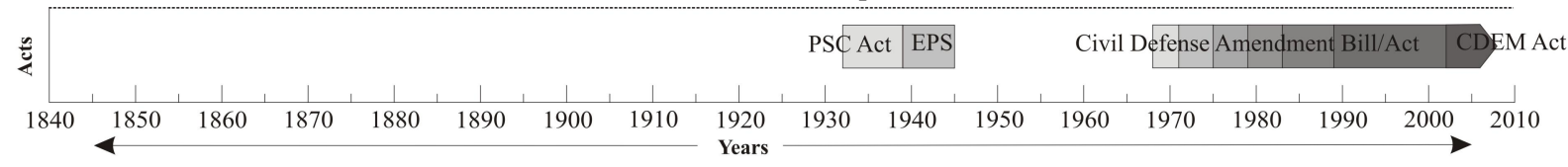

C. Acts for Emergency Response

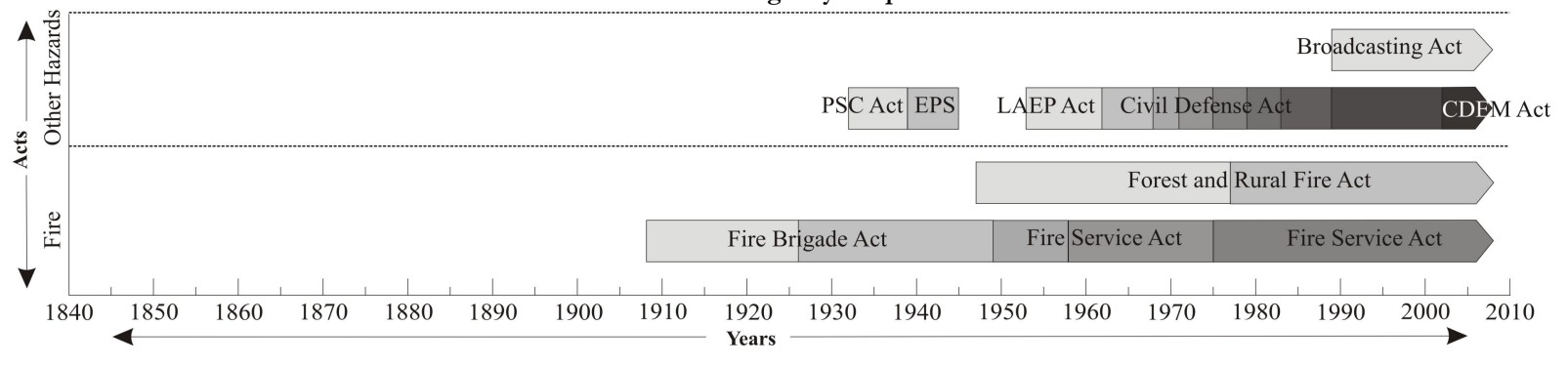

D. Acts for Recovery

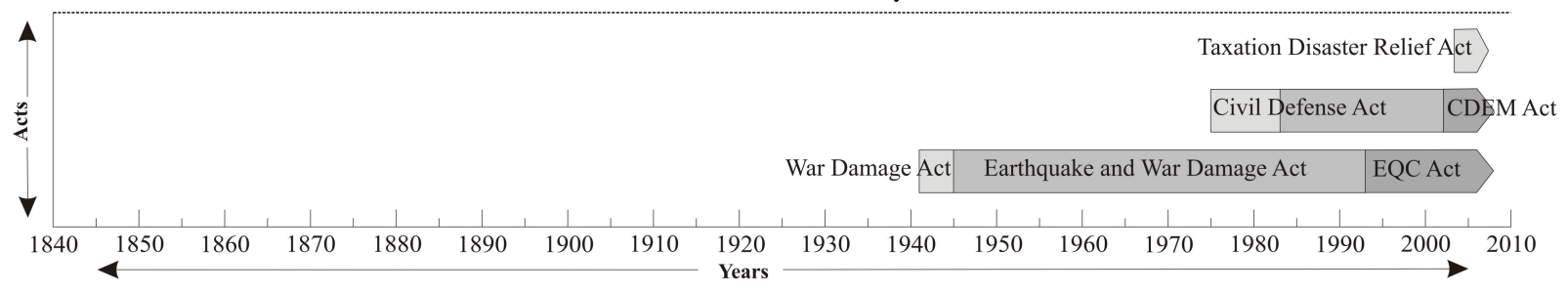

Based on Acheson, 1968; wmw.teara.govt.n₹; wnw.legislation.govt.n₹, Becker, J. et.al, 2000; wmw.civildefence.govt.n₹. 
Map: 7.2. Proposed River Design for Otaki, Hutt and Waikanae Rivers
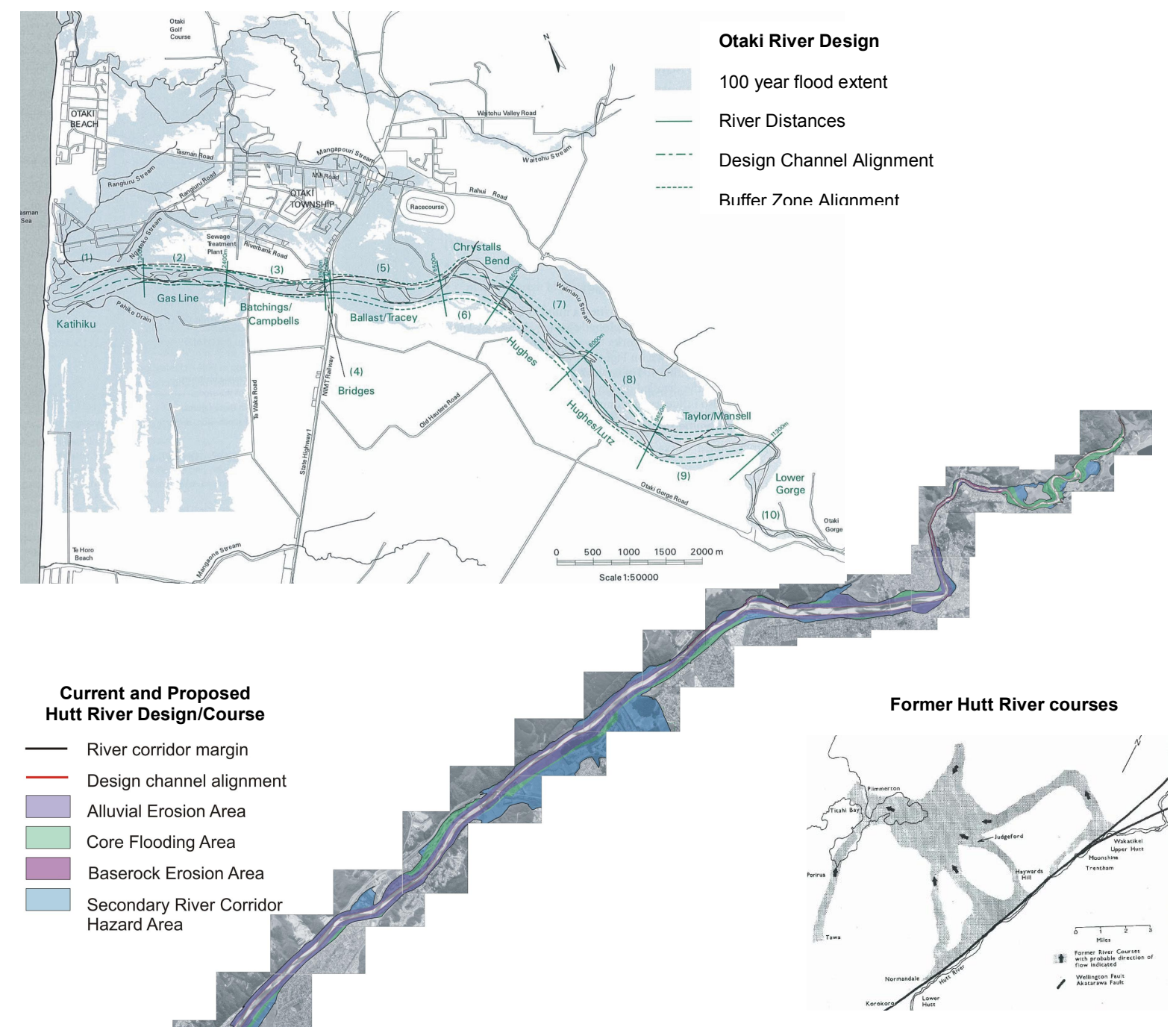

Former Hutt River courses

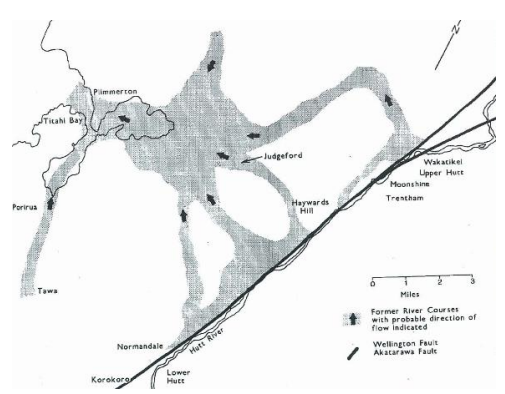

Waikanae River Design

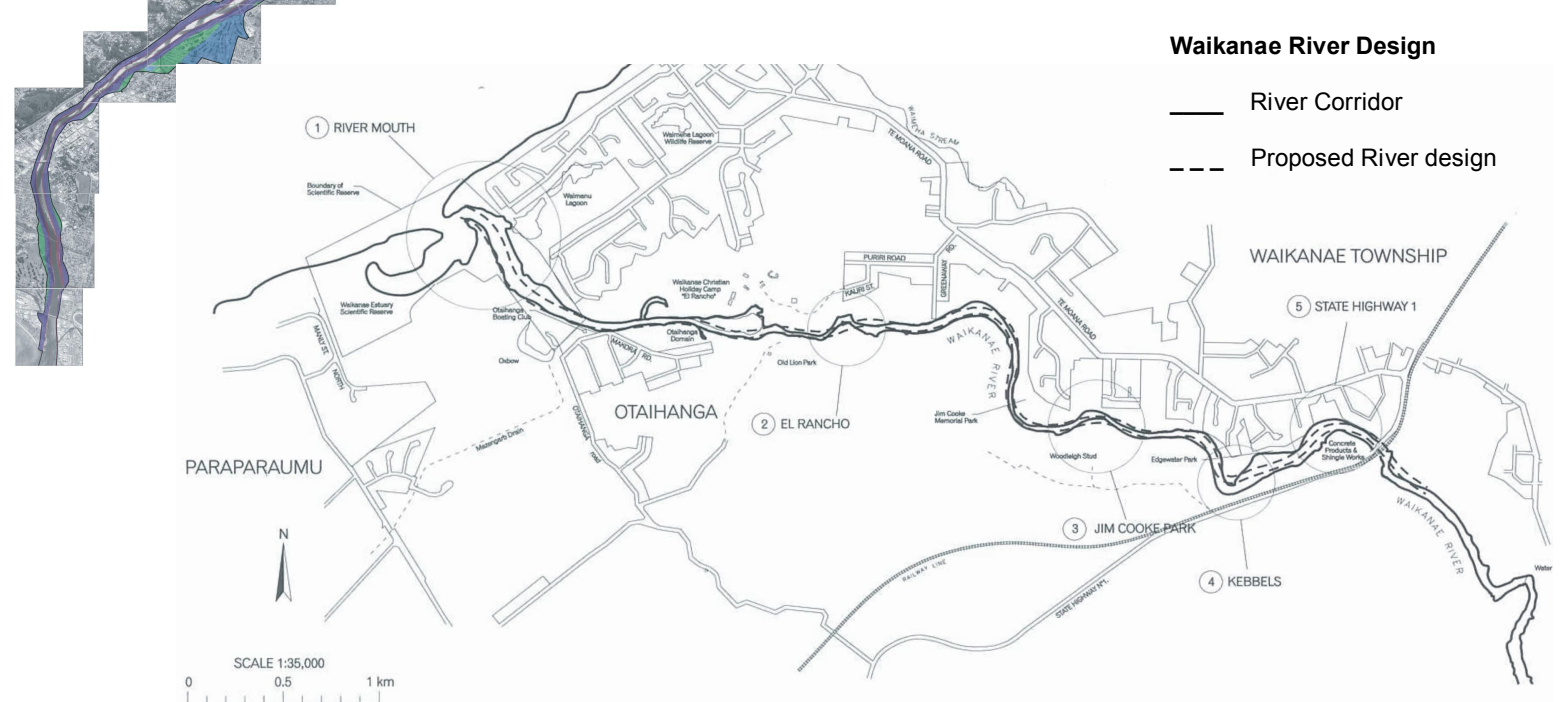

Source: Otaki Floodplain Management Plan, 1998, 38; Hutt Floodplain Management Plan, 2001, 192-206; Waikanae Floodplain Management Plan, 1997, 41, Easther,1991, 14.

The structural mitigation measures adopted for flood control in the region point towards forced control of the rivers for human use. The river designs suggested for the rivers in the region (Map: 7. 2) show that efforts will be made to contain the rivers within their existing bed or within 
their corridors in order to avoid future floods in their floodplains. It is rather a deliberate act of restricting change, which is an important characteristic of any ecosystem process. The purposeful acts to keep the rivers in their current paths have made them straighter at every attempt, which can also be seen as the process of conversion of 'rivers' into 'drains'. This disrupts the feedback system of rivers and associated processes in the larger context. Restricting all water within a river's corridor means holding more water for a long time that increase the frequency of high magnitude flood events. Heavy rain in such a situation would not cause the flooding of a river, which nourishes its floodplain with nutrients but would drain outflow or burst stop banks, which would bring disease and disaster for the properties settled aside. Further the associated changes in the temperature and speed of water could disturb the micro ecosystems, which contribute to the river ecology and cleanliness. The historical courses of Hutt River show that the river has experienced drastic changes in its flow path due to geological or climatic reasons (Map: 7.2). This is even possible in the current context. Controlling the river does not mean that it would not experience any change in its flow path, but when it would, the change would be drastic and unpredictable and could prove disastrous in the densely occupied floodplain.

Finally it can be concluded that despite having an integrated framework to manage natural hazards, the response to local hazards is not uniform throughout the region. The variations in the hazard response at the local level are governed by both biophysical and ecumenical processes that have shaped and modified the local hazardscape over time. Administrative response to hazards in the region is heavily inclined toward frequent hazards i.e. as flood and earthquake compared to others such as drought or volcanic ash fall, which are perceived to be of low risk. There is a lack of a detailed plan for CDEM at the local level with a specific focus on local hazardscape characteristics and response barriers. Further, variations are noted in the emphasis placed on different aspects of hazard response. While there are a number of measures for mitigation and preparedness, very few are noted for recovery. Also the emphasis on particular aspects of hazard response differs across institutions. While district plans primarily focus on hazard mitigation, the CDEM activities are mainly inclined towards hazard preparedness and emergency response. However, most of the district planners were less aware about various local hazards, despite having the responsibility to plan for hazards. Most structural measures adopted for hazard mitigation in the region although reducing the risk from high frequency low or medium magnitude events are less capable in dealing with high magnitude hazardous events. This has caused fatalism even in the civil defence officers and district planners about the hazard mitigation possibilities as none of them saw that more than 50 percent of potential damage could be reduced from any natural hazard. An important cause for not being able to see the mitigation possibilities is the perceived cause of hazards. Hazards have been primarily perceived by the officials either to affect an area due to hazard characteristics or due to the physical susceptibility of the place. The human role either through poor response or vulnerability has been mainly seen during low risk events such as 
flooding, drought and bushfire. Minimum emphasis and understanding of human vulnerability in the current response system have resulted in less focus on the vulnerability issues, and thus have enhanced the intensity of the hazardscape. In order to reduce the hazards and consequent risk, it is therefore important to base the response on the overall hazardscape characteristics rather than only on the hazards. 
Chapter: 8

Synthesis \& Conclusion

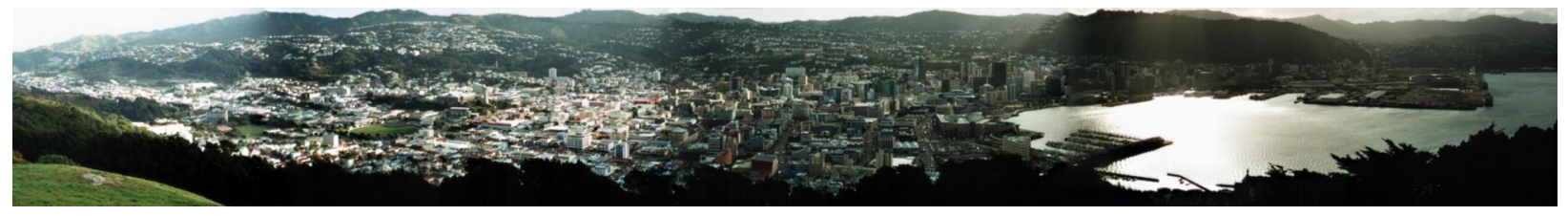


Hazard response has significant implications for consequent risks and disaster occurrence. An understanding of the factors governing hazard response throughout the region could help with decision making for effective hazard planning and management. This thesis proposed that it is the hazardscape which governs and influences the response to hazards at different levels, and therefore produces variations in the response over space and time. In order to achieve this aim, the thesis first explored the concept of hazardscape and then assessed its influences on the local and administrative response to natural hazards in the Wellington Region. The following paragraphs summarise the key findings of this research.

\subsection{Concept and Definition of Hazardscape}

Hazardscape embodies the ecological perspective of hazards and consequent risks, which build through a constant, implicit and intricate relationship between humans and the environment in a particular spatio-temporal context. Hazardscape can be defined as a dynamic scape which reflects the physical susceptibility of a place and vulnerability of human life and assets to various hazards in a given human ecological system. People, processes and place are the three elements or factors of hazardscape, while hazards, physical susceptibility and human vulnerability are its three resultant characteristics. However, overall hazardscape is more than the sum of its individual characteristics, as it also involves the awareness, perception and response culture of a place. Hazardscape and response share a mutual relationship with each other, and thereby are modified and influenced by each other.

\subsection{The Hazardscape of the Wellington Region}

The Wellington Region exhibits a remarkable variation in the nature and characteristics of natural hazards, physical susceptibility and human vulnerability. The following paragraphs describe a few key characteristics of the hazardscape of the Wellington Region.

\subsubsection{Physical Susceptibility of the Wellington Region to Natural Hazards}

The inherent and modified physical characteristics of the Wellington Region make it susceptible to a range of natural hazards. The location of the region dictates its susceptibility to frequent earthquakes due to the subduction of the Pacific Plate under the Indo-Australian Plate with consequential fault movements. Its location also makes it susceptible to tsunami through submarine earthquakes, landslides or volcanic eruptions in the Pacific Ocean. The frequency and intensity of windstorms, subtropical cyclones and volcanic ash fall are also governed by the location of the region. The geological characteristics of the region make it susceptible to landslides, erosion, liquefaction, ground shaking and subsidence. It also induces variations in the physical susceptibility to these hazards at the local level. As a result, the eastern section of the region is dominated by shallow slips and erosion, while the western hilly areas are particularly susceptible to 
rock and debris avalanches or debris falls. On the other hand, the loose sediments of the northwestern sand dunes along with the river valleys and reclaimed areas of the region are susceptible to high ground shaking, liquefaction and subsidence. Physiography further adds to the severity and number of hazards. Various landscape features such as steep slopes, fault alignments and coastal uplifts indicate both the past occurrences and potential threats from various biophysical processes.

The local variations in the mid latitude maritime climate of the region are also associated with numerous hazards. The rapid changes in the passage and intensity of pressure systems generate variations in the frequency and intensity of windstorms along with associated damage throughout the region. The topography induced variations in local rainfall on the other hand, produce different hazards across the region. While low rainfall in the east makes Wairarapa districts prone to recurrent droughts, heavy rainfall in the western districts is the cause of frequent landslips. The region also experiences thunderstorms and lightning, which mainly occur in its north western parts. However, snowfall is generally restricted to the upper reaches of the Tararua and the Rimutaka Ranges, and is therefore not a direct hazard in the region. The drainage pattern further modifies the susceptibility to various climatic and hydrological hazards. While short and dense drainage networks in the western section of the region result in quick flow of rain water and cause water scarcity, in the east long rivers arising in the Tararuas experience frequent floods. The variation in the local vegetation throughout the region produces variable physical susceptibility to bushfires. Also, the soil distribution patterns engender differential susceptibility to liquefaction, ground settlement and erosion. The physical susceptibility of a place therefore not only implies the hazards' characteristics, but also represents the connectivity between human and biophysical processes. It highlights the existing state of the relationship between humans and the environment, which then contributes to the hazard output.

\subsubsection{Human Vulnerability to Hazards in the Wellington Region}

Human vulnerability in the region is contributed to by a number of factors including demographic, socio-cultural, economic and political factors. The vulnerability index of the region based on demographic indicators points to Wellington City and the Kapiti Coast as the two most vulnerable districts. The high vulnerability of these two districts is linked with their high population growth along with high ratios of female, elderly and overseas populations. The aggregated social vulnerability index based on family type, education, language and ethnicity, on the other hand, places Porirua as the most vulnerable district followed by Wellington City and Lower Hutt City. The economic vulnerability index of the region based on work status, occupation, income, housing and means of communication again highlights Wellington City as the most vulnerable district followed by Lower Hutt and Porirua. The composite vulnerability of the region based on the summation of demographic, social and economic vulnerability, therefore puts Wellington City as the most vulnerable district followed by Porirua, Lower Hutt, the Kapiti Coast, Upper Hutt, Masterton, South Wairarapa and Carterton in descending order. The pattern shows that high vulnerability in the region is skewed towards densely populated urban areas.

The most vulnerable area in Wellington City is its Central Business District [CBD], which is occupied by a high international and student population, who are not only unaware of hazards but 
also fall into the low income group. The study shows that vulnerable mesh blocks in the region are located in close proximity of each other. However, in a wider context, the cause of vulnerability differs over space. For example, the vulnerability of the mesh blocks in the Waikanae area of the Kapiti Coast is attributed to the elderly population, in Lower Hutt to low income, and in Lambton Quay to both lack of awareness and low income. This suggests that while a common vulnerability reduction programme can not be applied to all of these areas, emergency response could be successful if planned by taking local vulnerability into consideration. It is also important to note that while the individual vulnerability in these mesh-blocks is transitory and varies over a short time span, the vulnerabilities associated with specific locations extend over a longer time. For example, an existing batch of students will be replaced by new ones or the current old age population will be replaced by a new generation of the elderly population. Therefore, unless there are major changes in urban design, the space remains vulnerable for a longer time due to continuously renewed vulnerability. The study also shows that the pattern of vulnerability varies on different spatial scales. Many areas which appear as highly vulnerable in the assessment at the mesh block level, appear less vulnerable at the area level, and their vulnerability is not visible at the district level. This highlights the significance of assessing vulnerability at local level.

The location and fragility of the regional infrastructure also increases the vulnerability of the local population. It could affect the real time response and recovery after a disaster due to interrupted services such as a loss of means of communication. Vulnerability at the local level is also affected by the human processes i.e. demographic, social, economic or political processes operating at a regional, national and global level. Large scale immigration to the country either for study or for work has enhanced the regional vulnerability through lack of awareness of hazards. The people, who have come as refugees due to political unrest or climate change not only face economic vulnerability, but are also unaware of the local hazardscape. They find problems in understanding a foreign language, which may produce a barrier in communicating their needs at the time of hazard occurrence. The data clearly highlight that the Middle Eastern, Latin American and African [MELAA] group is the most vulnerable group followed by Pacific people. Similarly, global economic recession in the past and current context has proved harmful for local people and especially for the vulnerable groups of society. The recession-induced unemployment and decline in income not only increases vulnerability by reducing coping capacity, but it also affects the adoption of hazard mitigation measures at an individual level.

\subsubsection{Natural Hazard Occurrence in the Wellington Region}

In the hazardscape of the Wellington Region, while low magnitude high frequency events are numerous, the occurrence of disaster is rare. Earthquake has the longest record of occurrence in the region. Hazards and consequent damage have expanded in the region over time irrespective of any major change in the natural environment. The modified physical susceptibility has allowed hazards to occur even in places of minimum natural susceptibility, such as flooding in hilly areas due to incapable and vulnerable drainage networks. Similarly, the removal of indigenous forests has enhanced erosion in pasture land and bushfire susceptibility in planted forests and shelterbelts. Population density and land use have played a crucial role in the spatial pattern of damage. While the damage from earthquakes, landslides and flooding is more frequent in western urban areas, the 
damage from flood, drought and bushfires is widespread in the eastern rural districts. Also, the threshold of hazard intensity causing damage in urban areas is less than that of rural areas. For example, all the damage from low magnitude earthquakes (i.e. 2.0-2.9) occurred in urban western districts and not a single damage claim was reported from any of the three rural districts in the east. Similarly, maximum damage from floods was claimed in Wellington City (30 percent) and less than three percent was claimed from any of the three rural districts of eastern Wairarapa, where rivers experience regular floods. All these characteristics clearly indicate a dominant role of humans behind development of the hazardscape in the Wellington Region.

The data also show that extensive damage in the region is often not caused by the most extreme hazard events. At the same time, neither the most vulnerable population was reported to be affected nor did the most susceptible places experience these intensive hazards. There is evidence that low magnitude events have caused significant damage in the region. For example, from 1997-2006 five earthquakes of magnitude 2.0-2.9 resulted in damage to the value of 33,334 NZD. Similarly, a flood with a 3-10 year return period caused damage valued at 790,000 NZD to the flood protection works on the Hutt River in 1997. The reason for such incidences could be found in the overall hazardscape of the region, where the population are increasingly occupying the most fragile and susceptible zones, and vulnerability to hazards has increased over time, which is partly related to the individual and administrative responses to hazards in the region.

\subsection{Public Response to Hazards and Influences of the Hazardscape}

The word 'response' in this study has been used in its broadest sense, which includes all actions i.e. adaptations or adjustments taken by the people for hazard mitigation, preparedness, emergency response or recovery. Long term adaptations which are widely adopted in the region, include building houses from wood, slanting roofs and section retaining walls. The adjustments for hazards, on the other hand, have been made only by a small proportion of people. Only 34 percent of the respondents said that they had taken mitigation measures to reduce damage from hazards. Only one percent of respondents said that they had built a stronger house or strengthened their existing house, while four percent of them had made major changes in their house in order to reduce hazards. More than 70 percent of the respondents, on the other hand, had taken nonstructural safety measures for disaster which were general throughout the region. The reasons behind the pattern of response were found to be related to the various characteristics of the hazardscape as mentioned below.

\subsubsection{Influences of Hazard Characteristics on Response}

The comparison of hazard characteristics with response show that response in the region is directed towards frequent hazards, which cause regular damage and have high risk in the near future, compared to those which may cause substantial damage but are not thought likely to occur in near future. Despite familiarity with many hazards, respondents found it hard to locate them in their future, especially the hazards of high magnitude. More respondents were prepared for the 
regular low magnitude high frequency hazard events as compared to the random events of low frequency and high magnitude. Predictability of hazards, on the other hand, has less influence on the response in the region. Although both areal extent and spatial dispersion of hazards have influenced overall response, there is no definite pattern as many respondents did not see hazards occurring in near space or time. Associated problems and the nature of regular damage from hazards have influenced hazard response more significantly than time and space specific hazard characteristics. Response is, however, less influenced by the controllability of hazards. It is also noted that respondents were more prepared for hazards for which protection measures are available, compared to those for which such measures are not available. The response in the region is also closely aligned with the calculated risk provided by the Wellington Regional Council for various hazards as compared to the overall risk perceived by the respondents. This indicates that the information provided by the local government has significant influence on the local hazard response.

\subsubsection{Influences of Physical Susceptibility on Hazard Response}

Physical susceptibility is another factor that has produced variations in the hazard response at local level. It has not only affected the hazard occurrence, but also the perception and response to hazards. However, the influence of physical susceptibility is more dominant for a few hazards as compared to others. The perception of bushfires and landslides in the region is closely aligned with the slope angle of the area where respondents reside. There is an increasing trend is noticed in the number of respondents who considered themselves to be exposed to landslide and bushfire with increasing slope angle. However, the frequency of these hazards as mentioned by the respondents does not increase consistently with increasing slope angle. This highlights the dominant influence of susceptibility on the perception of these hazards. A variation is also noted in the response to earthquakes with respect to the distance from fault line. Similarly, awareness of flood and coastal hazards decreases with increasing slope angle.

The rainfall pattern has also influenced the susceptibility, perception and therefore the response to hazards in the region. While in both low and high rainfall areas respondents perceived themselves as being exposed to flood and drought, a higher proportion of respondents in low rainfall areas mentioned being exposed to these hazards due to their high frequency. It could also be attributed to the nature-dependent occupation of respondents (i.e. farming especially in the eastern Wairarapa districts). However, there is less difference in the safety measures taken by the respondents across rainfall isozones. The comparison of the location of respondents in the floodplain susceptible to a 100 year flood event and the response to floods shows that more respondents living on the floodplain have taken measures for flood compared to those who live outside the floodplain.

The problems, frequency and potential damage related to windstorms along with the awareness of the hazard show a positive relationship with different wind speed zones. A higher proportion of respondents living in high wind zones perceived themselves as being exposed to windstorms compared to those in low wind speed zones. Influence of exposure on response is mainly noted for planting or removing trees outside the house. Also, a decline is observed in the 
proportion of respondents who felt very prepared for windstorms and who live in high wind speed zones. This is primarily because they could not see any control over high wind even if they could perceive its potential threat.

The actual bushfire susceptibility, on the other hand, had little effect on perception, awareness and response to this hazard. While the respondents living in very high bushfire susceptibility zones were not at all prepared for bushfires, those living outside the susceptible zones had taken mitigation measures and felt prepared for the hazard. The reason is linked to the perceived exposure due to the presence of surrounding bush along with the perceived cause of the hazard (i.e. either human or natural). While the respondents who felt exposed to bushfires due to the presence of bushes in the surrounding area took mitigation measures, the respondents who saw a human cause behind the hazard occurrence found that nothing could be done to reduce this hazard. Similarly, the respondents living in areas susceptible to liquefaction were less concerned about earthquakes compared to surface hazards such as flood, drought and tsunami. This is because flood, drought and tsunami are discernible to the respondents due to high awareness and frequency of these hazards. On the other hand, although the respondents living in the tsunami susceptible area were fearful of the hazard, they had not taken mitigation measures against it. One reason for not taking mitigation measures against tsunami was that respondents did not know what to do, except for the real time response when they would have to evacuate. On the other hand, since earthquakes are frequent in the region and there is a regular information supply from the district or regional councils, more respondents were prepared for earthquakes than most of the other hazards. As a result, the response to earthquake does not vary significantly across the region. However, differences are noticeable in terms of earthquake occurrence and perception in the areas susceptible to liquefaction or the areas close to fault lines. The physical susceptibility has therefore influenced the perception and response of people for flood, drought, landslides and windstorms to a greater extent as compared to liquefaction, cyclones, bushfires or volcanic ash fall. However, the information provided by local or regional councils is more generalised throughout the region and does not vary to a greater extent with respect to the variations in the physical susceptibility over space.

\subsubsection{Influences of Vulnerability on Hazard Response}

The influences of various aspects of vulnerability (i.e. exposure, fragility or sensitivity and lack of coping capacity and resilience) are also noticed as a factor behind the perception and response to hazards in the region. A variation is noted in the perceived cause of hazard exposure for different areas, people and respondents themselves. A high proportion of the respondents perceived either hazard characteristics or physical susceptibility as the main reason of hazard exposure in a particular area. Most respondents saw their family to be most affected by their most feared hazard, followed by themselves and then their neighbours. They see friends and community to be less affected compared to those who are likely to reside closer to them. The reason perceived to be the cause of exposure for other people included physical susceptibility, vulnerability, psychological conditions of the possible victims, poor response and disaster outcome, along with hazard characteristics, awareness and experience. Nearly 40 percent of the respondents believed 
unpredictability of hazards to be the main governing factor of their real time response to hazards, hence a source of their own vulnerability. Therefore, it can be said that there is a general tendency to see the cause of vulnerability as related to external physical influences rather than as a function of personal or institutional preparedness. However, the influences of individual characteristics are observed for perceived hazard exposure and response with respect to different groups of age, gender, ethnicity, religious orientation, education, hazard education, family size, work status, occupation, income, time of stay in the country, residential area or housing along with the vulnerability level of different areas.

While a positive relationship is apparent for the increasing proportion of respondents who perceived themselves to be exposed to cyclones and drought with increasing age, a negative relationship is noted for the perception of exposure to landslides and bushfires with age. The reason could relate to the fact that most of the aged population live away from steep slopes. Also, many elderly respondents were engaged in farming activities. Education has also influenced the perception of hazard exposure in the region. Respondents with formal educational qualifications perceived themselves to be exposed to all types of hazards compared to those with less or no educational qualification. Poor hazard perception is not only noted in the respondents who recently arrived in the country, but also among respondents who have lived here for up to 10 years.

Although most respondents at first did not recognise their personal characteristics influencing their vulnerability, when asked to rank the given characteristics for their influence on respondents' coping capacity and response to hazards, they agreed that these characteristics affect their vulnerability. For example, elderly respondents recognised that being old affects their vulnerability. Similarly, more women recognised that being a women and having children affects their coping capacity to disaster. Not recognising personal or others' vulnerability may result in enhanced vulnerability over time along with poor response.

Influences of vulnerability are also noted for variations in the hazard response. Since the highest proportion of respondents perceived themselves to be exposed to earthquakes and windstorms, a very high proportion of respondents took safety measures or felt prepared for these hazards. On the other hand, none of the respondents took safety measures for volcanic ash fall, but a high proportion of them felt prepared because they either did not perceive to be exposed, or they perceived a minor volcanic ash fall event. The elderly respondents cared less about hazards compared to young respondents. Similarly, the response from students and community support or NGO workers was also found to be low. Unemployed respondents made less change to their houses to reduce hazards as compared to those who were employed. While the respondents who recently moved to the country or to their current address (i.e. within a year), made the least amount of changes to their house or took mitigation measures to reduce hazards, the trend was opposite for the respondents who had lived longer in the country, area or house. This indicates that the movement of respondents has a significant implication for hazard mitigation as time plays a critical role in understanding of the hazardscape and adoption of appropriate measures.

The data also show that the respondents living in highly vulnerable zones had adopted less hazard mitigation or safety measures than those living in less vulnerable areas. The highest 
proportion of respondents who considered hazard issues during the purchase or renting of the house were either from moderately low or low vulnerability zones. Similarly, a high proportion of respondents from low vulnerability zones either made significant changes in their house to reduce hazard or they shifted house to avoid hazards. A consistent decline is observed in the proportion of respondents who took house insurance and lived in low vulnerability areas as compared to those who lived in areas of high vulnerability. In addition, the types of mitigation and safety measures taken by the respondents also decline significantly with increasing vulnerability. As Sen (1999) indicated, the reason could be attributed to fewer choices available for the highly vulnerable group because of low socio-economic conditions.

There is also difference with respect to perceived preparedness at the individual and area level. While a high proportion of male respondents felt very prepared for most hazards compared to female respondents, a smaller proportion of them perceived themselves to be not at all prepared. Also, respondents of less than 30 years of age did not find themselves to be very prepared for most hazards. The highest proportion of respondents who perceived themselves to be very prepared for earthquakes were from the elderly group (i.e. more than 60 years of age). Most respondents from MELAA group found most hazards to be either not applicable to them or they did not know about them. As a result they were not very prepared for any of the hazards except for a few who were prepared for floods. At the area level, despite a poor response, more respondents from high vulnerability zones perceived themselves to be prepared for most hazards compared to the respondents from low vulnerability zones. Therefore it can be concluded that vulnerability in the region has affected both perception and response to hazards.

\subsubsection{Influences of the Overall Hazardscape Characteristics on Response}

Besides the individual elements of the hazardscape (i.e. hazard characteristics, physical susceptibility and vulnerability), the response in the region is also influenced by its overall hazardscape characteristics, which also involves awareness, perception, past experiences, response culture and trust in the safety measures and response agencies. The highest proportion of respondents ( 66 percent) has not taken any mitigation measures to reduce hazards that can be attributed to the overall hazardscape characteristics, where disaster through hazards is rare. Since there is a high awareness about earthquakes and windstorms, more respondents have taken mitigation measures for these two hazards irrespective of their susceptibility to other hazards. Also, a major proportion of respondents living in tsunami susceptible areas find themselves to be not at all prepared for tsunami, as many of them were not aware of possible mitigation or safety measures. Awareness about the response agencies is also found to be low. Nearly 42 percent of the respondents said that they knew the location of their nearest civil defence centre, and a few of them wrongly perceived it to be their city or district council office.

The perception of vulnerability as influenced by unpredictability and physical susceptibility to hazards has resulted in greater reliance on warning systems and engineering solutions to reduce and respond to hazards rather than adapting to the change or reducing individual vulnerability. Even though people have taken safety measures, many of them have done this as a generic response rather than taking measures for a specific hazard. Their response is more a product of 
active campaigns from the Wellington Regional Council, and it has become a part of the response culture that is accepted by all. The highest proportion of respondents are not worried about any hazard followed by those who feel worried about most hazards, and then by those who feel safe from all hazards. The most feared hazard throughout the region is earthquake, irrespective of the varying susceptibility. Drought and windstorm on the other hand, are the most feared in the three rural districts of eastern Wairarapa. Bushfire is the most feared hazard in Upper Hutt followed by Porirua and South Wairarapa.

The main source of hazard information in the region is radio, followed by television, newspaper, local council and the internet. However, a variation is observed in the source of hazard information over space. While radio is most widely used in the three rural districts of eastern Wairarapa, it is least used in Wellington City, where television is the dominant source of hazard information. The use of newspapers for hazard information was noted highest in Lower Hutt and least in Carterton. Local council is sought as a source of hazard information for an average of 19 percent of the population throughout the region. It is sought the most in the Kapiti Coast (26 percent) and the least in Porirua (11 percent). The highest use of the internet as the source of hazard information is noted in Upper Hutt (24 percent) and lowest in Masterton (3 percent).

In spite of the popular belief among administrators and academics about the fatalism of local people in relation to hazard response, a high proportion of respondents believed that hazards can be mitigated. The perception of fatalism is noted highest for windstorms (11 percent) and lowest for bushfires (3 percent). A high proportion of respondents saw most hazards as natural processes except for bushfires, which are predominantly seen as having a human cause. Similarly, there is a dependence on the response of civil defence organisations because most respondents trust them highly for hazard information. On the other hand, religious institutions are the least trusted agency for hazard information, primarily because hazard information is not seen as the part of their job or alternatively, respondents either did not trust them or were atheist. While most respondents did not want any further information from the local council, about 13 percent wanted to know about the hazards they were exposed to at their particular place of residence. Others wanted to know how to respond, or the methods to reduce their vulnerability to hazards, where to go in case of tsunami occurrence, the role and responsibilities of civil defence organisations and items required for survival during hazard occurrence.

\subsection{Administrative Response to the Hazardscape of the Wellington Region}

The current Wellington Region Civil Defence and Emergency Management plan follows an integrated model of hazard response by including four 'Rs'(i.e. reduction, readiness, response and recovery), which aim for a uniform response throughout the region. However, despite having an integrative approach at the regional level, there are variations in the hazard response by individual districts, which can be attributed to variations in the local hazardscape. The assessment of 
administrative response to hazards highlights the shortcomings of the current response with respect to hazardscape characteristics, which increase the vulnerability in the hazardscape and influence the effectiveness of the adopted response measures.

The variations observed in the administrative response to hazards at the district level clearly highlight the influences of variations in local hazardscapes. The assessment of the city and district development plans of eight territorial local authorities in the region shows that there are variations in the emphasis placed on different hazards for mitigation in different districts. Earthquake and floods are the only two hazards which are mentioned in the development plan of Wellington city. The development plan of Porirua city, on the other hand, mentions the highest number of hazards including earthquakes, tsunami, landslides, cyclones and windstorms. Also, there are structural differences in the civil defence organisations managing regular hazards and response. While there is an active response to hazards from a civil defence team of eight full time staff in Wellington city, the number of staff in the civil defence team of Carterton district is only one, and this person works part-time. This clearly implies the difference in population size, resource availability, frequency of hazard occurrence and urban versus rural characteristics of these two districts. The differences are also noted in the information provided by the local administration to the residents. While maximum information about different types of hazards is provided by the Masterton district council, minimum hazard information was given in Porirua city (i.e. only for earthquake, bushfire and tsunami). The perception and response of civil defence officers and district planners also differed across the region. While most civil defence officers see themselves to be highly prepared for hazards, the proportion of respondents with same view was less in district planners, who viewed hazard response as primarily the function of civil defence officers.

Further, although the response in the region aims to achieve the four Rs there is an excessive emphasis on readiness compared to hazard reduction, emergency response or recovery. One reason could be related to the shared responsibility of hazard reduction between district and regional governments, along with further diversification under different departments. Also, many important mitigation measures are often compromised for economic reasons as the cost of hazard reduction is seen to exceed the risks. The prime methods of hazard reduction include engineering solutions i.e. strengthened building for earthquakes, retaining walls for landslides and stop banks for floods. However, most of these solutions are designed to survive a particular magnitude of respective hazards and therefore, they are likely to fail eventually in the case of high magnitude event, which could result in disaster. An important finding of this study is that recovery plans are still not in place for most districts. Many of the district planners also claimed that their perception and awareness of hazards would not be much different from the local people. This is unsatisfactory as district planners are responsible for land use planning for hazard mitigation.

Also, even though the Wellington Region Civil Defence and Emergency Management Plan adopts a holistic approach, it does not consider the local variations in the hazardscape, either in terms of physical susceptibility or vulnerability. It does not mention the variations in vulnerability or their different causes across the region. The hazard information provided by the local and regional council to people was generic throughout the region. Further, the absence of detailed 
plans for emergency management at the district level could easily undermine the real time hazard response. A few hazards are emphasised in most plans at the expense of others. For example, while there is excessive emphasis on hazard response to earthquake and flood, a few other intensive hazards have been consistently neglected for hazard response throughout the region, especially tsunami and volcanic ash fall.

The hazardscape therefore, highlights areas of weakness along with scope for the improvement of hazard response. This is because it not only refers to the conditions, but also about their cause. It also indicates the behaviour of various processes both natural and human, which may reduce or increase the intensity of hazard and subsequently, the hazardscape. For example, demographic processes such as local and international migrations have significantly influenced the response measures adopted by the respondents for hazard mitigation. While a significant proportion of respondents (21 percent) said that they were not aware of any hazard when they first moved into their house, another 60 percent knew only one or two hazards. Also, in the primary survey, a very small proportion of respondents mentioned that they had taken measures against landslides, and similarly, a small proportion of respondents said that they had built a strong house or strengthened their house or made any major structural changes to reduce hazards. This is mainly because most of the steep slopes in cities are densely occupied, and the population is likely to move more frequently (over space) for work or for other reasons compared to the rural population living in gentle slopes of rural Wairarapa districts. Houses on urban hills, especially in Wellington, Porirua, Lower Hutt and Upper Hutt City, are mainly occupied by a population who did not construct their own house. As a result, if there are any hazard mitigation measures taken at the time of construction, the current residents may not be fully aware of them due to their non-permanence. This is especially true with rental properties. None of the respondents mentioned wooden houses or slanting roofs as methods of hazard mitigation. This is because these methods are so much internalised in the housing culture that people take them as obvious rather than as mitigation measures.

Political and administrative processes further govern the local vulnerability, susceptibility and response to hazards. While the region is exposed to a range of hazards, the excessive emphasis on earthquake response is dominantly enforced by the administrative and political preferences. As a result, while measures such as wooden houses, building codes and survival kits are widely adopted in the region for earthquakes, such measures are absent for tsunami or other prevalent hazards. The dominant role of an active regional campaign for preparedness is also clear in the fact that although a large proportion of respondents took safety measures, many could not name the hazard for which they adopted the safety measures. Other human processes such as global economic recession, international migration, globalisation and climate change have also influenced the response in the region. This highlights the connectivity of hazardscape with various processes 
of the ecosystem, which could transfer varying degrees of change in the system, and therefore, could either intensify or weaken the local hazardscape.

It can be concluded that a hazardscape is an interwoven natural and human construct. The case study of the Wellington Region clearly portrays various elements and characteristics of its hazardscape that have influenced the local and regional response to hazards.

\subsection{Research Caveats and Perspectives}

The study faced many limitations and brought forth a few key concerns, which highlight the scope and perspectives for future research. One caveat of this research is its sampling method. In order to achieve the stated aims and objectives, the stratified purposive sampling method was selected. However, since the method was not random, the key findings of this research can not be generalised for the total population. Future studies could adopt a more statistically sound sampling method for a detailed analysis of the hazardscape at any particular location.

It would also have been better to assess and write all hazardscape chapters before conducting the primary survey. However, this was not possible as the data were collected from multiple sources, which took more than the anticipated time. There were various issues with the methodology for determining vulnerability that had to be resolved first, and it was a time consuming process. Therefore, in order to meet the objectives of this research within three years, the primary data collection survey had to be conducted first. The vulnerability index was calculated and plotted after the primary survey, and therefore, many vulnerability areas at the local level were missed in conducting the primary survey. This restricted analysis of response with respect to vulnerability attributed to particular subgroups of factors i.e. demographic, social or economic vulnerability. Future studies could further assess the level and cause of vulnerability and its implications on hazard response.

Since this thesis provides a holistic study, it looks at various factors and processes of the hazardscape from a distance and identifies their dominant roles. Future studies could assess these factors in detail at a particular location. In depth analysis of the hazardscape at the local level could further help to channel the resources for hazard management and planning in an appropriate manner.

\subsection{Hypothesis Revisited}

The adoption of a hazardscape concept to assess the hazardousness and sources of risk in a region has provided more insights than conventional approaches. Conventional studies that focus on specific aspects of hazards, risk or response in isolation may provide a useful level of detail for management purposes. However, the complex interconnections that emerge through the 
hazardscape lens allow an appreciation of the causes, controlling factors and trends in processes underlying hazard susceptibility, vulnerability and response.

This research was based on the hypothesis that:

'Whereas integrated regional planning is likely to produce a uniform response to hazard, hazardscape introduces variations in the local response throughout the region.'

Given the MCDEM has established a national CDEM plan, which gives the template and requirement to regions to produce a region-wide plan, it is reasonable to assume a tendency for a uniform response throughout the region. In addition, given that district plans and policies are required to be consistent with the overarching Regional Policy Statement and plans, one can also anticipate a degree of uniformity in response throughout the region. However, physical and human conditions that influence hazard characteristics, susceptibility, vulnerability, response and risk have been shown to vary dramatically within the region from east to west, from rural to urban, as well as in exposure to different hazards. It has been the purpose of this research to gather data and analyse the relationship of the variation of intra-regional response to the range of human and physical conditions throughout the region. In the final analysis, the hypothesis can be accepted because of identification of significant differences in response influenced by variations in the hazardscape. 
Bibliography

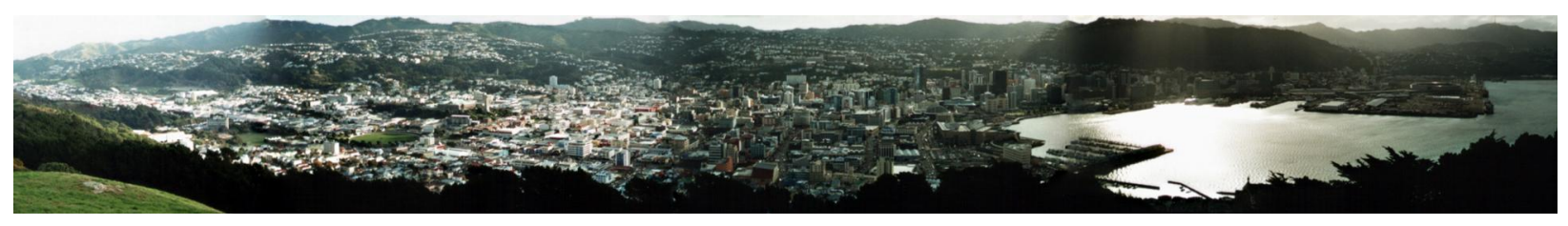




\section{Bibliography}

A

Adgar, W. N. (2000). 'Social and Ecological Resilience: Are They Related'. Progress in Human Geography. 24(3): 347-364.

Aitken, J. J. (1995). More Earthquakes Explained. Lower Hutt, NZ: Institute of Geological \& Nuclear Sciences.

Alexander, D. E. (1993). Natural Hazards. London: UCL Press. . (2002). Principles of Emergency Planning and Management. New York: Oxford University Press.

Alley, R. (Ed., 2007). New Zealand in world Affairs IV: 1990-2005. Wellington, NZ: Victoria University of Wellington \& The New Zealand Institute of International Affairs.

Ansell, R. \& Taber, J. (1996). Caught in the Crunch: Earthquakes and Volcanoes in New Zealand. Auckland: Harper Collins.

Armas, I. (2006). 'Earthquake Risk Perception in Bucharest, Romania'. Risk Analysis. 26(5): 12231234.

Australian Bureau of Meteorology. (2008). Global Wind Patterns. Retrieved November 13, 2008, from

http://images.google.com/imgres?imgurl=http://www.bom.gov.au/lam/climate/levelthree/ analclim/imagesm/glbwndap.jpg\&imgrefurl=http://www.bom.gov.au/lam/climate/levelthr ee $/$ analclim $/ \mathrm{glbwnd} \cdot \mathrm{htm} \& \mathrm{~h}=424 \& \mathrm{w}=425 \& \mathrm{sz}=45 \& \mathrm{hl}=$ en\&start $=12 \& u m=1 \& u s g=\ldots$ F6oq LS_Ra29T_XBvPC5qEYL5M8=\&tbnid=dP1DIDpe3UDRwM:\&tbnh=126\&tbnw=126\&pr ev $=/$ images $\% 3 \mathrm{Fq} \% 3 \mathrm{DGlobal} \% 2 \mathrm{Bwind} \% 2 \mathrm{Bpattern} \% 26 \mathrm{um} \% 3 \mathrm{D} 1 \% 26 \mathrm{hl} \% 3 \mathrm{Den} \% 26 \mathrm{sa} \% 3 \mathrm{D}$ $\mathrm{N}$

Babbie, E. R. (2008). The Basics of Social Research. $4^{\text {th }}$ ed. Australia: Thomson Wadsworth.

Background on Natural Hazards in New Zealand: Property Insight. (October 3, 2005). Retrieved May 4, 2008, from http://data.gns.cri.nz/pi/HazardInfo.pdf

Baggaley, E. J. (1967). A Geography of New Zealand: or A Systematic Geography of New Zealand. Melbourne, Australia: Thomas Nelson.

Bagnall, A. G. (1957). A History of Carterton: The Story of the First Hundred Years of the Settlement of Carterton (1857-1957). Carterton, NZ: The Carterton Borough Council.

(1976). Wairarapa: An Historical Excursion. Masterton, NZ: Masterton Hedley’s Bookshop Ltd.

Baker, T. \& Jones, A. (2005). Ground water Monitoring Technical Report. Retrieved August 14, 2008, from http:/ /www.gw.govt.nz/councilpublications/pdfs/Groundwater\%20Monitoring\%20Technical\%20Report.pdf

Bannister, C. (1999). Early History of the W airarapa. Christchurch, NZ: Cadsonbury.

Barrows, H. H. (1923). 'Geography as Human Ecology.' Annals of American Geographers. 13(1): 1-14.

Barry, J. (2007). Environment and Social Theory. $2^{\text {nd }}$ ed. London: Routledge. 
Bawman, I. (1995). Heritage Building Inventory. Vol. 1, 2 \& 3. Wellington, NZ: Wellington City Council.

Beable, M. E. \& McKerchar, A. I. (1982). 'Regional Flood Estimation in New Zealand'. In NWASCO (1984). 'Flooding.' In Scientific, Economic and Social Reviews of Natural Hazards in New Zealand. Edited by I. G. Speden \& M. J. Crozier. Wellington, NZ: National Commission for UNESCO.

Beck, U. (1999). World Risk Society. Malden: Polity Press.

Becker, J. \& Johnston, D. (2000). Planning and Policy for earthquake Hazard in New Zealand. Lower Hutt, NZ: Institute of Geological and Nuclear Sciences.

. (2002). 'Planning for Earthquake Hazard in New Zealand: A Study of Four Regions.' The Australian Journal of Emergency Management. 17(1): 1-8.

Begg, J. G. \& Mazengarb, C. (1996). Geology of the Wellington Area. Sheets R27, R28 and Part Q27. Institute of Geological and Nuclear Sciences Geological map 22. Lower Hutt, NZ: Institute of Geological and Nuclear Science Limited.

\& Johnston, M. R. (2000). Geology of the Wellington Area. Institute of Geological \& Nuclear Sciences 1: 250000 geological map 10. Lower Hutt, NZ: Institute of Geological \& Nuclear Sciences.

Benn, J. L. (2005). 'Landslide Events on the West Coast, South Island, 1867-2002.' New Zealand Geographer. 61: 3-13.

Berry, B. J. L. (1988). 'Book Review: Human Ecology: A Theoretical Essay by A. H. Hawley.' Contemporary Sociology. 17(2): 137-139.

Berryman, K. (1984). 'Active Folding and Faulting'. In Scientific, Economic and Social Reviews of Natural Hazards in New Zealand. Edited by I. G. Speden \& M. J. Crozier. Wellington: New Zealand National Commission for UNESCO.

(2005). Review of Tsunami Hazard and Risk in New Zealand. Client Report: 2005/105. Prepared for Ministry of Civil Defence and Emergency Management. Lower Hutt: Institute of Geological and Nuclear Sciences Limited.

Birkmann, J. (2006). 'Measuring Vulnerability to Promote Disaster-Resilient Societies: Conceptual Frameworks and Definitions.' In Measuring Vulnerability to Natural Hazards: Towards Disaster Resilient Societies. Edited by J. Birkmann. Tokyo: United Nations University Press.

Blakeley, R. (2006). Community Preparedness Survey Results. Retrieved April 15, 2008, from http://www.gw.govt.nz/council-reports/pdfs\%5Creportdocs\%5C2006_601_1_Report.pdf

Boffa Miskell Ltd \& Cochran, C. (2001). Inventory of Heritage Precincts. Wellington, NZ: Wellington City Council.

Bohle, H.G. (2001). 'Vulnerability and Criticality: Perspectives from Social Geography'. IHDP Update. Newsletter of the International Human Dimensions Programme on Global Environmental Change. 2: 1-7. Retrieved March 19, 2009, from http://www.ihdp.unibonn.de/html/publications/update/update01_02/IHDPUpdate01_02_bohle.html

Bradford, M. \& Carmichael, R. S. (2007). Notable Natural Disasters Events 1970 to 2006. Vol. 3. New Jersey, USA: Salem Press.

Briguglio, L. (2003). The Vulnerability Index and Small Island Developing States: A review of Conceptual and Methodological Issues. Malta: University of Malta. Retrieved October 31, 2008, from http://home.um.edu.mt/islands/vulnerability_paper_sep03.pdf

(2008). Measuring Vulnerability. Retrieved August 22, 2008, from http://www.unep.org/OurPlanet/imgversn/103/17_mea.htm

Britton, N. R. (1981). 'What Have New Zealanders Learnt From Earthquake Disasters In Their Own Country.' Disasters 5 (4): 384-390. 
(1988). 'Organised Behaviour in Disaster: A Review Essay.' International Journal of Mass Emergencies and Disasters. 6: 363-395.

(1991). 'Constraint or Effectiveness in Disaster Management: The Bureaucratic Imperative Versus Organisational Mission.' Canberra Bulletin of Public Administration. 64: 54-64.

, \& Lindsay, J. (1995a). 'Integrating City Planning and Emergency Preparedness: Some of the Reasons Why.' International Journal of Mass Emergencies and Disasters. 13(1): 93-106.

, \& Lindsay J. (1995b). 'Demonstrating the Need to Integrate City Planning and Emergency Preparedness: Two Case Studies.' International Journal of Mass Emergencies and Disasters. 13(1): 161-178.

(1999). 'Whither the Emergency Manager?' International Journal of Mass Emergencies and Disasters. 17(2): 223-235.

(2001). 'A new Emergency Management For the New Millennium?' Australian Journal of Emergency Management. Summer [2001-2002]: 44-54. Retrieved April 21, 2008, from http://www.ema.gov.au/agd/EMA/rwpattach.nsf/viewasattachmentpersonal/(C86520E41F 5EA5C8AAB6E66B851038D8) A_new_emergency_management_for_the_new_millenniu m.pdf/\$file/A_new_emergency_management_for_the_new_millennium.pdf

Broadcasting Standards Authority. (2006). Broadcasting Act. Retrieved September 21, 2007, from http://www.bsa.govt.nz/broadcastingact.htm

Broun, B. (February 7, 2006). 'Heartbreak floods back despite the warnings'. The Dominion Post. Pp. A2.

Building for earthquake resistance. (n.d). Retrieved July 27, 2007, from http://www.teara.govt.nz/EarthSeaAndSky/NaturalHazardsAndDisasters/Earthquakes/4/e $\mathrm{n}$

Bull, B. H. (1986). The Years Between Greytown Borough Centennial 1878-1978. Greytown Borough Council, NZ: Royal house Publishing.

Burton, I. Kates, R. W. and White, G. F. (1978). The Environment as Hazard. $1^{\text {st }}$ ed. New York: Oxford University Press. (1993). The Environment as Hazard. $2^{\text {nd }}$ ed. New York: The Guilford Press.

Butterworth, S. (1988). Petone: A History. Petone, NZ: Petone Borough Council.

C

Caruso, B. S. (2002). 'Temporal and Spatial Patterns of Extreme Low Flow and Effects on Stream Ecosystems in Otago, New Zealand.' Journal of Hydrology. 257: 115-113.

Catton, W. R. Jr. (1994). 'Foundation of Human Ecology.' Sociological Perspectives. 37(1): 75-95.

Centre for Advanced Engineering [CAE]. (1991a). Lifelines in Earthquakes: Wellington Case Study. Project Summary. Christchurch, NZ: University of Canterbury.

(1991b). Lifelines in Earthquakes: Wellington Case Study. Project Report. Christchurch, NZ: University of Canterbury.

Chairman's Monthly Report - February 2003. Retrieved October 3, 2006, from http://www.nrc.govt.nz/reports.and.news/chairmans.report/2003/index_february.shtml.

Cheng, K. \& Chao, R. (2001). 'Seismic Risk for New Zealand: 2001-2010.' In Proceedings of the Second International Workshop on Statistical Seismology. Edited by M. Bebbington \& C. D. Lai. Wellington, NZ: Victoria University of Wellington \& The Statistical Research and Consulting Centre, Massey University, Palmerston. 
Chorley, R. J. (1973). 'Geography as Human Ecology.' In Directions in Geography. Edited by R.J. Chorley. London: Methuen \& Co Ltd.

Clary, B. B. (1985). 'The Evolution and Structure of Natural Hazard Policies.' Public Administration Review, Special Issue: Emergency Management: A Challenge for Public Administration. 45: 20-28.

Clausen, B. \& Pearson, C. P. (1995). 'Regional Frequency Analysis for Annual Maximum Stream Flow Drought.' Journal of Hydrology. 173: 111-130.

CLIFLO, NIWA. (2007). Data for Meteorological Hazards: Rain, Temperature, Wind, Sunshine and Soil Moisture. Retrieved October, 2007, from http://cliflo.niwa.co.nz/

Combined Council Working Party - Environmental Constraints (June 24, 2005). Wellington Regional Strategy. Working Paper: 2.14. Retrieved April 12, 2008, from http://www.wrs.govt.nz/docs/a_final_env_constraints_draft_report_1_combined.pdf

Coomer, M. A., Johnston, D. M., Edmonson, L., Monks, D., Pedersen, S., \& Rodger, A. (2008). Emergency Management in schools: Wellington Survey. GNS Science report 2008/04. 28p. Lower Hutt: GNS Science.

Cordana, O. D. (2006). 'A System of Indicators for Disaster Risk Management in the Americas.' In Measuring Vulnerability to Natural Hazards: Towards Disaster Resilient Societies. Edited by J. Birkmann. Tokyo: United Nations University Press. Pp: 189-209.

Corson, M. W. (1999). 'Hazardscapes in Reunified Germany.' Environmental Hazards. 1: 57-68.

Cousins, W. J., Power, W. L., Destegul, U., King, A. B. (2008). Earthquake and Tsunami Losses from Major Earthquakes Affecting Wellington Region. Benfield Limited. 14p. Retrieved December 10, 2009 , from http://www.benfieldcorporaterisk.com/SiteCollectionDocuments/BenfieldCorporateRisk/ MediaAndResearch/BenfieldNZTsunamiDec2008.pdf

Cowan, J. (1998). The Effects of Media Descriptions on Judgements About Earthquakes. Unpublished Thesis for Master of Science in Psychology. Wellington, NZ: Victoria University of Wellington.

Cowie, C. A. (1957). 'Floods in New Zealand 1920-53.' In NWASCO (1984). In Flooding in Scientific, Economic and Social Reviews of Natural Hazards in New Zealand. Edited by I.G. Speden \& M. J. Crozier. Pp. 13. Wellington, NZ: New Zealand National Commission for UNESCO.

Creswell, J. W. (2003). Research Design-Qualitative, Quantitative and Mixed Methods Approaches. $2^{\text {nd }}$ ed. London, UK: Sage Publications.

Cross, J. A. (2001). 'Megacities and Small Towns: Different Perspective on Hazard Vulnerability.' Environmental Hazards. 3:63-80.

Crozier, M.J. (1986). Landslides: Causes, Consequences and Environment. London: Croom Helm. (1990). 'Landslides and Erosion in Wairarapa-Mechanisms, Controlling Factors and Processes and Regional Differences'. Occasional Paper 1, Series: ISSN-0114-9458. Wellington, NZ: Department of Geography, Victoria University of Wellington.

. (2005). 'Management Framework for Landslide Hazard and Risk: Issues and Options.' In Landslide Hazard and Risk. Edited by T. Glade, M. A. Anderson and M. J. Crozier. England: John Wiley and Sons Limited.

, \& Aggett, G. (2000). 'A Hazardous Place in Dynamic Wellington: A Contemporary Synthesis and Explanation of Wellington.' In Dynamic Wellington: A Contemporary synthesis and explanation of Wellington. Edited by J.A. McConchie, D. R. Winchester \& R. P. Willis. Wellington, NZ: Victoria University of Wellington.

, McConchie, J. A., Owen, R. C. \& Eyles, R. J. (1982). Mass Movement Erosion Wairarapa.

Wellington, NZ: Victoria University of Wellington. 
, McClure, J., Vercoe, J. \& Wilson, M. (2006). 'The Effects of Land Zoning Information on Judgement About Earthquake Damage'. Area. 38(2): 143-152.

Cutter, S. L. (2001). 'The Changing Nature of Risk and Hazards.' In American Hazardscapes. Washington, USA: Joseph Henry Press.

, Mitchell, J. T. \& Scott, M. S. (2000). 'Revealing the Vulnerability of People and Places: A Case Study of Georgetown County, South Carolina.' Annals of Association of American Geographers. 90(4): 713-737.

Boruff, B. J. \& Shirley, W. L. (2003). 'Social Vulnerability to Environmental Hazards.' Social

Science Quarterly. 84(2): 242-261. Retrieved December 4, 2008, from http://www.colorado.edu/hazards/resources/socy $4037 /$ Cutter $\% 20 \% 20 \% 20$ Social $\% 20$ vulnerabilit $\mathrm{y} \% 20$ to $\% 20$ environmental $\% 20$ hazards.pdf

D

Darienzo, M. et al. (2005). 'Local Tsunami Warning in the Pacific Coastal United States.' In Developing Tsunami- Resilient Communities: The National Tsunami Hazard Mitigation Program. Edited by E. N. Bernard. The Netherlands: Springer.

Department of Conservation. (2006). Rural fire control- What DOC does. Retrieved September 20, 2007, from http://www.doc.govt.nz/Conservation/Fire/index.asp

Department of Internal Affairs [DIA]. (2007). National Civil Defence Emergency Management Strategy, 2007. National Civil Defence Emergency Management Strategy Wellington. Retrieved April 18, 2008, from

http://www.civildefence.govt.nz/memwebsite.NSF/Files/National_CDEM_Strategy/\$file/ National-CDEM-strategy-2008.pdf

Department of Land and Survey (1969). Land Development- Wellington. Wellington, NZ.

Dibble, R. R. (1984). 'Volcanic Hazard in New Zealand.' In Scientific, Economic and Social Reviews of Natural Hazards in New Zealand. Edited by I. G. Speden and M. J. Crozier. Wellington, NZ: New Zealand National Commission for UNESCO.

Dietz, T., Frey, R. S. and Rosa, E. A. (2002). 'Risk, Technology and Society.' In Handbook of Environmental Sociology. Edited by R.E. Dunlap \& W. Michelson. London, UK: Greenwood Press.

Dilley, M. (2006). 'Disaster Risk Hotspots: A Project Summary.' In Measuring Vulnerability to Natural Hazards: Towards Disaster Resilient Societies. Edited by J. Birkmann. Tokyo: United Nations University Press.

Dreaver, A. J. (1984). Horowhenua County and its People: A centennial History. Levin, NZ: The Dunmore Press.

$\mathbf{E}$

Earthquake Commission [EQC]. (2007). Data of Earthquake, Landslide and Flood Damage: 1996-2007.

Easther, J. (1991). The Hutt River Te-Awa-Kai-Rangi - A Modern History 1840-1990: Hutt River Flood Control Scheme Review. Vol. 12. A History of River Management. Wellington: Wellington Regional Council.

Eiby, G. A. (1967). Earthquakes. London: Fredrick Muller Limited. 
ENZ. (2010). Your Cost of Living in New Zealand 2009. Retrieved January 22, 2010, from http://www.emigratenz.org/cost-of-living-in-new-zealand.HTML

Erickson, N. J. (1986). Creating Flood Disaster? New Zealand's Need For A New Approach To Urban Flood Hazard. Water and Soil Miscellaneous Publication no-77. Wellington, NZ: Ministry of Works and Development.

(1990). 'Natural Hazards: An Interactive Systems Approach.' In Natural Hazards 90' in Natural Hazard Assessment in New Zealand. Edited by M. J. Crozier. Wellington, NZ: Research School of Earth Sciences, Victoria University of Wellington.

. (2005). 'Hang-ups in flood hazard planning (part 1).' Planning Quarterly. December: 24-28.

(2005). 'Hang-ups in flood hazard planning (part 2).' Planning Quarterly. December: 24-28.

Explore Te Ara: The Encyclopaedia Of New Zealand [Te Ara] (2008a). Historic Earthquakes.
Retrieved
March
3, 2008,
from,

http://www.teara.govt.nz/EarthSeaAndSky/NaturalHazardsAndDisasters/HistoricEarthqua kes/2/ENZ-Resources/Standard/1/en

. (2008b). Wellington Harbour Before the Haowhenua Earthquake. Retrieved June 16, 2008, from http://www.teara.govt.nz/EarthSeaAndSky/NaturalHazardsAndDisasters/HistoricEarthqua kes/1/ENZ-Resources/Standard/4/en

(2008c). Hazardous Volcanoes. Retrieved June 2, 2008, from, http://www.teara.govt.nz/EarthSeaAndSky/NaturalHazardsAndDisasters/Volcanoes/8/E NZ-Resources/Standard/3/en

(2008d). Belmont Penneplain. Retrieved June 2, 2008, from, http://www.teara.govt.nz/Places/Wellington/Wellington/2/ENZ-

Resources/Standard/2/en

(2008e). Earthquakes in Māori tradition. Retrieved March 31, 2008, from http://www.teara.govt.nz/EarthSeaAndSky/NaturalHazardsAndDisasters/HistoricEarthqua kes $/ 1 /$ en

(2008f). Creation stories and landscape: Epic Earthquakes. Retrieved March 31, 2008, from http://www.teara.govt.nz/EarthSeaAndSky/NaturalHazardsAndDisasters/HistoricEarthqua $\mathrm{kes} / 3 / \mathrm{en}$

(2008c). Tropical Cyclones. Retrieved July 28, 2008, from http://www.teara.govt.nz/EarthSeaAndSky/ClimateAndAtmosphere/Weather/4/en

(2008d). Flooding in Kilbirnie, Wellington. Retrieved July 28, 2008, from http://www.teara.govt.nz/EarthSeaAndSky/ClimateAndAtmosphere/Weather/6/ENZ-

Resources/Standard/2/en

(2008e). Homeless. Retrieved July 28, 2008, from http://www.teara.govt.nz/EarthSeaAndSky/ClimateAndAtmosphere/Weather/7/ENZResources/Standard/1/en

(2008f). Wairarapa Drought. Retrieved May 12, 2008, from http://www.teara.govt.nz/EarthSeaAndSky/ClimateAndAtmosphere/Climate/4/ENZ-

Resources/Standard/3/en\#breadcrumbtop

(2009). Wellington. Retrieved May 26, 2009, from http://www.teara.govt.nz/Places/Wellington/Wellington/13/en

Eyles, G. O. (1983). 'Distribution and Severity of Present Soil Erosion in New Zealand.' New Zealand Geographer. 39(1): 12-28.

Eyles, R. J., Crozier, M. J. \& Wheeler, R. H. (1978). 'Landslips in Wellington City.' New Zealand Geographer. 34(2): 58-74. 
Farkas, E. (1984). 'Natural Air Pollution.' In Scientific, Economic and Social Reviews of Natural Hazards in New Zealand. Edited by I. G. Speden \& M. J. Crozier. Wellington, NZ: New Zealand National Commission for UNESCO.

Finnis, K., Standring, S., Johnston, D. \& Ronan, K. (2004). 'Children's understanding of natural hazards in Christchurch, New Zealand.' The Australian Journal of Emergency Management. 19(2): $11-20$.

Finnis, K. (2006). Resilience and Vulnerability in Communities Around Mt. Taranaki. Unpublished PhD thesis. University of Otago, Dunedin.

Forme Consulting Group Ltd [FGCL] (1998). Rural Fire Hazard in the Wellington Region. Report: WRC/RP-G-98/12. Wellington, NZ: Wellington Regional Council.

Fraser, E. D. G. (2009). 'The House is Both Empty and Sad: Social Vulnerability, Environmental Disturbance, Economic Change and the Irish Potato Famine.' In Assessing Vulnerability to Global Environmental Change: Making Research Useful for adaptation Decision Making and Policy. Edited by A.G. Patt, D. Schroter, R.J.J. Klein \& A.C. de la Vega-Leinert. London, UK: Earthscan.

Froggatt, P. (2009). Volcanic Hazards at Taupo Volcanic Centre. Retrieved January 20, 2009, from http://www.gns.cri.nz/what/earthact/volcanoes/nzvolcanoes/taupoprint.htm

Fuller, I. C. (2005). 'February Floods in the Lower North Island, 2004: Catastrophe-Causes and Consequences.' New Zealand Geographer. 61: 40-50.

\section{G}

Gee, M. D. (1992). Natural Hazard Assessment and Mapping Wellington Region. Unpublished Thesis for Doctor of Philosophy in Physical Geography. Wellington, NZ: Victoria University of Wellington.

GeoEnvironmental Consultants. (2001). Wellington Regional Tsunami Hazard Scoping Project. GeoEnvironment Client Report: GEO2001/20008/12. Wellington Regional Council Publication No. WRC/Rp-T-01/23. Wellington, NZ.

Geological and Nuclear Sciences Ltd [GNS]. (2008a). 23 January 1855: Tsunami from the Wairarapa earthquake. $\quad$ Retrieved May 20, 2008, from http://data.gns.cri.nz/hazardwatch/2004_01_01_historyarch.html . (2008b). The eruption of Ruapehu, June 1996. Retrieved May 20, 2008, from http://www.geonet.org.nz/volcano/our-volcanoes/ruapehu.html . (2008c). 11 September 1880: Derailment on the Rimutaka Incline. Retrieved May 20, 2008, from http://data.gns.cri.nz/hazardwatch/2003_09_01_historyarch.html 2008-05-20

(2008d). 29 March 1888: Wellington Train Stranded. Retrieved May 20, 2008, from http://data.gns.cri.nz/hazardwatch/2005_04_01_historyarch.html 2008-05-20

. (2008e). Hazard Watch for Wellington Region. Retrieved May 20, 2008, from http://www.hazardwatch.co.nz/

(2008f). $M$ 8.2, Wairarapa, January 23 1855. Retrieved May 10, 2008, from http://www.geonet.org.nz/images/earthquake/wairarapa-23-january-

1855/lge_wairarapa_turakirae_head.jpg 
Geonet. (2008a). Quake Search. Retrieved May 20, 2008, from http://magma.geonet.org.nz/resources/quakesearch/index.jsp

(2008b). Historic Quakes. Retrieved May 10, 2008, from http://www.geonet.org.nz/earthquake/historic-earthquakes/top-nz/quake-02.html

. (2008c). Volcano: Ruapehu: The Eruption of Ruapehu, June, 1996. Retrieved May 10, 2008, from http://www.geonet.org.nz/images/volcano/our-volcanoes/Ruapehu-Erupts-Jun-96-lge.jpg

Gibbs, H. S. (1980). New Zealand Soils: An Introduction. Wellington, NZ: Oxford University Press.

Gibb, J. G. (1981). 'Coastal Hazard Mapping as a Planning Technique for Waiapu County.' In NWASCO (1984). 'Flooding.' In Scientific, Economic and Social Reviews of Natural Hazards in New Zealand. Edited by I. G. Speden \& M. J. Crozier. Wellington, NZ: New Zealand National Commission for UNESCO.

Gilmour, A. E. (1964). Characteristics of Tsunamis (Seismic Sea Waves). New Zealand Oceanographic Institute Miscellaneous Publication No.12.

Glade, T. (1997). The Temporal and Spatial Occurrence of Rainstorm-Triggered Landslide Events in New Zealand. Unpublished Thesis for Doctor of Philosophy in Physical Geography. Wellington, NZ: Victoria University of Wellington.

, \& Crozier, M. J. (2005). 'The Nature of Landslide Hazard Impact.' In Landslide Hazard and Risk. Edited by T. Glade, M. A. Anderson \& M. J. Crozier. England: John Wiley and Sons.

Anderson, M. \& Crozier, M. J. (ed. 2005). Landslide Hazard and Risk. Chichester, UK: J. Wiley.

Godschalk, D. R. and Brower, D. J. (1985). 'Mitigation Strategies and Integrated Emergency Management.' Public Administration Review. Special Issue: Emergency Management: A Challenge for Public Administration. 45: 64-71.

Goff, J. R. \& McFadgen, B. G. (2003). 'Large Earthquakes and the Abandonment of Prehistoric Coastal Settlements in 15th Century New Zealand.' Geoarchaeology: An International Journal. 18 (6): 609-623. DOI:10.1002/gea.10082.

Gomez, E. T. (2008). 'Introduction: Modernization, Democracy, Equity and Identity.' In The State, Development and Identity in Multi-Ethnic Societies: Ethnicity, Equity and the Nation. Edited by N. Tarling \& E. T. Gomez. London, UK: Routledge.

Governor-General. (2005). National Civil Defence Emergency Management Plan Order-2005. Wellington. Retrieved May 5, 2008, from http://www.civildefence.govt.nz/memwebsite.nsf/Files/National\%20CDEM\%20Plan \%202 005/\$file/NatCDEMPlanOrder_43191.pdf

Grant, H. (2005a). Natural Hazards: Background Report. Wellington, NZ. Retrieved June 19, 2006, from http://66.102.7.104/search?q=cache:qzHO43hWxCIJ:www.gw.govt.nz/story_images/ $\cdots$

. (2005b). Natural Hazards: Background Report. GW/RP-T-05/302. Wellington, NZ: Greater Wellington Regional Council.

Grapes, R. (2000). Magnitude Eight Plus. Wellington, NZ: Victoria University Press.

Gray, W. (2001). 'Research for Resilience.' Tephra (February): 32-38.

Greater Wellington Regional Council [GWRC]. (n.d). A sustainable Region Detailed information Greater Wellington Regional Council's ten-year plan 2006-16 - Incorporating the 2006/07 Annual Plan. 2007. Retrieved April 18, 2008, from http://www.gw.govt.nz/story_images/3303_GW_LTCCP_Detaile_s6635.pdf

. (2002). Towards A Greater Wellington - Wellington Regional Council Ten Year Plan 2000-2010: 2002 Update Incorporating the 2002-2003 Annual Plan. Retrieved March 23, 2009, from http://www.gw.govt.nz/council-publications/pdfs/Corporate_20021129_090605.pdf 
. (June, 2007). Natural Hazards and Climate Change Effects: Draft Provision for the Regional Policy Statement. Retrieved June 16, 2007, from http://www.gw.govt.nz/story_images/4194_DraftNaturalHaza_s8300.pdf

. (2008). Annual Report 2008: Greater Wellington Regional Council. Retrieved March 23, 2009, from http://www.gw.govt.nz/council-publications/pdfs/Annual\%20report\%202008.pdf . (2009a). Maori history of the Greater Wellington Region. Retrieved April 13, 2009, from http://www.gw.govt.nz/section804.cfm

. (2009b). Big floods in the Wellington Region. Retrieved April 27, 2009, from http://www.gw.govt.nz/story6388.cfm?

. (2009c). Flooding. Retrieved June 30, 2009, from http://www.gw.govt.nz/story25433.cfm?

Griffiths, G. \& Ross, P. (1997). 'Principles of Managing Extreme Events.' In Floods and Droughts: The New Zealand Experience. Edited by M. P. Mosley \& C. P. Pearson. Christchurch, NZ: The Caxton Press.

Guillaumont, P. (2003). 'On the Economic Vulnerability of Low-Income Countries.' In Economic Vulnerability and Resilience of Small States. Edited by L. Briguglio \& E. J. Kisanga. Malta: Islands and Small States Institute of the University of Malta and the Commonwealth Secretariat.

$\mathbf{H}$

Hancox, G. T., Perrin, N. D. \& Dellow, G. D. (1997). Earthquake-Induced Landsliding In New Zealand and Implications For MM Intensity and Seismic Hazard Assessment. Prepared for Earthquake Commission Research Foundation. Client Report 43601B. Lower Hutt, NZ: Institute of Geological \& Nuclear Sciences.

Dellow, G. D., Massey, C. \& Perrin, N. D. (2007). 'Reconnaissance Studies of Landslides Caused by the July-October 2006 Rainstorms in Southern North Island, New Zealand'. GNS Science Report 2006/26. Lower Hutt: Institute of Geological \& Nuclear Sciences.

Handmer, J. (2004). 'Global Flooding.' In International Perspective on Natural Disasters: Occurrence, Mitigation and Consequences. Edited by J.P. Stoltman et al. The Netherlands: Kluwer Academic Publishers.

Hare, J. (September 13, 2007). 2007 Community Survey Result. Report 07.624. Retrieved April 15, 2008, from reports/pdfs\%5Creportdocs\%5C2007_624_1_Report.pdf http://www.gw.govt.nz/council-

Harmsworth, G. \& Raynor, B. (2005). 'Cultural Considerations in Landslide Risk Perception.' In Landslide Hazard and Risk. Edited by T. Glade, M. A. Anderson \& M. J. Crozier. England: John Wiley and Sons.

Hatherton, T. (1984). 'Earthquakes.' In Scientific, Economic and Social Reviews of Natural Hazards in New Zealand. Edited by I. G. Speden \& M. J. Crozier. Wellington: New Zealand National Commission for UNESCO.

Hawley, A. H. (1986). Human Ecology - A Theoretical Essay. Chicago, USA: The University of Chicago.

Hay, I. (1996). 'Neoliberalism and Criticism of Earthquake Insurance Arrangement in New Zealand.' Disasters. 20(1): 34-48.

Henstra, D. \& McBean, G. (2005). 'Canadian Disaster Management Policy: Moving Toward a Paradigm Shift?’ Canadian Public Policy/Analyse de Politiques. 31(3): 303-318. 
Heron, H. A. (1929). Early Wairarapa: An Account of the Nature and Development of the Wairarapa District of New Zealand From the Advent to the White Man to The Year 1860. Masterton, NZ: Palamontain \& Petherick.

Hessell, J. W. (1984a). 'Drought.' In Scientific, Economic and Social Reviews of Natural Hazards in New Zealand. Edited by I. G. Speden and M. J. Crozier. Wellington, NZ: New Zealand National Commission for UNESCO.

. (1984b). 'Climate Change.' In Scientific, Economic and Social Reviews of Natural Harards in New Zealand. Edited by I. G. Speden and M. J. Crozier. Wellington, NZ: New Zealand National Commission for UNESCO.

Hewitt, K. (1997). Regions of Risk: A Geographical Introduction to Disasters. Essex, UK: Longman.

\& Burton, I. (1971). The Hazardousness of a Place: A Regional Ecology of Damaging Events. Toronto: University of Toronto.

, \& Hare, F. K. (1973). Man and Environment: Conceptual Frameworks. Commission on College of Geography Resource Paper Number 20. Washington, USA: Association of American Geographers.

Hewitt, A. E. (1998). New Zealand Soil Classification. Landcare Research Science Series No. 1. Lincoln, NZ: Manaaki Whenua.

Hilhorst, D. (2004). 'Complexity and Diversity: Unlocking Social Domains of Disaster Response.' In Mapping Vulnerability-Disaster Development and People. Edited by G. Bankoff et al. London, UK: Earthscan.

Hogan, D. J. \& Marandola, E. Jr. (2007). Vulnerability to Natural Hazards in Population-Environment Studies. Background paper to the Population-Environment Research Network (PERN) Cyber seminar 1 on Population \& Natural Hazards 5-19 November 2007. Retrieved May 14, 2008, from

http://www.populationenvironmentresearch.org/papers/HoganMarandola_background_pa per.pdf

Howden-Chapman, P. et al. (2005). The Impact of Economic Recession on Youth Suicide: A comparison of New Zealand and Finland. Report 4: Social Explanations for Suicides in New Zealand. Retrieved December 19, 2008, from http://www.moh.govt.nz/moh.nsf/0/BEB6627B003586A5CC2570D400809A5B/\$File/the impactofeconomicrecessiononyouthsuicide.doc

Hufschmidt, G., Crozier, M. \& Glade, T. (2005). 'Evolution of Natural Risk: Research Framework and Perspectives.' Natural Hazards and Earth System Sciences. 5: 375-387.

Hull, A.G. (1998). 'Earthquakes- The big one!' In Awesome Forces-The natural hazards that threaten New Zealand. Edited by G. Hicks \& H. Campbell. Wellington, NZ: Te Papa.

Independence Evaluation Group [IEG]. (2006). Hazards of Nature, Risk to Development: An IEG Evaluation of World Bank. Assistance for Natural Disasters. Washington, USA: The World Bank.

Instituto de Estudios Ambientales [IDEA]. (2005). Indicators of Disaster Risk and Risk Management: Main Technical Report. Colombia: National University of Columbia and Inter-American Development Bank. Retrieved October 31, 2008, from http://198.186.239.116/sds/doc/Main\%20technical\%20report\%20IDEA.pdf

Invalid's Benefit. (2008). Retrieved December 17, 2008, from http://www.workandincome.govt.nz/individuals/a-z-benefits/invalids-

benefit.html\#Howmuchyoucanget2 
Jardine, C. G. and Hrudey, S. E. (2001). 'Mixed Messages in Risk Communication.' In Environmental Risk Planning and Management. Edited by S. Gerrard, R. K. Turner \& I. J. Bateman. Cheltenham, UK: An Elgar Reference Collection.

Jensen, S. (1998). 'New Zealand's Emergency Management System and the Role of Local Government.' The Australian Journal of Emergency Management. 13(1): 27-29.

Jensen, J. et al. (2006). New Zealand Living Standard 2004. Wellington: Centre for Social Research and Evaluation.

Jensen, B. (December 11, 2008). Essay: The End of the Golden Weather: The Financial Crisis, Global Recession, and What this Means for New Zealand. The New Zealand Institute. Retrieved January 5, 2008, from http://blog.nzx.com/wp-content/uploads/2008/12/endofthegoldenweather_ nzstitute111208.pdf

Jessamy, V. R. and Turner, R. K. (n.d.). Modelling Community Response and Perception to Natural Hazards: Lessons Learnt from Hurricane Lenny 1999. CSERGE Working Paper EDM 03-06. Retrieved May $\quad$ 5, 2008, from http://www.uea.ac.uk/env/cserge/pub/wp/edm/edm_2003_06.pdf

Johnson, B. B. (1993). 'Advancing Understanding of Knowledge's Role in Lay Risk Perception.' Risk- Issues in Health and Safety. 189 [summer]: 189-212.

Johnston, D. M., Bebbington, M. S., Lai, C. D., Houghton, B. F. \& Paton, D. (1999). 'Volcanic Hazard Perceptions: Comparative Shifts in Knowledge and Risk.' Disaster Prevention and Management. 8(2): 118-126.

. et al. (2002). Waikanae River Flood Risk Perceptions - Results of a Community Survey, August 2001. Institute of Geological \& Nuclear Sciences Report - 2002/06. Lower Hutt, NZ: Institute of Geological and Nuclear Sciences.

, Pettersson, R., Downes, G., Paton, D., Leonard, G., Pishief, K. \& Bell, R. (2008). Developing an effective tsunami warning system: Lessons from the 1960 Chile earthquake tsunami for New Zealand Coastal Communities.' Kotuitui: New Zealand Journal of Social Science. 3: $105-120$.

K

Kapiti Coast District Council. (2009). History. Retrieved January 10, 2009, from http://www.kapiticoast.govt.nz/DistrictDevelopment/History/

Kapoor, A. (2006). 2001 Bhuj Earthquake in Gujarat: A Geographical Analysis of Disaster Response. Unpublished Thesis for Doctor of Philosophy in Geography. Delhi, India: Delhi School of Economics, University of Delhi.

Kates, R. W. (1971). 'Natural Hazard in Human Ecological Perspective: Hypothesis and Models.' Economic Geography. 47(3): 438-451.

Keenan, D. (2008). 'A Nation Within? Maori People and Autonomy in New Zealand, 1840-2004.' In The State, Development and Identity in Multi-Ethnic Societies: Ethnicity, Equity and the Nation. Edited by N. Tarling \& E.T. Gomez. London, UK: Routledge.

Kelleher, J. A. (1991). Upper Hutt-The History. Upper Hutt, NZ: Cape Catley.

Kenny, G. J. et al. (1995). 'CLIMPACTS: An Integrated Model For Assessment of the Effects of Climate Change on the New Zealand Environment.' Journal of Biogeography. 22 (4/5): 883-895. 
Kerr, J. et al. (2003). Planning for Development of Land on or Close to Active Faults: A guideline to assist resource management planners in New Zealand. Wellington: Ministry for the Environment. Retrieved May 4, 2008, from http://www.mfe.govt.nz/publications/rma/planningdevelopment-active-faults-dec $04 / \mathrm{html} /$ page12.html

Kingsbury, P. (2000). 'Flood Warning and Awareness at Blandswood Peel Forest.' The Australian Journal of Emergency Management. 15(1): 33-35.

Köppen Climatic Classification. (2008). Encyclopaedia Britannica. Retrieved July 11, 2008, from Encyclopaedia Britannica

Online: http://www.britannica.com/EBchecked/topic/322068/Koppen-Climatic-Classification

Kunreuther, H. (1974). 'Disaster Insurance: A Tool for Hazard Mitigation.' The Journal of Risk and Insurance. 41(2): 287-303.

\section{$\mathbf{L}$}

Lake Taupo New Zealand. (2009). Volcanic Zone: A Thermal Wonderland. Retrieved January 20, 2009, from http://www.laketauponz.com/taupo/scenic/volcanic-zone.html

Larson, K. L. \& Santelmann, M. V. (2007). 'An Analysis of the Relationship between Residents' Proximity of Water and Attitudes about Resource Protection.' The Professional Geographer. 59 (2): 316-333.

Lawson, A. (May 15, 2005). 60\% of uni students live below poverty line. Retrieved December 4, 2008, from http://www.smh.com.au/news/National/60-of-uni-students-live-below-povertyline/2005/05/14/1116024407236.html

Lebel, L. et al. (2006). 'Assessing Institutionalised Capacities and Practices to Reduce the Risk of Flood Disaster.' In Measuring Vulnerability to Natural Hazards: Towards Disaster Resilient Societies. Edited by J. Birkmann. New York, USA: United Nations University Press.

Lee, J. M. \& Begg, J. G. (2002). Geology of the Wairarapa Area. Institute of Geological \& Nuclear Sciences 1: 250000 geological map 11. Lower Hutt, New Zealand: Institute of Geological \& Nuclear Sciences Limited.

Leigh, C. H. \& Sim, L. K. (1983). 'Attitude and Adjustments to the Flood Hazard in a Mixed Ethnic Community in Malacca Town, Peninsular Malaysia'. Singapore Journal of Tropical Geography. 4(1): 40-52.

Leighton, S. (2002). Lifelines in Porirua City: Vulnerability and Emergency Planning. Unpublished Research Report for Bachelor of Science (Honours) in Physical Geography. Wellington, NZ: Victoria University of Wellington.

Lindell, M. K. et al. (1997). 'Adoption and Implementation of Hazard Adjustment'. International Journal of Mass Emergencies and Disasters. 15(3): 327-453.

Linnerooth-Bayer, J. (2006). Risk and Vulnerability Programme. Research Plan 2006-2010. Retrieved August 12, 2006, from http://www.iiasa.ac.at/Research/RAV/index.html

\section{$\mathbf{M}$}

Marriot A. (2002). Earthquake Risk Perception and Preparedness in Newlands, Wellington. Unpublished Research Essay for Bachelor of Science (Honours). Wellington, NZ: Victoria University of Wellington. 
McAlister, D. (2007). Annual Ground Water Monitoring Report for the Wellington Region, 2006/07. GW/EMI-T-07/222. Wellington, NZ: Greater Wellington Regional Council. Cited on July 19, 2008, from http://www.gw.govt.nz/councilpublications/pdfs/Annual $\% 20$ Groundwater $\% 20$ Monitoring $\% 20$ Report $\% 20$ for $\% 20$ the $\% 20$

Wellington $\% 20$ Region $\% 20$ screen $\% 20$ version.pdf

McConchie, J. A. (1992). 'Water and Slope Stability.' In Waters of New Zealand. Edited by M. P. Mosely. Christchurch, NZ: The Caxton Press. (2000a). 'From Shaky Beginnings.' In Dynamic Wellington. Edited by J.A. McConchie, D. R. Winchester \& R. P. Willis. Wellington, NZ: Victoria University of Wellington. . (2000b). 'From Floods to Forecasts.' In Dynamic Wellington. Edited by J.A. McConchie, D. R. Winchester \& R. P. Willis. Wellington, NZ: Victoria University of Wellington.

McConnochie, H. (2004). After Words: Interviews and Letters From Survivors of the 1931 Hawke's Bay Earthquakes. Napier, NZ: Friends of Hawk's Bay Cultural Trust.

McFadgen, B. (2007). Hostile Shores: Catastrophic Events in Prehistoric New Zealand and Their Impact on Maori Coastal Communities. Auckland, NZ: Auckland University Press.

McGill, D. (n.d). Lower Hutt: The First Garden City. Petone, NZ: The Lower Hutt City Council.

McLaren, J. (2002). A Night of Terror: Wairarapa's 1942 Earthquake. Masterton, NZ: Wairarapa Archive.

Merrifield, A., Savage, M. \& Verejanes, D. (2001). 'Geographical Distribution of Foreshock Probabilities in New Zealand.' In Proceedings of the Second International Workshop on Statistical Seismology. Edited by M. Bebbington \& C. D. Lai. Palmerston North, NZ: The Statistical Research and Consulting Centre, Massey University.

Michaels, J. W. (1974). 'On the Relation Between Human Ecology and Behavioural Social Psychology'. Social Forces. 3(1): 313-321.

Middleton, D. (2001). 'The Role of New Zealand Earthquake Commission.' The Australian Journal of Emergency Management. 16(2): 57-62.

Mileti, D. S. (1999). Disaster by Design: A Reassessment of Natural Hazards in the United States. Washington, USA: Joseph Henry Press.

Millennium Ecosystem Assessment Board. (2005). Ecosystem and Human Well Being: Current State and Trends. Vol. 1. Edited by R. Hassan, R. Scholes \& N. Ash. Washington, USA: Island Press.

Miller, D. P. (1972). Once Upon A Village: A History of Lower Hutt, 1819-1965. Wellington, NZ: New Zealand University.

Miller, M., Paton, D. \& Johnston D. (1999). 'Community Vulnerability to Volcanic Hazard Consequences.' Disaster Prevention and Management. 8(4): 255-260.

Ministry for the Environment [MFE]. (n.d.). Flood Risk Management. Retrieved May 5, 2008, from http://www.mfe.govt.nz/issues/land/natural-hazard-mgmt/flood-protection.html (2004). Preparing for Climate Change: A Guide for Government in New Zealand. Retrieved May 04, 2008, from http://mfe.govt.nz/publications/climate/preparing-for-climate-changejul04/html/index.html

Ministry of Agriculture and Forestry [MAF]. (n.d.). On-farm Readiness and Recovery Plan for Adverse Climatic Events and Natural Disasters. Retrieved May 6, 2008, from http://www.maf.govt.nz/mafnet/rural-nz/assistance/adverse-events/pdfs/adverse-eventsbrochure-may07.pdf

Ministry of Civil Defence and Emergency Management [MCDEM]. (n.d). Civil Defence in New Zealand. Retrieved September 20, 2007, from http://www.civildefence.govt.nz/memwebsite.nsf/Files/Short $\% 20$ Historyof $\% 20$ Civil $\% 20 D$ efence/\$file/Short $\% 20$ Historyof $\% 20$ Civil $\% 20$ Defence.pdf 
. (1994). 'National Report of New Zealand: Prepared for the IDNDR mid-term review and the 1994 world conference on Natural Disaster Reduction.' Tephra. 13(1): 25.

. (2002). Preparing a Recovery Plan: Information for Local Authorities (ISA/02). Retrieved May 6, 2008, from

http://unpan1.un.org/intradoc/groups/public/documents/APCITY/UNPAN019473.pdf

. (2006). The Guide to the National Civil Defence Emergency Management Plan. Wellington, NZ: Author. Retrieved May 5, 2008, from

http://www.civildefence.govt.nz/memwebsite.NSF/wpg_URL/For-the-CDEM-Sector-

Publications-The-Guide?OpenDocument

(2008). Tsunami. Retrieved May 9, 2008, from

http://www.civildefence.govt.nz/memwebsite.nsf/wpg_url/for-the-cdem-sector-photo-

library-tsunami?opendocument.

. (2009). The Guide to the National Civil Defence Emergency Management Plan 2006. Wellington, Ministry of Civil Defence and Emergency Management. Retrieved January 28, 2010, from http://www.civildefence.govt.nz/memwebsite.nsf/wpg_URL/For-the-CDEM-Sector-

Publications-The-Guide?OpenDocument

Mitchell, J. K. (2000). 'What's in a Name? Issues of Terminology and Language in Hazard Research.’ Environmental Hazard. 2(3): 87-88.

, Devine, N. \& Jagger, K. (1989). 'A Contextual Model of Natural Hazard.' Geographical Review. 79(4): 391-409.

Mogil, H. M. (2007). Extreme Weather: Understanding the Science of Hurricanes, Tornadoes, Floods, Heat Waves, Snow Storms, Global Warming and Other Atmospheric Disturbances. New York, USA: Black Dog \& Leventhal Publishers.

Molloy, L. (1988). Soils in the New Zealand Landscape: The Living Mantle. Wellington, NZ: Mallinson Rendel \& New Zealand Society of Soil Science.

Morgan, J. (February 8, 2006). 'Band of Farmers bear brunt of damage from latest storm.' The Dominion Post. Pp: A3.

Mustafa, D. (2005). 'The Production of Urban Hazardscape in Pakistan: Modernity, Vulnerability and the Range of Choice.' Annals of Association of American Geographers. 95(3): 566-586.

Myers, M. F. \& Passerini, E. (2000). 'Floodplain Management: Historic Trends and Options for the Future.' In Floods. Edited by D. J. Parker. London, UK: Routledge.

National Climate Centre [NCC]. (2000). Climate Summary for 2000. Retrieved June 16, 2008, from http://www.niwa.co.nz/our-science/climate/publications/all/cs/annual/aclimsum_00

. (2001). Climate Summary for 2001. Retrieved June 16, 2008, from http://www.niwa.co.nz/ourscience/climate/publications/all/cs/annual/aclimsum_01

. (2002). Climate Summary for 2002. Retrieved June 16, 2008, from http://www.niwa.co.nz/ourscience/climate/publications/all/cs/annual/aclimsum_02

. (2003). Climate Summary for 2003. Retrieved June 16, 2008, from http://www.niwa.co.nz/ourscience/climate/publications/all/cs/annual/aclimsum_03

(2004). New Zealand National Climate Summary: The Year 2004. Retrieved June 16, 2008, from http://www.niwa.co.nz/_data/assets/pdf_file/0015/30732/aclimsum_04.pdf

(2005). New Zealand National Climate Summary: The Year 2005. Retrieved June 16, 2008, from http://www.niwa.co.nz/_data/assets/pdf_file/0020/30737/aclimsum_05.pdf 
(2006). New Zealand National Climate Summary: The Year 2006. Retrieved June 16, 2008, from http://www.niwa.co.nz/_data/assets/pdf_file/0016/30742/aclimsum_06.pdf

(2007). New Zealand National Climate Summary: The Year 2007. Retrieved June 16, 2008, from

http://www.niwa.co.nz/_data/assets/pdf_file/0006/63879/aclimsum_07.pdf

. (2008a). National Climate Summary- February 2008: A Northland Flood, But Generally a Very Dry North Island. Retrieved June 16, 2008, from

http://www.niwascience.co.nz/_data/assets/pdf_file/0005/67064/0802sum.pdf

. (2008b). New Zealand National Climate Summary: The Year 2008. Retrieved June 30, 2008, from http://www.niwa.co.nz/_data/assets/pdf_file/0008/81890/aclimsum_08.pdf

National Institute of Water and Atmospheric Research [NIWA]. (2008). NIWA Seabed Contours (Bathymetry). Retrieved June 15, 2008, from http://www.quickmap.co.nz/bathy2.htm

National Rural Fire Authority. (2008). Rural Fire Photos. Retrieved July 22, 2008, from http://nrfa.fire.org.nz/NR/exeres/E4EDF088-72CA-4458-A966-

DD7F25030ACE, frameless.htm?NRMODE=Published

Natural Hazard Research. (1970). Suggestions for Comparative Filed Observations on Natural Hazards. Working paper number-16. Revised Edition. Toronto.

Natural Hazard Centre [NHC]. (2009). Natural Hazards Update - No.7 February 2006. Retrieved April 27, 2009, from http://www.naturalhazards.net.nz/publications/ma/2006-07

Naumann, R. (2000). New Zealand Social Studies: A Strand Approach - Place and Environment. Auckland, NZ: New House.

Neall, V. E. et al. (1999). Volcanic Hazards at Ruapehu Volcano. Ministry of Civil Defence, Volcanic Hazards Information Series No. 8. Wellington, NZ.

Nelson, A. C., Dawkins, C. J. \& Sanchez, T.W. (2007). The social Impacts of Urban Containment. Burlington, USA: Ashgate.

Nigg, J. M. \& Mileti, D. (2002). 'Natural Hazards and Disaster.' In Handbook of Environmental Sociology. Edited by R. E. Dunlap and W. Michelson. London, UK: Greenwood.

New Zealand Council of Christian Social Service. (2008). Facts About Poverty in 2008 - A Summary. Retrieved December 4, 2008, from http://www.nzccss.org.nz/uploads/publications/Facts \% 20About $\%$ 20Poverty $\% 202008 \% 20$ Aug08.pdf

New Zealand Superannuation. (2008). Retrieved December 17, 2008, from http://www.sorted.org.nz/home/sorted-sections/retirement/new-zealand-superannuation

NWASCO. (1984). 'Flooding.' In Scientific, Economic and Social Reviews of Natural Hazards in New Zealand. Edited by I. G. Speden \& M. J. Crozier. Wellington, NZ: New Zealand National Commission for UNESCO.

$\mathbf{O}$

Official's Committee for Domestic \& External Security [ODESC]. (2007). National Hazardscape Report. Wellington, NZ: Department of the Prime Minister \& Cabinet.

Oliver-Smith, A. (2004). 'Theorizing Vulnerability in Globalized World: A Political Ecological Perspective.' In Mapping Vulnerability-Disaster Development and People. Edited by G. Bankoff et al. London, UK: Earthscan.

Olson, R., Podesta, B. \& Nigg, J. (1989). The Politics of Earthquake Prediction. Princeton, USA: Princeton University. 
$\mathbf{P}$

Parr, A. R. (1994). 'The Efficacy of the Neo-Liberal Individual Choice Model for Encouraging Post-Disaster Change: Developments in the East Cape Region of New Zealand Following Cyclone Bola (March 1988).' Disaster. 18(4): 301-311.

Paton, D, Johnston, D. \& Houghton, B. F. (1998). 'Organisational Response to a Volcanic Eruption.' Disaster Prevention and Management. 7(1): 5-13.

, et al. (2001). 'Community Resilience to Volcanic Hazard Consequences.' Natural Hazards 24(2): 157-169.

, Johnston, D. \& Saunders, W. (2006). Mapping Social Vulnerability to Natural Hazards Using GIS. Retrieved April 13, 2009, from http://www.qualityplanning.org.nz/pubs/MappingSocial-Vulnerability-to-Natural-Hazards-Using-GIS.pdf

. (2006). 'Disaster Resilience: Building Capacity to Co-exist with Natural Hazard and Their Consequences.' In Disaster Resilience: An Integrated Approach. Edited by D. Paton \& D. Johnston. Illinois, USA: Charles C Thomas.

Kelly, G. \& Doherty, M. (2006). 'Exploring the Complexity of Social and Ecological Resilience to Hazards.' In Disaster Resilience: An Integrated Approach. Edited by D. Paton \& D. Johnston. Illinois, USA: Charles C Thomas.

Patt, A. et al. (2009). 'Vulnerability Research and Assessment to Support Adaptation and Mitigation: Common Themes from the Diversity Approaches.' In Assessing Vulnerability to Global Environmental Change: Making Research Useful for adaptation Decision Making and Policy. Edited by A.G. Patt, D. Schroter, R.J.J. Klein \& A.C. de la Vega-Leinert. London, UK: Earthscan.

Patterson, B. (2000). 'The White Man's Right.' In Dynamic Wellington. Edited by J. A. McConchie, D. R. Winchester \& R. P. Willis. Wellington, NZ: Victoria University of Wellington.

Paterson, M. (2001). Volcanic Hazards in the Wairarapa. Planning and Resources Hazards and Emergency Management Wairarapa Division. Technical Report No. 01/01. Masterton, NZ: Wellington Regional Council, Wairarapa Division.

Pawson, E. \& Brooking, T. (2002). Environmental Histories of Wellington. South Melbourne, Australia: Oxford University Press.

Pearse, L., Johnston, D. \& Becker, J. (2001). 'Managing Natural Hazards in the Hawke's Bay, New Zealand.' The Australian Journal of Emergency Management. 16(3): 37-39.

Peterson, M. (1999). Marlborough District Natural Hazard and Risk Study. A Preliminary Report Prepared for Marlborough District Council. Wellington, NZ: Victoria University of Wellington.

Phillips, C. \& Marden, M. (2005). 'Reforestation Schemes to Manage Regional Landslide Risk.' In Landslide Hazard and Risk. Edited by T. Glade, M. A. Anderson \& M. J. Crozier. England: John Wiley and Sons.

Pillans, B. \& Huber, P. (1992). Earthquakes and Uplift History of Miramar Peninsula, Wellington. Unpublished Report to the Earthquake Commission. Wellington, NZ.

PIM. (n.d). Retrieved February 25, 2008, from http://www.massiveaction.co.nz/dictionary_def.php?id_item=203

Poata-Smith, Evan Te Ahu. (1997). 'The Political Economy of Inequality Between Maori and Pakeha.' In The Political Economy of New Zealand. Edited by C. Rudd \& B. Roper. Auckland, NZ: Oxford University Press.

Policy Quickies: Domestic Purposes Benefit. (2008). Retrieved December 17, 2008, from http://thehandmirror.blogspot.com/2008/10/policy-quickies-domestic-purposes.html 
Poole, A. L. (1983). 'Catchment Control in New Zealand.' In Water \& Soil Miscellaneous Publication No. 48. Wellington, NZ: National Water \& Soil Conservation Organisation.

Porima. (2009). Retrieved January 10, 2009, from http://en.wikipedia.org/wiki/Porirua.

Proposed Wairarapa Combined District Plan. (2006). Retrieved April 11, 2008, from http://www.swdc.govt.nz/container_pages/news.asp?IDID=25101018

\section{$\mathbf{R}$}

Reid, J. (1984). 'Wind Hazard.' In Scientific, Economic and Social Reviews of Natural Hazards in New Zealand. Edited by I. G. Speden \& M. J. Crozier. Wellington, NZ: New Zealand National Commission for UNESCO.

Resource Management Act. (1991). Retrieved July 16, 2007, from http://www.legislation.govt.nz/browse_vw.asp?content-set=pal_statutes

Ribot, J. C. (1995). 'The Causal Structure of Vulnerability: Its Application to Climate Impact Analysis.' GeoJournal. 35(2): 119-122.

Ridgway, R. (1984). 'Tsunami Hazard in New Zealand.' In Scientific, Economic and Social Reviews of Natural Hazards in New Zealand. Edited by I. G. Speden \& M. J. Crozier. Wellington, NZ: New Zealand National Commission for UNESCO.

Robinson, G. M., Loughran, R. J. \& Tranter, P. J. (2000). Australia and New Zealand. London, UK: Arnold.

Roche, M. (1994). Land and Water: Water and Soil Conservation and Central Government in New Zealand, 1941-1988. Wellington, NZ: Historical Branch, Department of Internal Affairs.

Rogers, A. (1996). New Zealand Tragedies: Earthquakes. New Zealand: Grantham House.

Ronan, K. R., Paton, D., Johnston, D. M. \& Houghton, F. (2000). 'Managing Societal Uncertainty in Volcanic Hazards: A Multidisciplinary Approach.' Disaster Prevention and Management. 9(5): 339-349.

, \& Johnston, D. M. (2001). 'Correlates of Hazard Education Programs for Youth.' Risk Analysis. 21(6): 1055-1063.

. (2003). 'Hazard Education for Youth: A Quasi-Experimental Investigation.' Risk Analysis. 23(5): 1009-1020.

Rushton, G. (1979). 'Commentary On Behavioural and Perception Geography.' Annals of the Association of American Geographers. 69(3): 463-464.

Rygel, L. O'Sullivan, D. \& Yarnal, B. (2006). 'A Method for Constructing a Social Vulnerability Index: An Application to Hurricane Storm Surges in A Developed Country'. Mitigation and Adaptation Strategies for Global Change. 11: 741-764. DOI: 10.1007/s11027-006-0265-6. Retrieved October 8, 2008, from http://www.springerlink.com.helicon.vuw.ac.nz/content/h011437x16330471/ fulltext.pdf

Rynn, J. M. N. (1975). Seismotectonics of the Arther's Pass Region, South Island New Zealand and Regional Variations in ts/tp. Unpublished Thesis for Doctor of Philosophy in Pure Sciences. Columbia University, USA. Michigan: Xerox University Microfilms.

Saarinen, T. F. (1969). Perception of Environment. Resource Paper No. 5. Association of American Geographers. Washington, USA: Commission on Collage Geography. 
Salinger, J. (1998). 'Wet 'n wild- Climate.' In Awesome Forces- The Natural Hazards That Threaten New Zealand. Edited by G. Hicks \& H. Campbell. Wellington, NZ: Te Papa.

Salinger, J. (2000). 'The Windy City.' In Dynamic Wellington. Edited by J. A. McConchie, D. R. Winchester \& R. P. Willis. Wellington, NZ: Victoria University of Wellington.

Salter, J. (1998). 'Public Safety Risk Management: Assessing the Latest National Guidelines.' Australian Journal of Emergency Management. Summer 1998/99: 50-53.

Scoones, I. (1999). 'New Ecology and the Social Sciences: What Prospects for a Fruitful Engagement?' Annual Review of Anthropology. 28: 479-507.

Semple, E. C. (1911). Influences of Geographic Environment: On the Basis of Ratzel's System of AnthropoGeography. London, UK: Constable and Company.

Sen, A. K. (1999). Development As Freedom. New York, USA: Knopf. . (2006). Identity and Violence: The Illusion of Destiny. New York, USA: W. W. Norton.

Services: Civil Defence. (n.d.). Retrieved September 7, 2006, from http://www.timaru.govt.nz/index.asp?sidenav=servnav.html\&mainpage $=$ services $/$ emergenc y/civil_defence.html

Seville, E. \& Metcalfe, J. (2005). Developing a hazard risk assessment framework for the New Zealand State bighway Network. Land Transport New Zealand research report 276. Canterbury, NZ.

Sickness Benefit. (2008). Retrieved December 18, 2008, from http://www.workandincome.govt.nz/individuals/a-z-benefits/sicknessbenefit.html\#Howmuchyoucanget2

Silverman, B. W. (1986). Density Estimation for Statistics and Data Analysis. New York, USA: Chapman and Hall. Retrieved May 22, 2008, from Arc GIS help.

Simpson-Housley, P. \& Curtis, F. A. (1983). 'Earthquake Occurrence, Experience and Appraisal in Wellington, New Zealand.' Professional Geographer. 35(4): 462-467.

Sjoberg, L. (2007). Emotion and Risk Perception. Paper prepared for the Preference Elicitation Group Workshop on Risk Perception, Attitudes and Behaviour. Sweden: University of Barcelona. Retrieved May 5, 2008, from http://www.dynamit.com/lennart/pdf/Emotions\%20and\%20risk\%20perceptio1\%20noc.pdf

Smith, K. (1992). Environmental Hazards: Assessing Risk and Reducing Disaster. $1^{\text {st }}$ ed. London, UK: Routledge.

. (2004), Environmental Hazards: Assessing Risk and Reducing Disaster. $4^{\text {th }}$ ed. London, UK: Routledge.

Spittal, M. J. (2003). Demographic and Psychological Factors and Preparation for Earthquakes. Unpublished Thesis for Doctor of Philosophy in Psychology. Victoria University of Wellington, Wellington.

Standards New Zealand. (2004). Risk Management: AS/NZS 4360: 2004. Wellington: Standards Australia/Standard New Zealand.

Statistics, New Zealand. (1998a). New Zealand Now: 65 Plus. Wellington, NZ. . (1998b). New Zealand Now: Asian New Zealanders. Wellington, NZ. . (1998c). New Zealand Now: Families \& Households. Wellington, NZ. (1998d). New Zealand Now: Maori. Wellington, NZ. . (1998e). New Zealand Now: People and Places. Wellington, NZ. (1998f). New Zealand Now: Young New Zealanders. Wellington, NZ. 
(1999a). New Zealand Standard Classification of Occupations. Retrieved December 15, 2008, from http://www.stats.govt.nz/NR/rdonlyres/1D8293AE-D42B-47FB-8A9E61B5F2A15494/0/NZSCO99.pdf

(1999b). New Zealand: A Regional Profile: Wellington. Retrieved December 25, 2008, from http://www.stats.govt.nz/NR/rdonlyres/7278B4FC-C093-4BB7-BE904000DE8DAFCB/0/Wellington.pdf

(2008). Trentham South Community Profile. Retrieved December 5, 2008, from http://www2.stats.govt.nz/domino/external/web/commprofiles.nsf/31ee49bea84378e fcc256d090001b4b6/334ca12d4bb8a795cc256d2b0075f944?OpenDocument

Statistics, New Zealand \& Ministry of Women's Affairs. (1998). New Zealand Now: Women. Wellington, NZ.

Stephens, R., Waldegrave, C. \& Frater, P. (1995). 'Measuring Poverty in New Zealand.' Social Policy Journal of New Zealand. Issue December 5, 1995. Retrieved March 5, 2009, from http://www.msd.govt.nz/documents/about-msd-and-our-work/publicationsresources/journals-and-magazines/social-policy-journal/spj05/spj5-measuring-poverty.doc

Stevens, G. (2005). 'The Totara Park Planning Tribunal 1964: Living With Active Fault'. GSNZ Newsletter. 137: 26-31.

Stirling, M. W., Wesnousky, S. G. \& Berryman, K. R. (1998). 'Probabilistic Seismic Hazard Analysis in New Zealand.' New Zealand Journal of Geology \& Geophysics. 41: 355-375.

Student Allowances. (2008). Retrieved December 17, 2008, from http://www.studylink.govt.nz/thinking-about-study/what-studylink-offers/study-starting-in2009/student-allowance/index.html

Salmond, C., Crampton, P. \& Sutton, F. (1998). 'NZDep91: A New Zealand Index of Deprivation.' Australian and New Zealand Journal of Public Health. 22 (7): 835-837.

\& Crampton, P. (2001). 'NZDEP96 - What Does It Measure?' Social Policy Journal of New Zealand 17: 82-100.

. (2002). 'NZDep2001 Index of Deprivation User Manual.' Wellington: Department of Public Health Wellington School of Medicine and Health Sciences.

, Crampton, P., King, P. \& Waldegrave, C. (2006). 'NZiDep: A New Zealand index of socioeconomic deprivation for individuals.' Social Science \& Medicine. 62 (6): 1474-1485.

Saunders, W., Forsyth, J., Johnston, D. \& Becker, J. (2007). 'Strengthening Linkages Between Land-use Planning and Emergency Management in New Zealand.' The Australian Journal of Emergency Management. 22(1): 36-43.

Saunders, W. \& Glassey, P. (2007). Guidelines for Assessing Planning Policy and Consent Requirements for Landslide-prone Land. GNS Science Miscellaneous Series 7. Retrieved December 10, 2009, from http://www.gns.cri.nz/services/hazardsplanning/downloads/landslideguidelines.pdf

$\mathbf{T}$

Tait, A. et al. (2002). Meteorological Hazards and the Potential Impacts of Climate Change in Wellington Region: A Scoping Study. Wellington, NZ: Wellington Regional Council.

Tansley, A. G. (1935). 'The Use and Abuse of Vegetational Concepts and Terms.' Ecology. 16(3): 284-307.

The Encyclopaedia of New Zealand. (1966). Fire Services. Retrieved July 24, 2007, from http://www.teara.govt.nz/1966/F/FireServices/FireServices/en

Thompson, D. (ed. 1995). The Concise Oxford Dictionary of Current English. $9^{\text {th }}$ ed. Oxford, UK: Clarendon Press. 
Thompson, M., Rayner, S. \& Ney, S. (2001). 'Risk and Governance Part-II: Policy in a Complex and Plurally Perceived World.' In Environmental Risk Planning and Management. Edited by S. Gerrard, R. K. Turner \& I.J. Bateman. Cheltenham, UK: An Elgar Reference Collection.

Thornton, J. (2003). The Reed Field Guide to New Zealand Geology: An Introduction to Rocks, Fossils and Minerals. Singapore: Reed Publishing.

Tibballs, G. (2005). Tsunami: The World's Most Terrifying Natural Disaster. London, UK: Carlton Books Ltd.

Tipler, K. (2007). Risk Perception, Preparedness, and Hazard Education Participation of Porirua School Children. Unpublished Thesis for Master of Science. Wellington, NZ: Victoria University of Wellington.

Tobin, G. A. \& Montz, B.E. (1997). Natural Hazards: Explanation and Integration. London, UK: The Guilford Press.

Tuan, Y. F. (1974). Topophilia: A study of Environmental Perception, Attitudes and Values. New Jersey, USA: Prentice-Hall.

Turner, B. L. et al. (2003). 'A Framework for Vulnerability Analysis in Sustainability science.' Proceedings of the National Academy of Sciences. 100(14): 8074-8079.

$\mathbf{U}$

Unemployment Benefit. (2008). Retrieved December 17, 2008, from http://www.workandincome.govt.nz/individuals/a-z-benefits/unemployment-benefit.html

Unemployment benefit for 20-24 year-olds. (2008). Retrieved December 17, 2008, from http://www.stats.govt.nz/analytical-reports/young-new-zealander/unemp-benifit.htm

V

Vatsa, K.S. (2004). 'Risk, Vulnerability, and Asset-based Approach to Disaster Risk Management.' International Journal of Sociology and Social Policy. 24(11): 1-48.

Vorcoe, J. (2002). Perception Versus Reality: Natural Hazards in Wellington. Research Essay B.Sc. (Hons) in Geography. Wellington, NZ: Victoria University of Wellington.

W

Wairarapa Engineering Lifelines Association [WELA]. (2003). Risk to Lifelines from Natural Hazards: A Wairarapa Engineering Lifeline Project. New Zealand: WELA.

Waitakere City. (April 7, 2008). Waitakere Tsunami Siren System Operational. Retrieved April 24, 2008, from http://www.scoop.co.nz/stories/AK0804/S00067.htm

Walker, G.R. (1999). 'Designing Future Disasters: An Australasian Perspective.' In The Changing Risk Landscape: Implications for Insurance Risk Management. Edited by N. R. Britton. Proceedings of a Conference Sponsored by Aon Group Australia Limited. Retrieved April 30, 2008, from http://www.aon.com.au/pdf/reinsurance/Aon_Designing_Disasters.pdf.

Walker, K. J. (2001). 'Uncertainty, Epistemic Communities and Public Policy.' In Ecology, Uncertainty and Policy: Managing Ecosystems for Sustainability. Edited by J. W. Handmer, T. W. Norton, \& S. R. Dovers. London, UK: Prentice Hall. 
Ward, N. J. (1997). The Impact of Urbanisation on the Water Quality and Hydrology of Kaiwharawhara Stream. Unpublished Thesis for Master of Science in Geography. Victoria University Wellington, Wellington.

WASCO-54. (1986). Stemming the Flow of Our Flood Problem. Wellington, NZ: National Water and Soil Conservation Authority.

Watt, E. (July 12, 2007a). 'Towns may have to move.' The Dominion Post. P. A1. . (July 12, 2007b). 'Wild winters will hit insurance bills'. The Dominion Post. P. A2.

Watts, L. (2003). The Hydrology and Meteorology of the Paekakarirki Storm 3 October 2003. Resource Investigation Department, Greater Wellington, Technical Report. Retrieved August 11, 2008, from http://www.gw.govt.nz/councilpublications/pdfs/Environment\%20Management_20040109_144524.pdf

. (2005). The 5-6 January 2005 Storm in the Wellington Region: Hydrology and Meteorology. Greater Wellington Resource Investigation Department, Technical Report. Retrieved August 11, 2008, from http://www.gw.govt.nz/council-publications/pdfs/5$6 \% 20 \mathrm{January} \% 202005 \% 20$ Storm $\% 20$ in $\% 20$ the $\% 20 \mathrm{~W}$.pdf

, \& Gordon, M. (2004). The 15-16 February 2004 Storm in the Wellington Region: Hydrology and Meteorology. Greater Wellington Resource Investigation Department, Technical Report. Retrieved August 11, 2008, from http://www.gw.govt.nz/councilpublications/pdfs/Environment\%20Management_20040310_163624.pdf

. (2006). The 4-7 July 2006 Storms in the Wellington Region: Hydrology and Meteorology. WGN_DOCS\#352907-V1 Retrieved August 11, 2008, from http://www.gw.govt.nz/council reports/pdfs\%5Creportdocs\%5C2006_391_1_Report.pdf

Waugh, J., Freestone, H. \& Lew, D. (1997). 'Historic Floods and Droughts in New Zealand.' In Flood and Droughts: The New Zealand Experience. Edited by M.P. Mosley \& C.P. Pearson. Christchurch, NZ: The Caxton Press.

Web, T. (2005). Review of New Zealand's preparedness tsunami hazard, comparison to risk and recommendations for treatment. Client Report 2005/162 December. Lower Hutt, NZ: Institute of Geological and Nuclear Sciences Limited.

Wellington City Libraries. (2008). Earthquakes. Retrieved May 22, 2008, from http://www.wcl.govt.nz/wellington/earthquakes.html\#w . (2009). The Sinking of the Wabine: 10 April 1968. Retrieved January 22, 2009, from http://www.wcl.govt.nz/heritage/wahine.html\#one

Wellington City Council. (2007). Urban Development-Overview. Retrieved September 24, 2007, from http://www.wellington.govt.nz/services/urban/index.html

(n.d.) District Plan. Retrieved March 26, 2008, from http://www.wellington.govt.nz/plans/district/volume3/vol3.html

Wellington Regional Council [WRC]. (1997). Waikanae Floodplain Management Plan: The Community's Plan for the Waikanae River and its Environment. Publication No. WRC/RI-T-97/45. Wellington, NZ: Wellington Regional Council.

(1998a). Otaki Floodplain Management Plan: The Community's Plan for the Otaki River and its Environment. Publication No. WRC/FPSA-G-98/28. Wellington, NZ: Wellington Regional Council.

(1998b). Annual Environment Report-1998. Number: 2. November, 1998. Publication No. WRC/RINV-G-98/49. Wellington, NZ: Wellington Regional Council.

. (March 5, 2008a). Wairarapa Drought Committee Formed. Retrieved August 9, 2008, from http://www.scoop.co.nz/stories/AK0803/S00049.htm 
. (2008b). Greater Wellington Flood protection. Retrieved December 23, 2008, from http://images.google.com/imgres?imgurl=http://www.gw.govt.nz/story_images/1385_ CopyofDSCF0087_s2706.JPG\&imgrefurl=http://www.gw.govt.nz/section1208.cfm\&usg= -mkogR4RQ-

Tzuq0FSeLZgpiZOC5s $=\& \mathrm{~h}=150 \& \mathrm{w}=200 \& \mathrm{sz}=17 \& \mathrm{hl}=\mathrm{en} \& \mathrm{start}=183 \& u \mathrm{~m}=1 \& \mathrm{tbnid}=$ YZSm8Xhs_sZAzM:\&tbnh=78\&tbnw=104\&prev $=/$ images $\% 3 \mathrm{Fq} \% 3 \mathrm{Dflood} \% 2 \mathrm{Bin} \% 2 \mathrm{Bwell}$ ington $\% 26$ start $\% 3 \mathrm{D} 180 \% 26$ ndsp $\% 3 \mathrm{D} 18 \% 26 \mathrm{um} \% 3 \mathrm{D} 1 \% 26 \mathrm{hl} \% 3 \mathrm{Den} \% 26 \mathrm{sa} \% 3 \mathrm{DN}$

Wellington Region Emergency Management Group [WREMG]. (2003). Hazard and Risk. Analysis for the Wellington Region Civil Defence Emergency Management Group Plan. Wellington: Wellington Region CDEM Group Office. WGN_DOCS-\#182980-VI: September 26, 2006.

. (2005). Wellington Region Civil Defence Emergency Management Group Plan. Retrieved May 7, 2008 , from

http://www.wrcdemg.govt.nz/site/story_images/CDEM_Plan_May2005_WEB1051021093 217.PDF

. (2006). Wellington Region Welfare Plan - Draft. Retrieved April 17, 2008, from http://www.gw.govt.nz/councilreports/pdfs\%5Creportdocs\%5C2006_603_3_Attachment.pdf

Wellington Tourism Statistics. (2007). Retrieved May 31, 2007, from http://www.wellingtonnz.com/AboutWellington/Tourism+Statistics/

Wessels, T. (2006). The Myth of Progress: Towards a Sustainable Future. London, UK: University Press of New England.

Wirth, L. (1945). 'Human Ecology.' The American Journal of Sociology. 50(6): 483-488.

Wisner, B., Blaikie, P., Cannon, T. \& Davis, I. (1994). At Risk: Natural Hazards, People's Vulnerability and Disasters. London, UK: Routledge.

Wisner, B. et al. (2003). At Risk: Natural Hazards, People's Vulnerability and Disasters. $2^{\text {nd }}$ ed. New York, USA: Routledge.

\section{Y}

Yska, R. (2006). Wellington: Biography of a City. Auckland, NZ: Reed. 
Appendix

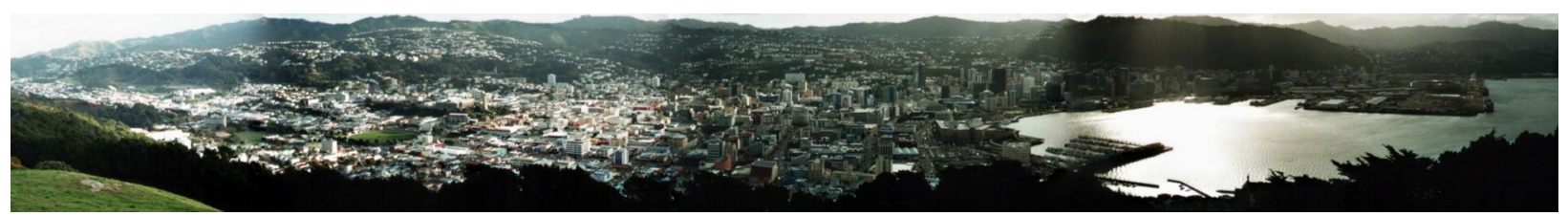




\section{Appendix-1}

\section{Questionnaire: Local People}

\section{Section-1: Information about natural hazards of your residential Area}

1. Tick the hazards you think you are exposed to at your residence.
$\square$ Earthquake
$\square$ Flood
$\square$ Landslide/slip
$\square$ Bushfire
$\square$ Windstorm/gale $\square$ Cyclone
$\square$ Tsunami
$\square$ Drought
$\square$ Volcanic Ash fall
$\square$ Other:

2. How problematic have the following hazards been for you at your current residence in the past? Please tick one box for each hazard

\begin{tabular}{|c|c|c|c|c|c|c|}
\hline Hazards & $\begin{array}{c}\text { Not } \\
\text { applicable }\end{array}$ & $\begin{array}{l}\text { Don't } \\
\text { know }\end{array}$ & $\begin{array}{c}\text { Not } \\
\text { problematic }\end{array}$ & Problematic & $\begin{array}{c}\text { Highly } \\
\text { problematic }\end{array}$ & Out of control \\
\hline Earthquake & $\square$ & $\square$ & $\square$ & $\square$ & $\square$ & $\square$ \\
\hline Flood & $\square$ & $\square$ & $\square$ & $\square$ & $\square$ & $\square$ \\
\hline Landslide/slip & $\square$ & $\square$ & $\square$ & $\square$ & $\square$ & $\square$ \\
\hline Bushfire & $\square$ & $\square$ & $\square$ & $\square$ & $\square$ & $\square$ \\
\hline Windstorm/gale & $\square$ & $\square$ & $\square$ & $\square$ & $\square$ & $\square$ \\
\hline Cyclone & $\square$ & $\square$ & $\square$ & $\square$ & $\square$ & $\square$ \\
\hline Tsunami & $\square$ & $\square$ & $\square$ & $\square$ & $\square$ & $\square$ \\
\hline Drought & $\square$ & $\square$ & $\square$ & $\square$ & $\square$ & $\square$ \\
\hline Volcanic ash-fall & $\square$ & $\square$ & $\square$ & $\square$ & $\square$ & $\square$ \\
\hline Other: & $\square$ & $\square$ & $\square$ & $\square$ & $\square$ & $\square$ \\
\hline
\end{tabular}

3. How frequently have the following hazards (damaging events) occurred in your residential area?

\begin{tabular}{|c|c|c|c|c|c|c|c|c|}
\hline Hazards & $\begin{array}{c}\text { Not } \\
\text { applicable }\end{array}$ & $\begin{array}{l}\text { Don't } \\
\text { know }\end{array}$ & $\begin{array}{l}\text { Once in a } \\
\text { month }\end{array}$ & $\begin{array}{c}\text { Once in a } \\
\text { year }\end{array}$ & $\begin{array}{l}\text { Once in } \\
5 \text { years }\end{array}$ & $\begin{array}{l}\text { Once in } \\
10 \text { years }\end{array}$ & $\begin{array}{c}\text { Once in } 20 \\
\text { years }\end{array}$ & $\begin{array}{l}\text { Any other: } \\
\text { Please specify }\end{array}$ \\
\hline Earthquake & $\square$ & $\square$ & $\square$ & $\square$ & $\square$ & $\square$ & $\square$ & \\
\hline Flood & $\square$ & $\square$ & $\square$ & $\square$ & $\square$ & $\square$ & $\square$ & \\
\hline Landslide/slip & $\square$ & $\square$ & $\square$ & $\square$ & $\square$ & $\square$ & $\square$ & \\
\hline Bushfire & $\square$ & $\square$ & $\square$ & $\square$ & $\square$ & $\square$ & $\square$ & \\
\hline Windstorm/gale & $\square$ & $\square$ & $\square$ & $\square$ & $\square$ & $\square$ & $\square$ & \\
\hline Cyclone & $\square$ & $\square$ & $\square$ & $\square$ & $\square$ & $\square$ & $\square$ & \\
\hline Tsunami & $\square$ & $\square$ & $\square$ & $\square$ & $\square$ & $\square$ & $\square$ & \\
\hline Drought & $\square$ & $\square$ & $\square$ & $\square$ & $\square$ & $\square$ & $\square$ & \\
\hline Volcanic ash-fall & $\square$ & $\square$ & $\square$ & $\square$ & $\square$ & $\square$ & $\square$ & \\
\hline Other: & $\square$ & $\square$ & $\square$ & $\square$ & $\square$ & $\square$ & $\square$ & \\
\hline
\end{tabular}




\section{Section-2: Information about your perception of natural hazards}

4. How do you see the following hazards as potential danger for you or your family in future? Please tick one box for each hazard.

\begin{tabular}{|c|c|c|c|c|c|c|c|c|}
\hline Hazards & $\begin{array}{c}\text { Not } \\
\text { applicable }\end{array}$ & $\begin{array}{l}\text { Don't } \\
\text { know }\end{array}$ & $\begin{array}{c}\text { Not } \\
\text { harmful }\end{array}$ & $\begin{array}{l}\text { Minor } \\
\text { damage }\end{array}$ & $\begin{array}{c}\text { Significant } \\
\text { property damage }\end{array}$ & $\begin{array}{l}\text { Physical } \\
\text { injuries }\end{array}$ & \begin{tabular}{|c|} 
Life \\
threatening
\end{tabular} & $\begin{array}{c}\text { Total } \\
\text { destruction }\end{array}$ \\
\hline Earthquake & $\square$ & $\square$ & $\square$ & $\square$ & $\square$ & $\square$ & $\square$ & $\square$ \\
\hline Flood & $\square$ & $\square$ & $\square$ & $\square$ & $\square$ & $\square$ & $\square$ & $\square$ \\
\hline Landslide/slip & $\square$ & $\square$ & $\square$ & $\square$ & $\square$ & $\square$ & $\square$ & $\square$ \\
\hline Bushfire & $\square$ & $\square$ & $\square$ & $\square$ & $\square$ & $\square$ & $\square$ & $\square$ \\
\hline Windstorm/gale & $\square$ & $\square$ & $\square$ & $\square$ & $\square$ & $\square$ & $\square$ & $\square$ \\
\hline Cyclone & $\square$ & $\square$ & $\square$ & $\square$ & $\square$ & $\square$ & $\square$ & $\square$ \\
\hline Tsunami & $\square$ & $\square$ & $\square$ & $\square$ & $\square$ & $\square$ & $\square$ & $\square$ \\
\hline Drought & $\square$ & $\square$ & $\square$ & $\square$ & $\square$ & $\square$ & $\square$ & $\square$ \\
\hline Volcanic ash-fall & $\square$ & $\square$ & $\square$ & $\square$ & $\square$ & $\square$ & $\square$ & $\square$ \\
\hline Other: & $\square$ & $\square$ & $\square$ & $\square$ & $\square$ & $\square$ & $\square$ & $\square$ \\
\hline
\end{tabular}

5. How soon do you expect a major hazard (damaging event) in the future in your residential area?

\begin{tabular}{|l|c|c|c|c|c|c|c|c|}
\hline Hazards & $\begin{array}{c}\text { Not } \\
\text { applicable }\end{array}$ & $\begin{array}{c}\text { Don't } \\
\text { know }\end{array}$ & $\begin{array}{c}\text { Don't } \\
\text { expect }\end{array}$ & $\begin{array}{c}\text { Within a } \\
\text { year }\end{array}$ & $\begin{array}{c}\text { Within } \\
\text { 2-5 years }\end{array}$ & $\begin{array}{c}\text { Within } \\
\text { 6-10 years }\end{array}$ & $\begin{array}{c}\text { Within } \\
\text { 10-20 years }\end{array}$ & $\begin{array}{c}\text { Beyond } \\
\text { 20 years }\end{array}$ \\
\hline Earthquake & $\square$ & $\square$ & $\square$ & $\square$ & $\square$ & $\square$ & $\square$ & $\square$ \\
\hline Flood & $\square$ & $\square$ & $\square$ & $\square$ & $\square$ & $\square$ & $\square$ & $\square$ \\
\hline Landslide/slip & $\square$ & $\square$ & $\square$ & $\square$ & $\square$ & $\square$ & $\square$ & $\square$ \\
\hline Bushfire & $\square$ & $\square$ & $\square$ & $\square$ & $\square$ & $\square$ & $\square$ & $\square$ \\
\hline Windstorm/gale & $\square$ & $\square$ & $\square$ & $\square$ & $\square$ & $\square$ & $\square$ & $\square$ \\
\hline Cyclone & $\square$ & $\square$ & $\square$ & $\square$ & $\square$ & $\square$ & $\square$ & $\square$ \\
\hline Tsunami & $\square$ & $\square$ & $\square$ & $\square$ & $\square$ & $\square$ & $\square$ & $\square$ \\
\hline Drought & $\square$ & $\square$ & $\square$ & $\square$ & $\square$ & $\square$ & $\square$ & $\square$ \\
\hline Volcanic ash-fall & $\square$ & $\square$ & $\square$ & $\square$ & $\square$ & $\square$ & $\square$ & $\square$ \\
\hline Other: & $\square$ & $\square$ & $\square$ & $\square$ & $\square$ & $\square$ & $\square$ & $\square$ \\
\hline
\end{tabular}

6. Are there any specific localities in your city/district which you think will be most or least likely to be affected in case of following hazard occurrence?

\begin{tabular}{|l|l|l|}
\hline Hazards & \multicolumn{1}{|c|}{ Localities that will be most affected } & Localities that will be least affected \\
\hline Earthquake & & \\
\hline Flood & & \\
\hline Landslide/slip & & \\
\hline Bushfire & & \\
\hline Windstorm/gale & & \\
\hline Cyclone & & \\
\hline Tsunami & & \\
\hline Drought & & \\
\hline Volcanic ash-fall & & \\
\hline Other: & & \\
\hline
\end{tabular}


7. How do you see yourself or your situation against the following hazards?

\begin{tabular}{|l|c|c|c|c|c|c|c|c|}
\hline Hazards & Safe & Protected & $\begin{array}{c}\text { Not } \\
\text { worried }\end{array}$ & $\begin{array}{c}\text { Over- } \\
\text { whelmed }\end{array}$ & Worried & Helpless & Weak & Unsafe \\
\hline Earthquake & $\square$ & $\square$ & $\square$ & $\square$ & $\square$ & $\square$ & $\square$ & $\square$ \\
\hline Flood & $\square$ & $\square$ & $\square$ & $\square$ & $\square$ & $\square$ & $\square$ & $\square$ \\
\hline Landslide/slip & $\square$ & $\square$ & $\square$ & $\square$ & $\square$ & $\square$ & $\square$ & $\square$ \\
\hline Bushfire & $\square$ & $\square$ & $\square$ & $\square$ & $\square$ & $\square$ & $\square$ & $\square$ \\
\hline Windstorm/gale & $\square$ & $\square$ & $\square$ & $\square$ & $\square$ & $\square$ & $\square$ & $\square$ \\
\hline Cyclone & $\square$ & $\square$ & $\square$ & $\square$ & $\square$ & $\square$ & $\square$ & $\square$ \\
\hline Tsunami & $\square$ & $\square$ & $\square$ & $\square$ & $\square$ & $\square$ & $\square$ & $\square$ \\
\hline Drought & $\square$ & $\square$ & $\square$ & $\square$ & $\square$ & $\square$ & $\square$ & $\square$ \\
\hline Volcanic ash-fall & $\square$ & $\square$ & $\square$ & $\square$ & $\square$ & $\square$ & $\square$ & $\square$ \\
\hline Other: & $\square$ & $\square$ & $\square$ & $\square$ & $\square$ & $\square$ & $\square$ & $\square$ \\
\hline
\end{tabular}

8. a. Which is your most feared hazard at your current residence?

b. Who do you think will be most affected by your most feared hazard and why? Rank in decreasing order, i.e. $1=$ Most affected.

\begin{tabular}{|l|l|l|}
\hline People affected & Rank & \multicolumn{1}{c|}{ Reason } \\
\hline Yourself & & \\
\hline Family & & \\
\hline Friend & & \\
\hline Neighbour & & \\
\hline Community (any specific: & & \\
\hline Other: & & \\
\hline
\end{tabular}

9. Which of the following do you think is the primary cause of hazard occurrence? Tick one for each hazard.

\begin{tabular}{|c|c|c|c|c|c|c|c|c|}
\hline Hazards & $\begin{array}{l}\text { Don't } \\
\text { know }\end{array}$ & $\begin{array}{l}\text { Act of } \\
\text { God }\end{array}$ & $\begin{array}{c}\text { Nature's } \\
\text { fury }\end{array}$ & $\begin{array}{c}\text { A natural } \\
\text { process }\end{array}$ & $\begin{array}{c}\text { Human } \\
\text { negligence }\end{array}$ & $\begin{array}{c}\text { Technological } \\
\text { failure }\end{array}$ & $\begin{array}{c}\text { Government } \\
\text { failure }\end{array}$ & Other \\
\hline Earthquake & $\square$ & $\square$ & $\square$ & $\square$ & $\square$ & $\square$ & $\square$ & \\
\hline Flood & $\square$ & $\square$ & $\square$ & $\square$ & $\square$ & $\square$ & $\square$ & \\
\hline Landslide/slip & $\square$ & $\square$ & $\square$ & $\square$ & $\square$ & $\square$ & $\square$ & \\
\hline Bushfire & $\square$ & $\square$ & $\square$ & $\square$ & $\square$ & $\square$ & $\square$ & \\
\hline Windstorm/gale & $\square$ & $\square$ & $\square$ & $\square$ & $\square$ & $\square$ & $\square$ & \\
\hline Cyclone & $\square$ & $\square$ & $\square$ & $\square$ & $\square$ & $\square$ & $\square$ & \\
\hline Tsunami & $\square$ & $\square$ & $\square$ & $\square$ & $\square$ & $\square$ & $\square$ & \\
\hline Drought & $\square$ & $\square$ & $\square$ & $\square$ & $\square$ & $\square$ & $\square$ & \\
\hline Volcanic ash-fall & $\square$ & $\square$ & $\square$ & $\square$ & $\square$ & $\square$ & $\square$ & \\
\hline Other: & $\square$ & $\square$ & $\square$ & $\square$ & $\square$ & $\square$ & $\square$ & \\
\hline
\end{tabular}


10. Do you think that potential damage from the following hazards can be reduced?

\begin{tabular}{|l|c|c|c|c|}
\hline Hazards & Yes & No & $\begin{array}{c}\text { Don't } \\
\text { know }\end{array}$ & Please specify the reason for your particular thinking \\
\hline Earthquake & $\square$ & $\square$ & $\square$ & \\
\hline Flood & $\square$ & $\square$ & $\square$ & \\
\hline Landslide/slip & $\square$ & $\square$ & $\square$ & \\
\hline Bushfire & $\square$ & $\square$ & $\square$ & \\
\hline Windstorm/gale & $\square$ & $\square$ & $\square$ & \\
\hline Cyclone & $\square$ & $\square$ & $\square$ & \\
\hline Tsunami & $\square$ & $\square$ & $\square$ & \\
\hline Drought & $\square$ & $\square$ & $\square$ & \\
\hline Volcanic ash-fall & $\square$ & $\square$ & $\square$ & \\
\hline Other: & $\square$ & $\square$ & $\square$ & \\
\hline
\end{tabular}

\section{Section-3: The source of your hazard information, your awareness and role of local council}

11. Please tick the main source of general hazard information for you?

$\square$ TV $\square$ Radio $\square$ Newspaper $\square$ Internet $\square$ Local council $\square$ Any other

12. a. Please tick the hazards for which you have received or seen information from your local council.

$\square$ Earthquake $\square$ Flood $\square$ Landslide/slip $\square$ Bushfire $\square$ Windstorm/gale $\square$ Cyclone

$\square$ Tsunami $\quad \square$ Drought $\square$ Volcanic Ash fall $\square$ Other:

b. Is there any other information about hazards that you would like to be provided by your local council?

13. Do you know the location of your nearest community emergency or civil defence centre?

$\square$ Yes $\square$ No if yes please specify location or name:

14. a. During an emergency, who would you be most likely to believe or trust for hazard information? Rank the following in decreasing order i.e. 1= Most trusted.

\begin{tabular}{|l|l|}
\hline Authorities/people & Rank \\
\hline $\begin{array}{l}\text { Local government official (Civil defence officer/council } \\
\text { member) }\end{array}$ & \\
\hline Non-governmental official (e.g. Red Cross) & \\
\hline Media person (TV/Radio/News paper) & \\
\hline Hazard experts from universities/research institutes & \\
\hline Teachers or academic people & \\
\hline Neighbours & \\
\hline Friends & \\
\hline Religious institutions (Church, temple or mosque etc.) & \\
\hline Community or any social network: & \\
\hline
\end{tabular}

14. b. Reason for your most trust:

14. c. Reason for your least trust: 


\section{Section-4: Information about your response to natural hazards}

15. a. Which hazards were you aware of when settling to this place?

b. Did you take any measures to cope with that when you settled in? $\square$ : Yes $\square$ : No If yes then specify:

16. Did you consider the possible hazards during the purchase or renting the house? $\square$ : Yes $\square$ : No

17. Have you ever shifted your house because of any hazards? $\square$ : Yes $\square$ : No If yes then:

When: name of hazard:

Did it help?

18. Have you made any changes in your house to prevent or reduce damage from any natural hazards?

$\square$ : Yes $\square$ : No if yes then specify:

\begin{tabular}{|l|l|l|}
\hline Change in house & Hazard & Specify the changes \\
\hline Strengthened house & & \\
\hline Raised platform & & \\
\hline Fixed roof and windows & & \\
\hline Other: & & \\
\hline
\end{tabular}

19. Which of the following factors do you think make you feel vulnerable or to think that you will not be able to respond effectively in case of hazard occurrence? Tick one box for each row and leave the rows that do not apply.

\begin{tabular}{|c|c|c|c|c|c|}
\hline \multirow[t]{2}{*}{ Factors affecting hazard response } & \multicolumn{5}{|c|}{ Not at all------------------------Scale ---------------------Affect strongly } \\
\hline & 1 & 2 & 3 & 4 & 5 \\
\hline Unpredictability of hazard & $\square$ & $\square$ & $\square$ & $\square$ & $\square$ \\
\hline Lack of knowledge about hazards & $\square$ & $\square$ & $\square$ & $\square$ & $\square$ \\
\hline Don't know what to do & $\square$ & $\square$ & $\square$ & $\square$ & $\square$ \\
\hline Financial constraints & $\square$ & $\square$ & $\square$ & $\square$ & $\square$ \\
\hline Being a migrant & $\square$ & $\square$ & $\square$ & $\square$ & $\square$ \\
\hline Being new to the place & $\square$ & $\square$ & $\square$ & $\square$ & $\square$ \\
\hline Being old & $\square$ & $\square$ & $\square$ & $\square$ & $\square$ \\
\hline Being disabled & $\square$ & $\square$ & $\square$ & $\square$ & $\square$ \\
\hline Being a woman & $\square$ & $\square$ & $\square$ & $\square$ & $\square$ \\
\hline Having small kids & $\square$ & $\square$ & $\square$ & $\square$ & $\square$ \\
\hline Fear & $\square$ & $\square$ & $\square$ & $\square$ & $\square$ \\
\hline Lack of family support & $\square$ & $\square$ & $\square$ & $\square$ & $\square$ \\
\hline Lack of local community support & $\square$ & $\square$ & $\square$ & $\square$ & $\square$ \\
\hline Being part of any specific group: & $\square$ & $\square$ & $\square$ & $\square$ & $\square$ \\
\hline Language barrier & $\square$ & $\square$ & $\square$ & $\square$ & $\square$ \\
\hline Short term stay at current place & $\square$ & $\square$ & $\square$ & $\square$ & $\square$ \\
\hline Other: & $\square$ & $\square$ & $\square$ & $\square$ & $\square$ \\
\hline
\end{tabular}


20. a. Please tick the assets for which you have taken insurance cover for natural hazards?

\begin{tabular}{|l|c|c|c|}
\hline Properties & Yes & No & Don't know \\
\hline House & $\square$ & $\square$ & $\square$ \\
\hline Household items/content insurance & $\square$ & $\square$ & $\square$ \\
\hline Crop/livestock/pasture insurance & $\square$ & $\square$ & $\square$ \\
\hline Other: & $\square$ & $\square$ & $\square$ \\
\hline
\end{tabular}

b. Have you made any claims due to any natural hazard? $\square$ : Yes $\square$ : No

c. Are you satisfied with your insurance cover $\square$ : Yes $\square$ : No $\quad$ If no, please specify the reason:

21. Is there any hazards safety measure or measure to reduce damage at your workplace?

$\square$ : Yes $\quad \square$ : No $\quad \square$ : Don’t know if yes please specify them:

\section{Section-5: Information about your preparedness to natural hazards}

22. a. Please tick the safety measures that you have taken to reduce the potential damage to you, your family or property from any natural hazard? Please give details for any other measures.
$\square$ None
$\square$ Cash reserve/savings
$\square$ Emergency plan
$\square$ Survival kit

$\square$ Any other measure for any specific hazard:

b. Name the hazard, for which you took the above hazard safety measures:

c. Does your survival kit have the followings?

\begin{tabular}{|l|c|c|l|c|c|}
\hline Things in survival kit & Yes & No & Things in survival kit & Yes & No \\
\hline $\begin{array}{l}\text { Canned dried food sufficient for at least } \\
\text { three days }\end{array}$ & $\square$ & $\square$ & Bottled water for at least 3 litre per person & $\square$ & $\square$ \\
\hline First aid kit including paracetamol & $\square$ & $\square$ & Personal medicines & $\square$ & $\square$ \\
\hline Spoons & $\square$ & $\square$ & Can opener & $\square$ \\
\hline Candles & $\square$ & $\square$ & Torch & $\square$ & $\square$ \\
\hline Extra Batteries & $\square$ & $\square$ & Water proof match/match & $\square$ & $\square$ \\
\hline Bucket & $\square$ & $\square$ & Plastic Rubbish Bags & $\square$ \\
\hline Blanket & $\square$ & $\square$ & Toilet paper & $\square$ & $\square$ \\
\hline Battery powered AM/FM radio & $\square$ & $\square$ & Warm clothing & $\square$ & $\square$ \\
\hline Important document & $\square$ & $\square$ & BBQ or other means of cooking & $\square$ & $\square$ \\
\hline Emergency contacts and numbers & $\square$ & $\square$ & Pet food & $\square$ & $\square$ \\
\hline
\end{tabular}

d. Is there any precautionary measure taken by your local community to reduce damage?
$\square$ : Yes
$\square: \mathrm{No}$
$\square$ : Don't know
If yes please specify them: 
23. To what extent do you believe yourself to be prepared for the following hazards?

\begin{tabular}{|l|c|c|c|c|c|c|}
\hline Hazards & Not applicable & Don't know & $\begin{array}{c}\text { Not at all } \\
\text { prepared }\end{array}$ & $\begin{array}{c}\text { Less } \\
\text { prepared }\end{array}$ & Fairly prepared & Very prepared \\
\hline Earthquake & $\square$ & $\square$ & $\square$ & $\square$ & $\square$ & $\square$ \\
\hline Flood & $\square$ & $\square$ & $\square$ & $\square$ & $\square$ & $\square$ \\
\hline Landslide/slip & $\square$ & $\square$ & $\square$ & $\square$ & $\square$ & $\square$ \\
\hline Bushfire & $\square$ & $\square$ & $\square$ & $\square$ & $\square$ & $\square$ \\
\hline Windstorm/gale & $\square$ & $\square$ & $\square$ & $\square$ & $\square$ & $\square$ \\
\hline Cyclone & $\square$ & $\square$ & $\square$ & $\square$ & $\square$ & $\square$ \\
\hline Tsunami & $\square$ & $\square$ & $\square$ & $\square$ & $\square$ & $\square$ \\
\hline Drought & $\square$ & $\square$ & $\square$ & $\square$ & $\square$ & $\square$ \\
\hline Volcanic ash-fall & $\square$ & $\square$ & $\square$ & $\square$ & $\square$ & $\square$ \\
\hline Other_c & $\square$ & $\square$ & $\square$ & $\square$ & $\square$ & $\square$ \\
\hline
\end{tabular}

24. Which of the following reason prevents you from being prepared for the following hazards?

\section{Reason that applies:}

(1). Cost of being prepared.

(2). Distance from hazard area.

(3). Lack of time

(4). I don't think it is necessary

(5). Hazard does not affect my house.

(6). I can bear the damage.

(7). Don't know what to do.

(8). Other reason (please specify against hazard).

\begin{tabular}{|l|l|}
\hline Hazards & $\begin{array}{c}\text { Please write the number of the given reasons } \\
\text { that prevents you from being prepared }\end{array}$ \\
\hline Earthquake & \\
\hline Flood & \\
\hline Landslide/slip & \\
\hline Bushfire & \\
\hline Windstorm/gale & \\
\hline Cyclone & \\
\hline Tsunami & \\
\hline Drought & \\
\hline Volcanic ash-fall & \\
\hline Other: & \\
\hline
\end{tabular}

\section{Section-6: Information about your past hazard experience and response to natural hazards.}

25. Have you experienced any significant damage due to any hazard at your current residence?

$\square$ Yes $\square$ No If yes then please explain:
a. When (year):
b. Hazard:

c. Did you receive any warning? $\square$ Yes $\square$ No If yes what did it say:

d. Type of Damage (physical, mental, or property damage):

e. Any Specific Cause for damage:

f. Did it involve evacuation? $\square$ Yes $\square$ No If yes then please specify the place where you found shelter and for how long:

g. Your response and coping strategy:

h. Lesson learnt: 
i. Any traditional or cultural practice that helped to cope with hazard:

j. How many times have you been affected by this hazard:

$k$. How has your experience influenced the following?

- Preparedness level:

- Coping Strategy:

- Recovery measures:

- Vulnerability:

- Thinking on hazard:

Section-7: Information about yourself in order to compare the answers from different kind of people

26. Please fill your personal details:

\begin{tabular}{|c|c|}
\hline Age & 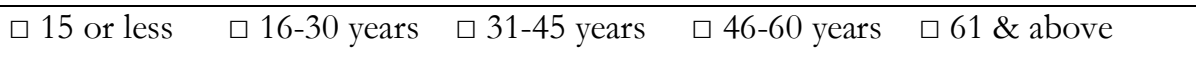 \\
\hline Gender & $\square$ Female \\
\hline Ethnicity & $\begin{array}{ll}\square \text { European } & \square \text { Maori } \\
\square \text { Pacific } & \square \text { Asian } \quad \square \text { other: }\end{array}$ \\
\hline Religion & $\square$ None $\square$ Christian $\quad \square$ Buddhism $\quad \square$ Hinduism $\quad \square$ Islam $\square$ other \\
\hline First Language & $\square$ English $\quad \square$ Maori $\square$ Other \\
\hline Residency & $\square$ Citizen $\quad \square$ Permanent Resident $\quad \square$ Work Permit $\quad \square$ \\
\hline Education & $\square$ None $\quad \square$ School $\quad \square$ College $\square$ University $\quad \square_{-}$ \\
\hline Hazard education & $\square$ University $\quad \square$ Vocational (specify :) \\
\hline Work status & 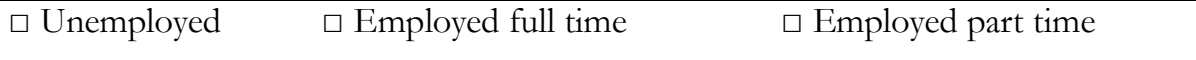 \\
\hline Occupation & $\square$ Farmer $\square$ self employed $\square$ Administration $\square$ Other: \\
\hline $\begin{array}{l}\text { Location of } \\
\text { workplace }\end{array}$ & $\begin{array}{l}\square \text { In the same city/district } \square \text { Outside city/district in } \\
\text { city/district. }\end{array}$ \\
\hline Mode of transport & $\square$ Car $\quad \square$ Bus $\quad \square$ Train $\quad \square$ Other: \\
\hline $\begin{array}{l}\text { Your or family's } \\
\text { annual income }\end{array}$ & $\begin{array}{lll}\square \text { None } & \square \text { Below } \$ 20,000 & \square \$ 20-50,000 \\
\square \$ 71-100,000 & \square \text { Above } \$ 100,000 & \end{array}$ \\
\hline $\begin{array}{l}\text { Household size } \\
\text { (number of } \\
\text { members) }\end{array}$ & 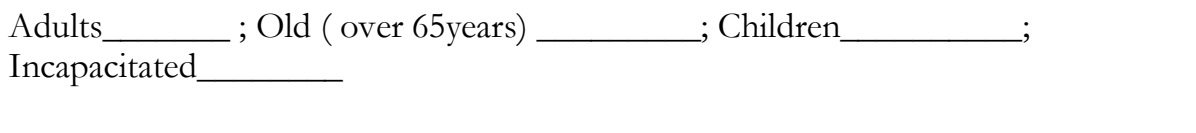 \\
\hline \multicolumn{2}{|l|}{ Dependents (no.) } \\
\hline $\begin{array}{l}\text { Year of residence in } \\
\text { NZ }\end{array}$ & 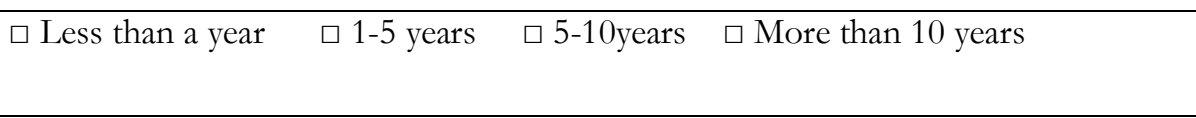 \\
\hline $\begin{array}{l}\text { Year of residence in } \\
\text { area }\end{array}$ & 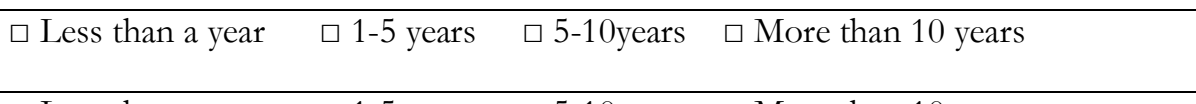 \\
\hline $\begin{array}{l}\text { Year of residence in } \\
\text { house }\end{array}$ & $\square$ Less than a year $\quad \square 1-5$ years $\quad \square 5$-10years $\square$ More than 10 years \\
\hline $\begin{array}{l}\text { Place of residence } \\
\text { before the current }\end{array}$ & _ Country: \\
\hline
\end{tabular}




\begin{tabular}{|l|l|}
\hline $\begin{array}{l}\text { Reason to live at the } \\
\text { current place }\end{array}$ & $\begin{array}{l}\square \text { Born here } \square \text { Employment } \square \text { Economic opportunity } \square \text { Near workplace } \\
\square \text { Nice view } \square \text { Other: }\end{array}$ \\
\hline Ownership of house & $\square$ Owned $\square$ Rent $\square$ Other: \\
\hline Current Address & \\
\hline
\end{tabular}

\section{Any comment for research:}

Thank you for your time and efforts to fill the questionnaire. 
Appendix-2

Questionnaire: Civil Defence Officers

\section{Questions on Hazards and their characteristics in the district}

1. Which are the common natural hazards (damaging events) in your area of jurisdiction?

2. Which hazard do you think is the most damaging for your district and why?

3. How severe are the following hazards in terms of magnitude in your city/district? Please encircle the appropriate number for each hazard.

\begin{tabular}{|l|c|c|c|c|c|c|}
\hline Hazards & $\begin{array}{c}\text { Not } \\
\text { Applicable }\end{array}$ & $\begin{array}{c}\text { Don't } \\
\text { know }\end{array}$ & $\begin{array}{c}\text { Not } \\
\text { Problematic }\end{array}$ & Problematic & $\begin{array}{c}\text { Highly } \\
\text { Problematic }\end{array}$ & Most serious \\
\hline Earthquake & $\square$ & $\square$ & $\square$ & $\square$ & $\square$ & $\square$ \\
\hline Flood & $\square$ & $\square$ & $\square$ & $\square$ & $\square$ & $\square$ \\
\hline Landslide/slip & $\square$ & $\square$ & $\square$ & $\square$ & $\square$ & $\square$ \\
\hline Bushfire & $\square$ & $\square$ & $\square$ & $\square$ & $\square$ & $\square$ \\
\hline Windstorm/gale & $\square$ & $\square$ & $\square$ & $\square$ & $\square$ & $\square$ \\
\hline Cyclone & $\square$ & $\square$ & $\square$ & $\square$ & $\square$ & $\square$ \\
\hline Tsunami & $\square$ & $\square$ & $\square$ & $\square$ & $\square$ & $\square$ \\
\hline Drought & $\square$ & $\square$ & $\square$ & $\square$ & $\square$ & $\square$ \\
\hline Volcanic ash-fall & $\square$ & $\square$ & $\square$ & $\square$ & $\square$ & $\square$ \\
\hline Other: & $\square$ & $\square$ & $\square$ & $\square$ & $\square$ & $\square$ \\
\hline
\end{tabular}

4. How frequently do the following hazards cause damage in your city/district? Please encircle appropriate number for each hazard.

\begin{tabular}{|l|c|c|c|c|c|c|c|c|}
\hline Hazards & $\begin{array}{c}\text { Not } \\
\text { Applicable }\end{array}$ & $\begin{array}{c}\text { Don't } \\
\text { know }\end{array}$ & $\begin{array}{c}\text { Once in a } \\
\text { month }\end{array}$ & $\begin{array}{c}\text { Once in a } \\
\text { year }\end{array}$ & $\begin{array}{c}\text { Once in } \\
\text { 5 years }\end{array}$ & $\begin{array}{c}\text { Once in } \\
\text { 10 years }\end{array}$ & $\begin{array}{c}\text { Once in 20 } \\
\text { years }\end{array}$ & $\begin{array}{c}\text { Any other } \\
\text { Please specify }\end{array}$ \\
\hline Earthquake & $\square$ & $\square$ & $\square$ & $\square$ & $\square$ & $\square$ & $\square$ & \\
\hline Flood & $\square$ & $\square$ & $\square$ & $\square$ & $\square$ & $\square$ & $\square$ & \\
\hline Landslide/slip & $\square$ & $\square$ & $\square$ & $\square$ & $\square$ & $\square$ & $\square$ & \\
\hline Bushfire & $\square$ & $\square$ & $\square$ & $\square$ & $\square$ & $\square$ & $\square$ & \\
\hline Windstorm/gale & $\square$ & $\square$ & $\square$ & $\square$ & $\square$ & $\square$ & $\square$ & \\
\hline Cyclone & $\square$ & $\square$ & $\square$ & $\square$ & $\square$ & $\square$ & $\square$ & \\
\hline Tsunami & $\square$ & $\square$ & $\square$ & $\square$ & $\square$ & $\square$ & $\square$ & \\
\hline Drought & $\square$ & $\square$ & $\square$ & $\square$ & $\square$ & $\square$ & $\square$ & $\square$ \\
\hline Volcanic ash-fall & $\square$ & $\square$ & $\square$ & $\square$ & $\square$ & $\square$ & $\square$ & $\square$ \\
\hline Other: & $\square$ & $\square$ & $\square$ & $\square$ & $\square$ & $\square$ & $\square$ & $\square$ \\
\hline
\end{tabular}


5. How do you see the following hazards as potential danger for your city/district?

\begin{tabular}{|l|c|c|c|c|c|c|c|c|}
\hline Hazards & $\begin{array}{c}\text { Not } \\
\text { Applicable }\end{array}$ & $\begin{array}{c}\text { Don't } \\
\text { know }\end{array}$ & $\begin{array}{c}\text { Not } \\
\text { harmful }\end{array}$ & $\begin{array}{c}\text { Minor } \\
\text { damage }\end{array}$ & $\begin{array}{c}\text { Significant } \\
\text { damage }\end{array}$ & $\begin{array}{c}\text { Injuries to } \\
\text { people }\end{array}$ & $\begin{array}{c}\text { Life } \\
\text { threatening }\end{array}$ & $\begin{array}{c}\text { Total } \\
\text { destruction }\end{array}$ \\
\hline Earthquake & $\square$ & $\square$ & $\square$ & $\square$ & $\square$ & $\square$ & $\square$ & $\square$ \\
\hline Flood & $\square$ & $\square$ & $\square$ & $\square$ & $\square$ & $\square$ & $\square$ & $\square$ \\
\hline Landslide/slip & $\square$ & $\square$ & $\square$ & $\square$ & $\square$ & $\square$ & $\square$ & $\square$ \\
\hline Bushfire & $\square$ & $\square$ & $\square$ & $\square$ & $\square$ & $\square$ & $\square$ & $\square$ \\
\hline Windstorm/gale & $\square$ & $\square$ & $\square$ & $\square$ & $\square$ & $\square$ & $\square$ & $\square$ \\
\hline Cyclone & $\square$ & $\square$ & $\square$ & $\square$ & $\square$ & $\square$ & $\square$ & $\square$ \\
\hline Tsunami & $\square$ & $\square$ & $\square$ & $\square$ & $\square$ & $\square$ & $\square$ & $\square$ \\
\hline Drought & $\square$ & $\square$ & $\square$ & $\square$ & $\square$ & $\square$ & $\square$ & $\square$ \\
\hline Volcanic ash-fall & $\square$ & $\square$ & $\square$ & $\square$ & $\square$ & $\square$ & $\square$ & $\square$ \\
\hline Other: & $\square$ & $\square$ & $\square$ & $\square$ & $\square$ & $\square$ & $\square$ & $\square$ \\
\hline
\end{tabular}

6. How near in future do you see a major hazard (damaging event) in your city/district?

\begin{tabular}{|l|c|c|c|c|c|c|c|c|c|}
\hline Hazards & $\begin{array}{c}\text { Not } \\
\text { Applicable }\end{array}$ & $\begin{array}{c}\text { Don't } \\
\text { know }\end{array}$ & $\begin{array}{c}\text { Don't } \\
\text { see }\end{array}$ & $\begin{array}{c}\text { Within a } \\
\text { month }\end{array}$ & $\begin{array}{c}\text { Within } \\
\text { a year }\end{array}$ & $\begin{array}{c}\text { Within } \\
\text { 2-5 years }\end{array}$ & $\begin{array}{c}\text { Within } \\
\text { 6-10 years }\end{array}$ & $\begin{array}{c}\text { Within 10- } \\
\text { 20 years }\end{array}$ & $\begin{array}{c}\text { Beyond } \\
\text { 20 years }\end{array}$ \\
\hline Earthquake & $\square$ & $\square$ & $\square$ & $\square$ & $\square$ & $\square$ & $\square$ & $\square$ & $\square$ \\
\hline Flood & $\square$ & $\square$ & $\square$ & $\square$ & $\square$ & $\square$ & $\square$ & $\square$ & $\square$ \\
\hline Landslide/slip & $\square$ & $\square$ & $\square$ & $\square$ & $\square$ & $\square$ & $\square$ & $\square$ & $\square$ \\
\hline Bushfire & $\square$ & $\square$ & $\square$ & $\square$ & $\square$ & $\square$ & $\square$ & $\square$ & $\square$ \\
\hline Windstorm/gale & $\square$ & $\square$ & $\square$ & $\square$ & $\square$ & $\square$ & $\square$ & $\square$ & $\square$ \\
\hline Cyclone & $\square$ & $\square$ & $\square$ & $\square$ & $\square$ & $\square$ & $\square$ & $\square$ & $\square$ \\
\hline Tsunami & $\square$ & $\square$ & $\square$ & $\square$ & $\square$ & $\square$ & $\square$ & $\square$ & $\square$ \\
\hline Drought & $\square$ & $\square$ & $\square$ & $\square$ & $\square$ & $\square$ & $\square$ & $\square$ & $\square$ \\
\hline Volcanic ash-fall & $\square$ & $\square$ & $\square$ & $\square$ & $\square$ & $\square$ & $\square$ & $\square$ & $\square$ \\
\hline Other: & $\square$ & $\square$ & $\square$ & $\square$ & $\square$ & $\square$ & $\square$ & $\square$ & $\square$ \\
\hline
\end{tabular}

7. Which areas/localities in your city/district council do you think are most likely to be affected by following hazards and why?

\begin{tabular}{|l|l|l|}
\hline Hazards & \multicolumn{1}{|c|}{ Most affected areas } & Reason \\
\hline Earthquake & & \\
\hline Flood & & \\
\hline Landslide/slip & & \\
\hline Bushfire & & \\
\hline Windstorm/gale & & \\
\hline Cyclone & & \\
\hline Tsunami & & \\
\hline Drought & & \\
\hline Volcanic ash-fall & & \\
\hline Other: & & \\
\hline
\end{tabular}


8. Which areas/localities in your city/district council do you think are least likely to be affected by following hazards and why?

\begin{tabular}{|l|l|l|}
\hline Hazards & \multicolumn{1}{|c|}{ Least affected areas } & Reason \\
\hline Earthquake & & \\
\hline Flood & & \\
\hline Landslide/slip & & \\
\hline Bushfire & & \\
\hline Windstorm/gale & & \\
\hline Cyclone & & \\
\hline Tsunami & & \\
\hline Drought & & \\
\hline Volcanic ash-fall & & \\
\hline Other: & & \\
\hline
\end{tabular}

9. How often have your CDEM organisation responded for the following hazards?

\begin{tabular}{|l|c|c|c|c|c|c|c|c|c|}
\hline Hazards & $\begin{array}{c}\text { Not } \\
\text { Applicable }\end{array}$ & $\begin{array}{c}\text { Don't } \\
\text { know }\end{array}$ & $\begin{array}{c}\text { Not } \\
\text { asked }\end{array}$ & $\begin{array}{c}\text { Within a } \\
\text { month }\end{array}$ & $\begin{array}{c}\text { Within } \\
\text { a year }\end{array}$ & $\begin{array}{c}\text { Within } \\
\text { 2-5 years }\end{array}$ & $\begin{array}{c}\text { Within } \\
\text { 6-10 years }\end{array}$ & $\begin{array}{c}\text { Within 10-20 } \\
\text { years }\end{array}$ & $\begin{array}{l}\text { Any other } \\
\text { Please specify }\end{array}$ \\
\hline Earthquake & $\square$ & $\square$ & $\square$ & $\square$ & $\square$ & $\square$ & $\square$ & $\square$ & $\square$ \\
\hline Flood & $\square$ & $\square$ & $\square$ & $\square$ & $\square$ & $\square$ & $\square$ & $\square$ & $\square$ \\
\hline Landslide/slip & $\square$ & $\square$ & $\square$ & $\square$ & $\square$ & $\square$ & $\square$ & $\square$ & $\square$ \\
\hline Bushfire & $\square$ & $\square$ & $\square$ & $\square$ & $\square$ & $\square$ & $\square$ & $\square$ & $\square$ \\
\hline Windstorm/gale & $\square$ & $\square$ & $\square$ & $\square$ & $\square$ & $\square$ & $\square$ & $\square$ & \\
\hline Cyclone & $\square$ & $\square$ & $\square$ & $\square$ & $\square$ & $\square$ & $\square$ & $\square$ & $\square$ \\
\hline Tsunami & $\square$ & $\square$ & $\square$ & $\square$ & $\square$ & $\square$ & $\square$ & $\square$ & $\square$ \\
\hline Drought & $\square$ & $\square$ & $\square$ & $\square$ & $\square$ & $\square$ & $\square$ & $\square$ & $\square$ \\
\hline Volcanic ash-fall & $\square$ & $\square$ & $\square$ & $\square$ & $\square$ & $\square$ & $\square$ & $\square$ & $\square$ \\
\hline Other: & $\square$ & $\square$ & $\square$ & $\square$ & $\square$ & $\square$ & $\square$ & $\square$ \\
\hline
\end{tabular}

10. Who do you think are the most vulnerable group to hazards in your community and why?

\section{Questions on Hazards reduction in the district}

11. To what extent do you think that potential damage can be reduced for these hazards?

\begin{tabular}{|l|c|c|c|c|c|c|c|c|}
\hline Hazards & $\begin{array}{c}\text { Not } \\
\text { Applicable }\end{array}$ & $\begin{array}{c}\text { Don't } \\
\text { know }\end{array}$ & $\begin{array}{c}\text { Not } \\
\text { possible }\end{array}$ & $\begin{array}{c}\text { Less than } \\
\mathbf{2 0} \%\end{array}$ & $\mathbf{2 1 - 4 0 \%}$ & 41-60\% & $\mathbf{6 1 - 8 0 \%}$ & $\mathbf{8 1 - 1 0 0 \%}$ \\
\hline Earthquake & $\square$ & $\square$ & $\square$ & $\square$ & $\square$ & $\square$ & $\square$ & $\square$ \\
\hline Flood & $\square$ & $\square$ & $\square$ & $\square$ & $\square$ & $\square$ & $\square$ & $\square$ \\
\hline Landslide/slip & $\square$ & $\square$ & $\square$ & $\square$ & $\square$ & $\square$ & $\square$ & $\square$ \\
\hline Bushfire & $\square$ & $\square$ & $\square$ & $\square$ & $\square$ & $\square$ & $\square$ & $\square$ \\
\hline Windstorm/gale & $\square$ & $\square$ & $\square$ & $\square$ & $\square$ & $\square$ & $\square$ & $\square$ \\
\hline Cyclone & $\square$ & $\square$ & $\square$ & $\square$ & $\square$ & $\square$ & $\square$ & $\square$ \\
\hline Tsunami & $\square$ & $\square$ & $\square$ & $\square$ & $\square$ & $\square$ & $\square$ & $\square$ \\
\hline Drought & $\square$ & $\square$ & $\square$ & $\square$ & $\square$ & $\square$ & $\square$ & $\square$ \\
\hline Volcanic ash-fall & $\square$ & $\square$ & $\square$ & $\square$ & $\square$ & $\square$ & $\square$ & $\square$ \\
\hline Other: & $\square$ & $\square$ & $\square$ & $\square$ & $\square$ & $\square$ & $\square$ & $\square$ \\
\hline
\end{tabular}


12. What are the major barriers to reduce the potential danger posed by hazards?

\begin{tabular}{|l|c|c|c|c|c|c|c|c|}
\hline Hazards & $\begin{array}{c}\text { Not } \\
\text { Applicable }\end{array}$ & $\begin{array}{c}\text { Don't } \\
\text { know }\end{array}$ & $\begin{array}{c}\text { Lack of } \\
\text { knowledge }\end{array}$ & $\begin{array}{c}\text { Lack of } \\
\text { expertise }\end{array}$ & $\begin{array}{c}\text { Lack of } \\
\text { finance }\end{array}$ & $\begin{array}{c}\text { Unwilling } \\
\text { ness }\end{array}$ & $\begin{array}{c}\text { Lack of } \\
\text { preparedness }\end{array}$ & Any other \\
\hline Earthquake & $\square$ & $\square$ & $\square$ & $\square$ & $\square$ & $\square$ & $\square$ & \\
\hline Flood & $\square$ & $\square$ & $\square$ & $\square$ & $\square$ & $\square$ & $\square$ & \\
\hline Landslide/slip & $\square$ & $\square$ & $\square$ & $\square$ & $\square$ & $\square$ & $\square$ & \\
\hline Bushfire & $\square$ & $\square$ & $\square$ & $\square$ & $\square$ & $\square$ & $\square$ & \\
\hline Windstorm/gale & $\square$ & $\square$ & $\square$ & $\square$ & $\square$ & $\square$ & $\square$ & \\
\hline Cyclone & $\square$ & $\square$ & $\square$ & $\square$ & $\square$ & $\square$ & $\square$ & \\
\hline Tsunami & $\square$ & $\square$ & $\square$ & $\square$ & $\square$ & $\square$ & $\square$ & \\
\hline Drought & $\square$ & $\square$ & $\square$ & $\square$ & $\square$ & $\square$ & $\square$ & $\square$ \\
\hline Volcanic ash-fall & $\square$ & $\square$ & $\square$ & $\square$ & $\square$ & $\square$ & $\square$ & $\square$ \\
\hline Other: & $\square$ & $\square$ & $\square$ & $\square$ & $\square$ & $\square$ & & $\square$ \\
\hline
\end{tabular}

13. Which of the following hazards are officially identified, located and mapped for the district?

\begin{tabular}{|l|c|c|c|l|c|c|c|}
\hline Hazard & Identified & Located & Mapped & Hazard & Identified & Located & Mapped \\
\hline Earthquake & $\square$ & $\square$ & $\square$ & Cyclone & $\square$ & $\square$ & $\square$ \\
\hline Flood & $\square$ & $\square$ & $\square$ & Tsunami & $\square$ & $\square$ & $\square$ \\
\hline Landslide/slip & $\square$ & $\square$ & $\square$ & Drought & $\square$ & $\square$ & $\square$ \\
\hline Bushfire & $\square$ & $\square$ & $\square$ & Volcanic ash-fall & $\square$ & $\square$ & $\square$ \\
\hline Windstorm/gale & $\square$ & $\square$ & $\square$ & Other: & $\square$ & $\square$ & $\square$ \\
\hline
\end{tabular}

14. a. What kind of work has been done in the city/district in order to control/reduce the risk from following natural hazards?

\begin{tabular}{|l|c|c|c|c|c|c|}
\hline Hazards & $\begin{array}{c}\text { Not } \\
\text { Applicable }\end{array}$ & $\begin{array}{c}\text { Don't } \\
\text { know }\end{array}$ & $\begin{array}{c}\text { Land use } \\
\text { regulation }\end{array}$ & $\begin{array}{c}\text { Engineering } \\
\text { solutions }\end{array}$ & $\begin{array}{c}\text { Afforestation } \\
\text { /shelter belt }\end{array}$ & $\begin{array}{c}\text { Any other } \\
\text { please specify }\end{array}$ \\
\hline Earthquake & $\square$ & $\square$ & $\square$ & $\square$ & $\square$ & \\
\hline Flood & $\square$ & $\square$ & $\square$ & $\square$ & $\square$ & \\
\hline Landslide/slip & $\square$ & $\square$ & $\square$ & $\square$ & $\square$ & \\
\hline Bushfire & $\square$ & $\square$ & $\square$ & $\square$ & $\square$ & \\
\hline Windstorm/gale & $\square$ & $\square$ & $\square$ & $\square$ & $\square$ & \\
\hline Cyclone & $\square$ & $\square$ & $\square$ & $\square$ & $\square$ & \\
\hline Tsunami & $\square$ & $\square$ & $\square$ & $\square$ & $\square$ & \\
\hline Drought & $\square$ & $\square$ & $\square$ & $\square$ & $\square$ & \\
\hline Volcanic ash-fall & $\square$ & $\square$ & $\square$ & $\square$ & $\square$ & \\
\hline Other: & $\square$ & $\square$ & $\square$ & $\square$ & $\square$ & \\
\hline
\end{tabular}

14. b. Please give location within city/ district and other details of work mentioned in 14.a.

\begin{tabular}{|l|l|}
\hline Type of work & Location and other details \\
\hline & \\
\hline & \\
\hline & \\
\hline & \\
\hline
\end{tabular}


15. a. Have any changes been made in location of significant institutions/services in your city/district in order to reduce the damage from following hazards?

\begin{tabular}{|c|c|c|c|c|c|c|c|c|c|c|}
\hline Hazards & $\begin{array}{c}\text { Not } \\
\text { Applicable }\end{array}$ & $\begin{array}{l}\text { Don't } \\
\text { know }\end{array}$ & $\begin{array}{c}\text { Council } \\
\text { offices }\end{array}$ & $\begin{array}{l}\text { CDM } \\
\text { office }\end{array}$ & $\begin{array}{c}\text { Hosp } \\
\text { ital }\end{array}$ & $\begin{array}{l}\text { Telecomm } \\
\text { unications }\end{array}$ & $\begin{array}{l}\text { Transport } \\
\text { Network }\end{array}$ & $\begin{array}{c}\text { Gas } \\
\text { supplies }\end{array}$ & $\begin{array}{c}\text { Electricity } \\
\text { supply }\end{array}$ & $\begin{array}{l}\text { Any } \\
\text { other }\end{array}$ \\
\hline Earthquake & $\square$ & $\square$ & $\square$ & $\square$ & $\square$ & $\square$ & $\square$ & $\square$ & $\square$ & \\
\hline Flood & $\square$ & $\square$ & $\square$ & $\square$ & $\square$ & $\square$ & $\square$ & $\square$ & $\square$ & \\
\hline Landslide/slip & $\square$ & $\square$ & $\square$ & $\square$ & $\square$ & $\square$ & $\square$ & $\square$ & $\square$ & \\
\hline Bushfire & $\square$ & $\square$ & $\square$ & $\square$ & $\square$ & $\square$ & $\square$ & $\square$ & $\square$ & \\
\hline Windstorm/gale & $\square$ & $\square$ & $\square$ & $\square$ & $\square$ & $\square$ & $\square$ & $\square$ & $\square$ & \\
\hline Cyclone & $\square$ & $\square$ & $\square$ & $\square$ & $\square$ & $\square$ & $\square$ & $\square$ & $\square$ & \\
\hline Tsunami & $\square$ & $\square$ & $\square$ & $\square$ & $\square$ & $\square$ & $\square$ & $\square$ & $\square$ & \\
\hline Drought & $\square$ & $\square$ & $\square$ & $\square$ & $\square$ & $\square$ & $\square$ & $\square$ & $\square$ & \\
\hline Volcanic ash-fall & $\square$ & $\square$ & $\square$ & $\square$ & $\square$ & $\square$ & $\square$ & $\square$ & $\square$ & \\
\hline Other: & $\square$ & $\square$ & $\square$ & $\square$ & $\square$ & $\square$ & $\square$ & $\square$ & $\square$ & \\
\hline
\end{tabular}

15. b. Please give location within city/district and other details of changes mentioned in 15.a.

\begin{tabular}{|l|l|}
\hline Changes made & Location and other details \\
\hline & \\
\hline & \\
\hline & \\
\hline & \\
\hline
\end{tabular}

16. a. Are there any alternative arrangements for significant institutions/services in city/district in case of following hazards occurrence?

\begin{tabular}{|l|c|c|c|c|c|c|c|c|c|c|}
\hline Hazards & $\begin{array}{c}\text { Not } \\
\text { Applicable }\end{array}$ & $\begin{array}{c}\text { Don't } \\
\text { know }\end{array}$ & $\begin{array}{c}\text { Council } \\
\text { offices }\end{array}$ & $\begin{array}{c}\text { CDM } \\
\text { office }\end{array}$ & $\begin{array}{c}\text { Hosp- } \\
\text { ital }\end{array}$ & $\begin{array}{c}\text { Telecomm } \\
\text { unications }\end{array}$ & $\begin{array}{c}\text { Transport } \\
\text { Network }\end{array}$ & $\begin{array}{c}\text { Gas } \\
\text { supplies }\end{array}$ & $\begin{array}{c}\text { Electricity } \\
\text { supply }\end{array}$ & $\begin{array}{c}\text { Any } \\
\text { other }\end{array}$ \\
\hline Earthquake & $\square$ & $\square$ & $\square$ & $\square$ & $\square$ & $\square$ & $\square$ & $\square$ & $\square$ & $\square$ \\
\hline Flood & $\square$ & $\square$ & $\square$ & $\square$ & $\square$ & $\square$ & $\square$ & $\square$ & $\square$ & $\square$ \\
\hline Landslide/slip & $\square$ & $\square$ & $\square$ & $\square$ & $\square$ & $\square$ & $\square$ & $\square$ & $\square$ & $\square$ \\
\hline Bushfire & $\square$ & $\square$ & $\square$ & $\square$ & $\square$ & $\square$ & $\square$ & $\square$ & $\square$ & $\square$ \\
\hline Windstorm/gale & $\square$ & $\square$ & $\square$ & $\square$ & $\square$ & $\square$ & $\square$ & $\square$ & $\square$ & $\square$ \\
\hline Cyclone & $\square$ & $\square$ & $\square$ & $\square$ & $\square$ & $\square$ & $\square$ & $\square$ & $\square$ & $\square$ \\
\hline Tsunami & $\square$ & $\square$ & $\square$ & $\square$ & $\square$ & $\square$ & $\square$ & $\square$ & $\square$ & $\square$ \\
\hline Drought & $\square$ & $\square$ & $\square$ & $\square$ & $\square$ & $\square$ & $\square$ & $\square$ & $\square$ & $\square$ \\
\hline Volcanic ash-fall & $\square$ & $\square$ & $\square$ & $\square$ & $\square$ & $\square$ & $\square$ & $\square$ & $\square$ & $\square$ \\
\hline Other: & $\square$ & $\square$ & $\square$ & $\square$ & $\square$ & $\square$ & $\square$ & $\square$ & $\square$ \\
\hline
\end{tabular}

16. b. Please give location within city/district and other details of alternative services mentioned in 16.a.

\begin{tabular}{|l|l|}
\hline Changes made & Location and other details \\
\hline & \\
\hline & \\
\hline & \\
\hline & \\
\hline
\end{tabular}


17. Has something been done to control or reduce the individual vulnerability against hazards?

\begin{tabular}{|l|l|}
\hline Hazards & \multicolumn{1}{|c|}{ Work done to control human vulnerability } \\
\hline Earthquake & \\
\hline Flood & \\
\hline Landslide/slip & \\
\hline Bushfire & \\
\hline Windstorm/gale & \\
\hline Cyclone & \\
\hline Tsunami & \\
\hline Drought & \\
\hline Volcanic ash-fall & \\
\hline Other: & \\
\hline
\end{tabular}

\section{Questions on Hazards Preparedness in the district}

18. Does the city/district have access to monitoring systems for the following?

\begin{tabular}{|l|c|c|c|c|c|c|}
\hline Hazards & $\begin{array}{c}\text { Not } \\
\text { Applicable }\end{array}$ & $\begin{array}{c}\text { Don't } \\
\text { know }\end{array}$ & $\begin{array}{c}\text { Hazard } \\
\text { occurrence }\end{array}$ & $\begin{array}{c}\text { Change in ground } \\
\text { conditions }\end{array}$ & Forecasting & Please specify the source \\
\hline Earthquake & $\square$ & $\square$ & $\square$ & $\square$ & $\square$ & \\
\hline Flood & $\square$ & $\square$ & $\square$ & $\square$ & $\square$ & \\
\hline Landslide/slip & $\square$ & $\square$ & $\square$ & $\square$ & $\square$ & \\
\hline Bushfire & $\square$ & $\square$ & $\square$ & $\square$ & $\square$ & \\
\hline Windstorm/gale & $\square$ & $\square$ & $\square$ & $\square$ & $\square$ & \\
\hline Cyclone & $\square$ & $\square$ & $\square$ & $\square$ & $\square$ & \\
\hline Tsunami & $\square$ & $\square$ & $\square$ & $\square$ & $\square$ & \\
\hline Drought & $\square$ & $\square$ & $\square$ & $\square$ & $\square$ & \\
\hline Volcanic ash-fall & $\square$ & $\square$ & $\square$ & $\square$ & $\square$ & \\
\hline Other: & $\square$ & $\square$ & $\square$ & $\square$ & $\square$ & \\
\hline
\end{tabular}

19. Are local people provided following information about hazards, vulnerability and response?

\begin{tabular}{|l|c|c|c|c|c|c|}
\hline Hazards & $\begin{array}{c}\text { Not } \\
\text { Applicable }\end{array}$ & $\begin{array}{c}\text { Don't } \\
\text { know }\end{array}$ & $\begin{array}{c}\text { Hazard } \\
\text { characteristics }\end{array}$ & $\begin{array}{c}\text { Their } \\
\text { Vulnerability }\end{array}$ & $\begin{array}{c}\text { How to } \\
\text { respond }\end{array}$ & Any other \\
\hline Earthquake & $\square$ & $\square$ & $\square$ & $\square$ & $\square$ & \\
\hline Flood & $\square$ & $\square$ & $\square$ & $\square$ & $\square$ & \\
\hline Landslide/slip & $\square$ & $\square$ & $\square$ & $\square$ & $\square$ & \\
\hline Bushfire & $\square$ & $\square$ & $\square$ & $\square$ & $\square$ & \\
\hline Windstorm/gale & $\square$ & $\square$ & $\square$ & $\square$ & $\square$ & \\
\hline Cyclone & $\square$ & $\square$ & $\square$ & $\square$ & $\square$ & \\
\hline Tsunami & $\square$ & $\square$ & $\square$ & $\square$ & $\square$ & \\
\hline Drought & $\square$ & $\square$ & $\square$ & $\square$ & $\square$ & \\
\hline Volcanic ash-fall & $\square$ & $\square$ & $\square$ & $\square$ & $\square$ & \\
\hline Other: & $\square$ & $\square$ & $\square$ & $\square$ & $\square$ & \\
\hline
\end{tabular}


20. What percentage of population do you think is aware of these hazards?

\begin{tabular}{|l|c|c|c|c|c|c|c|c|}
\hline Hazards & $\begin{array}{c}\text { Not } \\
\text { Applicable }\end{array}$ & $\begin{array}{c}\text { Don't } \\
\text { know }\end{array}$ & None & $\begin{array}{c}\text { Less than } \\
\mathbf{2 0 \%}\end{array}$ & $\mathbf{2 1 - 4 0 \%}$ & $\mathbf{4 1 - 6 0 \%}$ & $\mathbf{6 1 - 8 0 \%}$ & $\mathbf{8 1 - 1 0 0 \%}$ \\
\hline Earthquake & $\square$ & $\square$ & $\square$ & $\square$ & $\square$ & $\square$ & $\square$ & $\square$ \\
\hline Flood & $\square$ & $\square$ & $\square$ & $\square$ & $\square$ & $\square$ & $\square$ & $\square$ \\
\hline Landslide/slip & $\square$ & $\square$ & $\square$ & $\square$ & $\square$ & $\square$ & $\square$ & $\square$ \\
\hline Bushfire & $\square$ & $\square$ & $\square$ & $\square$ & $\square$ & $\square$ & $\square$ & $\square$ \\
\hline Windstorm/gale & $\square$ & $\square$ & $\square$ & $\square$ & $\square$ & $\square$ & $\square$ & $\square$ \\
\hline Cyclone & $\square$ & $\square$ & $\square$ & $\square$ & $\square$ & $\square$ & $\square$ & $\square$ \\
\hline Tsunami & $\square$ & $\square$ & $\square$ & $\square$ & $\square$ & $\square$ & $\square$ & $\square$ \\
\hline Drought & $\square$ & $\square$ & $\square$ & $\square$ & $\square$ & $\square$ & $\square$ & $\square$ \\
\hline Volcanic ash-fall & $\square$ & $\square$ & $\square$ & $\square$ & $\square$ & $\square$ & $\square$ & $\square$ \\
\hline Other: & $\square$ & $\square$ & $\square$ & $\square$ & $\square$ & $\square$ & $\square$ & $\square$ \\
\hline
\end{tabular}

21. What proportion of local people do you think is prepared to cope with these hazards?

\begin{tabular}{|l|c|c|c|c|c|c|c|c|}
\hline Hazards & $\begin{array}{c}\text { Not } \\
\text { Applicable }\end{array}$ & $\begin{array}{c}\text { Don't } \\
\text { know }\end{array}$ & None & $\begin{array}{c}\text { Less than } \\
\mathbf{2 0 \%}\end{array}$ & $\mathbf{2 1 - 4 0 \%}$ & $\mathbf{4 1 - 6 0 \%}$ & $\mathbf{6 1 - 8 0 \%}$ & $\mathbf{8 1 - 1 0 0 \%}$ \\
\hline Earthquake & $\square$ & $\square$ & $\square$ & $\square$ & $\square$ & $\square$ & $\square$ & $\square$ \\
\hline Flood & $\square$ & $\square$ & $\square$ & $\square$ & $\square$ & $\square$ & $\square$ & $\square$ \\
\hline Landslide/slip & $\square$ & $\square$ & $\square$ & $\square$ & $\square$ & $\square$ & $\square$ & $\square$ \\
\hline Bushfire & $\square$ & $\square$ & $\square$ & $\square$ & $\square$ & $\square$ & $\square$ & $\square$ \\
\hline Windstorm/gale & $\square$ & $\square$ & $\square$ & $\square$ & $\square$ & $\square$ & $\square$ & $\square$ \\
\hline Cyclone & $\square$ & $\square$ & $\square$ & $\square$ & $\square$ & $\square$ & $\square$ & $\square$ \\
\hline Tsunami & $\square$ & $\square$ & $\square$ & $\square$ & $\square$ & $\square$ & $\square$ & $\square$ \\
\hline Drought & $\square$ & $\square$ & $\square$ & $\square$ & $\square$ & $\square$ & $\square$ & $\square$ \\
\hline Volcanic ash-fall & $\square$ & $\square$ & $\square$ & $\square$ & $\square$ & $\square$ & $\square$ & $\square$ \\
\hline Other: & $\square$ & $\square$ & $\square$ & $\square$ & $\square$ & $\square$ & $\square$ & $\square$ \\
\hline
\end{tabular}

22. To what extent do you think local people are prepared to cope with these hazards?

\begin{tabular}{|l|c|c|c|c|c|c|}
\hline Hazards & $\begin{array}{c}\text { Not } \\
\text { Applicable }\end{array}$ & Don't know & $\begin{array}{c}\text { Not at all } \\
\text { Prepared }\end{array}$ & Poorly Prepared & $\begin{array}{c}\text { Moderately } \\
\text { Prepared }\end{array}$ & Well Prepared \\
\hline Earthquake & $\square$ & $\square$ & $\square$ & $\square$ & $\square$ & $\square$ \\
\hline Flood & $\square$ & $\square$ & $\square$ & $\square$ & $\square$ & $\square$ \\
\hline Landslide/slip & $\square$ & $\square$ & $\square$ & $\square$ & $\square$ & $\square$ \\
\hline Bushfire & $\square$ & $\square$ & $\square$ & $\square$ & $\square$ & $\square$ \\
\hline Windstorm/gale & $\square$ & $\square$ & $\square$ & $\square$ & $\square$ & $\square$ \\
\hline Cyclone & $\square$ & $\square$ & $\square$ & $\square$ & $\square$ & $\square$ \\
\hline Tsunami & $\square$ & $\square$ & $\square$ & $\square$ & $\square$ & $\square$ \\
\hline Drought & $\square$ & $\square$ & $\square$ & $\square$ & $\square$ & $\square$ \\
\hline Volcanic ash-fall & $\square$ & $\square$ & $\square$ & $\square$ & $\square$ & $\square$ \\
\hline Other: & $\square$ & $\square$ & $\square$ & $\square$ & $\square$ & $\square$ \\
\hline
\end{tabular}


23. To what extent is your organisation prepared to deal with major emergency in the district?

\begin{tabular}{|l|c|c|c|c|c|c|}
\hline Hazards & $\begin{array}{c}\text { Not } \\
\text { Applicable }\end{array}$ & Don't know & $\begin{array}{c}\text { Not at all } \\
\text { Prepared }\end{array}$ & Poorly Prepared & $\begin{array}{c}\text { Moderately } \\
\text { Prepared }\end{array}$ & Well Prepared \\
\hline Earthquake & $\square$ & $\square$ & $\square$ & $\square$ & $\square$ & $\square$ \\
\hline Flood & $\square$ & $\square$ & $\square$ & $\square$ & $\square$ & $\square$ \\
\hline Landslide/slip & $\square$ & $\square$ & $\square$ & $\square$ & $\square$ & $\square$ \\
\hline Bushfire & $\square$ & $\square$ & $\square$ & $\square$ & $\square$ & $\square$ \\
\hline Windstorm/gale & $\square$ & $\square$ & $\square$ & $\square$ & $\square$ & $\square$ \\
\hline Cyclone & $\square$ & $\square$ & $\square$ & $\square$ & $\square$ & $\square$ \\
\hline Tsunami & $\square$ & $\square$ & $\square$ & $\square$ & $\square$ & $\square$ \\
\hline Drought & $\square$ & $\square$ & $\square$ & $\square$ & $\square$ & $\square$ \\
\hline Volcanic ash-fall & $\square$ & $\square$ & $\square$ & $\square$ & $\square$ & $\square$ \\
\hline Other: & $\square$ & $\square$ & $\square$ & $\square$ & $\square$ \\
\hline
\end{tabular}

24. If your own organisation were affected by the hazards, how well prepared would it be?

\begin{tabular}{|l|c|c|c|c|c|c|}
\hline Hazards & $\begin{array}{c}\text { Not } \\
\text { Applicable }\end{array}$ & $\begin{array}{c}\text { Don't } \\
\text { know }\end{array}$ & Not prepared & $\begin{array}{c}\text { Poorly } \\
\text { Prepared }\end{array}$ & $\begin{array}{c}\text { Moderately } \\
\text { Prepared }\end{array}$ & Well Prepared \\
\hline Earthquake & $\square$ & $\square$ & $\square$ & $\square$ & $\square$ & $\square$ \\
\hline Flood & $\square$ & $\square$ & $\square$ & $\square$ & $\square$ & $\square$ \\
\hline Landslide/slip & $\square$ & $\square$ & $\square$ & $\square$ & $\square$ & $\square$ \\
\hline Bushfire & $\square$ & $\square$ & $\square$ & $\square$ & $\square$ & $\square$ \\
\hline Windstorm/gale & $\square$ & $\square$ & $\square$ & $\square$ & $\square$ & $\square$ \\
\hline Cyclone & $\square$ & $\square$ & $\square$ & $\square$ & $\square$ & $\square$ \\
\hline Tsunami & $\square$ & $\square$ & $\square$ & $\square$ & $\square$ & $\square$ \\
\hline Drought & $\square$ & $\square$ & $\square$ & $\square$ & $\square$ & $\square$ \\
\hline Volcanic ash-fall & $\square$ & $\square$ & $\square$ & $\square$ & $\square$ & $\square$ \\
\hline Other: & $\square$ & $\square$ & $\square$ & $\square$ & $\square$ & $\square$ \\
\hline
\end{tabular}

25. What are the major barriers to following forms of preparedness against natural hazards?

\begin{tabular}{|l|c|c|c|c|c|c|c|c|c|}
\hline Hazards & $\begin{array}{c}\text { Don't } \\
\text { know }\end{array}$ & $\begin{array}{c}\text { Unawar } \\
\text { eness }\end{array}$ & $\begin{array}{c}\text { Unwilling } \\
\text { ness }\end{array}$ & $\begin{array}{c}\text { Lack of } \\
\text { knowledge }\end{array}$ & $\begin{array}{c}\text { Financial } \\
\text { problems }\end{array}$ & $\begin{array}{c}\text { Lack of } \\
\text { staff }\end{array}$ & $\begin{array}{c}\text { Commun } \\
\text { ication }\end{array}$ & $\begin{array}{c}\text { Lack of } \\
\text { coordination }\end{array}$ & $\begin{array}{c}\text { Any other } \\
\text { please specify }\end{array}$ \\
\hline Public awareness & $\square$ & $\square$ & $\square$ & $\square$ & $\square$ & $\square$ & $\square$ & $\square$ & $\square$ \\
\hline Public Preparedness & $\square$ & $\square$ & $\square$ & $\square$ & $\square$ & $\square$ & $\square$ & $\square$ & \\
\hline $\begin{array}{l}\text { Your organisation } \\
\text { preparedness to deal } \\
\text { with major hazard in } \\
\text { district }\end{array}$ & $\square$ & $\square$ & $\square$ & $\square$ & $\square$ & $\square$ & $\square$ & $\square$ & \\
\hline $\begin{array}{l}\text { Your organisation } \\
\text { preparedness to deal } \\
\text { with hazard in your } \\
\text { organisation }\end{array}$ & $\square$ & $\square$ & $\square$ & $\square$ & $\square$ & $\square$ & $\square$ & $\square$ & \\
\hline
\end{tabular}

26. Does the district have appropriate warning system? $\square$ Yes $\square$ No

27. What is the mode of warning in the district? $\square$ TV $\square$ Radio $\square$ Siren $\square$ Any other

28. Are different levels of warnings issued in case of emergency? $\square$ Yes $\square$ No 
If yes then please specify the type: $\square$ alert $\square$ evacuation $\quad \square$ early warning

29. If a siren is used then what would be the main purpose of warning?

$\square$ alert $\square$ evacuation $\square$ early warning $\square$ Any other

30. How would people know that they have to switch on TV or radio?

31. Does the district have any of the following plans to deal with following hazards?

\begin{tabular}{|l|c|c|c|c|c|}
\hline \multicolumn{1}{|c|}{ Hazards } & $\begin{array}{c}\text { Civil defence } \\
\text { plan }\end{array}$ & $\begin{array}{c}\text { Evacuation } \\
\text { plan }\end{array}$ & $\begin{array}{c}\text { Hazard } \\
\text { specific plan }\end{array}$ & $\begin{array}{c}\text { Recovery } \\
\text { plan }\end{array}$ & Any other please specify \\
\hline Earthquake & $\square$ & $\square$ & $\square$ & $\square$ & \\
\hline Flood & $\square$ & $\square$ & $\square$ & $\square$ & \\
\hline Landslide/slip & $\square$ & $\square$ & $\square$ & $\square$ & \\
\hline Bushfire & $\square$ & $\square$ & $\square$ & $\square$ & \\
\hline Windstorm/gale & $\square$ & $\square$ & $\square$ & $\square$ & \\
\hline Cyclone & $\square$ & $\square$ & $\square$ & $\square$ & \\
\hline Tsunami & $\square$ & $\square$ & $\square$ & $\square$ & \\
\hline Drought & $\square$ & $\square$ & $\square$ & $\square$ & \\
\hline Volcanic ash-fall & $\square$ & $\square$ & $\square$ & $\square$ & \\
\hline Other: & $\square$ & $\square$ & $\square$ & $\square$ & \\
\hline
\end{tabular}

32. Do the following hazard plans for district specifically consider the vulnerability of people?

\begin{tabular}{|l|c|c|c|c|c|}
\hline Vulnerable people & $\begin{array}{c}\text { Civil defence } \\
\text { plan }\end{array}$ & $\begin{array}{c}\text { Evacuation } \\
\text { plan }\end{array}$ & $\begin{array}{c}\text { Hazard } \\
\text { specific plan }\end{array}$ & $\begin{array}{c}\text { Recovery } \\
\text { plan }\end{array}$ & $\begin{array}{c}\text { Please specify the implications } \\
\text { made for them }\end{array}$ \\
\hline Children & $\square$ & $\square$ & $\square$ & $\square$ & \\
\hline Women & $\square$ & $\square$ & $\square$ & $\square$ & \\
\hline Old & $\square$ & $\square$ & $\square$ & $\square$ & \\
\hline Disabled & $\square$ & $\square$ & $\square$ & $\square$ & \\
\hline Tourists & $\square$ & $\square$ & $\square$ & $\square$ & \\
\hline New Immigrants & $\square$ & $\square$ & $\square$ & $\square$ & \\
\hline Other: & & & & & \\
\hline
\end{tabular}

33. Does your organisation have any of the following plans for safety of its own employees?

\begin{tabular}{|l|c|c|c|c|c|l|}
\hline \multicolumn{1}{|c|}{ Hazards } & $\begin{array}{c}\text { Emergency mgt } \\
\text { plan }\end{array}$ & $\begin{array}{c}\text { Evacuation } \\
\text { plan }\end{array}$ & $\begin{array}{c}\text { Hazard } \\
\text { specific plan }\end{array}$ & Survival Kit & $\begin{array}{c}\text { Recovery } \\
\text { plan }\end{array}$ & $\begin{array}{c}\text { Any other please } \\
\text { specify }\end{array}$ \\
\hline Earthquake & $\square$ & $\square$ & $\square$ & $\square$ & $\square$ & \\
\hline Flood & $\square$ & $\square$ & $\square$ & $\square$ & $\square$ & \\
\hline Landslide/slip & $\square$ & $\square$ & $\square$ & $\square$ & $\square$ & \\
\hline Bushfire & $\square$ & $\square$ & $\square$ & $\square$ & $\square$ & \\
\hline Windstorm/gale & $\square$ & $\square$ & $\square$ & $\square$ & $\square$ & \\
\hline Cyclone & $\square$ & $\square$ & $\square$ & $\square$ & $\square$ & \\
\hline Tsunami & $\square$ & $\square$ & $\square$ & $\square$ & $\square$ & \\
\hline Drought & $\square$ & $\square$ & $\square$ & $\square$ & $\square$ & \\
\hline Volcanic ash-fall & $\square$ & $\square$ & $\square$ & $\square$ & $\square$ & \\
\hline Other: & $\square$ & $\square$ & $\square$ & $\square$ & $\square$ & \\
\hline
\end{tabular}


34. Do the following hazard management plans/survival kit of the organisation specifically consider vulnerability of employees and visitors?

\begin{tabular}{|l|c|c|c|c|c|c|}
\hline $\begin{array}{l}\text { Vulnerable } \\
\text { people }\end{array}$ & $\begin{array}{c}\text { Emergency } \\
\text { mgt plan }\end{array}$ & $\begin{array}{c}\text { Evacuation } \\
\text { plan }\end{array}$ & $\begin{array}{c}\text { Hazard } \\
\text { specific plan }\end{array}$ & $\begin{array}{c}\text { Survival } \\
\text { kit }\end{array}$ & $\begin{array}{c}\text { Survival } \\
\text { kit }\end{array}$ & $\begin{array}{c}\text { Please specify the provisions } \\
\text { made for them }\end{array}$ \\
\hline Women & $\square$ & $\square$ & $\square$ & $\square$ & $\square$ & \\
\hline Old & $\square$ & $\square$ & $\square$ & $\square$ & $\square$ & \\
\hline Disabled & $\square$ & $\square$ & $\square$ & $\square$ & $\square$ & \\
\hline Visitors & $\square$ & $\square$ & $\square$ & $\square$ & $\square$ & \\
\hline Other: & $\square$ & $\square$ & $\square$ & $\square$ & $\square$ & \\
\hline
\end{tabular}

35. Please provide following details about civil defence community emergency centres.

\begin{tabular}{|l|l|l|l|}
\hline Their role & Number & $\begin{array}{c}\text { Capacity to } \\
\text { accommodate people }\end{array}$ & Locations \\
\hline & & & \\
\cline { 3 - 4 } & & & \\
\cline { 3 - 4 } & & & \\
\hline
\end{tabular}

36. a. Has any disaster scenario been conducted in the district for any hazard? $\square$ Yes $\square$ No

b. Name of disaster:

c. How many times it has been carried out in past 5 years?

37. a. Are the personnel involved in hazard management trained to deal with hazards? $\square$ Yes $\square$ No

b. If yes then how often do you provide them training?

38. a. Does the district have stocked emergency resources to meet any disaster situation? $\square$ Yes $\square$ No

Please give the following information

\begin{tabular}{|l|l|l|l|}
\hline Materials stocked & $\begin{array}{l}\text { Number of } \\
\text { people it can } \\
\text { sustain }\end{array}$ & $\begin{array}{l}\text { Number of } \\
\text { days it can } \\
\text { sustain }\end{array}$ & $\begin{array}{l}\text { Name of hazard } \\
\text { taken in to } \\
\text { consideration }\end{array}$ \\
\hline$y$ & & & \\
\hline
\end{tabular}

39. a. Have you experienced any centrally declared emergency or disaster? $\square$ Yes $\square$ No

b. Can you enlist the following details about the district/city emergencies occurred in past 10 years? Please use extra paper if required.

\begin{tabular}{|l|l|l|l|l|}
\hline Date & Name of hazard & Area affected & People affected & Damage occurred \\
\hline & & & & \\
\hline & & & & \\
\hline & & & & \\
\hline & & & & \\
\hline
\end{tabular}


c. Please give following information about the most recent and major emergency you experienced:

Date: Location:

Damage:

People affected:

Any Specific Cause for damage

Your response

Lesson learnt

Any other comment

\section{Details of the organisation}

\begin{tabular}{|l|l|l|l|}
\hline Name: & \multicolumn{2}{|l|}{} \\
\hline Address: & \multicolumn{3}{|l|}{} \\
\hline Role concerning hazard: & \multicolumn{3}{|l|}{} \\
\hline Year of establishment: & Number of trained staff at a time: & \\
\hline Number of staff: & & Number of operating shifts: & \\
\hline Work schedule: & &
\end{tabular}

\section{Details of the organisation's building}

\begin{tabular}{|c|c|}
\hline Year of establishment: & Number of floors: \\
\hline $\begin{array}{l}\text { Number of fire } \\
\text { extinguishers: }\end{array}$ & $\begin{array}{l}\text { Number of emergency } \\
\text { exits: }\end{array}$ \\
\hline $\begin{array}{l}\text { Building is resistant to } \\
\text { hazards: }\end{array}$ & $\begin{array}{l}\square \text { Earthquake } \square \text { Flood } \square \text { Landslide/slip } \square \text { Bushfire } \square \text { Volcanic ash fall } \\
\square \text { Cyclone } \square \text { Tsunami } \square \text { Drought } \square \text { Windstorm/gale } \square:\end{array}$ \\
\hline $\begin{array}{l}\text { Building has suffered } \\
\text { following hazard damage in } \\
\text { past }\end{array}$ & $\begin{array}{l}\square \text { Earthquake } \square \text { Flood } \square \text { Landslide/slip } \square \text { Bushfire } \square \text { Volcanic ash fall } \\
\square \text { Cyclone } \square \text { Tsunami } \square \text { Drought } \square \text { Windstorm/gale } \square \text { : }\end{array}$ \\
\hline $\begin{array}{l}\text { Changes have been made } \\
\text { in the building to cope with } \\
\text { hazard }\end{array}$ & $\begin{array}{l}\square \text { Earthquake } \\
\square \text { Flood } \\
\square \text { Landslide/slip } \\
\square \text { Bushfire } \\
\square \text { Volcanic ash fall } \\
\square \text { Cyclone } \\
\square \text { Tsunami } \\
\square \text { Drought } \\
\square \text { Windstorm/gale } \\
\square \text { Other: }\end{array}$ \\
\hline
\end{tabular}

Any comment that you think would be useful for the research:

Thank you for your time and efforts to fill the questionmaire. 
Appendix-3

Questionnaire: District Planners

\section{Questions on Hazards and their characteristics in the district}

1. Which are the common natural hazards (damaging events) in your area of jurisdiction?

2. Which hazard do you think is the most damaging for your district and why?

3. How severe are the following hazards in terms of magnitude in your city/district? Please encircle the appropriate number for each hazard.

\begin{tabular}{|l|c|c|c|c|c|c|}
\hline Hazards & $\begin{array}{c}\text { Not } \\
\text { Applicable }\end{array}$ & $\begin{array}{c}\text { Don't } \\
\text { know }\end{array}$ & $\begin{array}{c}\text { Not } \\
\text { Problematic }\end{array}$ & Problematic & $\begin{array}{c}\text { Highly } \\
\text { Problematic }\end{array}$ & Most serious \\
\hline Earthquake & $\square$ & $\square$ & $\square$ & $\square$ & $\square$ & $\square$ \\
\hline Flood & $\square$ & $\square$ & $\square$ & $\square$ & $\square$ & $\square$ \\
\hline Landslide/slip & $\square$ & $\square$ & $\square$ & $\square$ & $\square$ & $\square$ \\
\hline Bushfire & $\square$ & $\square$ & $\square$ & $\square$ & $\square$ & $\square$ \\
\hline Windstorm/gale & $\square$ & $\square$ & $\square$ & $\square$ & $\square$ & $\square$ \\
\hline Cyclone & $\square$ & $\square$ & $\square$ & $\square$ & $\square$ & $\square$ \\
\hline Tsunami & $\square$ & $\square$ & $\square$ & $\square$ & $\square$ & $\square$ \\
\hline Drought & $\square$ & $\square$ & $\square$ & $\square$ & $\square$ & $\square$ \\
\hline Volcanic ash-fall & $\square$ & $\square$ & $\square$ & $\square$ & $\square$ & $\square$ \\
\hline Other: & $\square$ & $\square$ & $\square$ & $\square$ & & $\square$ \\
\hline
\end{tabular}

4. How frequently do the following hazards cause damage in your city/district? Please encircle appropriate number for each hazard.

\begin{tabular}{|c|c|c|c|c|c|c|c|c|}
\hline Hazards & $\begin{array}{c}\text { Not } \\
\text { Applicable }\end{array}$ & $\begin{array}{l}\text { Don't } \\
\text { know }\end{array}$ & $\begin{array}{c}\text { Once in a } \\
\text { month }\end{array}$ & $\begin{array}{c}\text { Once in a } \\
\text { year }\end{array}$ & $\begin{array}{l}\text { Once in } \\
5 \text { years }\end{array}$ & $\begin{array}{l}\text { Once in } \\
10 \text { years }\end{array}$ & $\begin{array}{c}\text { Once in } 20 \\
\text { years }\end{array}$ & $\begin{array}{l}\text { Any other } \\
\text { Please specify }\end{array}$ \\
\hline Earthquake & $\square$ & $\square$ & $\square$ & $\square$ & $\square$ & $\square$ & $\square$ & \\
\hline Flood & $\square$ & $\square$ & $\square$ & $\square$ & $\square$ & $\square$ & $\square$ & \\
\hline Landslide/slip & $\square$ & $\square$ & $\square$ & $\square$ & $\square$ & $\square$ & $\square$ & \\
\hline Bushfire & $\square$ & $\square$ & $\square$ & $\square$ & $\square$ & $\square$ & $\square$ & \\
\hline Windstorm/gale & $\square$ & $\square$ & $\square$ & $\square$ & $\square$ & $\square$ & $\square$ & \\
\hline Cyclone & $\square$ & $\square$ & $\square$ & $\square$ & $\square$ & $\square$ & $\square$ & \\
\hline Tsunami & $\square$ & $\square$ & $\square$ & $\square$ & $\square$ & $\square$ & $\square$ & \\
\hline Drought & $\square$ & $\square$ & $\square$ & $\square$ & $\square$ & $\square$ & $\square$ & \\
\hline Volcanic ash-fall & $\square$ & $\square$ & $\square$ & $\square$ & $\square$ & $\square$ & $\square$ & \\
\hline Other: & $\square$ & $\square$ & $\square$ & $\square$ & $\square$ & $\square$ & $\square$ & \\
\hline
\end{tabular}


5. How do you see the following hazards as potential danger for your city/district?

\begin{tabular}{|c|c|c|c|c|c|c|c|c|}
\hline Hazards & $\begin{array}{c}\text { Not } \\
\text { Applicable }\end{array}$ & $\begin{array}{l}\text { Don't } \\
\text { know }\end{array}$ & $\begin{array}{c}\text { Not } \\
\text { harmful }\end{array}$ & $\begin{array}{c}\text { Minor } \\
\text { damage }\end{array}$ & $\begin{array}{c}\text { Significant } \\
\text { damage }\end{array}$ & $\begin{array}{c}\text { Injuries to } \\
\text { people }\end{array}$ & $\begin{array}{c}\text { Life } \\
\text { threatening }\end{array}$ & $\begin{array}{c}\text { Total } \\
\text { destruction }\end{array}$ \\
\hline Earthquake & $\square$ & $\square$ & $\square$ & $\square$ & $\square$ & $\square$ & $\square$ & $\square$ \\
\hline Flood & $\square$ & $\square$ & $\square$ & $\square$ & $\square$ & $\square$ & $\square$ & $\square$ \\
\hline Landslide/slip & $\square$ & $\square$ & $\square$ & $\square$ & $\square$ & $\square$ & $\square$ & $\square$ \\
\hline Bushfire & $\square$ & $\square$ & $\square$ & $\square$ & $\square$ & $\square$ & $\square$ & $\square$ \\
\hline Windstorm/gale & $\square$ & $\square$ & $\square$ & $\square$ & $\square$ & $\square$ & $\square$ & $\square$ \\
\hline Cyclone & $\square$ & $\square$ & $\square$ & $\square$ & $\square$ & $\square$ & $\square$ & $\square$ \\
\hline Tsunami & $\square$ & $\square$ & $\square$ & $\square$ & $\square$ & $\square$ & $\square$ & $\square$ \\
\hline Drought & $\square$ & $\square$ & $\square$ & $\square$ & $\square$ & $\square$ & $\square$ & $\square$ \\
\hline Volcanic ash-fall & $\square$ & $\square$ & $\square$ & $\square$ & $\square$ & $\square$ & $\square$ & $\square$ \\
\hline Other: & $\square$ & $\square$ & $\square$ & $\square$ & $\square$ & $\square$ & $\square$ & $\square$ \\
\hline
\end{tabular}

6. How near in future do you see a major hazard (damaging event) in your city/district?

\begin{tabular}{|l|c|c|c|c|c|c|c|c|c|}
\hline Hazards & $\begin{array}{c}\text { Not } \\
\text { Applicable }\end{array}$ & $\begin{array}{c}\text { Don't } \\
\text { know }\end{array}$ & $\begin{array}{c}\text { Don't } \\
\text { see }\end{array}$ & $\begin{array}{c}\text { Within a } \\
\text { month }\end{array}$ & $\begin{array}{c}\text { Within } \\
\text { a year }\end{array}$ & $\begin{array}{c}\text { Within } \\
\text { 2-5 years }\end{array}$ & $\begin{array}{c}\text { Within } \\
\text { 6-10 years }\end{array}$ & $\begin{array}{c}\text { Within 10- } \\
\text { 20 years }\end{array}$ & $\begin{array}{c}\text { Beyond } \\
\text { 20 years }\end{array}$ \\
\hline Earthquake & $\square$ & $\square$ & $\square$ & $\square$ & $\square$ & $\square$ & $\square$ & $\square$ & $\square$ \\
\hline Flood & $\square$ & $\square$ & $\square$ & $\square$ & $\square$ & $\square$ & $\square$ & $\square$ & $\square$ \\
\hline Landslide/slip & $\square$ & $\square$ & $\square$ & $\square$ & $\square$ & $\square$ & $\square$ & $\square$ & $\square$ \\
\hline Bushfire & $\square$ & $\square$ & $\square$ & $\square$ & $\square$ & $\square$ & $\square$ & $\square$ & $\square$ \\
\hline Windstorm/gale & $\square$ & $\square$ & $\square$ & $\square$ & $\square$ & $\square$ & $\square$ & $\square$ & $\square$ \\
\hline Cyclone & $\square$ & $\square$ & $\square$ & $\square$ & $\square$ & $\square$ & $\square$ & $\square$ & $\square$ \\
\hline Tsunami & $\square$ & $\square$ & $\square$ & $\square$ & $\square$ & $\square$ & $\square$ & $\square$ & $\square$ \\
\hline Drought & $\square$ & $\square$ & $\square$ & $\square$ & $\square$ & $\square$ & $\square$ & $\square$ & $\square$ \\
\hline Volcanic ash-fall & $\square$ & $\square$ & $\square$ & $\square$ & $\square$ & $\square$ & $\square$ & $\square$ & $\square$ \\
\hline Other: & $\square$ & $\square$ & $\square$ & $\square$ & $\square$ & $\square$ & $\square$ & $\square$ & $\square$ \\
\hline
\end{tabular}

7. Which areas/localities in your city/district council do you think are most likely to be affected by following hazards and why?

\begin{tabular}{|l|l|l|}
\hline \multicolumn{1}{|c|}{ Hazards } & \multicolumn{1}{c|}{ Most affected areas Reason } \\
\hline Earthquake & & \\
\hline Flood & & \\
\hline Landslide/slip & & \\
\hline Bushfire & & \\
\hline Windstorm/gale & & \\
\hline Cyclone & & \\
\hline Tsunami & & \\
\hline Drought & & \\
\hline Volcanic ash-fall & & \\
\hline Other: & & \\
\hline
\end{tabular}


8. Which areas/localities in your city/district council do you think are least likely to be affected by following hazards and why?

\begin{tabular}{|l|l|l|}
\hline \multicolumn{1}{|c|}{ Hazards } & \multicolumn{1}{c|}{ Least affected areas Reason } \\
\hline Earthquake & & \\
\hline Flood & & \\
\hline Landslide/slip & & \\
\hline Bushfire & & \\
\hline Windstorm/gale & & \\
\hline Cyclone & & \\
\hline Tsunami & & \\
\hline Drought & & \\
\hline Volcanic ash-fall & & \\
\hline Other: & & \\
\hline
\end{tabular}

9. How often your district quarter has responded to following hazards?

\begin{tabular}{|l|c|c|c|c|c|c|c|c|c|}
\hline Hazards & $\begin{array}{c}\text { Not } \\
\text { Applicable }\end{array}$ & $\begin{array}{c}\text { Don't } \\
\text { know }\end{array}$ & $\begin{array}{c}\text { Not } \\
\text { asked }\end{array}$ & $\begin{array}{c}\text { Within a } \\
\text { month }\end{array}$ & $\begin{array}{c}\text { Within } \\
\text { a year }\end{array}$ & $\begin{array}{c}\text { Within } \\
\text { 2-5 years }\end{array}$ & $\begin{array}{c}\text { Within } \\
\text { 6-10 years }\end{array}$ & $\begin{array}{c}\text { Within 10-20 } \\
\text { years }\end{array}$ & $\begin{array}{l}\text { Any other } \\
\text { Please specify }\end{array}$ \\
\hline Earthquake & $\square$ & $\square$ & $\square$ & $\square$ & $\square$ & $\square$ & $\square$ & $\square$ & \\
\hline Flood & $\square$ & $\square$ & $\square$ & $\square$ & $\square$ & $\square$ & $\square$ & $\square$ & $\square$ \\
\hline Landslide/slip & $\square$ & $\square$ & $\square$ & $\square$ & $\square$ & $\square$ & $\square$ & $\square$ & $\square$ \\
\hline Bushfire & $\square$ & $\square$ & $\square$ & $\square$ & $\square$ & $\square$ & $\square$ & $\square$ & $\square$ \\
\hline Windstorm/gale & $\square$ & $\square$ & $\square$ & $\square$ & $\square$ & $\square$ & $\square$ & $\square$ & $\square$ \\
\hline Cyclone & $\square$ & $\square$ & $\square$ & $\square$ & $\square$ & $\square$ & $\square$ & $\square$ & $\square$ \\
\hline Tsunami & $\square$ & $\square$ & $\square$ & $\square$ & $\square$ & $\square$ & $\square$ & $\square$ & $\square$ \\
\hline Drought & $\square$ & $\square$ & $\square$ & $\square$ & $\square$ & $\square$ & $\square$ & $\square$ & $\square$ \\
\hline Volcanic ash-fall & $\square$ & $\square$ & $\square$ & $\square$ & $\square$ & $\square$ & $\square$ & $\square$ & $\square$ \\
\hline Other: & $\square$ & $\square$ & $\square$ & $\square$ & $\square$ & $\square$ & $\square$ & $\square$ \\
\hline
\end{tabular}

10. Who do you think are the most vulnerable group to hazards in your community and why?

Questions on Hazards reduction in the district:

11. To what extent do you think that potential damage can be reduced for these hazards?

\begin{tabular}{|l|c|c|c|c|c|c|c|c|}
\hline Hazards & $\begin{array}{c}\text { Not } \\
\text { Applicable }\end{array}$ & $\begin{array}{c}\text { Don't } \\
\text { know }\end{array}$ & $\begin{array}{c}\text { Not } \\
\text { possible }\end{array}$ & $\begin{array}{c}\text { Less than } \\
\mathbf{2 0 \%}\end{array}$ & $\mathbf{2 1 - 4 0 \%}$ & $\mathbf{4 1 - 6 0 \%}$ & $\mathbf{6 1 - 8 0 \%}$ & $\mathbf{8 1 - 1 0 0 \%}$ \\
\hline Earthquake & $\square$ & $\square$ & $\square$ & $\square$ & $\square$ & $\square$ & $\square$ & $\square$ \\
\hline Flood & $\square$ & $\square$ & $\square$ & $\square$ & $\square$ & $\square$ & $\square$ & $\square$ \\
\hline Landslide/slip & $\square$ & $\square$ & $\square$ & $\square$ & $\square$ & $\square$ & $\square$ & $\square$ \\
\hline Bushfire & $\square$ & $\square$ & $\square$ & $\square$ & $\square$ & $\square$ & $\square$ & $\square$ \\
\hline Windstorm/gale & $\square$ & $\square$ & $\square$ & $\square$ & $\square$ & $\square$ & $\square$ & $\square$ \\
\hline Cyclone & $\square$ & $\square$ & $\square$ & $\square$ & $\square$ & $\square$ & $\square$ & $\square$ \\
\hline Tsunami & $\square$ & $\square$ & $\square$ & $\square$ & $\square$ & $\square$ & $\square$ & $\square$ \\
\hline Drought & $\square$ & $\square$ & $\square$ & $\square$ & $\square$ & $\square$ & $\square$ & $\square$ \\
\hline Volcanic ash-fall & $\square$ & $\square$ & $\square$ & $\square$ & $\square$ & $\square$ & $\square$ & $\square$ \\
\hline Other: & $\square$ & $\square$ & $\square$ & $\square$ & $\square$ & $\square$ & $\square$ & $\square$ \\
\hline
\end{tabular}


12. What are the major barriers to reduce the potential danger posed by hazards?

\begin{tabular}{|l|c|c|c|c|c|c|c|c|}
\hline Hazards & $\begin{array}{c}\text { Not } \\
\text { Applicable }\end{array}$ & $\begin{array}{c}\text { Don't } \\
\text { know }\end{array}$ & $\begin{array}{c}\text { Lack of } \\
\text { knowledge }\end{array}$ & $\begin{array}{c}\text { Lack of } \\
\text { expertise }\end{array}$ & $\begin{array}{c}\text { Lack of } \\
\text { finance }\end{array}$ & $\begin{array}{c}\text { Unwillin } \\
\text { gness }\end{array}$ & $\begin{array}{c}\text { Lack of } \\
\text { preparedness }\end{array}$ & $\begin{array}{c}\text { Any other } \\
\text { please specify }\end{array}$ \\
\hline Earthquake & $\square$ & $\square$ & $\square$ & $\square$ & $\square$ & $\square$ & $\square$ & \\
\hline Flood & $\square$ & $\square$ & $\square$ & $\square$ & $\square$ & $\square$ & $\square$ & \\
\hline Landslide/slip & $\square$ & $\square$ & $\square$ & $\square$ & $\square$ & $\square$ & $\square$ & \\
\hline Bushfire & $\square$ & $\square$ & $\square$ & $\square$ & $\square$ & $\square$ & $\square$ & \\
\hline Windstorm/gale & $\square$ & $\square$ & $\square$ & $\square$ & $\square$ & $\square$ & $\square$ & \\
\hline Cyclone & $\square$ & $\square$ & $\square$ & $\square$ & $\square$ & $\square$ & $\square$ & \\
\hline Tsunami & $\square$ & $\square$ & $\square$ & $\square$ & $\square$ & $\square$ & $\square$ & \\
\hline Drought & $\square$ & $\square$ & $\square$ & $\square$ & $\square$ & $\square$ & $\square$ & \\
\hline Volcanic ash-fall & $\square$ & $\square$ & $\square$ & $\square$ & $\square$ & $\square$ & $\square$ & \\
\hline Other: & $\square$ & $\square$ & $\square$ & $\square$ & $\square$ & $\square$ & $\square$ & \\
\hline
\end{tabular}

13. Which of the following hazards are officially identified, located and mapped for district?

\begin{tabular}{|l|c|c|c|l|c|c|c|}
\hline Hazard & Identified & Located & Mapped & Hazard & Identified & Located & Mapped \\
\hline Earthquake & $\square$ & $\square$ & $\square$ & Cyclone & $\square$ & $\square$ & $\square$ \\
\hline Flood & $\square$ & $\square$ & $\square$ & Tsunami & $\square$ & $\square$ & $\square$ \\
\hline Landslide/slip & $\square$ & $\square$ & $\square$ & Drought & $\square$ & $\square$ & $\square$ \\
\hline Bushfire & $\square$ & $\square$ & $\square$ & Volcanic ash-fall & $\square$ & $\square$ & $\square$ \\
\hline Windstorm/gale & $\square$ & $\square$ & $\square$ & Other: & $\square$ & $\square$ & $\square$ \\
\hline
\end{tabular}

14. a. What kind of work has been done in the city/district in order to control/reduce the risk from the following hazards?

\begin{tabular}{|l|c|c|c|c|c|c|}
\hline Hazards & $\begin{array}{c}\text { Not } \\
\text { Applicable }\end{array}$ & $\begin{array}{c}\text { Don't } \\
\text { know }\end{array}$ & $\begin{array}{c}\text { Land use } \\
\text { regulation }\end{array}$ & $\begin{array}{c}\text { Engineering } \\
\text { solutions }\end{array}$ & $\begin{array}{c}\text { Afforestation } \\
\text { /shelter belt }\end{array}$ & $\begin{array}{c}\text { Any other } \\
\text { please specify }\end{array}$ \\
\hline Earthquake & $\square$ & $\square$ & $\square$ & $\square$ & $\square$ & \\
\hline Flood & $\square$ & $\square$ & $\square$ & $\square$ & $\square$ & \\
\hline Landslide/slip & $\square$ & $\square$ & $\square$ & $\square$ & $\square$ & \\
\hline Bushfire & $\square$ & $\square$ & $\square$ & $\square$ & $\square$ & \\
\hline Windstorm/gale & $\square$ & $\square$ & $\square$ & $\square$ & $\square$ & \\
\hline Cyclone & $\square$ & $\square$ & $\square$ & $\square$ & $\square$ & \\
\hline Tsunami & $\square$ & $\square$ & $\square$ & $\square$ & $\square$ & \\
\hline Drought & $\square$ & $\square$ & $\square$ & $\square$ & $\square$ & \\
\hline Volcanic ash-fall & $\square$ & $\square$ & $\square$ & $\square$ & $\square$ & \\
\hline Other: & $\square$ & $\square$ & $\square$ & $\square$ & $\square$ & \\
\hline
\end{tabular}

14. b. Please give location within city / district and other details of work mentioned in 14.a.

\begin{tabular}{|l|l|}
\hline Type of work & Location and other details \\
\hline & \\
\hline & \\
\hline & \\
\hline
\end{tabular}


15. a. Have any changes been made in location of significant institutions/services in your city/district in order to reduce the damage from following hazards?

\begin{tabular}{|l|c|c|c|c|c|c|c|c|c|c|}
\hline Hazards & $\begin{array}{c}\text { Not } \\
\text { Applicable }\end{array}$ & $\begin{array}{c}\text { Don't } \\
\text { know }\end{array}$ & $\begin{array}{c}\text { Council } \\
\text { offices }\end{array}$ & $\begin{array}{c}\text { CDM } \\
\text { office }\end{array}$ & $\begin{array}{c}\text { Hosp- } \\
\text { ital }\end{array}$ & $\begin{array}{c}\text { Telecomm } \\
\text { unications }\end{array}$ & $\begin{array}{c}\text { Transport } \\
\text { Network }\end{array}$ & $\begin{array}{c}\text { Gas } \\
\text { supplies }\end{array}$ & $\begin{array}{c}\text { Electricity } \\
\text { supply }\end{array}$ & $\begin{array}{c}\text { Any } \\
\text { other }\end{array}$ \\
\hline Earthquake & $\square$ & $\square$ & $\square$ & $\square$ & $\square$ & $\square$ & $\square$ & $\square$ & $\square$ & $\square$ \\
\hline Flood & $\square$ & $\square$ & $\square$ & $\square$ & $\square$ & $\square$ & $\square$ & $\square$ & $\square$ & $\square$ \\
\hline Landslide/slip & $\square$ & $\square$ & $\square$ & $\square$ & $\square$ & $\square$ & $\square$ & $\square$ & $\square$ & $\square$ \\
\hline Bushfire & $\square$ & $\square$ & $\square$ & $\square$ & $\square$ & $\square$ & $\square$ & $\square$ & $\square$ & $\square$ \\
\hline Windstorm/gale & $\square$ & $\square$ & $\square$ & $\square$ & $\square$ & $\square$ & $\square$ & $\square$ & $\square$ & $\square$ \\
\hline Cyclone & $\square$ & $\square$ & $\square$ & $\square$ & $\square$ & $\square$ & $\square$ & $\square$ & $\square$ & $\square$ \\
\hline Tsunami & $\square$ & $\square$ & $\square$ & $\square$ & $\square$ & $\square$ & $\square$ & $\square$ & $\square$ & $\square$ \\
\hline Drought & $\square$ & $\square$ & $\square$ & $\square$ & $\square$ & $\square$ & $\square$ & $\square$ & $\square$ & $\square$ \\
\hline Volcanic ash-fall & $\square$ & $\square$ & $\square$ & $\square$ & $\square$ & $\square$ & $\square$ & $\square$ & $\square$ \\
\hline Other: & $\square$ & $\square$ & $\square$ & $\square$ & $\square$ & $\square$ & $\square$ & $\square$ & $\square$ & $\square$ \\
\hline
\end{tabular}

15. b. Please give location within city/district and other details of changes mentioned in 15.a.

\begin{tabular}{|l|l|}
\hline Changes made & Location and other details \\
\hline & \\
\hline & \\
\hline & \\
\hline & \\
\hline
\end{tabular}

16. a. Are there any alternative arrangements for significant institutions/services in the city/district in case of following hazards occurrence?

\begin{tabular}{|l|c|c|c|c|c|c|c|c|c|c|}
\hline Hazards & $\begin{array}{r}\text { Not } \\
\text { Applicable }\end{array}$ & $\begin{array}{c}\text { Don't } \\
\text { know }\end{array}$ & $\begin{array}{c}\text { Council } \\
\text { offices }\end{array}$ & $\begin{array}{c}\text { CDM } \\
\text { office }\end{array}$ & $\begin{array}{c}\text { Hosp- } \\
\text { ital }\end{array}$ & $\begin{array}{c}\text { Telecomm } \\
\text { unications }\end{array}$ & $\begin{array}{c}\text { Nransport } \\
\text { Network }\end{array}$ & $\begin{array}{c}\text { Gas } \\
\text { supplies }\end{array}$ & $\begin{array}{c}\text { Electricity } \\
\text { supply }\end{array}$ & $\begin{array}{c}\text { Any } \\
\text { other }\end{array}$ \\
\hline Earthquake & $\square$ & $\square$ & $\square$ & $\square$ & $\square$ & $\square$ & $\square$ & $\square$ & $\square$ & $\square$ \\
\hline Flood & $\square$ & $\square$ & $\square$ & $\square$ & $\square$ & $\square$ & $\square$ & $\square$ & $\square$ & $\square$ \\
\hline Landslide/slip & $\square$ & $\square$ & $\square$ & $\square$ & $\square$ & $\square$ & $\square$ & $\square$ & $\square$ \\
\hline Bushfire & $\square$ & $\square$ & $\square$ & $\square$ & $\square$ & $\square$ & $\square$ & $\square$ & $\square$ & $\square$ \\
\hline Windstorm/gale & $\square$ & $\square$ & $\square$ & $\square$ & $\square$ & $\square$ & $\square$ & $\square$ & $\square$ & $\square$ \\
\hline Cyclone & $\square$ & $\square$ & $\square$ & $\square$ & $\square$ & $\square$ & $\square$ & $\square$ & $\square$ \\
\hline Tsunami & $\square$ & $\square$ & $\square$ & $\square$ & $\square$ & $\square$ & $\square$ & $\square$ & $\square$ \\
\hline Drought & $\square$ & $\square$ & $\square$ & $\square$ & $\square$ & $\square$ & $\square$ & $\square$ & $\square$ \\
\hline Volcanic ash-fall & $\square$ & $\square$ & $\square$ & $\square$ & $\square$ & $\square$ & $\square$ & $\square$ & $\square$ \\
\hline Other: & $\square$ & $\square$ & $\square$ & $\square$ & $\square$ & $\square$ & $\square$ & $\square$ & $\square$ & $\square$ \\
\hline
\end{tabular}

16. b. Please give location within city/district and other details of alternative services mentioned in 16.a.

\begin{tabular}{|l|l|}
\hline Changes made & Location and other details \\
\hline & \\
\hline & \\
\hline & \\
\hline & \\
\hline
\end{tabular}


17. Has something been done to control or reduce the individual vulnerability against hazards?

\begin{tabular}{|l|l|}
\hline Hazards & \\
\hline Earthquake & \\
\hline Flood & \\
\hline Landslide/slip & \\
\hline Bushfire & \\
\hline Windstorm/gale & \\
\hline Cyclone & \\
\hline Tsunami & \\
\hline Drought & \\
\hline Volcanic ash-fall & \\
\hline Other: & \\
\hline
\end{tabular}

\section{Questions on Hazards Preparedness in the district}

18. Are local people provided following information about hazards, vulnerability and response?

\begin{tabular}{|l|c|c|c|c|c|c|}
\hline Hazards & $\begin{array}{c}\text { Not } \\
\text { Applicable }\end{array}$ & $\begin{array}{c}\text { Don't } \\
\text { know }\end{array}$ & $\begin{array}{c}\text { Hazard } \\
\text { characteristics }\end{array}$ & $\begin{array}{c}\text { Their } \\
\text { Vulnerability }\end{array}$ & $\begin{array}{c}\text { How to } \\
\text { respond }\end{array}$ & Any other \\
\hline Earthquake & $\square$ & $\square$ & $\square$ & $\square$ & $\square$ & \\
\hline Flood & $\square$ & $\square$ & $\square$ & $\square$ & $\square$ & \\
\hline Landslide/slip & $\square$ & $\square$ & $\square$ & $\square$ & $\square$ & \\
\hline Bushfire & $\square$ & $\square$ & $\square$ & $\square$ & $\square$ & \\
\hline Windstorm/gale & $\square$ & $\square$ & $\square$ & $\square$ & $\square$ & \\
\hline Cyclone & $\square$ & $\square$ & $\square$ & $\square$ & $\square$ & \\
\hline Tsunami & $\square$ & $\square$ & $\square$ & $\square$ & $\square$ & \\
\hline Drought & $\square$ & $\square$ & $\square$ & $\square$ & $\square$ & \\
\hline Volcanic ash-fall & $\square$ & $\square$ & $\square$ & $\square$ & $\square$ & \\
\hline Other: & $\square$ & $\square$ & $\square$ & $\square$ & $\square$ & \\
\hline
\end{tabular}

19. What percentage of population do you think is aware of these hazards?

\begin{tabular}{|l|c|c|c|c|c|c|c|}
\hline Hazards & $\begin{array}{c}\text { Not } \\
\text { Applicable }\end{array}$ & $\begin{array}{c}\text { Don't } \\
\text { know }\end{array}$ & None & $\begin{array}{c}\text { Less than } \\
\text { 20\% }\end{array}$ & 21-40\% & 41-60\% & 61-80\% \\
\hline Earthquake & $\square$ & $\square$ & $\square$ & $\square$ & $\square$ & $\square$ & $\square$ \\
\hline Flood & $\square$ & $\square$ & $\square$ & $\square$ & $\square$ & $\square$ & $\square$ \\
\hline Landslide/slip & $\square$ & $\square$ & $\square$ & $\square$ & $\square$ & $\square$ & $\square$ \\
\hline Bushfire & $\square$ & $\square$ & $\square$ & $\square$ & $\square$ & $\square$ \\
\hline Windstorm/gale & $\square$ & $\square$ & $\square$ & $\square$ & $\square$ & $\square$ & $\square$ \\
\hline Cyclone & $\square$ & $\square$ & $\square$ & $\square$ & $\square$ & $\square$ & $\square$ \\
\hline Tsunami & $\square$ & $\square$ & $\square$ & $\square$ & $\square$ & $\square$ & $\square$ \\
\hline Drought & $\square$ & $\square$ & $\square$ & $\square$ & $\square$ & $\square$ & $\square$ \\
\hline Volcanic ash-fall & $\square$ & $\square$ & $\square$ & $\square$ & $\square$ & $\square$ & $\square$ \\
\hline Other: & $\square$ & $\square$ & $\square$ & $\square$ & $\square$ & $\square$ & $\square$ \\
\hline
\end{tabular}


20. What proportion of local people do you think is prepared to cope with these hazards?

\begin{tabular}{|l|c|c|c|c|c|c|c|c|}
\hline Hazards & $\begin{array}{c}\text { Not } \\
\text { Applicable }\end{array}$ & $\begin{array}{c}\text { Don't } \\
\text { know }\end{array}$ & None & $\begin{array}{c}\text { Less than } \\
\mathbf{2 0 \%}\end{array}$ & $\mathbf{2 1 - 4 0 \%}$ & $\mathbf{4 1 - 6 0 \%}$ & $\mathbf{6 1 - 8 0 \%}$ & $\mathbf{8 1 - 1 0 0 \%}$ \\
\hline Earthquake & $\square$ & $\square$ & $\square$ & $\square$ & $\square$ & $\square$ & $\square$ & $\square$ \\
\hline Flood & $\square$ & $\square$ & $\square$ & $\square$ & $\square$ & $\square$ & $\square$ & $\square$ \\
\hline Landslide/slip & $\square$ & $\square$ & $\square$ & $\square$ & $\square$ & $\square$ & $\square$ & $\square$ \\
\hline Bushfire & $\square$ & $\square$ & $\square$ & $\square$ & $\square$ & $\square$ & $\square$ & $\square$ \\
\hline Windstorm/gale & $\square$ & $\square$ & $\square$ & $\square$ & $\square$ & $\square$ & $\square$ & $\square$ \\
\hline Cyclone & $\square$ & $\square$ & $\square$ & $\square$ & $\square$ & $\square$ & $\square$ & $\square$ \\
\hline Tsunami & $\square$ & $\square$ & $\square$ & $\square$ & $\square$ & $\square$ & $\square$ & $\square$ \\
\hline Drought & $\square$ & $\square$ & $\square$ & $\square$ & $\square$ & $\square$ & $\square$ & $\square$ \\
\hline Volcanic ash-fall & $\square$ & $\square$ & $\square$ & $\square$ & $\square$ & $\square$ & $\square$ & $\square$ \\
\hline Other: & $\square$ & $\square$ & $\square$ & $\square$ & $\square$ & $\square$ & $\square$ & $\square$ \\
\hline
\end{tabular}

21. To what extent do you think local people are prepared to cope with these hazards?

\begin{tabular}{|l|c|c|c|c|c|c|}
\hline Hazards & $\begin{array}{c}\text { Not } \\
\text { Applicable }\end{array}$ & Don't know & $\begin{array}{c}\text { Not at all } \\
\text { Prepared }\end{array}$ & Poorly Prepared & $\begin{array}{c}\text { Moderately } \\
\text { Prepared }\end{array}$ & Well Prepared \\
\hline Earthquake & $\square$ & $\square$ & $\square$ & $\square$ & $\square$ & $\square$ \\
\hline Flood & $\square$ & $\square$ & $\square$ & $\square$ & $\square$ & $\square$ \\
\hline Landslide/slip & $\square$ & $\square$ & $\square$ & $\square$ & $\square$ & $\square$ \\
\hline Bushfire & $\square$ & $\square$ & $\square$ & $\square$ & $\square$ & $\square$ \\
\hline Windstorm/gale & $\square$ & $\square$ & $\square$ & $\square$ & $\square$ & $\square$ \\
\hline Cyclone & $\square$ & $\square$ & $\square$ & $\square$ & $\square$ & $\square$ \\
\hline Tsunami & $\square$ & $\square$ & $\square$ & $\square$ & $\square$ & $\square$ \\
\hline Drought & $\square$ & $\square$ & $\square$ & $\square$ & $\square$ & $\square$ \\
\hline Volcanic ash-fall & $\square$ & $\square$ & $\square$ & $\square$ & $\square$ & $\square$ \\
\hline Other: & $\square$ & $\square$ & $\square$ & $\square$ & $\square$ \\
\hline
\end{tabular}

22. To what extent is your organisation prepared to deal with major emergency in the district?

\begin{tabular}{|l|c|c|c|c|c|c|}
\hline Hazards & $\begin{array}{c}\text { Not } \\
\text { Applicable }\end{array}$ & Don't know & $\begin{array}{c}\text { Not at all } \\
\text { Prepared }\end{array}$ & Poorly Prepared & $\begin{array}{c}\text { Moderately } \\
\text { Prepared }\end{array}$ & Well Prepared \\
\hline Earthquake & $\square$ & $\square$ & $\square$ & $\square$ & $\square$ & $\square$ \\
\hline Flood & $\square$ & $\square$ & $\square$ & $\square$ & $\square$ & $\square$ \\
\hline Landslide/slip & $\square$ & $\square$ & $\square$ & $\square$ & $\square$ & $\square$ \\
\hline Bushfire & $\square$ & $\square$ & $\square$ & $\square$ & $\square$ & $\square$ \\
\hline Windstorm/gale & $\square$ & $\square$ & $\square$ & $\square$ & $\square$ & $\square$ \\
\hline Cyclone & $\square$ & $\square$ & $\square$ & $\square$ & $\square$ & $\square$ \\
\hline Tsunami & $\square$ & $\square$ & $\square$ & $\square$ & $\square$ & $\square$ \\
\hline Drought & $\square$ & $\square$ & $\square$ & $\square$ & $\square$ & $\square$ \\
\hline Volcanic ash-fall & $\square$ & $\square$ & $\square$ & $\square$ & $\square$ & $\square$ \\
\hline Other: & $\square$ & $\square$ & $\square$ & $\square$ & $\square$ & $\square$ \\
\hline
\end{tabular}


23. If your own organisation were affected by the hazards, how well prepared would it be?

\begin{tabular}{|l|c|c|c|c|c|c|}
\hline Hazards & $\begin{array}{c}\text { Not } \\
\text { Applicable }\end{array}$ & $\begin{array}{c}\text { Don't } \\
\text { know }\end{array}$ & Not prepared & $\begin{array}{c}\text { Poorly } \\
\text { Prepared }\end{array}$ & $\begin{array}{c}\text { Moderately } \\
\text { Prepared }\end{array}$ & Well Prepared \\
\hline Earthquake & $\square$ & $\square$ & $\square$ & $\square$ & $\square$ & $\square$ \\
\hline Flood & $\square$ & $\square$ & $\square$ & $\square$ & $\square$ & $\square$ \\
\hline Landslide/slip & $\square$ & $\square$ & $\square$ & $\square$ & $\square$ & $\square$ \\
\hline Bushfire & $\square$ & $\square$ & $\square$ & $\square$ & $\square$ & $\square$ \\
\hline Windstorm/gale & $\square$ & $\square$ & $\square$ & $\square$ & $\square$ & $\square$ \\
\hline Cyclone & $\square$ & $\square$ & $\square$ & $\square$ & $\square$ & $\square$ \\
\hline Tsunami & $\square$ & $\square$ & $\square$ & $\square$ & $\square$ & $\square$ \\
\hline Drought & $\square$ & $\square$ & $\square$ & $\square$ & $\square$ & $\square$ \\
\hline Volcanic ash-fall & $\square$ & $\square$ & $\square$ & $\square$ & $\square$ & $\square$ \\
\hline Other: & $\square$ & $\square$ & $\square$ & $\square$ & $\square$ \\
\hline
\end{tabular}

24. What are the major barriers to following forms of preparedness against natural hazards?

\begin{tabular}{|c|c|c|c|c|c|c|c|c|c|}
\hline Hazards & $\begin{array}{l}\text { Don't } \\
\text { know }\end{array}$ & $\begin{array}{l}\text { Unawa } \\
\text { reness }\end{array}$ & $\begin{array}{c}\text { Unwillin } \\
\text { gness }\end{array}$ & $\begin{array}{c}\text { Lack of } \\
\text { knowledge }\end{array}$ & $\begin{array}{l}\text { Financial } \\
\text { problems }\end{array}$ & \begin{tabular}{|c} 
Lack \\
of staff
\end{tabular} & $\begin{array}{l}\text { Commu } \\
\text { nication }\end{array}$ & $\begin{array}{c}\text { Lack of } \\
\text { coordination }\end{array}$ & $\begin{array}{l}\text { Any other } \\
\text { please }\end{array}$ \\
\hline Public awareness & $\square$ & $\square$ & $\square$ & $\square$ & $\square$ & $\square$ & $\square$ & $\square$ & \\
\hline Public Preparedness & $\square$ & $\square$ & $\square$ & $\square$ & $\square$ & $\square$ & $\square$ & $\square$ & \\
\hline $\begin{array}{l}\text { Your preparedness to } \\
\text { deal with major } \\
\text { hazard in district. }\end{array}$ & $\square$ & $\square$ & $\square$ & $\square$ & $\square$ & $\square$ & $\square$ & $\square$ & \\
\hline $\begin{array}{l}\text { Your preparedness to } \\
\text { deal with hazard in } \\
\text { your organisation. }\end{array}$ & $\square$ & $\square$ & $\square$ & $\square$ & $\square$ & $\square$ & $\square$ & $\square$ & \\
\hline
\end{tabular}

25. Does your organisation have any of the following plans for safety of its own employees?

\begin{tabular}{|l|c|c|c|c|c|c|}
\hline \multicolumn{1}{|c|}{ Hazards } & $\begin{array}{c}\text { Emergency } \\
\text { mgt plan }\end{array}$ & $\begin{array}{c}\text { Evacuation } \\
\text { plan }\end{array}$ & $\begin{array}{c}\text { Hazard } \\
\text { specific plan }\end{array}$ & $\begin{array}{c}\text { Survival } \\
\text { kit }\end{array}$ & $\begin{array}{c}\text { Recovery } \\
\text { plan }\end{array}$ & $\begin{array}{c}\text { Any other please } \\
\text { specify }\end{array}$ \\
\hline Earthquake & $\square$ & $\square$ & $\square$ & $\square$ & $\square$ & \\
\hline Flood & $\square$ & $\square$ & $\square$ & $\square$ & $\square$ & \\
\hline Landslide/slip & $\square$ & $\square$ & $\square$ & $\square$ & $\square$ & \\
\hline Bushfire & $\square$ & $\square$ & $\square$ & $\square$ & $\square$ & \\
\hline Windstorm/gale & $\square$ & $\square$ & $\square$ & $\square$ & $\square$ & \\
\hline Cyclone & $\square$ & $\square$ & $\square$ & $\square$ & $\square$ & \\
\hline Tsunami & $\square$ & $\square$ & $\square$ & $\square$ & $\square$ & \\
\hline Drought & $\square$ & $\square$ & $\square$ & $\square$ & $\square$ & \\
\hline Volcanic ash-fall & $\square$ & $\square$ & $\square$ & $\square$ & $\square$ & \\
\hline Other: & $\square$ & $\square$ & $\square$ & $\square$ & $\square$ & \\
\hline
\end{tabular}


26. Do the following hazard management plans/kit of the organisation consider vulnerability of employees and visitors?

\begin{tabular}{|l|c|c|c|c|c|c|}
\hline $\begin{array}{l}\text { Vulnerable } \\
\text { people }\end{array}$ & $\begin{array}{c}\text { Emergency } \\
\text { mgt plan }\end{array}$ & $\begin{array}{c}\text { Evacuation } \\
\text { plan }\end{array}$ & $\begin{array}{c}\text { Hazard } \\
\text { specific plan }\end{array}$ & $\begin{array}{c}\text { Survival } \\
\text { kit }\end{array}$ & $\begin{array}{c}\text { Recovery } \\
\text { plan }\end{array}$ & $\begin{array}{c}\text { Please specify the } \\
\text { implications made for them }\end{array}$ \\
\hline Women & $\square$ & $\square$ & $\square$ & $\square$ & $\square$ & \\
\hline Old & $\square$ & $\square$ & $\square$ & $\square$ & $\square$ & \\
\hline Disabled & $\square$ & $\square$ & $\square$ & $\square$ & $\square$ & \\
\hline Visitors & $\square$ & $\square$ & $\square$ & $\square$ & $\square$ & \\
\hline Other: & $\square$ & $\square$ & $\square$ & $\square$ & $\square$ & \\
\hline
\end{tabular}

27. Have you experienced any central declared emergency or disaster? $\square$ Yes $\square$ No

If yes then please give the following information:

Date:

Location:

Damage:

Any Specific Cause for damage

Your response

Lesson learnt

Any other comment

\section{Details of the organisation}

\begin{tabular}{|l|l|l|l|}
\hline Name: & \multicolumn{2}{|l|}{} \\
\hline Address: & \multicolumn{3}{|l|}{} \\
\hline Role concerning hazard: & \multicolumn{3}{|l|}{} \\
\hline Year of establishment: & \multicolumn{3}{|l|}{} \\
\hline Number of staff: & \multicolumn{2}{|l|}{ Number of trained staff at a time: } & \\
\hline Work schedule: & & Number of operating shifts: & \\
\hline
\end{tabular}

\section{Details of the organisation's building}

\begin{tabular}{|c|c|}
\hline Year of establishment: & Number of floors: \\
\hline $\begin{array}{l}\text { Number of fire } \\
\text { extinguishers: }\end{array}$ & $\begin{array}{l}\text { Number of emergency } \\
\text { exits: }\end{array}$ \\
\hline $\begin{array}{l}\text { Building is resistant to } \\
\text { hazards: }\end{array}$ & $\begin{array}{l}\square \text { Earthquake } \square \text { Flood } \square \text { Landslide/slip } \square \text { Bushfire } \square \text { Volcanic ash fall } \\
\square \text { Cyclone } \square \text { Tsunami } \square \text { Drought } \square \text { Windstorm/gale } \square:\end{array}$ \\
\hline $\begin{array}{l}\text { Building has suffered } \\
\text { following hazard damage in } \\
\text { past }\end{array}$ & $\begin{array}{l}\square \text { Earthquake } \square \text { Flood } \square \text { Landslide/slip } \square \text { Bushfire } \square \text { Volcanic ash fall } \\
\square \text { Cyclone } \square \text { Tsunami } \square \text { Drought } \square \text { Windstorm/gale } \square:\end{array}$ \\
\hline $\begin{array}{l}\text { Changes have been made } \\
\text { in the building to cope } \\
\text { with hazard }\end{array}$ & $\begin{array}{l}\square \text { Earthquake } \\
\square \text { Flood } \\
\square \text { Landslide/slip } \\
\square \text { Bushfire } \\
\square \text { Volcanic ash fall } \\
\square \text { Cyclone } \\
\square \text { Tsunami } \\
\square \text { Drought } \\
\square \text { Windstorm/gale } \\
\square \text { Other: }\end{array}$ \\
\hline
\end{tabular}


Any other comment that you think would be useful for the research:

Thank you for your time and efforts to fill the questionnaire. 
